\title{
2003 Initial Assessments of Closure for the C Tank Farm: Numerical Simulations
}

\author{
Z. F. Zhang \\ V. L. Freedman \\ M. D. White
}

July 2003

Pacific Northwest National Laboratory

Richland, WA 99352 


\title{
DISCLAIMER
}

This report was prepared as an account of work sponsored by an agency of the United States Government. Neither the United States Government nor any agency thereof, nor Battelle Memorial Institute, nor any of their employees, makes any warranty, express or implied, or assumes any legal liability or responsibility for the accuracy, completeness, or usefulness of any information, apparatus, product, or process disclosed, or represents that its use would not infringe privately owned rights. Reference herein to any specific commercial product, process, or service by trade name, trademark, manufacturer, or otherwise does not necessarily constitute or imply its endorsement, recommendation, or favoring by the United States Government or any agency thereof, or Battelle Memorial Institute. The views and opinions of authors expressed herein do not necessarily state or reflect those of the United States Government or any agency thereof.

\author{
PACIFIC NORTHWEST NATIONAL LABORATORY \\ operated by \\ BATTELLE \\ for the \\ UNITED STATES DEPARTMENT OF ENERGY \\ under Contract DE-ACO6-76RLO183O
}

Printed in the United States of America

$$
\begin{aligned}
& \text { Available to DOE and DOE contractors from the } \\
& \text { Office of Scientific and Technical Information, } \\
& \text { P.O. Box 62, Oak Ridge, TN 37831-0062; } \\
& \text { ph: }(865) 576-8401 \\
& \text { fax: (865) 576-5728 } \\
& \text { email: reports@adonis.osti.gov }
\end{aligned}
$$

\footnotetext{
Available to the public from the National Technical Information Service, U.S. Department of Commerce, 5285 Port Royal Rd., Springfield, VA 22161 ph: (800) 553-6847 fax: (703) 605-6900 email: orders@ntis.fedworld.gov online ordering: http://www.ntis.gov/ordering.htm
} 


\section{Initial Assessments of Closure for the C Tank Farm: Numerical Simulations}

Z. F. Zhang

V. L. Freedman

M. D. White

July 2003

Prepared for

the U.S. Department of Energy

under Contract DE-AC06-76RL01830

Pacific Northwest National Laboratory

Richland, WA 99352 


\section{Summary}

In support of CH2M HILL Hanford Group, Inc.'s (CHG) preparation of a Field Investigative Report (FIR) for the closure of the Hanford Site Single-Shell Tank (SST) Waste Management Area (WMA) tank farms, a set of numerical simulations of flow and solute transport was executed to investigate different potential contaminant source scenarios that may pose long-term risks to groundwater from the closure of the C Tank Farm. This report documents the simulation of 14 cases (plus two verification and five sensitivity cases) involving two-dimensional cross sections through the C Tank Farm (Tanks C-103-C112). Using a unit release scenario at Tank C-112, four different types of leaks were simulated. These simulations assessed the effect of past leaks and leaks during retrieval as well as residual wastes and ancillary equipment after closure. Two transported solutes were considered: uranium-238 (U-238) and technetium-99 (Tc-99). To evaluate the effect of sorption on contaminant transport, six different sorption coefficients were simulated for U-238. Overall, simulations results for the C Tank Farm showed that only a small fraction $(<1.2 \%)$ of the U-238 with sorption coefficients greater than $0.6 \mathrm{~mL} / \mathrm{g}$ migrated from the vadose zone in all of the cases. For the conservative solute, Tc-99, results showed that the simulations investigating leaks during retrieval demonstrated the highest peak concentrations and the earliest arrival times due to the high infiltration rate before water was added and surface barriers installed. Simulations investigating past leaks showed peaks and arrival times similar to the retrieval cases. Several different release rates were used to investigate contaminant transport from residual tank wastes. All showed similar peak concentrations and arrival times, except for the lowest initial release rate, which was 1,000 times slower than the highest release rate. Past leaks were also investigated with different release rate models, including advection-dominated, diffusion-dominated, and saltcake release models. Of the three models, peak concentrations were lowest and arrival times later for the saltcake model due to the low solubility (and hence lower release rate) of the residual tank waste solids. For the tank ancillary equipment leak case, the diffusion-dominated release rate model yielded peak concentrations and late arrival times that were similar to the majority of the past leak cases for residual tank wastes. For all source types, the peak concentrations and arrival times were sensitive to the estimated saturated hydraulic conductivity of the unconfined aquifer. When the saturated hydraulic conductivity was increased by a factor of 10 , peak concentrations at the first compliance point, the fence line boundary, were decreased by approximately the same magnitude. Peak arrival times also occurred earlier with the higher estimate of hydraulic conductivity. 


\section{Contents}

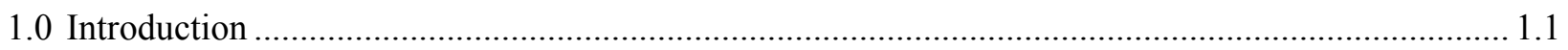

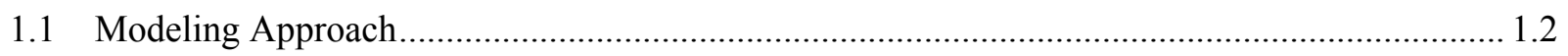

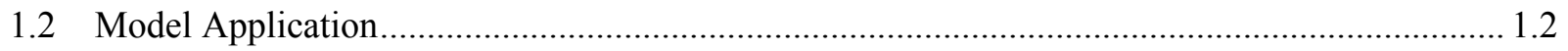

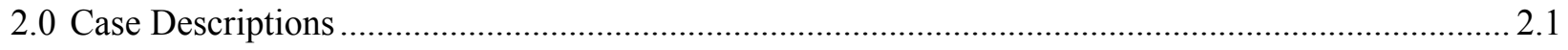

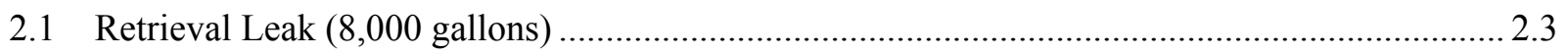

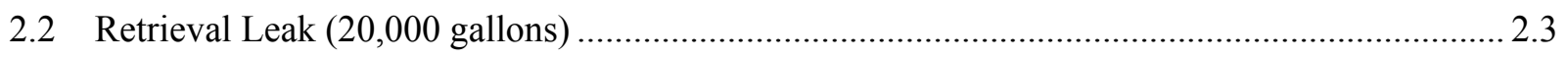

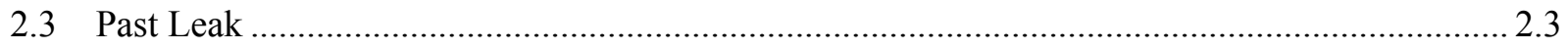

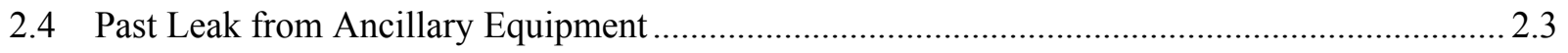

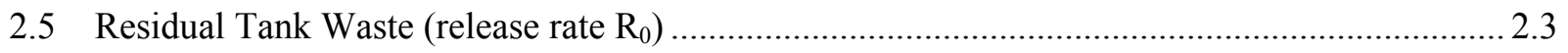

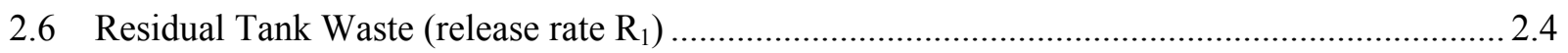

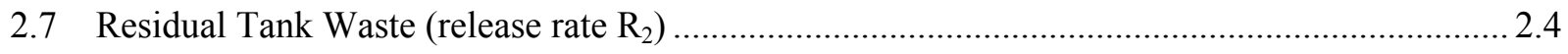

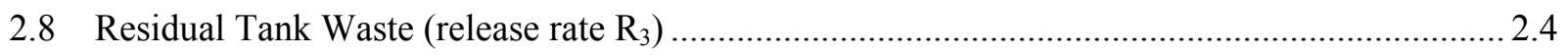

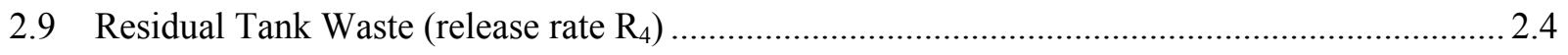

2.10 Residual Tank Waste (advection dominated) .......................................................................... 2.4

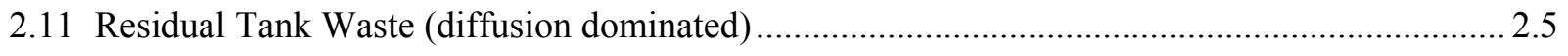

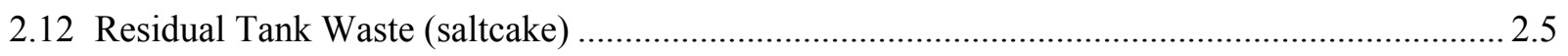

2.13 Residual Ancillary Equipment Waste (diffusion dominated) ……………………………......... 2.5

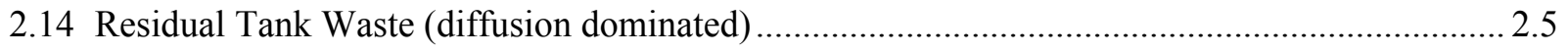

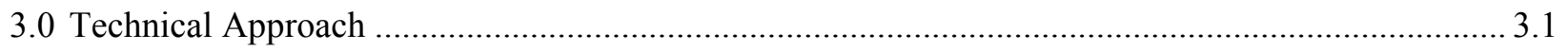

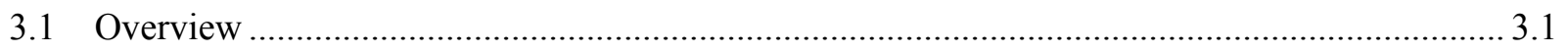

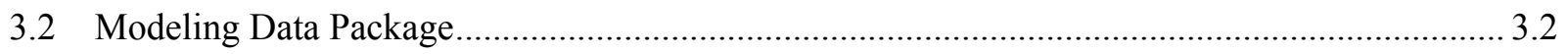

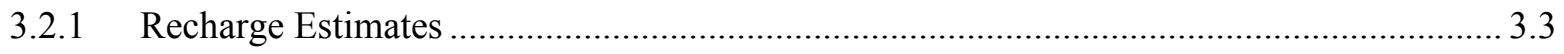

3.2.2 Vadose Zone Flow and Transport Properties …………................................................... 3.4

3.2.3 Stochastic Model for Macroscopic Anisotropy …………................................................... 3.4

3.2.4 Bulk Density and Sorption Coefficient ............................................................................. 3.6

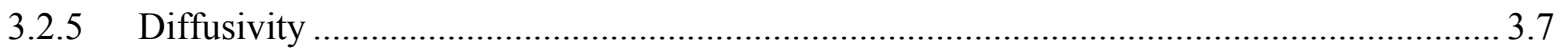

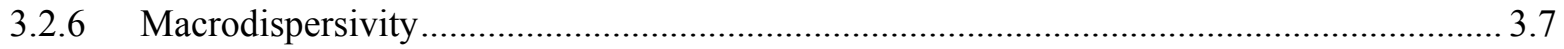

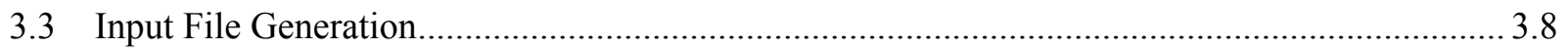

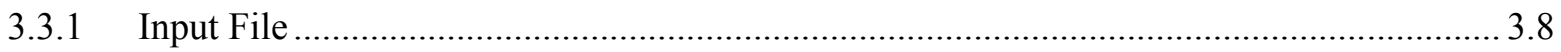

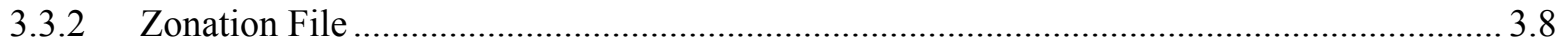

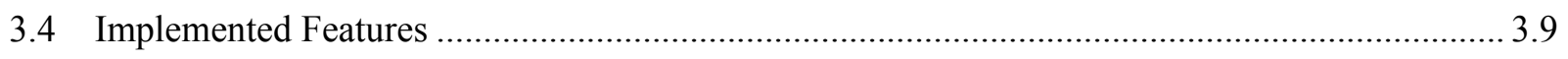

3.4.1 Advection-Dominated Release Model ...................................................................... 3.10

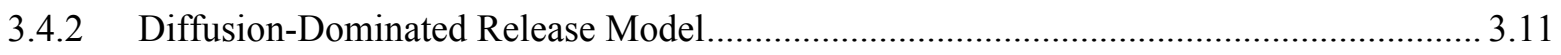

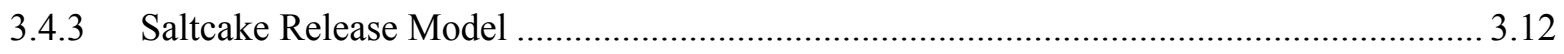

3.5 Source Terms

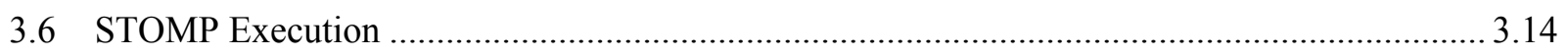

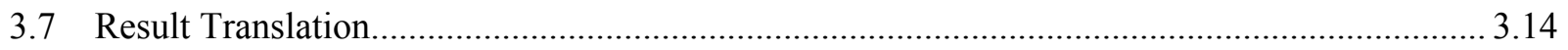

3.8 Analytical Groundwater Transport Modeling ..................................................................... 3.15 


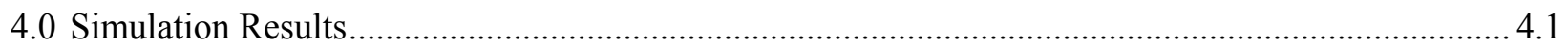

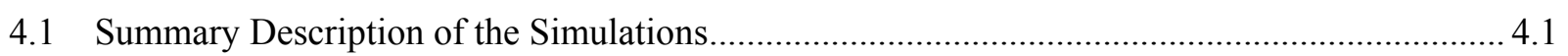

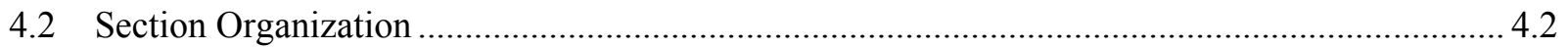

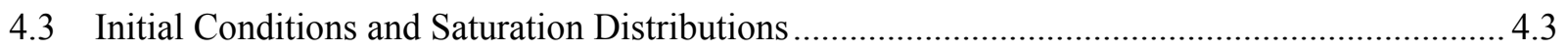

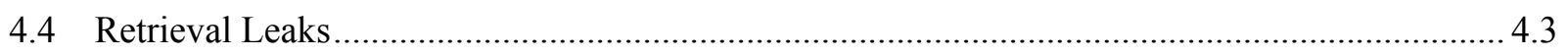

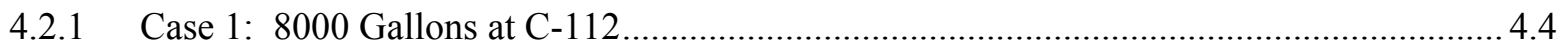

4.2.2 Case 1 (HiK): 8000 Gallons at C-112, C-109, C-106 and C-103 ...................................... 4.5

4.2.3 Case 1v: 8000 Gallons at C-112, C-109, C-106 and C-103 …....................................... 4.5

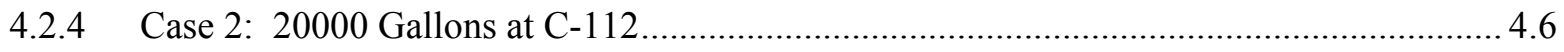

4.2.5 Leak Volume Effects: Comparison of Cases 1 and 2 ................................................... 4.6

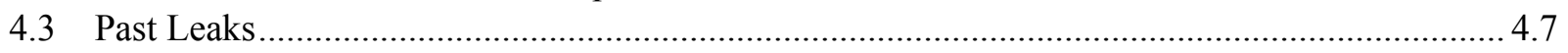

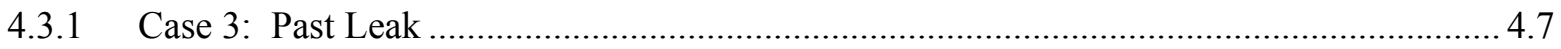

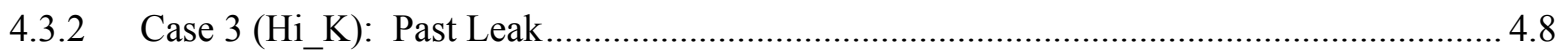

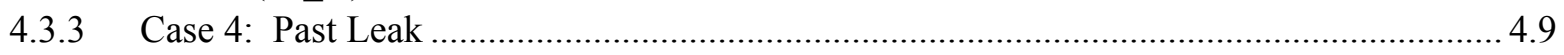

4.3.4 Case 4 (HiK): Past Leak................................................................................................. 4.9

4.3.5 Inventory Depth Effects: Comparison of Cases 3 and 4 ............................................. 4.10

4.4 Residual Tank Wastes with Rate-Controlled Releases......................................................... 4.10

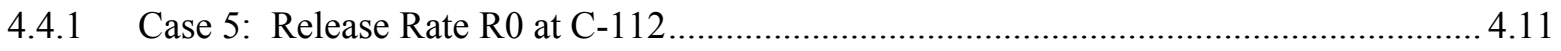

4.4.2 Case 5v: Release Rate $\mathrm{R}_{0}$ at C-112, C-109, C-106, and C-103 ….................................. 4.11

4.4.2 Case 6: Release Rate R1 at C-112 ................................................................................ 4.12

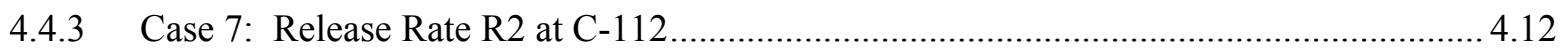

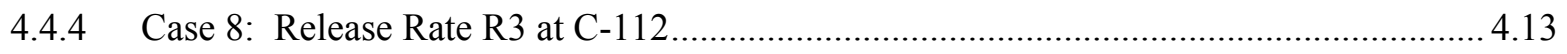

4.4.5 Case 9: Release Rate R4 at C-112 ................................................................................. 4.13

4.4.7 Release Rate Effects: Comparison of Cases 5-9..................................................... 4.14

4.5 Residual Tank Wastes with Different Controlling Processes................................................ 4.15

4.5.1 Case 10: Advection-Dominated Release ..................................................................... 4.15

4.5.2 Case 10 (HiK): Advection-Dominated Release .......................................................... 4.16

4.5.3 Case 11: Diffusion-Dominated Release ...................................................................... 4.17

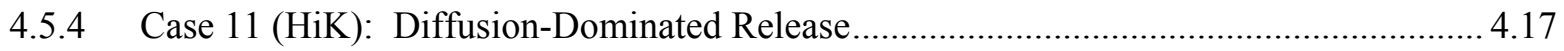

4.5.5 Case 14: Diffusion-Dominated Release ............................................................................18

4.5.6 Diffusion Coefficient Effects: Comparison of Cases 11 and 14 .................................... 4.18

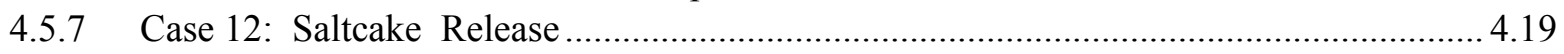

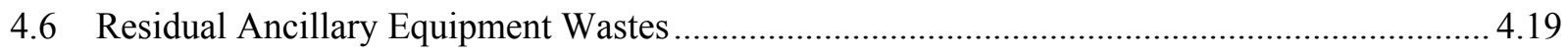

4.6.1 Case 13: Diffusion-Dominated Release ......................................................................... 4.19

4.7 Peak Concentrations and Arrival Times at Compliance Points.............................................. 4.20

4.7.1 Average Travel Time to Compliance Points ................................................................ 4.20

4.7.2 Peak Concentrations at Compliance Points ................................................................... 4.21

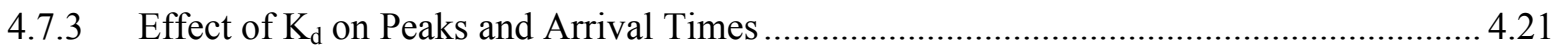

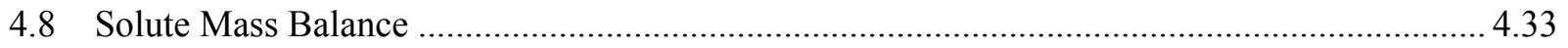

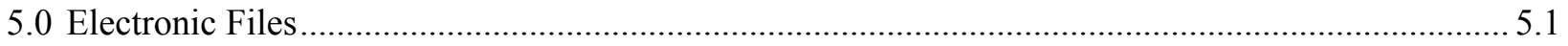

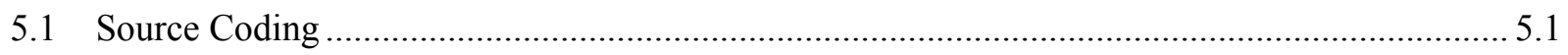

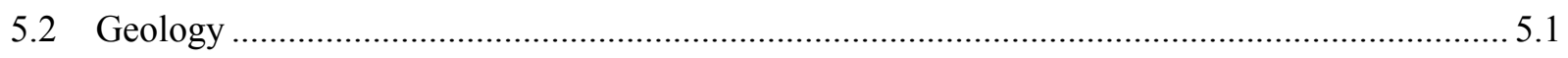

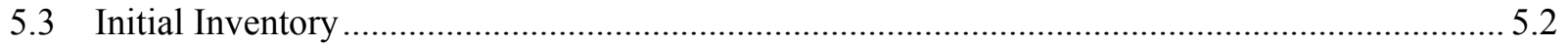




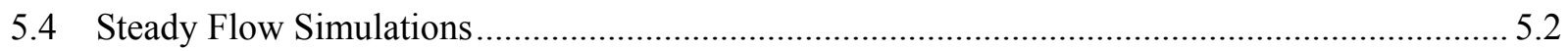

5.5 Coupled Vadose Zone and Unconfined Aquifer Modeling ...................................................... 5.2

5.6 Analytical Groundwater Transport Modeling .......................................................................... 5.4

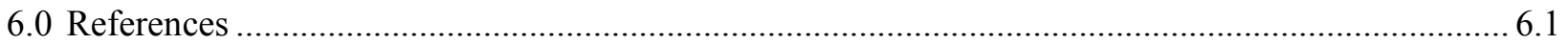

Appendix A: C Farm Saturation and Concentration Distributions .................................................... A.1

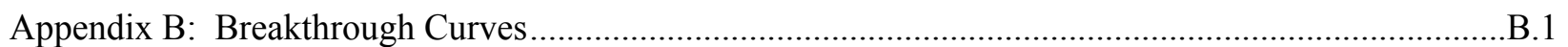




\section{Figures}

3.1 Northwest-Southeast Cross Section for C Tank Farm Through Tanks C-112, C-109, C-106 and C-103.

3.2 Rock/Soil Zonation for the Pre- and Post-Construction Periods of the C Tank Farm 3.10

\section{Tables}

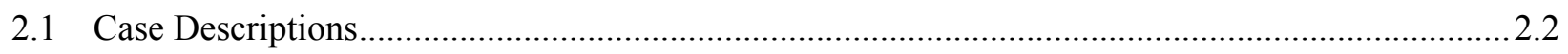

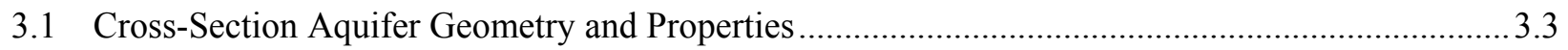

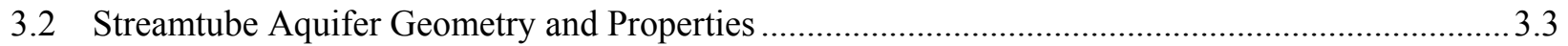

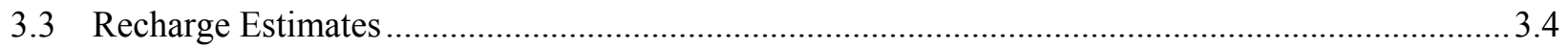

3.4 Composite van Genuchten-Mualem Parameters for Various Strata at C Tank Farm ......................3.4

3.5 Macroscopic Anisotropy Parameters Based on Polmann Equations for Strata at C Tank Farm ...... 3.6

3.6 Effective Parameter Estimates for Product of Bulk Density and Retardation Coefficient

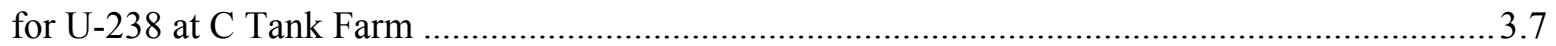

3.7 Nonreactive Macrodispersivity Estimates for Strata at the C Tank Farm....................................... 3.8

3.8 Input Parameters for the Three Release Models ......................................................................13

3.9 Distance to Compliance Point, Groundwater Velocity, and Travel Time from C Tank Farm ........3.15

3.10 Analytical Groundwater Transport Modeling Properties.......................................................... 3.17

4.1 Predicted Peak Concentrations and Arrival Times at Fence Line for Base Cases in Year 12000 .... 4.2

4.2 Predicted Peak Tc-99 Flux, Arrival Time, and Cumulative Mass at Year 12000....................... 4.22

4.3 Predicted Peak U-238 $\left(\mathrm{K}_{\mathrm{d}}=0.01\right)$ Flux, Arrival Time, and Cumulative Mass at Year $12000 \ldots \ldots . .4 .23$

4.4 Predicted Peak U-238 $\left(\mathrm{K}_{\mathrm{d}}=0.03\right)$ Flux, Arrival Time, and Cumulative Mass at Year $12000 \ldots \ldots . .4 .23$

4.5 Predicted Peak U-238 $\left(\mathrm{K}_{\mathrm{d}}=0.10\right)$ Flux, Arrival Time, and Cumulative Mass at Year $12000 \ldots . . .4 .24$

4.6 Predicted Peak U-238 $\left(\mathrm{K}_{\mathrm{d}}=0.30\right)$ Flux, Arrival Time, and Cumulative Mass at Year $12000 \ldots \ldots .4 .24$

4.7 Predicted Peak U-238 $\left(\mathrm{K}_{\mathrm{d}}=0.60\right)$ Flux, Arrival Time, and Cumulative Mass at Year $12000 \ldots \ldots . .4 .25$

4.8 Predicted Peak U-238 $\left(\mathrm{K}_{\mathrm{d}}=1.00\right)$ Flux, Arrival Time, and Cumulative Mass at Year $12000 \ldots \ldots . .4 .25$

4.9 Predicted Peak Tc-99 Aqueous Concentrations and Arrival Time Summary ................................ 4.26

4.10 Predicted Peak U-238 $\left(\mathrm{K}_{\mathrm{d}}=0.01\right)$ Aqueous Concentrations and Arrival Time Summary .............4.27

4.11 Predicted Peak U-238 $\left(\mathrm{K}_{\mathrm{d}}=0.03\right)$ Aqueous and Arrival Time Summary ................................... 4.28

4.12 Predicted Peak U-238 $\left(\mathrm{K}_{\mathrm{d}}=0.10\right)$ Aqueous Concentrations and Arrival Time Summary ............4.29

4.13 Predicted Peak U-238 $\left(\mathrm{K}_{\mathrm{d}}=0.30\right)$ Aqueous Concentrations and Arrival Time Summary ............4.30

4.14 Predicted Peak U-238 $\left(\mathrm{K}_{\mathrm{d}}=0.60\right)$ Aqueous Concentrations and Arrival Time Summary ............ 4.31

4.15 Predicted Peak U-238 $\left(\mathrm{K}_{\mathrm{d}}=1.00\right)$ Aqueous Concentrations and Arrival Time Summary ............. 4.32

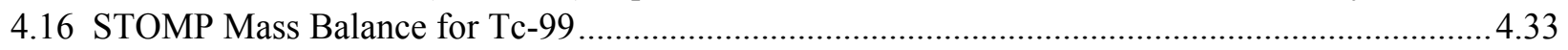

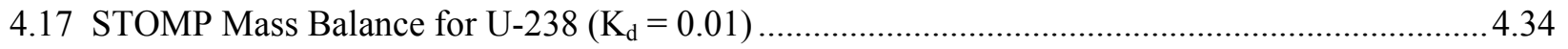

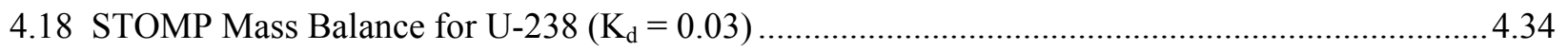

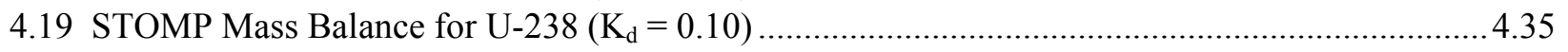

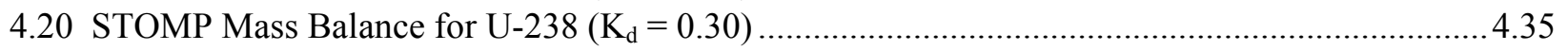

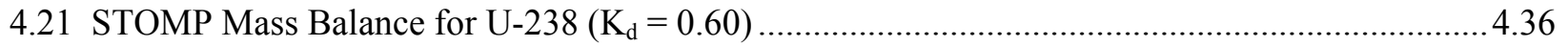

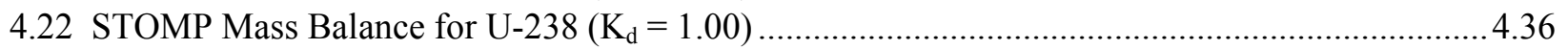

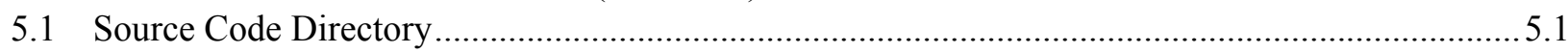

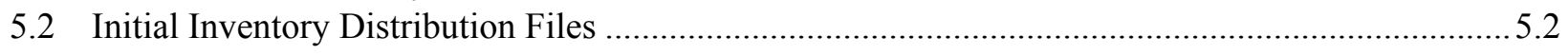


5.3. Steady Flow Initial Condition Files

5.4. Coupled Vadose Zone and Unconfined Aquifer Modeling Files..................................................5.3

5.5. Analytical Groundwater Transport Modeling Files ...................................................................... 5.4 


\subsection{Introduction}

The U.S. Department of Energy (DOE) is charged with evaluating the impacts associated with closure of the single shell tanks (SSTs) and double shell tanks (DSTs) at the Hanford tank farms. In keeping with this charge, DOE has begun a series of field investigations at the C Tank Farm in the 200 East Area that are made necessary by the Tri-Party Agreement (TPA) (TPA M-45-98-03) (Ecology et al. 1989). Under the TPA, the SSTs and DSTs are Resource Conservation and Recovery Act (RCRA) hazardous waste management units that will eventually be closed under State Dangerous Waste regulations (WAC 173-303). To evaluate the risks associated with these closure activities, this report documents numerical simulations that investigated the effects closure of $\mathrm{C}$ Tank Farm will have on groundwater resources. In these analyses, it is assumed that the $\mathrm{C}$ Tank Farm will be closed as a landfill. The potential waste sources include past leaks, spills, retrieval leaks, and residual tank waste from tanks and tank ancillary equipment.

The modeling approach used in this study at the C Tank Farm is similar to the S-SX FIR (White et al. 2001) and B-BX-BY modeling reports (Freedman et al. 2002). The specific objectives of the numerical assessment are to quantify the risks posed by tank closure. The assessments of this investigation focus specifically on impacts to groundwater resources (i.e., concentration of contaminants in the groundwater). By providing quantitative comparisons of the different potential contaminant sources, the results from this evaluation may affect current operations or future decisions on retrieval of tank waste and closure of the C Tank Farm.

This report documents initial investigations performed via numerical simulation of contaminant migration beneath the $\mathrm{C}$ Tank Farm and the calculation of peak concentrations and arrival times at points of compliance. The report is divided into sections that generally follow the overall simulation procedures. First, the objectives are summarized and then the numerical simulations that were executed are listed. Next the process of converting the data provided in the Modeling Data Package (MDP) (Khaleel et al. 2003) into input files for the STOMP simulator is described. Much of this discussion relies on the reader having access to the STOMP guide documents and focuses on the correlation between the MDP and STOMP input cards. Three new solute transport models were implemented into the STOMP simulator (White and Oostrom 2000a, 2000b) for this investigation: advection, diffusion, and saltcake release models for the residual waste, as described in Khaleel et al. (2003). Implementation of these capabilities into the STOMP simulator is described, and the code compilation and execution on workstations operating under Linux are summarized. This is followed by a description of the extent of contamination within the vadose zone, movement of contaminants through the vadose zone to the groundwater, and movement of contaminants through the groundwater to points of compliance.

The principal objective for these investigations was executing the simulations specified in the MDP using widely accepted, scientifically based computational software and reporting the generated results. To promote an open exchange of scientific knowledge and ideas, the software used in this study will be made available, upon request, to the U.S. Government and its contractors. To ensure that these simulations can be repeated in the future, the source coding, input files, and output files have been stored in electronic form and are also available to the U.S. Government and its contractors. Although Battelle - Pacific Northwest Division maintains a copyright on the STOMP simulator, the U.S. Government retains a paid-up, nonexclusive, irrevocable worldwide license to reproduce, prepare derivative works, and perform and display publicly by or for the U.S. Government, including the right to distribute to other government contractors. Numerical simulation of contaminant migration through the vadose zone and unconfined aquifer beneath 
the C Tank Farm required converting information in the MDP into electronic input that could be interpreted by the STOMP simulator, executing the software, and translating the simulation output into graphical form for reporting. This procedure is described in the final section of the report.

\subsection{Modeling Approach}

The scope and data required to perform the numerical simulations are documented in the MDP (Khaleel et al. 2003) provided by CH2M HILL Hanford Group, Inc. The numerical simulations were executed with the STOMP simulator (White and Oostrom 2000a, 2000b), which modeled the vadose zone as an aqueous-gas porous media system where transport through the gas phase was neglected. All simulations used the infinite dilution assumption for coupling fluid flow and contaminant transport.

Fluid flow within the vadose zone was described using Richard's equation, whereas contaminant transport was described using the conventional advective-dispersive transport equation with an equilibrium linear sorption coefficient $\left(\mathrm{K}_{\mathrm{d}}\right)$ formulation. Stratigraphic information for the cross sections was based on the studies of Lindsey and Reynolds (2001) and the MDP (Khaleel et al. 2003). These cross sections include dipping strata and, when combined with the Polmann (1990) model for anisotropy in relative permeability for unsaturated soils, allow the simulator to model the enhanced spreading at the fine- to coarse-grained interfaces and the increased downslope movement of water along these interfaces.

Modeling parameters used to describe soil-moisture retention, phase relative permeability, saturated hydraulic conductivity (intrinsic permeability), and bulk density (porosity) for individual strata were based on data collected from 200 Area soils (Khaleel et al. 2003). For each stratum (soil type) defined on the cross-section stratigraphy, the small-scale laboratory measurements were scaled spatially upward using the Polmann (1990) model to obtain equivalent horizontal and vertical unsaturated hydraulic conductivities as a function of mean tension. This scaling technique yielded a mathematical expression describing macroscopic anisotropy in the unsaturated hydraulic conductivity as a function of mean tension for each stratum. When multiple soil samples were available for a given stratum, arithmetic averaging of van Genuchten parameters (van Genuchten 1980) was used to define the soil-moisture retention function for each stratum. When multiple soil samples were unavailable for a given stratum, data were used from soil samples taken from the same stratum. Hydraulic properties were determined from laboratory measurements of soil moisture retention and unsaturated hydraulic conductivity when available. This approach avoided extrapolating unsaturated hydraulic conductivities (van Genuchten 1980; Mualem 1976) to dry conditions based on a saturated conductivity estimate (Khaleel et al. 1995). To reflect field conditions, laboratory data were corrected for the presence of any gravel fraction in the sediment samples (Khaleel and Relyea 1997).

\subsection{Model Application}

A steady flow simulation was run to establish flow conditions for the C Tank Farm before the tank farm was in place. Steady flow conditions for the preconstruction period were established using a constant surface recharge of meteoric water and fixing the aquifer flux across the cross section. No solute transport was considered during the steady flow simulations. Transient simulations involved both fluid flow and solute transport and were simulated in two stages. In the first stage, flow and solute transport was simulated while the tanks were still intact. The second stage of the simulation predicted flow and solute transport after tank integrity was lost. The transient simulations started with the flow conditions from the 
previous simulation and responded to changes in meteoric recharge caused by barrier emplacements and/or tank degradation. Two simulations also considered retrieval leaks. The incoming aquifer water flux remained fixed throughout the transient simulation.

Initial conditions for solute concentrations were based on the source type and assumed lateral extent for U-238 and Tc-99 (Khaleel et al. 2003). As specified by the data package, two contaminant species (Tc-99 and U-238) were used to represent a range of constituent mobility in these analyses. A two-dimensional northwest-to-southeast cross section through the C Tank Farm, traversing four SSTs, was used to model fluid flow and solute transport. Hence, concentrations do not account for spreading or dilution of solutes in the third dimension. Grid resolutions for all simulations were $1 \mathrm{~m}$ in the horizontal and $1 \mathrm{~m}$ in the vertical. The simulation domain extended horizontally $180 \mathrm{~m}$ and $13 \mathrm{~m}$ past the fence line boundary. From the ground surface, the simulation domain extended vertically to $15 \mathrm{~m}$ below the water table and about $97 \mathrm{~m}$ below ground surface (bgs).

Several different potential contaminant sources were considered, including retrieval leaks (spills), past leaks, and residual tank waste from tanks and tank ancillary equipment. Each source was simulated as a unit inventory release. Unit inventory releases of the contaminants were used for solute transport so that inventories could be scaled eventually to the estimated leak inventory for the C Tank Farm independently of the applied water. All unit releases in the simulations originated from $\mathrm{C}-112$, the tank farthest from the exit boundary. Releases from this tank were considered so that contaminant transport behavior beneath each of the tanks could be analyzed. To test whether contaminant transport originating from other tanks is similar, two verification cases were run that considered unit releases from each of the four tanks in the cross section. Five of the cases were run with a higher value of saturated hydraulic conductivity for the aquifer. For all of the simulation cases, results from vadose zone-aquifer simulations were then transported using streamtube modeling to its downstream compliance points.

In keeping with the approach taken for modeling fluid flow, solute transport properties for bulk density, diffusivity, and dispersivity were specified for each stratum. Contaminant mobility was defined through an equilibrium linear sorption coefficient $\left(\mathrm{K}_{\mathrm{d}}\right)$. Uncertainty remains about the linear sorption coefficient and the applicability of a linear-sorption model for U-238. As a result, a range of linear sorption coefficients was used in the modeling to assess the migration behavior of $\mathrm{U}-238$ (e.g., $\mathrm{K}_{\mathrm{d}}=0.01,0.03,0.1,0.3,0.6$, and $1.0 \mathrm{~mL} / \mathrm{g})$. There is little doubt, however, that the linear sorption coefficient $\left(\mathrm{K}_{\mathrm{d}}\right)$ for Tc-99 is close to $0 \mathrm{~mL} / \mathrm{g}$ in Hanford sediments. This low $\mathrm{K}_{\mathrm{d}}$, coupled with its long half-life $\left(2.03 \times 10^{5} \mathrm{yr}\right)$, allows Tc-99 to migrate long distances in both the vadose zone and groundwater, posing a threat to groundwater quality for a long period of time. 


\subsection{Case Descriptions}

The flow and solute transport simulations executed in this report were specified in the MDP (Khaleel et al. 2003). This suite of simulations investigated the impacts on groundwater resources from potential contaminant sources, which included retrieval leaks (spills), past leaks, and residual tank waste from tanks and tank ancillary equipment. Also investigated in this study was the effect of sensitivity of leaks, contaminant release rates, sorption, and initial inventory placement on solute transport. The sensitivity of the aquifer's saturated hydraulic conductivity in contaminant transport was also examined. A twodimensional cross section representing a northwest-southeast transect through the C Tank Farm was used for the computational domain. No scaling of concentrations and water sources was performed to convert the reported concentrations to an effective concentration in three dimensions. The following simulations were conducted for the cross section that included Tanks C-112, C-109, C-106 and C-103 (shown in Figure 3.2):

- Inventory leaks during retrieval using a unit release at Tank C-112 (Cases 1 and 2)

- Past inventory leaks with a unit release between Tanks C-112 and C-109 (Cases 3 and 4)

- Residual waste leachates from tanks following closure using a unit release at Tank C-112 (Cases 5-12, 14)

- Residual waste leachates from tank ancillary equipment following closure using a unit release at Tank C-112 (Case 13)

Data from verification simulations were provided to test the principal of superposition with respect to contaminant transport:

- Inventory leaks during retrieval using a unit release at Tanks -112, -109, -106 and -103 (Case 1 verification)

- Residual waste leachates from tanks following closure using a unit release at Tank C-112, $-109,-106$ and -103 (Case 5 verification)

The effect of increasing the aquifer's saturated hydraulic conductivity was investigated in the following simulations:

- Inventory leaks during retrieval using a unit release at Tank C-112 (Case 1)

- Past inventory leaks with a unit release between Tanks C-112 and C-109 (Cases 3 and 4)

- Residual waste leachates from tanks following closure using a unit release at Tank C-112 (Cases 10 and 11)

Simulations were executed for a period of compliance of approximately 10,000 years. Because tank integrity was presumably lost in January 2050 (and in the year 2500 for Case 9), the simulation of flow and transport in each case was carried out in two stages, one from 1945 to 2050 (2500 for Case 9) and the other from 2050 (2500 for Case 9) to 12000. Once tank integrity was lost, backfill material replaced the impermeable tank structures, except in the diffusion-dominated simulations, where grout filled the tanks. Initial flow conditions for the first stages of the simulation were established with a steady-state flow simulation that assumed a natural infiltration rate of $3.5 \mathrm{~mm} / \mathrm{yr}$. The cases are summarized in Table 2.1 and described in the sections that follow. 


\begin{tabular}{|c|c|c|c|c|c|c|c|c|c|c|c|c|c|c|c|c|}
\hline \multirow{4}{*}{ 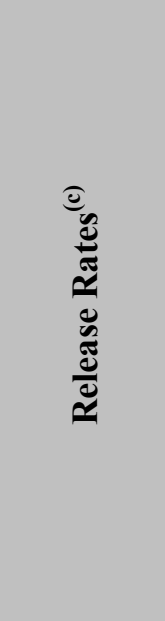 } & 兽 & & & & & $n$ & $\curvearrowleft$ & ๙ू & $\begin{array}{l}\mathscr{2} \\
\hat{\sigma} \\
\text { aे }\end{array}$ & $\stackrel{0}{ }$ & & & & & & \multirow{9}{*}{ 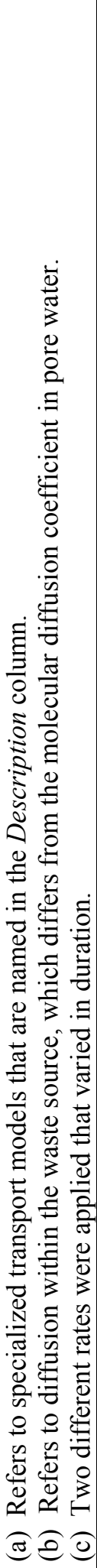 } \\
\hline & 吾 & & & & & 응 & 응 & ?으 & $\stackrel{+}{\circ}$ & 응 & & & & & & \\
\hline & 䓢 & & & & & 8 & $\stackrel{8}{\circ}$ & 8 & $\stackrel{8}{8}$ & & & & & & & \\
\hline & 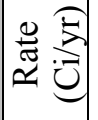 & & & & & $\stackrel{1}{0}$ & $\stackrel{+}{\circ}$ & ?o & io & & & & & & & \\
\hline 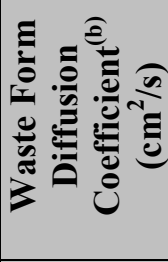 & & & & & & & & & & & & 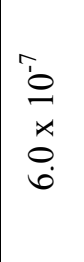 & & $\begin{array}{l}i 0 \\
\dot{x} \\
0 \\
0 \\
0\end{array}$ & $\begin{array}{l}\infty \\
0 \\
x \\
0 \\
0 \\
\dot{n}\end{array}$ & \\
\hline 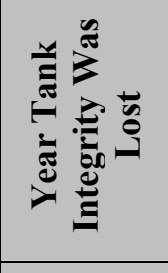 & & 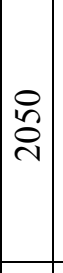 & 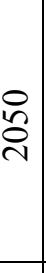 & $\begin{array}{l}\stackrel{2}{2} \\
\stackrel{2}{N}\end{array}$ & 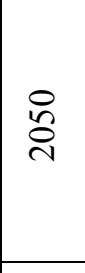 & 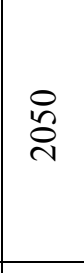 & 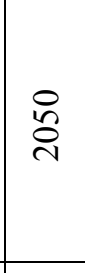 & 尽 & 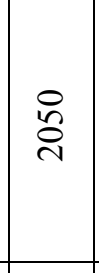 & $\begin{array}{l}8 \\
\stackrel{2}{n} \\
\sim\end{array}$ & ஜ̊ & i̊̀ & iి & 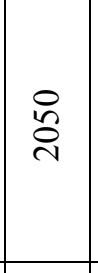 & ஜ̊ & \\
\hline 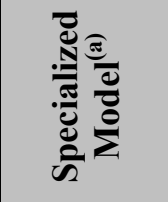 & & & & & & & & & & & $x$ & $x$ & $x$ & $x$ & $x$ & \\
\hline & & 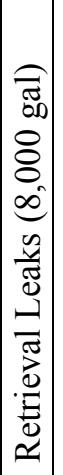 & 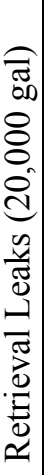 & 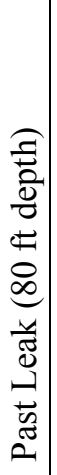 & 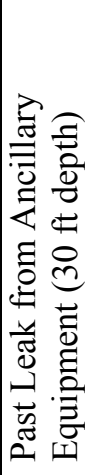 & 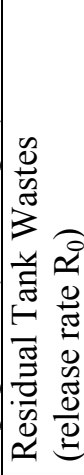 & 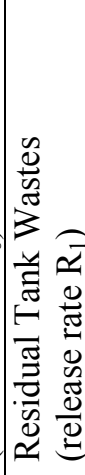 & 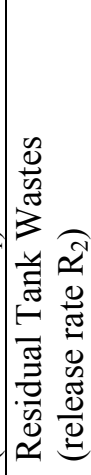 & 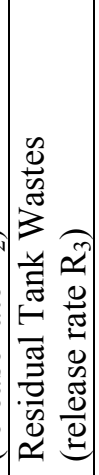 & 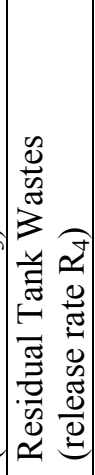 & 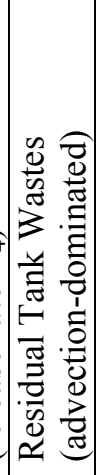 & 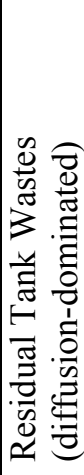 & 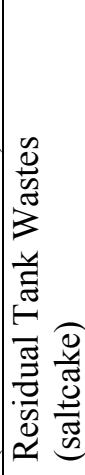 & 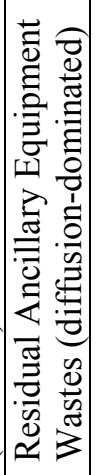 & 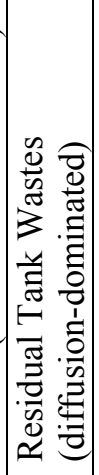 & \\
\hline שֶ & & -1 & $\sim$ & $n$ & $\nabla$ & in & 6 & $r$ & $\infty$ & $a$ & $ㅇ$ & $=$ & $\simeq$ & $\underline{n}$ & $\Xi$ & \\
\hline
\end{tabular}




\subsection{Retrieval Leak (8,000 gallons)}

This scenario (Case 1) investigated a retrieval leak of 8,000 gallons that was in the lower-right corner of Tank C-112 and began on the first day of the year 2000. The leak lasted for 14 days and contained a unit release of each of the contaminant species (Tc-99 and U-238). The U-238 contaminant was simulated with six different linear sorption coefficients $\left(\mathrm{K}_{\mathrm{d}}=0.01,0.03,0.1,0.3,0.6\right.$, and $\left.1.0 \mathrm{~mL} / \mathrm{g}\right)$.

\subsection{Retrieval Leak (20,000 gallons)}

This scenario (Case 2) investigated a retrieval leak of 20,000 gallons that was in the lower-right corner of Tank C-112 and began on the first day of the year 2000. The leak lasted 14 days and contained a unit release of each of the contaminant species (Tc-99 and U-238). The U-238 contaminant was simulated with six different linear sorption coefficients $\left(\mathrm{K}_{\mathrm{d}}=0.01,0.03,0.1,0.3,0.6\right.$, and $\left.1.0 \mathrm{~mL} / \mathrm{g}\right)$.

\subsection{Past Leak (80 ft depth)}

This scenario (Case 3) investigated a past leak at a depth of $80 \mathrm{ft}$ bgs $(24.4 \mathrm{~m})$ and an inventory diameter of $22.9 \mathrm{ft}(7 \mathrm{~m})$ located between Tanks C-112 and C-109. The leak began on the first day of the year 2000. A unit release of each of the contaminant species (Tc-99 and U-238) was simulated. The $\mathrm{U}-238$ contaminant was simulated with six different linear sorption coefficients $\left(\mathrm{K}_{\mathrm{d}}=0.01,0.03,0.1,0.3\right.$, 0.6 , and $1.0 \mathrm{~mL} / \mathrm{g}$ ).

\subsection{Past Leak from Ancillary Equipment (30 ft depth)}

This scenario (Case 4) investigated a past leak at a depth of $30 \mathrm{ft}$ bgs $(9.1 \mathrm{~m})$ and an inventory diameter of $22.9 \mathrm{ft}(7 \mathrm{~m})$ located between Tanks C-112 and C-109. The leak began on the first day of the year 2000. A unit release of each of the contaminant species (Tc-99 and U-238) was simulated. The U-238 contaminant was simulated with six different linear sorption coefficients $\left(\mathrm{K}_{\mathrm{d}}=0.01,0.03,0.1,0.3\right.$, 0.6 , and $1.0 \mathrm{~mL} / \mathrm{g})$.

\subsection{Residual Tank Waste (release rate $\mathbf{R}_{0}$ )}

This scenario (Case 5) investigated a residual tank waste source with release rate $\mathrm{R}_{0}$, which was defined as $10^{-3} \mathrm{Ci} / \mathrm{yr}$ for 500 years, followed by $0.1 \mathrm{Ci} / \mathrm{yr}$ for 5 years. The release occurred over the bottom width of Tank C-112. The leak began on the first day of the year 2050, the date when tank integrity was lost. A unit release of each of the contaminant species (Tc-99 and U-238) was simulated. The U-238 contaminant was simulated with six different linear sorption coefficients $\left(\mathrm{K}_{\mathrm{d}}=0.01,0.03,0.1\right.$, $0.3,0.6$, and $1.0 \mathrm{~mL} / \mathrm{g}$ ). 


\subsection{Residual Tank Waste (release rate $\mathbf{R}_{1}$ )}

This scenario (Case 6) investigated a residual tank waste source with release rate $\mathrm{R}_{1}$, which was defined as $10^{-4} \mathrm{Ci} / \mathrm{yr}$ for 500 years, followed by $10^{-3} \mathrm{Ci} / \mathrm{yr}$ for 95 years. The release occurred over the bottom width of Tank C-112. The leak began on the first day in the year 2050, the date when tank integrity was lost. A unit release of each of the contaminant species (Tc-99 and U-238) was simulated. The U-238 contaminant was simulated with six different linear sorption coefficients $\left(\mathrm{K}_{\mathrm{d}}=0.01,0.03,0.1\right.$, $0.3,0.6$, and $1.0 \mathrm{~mL} / \mathrm{g}$ ).

\subsection{Residual Tank Waste (release rate $\mathbf{R}_{2}$ )}

This scenario (Case 7) investigated a residual tank waste source with a release rate $\mathrm{R}_{2}$, which was defined as $10^{-5} \mathrm{Ci} / \mathrm{yr}$ for 500 years, followed by $10^{-2} \mathrm{Ci} / \mathrm{yr}$ for 995 years. The release occurred over the bottom width of Tank C-112. The leak began on the first day of the year 2050, the date when tank integrity was lost. A unit release of each of the contaminant species (Tc-99 and U-238) was simulated. The U-238 contaminant was simulated with six different linear sorption coefficients $\left(\mathrm{K}_{\mathrm{d}}=0.01,0.03,0.1\right.$, $0.3,0.6$, and $1.0 \mathrm{~mL} / \mathrm{g}$ ).

\subsection{Residual Tank Waste (release rate $\mathbf{R}_{3}$ )}

This scenario (Case 8) investigated a residual tank waste source with a release rate $\mathrm{R}_{3}$, which was defined as $10^{-6} \mathrm{Ci} / \mathrm{yr}$ for 500 years, followed by $10^{-4} \mathrm{Ci} / \mathrm{yr}$ for 9,995 years. The release occurred over the bottom width of Tank C-112. The leak began on the first day of the year 2050, the date when tank integrity was lost. This was the only case in which a full unit release of each contaminant species (Tc-99 and U-238) was not simulated. This occurred because the full release was to last 10,495 years. Because the release began in the year 2050, and flow and transport was simulated to the year 12000, 545 years of the planned release did not occur. The U-238 contaminant was simulated with six different linear sorption coefficients $\left(\mathrm{K}_{\mathrm{d}}=0.01,0.03,0.1,0.3,0.6\right.$, and $\left.1.0 \mathrm{~mL} / \mathrm{g}\right)$.

\subsection{Residual Tank Waste (release rate $\mathbf{R}_{4}$ )}

This scenario (Case 9) investigated a residual tank waste source with release rate $\mathrm{R}_{4}$, which was defined as $0.1 \mathrm{Ci} / \mathrm{yr}$ for 10 years. The release occurred over the bottom width of Tank $\mathrm{C}-112$. The leak began on the first day in the year 2500, the date when tank integrity was lost. A unit release of each of the contaminant species (Tc-99 and U-238) was simulated. The U-238 contaminant was simulated with six different linear sorption coefficients $\left(\mathrm{K}_{\mathrm{d}}=0.01,0.03,0.1,0.3,0.6\right.$, and $\left.1.0 \mathrm{~mL} / \mathrm{g}\right)$.

\subsection{Residual Tank Waste (advection dominated)}

This scenario (Case 10) investigated a residual tank waste source using an advection-dominated release model. The release occurred over the bottom width of Tank C-112, with a source thickness of $0.825 \mathrm{~m}$. The leak began on the first day of the year 2050, the date when tank integrity was lost. A unit 
release of each of the contaminant species (Tc-99 and U-238) was simulated. The U-238 contaminant was simulated with six different linear sorption coefficients $\left(\mathrm{K}_{\mathrm{d}}=0.01,0.03,0.1,0.3,0.6\right.$, and $\left.1.0 \mathrm{~mL} / \mathrm{g}\right)$.

\subsection{Residual Tank Waste (diffusion dominated)}

This scenario (Case 11) investigated a residual tank waste source using a diffusion-dominated release model and a diffusion coefficient of $6 \times 10^{-7} \mathrm{~cm}^{2} / \mathrm{s}$. The release occurred over the bottom width of Tank C-112 with a source thickness of $0.825 \mathrm{~m}$. The leak began on the first day of the year 2050, the date tank integrity was lost. Grout was used as tank fill material beginning in the year 2050. A unit release of each of the contaminant species (Tc-99 and U-238) was simulated. The U-238 contaminant was simulated with six different linear sorption coefficients $\left(\mathrm{K}_{\mathrm{d}}=0.01,0.03,0.1,0.3,0.6\right.$, and $\left.1.0 \mathrm{~mL} / \mathrm{g}\right)$.

\subsection{Residual Tank Waste (saltcake)}

This scenario (Case 12) investigated a residual tank waste source using a saltcake release model that assumed an aqueous solubility of $360 \mathrm{mg} / \mathrm{L}$ for the residual waste. The release occurred over the bottom width of Tank C-112 with a source thickness of $0.825 \mathrm{~m}$. The leak began on the first day in the year 2050, the date when tank integrity was lost. A unit release of each of the contaminant species (Tc-99 and U238) was simulated. The U-238 contaminant was simulated with six different linear sorption coefficients $\left(\mathrm{K}_{\mathrm{d}}=0.01,0.03,0.1,0.3,0.6\right.$, and $\left.1.0 \mathrm{~mL} / \mathrm{g}\right)$.

\subsection{Residual Ancillary Equipment Waste (diffusion dominated)}

This scenario (Case 13) investigated a residual ancillary equipment waste source using a diffusiondominated release model and a diffusion coefficient of $6 \times 10^{-7} \mathrm{~cm}^{2} / \mathrm{s}$. The waste source originated between Tanks C-112 and C-109 at a depth of $20 \mathrm{ft}(6.1 \mathrm{~m})$ below ground surface with an inventory diameter of $22.9 \mathrm{ft}(7 \mathrm{~m})$. Grout was used as tank fill material. The leak began on the first day of the year 2050, the date when tank integrity was lost. A unit release of each of the contaminant species (Tc-99 and U-238) was simulated. The U-238 contaminant was simulated with six different linear sorption coefficients $\left(\mathrm{K}_{\mathrm{d}}=0.01,0.03,0.1,0.3,0.6\right.$, and $\left.1.0 \mathrm{~mL} / \mathrm{g}\right)$.

\subsection{Residual Tank Waste (diffusion dominated)}

This scenario (Case 14) investigated a residual tank waste source using a diffusion-dominated release model and a diffusion coefficient of $5 \times 10^{-8} \mathrm{~cm}^{2} / \mathrm{s}$. The release occurred over the bottom width of Tank C-112 with a source thickness of $0.825 \mathrm{~m}$. The leak began on the first day of the year 2050, the date when tank integrity was lost. Grout was used as tank fill material beginning in the year 2050. A unit release of each of the contaminant species (Tc-99 and U-238) was simulated. The U-238 contaminant was simulated with six different linear sorption coefficients $\left(\mathrm{K}_{\mathrm{d}}=0.01,0.03,0.1,0.3,0.6\right.$, and $\left.1.0 \mathrm{~mL} / \mathrm{g}\right)$. 


\subsection{Technical Approach}

A multistep approach was used to execute the simulations described in the modeling data package (Khaleel et al. 2003). In brief, the approach involved converting information in the data package to a suite of input files, executing the STOMP simulator, translating the simulation results into graphical form, and determining solute concentrations at the compliance points. This section provides an overview, followed by a more extensive review of these steps. In the discussions that follow, MDP refers to the modeling data package (Khaleel et al. 2003).

\subsection{Overview}

Two types of input are defined in a STOMP simulation: 1) a simulation control and material definition file, and 2) a soil zonation file. Modeling input data stored in these files were developed from the modeling data package in conjunction with the discretization of the physical domain. The physical domain was a northwest-southeast two-dimensional cross section in the C Tank Farm. The physical domain was discretized using a Cartesian grid with uniform horizontal and vertical spacing of $1 \mathrm{~m}$.

Graphical representations of geologic interpretations and engineered structures in the C Tank Farm subsurface (Khaleel et al. 2003, Appendix B) were converted to zonation maps based on the Cartesian discretization of the physical domain. Hydrologic properties, as defined in the MDP, for each of six identified soil types were converted to input in the form of STOMP input cards. Transport property data for the two contaminants and six soil-type combinations were converted to input in the form of STOMP input cards. The conceptual model was then completed by converting boundary conditions and sources, as specified in the MDP, into input in the form of STOMP input cards, specifying execution controls and requesting output data.

Time-varying surface recharge and tank leaks required a transient flow solution to be executed with the solute transport calculations. The transient flow and transport simulations were initiated using a steady flow solution to the boundary value problem using the initial boundary values. This approach neglects time variations in surface recharge prior to the start of simulation. The steady flow initial condition was generated with a simulation to steady flow conditions. The same steady-state flow solution was used for each of the 14 cases executed in this work. This represented the preconstruction time period for the C Tank Farm. This simulation did not involve solute transport and was executed as a transient simulation from a unit-gradient initial condition to a steady flow condition that honored the surface recharge and unconfined aquifer flux. The steady flow and transient simulations were executed on a Linux workstation. For compatibility between platforms, the input, zonation, and inventory files were maintained as ASCII formatted files.

The steady flow solution was then used as an initial condition for the 14 transient flow and solute transport cases executed in this work. Because in all cases tank integrity was eventually lost, the transient simulations were simulated in two stages. In the first stage, flow and solute transport were simulated while the tanks were still intact. In this stage, nodes representing the tanks were inactive, hence impermeable to flow and transport. In the second stage, once tank integrity was lost, these nodes were converted to active nodes with a material type identical to that surrounding the tanks in the C Tank Farm. 
Simulation results were written to three types of output files: 1) a reflected input and reference node file, 2) a series of plot files, and 3) a series of surface-flux files. The reflected input and reference node file contains a translation of the input files as interpreted by the simulator (e.g., with unit conversions) and a time sequence of the simulation history and chosen variables (e.g., aqueous pressure, moisture content, solute concentrations, Darcy fluxes) at selected grid locations. Plot files contain variable data for all grid points at selected simulation times. These files are used to generate color-scaled plots and animations through Tecplot. ${ }^{(a)}$ A utility program, PlotTec, is used to translate STOMP plot files into Tecplotformatted input files. Surface-flux files contain rate and integral information about fluxes crossing userdefined internal or external boundaries. Solute fluxes and aqueous fluxes at the downgradient domain boundary within the groundwater are used to calculate average solute concentrations and source rates. Surface-flux files are also used to generate rate and integral plots of solutes exiting the computational domain and entering the groundwater. A utility program, Surfcalc, was used to translate STOMP surfaceflux files into formatted input files suitable for plotting.

Solute breakthrough curves for the aquifer, or solute concentrations as a function of time at the compliance points outside the $\mathrm{C}$ Tank Farm, were computed by extrapolating solute concentrations exiting the STOMP computational domain. An analytical solution to the advection-dispersion equation for solute transport through a saturated porous media in three dimensions was used, following the approach described by Baetslé (1969) and documented in Domenico and Schwartz (1990). This approach assumed that the solute originated at a point source as a series of slugs released over time. The method of superposition was used to integrate the slug releases. The solute mass from each slug migrated from the point source by advective-dispersive transport in a steady, uniform flow field. As the solute mass was transported advectively with the flow, it spread longitudinally and transversely via hydrodynamic dispersion and molecular diffusion. The mass flux of solute used as input was computed from the STOMP surface file output for mass flux exiting the 15-m-thick aquifer at the east side of the domain. Aquifer recharge along the groundwater flow path was neglected in translating solute concentrations to the compliance points.

\subsection{Modeling Data Package}

Meteoric recharge and parameters for vadose zone flow and transport were provided in the MDP. Additional data on aquifer parameters and dimensions are summarized in Tables 3.1 and 3.2. Selected data are repeated in this section.

Differences in aquifer velocities reported in the Groundwater Monitoring Report (Bergeron and Wurstner 2000) and velocities used in the unsaturated (STOMP) and saturated (streamtube) modeling occur due to differences in spatial variability of hydraulic conductivity and hydraulic gradient. For example, the hydraulic gradient in the cross section used in the STOMP modeling is smaller than the gradient that spans the distance between the $\mathrm{C}$ Tank Farm and the Columbia River. As a result, groundwater velocity estimates used in this analysis differ from that reported by Bergeron and Wurstner (2000).

(a) Amtec Engineering, Inc. 2002. Tecplot, Version 9.0. Bellevue, WA. 
Table 3.1. Cross-Section Aquifer Geometry and Properties

\begin{tabular}{|l|l|l||}
\hline \multicolumn{1}{|c|}{ Parameter } & \multicolumn{1}{|c||}{ Value } & \multicolumn{1}{c|}{ Reference } \\
\hline Aquifer Hydraulic Conductivity & $0.48 \mathrm{~m} /$ day & MDP (Khaleel et al. 2003) \\
Effective Porosity & 0.138 & \\
Hydraulic Gradient & $0.00045 \mathrm{~m} / \mathrm{m}$ & \\
Aquifer Thickness & $15 \mathrm{~m}$ & Groundwater Monitoring Report \\
Groundwater Velocity & $0.8 \mathrm{~m} /$ day & (Bergeron and Wurstner 2000, \\
& & Table A.2) \\
\hline
\end{tabular}

Table 3.2. Streamtube Aquifer Geometry and Properties

\begin{tabular}{|l|c|l||}
\hline \multicolumn{1}{|c|}{ Parameter } & Value & \multicolumn{1}{|c||}{ Reference } \\
\hline \multicolumn{3}{|c||}{ Northward Path Through Gap } \\
\hline Distance to exclusion boundary & $3.8 \mathrm{~km}$ & VAM3D Simulation Travel Markers \\
Travel time to exclusion boundary & $40 \mathrm{yr}$ & (Law et al. 1996; Lu 1996) \\
Mean velocity to exclusion boundary & $93.8 \mathrm{~m} / \mathrm{yr}$ & \\
\hline Distance to river boundary & $20.6 \mathrm{~km}$ & VAM3D Simulation Travel Markers \\
Travel time to river boundary & $580 \mathrm{yr}$ & (Law et al. 1996; Lu 1996) \\
Mean velocity to river boundary & $35.5 \mathrm{~m} / \mathrm{yr}$ & \\
\hline \multicolumn{3}{|c||}{ Southeast Path } \\
\hline Distance to exclusion boundary & $2.9 \mathrm{~km}$ & VAM3D Simulation Travel Markers \\
Travel time to exclusion boundary & $40 \mathrm{yr}$ & (Law et al. 1996; Lu 1996) \\
Mean velocity to exclusion boundary & $115 \mathrm{~m} / \mathrm{yr}$ & \\
\hline Distance to river boundary & $14.3 \mathrm{~km}$ & VAM3D Simulation Travel Markers \\
Travel time to river boundary & $260 \mathrm{yr}$ & (Law et al. 1996; Lu 1996) \\
Mean velocity to river boundary & $61.5 \mathrm{~m} / \mathrm{yr}$ & \\
\hline
\end{tabular}

\subsubsection{Recharge Estimates}

Portions of the C Tank Farm surfaces are covered with gravel to prevent vegetative growth and provide radiation shielding for site workers. Bare gravel surfaces, however, enhance net infiltration of meteoric water compared with undisturbed, naturally vegetated surfaces. Between tanks, infiltration is further enhanced by the effect of percolating water being diverted by the impermeable sloping surface of the tank domes.

Recharge rates for all 14 cases were varied to represent various stages of tank and barrier construction. For example, the beginning of the simulation represents the tank preconstruction period, and recharge is estimated at $3.5 \mathrm{~mm} / \mathrm{yr}$. Once the tanks are in place in the year 1945, recharge rates increase 
to their current estimate of $100 \mathrm{~mm} / \mathrm{yr}$. In the year 2050, a protective barrier is installed at the surface, and the recharge rate estimate decreases to $0.5 \mathrm{~mm} / \mathrm{yr}$. The recharge rate is increased again to $3.5 \mathrm{~mm} / \mathrm{yr}$ when degradation of the barrier occurs in the year 2550. These values are summarized in Table 3.3

(Khaleel et al. 2003).

Table 3.3. Recharge Estimates

\begin{tabular}{|c|c|c|c|c||}
\hline Years & Pre-1945 & $\mathbf{1 9 4 5 - 2 0 5 0}$ & $\mathbf{2 0 5 0 - 2 5 5 0}$ & $\mathbf{2 5 5 0 - 1 2 0 0 0}$ \\
\hline $\begin{array}{c}\text { Recharge Rate } \\
(\mathrm{mm} / \mathrm{yr})\end{array}$ & 3.5 & 100.0 & 0.5 & 3.5 \\
\hline
\end{tabular}

\subsubsection{Vadose Zone Flow and Transport Properties}

Upscaled values of parameters for fluid flow and solute transport for the vadose zone were used in these investigations. Details for computing upscaled parameters are provided in Khaleel et al. (2003). Fluid flow parameters for the vadose zone include soil moisture retention characteristics and saturated hydraulic conductivity. Solute transport parameters include bulk density, diffusivity, sorption coefficients, and macrodispersivity. Table 3.4 lists the composite, fitted van Genuchten-Mualem parameters (van Genuchten 1980) for various strata at the C Tank Farm. Note that the material type numbers are identical to those indicated in the MDP Section 4.2.

Table 3.4. Composite van Genuchten-Mualem Parameters for Various Strata at the C Tank Farm (Khaleel et al. 2003, Appendix C)

\begin{tabular}{|l|c|c|c|c|c|c|c|}
\hline Strata/Material Type & $\begin{array}{c}\text { Number of } \\
\text { Samples }\end{array}$ & $\theta_{\mathbf{s}}$ & $\theta_{\mathbf{r}}$ & $\begin{array}{c}\alpha \\
\mathbf{1 / c m}\end{array}$ & $\mathbf{n}$ & $\boldsymbol{l}$ & $\begin{array}{c}\mathbf{K}_{\mathbf{s}} \\
\mathbf{c m} / \mathbf{s}\end{array}$ \\
\hline Backfill (1) & 10 & 0.1380 & 0.0100 & 0.0210 & 1.3740 & 0.5 & $5.60 \mathrm{e}-04$ \\
Sand H2 (2) & 12 & 0.3819 & 0.0443 & 0.117 & 1.6162 & 0.5 & $9.88 \mathrm{e}-05$ \\
Gravelly Sand H3 (3) & 8 & 0.2688 & 0.0151 & 0.0197 & 1.4194 & 0.5 & $5.15 \mathrm{e}-04$ \\
Gravelly Sand H1 (4) & 11 & 0.2126 & 0.0032 & 0.0141 & 1.3730 & 0.5 & $2.62 \mathrm{e}-04$ \\
Hanford-Ringold/ & 10 & 0.1380 & 0.0100 & 0.0210 & 1.3740 & 0.5 & $5.60 \mathrm{e}-04$ \\
Plio-Pleistocene (5) & 10 & 0.1380 & 0.0100 & 0.0210 & 1.3740 & 0.5 & $5.60 \mathrm{e}-04$ \\
Aquifer &
\end{tabular}

\subsubsection{Stochastic Model for Macroscopic Anisotropy}

Variable tension-dependent anisotropy provides a framework for upscaling small-scale laboratory measurements to the effective (i.e., upscaled) properties for the large-scale tank farm vadose zone. A stochastic model (Polmann 1990) was used to evaluate tension-dependent anisotropy for sediments at the C Tank Farm; details are in Khaleel et al. (2003, Appendix C). The following is a brief description of the variable anisotropy model used in this investigation. 
Yeh et al. (1985) analyzed steady unsaturated flow through heterogeneous porous media using a stochastic model; parameters such as hydraulic conductivity were treated as random variables rather than deterministic quantities. The Gardner (1958) relationship was used by Yeh et al. (1985) to describe unsaturated hydraulic conductivity as a function of saturated hydraulic conductivity and tension according to Equation (3.1):

$$
K(\psi)=K_{S} \exp (-\beta \psi)
$$

where $K$ is the unsaturated hydraulic conductivity, $K_{S}$ is the saturated hydraulic conductivity, $\psi$ is the tension, and $\beta$ is a fitting parameter. Eq. (3.1) can be written as shown in Eq. (3.2). This form is referred to as the log-linear model:

$$
\ln K(\psi)=\ln K_{s}-\beta \psi
$$

because the log of the hydraulic conductivity is linearly related to the tension through a constant slope. A constant slope, however, is often inadequate for describing $\ln K(\psi)$ over the range of tension of interest for field applications. As an alterative, $\beta$ can be approximated locally by straight lines over a range of tensions. The $\ln K_{S}$ term can then be derived by extrapolating the local slopes to zero tension.

Using a linear correlation model between the zero-tension intercept and $\beta$, Polmann (1990) presented a generalized model that accounts for the cross-correlation of the local soil property (i.e., $\ln K_{s}$ and $\beta$ ) residual fluctuations. Compared with the uncorrelated $\ln K_{s}$ and $\beta$ model, partial correlation of the properties was shown to have a significant impact on the magnitude of the effective parameters derived from the stochastic theory. The Polmann (1990) equations for deriving the effective parameters are shown in Eq. (3.3) through (3.6):

$$
\begin{gathered}
\langle\operatorname{LnK}(\psi)\rangle=\left\langle\operatorname{Ln} K_{s}\right\rangle-A\langle\psi\rangle-\frac{\sigma_{L n K s}^{2} \lambda\left[p-p^{2}\langle\psi\rangle-\zeta^{2}\langle\psi\rangle\right]}{(1+A \lambda)} \\
\sigma_{L n K(\psi)}^{2}=\frac{\left.\sigma_{L n K s}^{2} \mid(1-p\langle\psi\rangle)^{2}+\zeta^{2}\langle\psi\rangle^{2}\right]}{(1+A \lambda)} \\
K_{h}^{e q}=\exp \left[\langle\operatorname{LnK}(\psi)\rangle+\frac{\sigma_{L n K(\psi)}^{2}}{2}\right] \\
K_{v}^{e q}=\exp \left[\langle\operatorname{LnK}(\psi)\rangle-\frac{\sigma_{L n K(\psi)}^{2}}{2}\right]
\end{gathered}
$$

where 


$$
\begin{array}{ll}
\sigma_{\mathrm{LnK}}^{2} & =\text { the variance of log unsaturated conductivity } \\
\langle\psi\rangle & =\text { the mean tension } \\
\sigma_{\mathrm{LnKS}}^{2} & =\text { the variance of } \ln K_{S} \\
\left\langle\operatorname{Ln} K_{S}\right\rangle & =\text { the mean of } \ln K_{S} \\
p & =\text { the slope of the } \beta \text { versus } \ln K_{S} \text { regression line } \\
& \zeta=\frac{\sigma_{\delta}}{\sigma_{L n K s}} \\
\sigma_{\delta} & =\text { the standard deviation of the residuals in the } \beta \text { versus } \ln K_{S} \text { regression } \\
A & =\text { the mean slope, } \beta, \text { for } \ln K_{S} \text { versus } \psi \\
\lambda & =\text { the vertical correlation length for } \ln K_{S} \\
K_{h}^{e q} & =\text { the equivalent unsaturated horizontal hydraulic conductivity } \\
K_{v}^{e q} &
\end{array}
$$

Macroscopic anisotropy parameter estimates for the strata at the C Tank Farm are listed in Table 3.5. Details on these parameters and their derivation are included in Khaleel et al. (2003, Appendix C) and White et al. (2001).

Table 3.5. Macroscopic Anisotropy Parameters Based on Polmann Equations for Strata at the C Tank Farm (Khaleel et al. 2003, Section 4.2)

\begin{tabular}{||l|c|c|c|c|c|c|c||}
\hline $\begin{array}{c}\text { Strata/Material } \\
\text { Type }\end{array}$ & $\begin{array}{c}\text { No. of } \\
\text { Samples }\end{array}$ & $\left\langle\operatorname{Ln} K_{S}\right\rangle$ & $\sigma_{\text {LnKs }}^{2}$ & $p$ & $\zeta$ & $\begin{array}{c}\lambda \\
(\mathrm{cm})\end{array}$ & $A$ \\
\hline Backfill (1) & 10 & -15.76 & 3.56 & $-1.1 \mathrm{e}-4$ & $1.84 \mathrm{e}-4$ & 30 & 0.00371 \\
Sand H2 (2) & 12 & -14.59 & 1.50 & $-7.2 \mathrm{e}-4$ & $6.55 \mathrm{e}-4$ & 50 & 0.00620 \\
Gravelly Sand H3 (3) & 11 & -14.85 & 1.94 & $-2.6 \mathrm{e}-4$ & $2.50 \mathrm{e}-4$ & 30 & 0.00368 \\
Gravelly Sand H1 (4) & 8 & -15.30 & 1.83 & $-5.6 \mathrm{e}-4$ & $5.16 \mathrm{e}-4$ & 50 & 0.00415 \\
Hanford-Ringold/ & 10 & -15.76 & 3.56 & $-1.1 \mathrm{E}-4$ & $1.84 \mathrm{E}-4$ & 30 & 0.00371 \\
Plio-Pleistocene (5) & & & & & & \\
\hline
\end{tabular}

\subsubsection{Bulk Density and Sorption Coefficient}

Both bulk density $\left(\rho_{b}\right)$ and the sorption coefficient $\left(K_{d}\right)$ estimates were needed to calculate retardation factors for different solute species. The effective, large-scale estimate for the product $\rho_{b} K_{d}$ was considered to be the average of the product of small-scale laboratory measurements for bulk density and distribution coefficient (Gelhar 1993). Effective large-scale estimates of bulk density, distribution coefficient, and their product for $\mathrm{U}-238$ for a $\mathrm{K}_{\mathrm{d}}$ of $0.6 \mathrm{~mL} / \mathrm{g}$ are listed in Table 3.6 for the five strata samples. 
Table 3.6. Effective Parameter Estimates for the Product of Bulk Density and Retardation Coefficient for U-238 at the C Tank Farm

\begin{tabular}{|l|c|c|c|}
\hline \multicolumn{1}{|c|}{ Strata/Material } & $K_{d}$ & $E\left[\rho_{b}\right]$ & $E\left[\rho_{b} K_{d}\right]$ \\
\hline Backfill (1) & $0.6 \mathrm{~mL} / \mathrm{g}$ & 2.13 & 0.59 \\
Sand H2 (2) & $0.6 \mathrm{~mL} / \mathrm{g}$ & 1.76 & 1.04 \\
Gravelly Sand H3 (3) & $0.6 \mathrm{~mL} / \mathrm{g}$ & 2.07 & 1.24 \\
Gravelly Sand H1 (4) & $0.6 \mathrm{~mL} / \mathrm{g}$ & 1.94 & 1.17 \\
Hanford-Ringold/ & $0.6 \mathrm{~mL} / \mathrm{g}$ & 2.13 & 0.59 \\
Plio-Pleistocene (5) & $0.6 \mathrm{~mL} / \mathrm{g}$ & 2.13 & 0.59 \\
Aquifer &
\end{tabular}

The average $\rho_{b}, E\left[\rho_{b}\right]$ estimates were based on data in Khaleel et al. (2003). The $K_{d}$ estimates for U-238 were based on Kaplan and Serne (1999) data for undisturbed sediments. The distribution coefficient for the Tc-99 was estimated to be zero.

\subsubsection{Diffusivity}

It was assumed that the effective, large-scale diffusion coefficients for all strata at the $\mathrm{C}$ Tank Farm were a function of volumetric moisture content and could be expressed using the Millington and Quirk (1961) empirical relation, as shown in Eq. 3.7:

$$
D_{e}(\theta)=D_{o} \frac{\theta^{10 / 3}}{\theta_{s}^{2}}
$$

where $D_{e}$ is the effective diffusion coefficient of an ionic species, $D_{o}$ is the molecular diffusion coefficient for the species in water, $\theta$ is the water content, and $\theta_{S}$ is the saturated water content. The molecular diffusion coefficient for all species in pore water was assumed to be $2.5 \times 10^{-5} \mathrm{~cm}^{2} / \mathrm{s}$ (Kincaid et al. 1995).

\subsubsection{Macrodispersivity}

Field-scale dispersivities are referred to as macrodispersivities. The heterogeneities that exist at various length scales result in a scale dependence of macrodispersivities. An extended review is provided in Appendix C of Khaleel et al. (2003) on the rationale for vadose zone macrodispersivity estimates. Macrodispersivity estimates were needed for both reactive (U-238) and nonreactive (Tc-99) species. Estimates for the nonreactive species are listed in Table 3.7.

The net effect of species sorption is to retard the migration through geologic media. Soil sorption is a function of the species and soil properties and varies spatially with soil properties (Gelhar 1993; Talbott and Gelhar 1994). Stochastic analysis results for macrodispersivity enhancement for the five strata are presented in Appendix C of Khaleel et al. (2003) for the reactive species (U-238). In this analysis, the 
Table 3.7. Nonreactive Macrodispersivity Estimates for Strata at the C Tank Farm

\begin{tabular}{|l|c|c|c|c|}
\hline \multicolumn{1}{|c|}{ Strata/Material } & $\sigma_{\text {InK }}^{2}$ & $\begin{array}{c}\text { Correlation } \\
\text { Length } \boldsymbol{\lambda}, \mathbf{c m}\end{array}$ & $\mathbf{A}_{\mathbf{L}}, \mathbf{c m}$ & $\mathbf{A}_{\mathbf{T}}, \mathbf{c m}$ \\
\hline Backfill (1) & 4.54 & 30 & $\sim 150$ & 15 \\
Sand H2 (2) & 4.60 & 30 & $\sim 150$ & 15 \\
Gravelly Sand H3 (3) & 3.19 & 30 & $\sim 100$ & 10 \\
Gravelly Sand H1 (4) & 4.95 & 30 & $\sim 100$ & 10 \\
Hanford-Ringold/ & 0.92 & 30 & $\sim 150$ & 15 \\
Plio-Pleistocene (5) & & & $\sim 150$ & 15 \\
Aquifer & 4.54 & 30 & & \\
\hline
\end{tabular}

unsaturated hydraulic conductivities were evaluated at a tension of $100 \mathrm{~cm}$ via the fitted van GenuchtenMualem relation. The macrodispersivity enhancement ranged from 1.06 for sandy sediments to about 2.24 for Plio-Pleistocene (silty) sediments.

\subsection{Input File Generation}

Two types of input files were used to drive the STOMP simulator: 1) a simulation control file and material definition (input) and 2) a soil zonation file (zonation). All input files were written and stored in ASCII text format. The simulation control and material definition input files were assembled using a conventional text editor, whereas the zonation file was generated with a utility program.

\subsubsection{Input File}

As described in the STOMP User's Guide (White and Oostrom 2000a), the input file is divided into cards that group common data (e.g., solution control, hydraulic properties, output control, boundary conditions). The input files for the simulated cases will be provided in electronic form (see Section 5).

\subsubsection{Zonation File}

The zonation file is an ordered listing (i.e., I,J,K indexing) of integers that identify the rock/soil type for every grid cell in the computational domain. Inactive nodes are assigned an integer value of zero, and rock/soil types are assigned numbers in accordance with the ordered listing of rock/soil types in the rock/ soil zonation card. For example, an integer value of one in the zonation file refers to backfill, and a value of three refers to gravelly sand H3. Zonation files for the executed simulations were generated for the C cross section shown in Figure 3.1 (also shown in MDP, Appendix B). Color delineated images of the zonation files for the C Tank Farm cross sections are shown in Figure 3.2. In Figure 3.2a, the preconstruction period for the tank farm is shown. Figure 3.2b shows the post-construction tank farm cross section, where the $\mathrm{H} 1$ gravelly sand unit has been replaced with backfill material surrounding the tanks. These files were generated from digitized versions of the geologic cross sections for the C Tank Farm (Figure 3.1). 


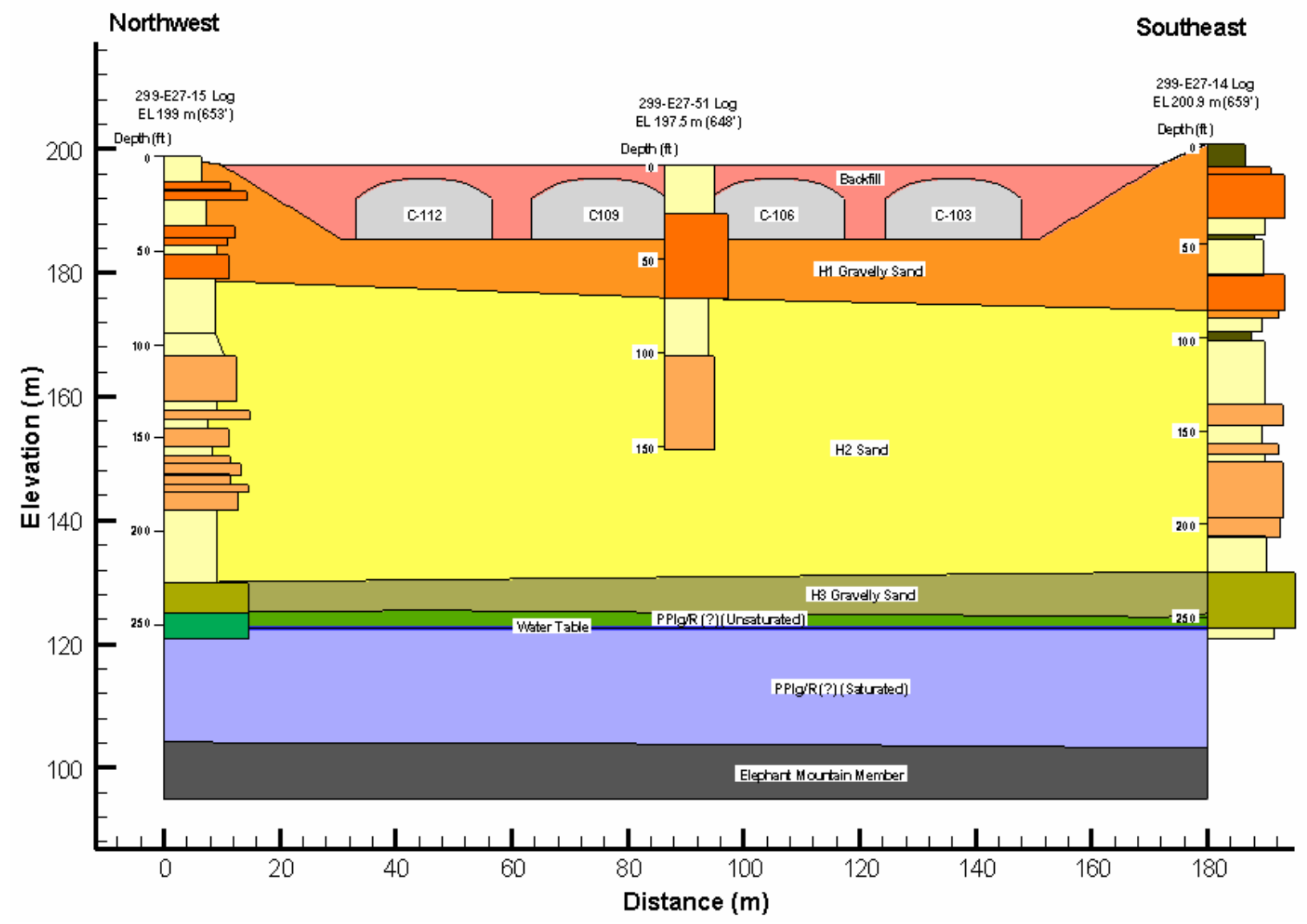

Figure 3.1. Northwest - Southeast Cross Section for the C Tank Farm Through Tanks C-112, C-109, C-106 and C-103 (after Khaleel et al. 2003)

The cross section containing Tanks C-112, -109, -106 and -103 (Figure 3.2b), was modeled using a computation domain with a horizontal extent of $180 \mathrm{~m}$, a vertical extent of $97 \mathrm{~m}$, and unit width. Spacing of $1 \mathrm{~m}$ was used for the computational grid in both the horizontal and vertical directions. The geology for both of these cross sections is a primarily layered system created by alluvial deposition, with a more permeable gravely sand stratum that forms the foundation for the tank bottoms.

\subsection{Implemented Features}

For the S-SX field investigation (White et al. 2001), the STOMP simulator, as documented in White and Oostrom (2000a, 2000b) and Nichols et al. (2000), was modified to extend its capabilities for modeling saturation dependent anisotropy, enhanced macrodispersivity, and specialized Courant number control. These features were also implemented for the $\mathrm{C}$ Tank Farm simulations. For a detailed description of these features, refer to White et al. (2001). 

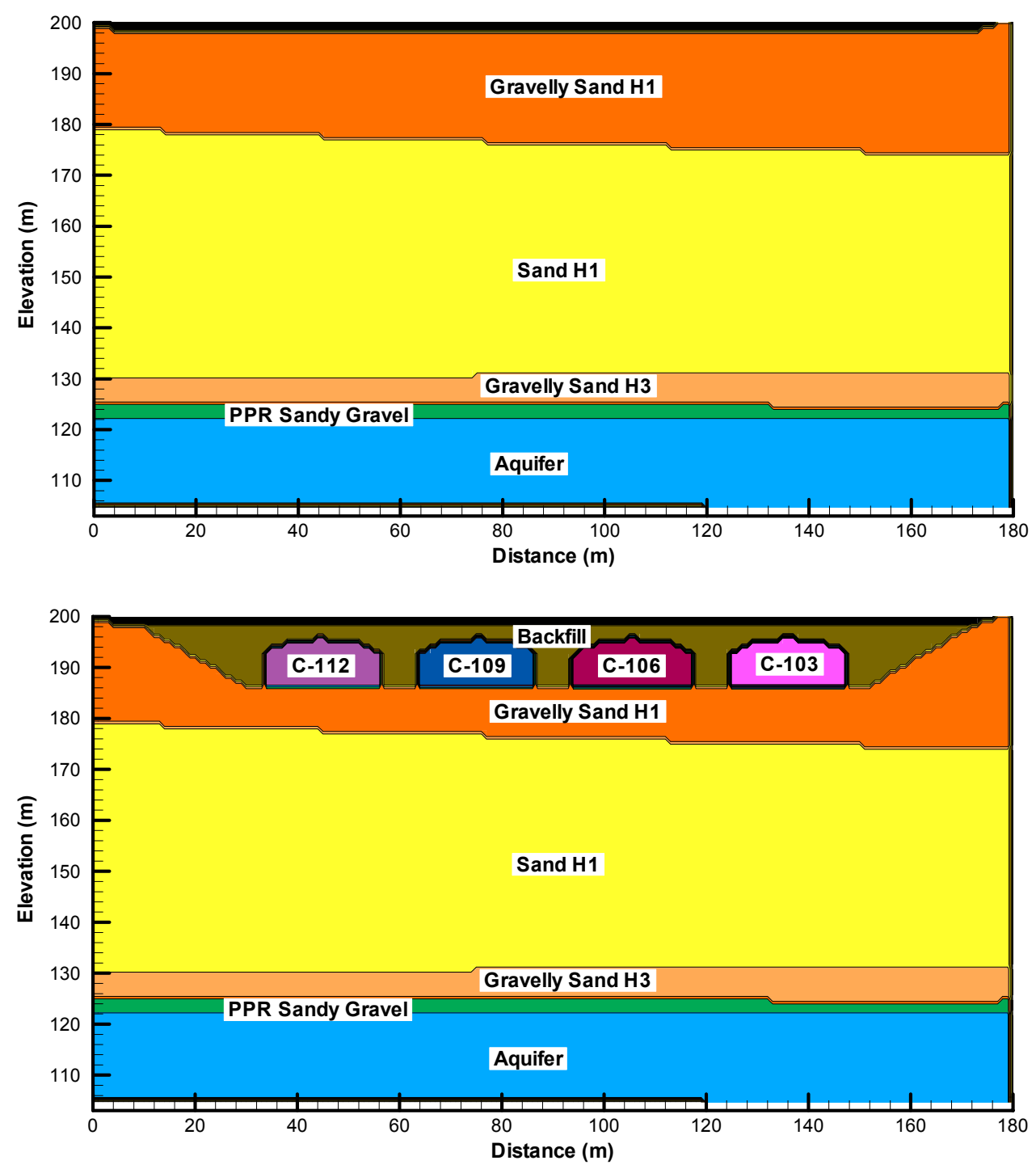

Figure 3.2. Rock/Soil Zonation for the Pre- and Post-Construction Periods of the C Tank Farm

In addition to these features, three different release models were implemented in the STOMP simulator for describing radionuclide releases from the tank wastes. These include advection-dominated, diffusion-dominated and saltcake release models and were used to account for different release mechanisms in the tank wastes. For all three of the models described below, the average release rate for the current time step was determined by integrating the rate equations at the beginning and end of each time step. The release rate was then determined by differencing the integrated rates over the time step.

\subsubsection{Advection-Dominated Release Model}

The advection-dominated release model, also known as the mixing-cell cascade model, was used to simulate releases from stabilized (grouted tank or tank ancillary) waste. For stabilized waste, the contaminants were released into the subsurface at a rate determined by both the rate of infiltrating water and 
the amount of dispersion occurring within the source. In the mixing-cell cascade model of Kozak et al. (1990), the tank interior was considered to comprise a series of cascading, $\mathrm{N}$ equal-sized, well-stirred cells, where the total volume of the $\mathrm{N}$ cells was equal to the volume of the tank residual waste. The mixing-cell cascade model for $\mathrm{N}$ equal-sized cells is defined as

$$
Q(t)=q A C_{0} \exp (-\gamma N t) \sum_{i=1}^{N} \frac{(\gamma N t)^{i-1}}{(i-1) !}
$$

where $Q$ is the release rate, $t$ is time, $q$ is the vertical Darcy flux, $A$ is the horizontal (planar) area of the tank interior, $\gamma$ is equal to $\mathrm{q} /(\theta \mathrm{R}), \theta$ is the volumetric moisture content in the residual waste, and $R$ is the retardation factor, which is assumed to be equal to 1 . The initial concentration of contaminant $\left(C_{o}\right)$ in the interstitial water is determined as

$$
C_{0}=\frac{m}{\theta V R}
$$

where $\mathrm{m}$ is the total inventory, which is unity in these analyses, and $V$ represents the total volume of the residual waste. By defining a source thickness for the residual wastes as $\mathrm{d}=\mathrm{V} / \mathrm{A}$, and substituting Eq. 3.9 and $\mathrm{q}=\gamma \theta \mathrm{R}$ into Eq. 3.8, the advection-dominated release model can be written as

$$
Q(t)=\frac{\gamma}{d} \exp (-\gamma N t) \sum_{i=1}^{N} \frac{(\gamma N t)^{i-1}}{(i-1) !}
$$

Two values, the number of mixing cells $(N)$ and the source thickness $(d)$, were required as inputs to the STOMP simulator. Values used in this analysis are shown in Table 3.8.

The advection-dominated release rate for a given time step was determined by differencing the integral of Eq. (3.10) with respect to time at the beginning and end of the time step and dividing this difference by the time step. As a closed-form solution for the integral of Equation (3.10) with respect to time is dependent on N (the number of mixing cells), STOMP solves Eq. 3.10 using Romberg integration (Press et al. 1992). Romberg integration is a recursive method that uses the extended trapezoidal rule for integration, which progressively increases the number of trapezoids under the curve to reduce the error term to a previously set tolerance.

\subsubsection{Diffusion-Dominated Release Model}

The diffusion-dominated release model is used to simulate the release of contaminants from stabilized (e.g., grouted tank or tank ancillary) wastes. With little or no advection through the waste container, the release can be modeled as a diffusion-limited process given as (Khaleel et al. 2003)

$$
Q(t)=\frac{I}{d} \sqrt{\frac{D_{e}}{\pi t}}
$$

where $D_{e}$ is the effective diffusion coefficient. $I$ is the total inventory defined as 


$$
I=C_{0} \sum_{i} V_{i}=C_{0} V_{T}
$$

where $V_{T}$ is the total volume of all cells.

Two values, the diffusion coefficient within the waste source $\left(D_{e}\right)$ and the source thickness $(d)$, were required as inputs to the STOMP simulator. Values used in this analysis are shown in Table 3.8.

As with the advection-dominated release model, the release rate for a given time step was determined by differencing the integral of Eq. 3.11 over the time step. A closed-form integral solution was used to determine the average release rate for the diffusion-dominated model. The total amount of mass released is given as

$$
M(t)=\frac{2 I}{d} \sqrt{\frac{D_{e} t}{\pi}}
$$

where $M$ is the current quantity of the contaminant (in Ci) at time $t$.

\subsubsection{Saltcake Release Model}

Solubility-controlled release models assume that a solid controls the solution concentration in the aqueous phase of the constituents being released. Solubility models are thermodynamic equilibrium models and do not consider kinetics. Although no empirical solubility models exist for modeling contaminants from residual tank wastes, a solubility-controlled release model (i.e. "saltcake" model) has been postulated (Khaleel et al. 2003). This saltcake release model assumes congruent dissolution with respect to sodium nitrate and may have limited application to the C Tank Farm waste constituents (Khaleel et al. 2003). When applied to residual tank wastes, the term "cake" applies to the sludge and hard heel residual in the tanks that compose the structural matrix.

The saltcake model considered in this analysis consisted of a very simple mathematical formulation containing a flux, waste source thickness, and waste solid solubility term. The contaminant release mechanism of the cake model was the dissolution of the "structural matrix." As the matrix dissolved, all of the contaminants were assumed to leach congruently at the same rate. The release rate model implemented in STOMP was given as

$$
Q(t)=\frac{\Delta M}{\Delta t}=-\frac{M q s t}{d \rho_{m}}
$$

where $s$ is the aqueous solubility of the saltcake, $d$ is the source thickness, and $\rho_{m}$ is the density of the waste.

Three values, the solubility $(s)$, the source thickness $(d)$, and the density of the waste $\left(\rho_{m}\right)$ were required as inputs to the STOMP simulator. Values used in this analysis are shown in Table 3.8. 
A closed-form integral solution was used to determine the average release rate for salt-cake model. Integration of Eq. 3.14 yields

$$
\int \frac{1}{M} d M=\int_{0}^{t}\left(-\frac{q s}{d \rho_{m}}\right) d t
$$

and the amount of contaminant remaining in the salt cake is given as

$$
M=M_{0}\left[\exp \left(-\frac{q s t}{d \rho_{m}}\right)\right]
$$

where $M_{0}$ is the initial quantity of the contaminant. As with advection- and diffusion-dominated release models, the release rate for a given time step was determined by differencing Eq. 3.16 over the time step.

Table 3.8. Input Parameters for the Three Release Models

\begin{tabular}{|l|c||l|c||l|c||}
\hline \multicolumn{2}{|c||}{ Advection-Dominated } & \multicolumn{2}{c||}{ Diffusion-Dominated } & \multicolumn{2}{c||}{ Saltcake } \\
\hline \multicolumn{1}{|c|}{ Parameter } & Value & Parameter & Value & \multicolumn{1}{c||}{ Parameter } & Value \\
\hline $\begin{array}{l}\text { Source } \\
\text { Thickness }(d)\end{array}$ & $0.825 \mathrm{~m}$ & $\begin{array}{l}\text { Source } \\
\text { Thickness }(d)\end{array}$ & $0.825 \mathrm{~m}$ & $\begin{array}{l}\text { Source } \\
\text { Thickness }(d)\end{array}$ & $0.825 \mathrm{~m}$ \\
\hline $\begin{array}{l}\text { Number of } \\
\text { Mixing Cells } \\
(N)\end{array}$ & \multirow{2}{*}{10} & $\begin{array}{l}\text { Diffusion } \\
\text { Coefficient } \\
\left(D_{e}\right)\end{array}$ & $\begin{array}{l}6.0 \times 10^{-7} \mathrm{~cm}^{2} / \mathrm{s} \\
5.0 \times 10^{-8} \mathrm{~cm}^{2} / \mathrm{s}\end{array}$ & $\begin{array}{l}\text { Aqueous } \\
\text { Solubility }(s)\end{array}$ & $360 \mathrm{mg} / \mathrm{L}$ \\
& & & Waste \\
Density $\left(\rho_{m}\right)$ & $1.7 \mathrm{~g} / \mathrm{cm}^{3}$ \\
\hline
\end{tabular}

\subsection{Source Terms}

The source terms in these analyses consisted of four different source types, including 1) leaks during retrieval, 2) past leaks and spills, 3) residual waste leachate from tanks following closure, and 4) residual waste leachate from tank ancillary equipment following closure. For the cases simulating past leaks, these scenarios represent tank waste that leaked into the vadose zone prior to retrieval and closure activities. For the retrieval leakage scenarios, this source type represents leaks that might occur during waste retrieval operations using water-based sluicing. Releases from the residual wastes (from both tank and tank ancillary equipment) may occur over an extended period following the closure of the tank farm. Contaminant migration would occur when infiltrating water comes into contact with the tanks or tank ancillary equipment. Dissolved contaminants then have the potential to mobilize in the vadose zone and enter the groundwater table.

For all 14 cases presented in this report, sources are located near or at $\mathrm{C}-112$, the tank farthest from the exit boundary. All sources are simulated as a unit curie so that results can be scaled when actual source inventories are known. Two additional cases were run with a unit source at each of the four tanks 
in the cross section. These cases are presented to compare the transport behavior of the contaminants in the various tanks.

\subsection{STOMP Execution}

The reported simulations were executed on Linux workstations. All executables were generated from a single source code that is readable and available in electronic form (Section 6). Executing the simulator required two steps: 1) compiling the source code with a parameters definition file and 2) executing the compiled code on a workstation or personal computer. The executable forms of the STOMP simulator were generated for these investigations using the default level of optimization for each compiler. STOMP was coded following ASCII FORTRAN 77 protocols and yielded no warning or error messages during compilation. The size of the computational domains ( $\sim 18,000$ nodes) necessitates the use of a conjugate gradient linear system solver with a compact storage scheme for the Jacobian matrix. The STOMP simulator uses the SPLIB solver (Bramley and Wang 1995) for sparse linear systems for solutions implementing conjugate gradient solvers. The SPLIB solver is a collection of libraries that must be assembled on the executing computer and linked to the STOMP simulator during compilation. The SPLIB files and instructions necessary to complete the compilation and execution of the STOMP simulator will be available in electronic form (Section 6).

\subsection{Result Translation}

For these investigations, the STOMP simulator read a series of input files and generated an output file, surface flux files, and a series of plot files. As described previously, the STOMP output file contains reflected data from the input files, simulation progression information, and reference-node output. The output files were used only for verification and simulation tracking. Input, output, plot, and surface-flux files are located in the simulation case directories and will be available in electronic format (Section 5).

Because a two-dimensional cross section through the C Tank Farm was used, reported concentrations are for a unit width inventory. No scaling of concentrations and water sources was performed to convert the reported concentrations to a three-dimensional plume.

Concentration calculations for the breakthrough curves presented in Appendix B were made using STOMP output values for solute mass and water mass fluxes at the fence line. These data were recorded in STOMP surface files and used to calculate average groundwater concentrations and average fence line concentrations. Both concentration calculations were scaled using the water flux at the fence line rather than aquifer thickness. For example, average concentrations at the fence line $\left(\mathrm{C}_{\mathrm{fl}}\right)$ were computed as

$$
C_{f l}=\frac{\text { Solute Mass Flux at Fence Line }(\mathrm{Ci} / \text { day) }}{\text { Water Mass Flux Fenceline ( L / day) }}
$$

Similarly, average concentrations at the water table $\left(\mathrm{C}_{\mathrm{wt}}\right)$ were calculated as

$$
C_{w t}=\frac{\text { Solute Mass Flux at WaterTable }(\mathrm{Ci} / \text { day })}{\text { Water Mass Flux Fenceline }(\mathrm{L} / \text { day })}
$$


Fence line concentrations were then used as sources in the analytic aquifer streamtube model described in the next section to predict concentrations at the distal compliance points.

\subsection{Analytical Groundwater Transport Modeling}

An instantaneous point source model (Baetslé 1969) was used to calculate the concentration of contaminant species originating at the C Tank Farm and traveling to four remote compliance points along two potential groundwater flow paths. The two compliance points along the southeast pathway are 1) the 200 Area exclusion boundary ( $\sim 2.9 \mathrm{~km}$ east of the $200 \mathrm{E}$ Area), and 2$)$ the Columbia River $(\sim 14.3 \mathrm{~km}$ southeast of the C Tank Farm) (see Table 3.9). The two compliance points along the northeast pathway through the Gable Butte/Gable Mountain gap are 1) the 200 Area exclusion boundary $(\sim 3.8 \mathrm{~km}$ north of the 200 E Area), and 2) the Columbia River ( $20.6 \mathrm{~km}$ northeast of the C Tank Farm) (see Table 3.9 and Figure 3.3). The distance to each compliance point along the groundwater flow path was based on streamlines derived from the VAM3D site-wide groundwater models of Law et al. (1996) and Lu (1996).

Table 3.9. Distance to Compliance Point, Groundwater Velocity, and Travel Time from C Tank Farm

\begin{tabular}{||l|c|c|c||}
\hline \multicolumn{1}{||c|}{ Compliance Point } & Distance, $\mathbf{m}$ & Velocity, m/yr & Time, yr \\
\hline \multicolumn{4}{|c||}{ Northward Path thru Gap } \\
\hline Exclusion Boundary & 3,800 & 93.8 & 40 \\
Columbia River & 20,600 & 35.5 & 580 \\
\hline \multicolumn{5}{|c||}{ Southeast Path } \\
\hline Exclusion Boundary & 2,900 & 115 & 40 \\
Columbia River & 14,300 & 61.5 & 260 \\
\hline
\end{tabular}

Steady flow conditions, water table maps, and streamlines generated from the VAM3D simulation are reported by Khaleel et al. (2003). The analytical groundwater model assumed transport from a point source from a series of solute slugs and considers longitudinal and horizontal transverse dispersion, as well as molecular diffusion. The method of superposition was used to integrate the individual slug sources. The instantaneous point source model for a three dimensional space, as reported by Domenico and Schwartz (1990), is shown in Eq. (3.19):

$$
C(x, y, z, t)=\left[\frac{C_{0} V_{0}}{\left(8(\pi t)^{3 / 2}\left(D_{x} D_{y} D_{z}\right)^{1 / 2}\right)}\right] \exp \left[-\frac{(x-v t)^{2}}{4 D_{x} t}-\frac{y^{2}}{4 D_{y} t}-\frac{z^{2}}{4 D_{z} t}-\lambda t\right]
$$

where $\mathrm{C}$ is the solute concentration as a function of position and time (pCi/L or $\mu \mathrm{g} / \mathrm{L}), \mathrm{C}_{0} \mathrm{~V}_{0}$ is the instantaneous source of solute mass ( $\mathrm{pCi}$ or $\mu \mathrm{g}$ ), $D_{x}, D_{y}, D_{z}$ are spatial components of the hydrodynamic dispersion coefficient $\left(\mathrm{m}^{2} / \mathrm{yr}\right), x, y, z$ are spatial distances from the solute source $(\mathrm{m}), t$ is the time (yr), 


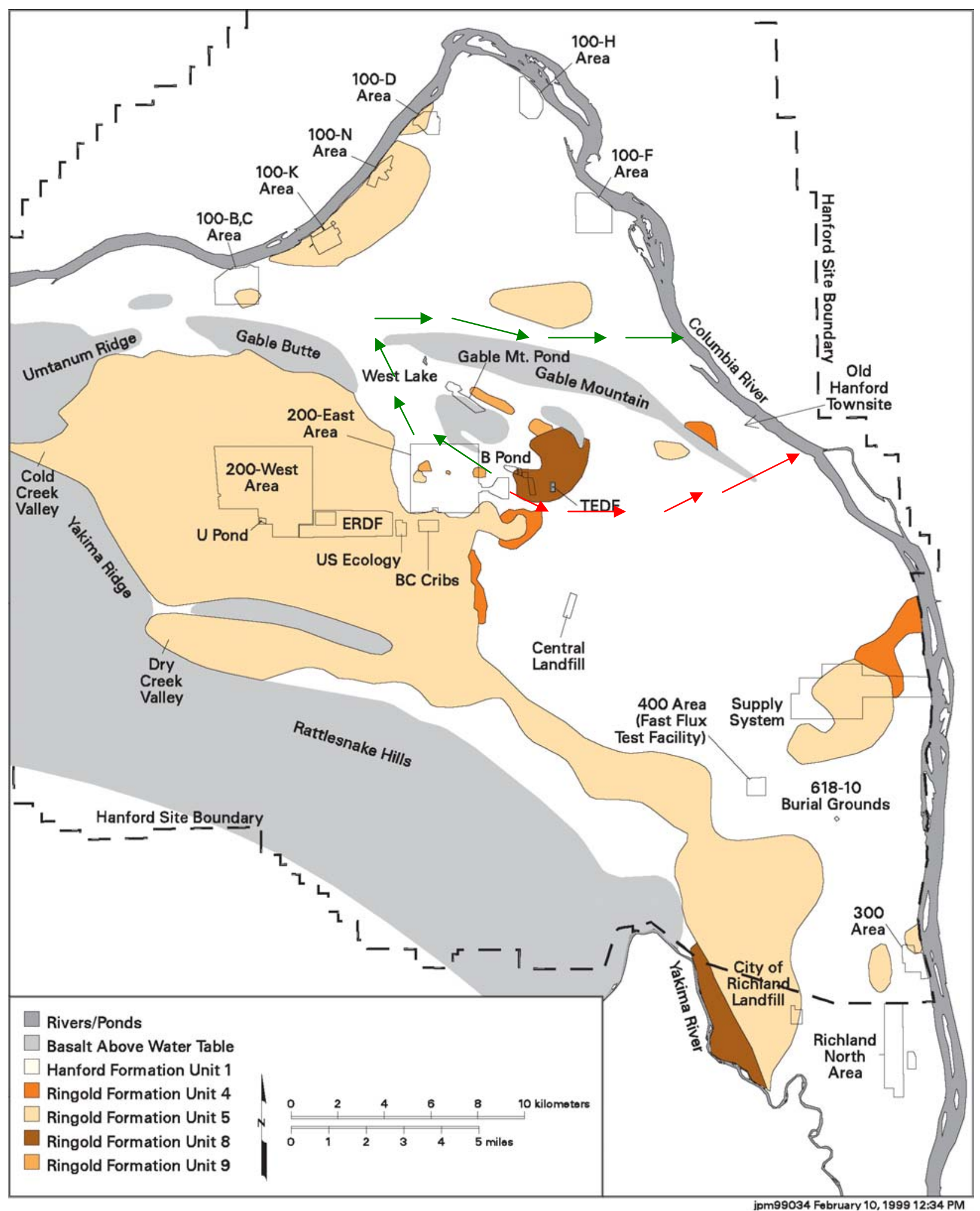

Figure 3.3. Map of SGM Hydrogeologic Units Containing the Water Table in March 1999. Red arrows approximate the potential groundwater path line southeast of the gap; green arrows approximate the potential groundwater path line through the gap. 
$\lambda$ is the solutespecies radioactive decay half-life ( $\mathrm{yr}$ ), and $v$ is the pore-water velocity ( $\mathrm{m} / \mathrm{yr})$. The spatial components of hydrodynamic dispersion coefficients include dispersive and diffusive elements, according to Eq. (3.20):

$$
D_{i}=\alpha_{i} v+D_{m} \text { for } i=x, y, z
$$

where $\alpha_{i}$ is the dispersivity $(\mathrm{m})$, and $D_{m}$ is the molecular diffusion coefficient ( $\left.\mathrm{m}^{2} / \mathrm{yr}\right)$.

Material property maps for the three elemental layers of the VAM3D site-wide groundwater model (SGM) are reported in Khaleel et al. (2003) who also report hydraulic properties for each of the 18 soil zones identified in the VAM3D SGM, including hydraulic conductivity in the north-south, east-west, and vertical directions, specific storage, and porosity. The VAM3D SGM assumed equal values for the northsouth and east-west hydraulic conductivity and a vertical conductivity one order of magnitude less than the horizontal components. Specific storage was assumed constant across the site at $1.0 \times 10^{-6} \mathrm{~L} / \mathrm{m}$, and porosities were either 0.1 or 0.25 .

Distances and travel times from the C Tank Farm to the four compliance points were derived from streamline results from steady-state VAM3D unconfined aquifer flow simulations of the Hanford Site (Lu 1996). The simulation results were taken from "post-Hanford" or future conditions representing the water table at the Site without the effect of unconfined aquifer discharges from Hanford operations. Results of the VAM3D simulated hydraulic heads and streamlines are shown in Lu (1996, Figures 15 and 19). Two streamlines are analyzed (Lu 1996, Figure 19) starting at the C Tank Farm to determine the unconfined aquifer path length to the river. Travel markers indicating 20-year intervals on the streamlines were used to estimate the travel time to the river from the C Tank Farm. One streamline initially goes north from the C Tank Farm in the 200 East Area through the gap between Gable Mountain and Gable Butte and then east to the Columbia River (green arrows, Figure 3.3). The second (and shorter) streamline goes directly east to the river south of Gable Mountain (red arrows, Figure 3.3). Because other groundwater flow simulations of the Hanford Site and Hanford monitoring data have shown the potential for groundwater flow north through the Gable Mountain/Gable Butte gap, both streamlines were used in this analysis.

The concentration at compliance points is calculated by a FORTRAN code (disp.f) that implements the instantaneous pulse equation. Input to the model is read from two separate files. The distance from the source zone to each compliance point in the longitudinal (x direction) and groundwater velocity for each successive interval is listed in Table 3.9. The distances reported in Table 3.9 represent the longitudinal distance $\mathrm{x}$ of Eq. (3.14) and (3.15). Values for the $\mathrm{y}$ and $\mathrm{z}$ directions are assigned values of zero signifying that the point of observation was along the longitudinal centerline. The other parameters used by the first input file (runpoint.csh) in the analytical groundwater model are listed in Table 3.10.

Table 3.10. Analytical Groundwater Transport Modeling Properties

\begin{tabular}{|l|l|}
\hline \multicolumn{1}{|c|}{ Parameter } & \multicolumn{1}{c|}{ Value } \\
\hline Horizontal dispersivity & $3.05 \mathrm{~m}$ \\
Vertical dispersivity & $0.01 \mathrm{~m}$ \\
Longitudinal dispersivity & $30.5 \mathrm{~m}$ \\
Molecular diffusion & $0.079 \mathrm{~m}^{2} / \mathrm{yr}$ \\
\hline
\end{tabular}


The second input file provided solute mass flux across C Tank Farm as a function of time for U-238 and Tc-99. The concentration at each compliance point is calculated for a time series of solute release events using linear superposition of Eq. 3.16 for each release event. The 10,000-year period for the C tank analysis, between years 2000 and 12000, was modeled using 10,000 uniformly spaced solute release events. Radiological decay of the species was not considered. 


\subsection{Simulation Results}

This section reports key fluid flow and solute transport behavior, breakthrough curves, and mass balances for the C Tank Farm simulations at the groundwater table, fence line, and two downgradient compliance points. Two-dimensional simulations in STOMP were used to determine fluid flow and solute transport behavior at the groundwater table and fence line for the C-112 to C-103 cross section. Resulting concentrations were not scaled to account for spreading and dilution associated with a threedimensional plume. An analytical, one-dimensional streamtube model that accounts for threedimensional diffusion and dispersion is used to predict solute transport behavior at the downstream compliance points.

\subsection{Summary Description of the Simulations}

Using a unit release at Tank C-112, 14 simulations were run to investigate the effect of four different source types. These source types included 1) leaks during retrieval (Cases 1 and 2), 2) past leaks (Cases 3 and 4), 3) residual waste leachates from tanks after closure (Cases 5-12, 14), and 4) residual waste leachates from tank ancillary equipment following closure (Case 13). Two cases (Cases 1v and 5v, the verification cases) simulated contaminant transport from all four of the tanks in the cross section. Five cases (HiK Cases 1, 3, 4, 10 and 11) investigated contaminant transport with a saturated hydraulic conductivity in the aquifer that was one order of magnitude higher than the original 14 cases.

Six different sorption coefficients $\left(\mathrm{K}_{\mathrm{d}}=0.01,0.03,0.1,0.3,0.6\right.$, and $\left.1.0 \mathrm{~mL} / \mathrm{g}\right)$ were used to simulate a wide range of retardation for the U-238 species. However, for $K_{d} \geq 0.60 \mathrm{~mL} / \mathrm{g}$, the solute travel times were so long that the amount of mass migrating into the groundwater was insignificant. As a result, no breakthrough curves are presented for solute species with these $K_{d}$ values for any of the simulations. The conservative species, Tc-99, was assumed to have a $\mathrm{K}_{\mathrm{d}}=0$. In the results presented in this report, the notation " $\mathrm{U}: \mathrm{K}_{\mathrm{d}}$ " is used to represent each of the uranium contaminant species from Tank C-112. For example, $\mathrm{U}: 0.01$ represents the uranium contaminant with $\mathrm{K}_{\mathrm{d}}=0.01 \mathrm{~mL} / \mathrm{g}$. If the contaminant source was located at multiple tanks (as in Cases $1 \mathrm{v}$ and 5v), the notation "Tc:tank\#" or "U:tank\#: $\mathrm{K}_{\mathrm{d}}$ " is used. For example, Tc:C106 represents the technetium from Tank C-106 and U:C103:0.03 the uranium species from Tank C-103 with $\mathrm{K}_{\mathrm{d}}=0.03 \mathrm{~mL} / \mathrm{g}$.

As discussed in Section 2, because tank integrity was presumably lost in January 2050 (2500 for Case 9), the simulation of flow and transport of each case has been carried out in two stages, one from 1945 to 2050 (2500 for Case 9) and the other from 2050 (2500 for Case 9) to 12000. Initial flow conditions for the first stages of the simulation were established with a steady-state flow simulation that assumed a natural infiltration rate of $3.5 \mathrm{~mm} / \mathrm{yr}$.

For the analytical groundwater transport model, concentration decreases occurred through longitudinal, transverse horizontal, and transverse vertical dispersion as well as molecular diffusion. Radioactive decay was not considered because Tc-99 and U-238 have long half-lives. Data on two potential flow paths, one to the southeast and the other northward through the gap, are presented for the exclusion boundary and the Columbia River compliance points. The first streamline segment extended from the C-Tank Farm fence line to the 200 Area exclusion boundary and the second from the C Tank Farm fence line to the Columbia River. Thus results for four downstream compliance points are presented. 


\subsection{Section Organization}

Saturations and inventory profiles are shown in Appendix A. The mass flux, cumulative activity, and breakthrough curves (BTC) for the various cases are presented in Appendix B. Because solute concentrations at the groundwater table were scaled by the water flux at the fence line (see Eq. 3.17, Section 3.7), BTCs at the groundwater and fence line compliance points demonstrated similar behavior. Though contaminant concentrations are reported in curies for the sake of simplicity, the term "mass" is substituted for "activity." The peak mass fluxes and arrival times at the groundwater table and the fence line are summarized in Tables 4.2 through 4.8. The peak concentrations and arrival times at the groundwater table, the fence line, the exclusion boundary, and the Columbia River are summarized in Tables 4.9 through 4.15. The mass balance for each contaminant in each case is summarized in Tables 4.16 through 4.22.

Saturation and concentration distribution profiles shown in Appendix A also show interfaces between the material types. Tank outlines are shown in these figures, even though tank integrity was lost in the year 2050 (year 2500 for Case 9). Hence, figures predicting water and solute transport movement after these dates show tanks as permeable structures. However, tanks were assumed to be filled with backfill or grout after tank integrity was lost, and tank outlines exist in these figures only as points of reference.

The STOMP simulation results were written to 1) reference nodes, 2) plot files, and 3) surface flux output. STOMP was modified so that the surface flux outputs are stored in multiple files whose names are defined by the user. Each plot file includes values for saturation, aqueous pressure, moisture content, and concentration of each of the seven solute species. Each surface output file contains solute and fluid fluxes for each solute as well as its cumulative mass.

In the sections that follow, results are reported for each case organized by source type. A summary description and comparison of results follows the individual case descriptions. Two different base cases were considered when discussing relative peak concentrations due to the difference in the time scale of occurrence. Case 1 was the base case for Cases 2-4, and Case 11 was the base case for Cases 5-14 (see Table 4.1).

Table 4.1. Predicted Peak Concentrations $(\mathrm{Ci} / \mathrm{L})$ and Arrival Times at the Fence Line for the Two Base Cases in Year 12000

\begin{tabular}{|c|c|c|c|c||}
\hline \multirow{2}{*}{ Species } & \multicolumn{2}{|c|}{ Case 1 } & \multicolumn{2}{c||}{ Case 11 } \\
\cline { 2 - 5 } & $\begin{array}{c}\text { Concentration } \\
(\mathbf{C i} / \mathbf{L})\end{array}$ & $\begin{array}{c}\text { Arrival Time } \\
(\mathbf{y r})\end{array}$ & $\begin{array}{c}\text { Concentration } \\
(\mathbf{C i} / \mathbf{L})\end{array}$ & $\begin{array}{c}\text { Arrival Time } \\
(\mathbf{y r})\end{array}$ \\
\hline Tc-99 & $1.57 \mathrm{E}-07$ & 2087 & $2.05 \mathrm{E}-08$ & 5621 \\
$\mathrm{U}: 0.01$ & $8.98 \mathrm{E}-08$ & 2095 & $1.96 \mathrm{E}-08$ & 6060 \\
$\mathrm{U}: 0: 03$ & $3.60 \mathrm{E}-08$ & 3921 & $1.76 \mathrm{E}-08$ & 6920 \\
$\mathrm{U}: 0.10$ & $2.41 \mathrm{E}-08$ & 6107 & $1.30 \mathrm{E}-08$ & 9854 \\
$\mathrm{U}: 0.30$ & $1.17 \mathrm{E}-08$ & 12000 & $1.13 \mathrm{E}-09$ & 12000 \\
\hline
\end{tabular}


Because of the similarity in results for the streamtube groundwater modeling, these results are presented in a separate section after the discussion of the individual cases. In only a few cases are the streamtube modeling results discussed in the individual case descriptions. For the two verification cases, streamtube modeling results appear in Appendix B but are not included in the general discussion.

\subsection{Initial Conditions and Saturation Distributions}

The saturation field was dependent on the surface recharge, hydrologic parameters, soil distribution, and impermeable structures (e.g., SSTs). Because recharge rates for all 14 cases were the same, the saturation distribution within the domain did not vary much among the cases. Recharge rates were varied to represent various stages of tank and barrier construction. For example, the beginning of the simulation represents the tank preconstruction period. Once the tanks were in place in the year 1945, recharge rates increased and then decreased once a protective barrier was in place in the year 2050. The recharge rate increases again when degradation of the barrier occurs in the year 2550. As outlined below, overall moisture content in the vadose zone was affected by the change in recharge rates. However, the water table level showed little variation with changes in the surface recharge rate.

The initial moisture condition in 1945 for all cases was achieved by running a simulation for the cross section using a recharge rate of $3.5 \mathrm{~mm} / \mathrm{yr}$ for 1000 years (see Figure A.1a). Because this period represents the preconstruction period of the C Tank Farm, the simulation was run without the four tanks in place. These conditions yielded a mean water content in the vadose zone of $0.121 \mathrm{~m}^{3} / \mathrm{m}^{3}$.

From 1945 to 2050 , the recharge was assumed to increase from the preconstruction estimate of $3.5 \mathrm{~mm} / \mathrm{yr}$ to the current value of $100 \mathrm{~mm} / \mathrm{yr}$. This change was due to the replacement of the gravel-sand layer at the top of the domain (unit H1, see Figure 3.2) with a porous backfill material, which increased the mean water content by nearly $50 \%\left(0.179 \mathrm{~m}^{3} / \mathrm{m}^{3}\right)$ in the vadose zone in the year 2050 (Figure A.2a).

From 2050 to 2550 , the annual recharge rate was decreased to the barrier design value of $0.5 \mathrm{~mm} / \mathrm{yr}$, causing a subsequent decrease in the soil water content. In the year 2550 the mean water content in the vadose zone for all cases was $0.104 \mathrm{~m}^{3} / \mathrm{m}^{3}$, which was a decrease of $42 \%$ from the year 2050 . Beginning in the year 2550 the barrier degrades, increasing the recharge rate to $3.5 \mathrm{~mm} / \mathrm{yr}$. By the end of the simulations at year 12000 , the mean water content was $0.116 \mathrm{~m}^{3} / \mathrm{m}^{3}$, which is close to the average water content of the preconstruction period $\left(0.121 \mathrm{~m}^{3} / \mathrm{m}^{3}\right)$. Even with the flux of water entering the domain in Cases 1 and 2 (30.3 and $75.7 \mathrm{~m}^{3}$, respectively), the overall moisture content in the vadose zone in the year 12000 was the same as that for the other 12 cases that did not simulate water leaks during retrieval (see Figures A.2b and A.13b).

\subsection{Retrieval Leaks}

Two simulation cases, Cases 1 and 2, predicted transport behavior for contaminants originating from leaks that might occur during waste retrieval operations using water-based sluicing. Two retrieval rates were simulated in each case: Case 1 with a unit release of each contaminant in 8,000 gallons, and Case 2 with a unit release of each contaminant in 20,000 gallons of water. Both of these cases simulated the source at Tank C-112. To examine the sensitivity of contaminant transport to hydraulic conductivity, a third simulation was run for Case 1 (HiK), where the saturated hydraulic conductivity of the aquifer was 
increased by an order of magnitude. A fourth case, a verification case for Case 1, simulated unit releases of contaminants in 8,000 gallons of water at each of the four tanks in the simulation domain.

\subsubsection{Case 1: 8000 Gallons at C-112}

Case 1 was a retrieval leak of 8,000 gallons at the lower-right corner of Tank C-112 that began on the first day of the year 2000. The leak lasted for 14 days and contained a unit release of each of the contaminant species (Tc-99 and U-238). Plot-file output for this simulation was generated at the beginning (year 2000 ) and the end (14 days after January 1, 2000) of the leak and the years 2001, 2010, 2050, 2100, 2500, $3000,4000,5000,6000,8000,10000$, and 12000 .

The aqueous saturation fields for the $\mathrm{C}-112$ to $\mathrm{C}-103$ cross section at the time the leakage ended are shown in Figure A.1b, which shows the effects of the tank leak on the moisture content distribution in the subsurface. For example, the soil at the leak was completely saturated at the end of the 14 days. Saturations near the leak were much higher than anywhere else in the vadose zone. This effect, however, disappeared by the year 2050, as shown in Figure A.2a, because the volume of the leak is small compared with the recharge entering the system at $100 \mathrm{~mm} / \mathrm{yr}$. Once the recharge was decreased, saturations decreased in the vadose zone. This effect is shown in Figure A.2b, which plots the aqueous saturation field in the year 12000 .

The distribution of the aqueous concentration of the contaminants at the time the leak ended (January 15, 2000) and year 12000 is shown as color images in Figures A.3 through A.9 in logarithmic scale. Tc-99 moved faster than the other contaminants because it did not sorb to subsurface materials. For U-238, the species with larger $\mathrm{K}_{\mathrm{d}}$ values transported slower than the U-238 contaminant with lower $\mathrm{K}_{\mathrm{d}}$ values. For example, in the year 12000 nearly all (99.8\%) the Tc-99 and U-238 species with $\mathrm{K}_{\mathrm{d}} \leq 0.03 \mathrm{~mL} / \mathrm{g}$ had migrated past the fence line and exited the domain. For U-238 compounds with $\mathrm{K}_{\mathrm{d}} \geq 0.6 \mathrm{~mL} / \mathrm{g}$, nearly all (99.9\%) of the contaminant was still in the vadose zone.

Figures B.1 through B.8 plot the mass flux, cumulative mass, and BTCs for each of the contaminants. Figure B.1 shows mass flux and cumulative activity for Tc-99 at the groundwater table and fence line, which display double peaks (Figure B.1) due to variations in the recharge rate. For U-238 double peaks also occurred, although the peaks progressively lowered and flattened as $\mathrm{K}_{\mathrm{d}}$ values increased. For example, the first peak was higher than the second for Tc-99 $\left(\mathrm{K}_{\mathrm{d}}=0 \mathrm{~mL} / \mathrm{g}\right)$ and $\mathrm{U}-238\left(\mathrm{~K}_{\mathrm{d}}=0.01 \mathrm{~mL} / \mathrm{g}\right)$, (Figures B.1 and B.3, respectively). For $\mathrm{K}_{\mathrm{d}}=0.03$ (Figure B.5) and $\mathrm{K}_{\mathrm{d}}=0.10 \mathrm{~mL} / \mathrm{g}$ (Figure B.7), the second peak on the mass flux curve was higher than the first. For $\mathrm{K}_{\mathrm{d}}=0.30 \mathrm{~mL} / \mathrm{g}$ or larger, the peak flux had not shown up by the year 12000 . By 12000 , the percentage of contaminants that had transported past the fence line boundary was $100 \%$ for Tc-99, U:0.01, and U:0.03; $99.8 \%$ for U: $0.10 ; 32.5 \%$ for U:0.30; $0.1 \%$ for $\mathrm{U}: 0.60$; and $0.0 \%$ for $\mathrm{U}: 1.00$.

The peak concentration of Tc-99 at the fence line $\left(\mathrm{C}_{\mathrm{fl}}\right)$ was $1.61 \times 10^{-7} \mathrm{Ci} / \mathrm{L}$. Relative to Tc-99, peak concentrations at the fence line for $\mathrm{U}-238$ species with different $\mathrm{K}_{\mathrm{d}}$ values were $58.6 \%$ for $\mathrm{U}: 0.01,22.4 \%$ for $\mathrm{U}: 0.03$, and $15 \%$ for $\mathrm{U}: 0.10$. The arrival times for the peaks were years 2109 for Tc-99, 2121 for $\mathrm{U}: 0.01,3955$ for $\mathrm{U}: 0.03$, and 6169 for $\mathrm{U}: 0.10$. These results are summarized at the end of this report, along with peak concentrations and arrival times at the downstream compliance points. These results were obtained using the streamtube model described in Section 3.8 for the exclusion boundary and the Columbia River along two potential groundwater flow paths. 


\subsubsection{Case 1 (HiK): 8000 Gallons at C-112, C-109, C-106 and C-103}

Case $1(\mathrm{HiK})$ simulation investigated a retrieval leak of 8,000 gallons at the lower right corner of Tank C-112 that started on the first day of the year 2000. The saturated hydraulic conductivity of the aquifer was 10 times higher than Case 1. The leak lasted 14 days and contained a unit release of each of the contaminant species (Tc-99 and U-238). Plot-file output for this simulation was generated at the beginning (year 2000) and the end of the leak (14 days after January 1,2000) and the years 2001, 2010, 2050, 2100, 2500, 3000, 4000, 5000, 6000, 8000, 10000, and 12000 .

The saturation distributions at the time the leak ended (year 2000.04) and at the end of the simulation (year 12000) are shown in Figure A.13. The distribution of the aqueous concentrations of contaminants in the same years is shown in Figures A.14 through A.20 in logarithmic scale. As in Case 1, Tc-99 moved faster than the other contaminants since it did not sorb to subsurface materials. For U-238, the species with larger $\mathrm{K}_{\mathrm{d}}$ values transported slower than the U-238 contaminant with lower $\mathrm{K}_{\mathrm{d}}$ values.

Figures B.25 through B.32 plot the mass flux, cumulative mass, and breakthrough curves for each contaminant. By 12000 , the percentages of contaminant that had transported past the fence line boundary were $100 \%$ for Tc-99, U:0.01, and U:0.03; $99.9 \%$ for U:0.10; $36.1 \%$ for $\mathrm{U}: 0.30 ; 0.2 \%$ for $\mathrm{U}: 0.60$; and $0 \%$ for $\mathrm{U}: 1.00$.

The peak concentration of Tc-99 at the fence line was $1.96 \times 10^{-8} \mathrm{Ci} / \mathrm{L}$, which was $12.2 \%$ of the peak concentration predicted in Case 1. Relative to Tc-99, peak concentrations for U-238 species with different $\mathrm{K}_{\mathrm{d}}$ values at the fence line were $55.6 \%$ for $\mathrm{U}: 0.01,18.2 \%$ for $\mathrm{U}: 0.03$, and $12.2 \%$ for $\mathrm{U}: 0.10$. The arrival times for the peaks were 2082 for Tc-99, 2089 for U:0.01, 3892 for U:0.03, and 6052 for U:0.10. The results are summarized at the end of the section, along with peak concentrations and arrival times at the downstream compliance points. Results were obtained using the streamtube model described in Section 3.8 for the exclusion boundary and the Columbia River along two potential groundwater flow paths.

\subsubsection{Case 1v: 8000 Gallons at C-112, C-109, C-106 and C-103}

As a verification of Case 1, Case 1v was a retrieval leak of 8,000 gallons at the lower-right corner of each of the four tanks in the domain. All of the leaks began on the first day of the year 2000 and continued for 14 days. Each retrieval leak contained a unit release of Tc-99 and U-238 with a $\mathrm{K}_{\mathrm{d}}$ of $0.03 \mathrm{~mL} / \mathrm{g}$. No other $\mathrm{K}_{\mathrm{d}}$ values were used in this simulation. Soil water distribution at the end of the leakage is shown in Figure A.10a, which shows that the four plumes were similar in shape. However, due to the sloped interface between materials $\mathrm{H} 1$ and $\mathrm{H} 2$, flow from the left-most tank (C-112) had slightly stronger lateral movement. After 10,000 years of simulation, however, the saturation distribution at the year 12000 (Figure A.10b) was the same as in Case 1, where only one retrieval leak occurred at Tank C-112 (Figure A.2b).

After 14 days, when the retrieval leaks stopped, all four of the Tc-99 plumes (Figure A.10a) were similar to the single-leak case at Tank C-112 in shape and concentration distribution (Figure A.2a). All four plumes also migrated at nearly the same velocity. By the year 12000, the percentage of contaminants that had passed the fence line boundary was $100 \%$ for Tc and $99.8 \sim 99.9 \%$ for U:0.03. 
Figures B.9 through B.24 plot the mass flux, cumulative mass, and BTCs of each contaminant. The peak fluxes, concentrations, and arrival times of the same contaminant released from different tanks were similar. For example, the peak concentrations at the fence line were $1.60 \times 10^{-7}, 1.85 \times 10^{-7}, 2.15 \times 10^{-7}$, and $1.63 \times 10^{-7} \mathrm{Ci} / \mathrm{L}$ for the Tc-99 released from Tanks C-103 (Figure B.10a), C-106 (Figure B.12a), C-109 (Figure B.14a), and C-112 (Figure B.16a), respectively. The corresponding peak arrival times were 2087, 2094, 2096, and 2108. The peak concentrations were nearly the same as those when there was only one retrieval leak at Tank $\mathrm{C}-112\left(1.61 \times 10^{-7} \mathrm{Ci} / \mathrm{L}\right)$. For the two leaks near the tanks in the center of the domain, the horizontal distance between leaks has only a small effect on peak arrival times. Beneath the two tanks, the stratigraphy was nearly identical. The effect of shedding from recharge was also nearly the same for both of the tanks (see Figure A.2a). For the tanks closest to the exit boundary, the difference in peak arrival times at the fence line was seven years, whereas the difference in peak arrival times for the two tanks farthest from the boundary was 12 years. This nonsymmetrical effect was due to the asymmetry in the saturation distribution caused by the sloping interfaces between the backfill and $\mathrm{H} 1$ gravelly sand materials (Figure A.1a).

\subsubsection{Case 2: 20000 Gallons at C-112}

The Case 2 simulation investigated a retrieval leak of 20,000 gallons at the lower right corner of Tank $\mathrm{C}-112$ that started on the first day of the year 2000. The leak lasted 14 days and contained a unit release of each of the contaminant species (Tc-99 and U-238). Plot-file output for this simulation was generated at the beginning (year 2000) and the end (14 days after January 1,2000) of the leak and the years 2001, 2010, 2050, 2100, 2500, 3000, 4000, 5000, 6000, 8000, 10000, and 12000 .

The saturation distributions at years 2050 and 12000 are shown in Figure A.21. The concentration distributions of the contaminants at years 2050 and 12000 are shown in Figures A.22-A.28. The mass flux, cumulative activity, and BTCs of each contaminant are shown in Figures B.33-B.40. As in Case 1, mass flux curves demonstrated double peaks due to variations in recharge. For $K_{d} \geq 0.03$, the second peak in the mass flux curve was higher than the first. For $\mathrm{K}_{\mathrm{d}}=0.30 \mathrm{~mL} / \mathrm{g}$ or larger the peak flux had not shown up by the year 12000. By 12000, the percentage of contaminants that had transported past the fence line boundary was $100 \%$ for Tc-99, U:0.01, and U:0.03; $99.8 \%$ for U: $0.10 ; 32.3 \%$ for U:0.30; $0.1 \%$ for $\mathrm{U}: 0.60$; and $0 \%$ for $\mathrm{U}: 1.00$.

The peak concentration of Tc-99 at the fence line was $1.94 \times 10^{-7} \mathrm{Ci} / \mathrm{L}$, a $20 \%$ increase over the peak concentration in Case 1. Relative to Tc-99, peak concentrations for the U-238 compounds were 59.3\% for $\mathrm{U}: 0.01,18 \%$ for $\mathrm{U}: 0.03$, and $12.3 \%$ for $\mathrm{U}: 0.10$. The arrival times of peak $\mathrm{C}_{\mathrm{fl}}$ were 2101 for $\mathrm{Tc}-99$, 2110 for U:0.01, 3914 for U:0.03, and 6159 for U:0.10. These results are summarized at the end of this report, along with peak concentrations and arrival times at the downstream compliance points. These results were obtained using the streamtube model described in Section 3.8 for the exclusion boundary and the Columbia River along two potential groundwater flow paths.

\subsubsection{Leak Volume Effects: Comparison of Cases 1 and 2}

A comparison of results of Cases 1 and 2 shows that when the leak volume was increased $150 \%$ the Tc-99 peak concentrations at all the compliance points increased by $20 \sim 24 \%$, and the arrival times were

$7 \sim 10$ years earlier. The peak concentrations of U-238 with $\mathrm{K}_{\mathrm{d}}=0.01 \mathrm{~mL} / \mathrm{g}$ increased by $22 \sim 29 \%$, and the arrival times were $10 \sim 12$ years earlier. For $\mathrm{K}_{\mathrm{d}} \geq 0.03 \mathrm{~mL} / \mathrm{g}$, the second peak in the mass flux curves was 
higher than the first in both cases. Peak concentrations of U-238 with $\mathrm{K}_{\mathrm{d}} \geq 0.03 \mathrm{~mL} / \mathrm{g}$ differed no more than $3 \%$ in the two cases, suggesting that the leak volume had relatively little effect on contaminant transport behavior because the volume of leak water was very small compared with the volume of meteoric recharge entering the domain.

The differences in mass flux between Cases 1 and 2 were similar to those of concentration. For example, when the leak volume increased 1.5 times, the Tc-99 peak mass flux at the water table and the fence line increased $24 \sim 27 \%$ and arrival times were $7 \sim 10$ years earlier. However, the cumulative mass migrating out of the fence line did not show any difference between cases. At the year 12000, the percentage of contaminants that had exited the fence line was nearly identical in both cases.

The sensitivity of the system to the magnitude of the aquifer saturated hydraulic conductivity was demonstrated by comparing Cases 1 and 1 (Hi_K). An order of magnitude increase in the hydraulic conductivity of the unconfined aquifer resulted in an 84.9 90.1\% decrease in the peak concentration at the fence line for Tc-99 and U-238 with a $\mathrm{K}_{\mathrm{d}} \leq 0.06 \mathrm{~mL} / \mathrm{g}$. The peak concentration arrival times at the fence line were 27 years earlier for Tc-99, 32 years earlier for U:0.01, 63 years earlier for U:0.03, and 117 years earlier for $\mathrm{U}: 0.10$.

\subsection{Past Leaks}

Cases 3 and 4 predicted transport behavior for contaminants originating from past leaks. Two source depths were simulated in each case: Case 3 with a unit release of each contaminant at a depth of $80 \mathrm{ft}$ (24.4 $\mathrm{m})$ and Case 4 with a unit release of each contaminant at a depth of $30 \mathrm{ft}(9.1 \mathrm{~m})$. To examine the sensitivity of contaminant transport to hydraulic conductivity, simulations were run for both cases with the saturated hydraulic conductivity of the aquifer increased by an order of magnitude. For all of these cases, the inventory was located between Tanks C-112 and C-109 with a source width of $22.9 \mathrm{ft}(7.0 \mathrm{~m})$.

\subsubsection{Case 3: Past Leak $($ depth $=80 \mathrm{ft})$}

The Case 3 simulation investigated a past leak at a depth of $80 \mathrm{ft}$ bgs $(24.4 \mathrm{~m})$ and an inventory diameter of $22.9 \mathrm{ft}(7 \mathrm{~m})$ between Tanks C-112 and C-109. The leak occurred on the first day of the year 2000. A unit release of each of the contaminant species (Tc-99 and U-238) was simulated. Plot-file output for this simulation was generated at the beginning (year 2000) and the end (one day after January 1, 2000, the day the leak began) of the leak and the years 2001, 2010, 2050, 2100, 2500, 3000, 4000, $5000,6000,8000,10000$, and 12000. Each plot file includes values for saturation, aqueous pressure, moisture content, and concentration of the seven solute species.

The saturation distributions at years 2050 and 12000 are shown in Figure A.29. The concentration distributions of the contaminants at years 2050 and 12000 are shown in Figures A.30 through A.36. As shown in these figures, by the year 2050 all of the contaminants dispersed upward toward the bottom of Tank C-109, largely due to diffusion. Contaminants with smaller values of $\mathrm{K}_{\mathrm{d}}$ were more dispersed. Although all of the contaminants reached the groundwater table by the year 12000 , only contaminants with a $K_{d} \leq 0.03 \mathrm{~mL} / \mathrm{g}$ had arrived by 2050 .

The mass flux, cumulative mass, and BTCs of each contaminant are shown in Figures B.41-B.48. The curves of mass flux (Figures B.41, B.43, B.45, and B.47) and BTCs (Figures B.42, B.44, B.46, and 
B.48) had double peaks for contaminants with $\mathrm{K}_{\mathrm{d}} \leq 0.03 \mathrm{~mL} / \mathrm{g}$. By the year 12000 , the percentage of contaminants that had exited the fence line was $100 \%$ for Tc-99, U:0.01, and U:0.03; $99.9 \%$ for U:0.10; $52.6 \%$ for $\mathrm{U}: 0.30 ; 0.9 \%$ for $\mathrm{U}: 0.60$; and $0 \%$ for $\mathrm{U}: 1.00$.

The peak concentration of Tc-99 at the fence line was $1.59 \times 10^{-7} \mathrm{Ci} / \mathrm{L}$, nearly identical to Case 1 . Peak concentrations for U-238 compounds with different $K_{d}$ values at the fence line were $57.7 \%$ for $\mathrm{U}: 0.01,25.3 \%$ for $\mathrm{U}: 0.03$, and $16.7 \%$ for $\mathrm{U}: 0.10$. The arrival times for the peak fence line concentrations were years 2119 for Tc-99, 2135 for U:0.01, 3755 for U:0.03, and 5645 for U:0.10. These results are summarized at the end of this report, along with peak concentrations and arrival times at the downstream compliance points. The results were obtained using the streamtube model described in Section 3.8 for the exclusion boundary and the Columbia River along two potential groundwater flow paths.

\subsubsection{Case 3 (Hi_K): Past Leak (depth $=80 \mathrm{ft})$}

The Case 3 (Hi_K) simulation investigated a past leak between Tanks C-112 and C-109 at a depth of $80 \mathrm{ft}$ bgs $(24.4 \mathrm{~m})$ and an inventory diameter of $22.9 \mathrm{ft}(7 \mathrm{~m})$. The saturated hydraulic conductivity of the aquifer was 10 times higher than in Case 3. The leak occurred on the first day of the year 2000. A unit release of each of the contaminant species (Tc-99 and U-238) was simulated. Plot-file output for this simulation was generated at the beginning (year 2000) and the end (one day after January 1, 2000) of the leak and years 2001, 2010, 2050, 2100, 2500, 3000, 4000, 5000, 6000, 8000, 10000, and 12000. Each plot file includes values for saturation, aqueous pressure, moisture content, and concentrations of the seven solute species.

The saturation distributions at years 2050 and 12000 are shown in Figure A.37. The concentration distributions of the contaminants at years 2050 and 12000 are shown in Figures A.38 through A.44. As shown in these figures, by the year 2050 all of the contaminants dispersed upward toward the bottom of Tank C-109, largely due to diffusion. Contaminants with smaller values of $\mathrm{K}_{\mathrm{d}}$ were more dispersed. Although all of the contaminants reached the groundwater table by the year 12000 , only contaminants with a $\mathrm{K}_{\mathrm{d}} \leq 0.03 \mathrm{~mL} / \mathrm{g}$ had arrived by the year 2050 .

The mass flux, cumulative mass, and BTCs of each contaminant are shown in Figures B.49-B.56. By the year 12000 , the percentage of contaminants that had exited the fence line was $100 \%$ for Tc-99, $\mathrm{U}: 0.01, \mathrm{U}: 0.03$, and $\mathrm{U}: 0.10 ; 56.3 \%$ for $\mathrm{U}: 0.30 ; 1.4 \%$ for $\mathrm{U}: 0.60$; and $0 \%$ for $\mathrm{U}: 1.00$.

The peak concentration of Tc-99 at the fence line was $1.88 \times 10^{-8} \mathrm{Ci} / \mathrm{L}$, which was $11.7 \%$ of the peak concentration predicted in Case 1. Peak concentrations for U-238 compounds with different $\mathrm{K}_{\mathrm{d}}$ values at the fence line were $56.9 \%$ for U:0.01, $21.2 \%$ for U:0.03, and $14.1 \%$ for $\mathrm{U}: 0.10$. The arrival times for the peak fence line concentrations were years 2092 for Tc-99, 2103 for U:0.01, 3601 for U:0.03, and 5537 for $\mathrm{U}: 0.10$. These results are summarized at the end of this section, along with peak concentrations and arrival times at the downstream compliance points. These results were obtained using the streamtube model described in Section 3.8 for the exclusion boundary and the Columbia River along two potential groundwater flow paths. 


\subsubsection{Case 4: Past Leak $($ depth $=30 \mathrm{ft})$}

The Case 4 simulation investigated a past leak between Tanks C-112 and C-109 at a depth of $30 \mathrm{ft}$ bgs $(9.1 \mathrm{~m})$ and an inventory diameter of $22.9 \mathrm{ft}(7 \mathrm{~m})$. The leak occurred on the first day of the year 2000. A unit release of each of the contaminant species (Tc-99 and U-238) was simulated. Plot-file output for this simulation was generated at the beginning (year 2000) and the end (one day after January 1, 2000, the day the leak began) of the leak and the years 2001, 2010, 2050, 2100, 2500, 3000, 4000, $5000,6000,8000,10000$, and 12000. Each plot file includes values for saturation, aqueous pressure, moisture content, and concentration of the seven solute species.

The saturation distribution at years 2050 and 12000 for this case was the same as that for Case 3 (Figure A.29). The concentration distributions of the contaminants at years 2050 and 12000 are shown in Figures A.45-A.51. Similar to Case 3, the contaminants in Case 4 also dispersed vertically toward the ground surface due to diffusive processes. Unlike Case 3, however, this upward movement reached the ground surface for U-238 compounds with a $\mathrm{K}_{\mathrm{d}} \geq 0.10 \mathrm{~mL} / \mathrm{g}$. In the year 2050, only Tc-99 and U-238 with $\mathrm{K}_{\mathrm{d}}=0.01 \mathrm{~mL} / \mathrm{g}$ had entered the groundwater. All of the contaminants reached the groundwater table by the year 12000; however, only a small percentage of the original unit release of U-238 with a $\mathrm{K}_{\mathrm{d}}$ of $1.00 \mathrm{~mL} / \mathrm{g}\left(1.8 \times 10^{-6} \%\right)$ had reached the groundwater table.

The mass flux, cumulative mass, and BTCs for each contaminant are shown in Figures B.57-B.64. By the year 12000, the percentage of contaminants that had migrated past the fence line boundary was $100 \%$ for Tc-99, U:0.01, and U:0.03; $99.7 \%$ for $\mathrm{U}: 0.10 ; 24.3 \%$ for U:0.30; $0.03 \%$ for U: 0.60 ; and $0 \%$ for $\mathrm{U}: 1.00$.

The peak concentration of Tc-99 at the fence line was $6.45 \times 10^{-8} \mathrm{Ci} / \mathrm{L}$, which was $40.1 \%$ of the peak concentration predicted for Case 1. Peak concentrations for U-238 compounds with different $\mathrm{K}_{\mathrm{d}}$ values at the fence line were $68.7 \%$ for $\mathrm{U}: 0.01,59.1 \%$ for $\mathrm{U}: 0.03$, and $38.4 \%$ for $\mathrm{U}: 0.10$. The arrival times for the peak fence line concentrations were years 2145 for Tc-99, 3646 for U:0.01, 4294 for U:0.03, and 6600 for $\mathrm{U}: 0.10$. These results are summarized at the end of this report, along with peak concentrations and arrival times at the downstream compliance points. These results were obtained using the streamtube model described in Section 3.8 for the exclusion boundary and the Columbia River along two potential groundwater flow paths.

\subsubsection{Case 4 (HiK): Past Leak (depth $=30 \mathrm{ft})$}

The Case 4 (HiK) simulation investigated a past leak between Tanks C-112 and C-109 at a depth of $30 \mathrm{ft}(9.1 \mathrm{~m})$ and an inventory diameter of $22.9 \mathrm{ft}(7 \mathrm{~m})$. The saturated hydraulic conductivity of the aquifer was 10 times higher than Case 4. The leak occurred on the first day of the year 2000. A unit release of each contaminant species (Tc-99 and U-238) was simulated. Plot-file output for this simulation was generated at the beginning (year 2000) and the end (one day after January 1, 2000, the day the leak began) of the leak and years 2001, 2010, 2050, 2100, 2500, 3000, 4000, 5000,6000, 8000, 10000, and 12000. Each plot file includes saturation, aqueous pressure, moisture content, and concentration of the seven solute species. 
The saturation distributions at years 2050 and 12000 for this case were the same as Case 3 (HiK) (Figure A.37). The concentration distributions of the contaminants at years 2050 and 12000 are shown in Figures A.52-A.58. In 2050, only Tc-99 and U-238 with $\mathrm{K}_{\mathrm{d}}=0.01 \mathrm{~mL} / \mathrm{g}$ had entered the groundwater.

The mass flux, cumulative mass, and BTCs for each contaminant are shown in Figures B.73-B.80. By the year 12000, the percentage of contaminants that had migrated past the fence line boundary was $100 \%$ for Tc-99, U:0.01, and U:0.03; $99.8 \%$ for $\mathrm{U}: 0.10 ; 27.5 \%$ for $\mathrm{U}: 0.30 ; 0.05 \%$ for $\mathrm{U}: 0.60$; and $0 \%$ for $\mathrm{U}: 1.00$.

The peak concentration of Tc-99 at the fence line was $7.26 \times 10^{-9} \mathrm{Ci} / \mathrm{L}$, which was $4.5 \%$ of the peak concentration predicted in Case 1. Peak concentrations at the fence line for U-238 species with different $\mathrm{K}_{\mathrm{d}}$ values were $60.6 \%$ for $\mathrm{U}: 0.01,52.2 \%$ for $\mathrm{U}: 0.03$, and $34 \%$ for $\mathrm{U}: 0.10$. The arrival times for the peak fence line concentrations were years 2114 for Tc-99, 3600 for U:0.01, 4232 for U:0.03, and 6482 for $\mathrm{U}: 0.10$. These results are summarized at the end of the report, along with peak concentrations and arrival times at the downstream compliance points. These results were obtained using the streamtube model described in Section 3.8 for the exclusion boundary and the Columbia River along two potential groundwater flow paths.

\subsubsection{Inventory Depth Effects: Comparison of Cases 3 and 4}

Vertical movement toward the ground surface by diffusion was evident in both Cases 3 and 4 . However, because the inventory depth in Case 4 was shallower than that in Case 3, vertical movement to the ground surface occurred for U-238 with a $K_{d} \geq 0.10$ at the shallower depth by year 2050 . The arrival times for peak concentrations of Tc-99 at the downstream compliance points (see Section 4.8) were about 13 16 yr later in Case 4 than in Case 3. This delay in the arrival of the peak concentration increased with higher values of $K_{d}$. For example, when $K_{d}=0.03 \mathrm{~mL} / \mathrm{g}$, the arrival time of peak concentration at the fence line was 539 years later in Case 4 than in Case 3.

The sensitivity of the system to the magnitude of the aquifer saturated hydraulic conductivity was demonstrated by comparing the base cases for inventory depth effects (Cases 3 and 4) with the higher saturated hydraulic conductivity cases [Cases 3 (HiK) and $4(\mathrm{HiK})$ ]. For Case 3, an order of magnitude increase in the hydraulic conductivity of the unconfined aquifer resulted in a decrease in the peak concentration at the fence line by $86.6 \sim 90.1 \%$ for Tc-99 and U-238 species with a $\mathrm{K}_{\mathrm{d}} \leq 0.06 \mathrm{~mL} / \mathrm{g}$. Peak concentration arrival times at the fence line were 27 years earlier for Tc, 32 years for $\mathrm{U}: 0.01,64$ years for $\mathrm{U}: 0.03$ and 108 years for $\mathrm{U}: 0.10$. For Case 4 , the increase in hydraulic conductivity resulted in peak concentrations at the fence line decreasing by $84.0 \sim 90.1 \%$ for Tc-99 and U-238 species with $\mathrm{K}_{\mathrm{d}} \leq 0.06 \mathrm{~mL} / \mathrm{g}$. The peak concentration arrival times at the fence line were 28 years earlier for Tc, 46 years for U:0.01, 62 years for $\mathrm{U}: 0.03$, and 118 years for $\mathrm{U}: 0.10$.

\subsection{Residual Tank Wastes with Rate-Controlled Releases}

Cases 5 through 9 investigated contaminant transport behavior from residual tank wastes. These releases can occur when water infiltrates residual tank wastes, thereby mobilizing contaminants. It is expected that such releases would occur over an extended period of time following closure. Five timevarying release rates were investigated. For Cases 5-8 contaminants were mobilized on the first day of the year 2050. For Case 9, contaminant transport began in the year 2500, 450 years later than the other 
cases. Peak concentration predictions were compared with Case 11 (see Table 4.1 and Section 4.5.3), which was considered the base case for these simulations.

\subsubsection{Case 5: Release Rate R0 at C-112 (10-3 Ci/yr for 500 yr and 10-1 Ci/yr for 5 yr)}

This scenario (Case 5) investigated a residual tank waste source with release rate $\mathrm{R}_{0}$ defined as $10^{-3} \mathrm{Ci} / \mathrm{yr}$ for 500 years followed by a rate of $0.1 \mathrm{Ci} / \mathrm{yr}$ for five years. The release occurred over the bottom width of Tank C-112. The leak began on the first day of year 2050, the date when tank integrity was lost. Plot-file output for this simulation was generated at the beginning of the leak (year 2050) and the years 2550, 2555, 2600, 3000, 4000, 5000, 6000, 8000, 10000, and 12000. Each plot file includes values for saturation, aqueous pressure, moisture content, and concentration of the seven solute species.

The saturation distributions at years 2050 and 12000 were the same as those in Case 3 (Figure A.29). Concentration distributions of the contaminants at years 2555 and 12000 are shown in Figures A.59A.65. As shown in these figures, at the end of the release in the year 2555, significant upward movement occurred due to diffusion. Tc-99 and U-238 with a $\mathrm{K}_{\mathrm{d}}$ of $0.01 \mathrm{~mL} / \mathrm{g}$ had been transported to the ground surface. By the year 2555, no contaminants had reached the groundwater table.

Mass flux, cumulative mass, and BTCs for each contaminant are shown in Figures B.73 through B.80. Due to the gradual release of contaminants, peak concentrations for Case 5 were smaller than those of Cases 1-4. By the year 12000, the percentages of contaminant that had migrated past the fence line boundary were $100 \%$ for Tc-99, U:0.01, and U:0.03; $98.2 \%$ for U:0.10; $7.9 \%$ for U:0.30; and $0 \%$ for both $\mathrm{U}: 0.60$ and $\mathrm{U}: 1.00$.

The peak concentration of Tc-99 at the fence line was $6.50 \times 10^{-8} \mathrm{Ci} / \mathrm{L}$, which was 3.16 times greater than the peak concentration predicted in Case 11. Peak concentrations at the fence line for U-238 compounds with different $\mathrm{K}_{\mathrm{d}}$ values were $85.7 \%$ for $\mathrm{U}: 0.01,68.6 \%$ for $\mathrm{U}: 0.03$, and $40.3 \%$ for U:0.10. The arrival times for the peak fence line concentrations were years 4827 for Tc-99, 5154 for U:0.01, 5826 for $\mathrm{U}: 0.03$, and 8170 for $\mathrm{U}: 0.10$. These results are summarized at the end of this report, along with peak concentrations and arrival times at the downstream compliance points. These results were obtained using the streamtube model described in Section 3.8 for the exclusion boundary and the Columbia River along two potential groundwater flow paths.

\subsubsection{Case 5v: Release Rate $R_{0}$ at $C-112, C-109, C-106$, and $C-103\left(10^{-3} \mathrm{Ci} / \mathrm{yr}\right.$ for 500 yr and $10^{-1} \mathrm{Ci} / \mathrm{yr}$ for $5 \mathrm{yr}$ )}

As a verification of Case 5, Case $5 \mathrm{v}$ simulated residual tank waste sources with a release rate $\mathrm{R}_{0}$, defined as $10^{-3} \mathrm{Ci} / \mathrm{yr}$ for 500 years followed by a rate of $0.1 \mathrm{Ci} / \mathrm{yr}$ for five years. The releases occurred over the bottom widths of each of the four tanks in the domain. All of the releases began on the first day of the year 2050, and each residual tank waste source contained a unit release of Tc-99 and U-238 with a $\mathrm{K}_{\mathrm{d}}=0.03 \mathrm{~mL} / \mathrm{g}$. No other $\mathrm{K}_{\mathrm{d}}$ values were used in this simulation. Tc-99 and U-238 concentration distributions are shown in Figures A.66a and A.67a, which show that the four plumes for each contaminant were similar in shape and migrated at nearly the same velocity. By the year 12000 (Figure A.66b and A.67b), all of the contaminants had exited the domain. 
Figures B.81 through B.96 plot the mass flux, cumulative mass, and BTCs of each contaminant. The peak fluxes, concentrations, and arrival times of the contaminants released from different tanks were similar. For example, the peak concentrations of Tc-99 released from Tanks C-103 (Figure B.82a), C-106 (Figure B.84a), C-109 (Figure B.86a), and C-112 (Figure B.88a), respectively, at the fence line were $6.83 \times 10^{-8}, 6.62 \times 10^{-8}, 6.51 \times 10^{-8}$, and $6.50 \times 10^{-8} \mathrm{Ci} / \mathrm{L}$. The corresponding peak arrival times were 4719 , 4781, 4818, and 4827. As in Case 1v, nonsymmetrical transport behavior occurred due to asymmetry in stratigraphy and saturation distributions. Relative to the single residual waste source case (Case 5), peak concentrations and arrival times of the contaminants were nearly the same. For example, for Tc-99 released from only C-112, the peak concentration was $6.50 \times 10^{-8} \mathrm{Ci} / \mathrm{L}$ and arrival time was year 4827 (Figure B.74a).

\subsubsection{Case 6: Release Rate R1 at C-112 (10-4 Ci/yr for 500 yr and 10-2 Ci/yr for 95 yr)}

Case 6 investigated a residual tank waste source with a release rate $\mathrm{R}_{1}$, defined as $10^{-4} \mathrm{Ci} / \mathrm{yr}$ for 500 years followed by a rate of $10^{-3} \mathrm{Ci} / \mathrm{yr}$ for 95 years. The release occurred over the bottom width of Tank C-112. The leak began on the first day of the year 2050, the date when tank integrity was lost. Plot-file output for this simulation was generated at the beginning of the leakage (year 2050) and the years 2550 , $2555,2600,3000,4000,5000,6000,8000,10000$, and 12000. Each plot file includes values for saturation, aqueous pressure, moisture content, and concentration of the seven solute species.

The saturation distributions at years 2050 and 12000 were the same as those in Case 3 (Figure A.29). The concentration distributions of the contaminants at years 2555 and 12000 are shown in Figures A.68A.74. Mass flux, cumulative mass, and BTCs for each contaminant are shown in Figures B.97-B.104. By the year 12000, the percentage of contaminants that had migrated past the fence line boundary was $100 \%$ for Tc-99, U:0.01, and U:0.03; $98.1 \%$ for U:0.10; $7.7 \%$ for U:0.30; and $0 \%$ for both U:0.60 and $\mathrm{U}: 1.00$.

Peak concentrations at the fence line were nearly identical to Case 5 for all the contaminants. The peak concentration of Tc-99 at the fence line was $6.50 \times 10^{-8} \mathrm{Ci} / \mathrm{L}, 3.16$ times greater than the peak concentration predicted in Case 11. Peak concentrations for U-238 species with different $\mathrm{K}_{\mathrm{d}}$ values at the fence line were $85.7 \%$ for $\mathrm{U}: 0.01,68.6 \%$ for $\mathrm{U}: 0.03$, and $40.3 \%$ for $\mathrm{U}: 0.10$. The arrival times for the peak fence line concentrations were years 4864 for Tc-99, 5192 for U:0.01, 5862 for U:0.03, and 8203 for $\mathrm{U}: 0.10$. These results are summarized at the end of this report, along with peak concentrations and arrival times at the downstream compliance points. These results were obtained using the streamtube model described in Section 3.8 for the exclusion boundary and the Columbia River along two potential groundwater flow paths.

\subsubsection{Case 7: Release Rate $\mathrm{R} 2$ at $\mathrm{C}-112(10-5 \mathrm{Ci} / \mathrm{yr}$ for $500 \mathrm{yr}$ and $10-3 \mathrm{Ci} / \mathrm{yr}$ for $995 \mathrm{yr})$}

Case 7 investigated a residual tank waste source with a release rate $\mathrm{R}_{2}$, defined as $10^{-5} \mathrm{Ci} / \mathrm{yr}$ for 500 years followed by a rate of $10^{-3} \mathrm{Ci} / \mathrm{yr}$ for 995 years. The release occurred over the bottom width of Tank C-112. The leak began on the first day of the year 2050, the date when tank integrity was lost. Plot-file output for this simulation was generated at the beginning of the leakage (year 2050) and the years 2550, $2555,2600,3000,4000,5000,6000,8000,10000$, and 12000. Each plot file includes values for saturation, aqueous pressure, moisture content, and concentration of the seven solute species. 
The saturation distributions at years 2050 and 12000 were the same as those in Case 3 (Figure A.29). The concentration distributions of the contaminants at years 2555 and 12000 are shown in Figures A.75A.81. Mass flux, cumulative mass, and BTCs of each contaminant are shown in Figures B.105-B.112. By the year 12000, the percentage of contaminants that had migrated past the fence line boundary was $100 \%$ for Tc-99, U:0.01, and U:0.03; $96.7 \%$ for U:0.10; $5.2 \%$ for U:0.30; and $0 \%$ for both U:0.60 and $\mathrm{U}: 1.00$.

The peak concentration of Tc-99 at the fence line was $5.62 \times 10^{-8} \mathrm{Ci} / \mathrm{L}, 2.73$ times greater than the peak concentration predicted in Case 11. Peak concentrations of U-238 compounds at the fence line with different $\mathrm{K}_{\mathrm{d}}$ values were $89 \%$ for $\mathrm{U}: 0.01,74 \%$ for $\mathrm{U}: 0.03$, and $45.6 \%$ for $\mathrm{U}: 0.10$. The arrival times for the peak fence line concentrations were years 5355 for Tc-99, 5675 for U:0.01, 6339 for U:0.03, and 8662 for $\mathrm{U}: 0.10$. These results are summarized at the end of this report, along with peak concentrations and arrival times at the downstream compliance points. These results were obtained using the streamtube model described in Section 3.8 for the exclusion boundary and the Columbia River along two potential groundwater flow paths.

\subsubsection{Case 8: Release Rate R3 at C-112 (10-6 Ci/yr for $500 \mathrm{yr}$ and 10-4 Ci/yr for $9995 \mathrm{yr})$}

Case 8 investigated a residual tank waste source with release rate $\mathrm{R}_{3}$, defined as $10^{-6} \mathrm{Ci} / \mathrm{yr}$ for 500 years followed by a rate of $10^{-4} \mathrm{Ci} / \mathrm{yr}$ for 9,995 years. The release occurred over the bottom width of Tank C-112. The leak began on the first day of the year 2050, the date when tank integrity was lost. Plot-file output for this simulation was generated at the beginning of the leakage (year 2050) and the years 2550, $2555,2600,3000,4000,5000,6000,8000,10000$, and 12000. Each plot file includes values for saturation, aqueous pressure, moisture content, and concentration of the seven solute species.

The saturation distributions at years 2050 and 12000 were the same as those in Case 3 (Figure A.29). The concentration distributions of the contaminants at years 2555 and 12000 are shown in Figures A.82A.88. Mass flux, cumulative mass, and BTCs for each contaminant are shown in Figures B.113-B.120. By the year 12000, the percentage of contaminant that had migrated past the fence line boundary was $70.1 \%$ for Tc-99, $66.5 \%$ for $\mathrm{U}: 0.01,59.3 \%$ for $\mathrm{U}: 0.03,34.2 \%$ for $\mathrm{U}: 0.10,0.7 \%$ for $\mathrm{U}: 0.30$, and $0 \%$ for both $\mathrm{U}: 0.60$ and $\mathrm{U}: 1.00$.

The peak concentration of Tc-99 at the fence line was $8.55 \times 10^{-9} \mathrm{Ci} / \mathrm{L}, 41.5 \%$ of the peak concentration predicted in Case 11. Peak concentrations of U-238 compounds at the fence line with different $\mathrm{K}_{\mathrm{d}}$ values were $100 \%$ for $\mathrm{U}: 0.01,100 \%$ for $\mathrm{U}: 0.03$, and $98.2 \%$ for $\mathrm{U}: 0.10$. The arrival times for the peak fence line concentrations were years 9538 for Tc-99, 9693 for U:0.01, 11437 for U:0.03, and 12000 for $\mathrm{U}: 0.10$. These results are summarized at the end of this report, along with peak concentrations and arrival times at the downstream compliance points. These results were obtained using the streamtube model described in Section 3.8 for the exclusion boundary and the Columbia River along two potential groundwater flow paths.

\subsubsection{Case 9: Release Rate R4 at C-112 (10-1 Ci/yr for $10 \mathrm{yr})$}

Case 9 investigated a residual tank waste source with a release rate $\mathrm{R}_{4}$, defined as $0.1 \mathrm{Ci} / \mathrm{yr}$ for 10 years. The release occurred over the bottom width of Tank C-112. The leak began on the first day of the year 2500, the date when tank integrity was lost. Plot-file output for this simulation was generated at the 
beginning of the leakage (year 2500) and the years 2550, 2600, 3000, 4000, 5000, 6000, 8000, 10000, and 12000. Each plot file includes values for saturation, aqueous pressure, moisture content, and concentration of the seven solute species.

The saturation distributions at years 2050 and 12000 were the same as those in Case 3 (Figure A.29). The concentration distributions of the contaminants at years 2555 and 12000 are shown in Figures A.89A.95. The mass flux, cumulative mass, and BTCs of each contaminant are shown in Figures B.121B.128. By the year 12000 , the percentage of contaminants that had migrated past the fence line boundary was $100 \%$ for Tc-99, U:0.01, and U:0.03; $98.3 \%$ for U:0.10; $8.4 \%$ for U:0.30; and $0 \%$ for both U:0.60 and $\mathrm{U}: 1.00$.

The peak concentration of Tc-99 at the fence line was $6.51 \times 10^{-8} \mathrm{Ci} / \mathrm{L}, 3.16$ times greater than that predicted in Case 11. Peak concentrations of U-238 compounds with different $\mathrm{K}_{d}$ values at the fence line were $85.7 \%$ for $\mathrm{U}: 0.01,68.7 \%$ for $\mathrm{U}: 0.03$, and $40.2 \%$ for $\mathrm{U}: 0.10$. The arrival times for the peak fence line concentrations were years 4798 for Tc-99, 5119 for U:0.01, 5783 for U:0.03, and 8096 for U:0.10. These results are summarized at the end of this report, along with peak concentrations and arrival times at the downstream compliance points. The results were obtained using the streamtube model described in Section 3.8 for the exclusion boundary and the Columbia River along two potential groundwater flow paths.

\subsubsection{Release Rate Effects: Comparison of Cases 5-9}

A comparison of release rate effects is straightforward for Cases 5-8 because tank integrity was lost in the same year (2050) and release rates were divided into two separate stages. In the first stage, there was a slow release from the residual tank wastes for 500 years, and in the second stage the release rate was increased by a factor of 100 . In each case, the duration of the second release stage was dependent on the amount of time it took to release a unit curie of the solutes. Because the release rate was higher in the second stage, the magnitude of the second-stage release rate controlled the peak concentration at the compliance points.

The second stage of the release was progressively decreased by an order of magnitude from the previous case for Cases 5-8. The effect on peak concentration was not significant in Cases 5 and 6 . For Case 7, peak concentrations decreased by about $13 \%$ for Tc-99, $10 \%$ for U:0.01, 7\% for U:0.03, and 2\% for $\mathrm{U}: 0.10$ from the peaks predicted in the Case 5 simulation. Arrival times of the peak concentrations at the downstream compliance points (see Section 4.8) were delayed by 491 528 years. At the end of the simulation in Case 8 , only $94.5 \%$ of the contaminants had been released. Relative to Case 5 , peak concentrations decreased by $67 \sim 87 \%$ and the arrival times of peak concentration delayed by over 4000 years. One special characteristic of Case 8 is that once concentrations reached their peak values they remained constant until the end of the simulation.

Recharge rates affected arrival times of the peak concentrations - they were higher during the second stage of the release, which accelerated contaminant transport. For example, from 2050-2550 the recharge rate was $0.5 \mathrm{~mm} / \mathrm{yr}$. At the start of the second stage of release, recharge rates increased to $3.5 \mathrm{~mm} / \mathrm{yr}$ due to the degradation of the surface barrier. In Case 5, the peak concentration of Tc-99 arrived at the fence line boundary in the year 4827, 2272 years after all the contaminants were released. In Case 6, the release was 90 years longer. Peak concentration of Tc-99 at the fence line arrived in the year 4864, 2219 years 
after the contaminant release stopped. In Case 7, the release lasted 990 years longer than Case 5. Peak concentration of Tc-99 arrived at the fence line boundary in 5355, 1815 years after the release terminated. In Case 8, the release time was to be 9990 years longer than Case 5. The peak concentration of Tc-99 arrived at the boundary in the year 9538 , before a full curie of contaminants was released.

Case 9 differed from Cases 5-8 in that tank integrity lasted 450 years longer and a constant release rate was simulated. The release from the tank waste started in the year 2500 and terminated in 2510 . Hence, the release stopped 45 years earlier than Case 5. Due to the long travel time (over 2000 years) of the contaminants in the vadose zone, peak concentrations were similar to those predicted in Case 5. Peak concentration arrival times at the compliance points were $3 \sim 8$ years earlier than those in Case 5

\subsection{Residual Tank Wastes with Different Controlling Processes}

Cases 10-14 also simulated contaminant transport behavior from residual tank wastes. This type of release occurs when water infiltrates residual tank wastes and mobilizes contaminants. Unlike Cases 5-9, which assumed constant release rates over specified time periods, different physical processes such as advection, diffusion, and dissolution controlled the release rates for these scenarios. Three controlling processes were considered. In Case 10, an advection-dominated release model (Eq. 3.10) was used to predict contaminant transport behavior that considered mixing processes occurring within the residual wastes. For stabilized waste, contaminants were released into the subsurface at a rate determined by both the rate of infiltrating water and the amount of dispersion occurring within the source. Cases 11 and 14 assumed that little or no advection occurred in the residual tank waste source; thus the release was modeled as a diffusion-limited process (Eq. 3.11). In Case 12, it was assumed that the solid residual tank wastes release rate was controlled by solubility. The saltcake release model used in the Case 12 analysis is presented in Eq. (3.14). As in previous cases (1,3, and 4), the sensitivity of contaminant transport to hydraulic conductivity was examined by increasing the saturated hydraulic conductivity of the aquifer for Cases 10 and 11 (HiK). Peak concentration predictions were compared with Case 11 (see Table 4.1 and Section 4.5.3), which is considered the base case for these simulations.

\subsubsection{Case 10: Advection-Dominated Release}

Case 10 investigated a residual tank waste source using an advection-dominated release model. The release occurred over the bottom width of Tank C-112 with a source thickness of $0.825 \mathrm{~m}$. The number of mixing cells used in the advection-dominated release model was 10. The leak began on the first day of the year 2050, the date when tank integrity was lost. Plot-file output for this simulation was generated at the beginning of the leakage (year 2050) and the years 2100, 2300, 2600, 3000, 4000, 5000, 6000, 8000, 10000 , and 12000. Each plot file includes values for saturation, aqueous pressure, moisture content, and concentration of the seven solute species.

The saturation distributions at years 2050 and 12000 were the same as those in Case 3 (Figure A.29). The concentration distributions of the contaminants at years 2600 and 12000 are shown in Figures A.96A.102. Mass flux, cumulative mass, and BTCs for each contaminant are shown in Figures B.129-B.136. By the year 12000, the percentage of contaminant that had migrated past the fence line boundary was $100 \%$ for Tc-99, U:0.01, and U:0.03; $98.2 \%$ for U:0.10; and $7.6 \%$ for $\mathrm{U}: 0.30$. 
In this scenario, the release rate was dependent on both water flow and the amount of dispersion occurring from the residual tank waste source. After approximately 20 years, $99 \%$ of the contaminants had entered the subsurface. The peak concentration of Tc-99 at the fence line was $6.50 \times 10^{-8} \mathrm{Ci} / \mathrm{L}, 3.15$ times greater than the peak concentration predicted in Case 11. Peak concentrations at the fence line for U-238 compounds with different $\mathrm{K}_{\mathrm{d}}$ values were $85.5 \%$ for $\mathrm{U}: 0.01,68.3 \%$ for $\mathrm{U}: 0.03$, and $40 \%$ for U:0.10. Peak concentrations of all the contaminants were similar to those predicted for Cases 5, 6, and 9. Arrival times for the peak fence line concentrations were years 5025 for U:0.01, 5714 for U:0.03, and 8111 for U:0.10. These results are summarized at the end of the report, along with peak concentrations and arrival times at the downstream compliance points.

\subsubsection{Case 10 (HiK): Advection-Dominated Release}

Case 10 (HiK) investigated a residual tank waste source using an advection-dominated release model. The release occurred over the bottom width of Tank C-112 with a source thickness of $0.825 \mathrm{~m}$. The saturated hydraulic conductivity of the aquifer was 10 times higher than Case 10. The number of mixing cells used in the advection-dominated release model was 10. The leak began on the first day of the year 2050, the date when tank integrity was lost. Plot-file output for this simulation was generated at the beginning of the leakage (year 2050) and the years 2100, 2300, 2600, 3000, 4000, 5000, 6000, 8000, 10000 , and 12000. Each plot file includes values for saturation, aqueous pressure, moisture content, and concentration of the seven solute species.

The saturation distributions at years 2050 and 12000 for this case was the same as that for Case 3 (HiK) (Figure A.37). The concentration distributions of the contaminants at years 2600 and 12000 are shown in Figures A.103-A.109. Mass flux, cumulative mass, and BTCs for each contaminant are shown in Figures B.137-B.144. By the year 12000, the percentage of contaminants that had migrated past the fence line boundary was $100 \%$ for Tc-99, U:0.01, and U:0.03; $98.5 \%$ for U:0.10; $9.4 \%$ for U:0.30; and $0 \%$ for $\mathrm{U}: 0.60$ and $\mathrm{U}: 1.00$.

As in Case 10, the release rate was dependent on both water flow and the amount of dispersion occurring from the residual tank waste source. After approximately 20 years, $99 \%$ of the contaminants had entered the subsurface. The peak concentration of Tc-99 at the fence line was $6.46 \times 10^{-9} \mathrm{Ci} / \mathrm{L}, 31.4 \%$ of that predicted in Case 11. Peak concentrations for U-238 compounds with different $\mathrm{K}_{\mathrm{d}}$ values at the fence line were $85.6 \%$ for $\mathrm{U}: 0.01,68.4 \%$ for $\mathrm{U}: 0.03$, and $40.1 \%$ for $\mathrm{U}: 0.10$. Arrival times for the peak fence line concentrations were years 4651 for Tc, 4976 for U:0.01, 5647 for U:0.03, and 7996 for U:0.10. These results are summarized at the end of this section, along with peak concentrations and arrival times at the downstream compliance points.

The sensitivity of the system to the magnitude of the aquifer saturated hydraulic conductivity was demonstrated by comparing Cases 10 and 10 (Hi_K). An order of magnitude increase in the hydraulic conductivity of the unconfined aquifer resulted in an 88.6 90.1\% decrease in the peak concentration at the fence line for Tc-99 and U-238 with a $\mathrm{K}_{\mathrm{d}} \leq 0.06 \mathrm{~mL} / \mathrm{g}$. The peak concentration arrival times at the fence line were 43 years earlier for Tc, 49 years for U:0.01, 67 years for U:0.03, and 115 years for U:0.10. 


\subsubsection{Case 11: Diffusion-Dominated Release $(D 1=6 \times 10-7 \mathrm{~cm} 2 / \mathrm{s})$}

This case investigated a residual tank waste source using a diffusion-dominated release model and a diffusion coefficient of $6 \times 10^{-7} \mathrm{~cm}^{2} / \mathrm{s}$. The release occurred over the bottom width of Tank C-112 with a source thickness of $0.825 \mathrm{~m}$. The leak began on the first day of the year 2050, the date when tank integrity was lost. Grout was used as tank fill material beginning in the year 2050. Plot-file output for this simulation was generated at the beginning of the leakage (year 2050) and the years 2100, 2300, 2600, $3000,4000,5000,6000,8000,10000$, and 12000. Each plot file includes values for saturation, aqueous pressure, moisture content, and concentration of the seven solute species.

The saturation distributions at years 2050 and 12000 were the same as those in Case 3 (Figure A.29). The concentration distributions of the contaminants at years 2050 and 12000 are shown in Figures A.110A.116. Mass flux, cumulative mass, and BTCs for each contaminant are shown in Figures B.145-B.152. By the year 12000, the percentage of contaminants that had migrated past the fence line boundary was $100 \%$ for Tc-99 and U:0.01, 86.6\% for U:0.03, $60.0 \%$ for $\mathrm{U}: 0.10$, and $1 \%$ for $\mathrm{U}: 0.30$.

The peak concentration of Tc-99 at the fence line was $2.06 \times 10^{-8} \mathrm{Ci} / \mathrm{L}$, which was $12.8 \%$ of the peak concentration predicted in Case 1 (the other base case). At the fence line, peak concentrations of U-238 compounds with different $\mathrm{K}_{\mathrm{d}}$ values were $95.1 \%$ for $\mathrm{U}: 0.01,85.4 \%$ for $\mathrm{U}: 0.03$, and $63.6 \%$ for $\mathrm{U}: 0.10$. Arrival times for the peak fence line concentrations were years 5653 for Tc-99, 6085 for U:0.01, 6952 for $\mathrm{U}: 0.03$, and 9937 for $\mathrm{U}: 0.10$. These results are summarized at the end of the report, along with peak concentrations and arrival times at the downstream compliance points. A comparison of results for two values of the diffusion coefficient appears in Section 4.4.4.

\subsubsection{Case 11 (HiK): Diffusion-Dominated Release $\left(D_{1}=6 \times 10^{-7} \mathrm{~cm}^{2} / \mathrm{s}\right)$}

This case investigated a residual tank waste source using a diffusion-dominated release model and a diffusion coefficient of $6 \times 10^{-7} \mathrm{~cm}^{2} / \mathrm{s}$. The saturated hydraulic conductivity of the aquifer was 10 times higher than in Case 11. The release occurred over the bottom width of Tank C-112 with a source thickness of $0.825 \mathrm{~m}$. The leak began on the first day of the year 2050, the date when tank integrity was lost. Grout was used as tank fill material beginning in the year 2050. Plot-file output for this simulation was generated at the beginning of the leakage (year 2050) and the years 2100, 2300, 2600, 3000, 4000, 5000, $6000,8000,10000$, and 12000 . Each plot file includes values for saturation, aqueous pressure, moisture content, and concentration of the seven solute species.

The saturation distributions at years 2050 and 12000 for this case were the same as those for Case 3 (HiK) (Figure A.37). The concentration distributions of the contaminants at years 2050 and 12000 are shown in Figures A.117-A.123. Mass flux, cumulative mass, and BTCs for each contaminant are shown in Figures B.153-B.160. By the year 12000, the percentage of contaminants that had migrated past the fence line boundary was $100 \%$ for Tc-99 and U:0.01, 87\% for U:0.03, $61.4 \%$ for $\mathrm{U}: 0.10$, and $1.3 \%$ for $\mathrm{U}: 0.30$.

The peak concentration of Tc-99 at the fence line was $2.04 \times 10^{-9} \mathrm{Ci} / \mathrm{L}, 9.9 \%$ of the peak concentration predicted in Case 11. At the fence line, peak concentrations for U-238 compounds with different $\mathrm{K}_{\mathrm{d}}$ values were $95.1 \%$ for $\mathrm{U}: 0.01,85.8 \%$ for $\mathrm{U}: 0.03$, and $63.2 \%$ for $\mathrm{U}: 0.10$. Arrival times for the peak fence line concentrations were years 5605 for Tc-99, 6035 for U:0.01, 6891 for U:0.03, and 9802 for U:0.10. 
These results are summarized at the end of this section, along with peak concentrations and arrival times at the downstream compliance points.

\subsubsection{Case 14: Diffusion-Dominated Release $\left(D_{1}=5 \times 10^{-8} \mathrm{~cm}^{2} / \mathrm{s}\right)$}

This case investigated a residual tank waste source using a diffusion-dominated release model and a diffusion coefficient of $5 \times 10^{-8} \mathrm{~cm}^{2} / \mathrm{s}$. The release occurred over the bottom width of Tank $\mathrm{C}-112$ with a source thickness of $0.825 \mathrm{~m}$. The leak began on the first day of the year 2050, the date when tank integrity was lost. Grout was used as tank fill material beginning in the year 2050. Plot-file output for this simulation was generated at the beginning of the leakage (year 2050) and the years 2100, 2300, 2600, $3000,4000,5000,6000,8000,10000$, and 12000. Each plot file includes values for saturation, aqueous pressure, moisture content, and concentration of the seven solute species.

The saturation distributions at years 2050 and 12000 were the same as those in Case 3 (Figure A.29). The concentration distributions of the contaminants at years 2050 and 12000 are shown in Figures A.138A.144. Mass flux, cumulative mass, and BTCs for each contaminant are shown in Figures B.177-B.184. By the year 12000, the percentage of contaminants that had migrated past the fence line boundary was $88.7 \%$ for Tc-99, $87 \%$ for $\mathrm{U}: 0.01,81.3 \%$ for $\mathrm{U}: 0.03,49 \%$ for $\mathrm{U}: 0.10$, and $0.6 \%$ for $\mathrm{U}: 0.30$.

The peak concentration of Tc-99 at the fence line was $1.54 \times 10^{-8} \mathrm{Ci} / \mathrm{L}, 74.8 \%$ of the peak concentration predicted in Case 11. At the fence line, peak concentrations for U-238 compounds with different $\mathrm{K}_{\mathrm{d}}$ values were $98.7 \%$ for $\mathrm{U}: 0.01,94.8 \%$ for $\mathrm{U}: 0.03$, and $77.3 \%$ for $\mathrm{U}: 0.10$. Arrival times for the peak fence line concentrations were years 6877 for Tc-99, 7279 for U:0.01, 8092 for U:0.03, and 10925 for U:0.10. These results are summarized at the end of this report, along with peak concentrations and arrival times at the downstream compliance points. A comparison of results for the two values of diffusion coefficient follows.

\subsubsection{Diffusion Coefficient Effects: Comparison of Cases 11 and 14}

In the diffusion-dominated release scenarios, the contaminant release rate was dependent only on diffusion (without advection). When the diffusion coefficient decreased from $6 \times 10^{-7} \mathrm{~cm}^{2} / \mathrm{s}$ (Case 11) to $5 \times 10^{-8} \mathrm{~cm}^{2} / \mathrm{s}$ (Case 14), the time needed for $99 \%$ of the contaminants to be released increased from 229 years to 2815 years. The peak concentration at the fence line decreased by $25.2 \%$ for Tc- $99,22.4 \%$ for $\mathrm{U}: 0.01,17.6 \%$ for $\mathrm{U}: 0.03$, and $9.2 \%$ for $\mathrm{U}: 0.10$. Arrival times for the peak fence line concentrations were delayed by 1224 years for Tc-99, 1194 years for U:0.01, 1140 years for U:0.03, and 988 years for U:0.10. The total amount of mass migrating past the fence line boundary by the year 12000 decreased by about $3.3 \sim 11$ percentage points for contaminants with $\mathrm{K}_{\mathrm{d}} \leq 0.10 \mathrm{~mL} / \mathrm{g}$.

The sensitivity of the system to the magnitude of the aquifer saturated hydraulic conductivity was demonstrated by comparing Cases 11 and 11 (Hi_K). An order of magnitude increase in the hydraulic conductivity of the unconfined aquifer resulted in an $87.8 \sim 90.2 \%$ decrease in the peak concentration at the fence line for Tc-99 and U-238 with a $\mathrm{K}_{\mathrm{d}} \leq 0.06 \mathrm{~mL} / \mathrm{g}$. The peak concentration arrival times at the fence line were 48 years earlier for Tc, 50 years for U:0.01, 61 years for $\mathrm{U}: 0.03$, and 135 years for $\mathrm{U}: 0.10$. 


\subsubsection{Case 12: Saltcake (solubility-controlled) Release}

This case investigated a residual tank waste source using a saltcake release model that assumed an aqueous solubility of $360 \mathrm{mg} / \mathrm{L}$ for the residual waste. The release occurred over the bottom width of Tank C-112 with a source thickness of $0.825 \mathrm{~m}$. The leak began on the first day of the year 2050, the date when tank integrity was lost. Plot-file output for this simulation was generated at the beginning of the leakage (year 2050) and the years 2100, 2300, 2600, 3000, 4000, 5000, 6000, 8000, 10000, and 12000 and includes values for saturation, aqueous pressure, moisture content, and concentration of the seven solute species.

The saturation distributions at years 2050 and 12000 were the same as those in Case 3 (Figure A.29). The concentration distributions of the contaminants at years 2050 and 12000 are shown in Figures A.124A.130. Mass flux, cumulative mass, and BTCs for each contaminant are shown in Figures B.161-B.168. By the year 12000, the percentage of contaminants that had migrated past the fence line boundary was $0.59 \%$ for Tc-99, $0.56 \%$ for $\mathrm{U}: 0.01,0.50 \%$ for $\mathrm{U}: 0.03,0.30 \%$ for $\mathrm{U}: 0.10$, and $0.01 \%$ for $\mathrm{U}: 0.30$.

Due to the low solubility of the residual tank wastes assumed in this simulation, only $0.782 \%$ of the solutes were released by year 12000 . Consequently, the peak concentrations of the contaminants were about two orders of magnitude smaller than those of Case 1. The peak concentration of Tc-99 at the fence line was $6.98 \times 10^{-11} \mathrm{Ci} / \mathrm{L}, 0.3 \%$ of the peak concentration predicted in Case 11 . At the fence line, peak concentrations for U-238 compounds with different $K_{d}$ values were $97.9 \%$ for $U: 0.01,96.6 \%$ for $U: 0.03$, $95.6 \%$ for $\mathrm{U}: 0.10$, and $9.4 \%$ for $\mathrm{U}: 0.30$. Arrival times for the peak fence line concentrations were years 5610 for Tc, 6335 for U:0.01, 8008 for U:0.03, and 12000 for U:0.10. These results are summarized at the end of this report, along with peak concentrations and arrival times at the downstream compliance points. The results were obtained using the streamtube model described in Section 3.8 for the exclusion boundary and the Columbia River along two potential groundwater flow paths.

\subsection{Residual Ancillary Equipment Wastes}

Case 13 investigated contaminant transport behavior from residual ancillary equipment wastes. These releases can occur when ancillary equipment left behind after closure activities comes into contact with water. Diffusive processes are expected to dominate in subsequent mobilization of the contaminants. Hence, the diffusion-dominated model used in Cases 11 and 14 (Eq. 3.10) was used to describe the transport behavior for residual ancillary equipment waste sources. Peak concentration predictions were compared with Case 11 (see Table 4.1 and Section 4.5.3), which is the base case for this simulation.

\subsubsection{Case 13: Diffusion-Dominated Release $\left(D_{1}=6 \times 10^{-7} \mathrm{~cm}^{2} / \mathrm{s}\right)$}

This case investigated a residual ancillary equipment waste source using a diffusion-dominated release model and a diffusion coefficient of $6 \times 10^{-7} \mathrm{~cm}^{2} / \mathrm{s}$. The waste source originated between Tanks $\mathrm{C}-112$ and C-109at a depth of $20 \mathrm{ft}(6.1 \mathrm{~m})$ bgs with an inventory diameter of $22.9 \mathrm{ft}(7 \mathrm{~m})$. Grout was used as tank fill material. The leak began on the first day of the year 2050, the date when tank integrity was lost. Plot-file output for this simulation was generated at the beginning of the leakage (year 2050) and the years $2100,2300,2600,3000,4000,5000,6000,8000,10000$, and 12000. Output includes values for saturation, aqueous pressure, moisture content, and concentration of the seven solute species. 
The saturation distributions at years 2050 and 12000 were the same as those in Case 3 (Figure A.29). The concentration distributions of the contaminants at years 2050 and 12000 are shown in Figures A.131A.137. Mass flux, cumulative mass, and BTCs for each contaminant are shown in Figures B.169-B.176. By the year 12000, the percentage of contaminants that had migrated past the fence line boundary was $96.8 \%$ for Tc-99, $96.4 \%$ for $\mathrm{U}: 0.01,95 \%$ for $\mathrm{U}: 0.03,84.1 \%$ for $\mathrm{U}: 0.10$, and $3.3 \%$ for $\mathrm{U}: 0.30$.

The peak concentration of Tc-99 at the fence line was $4.12 \times 10^{-8} \mathrm{Ci} / \mathrm{L}$, twice that predicted in Case 11 . At the fence line, peak concentrations for U-238 compounds with different $\mathrm{K}_{\mathrm{d}}$ values were $88.8 \%$ for $\mathrm{U}: 0.01,75.5 \%$ for $\mathrm{U}: 0.03$, and $48.3 \%$ for $\mathrm{U}: 0.10$. Arrival times for the peak fence line concentrations were years 4929 for Tc-99, 5289 for U:0.01, 6019 for U:0.03, and 8583 for U:0.10. These results are summarized at the end of the report, along with peak concentrations and arrival times at the downstream compliance points. A comparison of results for the two different values of diffusion coefficient appears in Section 4.7. These results were obtained using the streamtube model described in Section 3.8 for the exclusion boundary and the Columbia River along two potential groundwater flow paths.

\subsection{Peak Concentrations and Arrival Times at Compliance Points}

The peak mass fluxes and their corresponding arrival times presented in Tables 4.2-4.8 correspond to predictions made by the STOMP simulator. Also reported in these tables is the cumulative mass of the contaminant transported into the groundwater. The peak concentrations and arrival times reported in Tables 4.9-4.15 correspond to predictions made by both STOMP and the analytical streamtube model. Whereas peaks reported for the groundwater table and fence line boundaries correspond to predictions made by STOMP, those reported for the downstream compliance points, the exclusion and Columbia River boundaries, were made using the analytical streamtube model described in Section 3.8. Two travel paths were considered, one traveling southeast to the Columbia River and the other northward through the Gable Mountain-Gable Butte gap (see Figure 3.3). Because predictions in peak concentrations and arrival times were similar in all of the cases, a general discussion of contaminant behavior appears below.

\subsubsection{Average Travel Time to Compliance Points}

Because of the similarity in peak concentrations and arrival times for the same contaminants at each of the compliance points, average solute travel times were calculated. Excluded from the average calculation are the results from Cases 8 and 12. These case scenarios simulated slow contaminant releases whose BTCs (Figures B.89-96, B.121-128) did not demonstrate clear peaks.

On average, travel time from the water table beneath Tank C-112 for Tc-99 to the fence line boundary was approximately 25 years. Predictions for groundwater flow using the analytical streamtube model showed that if groundwater flowed southeast to the Columbia River, travel time was approximately 23 years from the fence line to the exclusion boundary and 234 years to the Columbia River. The arrival times at the Columbia River boundary for a groundwater travel path northeast through the Gable Mountain-Gable Butte gap were approximately 2.5 times longer than the southeast path.

Contaminant travel times increased with increasingly higher values of $\mathrm{K}_{\mathrm{d}}$. For example, for U-238 with a $\mathrm{K}_{\mathrm{d}}=0.1 \mathrm{~mL} / \mathrm{g}$, travel time from the water table to the fence line was 66 years. On average, if the flow took the southeast path through the gap, another 52 years were required for the contaminant to arrive at the exclusion boundary and 419 years to the Columbia River. 


\subsubsection{Peak Concentrations at Compliance Points}

As previously stated, solute concentrations at the groundwater table were scaled by the water flux at the fence line (see Eq. 3.18, Section 3.7), and, as a result, BTCs at the groundwater table and fence line compliance points demonstrated similar behavior. A time shift, however, existed between the BTCs. For all cases, peak concentrations arrived later at the fence line than at the groundwater table. In general, peak concentration values at the two compliance points were similar. The peak concentrations of the contaminants with $K_{d} \leq 0.01 \mathrm{~mL} / \mathrm{g}$ at the fence line were slightly higher $(\leq 3 \%)$ than those predicted at the groundwater table because some of the contaminant arrived at the fence line boundary in the vadose zone and never entered the groundwater.

Peak concentrations at the exclusion boundary were much lower than those at the fence line. For the four contaminants with $\mathrm{K}_{\mathrm{d}} \leq 0.1 \mathrm{~mL} / \mathrm{g}$, if the flow took the path south of the gap, the peak concentration values at the exclusion boundary averaged $1.6 \sim 2.7 \%$ of the predicted concentration at the fence line; peak concentration values at the Columbia River were $0.58 \sim 0.98 \%$ of the peak concentrations at the fence line. If the flow took the path north of the gap, the peak concentration values at the exclusion boundary were $1.5 \sim 2.5 \%$ of the predicted concentration at the fence line. Peak concentration values at the Columbia River were $0.64 \sim 1.11 \%$ of those at the fence line. Although peak concentrations at the river were always smaller than those at the exclusion boundary, predicted concentrations at the river were sometimes slightly larger than at the exclusion boundary due to the time delay of the peaks. For example, the peak concentration at the Columbia River boundary along the northward path in Case 1 appeared at year $2707-561$ years later than at the exclusion boundary (Figure B.2b).

Five of the cases presented in this report examined the effect of increasing the estimated saturated hydraulic conductivity of the aquifer [Cases 1, 3, 4, 10, and $11(\mathrm{HiK})$ ]. As reported in earlier sections, peak concentrations at the fence line decreased by nearly an order of magnitude when the hydraulic conductivity was increased by a factor of 10 . By contrast, however, peak concentrations at the exclusion and Columbia River boundaries experienced a slight increase (no more than 11\%) due to this change. This result occurred because the higher estimated value of saturated hydraulic conductivity increased the mass flux at the exit boundary in the STOMP simulations. Because input into the streamtube model was the mass flux at the exit boundary, increasing the hydraulic conductivity also increased the peak concentrations at the compliance boundaries.

\subsubsection{Effect of $K_{d}$ on Peaks and Arrival Times}

Based on the arrival times of the peak mass fluxes and concentration values shown in Tables 4.24.15 , contaminant travel time increased with $\mathrm{K}_{\mathrm{d}}$. For $\mathrm{K}_{\mathrm{d}}$ values $\geq 0.60 \mathrm{~mL} / \mathrm{g}$, the travel times were so long that the amount of mass arriving at the water table was quite small. For example, for $\mathrm{K}_{\mathrm{d}}=0.6 \mathrm{~mL} / \mathrm{g}$, only $1.2 \%$ of the total mass in the system entered the groundwater in Case 3; for all other cases, no more than $0.2 \%$ of the total contaminant release exited the vadose zone. For $\mathrm{K}_{\mathrm{d}}$ values $\geq 0.30 \mathrm{~mL} / \mathrm{g}$, the arrival times of either the peak mass fluxes or the peak concentrations at any of the compliance points were either at the beginning of the simulation (start year 1945) or at the end (year 12000). This result implies that the true peaks may have not shown up by the end of the simulation. 
Table 4.2. Predicted Peak Tc-99 Flux (Ci/yr), Arrival Time, and Cumulative Mass (Ci) at Year 12000

\begin{tabular}{|l|c|c|c|c|c|c||}
\hline \multicolumn{1}{|c|}{ Case } & \multicolumn{3}{|c|}{ Groundwater Table } & \multicolumn{3}{c||}{ Fence Line } \\
\hline & Flux (Ci/yr) & $\begin{array}{c}\text { Arrival } \\
\text { Time (yr) }\end{array}$ & $\begin{array}{c}\text { Cumulative } \\
\text { Mass (Ci) }\end{array}$ & Flux (Ci/yr) & $\begin{array}{c}\text { Arrival } \\
\text { Time (yr) }\end{array}$ & $\begin{array}{c}\text { Cumulative } \\
\text { Mass (Ci) }\end{array}$ \\
\hline 1 & $2.32 \mathrm{E}-03$ & 2078 & 1.00 & $2.13 \mathrm{E}-03$ & 2105 & 1.00 \\
1 (HiK) & $2.41 \mathrm{E}-03$ & 2078 & 1.00 & $2.38 \mathrm{E}-03$ & 2081 & 1.00 \\
2 & $2.95 \mathrm{E}-03$ & 2072 & 1.00 & $2.65 \mathrm{E}-03$ & 2096 & 1.00 \\
3 & $2.19 \mathrm{E}-03$ & 2089 & 1.00 & $2.06 \mathrm{E}-03$ & 2115 & 1.00 \\
3 (HiK) & $2.28 \mathrm{E}-03$ & 2089 & 1.00 & $2.26 \mathrm{E}-03$ & 2091 & 1.00 \\
4 & $8.28 \mathrm{E}-04$ & 2112 & 1.00 & $8.04 \mathrm{E}-04$ & 2140 & 1.00 \\
$4(\mathrm{HiK})$ & $8.71 \mathrm{E}-04$ & 2113 & 1.00 & $8.68 \mathrm{E}-04$ & 2116 & 1.00 \\
5 & $7.60 \mathrm{E}-04$ & 4803 & 1.00 & $7.61 \mathrm{E}-04$ & 4828 & 1.00 \\
6 & $7.60 \mathrm{E}-04$ & 4840 & 1.00 & $7.61 \mathrm{E}-04$ & 4865 & 1.00 \\
7 & $6.56 \mathrm{E}-04$ & 5328 & 1.00 & $6.57 \mathrm{E}-04$ & 5357 & 1.00 \\
8 & $9.99 \mathrm{E}-05$ & 9282 & 0.70 & $1.00 \mathrm{E}-04$ & 8832 & 0.70 \\
9 & $7.61 \mathrm{E}-04$ & 4798 & 1.00 & $7.62 \mathrm{E}-04$ & 4825 & 1.00 \\
10 & $7.59 \mathrm{E}-04$ & 4667 & 1.00 & $7.60 \mathrm{E}-04$ & 4692 & 1.00 \\
$10(\mathrm{HiK})$ & $7.64 \mathrm{E}-04$ & 4649 & 1.00 & $7.64 \mathrm{E}-04$ & 4653 & 1.00 \\
11 & $2.40 \mathrm{E}-04$ & 5623 & 0.92 & $2.41 \mathrm{E}-04$ & 5655 & 0.92 \\
11 (HiK) & $2.41 \mathrm{E}-04$ & 5607 & 0.92 & $2.41 \mathrm{E}-04$ & 5610 & 0.92 \\
12 & $8.16 \mathrm{E}-07$ & 5589 & 0.01 & $8.17 \mathrm{E}-07$ & 5613 & 0.01 \\
13 & $4.81 \mathrm{E}-04$ & 4906 & 0.97 & $4.82 \mathrm{E}-04$ & 4929 & 0.97 \\
14 & $1.80 \mathrm{E}-04$ & 6844 & 0.89 & $1.80 \mathrm{E}-04$ & 6870 & 0.89 \\
\hline
\end{tabular}


Table 4.3. Predicted Peak U-238 $\left(\mathrm{K}_{\mathrm{d}}=0.01\right)$ Flux, Arrival Time, and Cumulative Mass at Year 12000

\begin{tabular}{||l|c|c|c|c|c|c||}
\hline \multicolumn{1}{|c|}{ Case } & \multicolumn{3}{|c|}{ Groundwater Table } & \multicolumn{3}{c||}{ Fence Line } \\
\hline & Flux (Ci/yr) & $\begin{array}{c}\text { Arrival } \\
\text { Time (yr) }\end{array}$ & $\begin{array}{c}\text { Cumulative } \\
\text { Mass (Ci) }\end{array}$ & Flux (Ci/yr) & $\begin{array}{c}\text { Arrival } \\
\text { Time (yr) }\end{array}$ & $\begin{array}{c}\text { Cumulative } \\
\text { Mass (Ci) }\end{array}$ \\
\hline 1 & $1.27 \mathrm{E}-03$ & 2084 & 1.00 & $1.18 \mathrm{E}-03$ & 2116 & 1.00 \\
$1(\mathrm{HiK})$ & $1.33 \mathrm{E}-03$ & 2084 & 1.00 & $1.32 \mathrm{E}-03$ & 2088 & 1.00 \\
2 & $1.68 \mathrm{E}-03$ & 2075 & 1.00 & $1.52 \mathrm{E}-03$ & 2106 & 1.00 \\
3 & $1.22 \mathrm{E}-03$ & 2098 & 1.00 & $1.16 \mathrm{E}-03$ & 2130 & 1.00 \\
$3(\mathrm{HiK})$ & $1.29 \mathrm{E}-03$ & 2099 & 1.00 & $1.28 \mathrm{E}-03$ & 2102 & 1.00 \\
4 & $5.18 \mathrm{E}-04$ & 3618 & 1.00 & $5.19 \mathrm{E}-04$ & 3647 & 1.00 \\
$4(\mathrm{HiK})$ & $5.20 \mathrm{E}-04$ & 3598 & 1.00 & $5.21 \mathrm{E}-04$ & 3601 & 1.00 \\
5 & $6.51 \mathrm{E}-04$ & 5124 & 1.00 & $6.52 \mathrm{E}-04$ & 5154 & 1.00 \\
6 & $6.51 \mathrm{E}-04$ & 5161 & 1.00 & $6.52 \mathrm{E}-04$ & 5193 & 1.00 \\
7 & $5.84 \mathrm{E}-04$ & 5645 & 1.00 & $5.84 \mathrm{E}-04$ & 5675 & 1.00 \\
8 & $9.99 \mathrm{E}-05$ & 10631 & 0.67 & $1.00 \mathrm{E}-04$ & 9975 & 0.67 \\
9 & $6.52 \mathrm{E}-04$ & 5120 & 1.00 & $6.53 \mathrm{E}-04$ & 5151 & 1.00 \\
10 & $6.50 \mathrm{E}-04$ & 4996 & 1.00 & $6.51 \mathrm{E}-04$ & 5025 & 1.00 \\
$10(\mathrm{HiK})$ & $6.54 \mathrm{E}-04$ & 4975 & 1.00 & $6.54 \mathrm{E}-04$ & 4977 & 1.00 \\
11 & $2.29 \mathrm{E}-04$ & 6060 & 0.91 & $2.29 \mathrm{E}-04$ & 6085 & 0.91 \\
$11(\mathrm{HiK})$ & $2.29 \mathrm{E}-04$ & 6030 & 0.91 & $2.30 \mathrm{E}-04$ & 6031 & 0.91 \\
12 & $7.98 \mathrm{E}-07$ & 6306 & 0.01 & $7.99 \mathrm{E}-07$ & 6329 & 0.01 \\
13 & $4.27 \mathrm{E}-04$ & 5263 & 0.96 & $4.28 \mathrm{E}-04$ & 5290 & 0.96 \\
14 & $1.78 \mathrm{E}-04$ & 7243 & 0.87 & $1.78 \mathrm{E}-04$ & 7274 & 0.87 \\
\hline
\end{tabular}

Table 4.4. Predicted Peak U-238 $\left(\mathrm{K}_{\mathrm{d}}=0.03\right)$ Flux, Arrival Time, and Cumulative Mass at Year 12000

\begin{tabular}{|c|c|c|c|c|c|c|}
\hline \multirow[t]{2}{*}{ Case } & \multicolumn{3}{|c|}{ Groundwater Table } & \multicolumn{3}{|c|}{ Fence Line } \\
\hline & $\begin{array}{c}\text { Flux } \\
(\mathrm{Ci} / \mathrm{yr})\end{array}$ & $\begin{array}{c}\text { Arrival } \\
\text { Time (yr) }\end{array}$ & $\begin{array}{l}\text { Cumulative } \\
\text { Mass (Ci) }\end{array}$ & $\begin{array}{c}\text { Flux } \\
(\mathrm{Ci} / \mathrm{yr})\end{array}$ & $\begin{array}{c}\text { Arrival } \\
\text { Time (yr) }\end{array}$ & $\begin{array}{l}\text { Cumulative } \\
\text { Mass (Ci) }\end{array}$ \\
\hline 1 & $4.21 \mathrm{E}-04$ & 3916 & 1.00 & $4.21 \mathrm{E}-04$ & 3953 & 1.00 \\
\hline $1(\mathrm{HiK})$ & $4.22 \mathrm{E}-04$ & 3888 & 1.00 & $4.23 \mathrm{E}-04$ & 3895 & 1.00 \\
\hline 2 & $4.68 \mathrm{E}-04$ & 2087 & 1.00 & $4.32 \mathrm{E}-04$ & 2131 & 1.00 \\
\hline 3 & 4.70E-04 & 3719 & 1.00 & 4.70E-04 & 3756 & 1.00 \\
\hline 3 (HiK) & 4.72E-04 & 3691 & 1.00 & 4.73E-04 & 3694 & 1.00 \\
\hline 4 & $4.45 \mathrm{E}-04$ & 4261 & 1.00 & $4.46 \mathrm{E}-04$ & 4295 & 1.00 \\
\hline $4(\mathrm{HiK})$ & $4.48 \mathrm{E}-04$ & 4229 & 1.00 & 4.48E-04 & 4237 & 1.00 \\
\hline 5 & $5.21 \mathrm{E}-04$ & 5789 & 1.00 & $5.22 \mathrm{E}-04$ & 5824 & 1.00 \\
\hline 6 & $5.22 \mathrm{E}-04$ & 5823 & 1.00 & $5.22 \mathrm{E}-04$ & 5864 & 1.00 \\
\hline 7 & $4.86 \mathrm{E}-04$ & 6298 & 1.00 & $4.86 \mathrm{E}-04$ & 6335 & 1.00 \\
\hline 8 & $9.99 \mathrm{E}-05$ & 11383 & 0.60 & $1.00 \mathrm{E}-04$ & 11784 & 0.59 \\
\hline 9 & $5.22 \mathrm{E}-04$ & 5784 & 1.00 & $5.23 \mathrm{E}-04$ & 5821 & 1.00 \\
\hline 10 & $5.19 \mathrm{E}-04$ & 5677 & 1.00 & $5.20 \mathrm{E}-04$ & 5714 & 1.00 \\
\hline $10(\mathrm{HiK})$ & $5.23 \mathrm{E}-04$ & 5644 & 1.00 & $5.23 \mathrm{E}-04$ & 5647 & 1.00 \\
\hline 11 & $2.06 \mathrm{E}-04$ & 6915 & 0.87 & $2.06 \mathrm{E}-04$ & 6953 & 0.87 \\
\hline 11 (HiK) & $2.06 \mathrm{E}-04$ & 6888 & 0.87 & $2.07 \mathrm{E}-04$ & 6887 & 0.87 \\
\hline 12 & $7.88 \mathrm{E}-07$ & 7986 & 0.01 & 7.89E-07 & 8043 & 0.01 \\
\hline 13 & $3.63 \mathrm{E}-04$ & 5983 & 0.95 & $3.64 \mathrm{E}-04$ & 6018 & 0.95 \\
\hline 14 & $1.70 \mathrm{E}-04$ & 8054 & 0.81 & $1.70 \mathrm{E}-04$ & 8088 & 0.81 \\
\hline
\end{tabular}


Table 4.5. Predicted Peak U-238 $\left(\mathrm{K}_{\mathrm{d}}=0.10\right)$ Flux, Arrival Time, and Cumulative Mass at Year 12000

\begin{tabular}{|c|c|c|c|c|c|c|}
\hline \multirow[t]{2}{*}{ Case } & \multicolumn{3}{|c|}{ Groundwater Table } & \multicolumn{3}{|c|}{ Fence Line } \\
\hline & $\begin{array}{c}\text { Flux } \\
(\mathrm{Ci} / \mathrm{yr})\end{array}$ & $\begin{array}{c}\text { Arrival } \\
\text { Time (yr) }\end{array}$ & $\begin{array}{c}\text { Cumulative } \\
\text { Mass (Ci) }\end{array}$ & $\begin{array}{c}\text { Flux } \\
(\mathrm{Ci} / \mathrm{yr})\end{array}$ & $\begin{array}{c}\text { Arrival } \\
\text { Time (yr) }\end{array}$ & $\begin{array}{c}\text { Cumulative } \\
\text { Mass (Ci) }\end{array}$ \\
\hline 1 & $2.82 \mathrm{E}-04$ & 6107 & 1.00 & $2.82 \mathrm{E}-04$ & 6171 & 1.00 \\
\hline $1(\mathrm{HiK})$ & $2.84 \mathrm{E}-04$ & 6050 & 1.00 & $2.84 \mathrm{E}-04$ & 6056 & 1.00 \\
\hline 2 & $2.78 \mathrm{E}-04$ & 6097 & 1.00 & $2.78 \mathrm{E}-04$ & 6163 & 1.00 \\
\hline 3 & $3.11 \mathrm{E}-04$ & 5583 & 1.00 & $3.11 \mathrm{E}-04$ & 5643 & 1.00 \\
\hline $3(\mathrm{HiK})$ & $3.13 \mathrm{E}-04$ & 5529 & 1.00 & $3.13 \mathrm{E}-04$ & 5536 & 1.00 \\
\hline 4 & $2.90 \mathrm{E}-04$ & 6539 & 1.00 & $2.90 \mathrm{E}-04$ & 6598 & 1.00 \\
\hline $4(\mathrm{HiK})$ & $2.92 \mathrm{E}-04$ & 6484 & 1.00 & 2.92E-04 & 6490 & 1.00 \\
\hline 5 & $3.06 \mathrm{E}-04$ & 8103 & 0.98 & $3.07 \mathrm{E}-04$ & 8166 & 0.98 \\
\hline 6 & $3.06 \mathrm{E}-04$ & 8144 & 0.98 & $3.07 \mathrm{E}-04$ & 8206 & 0.98 \\
\hline 7 & $2.99 \mathrm{E}-04$ & 8599 & 0.97 & $2.99 \mathrm{E}-04$ & 8667 & 0.97 \\
\hline 8 & $9.82 \mathrm{E}-05$ & 12000 & 0.35 & $9.82 \mathrm{E}-05$ & 12000 & 0.34 \\
\hline 9 & $3.06 \mathrm{E}-04$ & 8095 & 0.98 & $3.07 \mathrm{E}-04$ & 8165 & 0.98 \\
\hline 10 & $3.04 \mathrm{E}-04$ & 8046 & 0.98 & $3.04 \mathrm{E}-04$ & 8110 & 0.98 \\
\hline $10(\mathrm{HiK})$ & $3.06 \mathrm{E}-04$ & 7980 & 0.98 & $3.06 \mathrm{E}-04$ & 7993 & 0.99 \\
\hline 11 & $1.52 \mathrm{E}-04$ & 9861 & 0.61 & $1.53 \mathrm{E}-04$ & 9926 & 0.60 \\
\hline $11(\mathrm{HiK})$ & $1.53 \mathrm{E}-04$ & 9793 & 0.61 & $1.53 \mathrm{E}-04$ & 9901 & 0.61 \\
\hline 12 & $7.80 \mathrm{E}-07$ & 12000 & 0.00 & $7.80 \mathrm{E}-07$ & 12000 & 0.00 \\
\hline 13 & $2.32 \mathrm{E}-04$ & 8520 & 0.84 & $2.33 \mathrm{E}-04$ & 8581 & 0.84 \\
\hline 14 & $1.39 \mathrm{E}-04$ & 10864 & 0.50 & $1.39 \mathrm{E}-04$ & 10944 & 0.49 \\
\hline
\end{tabular}

Table 4.6. Predicted Peak U-238 $\left(\mathrm{K}_{\mathrm{d}}=0.30\right)$ Flux, Arrival Time, and Cumulative Mass at Year 12000

\begin{tabular}{|c|c|c|c|c|c|c|}
\hline \multirow[t]{2}{*}{ Case } & \multicolumn{3}{|c|}{ Groundwater Table } & \multicolumn{3}{|c|}{ Fence Line } \\
\hline & $\begin{array}{c}\text { Flux } \\
(\mathrm{Ci} / \mathrm{yr})\end{array}$ & $\begin{array}{c}\text { Arrival } \\
\text { Time (yr) }\end{array}$ & $\begin{array}{c}\text { Cumulative } \\
\text { Mass (Ci) }\end{array}$ & $\begin{array}{l}\text { Flux } \\
(\mathrm{Ci} / \mathrm{yr})\end{array}$ & $\begin{array}{c}\text { Arrival } \\
\text { Time (yr) }\end{array}$ & $\begin{array}{l}\text { Cumulative } \\
\text { Mass (Ci) }\end{array}$ \\
\hline 1 & $1.37 \mathrm{E}-04$ & 12000 & 0.34 & $1.36 \mathrm{E}-04$ & 12000 & 0.33 \\
\hline $1(\mathrm{HiK})$ & $1.40 \mathrm{E}-04$ & 12000 & 0.36 & $1.39 \mathrm{E}-04$ & 11999 & 0.36 \\
\hline 2 & $1.36 \mathrm{E}-04$ & 11999 & 0.34 & $1.35 \mathrm{E}-04$ & 12000 & 0.32 \\
\hline 3 & $1.50 \mathrm{E}-04$ & 11024 & 0.54 & $1.51 \mathrm{E}-04$ & 11157 & 0.53 \\
\hline $3(\mathrm{HiK})$ & $1.52 \mathrm{E}-04$ & 10893 & 0.57 & $1.52 \mathrm{E}-04$ & 10897 & 0.56 \\
\hline 4 & $1.28 \mathrm{E}-04$ & 12000 & 0.26 & $1.25 \mathrm{E}-04$ & 12000 & 0.24 \\
\hline $4(\mathrm{HiK})$ & $1.31 \mathrm{E}-04$ & 12000 & 0.28 & $1.31 \mathrm{E}-04$ & 12000 & 0.27 \\
\hline 5 & $7.57 \mathrm{E}-05$ & 12000 & 0.09 & $7.00 \mathrm{E}-05$ & 12000 & 0.08 \\
\hline 6 & $7.42 \mathrm{E}-05$ & 12000 & 0.09 & $6.85 \mathrm{E}-05$ & 12000 & 0.08 \\
\hline 7 & $5.76 \mathrm{E}-05$ & 12000 & 0.06 & $5.23 \mathrm{E}-05$ & 12000 & 0.05 \\
\hline 8 & $9.20 \mathrm{E}-06$ & 12000 & 0.01 & $8.11 \mathrm{E}-06$ & 12000 & 0.01 \\
\hline 9 & $7.59 \mathrm{E}-05$ & 12000 & 0.09 & $7.01 \mathrm{E}-05$ & 12000 & 0.08 \\
\hline 10 & $7.28 \mathrm{E}-05$ & 12000 & 0.09 & $6.72 \mathrm{E}-05$ & 12000 & 0.08 \\
\hline 10 (HiK) & $7.80 \mathrm{E}-05$ & 12000 & 0.10 & $7.74 \mathrm{E}-05$ & 12000 & 0.09 \\
\hline 11 & $1.32 \mathrm{E}-05$ & 12000 & 0.01 & $1.17 \mathrm{E}-05$ & 12000 & 0.01 \\
\hline 11 (HiK) & $1.45 \mathrm{E}-05$ & 12000 & 0.01 & $1.44 \mathrm{E}-05$ & 12000 & 0.01 \\
\hline 12 & $8.67 \mathrm{E}-08$ & 12000 & 0.00 & 7.69E-08 & 12000 & 0.00 \\
\hline 13 & $3.82 \mathrm{E}-05$ & 12000 & 0.04 & $3.47 \mathrm{E}-05$ & 12000 & 0.03 \\
\hline 14 & $8.00 \mathrm{E}-06$ & 12000 & 0.01 & 6.97E-06 & 12000 & 0.01 \\
\hline
\end{tabular}


Table 4.7. Predicted Peak U-238 $\left(\mathrm{K}_{\mathrm{d}}=0.60\right)$ Flux, Arrival Time, and Cumulative Mass at Year 12000

\begin{tabular}{|c|c|c|c|c|c|c|}
\hline \multirow[t]{2}{*}{ Case } & \multicolumn{3}{|c|}{ Groundwater Table } & \multicolumn{3}{|c|}{ Fence Line } \\
\hline & $\begin{array}{c}\text { Flux } \\
(\mathrm{Ci} / \mathrm{yr})\end{array}$ & $\begin{array}{c}\text { Arrival } \\
\text { Time (yr) }\end{array}$ & $\begin{array}{c}\text { Cumulative } \\
\text { Mass (Ci) }\end{array}$ & $\begin{array}{l}\text { Flux } \\
(\mathrm{Ci} / \mathrm{yr})\end{array}$ & $\begin{array}{c}\text { Arrival } \\
\text { Time (yr) }\end{array}$ & $\begin{array}{c}\text { Cumulative } \\
\text { Mass (Ci) }\end{array}$ \\
\hline 1 & $1.80 \mathrm{E}-06$ & 12000 & 0.00 & $1.37 \mathrm{E}-06$ & 12000 & 0.00 \\
\hline 1 (HiK) & $2.15 \mathrm{E}-06$ & 12000 & 0.00 & $2.09 \mathrm{E}-06$ & 12000 & 0.00 \\
\hline 2 & $1.84 \mathrm{E}-06$ & 12000 & 0.00 & $1.41 \mathrm{E}-06$ & 12000 & 0.00 \\
\hline 3 & $1.11 \mathrm{E}-05$ & 12000 & 0.01 & $9.27 \mathrm{E}-06$ & 12000 & 0.01 \\
\hline 3 (HiK) & $1.28 \mathrm{E}-05$ & 12000 & 0.01 & $1.26 \mathrm{E}-05$ & 12000 & 0.01 \\
\hline 4 & $6.57 \mathrm{E}-07$ & 12000 & 0.00 & $4.80 \mathrm{E}-07$ & 12000 & 0.00 \\
\hline $4(\mathrm{HiK})$ & $7.99 \mathrm{E}-07$ & 12000 & 0.00 & $7.76 \mathrm{E}-07$ & 12000 & 0.00 \\
\hline 5 & $6.44 \mathrm{E}-08$ & 12000 & 0.00 & $3.86 \mathrm{E}-08$ & 12000 & 0.00 \\
\hline 6 & $5.98 \mathrm{E}-08$ & 12000 & 0.00 & $3.57 \mathrm{E}-08$ & 12000 & 0.00 \\
\hline 7 & $2.96 \mathrm{E}-08$ & 12000 & 0.00 & $1.70 \mathrm{E}-08$ & 12000 & 0.00 \\
\hline 8 & $3.31 \mathrm{E}-09$ & 12000 & 0.00 & $1.87 \mathrm{E}-09$ & 12000 & 0.00 \\
\hline 9 & $6.44 \mathrm{E}-08$ & 12000 & 0.00 & $3.86 \mathrm{E}-08$ & 12000 & 0.00 \\
\hline 10 & $5.21 \mathrm{E}-08$ & 12000 & 0.00 & $3.11 \mathrm{E}-08$ & 12000 & 0.00 \\
\hline $10(\mathrm{HiK})$ & $6.69 \mathrm{E}-08$ & 12000 & 0.00 & $6.38 \mathrm{E}-08$ & 12000 & 0.00 \\
\hline 11 & $2.93 \mathrm{E}-09$ & 12000 & 0.00 & $1.68 \mathrm{E}-09$ & 12000 & 0.00 \\
\hline 11 (HiK) & $3.82 \mathrm{E}-09$ & 12000 & 0.00 & $3.62 \mathrm{E}-09$ & 12000 & 0.00 \\
\hline 12 & $2.95 \mathrm{E}-11$ & 12000 & 0.00 & $1.61 \mathrm{E}-11$ & 12000 & 0.00 \\
\hline 13 & $7.58 \mathrm{E}-09$ & 12000 & 0.00 & $4.43 \mathrm{E}-09$ & 12000 & 0.00 \\
\hline 14 & $1.44 \mathrm{E}-09$ & 12000 & 0.00 & $8.11 \mathrm{E}-10$ & 12000 & 0.00 \\
\hline
\end{tabular}

Table 4.8. Predicted Peak U-238 $\left(\mathrm{K}_{\mathrm{d}}=1.00\right)$ Flux, Arrival Time, and Cumulative Mass at Year 12000

\begin{tabular}{||l|c|c|c|c|c|c||}
\hline \multicolumn{1}{|c|}{ Case } & \multicolumn{3}{|c|}{ Groundwater Table } & \multicolumn{3}{c||}{ Fence Line } \\
\hline & $\begin{array}{c}\text { Flux } \\
(\mathrm{Ci} / \mathrm{yr})\end{array}$ & $\begin{array}{c}\text { Arrival } \\
\text { Time }(\mathrm{yr})\end{array}$ & $\begin{array}{c}\text { Cumulative } \\
\text { Mass }(\mathrm{Ci})\end{array}$ & $\begin{array}{c}\text { Flux } \\
(\mathrm{Ci} / \mathrm{yr})\end{array}$ & $\begin{array}{c}\text { Arrival } \\
\text { Time }(\mathrm{yr})\end{array}$ & $\begin{array}{c}\text { Cumulative } \\
\text { Mass (Ci) }\end{array}$ \\
\hline 1 & $3.95 \mathrm{E}-10$ & 12000 & 0.00 & $1.81 \mathrm{E}-10$ & 12000 & 0.00 \\
$1(\mathrm{HiK})$ & $5.48 \mathrm{E}-10$ & 12000 & 0.00 & $5.08 \mathrm{E}-10$ & 12000 & 0.00 \\
2 & $4.46 \mathrm{E}-10$ & 12000 & 0.00 & $2.08 \mathrm{E}-10$ & 12000 & 0.00 \\
3 & $2.30 \mathrm{E}-08$ & 12000 & 0.00 & $1.27 \mathrm{E}-08$ & 12000 & 0.00 \\
$3(\mathrm{HiK})$ & $3.06 \mathrm{E}-08$ & 12000 & 0.00 & $2.89 \mathrm{E}-08$ & 12000 & 0.00 \\
4 & $4.32 \mathrm{E}-11$ & 12000 & 0.00 & $1.75 \mathrm{E}-11$ & 12000 & 0.00 \\
$4(\mathrm{HiK})$ & $6.06 \mathrm{E}-11$ & 12000 & 0.00 & $5.42 \mathrm{E}-11$ & 12000 & 0.00 \\
5 & $1.06 \mathrm{E}-12$ & 12000 & 0.00 & $0.00 \mathrm{E}+00$ & 12000 & 0.00 \\
6 & $9.30 \mathrm{E}-13$ & 12000 & 0.00 & $0.00 \mathrm{E}+00$ & 12000 & 0.00 \\
7 & $2.67 \mathrm{E}-13$ & 12000 & 0.00 & $0.00 \mathrm{E}+00$ & 12000 & 0.00 \\
8 & $0.00 \mathrm{E}+00$ & 12000 & 0.00 & $0.00 \mathrm{E}+00$ & 12000 & 0.00 \\
9 & $1.06 \mathrm{E}-12$ & 12000 & 0.00 & $0.00 \mathrm{E}+00$ & 12000 & 0.00 \\
10 & $6.41 \mathrm{E}-13$ & 12000 & 0.00 & $0.00 \mathrm{E}+00$ & 12000 & 0.00 \\
$10(\mathrm{HiK})$ & $9.59 \mathrm{E}-13$ & 12000 & 0.00 & $0.00 \mathrm{E}+00$ & 12000 & 0.00 \\
11 & $0.00 \mathrm{E}+00$ & 12000 & 0.00 & $0.00 \mathrm{E}+00$ & 12000 & 0.00 \\
$11(\mathrm{HiK})$ & $0.00 \mathrm{E}+00$ & 12000 & 0.00 & $0.00 \mathrm{E}+00$ & 12000 & 0.00 \\
12 & $0.00 \mathrm{E}+00$ & 12000 & 0.00 & $0.00 \mathrm{E}+00$ & 12000 & 0.00 \\
13 & $0.00 \mathrm{E}+00$ & 12000 & 0.00 & $0.00 \mathrm{E}+00$ & 12000 & 0.00 \\
14 & $0.00 \mathrm{E}+00$ & 12000 & 0.00 & $0.00 \mathrm{E}+00$ & 12000 & 0.00 \\
\hline
\end{tabular}




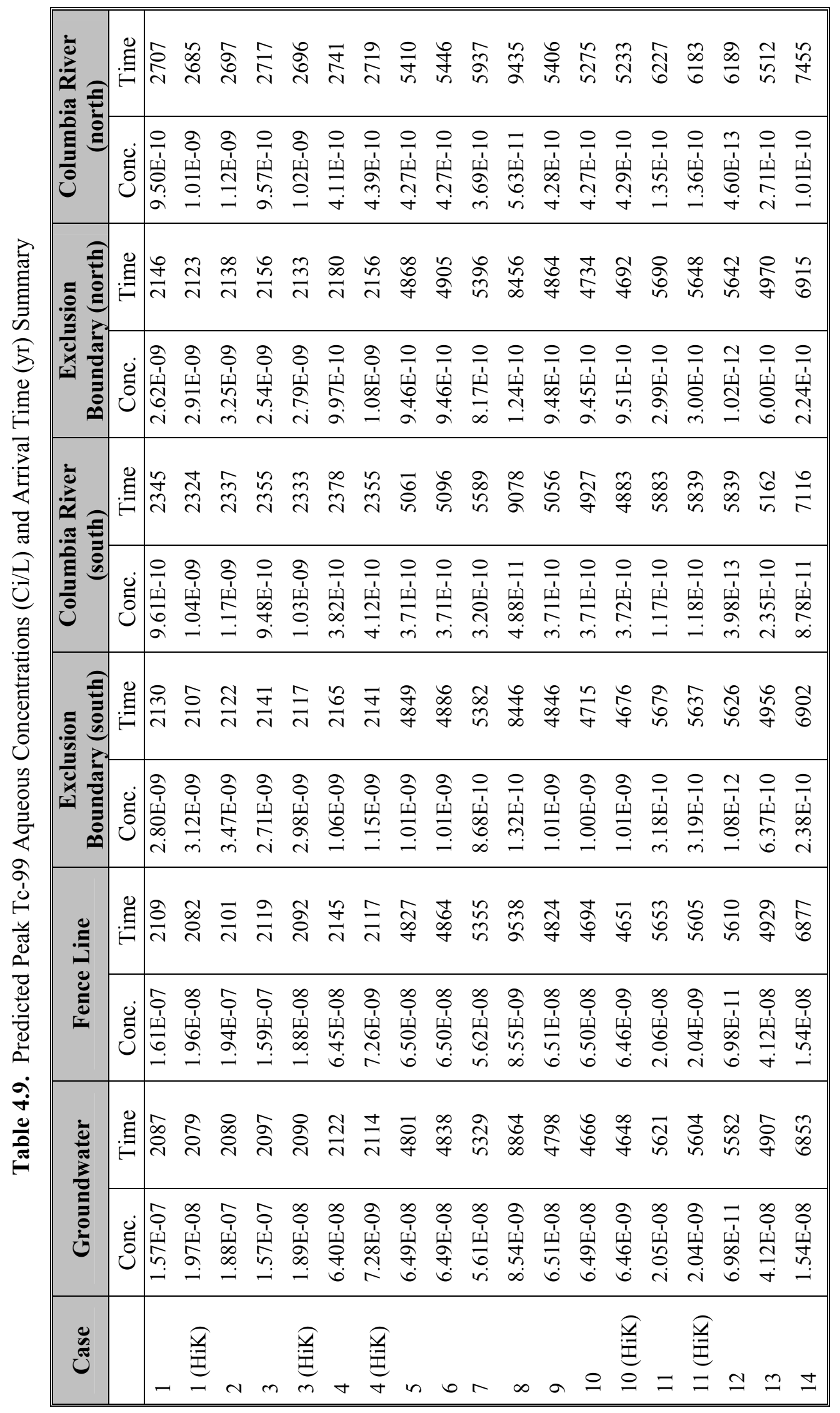




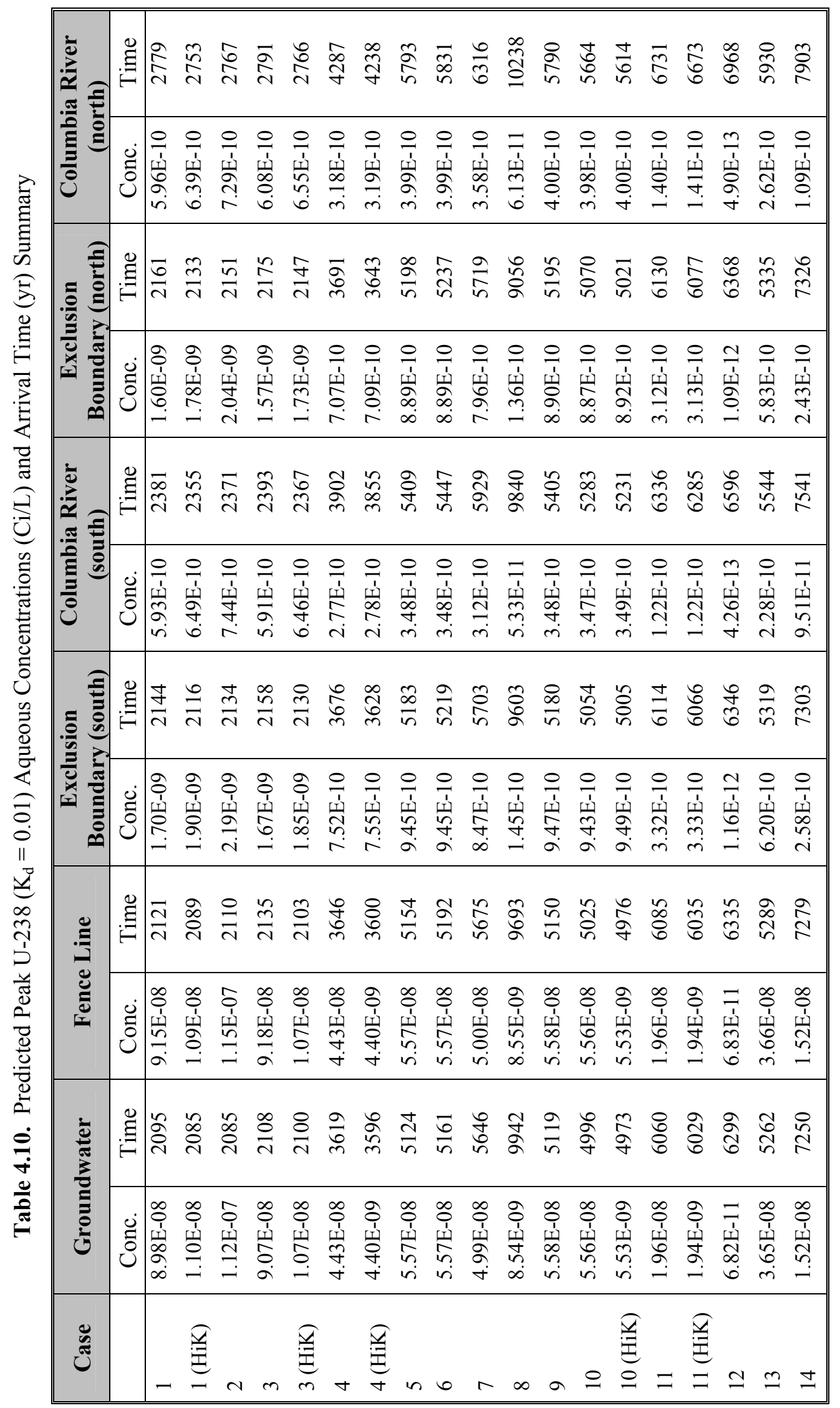




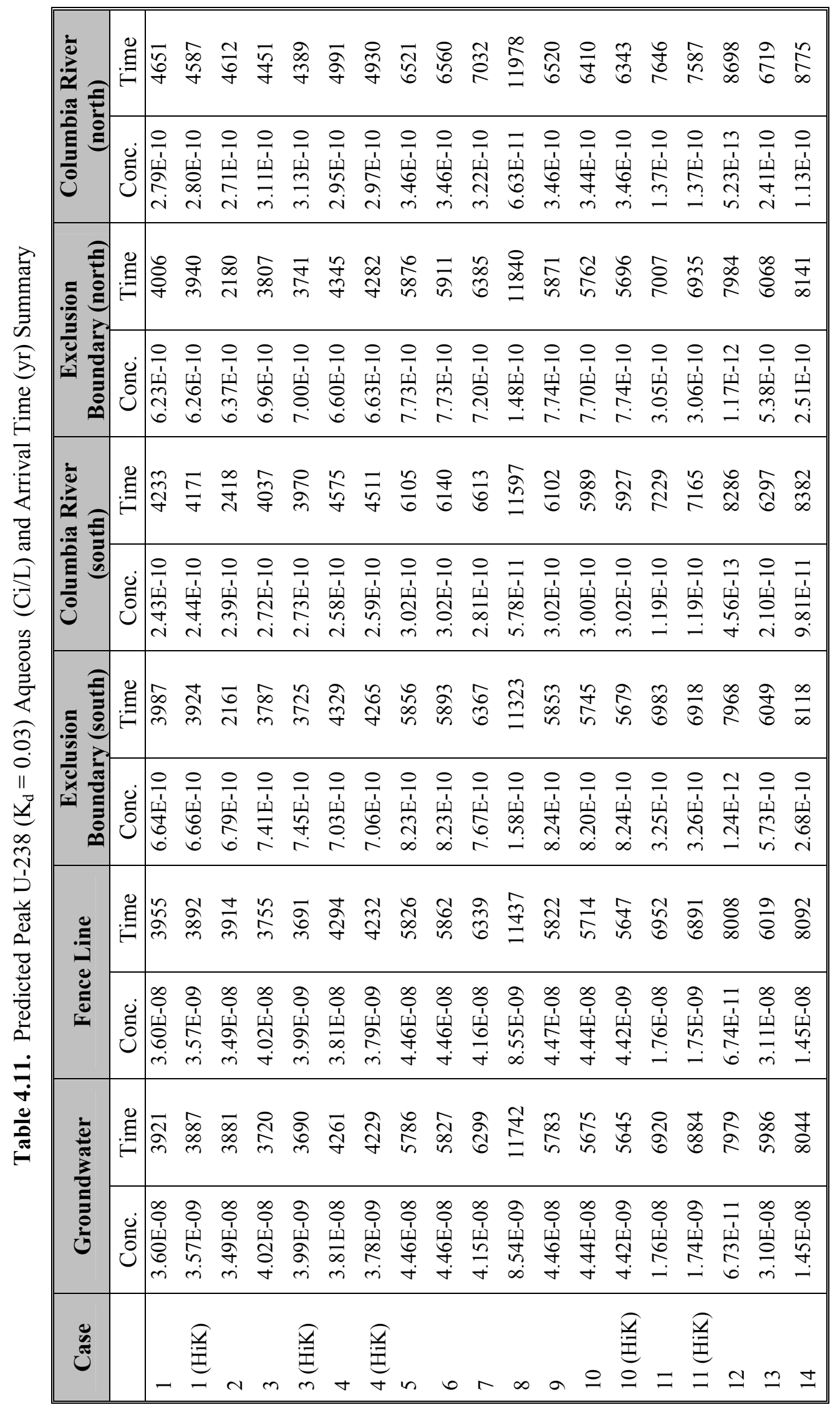




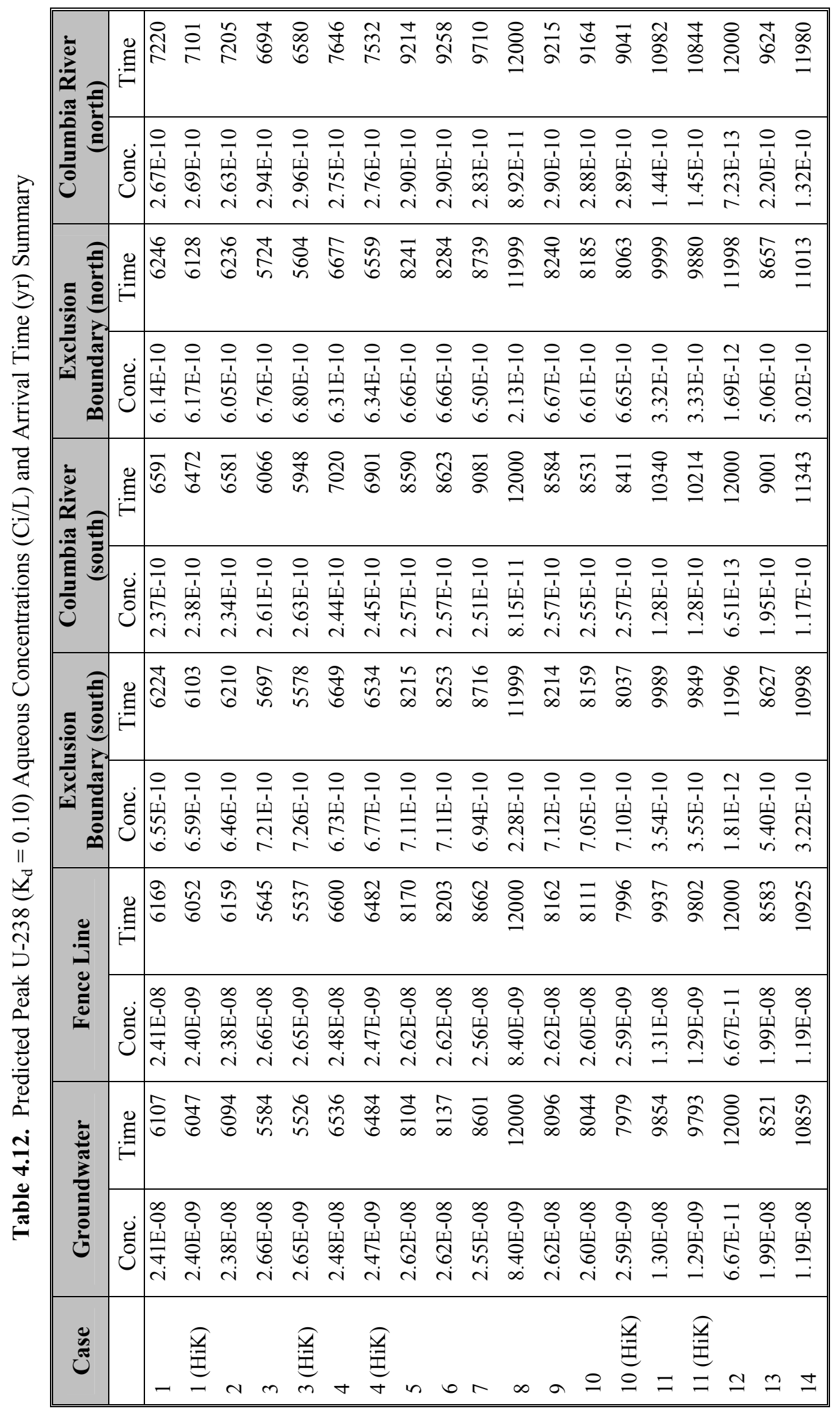




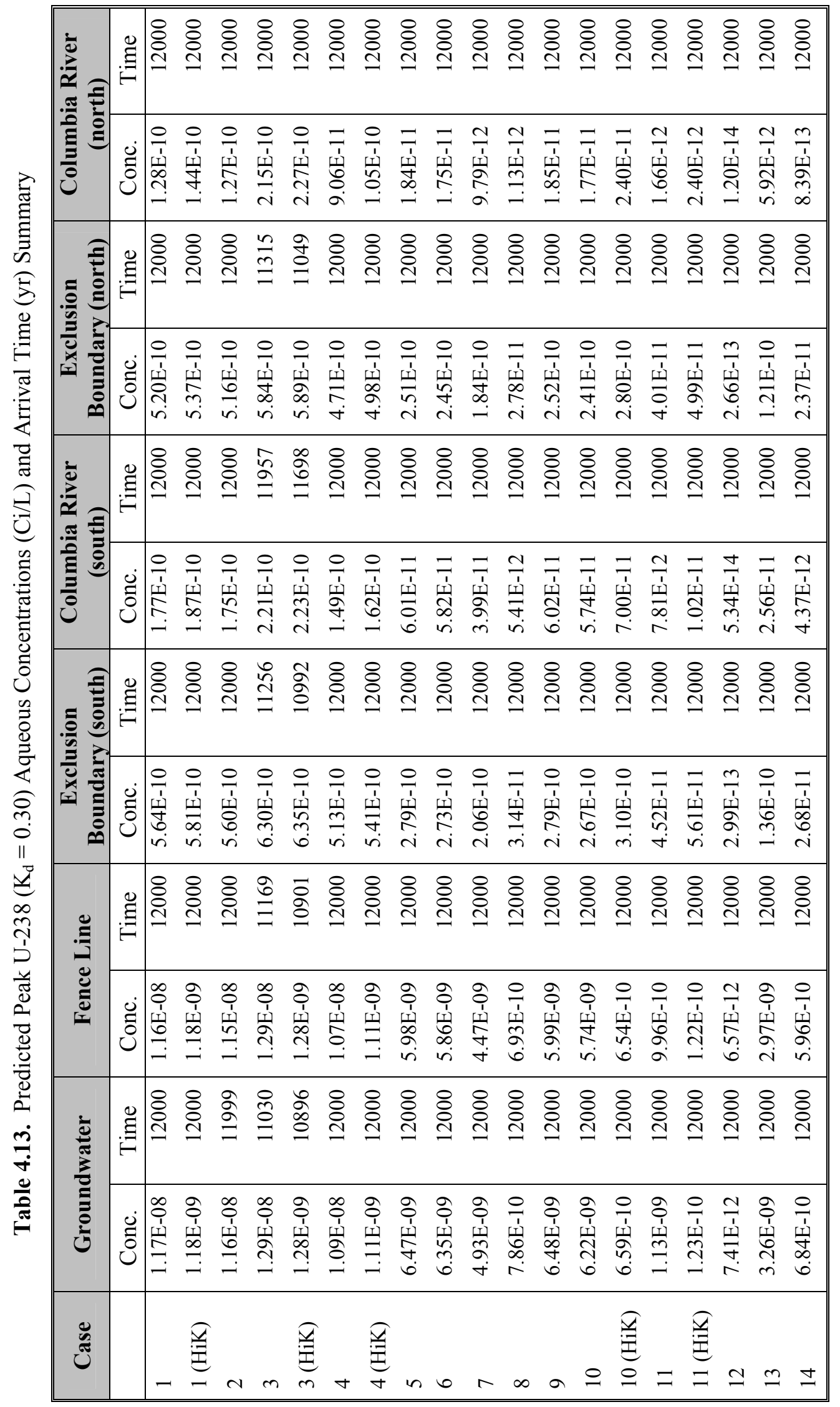




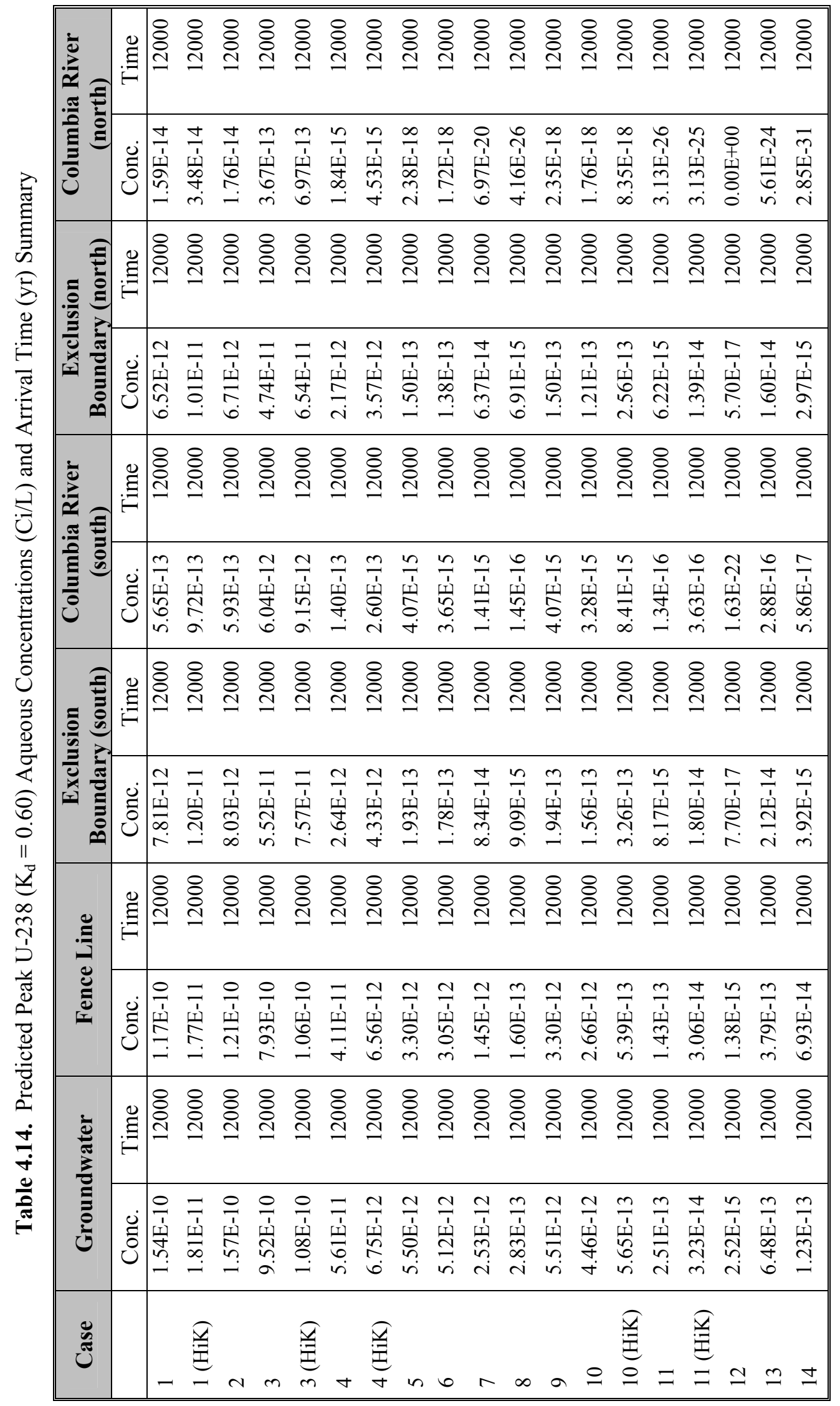




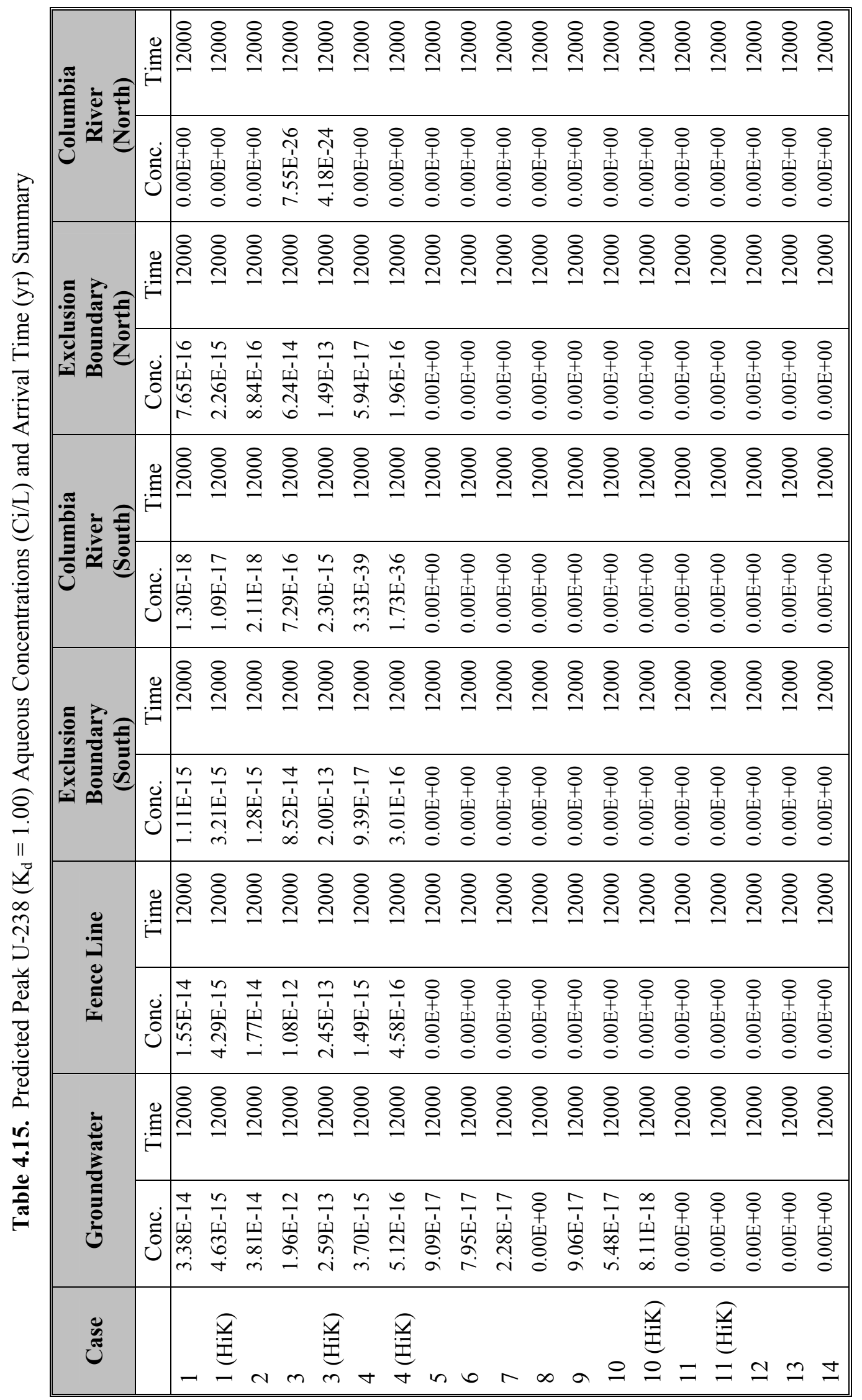




\subsection{Solute Mass Balance}

Mass balance checks were performed on the seven solutes (Tc-99 and U-238 with different values of $\mathrm{K}_{\mathrm{d}}$ ) for each simulation case, using the expression

$$
m_{\text {error }}=\frac{m_{\text {released }}-m_{\text {domain }}-m_{\text {exit }}}{m_{\text {released }}} \times 100 \%
$$

where $\mathrm{m}_{\text {error }}$ is the mass balance error in percent, $\mathrm{m}_{\text {released }}$ is the total amount of solute released in the system, $\mathrm{m}_{\text {domain }}$ is the solute inventory in the domain computed from the STOMP plot-file output at year 12000 , and $\mathrm{m}_{\text {exit }}$ is the integrated solute inventory, leaving the computational domain computed from the STOMP surface-flux output. The amount of each solute released into the system was one curie except in cases that involved slow releases (Cases 8 and 12, with Tc-99 at 0.9455 and $0.0078 \mathrm{Ci}$, respectively). The solute mass leaving the computational domain through the aquifer was determined using surface-flux output on the eastern side of the domain. The surface-flux output provided both the solute-flux rate and cumulative mass. Other than solving the solute mass conservation equations, the STOMP simulator contains no algorithms for correcting local or global mass. Therefore, mass balance errors represent the actual mass balance errors from the conservation equations. Expressed as percent error, mass balance errors were small, as shown in Tables 4.16-4.22 for the seven contaminants, respectively.

Table 4.16. STOMP Mass Balance for Tc-99

\begin{tabular}{|l|c|c|c|c|}
\hline \multicolumn{1}{|c|}{ Case } & Released & Domain & Exit & \% Error \\
\hline 1 & $1.000000 \mathrm{E}+00$ & $0.000000 \mathrm{E}+00$ & $1.000757 \mathrm{E}+00$ & $-7.57 \mathrm{E}-02$ \\
$1(\mathrm{HiK})$ & $1.000000 \mathrm{E}+00$ & $0.000000 \mathrm{E}+00$ & $1.000143 \mathrm{E}+00$ & $-1.43 \mathrm{E}-02$ \\
2 & $1.000000 \mathrm{E}+00$ & $0.000000 \mathrm{E}+00$ & $1.001007 \mathrm{E}+00$ & $-1.01 \mathrm{E}-01$ \\
3 & $1.000000 \mathrm{E}+00$ & $0.000000 \mathrm{E}+00$ & $1.000641 \mathrm{E}+00$ & $-6.41 \mathrm{E}-02$ \\
$3(\mathrm{HiK})$ & $1.000000 \mathrm{E}+00$ & $0.000000 \mathrm{E}+00$ & $1.000120 \mathrm{E}+00$ & $-1.20 \mathrm{E}-02$ \\
4 & $1.000000 \mathrm{E}+00$ & $0.000000 \mathrm{E}+00$ & $1.000195 \mathrm{E}+00$ & $-1.95 \mathrm{E}-02$ \\
$4(\mathrm{HiK})$ & $1.000000 \mathrm{E}+00$ & $0.000000 \mathrm{E}+00$ & $1.000030 \mathrm{E}+00$ & $-3.00 \mathrm{E}-03$ \\
5 & $1.000000 \mathrm{E}+00$ & $4.533010 \mathrm{E}-11$ & $9.999988 \mathrm{E}-01$ & $1.19 \mathrm{E}-04$ \\
6 & $1.000000 \mathrm{E}+00$ & $5.664947 \mathrm{E}-11$ & $9.999990 \mathrm{E}-01$ & $1.01 \mathrm{E}-04$ \\
7 & $1.000000 \mathrm{E}+00$ & $8.056550 \mathrm{E}-10$ & $9.999991 \mathrm{E}-01$ & $8.93 \mathrm{E}-05$ \\
8 & $9.455000 \mathrm{E}-01$ & $2.443630 \mathrm{E}-01$ & $7.011352 \mathrm{E}-01$ & $1.95 \mathrm{E}-04$ \\
9 & $1.000000 \mathrm{E}+00$ & $4.375999 \mathrm{E}-11$ & $9.999988 \mathrm{E}-01$ & $1.19 \mathrm{E}-04$ \\
10 & $1.000000 \mathrm{E}+00$ & $1.747967 \mathrm{E}-11$ & $9.999990 \mathrm{E}-01$ & $1.01 \mathrm{E}-04$ \\
$10(\mathrm{HiK})$ & $1.000000 \mathrm{E}+00$ & $1.298268 \mathrm{E}-11$ & $9.999866 \mathrm{E}-01$ & $1.34 \mathrm{E}-03$ \\
11 & $1.000000 \mathrm{E}+00$ & $7.916725 \mathrm{E}-02$ & $9.203522 \mathrm{E}-01$ & $4.81 \mathrm{E}-02$ \\
$11(\mathrm{HiK})$ & $1.000000 \mathrm{E}+00$ & $7.789560 \mathrm{E}-02$ & $9.219201 \mathrm{E}-01$ & $1.84 \mathrm{E}-02$ \\
12 & $7.820302 \mathrm{E}-03$ & $1.930155 \mathrm{E}-03$ & $5.890129 \mathrm{E}-03$ & $2.26 \mathrm{E}-04$ \\
13 & $1.000000 \mathrm{E}+00$ & $3.168849 \mathrm{E}-02$ & $9.682043 \mathrm{E}-01$ & $1.07 \mathrm{E}-02$ \\
14 & $1.000000 \mathrm{E}+00$ & $1.126087 \mathrm{E}-01$ & $8.869527 \mathrm{E}-01$ & $4.39 \mathrm{E}-02$ \\
\hline
\end{tabular}


Table 4.17. STOMP Mass Balance for $U-238\left(K_{d}=0.01\right)$

\begin{tabular}{|c|c|c|c|c||}
\hline Case & Released & Domain & Exit & \% Error \\
\hline 1 & $1.000000 \mathrm{E}+00$ & $6.672241 \mathrm{E}-11$ & $1.000374 \mathrm{E}+00$ & $-3.74 \mathrm{E}-02$ \\
$1(\mathrm{HiK})$ & $1.000000 \mathrm{E}+00$ & $5.675904 \mathrm{E}-11$ & $1.000076 \mathrm{E}+00$ & $-7.61 \mathrm{E}-03$ \\
2 & $1.000000 \mathrm{E}+00$ & $5.518370 \mathrm{E}-11$ & $1.000542 \mathrm{E}+00$ & $-5.42 \mathrm{E}-02$ \\
3 & $1.000000 \mathrm{E}+00$ & $1.332610 \mathrm{E}-11$ & $1.000300 \mathrm{E}+00$ & $-3.00 \mathrm{E}-02$ \\
$3(\mathrm{HiK})$ & $1.000000 \mathrm{E}+00$ & $9.919453 \mathrm{E}-12$ & $1.000058 \mathrm{E}+00$ & $-5.81 \mathrm{E}-03$ \\
4 & $1.000000 \mathrm{E}+00$ & $1.795036 \mathrm{E}-10$ & $1.000067 \mathrm{E}+00$ & $-6.70 \mathrm{E}-03$ \\
$4(\mathrm{HiK})$ & $1.000000 \mathrm{E}+00$ & $1.526382 \mathrm{E}-10$ & $1.000010 \mathrm{E}+00$ & $-1.00 \mathrm{E}-03$ \\
5 & $1.000000 \mathrm{E}+00$ & $1.248075 \mathrm{E}-08$ & $9.999984 \mathrm{E}-01$ & $1.60 \mathrm{E}-04$ \\
6 & $1.000000 \mathrm{E}+00$ & $1.395160 \mathrm{E}-08$ & $9.999985 \mathrm{E}-01$ & $1.48 \mathrm{E}-04$ \\
7 & $1.000000 \mathrm{E}+00$ & $7.293749 \mathrm{E}-08$ & $9.999986 \mathrm{E}-01$ & $1.30 \mathrm{E}-04$ \\
8 & $9.455000 \mathrm{E}-01$ & $2.804881 \mathrm{E}-01$ & $6.650092 \mathrm{E}-01$ & $2.84 \mathrm{E}-04$ \\
9 & $1.000000 \mathrm{E}+00$ & $1.226710 \mathrm{E}-08$ & $9.999983 \mathrm{E}-01$ & $1.72 \mathrm{E}-04$ \\
10 & $1.000000 \mathrm{E}+00$ & $8.601665 \mathrm{E}-09$ & $9.999984 \mathrm{E}-01$ & $1.60 \mathrm{E}-04$ \\
$10(\mathrm{HiK})$ & $1.000000 \mathrm{E}+00$ & $7.043708 \mathrm{E}-09$ & $9.999895 \mathrm{E}-01$ & $1.05 \mathrm{E}-03$ \\
11 & $1.000000 \mathrm{E}+00$ & $9.130158 \mathrm{E}-02$ & $9.081461 \mathrm{E}-01$ & $5.52 \mathrm{E}-02$ \\
$11(\mathrm{HiK})$ & $1.000000 \mathrm{E}+00$ & $8.956438 \mathrm{E}-02$ & $9.102211 \mathrm{E}-01$ & $2.15 \mathrm{E}-02$ \\
12 & $7.820302 \mathrm{E}-03$ & $2.219314 \mathrm{E}-03$ & $5.600966 \mathrm{E}-03$ & $2.83 \mathrm{E}-04$ \\
13 & $1.000000 \mathrm{E}+00$ & $3.605969 \mathrm{E}-02$ & $9.638255 \mathrm{E}-01$ & $1.15 \mathrm{E}-02$ \\
14 & $1.000000 \mathrm{E}+00$ & $1.299202 \mathrm{E}-01$ & $8.695770 \mathrm{E}-01$ & $5.03 \mathrm{E}-02$ \\
\hline \hline
\end{tabular}

Table 4.18. STOMP Mass Balance for $U-238\left(K_{d}=0.03\right)$

\begin{tabular}{|l|r|l|l|l|}
\hline \multicolumn{1}{|c|}{ Case } & Released & Domain & Exit & \% Error \\
\hline 1 & $1.000000 \mathrm{E}+00$ & $6.415574 \mathrm{E}-08$ & $1.000065 \mathrm{E}+00$ & $-6.50 \mathrm{E}-03$ \\
$1(\mathrm{HiK})$ & $1.000000 \mathrm{E}+00$ & $5.255918 \mathrm{E}-08$ & $1.000015 \mathrm{E}+00$ & $-1.51 \mathrm{E}-03$ \\
2 & $1.000000 \mathrm{E}+00$ & $6.151723 \mathrm{E}-08$ & $1.000118 \mathrm{E}+00$ & $-1.18 \mathrm{E}-02$ \\
3 & $1.000000 \mathrm{E}+00$ & $2.382405 \mathrm{E}-08$ & $1.000045 \mathrm{E}+00$ & $-4.50 \mathrm{E}-03$ \\
$3(\mathrm{HiK})$ & $1.000000 \mathrm{E}+00$ & $1.958077 \mathrm{E}-08$ & $1.000009 \mathrm{E}+00$ & $-8.96 \mathrm{E}-04$ \\
4 & $1.000000 \mathrm{E}+00$ & $1.236253 \mathrm{E}-07$ & $1.000005 \mathrm{E}+00$ & $-5.13 \mathrm{E}-04$ \\
$4(\mathrm{HiK})$ & $1.000000 \mathrm{E}+00$ & $1.017968 \mathrm{E}-07$ & $1.000001 \mathrm{E}+00$ & $-1.06 \mathrm{E}-04$ \\
5 & $1.000000 \mathrm{E}+00$ & $2.982352 \mathrm{E}-06$ & $9.999955 \mathrm{E}-01$ & $1.49 \mathrm{E}-04$ \\
6 & $1.000000 \mathrm{E}+00$ & $3.257756 \mathrm{E}-06$ & $9.999953 \mathrm{E}-01$ & $1.45 \mathrm{E}-04$ \\
7 & $1.000000 \mathrm{E}+00$ & $1.142003 \mathrm{E}-05$ & $9.999872 \mathrm{E}-01$ & $1.39 \mathrm{E}-04$ \\
8 & $9.455000 \mathrm{E}-01$ & $3.527776 \mathrm{E}-01$ & $5.927196 \mathrm{E}-01$ & $2.93 \mathrm{E}-04$ \\
9 & $1.000000 \mathrm{E}+00$ & $2.942570 \mathrm{E}-06$ & $9.999955 \mathrm{E}-01$ & $1.53 \mathrm{E}-04$ \\
10 & $1.000000 \mathrm{E}+00$ & $2.328466 \mathrm{E}-06$ & $9.999959 \mathrm{E}-01$ & $1.78 \mathrm{E}-04$ \\
$10(\mathrm{HiK})$ & $1.000000 \mathrm{E}+00$ & $1.909041 \mathrm{E}-06$ & $9.999884 \mathrm{E}-01$ & $9.71 \mathrm{E}-04$ \\
11 & $1.000000 \mathrm{E}+00$ & $1.333796 \mathrm{E}-01$ & $8.661004 \mathrm{E}-01$ & $5.20 \mathrm{E}-02$ \\
$11(\mathrm{HiK})$ & $1.000000 \mathrm{E}+00$ & $1.301998 \mathrm{E}-01$ & $8.696041 \mathrm{E}-01$ & $1.96 \mathrm{E}-02$ \\
12 & $7.820302 \mathrm{E}-03$ & $2.798621 \mathrm{E}-03$ & $5.021657 \mathrm{E}-03$ & $3.04 \mathrm{E}-04$ \\
13 & $1.000000 \mathrm{E}+00$ & $4.959167 \mathrm{E}-02$ & $9.503149 \mathrm{E}-01$ & $9.35 \mathrm{E}-03$ \\
14 & $1.000000 \mathrm{E}+00$ & $1.865788 \mathrm{E}-01$ & $8.129578 \mathrm{E}-01$ & $4.63 \mathrm{E}-02$ \\
\hline
\end{tabular}


Table 4.19. STOMP Mass Balance for $U-238\left(\mathrm{~K}_{\mathrm{d}}=0.10\right)$

\begin{tabular}{|l|c|c|r|r||}
\hline \multicolumn{1}{|c|}{ Case } & Released & Domain & \multicolumn{1}{c|}{ Exit } & \multicolumn{1}{c|}{ \% Error } \\
\hline 1 & $1.000000 \mathrm{E}+00$ & $1.820893 \mathrm{E}-03$ & $9.981788 \mathrm{E}-01$ & $3.27 \mathrm{E}-05$ \\
$1(\mathrm{HiK})$ & $1.000000 \mathrm{E}+00$ & $1.512807 \mathrm{E}-03$ & $9.984875 \mathrm{E}-01$ & $-2.79 \mathrm{E}-05$ \\
2 & $1.000000 \mathrm{E}+00$ & $1.840616 \mathrm{E}-03$ & $9.981592 \mathrm{E}-01$ & $1.54 \mathrm{E}-05$ \\
3 & $1.000000 \mathrm{E}+00$ & $6.603095 \mathrm{E}-04$ & $9.993397 \mathrm{E}-01$ & $-9.26 \mathrm{E}-07$ \\
$3(\mathrm{HiK})$ & $1.000000 \mathrm{E}+00$ & $5.457250 \mathrm{E}-04$ & $9.994545 \mathrm{E}-01$ & $-2.23 \mathrm{E}-05$ \\
4 & $1.000000 \mathrm{E}+00$ & $2.970166 \mathrm{E}-03$ & $9.970298 \mathrm{E}-01$ & $5.29 \mathrm{E}-06$ \\
$4(\mathrm{HiK})$ & $1.000000 \mathrm{E}+00$ & $2.490890 \mathrm{E}-03$ & $9.975101 \mathrm{E}-01$ & $-9.66 \mathrm{E}-05$ \\
5 & $1.000000 \mathrm{E}+00$ & $1.866260 \mathrm{E}-02$ & $9.813362 \mathrm{E}-01$ & $1.22 \mathrm{E}-04$ \\
6 & $1.000000 \mathrm{E}+00$ & $1.949844 \mathrm{E}-02$ & $9.805003 \mathrm{E}-01$ & $1.28 \mathrm{E}-04$ \\
7 & $1.000000 \mathrm{E}+00$ & $3.369953 \mathrm{E}-02$ & $9.662992 \mathrm{E}-01$ & $1.29 \mathrm{E}-04$ \\
8 & $9.455000 \mathrm{E}-01$ & $6.043256 \mathrm{E}-01$ & $3.411690 \mathrm{E}-01$ & $5.74 \mathrm{E}-04$ \\
9 & $1.000000 \mathrm{E}+00$ & $1.855251 \mathrm{E}-02$ & $9.814462 \mathrm{E}-01$ & $1.28 \mathrm{E}-04$ \\
10 & $1.000000 \mathrm{E}+00$ & $1.778828 \mathrm{E}-02$ & $9.822098 \mathrm{E}-01$ & $1.92 \mathrm{E}-04$ \\
$10(\mathrm{HiK})$ & $1.000000 \mathrm{E}+00$ & $1.506156 \mathrm{E}-02$ & $9.849390 \mathrm{E}-01$ & $-5.37 \mathrm{E}-05$ \\
11 & $1.000000 \mathrm{E}+00$ & $4.008301 \mathrm{E}-01$ & $5.988398 \mathrm{E}-01$ & $3.30 \mathrm{E}-02$ \\
$11(\mathrm{HiK})$ & $1.000000 \mathrm{E}+00$ & $3.864728 \mathrm{E}-01$ & $6.134346 \mathrm{E}-01$ & $9.26 \mathrm{E}-03$ \\
12 & $7.820302 \mathrm{E}-03$ & $4.824202 \mathrm{E}-03$ & $2.996062 \mathrm{E}-03$ & $4.82 \mathrm{E}-04$ \\
13 & $1.000000 \mathrm{E}+00$ & $1.597500 \mathrm{E}-01$ & $8.402107 \mathrm{E}-01$ & $3.93 \mathrm{E}-03$ \\
14 & $1.000000 \mathrm{E}+00$ & $5.108760 \mathrm{E}-01$ & $4.888813 \mathrm{E}-01$ & $2.43 \mathrm{E}-02$ \\
\hline \hline
\end{tabular}

Table 4.20. STOMP Mass Balance for $\mathrm{U}-238\left(\mathrm{~K}_{\mathrm{d}}=0.30\right)$

\begin{tabular}{|l|r|r|r|r||}
\hline \multicolumn{1}{|c|}{ Case } & Released & Domain & \multicolumn{1}{c|}{ Exit } & \multicolumn{1}{c|}{ \% Error } \\
\hline 1 & $1.000000 \mathrm{E}+00$ & $6.767227 \mathrm{E}-01$ & $3.232683 \mathrm{E}-01$ & $9.06 \mathrm{E}-04$ \\
$1(\mathrm{HiK})$ & $1.000000 \mathrm{E}+00$ & $6.389535 \mathrm{E}-01$ & $3.610842 \mathrm{E}-01$ & $-3.77 \mathrm{E}-03$ \\
2 & $1.000000 \mathrm{E}+00$ & $6.786346 \mathrm{E}-01$ & $3.213562 \mathrm{E}-01$ & $9.15 \mathrm{E}-04$ \\
3 & $1.000000 \mathrm{E}+00$ & $4.763605 \mathrm{E}-01$ & $5.236349 \mathrm{E}-01$ & $4.62 \mathrm{E}-04$ \\
$3(\mathrm{HiK})$ & $1.000000 \mathrm{E}+00$ & $4.368379 \mathrm{E}-01$ & $5.632051 \mathrm{E}-01$ & $-4.30 \mathrm{E}-03$ \\
4 & $1.000000 \mathrm{E}+00$ & $7.589161 \mathrm{E}-01$ & $2.410761 \mathrm{E}-01$ & $7.76 \mathrm{E}-04$ \\
$4(\mathrm{HiK})$ & $1.000000 \mathrm{E}+00$ & $7.253882 \mathrm{E}-01$ & $2.746476 \mathrm{E}-01$ & $-3.58 \mathrm{E}-03$ \\
5 & $1.000000 \mathrm{E}+00$ & $9.216971 \mathrm{E}-01$ & $7.829577 \mathrm{E}-02$ & $7.15 \mathrm{E}-04$ \\
6 & $1.000000 \mathrm{E}+00$ & $9.243751 \mathrm{E}-01$ & $7.561571 \mathrm{E}-02$ & $9.17 \mathrm{E}-04$ \\
7 & $1.000000 \mathrm{E}+00$ & $9.489265 \mathrm{E}-01$ & $5.106775 \mathrm{E}-02$ & $5.80 \mathrm{E}-04$ \\
8 & $9.455000 \mathrm{E}-01$ & $9.385057 \mathrm{E}-01$ & $6.991445 \mathrm{E}-03$ & $3.03 \mathrm{E}-04$ \\
9 & $1.000000 \mathrm{E}+00$ & $9.215366 \mathrm{E}-01$ & $7.845600 \mathrm{E}-02$ & $7.44 \mathrm{E}-04$ \\
10 & $1.000000 \mathrm{E}+00$ & $9.250431 \mathrm{E}-01$ & $7.495028 \mathrm{E}-02$ & $6.68 \mathrm{E}-04$ \\
$10(\mathrm{HiK})$ & $1.000000 \mathrm{E}+00$ & $9.060782 \mathrm{E}-01$ & $9.394199 \mathrm{E}-02$ & $-2.01 \mathrm{E}-03$ \\
11 & $1.000000 \mathrm{E}+00$ & $9.898858 \mathrm{E}-01$ & $1.010964 \mathrm{E}-02$ & $4.55 \mathrm{E}-04$ \\
$11(\mathrm{HiK})$ & $1.000000 \mathrm{E}+00$ & $9.866080 \mathrm{E}-01$ & $1.339225 \mathrm{E}-02$ & $-2.78 \mathrm{E}-05$ \\
12 & $7.820302 \mathrm{E}-03$ & $7.751192 \mathrm{E}-03$ & $6.909587 \mathrm{E}-05$ & $1.71 \mathrm{E}-04$ \\
13 & $1.000000 \mathrm{E}+00$ & $9.673185 \mathrm{E}-01$ & $3.267277 \mathrm{E}-02$ & $8.75 \mathrm{E}-04$ \\
14 & $1.000000 \mathrm{E}+00$ & $9.943140 \mathrm{E}-01$ & $5.683423 \mathrm{E}-03$ & $2.56 \mathrm{E}-04$ \\
\hline \hline
\end{tabular}


Table 4.21. STOMP Mass Balance for $U-238\left(K_{d}=0.60\right)$

\begin{tabular}{|l|l|l|l|r||}
\hline \multicolumn{1}{|c|}{ Case } & Released & Domain & Exit & \% Error \\
\hline 1 & $1.000000 \mathrm{E}+00$ & $9.989628 \mathrm{E}-01$ & $1.034490 \mathrm{E}-03$ & $2.69 \mathrm{E}-04$ \\
$1(\mathrm{HiK})$ & $1.000000 \mathrm{E}+00$ & $9.982645 \mathrm{E}-01$ & $1.733294 \mathrm{E}-03$ & $2.21 \mathrm{E}-04$ \\
2 & $1.000000 \mathrm{E}+00$ & $9.989231 \mathrm{E}-01$ & $1.073890 \mathrm{E}-03$ & $2.99 \mathrm{E}-04$ \\
3 & $1.000000 \mathrm{E}+00$ & $9.908570 \mathrm{E}-01$ & $9.138243 \mathrm{E}-03$ & $4.81 \mathrm{E}-04$ \\
$3(\mathrm{HiK})$ & $1.000000 \mathrm{E}+00$ & $9.863231 \mathrm{E}-01$ & $1.367707 \mathrm{E}-02$ & $-1.88 \mathrm{E}-05$ \\
4 & $1.000000 \mathrm{E}+00$ & $9.996912 \mathrm{E}-01$ & $3.063322 \mathrm{E}-04$ & $2.48 \mathrm{E}-04$ \\
$4(\mathrm{HiK})$ & $1.000000 \mathrm{E}+00$ & $9.994506 \mathrm{E}-01$ & $5.459972 \mathrm{E}-04$ & $3.44 \mathrm{E}-04$ \\
5 & $1.000000 \mathrm{E}+00$ & $9.999808 \mathrm{E}-01$ & $1.691668 \mathrm{E}-05$ & $2.28 \mathrm{E}-04$ \\
6 & $1.000000 \mathrm{E}+00$ & $9.999828 \mathrm{E}-01$ & $1.549676 \mathrm{E}-05$ & $1.67 \mathrm{E}-04$ \\
7 & $1.000000 \mathrm{E}+00$ & $9.999920 \mathrm{E}-01$ & $6.927548 \mathrm{E}-06$ & $1.12 \mathrm{E}-04$ \\
8 & $9.455000 \mathrm{E}-01$ & $9.454984 \mathrm{E}-01$ & $7.441735 \mathrm{E}-07$ & $9.78 \mathrm{E}-05$ \\
9 & $1.000000 \mathrm{E}+00$ & $9.999806 \mathrm{E}-01$ & $1.692245 \mathrm{E}-05$ & $2.45 \mathrm{E}-04$ \\
10 & $1.000000 \mathrm{E}+00$ & $9.999836 \mathrm{E}-01$ & $1.363567 \mathrm{E}-05$ & $2.76 \mathrm{E}-04$ \\
$10(\mathrm{HiK})$ & $1.000000 \mathrm{E}+00$ & $9.999652 \mathrm{E}-01$ & $3.148036 \mathrm{E}-05$ & $3.33 \mathrm{E}-04$ \\
11 & $1.000000 \mathrm{E}+00$ & $9.999961 \mathrm{E}-01$ & $6.726757 \mathrm{E}-07$ & $3.20 \mathrm{E}-04$ \\
$11(\mathrm{HiK})$ & $1.000000 \mathrm{E}+00$ & $9.999955 \mathrm{E}-01$ & $1.634566 \mathrm{E}-06$ & $2.84 \mathrm{E}-04$ \\
12 & $7.820302 \mathrm{E}-03$ & $7.820297 \mathrm{E}-03$ & $5.143364 \mathrm{E}-09$ & $-6.22 \mathrm{E}-06$ \\
13 & $1.000000 \mathrm{E}+00$ & $9.999930 \mathrm{E}-01$ & $1.681079 \mathrm{E}-06$ & $5.29 \mathrm{E}-04$ \\
14 & $1.000000 \mathrm{E}+00$ & $9.999974 \mathrm{E}-01$ & $3.161388 \mathrm{E}-07$ & $2.31 \mathrm{E}-04$ \\
\hline
\end{tabular}

Table 4.22. STOMP Mass Balance for U-238 $\left(\mathrm{K}_{\mathrm{d}}=1.00\right)$

\begin{tabular}{|l|l|l|l|l|}
\hline \multicolumn{1}{|c|}{ Case } & Released & Domain & Exit & \% Error \\
\hline 1 & $1.000000 \mathrm{E}+00$ & $9.999976 \mathrm{E}-01$ & $7.590741 \mathrm{E}-08$ & $2.37 \mathrm{E}-04$ \\
$1(\mathrm{HiK})$ & $1.000000 \mathrm{E}+00$ & $9.999969 \mathrm{E}-01$ & $2.468346 \mathrm{E}-07$ & $2.85 \mathrm{E}-04$ \\
2 & $1.000000 \mathrm{E}+00$ & $9.999980 \mathrm{E}-01$ & $8.828153 \mathrm{E}-08$ & $1.94 \mathrm{E}-04$ \\
3 & $1.000000 \mathrm{E}+00$ & $9.999907 \mathrm{E}-01$ & $6.781983 \mathrm{E}-06$ & $2.52 \mathrm{E}-04$ \\
$3(\mathrm{HiK})$ & $1.000000 \mathrm{E}+00$ & $9.999800 \mathrm{E}-01$ & $1.786430 \mathrm{E}-05$ & $2.16 \mathrm{E}-04$ \\
4 & $1.000000 \mathrm{E}+00$ & $9.999995 \mathrm{E}-01$ & $5.199722 \mathrm{E}-09$ & $5.31 \mathrm{E}-05$ \\
$4(\mathrm{HiK})$ & $1.000000 \mathrm{E}+00$ & $9.999982 \mathrm{E}-01$ & $1.896471 \mathrm{E}-08$ & $1.83 \mathrm{E}-04$ \\
5 & $1.000000 \mathrm{E}+00$ & $9.999988 \mathrm{E}-01$ & $0.000000 \mathrm{E}+00$ & $1.25 \mathrm{E}-04$ \\
6 & $1.000000 \mathrm{E}+00$ & $9.999983 \mathrm{E}-01$ & $0.000000 \mathrm{E}+00$ & $1.73 \mathrm{E}-04$ \\
7 & $1.000000 \mathrm{E}+00$ & $9.999983 \mathrm{E}-01$ & $0.000000 \mathrm{E}+00$ & $1.73 \mathrm{E}-04$ \\
8 & $9.455000 \mathrm{E}-01$ & $9.454993 \mathrm{E}-01$ & $0.000000 \mathrm{E}+00$ & $7.56 \mathrm{E}-05$ \\
9 & $1.000000 \mathrm{E}+00$ & $9.999985 \mathrm{E}-01$ & $0.000000 \mathrm{E}+00$ & $1.55 \mathrm{E}-04$ \\
10 & $1.000000 \mathrm{E}+00$ & $9.999978 \mathrm{E}-01$ & $0.000000 \mathrm{E}+00$ & $2.21 \mathrm{E}-04$ \\
$10(\mathrm{HiK})$ & $1.000000 \mathrm{E}+00$ & $9.999983 \mathrm{E}-01$ & $0.000000 \mathrm{E}+00$ & $1.67 \mathrm{E}-04$ \\
11 & $1.000000 \mathrm{E}+00$ & $9.999989 \mathrm{E}-01$ & $0.000000 \mathrm{E}+00$ & $1.07 \mathrm{E}-04$ \\
$11(\mathrm{HiK})$ & $1.000000 \mathrm{E}+00$ & $9.999990 \mathrm{E}-01$ & $0.000000 \mathrm{E}+00$ & $1.01 \mathrm{E}-04$ \\
12 & $7.820302 \mathrm{E}-03$ & $7.820302 \mathrm{E}-03$ & $0.000000 \mathrm{E}+00$ & $0.00 \mathrm{E}+00$ \\
13 & $1.000000 \mathrm{E}+00$ & $9.999976 \mathrm{E}-01$ & $0.000000 \mathrm{E}+00$ & $2.38 \mathrm{E}-04$ \\
14 & $1.000000 \mathrm{E}+00$ & $9.999996 \mathrm{E}-01$ & $0.000000 \mathrm{E}+00$ & $3.58 \mathrm{E}-05$ \\
\hline
\end{tabular}




\subsection{Electronic Files}

The principal objectives of this investigation were to conduct the simulations and analyses using an open scientific approach and to provide modeling results that could be verified and repeated. In partial fulfillment of these objectives, the source coding for the STOMP simulator, ancillary utilities coding, input files, simulation output files, and converted result files are provided in electronic form with enough detail to enable the reported calculations to be repeated. This section describes the directory structure and contents of the files stored in electronic format.

\subsection{Source Coding}

Source code for the STOMP simulator is stored in the "stomp_src" directory. Ancillary utilities are stored in the "source" directory. The STOMP source code is in the file "stomp1_sp.f" and comprises a main calling routine and subroutines listed in alphabetical order. The STOMP source code can be compiled with a FORTRAN 77 compiler, which includes the files "parameters" and "commons." The "parameters" file was dimensioned for all of the simulations. Once compiled, the STOMP simulator must be linked with the "splib.a" library configured for a particular compiler. Files and instructions needed to create the "splib.a" library are included in the file "splib.tar.gz." The location of source coding for the various conversion and translations utilities used during these investigations is shown in Table 5.1.

Table 5.1. Source Code Directory

\begin{tabular}{|l|l|l|}
\hline \multicolumn{1}{|c|}{ Program Name } & \multicolumn{1}{|c|}{ Source Code File } & \multicolumn{1}{c|}{ Auxiliary Files } \\
\hline InvSTOMP & inv_stomp.f & \\
PlotTec & plot_tec.f & \\
STOMP & stomp1_sp.f & commons, parameters \\
Surfcalc & surfcalc.c & \\
Combobtcs & combobtcs.c & \\
Disp & point3d_disp.f & \\
\hline
\end{tabular}

\subsection{Geology}

Zonation files to define the rock/soil-type and inactive-node distributions were provided with the MDP (Khaleel et al. 2003). These lithologic descriptions were based on inferences drawn from groundwater monitoring wells near the C Tank Farm and from grain size data and supplemented by information from tank farm drywells and excavation (e.g., Price and Fecht 1976a,1976b). Zonation files are stored in the individual case directories (grid_1x1_1.dat). Within the zonation file is information on the inactive nodes that define the tanks and cross-section boundaries. Rock/soil zonation files can be visualized as two-dimensional color-scaled images with Tecplot by opening the layout file for the cross section. 


\subsection{Initial Inventory}

Inventory files to define the initial inventory distribution of the solute species for Cases 3 and 4 were generated using the utility InvSTOMP. Inventory files are stored in the "conc" directory, which is subdivided into case 3 and case 4 subdirectories. A catalogue of the input files for the InvSTOMP utility and initial inventory distribution files for the investigated simulations is given in Table 5.2, where the solute species indicators, $u$ and tc refer to the solute species U-238 and Tc-99, respectively.

Table 5.2. Initial Inventory Distribution Files

\begin{tabular}{|l|l|l|}
\hline \multicolumn{1}{|c|}{ File Name } & \multicolumn{1}{|c|}{ Description } & \multicolumn{1}{|c|}{ File Type } \\
\hline inv_*_c & InvSTOMP input file & Text \\
c_*_inv.asc & STOMP initial-inventory-distribution input file & Text \\
c_*inv.asc.plt & Tecplot formatted file of initial inventory distribution & Text \\
\hline * Represents the solute species (e.g., u or tc). & \\
\hline
\end{tabular}

\subsection{Steady Flow Simulations}

A steady flow simulation was executed to generate initial condition flow fields for each of the transient solute transport simulations. This simulation is found in the "case 00 " directory and was executed with the STOMP simulator, which produced a "restart" file that described the steady flow field. The input, output, and restart files are catalogued in Table 5.3.

Table 5.3. Steady Flow Initial Condition Files

\begin{tabular}{|l|l|l|}
\hline File Name & \multicolumn{1}{|c|}{ Description } & File Type \\
\hline input & STOMP input file & Text \\
output & STOMP reference-node output file & Text \\
plot & STOMP plot-file output file & Text \\
restart & STOMP restart file & Text \\
\hline
\end{tabular}

\subsection{Coupled Vadose Zone and Unconfined Aquifer Modeling}

Coupled vadose zone and unconfined aquifer modeling files are stored in directories named according to case number (e.g., directory "case 01 " holds files associated with the Case 1 simulations). Verification case directories are identified with a "v" appended to the case number (e.g., case05v). Sensitivity cases that examined the effect of higher saturated hydraulic conductivity are identified with "_HiK" appended to the case number (e.g., case10_HiK). Within all of these directories are subdirectories for the two stages of the simulations, "1945to2050" and "2050to12000." These subdirectories hold input files, zonation files, reference-node output files, plot-file output files, and surface-flux output files. Also within the case directories are subdirectories containing converted plot-file output, Tecplot layout files, solute concentration and mass flux data files, and images. Breakthrough curve data are contained in the "btc" subdirectory, whereas the "tecplot" subdirectory contains encapsulated postscript (eps) images and data on 
concentration and saturation distributions in the cross section for distinct points in time. Table 5.4 summarizes the naming conventions for the files stored under each case directory.

Table 5.4. Coupled Vadose Zone and Unconfined Aquifer Modeling Files

\begin{tabular}{|c|c|c|}
\hline File Name & Description & File Type \\
\hline Input & STOMP simulator input & Text \\
\hline Output & STOMP simulator reference-node output & Text \\
\hline fn.srf & STOMP simulator surface-flux output & Text \\
\hline$f n \_$tol.srf & $\begin{array}{l}\text { Modified STOMP simulator surface-flux output so that the } \\
\text { cumulative flux is continuous between stages } 1 \text { and } 2\end{array}$ & Text \\
\hline p\#.plt & Tecplot data file for color-scale images of plot-file output & Tecplot binary \\
\hline$y r_{-}$type_*.eps & $\begin{array}{l}\text { Image file showing concentration or saturation profiles at } \\
\text { distinct points in time }\end{array}$ & \\
\hline prepsurf_fenceline.csh & C-Shell script for computing BTCs at the fence line & Text \\
\hline prepsurf_gwtable.csh & C-Shell script for computing BTCs at the groundwater table & Text \\
\hline *_location_mf.dat & Solute mass flux breakthrough data at the fence line & Text \\
\hline *_location_c.dat & Solute concentration breakthrough data at the fence line & Text \\
\hline *_location_mf.eps & $\begin{array}{l}\text { Mass flux breakthrough curve (encapsulated postscript file) } \\
\text { generated using rungnu.csh }\end{array}$ & Text/Image \\
\hline *_location_mf.eps & $\begin{array}{l}\text { Image file containing mass flux breakthrough curves } \\
\text { (generated using rungnu.csh) }\end{array}$ & Text/Image \\
\hline \multicolumn{3}{|c|}{$\begin{array}{l}\text { Notes: } \\
\text { \# is the plot file number indicator (e.g., plot.175, plot.3462, etc) } \\
f n \text { is the user-defined filename } \\
y r \text { represents the calendar year plotted in the image file } \\
\left.* \text { is the plot variable [e.g., sat (saturation), ac tc (aqueous conc tc), vc_u: } 0.10 \text { (u total conc w/ } \mathrm{K}_{\mathrm{d}}=0.10\right] \text {. } \\
\text { location represents the fence line or the gwtable (groundwater table) locations }\end{array}$} \\
\hline
\end{tabular}

To distinguish concentration data for U-238 with a source at Tank C-112, the notation $u: K_{d}$ was used. For example, for files containing data on U-238 with a $\mathrm{K}_{\mathrm{d}}=0.01 \mathrm{~mL} / \mathrm{g}, u: 0.01$ was used in the filename (see Table 5.4). If there were more than one contaminant source in the simulation, then the notation Tc:tank\# or U:tank\#: $\mathrm{K}_{\mathrm{d}}$ was used to represent the contaminants. For example, Tc:C106 represents the technetium from Tank C-106 and $U: C 103: 0 . \mathrm{U}-238$ from Tank C-103 with $\mathrm{K}_{\mathrm{d}}=0.03 \mathrm{~mL} / \mathrm{g}$.

For each transient flow and solute transport simulation, the STOMP simulator read an input file, restart file, zonation file, and solute inventory file and generated one reference-node output file, one or more plot-file output files, and one or more surface-flux output files. The STOMP-generated plot-file output files were converted to Tecplot ASCII format using the PlotTec utility. These ASCII files, when visualized through Tecplot, were used to generate color-scaled images of saturation and solute concentration for selected points in time.

The STOMP-generated surface-flux output files were translated to ASCII mass flux and concentration text format using prepsurf.c and combobtc.c utilities. These files contain aqueous volumetric flux and solute mass flux at the groundwater and fence line boundaries with the groundwater for each simulation year. 
Plot-file output can be viewed as color-scaled, two-dimensional images by viewing the encapsulated postscript file. Surface-flux output and breakthrough curves can be viewed as plots using standard graphing software (e.g., gnuplot, Excel) for the cross section of interest. Reference-node data can be viewed by editing the reference-node output file.

\subsection{Analytical Groundwater Transport Modeling}

Data files (input, output, and csh script files) for the analytical groundwater transport model were archived in the case figure directories (bxfigs and trenchfigs) (Table 5.5). C-Shell scripts for running the analytical model (disp) and generating plots are included in these directories. These scripts (runpoint.csh) also contain the flow-path length, velocity, and hydraulic parameters. The analytical model script creates output files for each species that contains the time and calculated concentrations at each compliance point in columns. Additional scripts were developed and archived in the case directories for generating plots from the analytical results (runcombo.csh and rungnu.csh). These scripts were executed for each case directory to generate the encapsulated postscript files for the plots of the results used in this report.

Table 5.5. Analytical Groundwater Transport Modeling Files

\begin{tabular}{|c|c|c|}
\hline File Name & Description & File Type \\
\hline runallmodels.csh & $\begin{array}{l}\text { C-Shell script for executing series of c-shell scripts used to generate } \\
\text { breakthrough curves }\end{array}$ & Text \\
\hline runpoint.csh & $\begin{array}{l}\text { C-Shell script for executing the analytical model (includes model } \\
\text { parameters) }\end{array}$ & Text \\
\hline runcombo.csh & $\begin{array}{l}\text { C-Shell script for combining breakthrough data at the groundwater } \\
\text { table, fence line, exclusion boundary, and Columbia River into one file }\end{array}$ & Text \\
\hline run_gnu.csh & C-Shell script for generating breakthrough curve plot files & \\
\hline riv_thrugap_*.btc & $\begin{array}{l}\text { Solute-concentration breakthrough data at the Columbia River for the } \\
\text { flow path through the gap }\end{array}$ & Text \\
\hline exc_thrugap_*.btc & $\begin{array}{l}\text { Solute-concentration breakthrough data at the exclusion boundary for } \\
\text { the flow path through the gap }\end{array}$ & Text \\
\hline riv_sgap_*.btc & $\begin{array}{l}\text { Solute-concentration breakthrough data at the Columbia River for the } \\
\text { flow path south of the gap }\end{array}$ & Text \\
\hline exc_sgap_*btc & $\begin{array}{l}\text { Solute-concentration breakthrough data at the exclusion boundary for } \\
\text { the flow path south of the gap }\end{array}$ & Text \\
\hline all_*_thrugap.dat & $\begin{array}{l}\text { Solute-concentration breakthrough data at all compliance points for the } \\
\text { groundwater flow path north and thru the gap }\end{array}$ & Text \\
\hline all_*_sgap.dat & $\begin{array}{l}\text { Solute-concentration breakthrough data at all compliance points for the } \\
\text { groundwater flow path south of the gap }\end{array}$ & Text \\
\hline *_thrugap_c.eps & $\begin{array}{l}\text { Image file containing concentration breakthrough curve data at the } \\
\text { groundwater, fence line, exclusion boundary, and Columbia River for } \\
\text { the flow path through the gap }\end{array}$ & Text/image \\
\hline *_sgap_c.eps & $\begin{array}{l}\text { Image file containing concentration breakthrough curve data at the } \\
\text { groundwater, fence line, exclusion boundary, and Columbia River for } \\
\text { the flow path south of the gap }\end{array}$ & Text/Image \\
\hline \multicolumn{3}{|c|}{ * Indicates the solute species (e.g., u: $\left.\mathrm{K}_{\mathrm{d}}, \mathrm{tc}\right)$} \\
\hline
\end{tabular}




\subsection{References}

Baetslé LH. 1969. "Migration of radionuclides in porous media." Progress in Nuclear Energy Series XII, Health Physics, AMF Duhamel, ed. Pergamon Press, Elmsford, NY, pp. 707-730.

Bergeron MP and SK Wurstner. 2000. Groundwater Calculations Supporting the 2001 Immobilized Low-Activity Waste Disposal Facility Performance Assessment at the Hanford Site in Southeastern Washington. PNNL-13400, Pacific Northwest National Laboratory, Richland, WA.

Bramley R and X Wang. 1995. SPLIB: A Library of Iterative Methods for Sparse Linear Systems. Indiana University, Bloomington.

Domenico PA and FW Schwartz. 1990. Physical and Chemical Hydrogeology. John Wiley \& Sons, New York, pp. 824.

Freedman, VL, MW Williams, CR Cole, MD White and MP Bergeron. 2002. 2002 Initial Assessments for B-BX-BY Field Investigation Report (FIR): Numerical Simulations. PNNL-13949, Pacific Northwest National Laboratory, Richland, WA.

Gardner WR. 1958. "Some Steady-State Solutions of the Unsaturated Moisture Flow Equation with Applications to Evaporation From a Water Table.” Soil Science, 85:228-232.

Gelhar LW. 1993. Stochastic Subsurface Hydrology. Prentice Hall, Englewood Cliffs, NJ.

Kaplan DL and RJ Serne. 1999. Geochemical Data Package for the Immobilized Low-Activity Waste Performance Assessment. PNNL-13037, Pacific Northwest National Laboratory, Richland, WA.

Khaleel R, JF Relyea, and JL Conca. 1995. "Evaluation of van-Genuchten-Mualem relationships to estimate unsaturated conductivity at low water contents." Water Resources Research, 31:2659-2668.

Khaleel R and JF Relyea. 1997. "Correcting laboratory-measured moisture retention data for gravels." Water Resources Research, 33:1875-1878.

Khaleel R, MP Connelly, D Crumpler, TE Jones, AJ Knepp, FM Mann, B McMahon, CW Miller and MI Wood. 2003. Modeling Data Package for an Initial Assessment of Closure for C Tank Farm. RPP-13310 Rev. 0, CH2M HILL Hanford Group, Inc., Richland, WA.

Kincaid CT, JW Shade, GA Whyatt, MG Piepho, K Rhoads, JA Voogd, JH Westsik Jr, MD Freshley, KA Blanchard, and BG Lauzon. 1995. Performance Assessment of Grouted Double-Shell Tank Waste Disposal at Hanford. WHC-SD-WM-EE-004 Rev. 1, Westinghouse Hanford Company, Richland, WA.

Kozak MW, MSY Chu, PA Mattingly, JD Johnson, and JT McCord. 1990. Background Information for the Development of a Low-Level Waste Performance Assessment Methodology. NUREG/CR-453

(SAND90-0375), Vol. 5. U.S. Nuclear Regulatory Commission, Washington, D.C.

Law A, S Panday, C Denslow, K Fecht, and A Knepp. 1996. Hanford Site-Wide Groundwater Flow and Transport Model Calibration Report. BHI-00608 Rev. 0, Bechtel Hanford, Inc., Richland, WA.

Lindsey KA and KD Reynolds. 2001. Vadose Zone Geology of Boreholes 299-E33-45 and 299-E33-46

B-BX-BY Waste Management Area, Hanford Site, South-Central Washington. RPP-8681 Rev. 0, CH2M HILL Hanford Group, Inc., Richland, WA. 
Lu AH. 1996. Contaminant Transport in the Unconfined Aquifer; Input to the Low Level Tank Waste Interim Performance Assessment. WHC-SD-WM-RPT-214, Westinghouse Hanford Co., Richland, WA. Millington RJ and JP Quirk. 1961. "Permeability of Porous Media.” Nature 183:387-388.

Mualem Y. 1976. "A New Model for Predicting the Hydraulic Conductivity of Unsaturated Porous Media." Water Resources Research 12:513-522.

Nichols WE, M Oostrom, and MD White. 2000. STOMP Subsurface Transport Over Multiple Phases, Version 2.0, Application Guide. PNNL-12028, Pacific Northwest National Laboratory, Richland, WA.

Polmann DJ. 1990. Application of Stochastic Methods to Transient Flow and Transport in Heterogeneous Unsaturated Soils. Ph.D. Thesis, Massachusetts Institute of Technology, Cambridge.

Press WH, BP Flannery, SA Teukolsky, and WT Vetterling. 1992. "Romberg Integration." §4.3 in Numerical Recipes in FORTRAN: The Art of Scientific Computing, 2nd ed. Cambridge, England: Cambridge University Press, pp. 134-135.

Price WH and KR Fecht. 1976a. Geology of the 241-S Tank Farm. ARH-LD-133, Atlantic Richfield Hanford Company, Richland, WA.

Price WH and KR Fecht. 1976b. Geology of the 241-SX Tank Farm. ARH-LD-134, Atlantic Richfield Hanford Company, Richland, WA.

Talbott ME and LW Gelhar. 1994. Performance Assessment of a Hypothetical Low-Level Waste Facility: Groundwater Flow and Transport Simulation. NUREG/CR-6114 Vol. 3, U.S. Nuclear Regulatory Commission, Washington, D.C.

van Genuchten MT. 1980. "A Closed-Form Equation for Predicting the Hydraulic Conductivity of Unsaturated Soils.” Soil Science Society of America Journal 44:892-898.

Washington State Department of Ecology, U.S.Environmental Protection Agency, and U.S. Department of Energy. 1989 and as Amended Through December 31, 1998. Hanford Federal Facility Agreement and Consent Order. 89-10 Rev. 5, Ecology, EPA, and DOE, Olympia, WA.

White MD and M Oostrom. 2000a. STOMP Subsurface Transport Over Multiple Phases, Version 2.0, Theory Guide. PNNL-12030, Pacific Northwest National Laboratory, Richland, WA.

White MD and M Oostrom. 2000b. STOMP Subsurface Transport Over Multiple Phases, Version 2.0, User's Guide. PNNL-12034, Pacific Northwest National Laboratory, Richland, WA.

White MD, M Oostrom, MD Williams, CR Cole and MP Bergeron. 2001. FY00 Initial Assessments for S-SX Field Investigation Report (FIR): Simulations of Contaminant Migration with Surface Barriers. PNWD-3111, Pacific Northwest National Laboratory, Richland, WA.

Yeh TCJ, LW Gelhar and AL Gutjahr. 1985. "Stochastic Analysis of Unsaturated Flow in Heterogeneous Soils, 2. Statistically Anisotropic Media with Variable $\alpha$. ." Water Resources Research 21:457-464. 


\section{Appendix A: C Farm Saturation and Concentration Distributions}



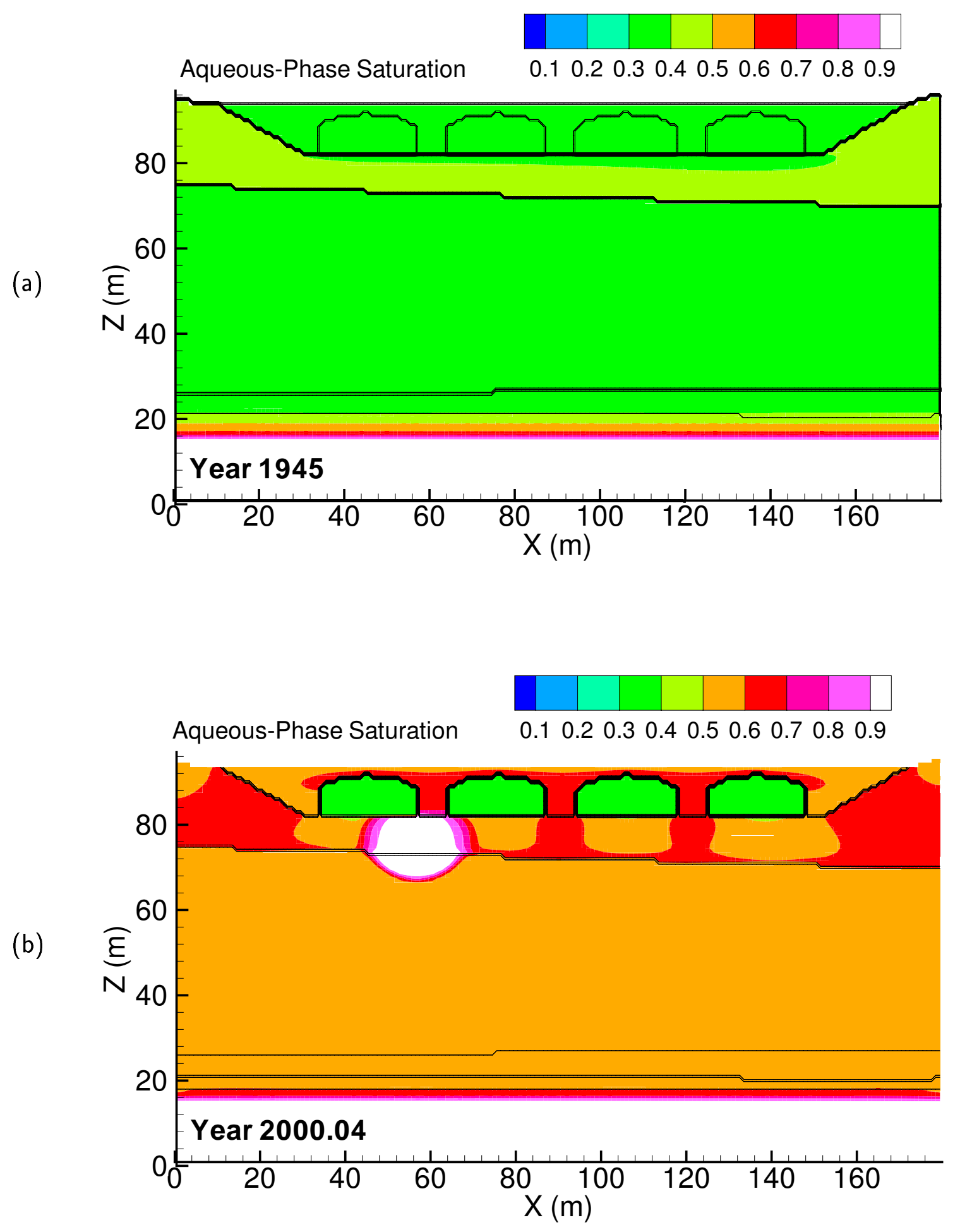

Figure A.1. Case 1, Aqueous saturation at (a) year 1945 and (b) 01/15/2000 

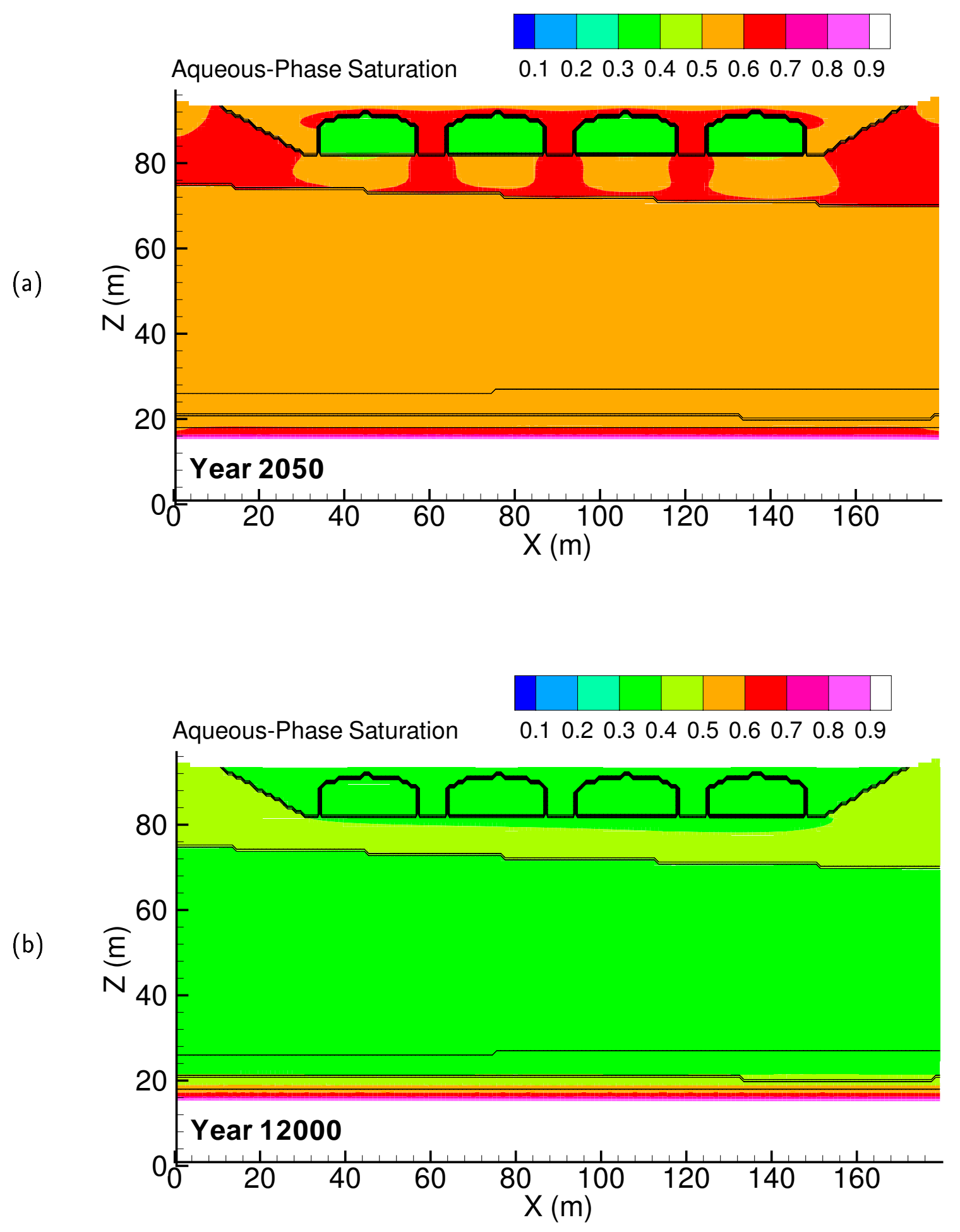

Figure A.2. Case 1, Aqueous saturation at (a) year 2050 and (b) year 12000 

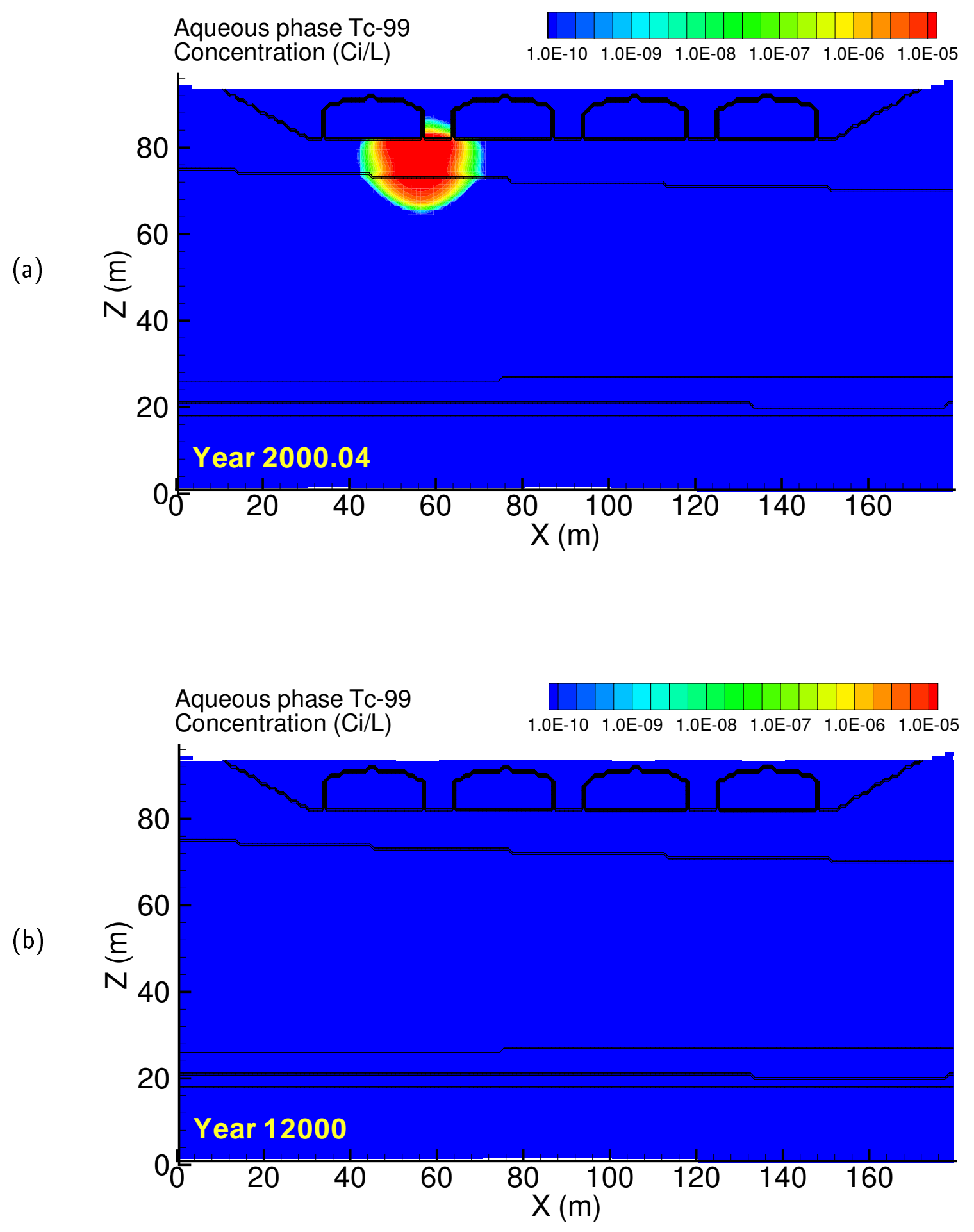

Figure A.3. Case 1, Tc-99 aqueous concentration at (a) 01/15/2000 and (b) year 12000 

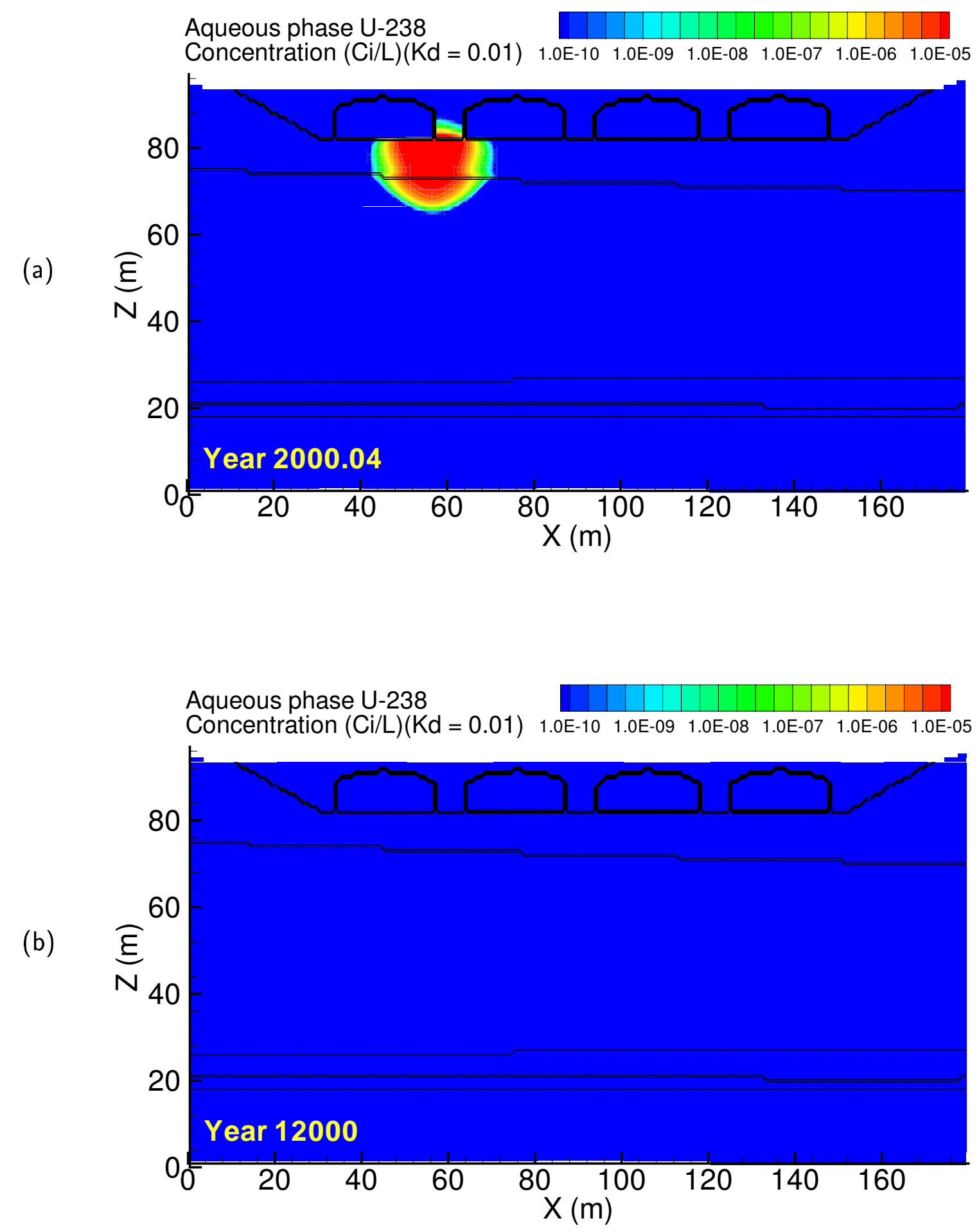

Figure A.4. Case 1, U-238 ( $\left.\mathrm{K}_{d}=0.01\right)$ aqueous concentration at (a) $01 / 15 / 2000$ and (b) year 12000 

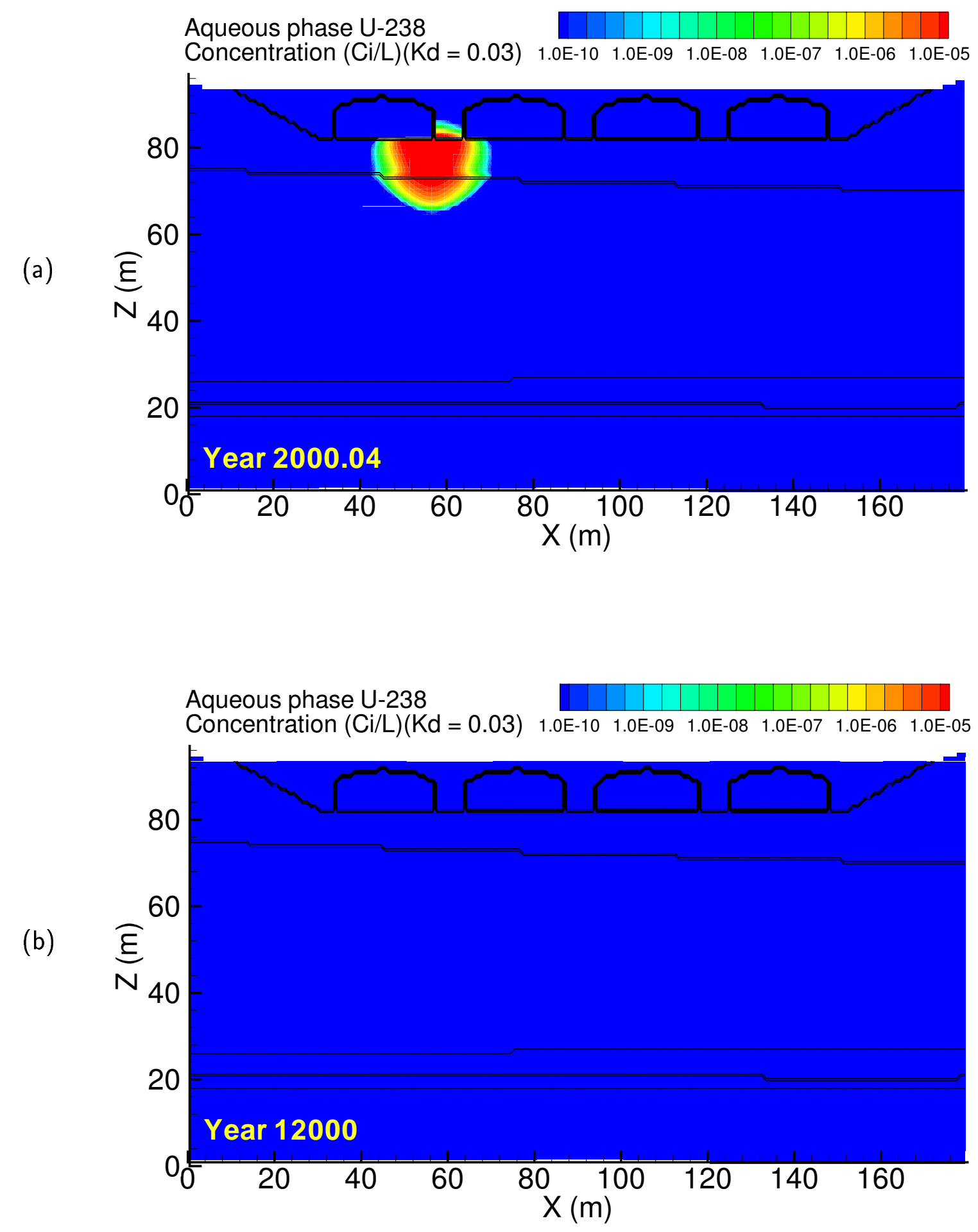

Figure A.5. Case 1, U-238 $\left(\mathrm{K}_{d}=0.03\right)$ aqueous concentration at (a) $01 / 15 / 2000$ and (b) year 12000 

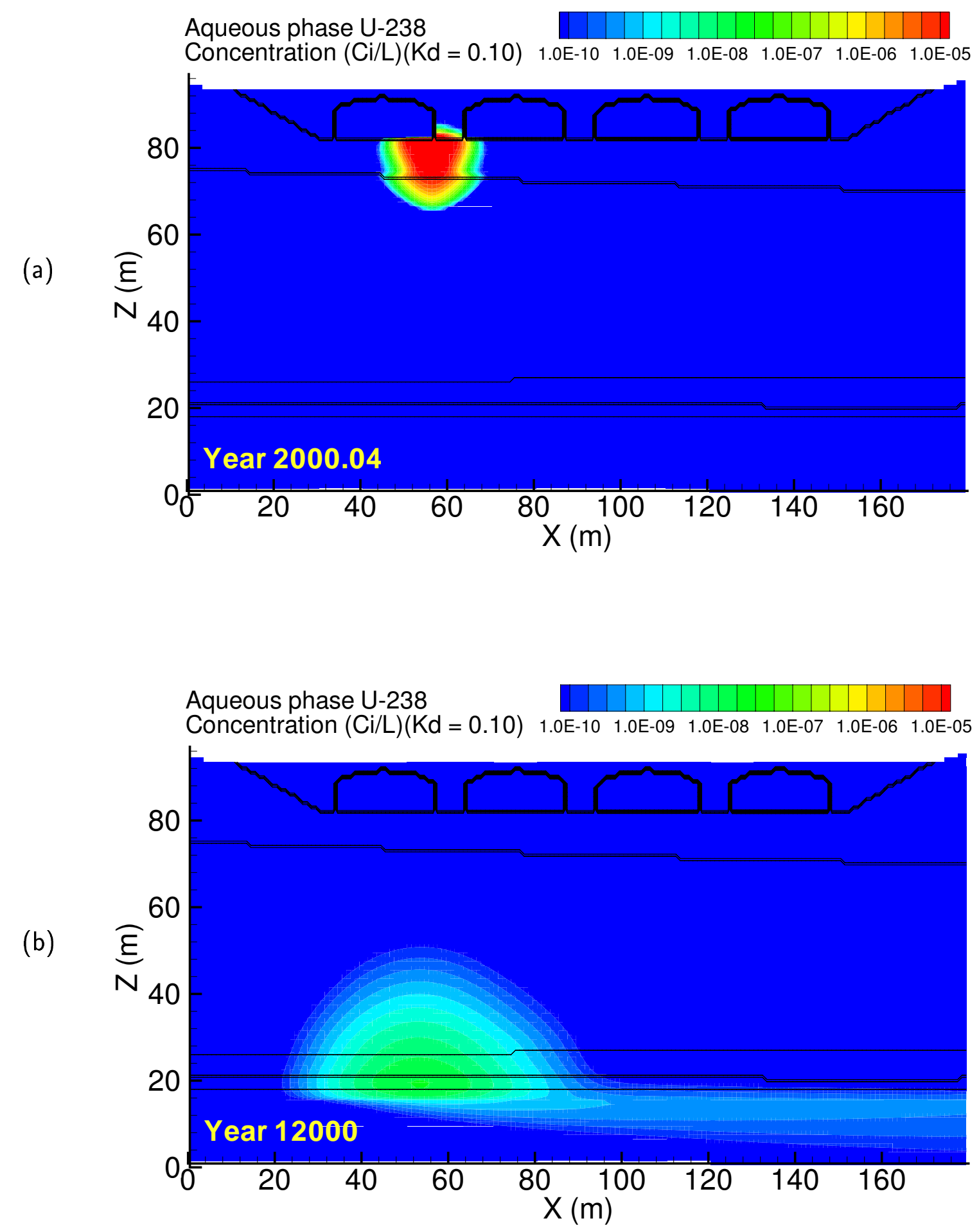

Figure A.6. Case 1, U-238 $\left(\mathrm{K}_{d}=0.10\right)$ aqueous concentration at (a) $01 / 15 / 2000$ and (b) year 12000 

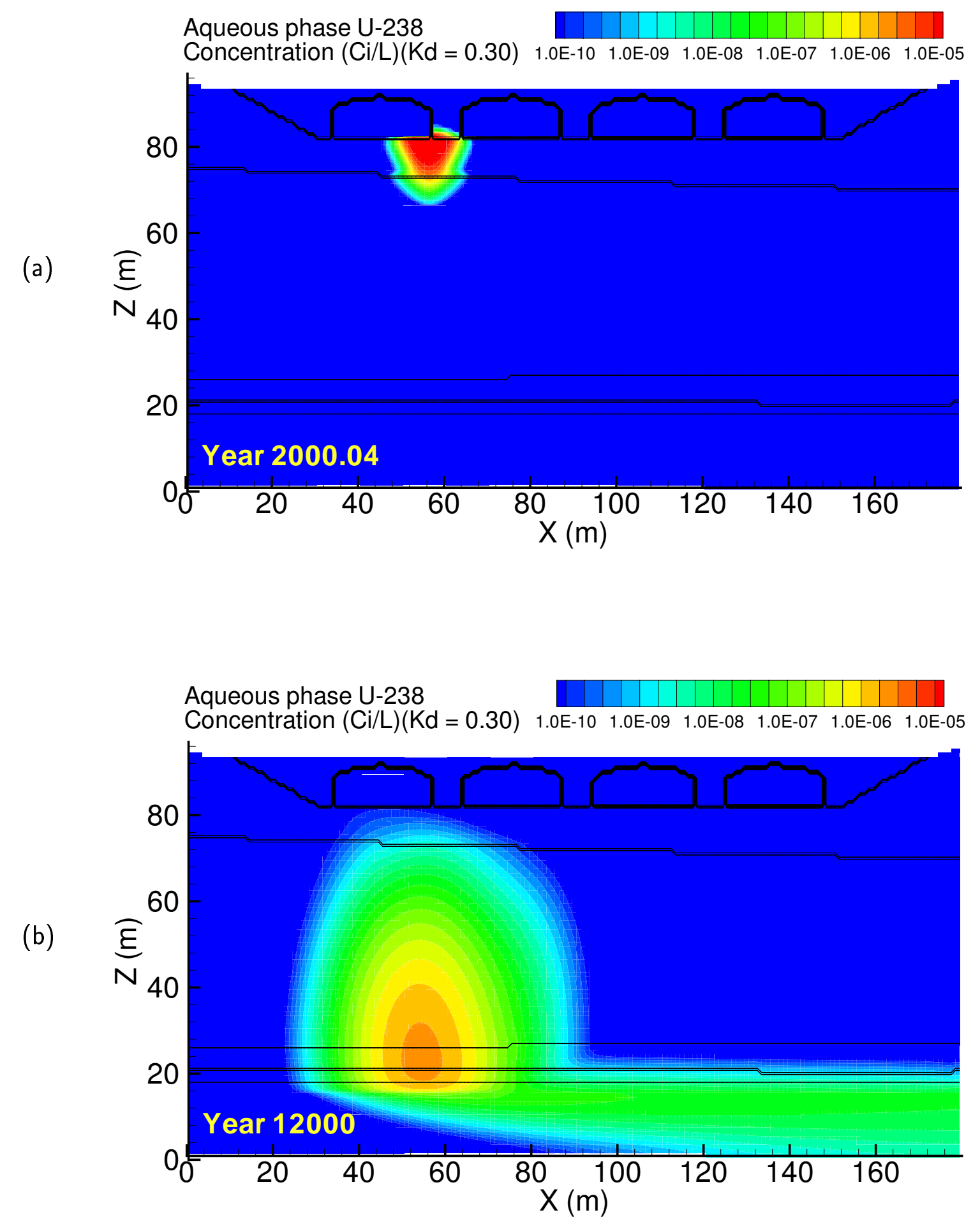

Figure A.7. Case 1, U-238 $\left(\mathrm{K}_{d}=0.30\right)$ aqueous concentration at (a) $01 / 15 / 2000$ and (b) year 12000 

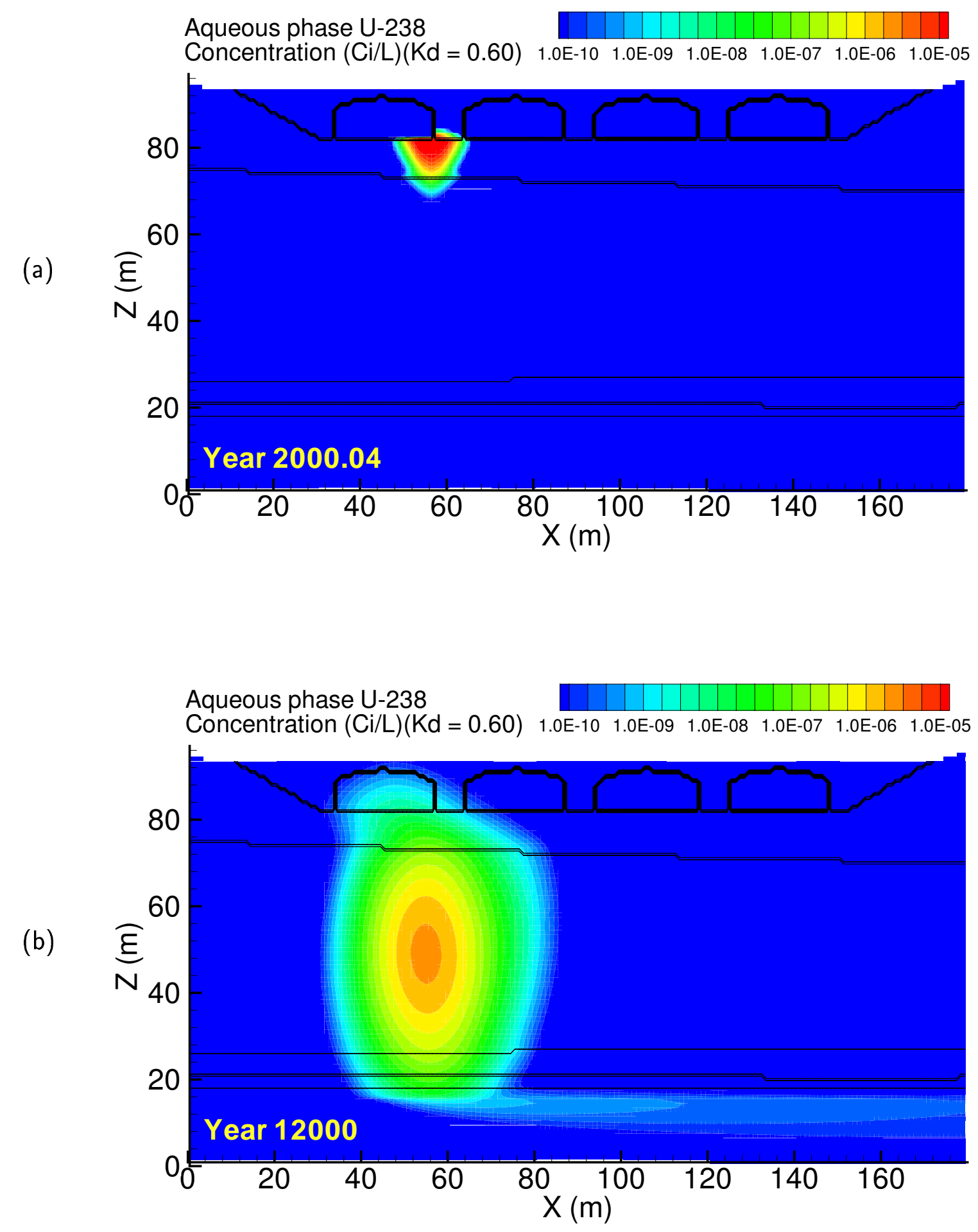

Figure A.8. Case 1, U-238 $\left(\mathrm{K}_{d}=0.60\right)$ aqueous concentration at (a) $01 / 15 / 2000$ and (b) year 12000 

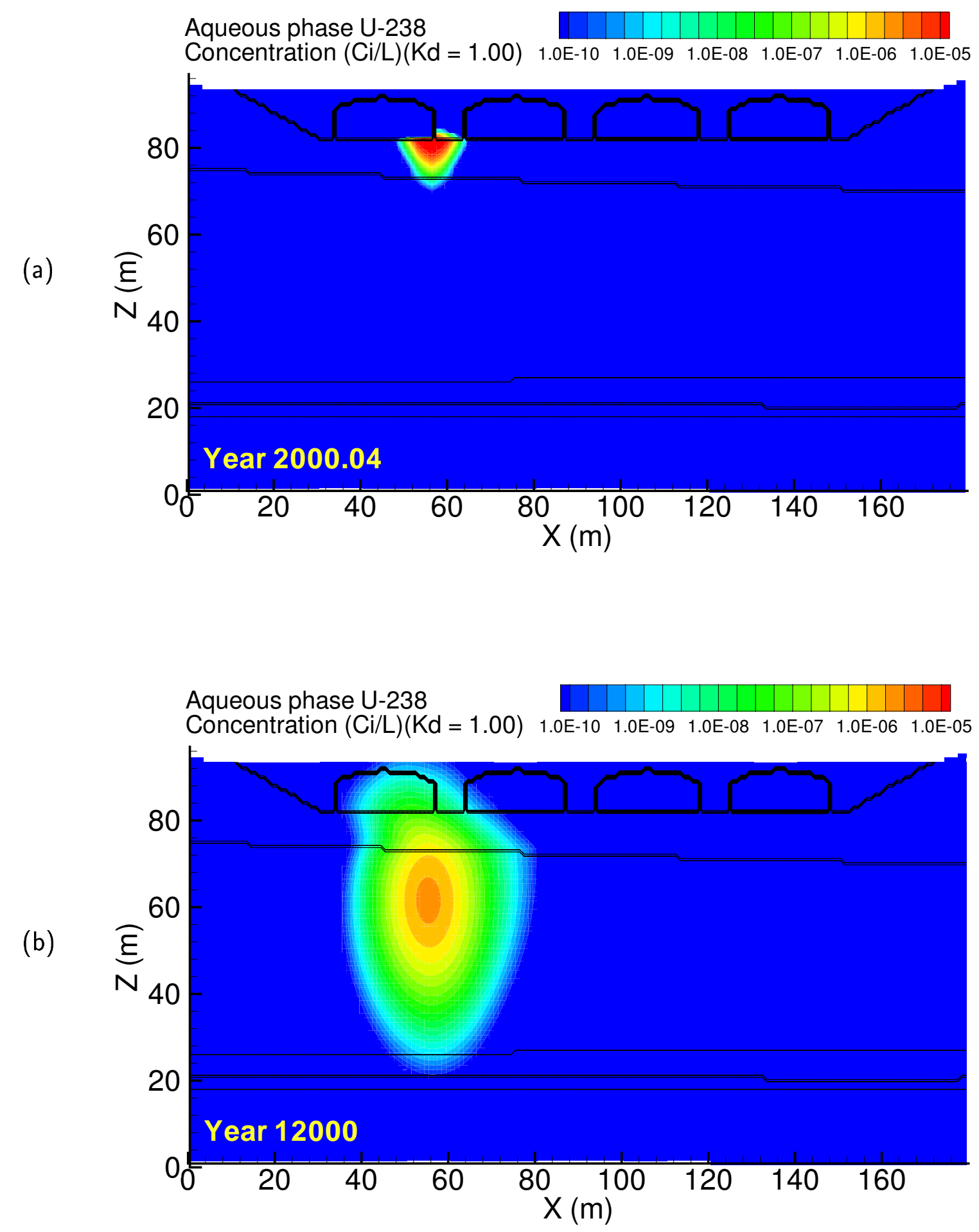

Figure A.9. Case 1, U-238 $\left(\mathrm{K}_{d}=1.00\right)$ aqueous concentration at (a) $01 / 15 / 2000$ and (b) year 12000 

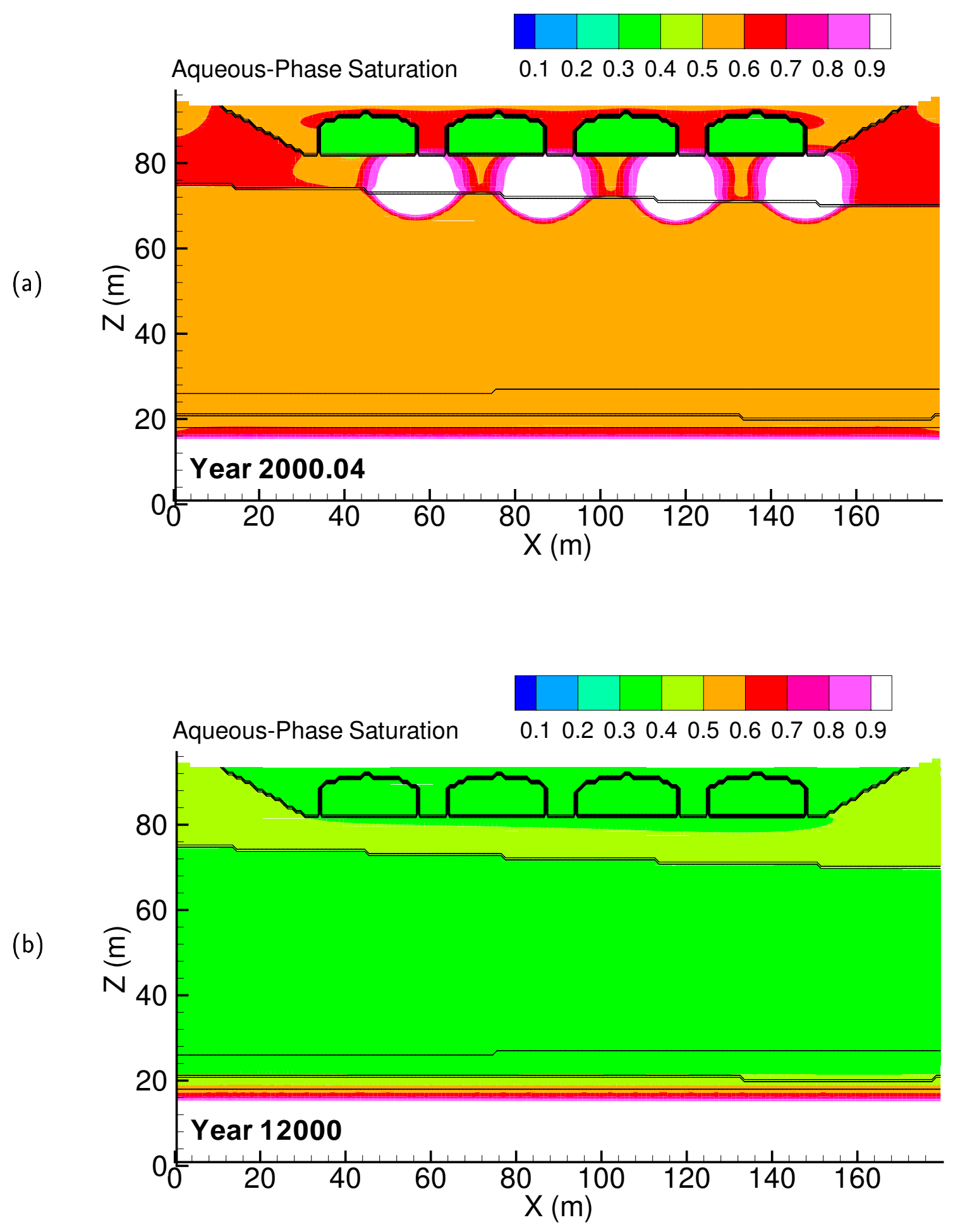

Figure A.10. Case 1v, Aqueous saturation at (a) 01/15/2000 and (b) year 12000 

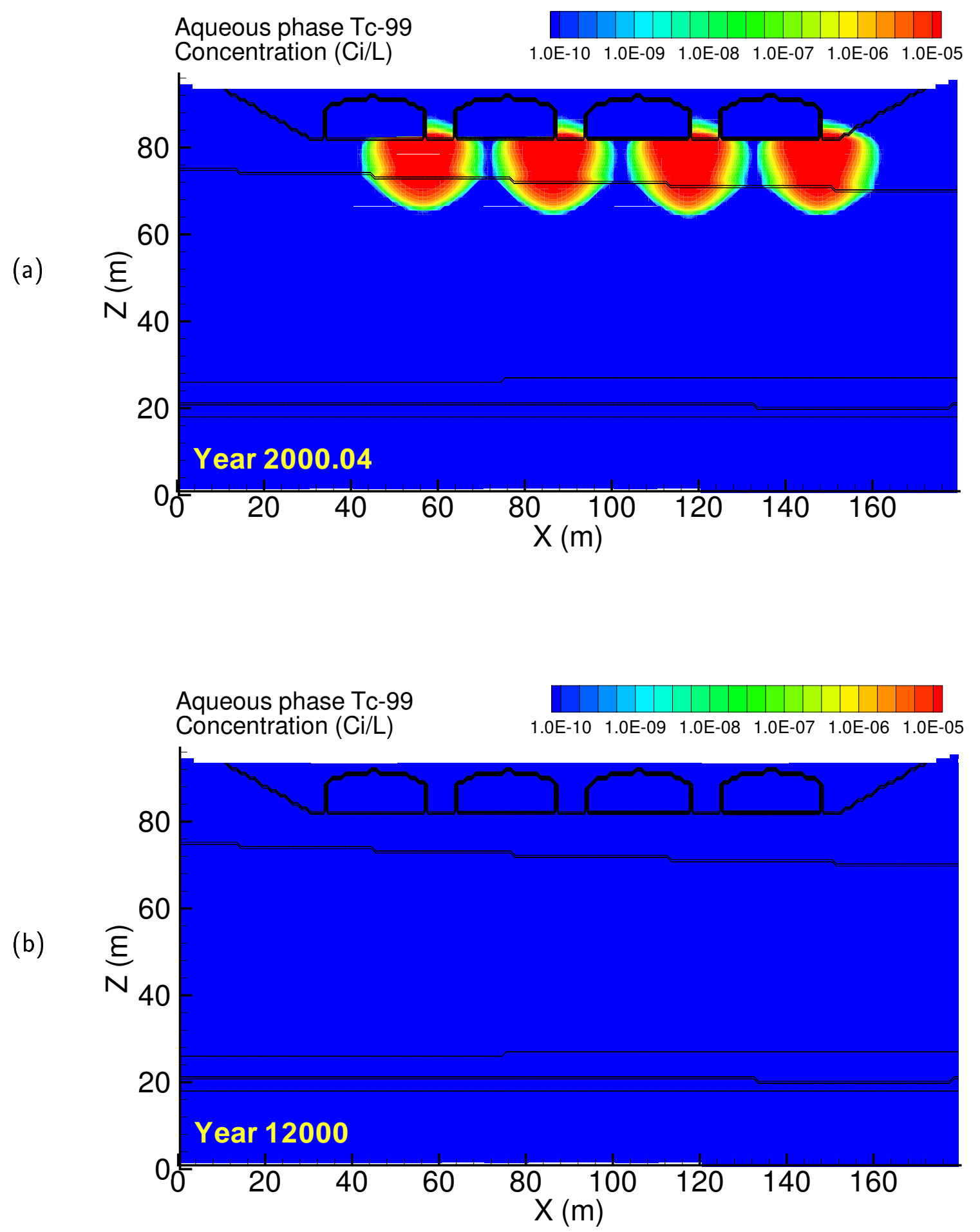

Figure A.11. Case 1v, Tc-99 aqueous concentration at (a) 01/15/2000 and (b) year 12000 

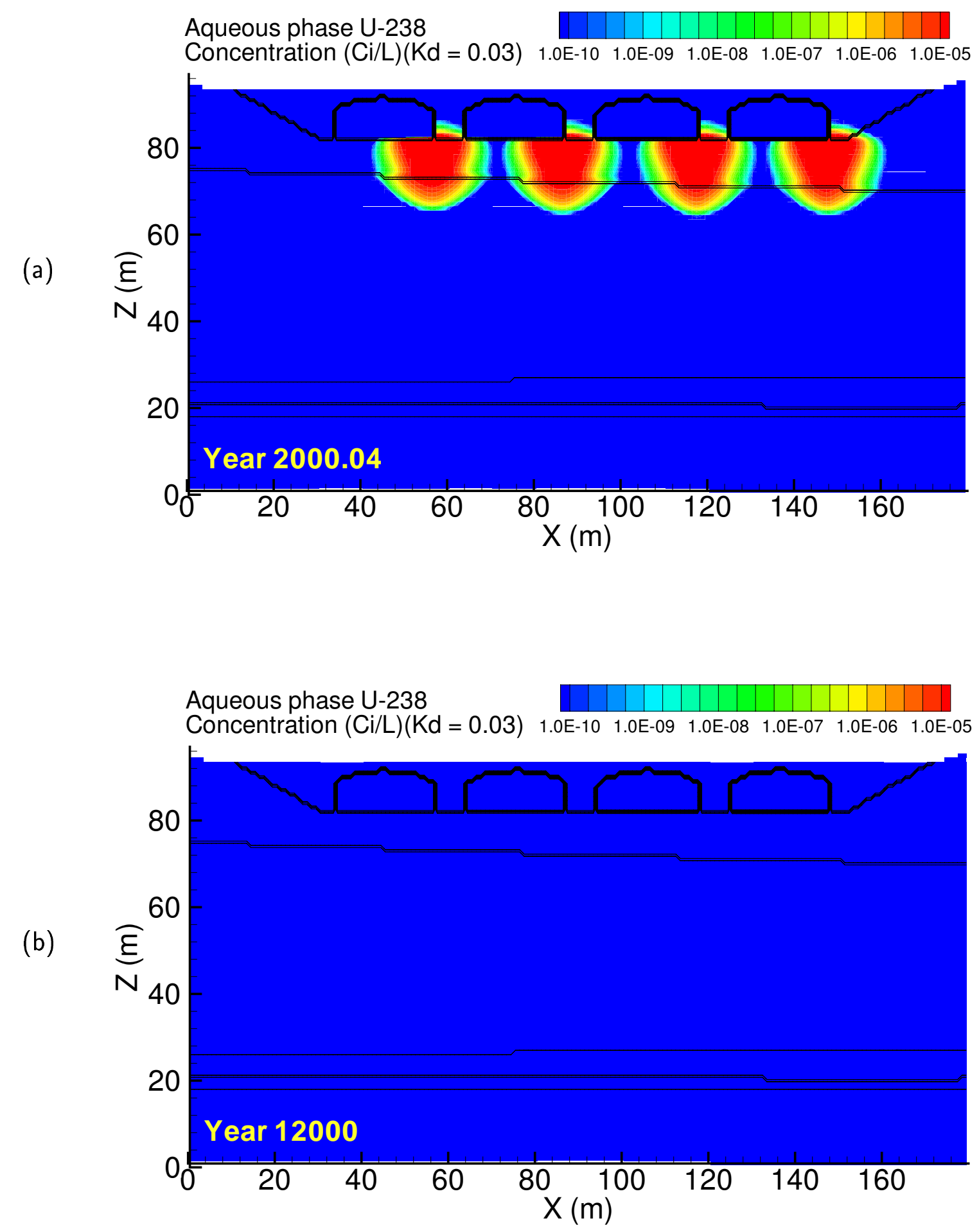

Figure A.12. Case $1 v$, U-238 $\left(\mathrm{K}_{d}=0.03\right)$ aqueous concentration at (a) $01 / 15 / 2000$ and (b) year 12000 

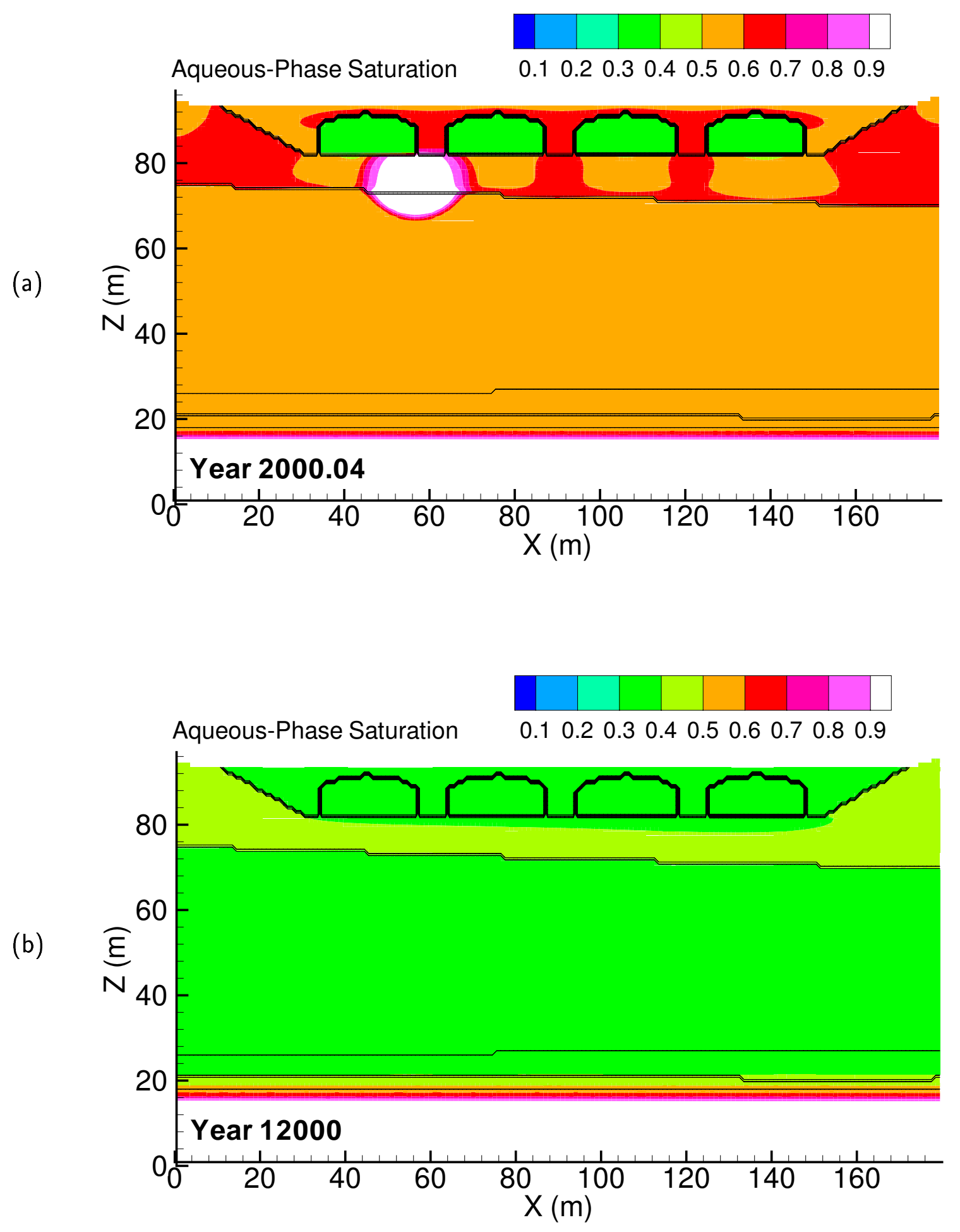

Figure A.13. Case 1-HiK, Aqueous saturation at (a) 01/15/2000 and (b) year 12000 

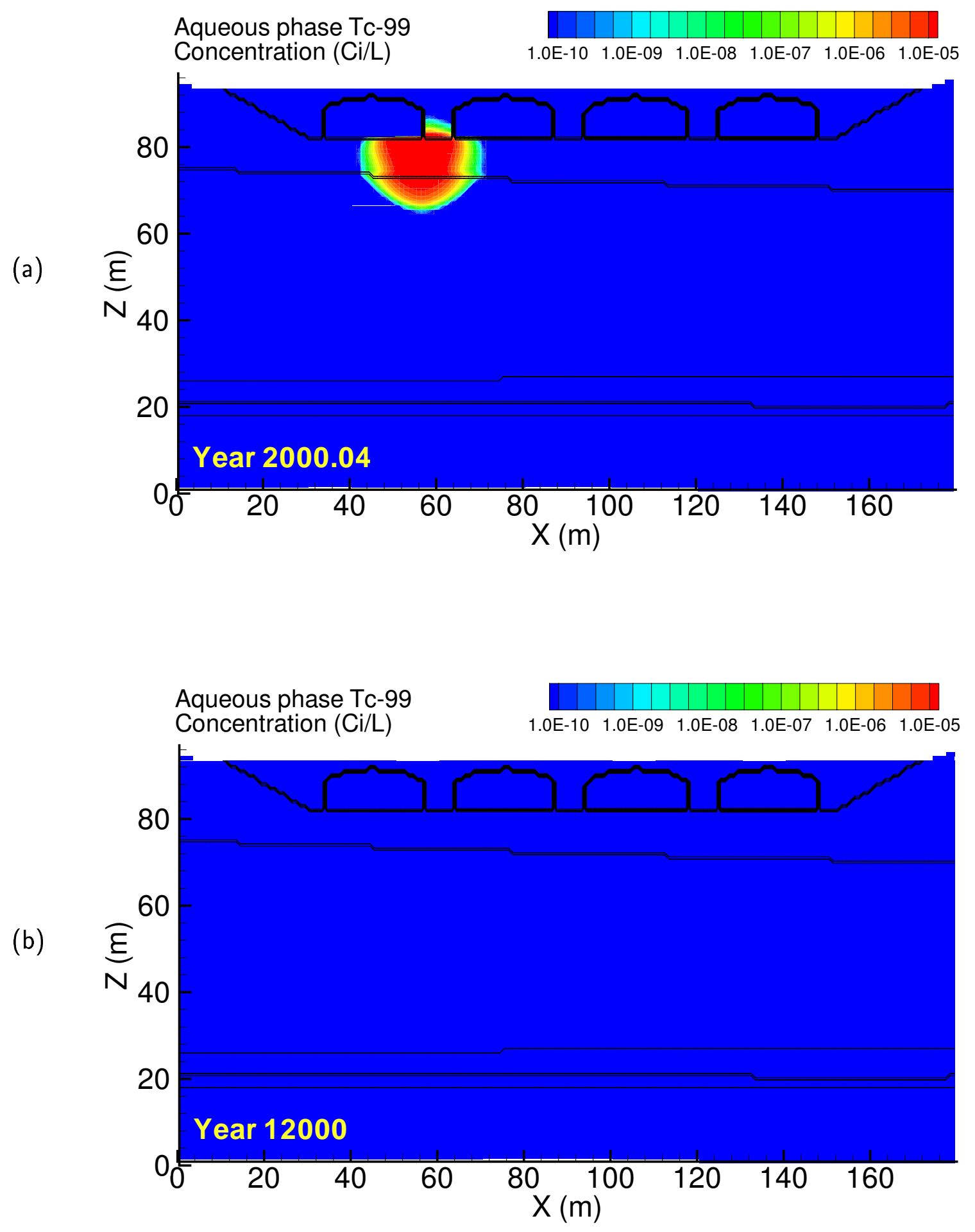

Figure A.14. Case 1-HiK, Tc-99 aqueous concentration at (a) 01/15/2000 and (b) year 12000 

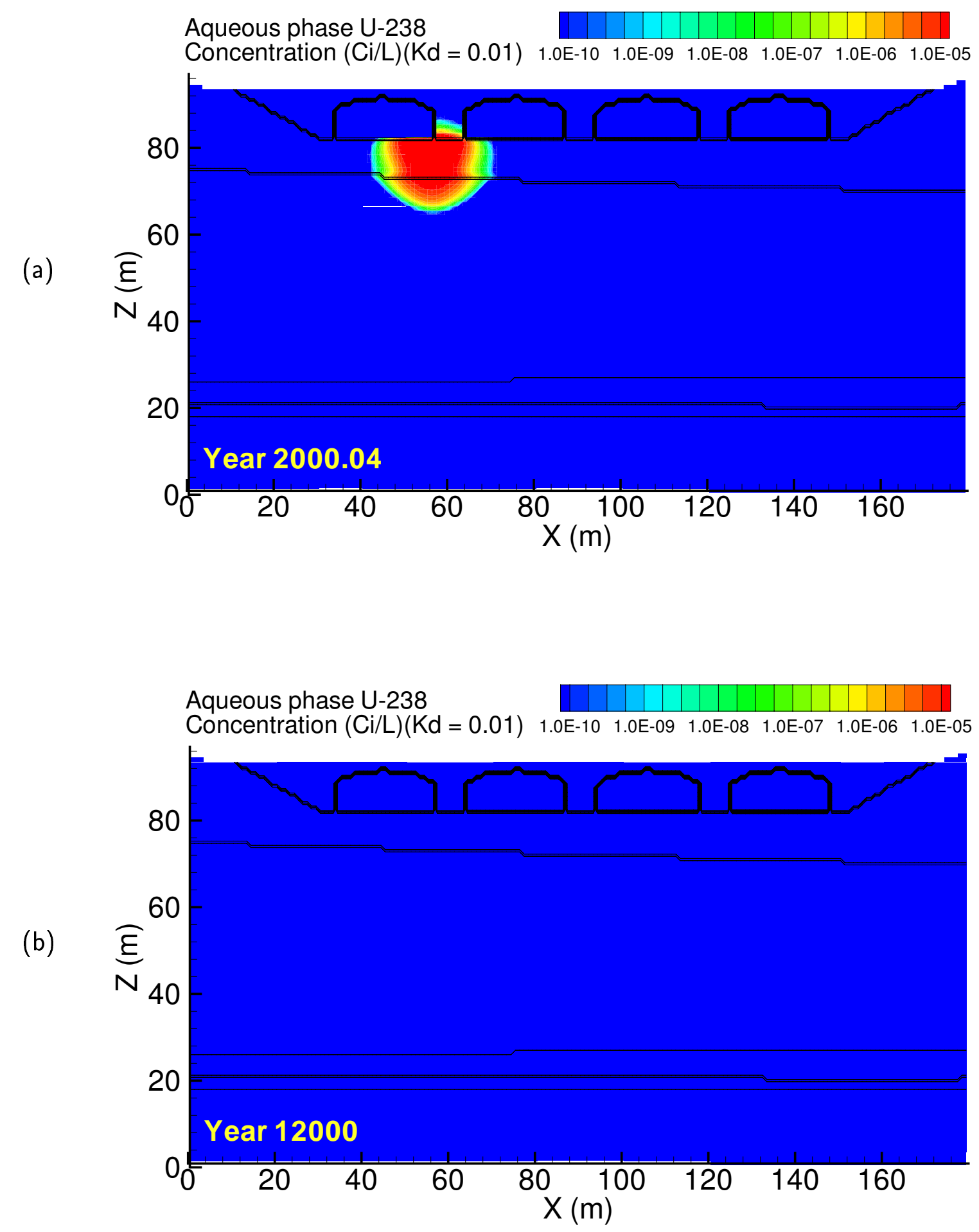

Figure A.15. Case 1-HiK, U-238 ( $\left.\mathrm{K}_{d}=0.01\right)$ aqueous concentration at (a) $01 / 15 / 2000$ and (b) year 12000 

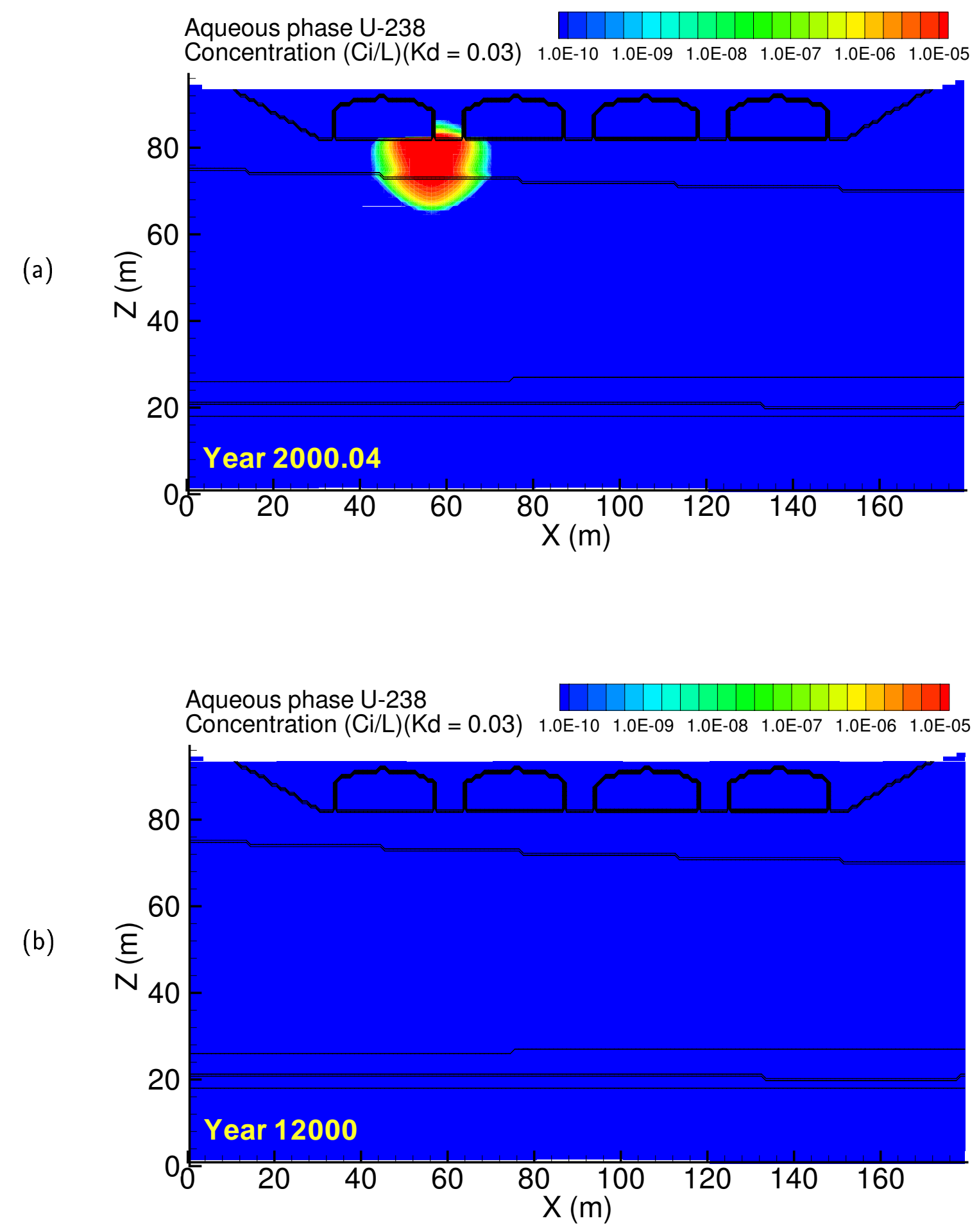

Figure A.16. Case 1-HiK, U-238 ( $\mathrm{K}_{d}=0.03$ ) aqueous concentration at (a) 01/15/2000 and (b) year 12000 

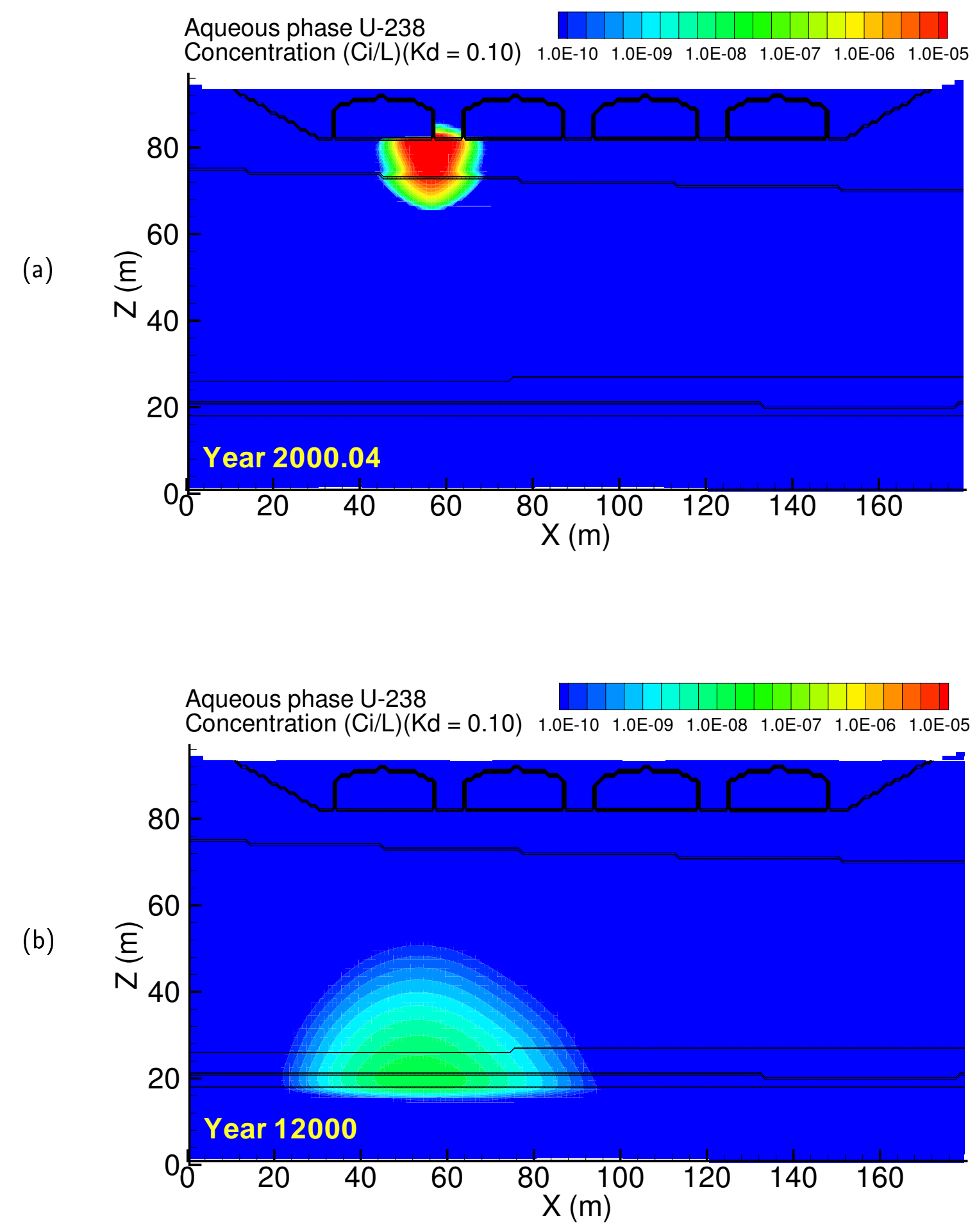

Figure A.17. Case 1-HiK, U-238 ( $\left.\mathrm{K}_{d}=0.10\right)$ aqueous concentration at (a) $01 / 15 / 2000$ and (b) year 12000 

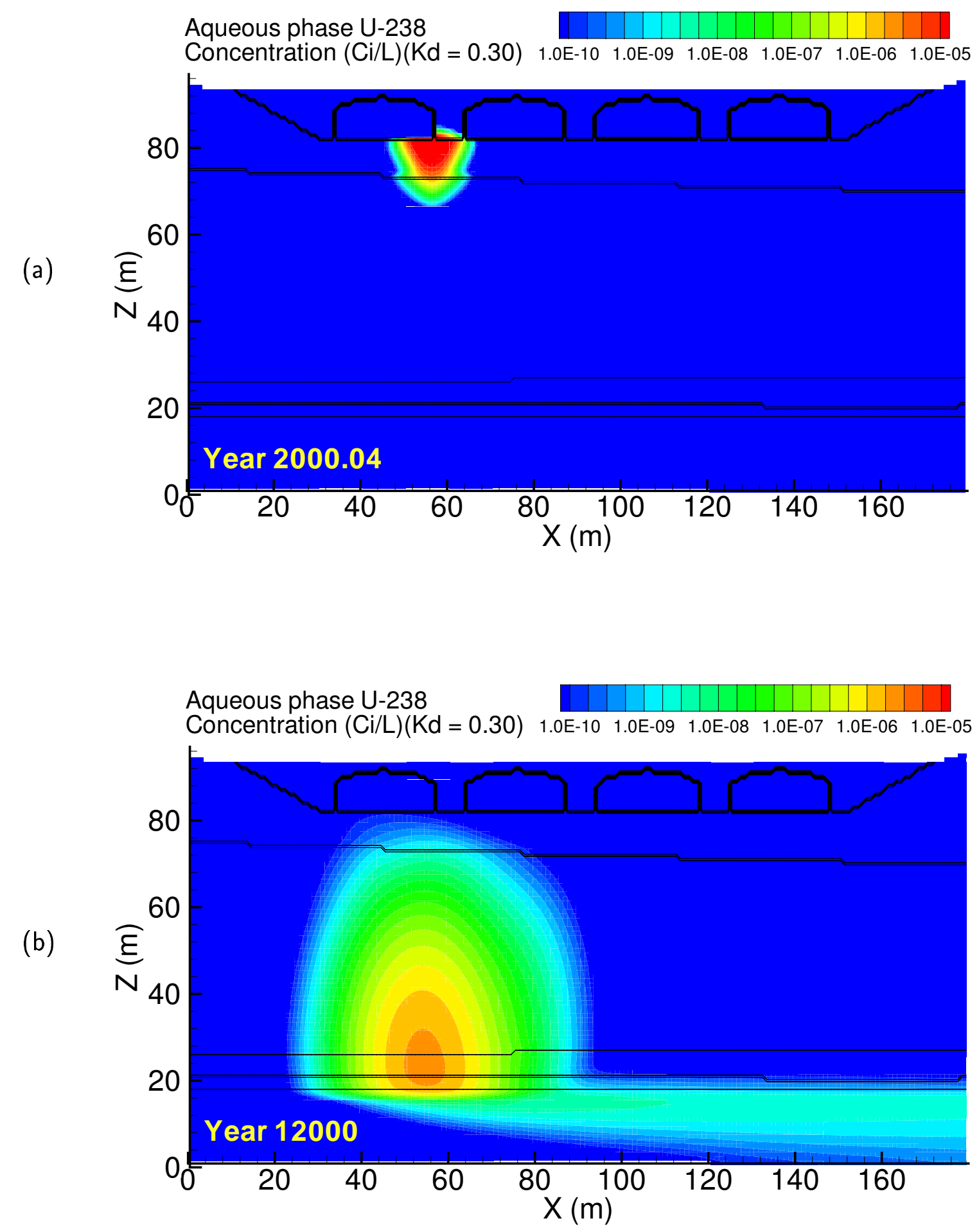

Figure A.18. Case 1-HiK, U-238 ( $\left.\mathrm{K}_{d}=0.30\right)$ aqueous concentration at (a) $01 / 15 / 2000$ and (b) year 12000 

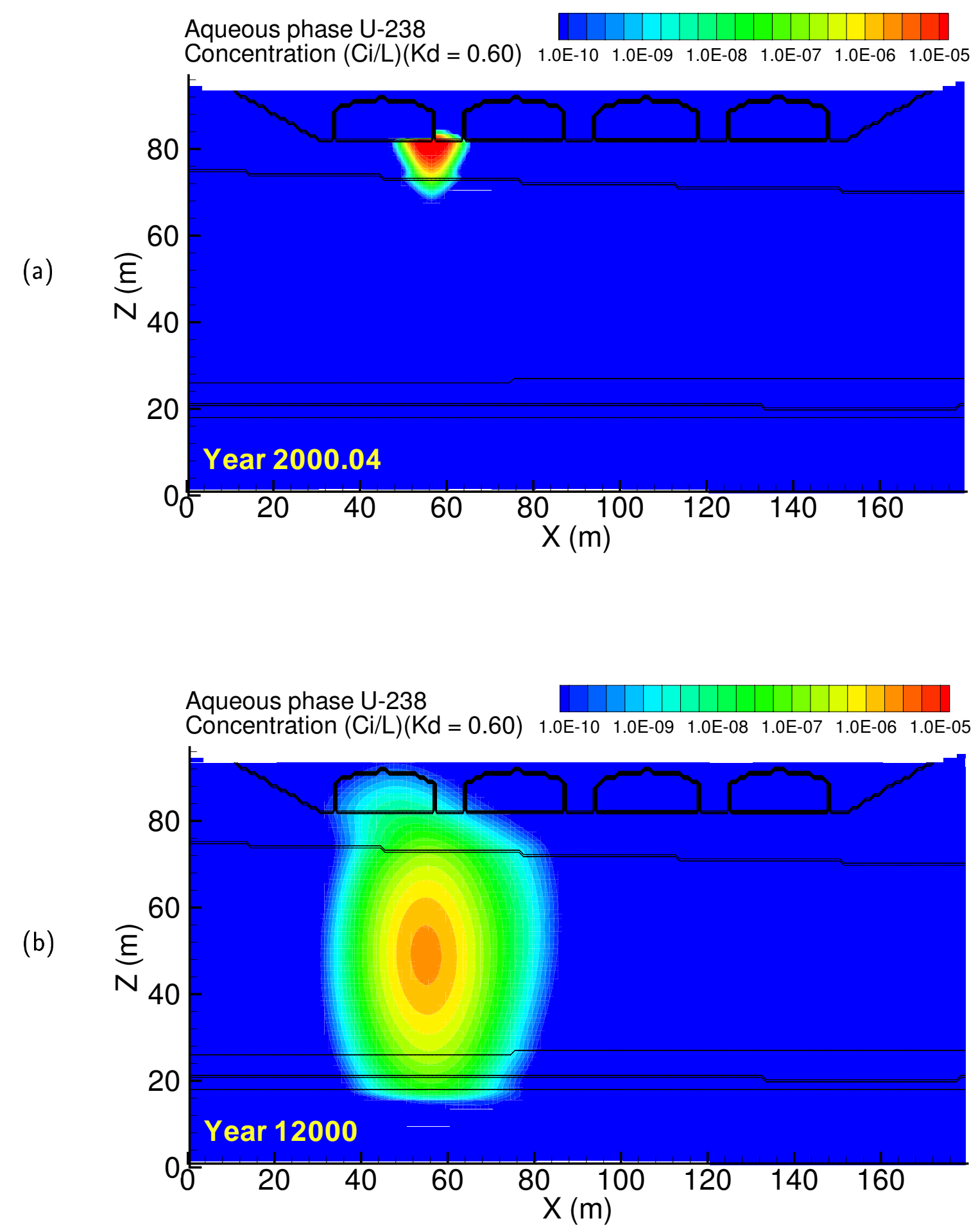

Figure A.19. Case 1-HiK, U-238 $\left(\mathrm{K}_{d}=0.60\right)$ aqueous concentration at (a) $01 / 15 / 2000$ and (b) year 12000 

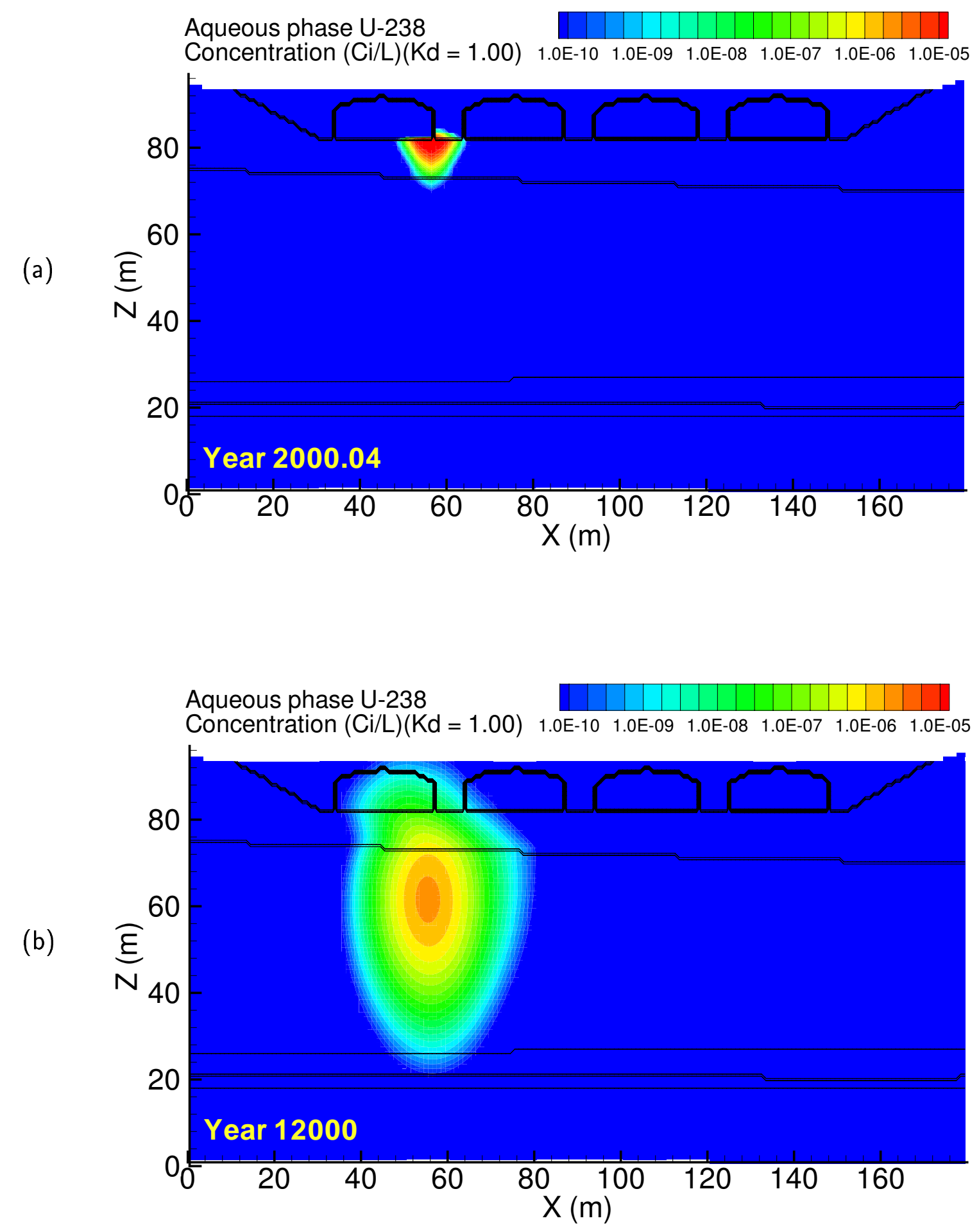

Figure A.20. Case 1-HiK, U-238 ( $\left.\mathrm{K}_{d}=1.00\right)$ aqueous concentration at (a) $01 / 15 / 2000$ and (b) year 12000 

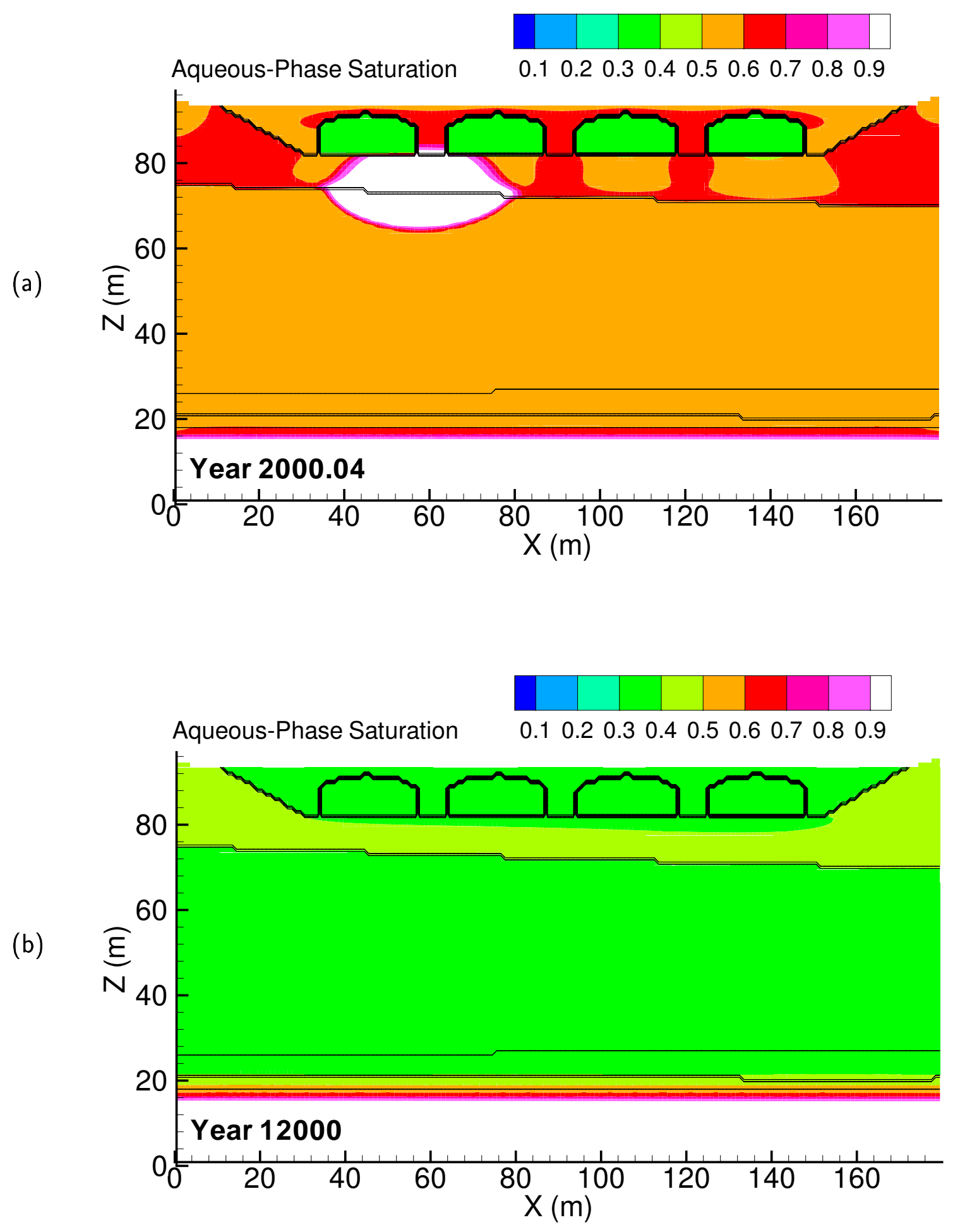

Figure A.21. Case 2, Aqueous saturation at (a) 01/15/2000 and (b) year 12000 

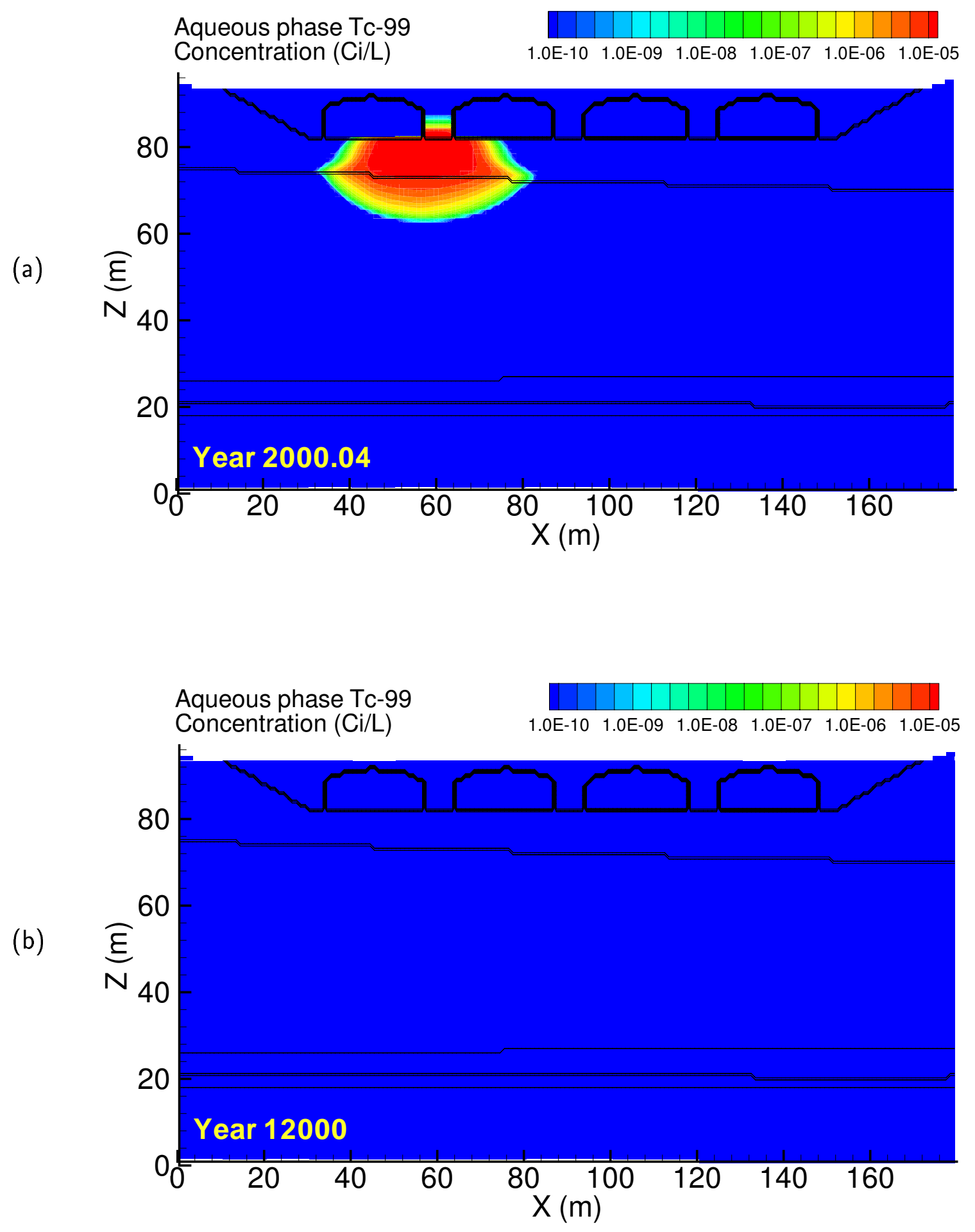

Figure A.22. Case 2, Tc-99 aqueous concentration at (a) 01/15/2000 and (b) year 12000 

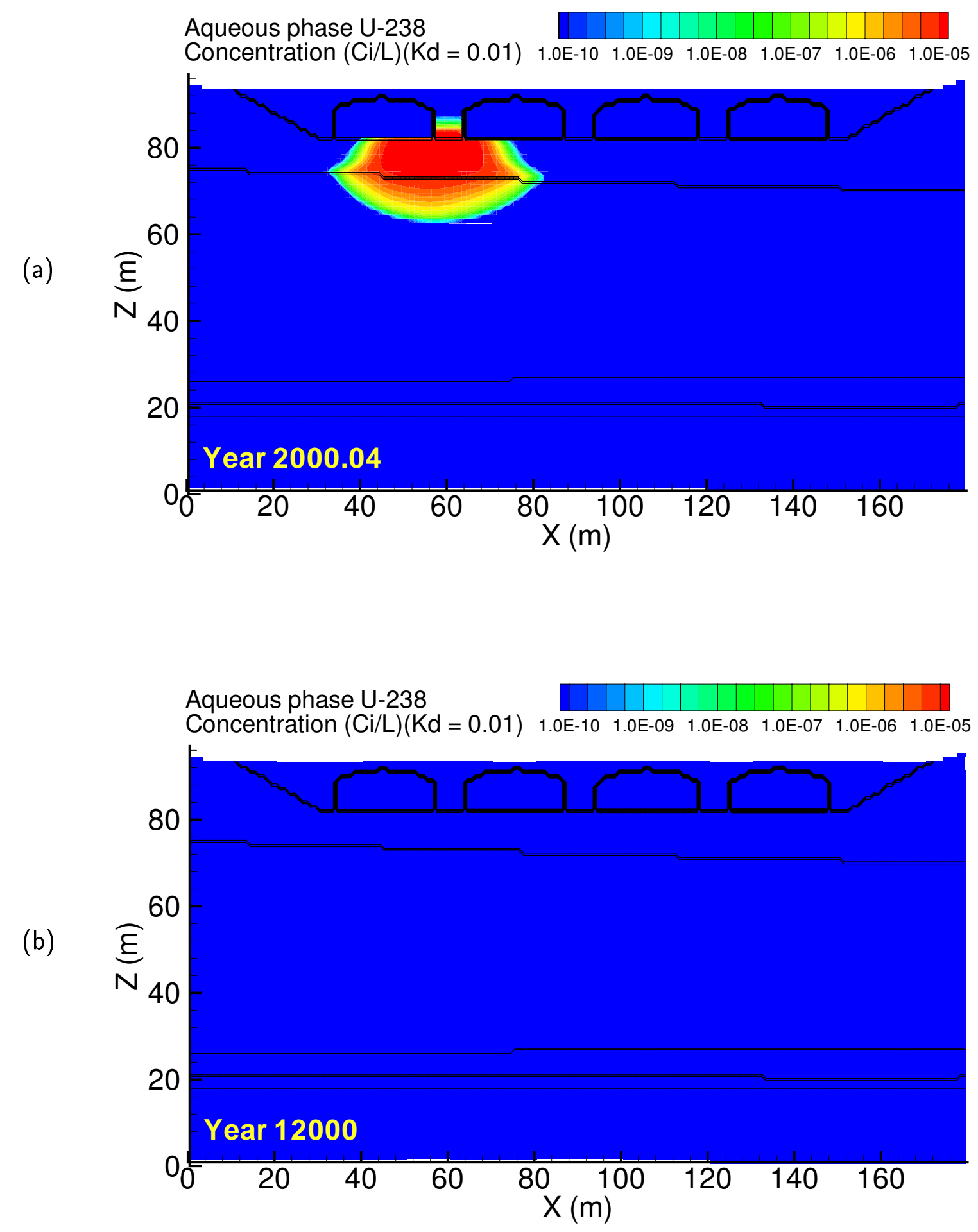

Figure A.23. Case 2, U-238 $\left(\mathrm{K}_{d}=0.01\right)$ aqueous concentration at (a) $01 / 15 / 2000$ and (b) year 12000 

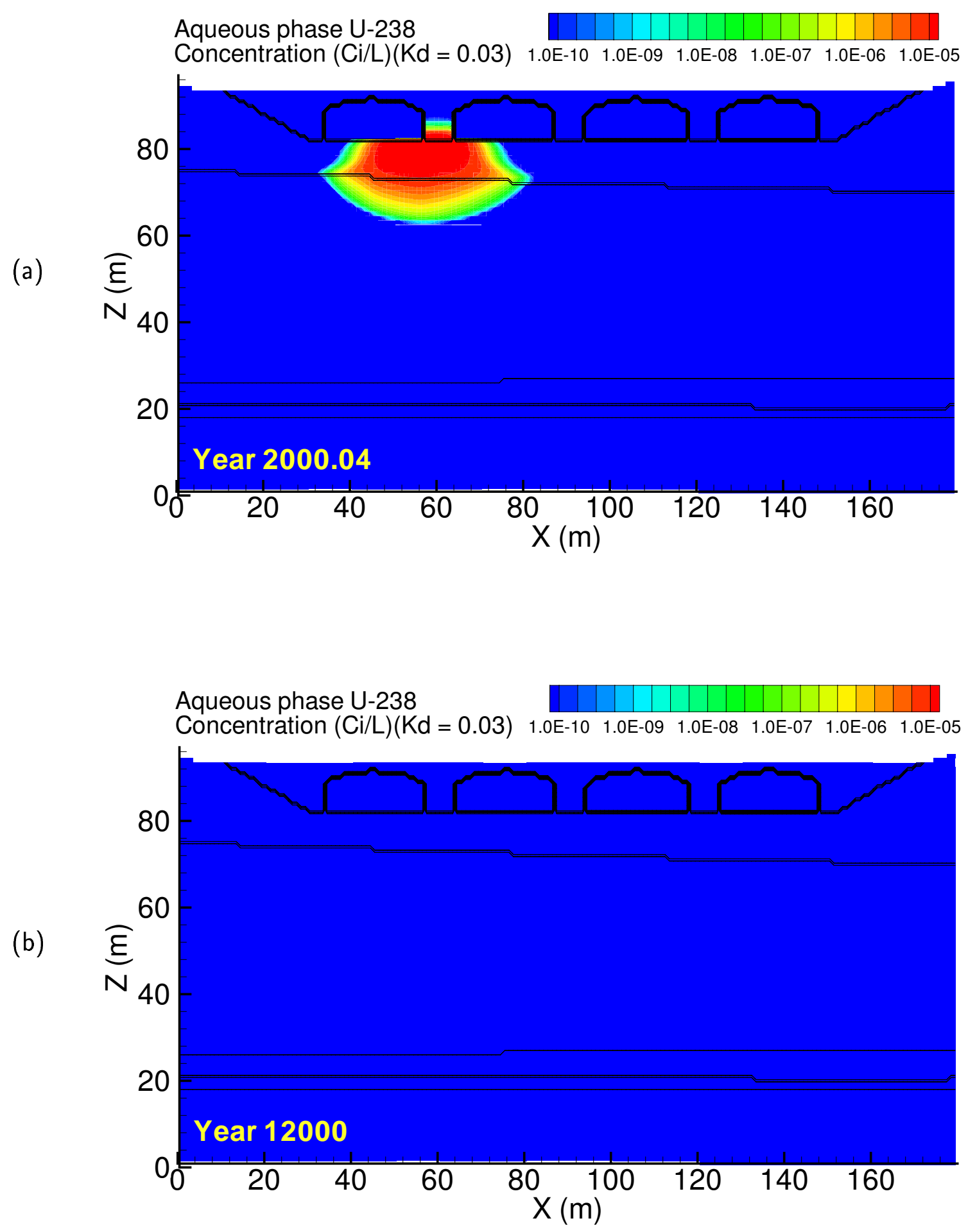

Figure A.24. Case 2, U-238 $\left(\mathrm{K}_{d}=0.03\right)$ aqueous concentration at (a) $01 / 15 / 2000$ and (b) year 12000 

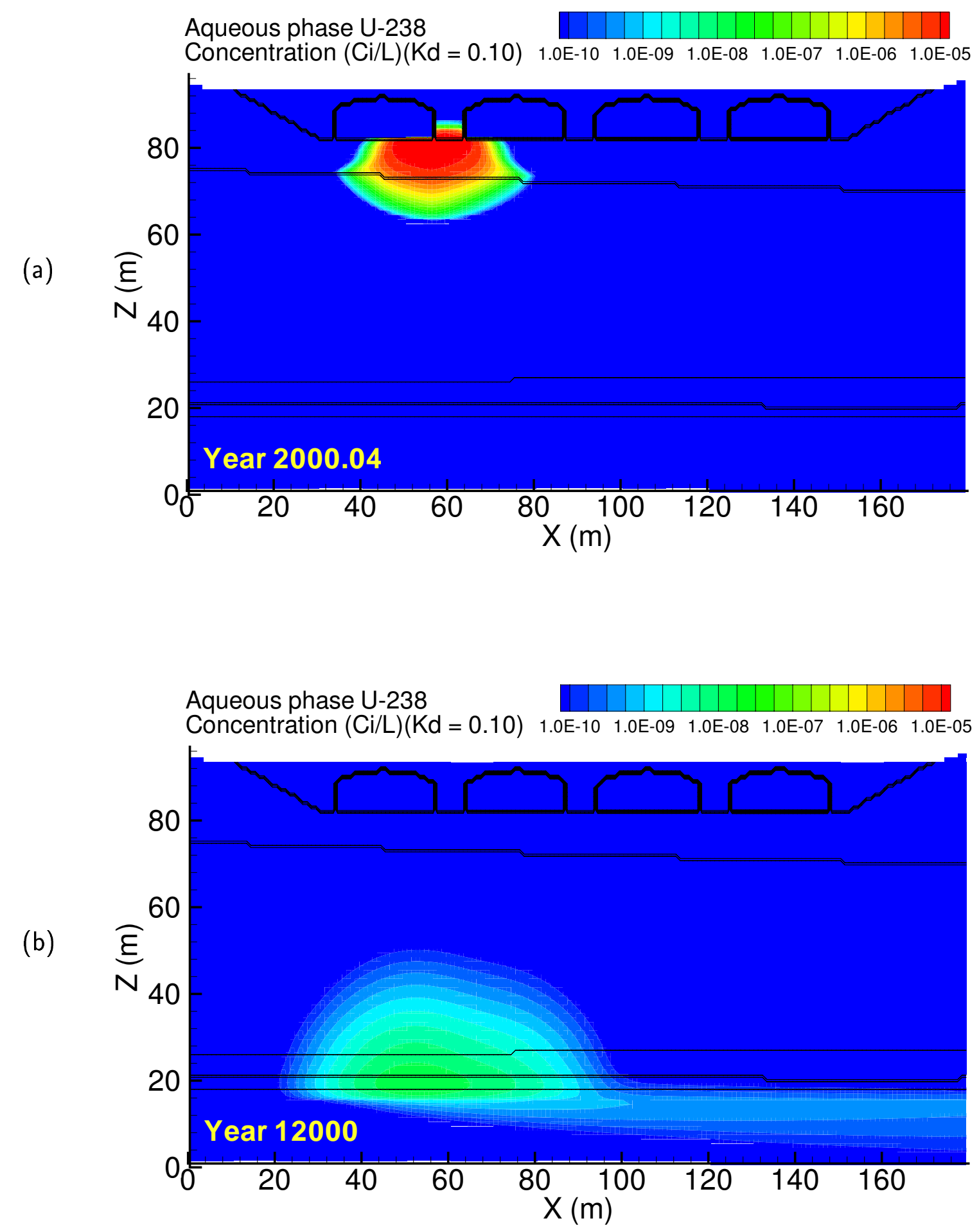

Figure A.25. Case 2, U-238 ( $\left.\mathrm{K}_{d}=0.10\right)$ aqueous concentration at (a) $01 / 15 / 2000$ and (b) year 12000 

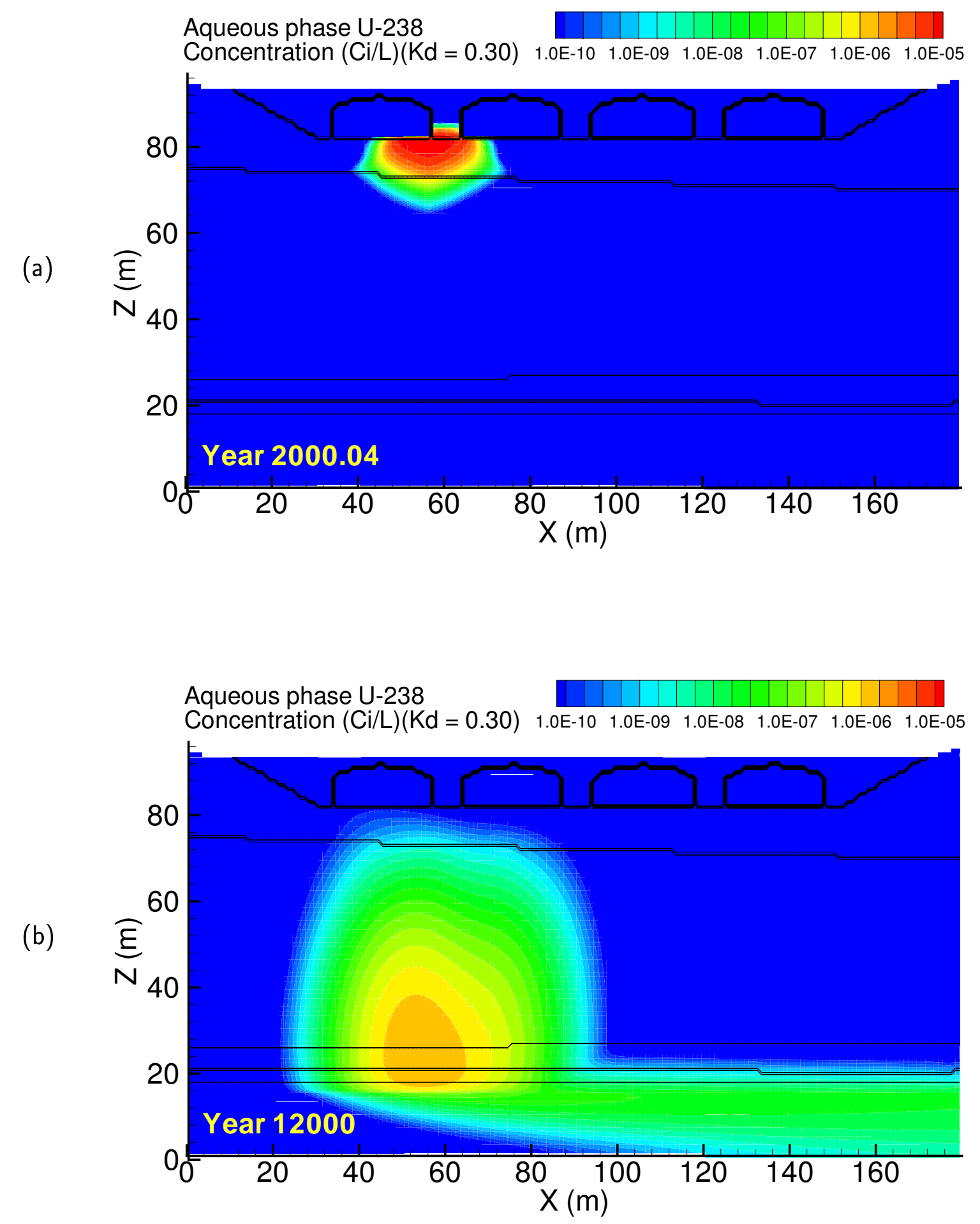

Figure A.26. Case 2, U-238 $\left(\mathrm{K}_{d}=0.30\right)$ aqueous concentration at (a) $01 / 15 / 2000$ and (b) year 12000 

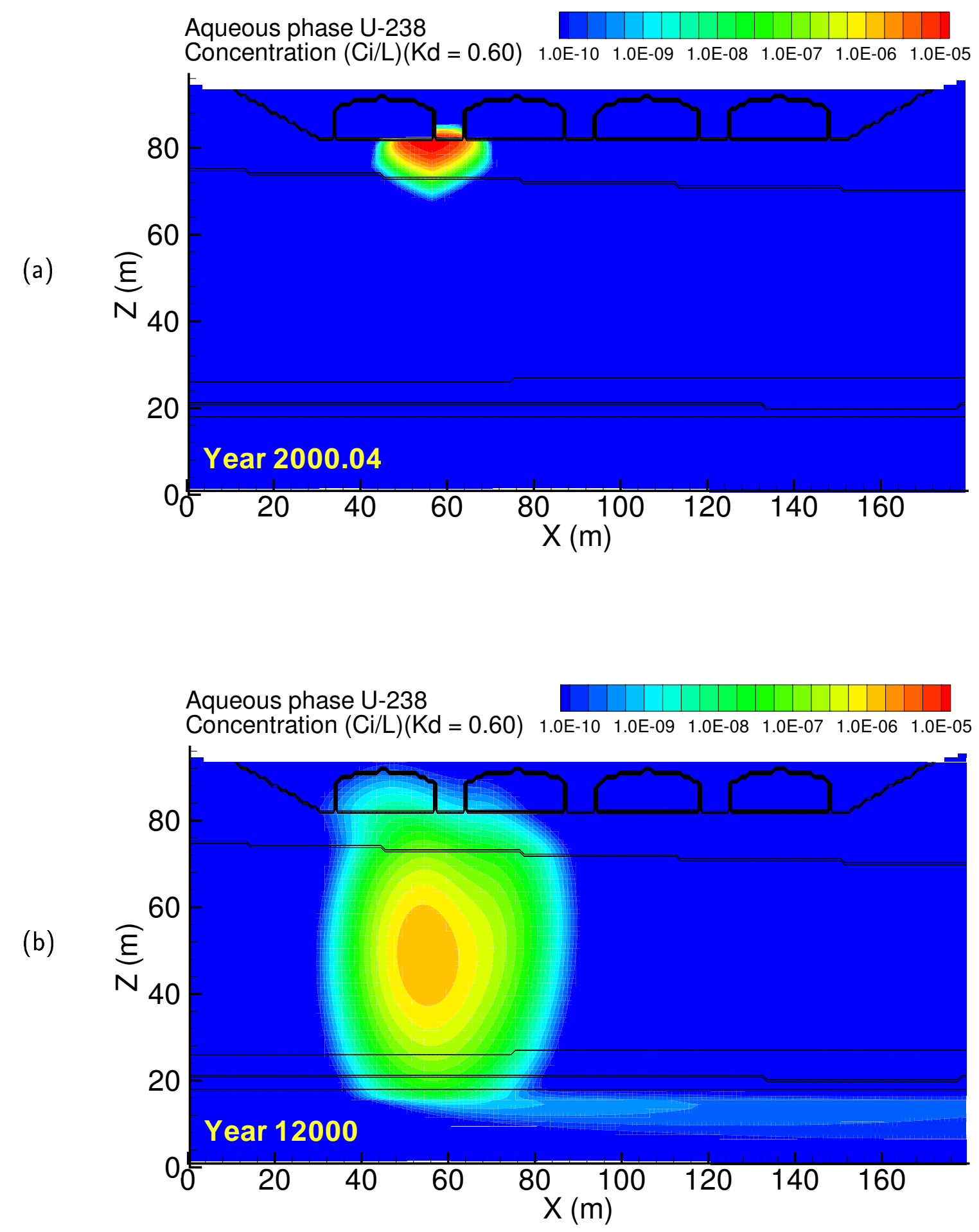

Figure A.27. Case 2, U-238 $\left(\mathrm{K}_{d}=0.60\right)$ aqueous concentration at (a) $01 / 15 / 2000$ and (b) year 12000 

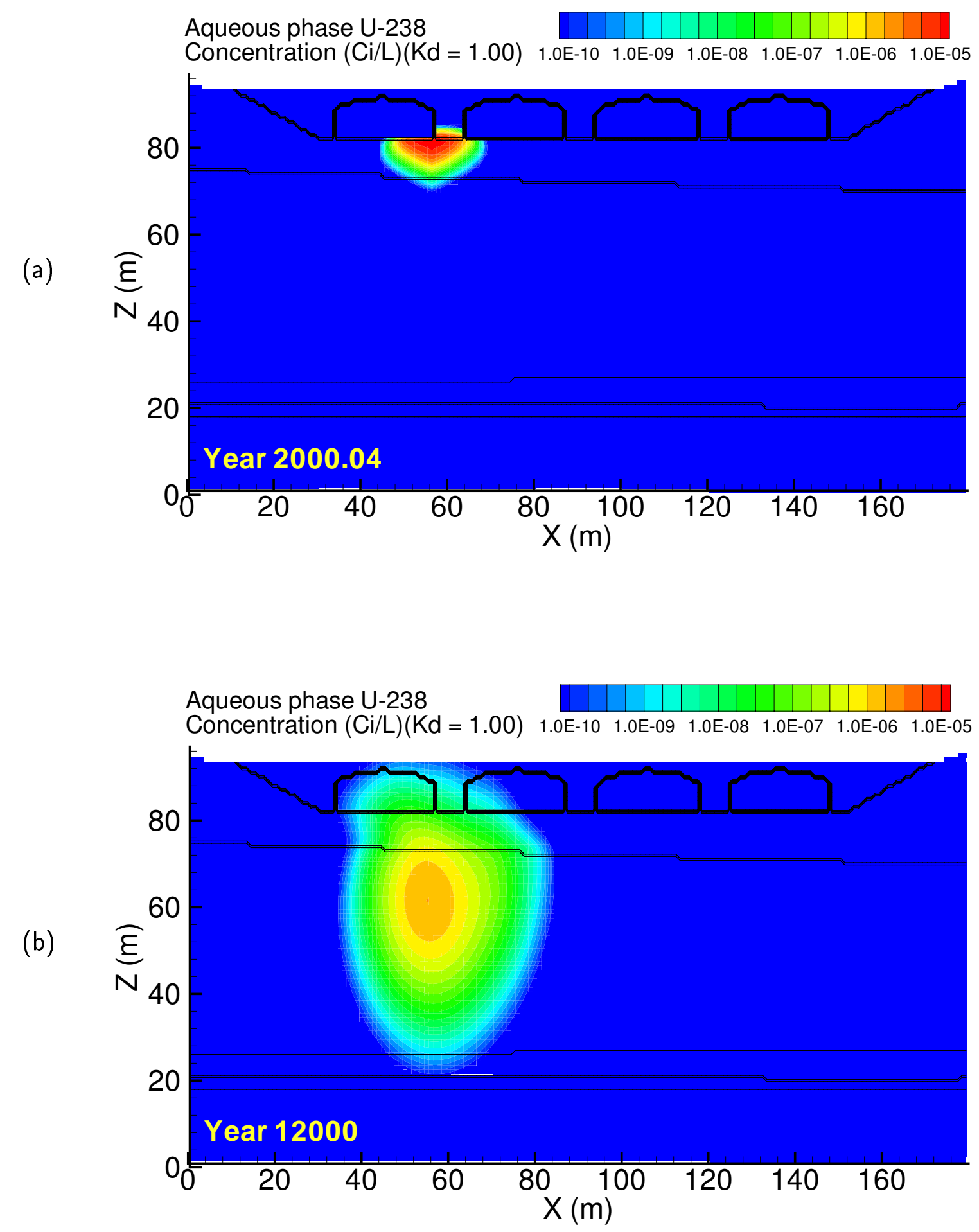

Figure A.28. Case 2, U-238 $\left(\mathrm{K}_{d}=1.00\right)$ aqueous concentration at (a) $01 / 15 / 2000$ and (b) year 12000 

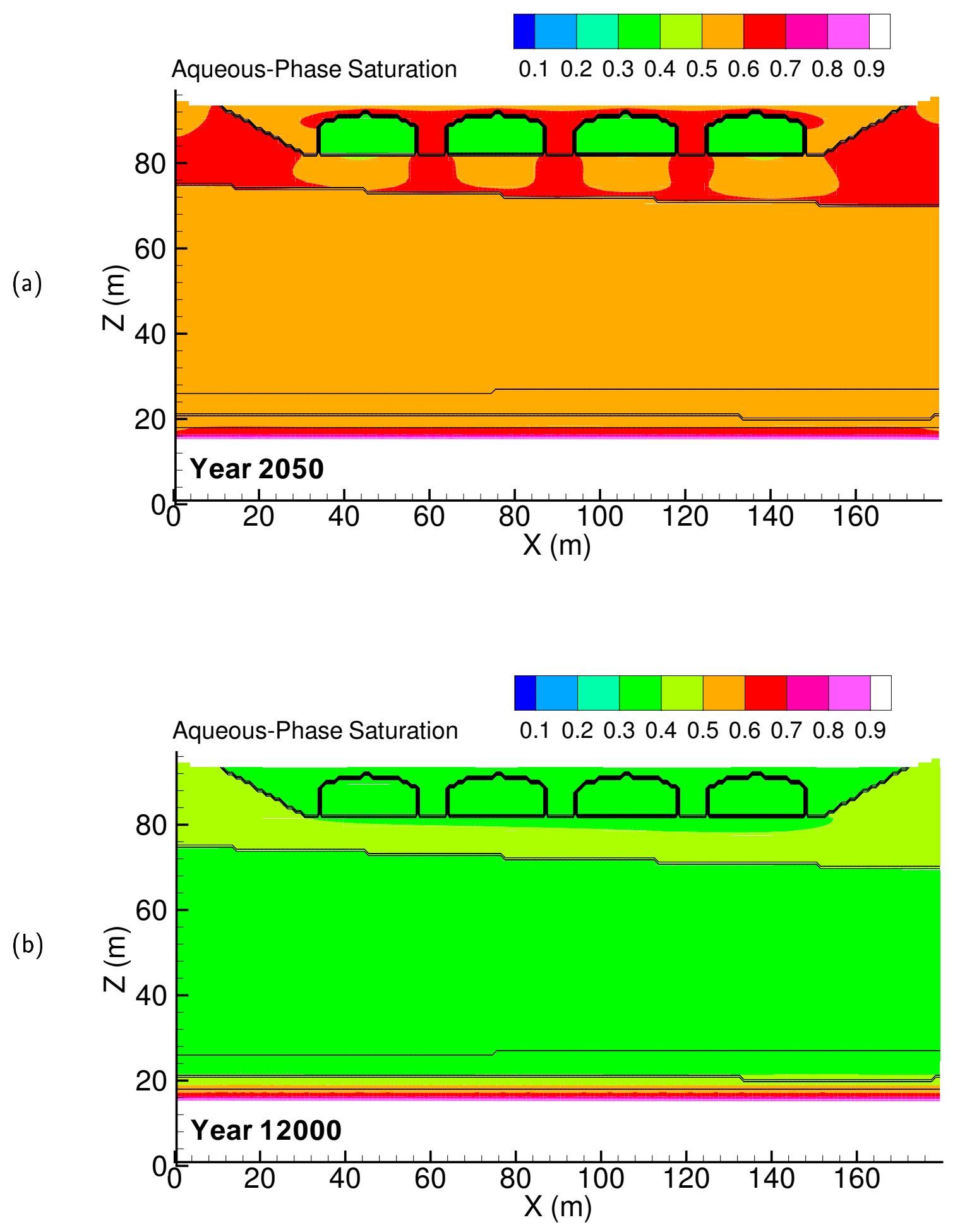

Figure A.29. Case 3, Aqueous saturation at (a) 2050 and (b) year 12000 

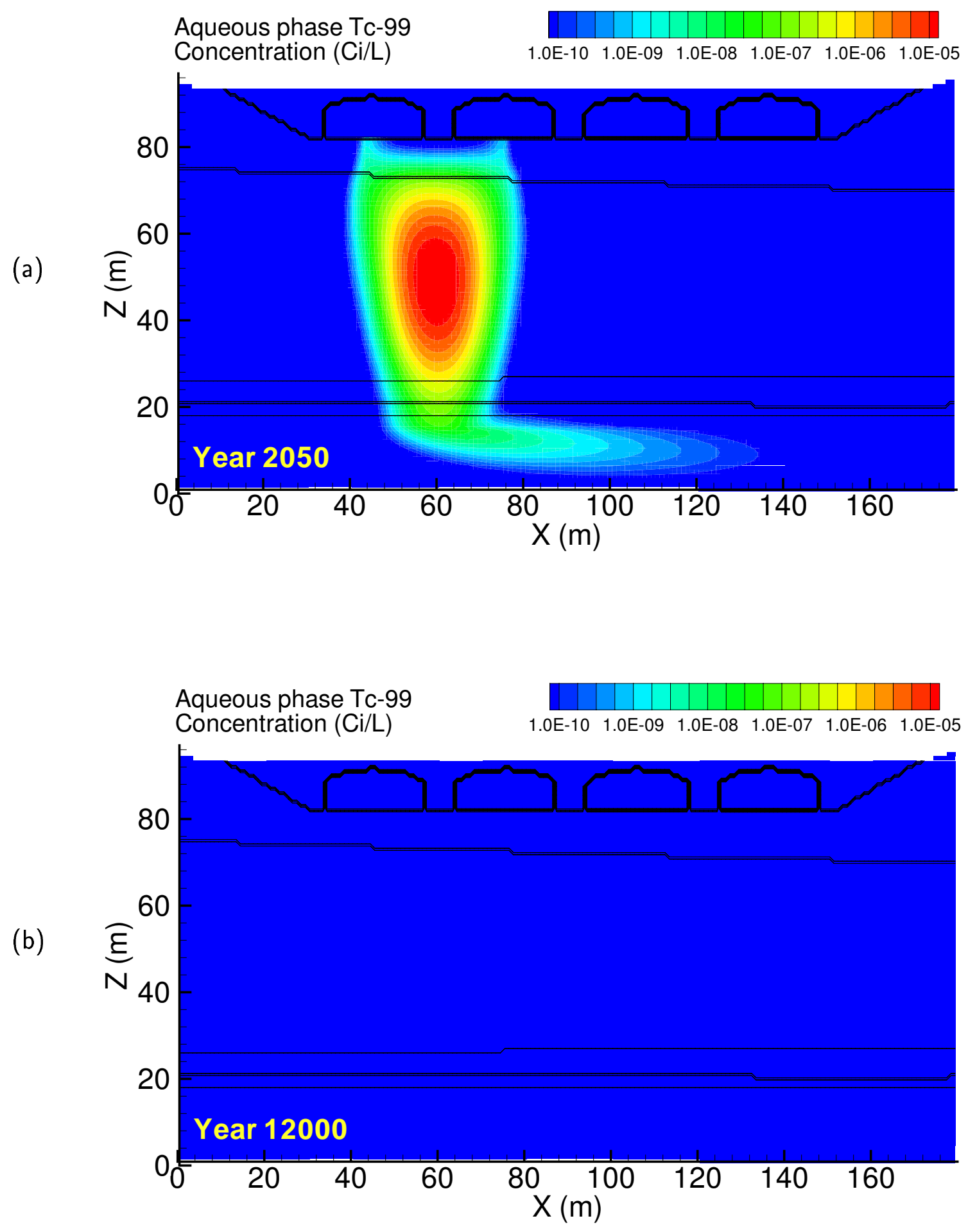

Figure A.30. Case 3, Tc-99 aqueous concentration at (a) 2050 and (b) year 12000 

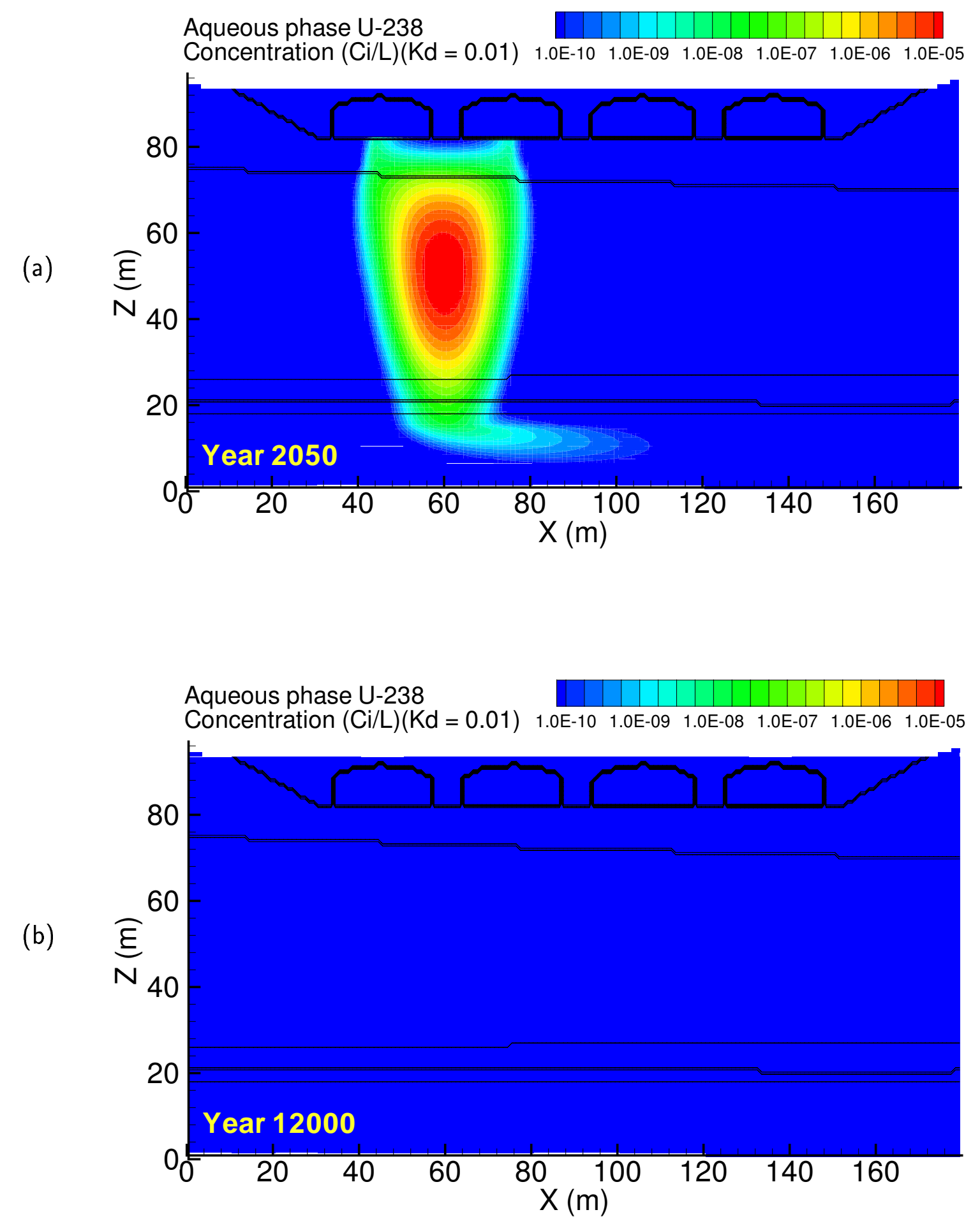

Figure A.31. Case 3, U-238 $\left(\mathrm{K}_{d}=0.01\right)$ aqueous concentration at (a) 2050 and (b) year 12000 

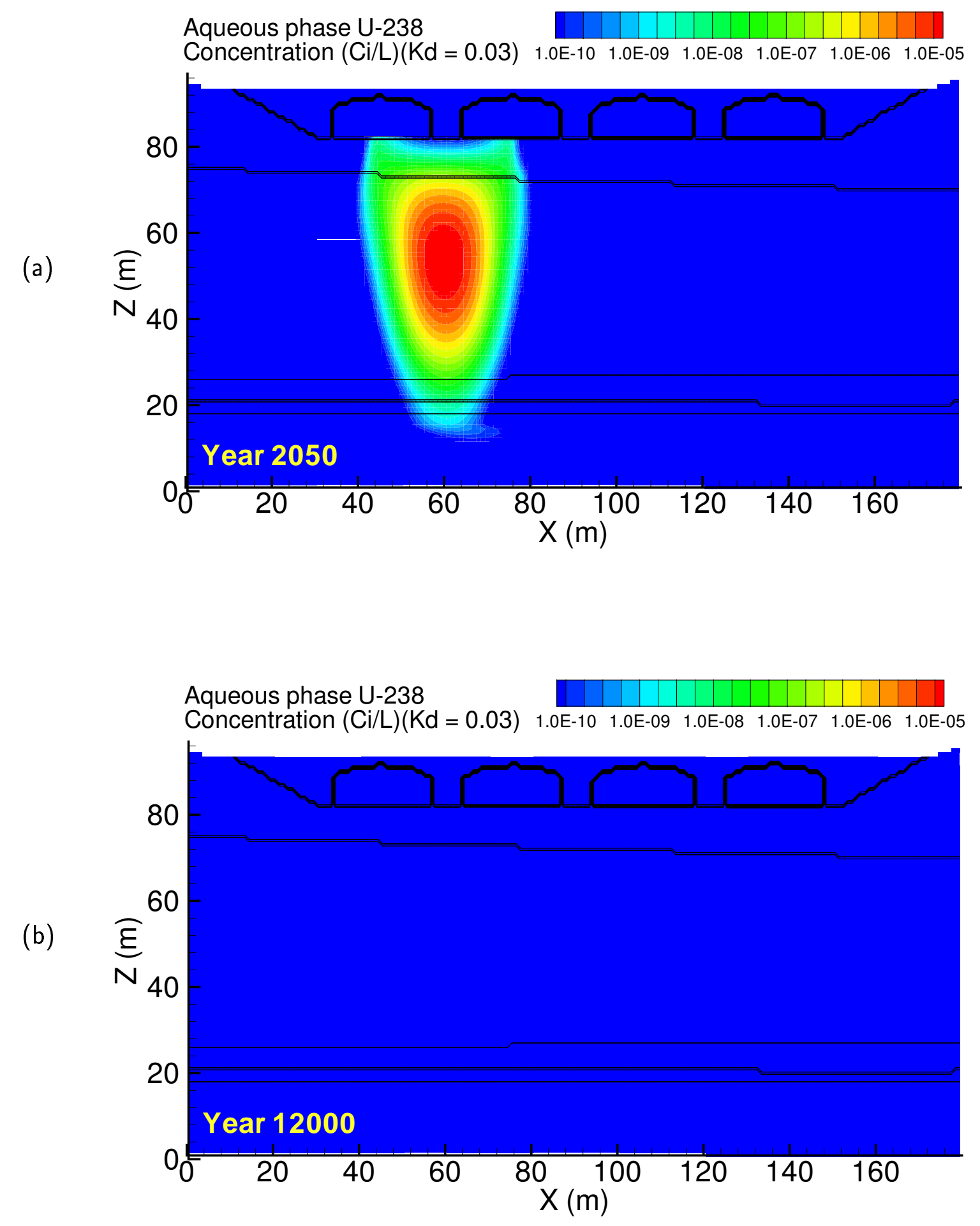

Figure A.32. Case 3, U-238 $\left(\mathrm{K}_{d}=0.03\right)$ aqueous concentration at (a) 2050 and (b) year 12000 

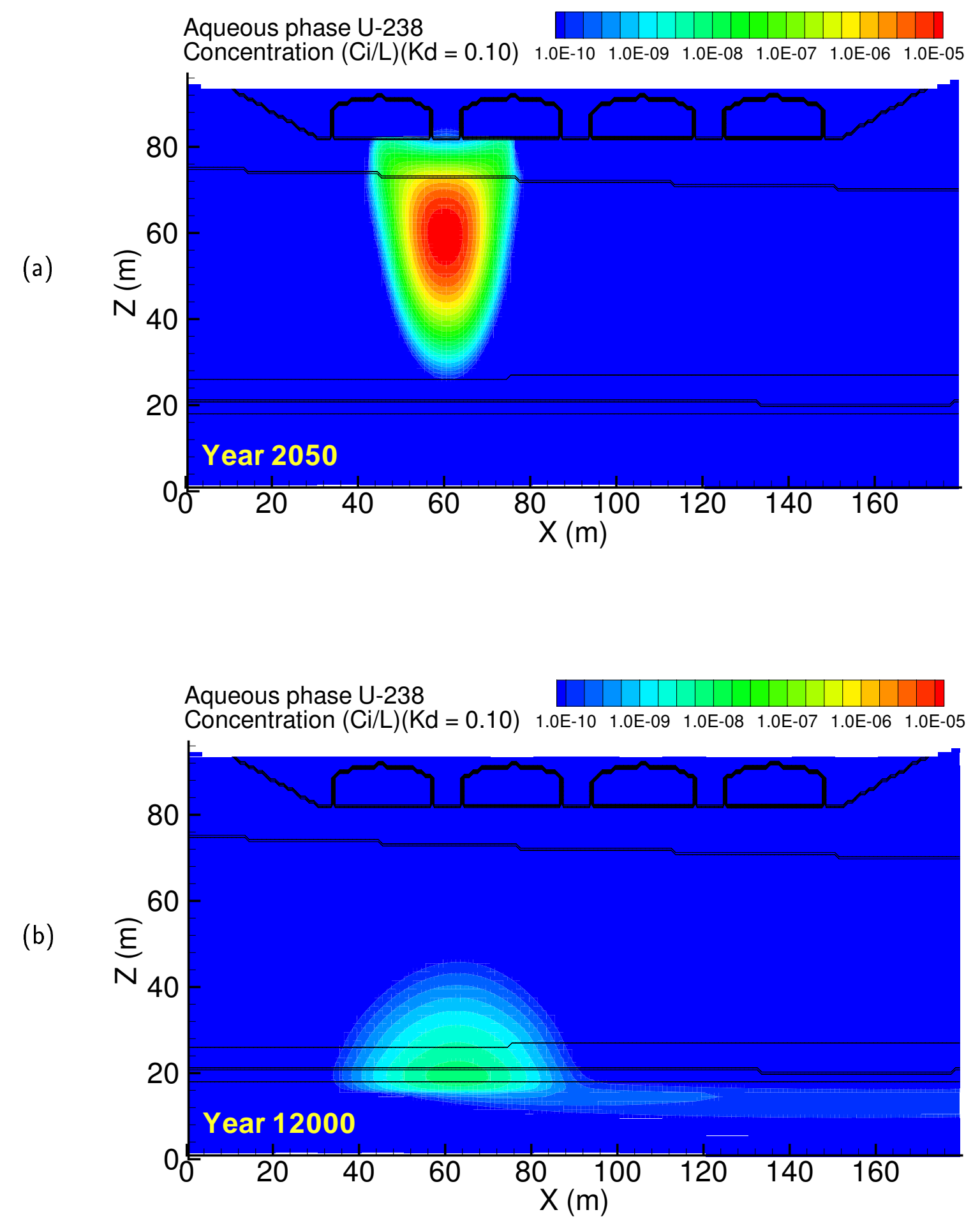

Figure A.33. Case 3, U-238 $\left(\mathrm{K}_{d}=0.10\right)$ aqueous concentration at (a) 2050 and (b) year 12000 

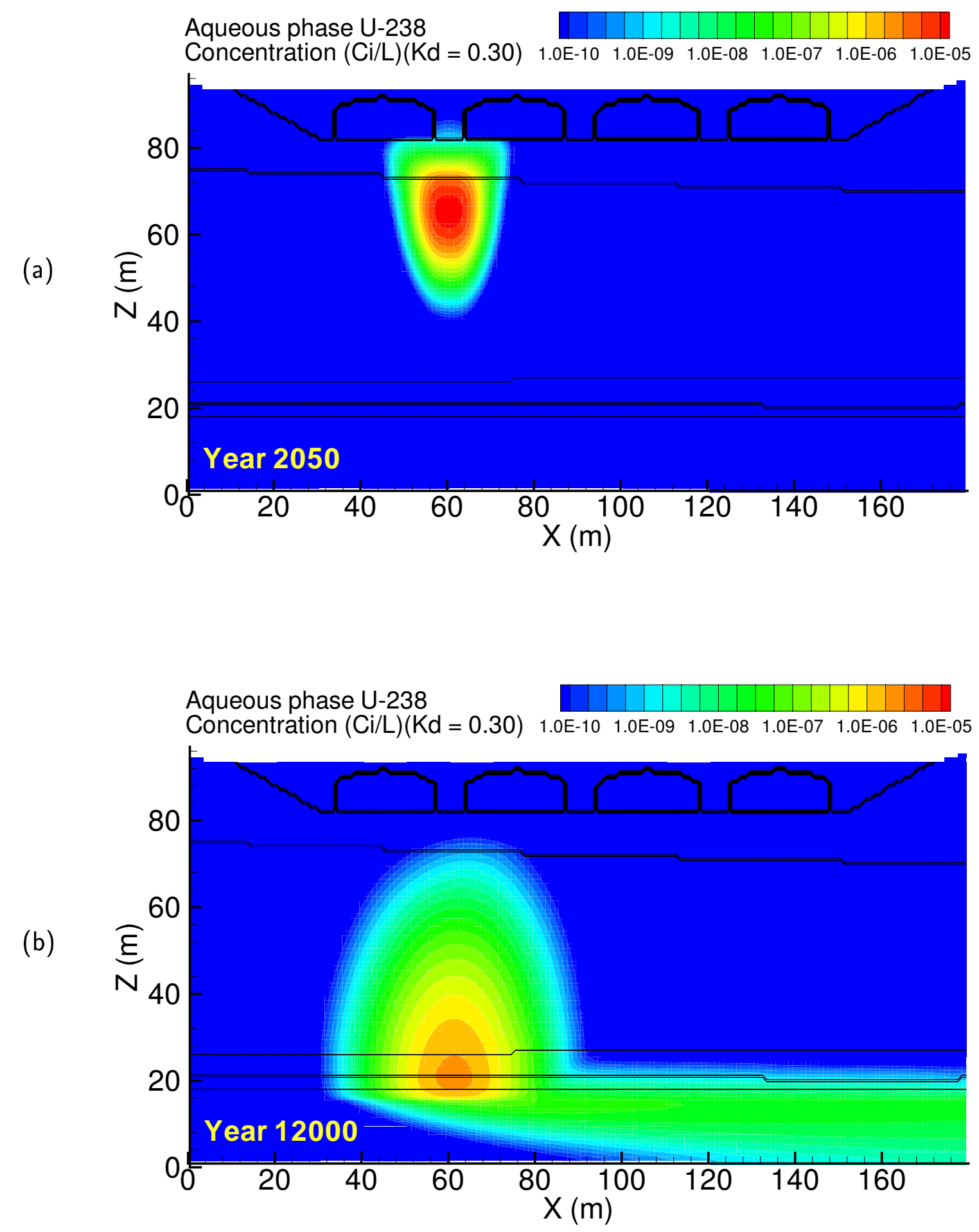

Figure A.34. Case 3, U-238 $\left(\mathrm{K}_{d}=0.30\right)$ aqueous concentration at (a) 2050 and (b) year 12000 

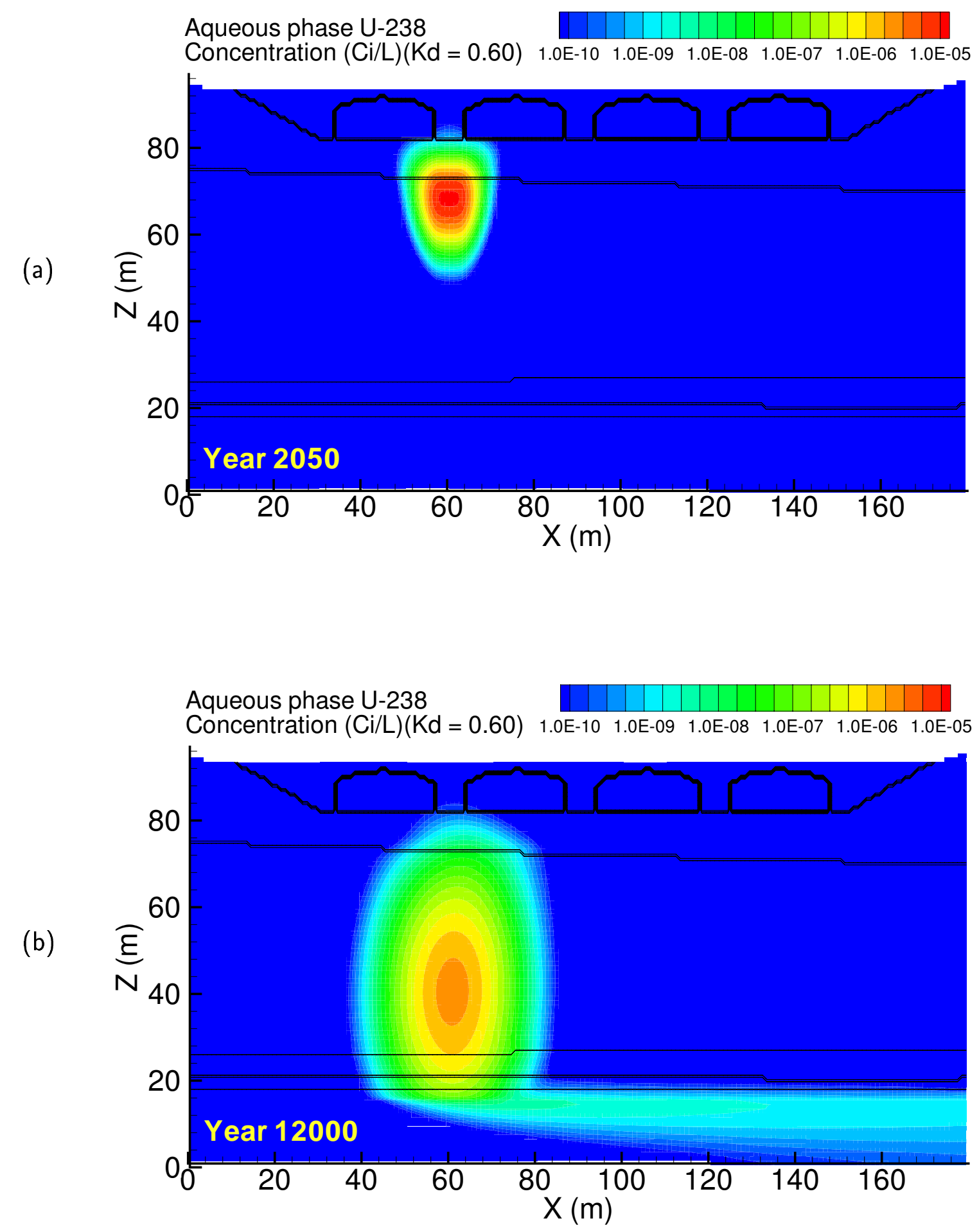

Figure A.35. Case 3, U-238 $\left(\mathrm{K}_{d}=0.60\right)$ aqueous concentration at (a) 2050 and (b) year 12000 

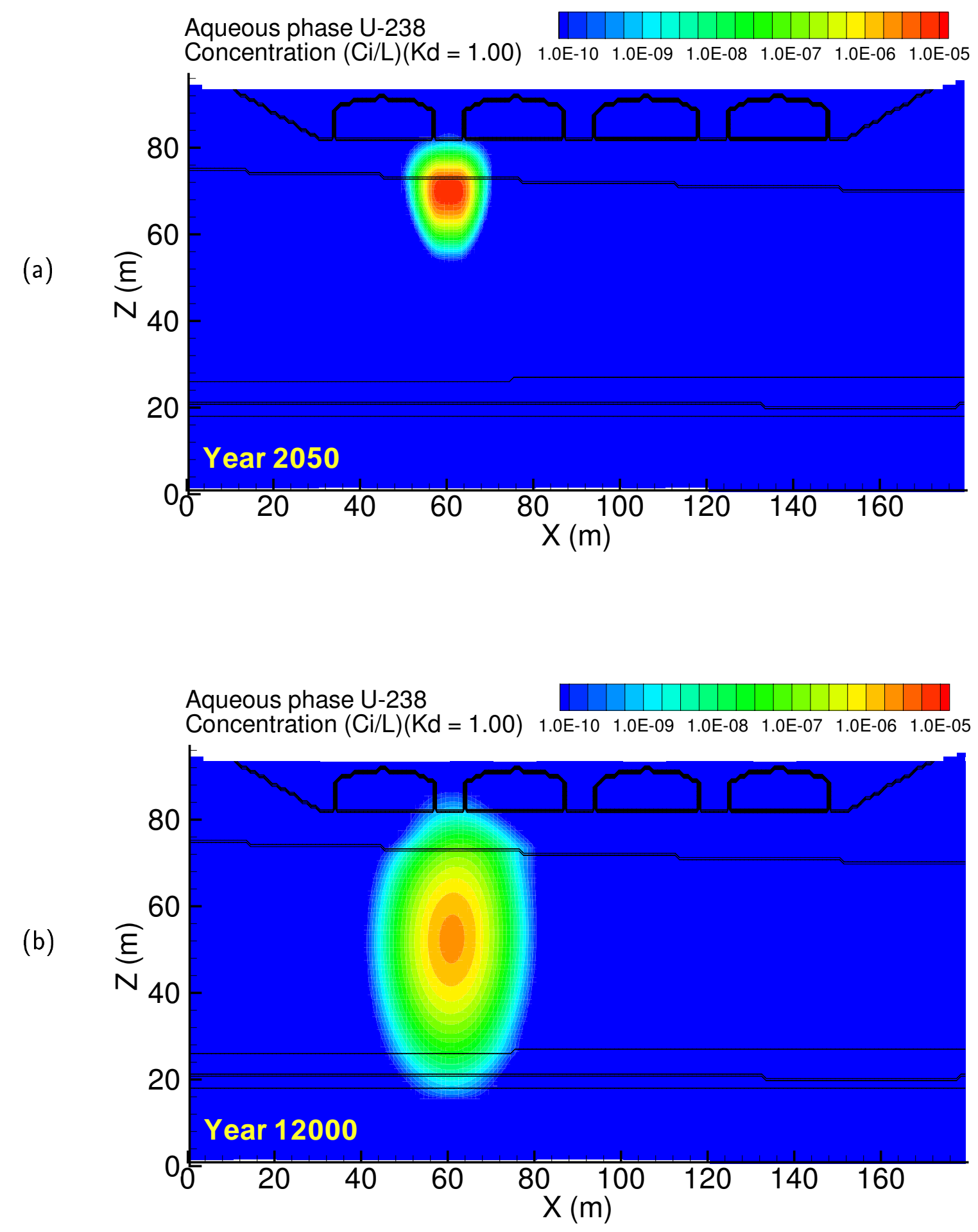

Figure A.36. Case 3, U-238 $\left(\mathrm{K}_{d}=1.00\right)$ aqueous concentration at (a) 2050 and (b) year 12000 

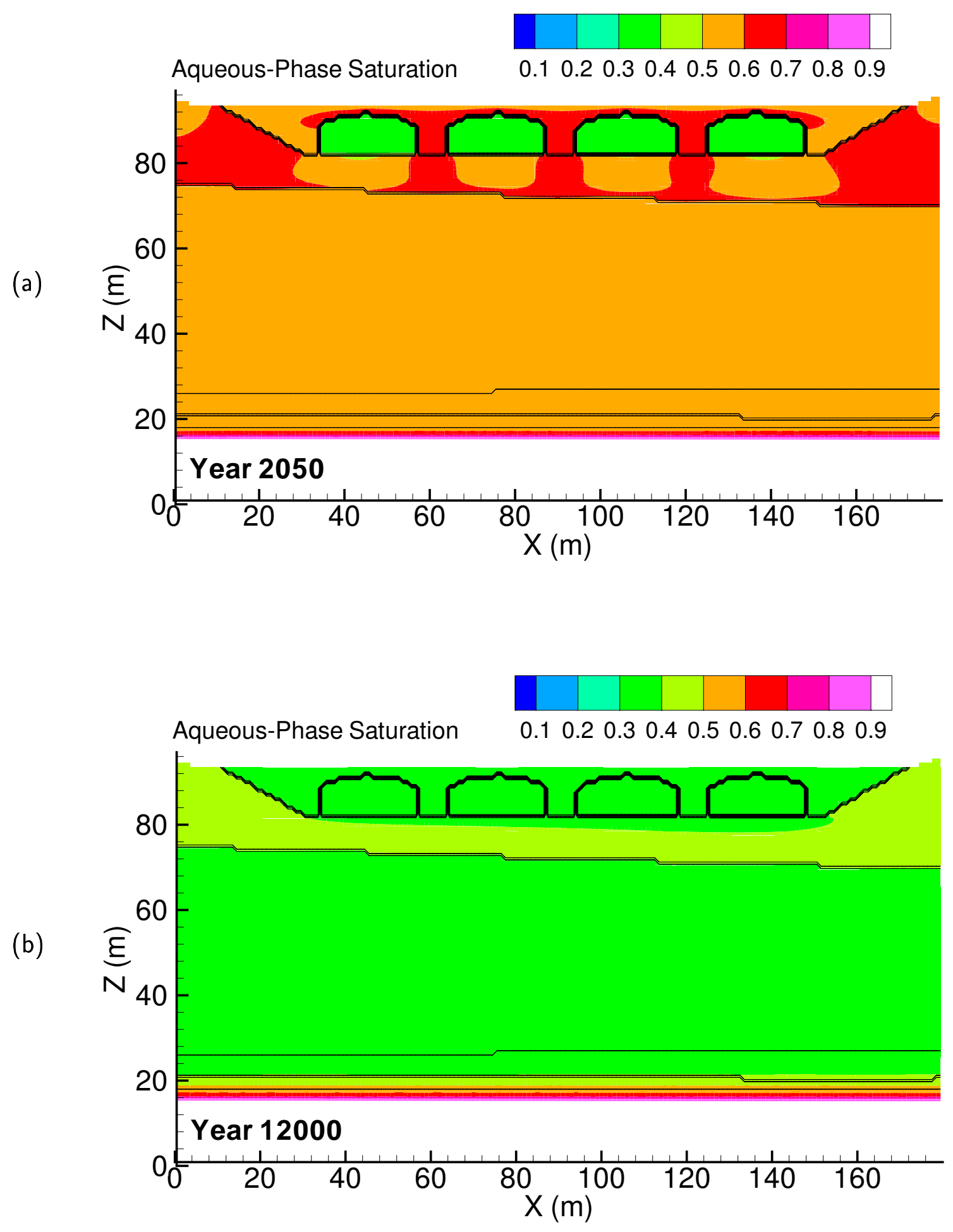

Figure A.37. Case 3-HiK, Aqueous saturation at (a) 2050 and (b) year 12000 

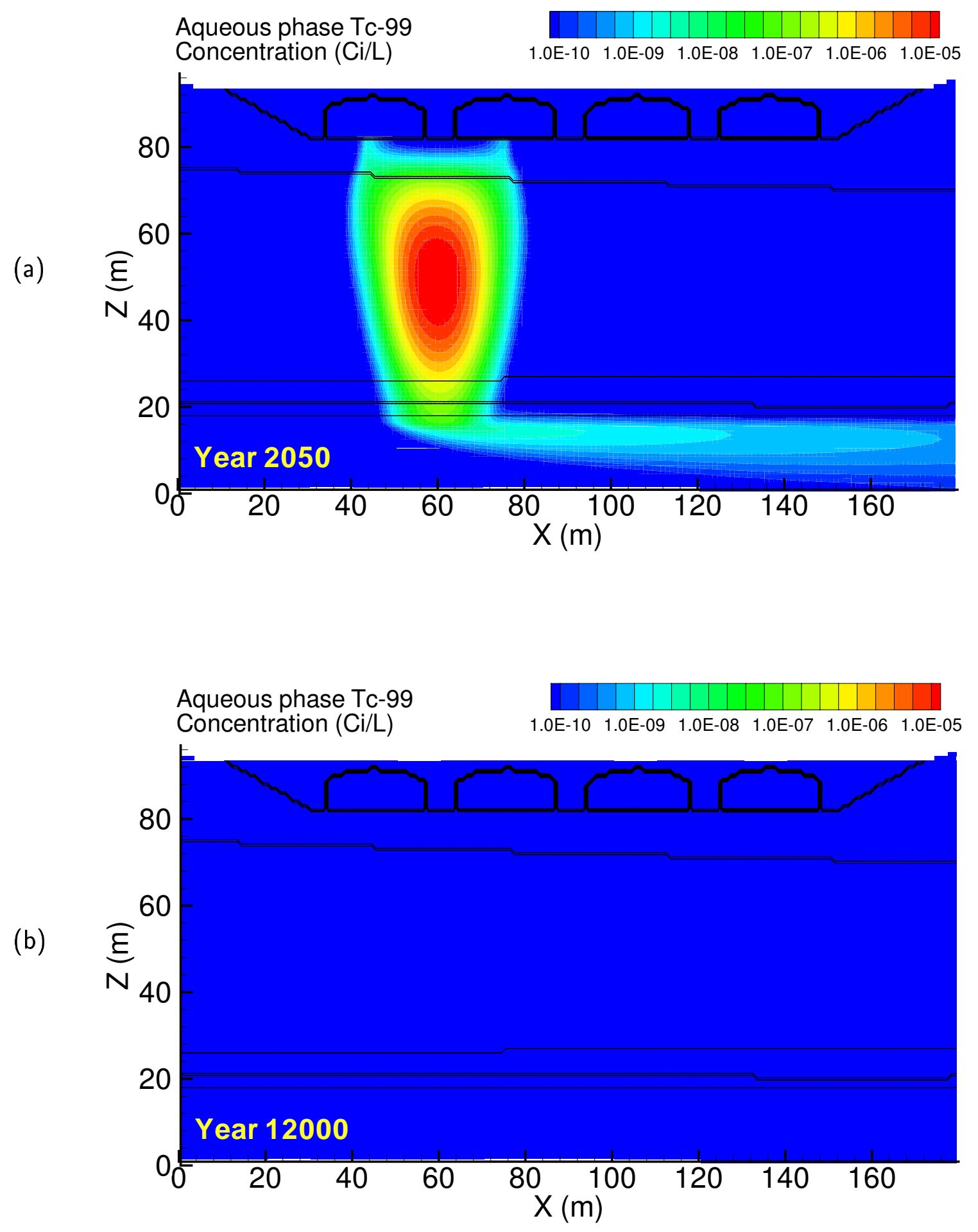

Figure A.38. Case 3-HiK, Tc-99 aqueous concentration at (a) 2050 and (b) year 12000 

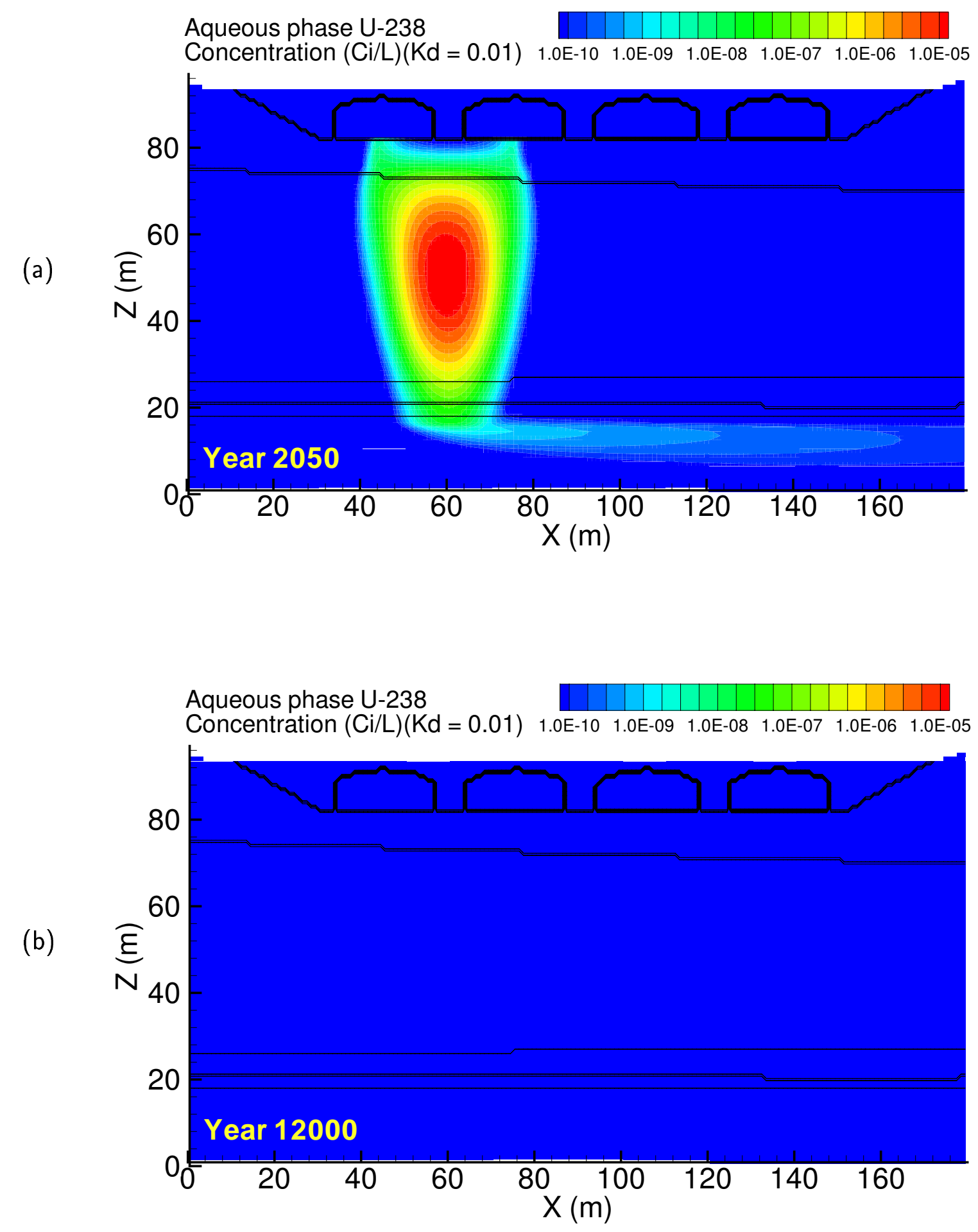

Figure A.39. Case 3-HiK, U-238 $\left(\mathrm{K}_{d}=0.01\right)$ aqueous concentration at (a) 2050 and (b) year 12000 

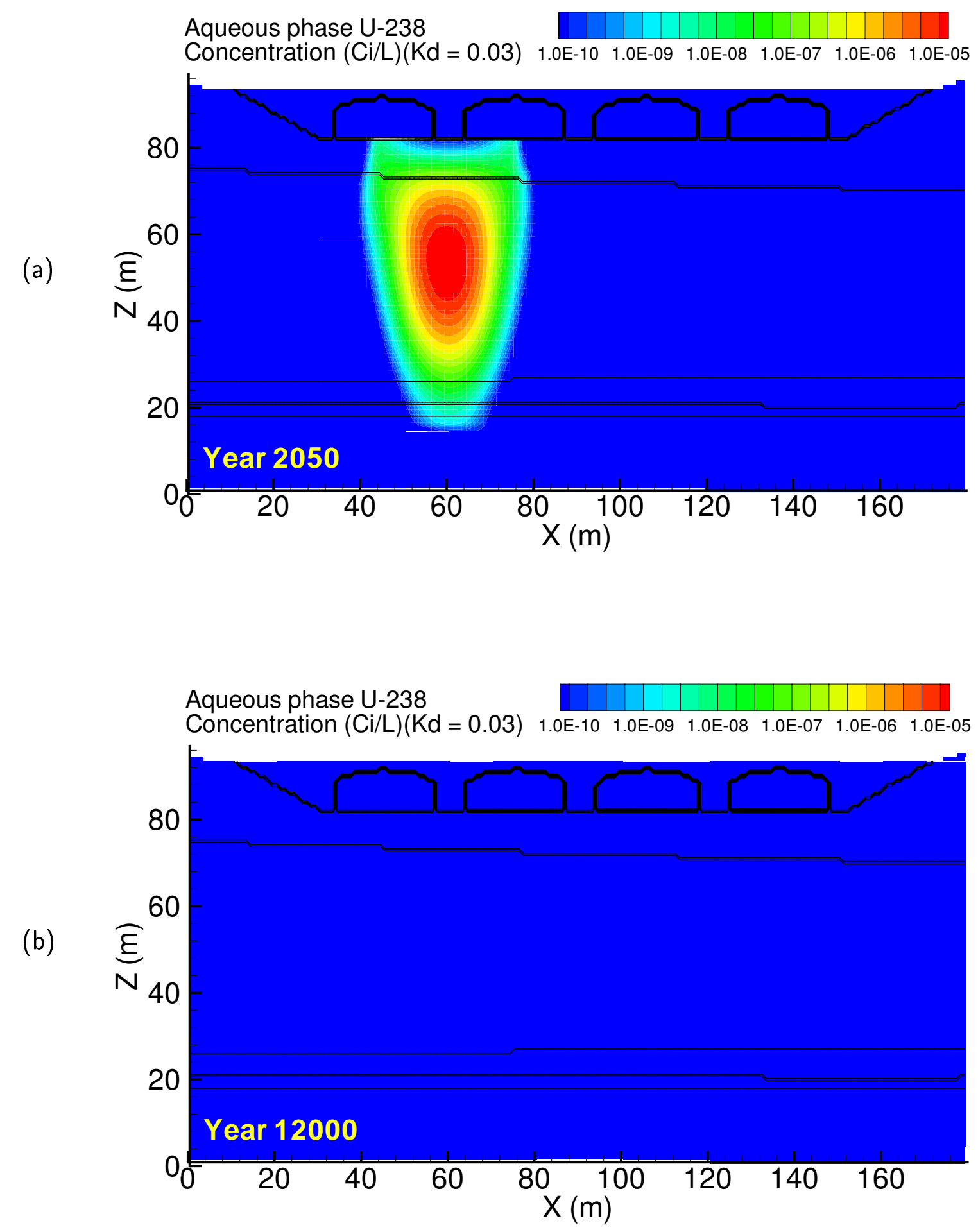

Figure A.40. Case 3-HiK, U-238 $\left(\mathrm{K}_{d}=0.03\right)$ aqueous concentration at (a) 2050 and (b) year 12000 

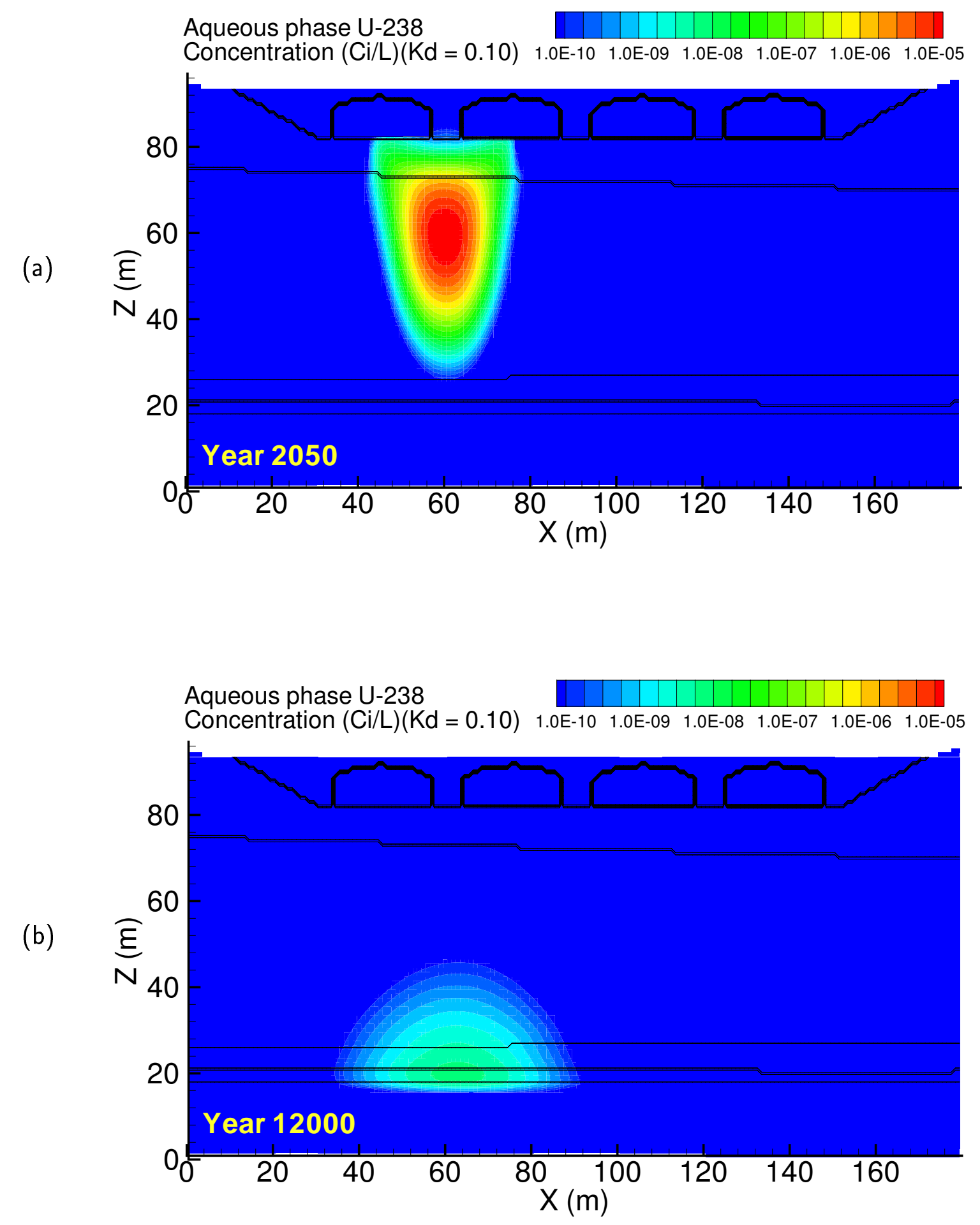

Figure A.41. Case 3-HiK, U-238 $\left(\mathrm{K}_{d}=0.10\right)$ aqueous concentration at (a) 2050 and (b) year 12000 

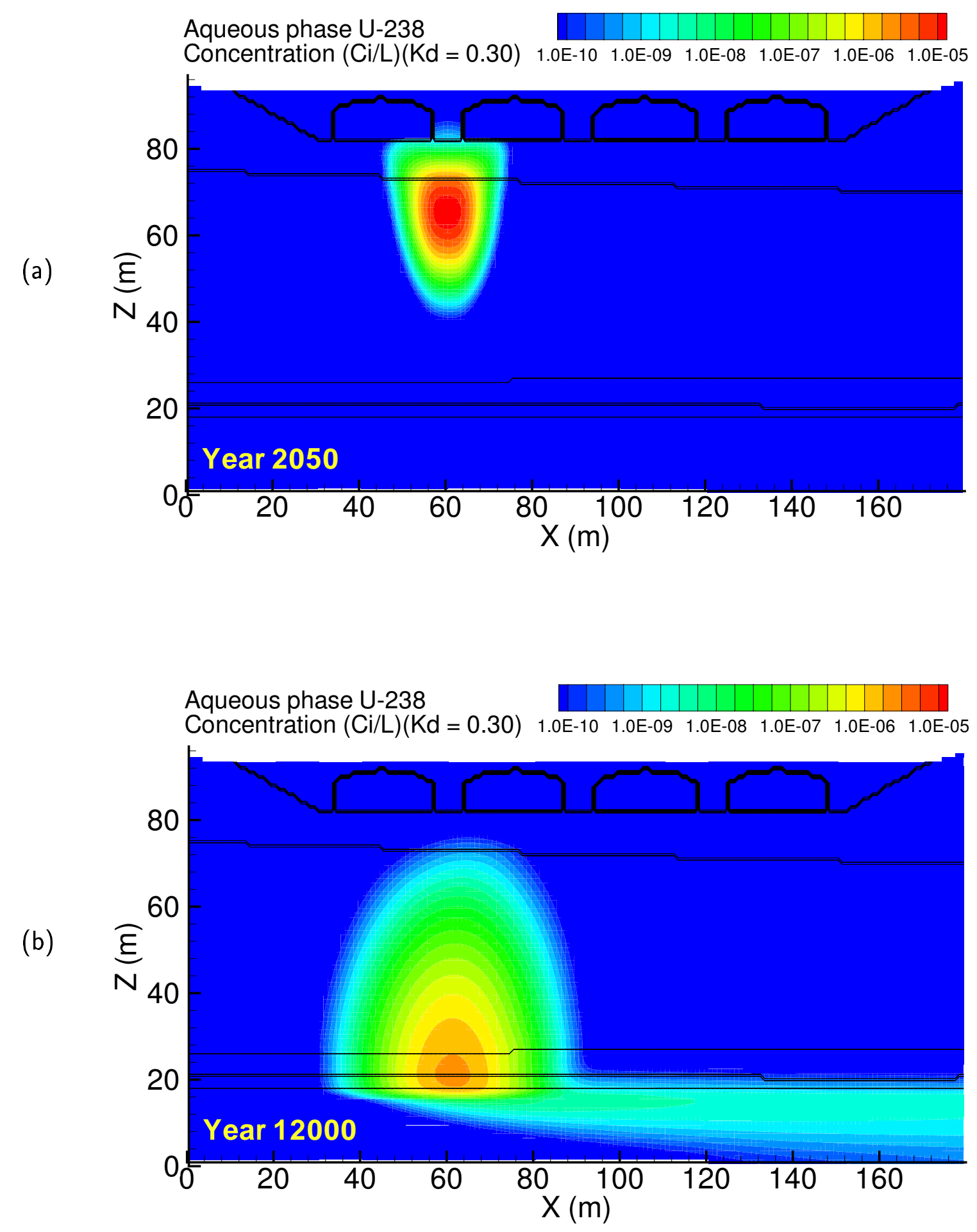

Figure A.42. Case 3-HiK, U-238 $\left(\mathrm{K}_{d}=0.30\right)$ aqueous concentration at (a) 2050 and (b) year 12000 

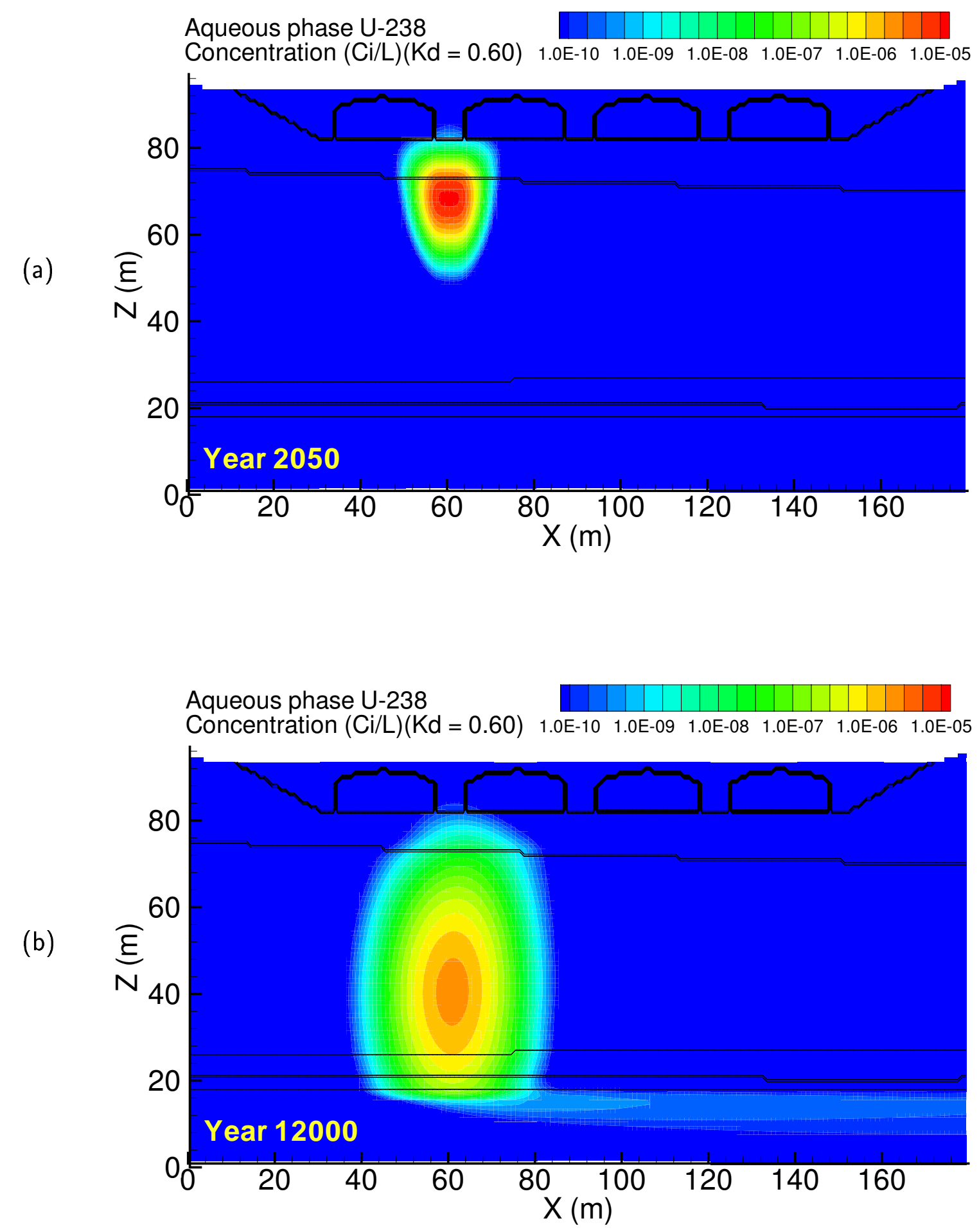

Figure A.43. Case 3-HiK, U-238 $\left(\mathrm{K}_{d}=0.60\right)$ aqueous concentration at (a) 2050 and (b) year 12000 

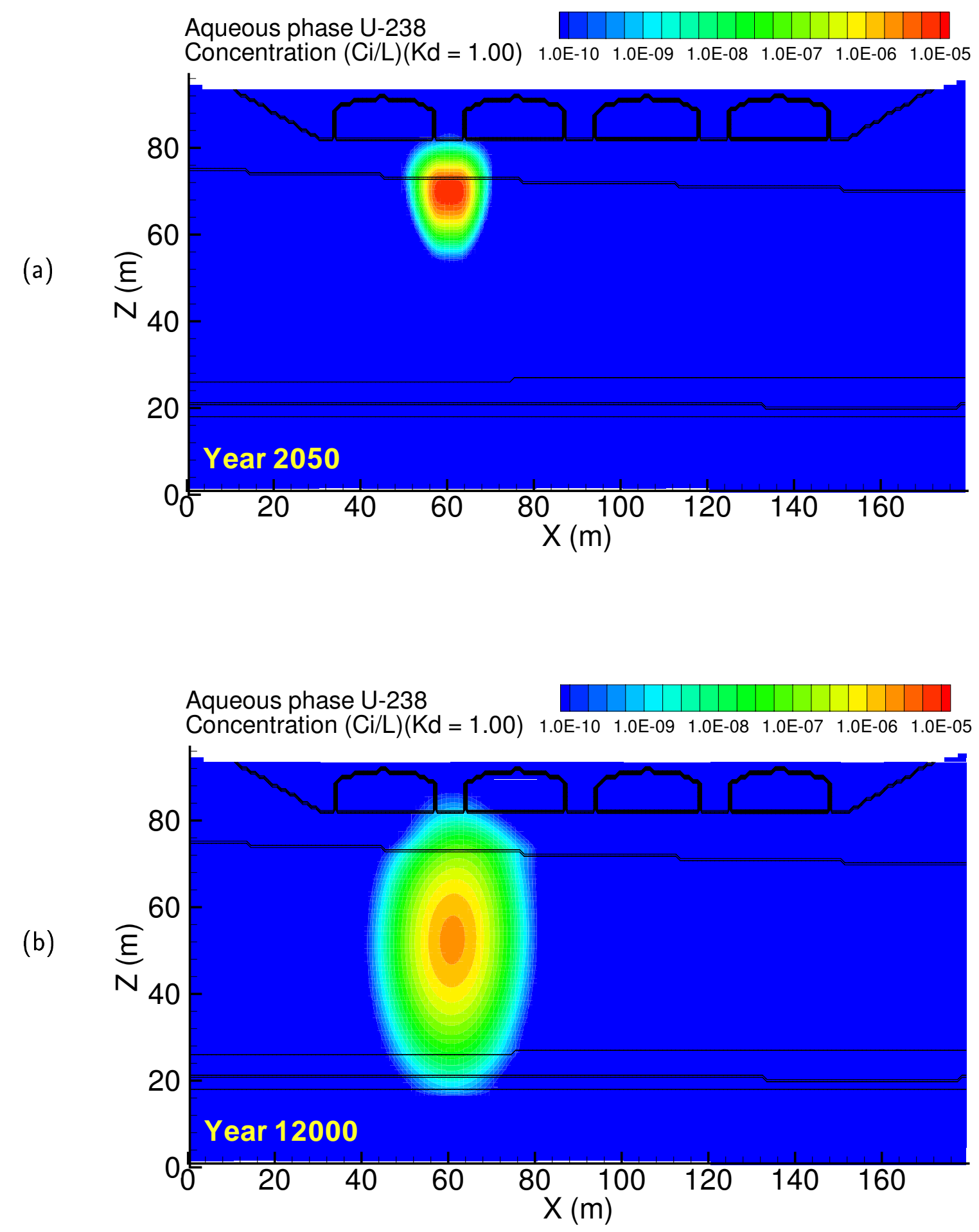

Figure A.44. Case 3-HiK, U-238 $\left(\mathrm{K}_{d}=1.00\right)$ aqueous concentration at (a) 2050 and (b) year 12000 

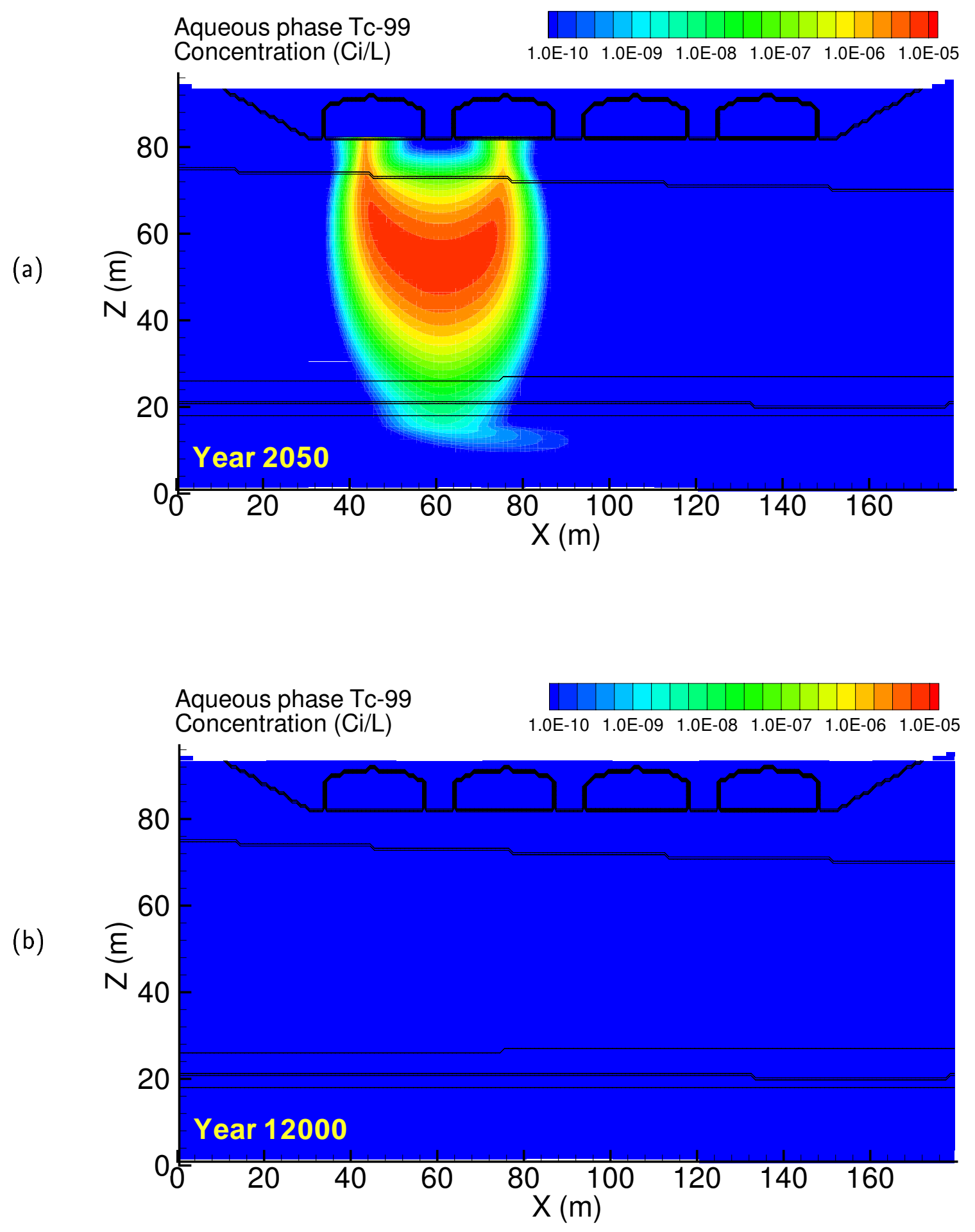

Figure A.45. Case 4, Tc-99 aqueous concentration at (a) 2050 and (b) year 12000 

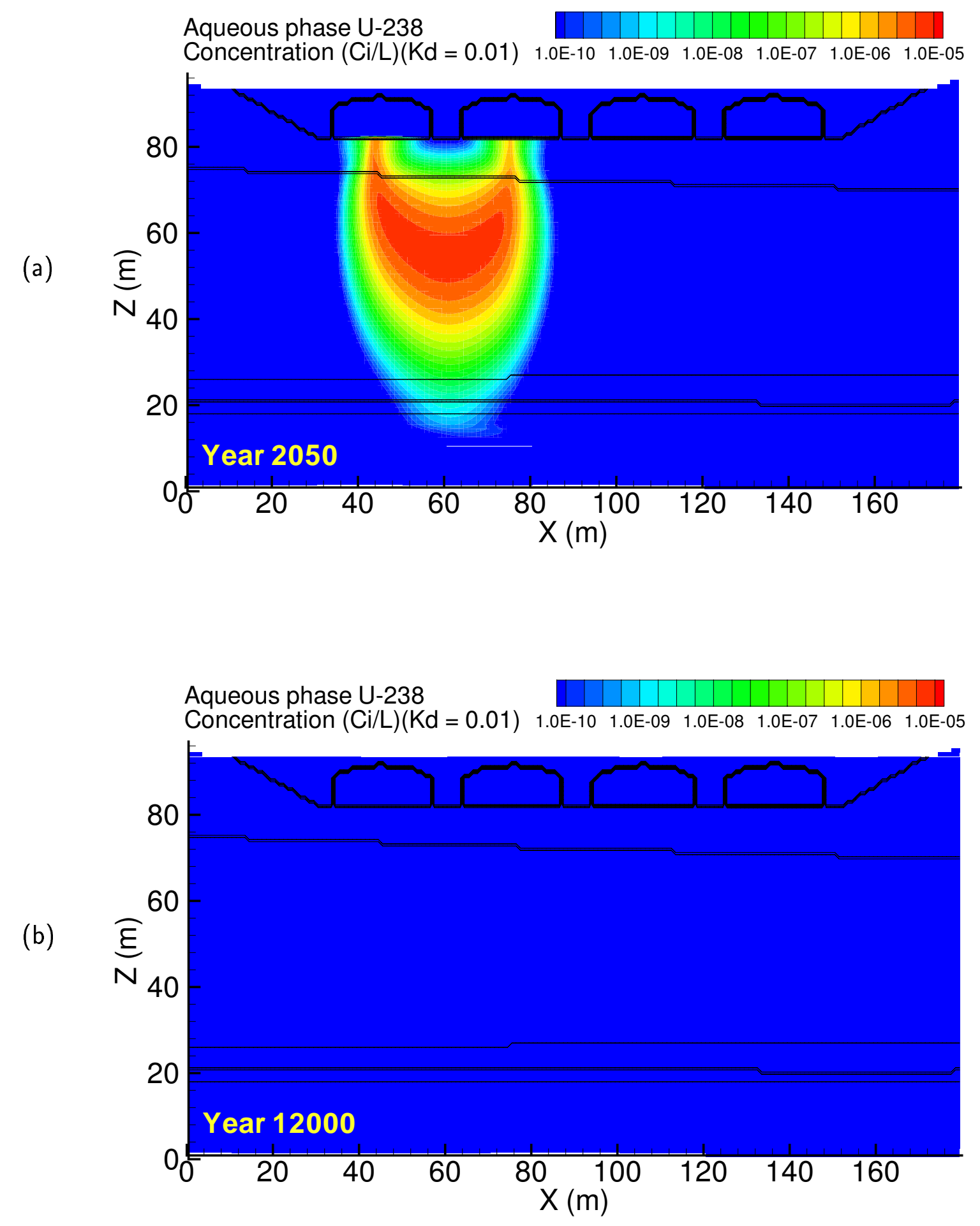

Figure A.46. Case 4, U-238 $\left(\mathrm{K}_{d}=0.01\right)$ aqueous concentration at (a) 2050 and (b) year 12000 

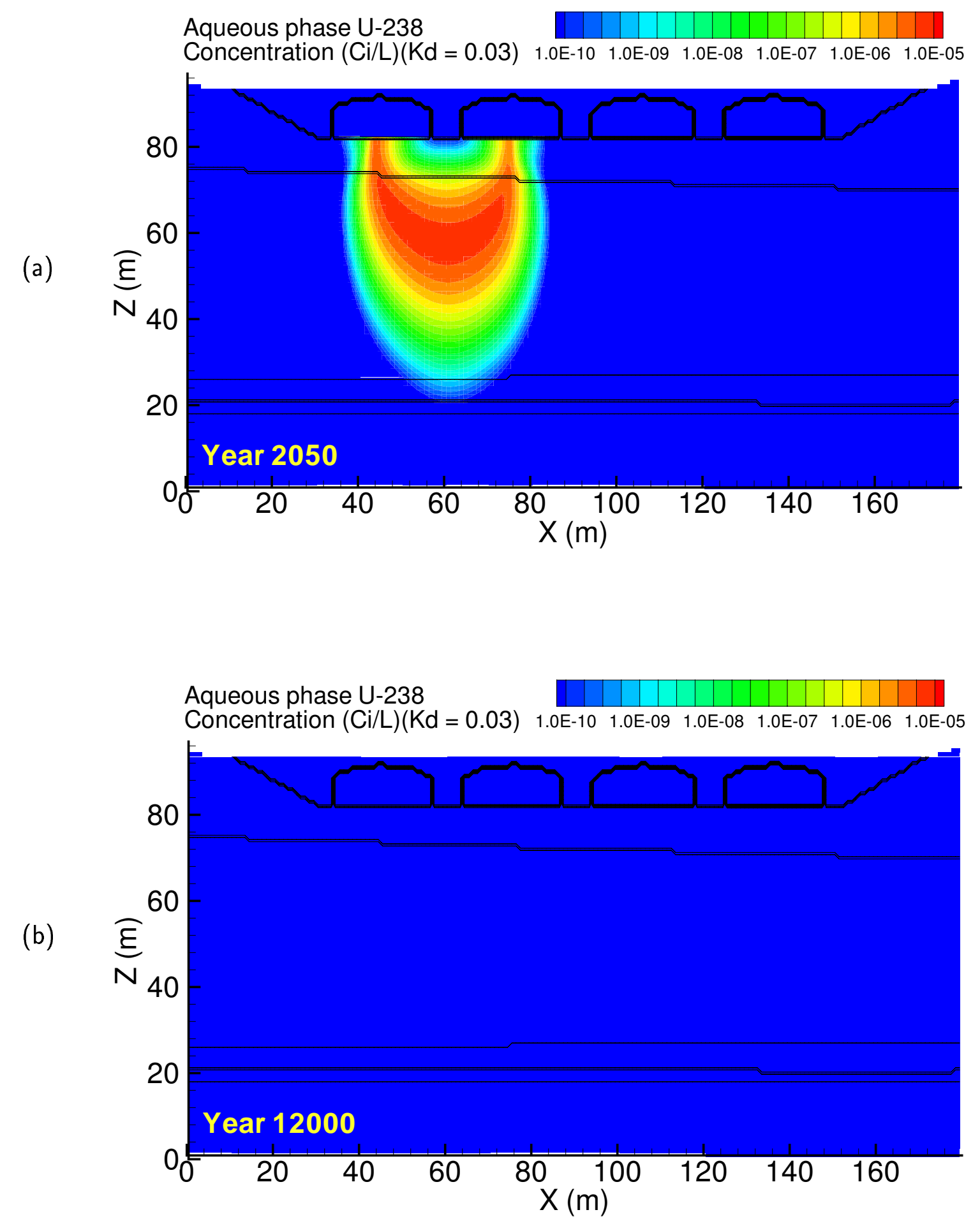

Figure A.47. Case 4, U-238 $\left(\mathrm{K}_{d}=0.03\right)$ aqueous concentration at (a) 2050 and (b) year 12000 

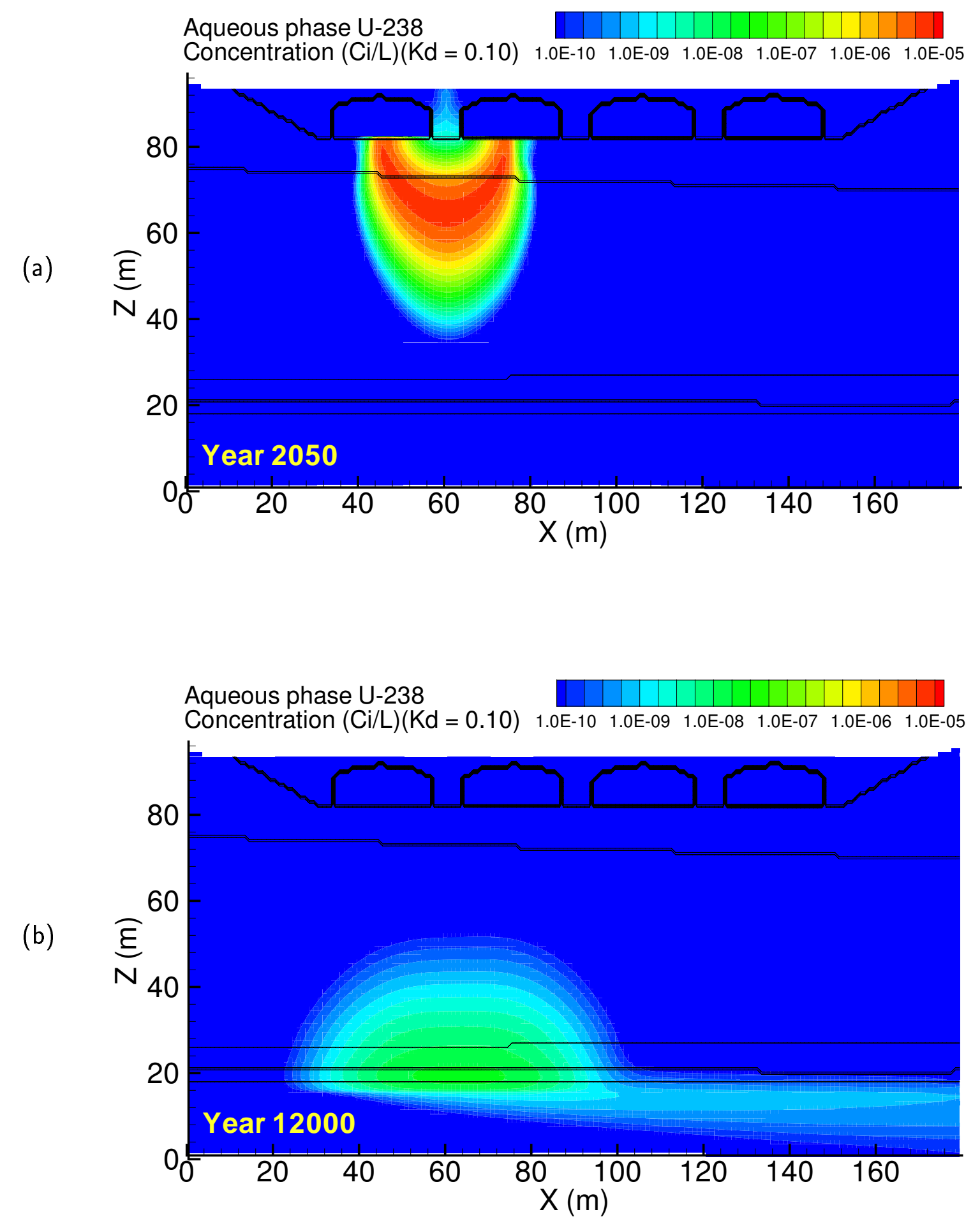

Figure A.48. Case 4, U-238 $\left(\mathrm{K}_{d}=0.10\right)$ aqueous concentration at (a) 2050 and (b) year 12000 

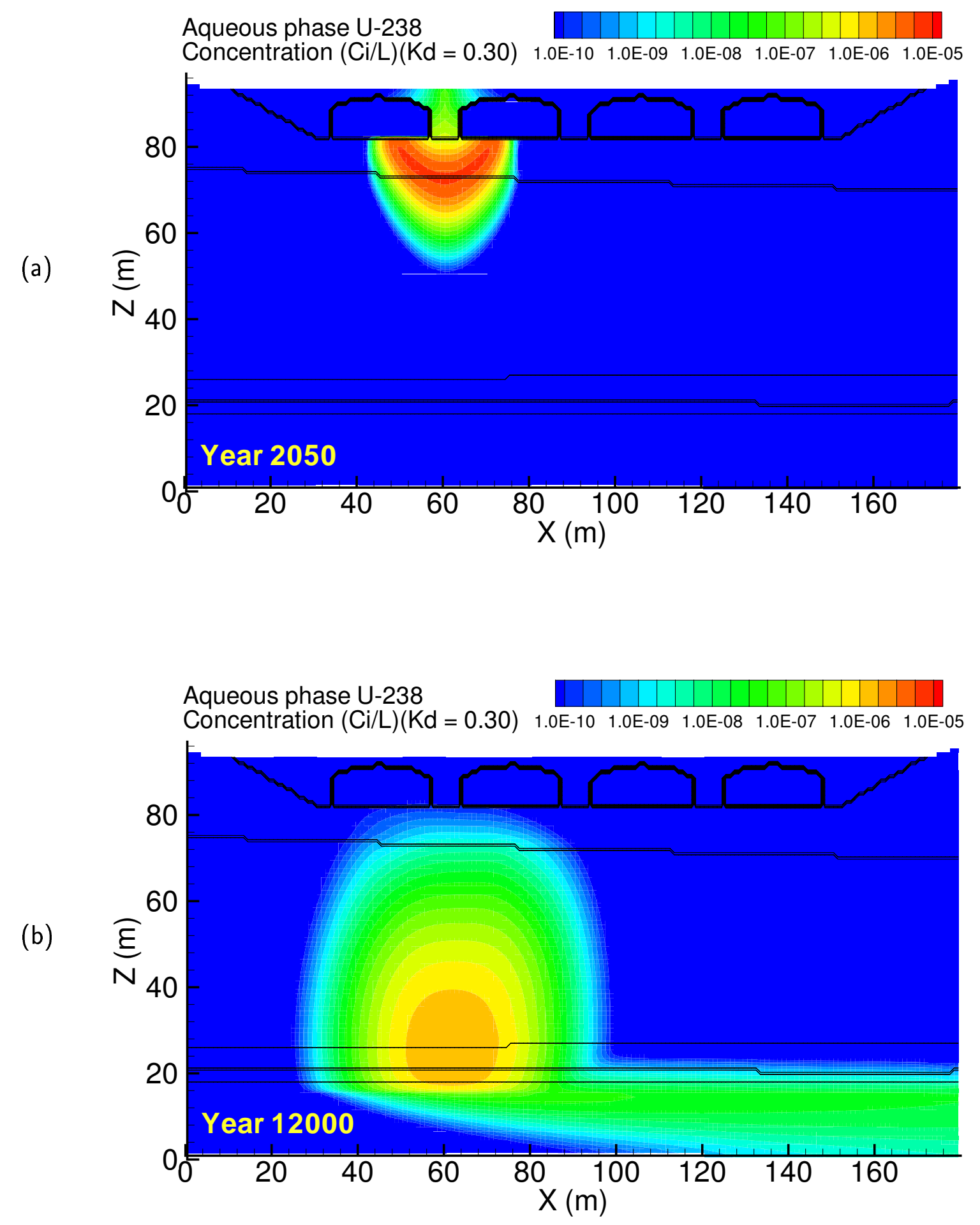

Figure A.49. Case 4, U-238 $\left(\mathrm{K}_{d}=0.30\right)$ aqueous concentration at (a) 2050 and (b) year 12000 

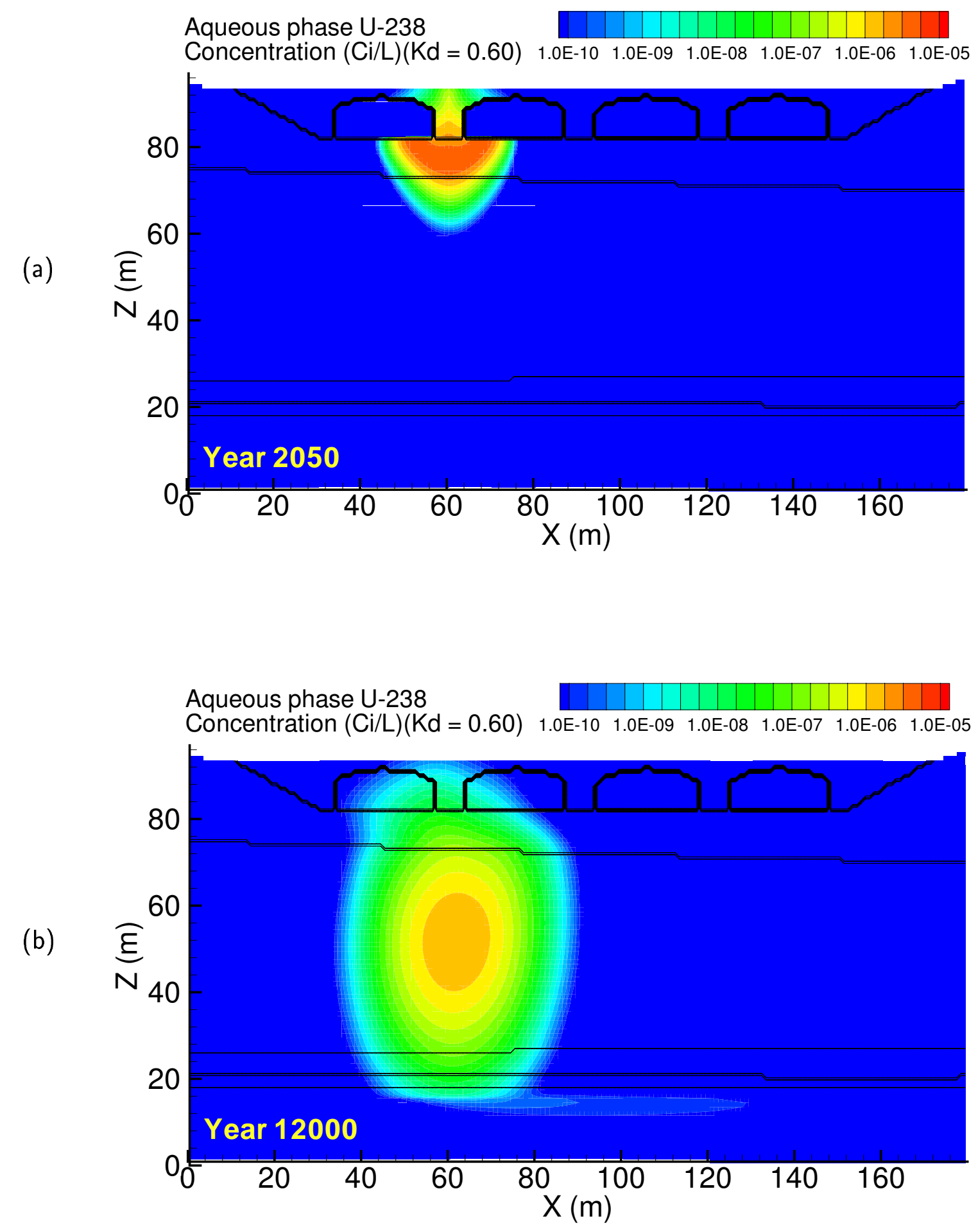

Figure A.50. Case 4, U-238 $\left(\mathrm{K}_{d}=0.60\right)$ aqueous concentration at (a) 2050 and (b) year 12000 

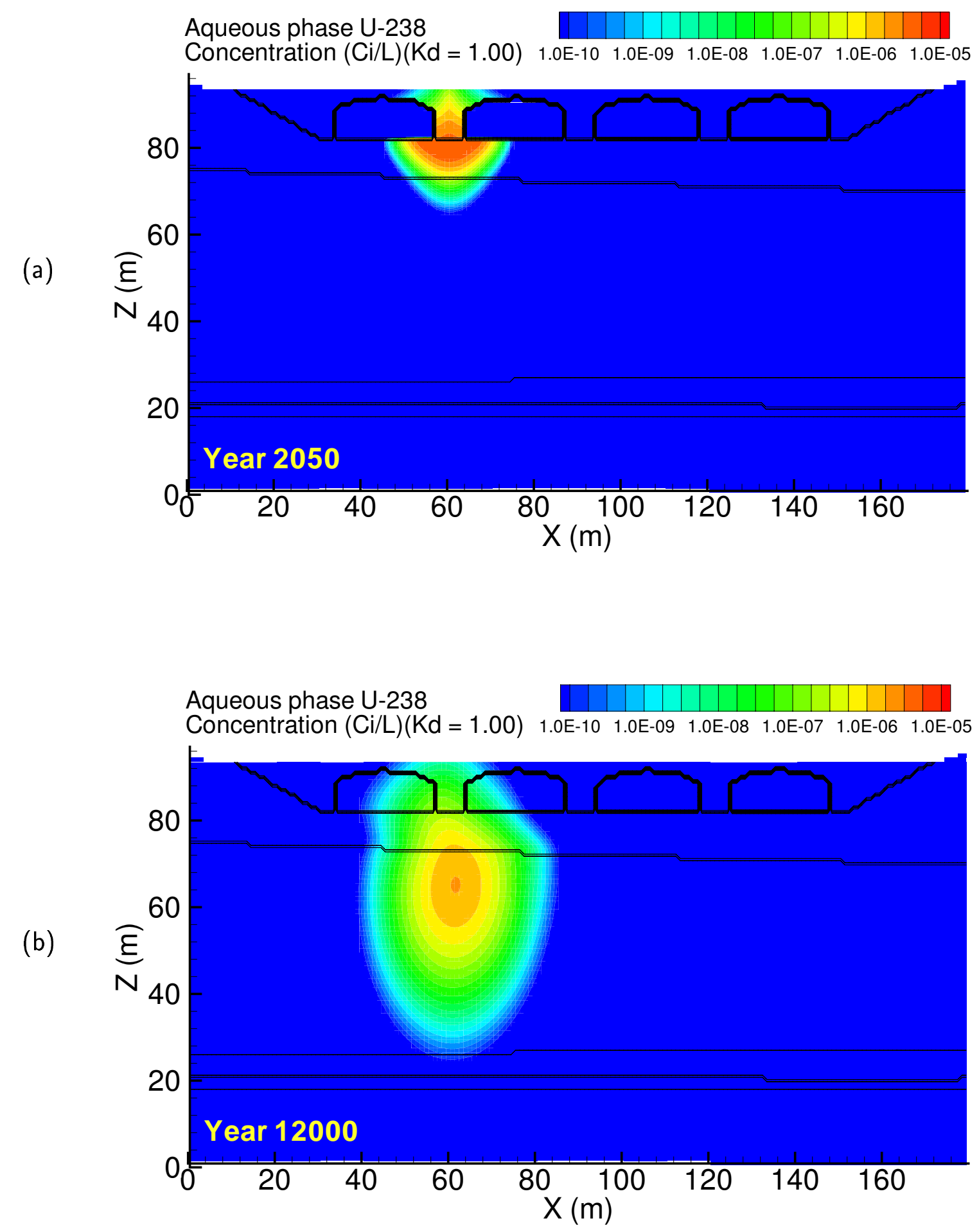

Figure A.51. Case 4, U-238 $\left(\mathrm{K}_{d}=1.00\right)$ aqueous concentration at (a) 2050 and (b) year 12000 

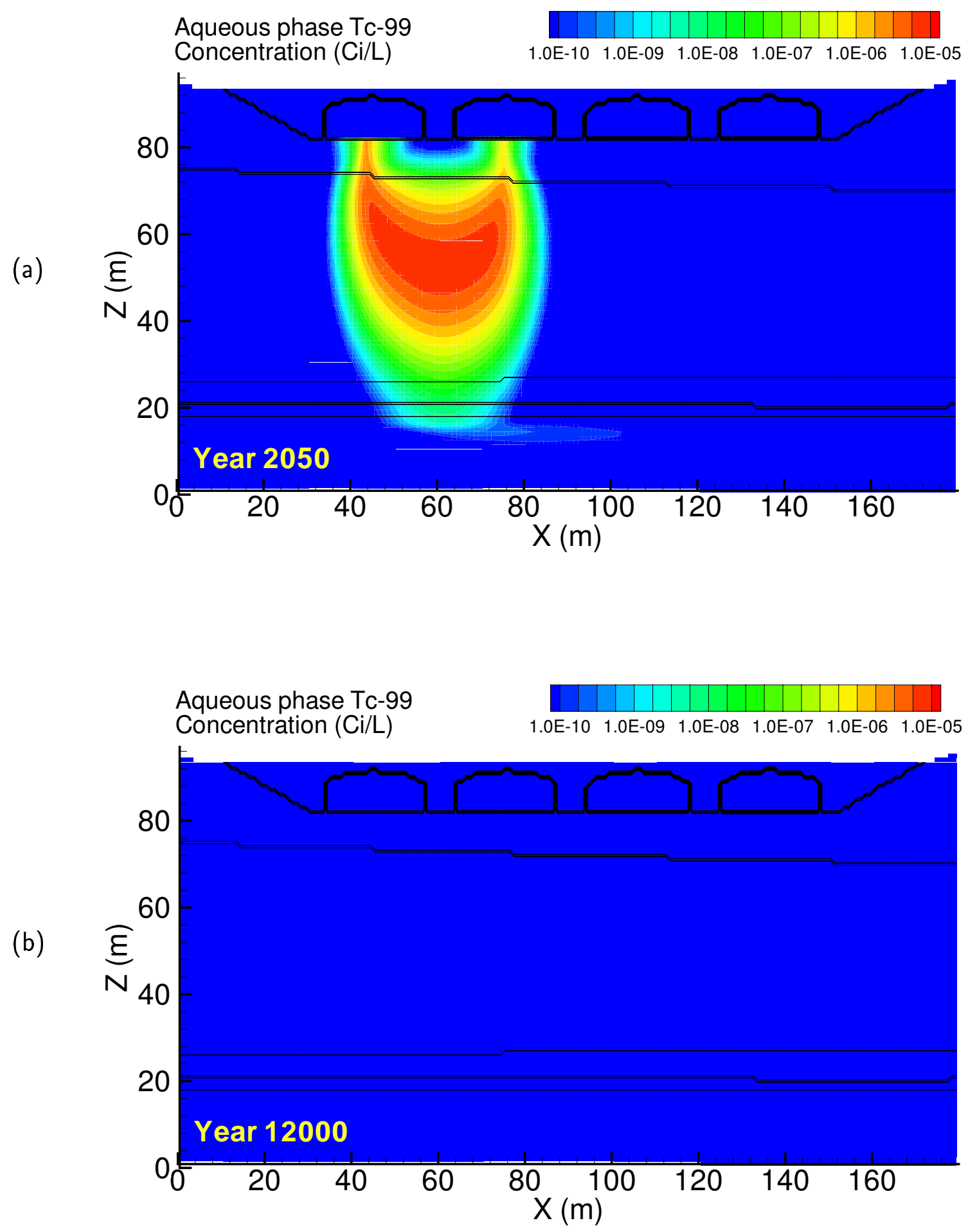

Figure A.52. Case4-HiK Tc-99 aqueous concentration at (a) 2050 and (b) year 12000. 

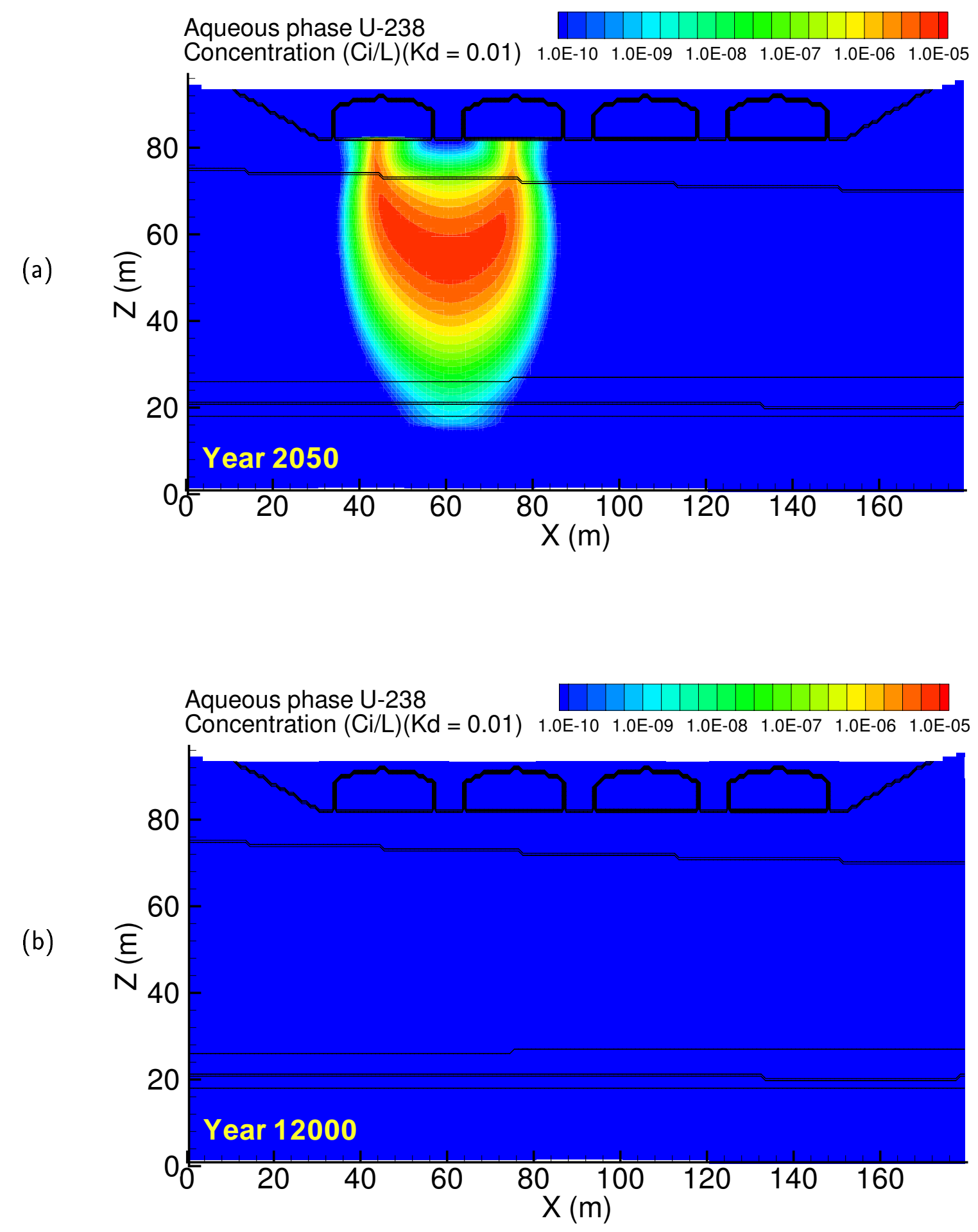

Figure A.53. Case4-HiK U-238 $\left(\mathrm{K}_{d}=0.01\right)$ aqueous concentration at (a) 2050 and (b) year 12000. 

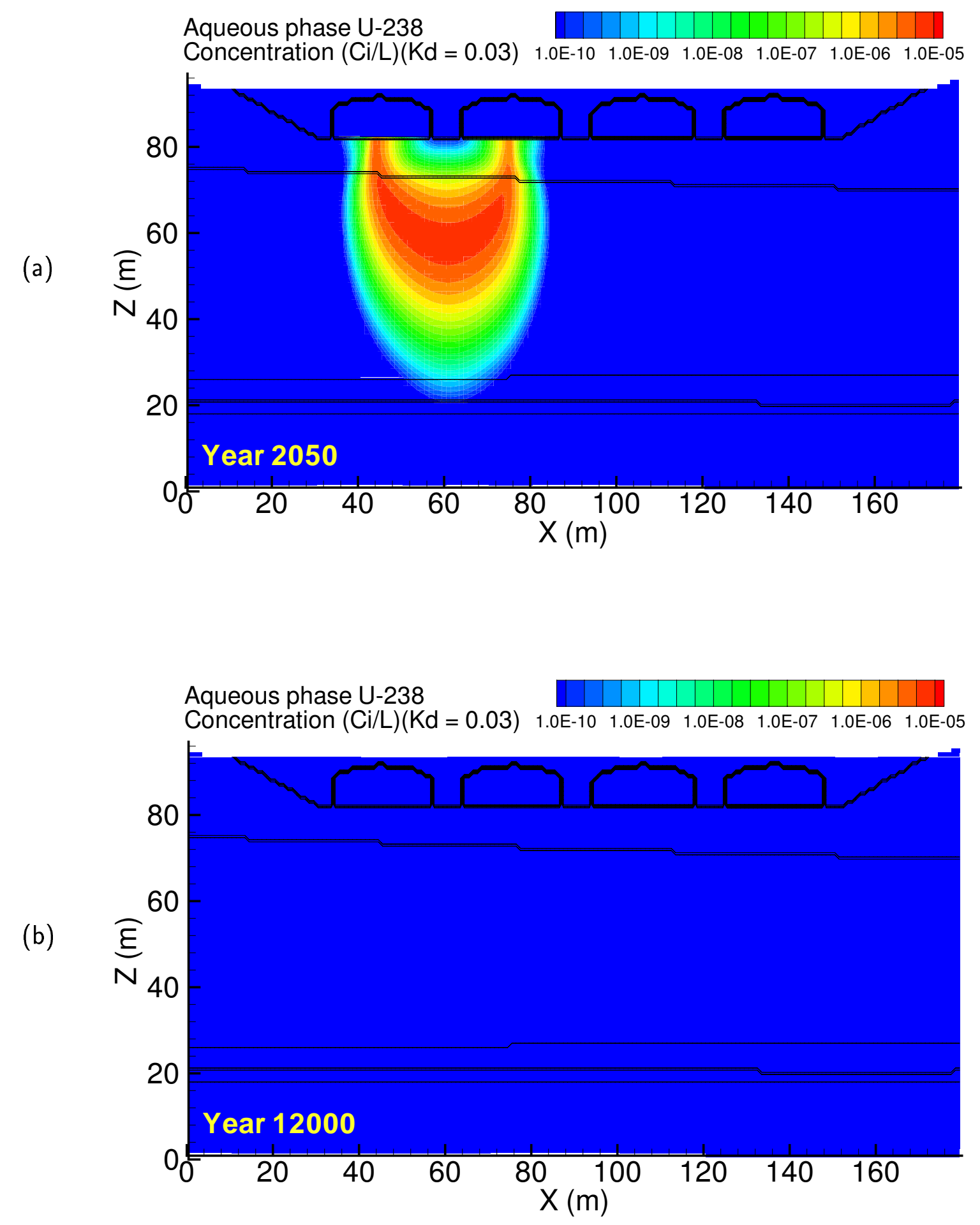

Figure A.54. Case4-HiK U-238 $\left(\mathrm{K}_{d}=0.03\right)$ aqueous concentration at (a) 2050 and (b) year 12000. 

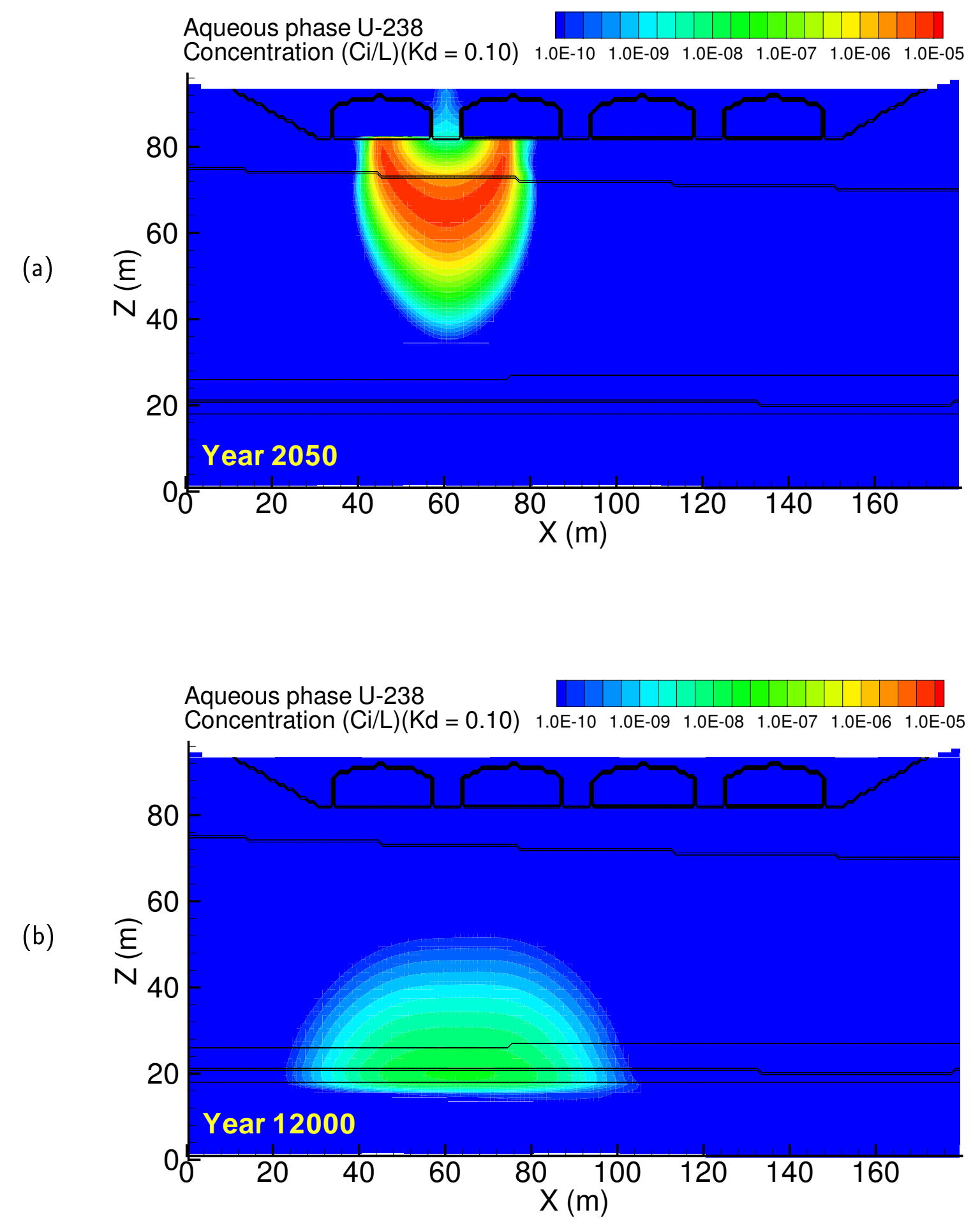

Figure A.55. Case4-HiK U-238 $\left(\mathrm{K}_{d}=0.10\right)$ aqueous concentration at (a) 2050 and (b) year 12000. 

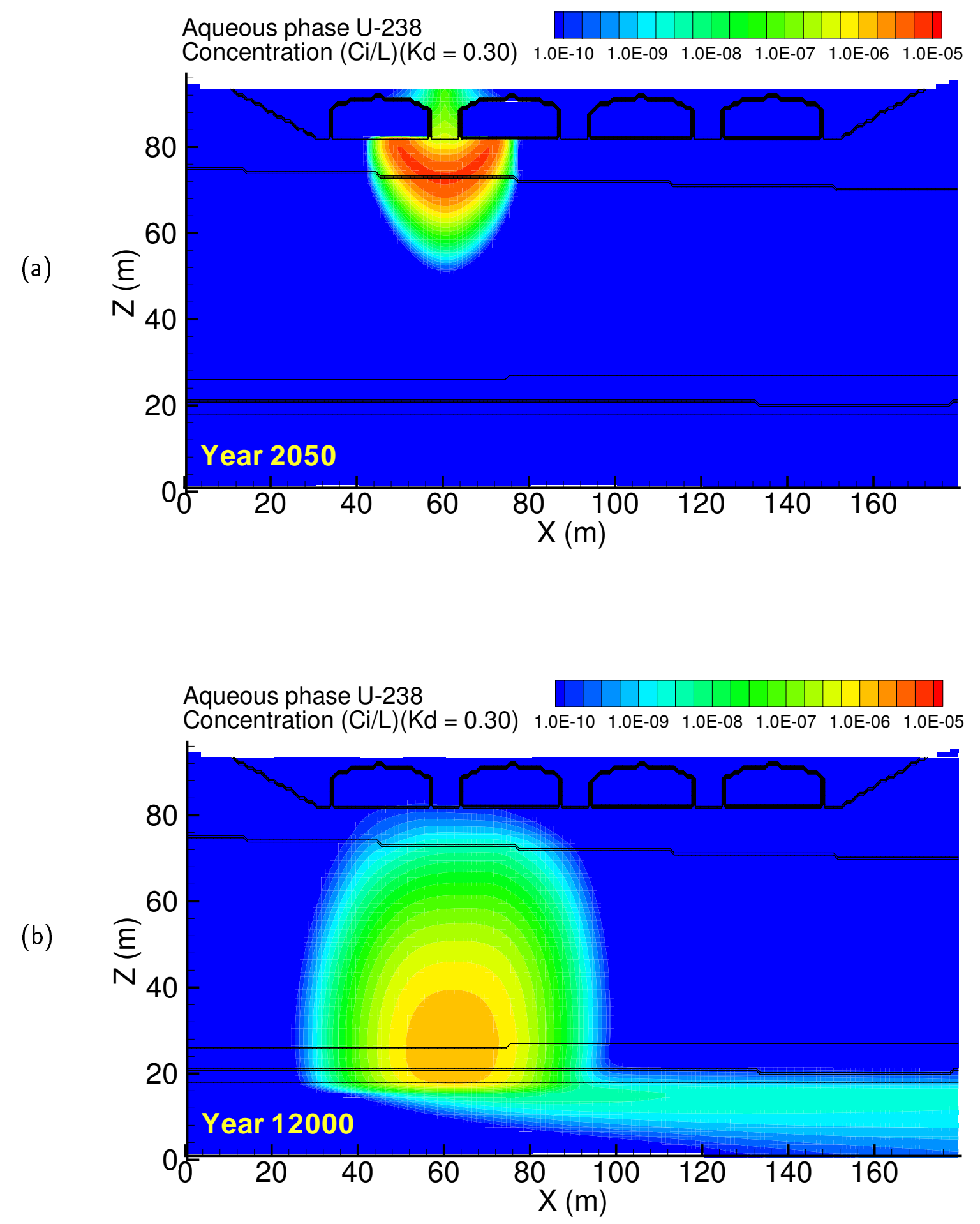

Figure A.56. Case4-HiK U-238 $\left(\mathrm{K}_{d}=0.30\right)$ aqueous concentration at (a) 2050 and (b) year 12000. 

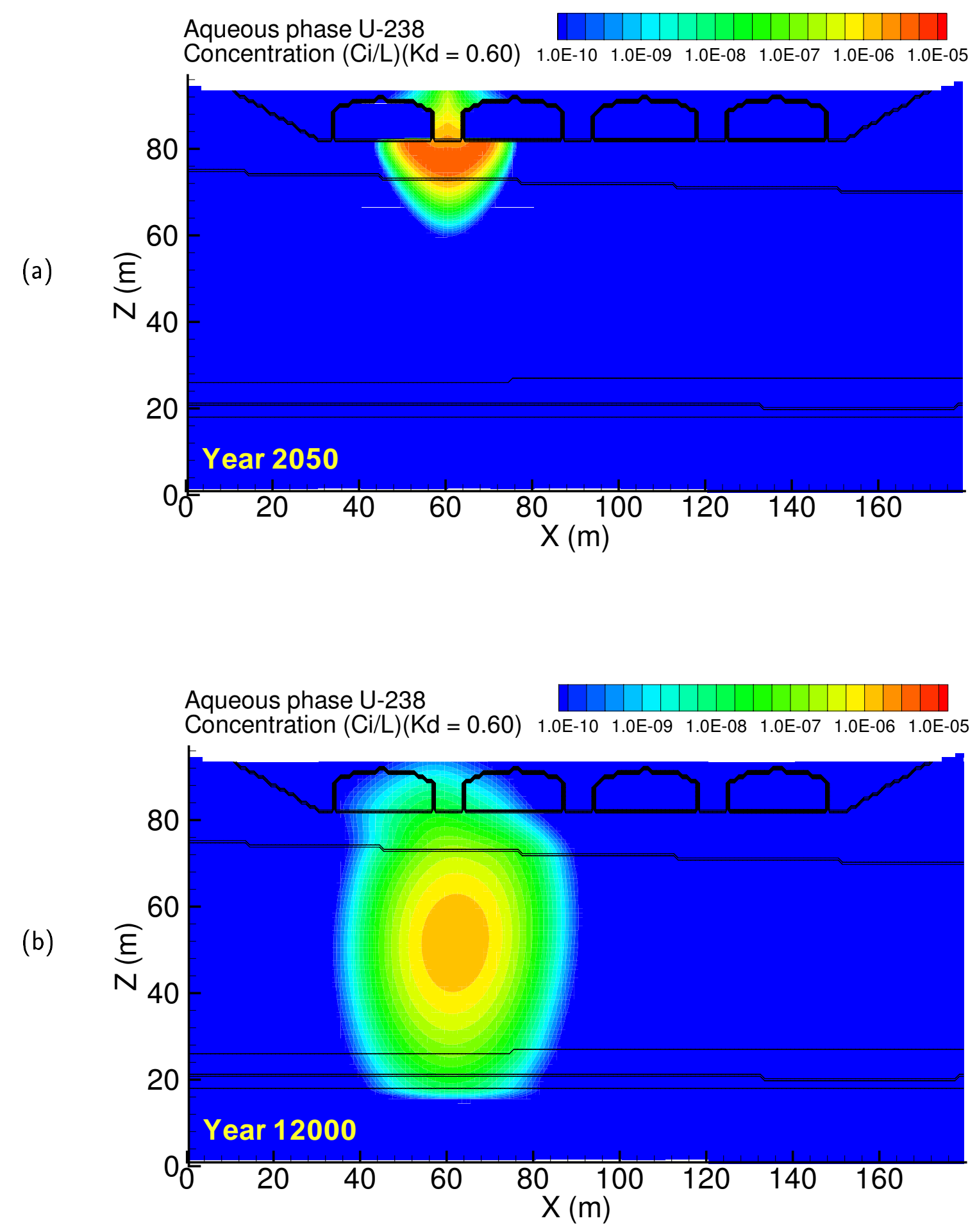

Figure A.57. Case4-HiK U-238 $\left(\mathrm{K}_{d}=0.60\right)$ aqueous concentration at (a) 2050 and (b) year 12000. 

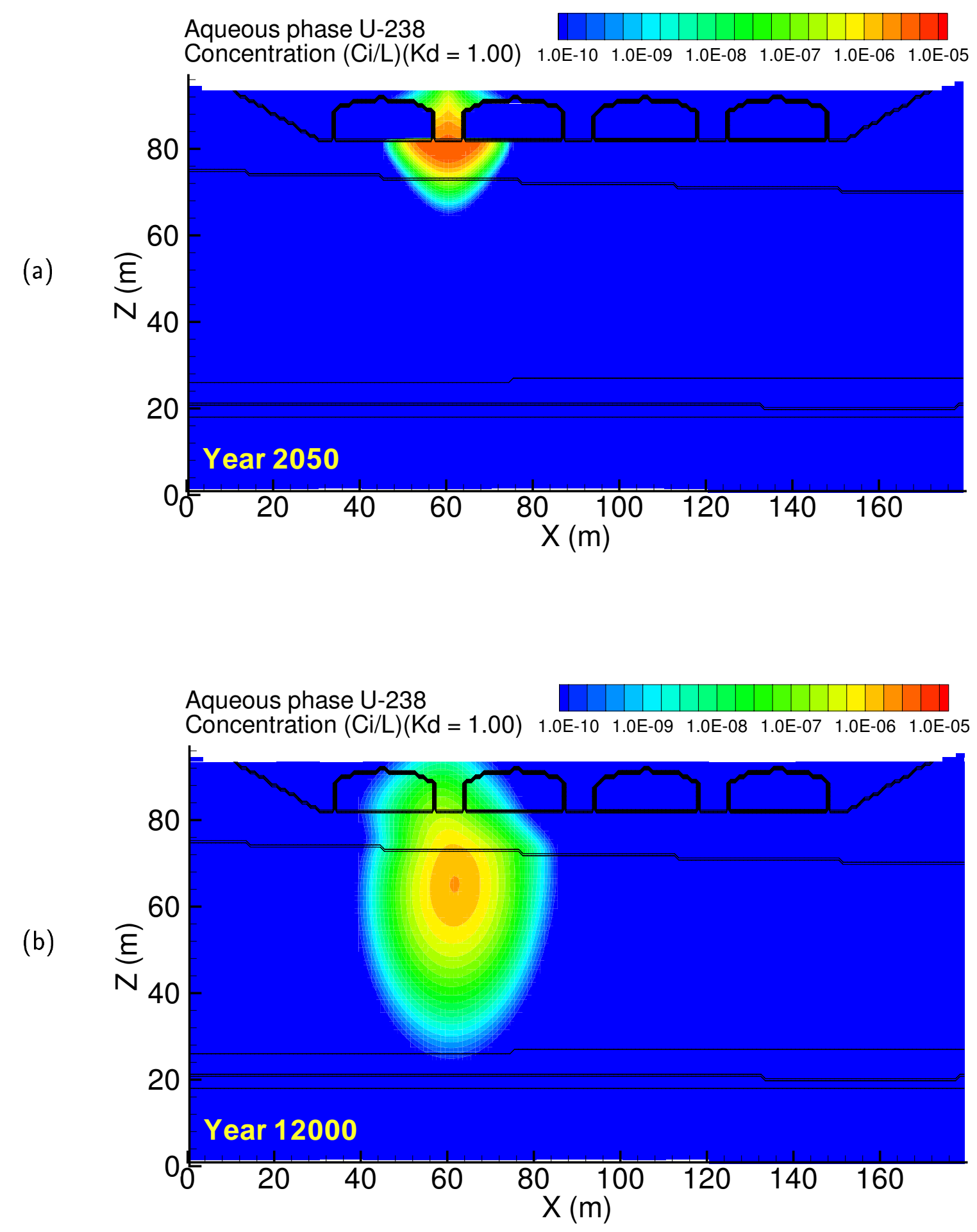

Figure A.58. Case4-HiK U-238 $\left(\mathrm{K}_{d}=1.00\right)$ aqueous concentration at (a) 2050 and (b) year 12000. 

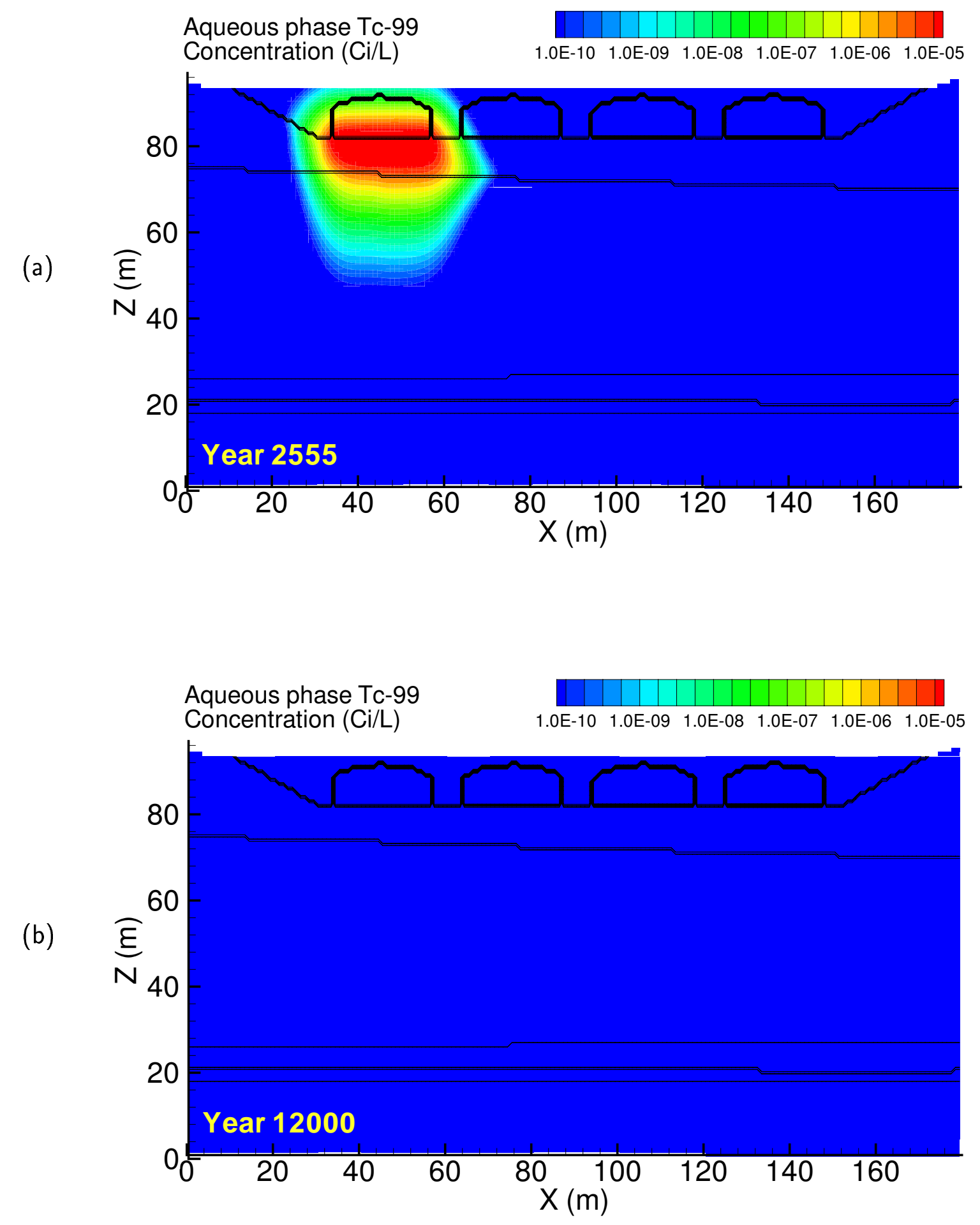

Figure A.59. Case 5, Tc-99 aqueous concentration at (a) year 2555 and (b) year 12000 

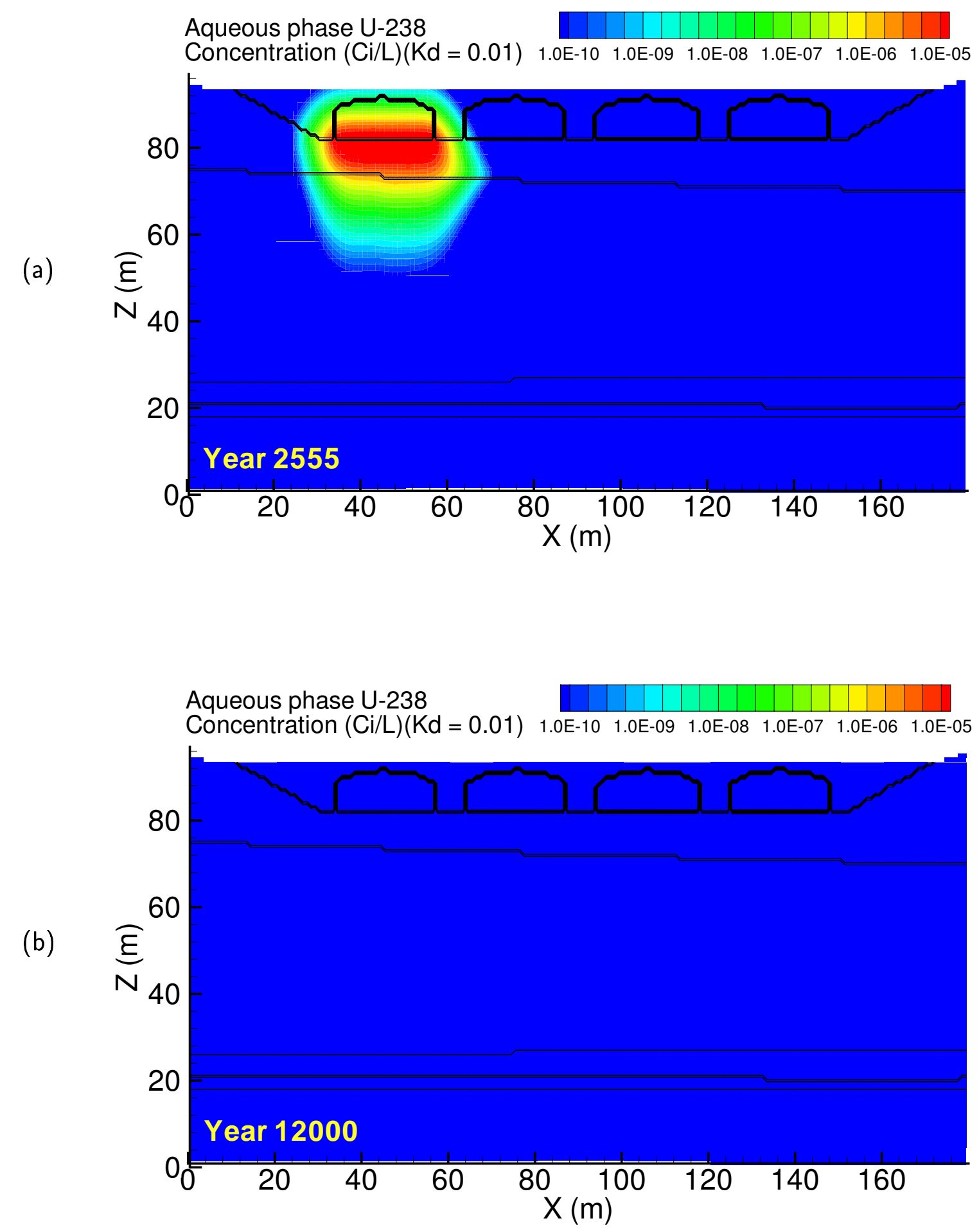

Figure A.60. Case 5, U-238 $\left(\mathrm{K}_{d}=0.01\right)$ aqueous concentration at (a) year 2555 and (b) year 12000 

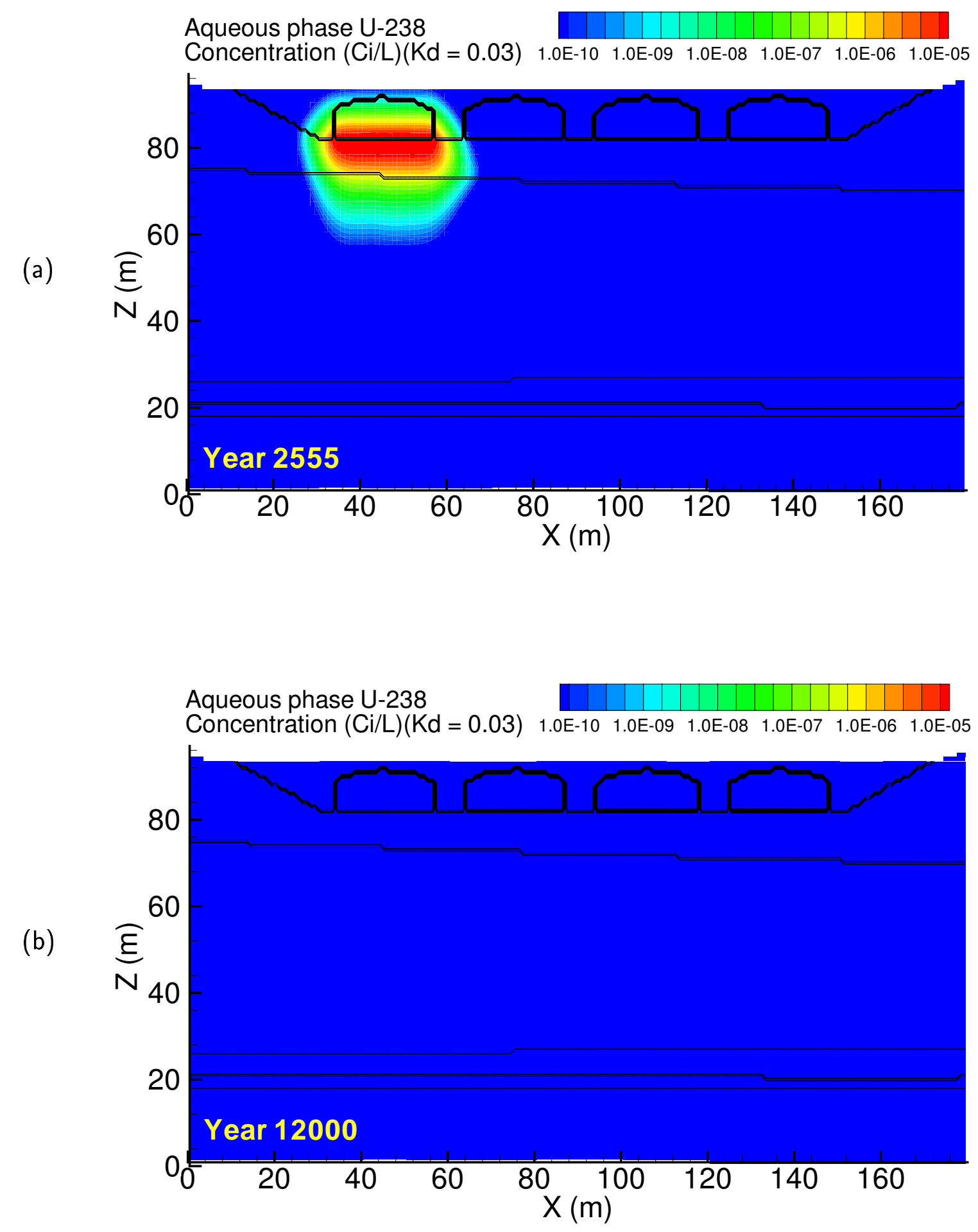

Figure A.61. Case 5, U-238 $\left(\mathrm{K}_{d}=0.03\right)$ aqueous concentration at (a) year 2555 and (b) year 12000 

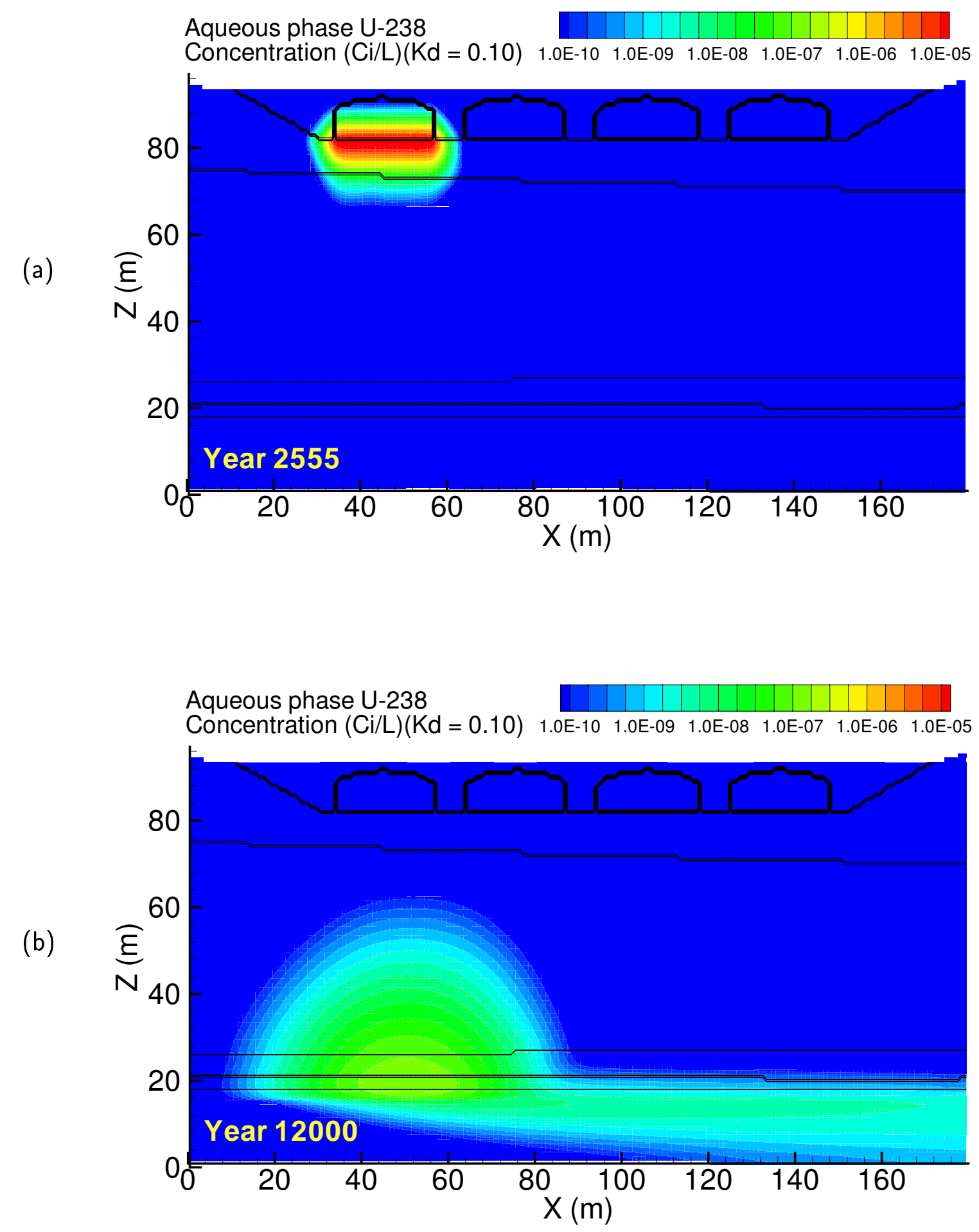

Figure A.62. Case 5, U-238 $\left(\mathrm{K}_{d}=0.10\right)$ aqueous concentration at (a) year 2555 and (b) year 12000 

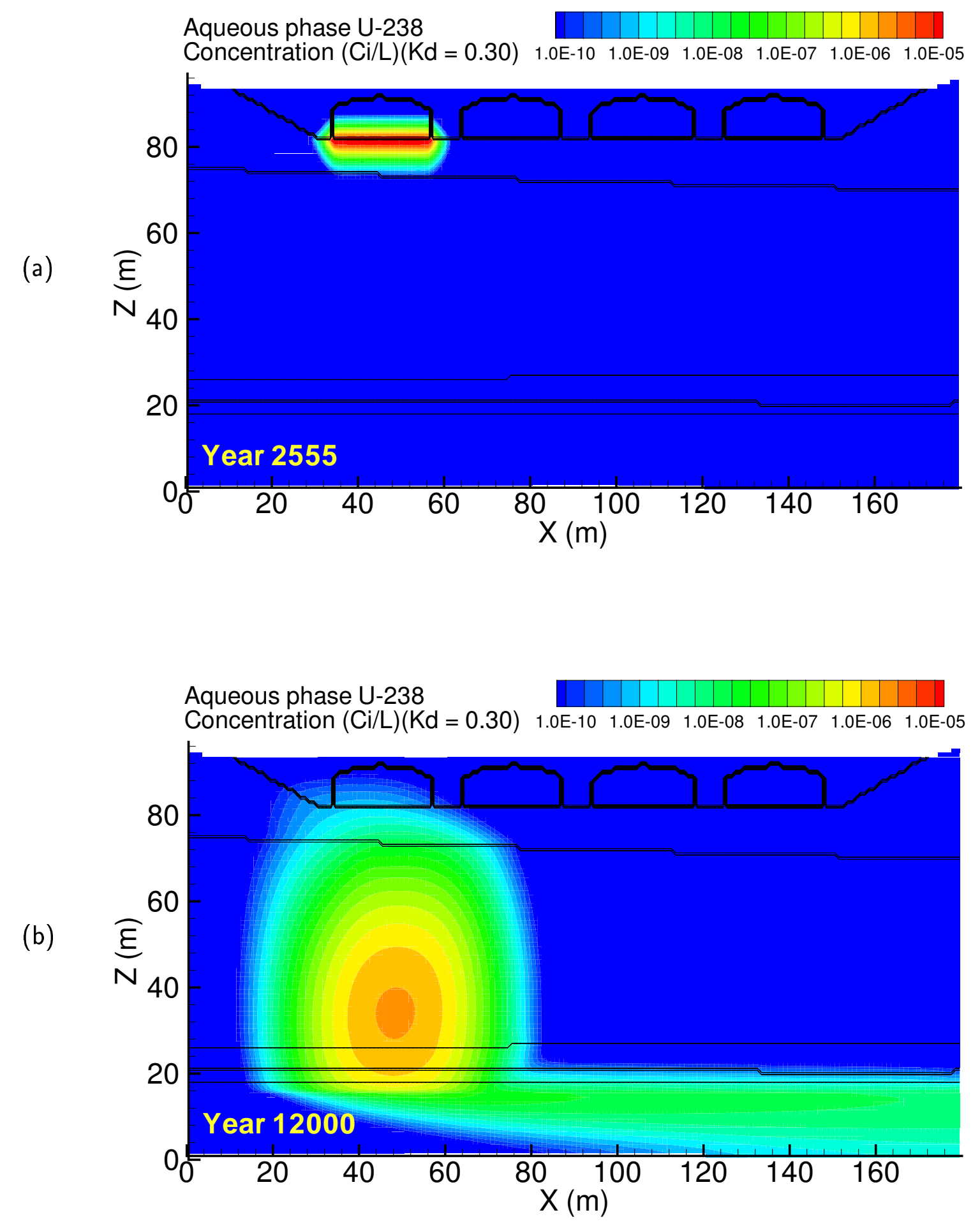

Figure A.63. Case 5, U-238 $\left(\mathrm{K}_{d}=0.30\right)$ aqueous concentration at (a) year 2555 and (b) year 12000 

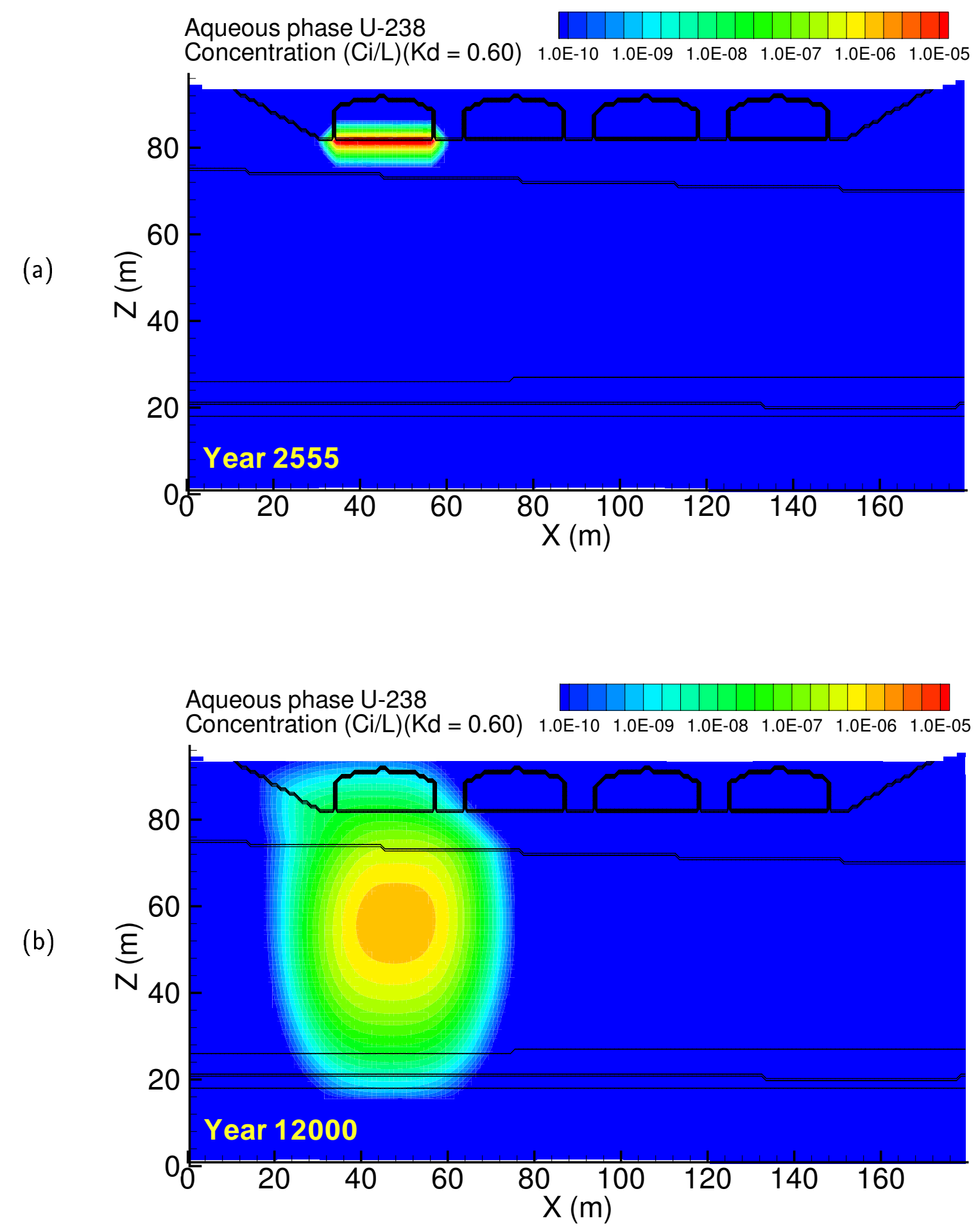

Figure A.64. Case 5, U-238 $\left(\mathrm{K}_{d}=0.60\right)$ aqueous concentration at (a) year 2555 and (b) year 12000 

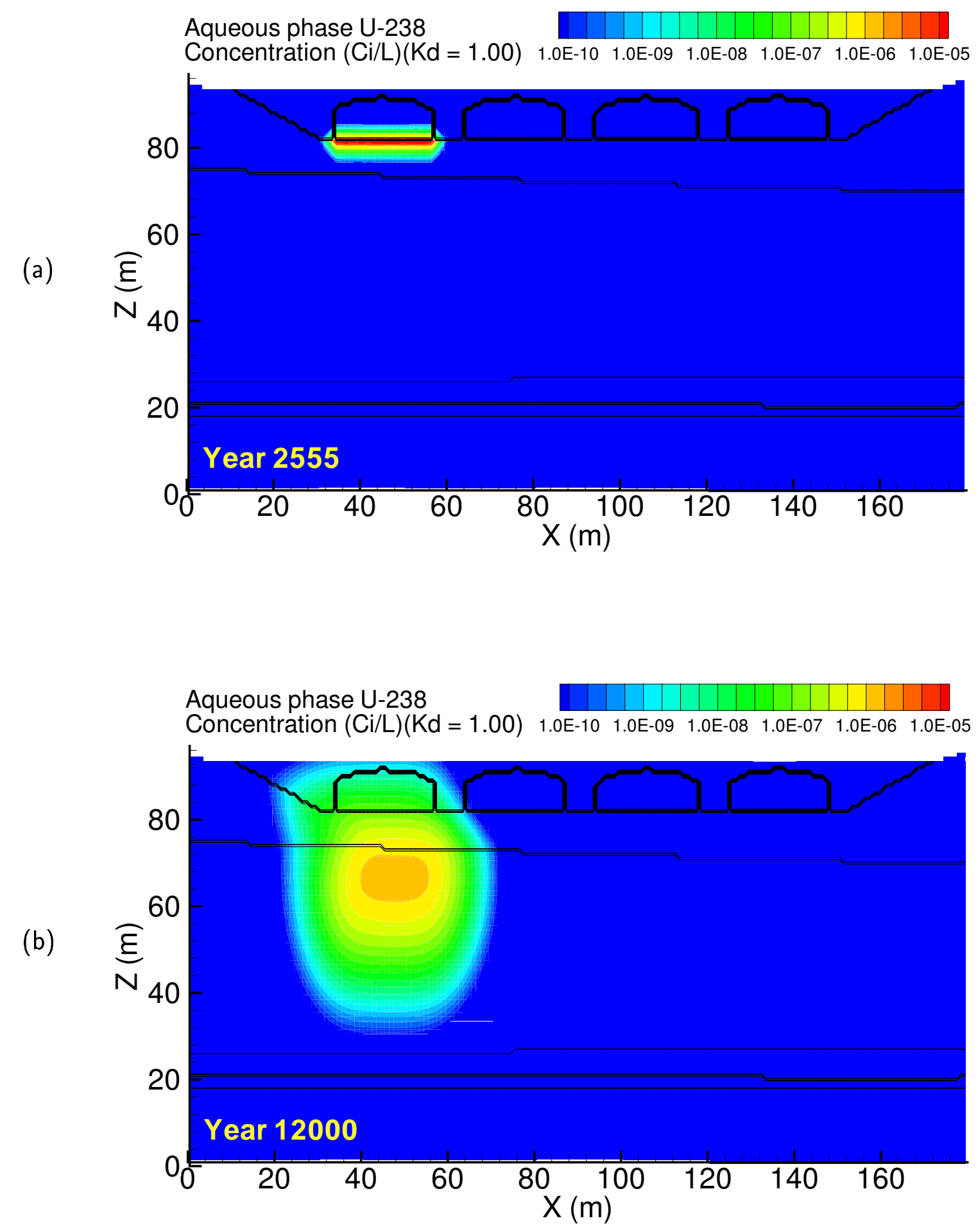

Figure A.65. Case 5, U-238 $\left(\mathrm{K}_{d}=1.00\right)$ aqueous concentration at (a) year 2555 and (b) year 12000 

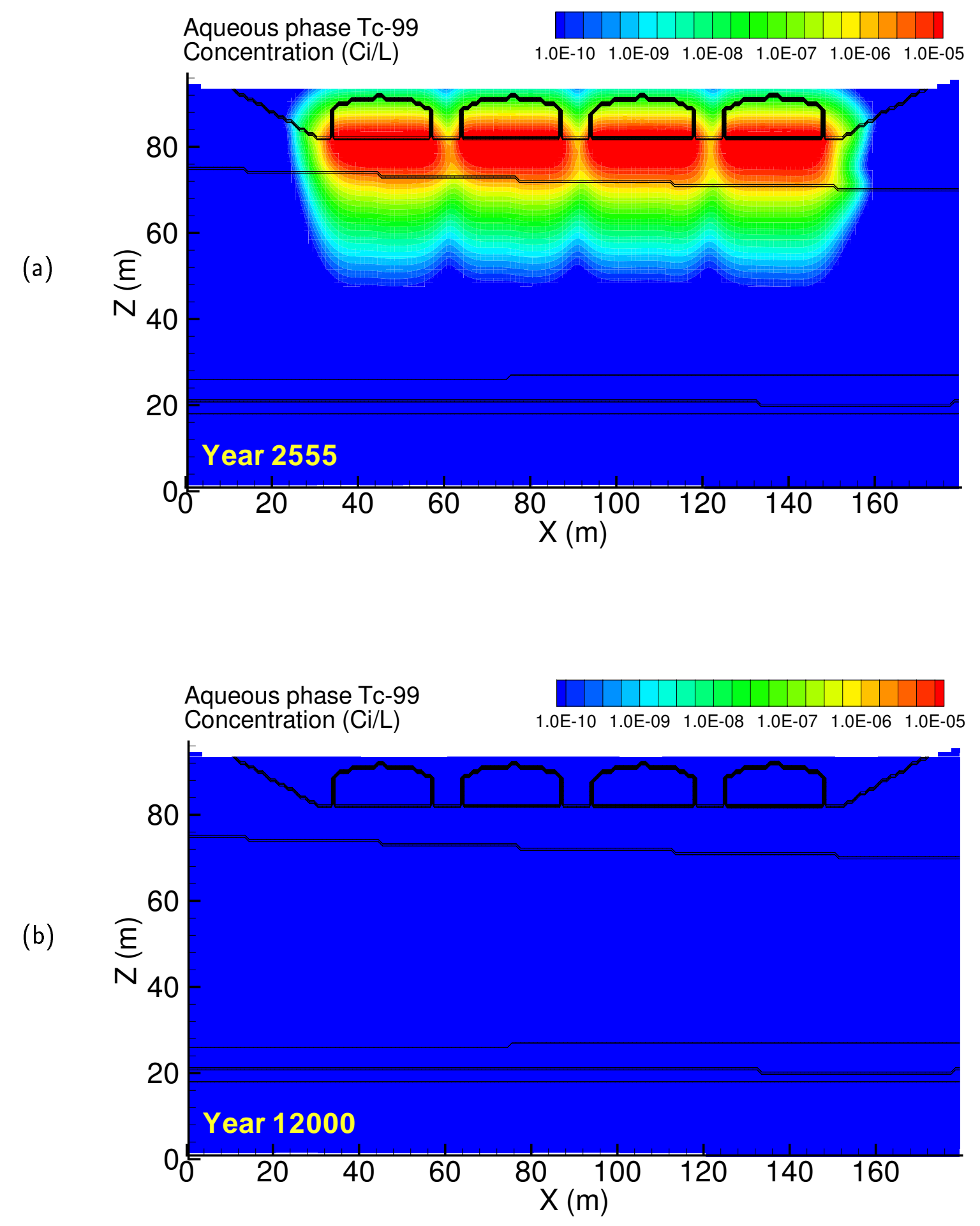

Figure A.66. Case 5v, Tc-99 aqueous concentration at (a) year 2555 and (b) year 12000 

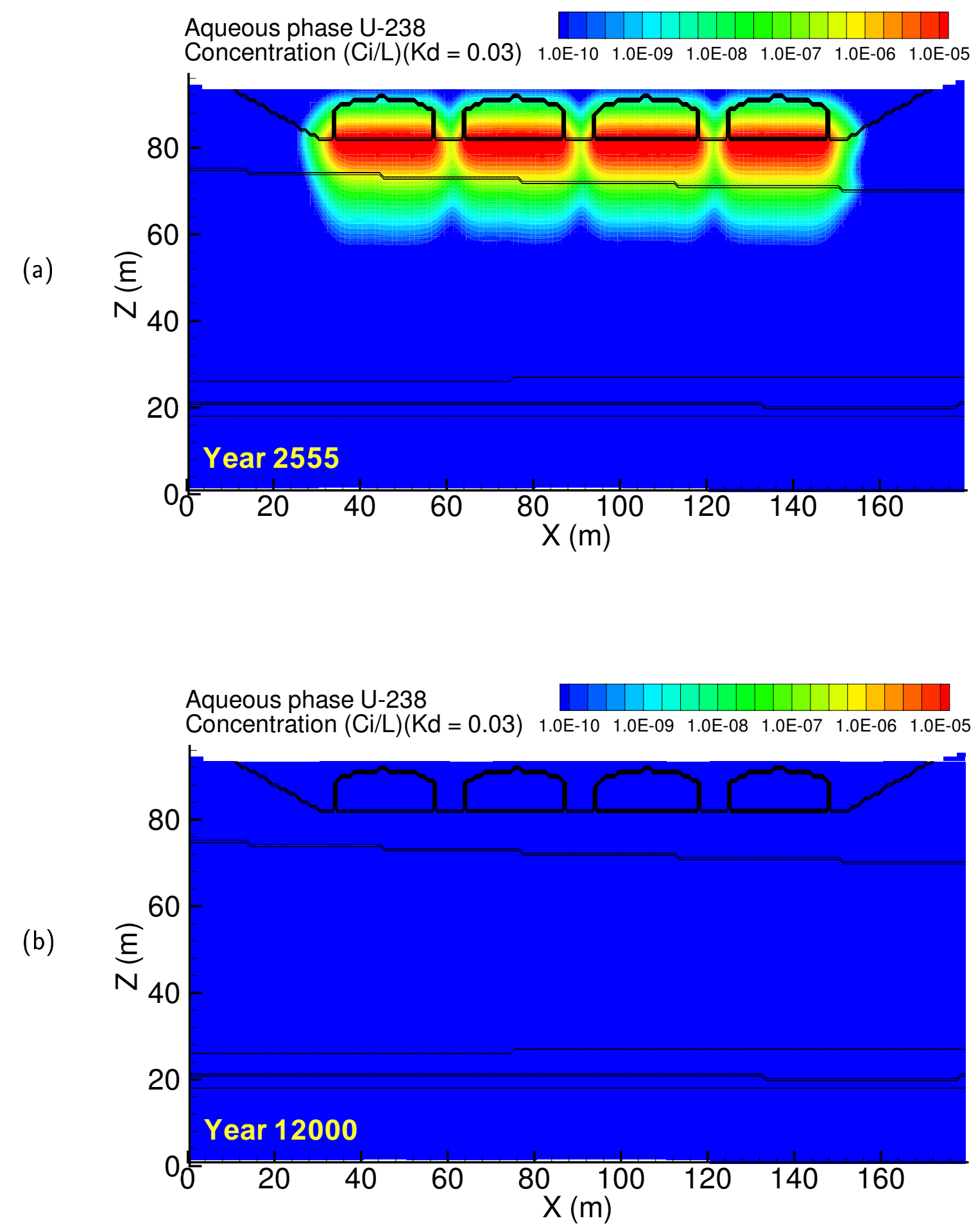

Figure A.67. Case 5v, U-238 $\left(\mathrm{K}_{d}=0.03\right)$ aqueous concentration at (a) year 2555 and (b) year 12000 

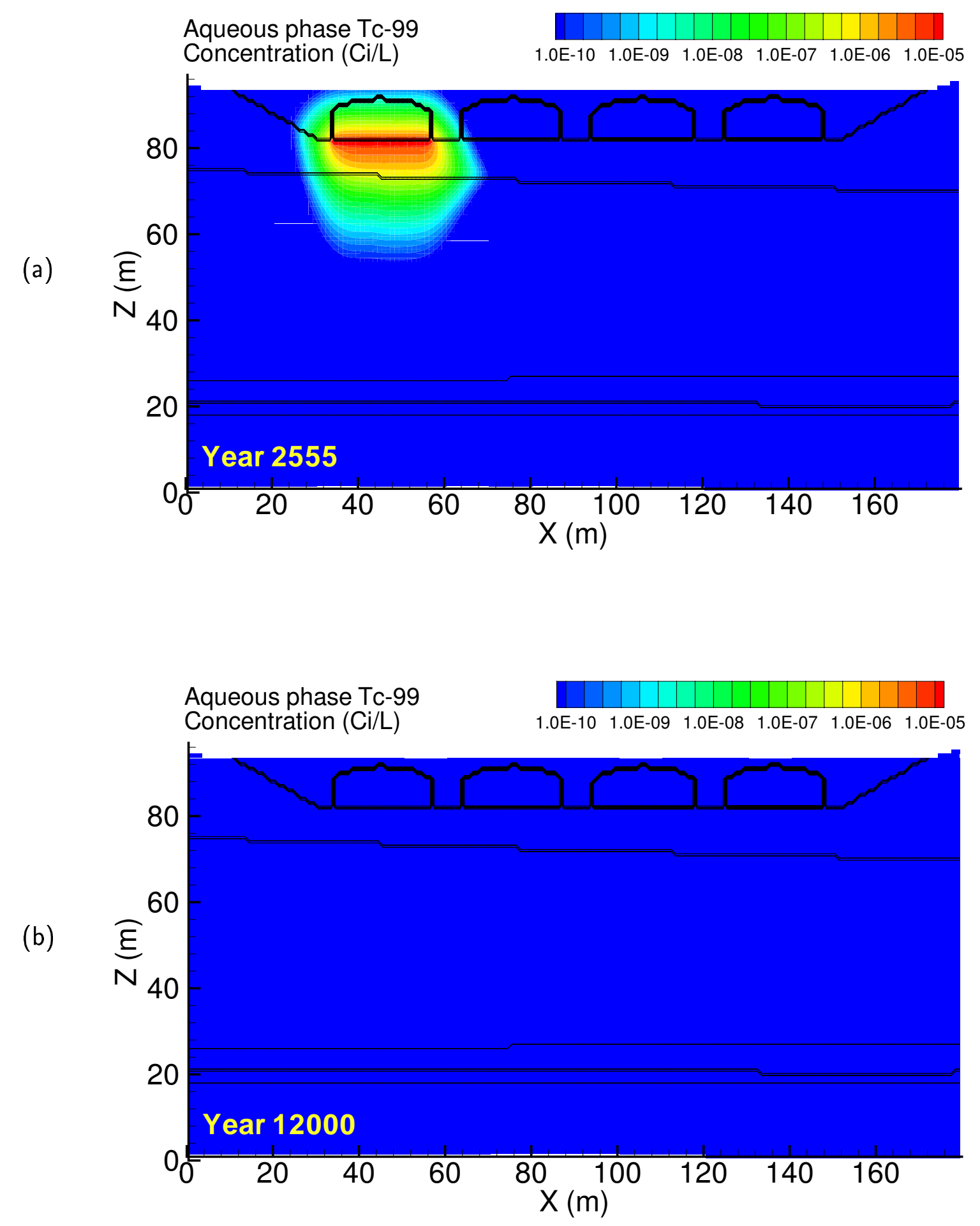

Figure A.68. Case 6, Tc-99 aqueous concentration at (a) year 2555 and (b) year 12000 

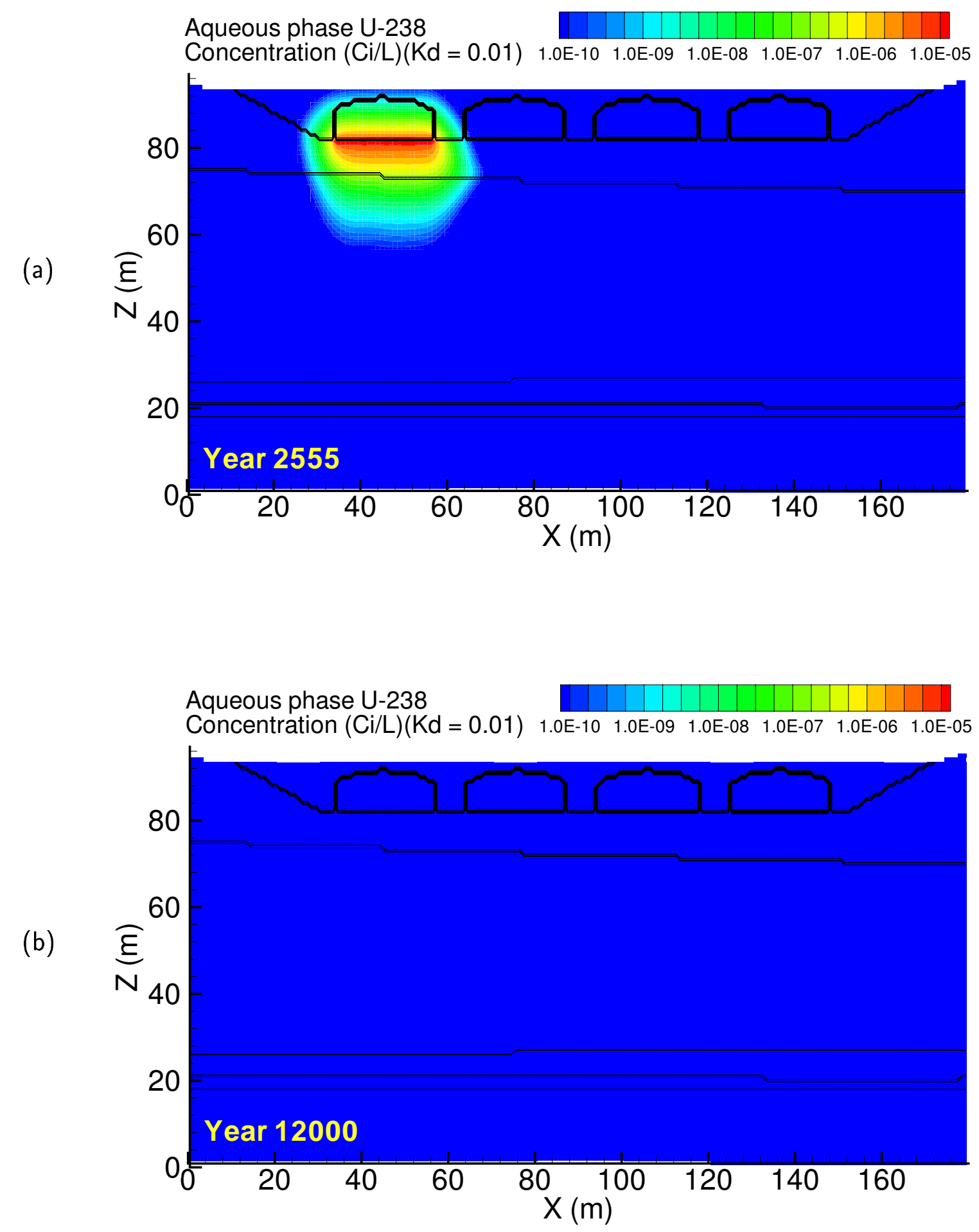

Figure A.69. Case 6, U-238 $\left(\mathrm{K}_{d}=0.01\right)$ aqueous concentration at (a) year 2555 and (b) year 12000 

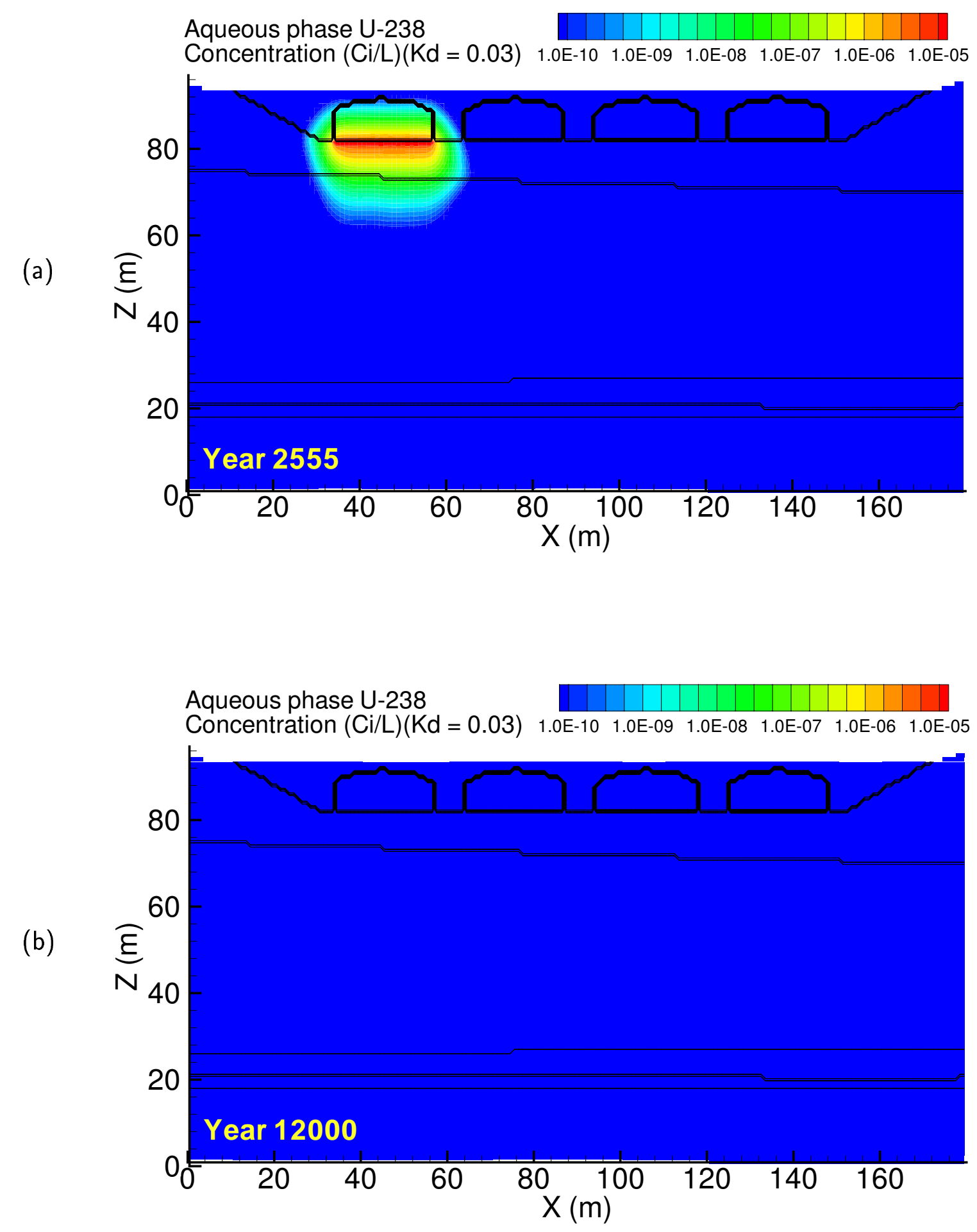

Figure A.70. Case 6, U-238 $\left(\mathrm{K}_{d}=0.03\right)$ aqueous concentration at (a) year 2555 and (b) year 12000 

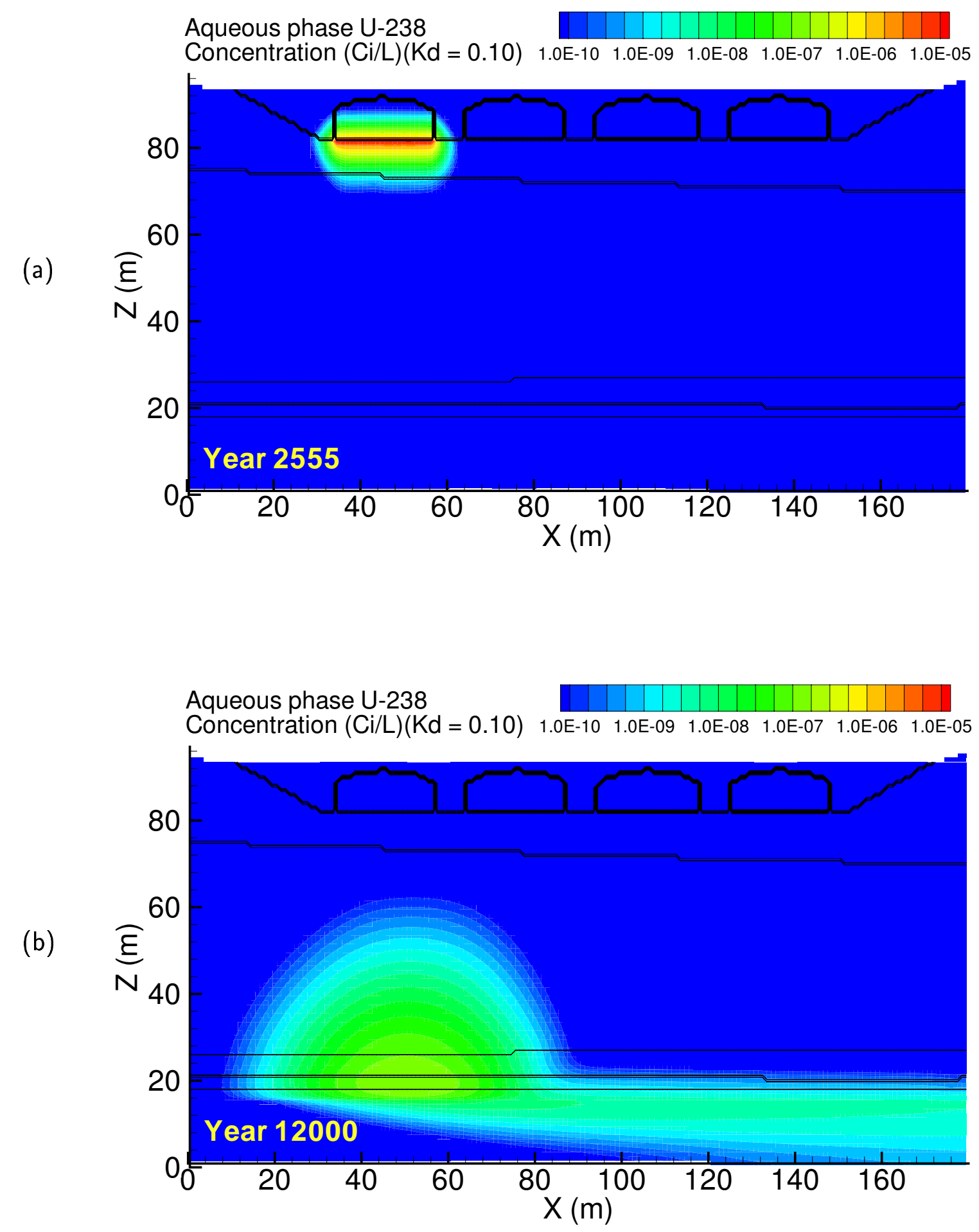

Figure A.71. Case 6, U-238 $\left(\mathrm{K}_{d}=0.10\right)$ aqueous concentration at (a) year 2555 and (b) year 12000 

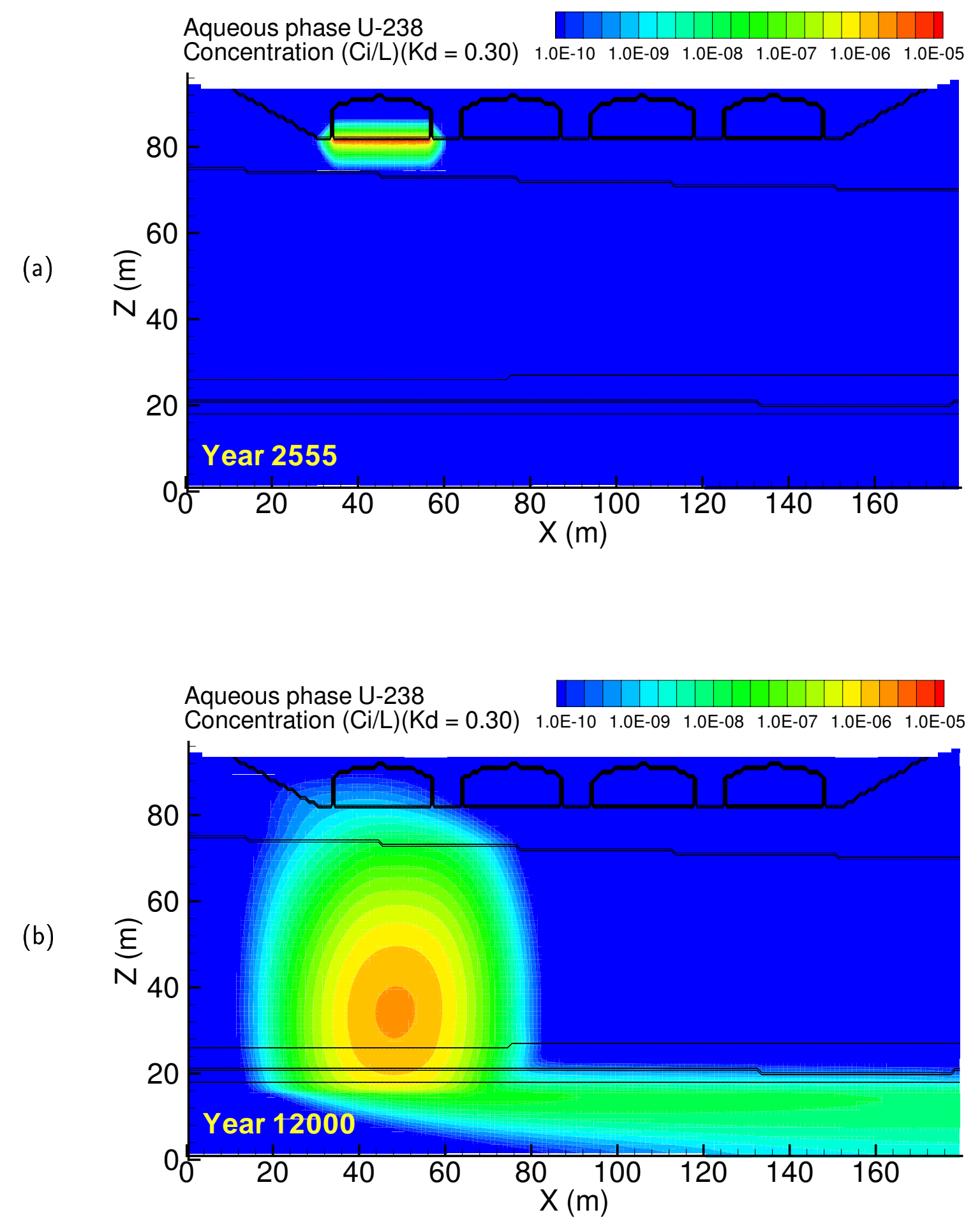

Figure A.72. Case 6, U-238 $\left(\mathrm{K}_{d}=0.30\right)$ aqueous concentration at (a) year 2555 and (b) year 12000 

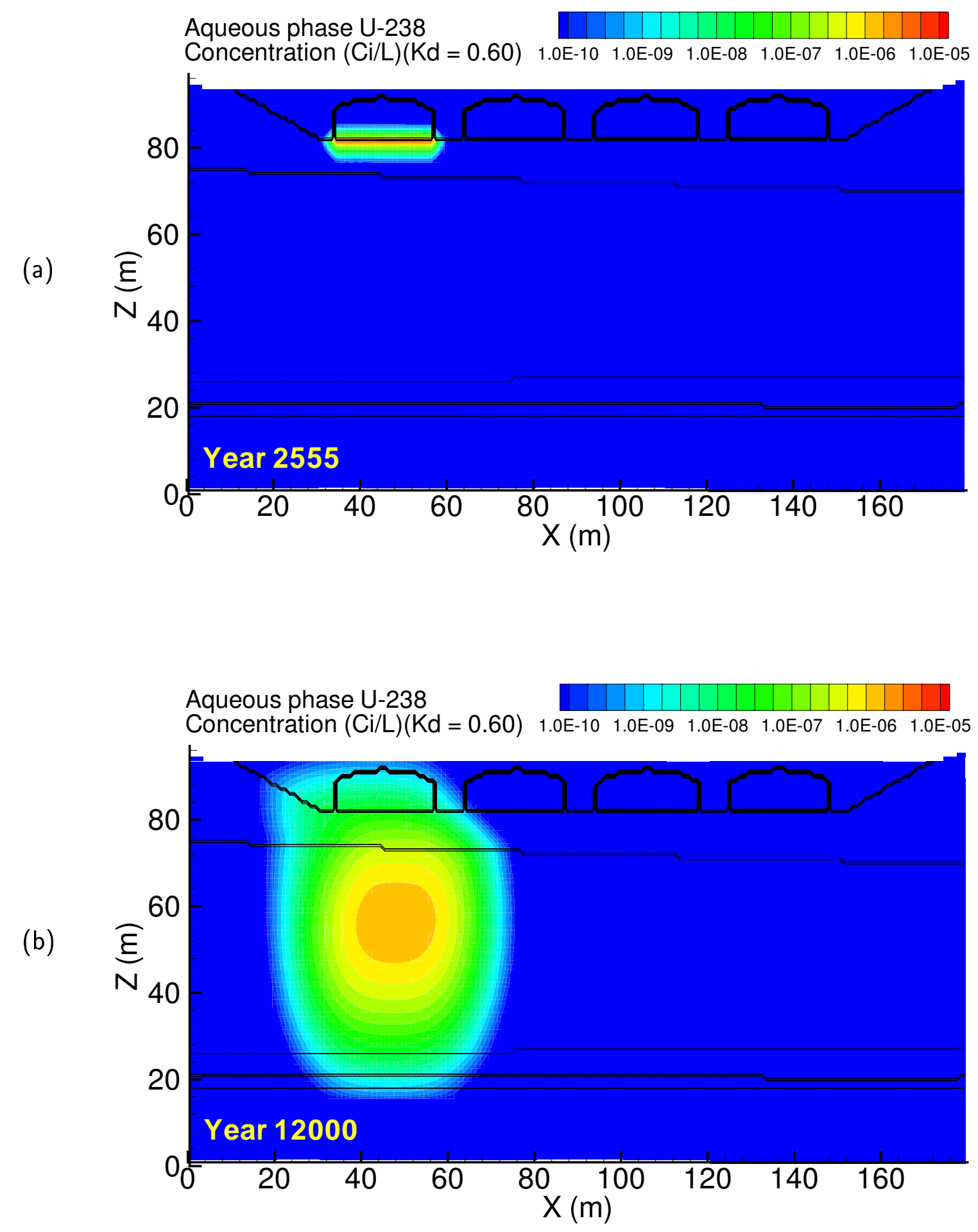

Figure A.73. Case 6, U-238 $\left(\mathrm{K}_{d}=0.60\right)$ aqueous concentration at (a) year 2555 and (b) year 12000 

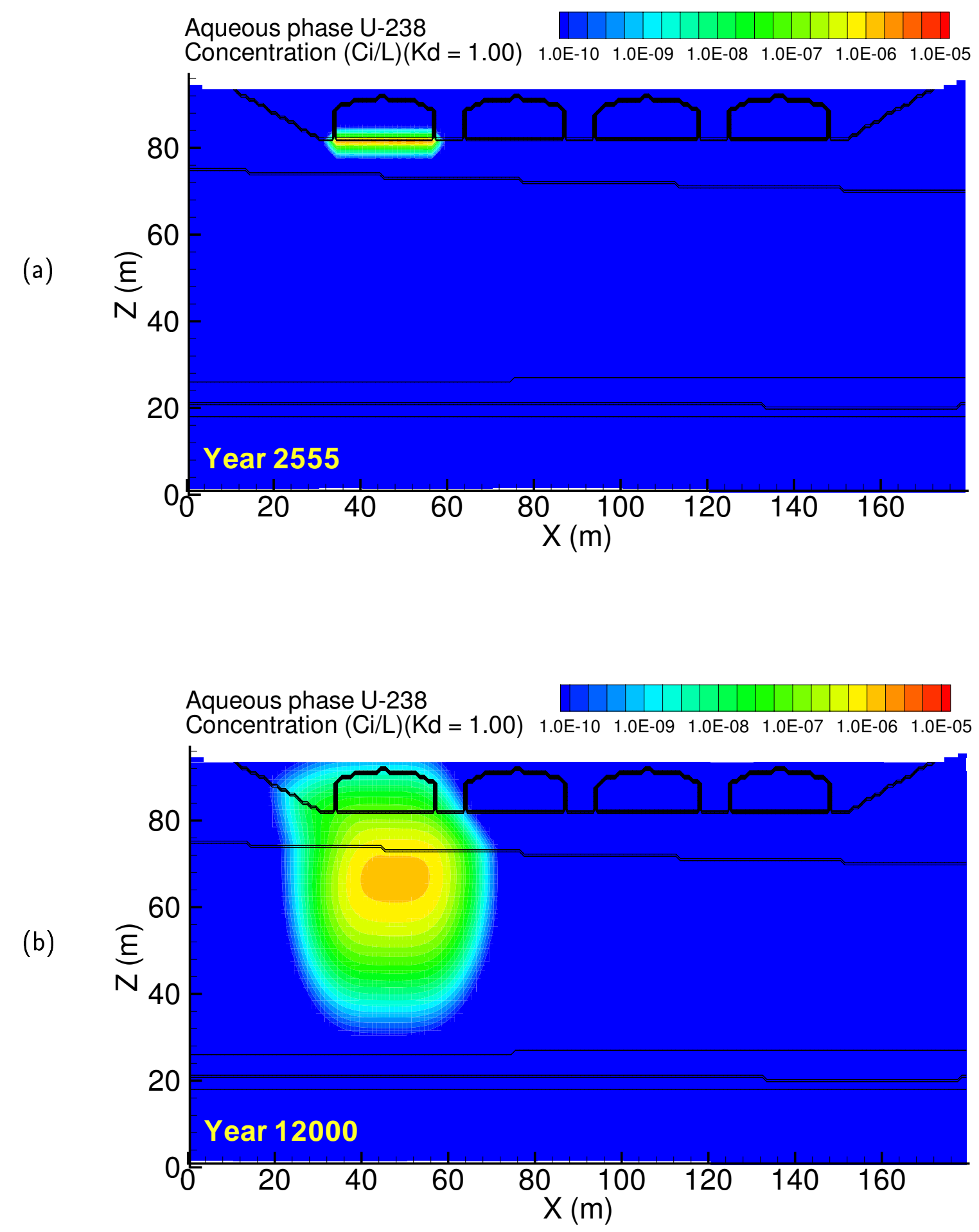

Figure A.74. Case 6, U-238 $\left(\mathrm{K}_{d}=1.00\right)$ aqueous concentration at (a) year 2555 and (b) year 12000 

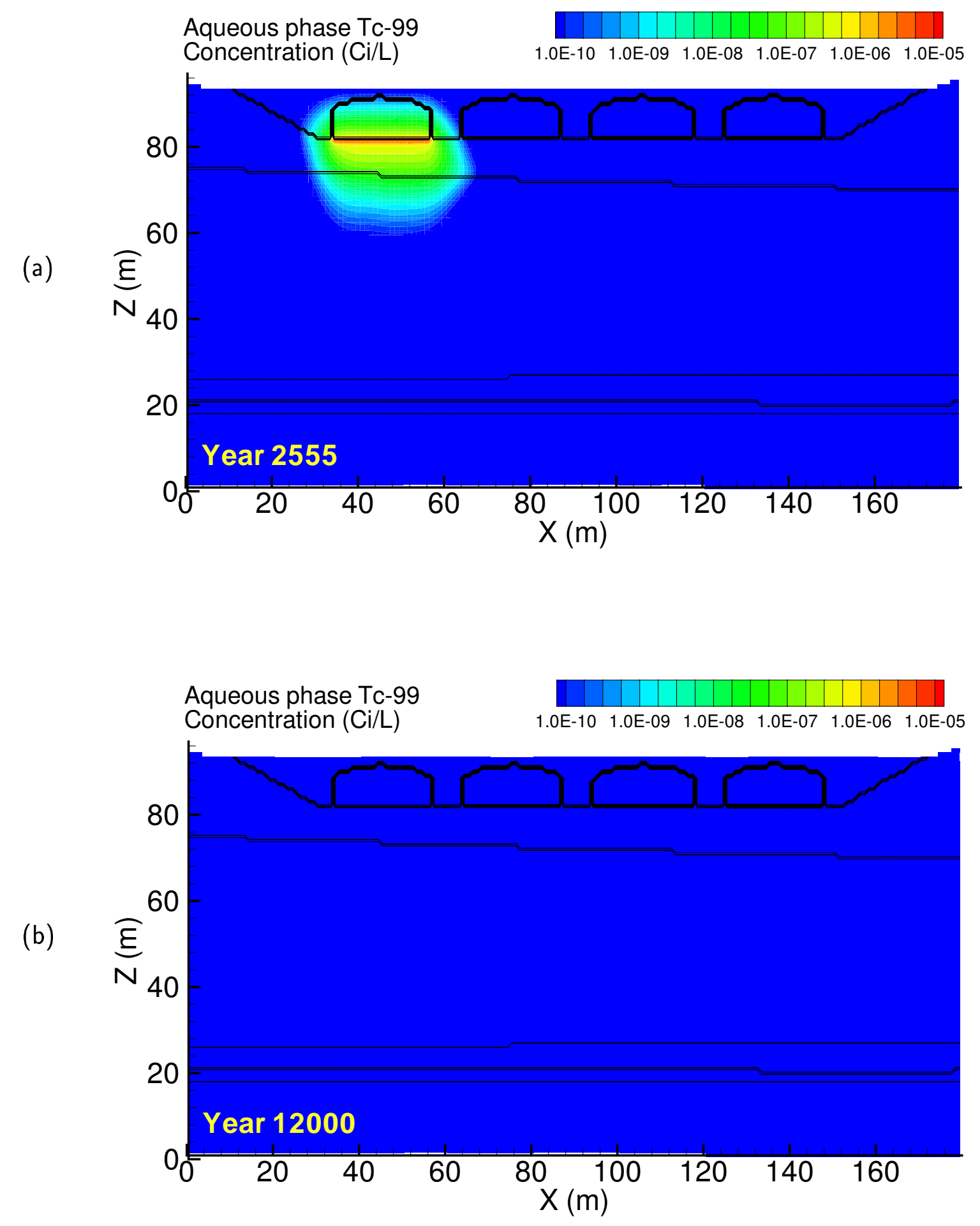

Figure A.75. Case 7, Tc-99 aqueous concentration at (a) year 2555 and (b) year 12000 

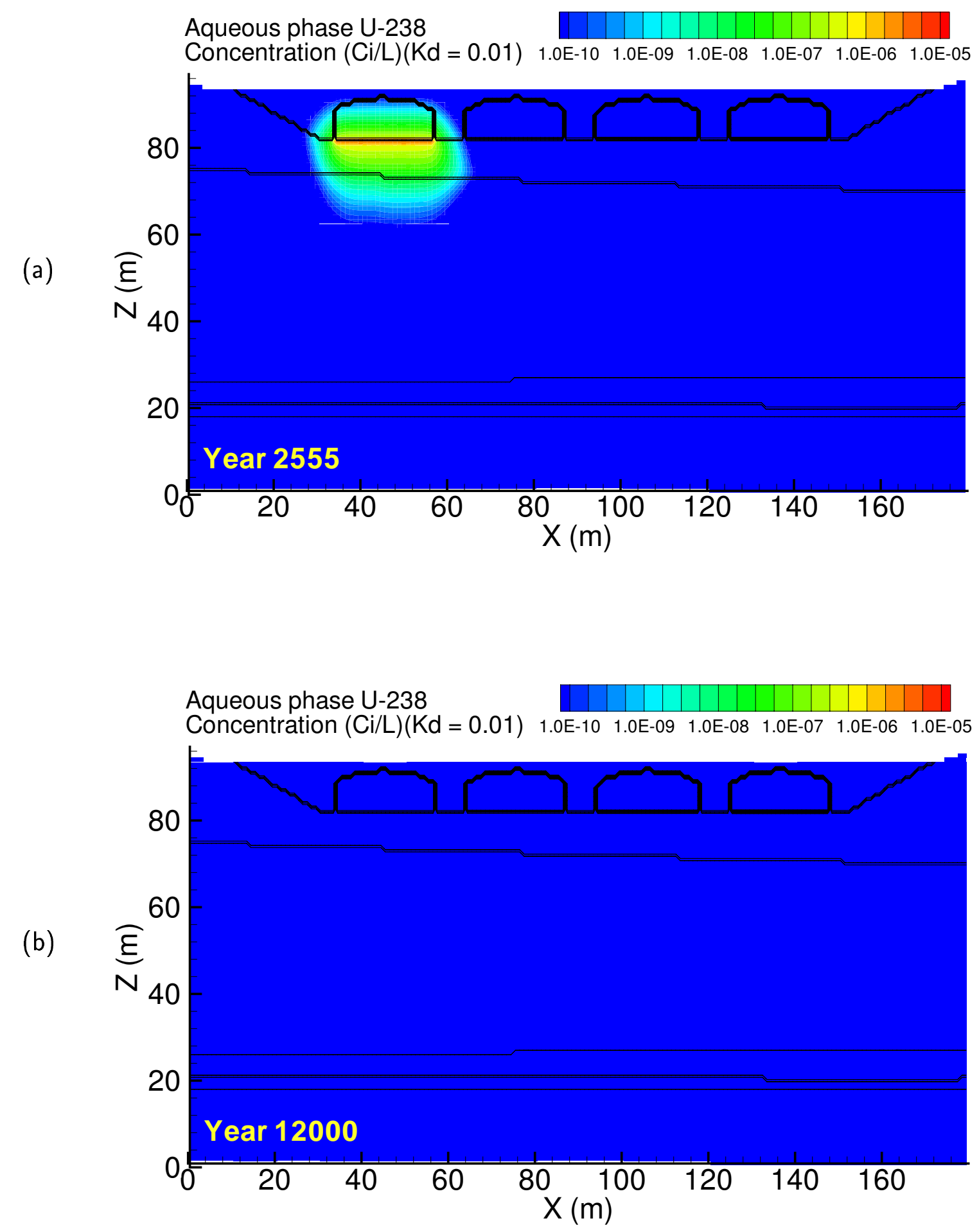

Figure A.76. Case 7, U-238 $\left(\mathrm{K}_{d}=0.01\right)$ aqueous concentration at (a) year 2555 and (b) year 12000 

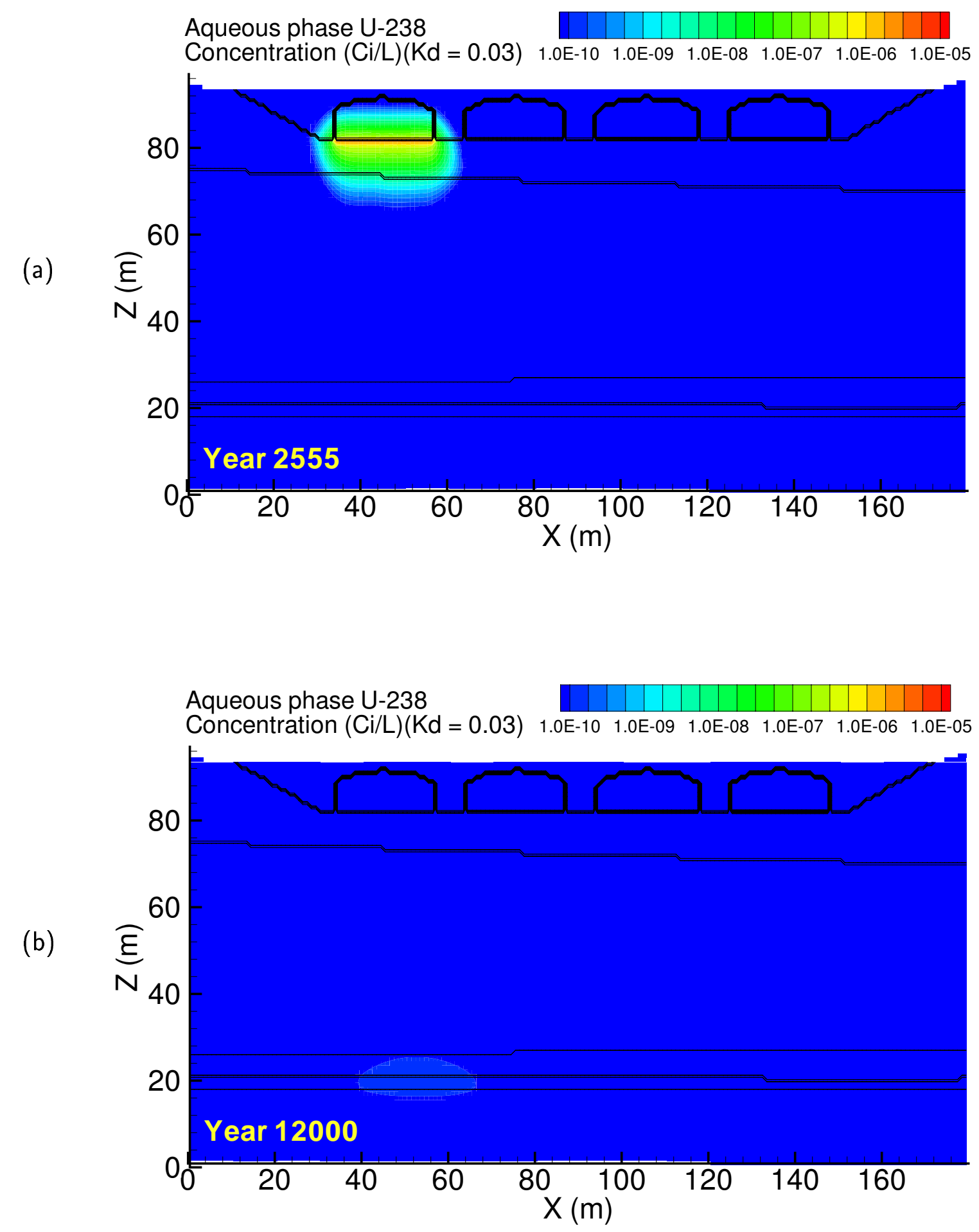

Figure A.77. Case 7, U-238 $\left(\mathrm{K}_{d}=0.03\right)$ aqueous concentration at (a) year 2555 and (b) year 12000 

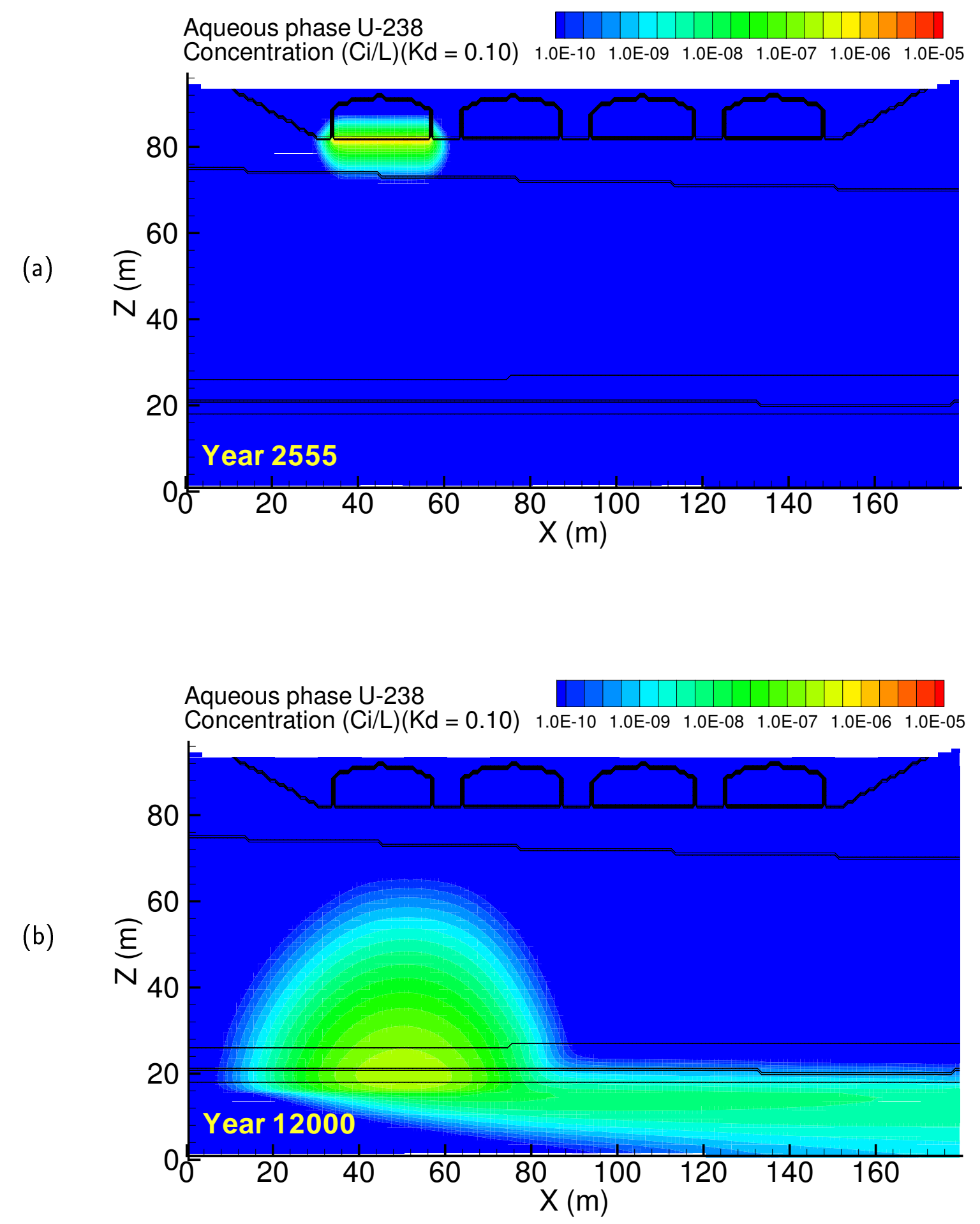

Figure A.78. Case 7, U-238 $\left(\mathrm{K}_{d}=0.10\right)$ aqueous concentration at (a) year 2555 and (b) year 12000 

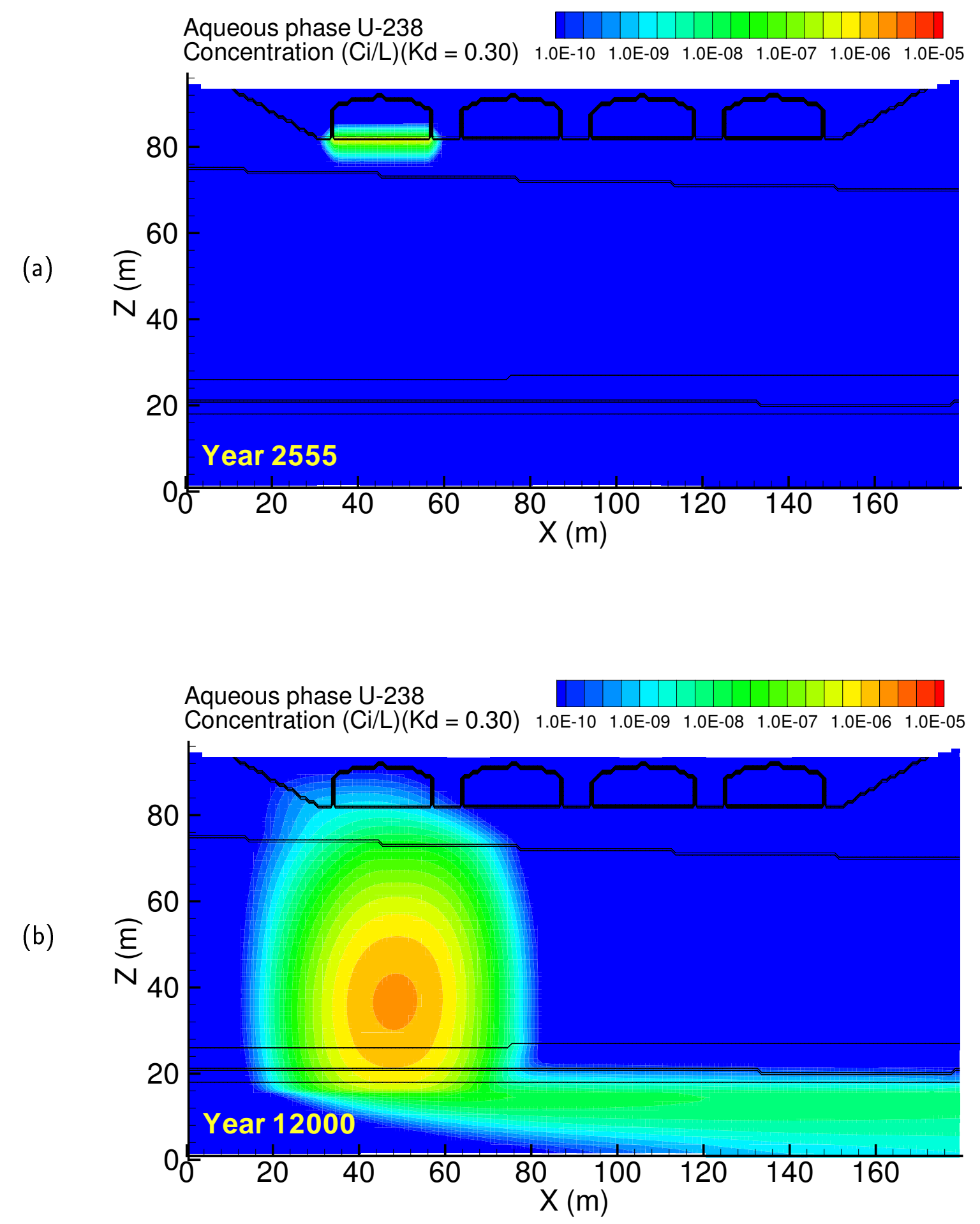

Figure A.79. Case 7, U-238 $\left(\mathrm{K}_{d}=0.30\right)$ aqueous concentration at (a) year 2555 and (b) year 12000 

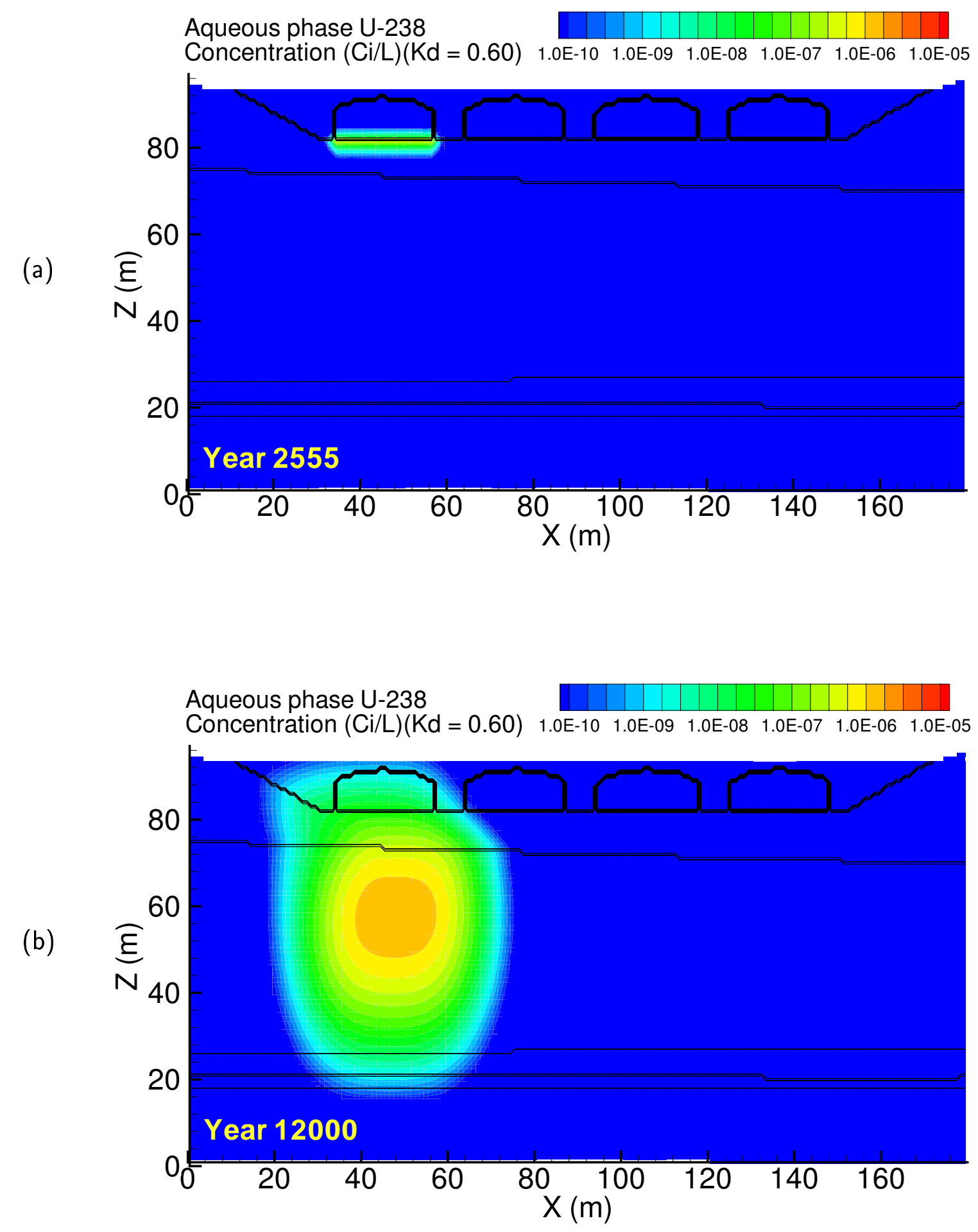

Figure A.80. Case 7, U-238 $\left(\mathrm{K}_{d}=0.60\right)$ aqueous concentration at (a) year 2555 and (b) year 12000 

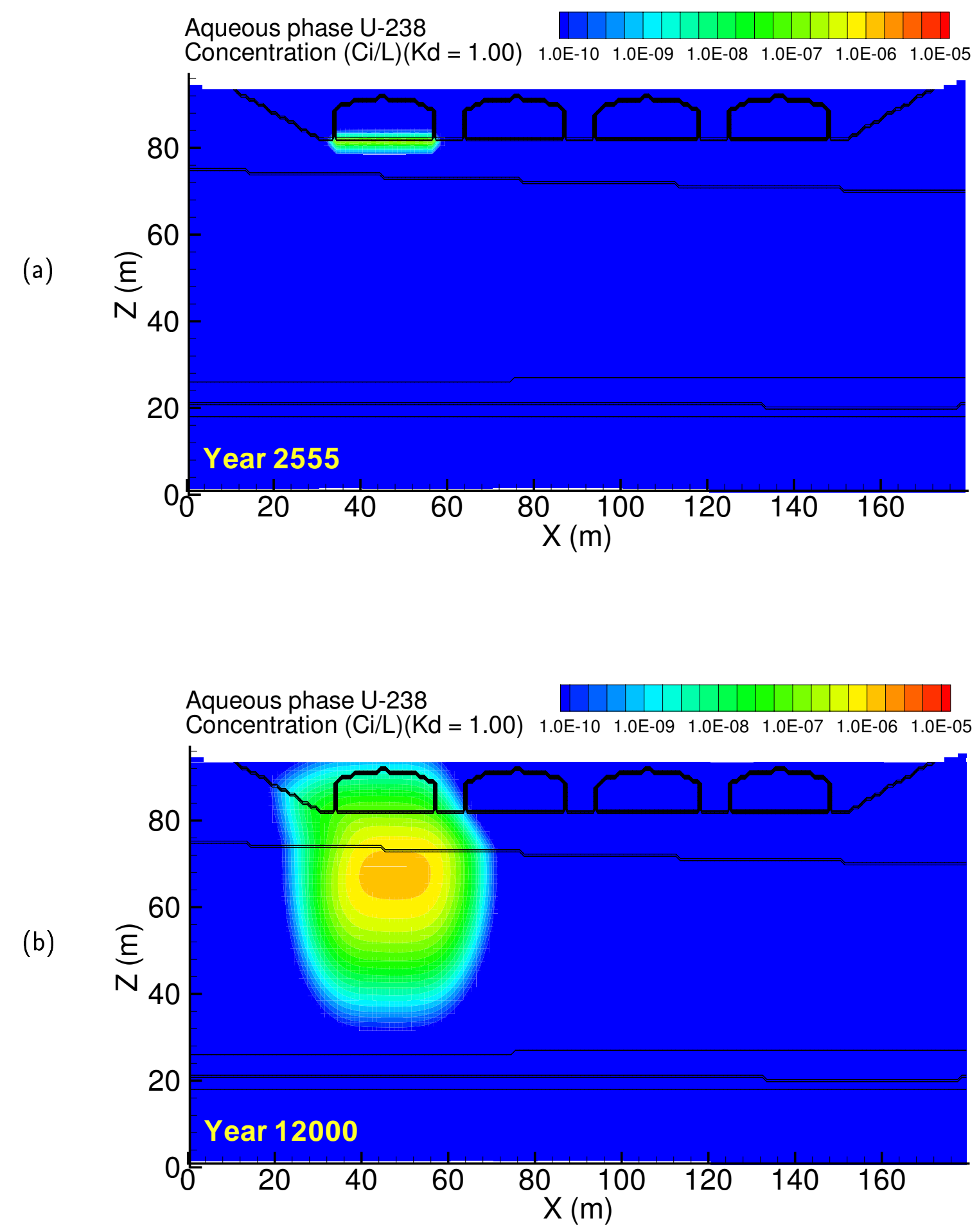

Figure A.81. Case 7, U-238 $\left(\mathrm{K}_{d}=1.00\right)$ aqueous concentration at (a) year 2555 and (b) year 12000 

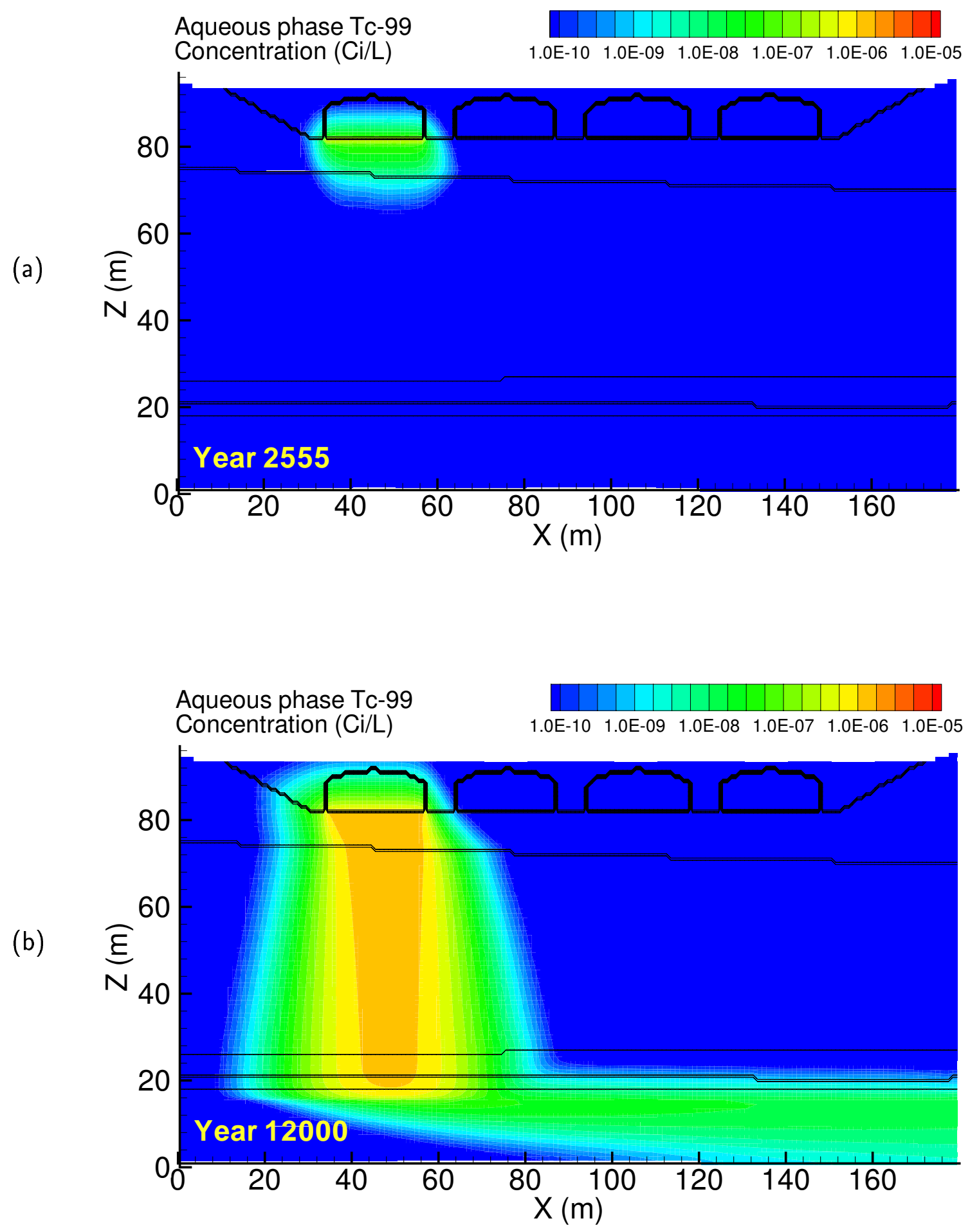

Figure A.82. Case 8, Tc-99 aqueous concentration at (a) year 2555 and (b) year 12000 

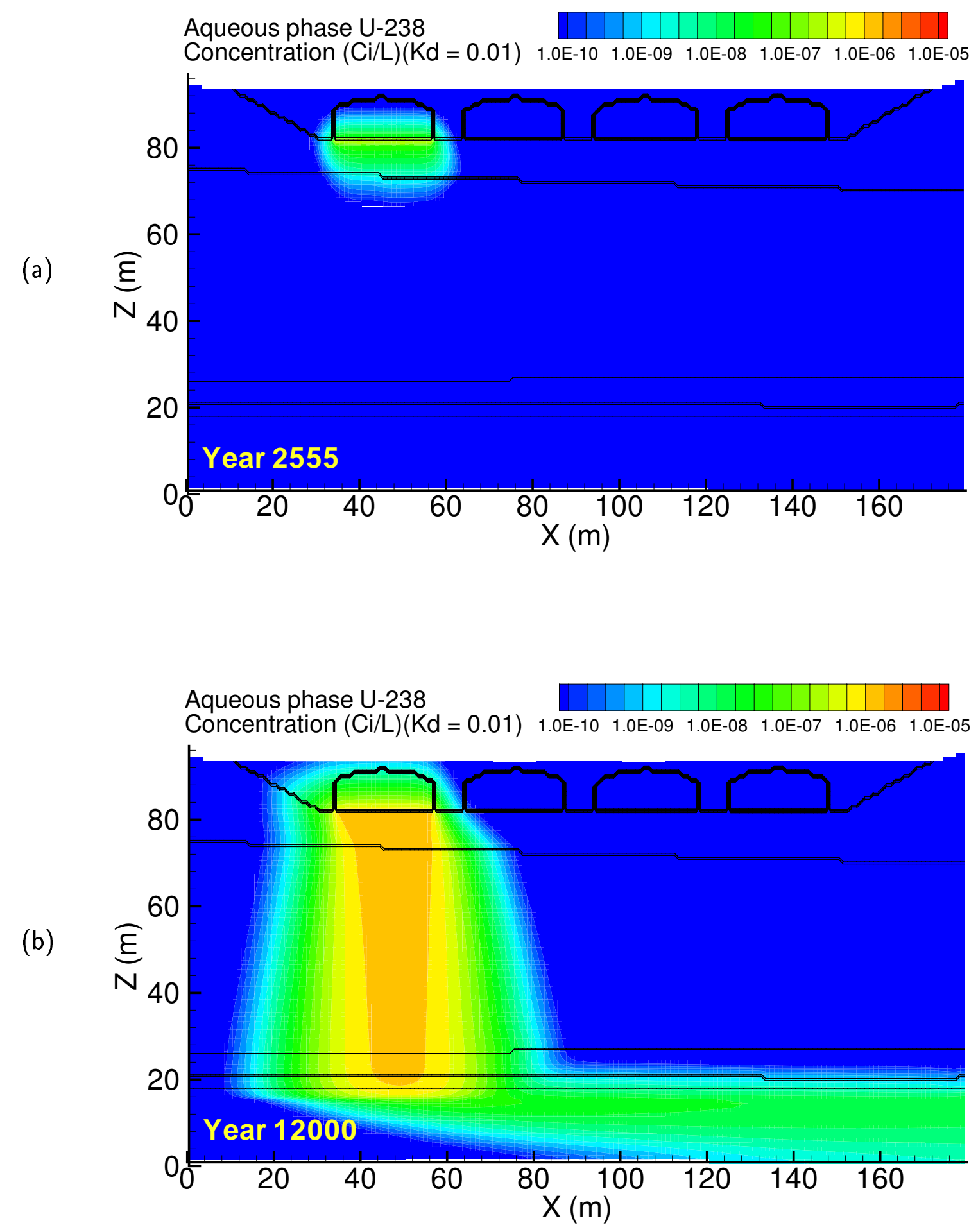

Figure A.83. Case 8, U-238 $\left(\mathrm{K}_{d}=0.01\right)$ aqueous concentration at (a) year 2555 and (b) year 12000 

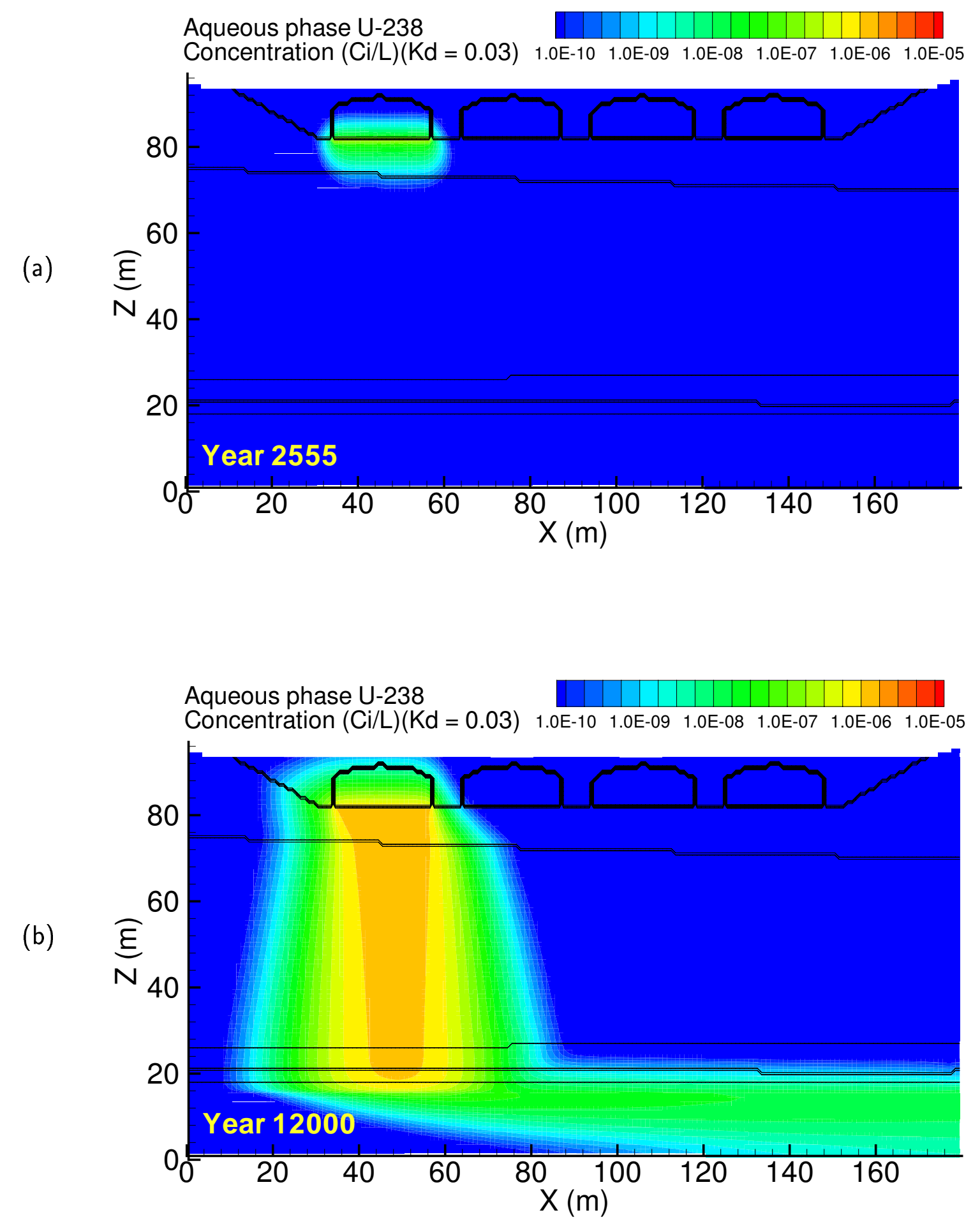

Figure A.84. Case 8, U-238 $\left(\mathrm{K}_{d}=0.03\right)$ aqueous concentration at (a) year 2555 and (b) year 12000 

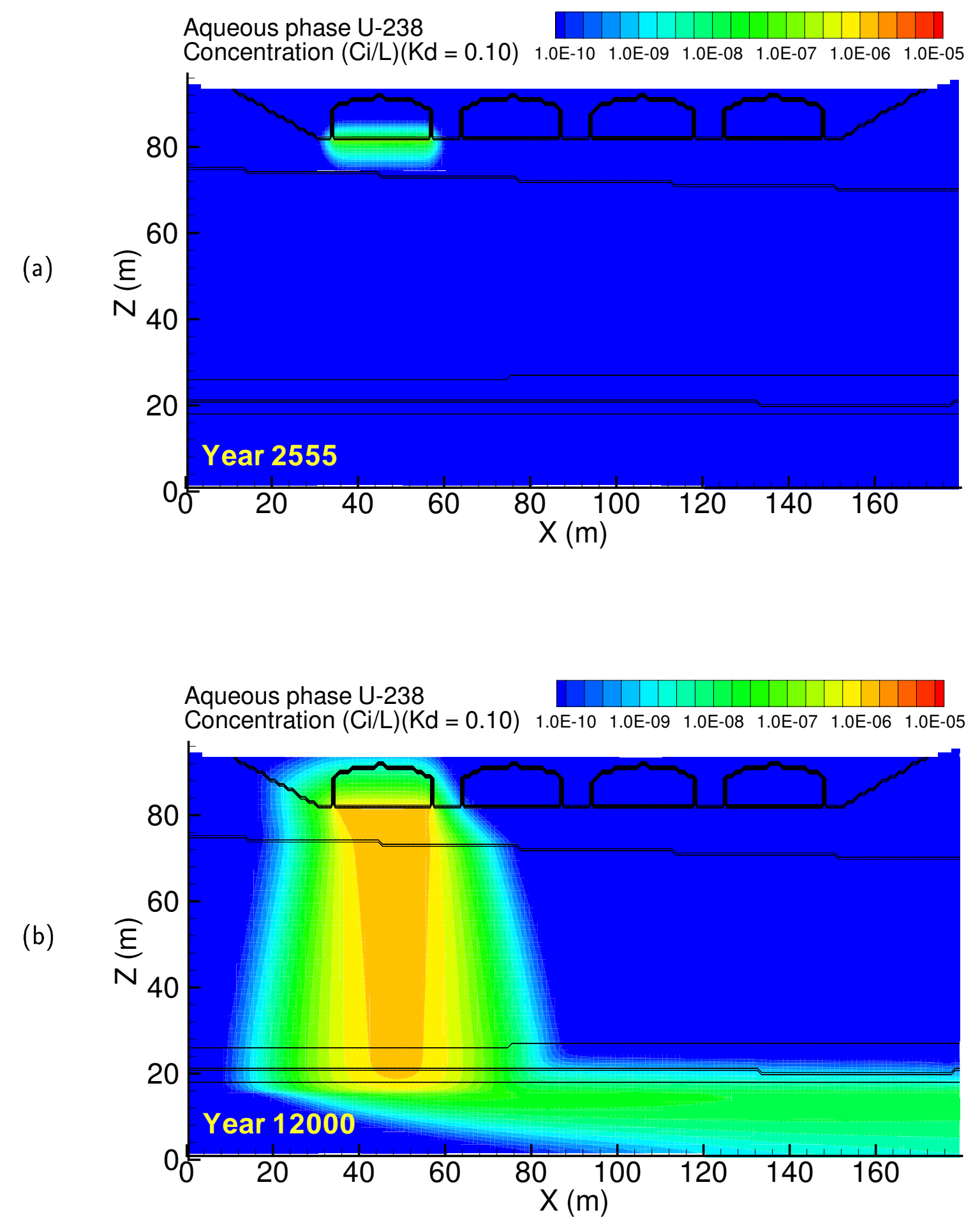

Figure A.85. Case 8, U-238 $\left(\mathrm{K}_{d}=0.10\right)$ aqueous concentration at (a) year 2555 and (b) year 12000 

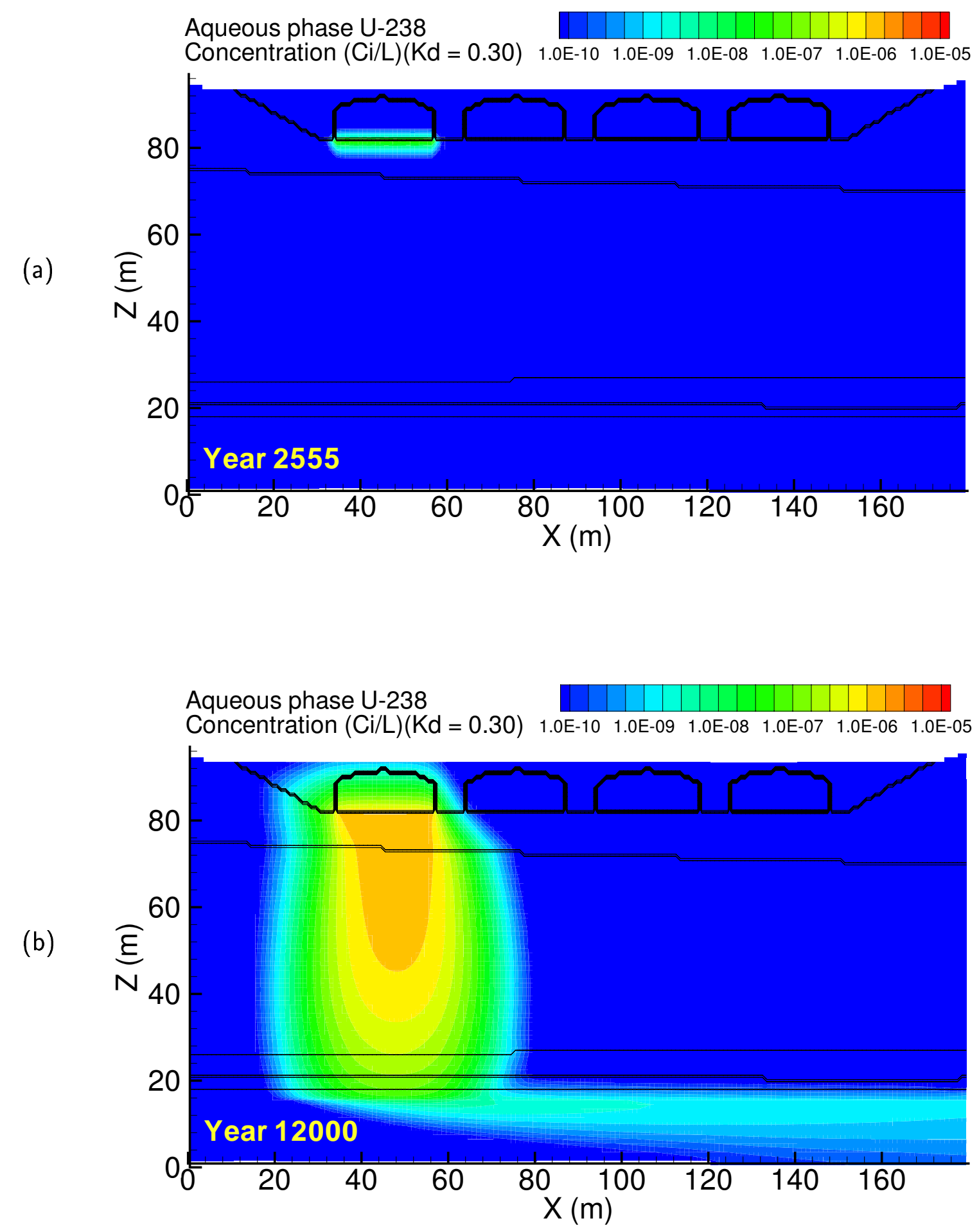

Figure A.86. Case 8, U-238 $\left(\mathrm{K}_{d}=0.30\right)$ aqueous concentration at (a) year 2555 and (b) year 12000 

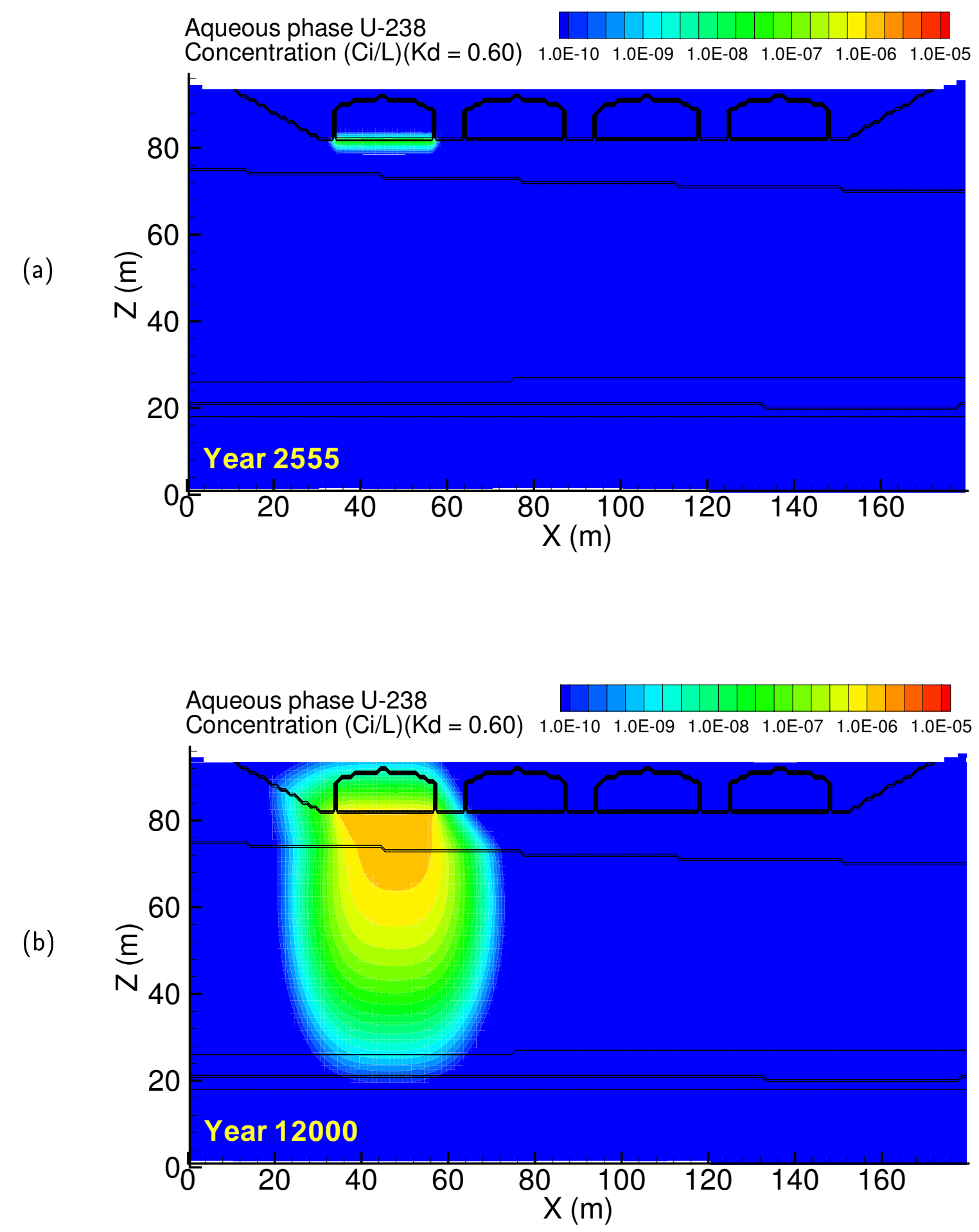

Figure A.87. Case 8, U-238 $\left(\mathrm{K}_{d}=0.60\right)$ aqueous concentration at (a) year 2555 and (b) year 12000 

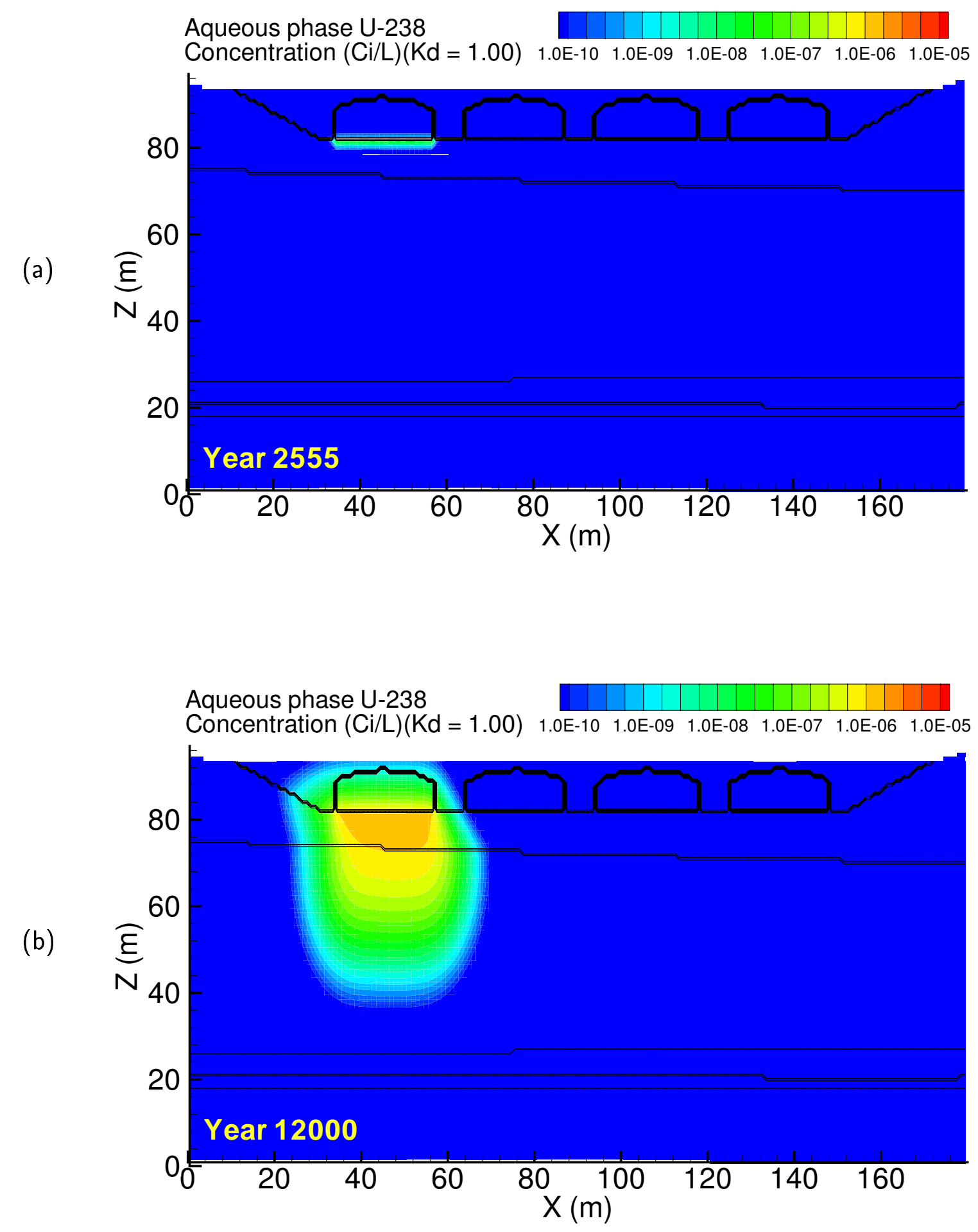

Figure A.88. Case 8, U-238 $\left(\mathrm{K}_{d}=1.00\right)$ aqueous concentration at (a) year 2555 and (b) year 12000 

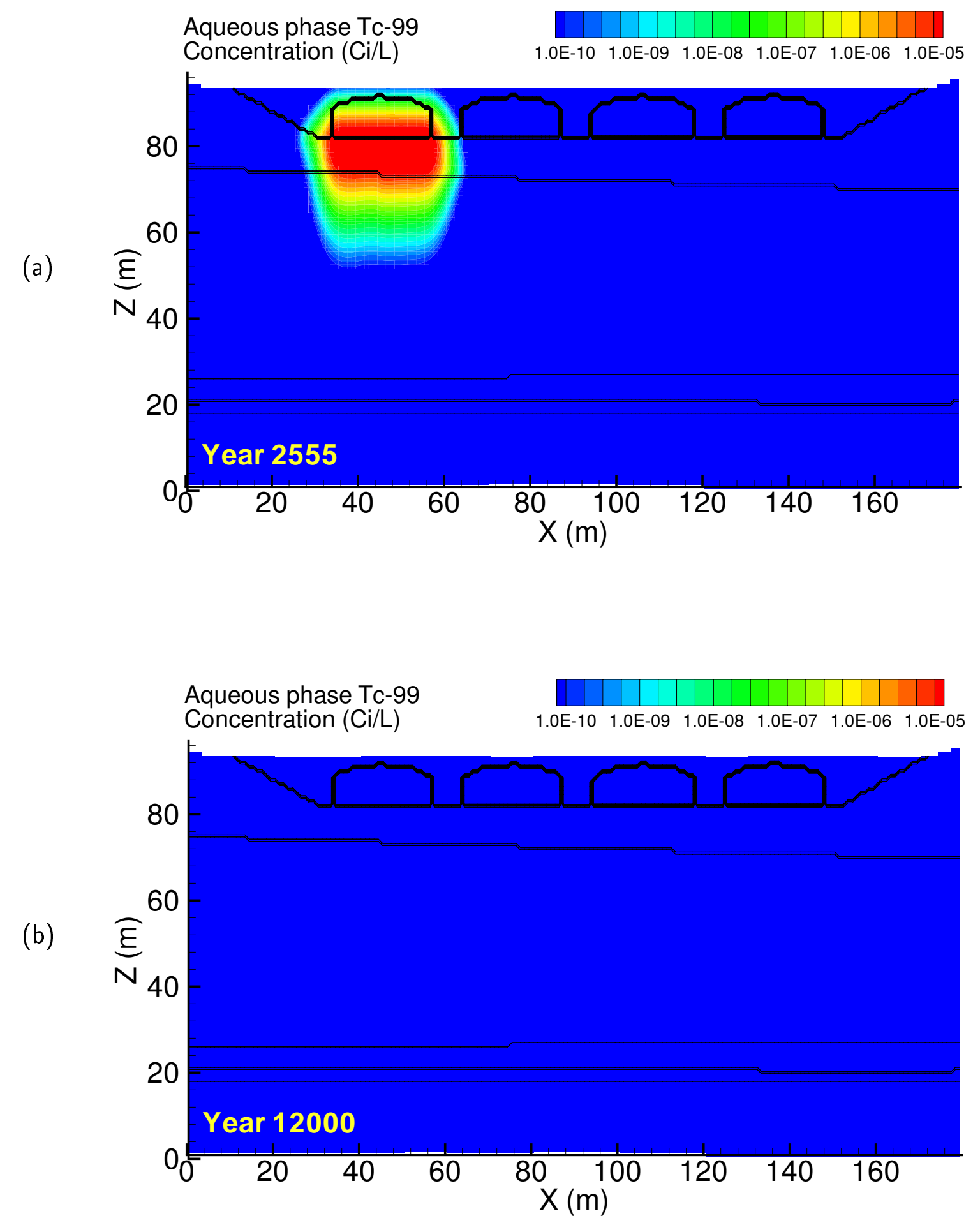

Figure A.89. Case 9, Tc-99 aqueous concentration at (a) year 2555 and (b) year 12000 

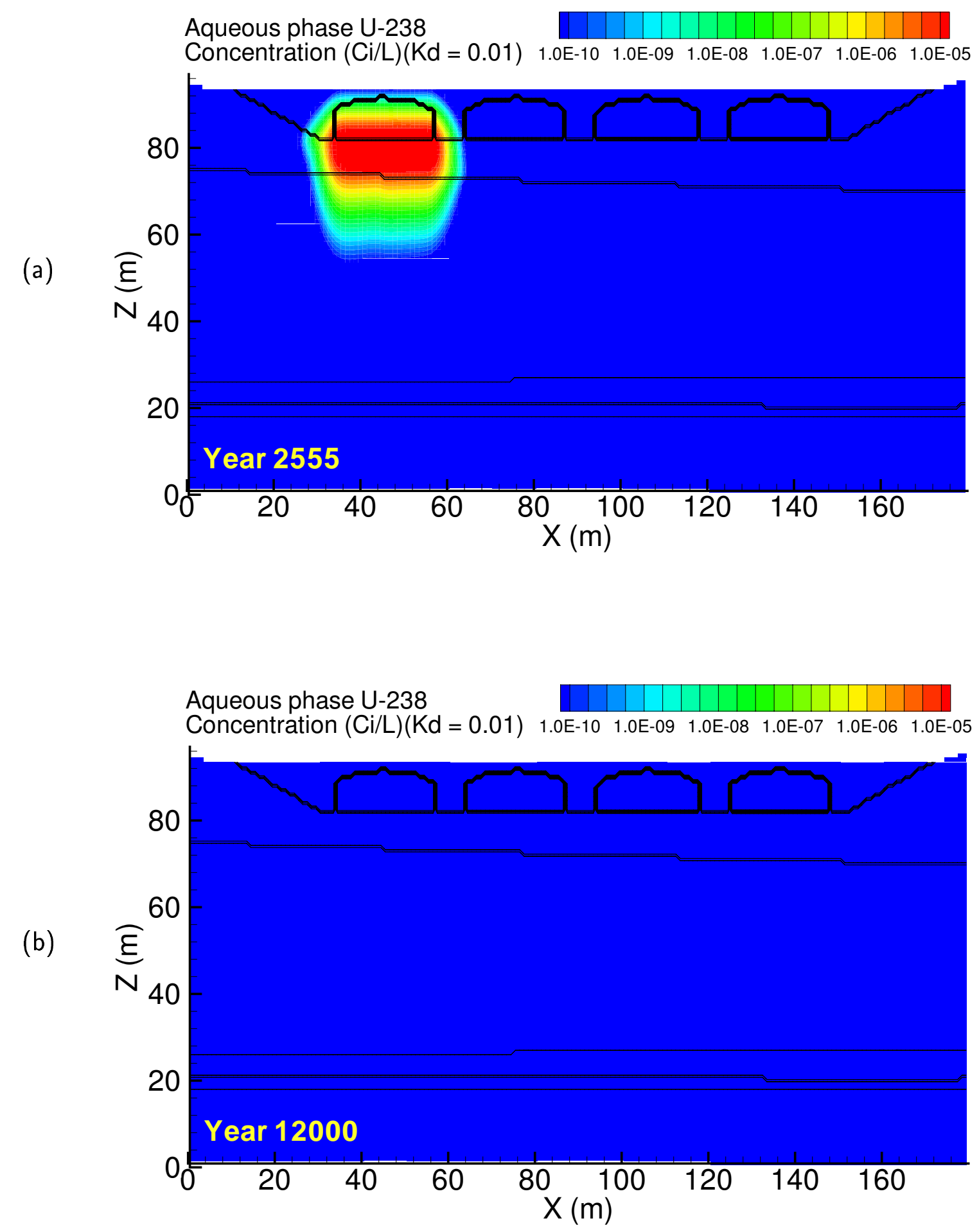

Figure A.90. Case 9, U-238 $\left(\mathrm{K}_{d}=0.01\right)$ aqueous concentration at (a) year 2555 and (b) year 12000 

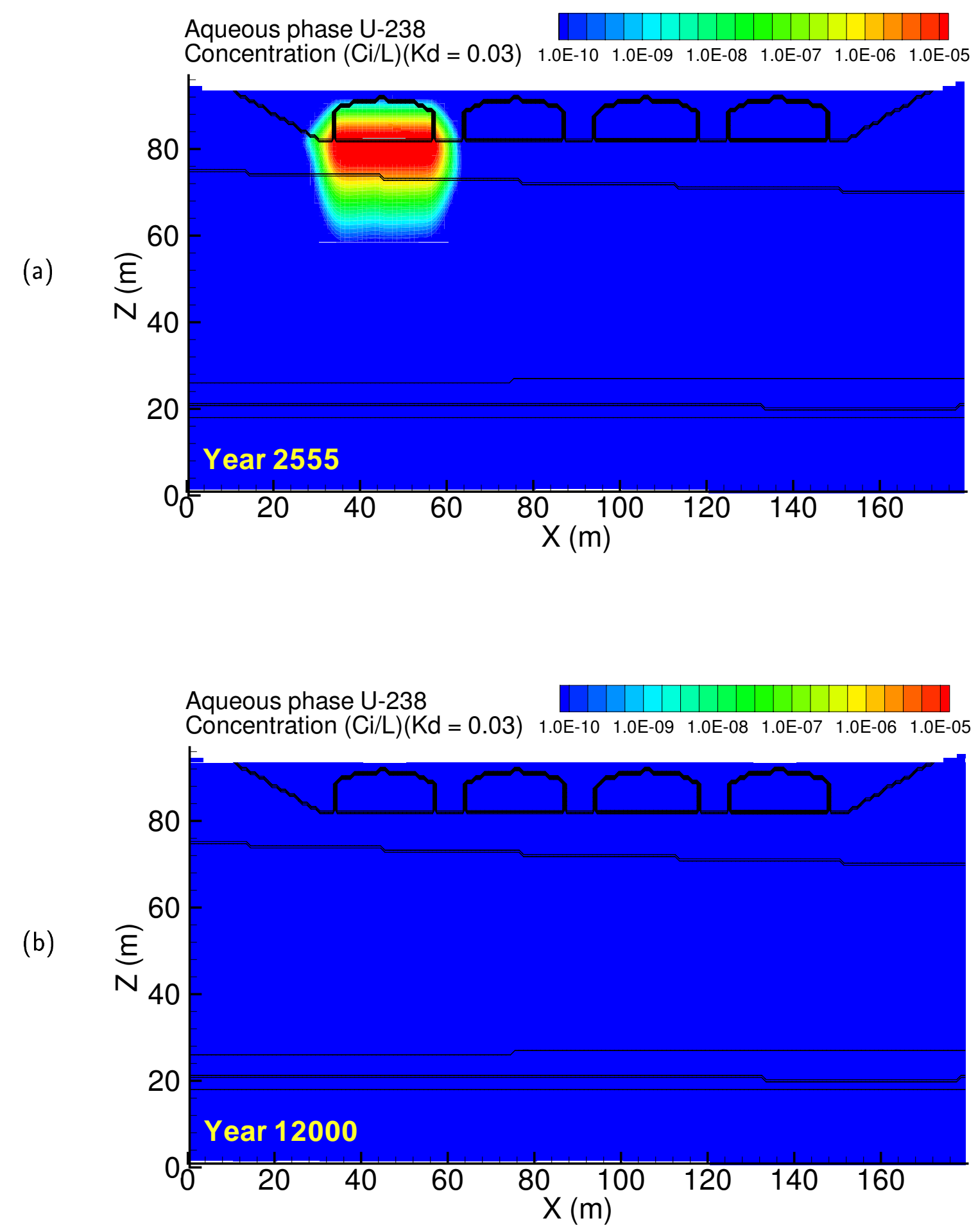

Figure A.91. Case 9, U-238 $\left(\mathrm{K}_{d}=0.03\right)$ aqueous concentration at (a) year 2555 and (b) year 12000 

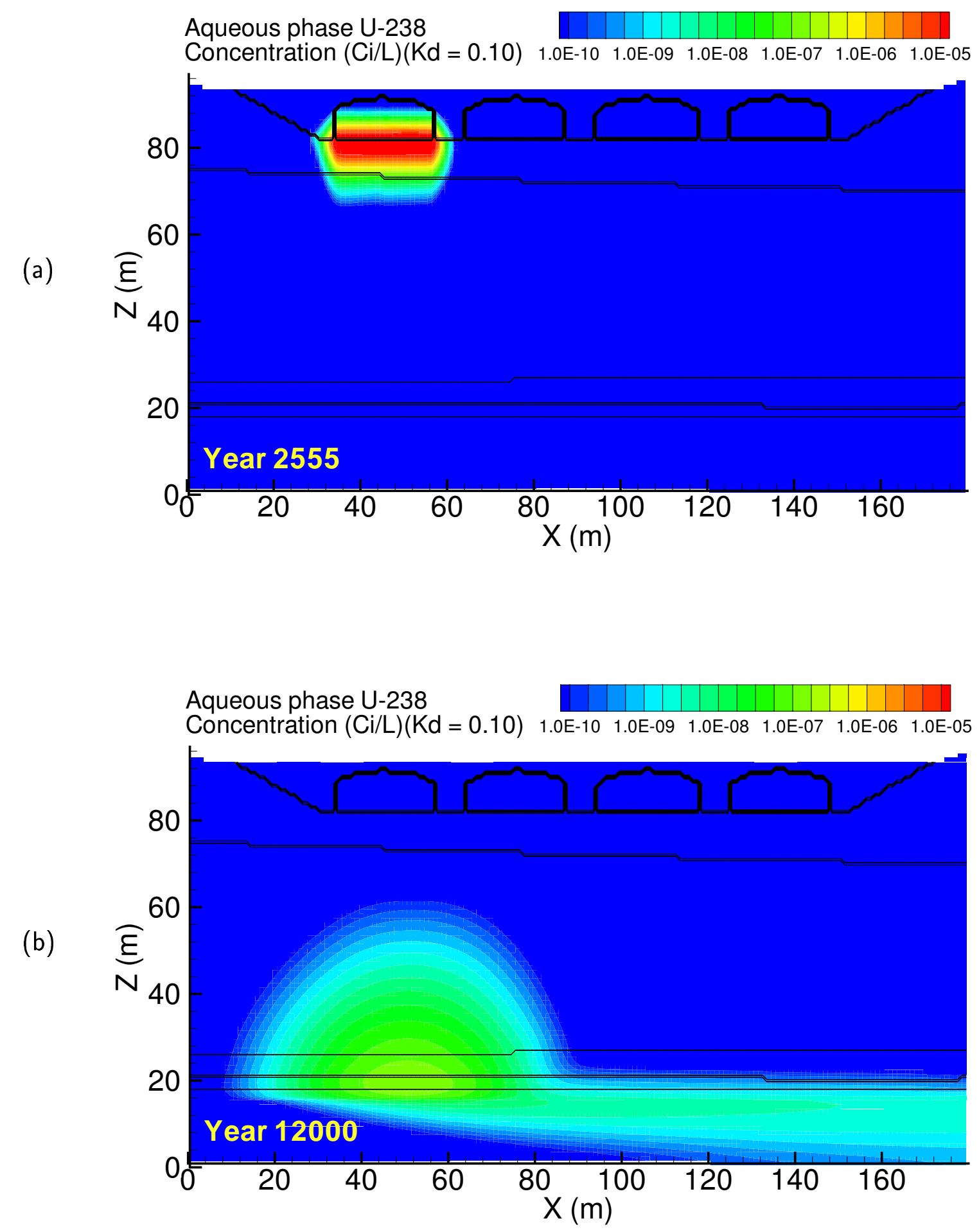

Figure A.92. Case 9, U-238 $\left(\mathrm{K}_{d}=0.10\right)$ aqueous concentration at (a) year 2555 and (b) year 12000 

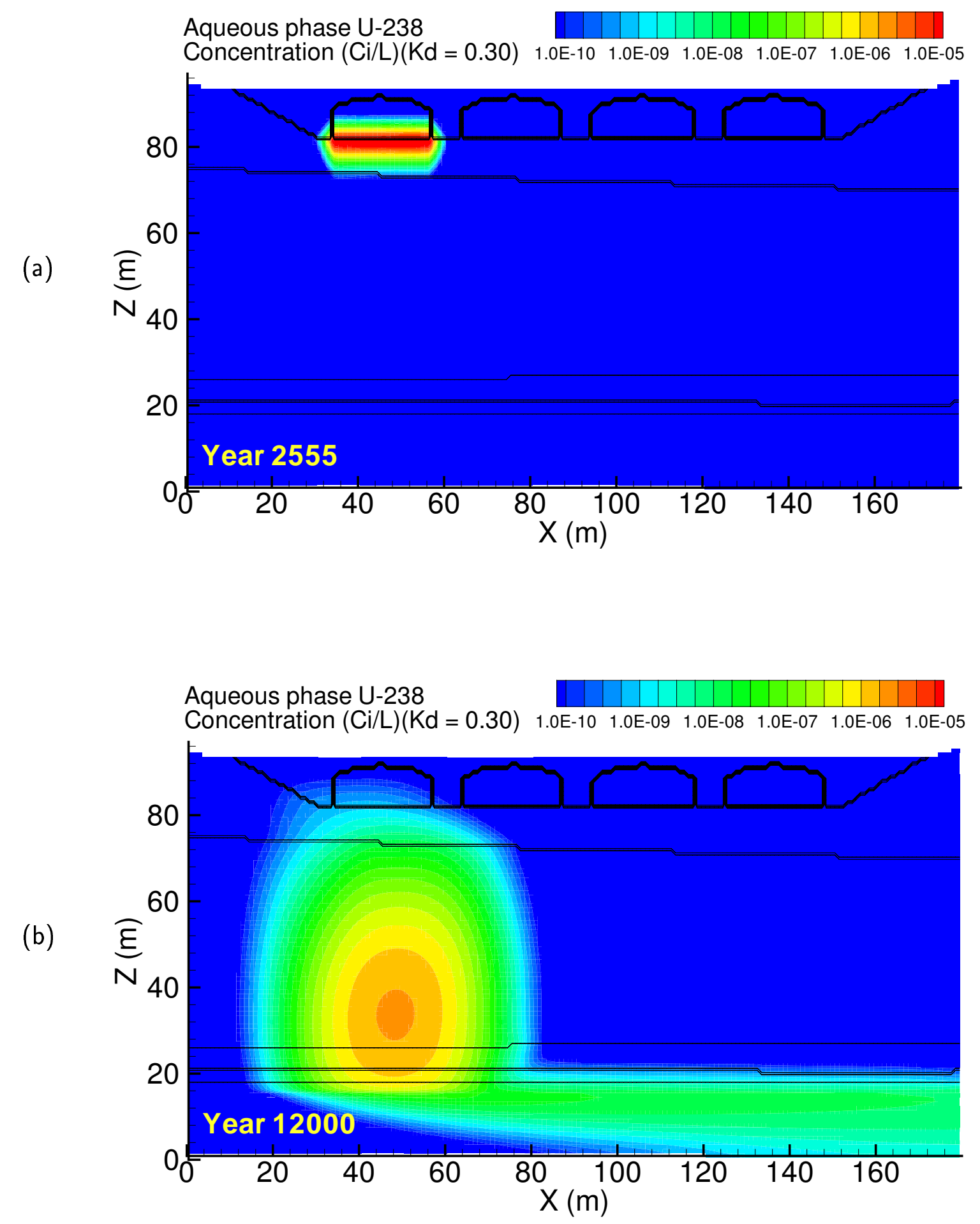

Figure A.93. Case 9, U-238 $\left(\mathrm{K}_{d}=0.30\right)$ aqueous concentration at (a) year 2555 and (b) year 12000 

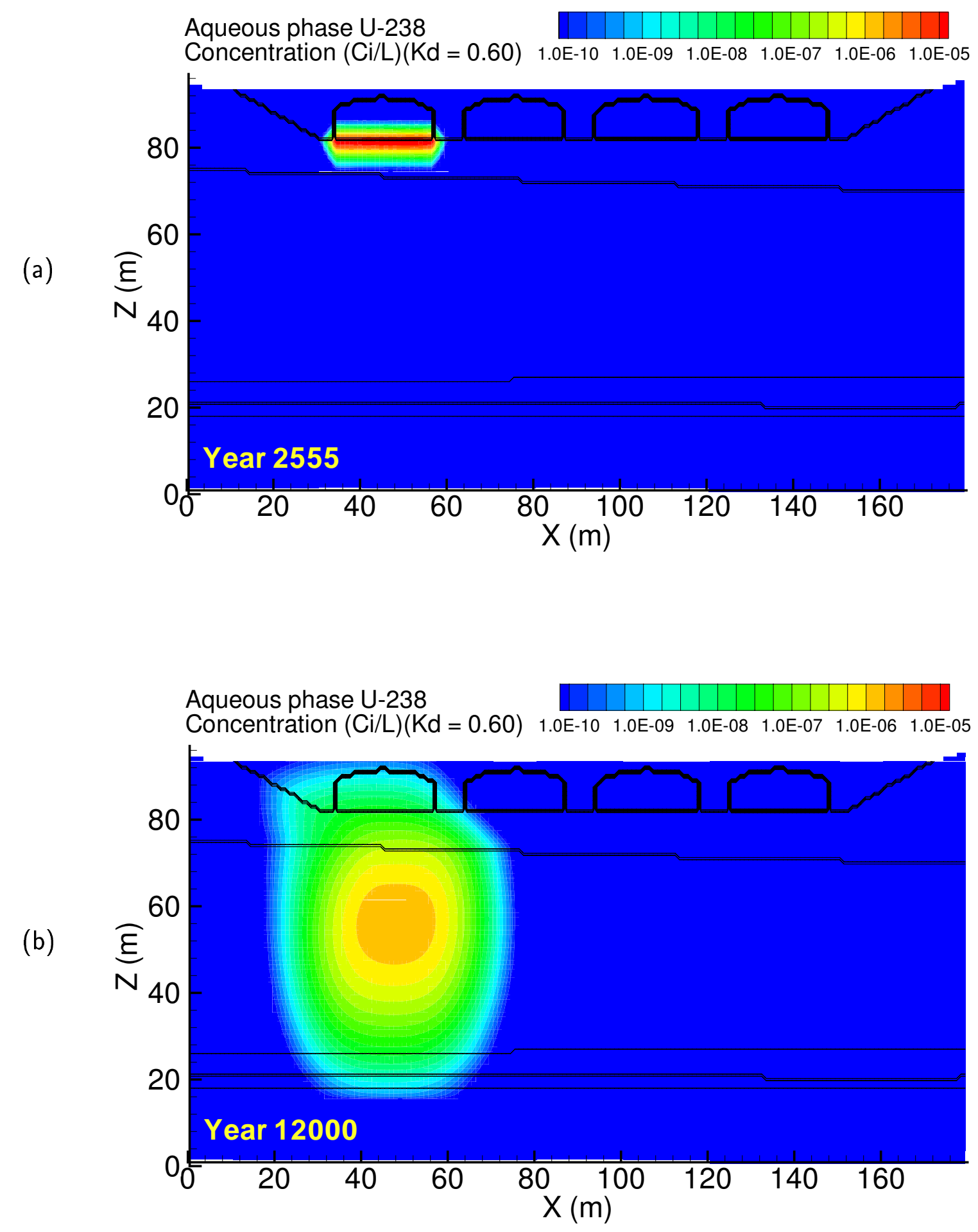

Figure A.94. Case 9, U-238 $\left(\mathrm{K}_{d}=0.60\right)$ aqueous concentration at (a) year 2555 and (b) year 12000 

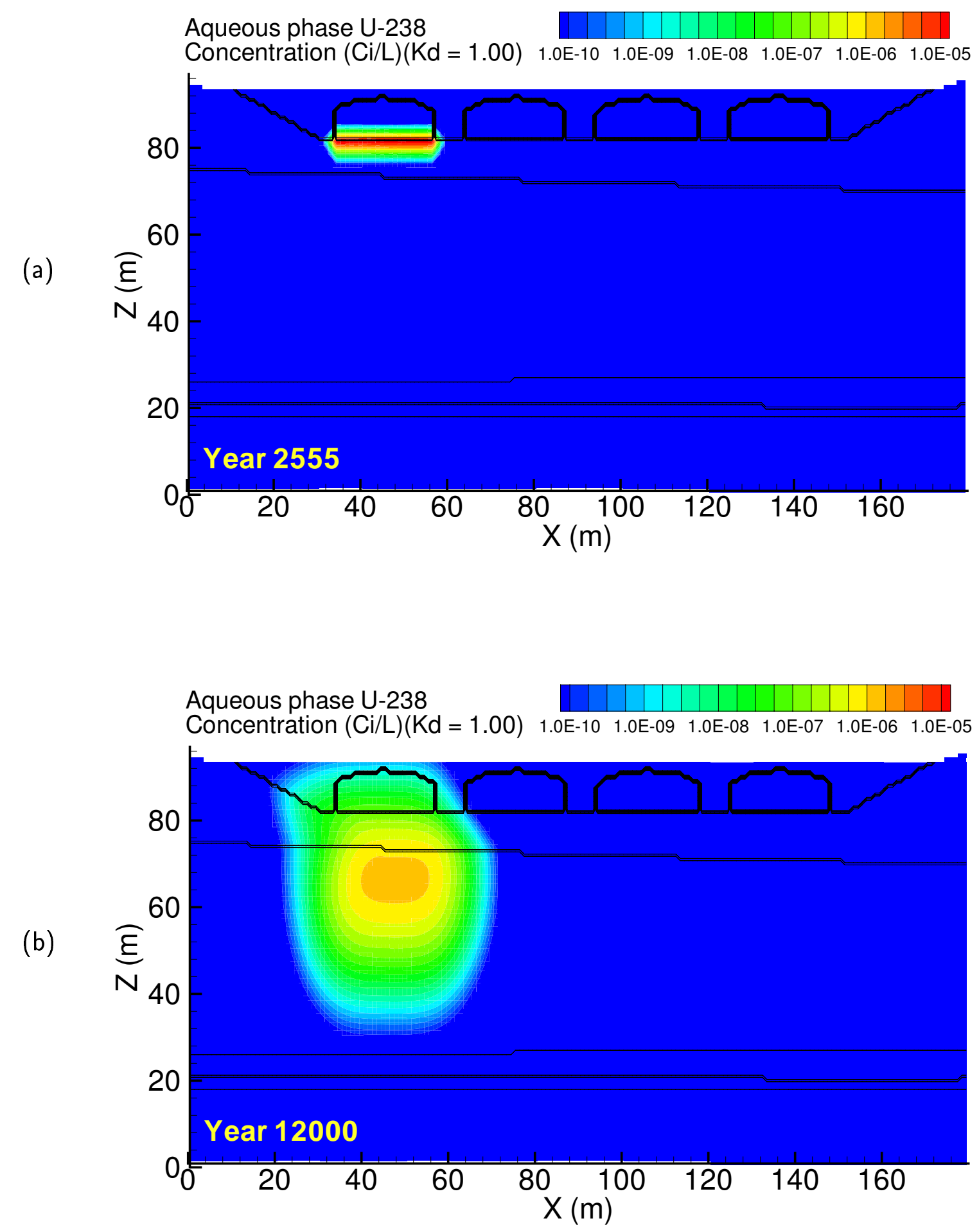

Figure A.95. Case 9, U-238 $\left(\mathrm{K}_{d}=1.00\right)$ aqueous concentration at (a) year 2555 and (b) year 12000 

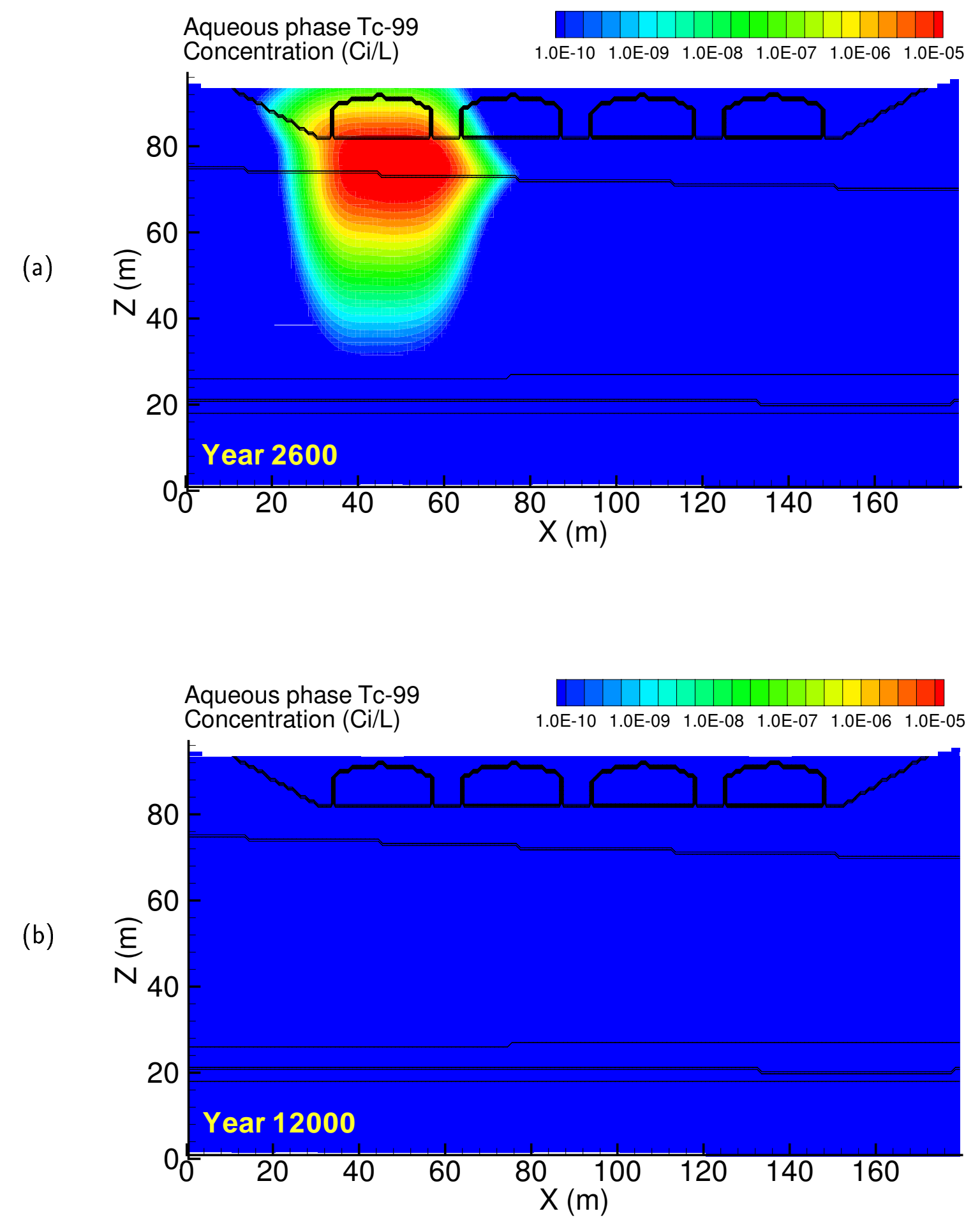

Figure A.96. Case 10, Tc-99 aqueous concentration at (a) year 2600 and (b) year 12000 

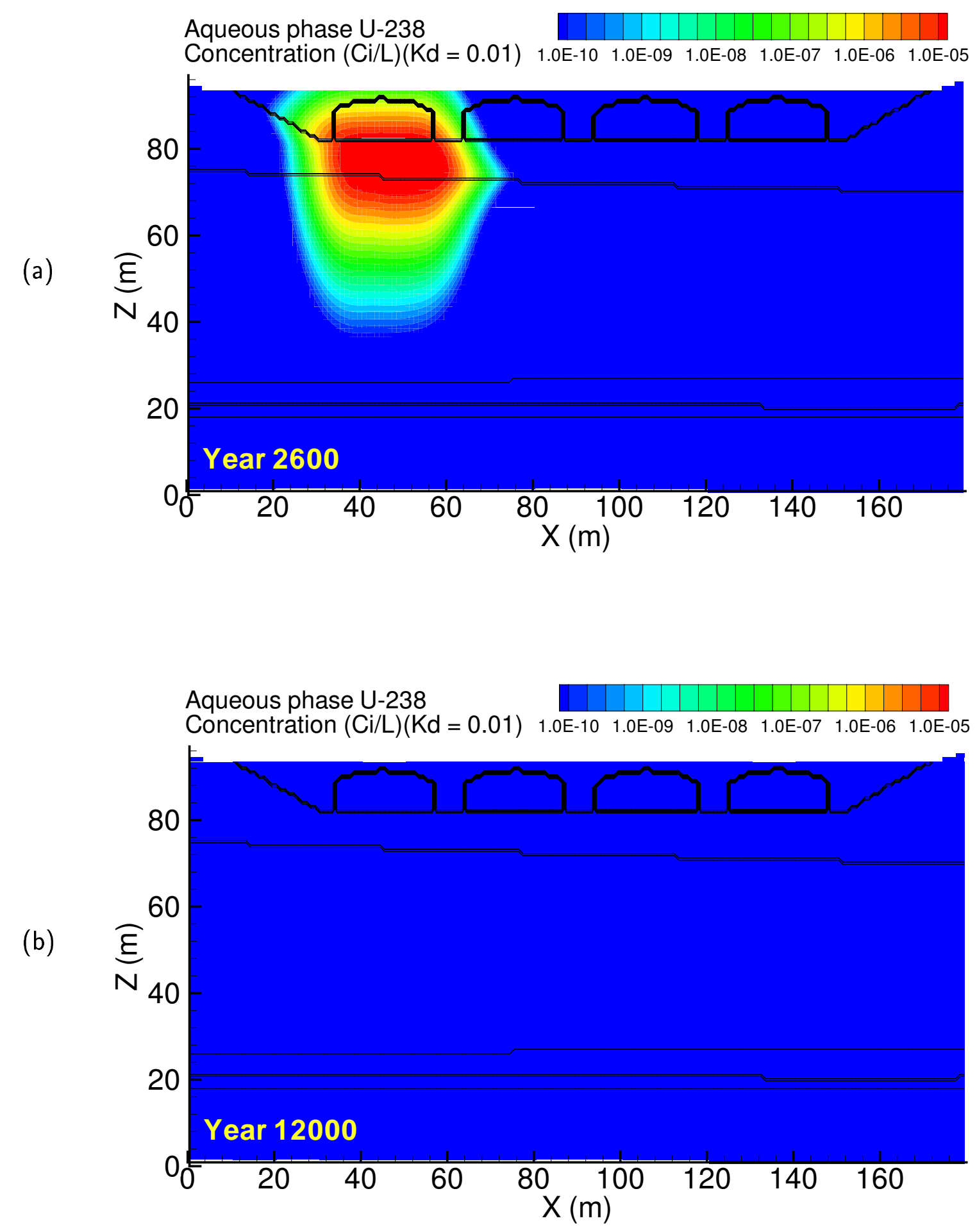

Figure A.97. Case 10, U-238 $\left(\mathrm{K}_{d}=0.01\right)$ aqueous concentration at (a) year 2600 and (b) year 12000 

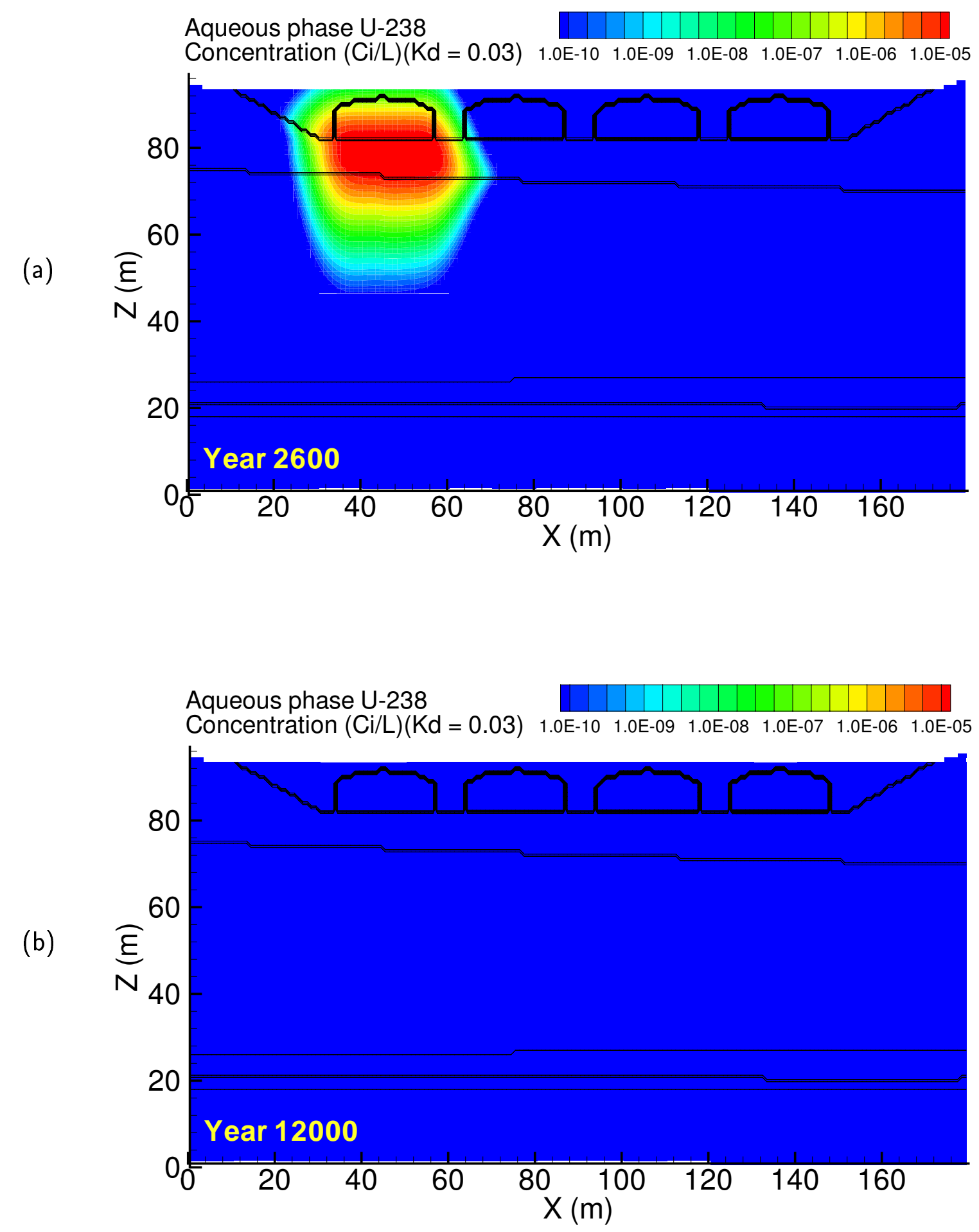

Figure A.98. Case 10, U-238 $\left(\mathrm{K}_{d}=0.03\right)$ aqueous concentration at (a) year 2600 and (b) year 12000 

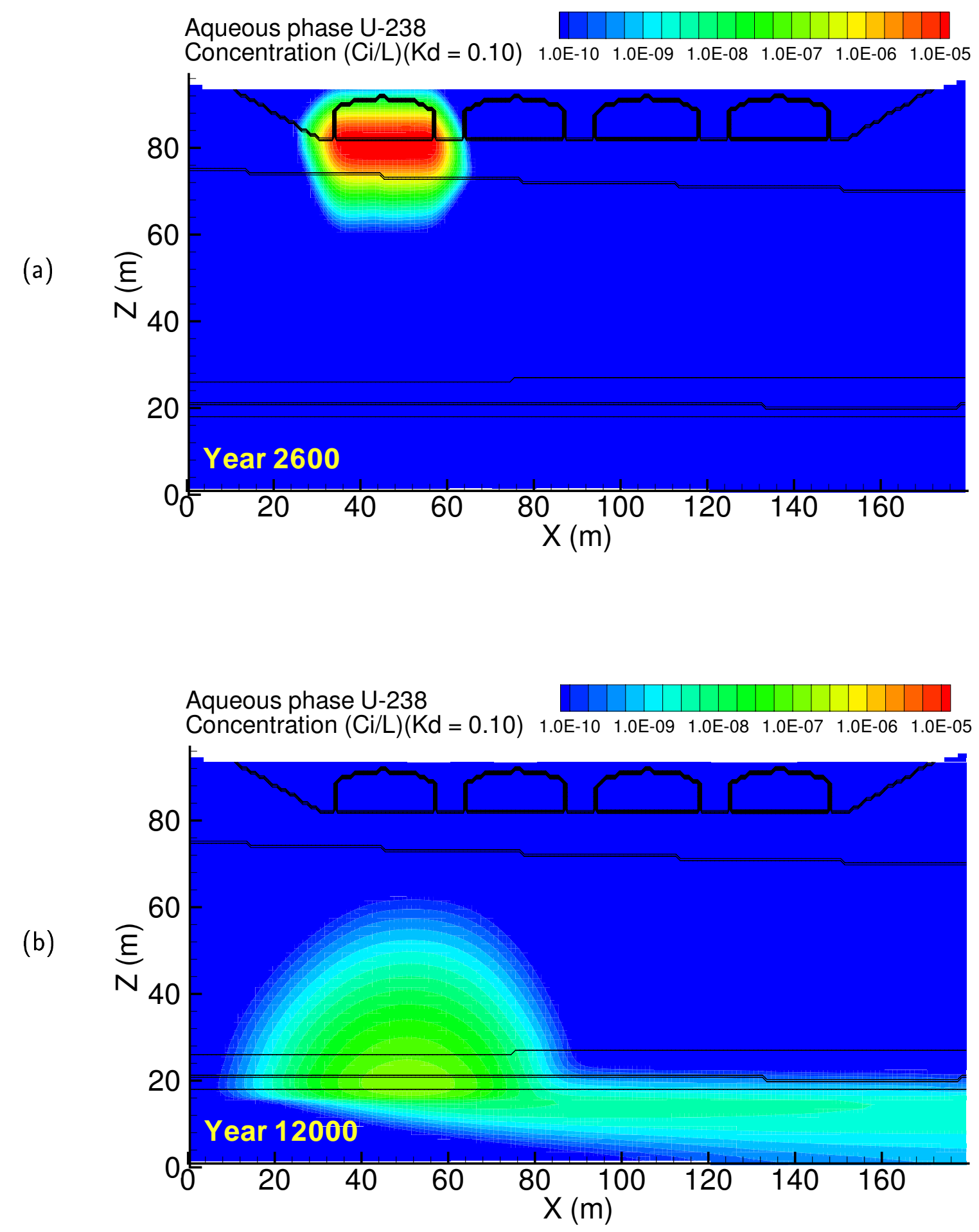

Figure A.99. Case 10, U-238 $\left(\mathrm{K}_{d}=0.10\right)$ aqueous concentration at (a) year 2600 and (b) year 12000 

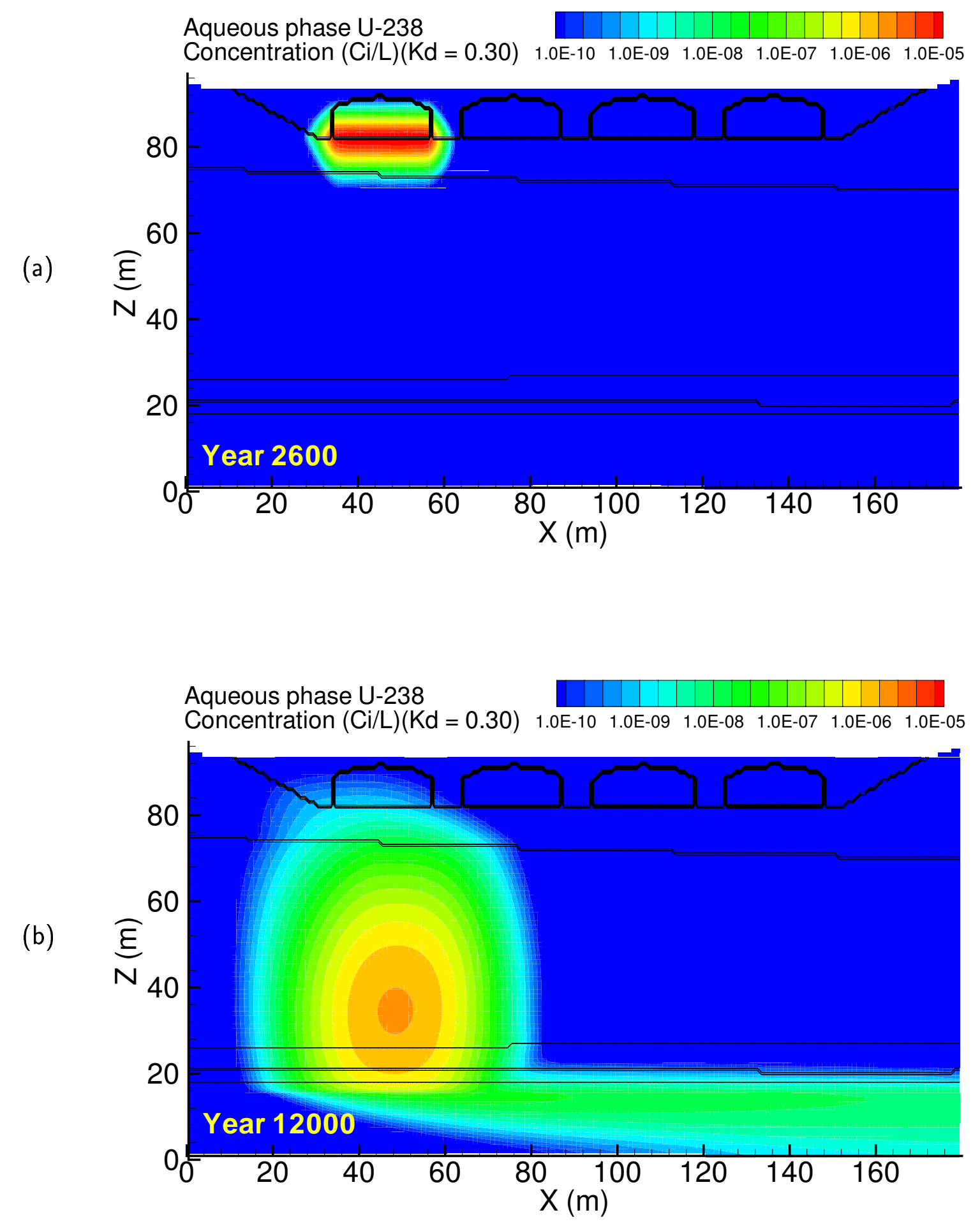

Figure A.100. Case 10, U-238 $\left(\mathrm{K}_{d}=0.30\right)$ aqueous concentration at (a) year 2600 and (b) year 12000 

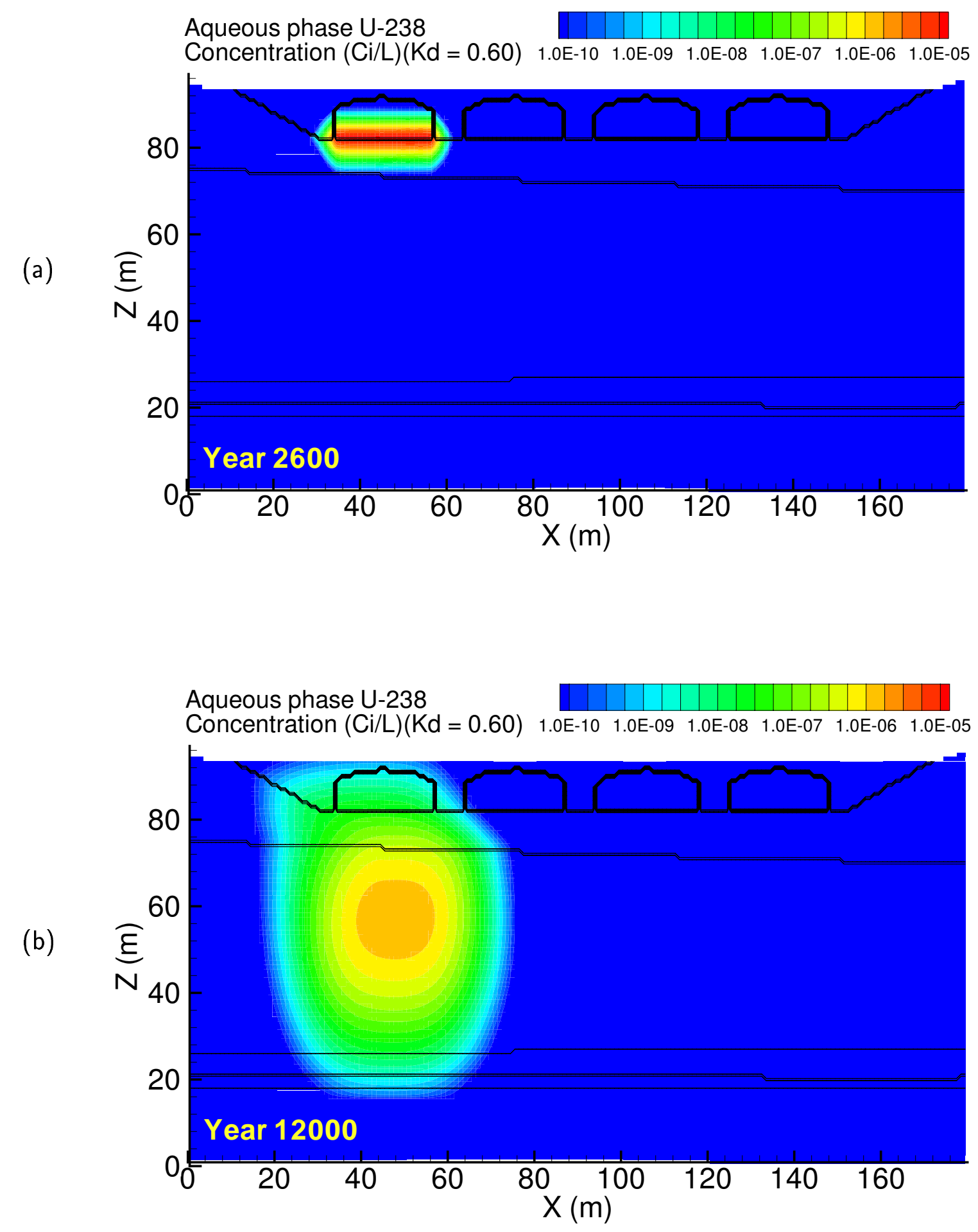

Figure A.101. Case 10, U-238 $\left(\mathrm{K}_{d}=0.60\right)$ aqueous concentration at (a) year 2600 and (b) year 12000 

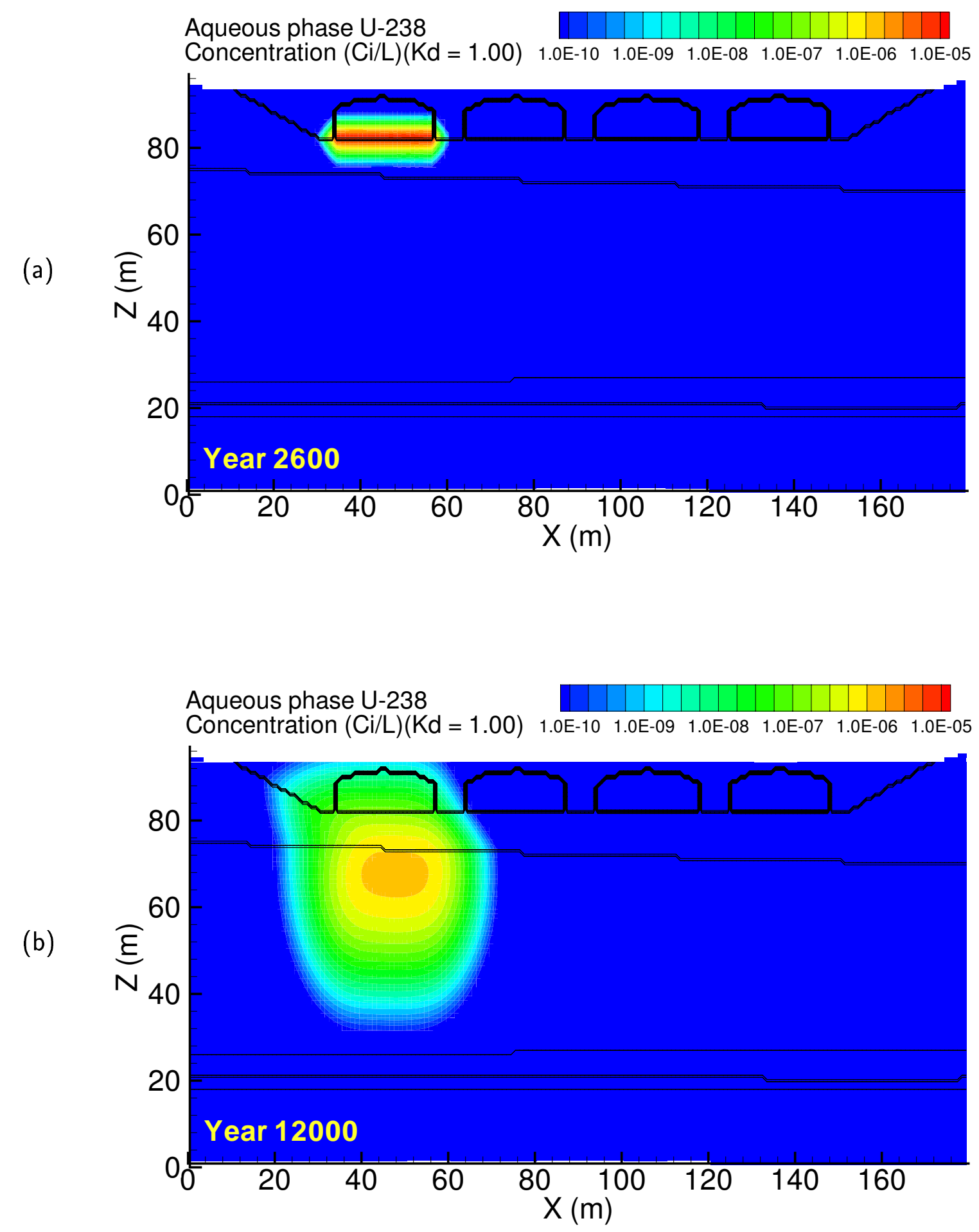

Figure A.102. Case 10, U-238 $\left(\mathrm{K}_{d}=1.00\right)$ aqueous concentration at (a) year 2600 and (b) year 12000 

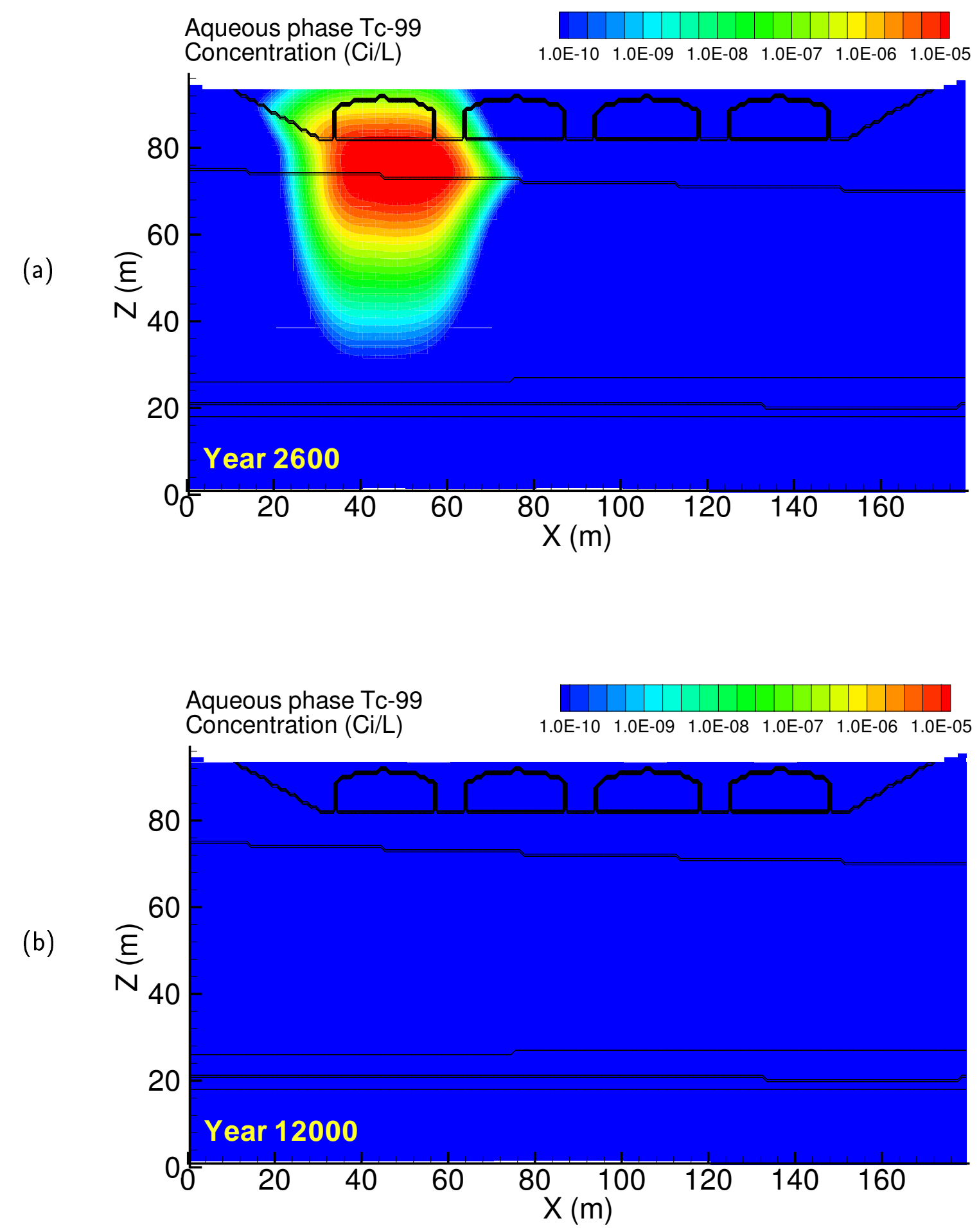

Figure A.103. Case 10-HiK, Tc-99 aqueous concentration at (a) year 2600 and (b) year 12000 

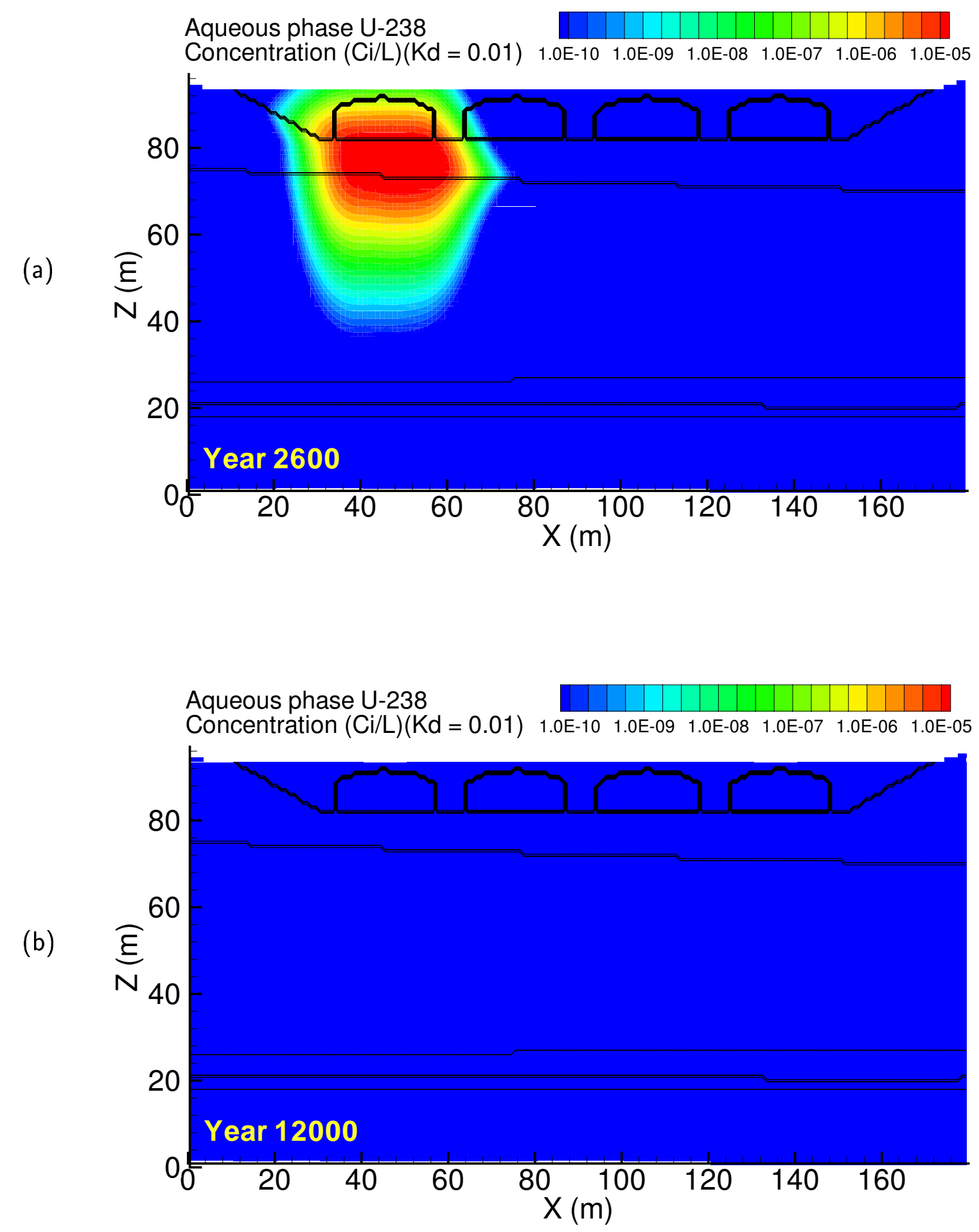

Figure A.104. Case 10-HiK, U-238 $\left(\mathrm{K}_{d}=0.01\right)$ aqueous concentration at (a) year 2600 and (b) year 12000 

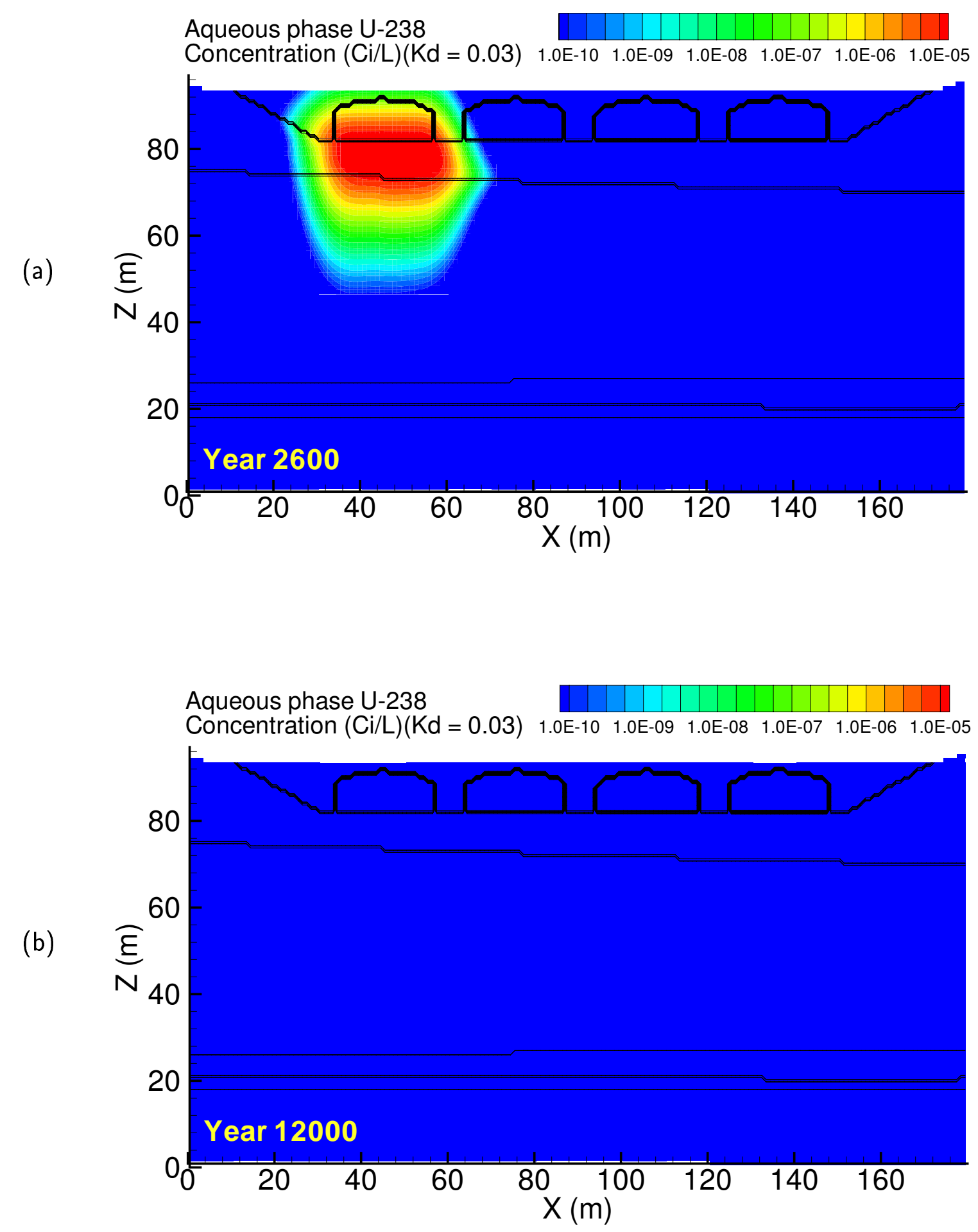

Figure A.105. Case 10-HiK U-238 $\left(\mathrm{K}_{d}=0.03\right)$ aqueous concentration at (a) year 2600 and (b) year 12000 

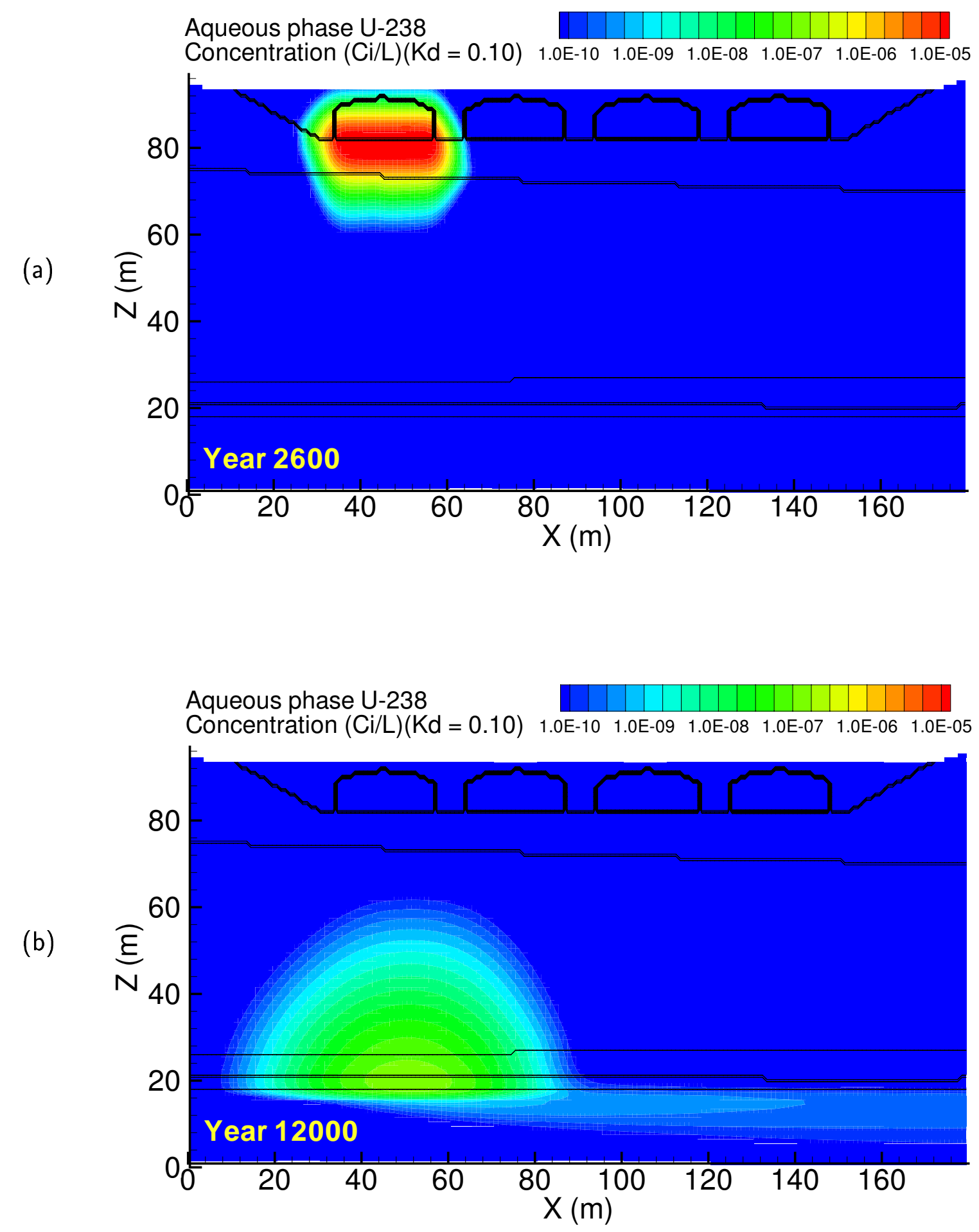

Figure A.106. Case 10-HiK, U-238 $\left(\mathrm{K}_{d}=0.10\right)$ aqueous concentration at (a) year 2600 and (b) year 12000 

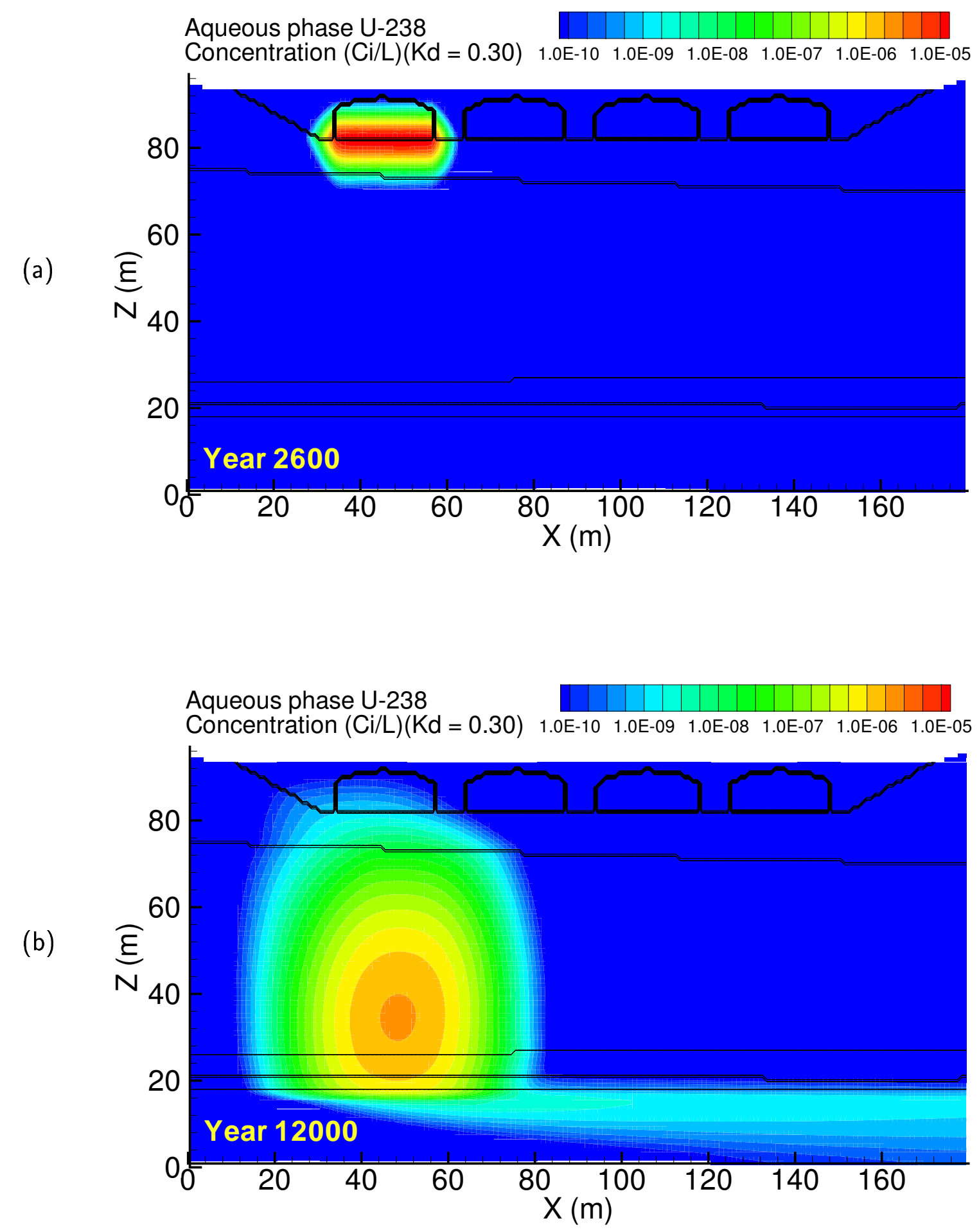

Figure A.107. Case 10-HiK, U-238 $\left(\mathrm{K}_{d}=0.30\right)$ aqueous concentration at (a) year 2600 and (b) year 12000 

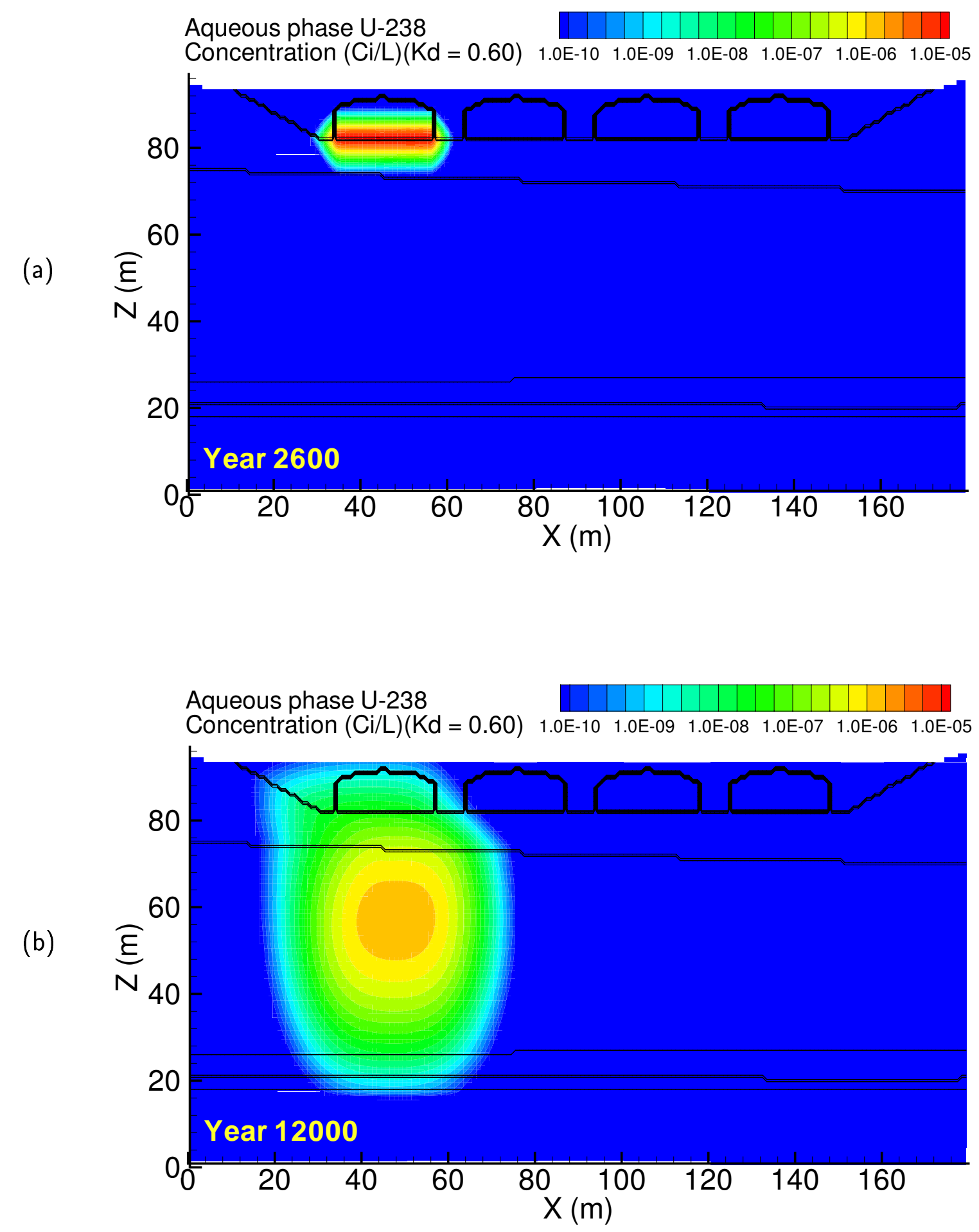

Figure A.108. Case 10-HiK, U-238 $\left(\mathrm{K}_{d}=0.60\right)$ aqueous concentration at (a) year 2600 and (b) year 12000 

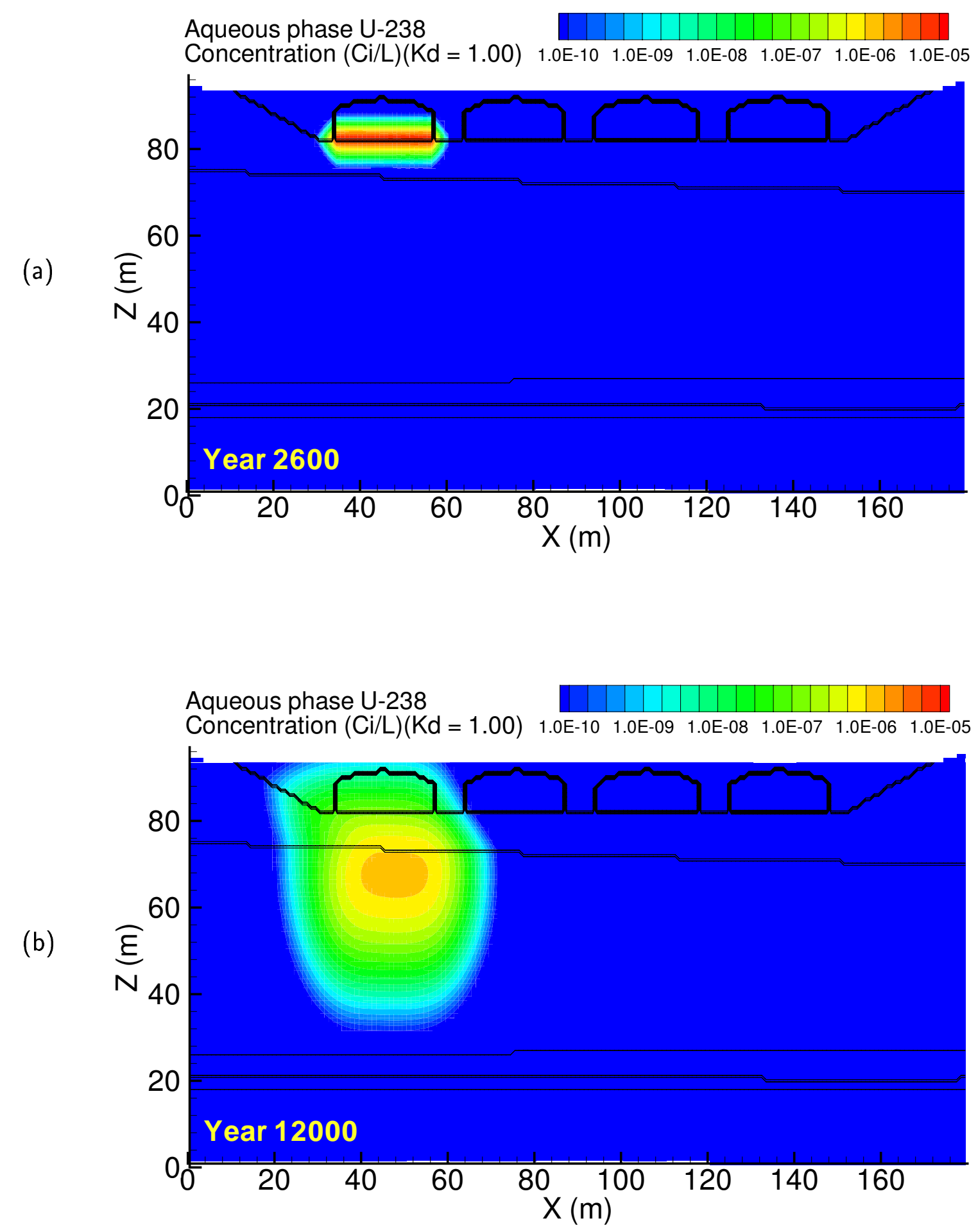

Figure A.109. Case 10-HiK, U-238 $\left(\mathrm{K}_{d}=1.00\right)$ aqueous concentration at (a) year 2600 and (b) year 12000 

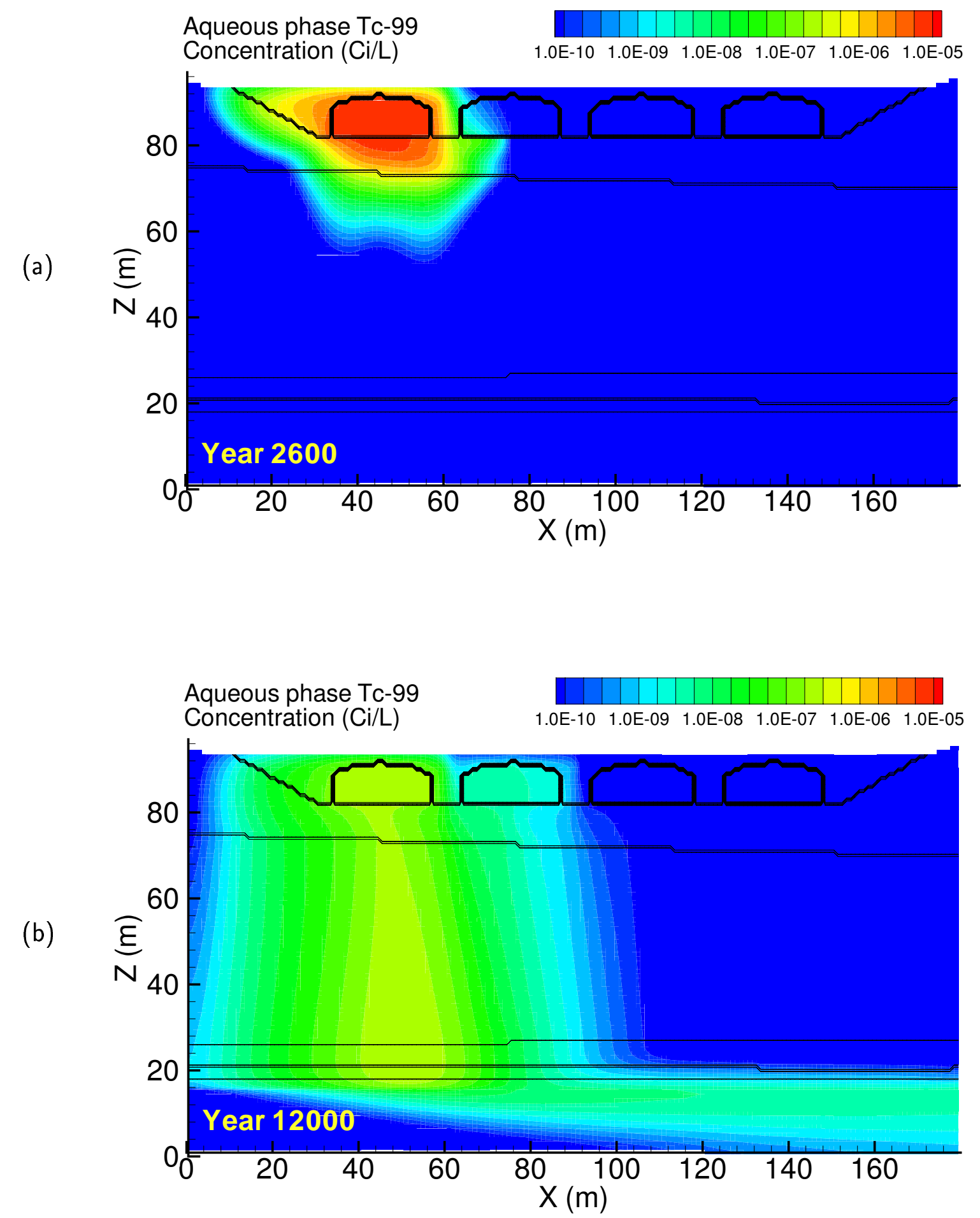

Figure A.110. Case 11, Tc-99 aqueous concentration at (a) year 2600 and (b) year 12000 

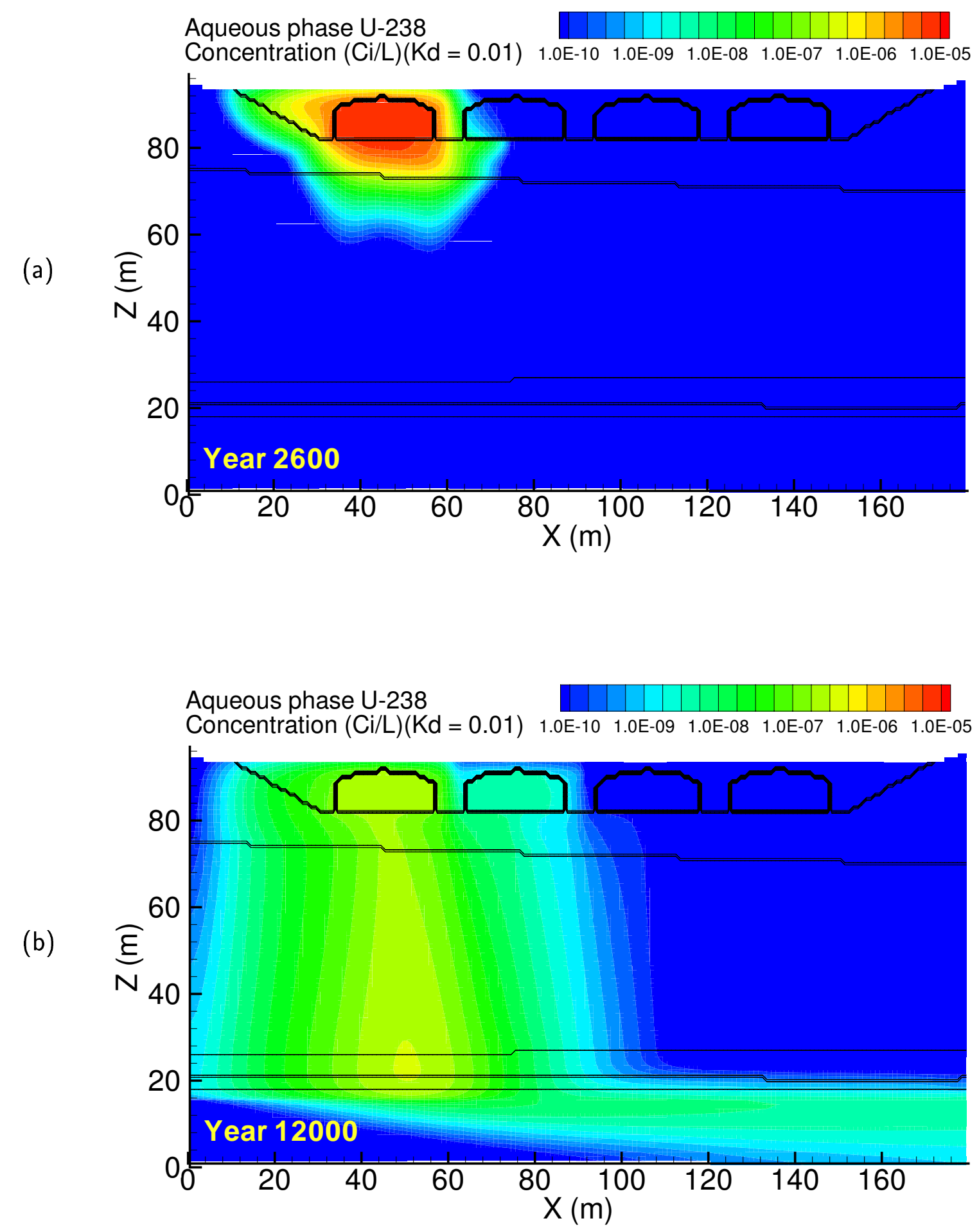

Figure A.111. Case 11, U-238 $\left(\mathrm{K}_{d}=0.01\right)$ aqueous concentration at (a) year 2600 and (b) year 12000 

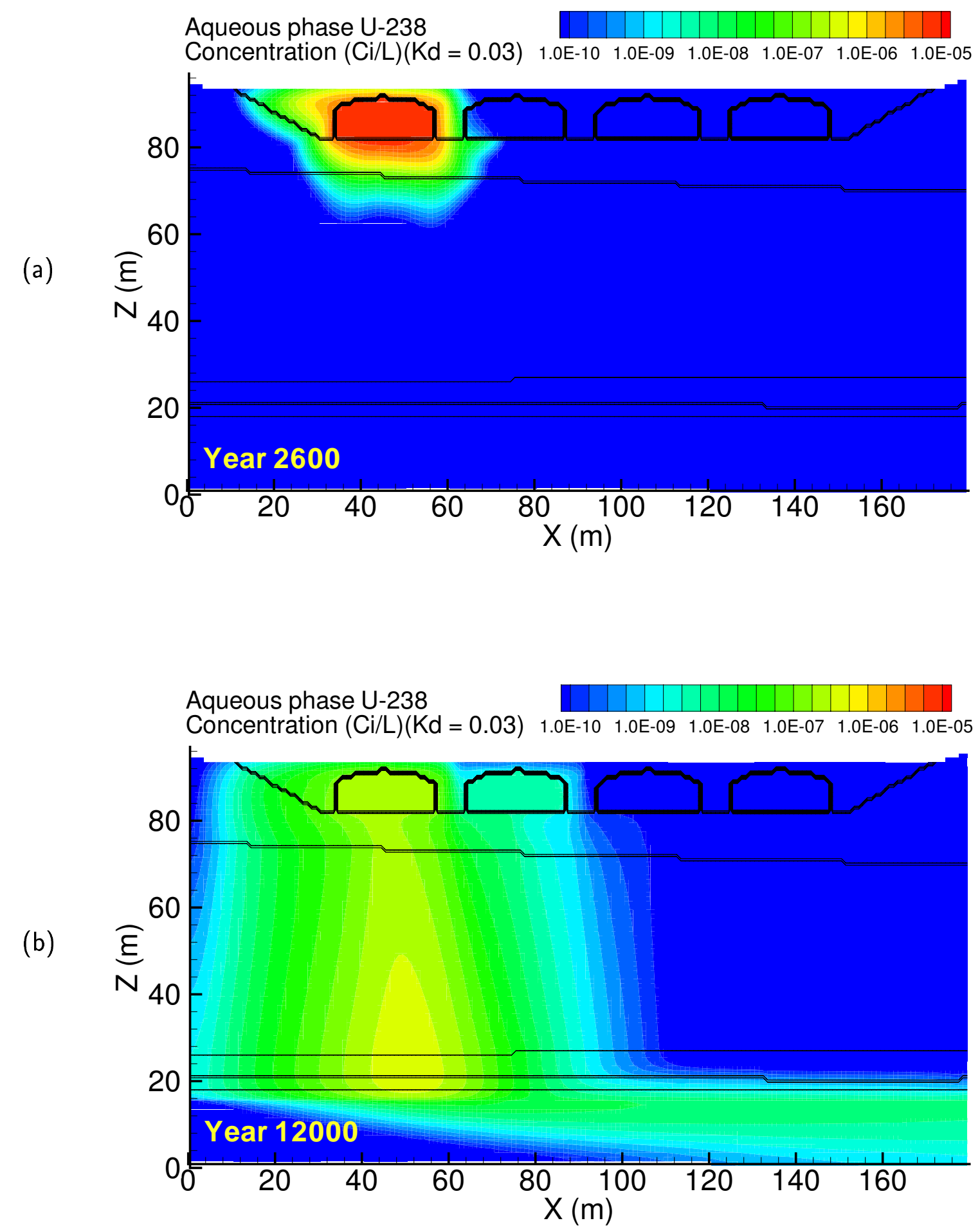

Figure A.112. Case 11, U-238 $\left(\mathrm{K}_{d}=0.03\right)$ aqueous concentration at (a) year 2600 and (b) year 12000 

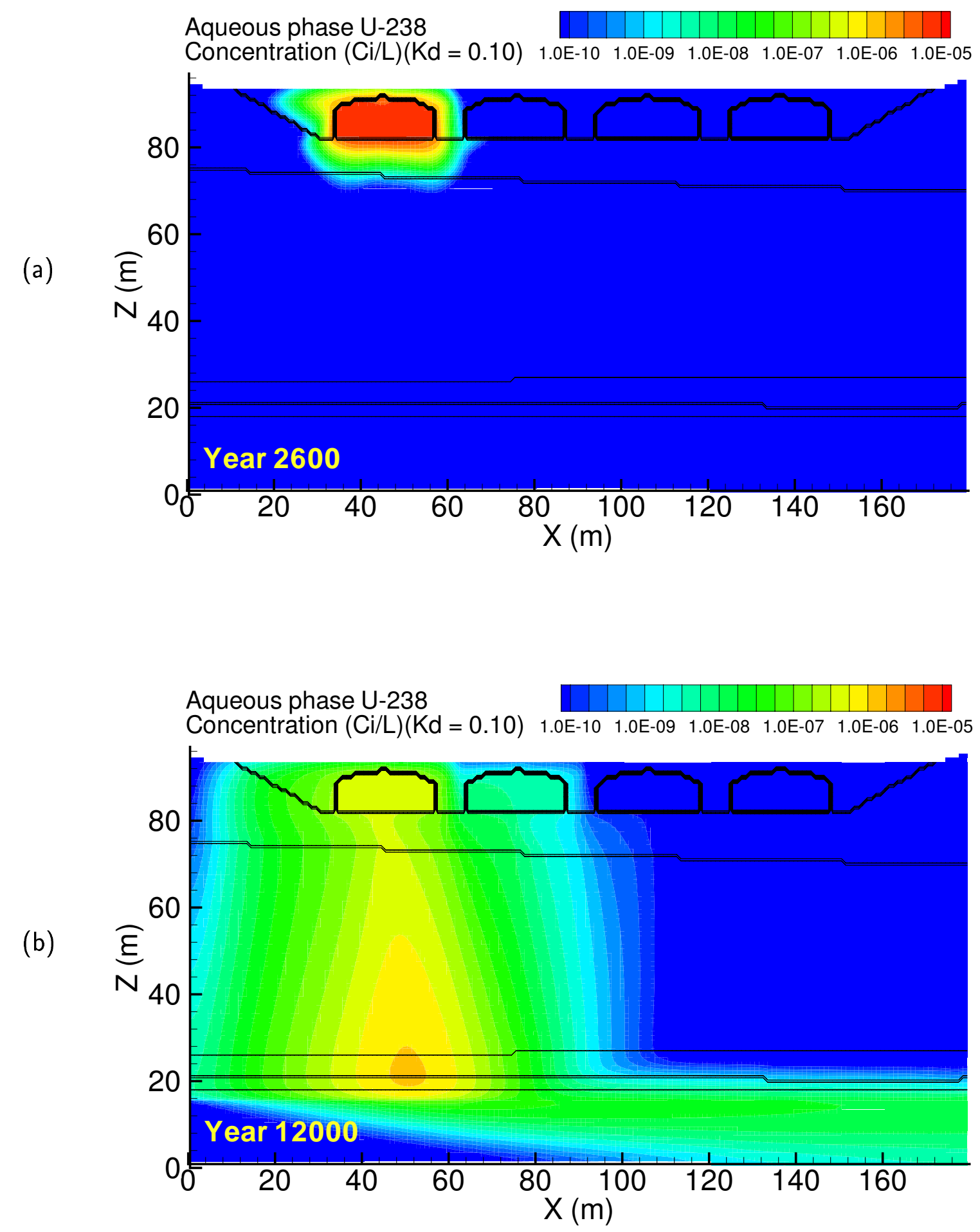

Figure A.113. Case 11, U-238 $\left(\mathrm{K}_{d}=0.10\right)$ aqueous concentration at (a) year 2600 and (b) year 12000 

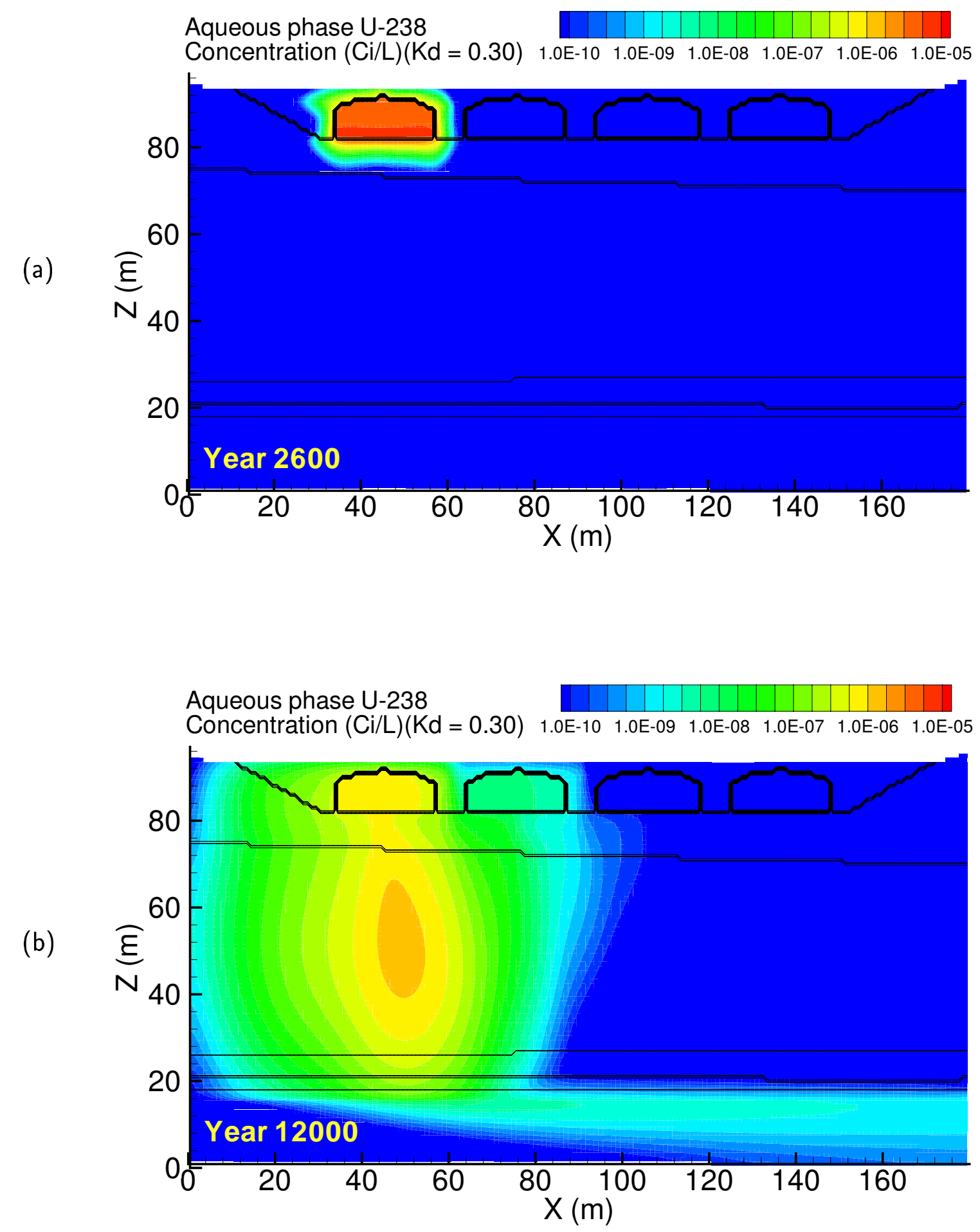

Figure A.114. Case 11, U-238 $\left(\mathrm{K}_{d}=0.30\right)$ aqueous concentration at (a) year 2600 and (b) year 12000 

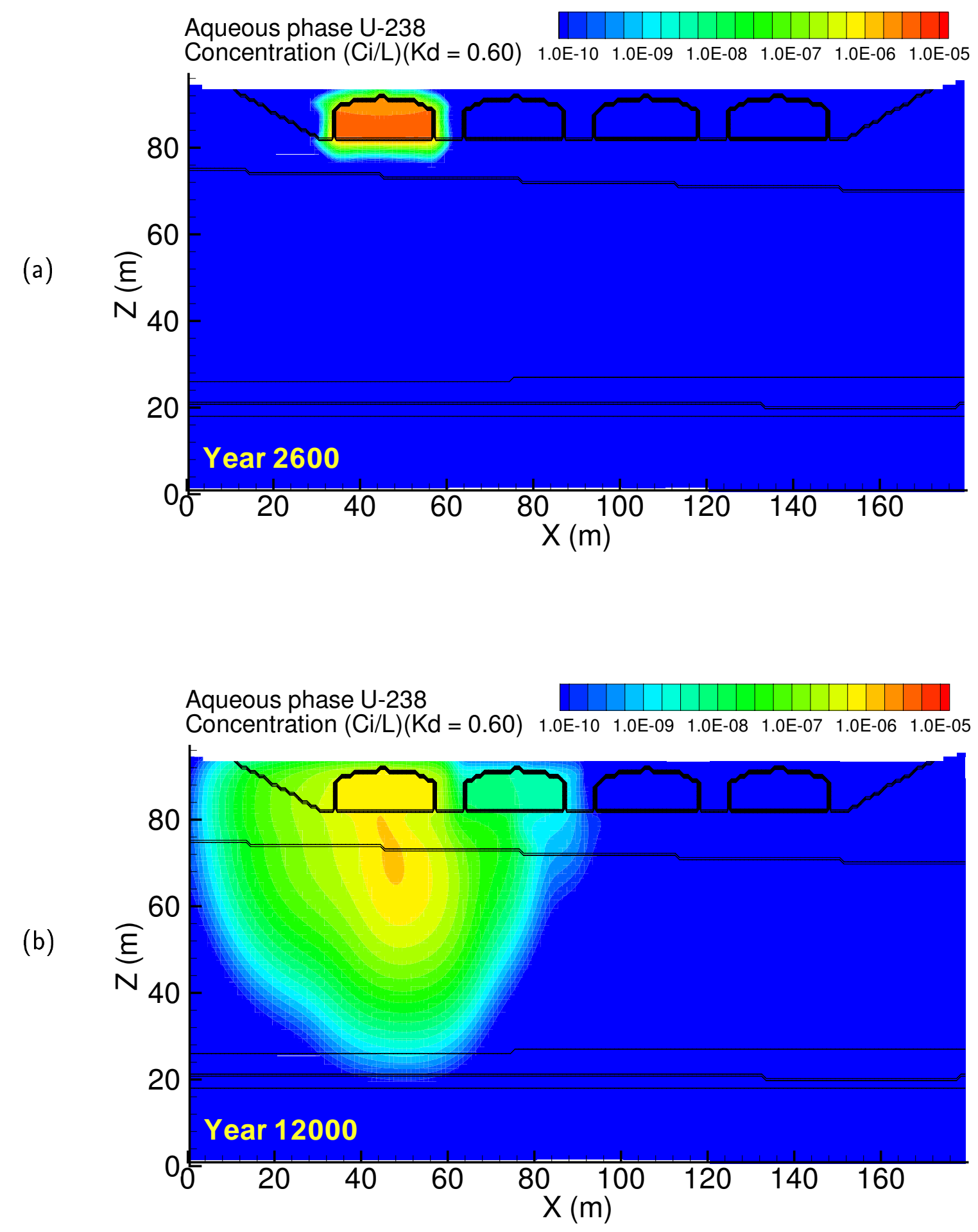

Figure A.115. Case 11, U-238 $\left(\mathrm{K}_{d}=0.60\right)$ aqueous concentration at (a) year 2600 and (b) year 12000 

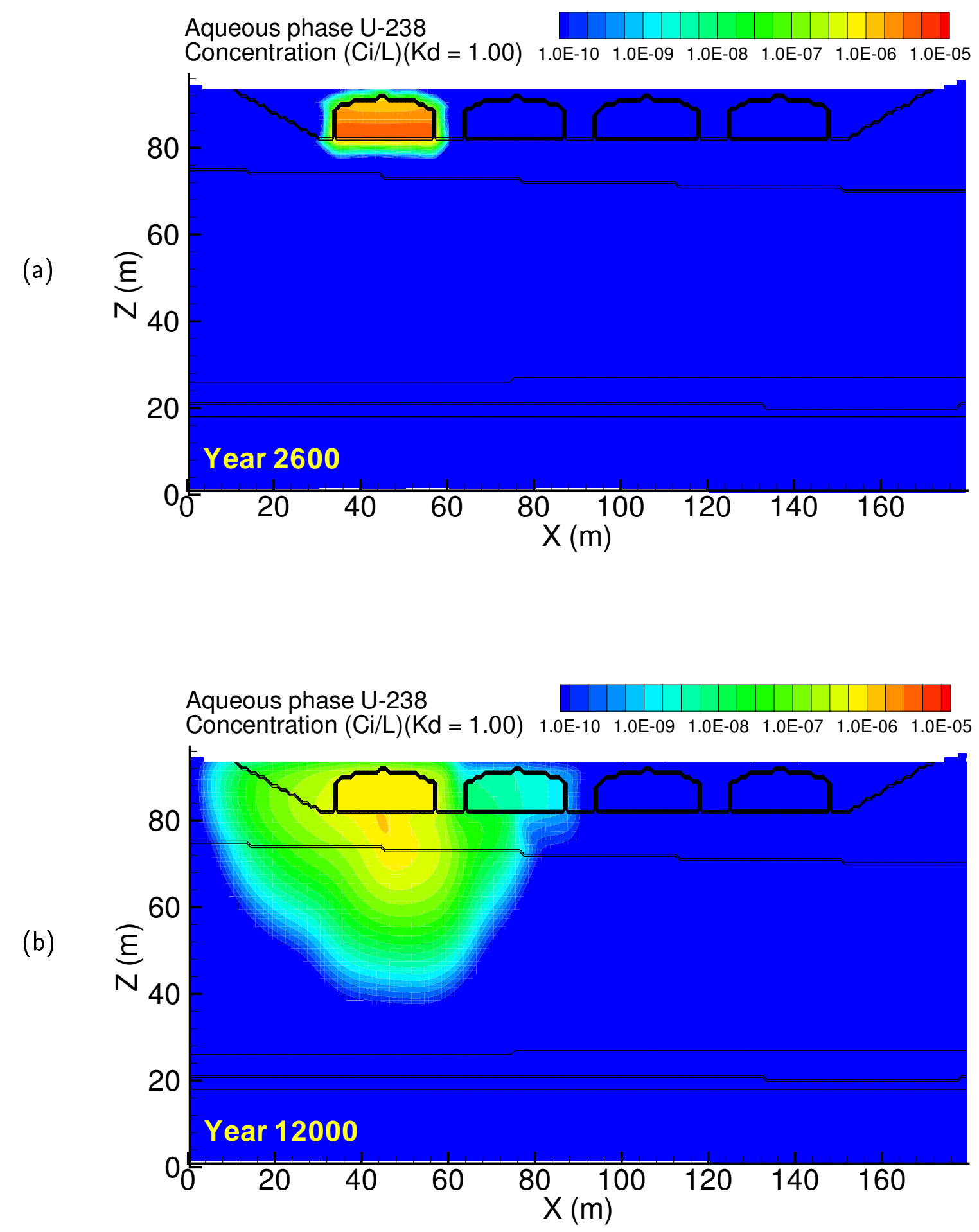

Figure A.116. Case 11, U-238 $\left(\mathrm{K}_{d}=1.00\right)$ aqueous concentration at (a) year 2600 and (b) year 12000 

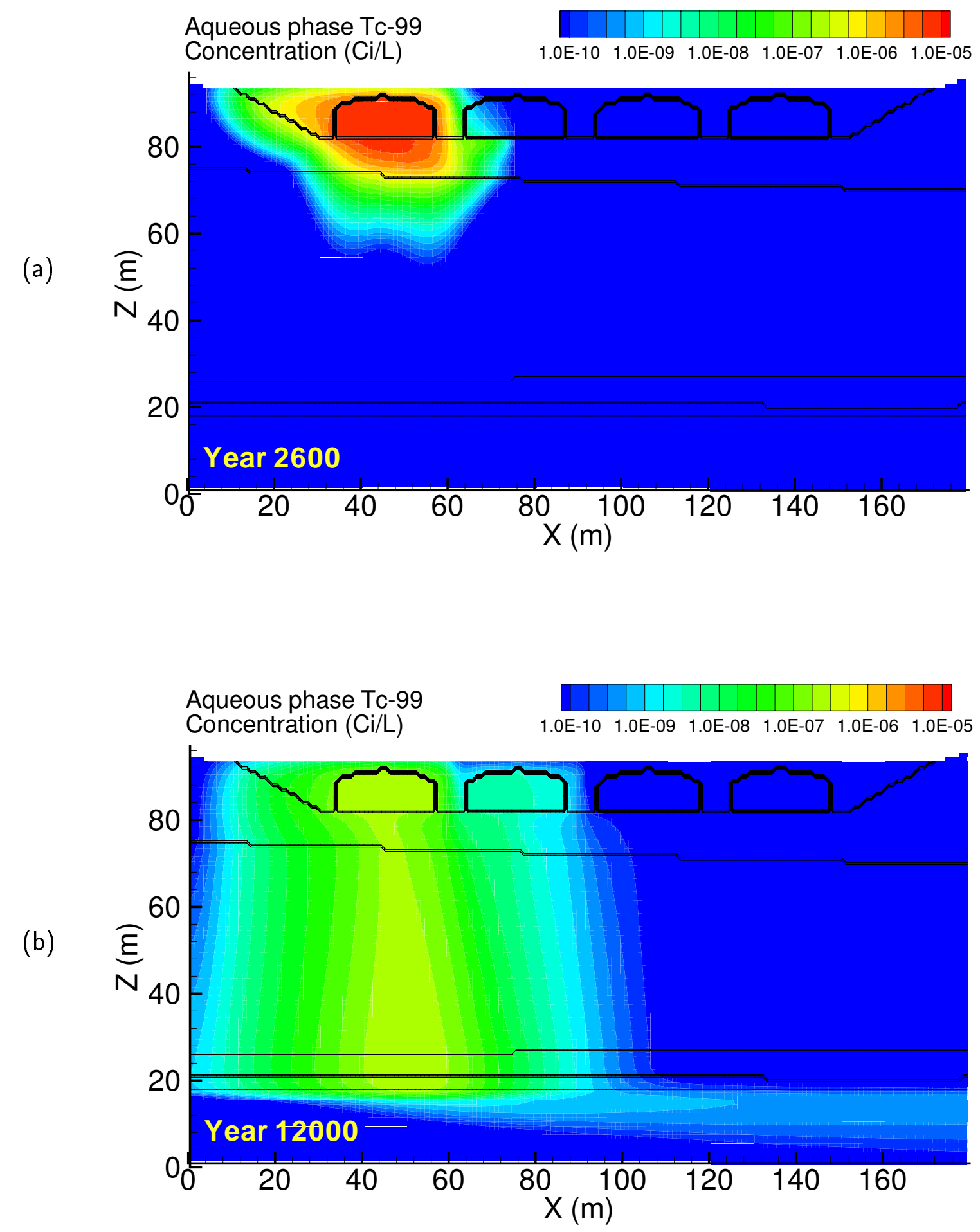

Figure A.117. Case 11-HiK, Tc-99 aqueous concentration at (a) year 2600 and (b) year 12000 

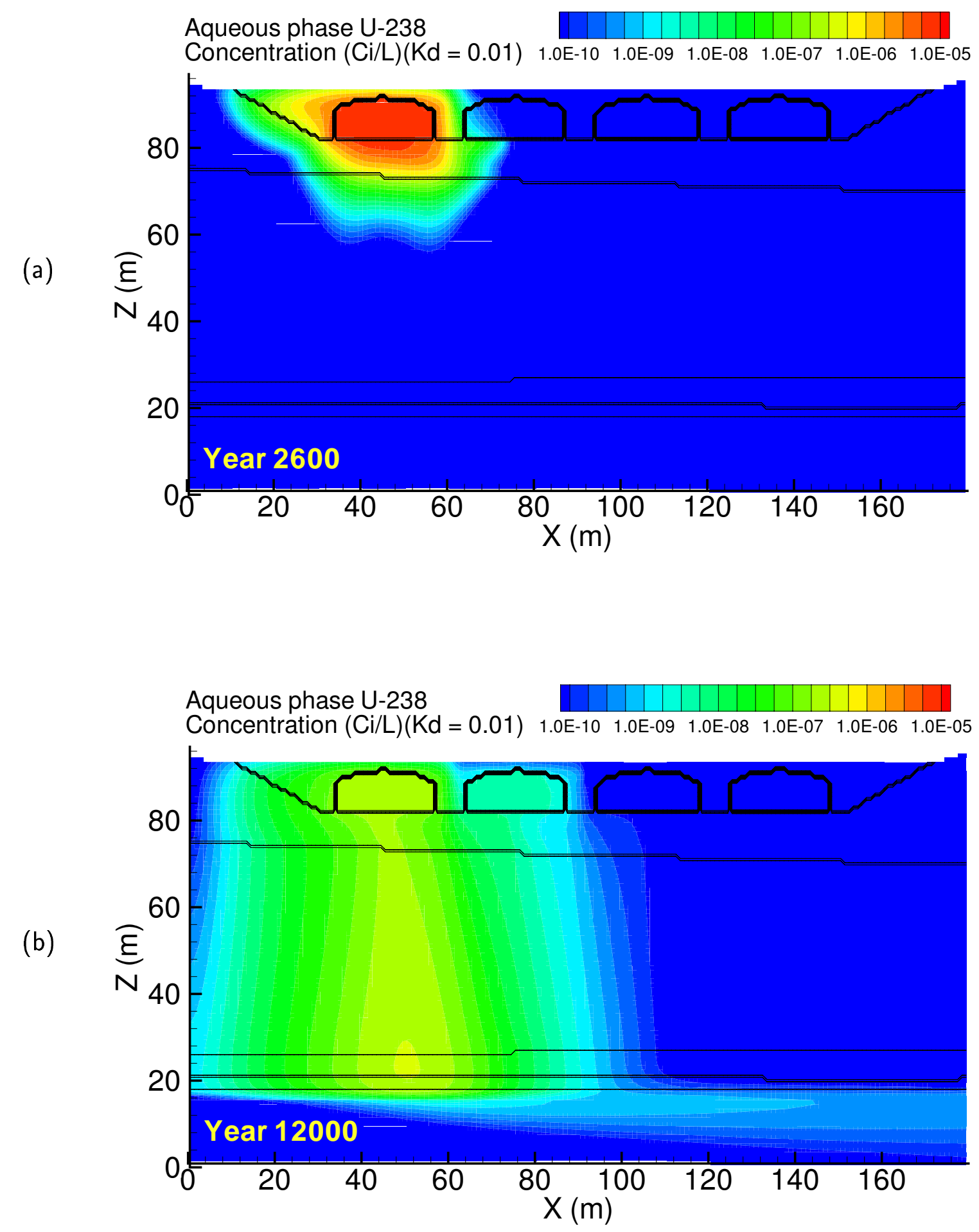

Figure A.118. Case 11-HiK, U-238 $\left(\mathrm{K}_{d}=0.01\right)$ aqueous concentration at (a) year 2600 and (b) year 12000 

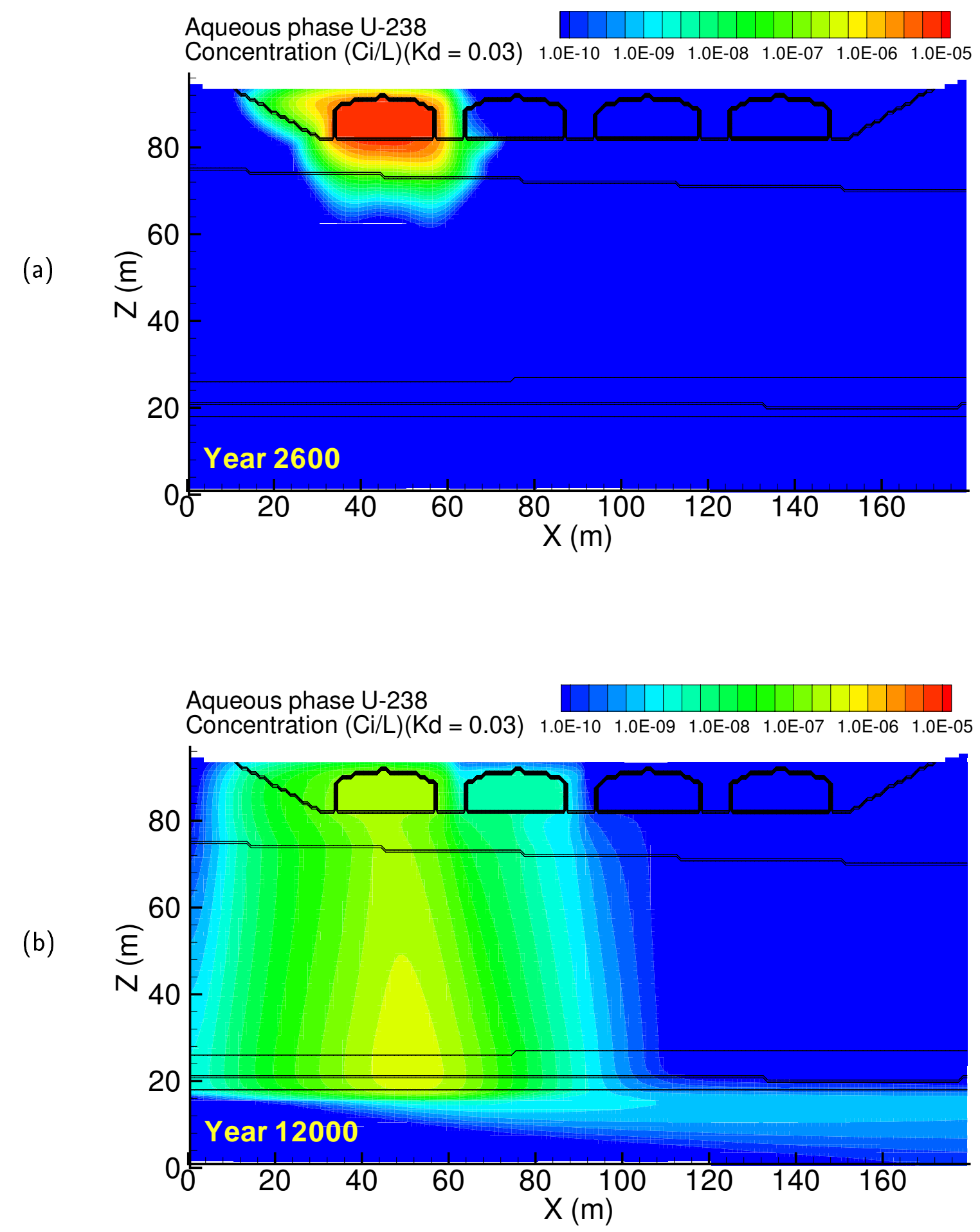

Figure A.119. Case 11-HiK, U-238 $\left(\mathrm{K}_{d}=0.03\right)$ aqueous concentration at (a) year 2600 and (b) year 12000 

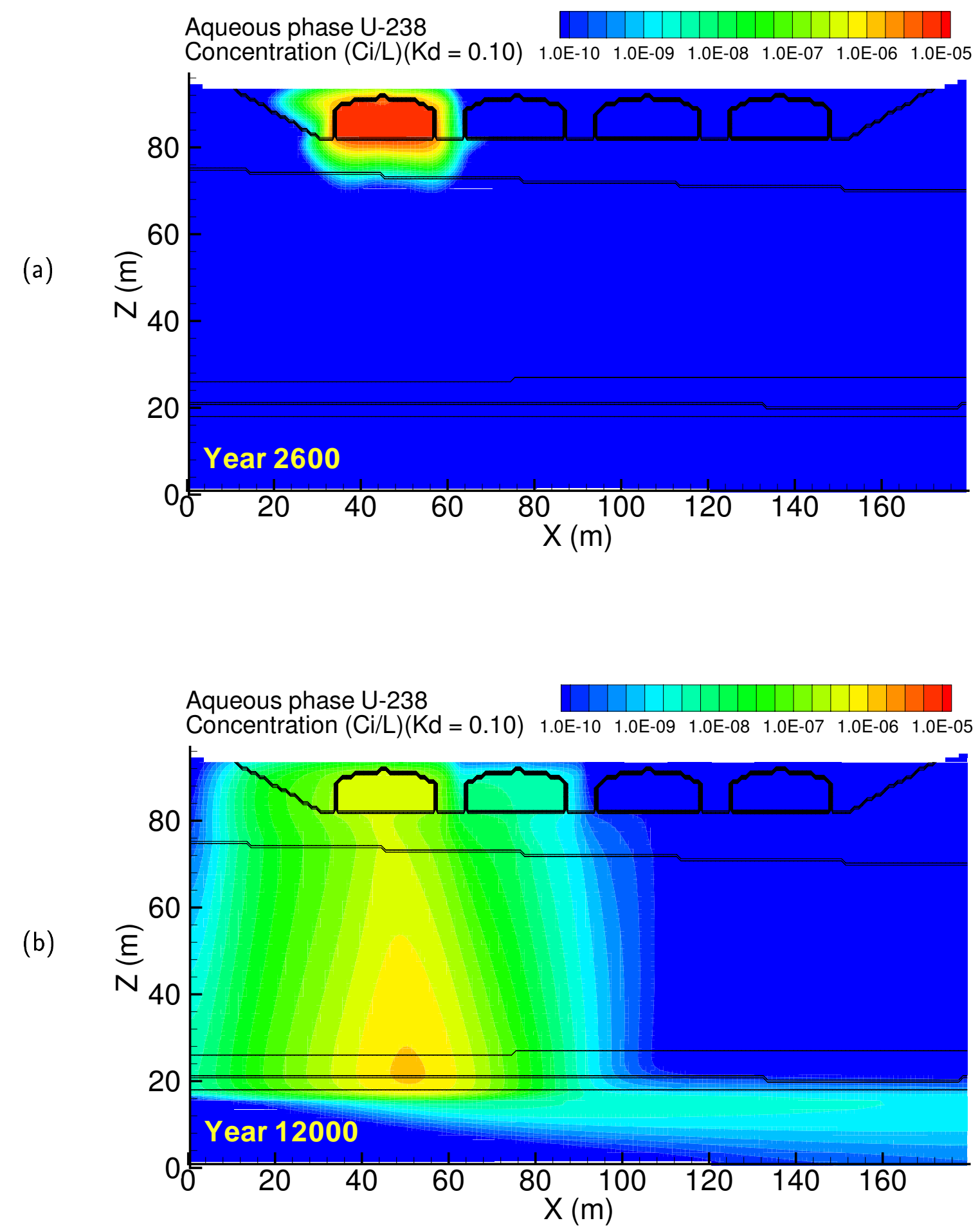

Figure A.120. Case 11-HiK, U-238 $\left(\mathrm{K}_{d}=0.10\right)$ aqueous concentration at (a) year 2600 and (b) year 12000 

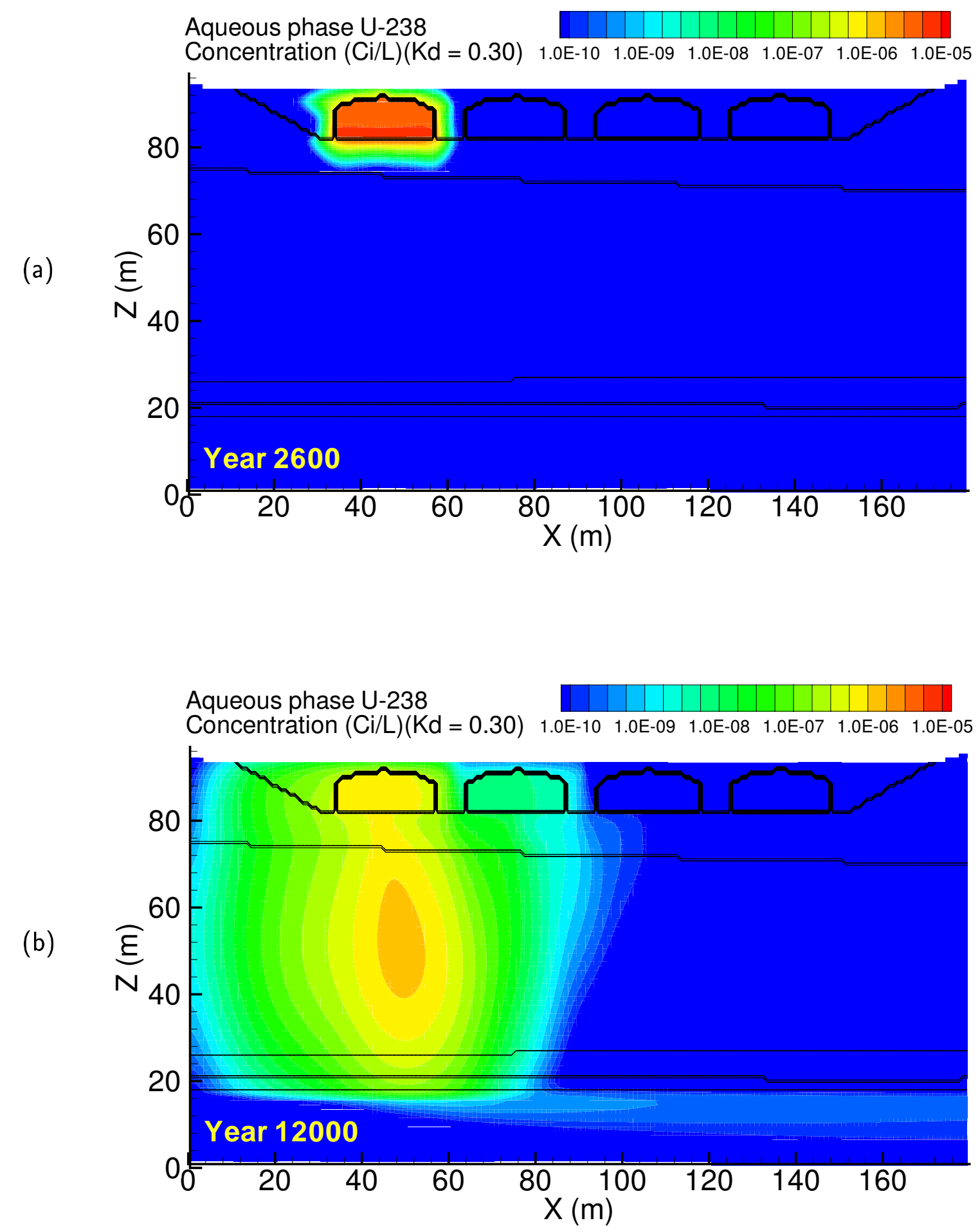

Figure A.121. Case 11-HiK, U-238 $\left(\mathrm{K}_{d}=0.30\right)$ aqueous concentration at (a) year 2600 and (b) year 12000 

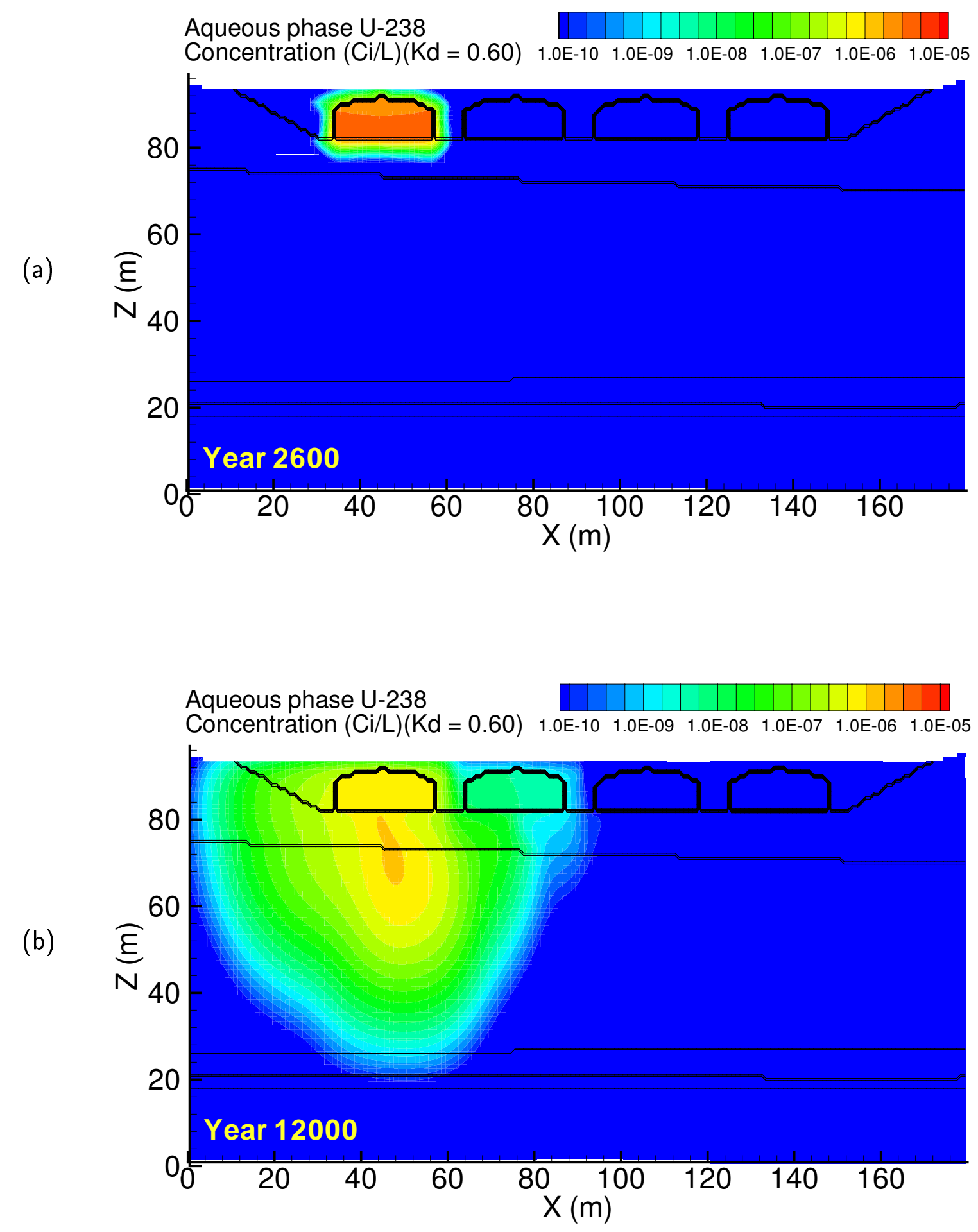

Figure A.122. Case 11-HiK, U-238 $\left(\mathrm{K}_{d}=0.60\right)$ aqueous concentration at (a) year 2600 and (b) year 12000 

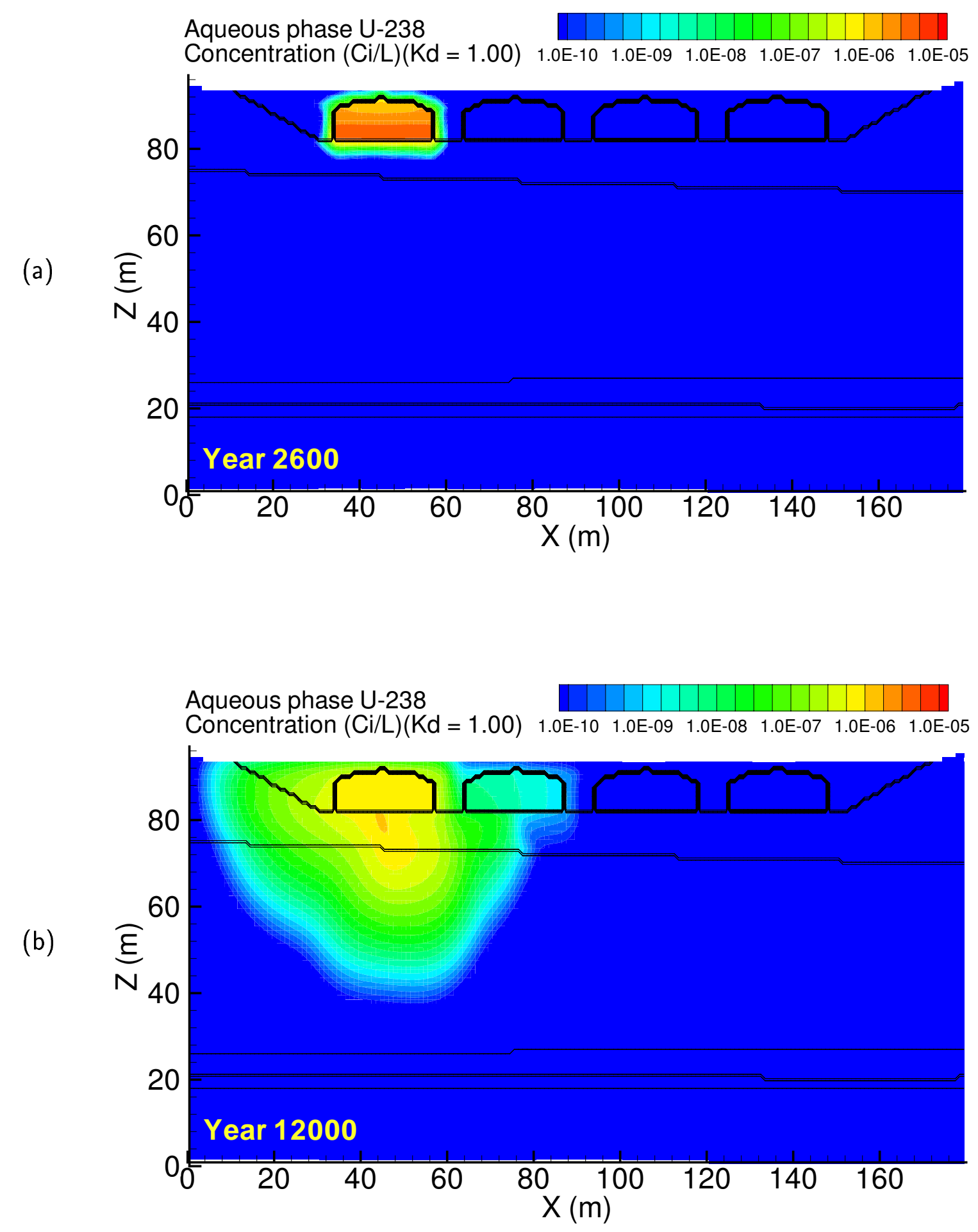

Figure A.123. Case 11-HiK, U-238 $\left(\mathrm{K}_{d}=1.00\right)$ aqueous concentration at (a) year 2600 and (b) year 12000 

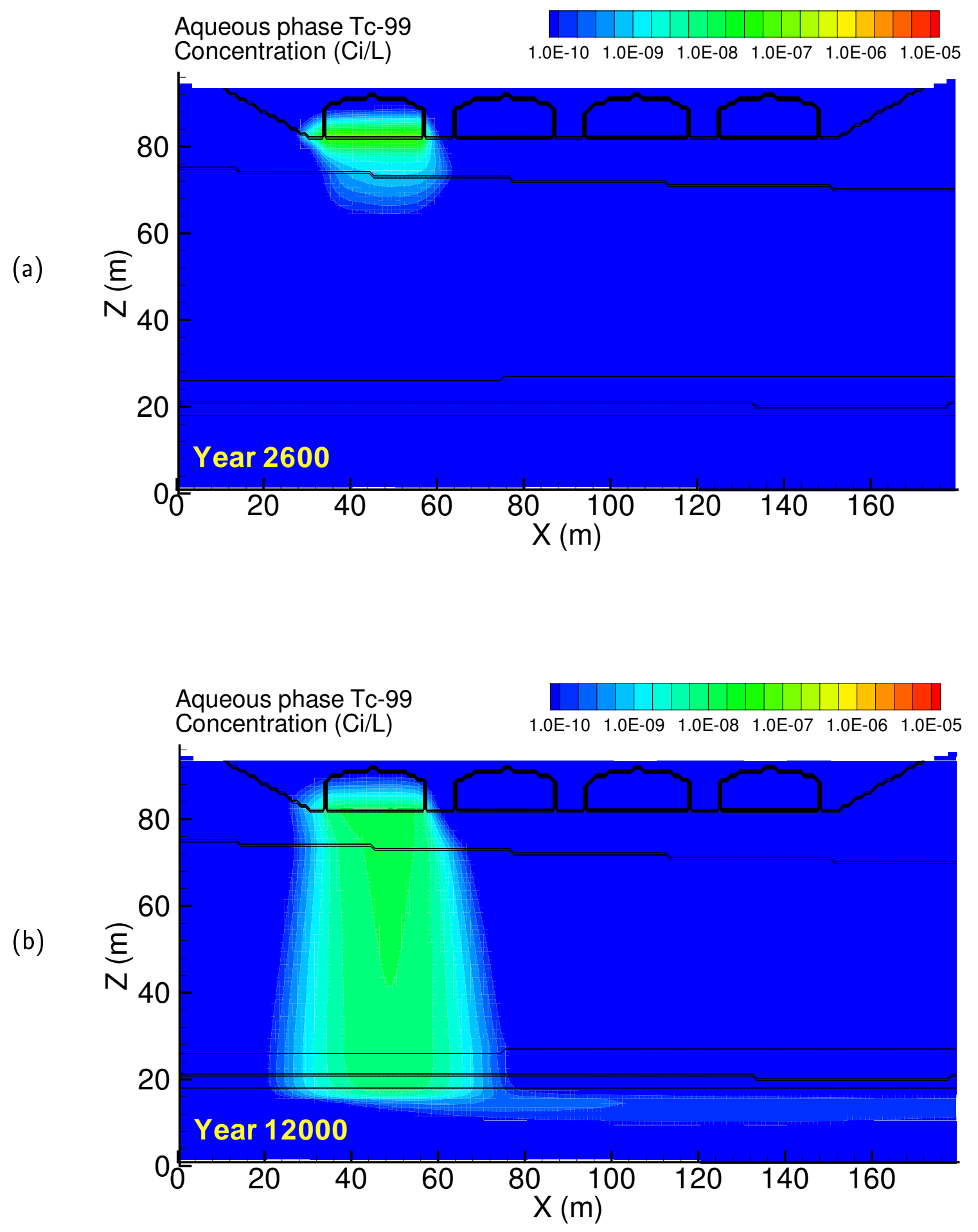

Figure A.124. Case 12, Tc-99 aqueous concentration at (a) year 2600 and (b) year 12000 

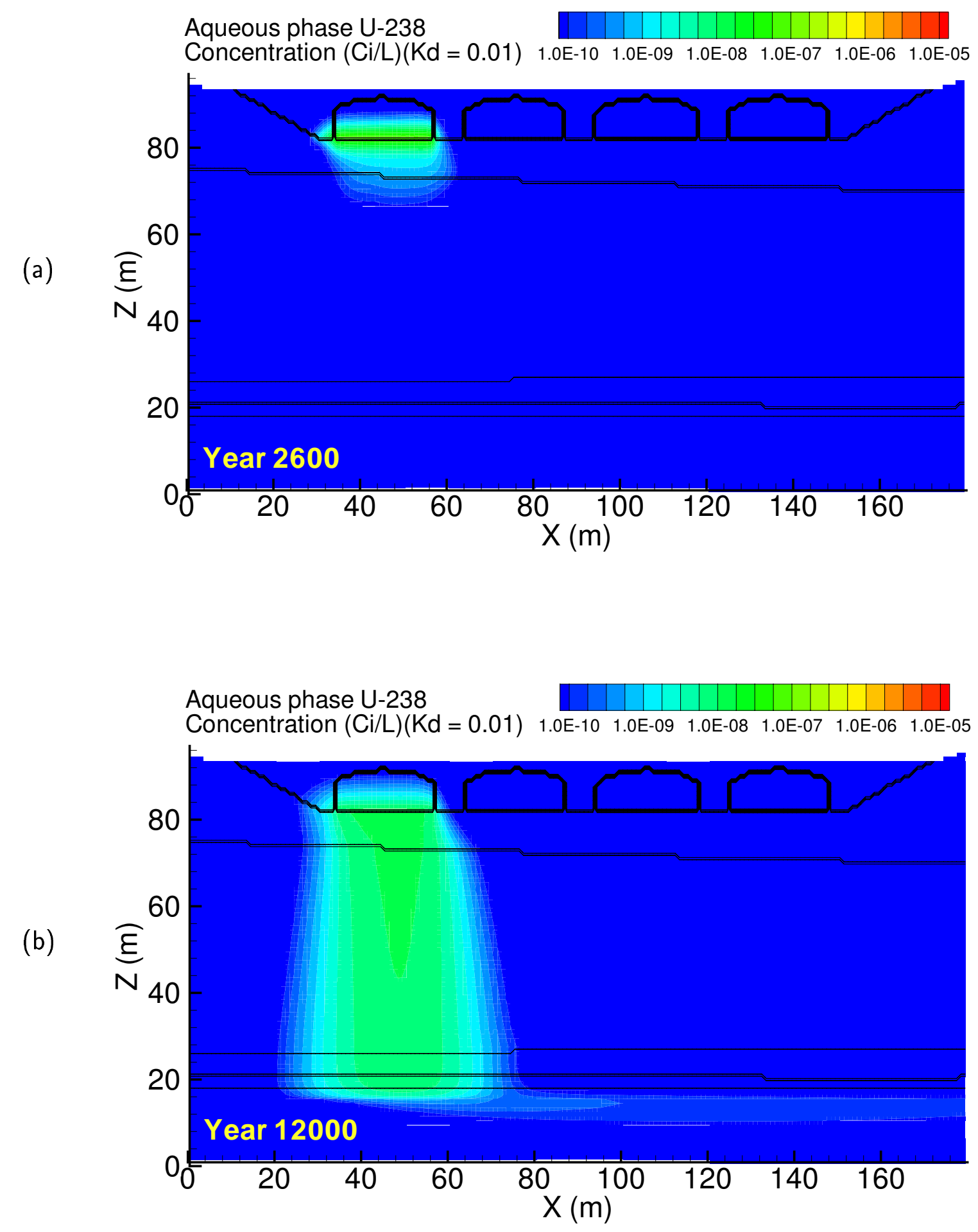

Figure A.125. Case 12, U-238 $\left(\mathrm{K}_{d}=0.01\right)$ aqueous concentration at (a) year 2600 and (b) year 12000 

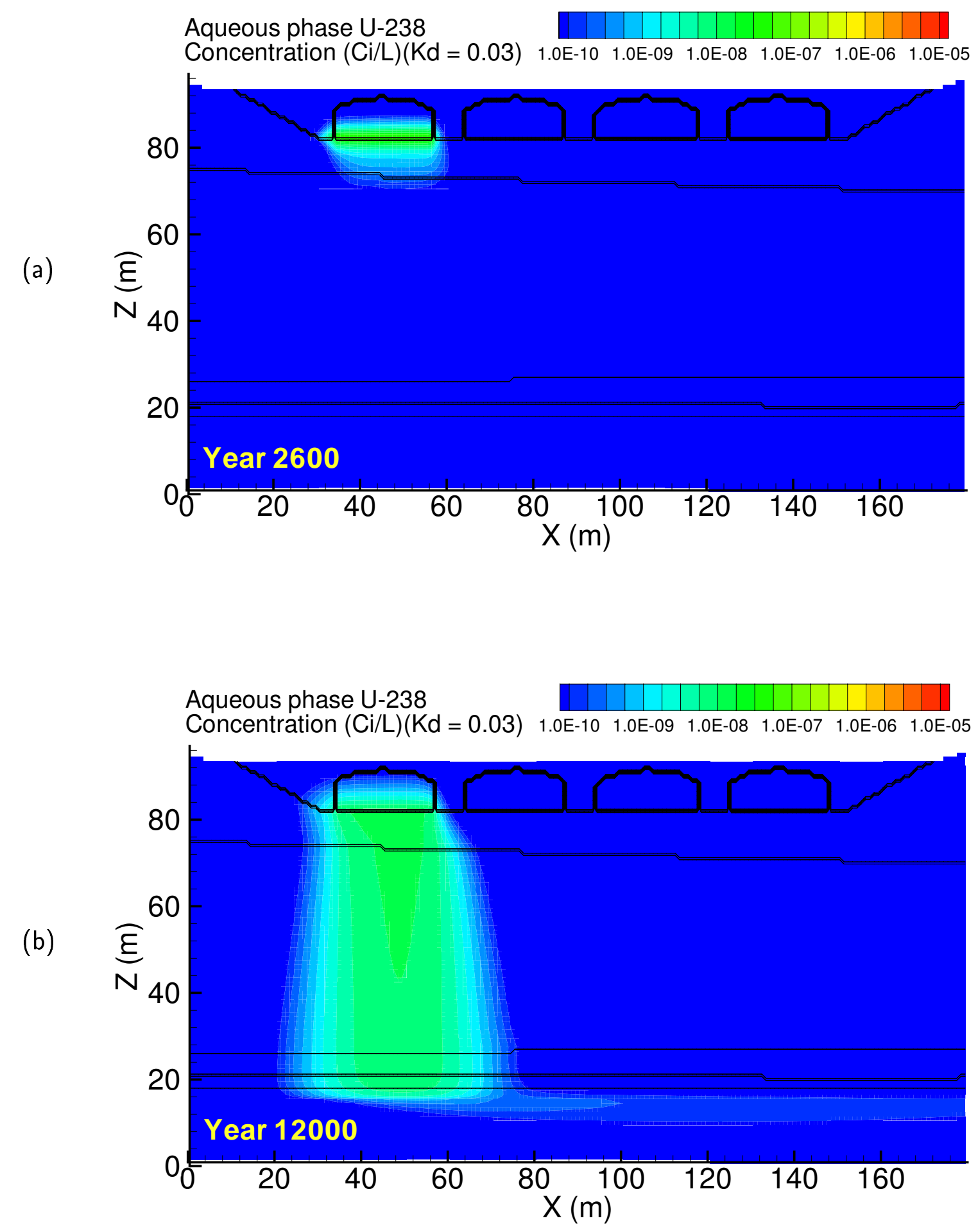

Figure A.126. Case 12, U-238 $\left(\mathrm{K}_{d}=0.03\right)$ aqueous concentration at (a) year 2600 and (b) year 12000 

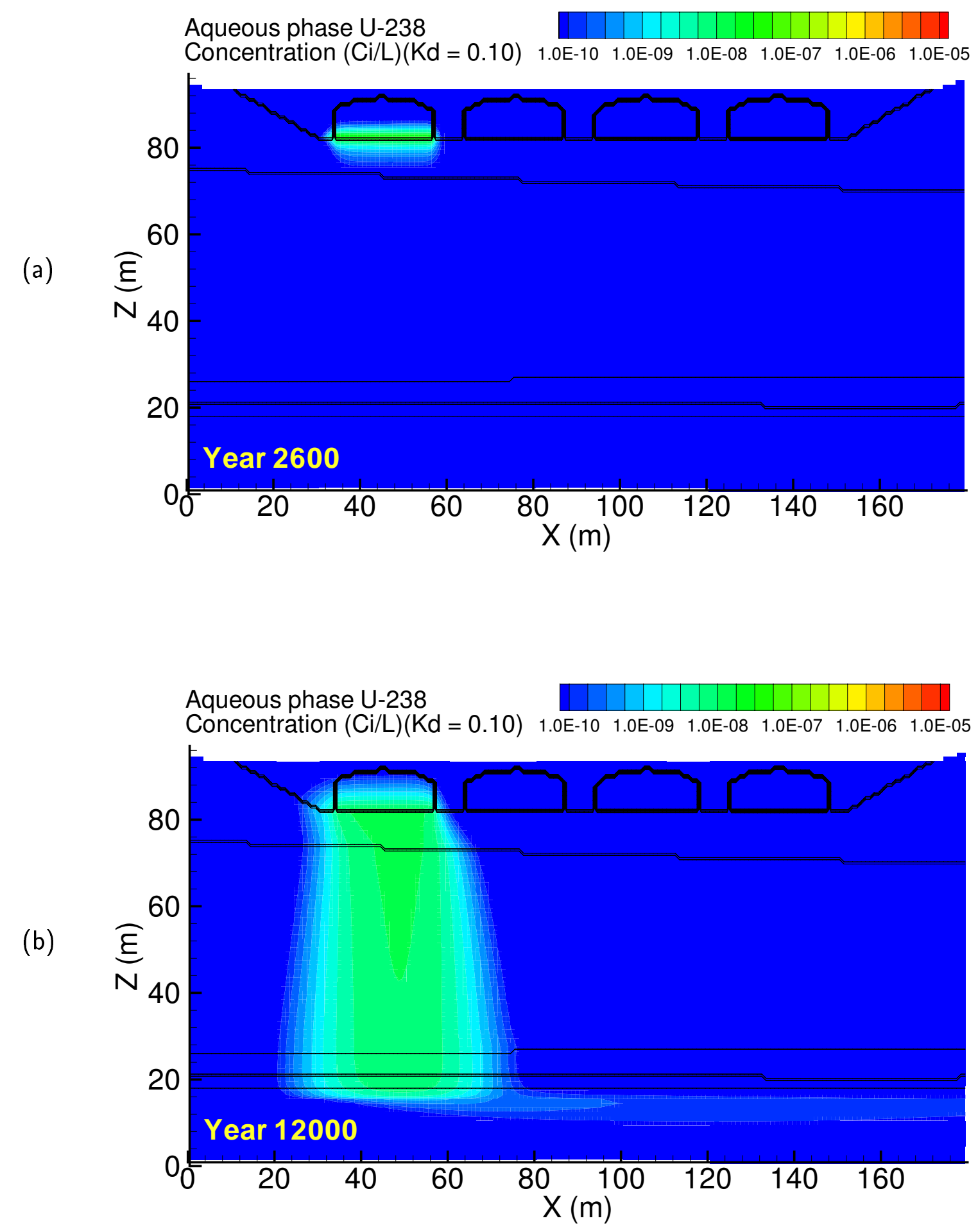

Figure A.127. Case 12, U-238 $\left(\mathrm{K}_{d}=0.10\right)$ aqueous concentration at (a) year 2600 and (b) year 12000 

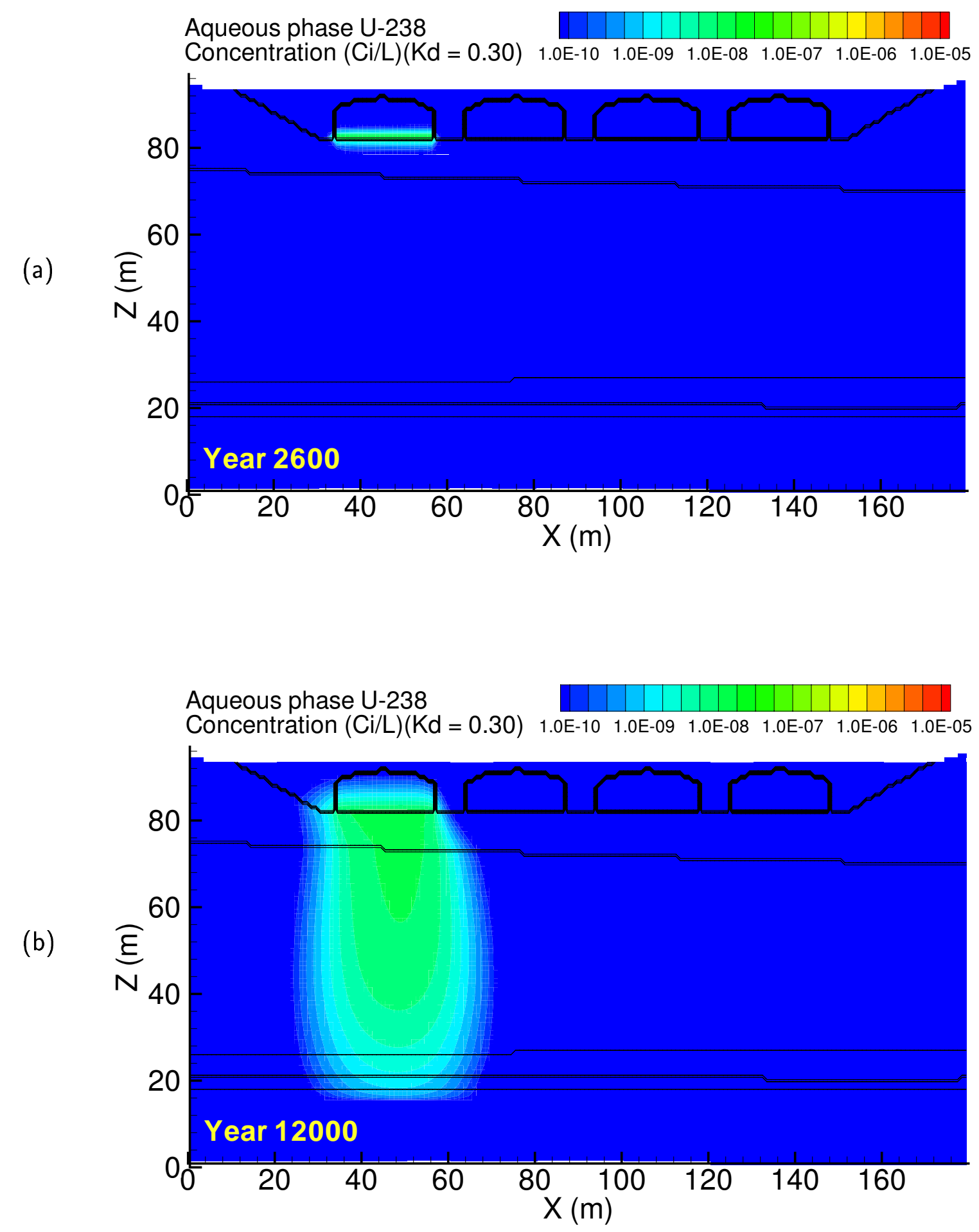

Figure A.128. Case 12, U-238 $\left(\mathrm{K}_{d}=0.30\right)$ aqueous concentration at (a) year 2600 and (b) year 12000 

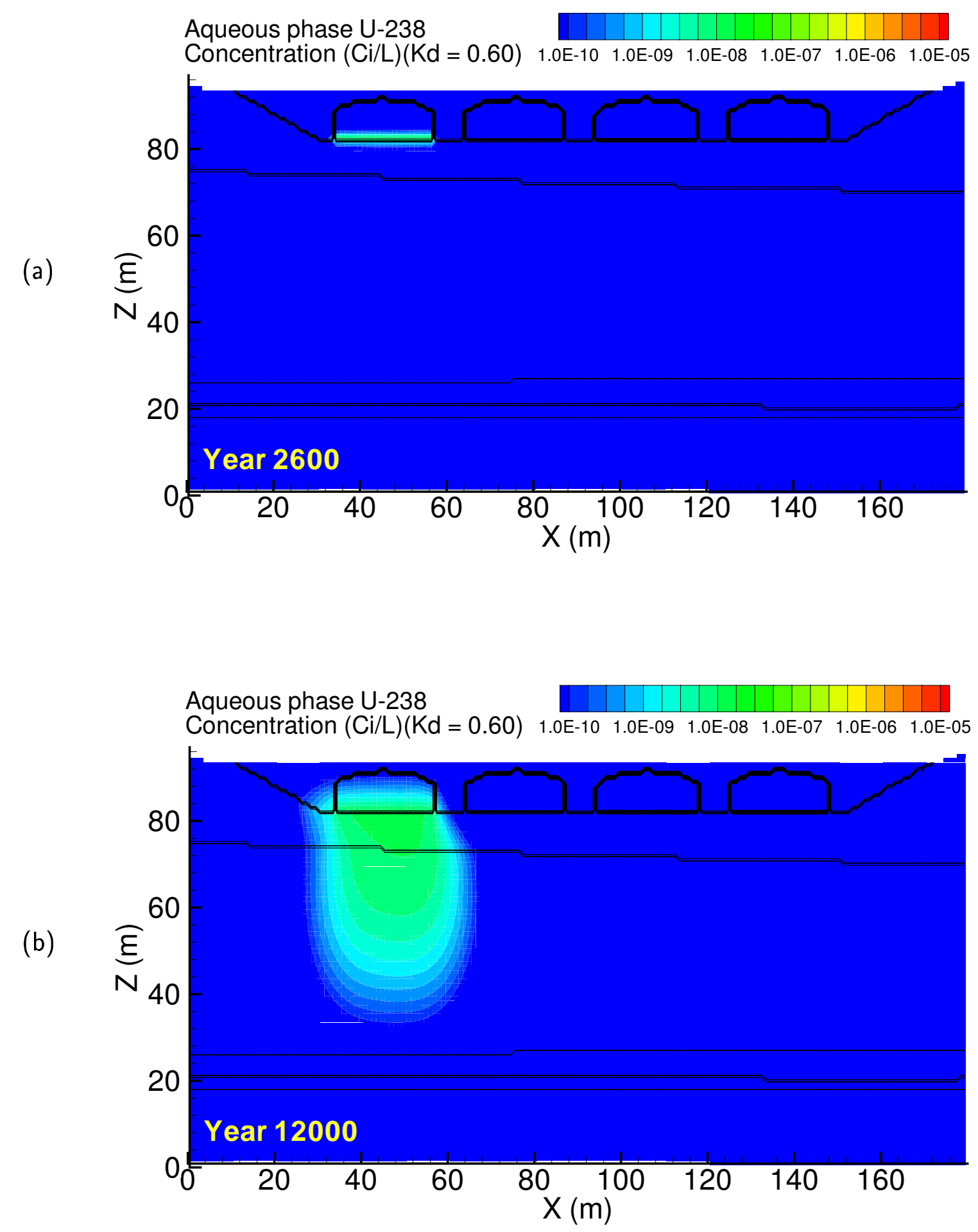

Figure A.129. Case 12, U-238 $\left(\mathrm{K}_{d}=0.60\right)$ aqueous concentration at (a) year 2600 and (b) year 12000 

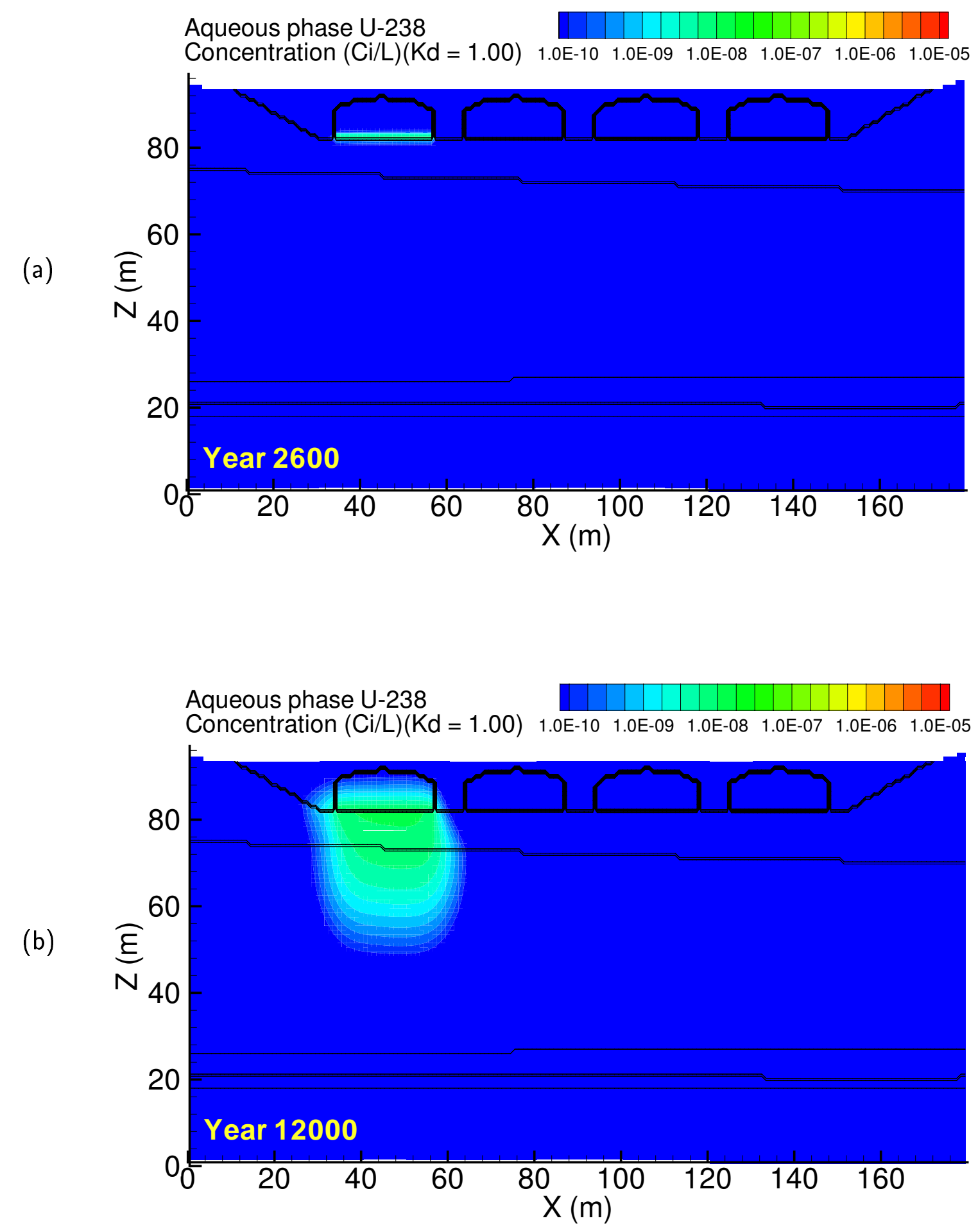

Figure A.130. Case 12, U-238 $\left(\mathrm{K}_{d}=1.00\right)$ aqueous concentration at (a) year 2600 and (b) year 12000 

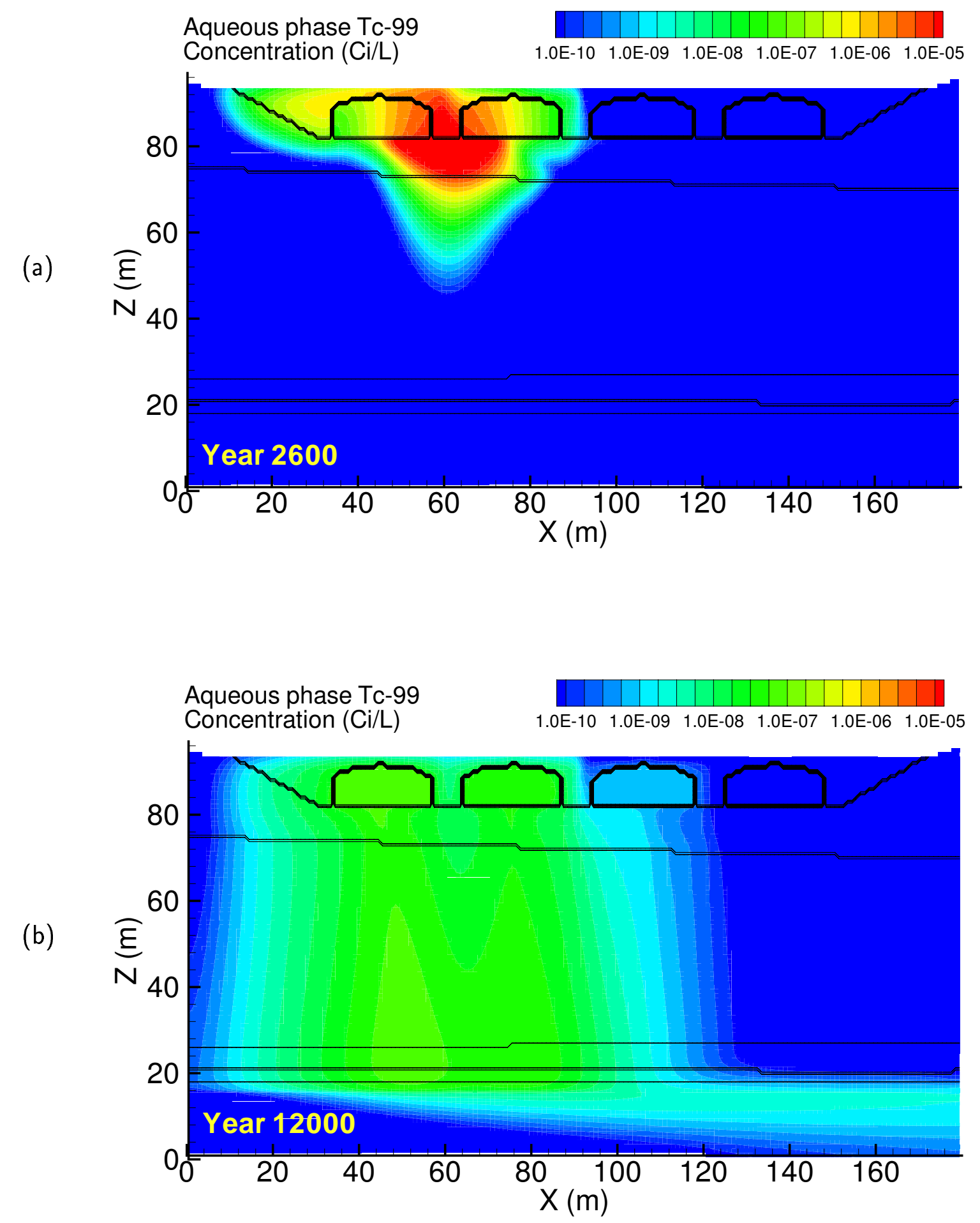

Figure A.131. Case 13, Tc-99 aqueous concentration at (a) year 2600 and (b) year 12000 

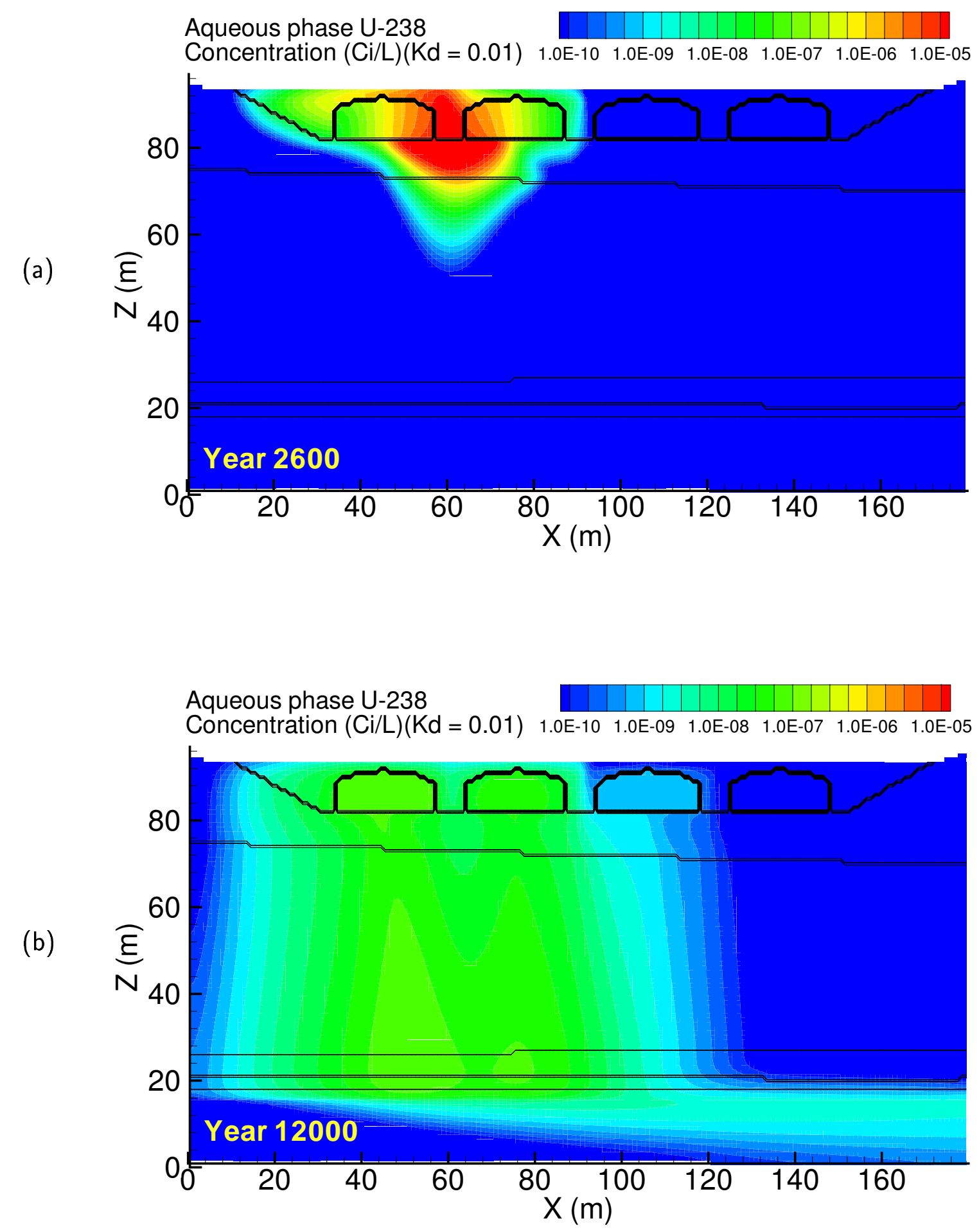

Figure A.132. Case 13, U-238 $\left(\mathrm{K}_{d}=0.01\right)$ aqueous concentration at (a) year 2600 and (b) year 12000 

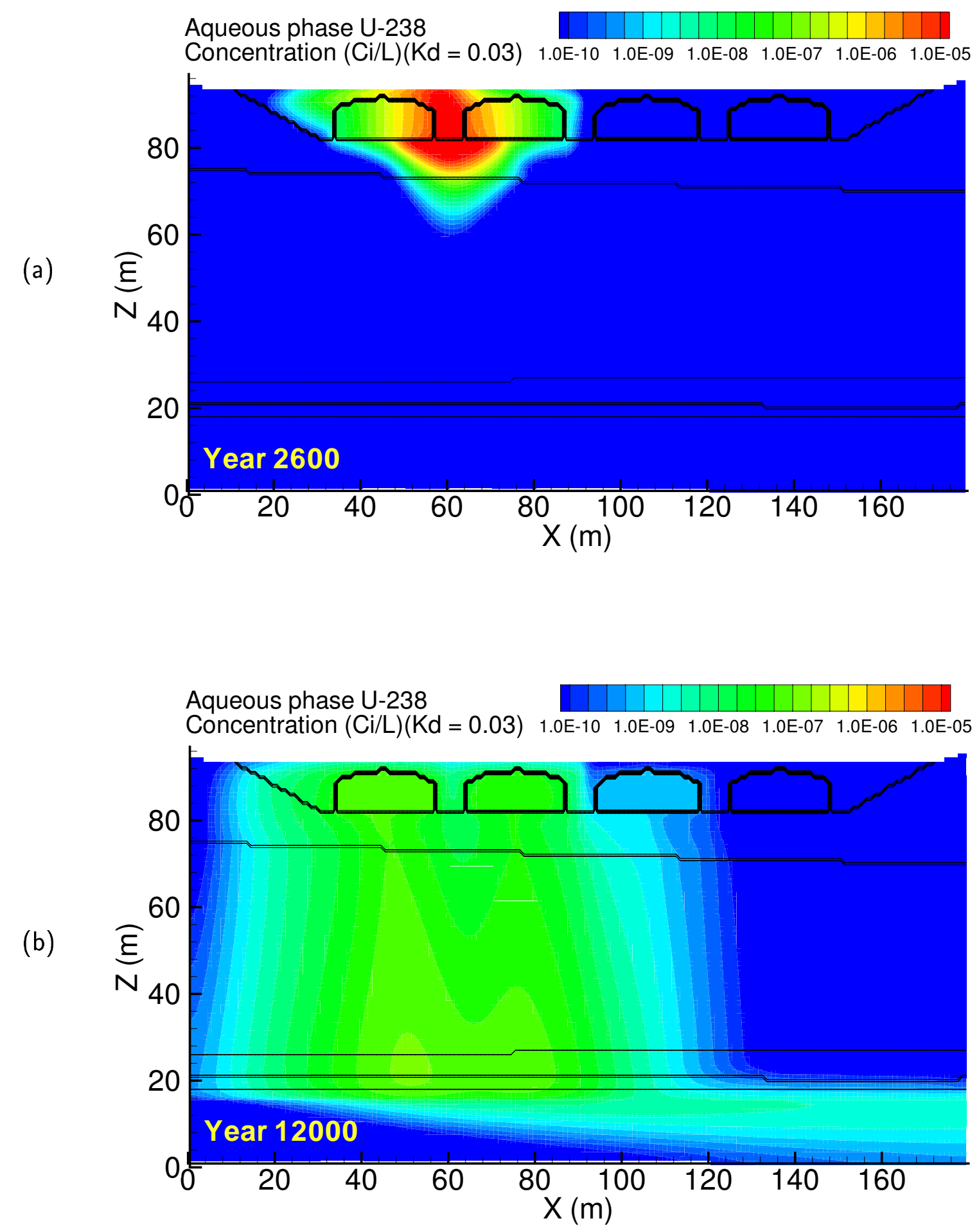

Figure A.133. Case 13, U-238 $\left(\mathrm{K}_{d}=0.03\right)$ aqueous concentration at (a) year 2600 and (b) year 12000 

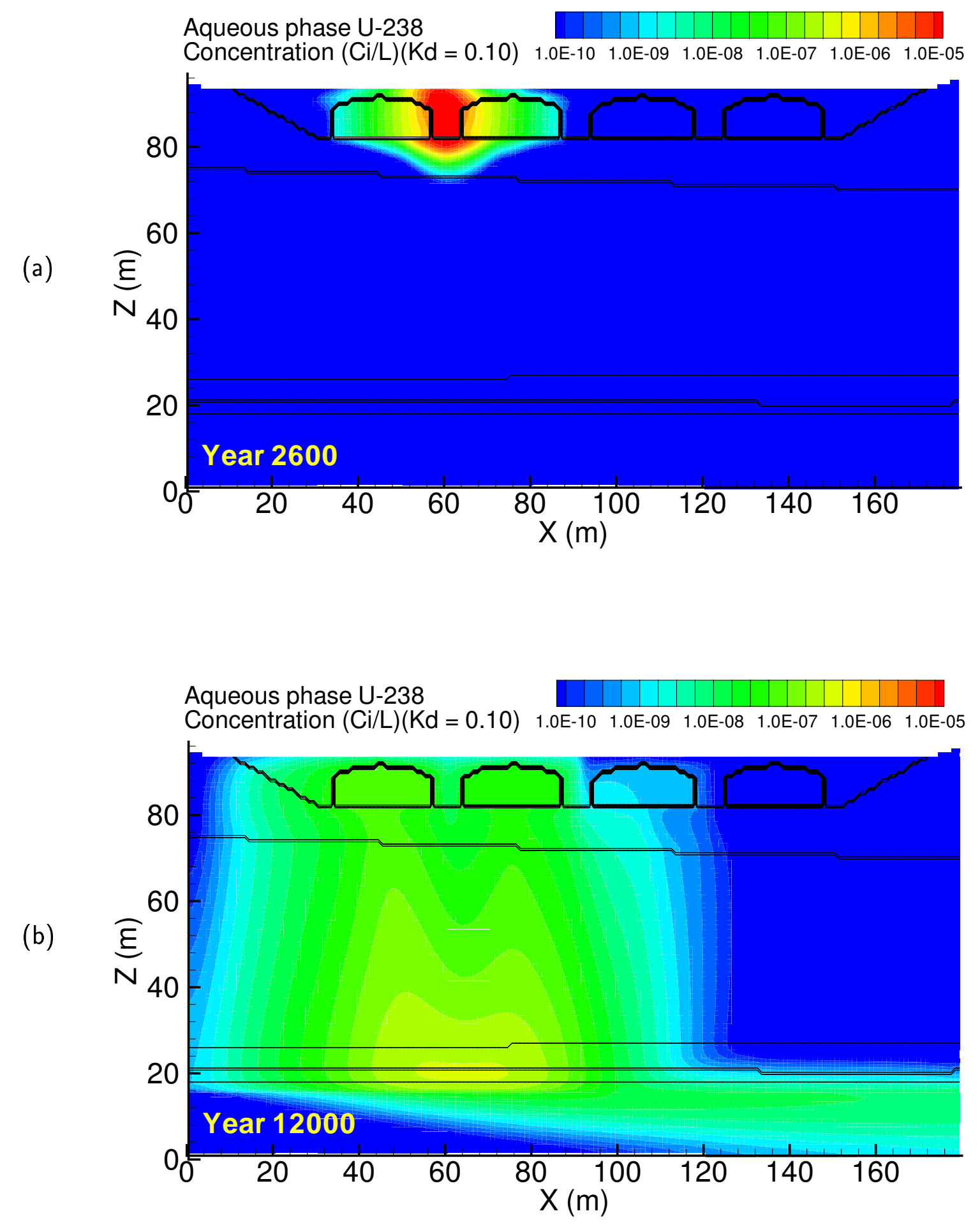

Figure A.134. Case 13, U-238 $\left(\mathrm{K}_{d}=0.10\right)$ aqueous concentration at (a) year 2600 and (b) year 12000 

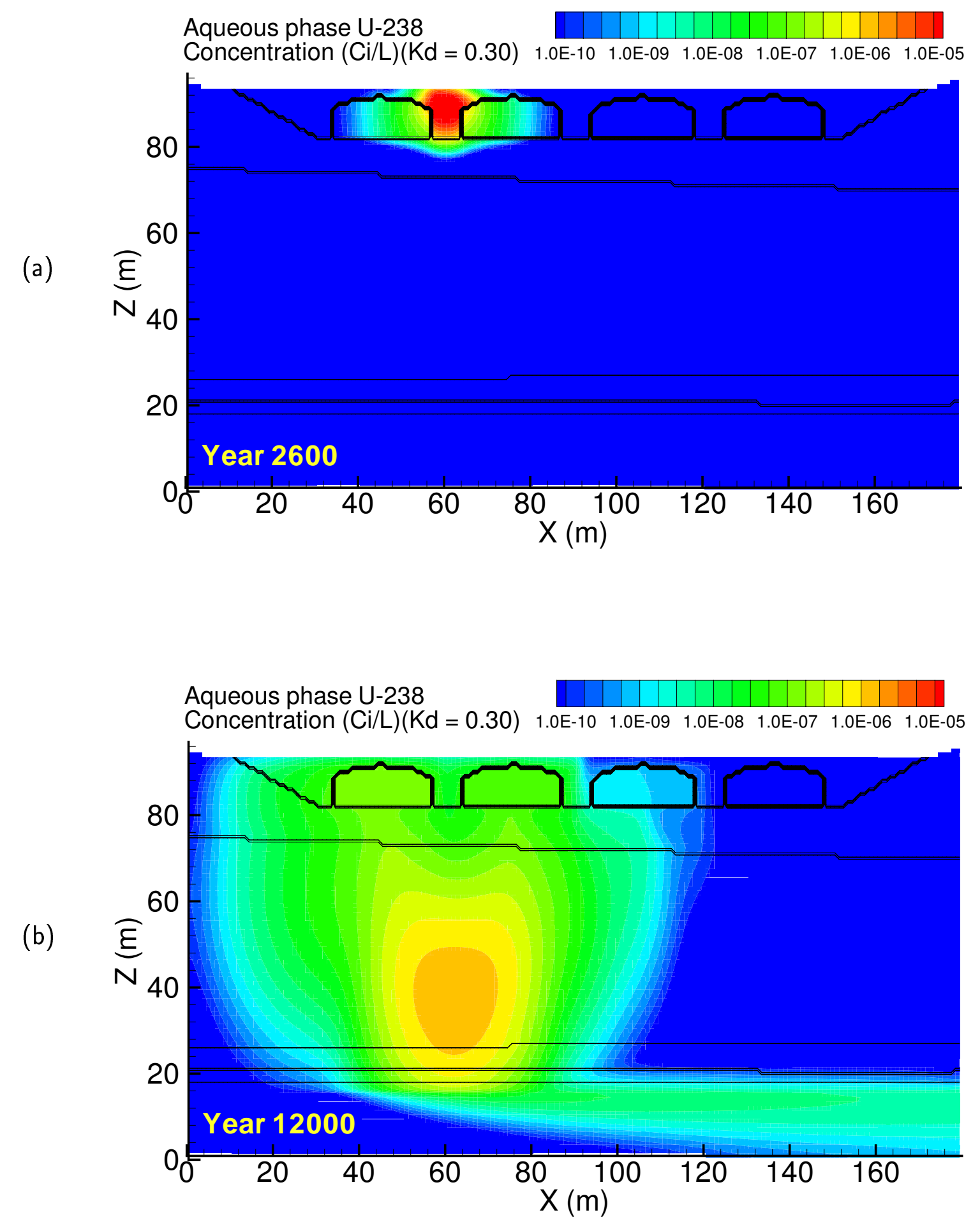

Figure A.135. Case 13, U-238 $\left(\mathrm{K}_{d}=0.30\right)$ aqueous concentration at (a) year 2600 and (b) year 12000 

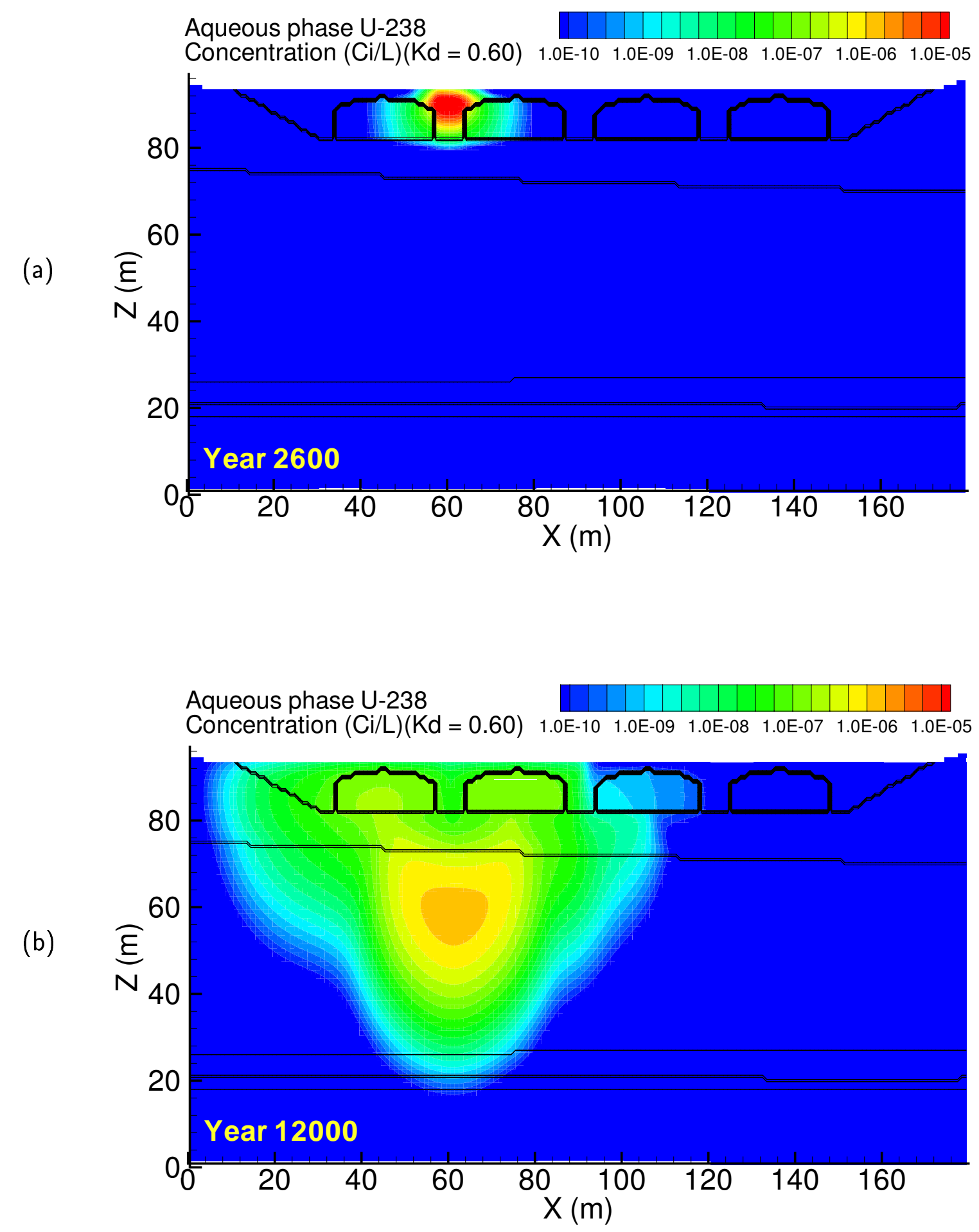

Figure A.136. Case 13, U-238 $\left(\mathrm{K}_{d}=0.60\right)$ aqueous concentration at (a) year 2600 and (b) year 12000 

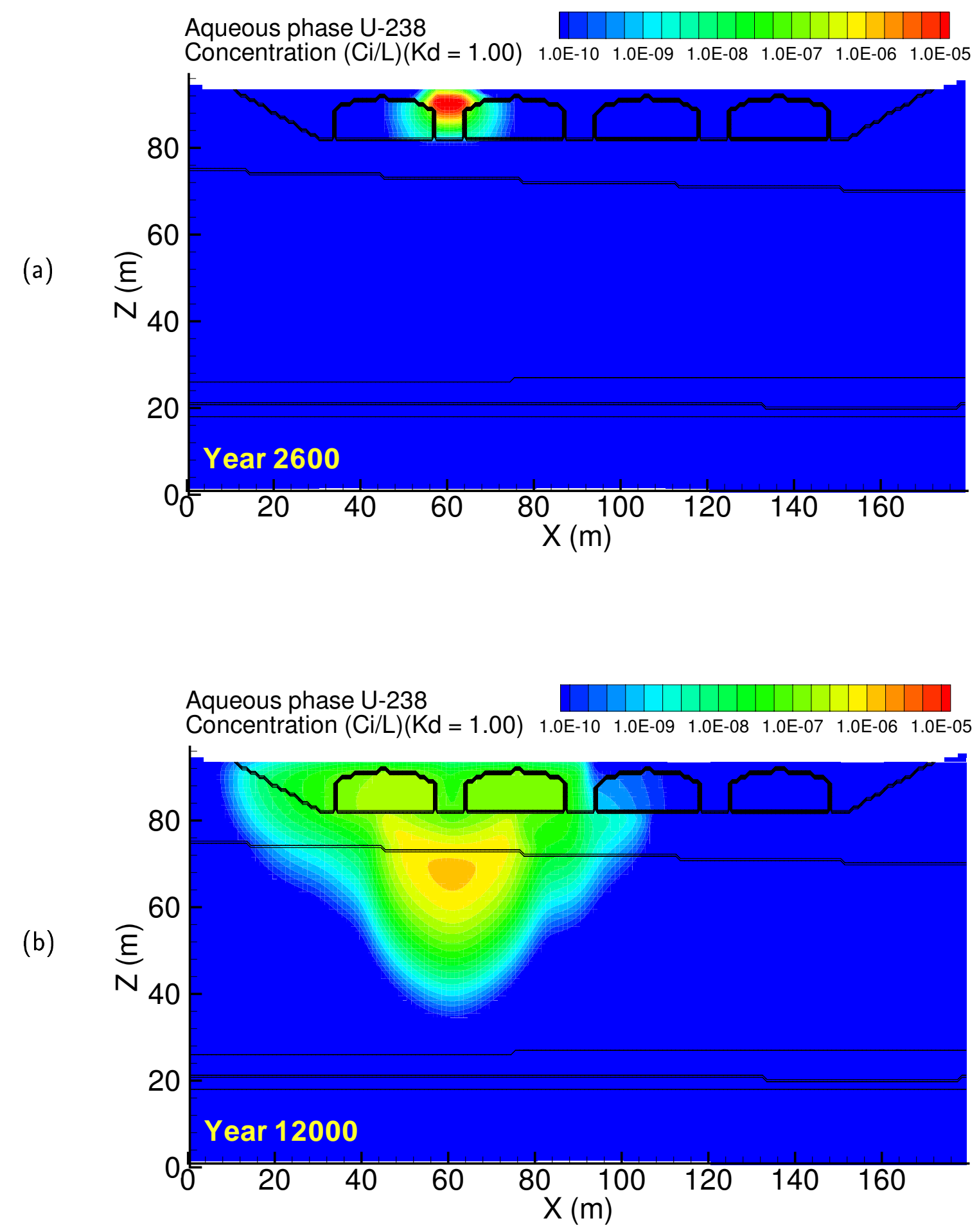

Figure A.137. Case 13, U-238 $\left(\mathrm{K}_{d}=1.00\right)$ aqueous concentration at (a) year 2600 and (b) year 12000 

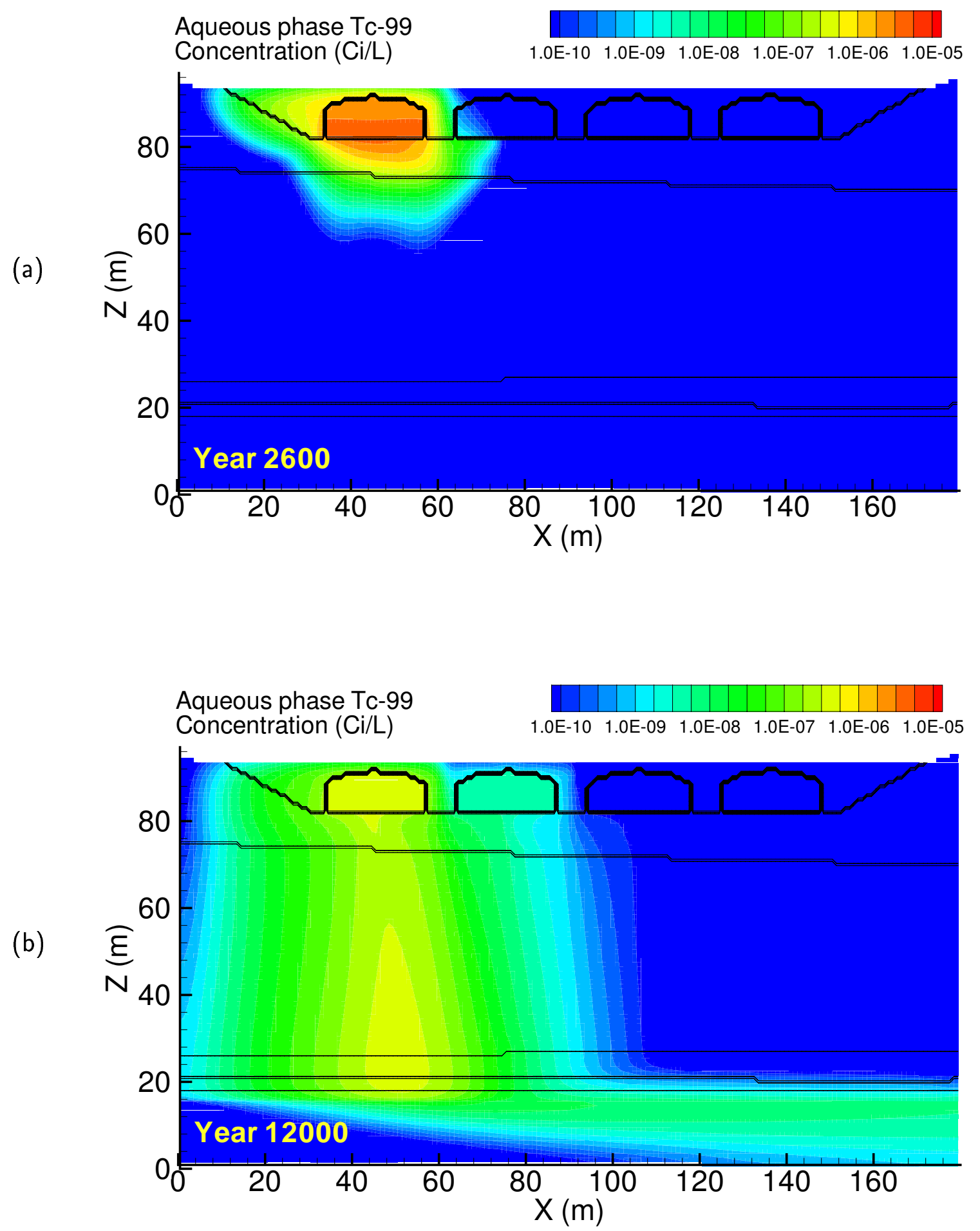

Figure A.138. Case 14, Tc-99 aqueous concentration at (a) year 2600 and (b) year 12000 

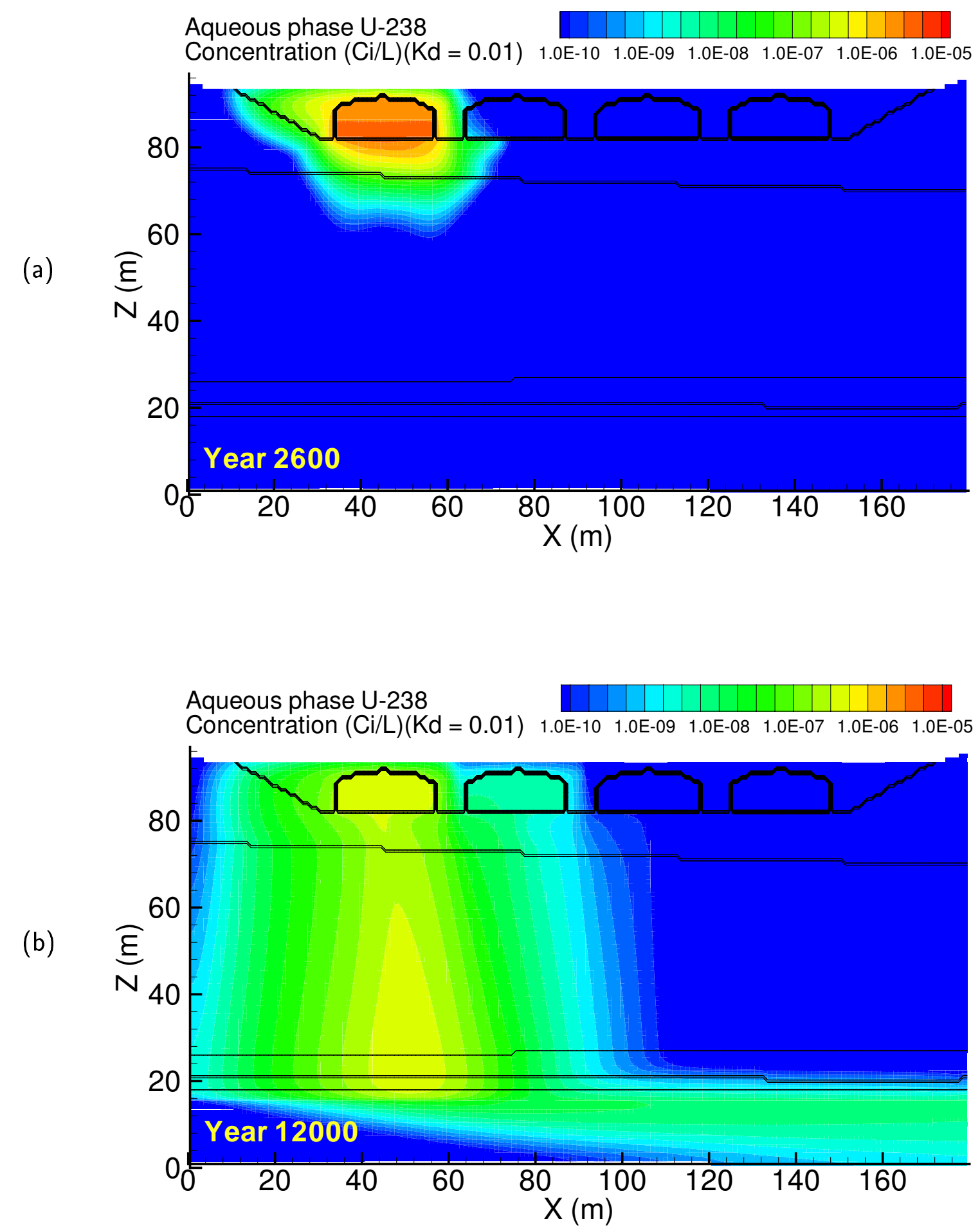

Figure A.139. Case 14, U-238 $\left(\mathrm{K}_{d}=0.01\right)$ aqueous concentration at (a) year 2600 and (b) year 12000 

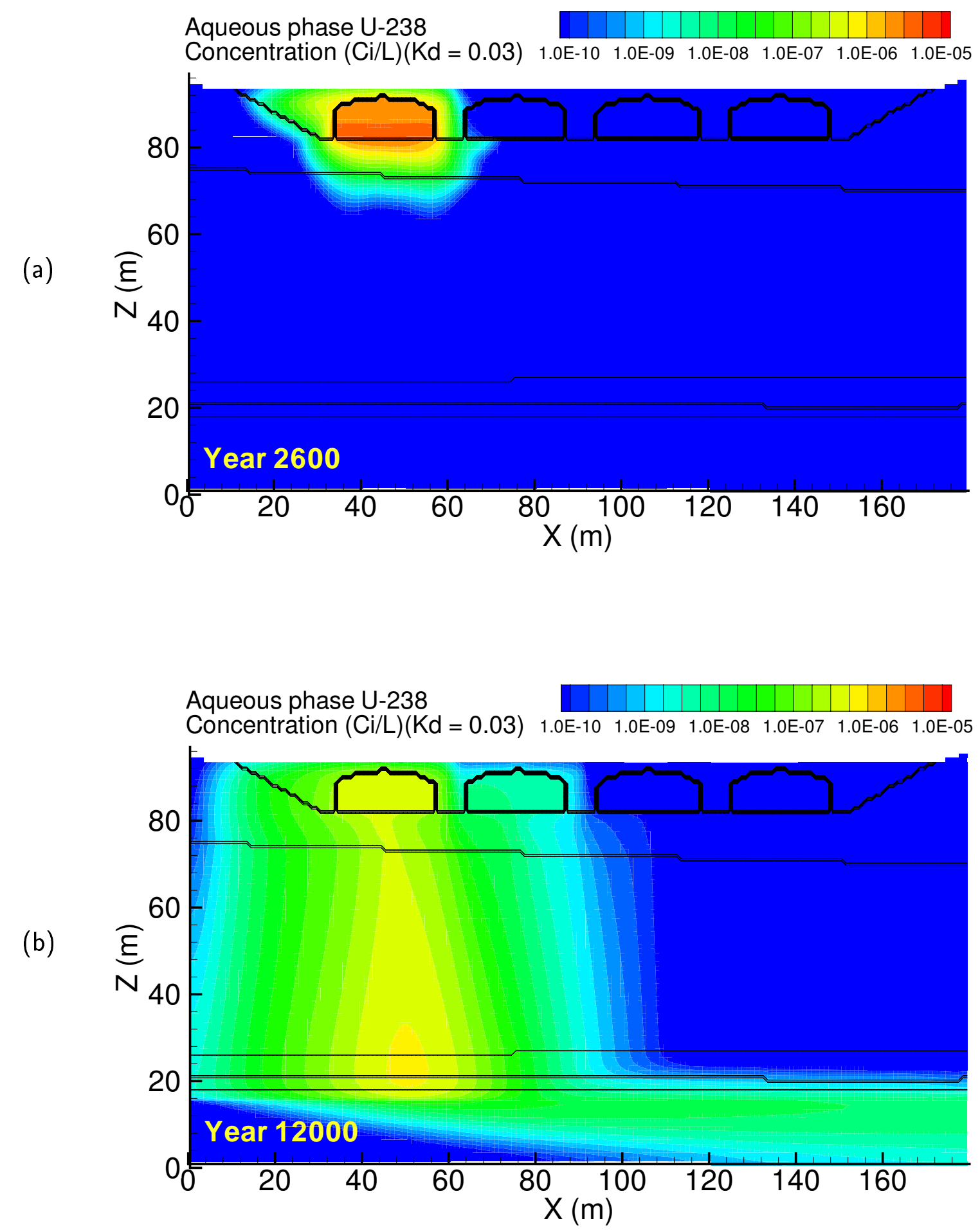

Figure A.140. Case 14, U-238 $\left(\mathrm{K}_{d}=0.03\right)$ aqueous concentration at (a) year 2600 and (b) year 12000 

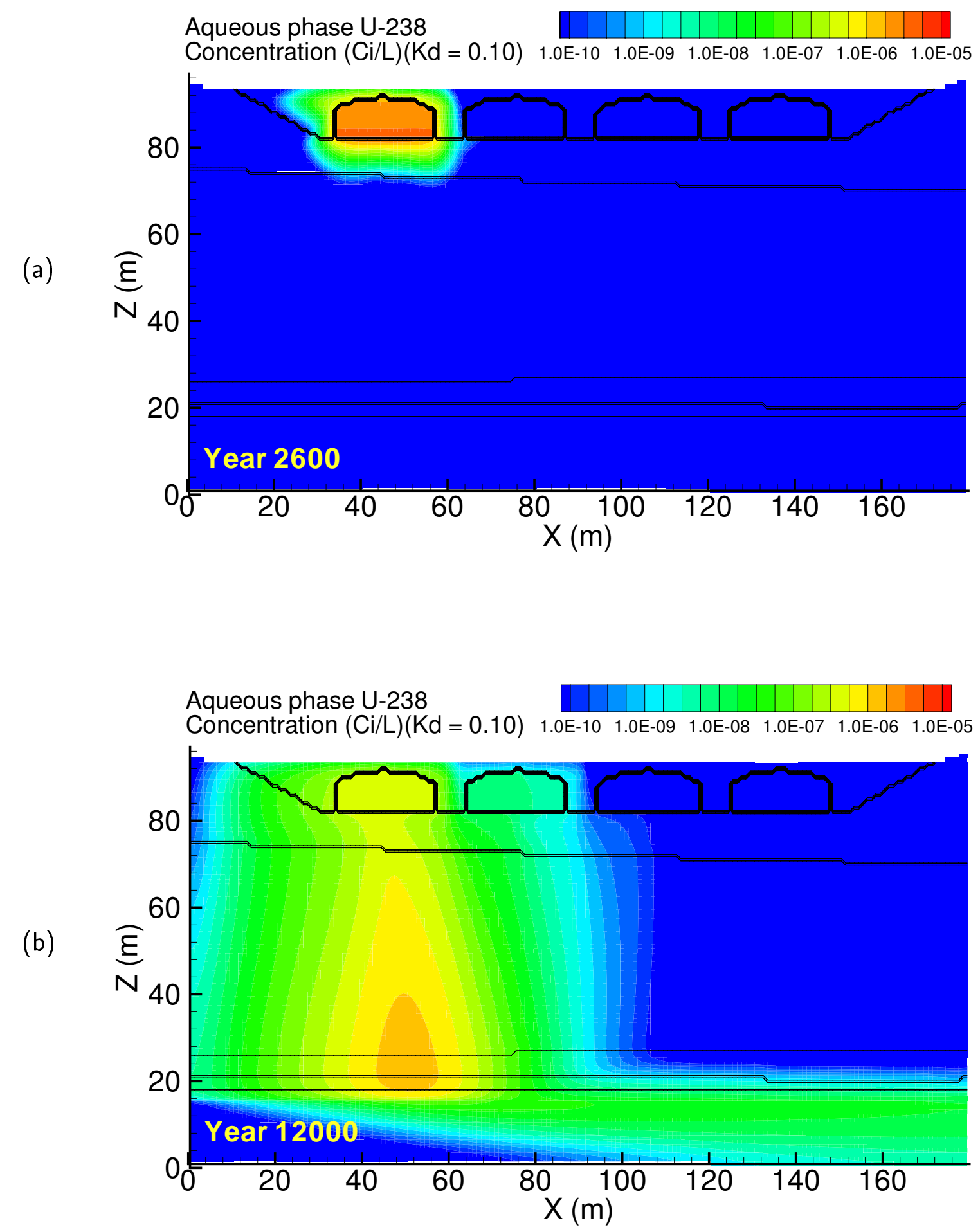

Figure A.141. Case 14, U-238 $\left(\mathrm{K}_{d}=0.10\right)$ aqueous concentration at (a) year 2600 and (b) year 12000 

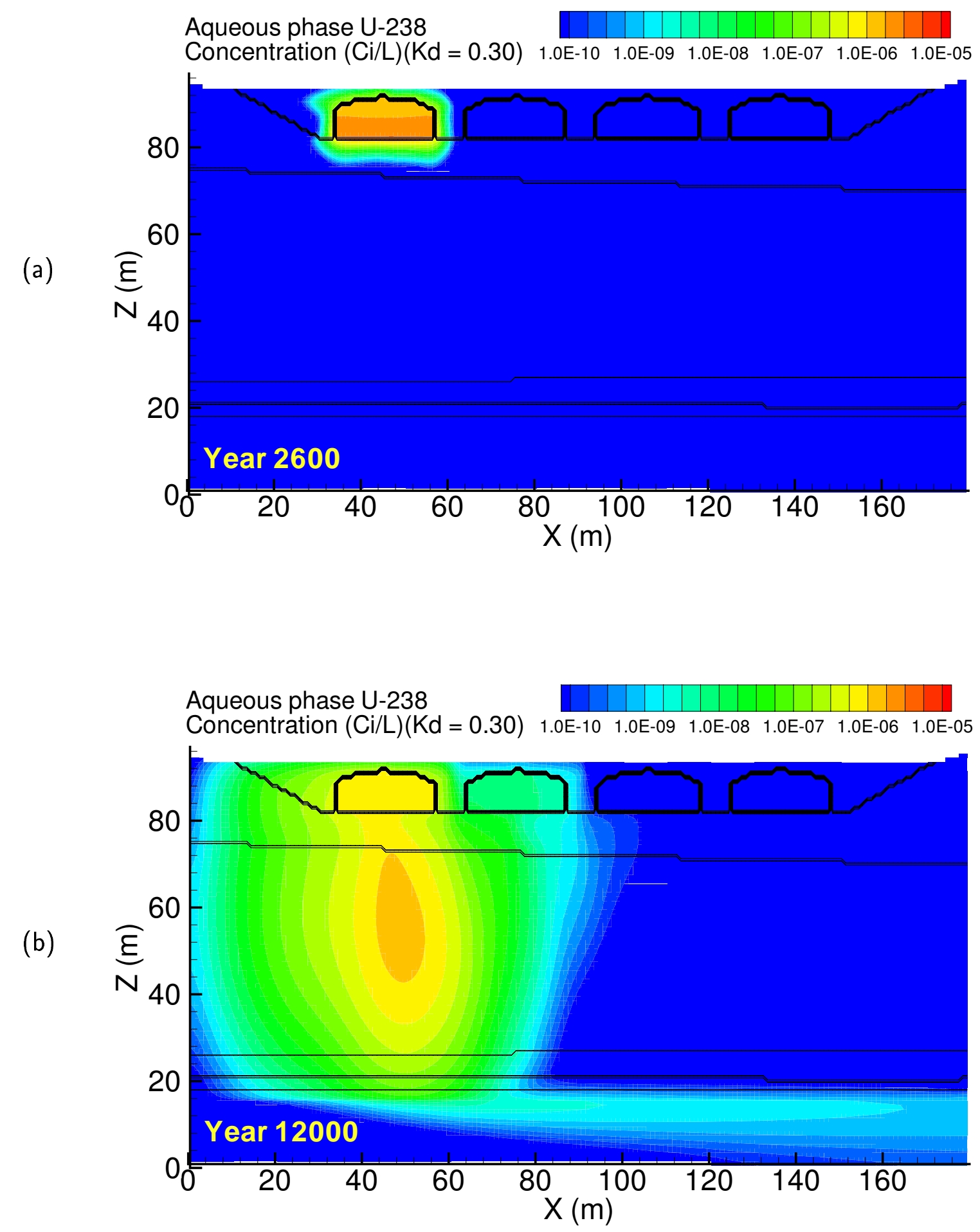

Figure A.142. Case 14, U-238 $\left(\mathrm{K}_{d}=0.30\right)$ aqueous concentration at (a) year 2600 and (b) year 12000 

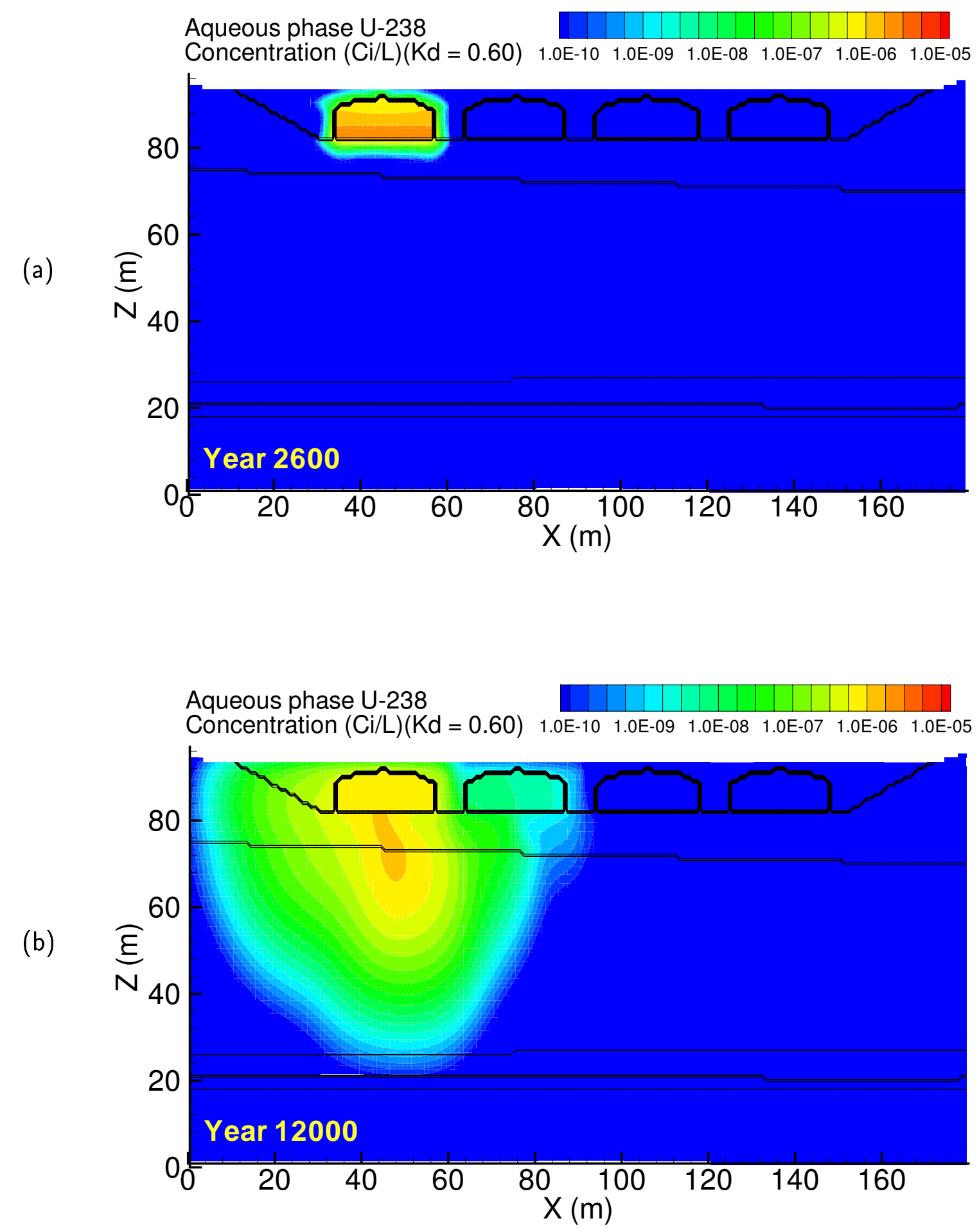

Figure A.143. Case 14, U-238 $\left(\mathrm{K}_{d}=0.60\right)$ aqueous concentration at (a) year 2600 and (b) year 12000 

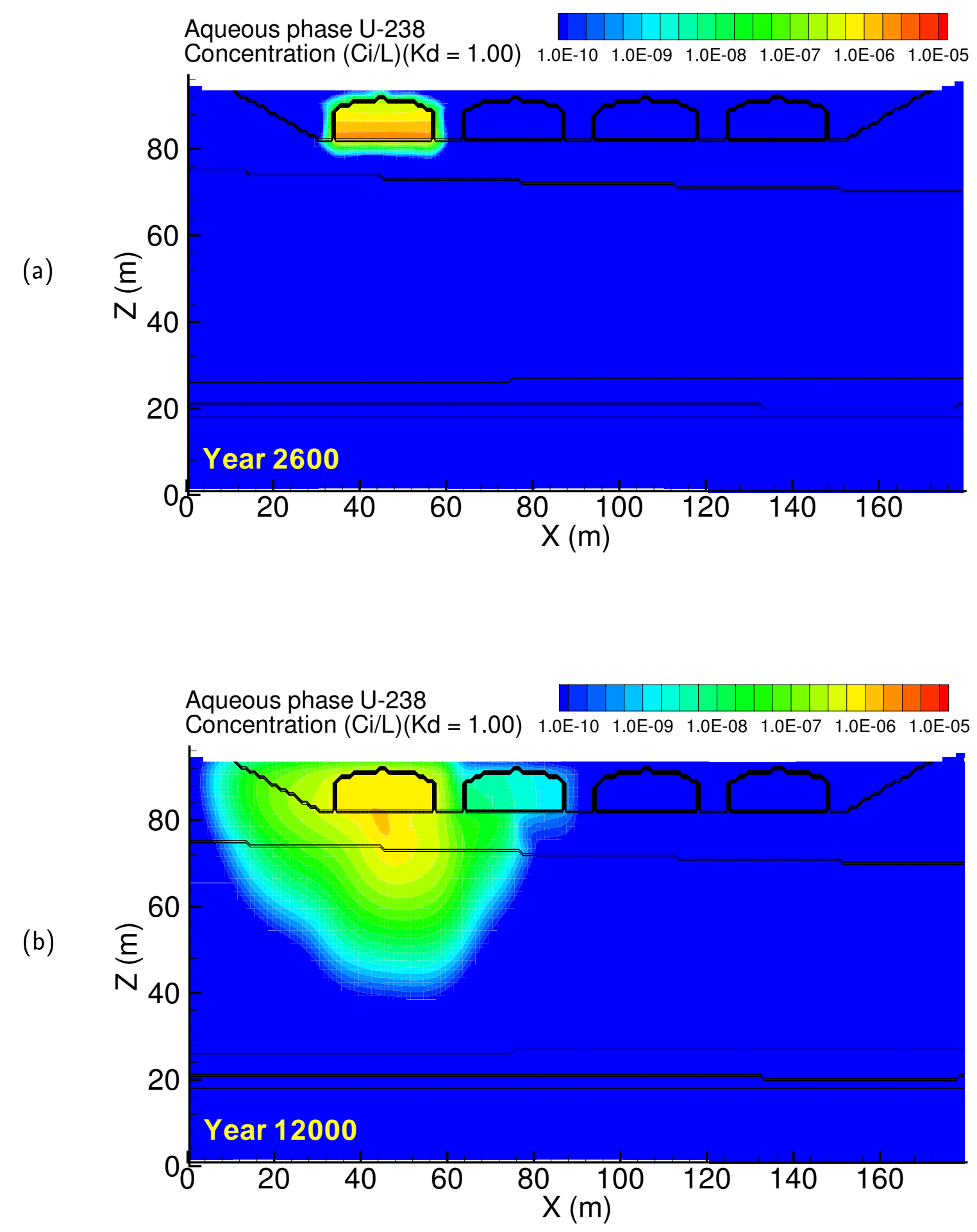

Figure A.144. Case 14, U-238 $\left(\mathrm{K}_{d}=1.00\right)$ aqueous concentration at (a) year 2600 and (b) year 12000 


\section{Appendix B: Breakthrough Curves}


(a)

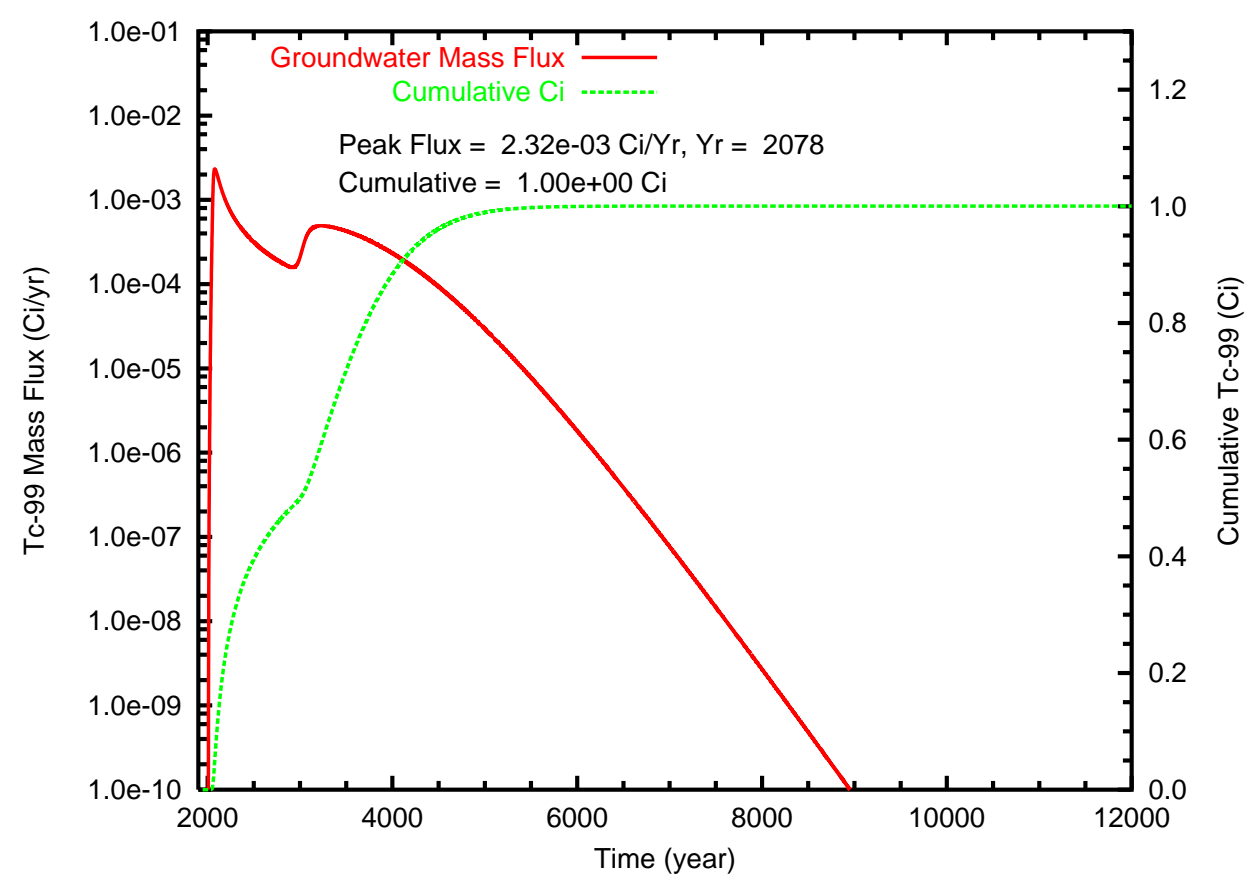

(b)

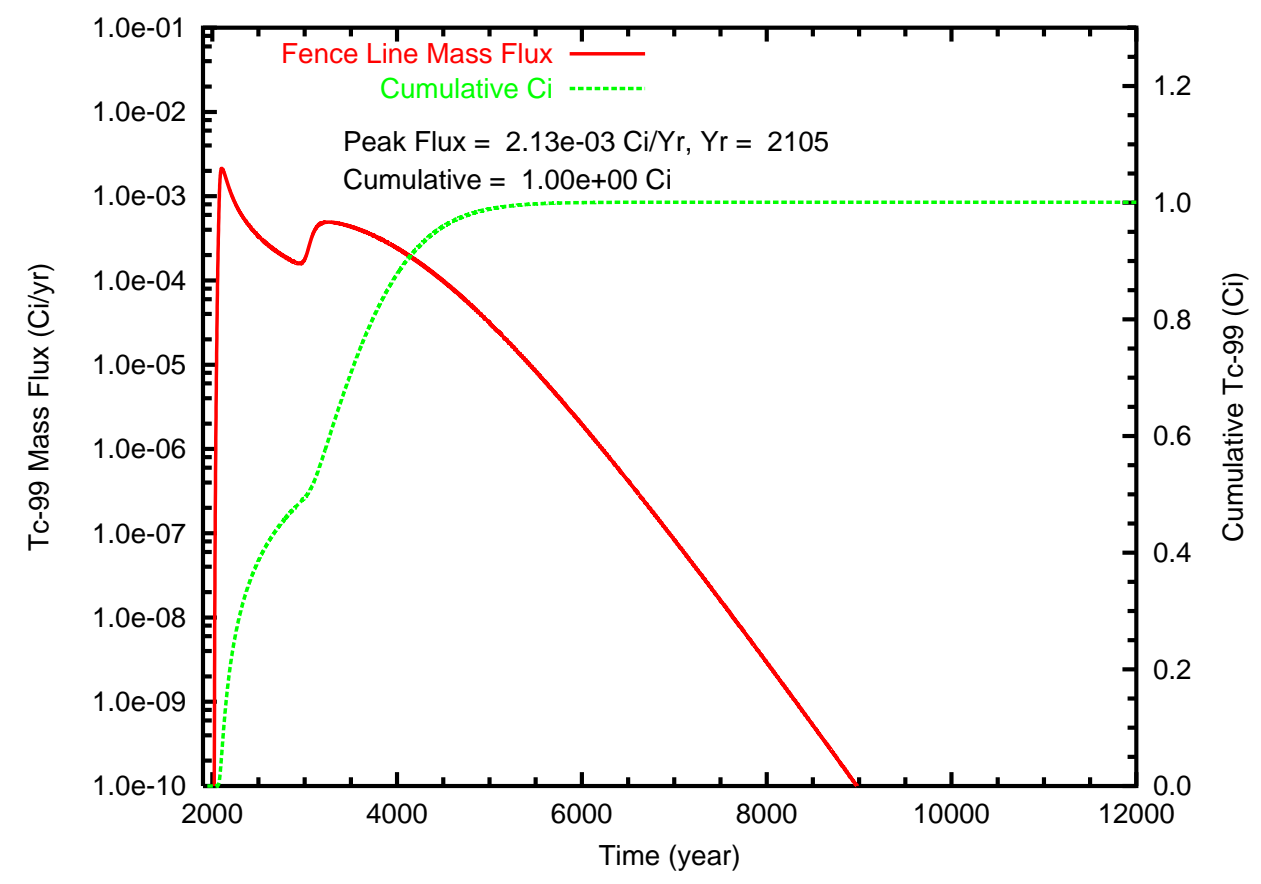

Figure B.1. Case 1, Tc-99 mass flux and cumulative mass at (a) the groundwater table and (b) the fence line

B.1 
(a)

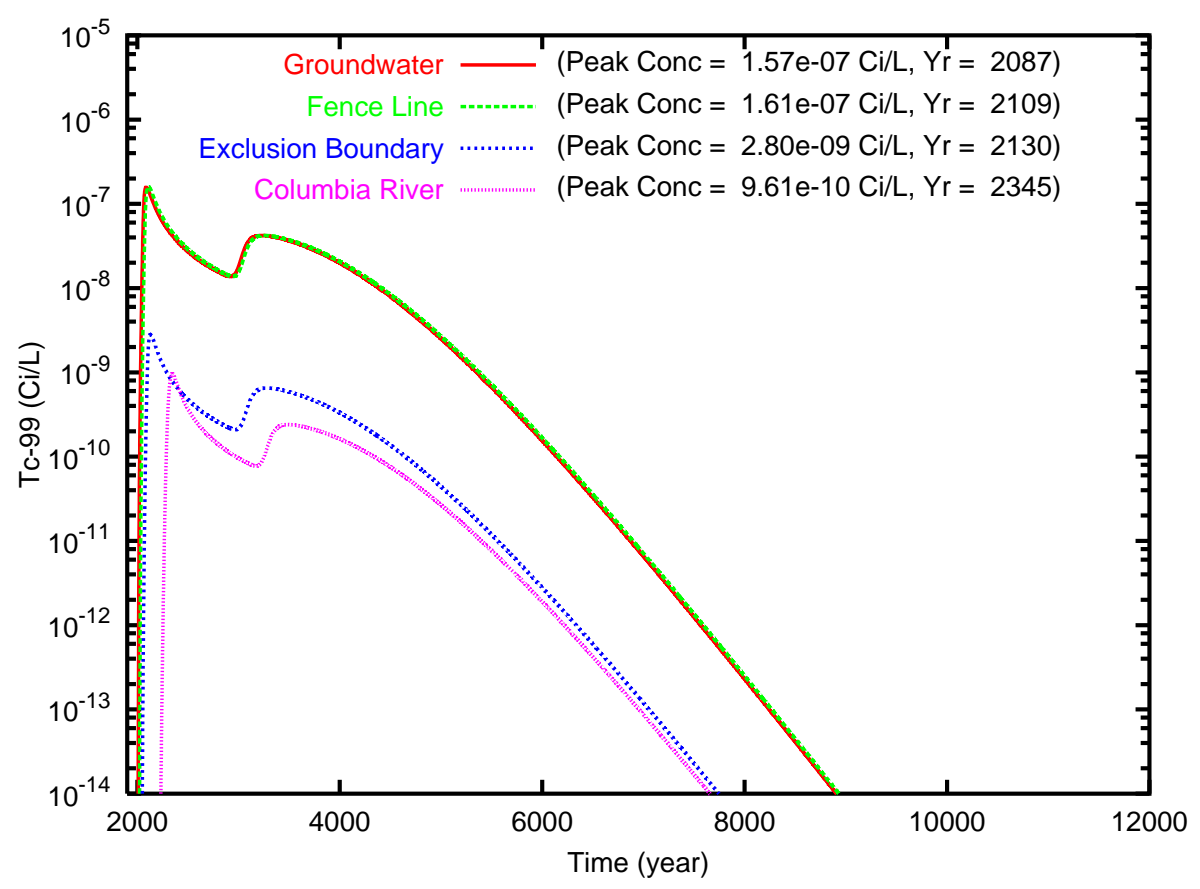

(b)

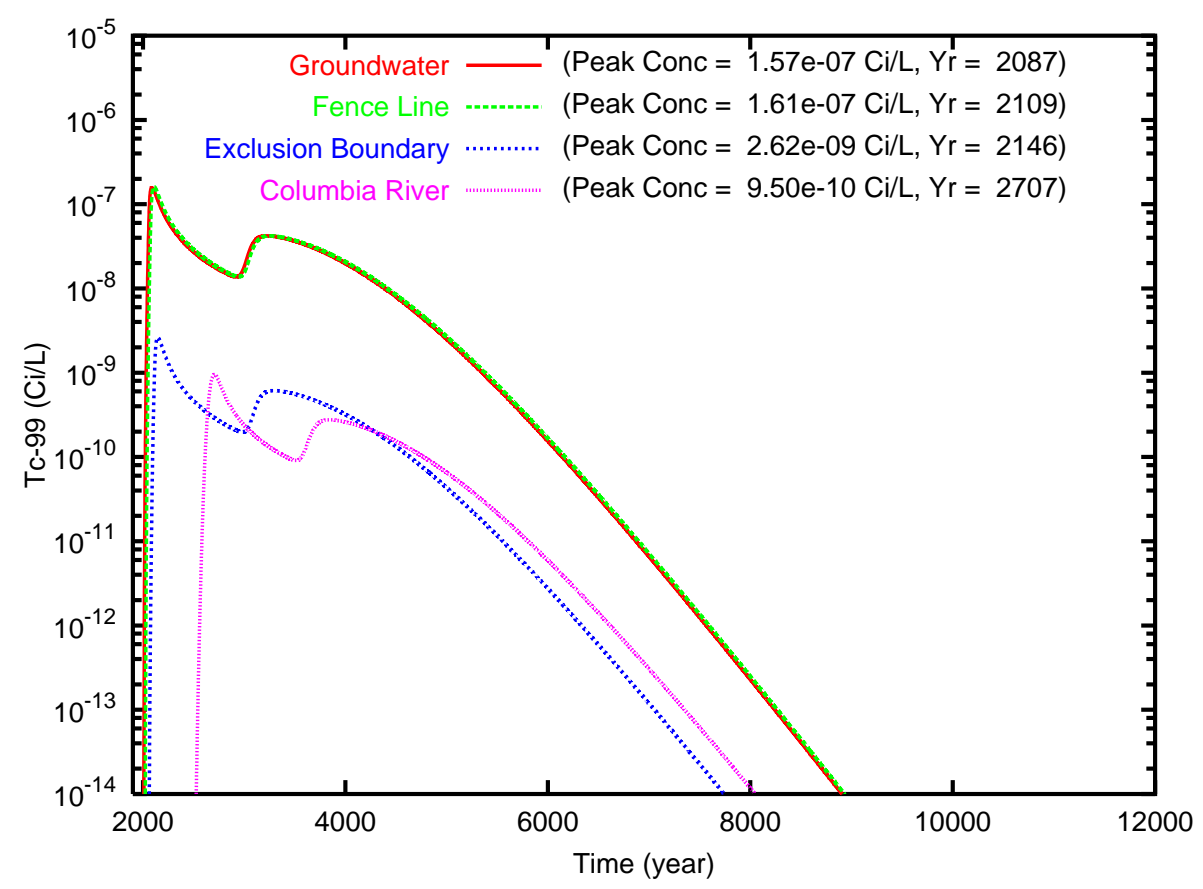

Figure B.2. Case 1, Tc-99 concentration versus time for the fence line, exclusion boundary and Columbia River compliance points for travel paths (a) southeast and (b) north through the gap 
(a)

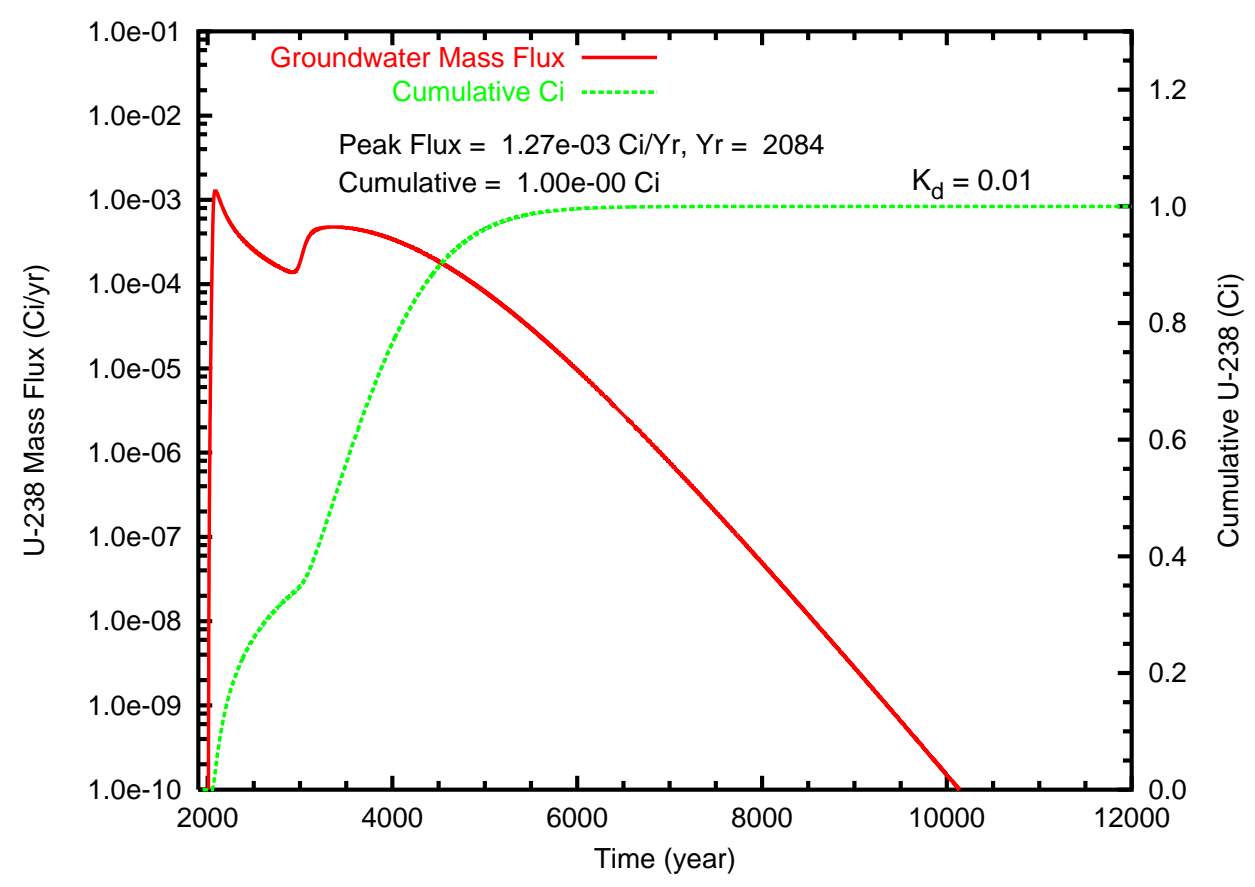

(b)

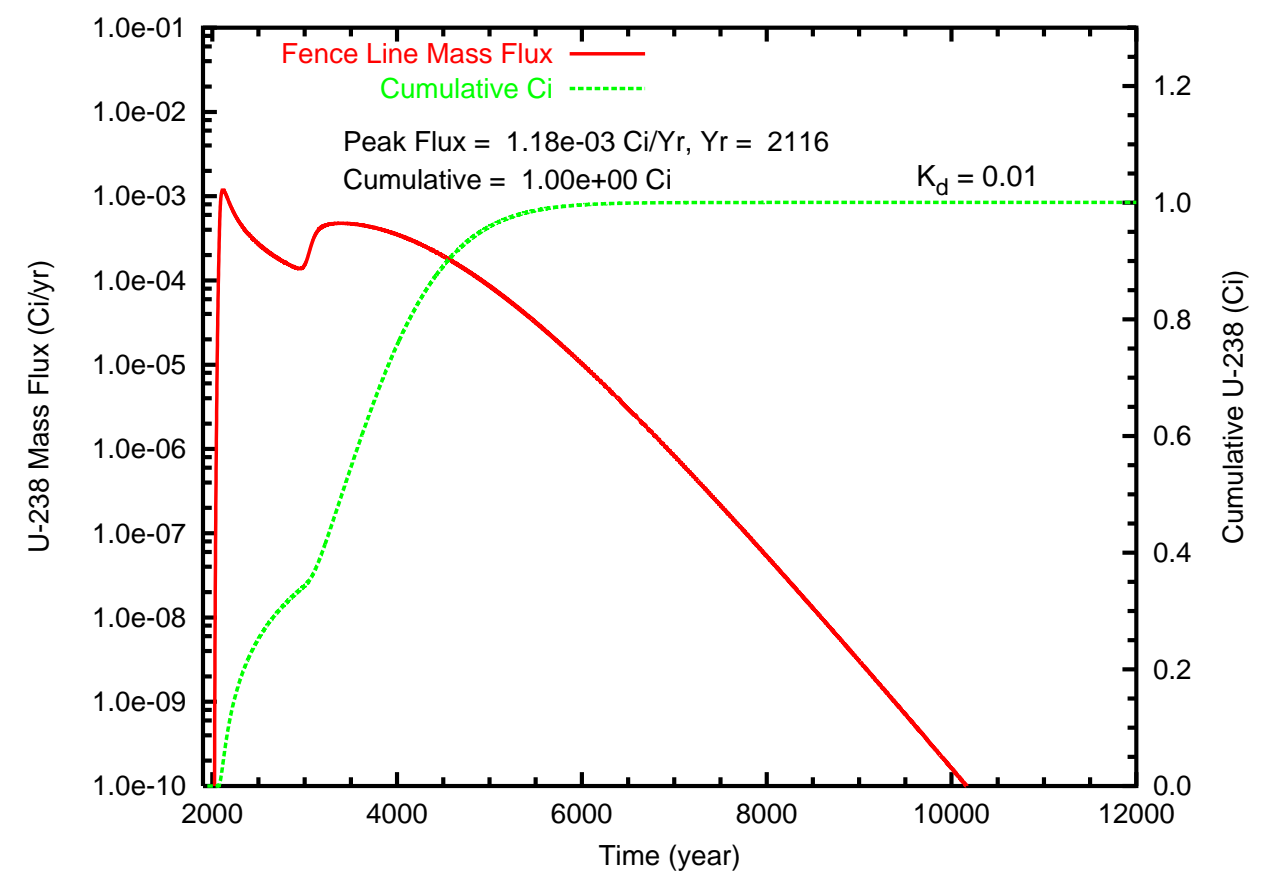

Figure B.3. Case 1, U-238 $\left(\mathrm{K}_{d}=0.01\right)$ mass flux $(\mathrm{Ci} / \mathrm{L})$ and cumulative mass $(\mathrm{Ci})$ at (a) the groundwater table and (b) the fence line 
(a)

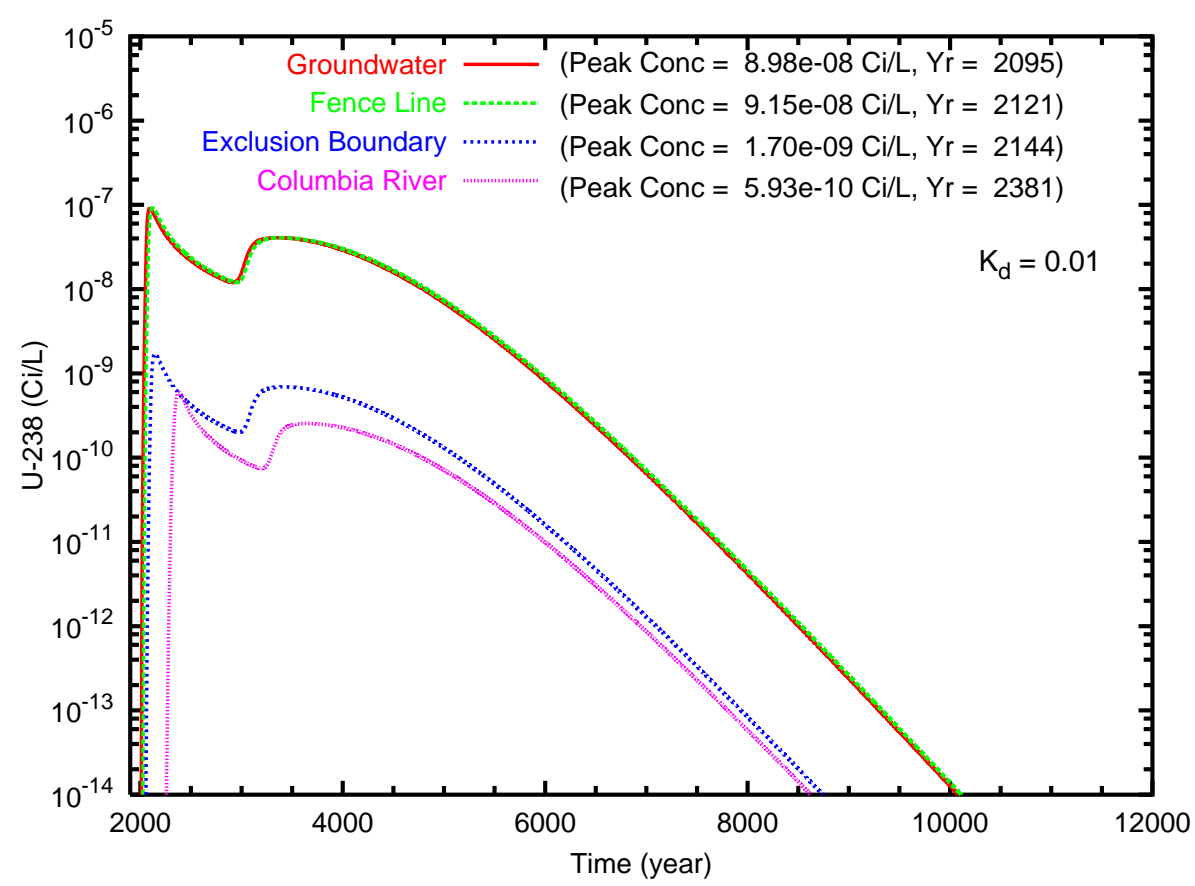

(b)

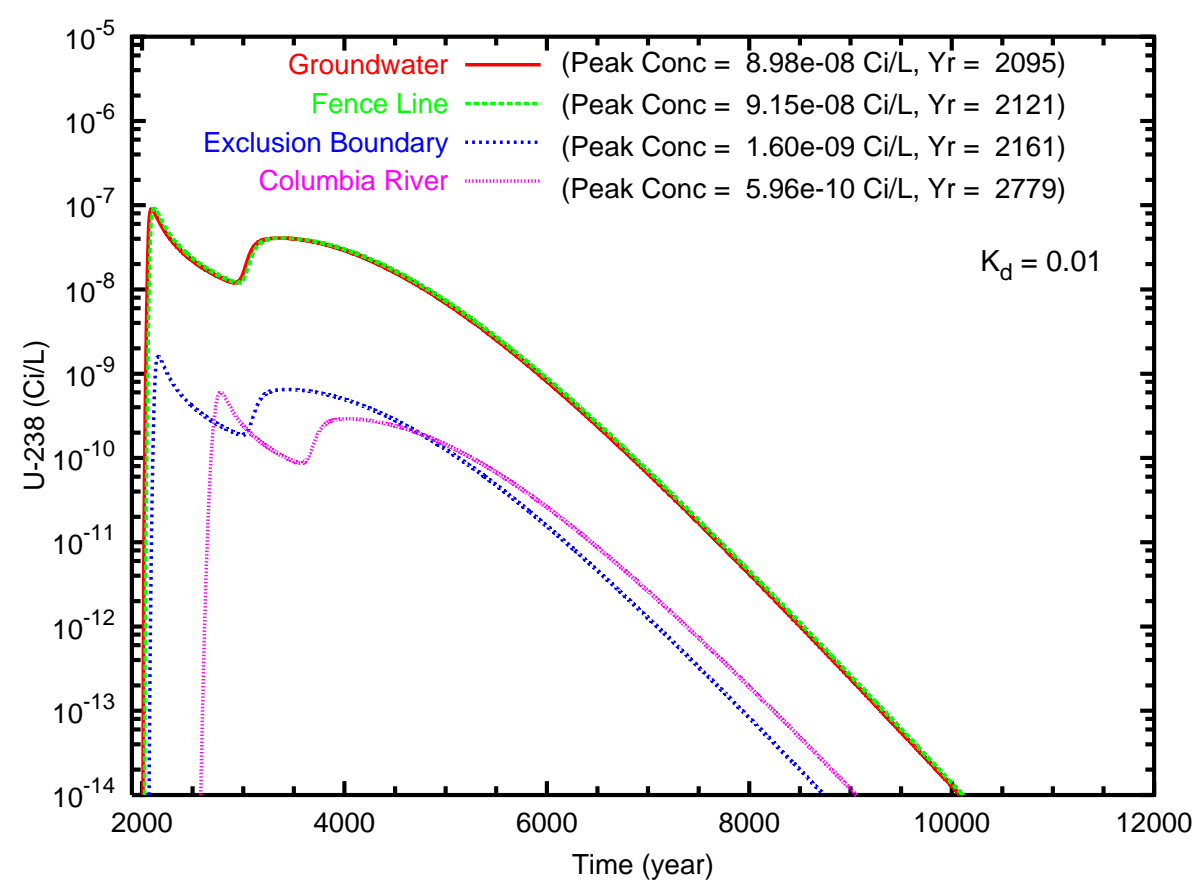

Figure B.4. Case 1, U-238 $\left(\mathrm{K}_{d}=0.01\right)$ concentration versus time for the fence line exclusion boundary and Columbia River compliance points for travel paths (a) southeast and (b) north through the gap 
(a)

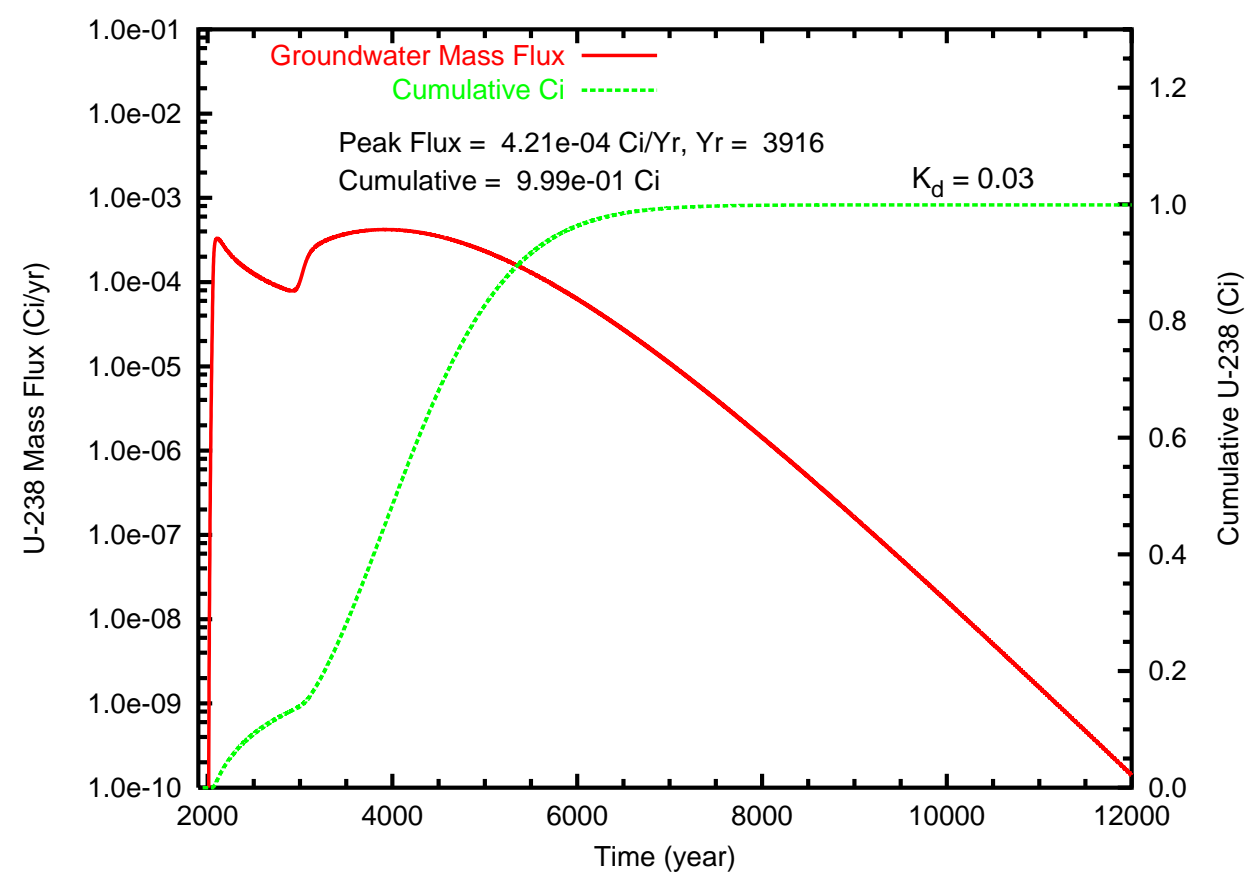

(b)

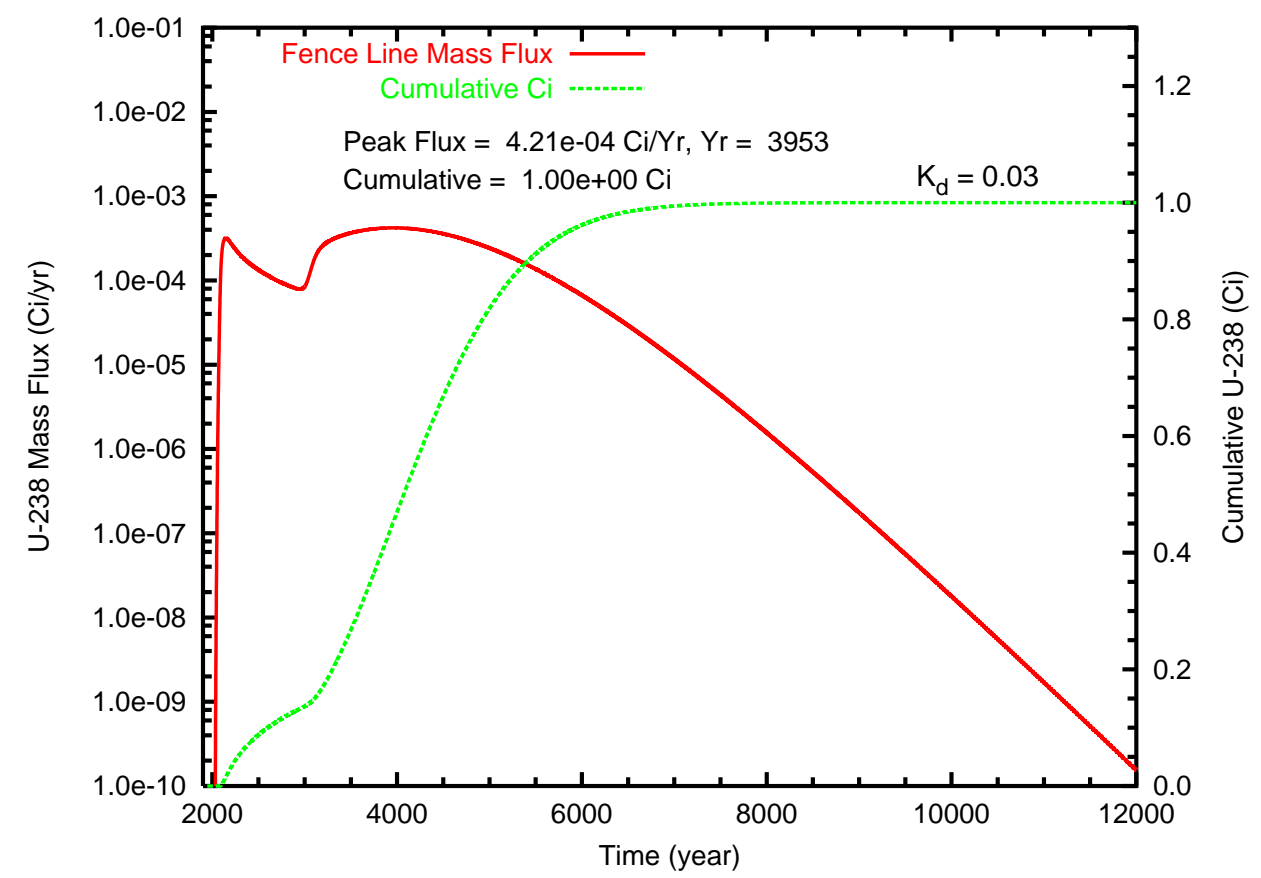

Figure B.5. Case 1, U-238 $\left(\mathrm{K}_{d}=0.03\right)$ mass flux $(\mathrm{Ci} / \mathrm{L})$ and cumulative mass $(\mathrm{Ci})$ at (a) the groundwater table and (b) the fence line 
(a)

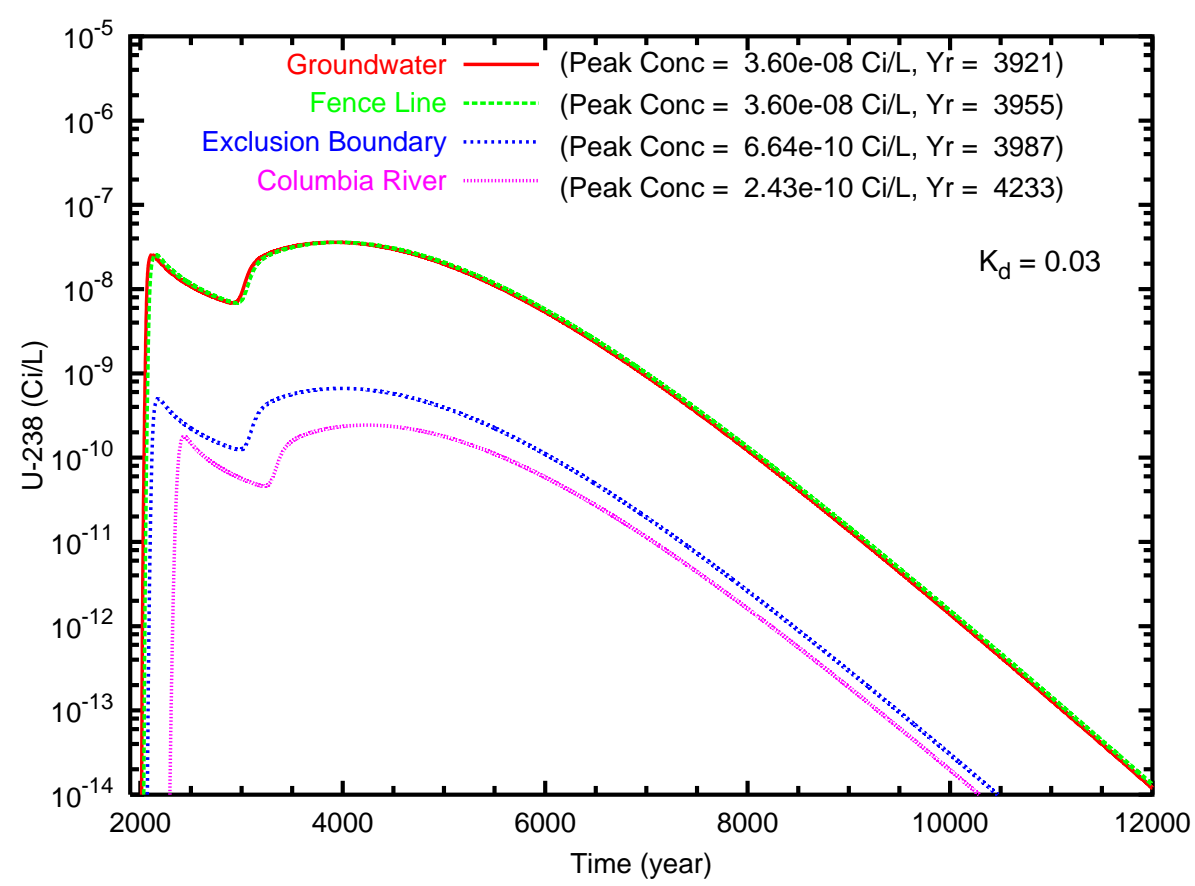

(b)

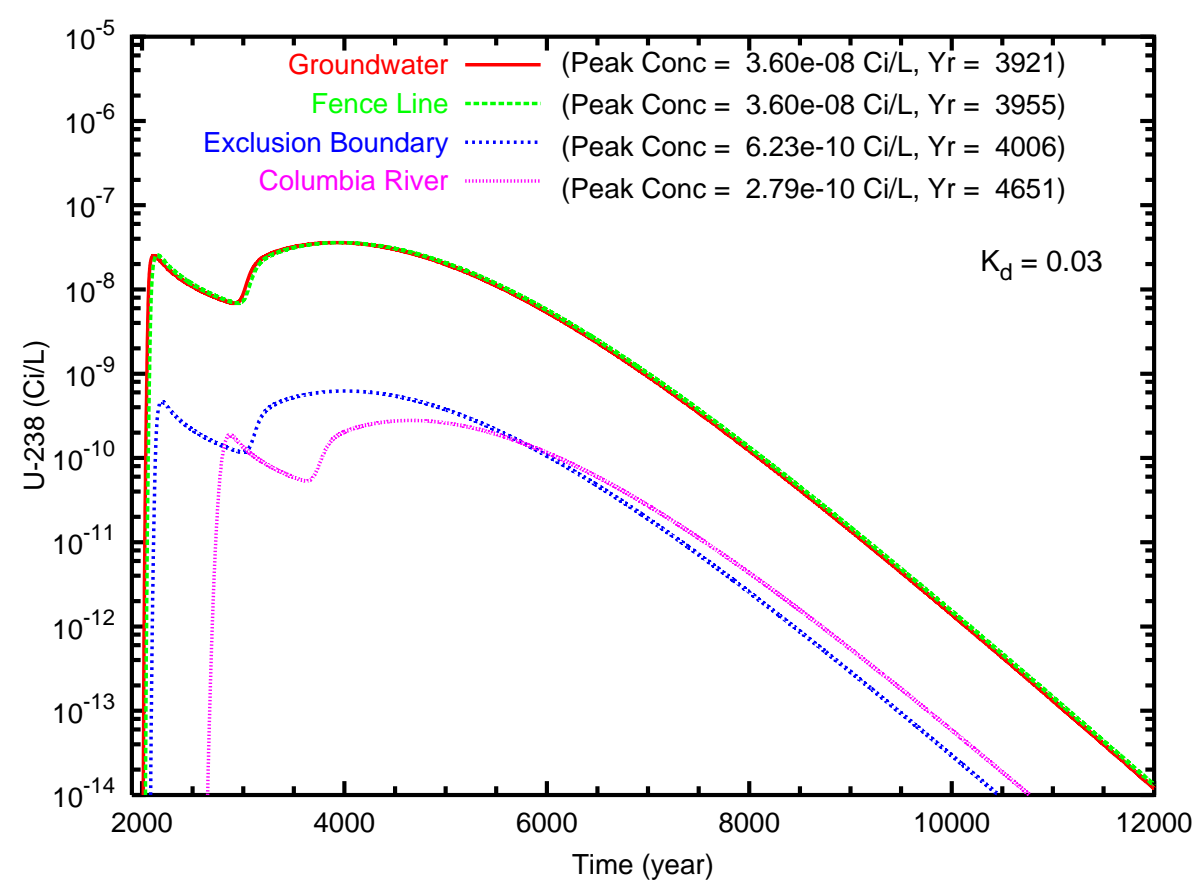

Figure B.6. Case 1, U-238 $\left(\mathrm{K}_{d}=0.03\right)$ concentration versus time for the fence line exclusion boundary and Columbia River compliance points for travel paths (a) southeast and (b) north through the gap 
(a)

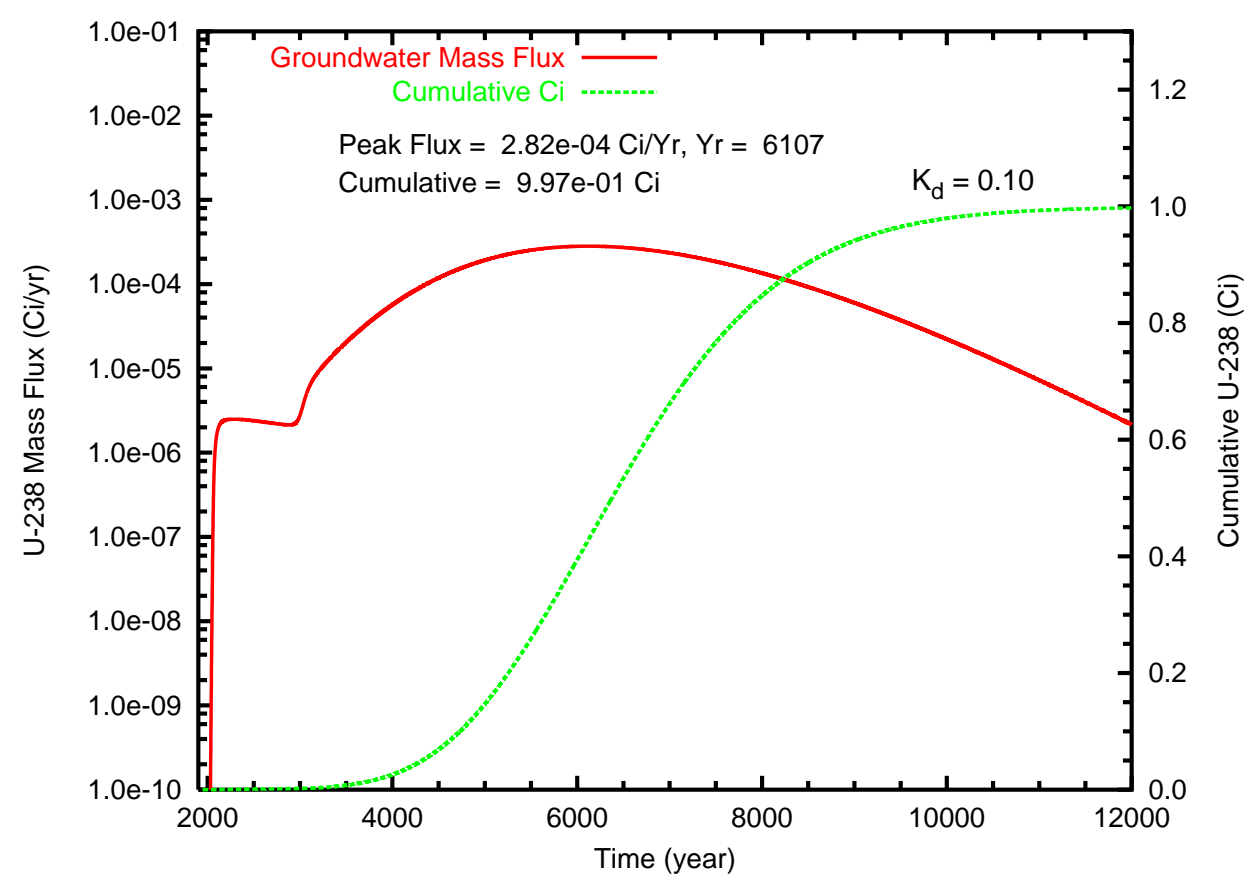

(b)

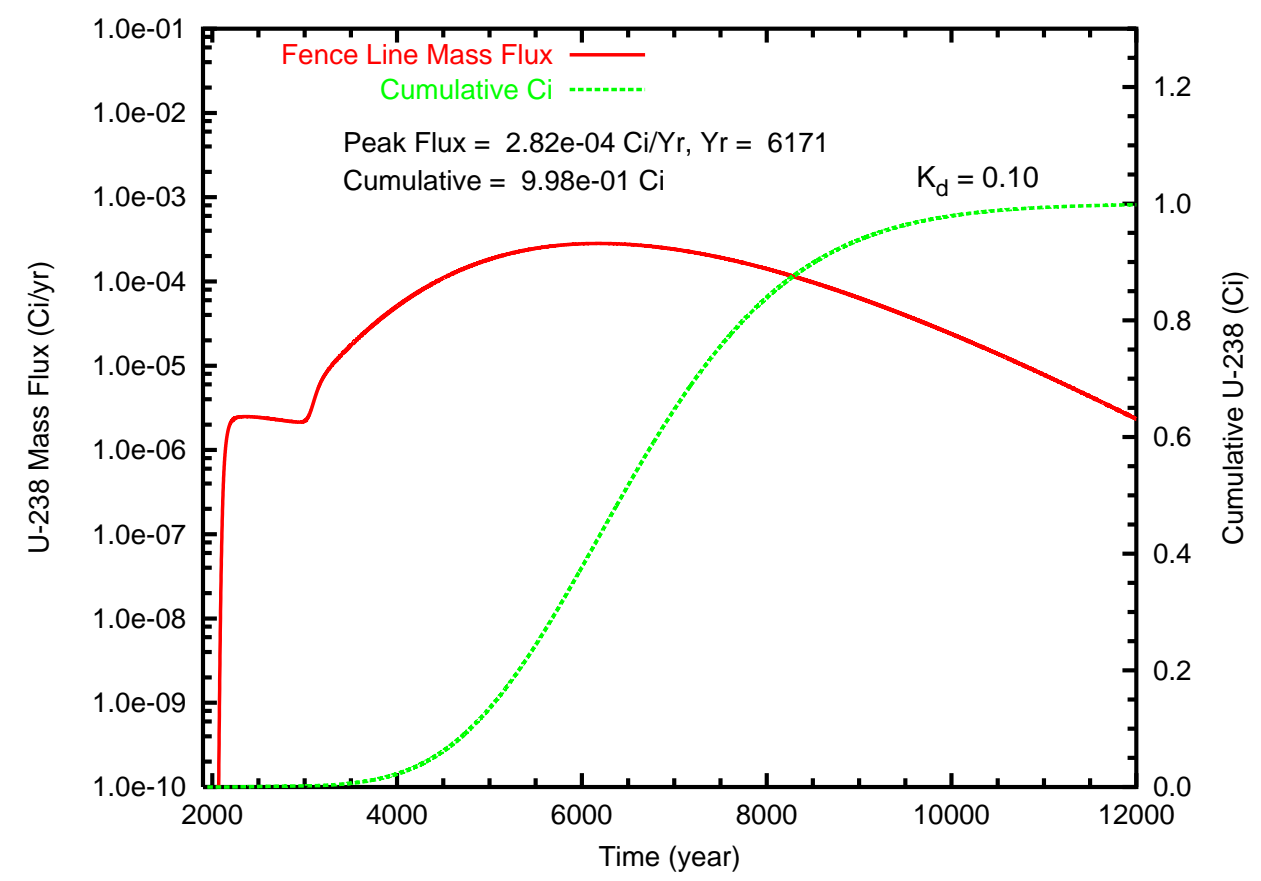

Figure B.7. Case 1, U-238 $\left(\mathrm{K}_{d}=0.10\right)$ mass flux $(\mathrm{Ci} / \mathrm{L})$ and cumulative mass $(\mathrm{Ci})$ at (a) the groundwater table and (b) the fence line 
(a)

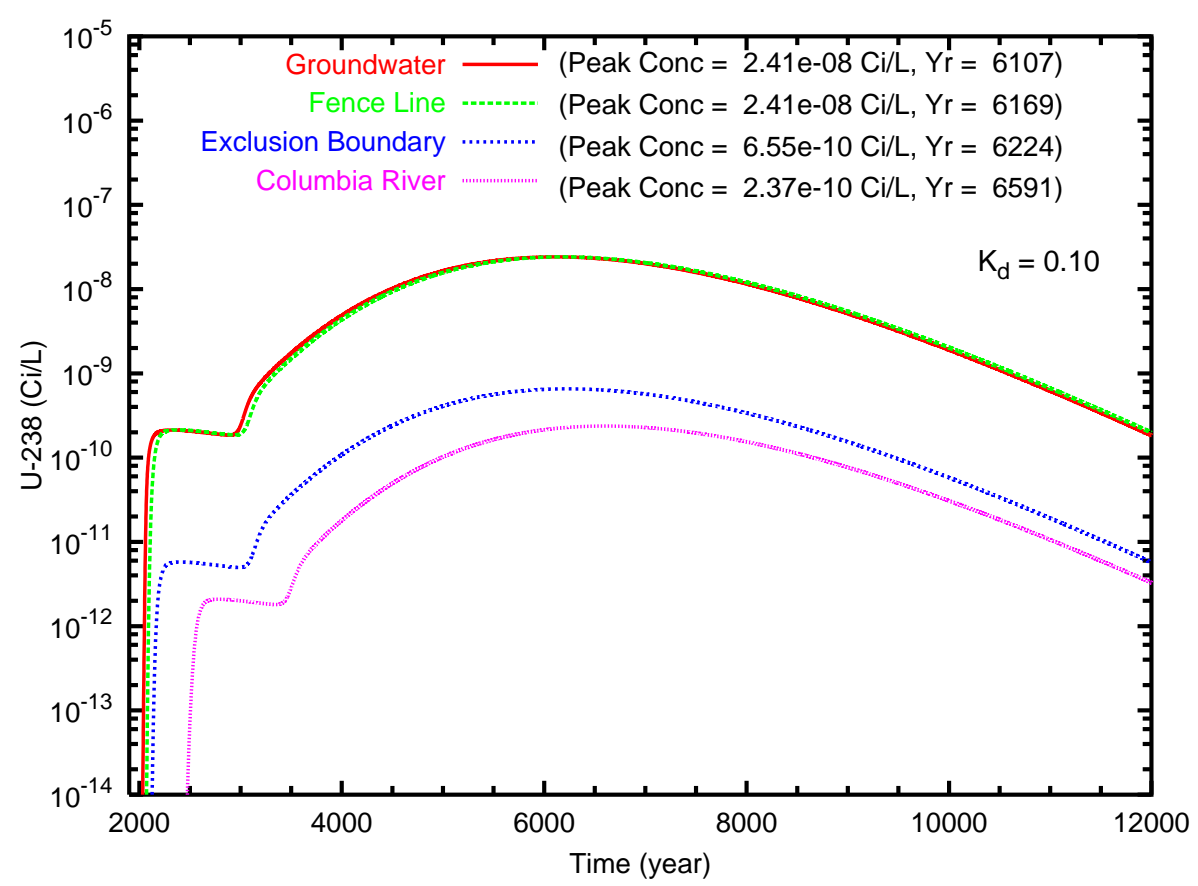

(b)

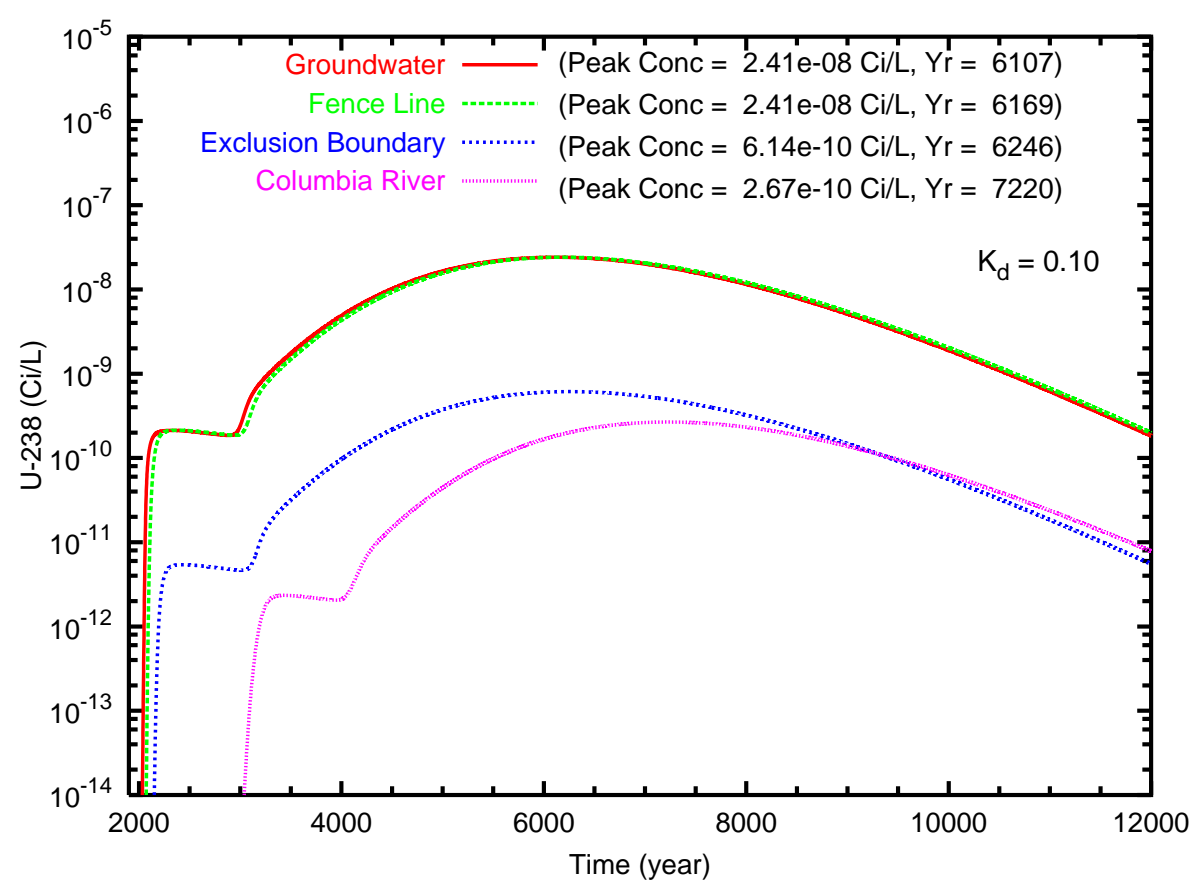

Figure B.8. Case 1, U-238 $\left(\mathrm{K}_{d}=0.10\right)$ concentration versus time for the fence line exclusion boundary and Columbia River compliance points for travel paths (a) southeast and (b) north through the gap 
(a)

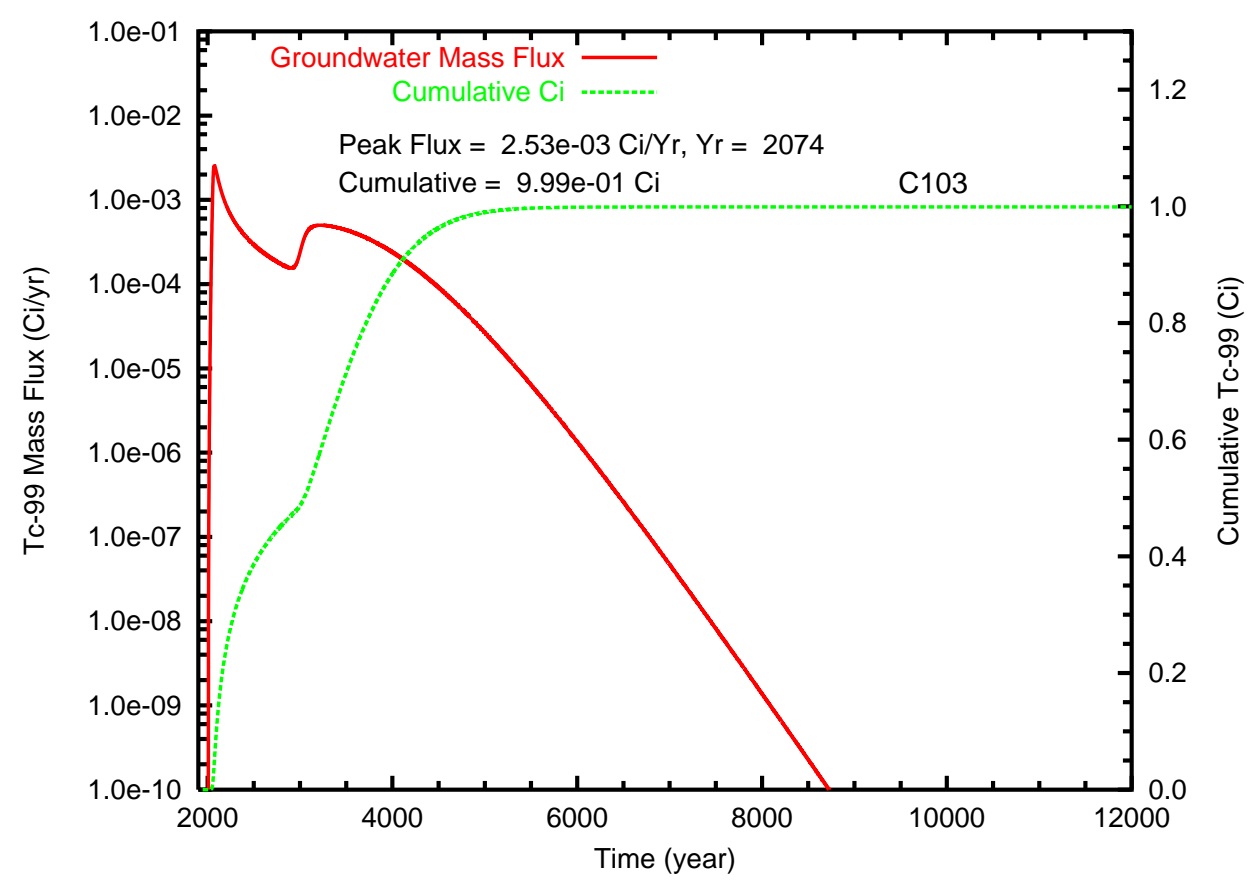

(b)

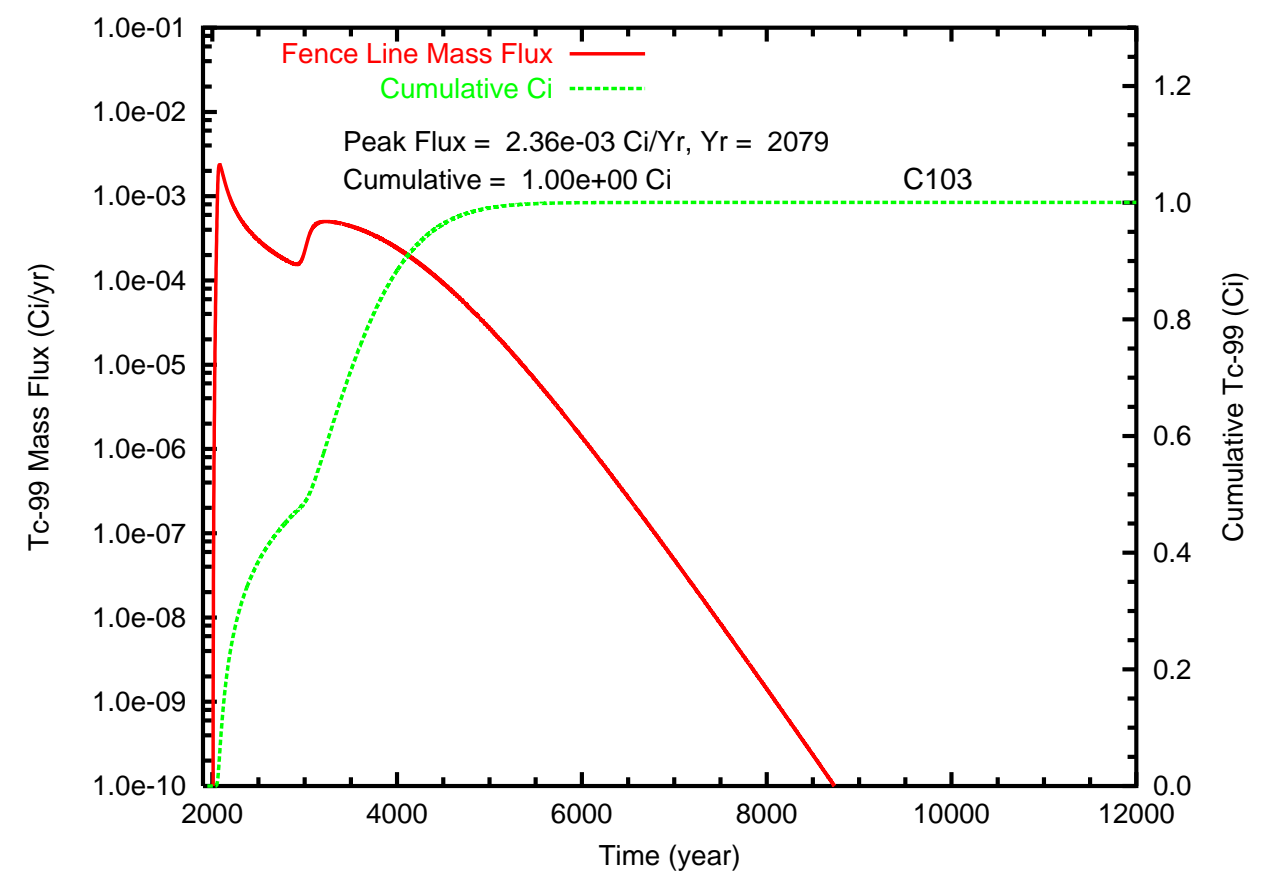

Figure B.9. Case 1v, Tc-99 mass flux and cumulative mass for Tank C-103 at (a) the groundwater table and (b) the fence line 
(a)

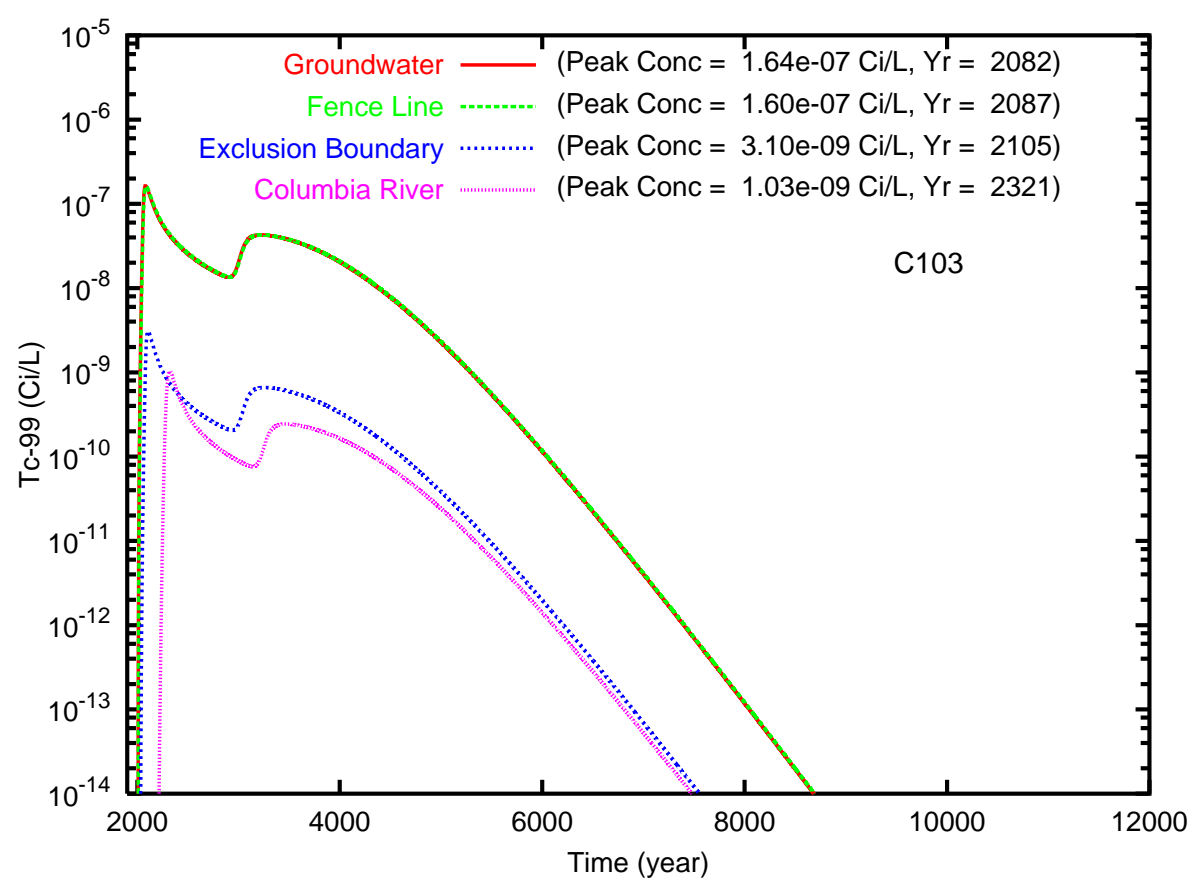

(b)

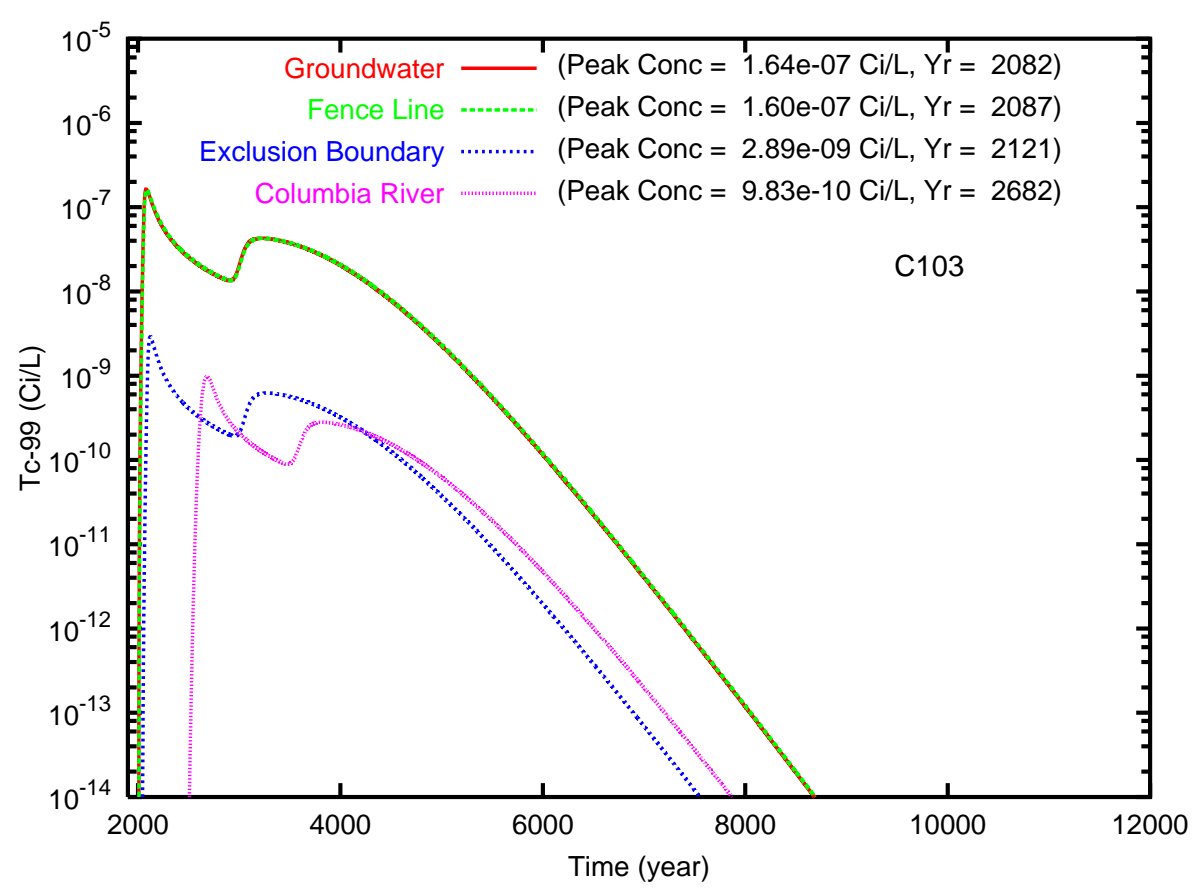

Figure B.10. Case 1v, Tc-99 concentration versus time (Tank C-103) for the fence line, exclusion boundary and Columbia River compliance points for travel paths (a) southeast and (b) north through the gap 
(a)

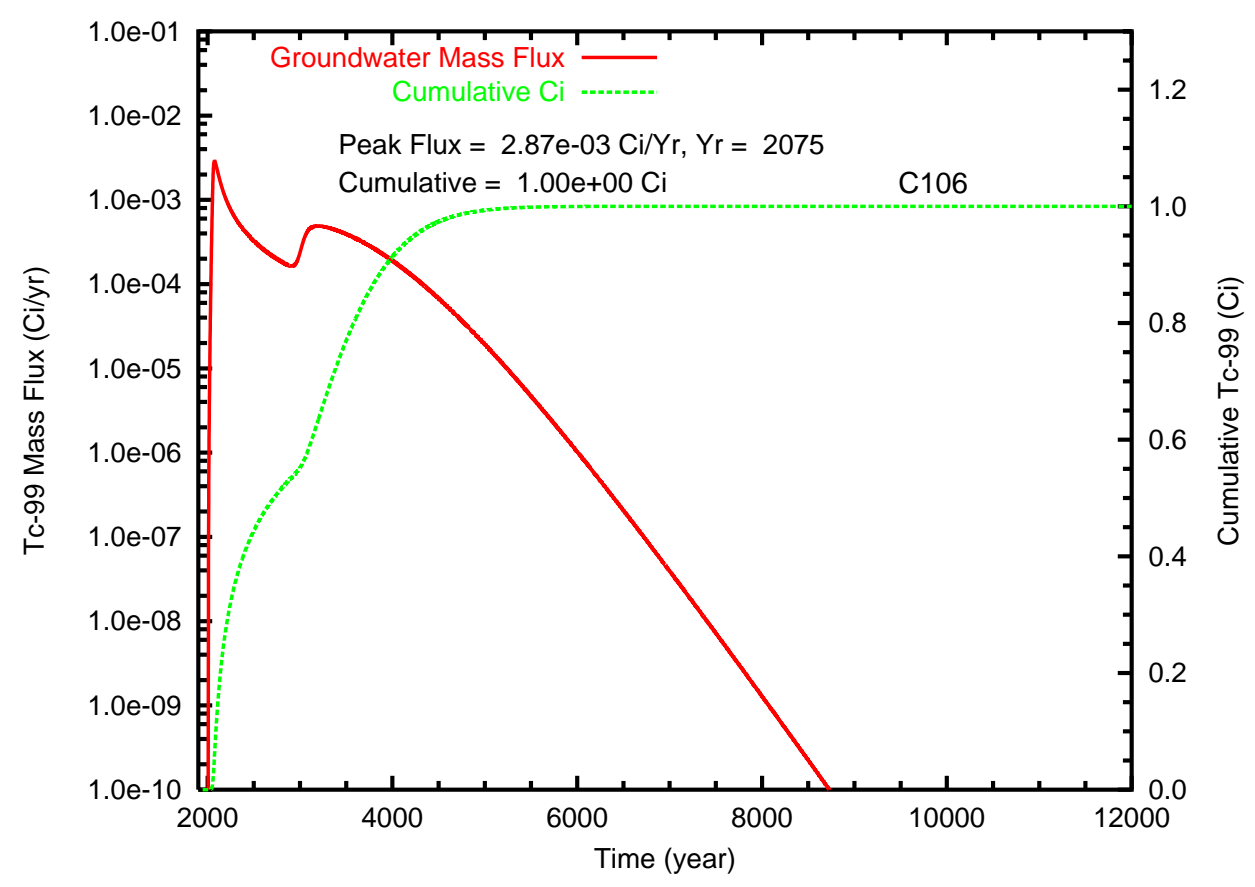

(b)

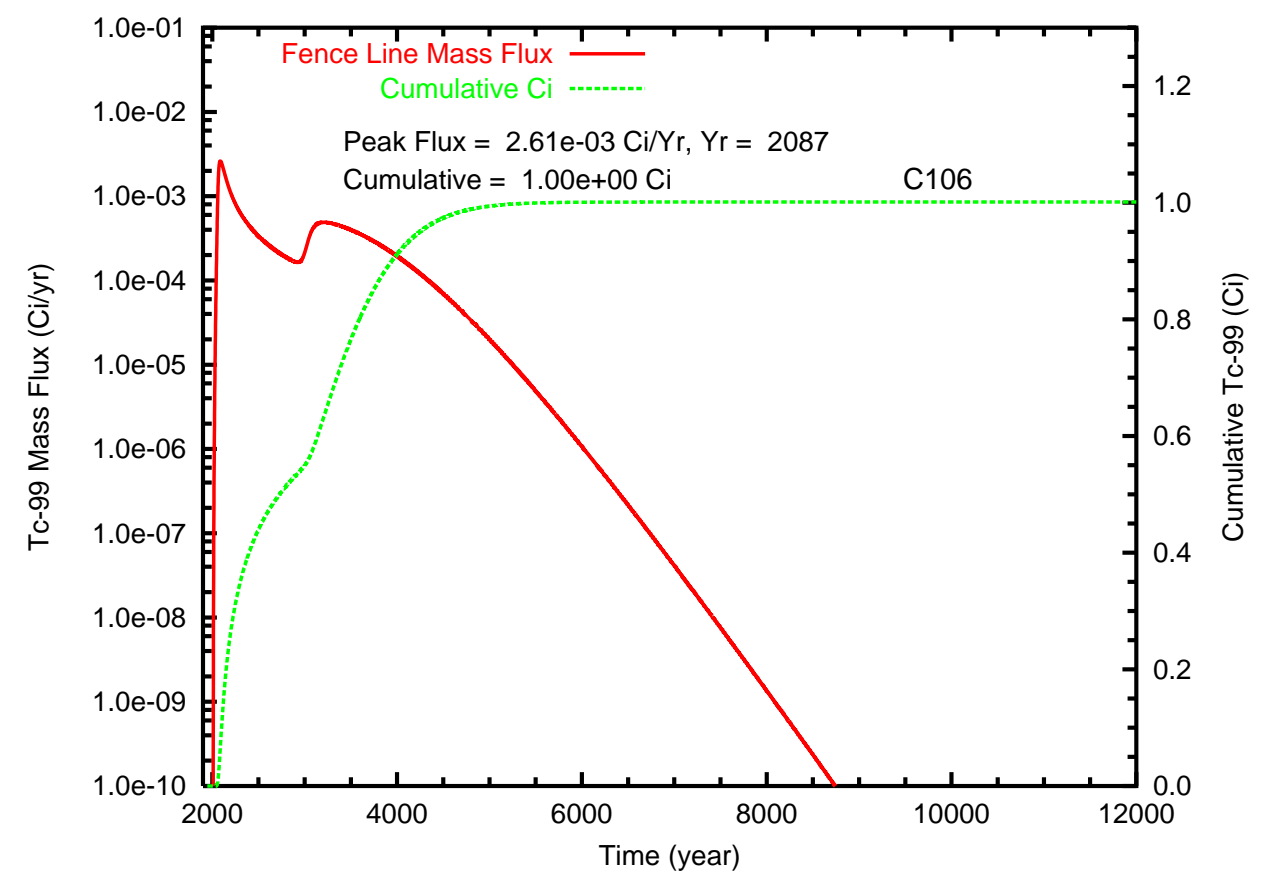

Figure B.11. Case 1v, Tc-99 mass flux and cumulative mass for Tank C-106 at (a) the groundwater table and (b) the fence line 
(a)

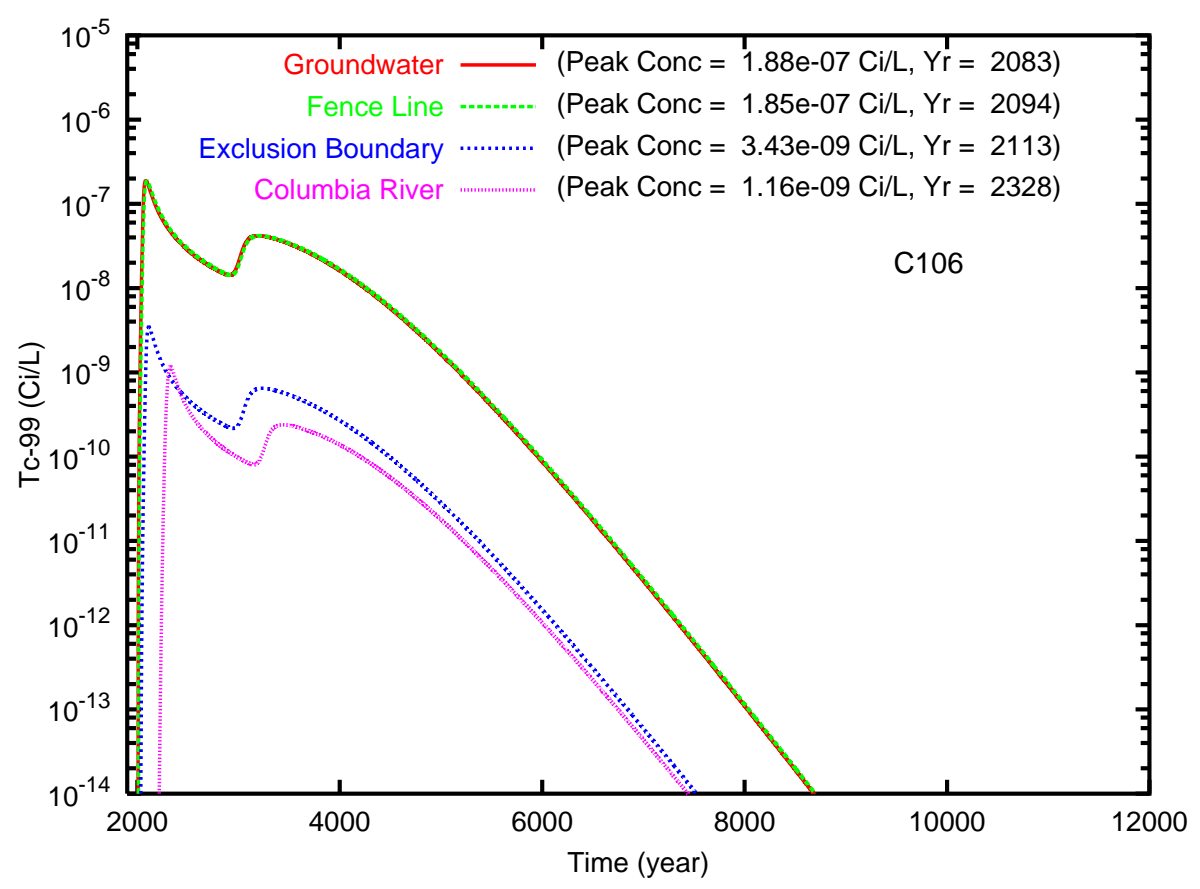

(b)

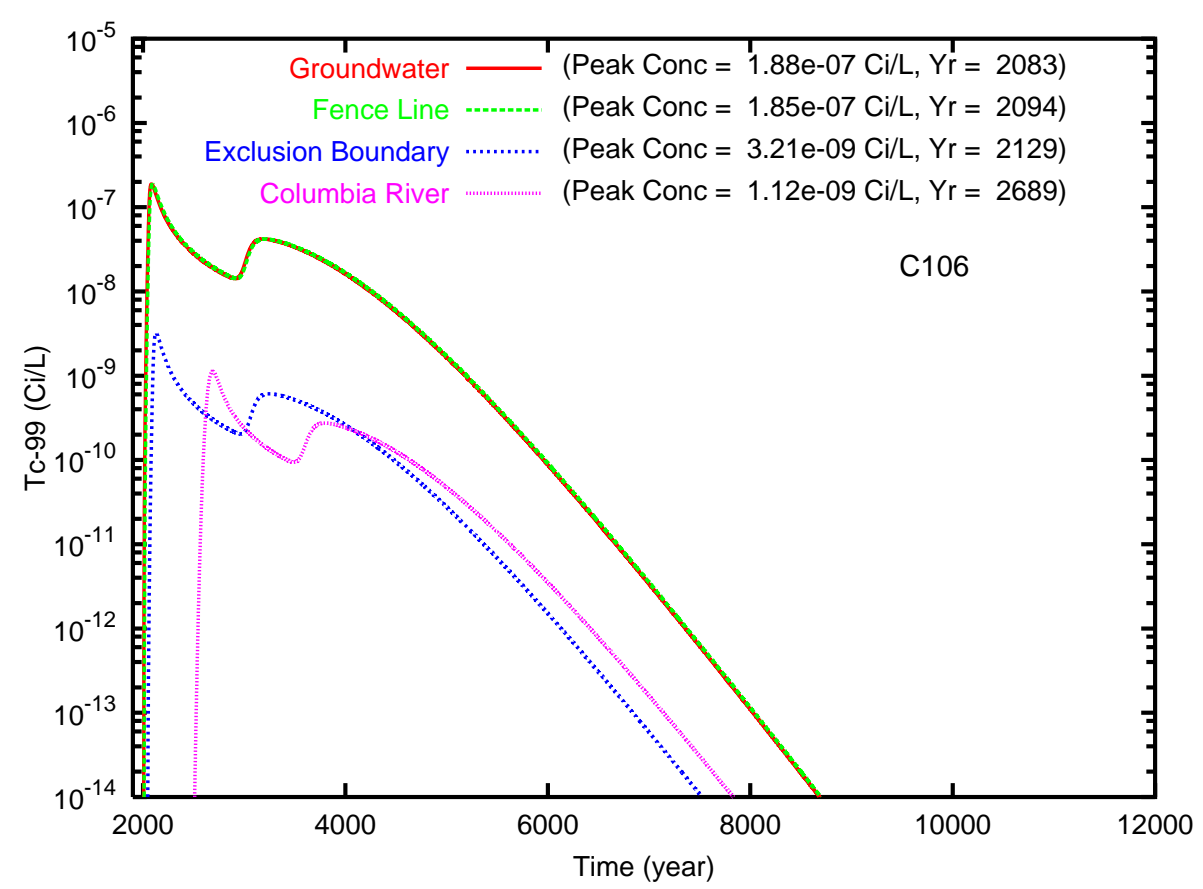

Figure B.12. Case 1v, Tc-99 concentration versus time (Tank C-106) for the fence line, exclusion boundary and Columbia River compliance points for travel paths (a) southeast and (b) north through the gap 
(a)

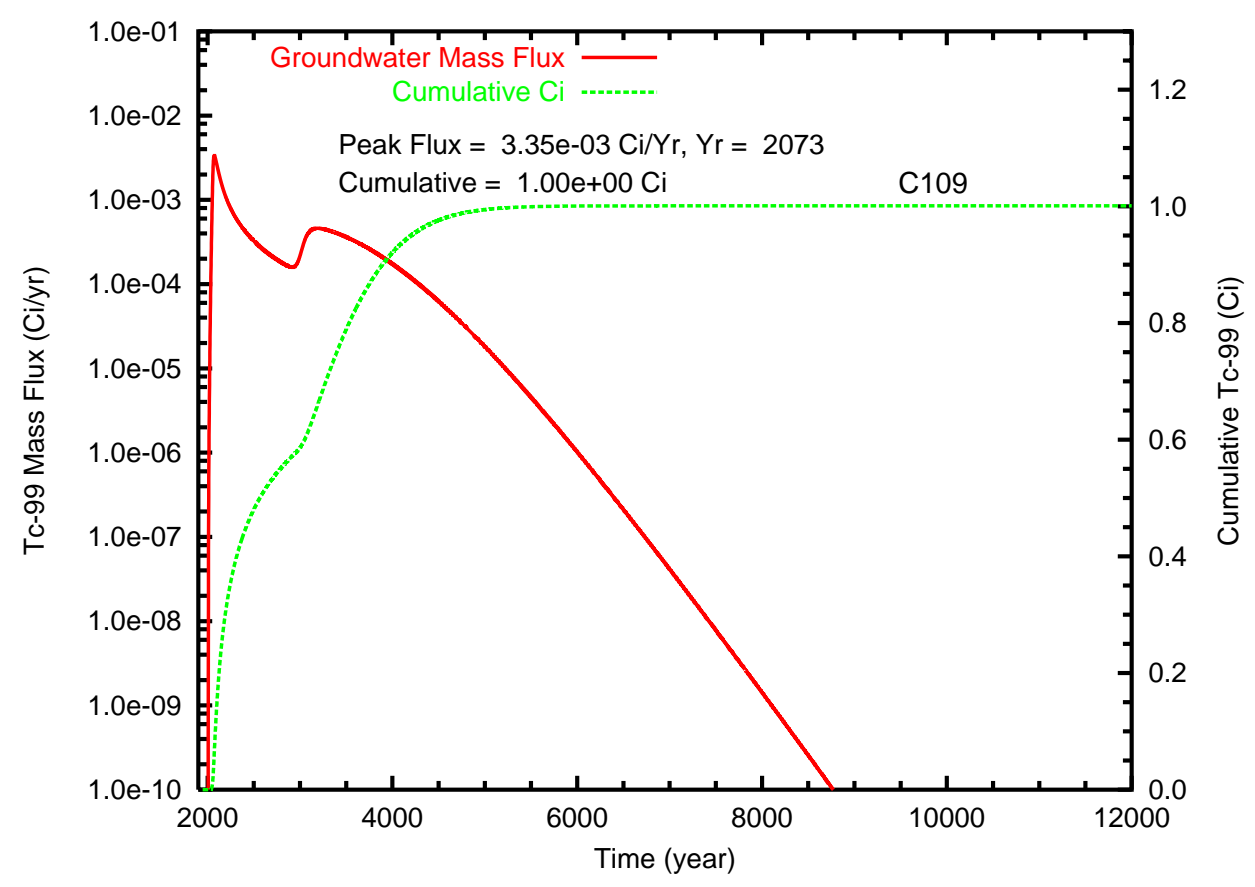

(b)

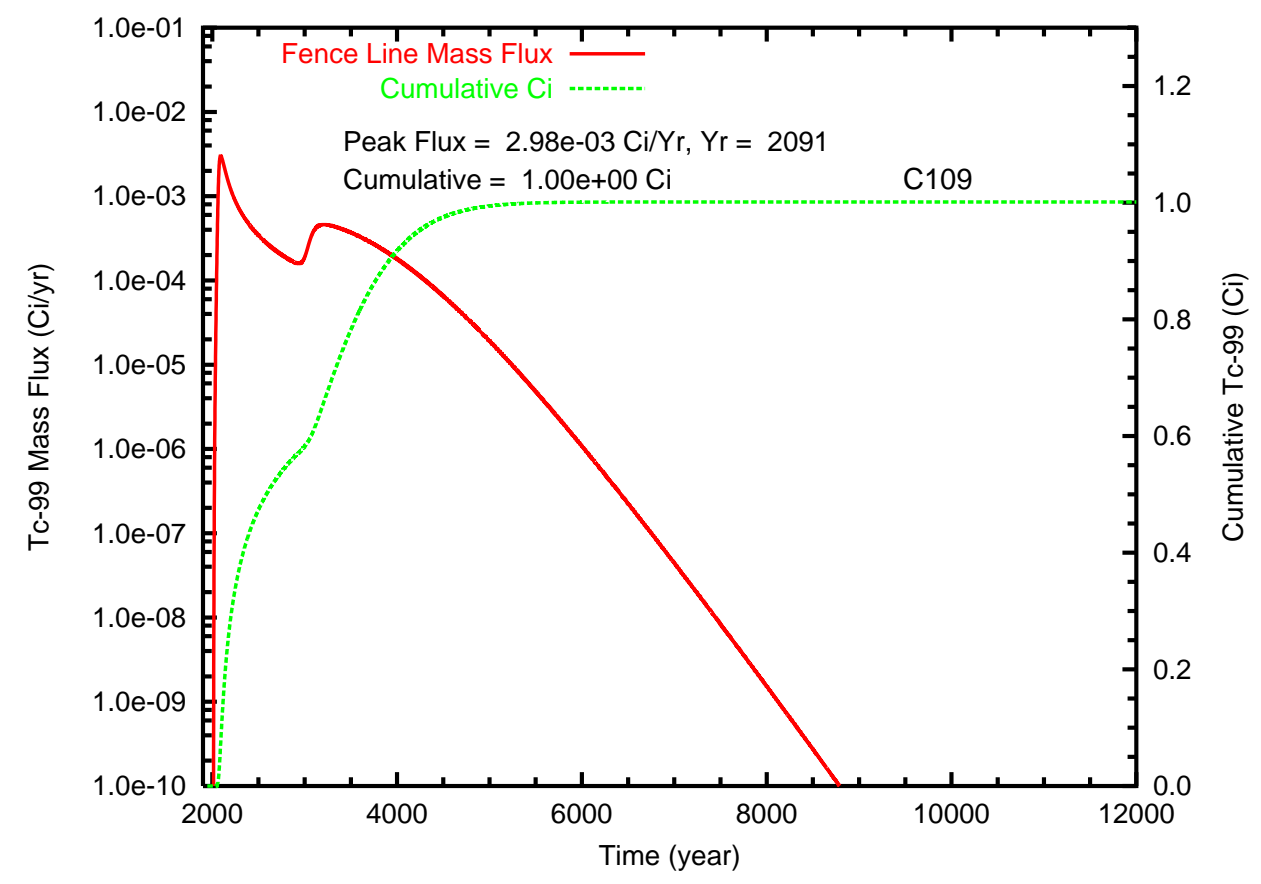

Figure B.13. Case 1v, Tc-99 mass flux and cumulative mass for Tank C-109 at (a) the groundwater table and (b) the fence line 
(a)

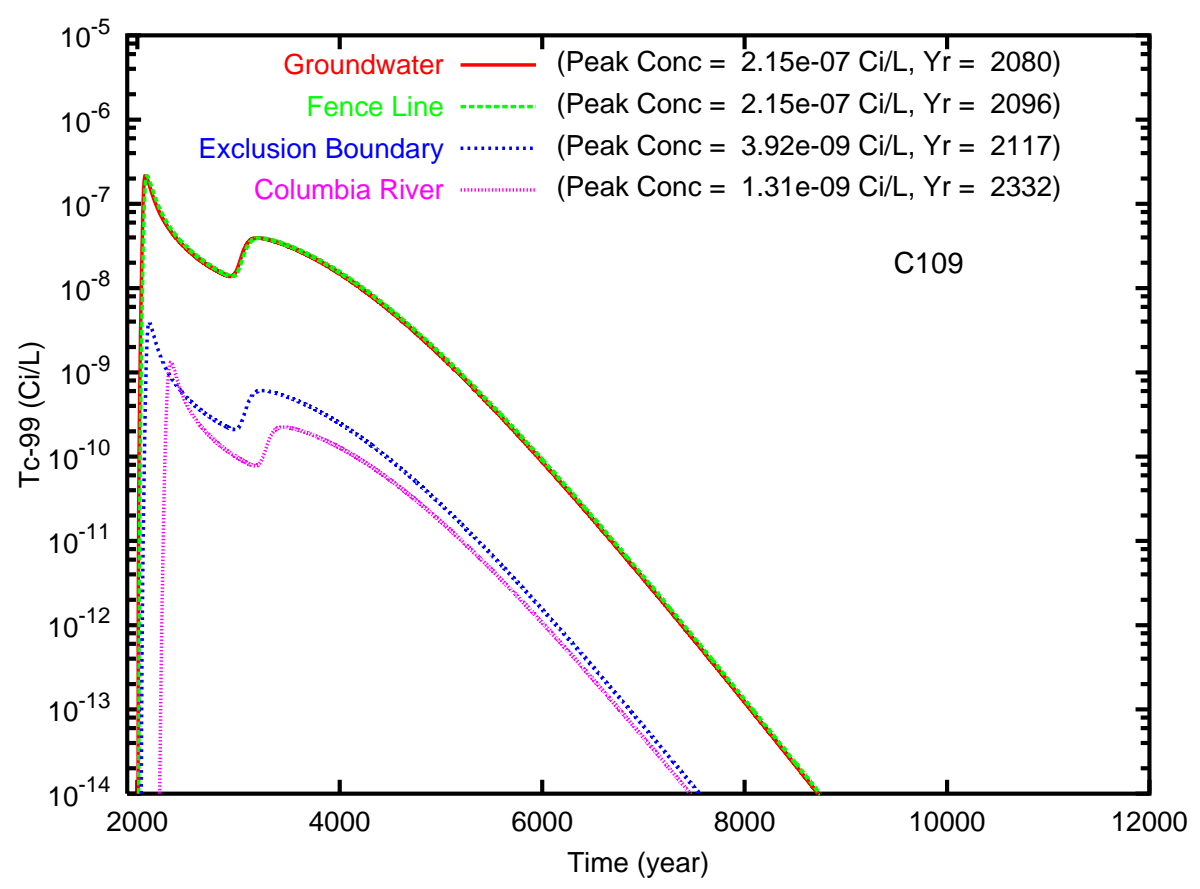

(b)

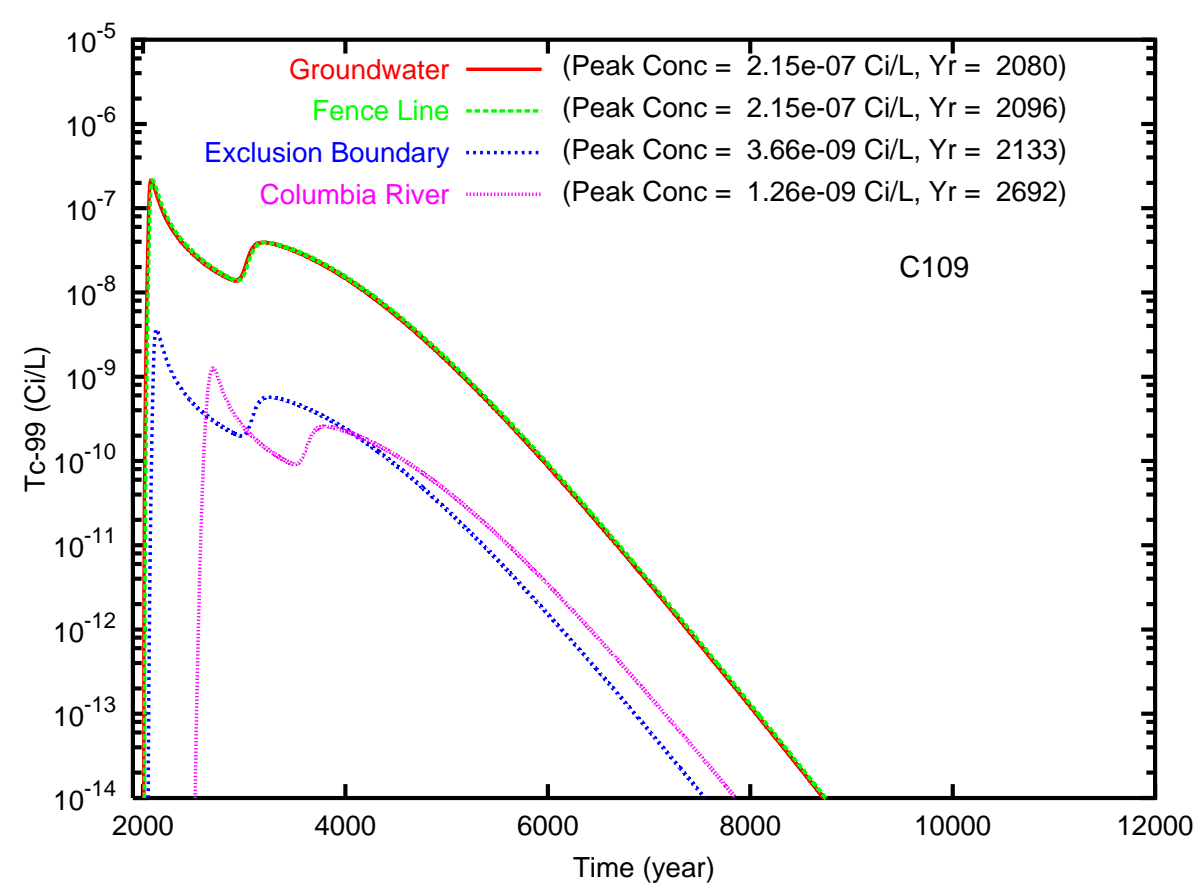

Figure B.14. Case 1v, Tc-99 concentration versus time (Tank C-109) for the fence line, exclusion boundary and Columbia River compliance points for travel paths (a) southeast and (b) north through the gap 
(a)

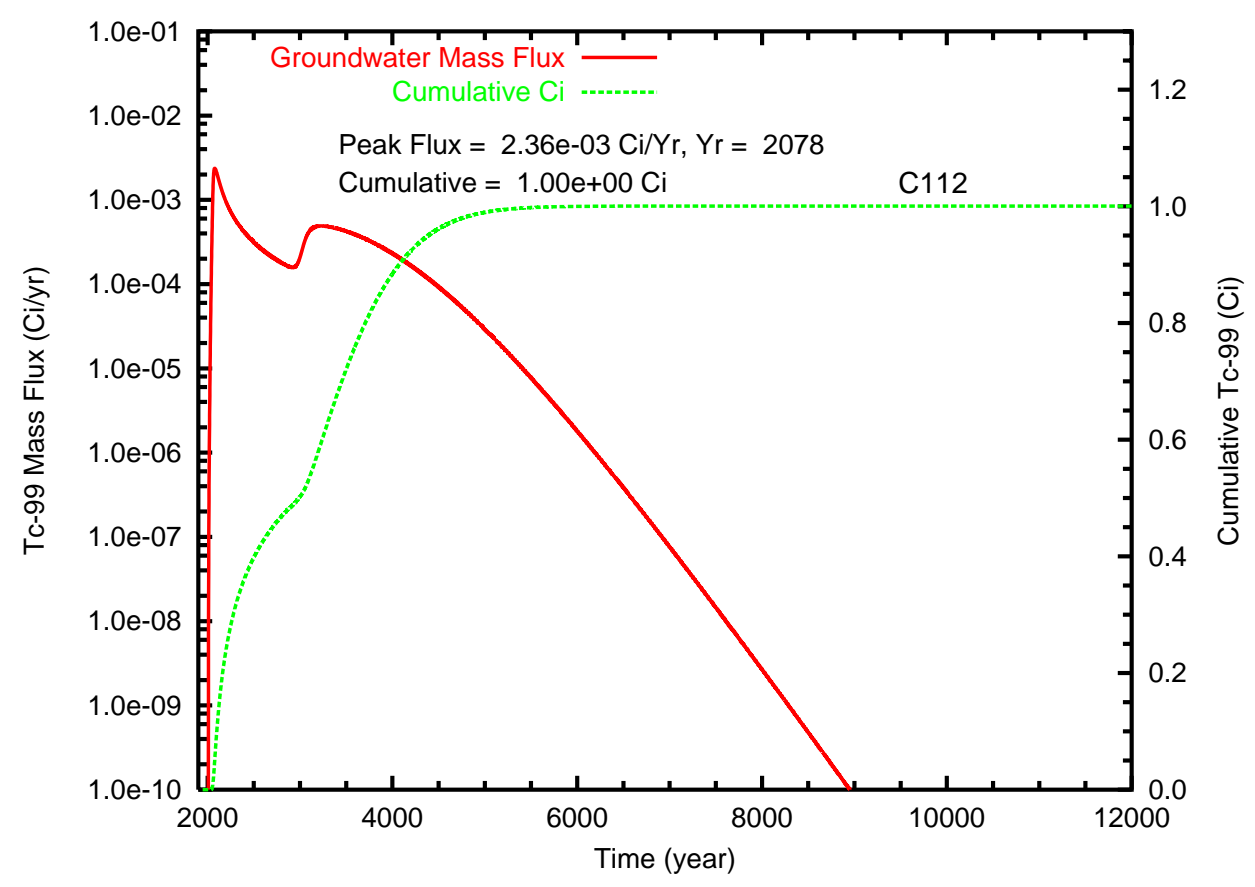

(b)

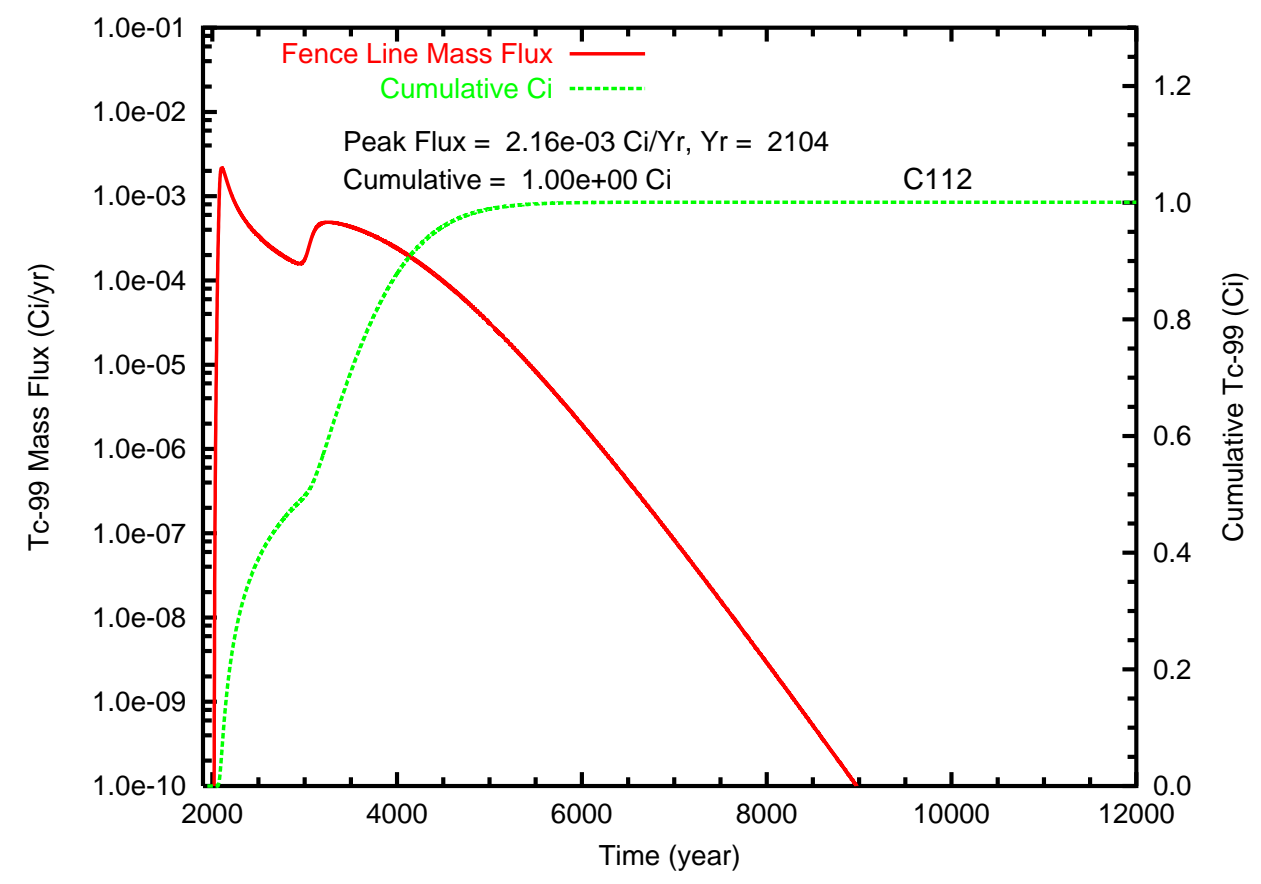

Figure B.15. Case 1v, Tc-99 mass flux and cumulative mass for Tank C-112 at (a) the groundwater table and (b) the fence line 
(a)

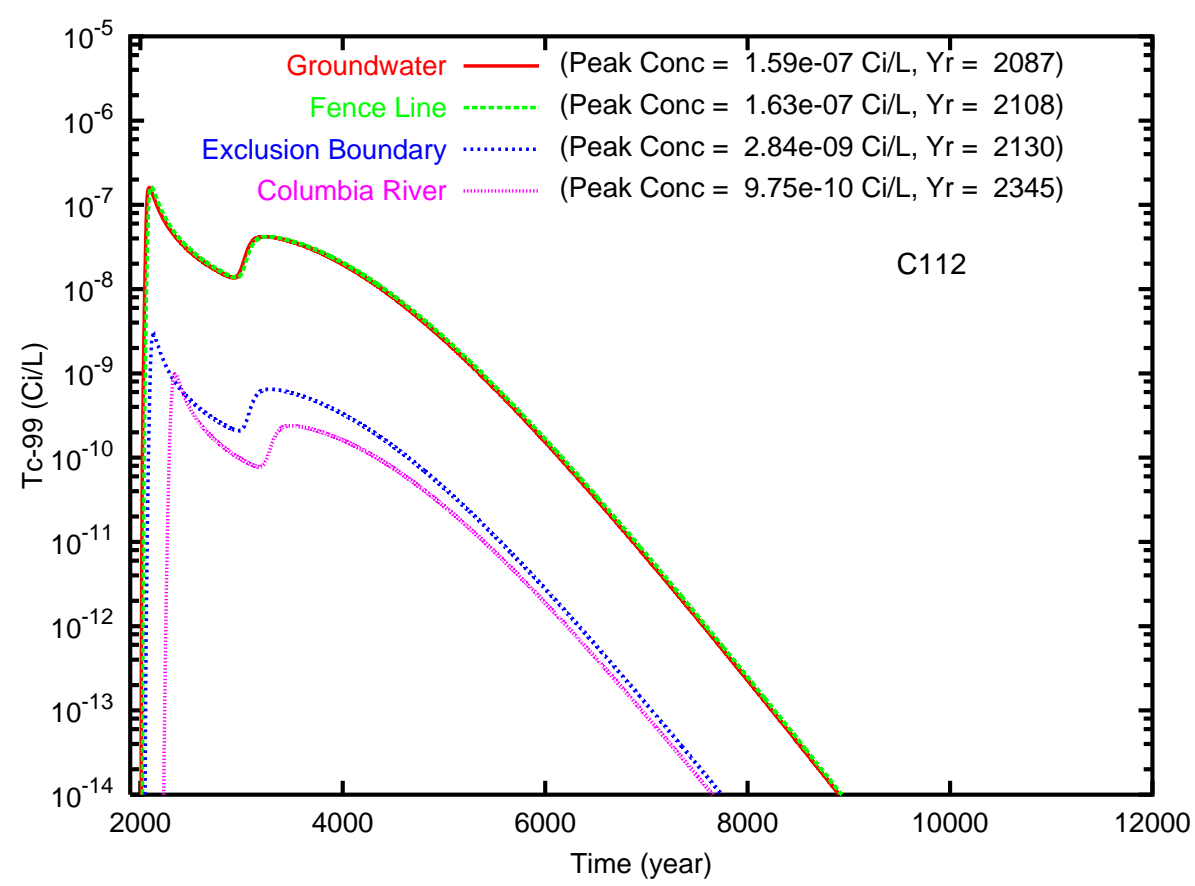

(b)

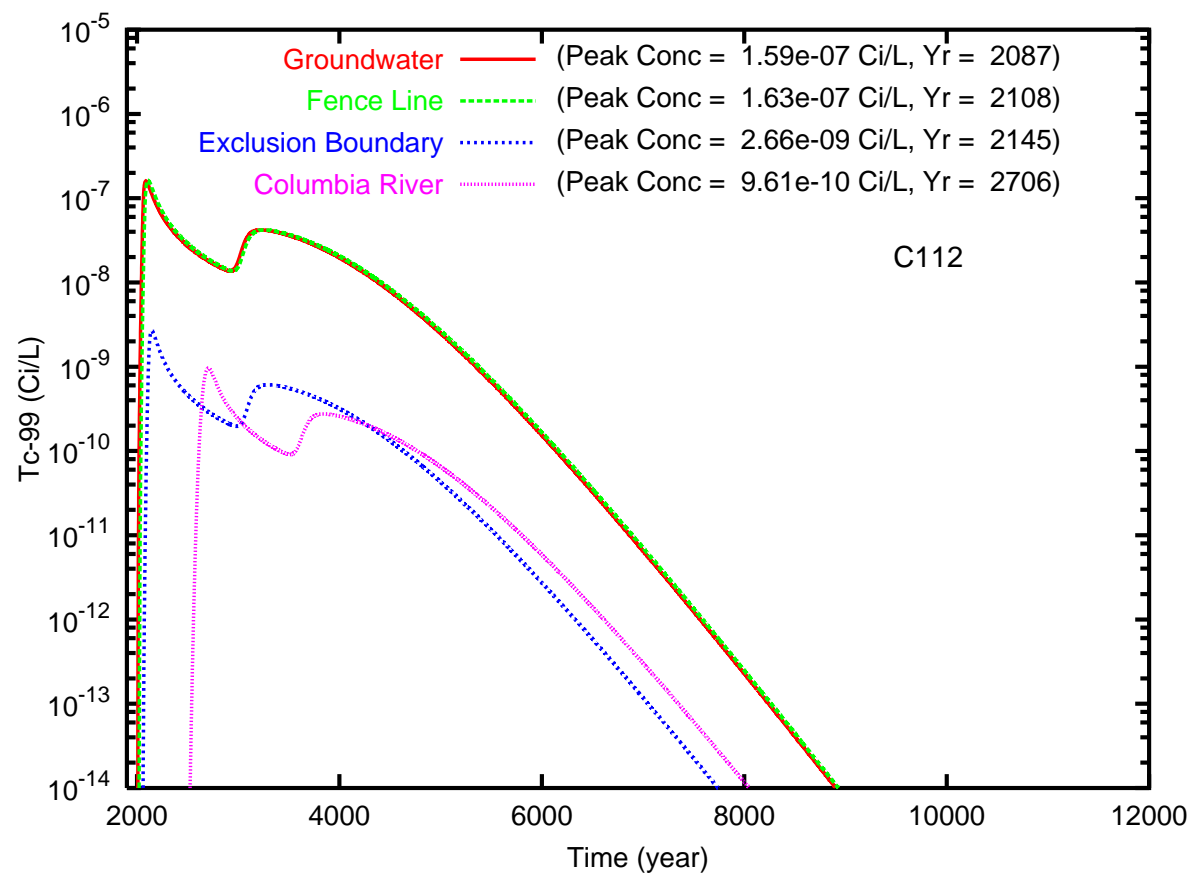

Figure B.16. Case 1v, Tc-99 concentration versus time (Tank C-112) for the fence line, exclusion boundary and Columbia River compliance points for travel paths (a) southeast and (b) north through the gap 
(a)

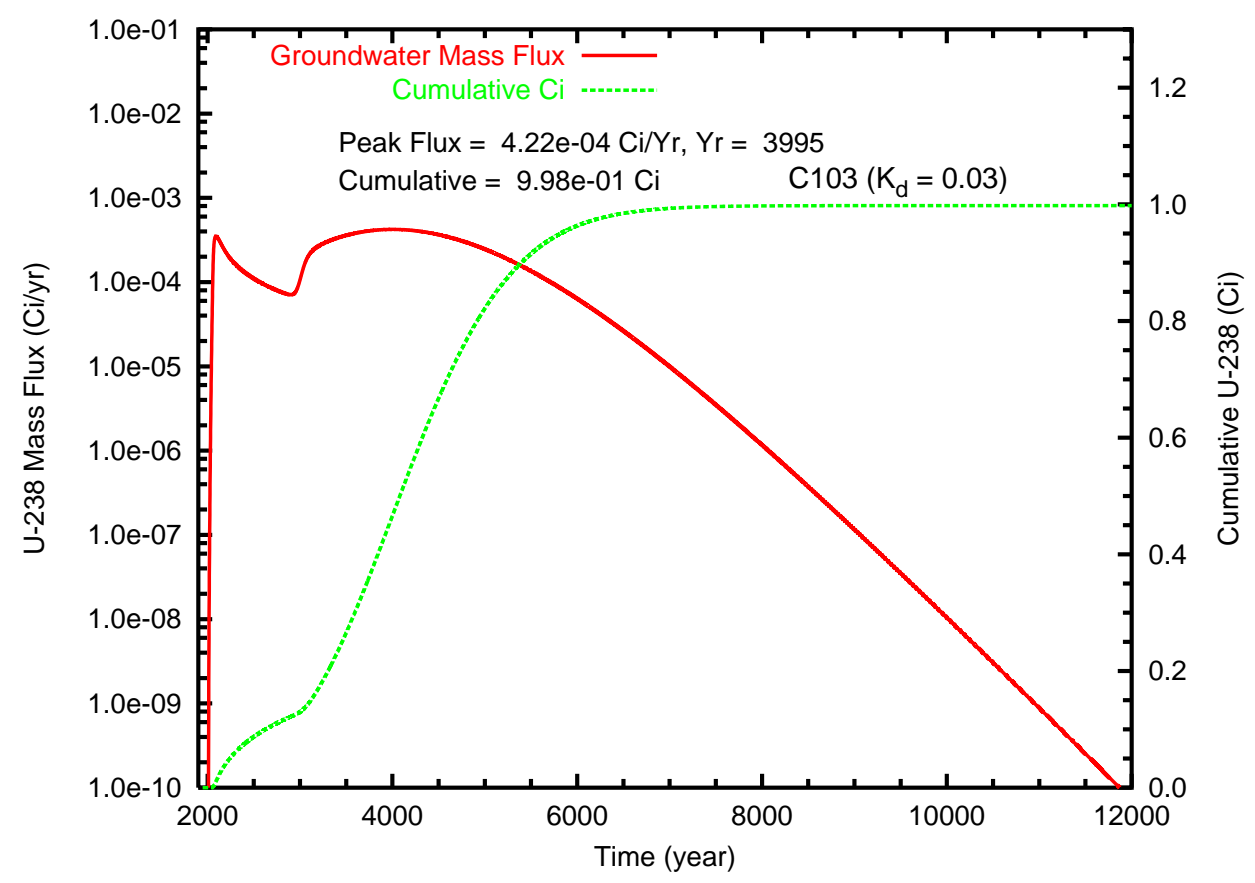

(b)

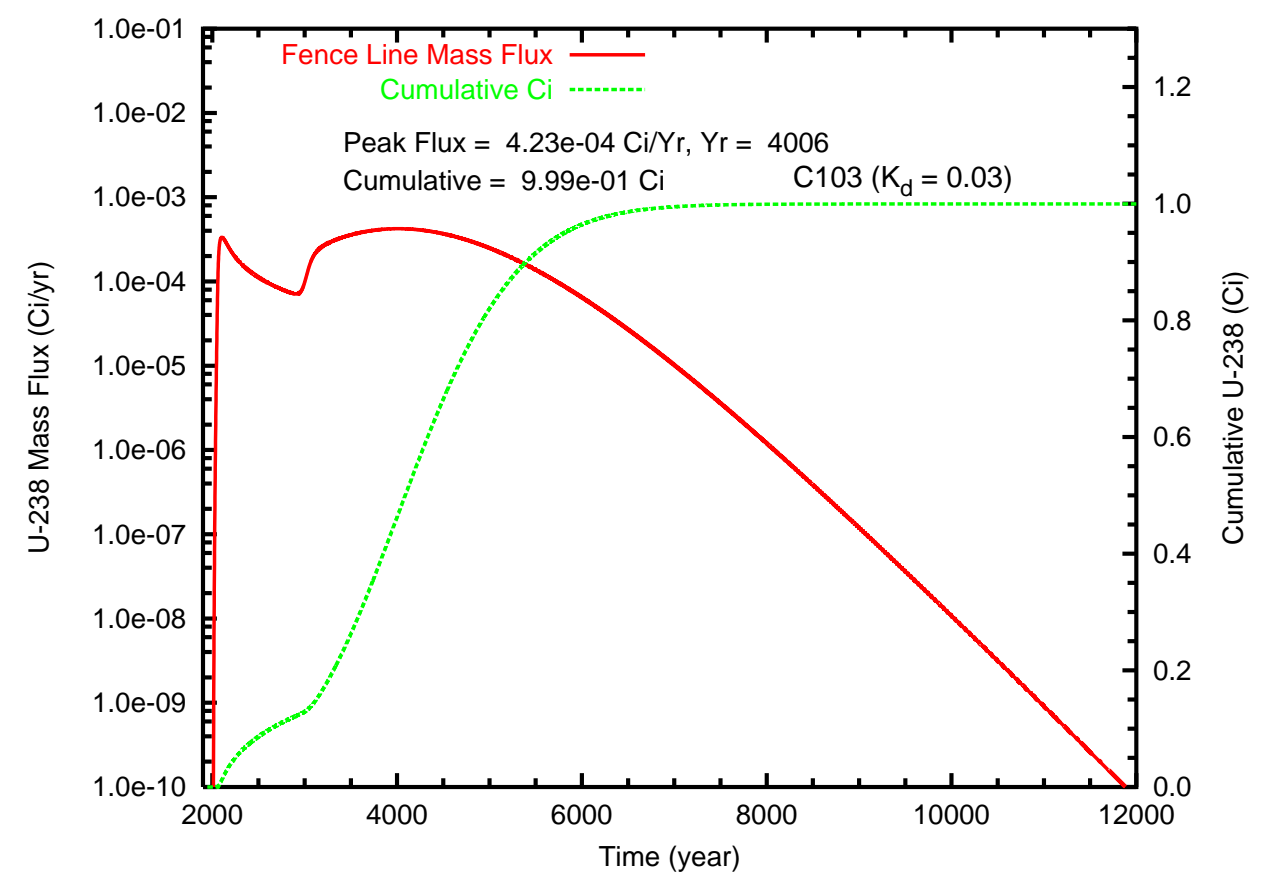

Figure B.17. Case 1v, U-238 mass flux and cumulative mass for Tank C-103 at (a) the groundwater table and (b) the fence line 
(a)

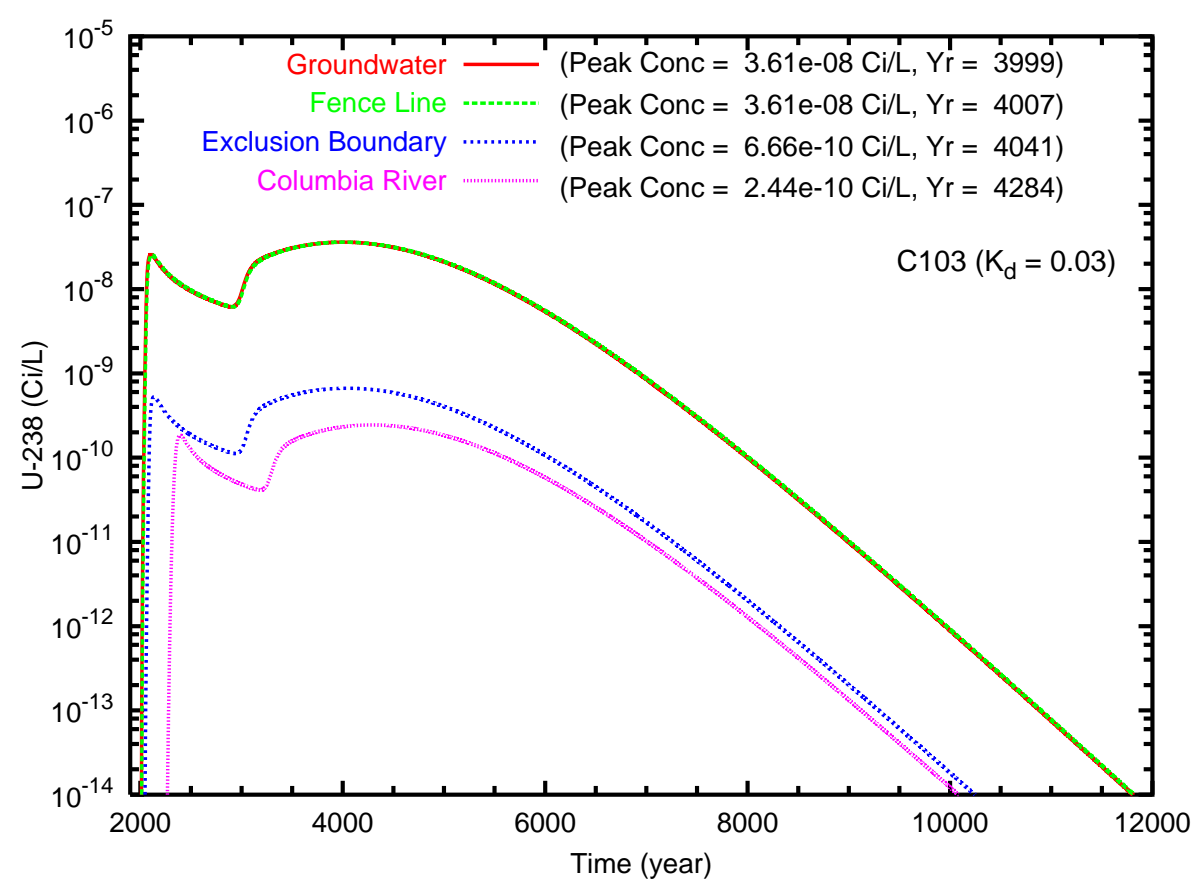

(b)

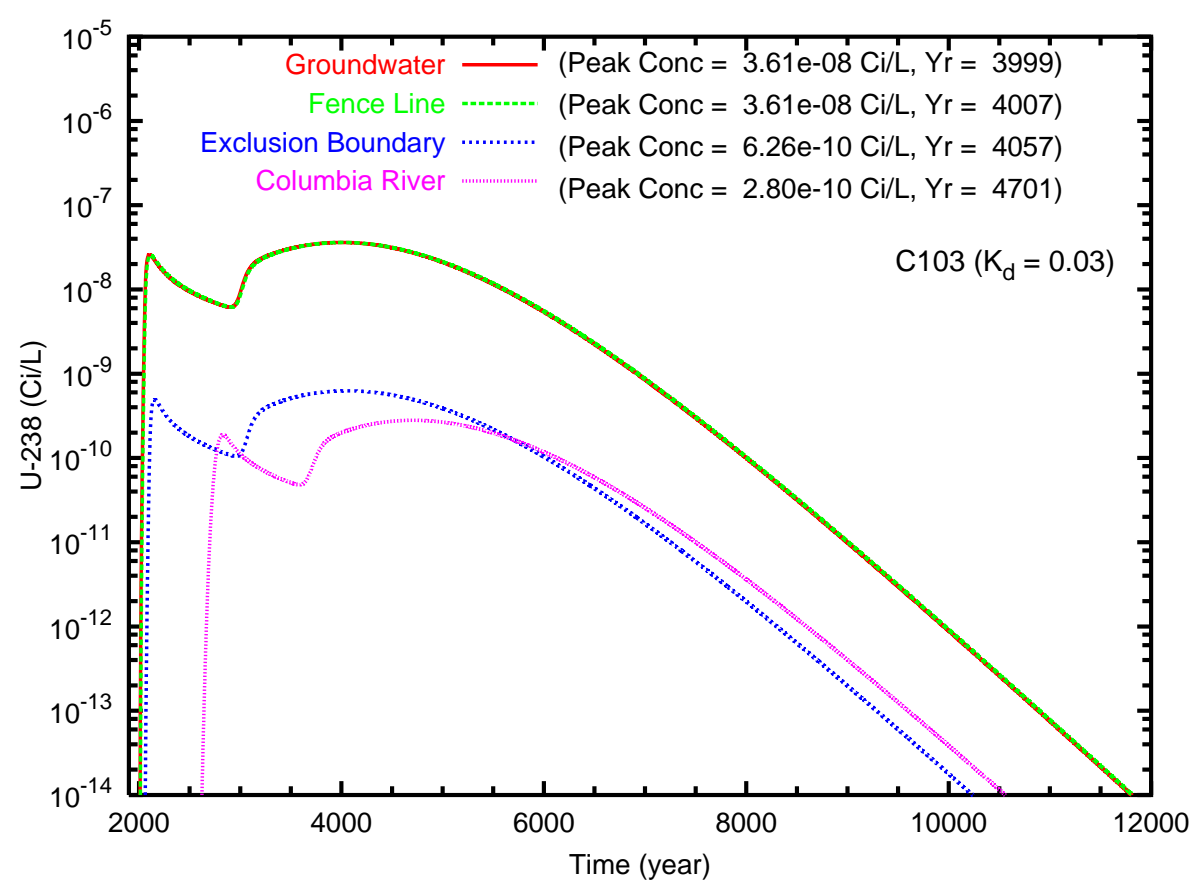

Figure B.18. Case $1 \mathrm{v}, \mathrm{U}-238\left(\mathrm{~K}_{d}=0.03\right)$ concentration versus time (Tank C-103) for the fence line, exclusion boundary and Columbia River compliance points for travel paths (a) southeast and (b) north through the gap 
(a)

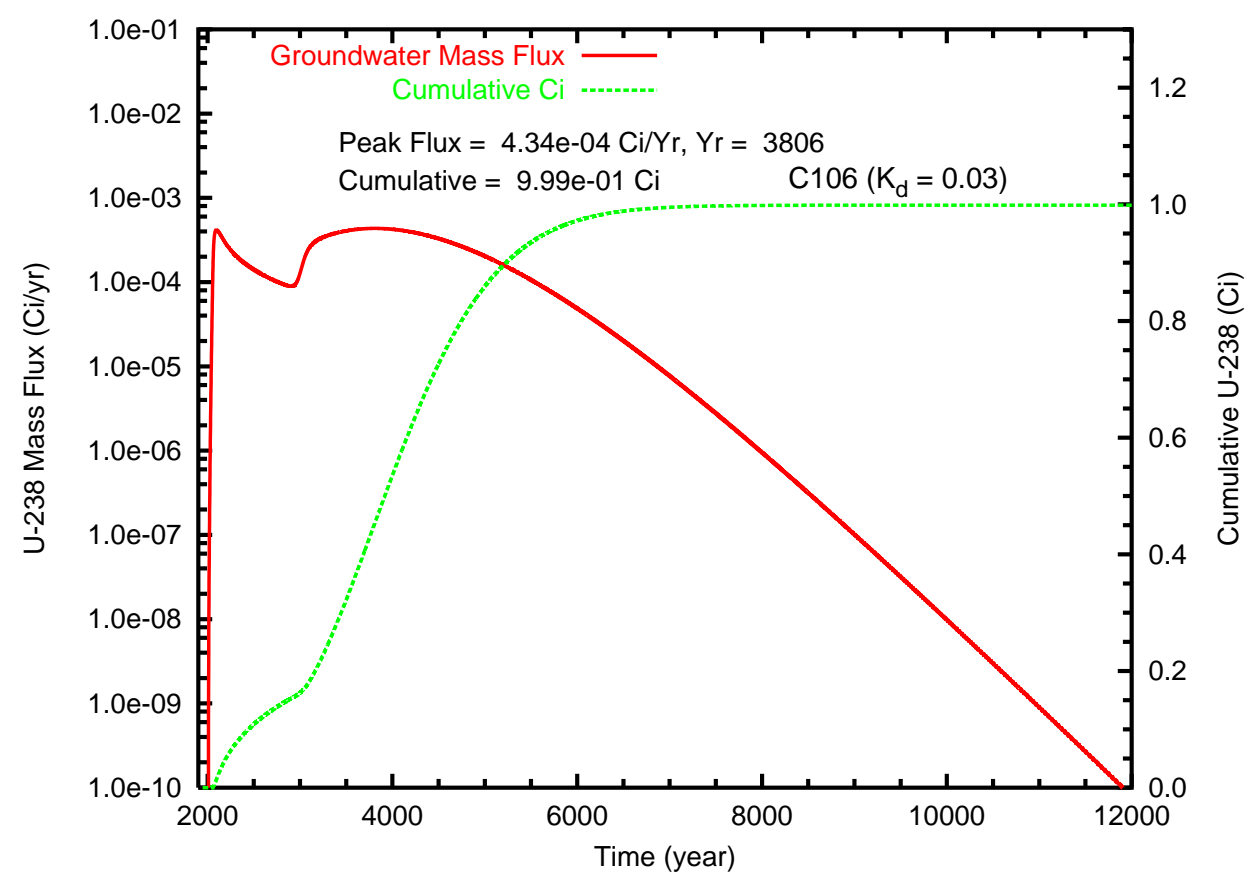

(b)

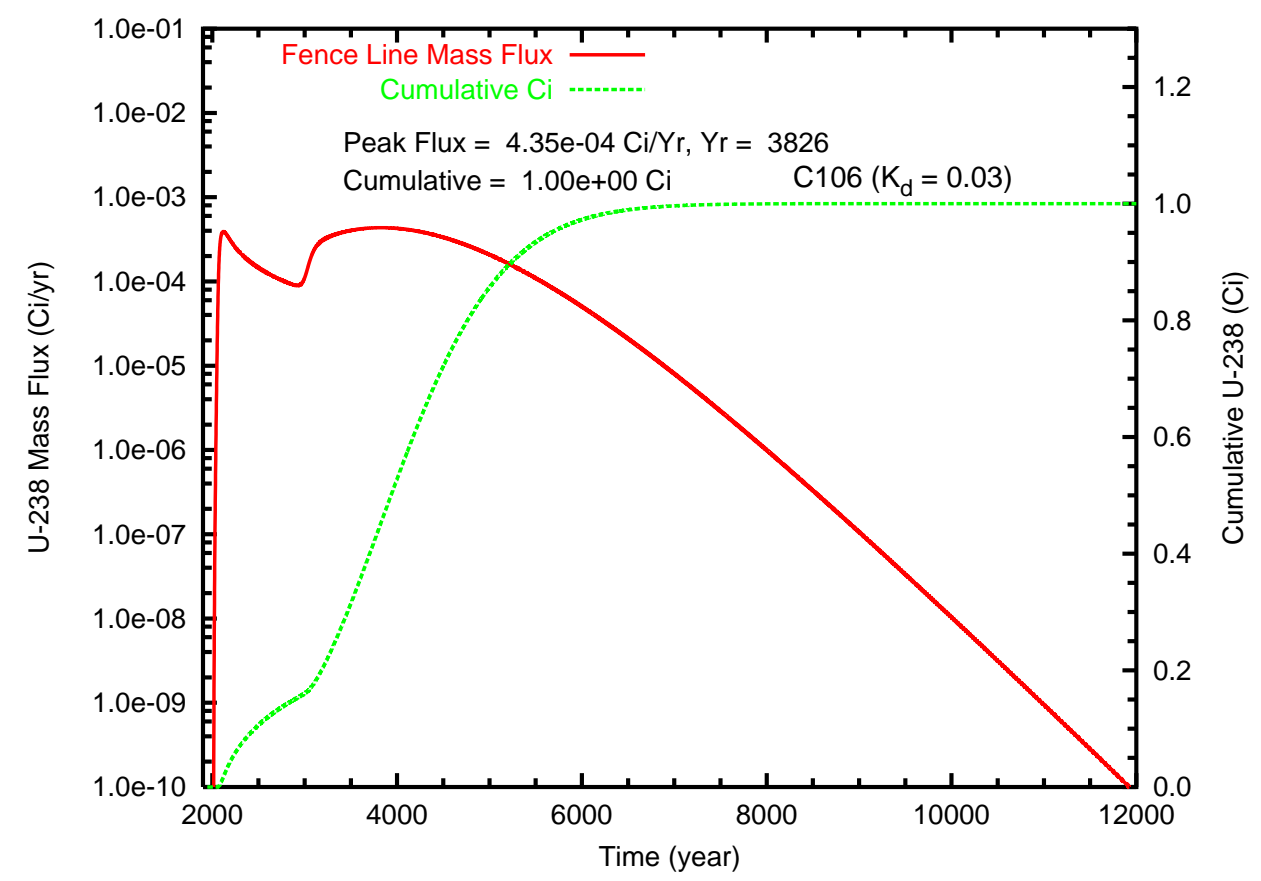

Figure B.19. Case 1v, U-238 mass flux and cumulative mass for Tank C-106 at (a) the groundwater table and (b) the fence line 
(a)

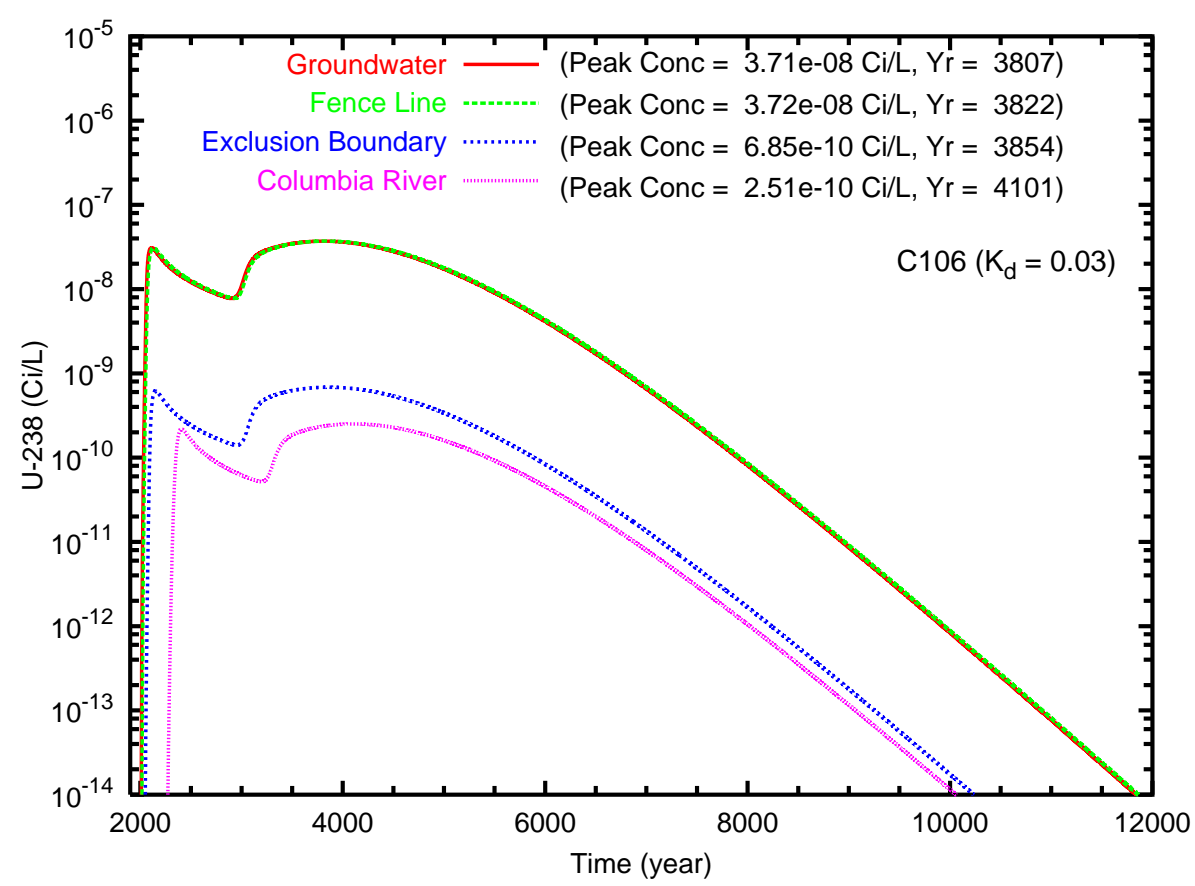

(b)

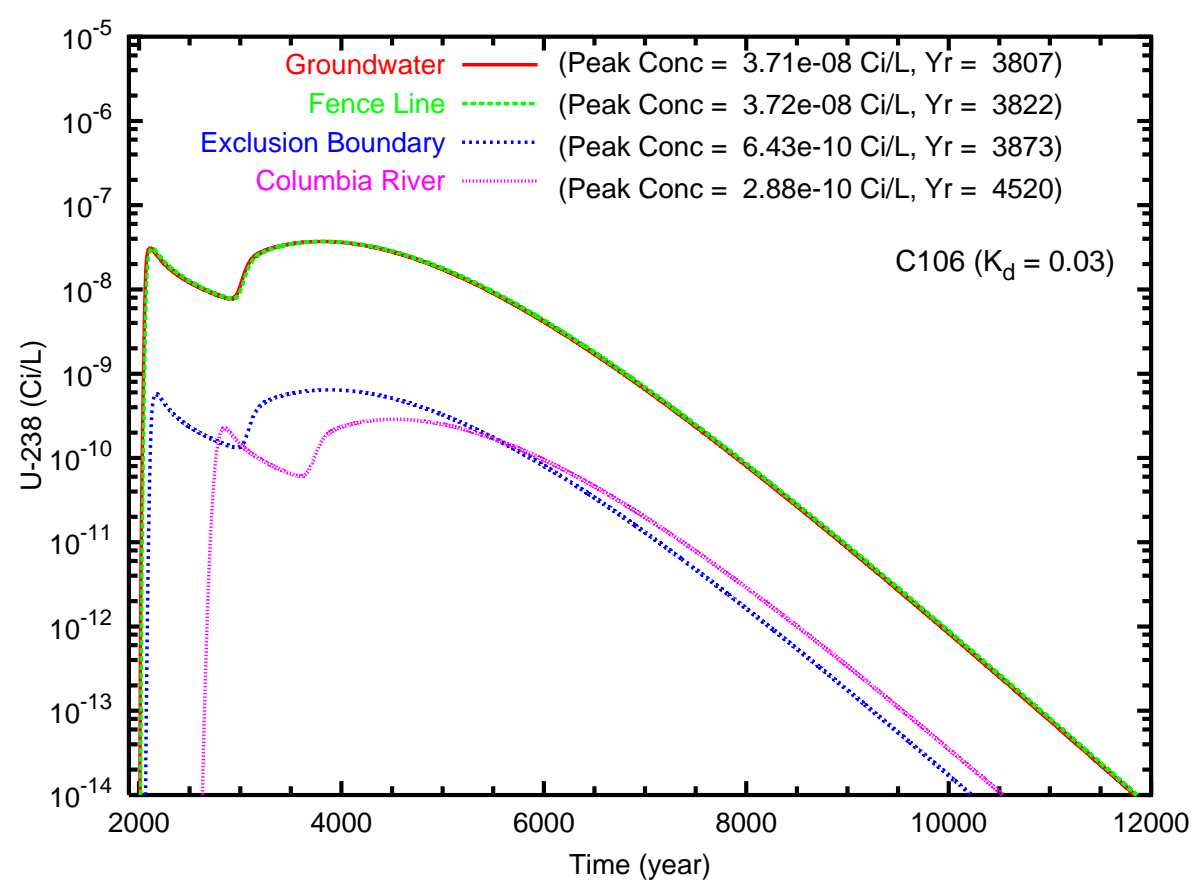

Figure B.20. Case $1 \mathrm{v}, \mathrm{U}-238\left(\mathrm{~K}_{d}=0.03\right)$ concentration versus time (Tank C-106) for the fence line, exclusion boundary and Columbia River compliance points for travel paths (a) southeast and (b) north through the gap 
(a)

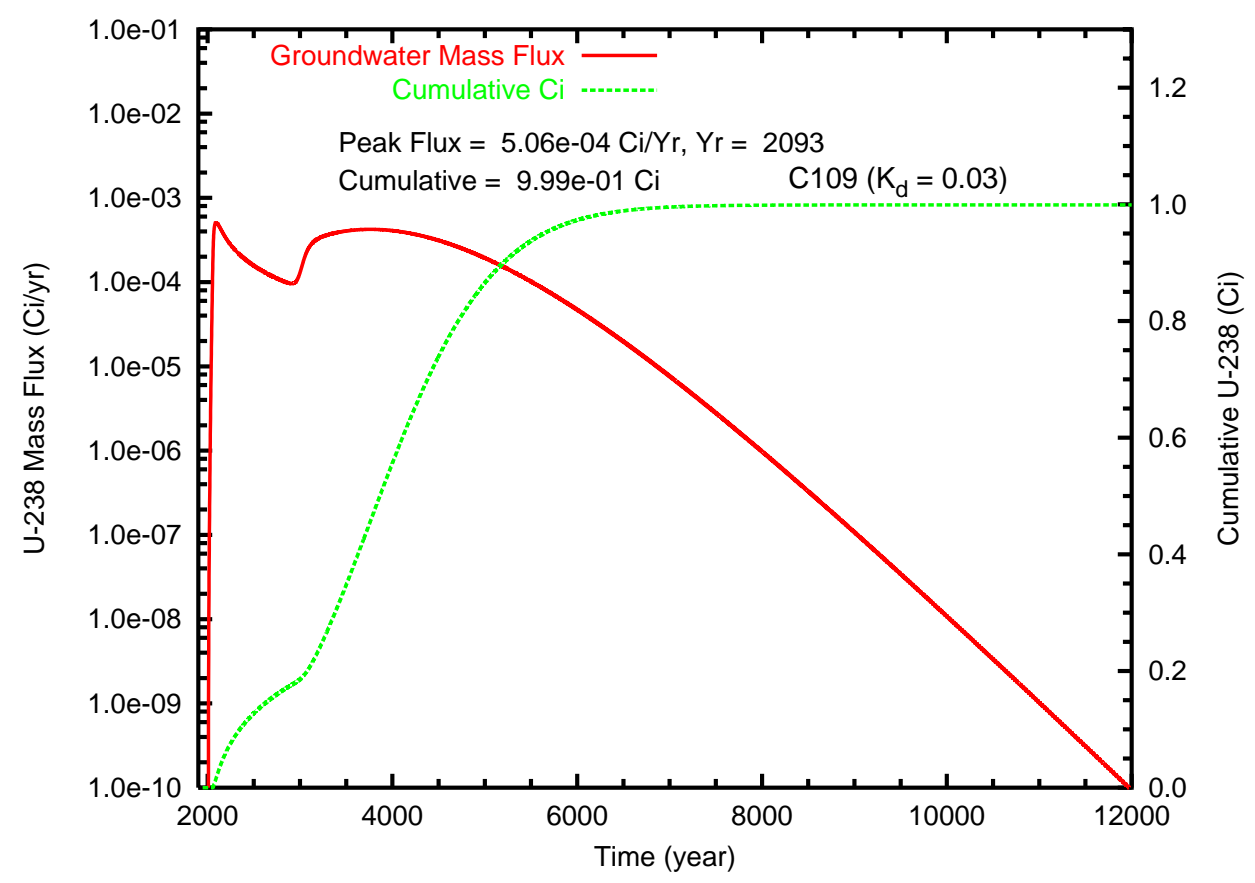

(b)

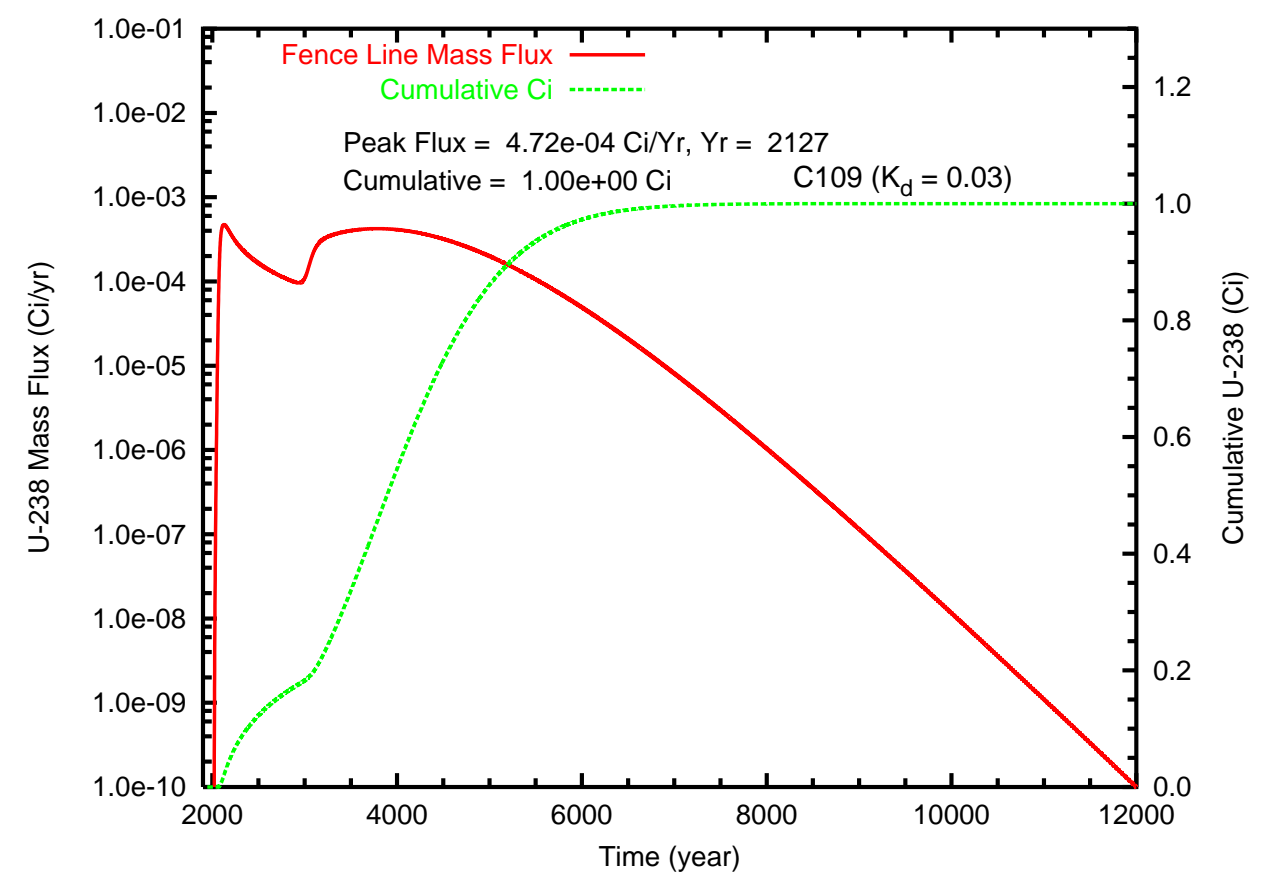

Figure B.21. Case 1v, U-238 mass flux and cumulative mass for Tank C-109 at (a) the groundwater table and (b) the fence line 
(a)

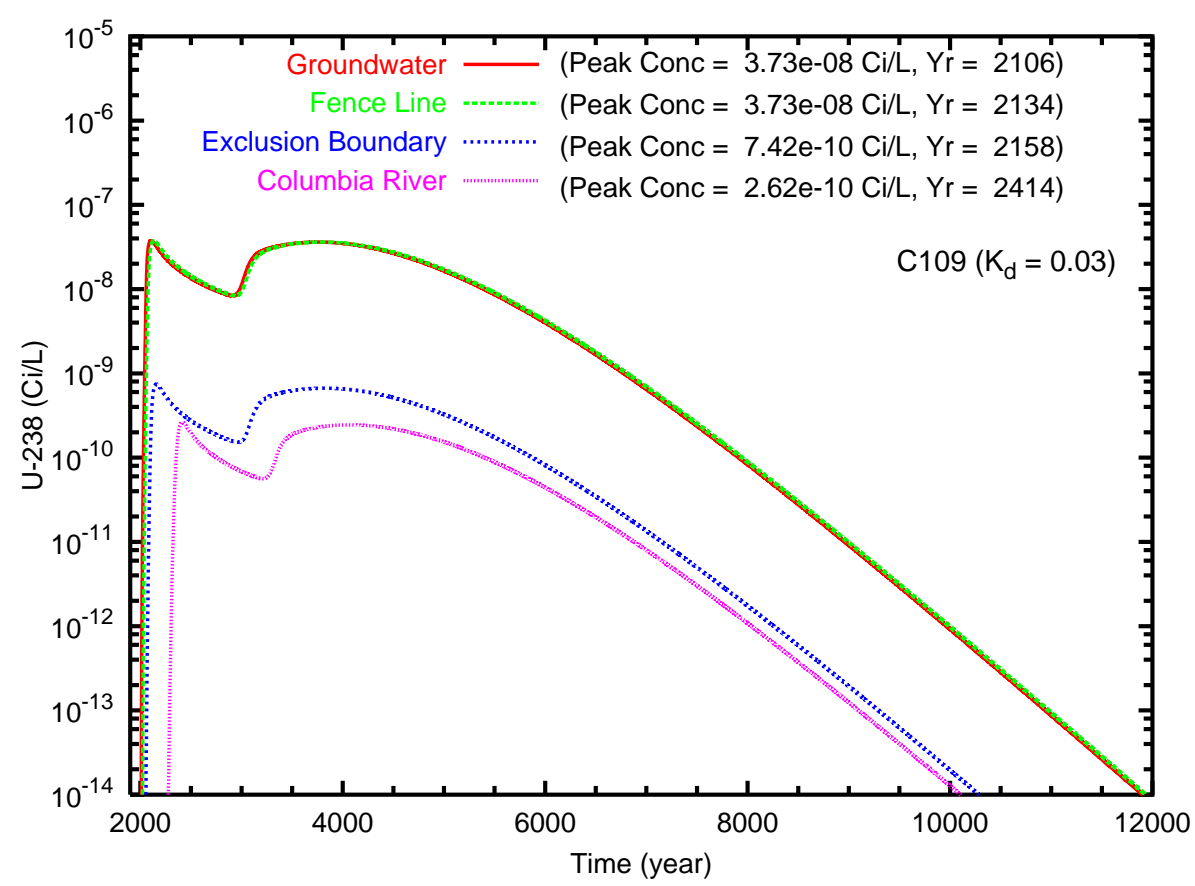

(b)

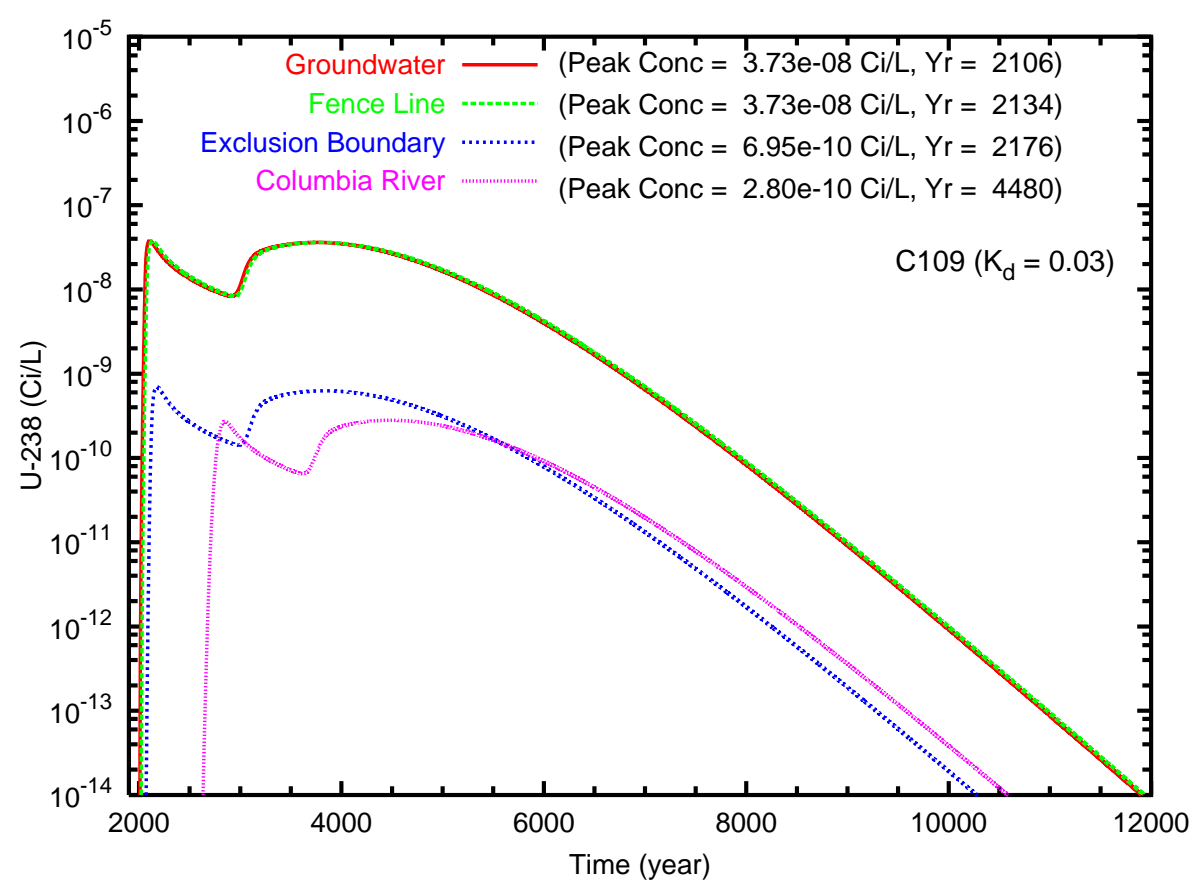

Figure B.22. Case $1 \mathrm{v}, \mathrm{U}-238\left(\mathrm{~K}_{d}=0.03\right)$ concentration versus time (Tank C-109) for the fence line, exclusion boundary and Columbia River compliance points for travel paths (a) southeast and (b) north through the gap 
(a)

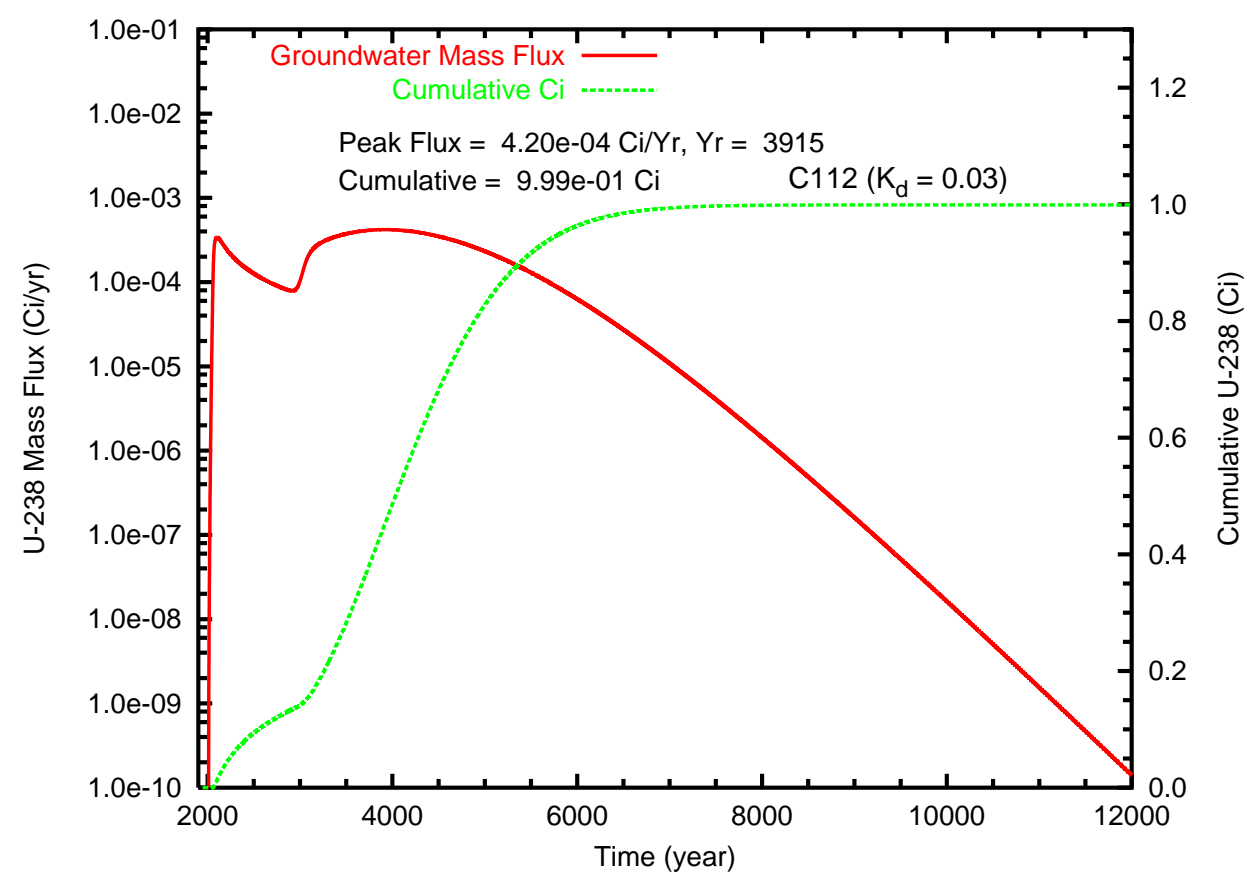

(b)

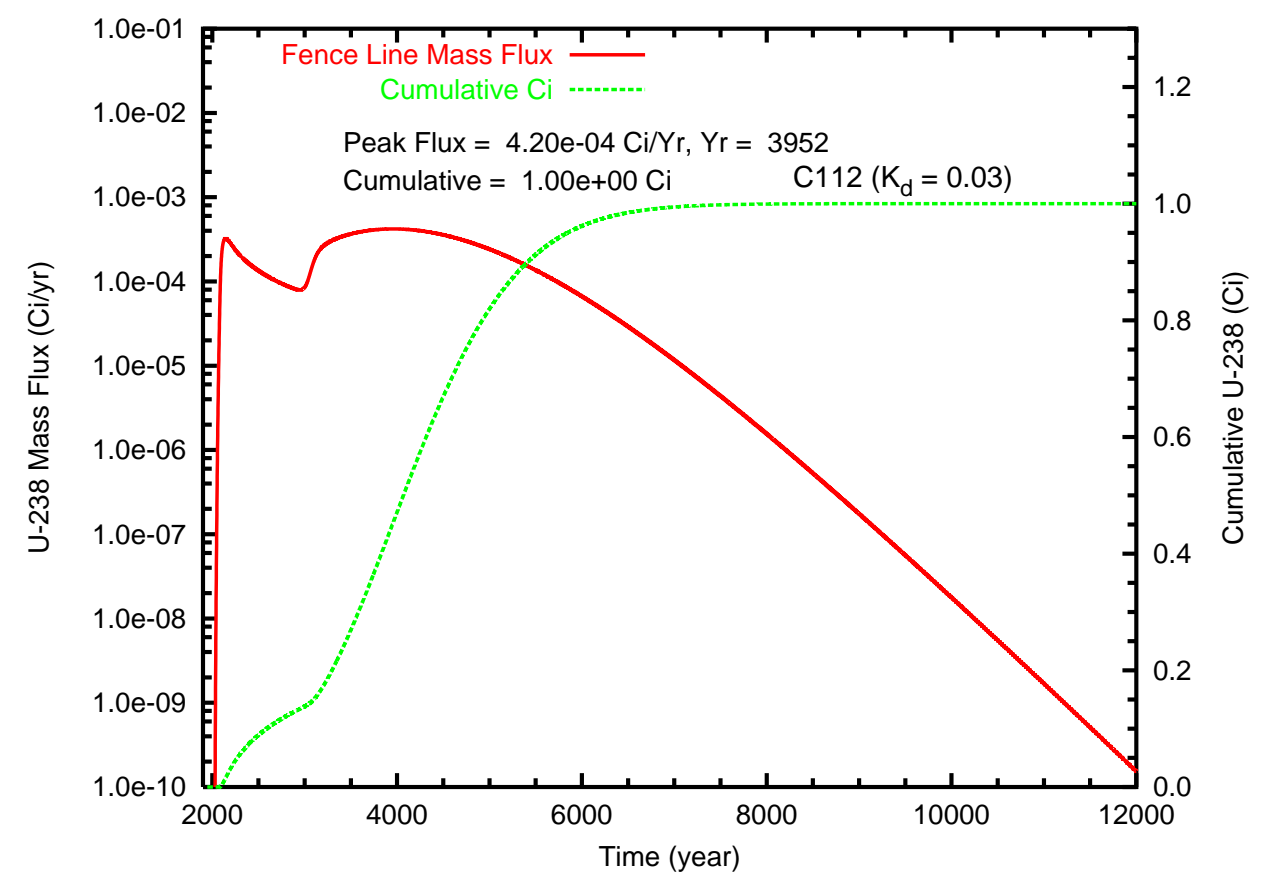

Figure B.23. Case 1v, U-238 mass flux and cumulative mass for Tank C-112 at (a) the groundwater table and (b) the fence line 
(a)

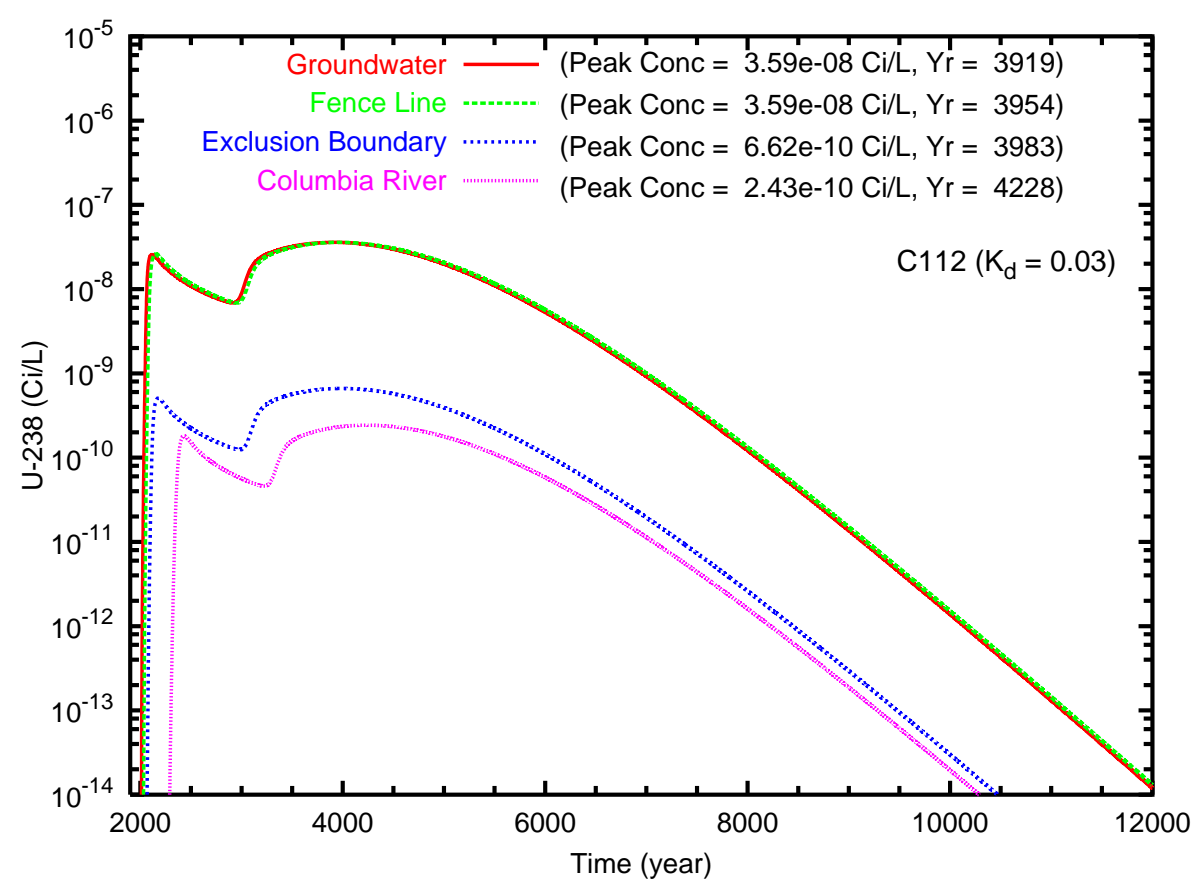

(b)

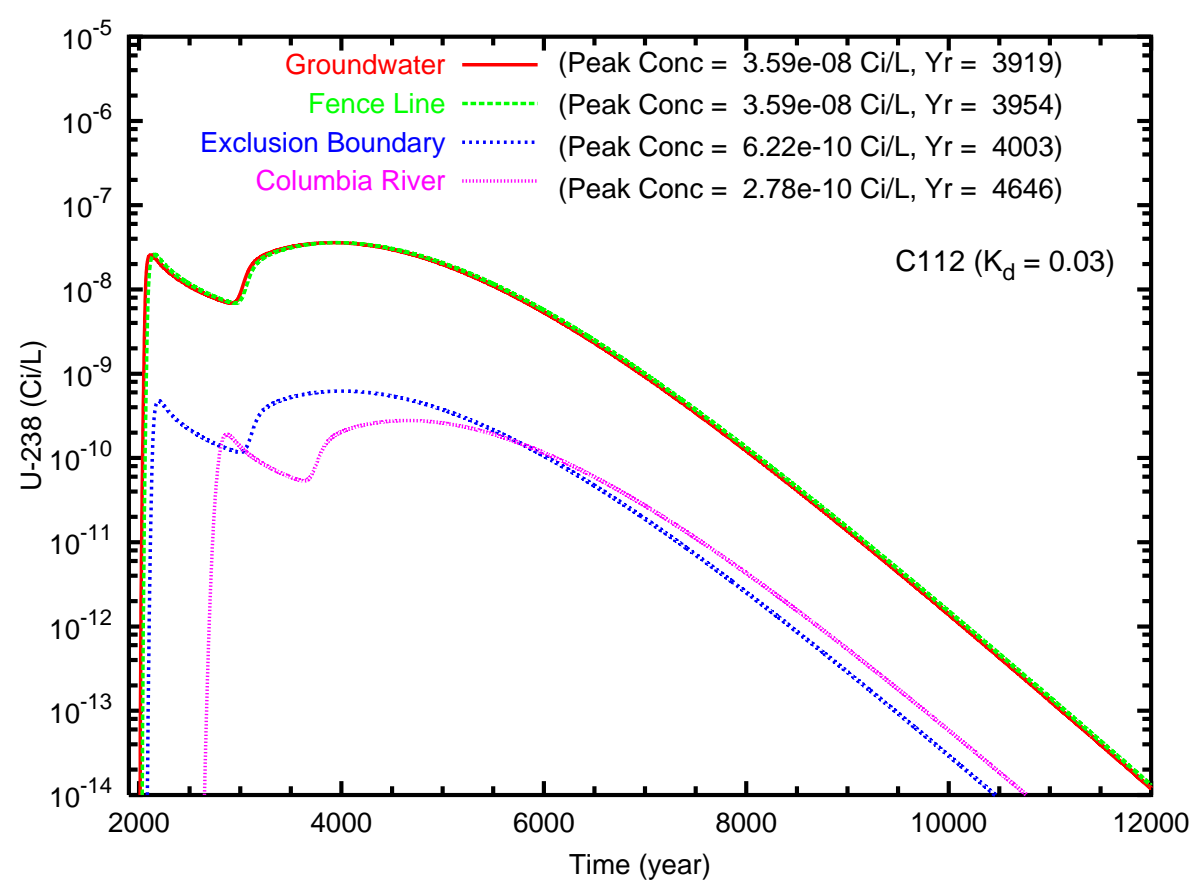

Figure B.24. Case $1 \mathrm{v}, \mathrm{U}-238\left(\mathrm{~K}_{d}=0.03\right)$ concentration versus time (Tank C-112) for the fence line, exclusion boundary and Columbia River compliance points for travel paths (a) southeast and (b) north through the gap 
(a)

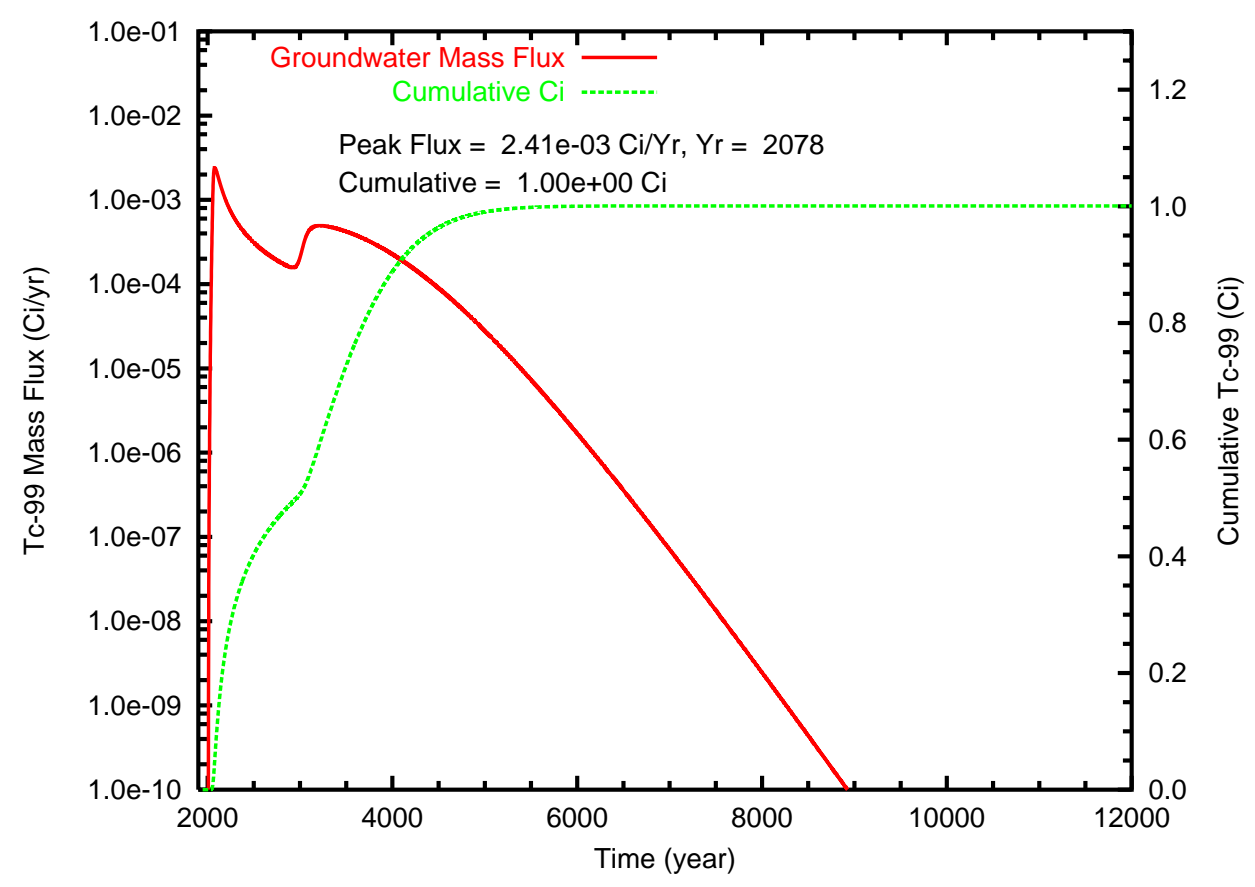

(b)

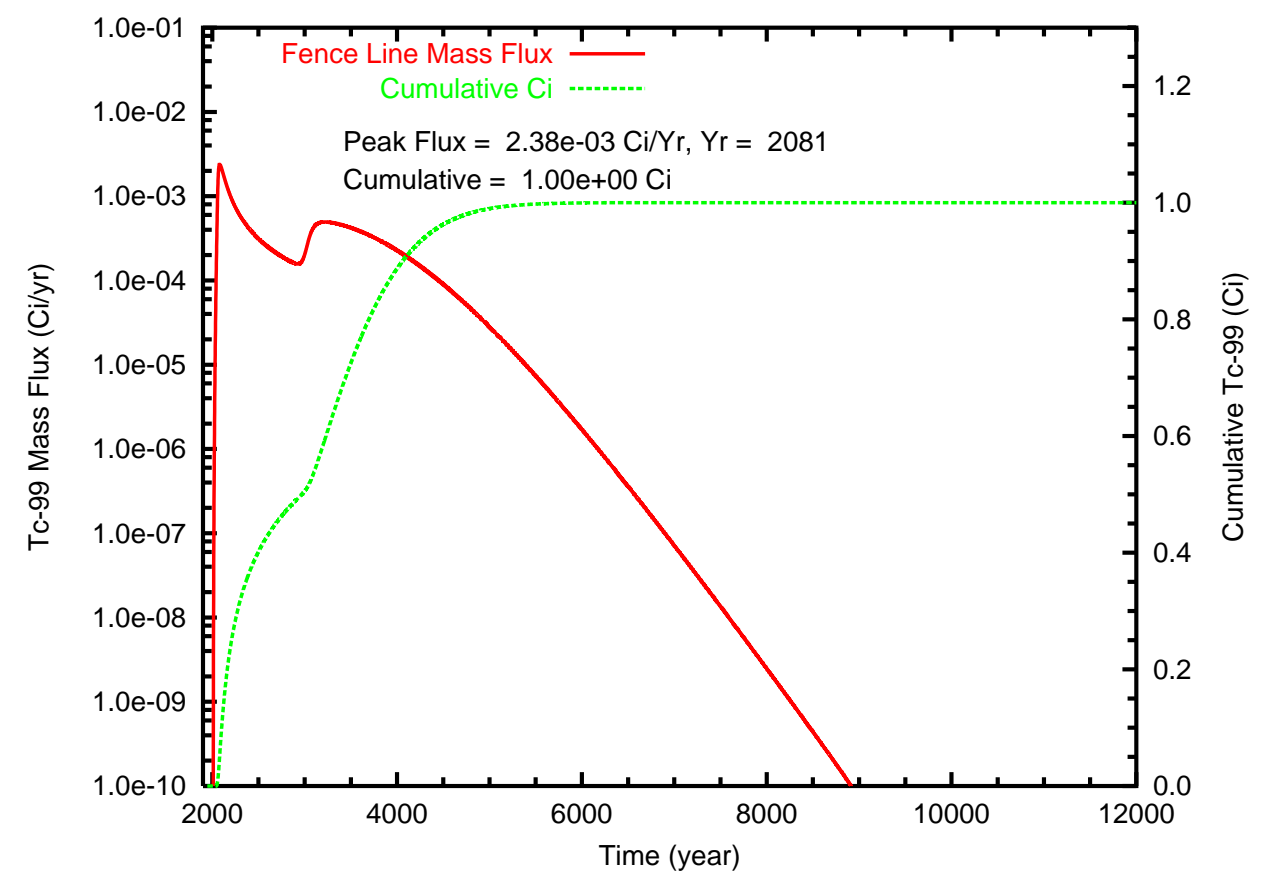

Figure B.25. Case 1-HiK, Tc-99 mass flux and cumulative mass at (a) the groundwater table and (b) the fence line 
(a)

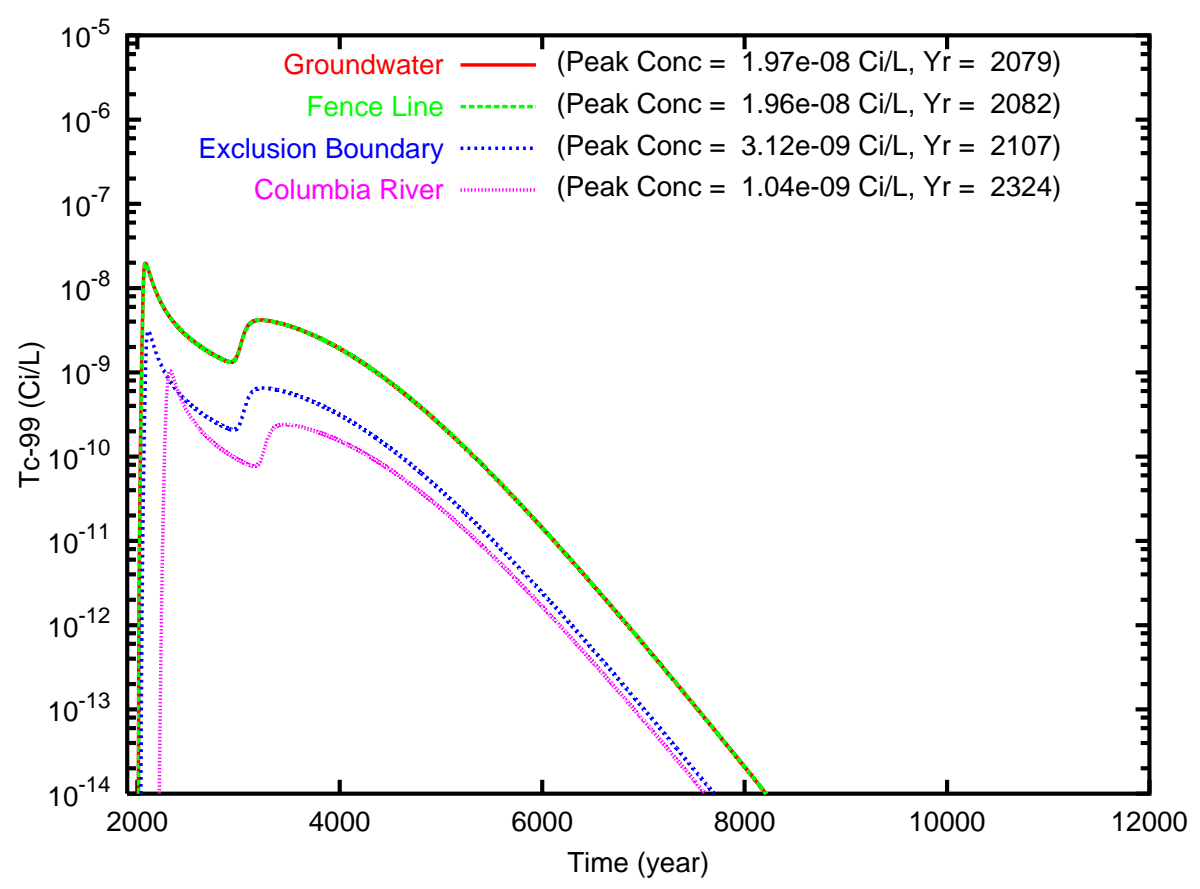

(b)

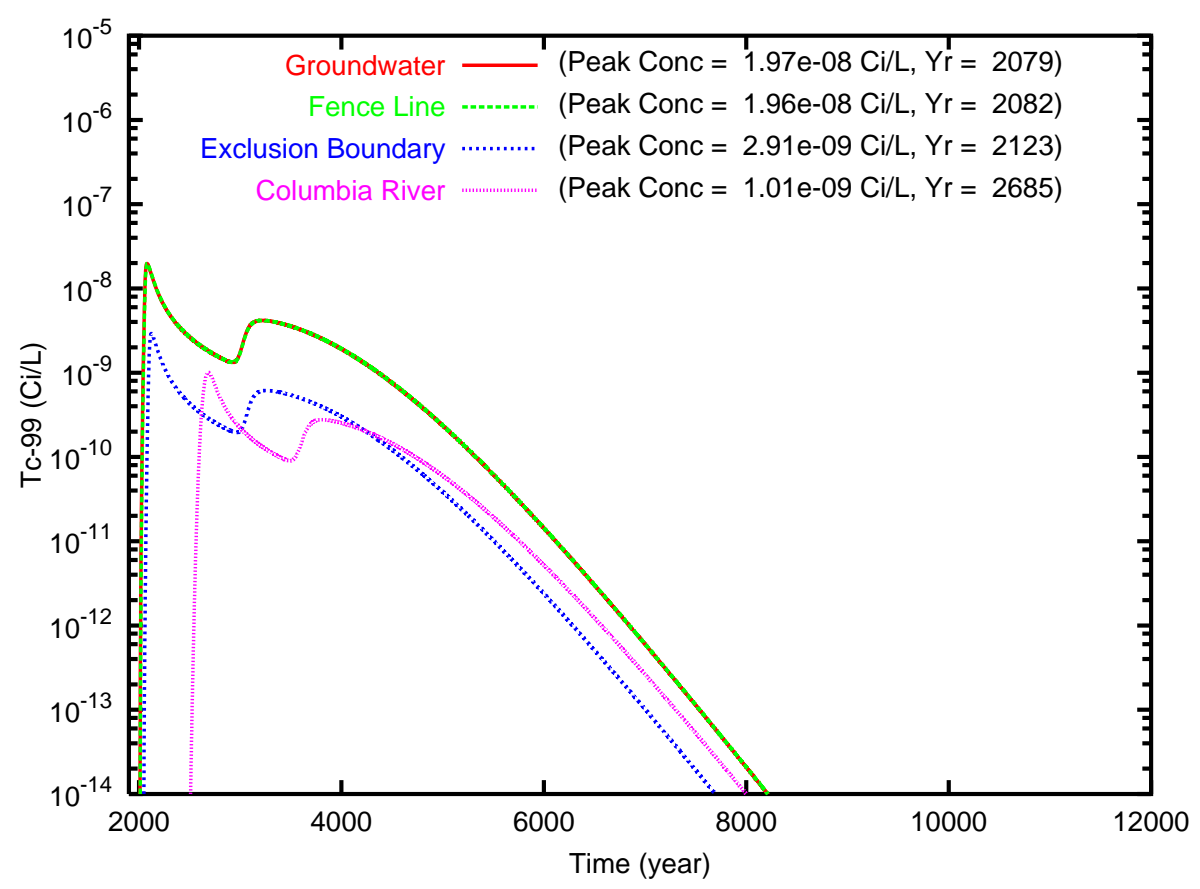

Figure B.26. Case 1-HiK, Tc-99 concentration versus time for the fence line, exclusion boundary and Columbia River compliance points for travel paths (a) southeast and (b) north through the gap 
(a)

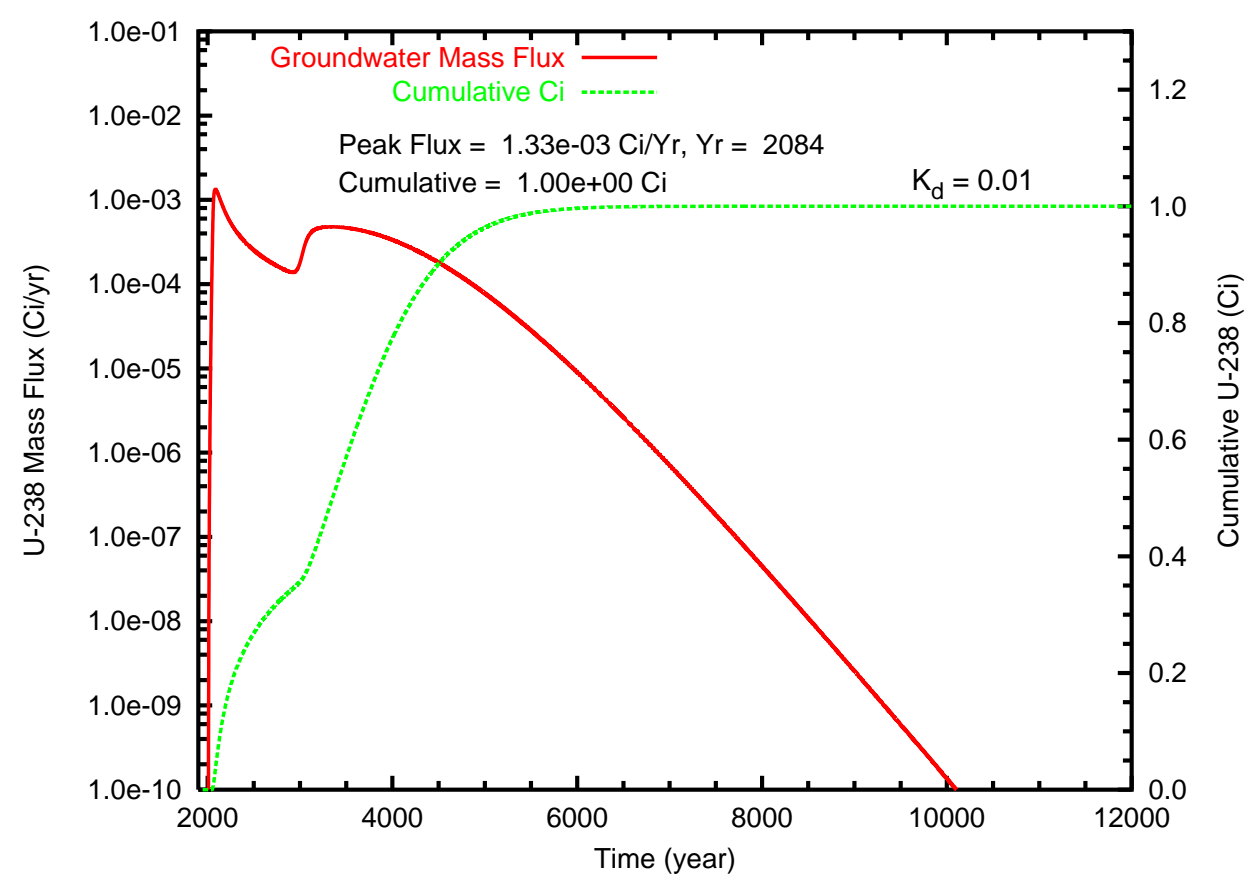

(b)

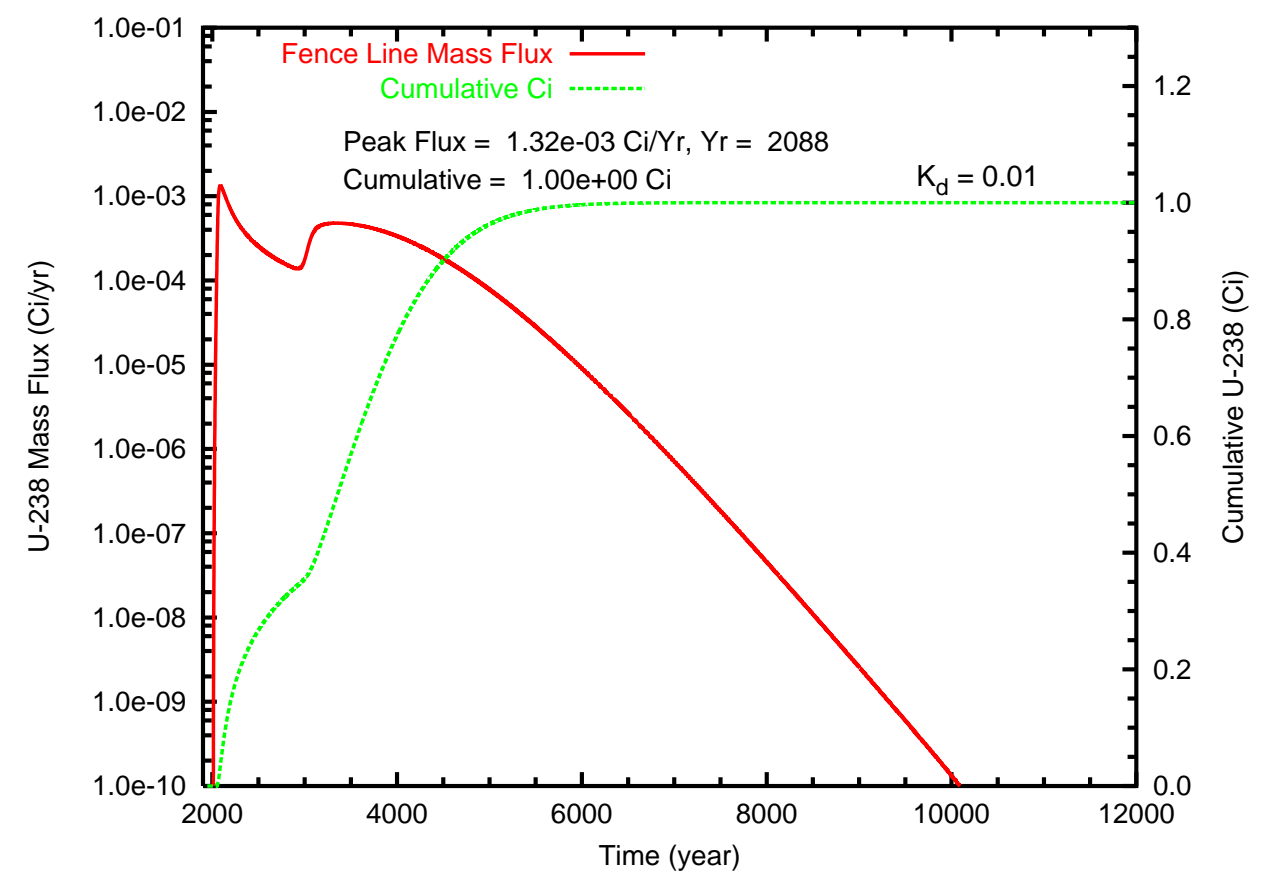

Figure B.27. Case 1-HiK, U-238 $\left(\mathrm{K}_{d}=0.01\right)$ mass flux $(\mathrm{Ci} / \mathrm{L})$ and cumulative mass $(\mathrm{Ci})$ at (a) the groundwater table and (b) the fence line 
(a)

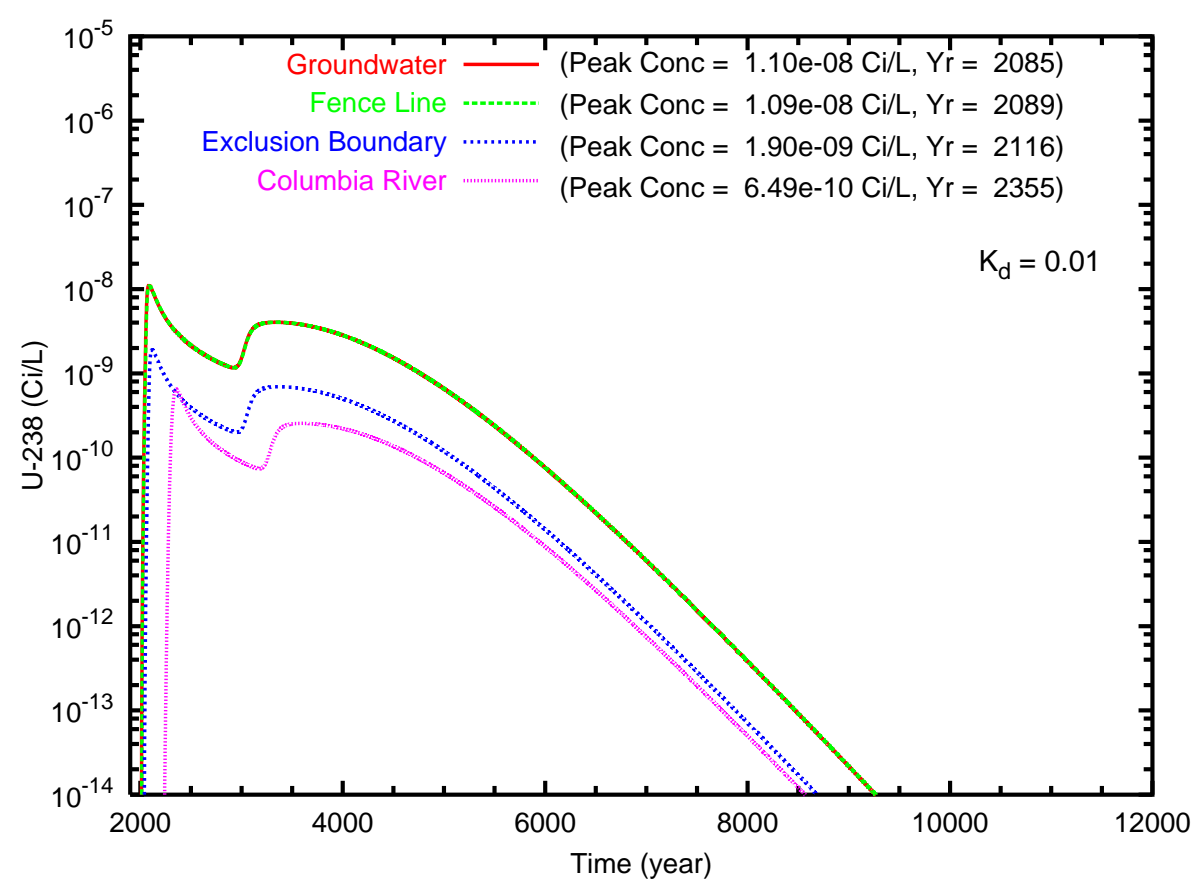

(b)

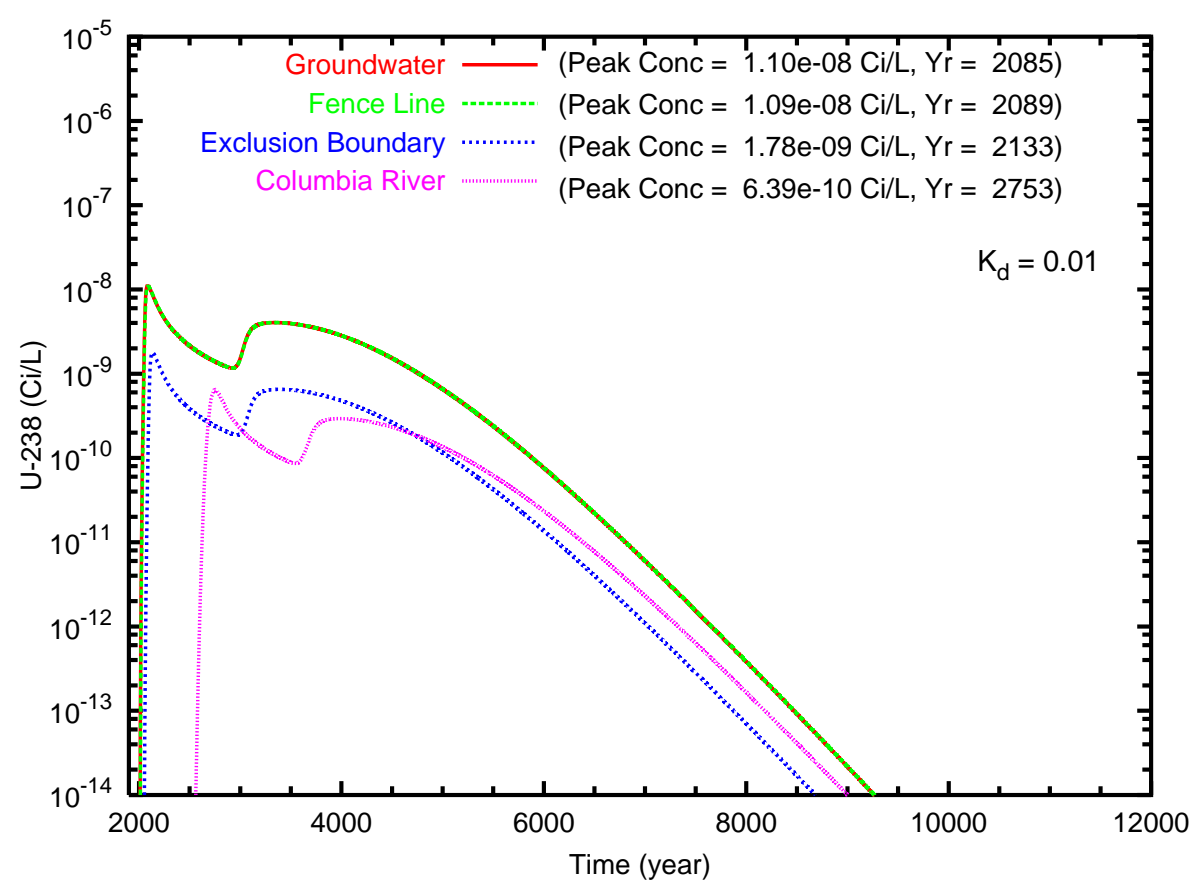

Figure B.28. Case 1-HiK, U-238 $\left(\mathrm{K}_{d}=0.01\right)$ concentration versus time for the fence line exclusion boundary and Columbia River compliance points for travel paths (a) southeast and (b) north through the gap 
(a)

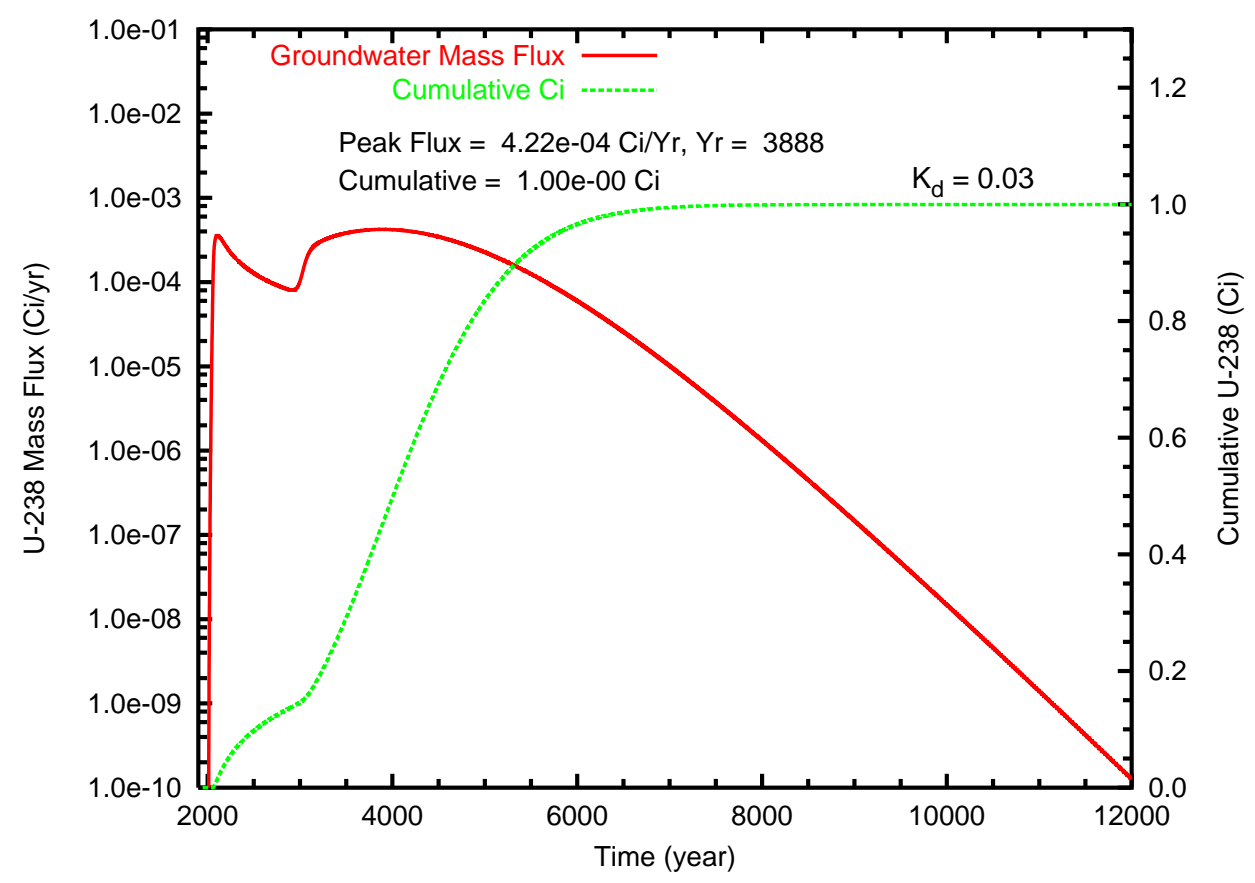

(b)

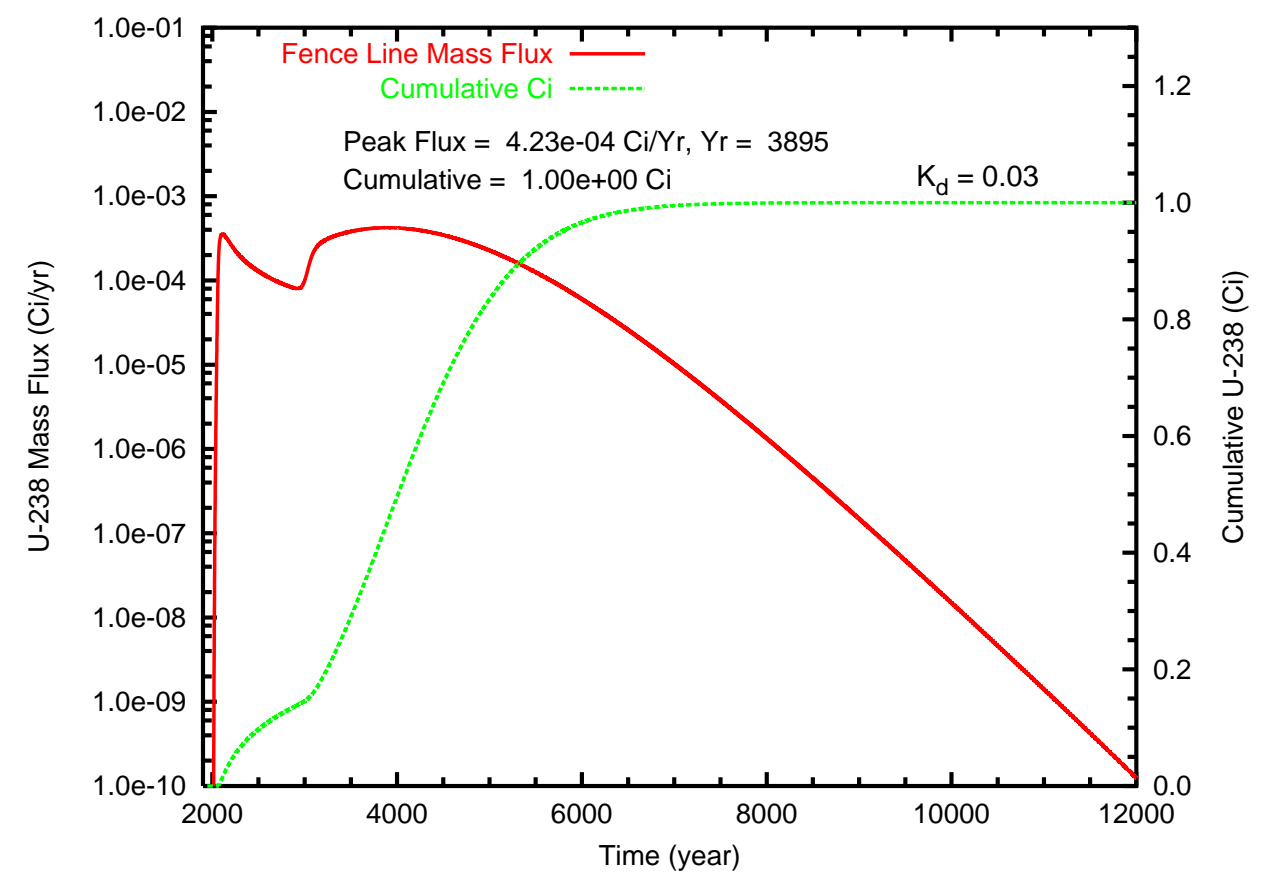

Figure B.29. Case 1-HiK, U-238 $\left(\mathrm{K}_{d}=0.03\right)$ mass flux $(\mathrm{Ci} / \mathrm{L})$ and cumulative mass $(\mathrm{Ci})$ at (a) the groundwater table and (b) the fence line 
(a)

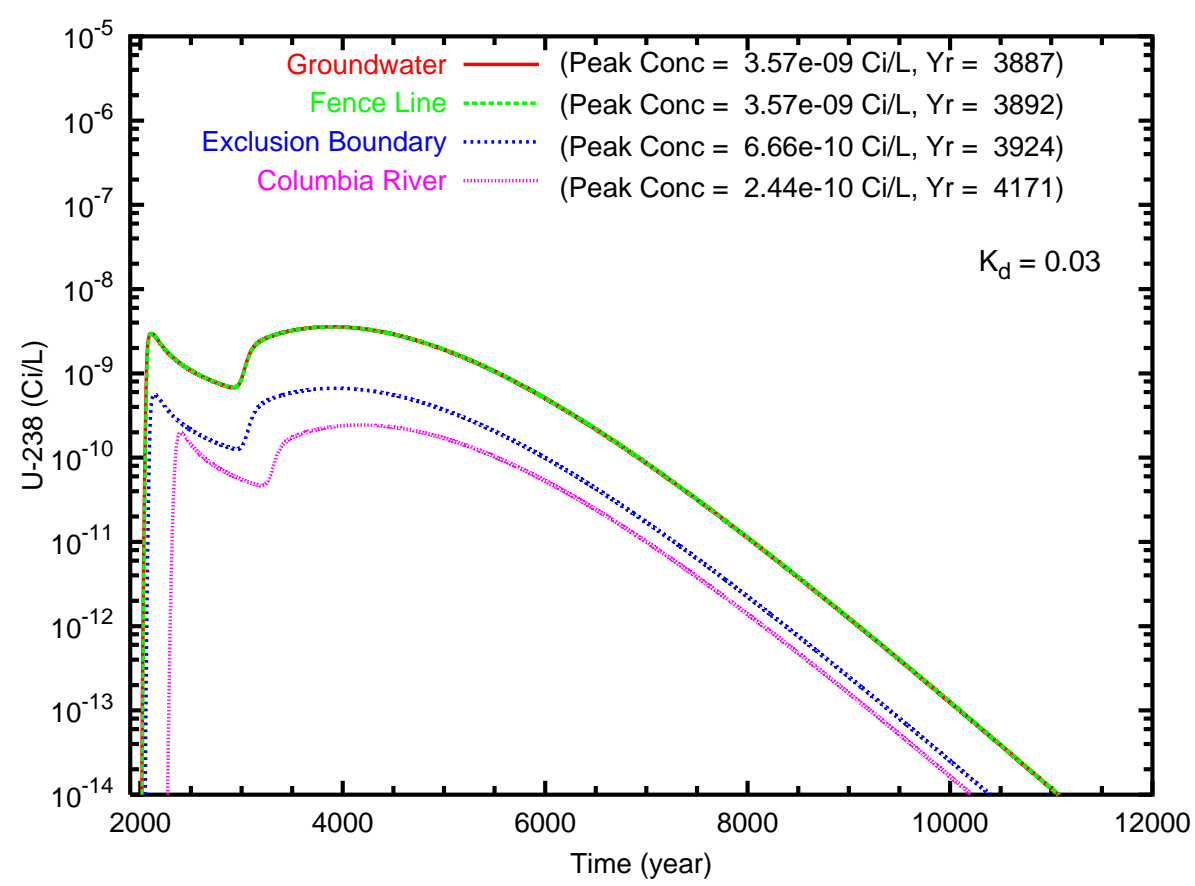

(b)

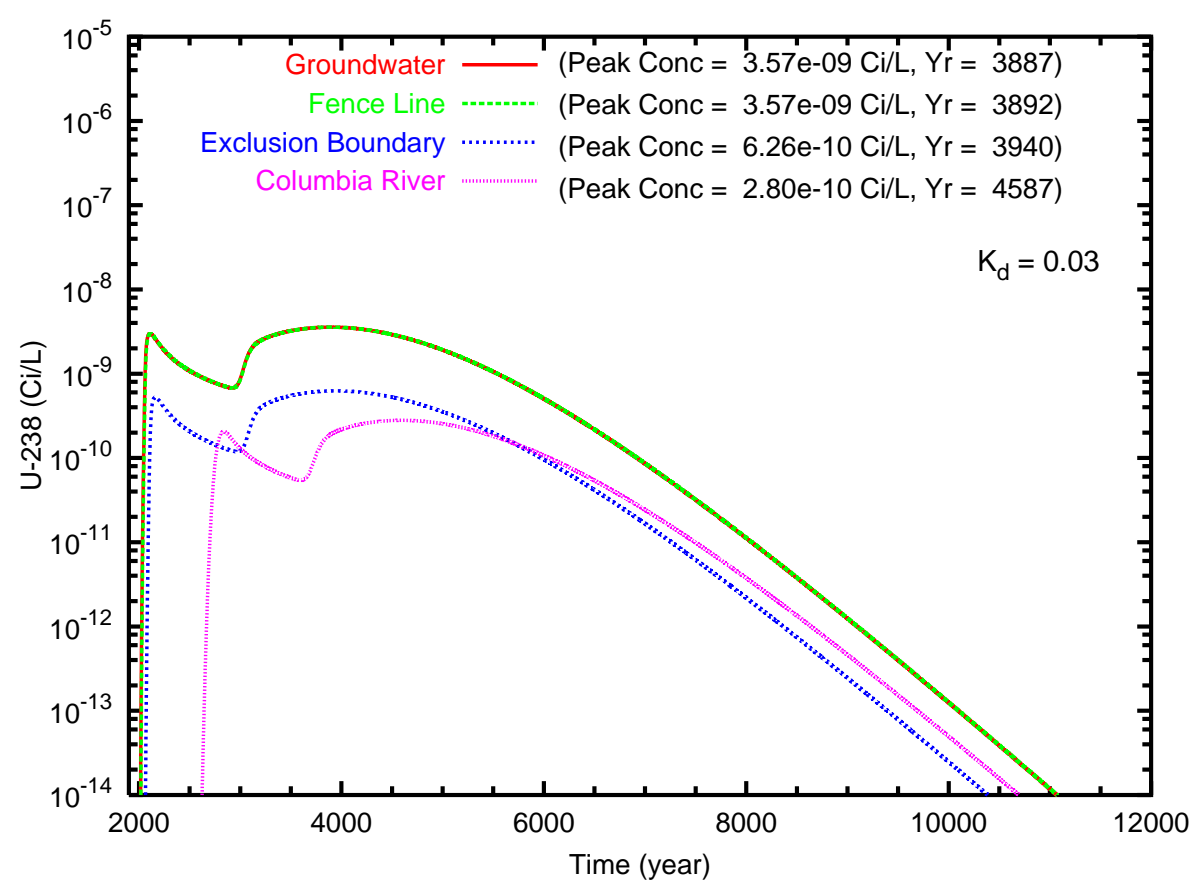

Figure B.30. Case 1-HiK, U-238 $\left(\mathrm{K}_{d}=0.03\right)$ concentration versus time for the fence line exclusion boundary and Columbia River compliance points for travel paths (a) southeast and (b) north through the gap 
(a)

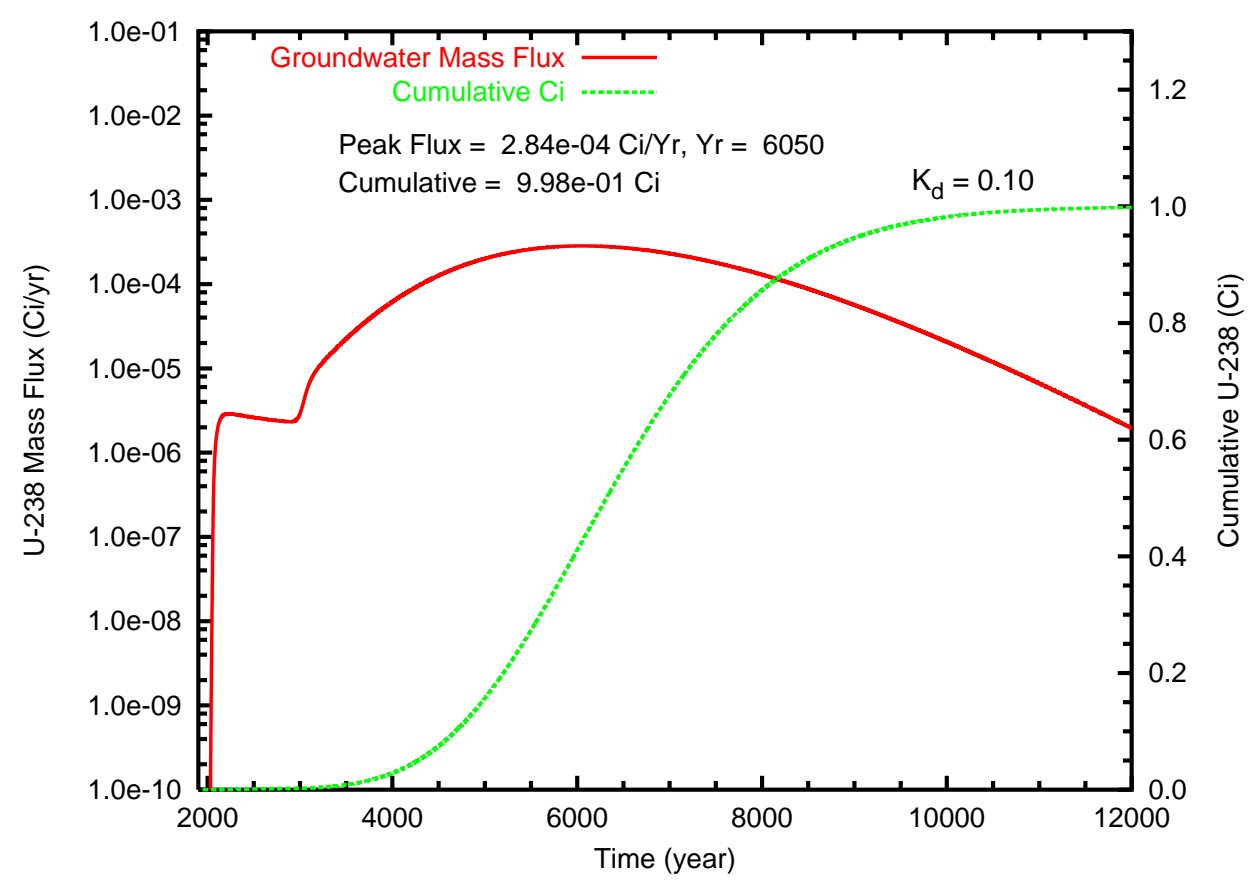

(b)

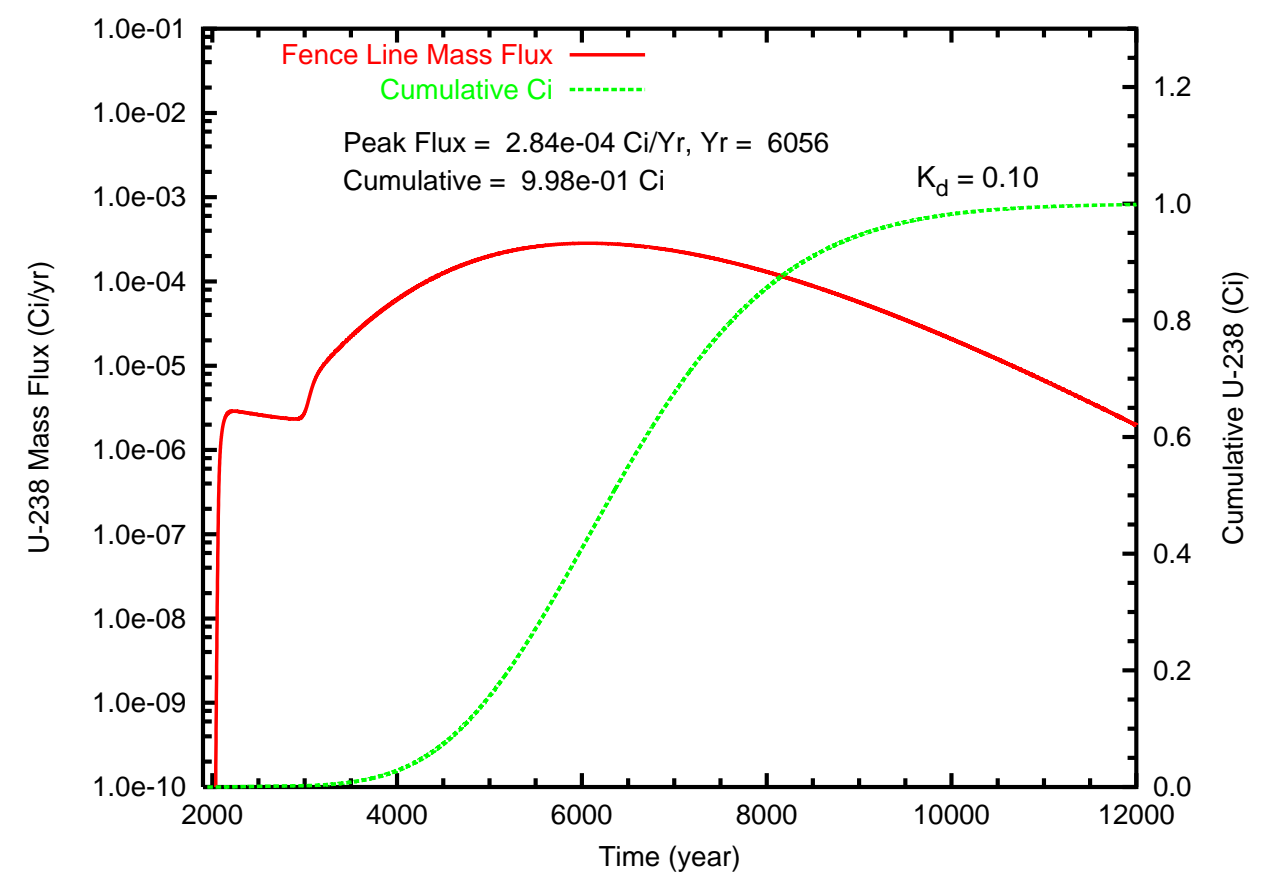

Figure B.31. Case 1-HiK, U-238 $\left(\mathrm{K}_{d}=0.10\right)$ mass flux $(\mathrm{Ci} / \mathrm{L})$ and cumulative mass $(\mathrm{Ci})$ at (a) the groundwater table and (b) the fence line 
(a)

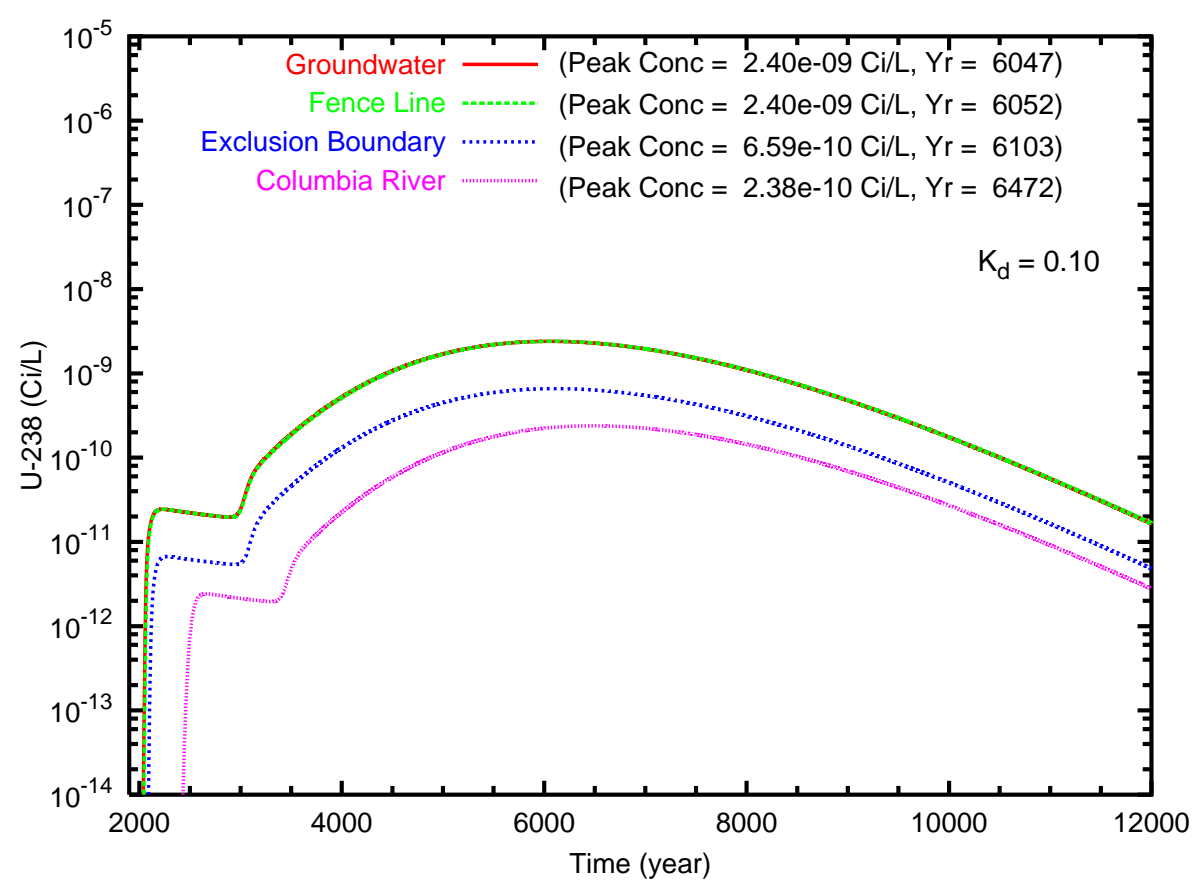

(b)

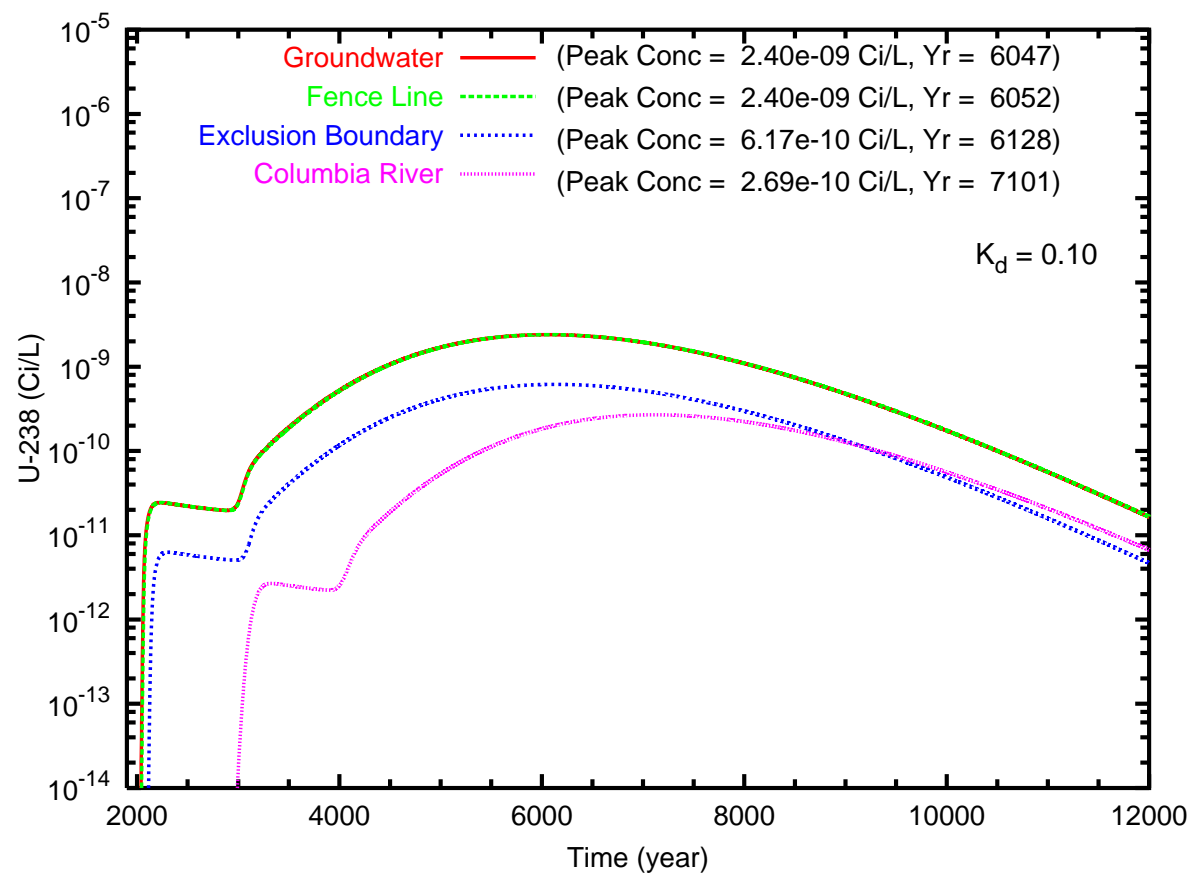

Figure B.32. Case 1-HiK, U-238 $\left(\mathrm{K}_{d}=0.10\right)$ concentration versus time for the fence line exclusion boundary and Columbia River compliance points for travel paths (a) southeast and (b) north through the gap 
(a)

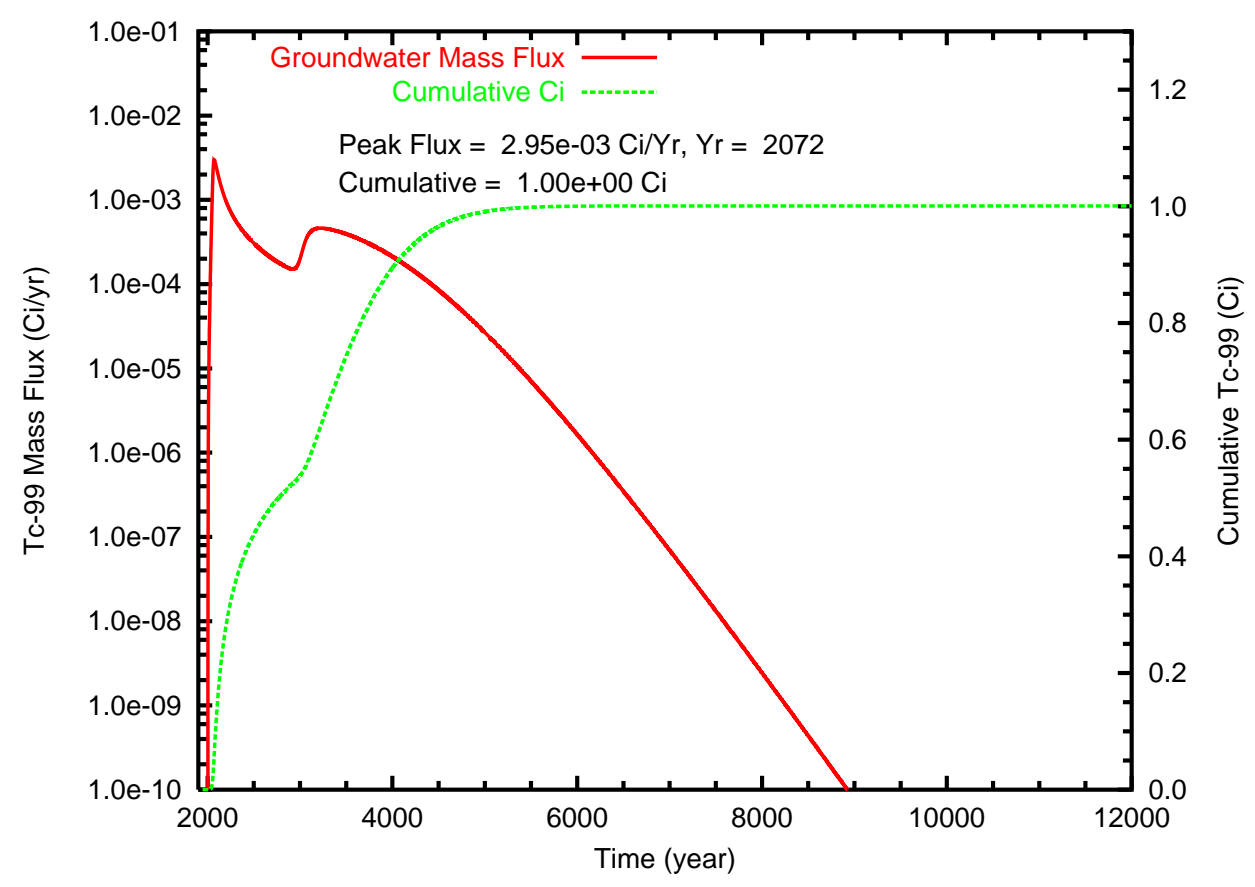

(b)

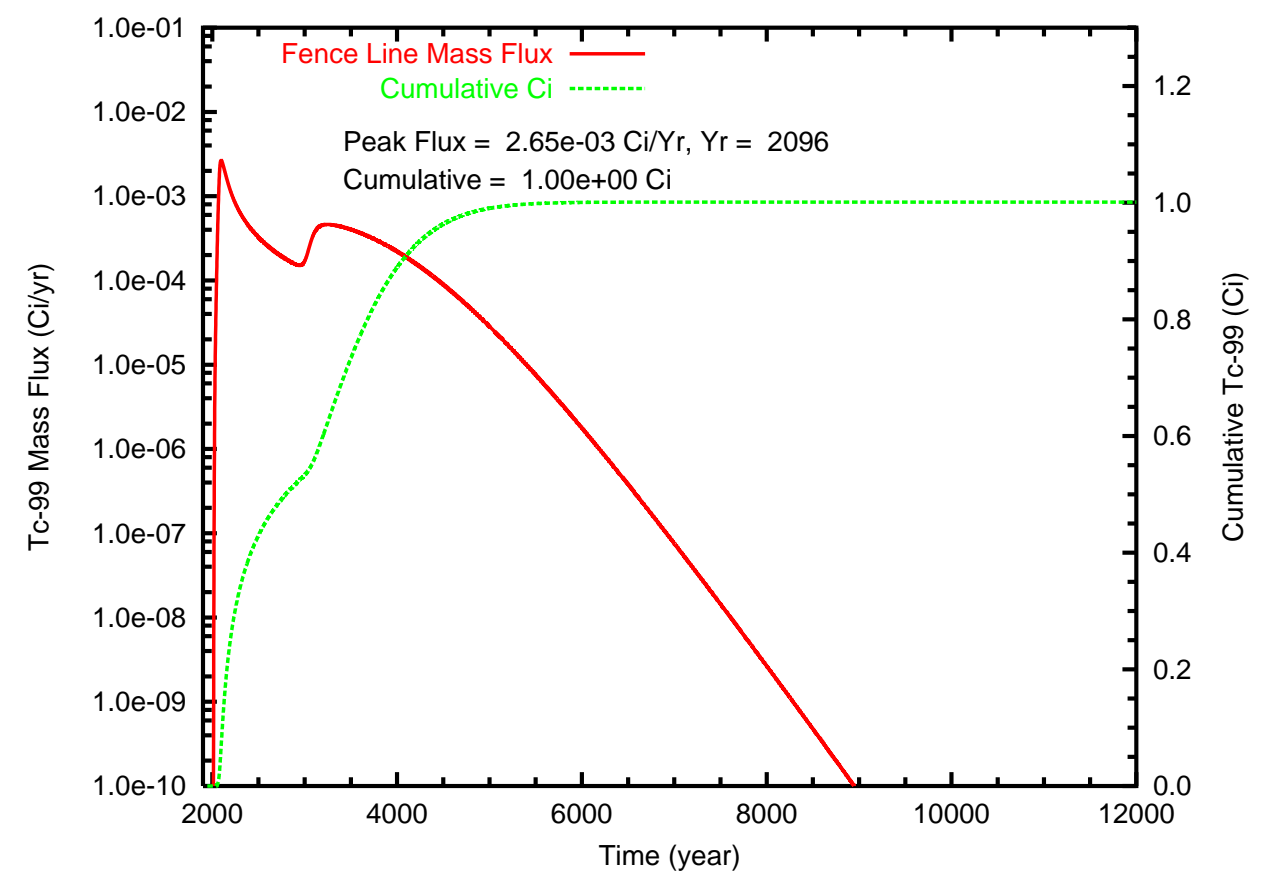

Figure B.33. Case 2, Tc-99 mass flux and cumulative mass at (a) the groundwater table and (b) the fence line 
(a)

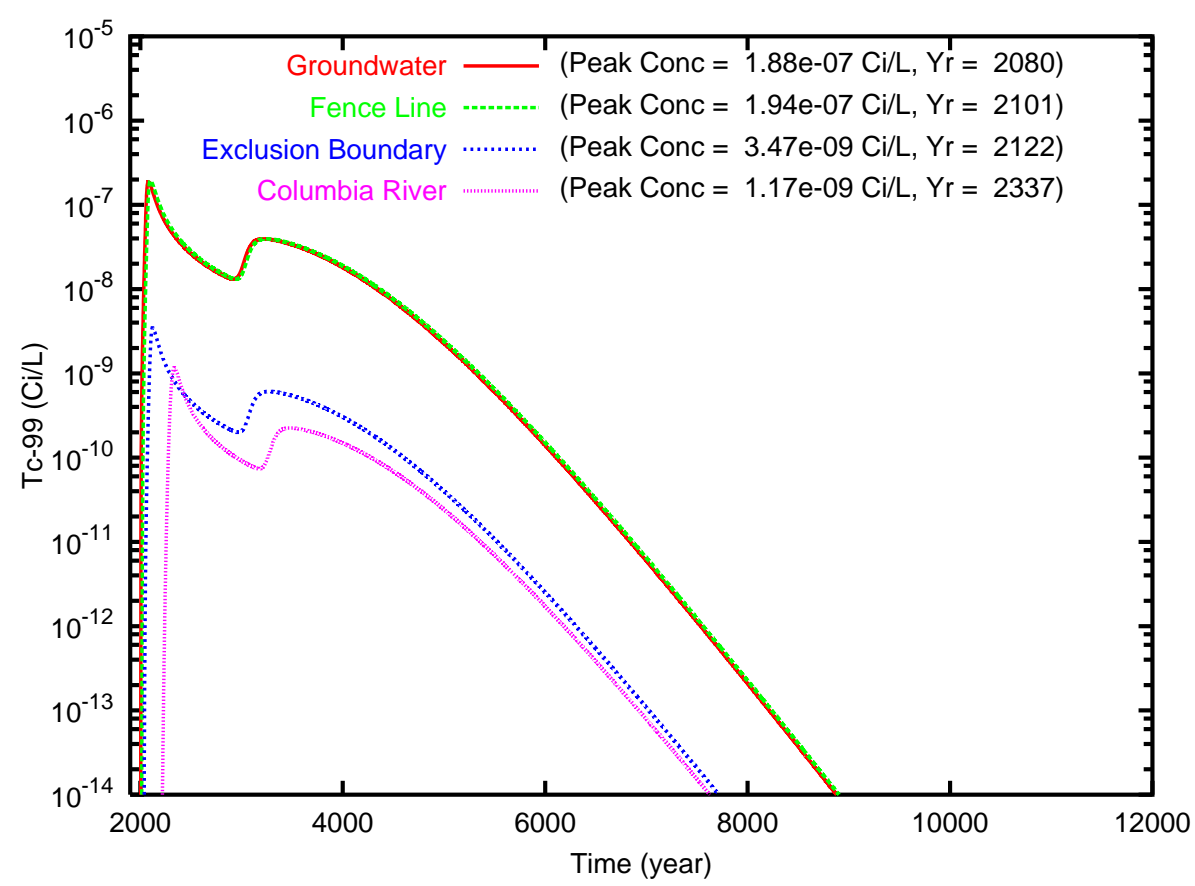

(b)

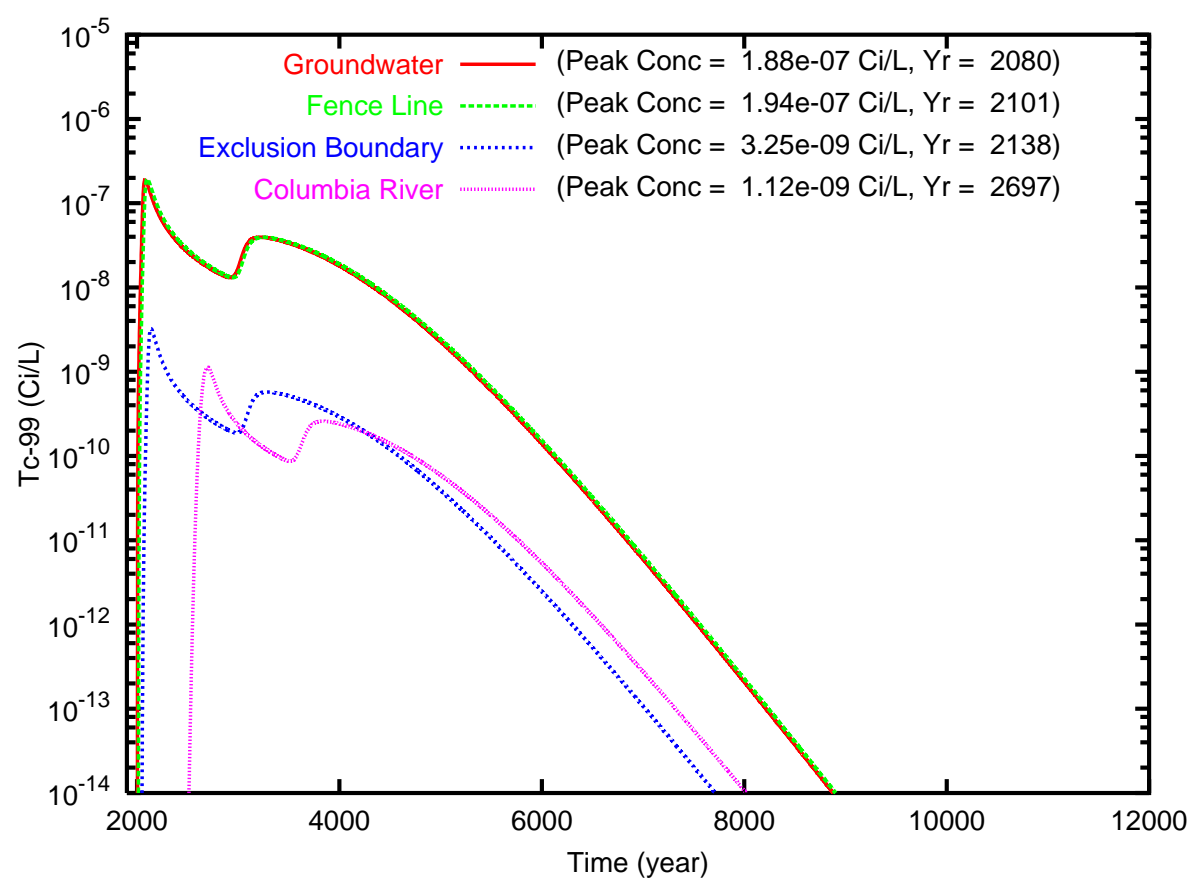

Figure B.34. Case 2, Tc-99 concentration versus time for the fence line, exclusion boundary and Columbia River compliance points for travel paths (a) southeast and (b) north through the gap 
(a)

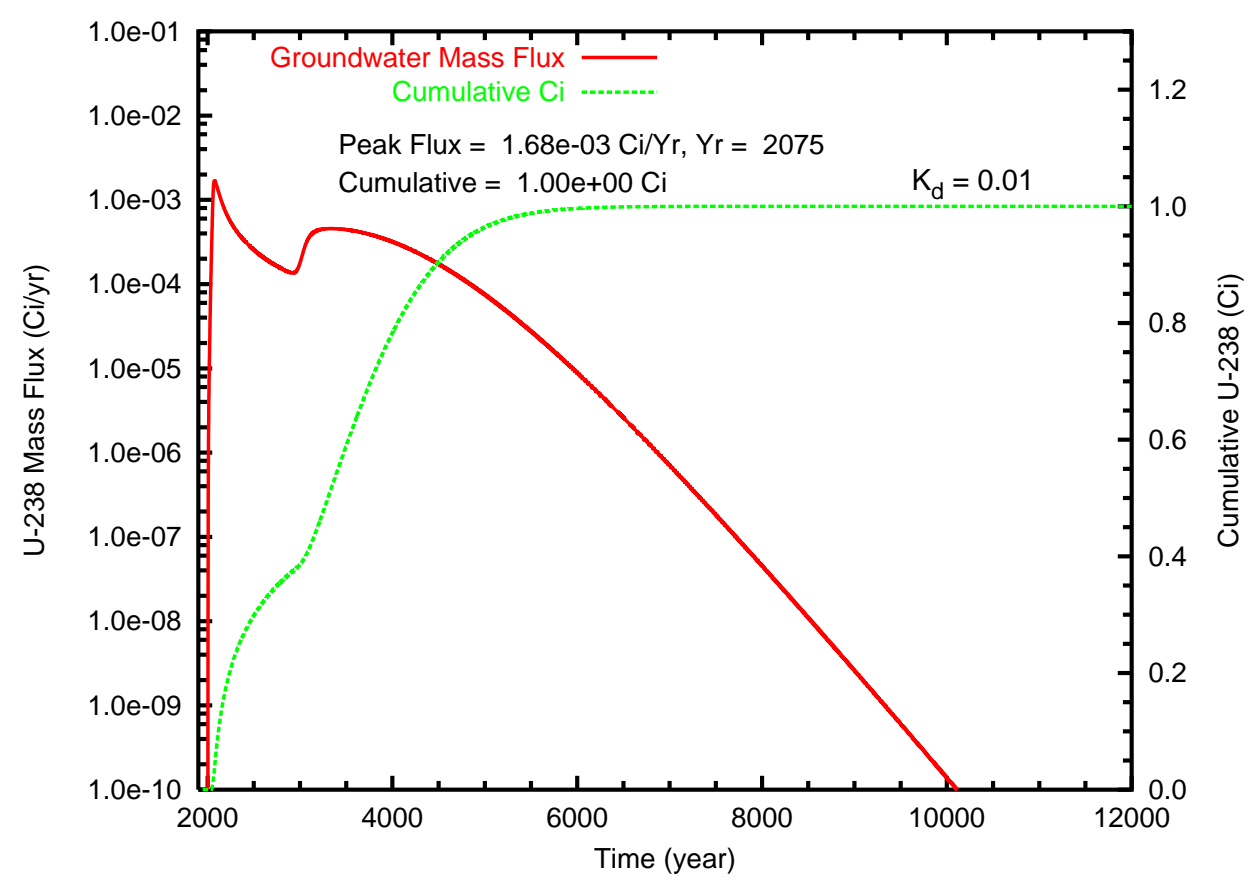

(b)

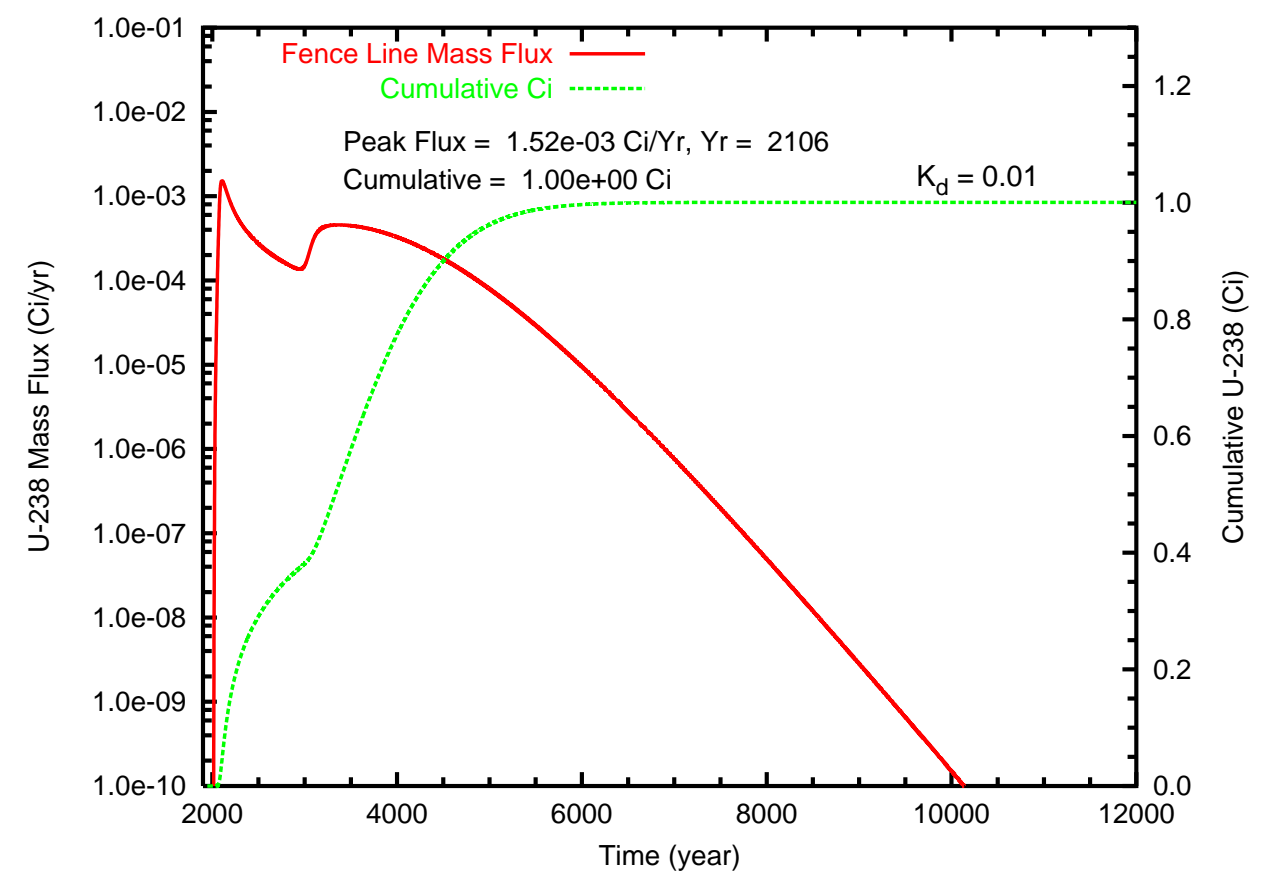

Figure B.35. Case $2, \mathrm{U}-238\left(\mathrm{~K}_{d}=0.01\right)$ mass flux $(\mathrm{Ci} / \mathrm{L})$ and cumulative mass $(\mathrm{Ci})$ at (a) the groundwater table and (b) the fence line 
(a)

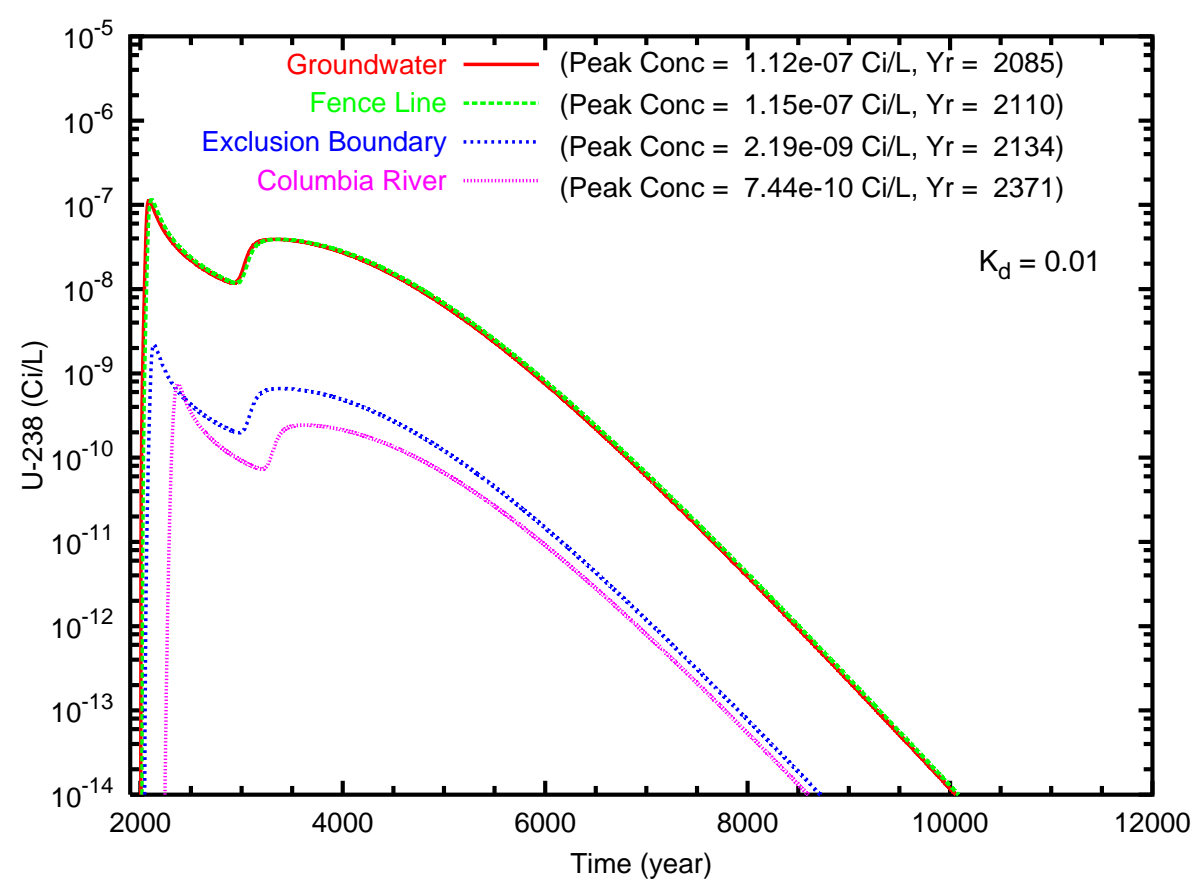

(b)

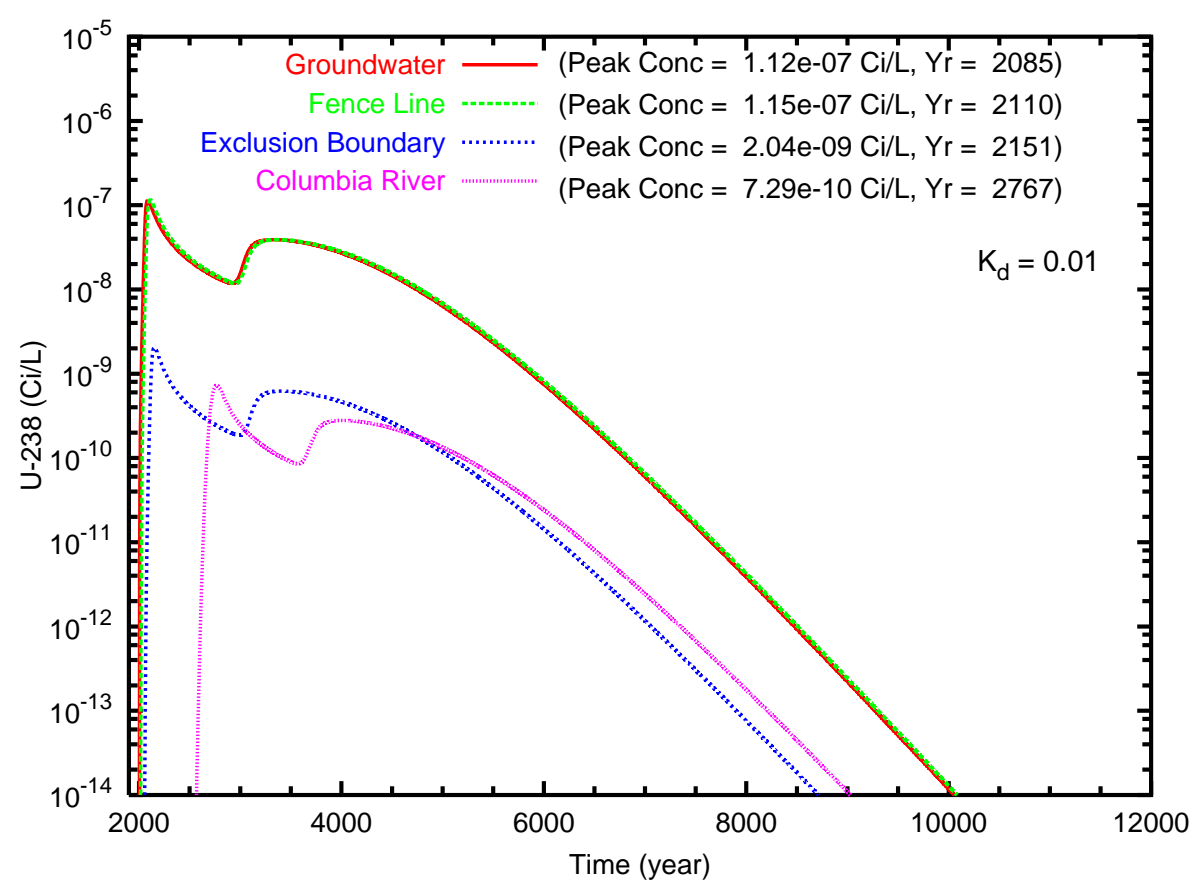

Figure B.36. Case 2, U-238 $\left(\mathrm{K}_{d}=0.01\right)$ concentration versus time for the fence line exclusion boundary and Columbia River compliance points for travel paths (a) southeast and (b) north through the gap 
(a)

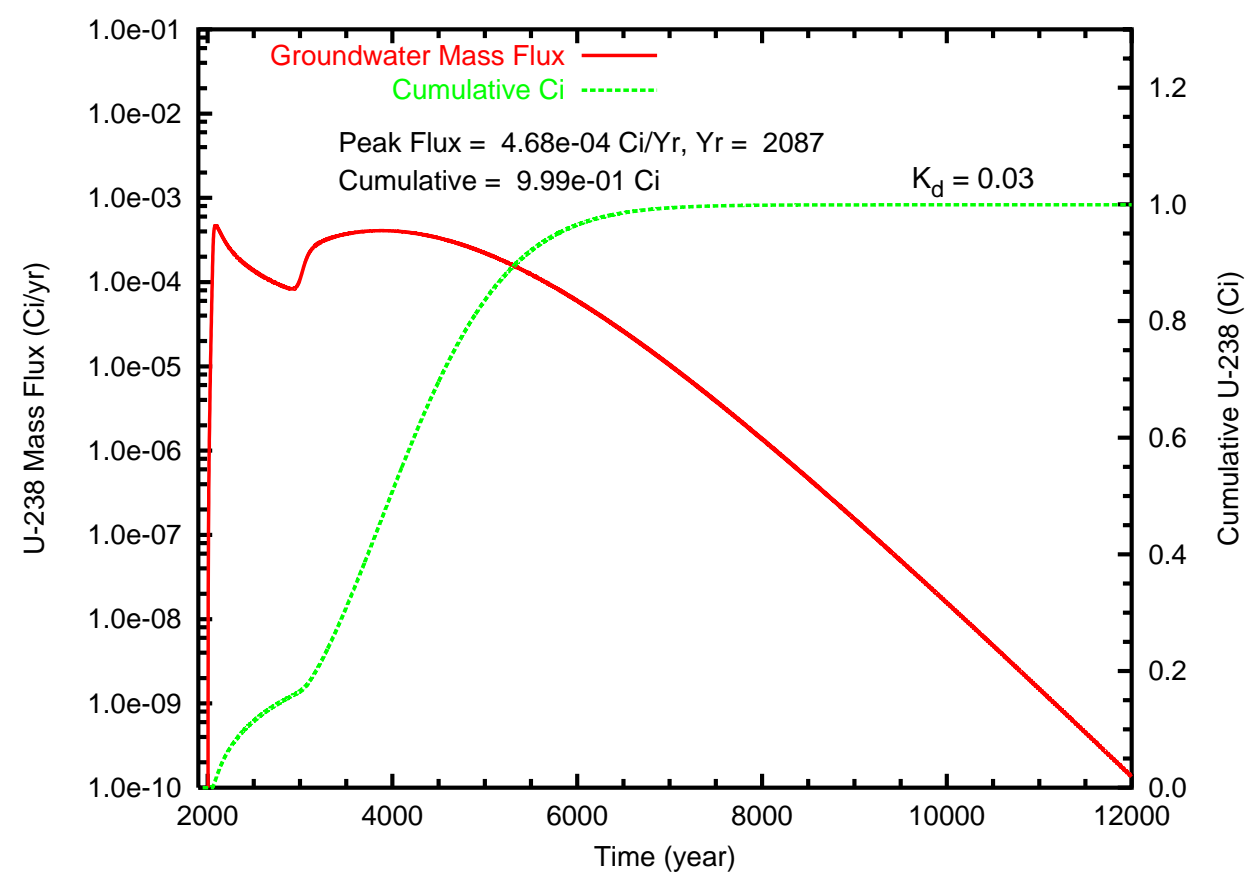

(b)

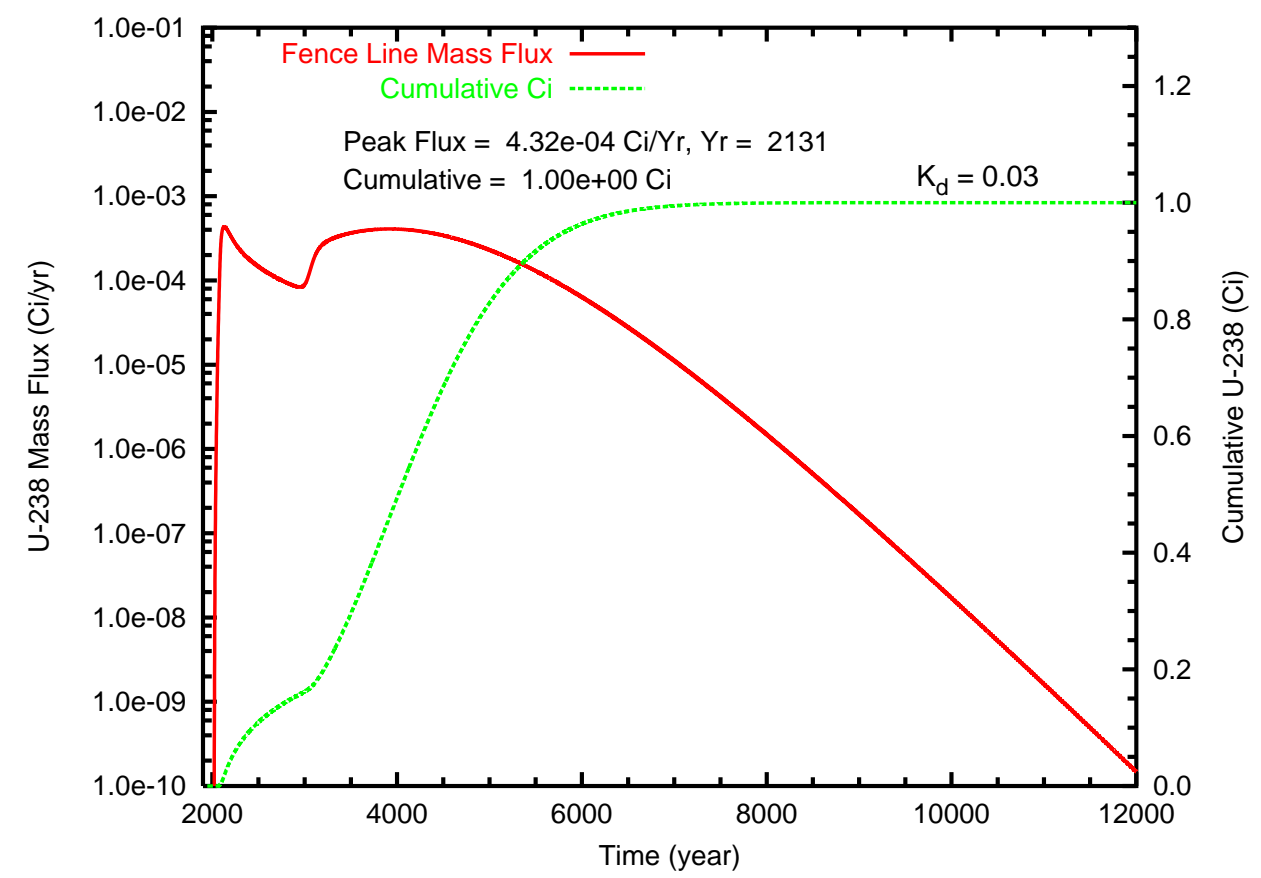

Figure B.37. Case 2, U-238 $\left(\mathrm{K}_{d}=0.03\right)$ mass flux $(\mathrm{Ci} / \mathrm{L})$ and cumulative mass $(\mathrm{Ci})$ at (a) the groundwater table and (b) the fence line 
(a)

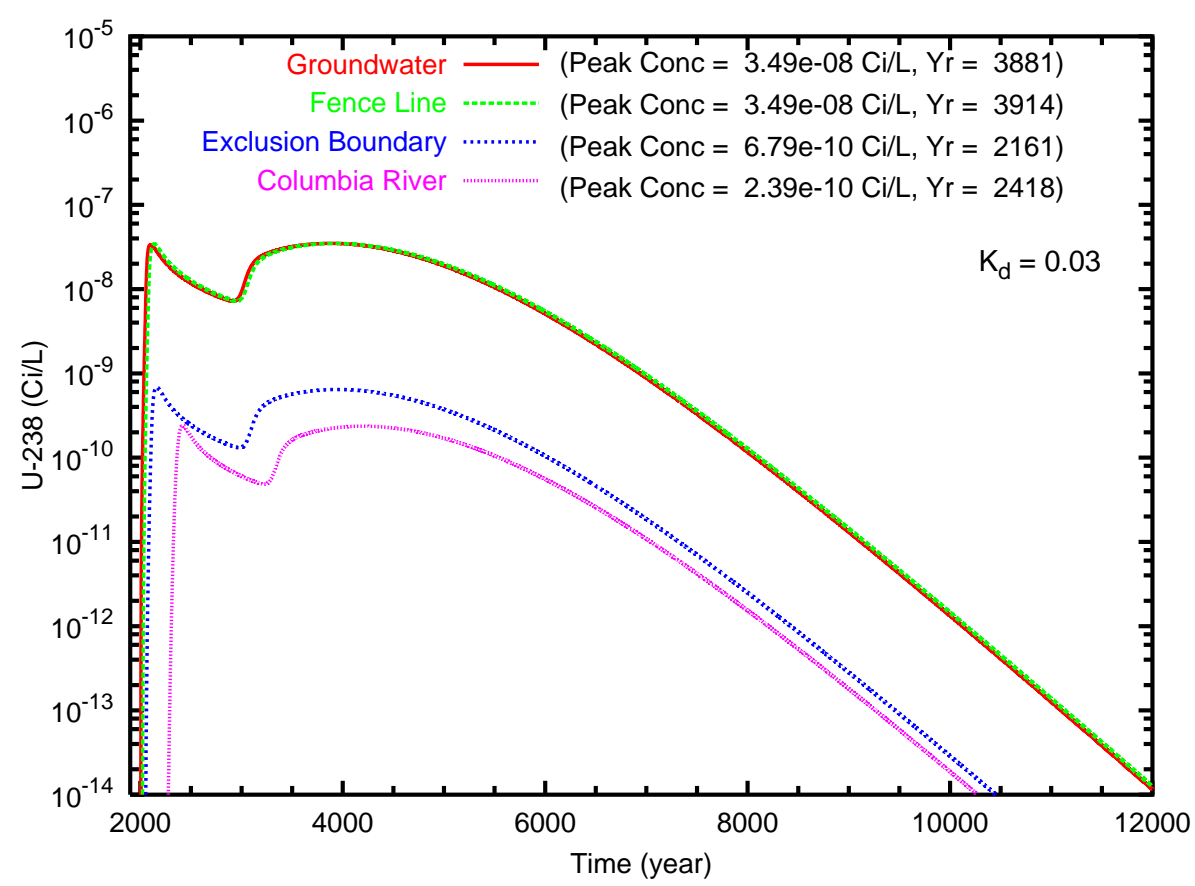

(b)

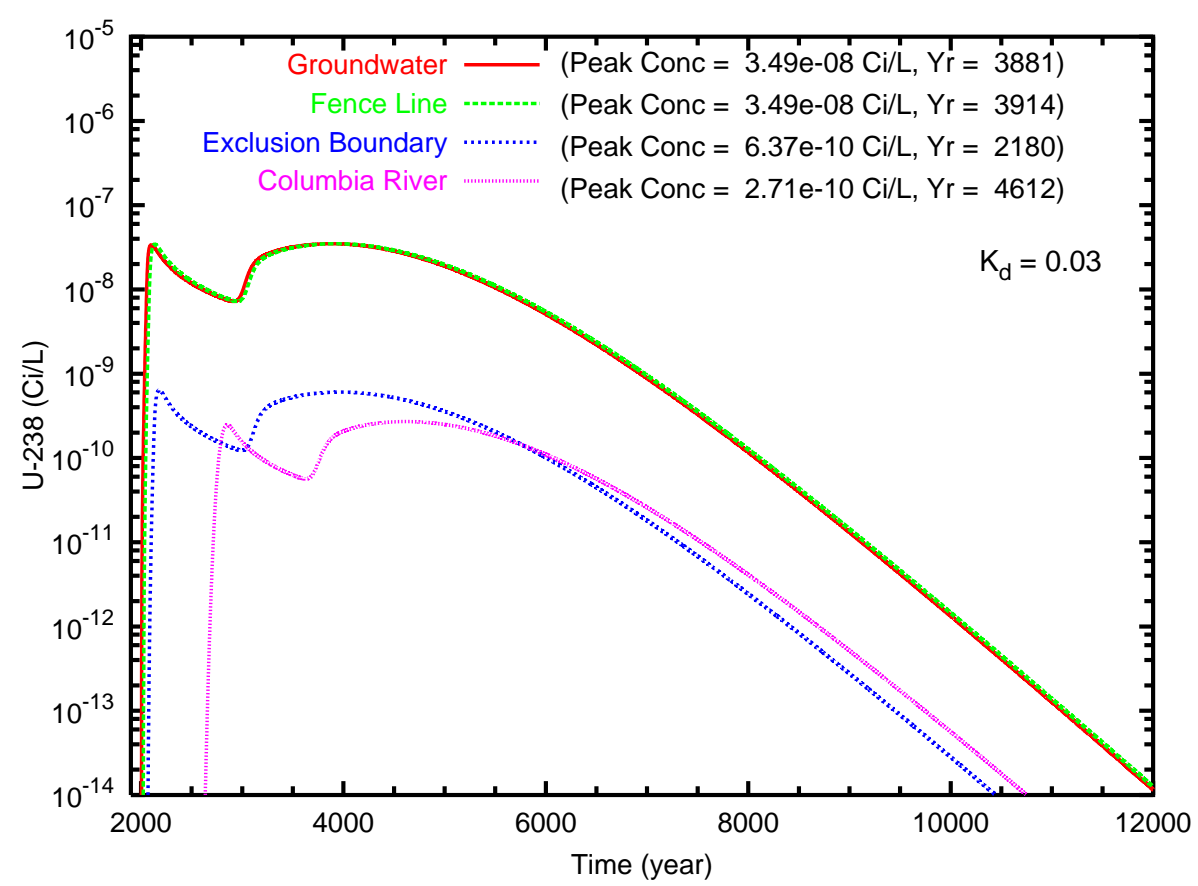

Figure B.38. Case 2, U-238 $\left(\mathrm{K}_{d}=0.03\right)$ concentration versus time for the fence line exclusion boundary and Columbia River compliance points for travel paths (a) southeast and (b) north through the gap 
(a)

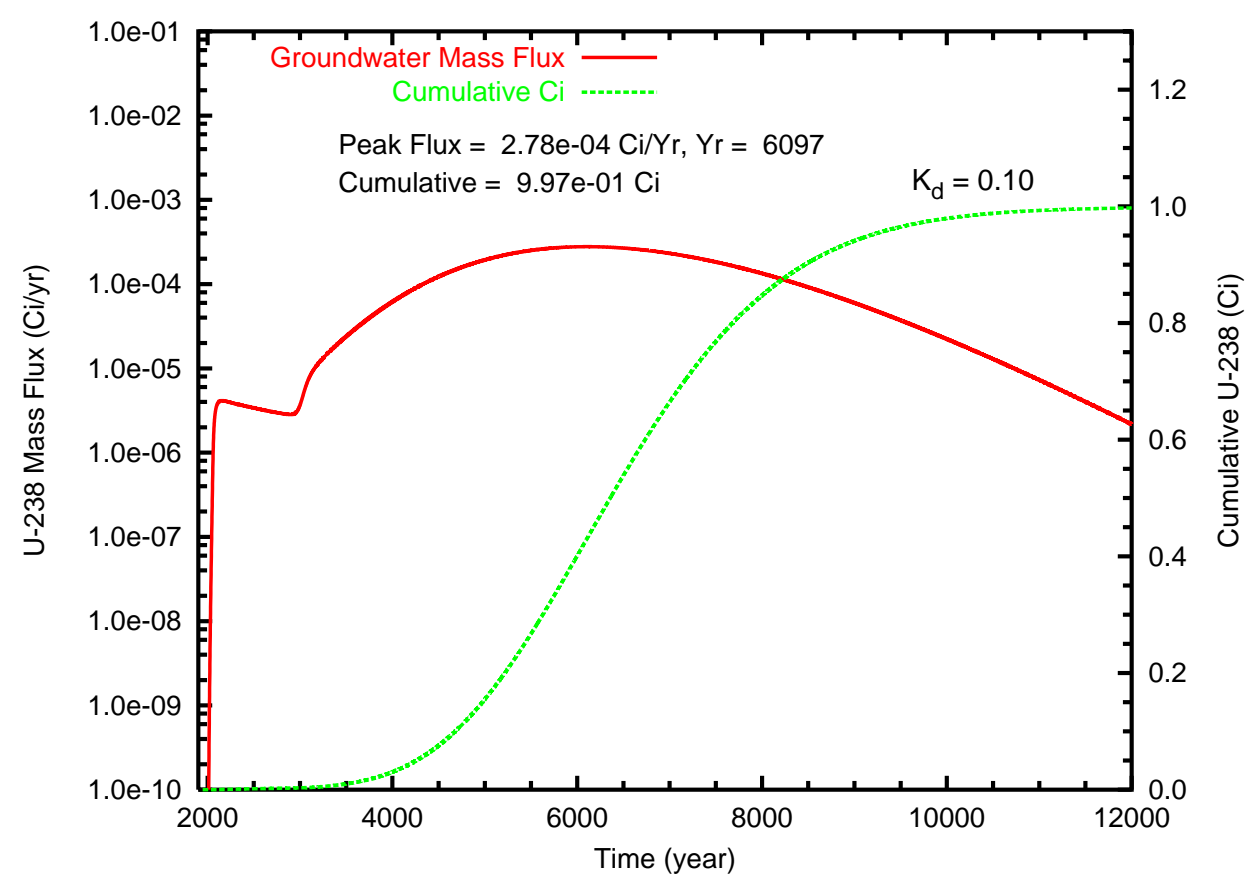

(b)

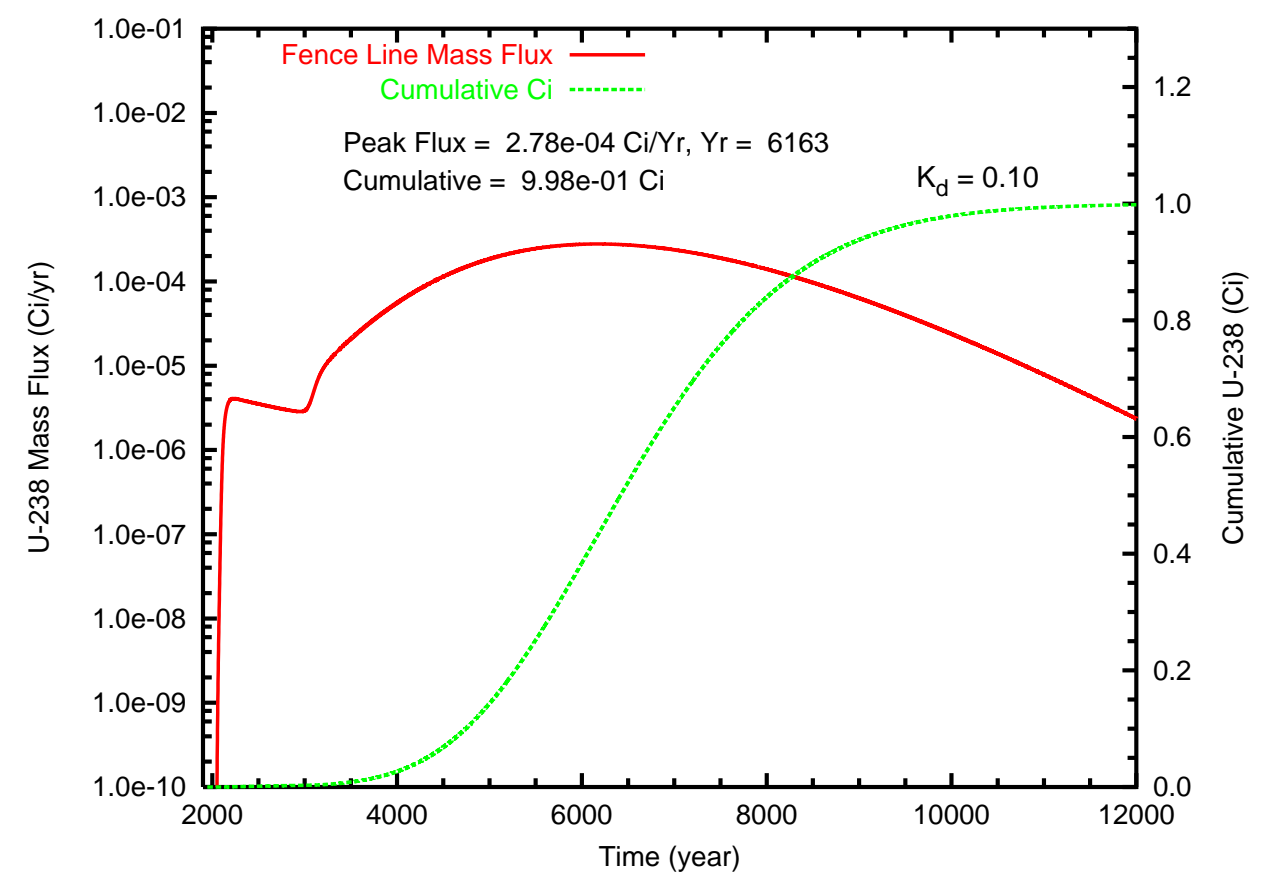

Figure B.39. Case 2, U-238 $\left(\mathrm{K}_{d}=0.10\right)$ mass flux $(\mathrm{Ci} / \mathrm{L})$ and cumulative mass $(\mathrm{Ci})$ at (a) the groundwater table and (b) the fence line 
(a)

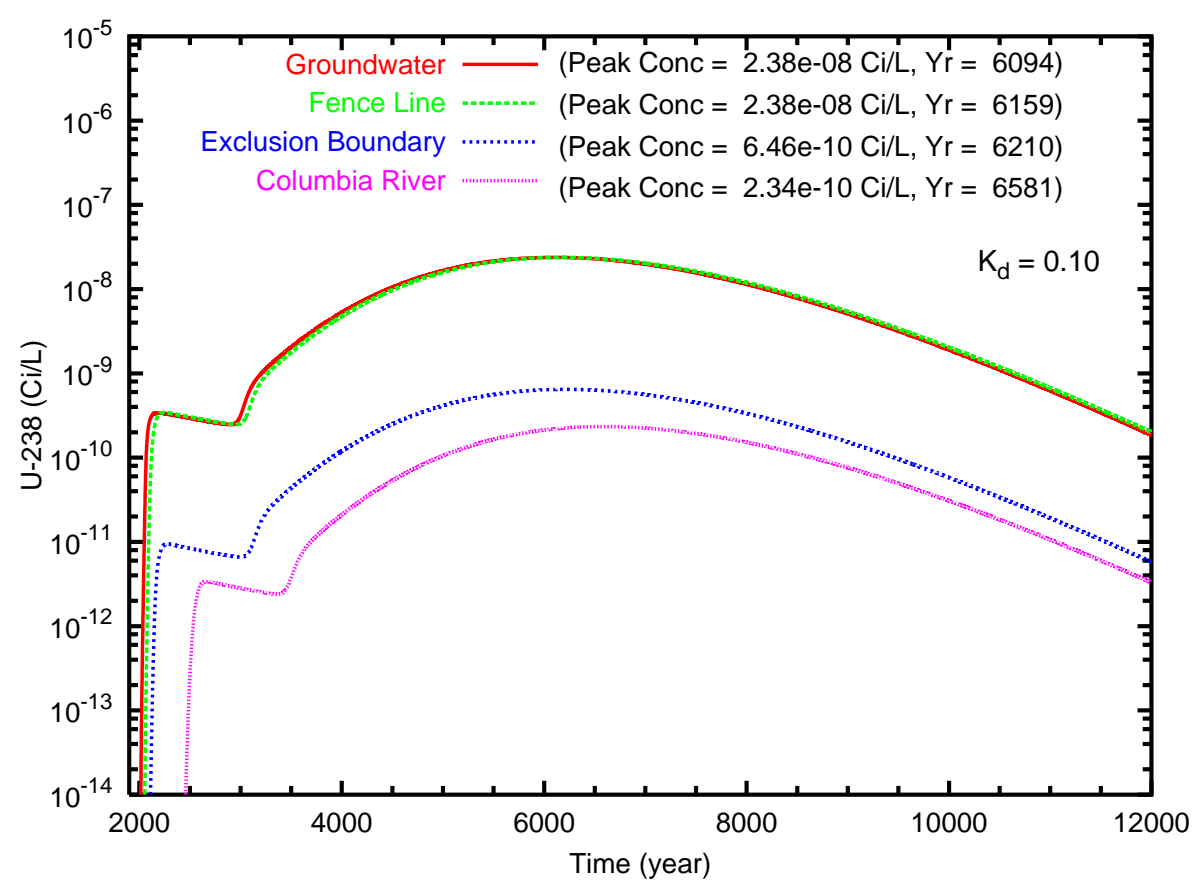

(b)

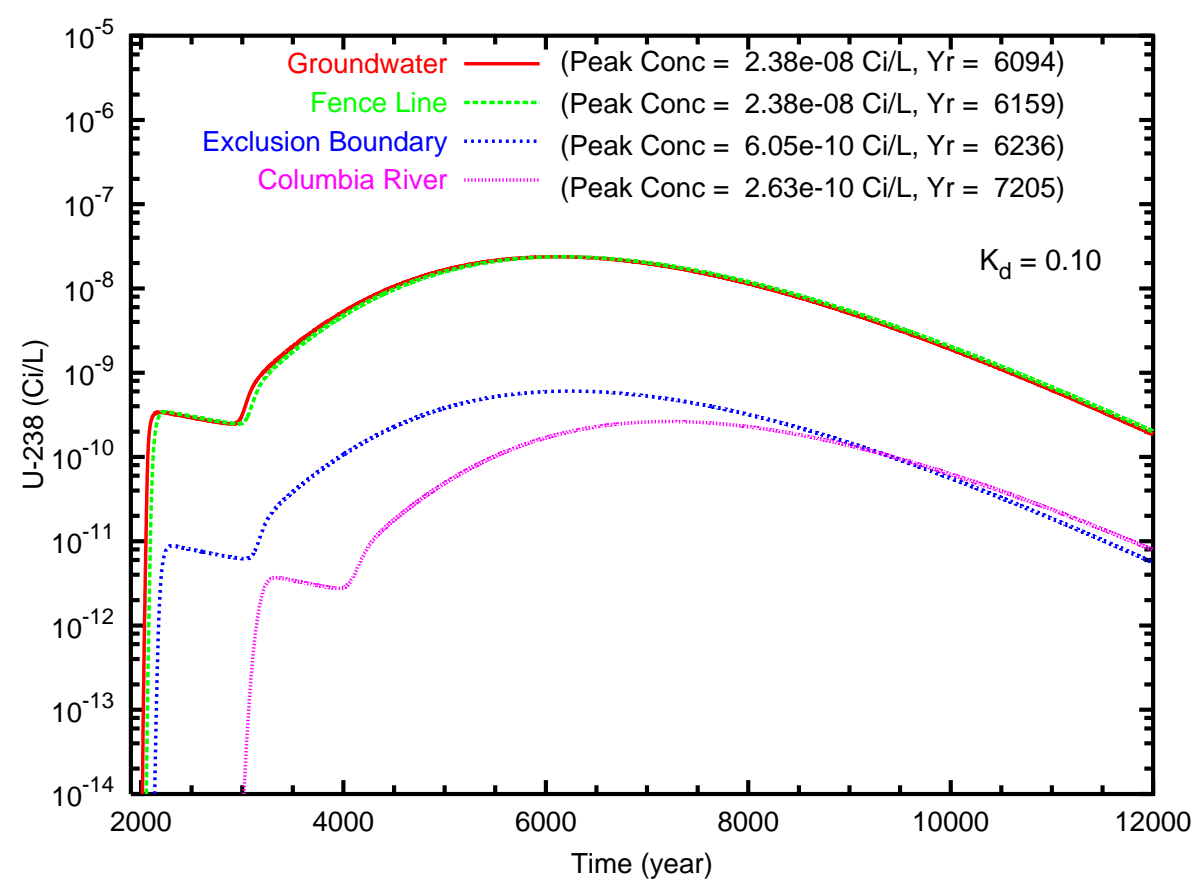

Figure B.40. Case 2, U-238 $\left(\mathrm{K}_{d}=0.10\right)$ concentration versus time for the fence line exclusion boundary and Columbia River compliance points for travel paths (a) southeast and (b) north through the gap 
(a)

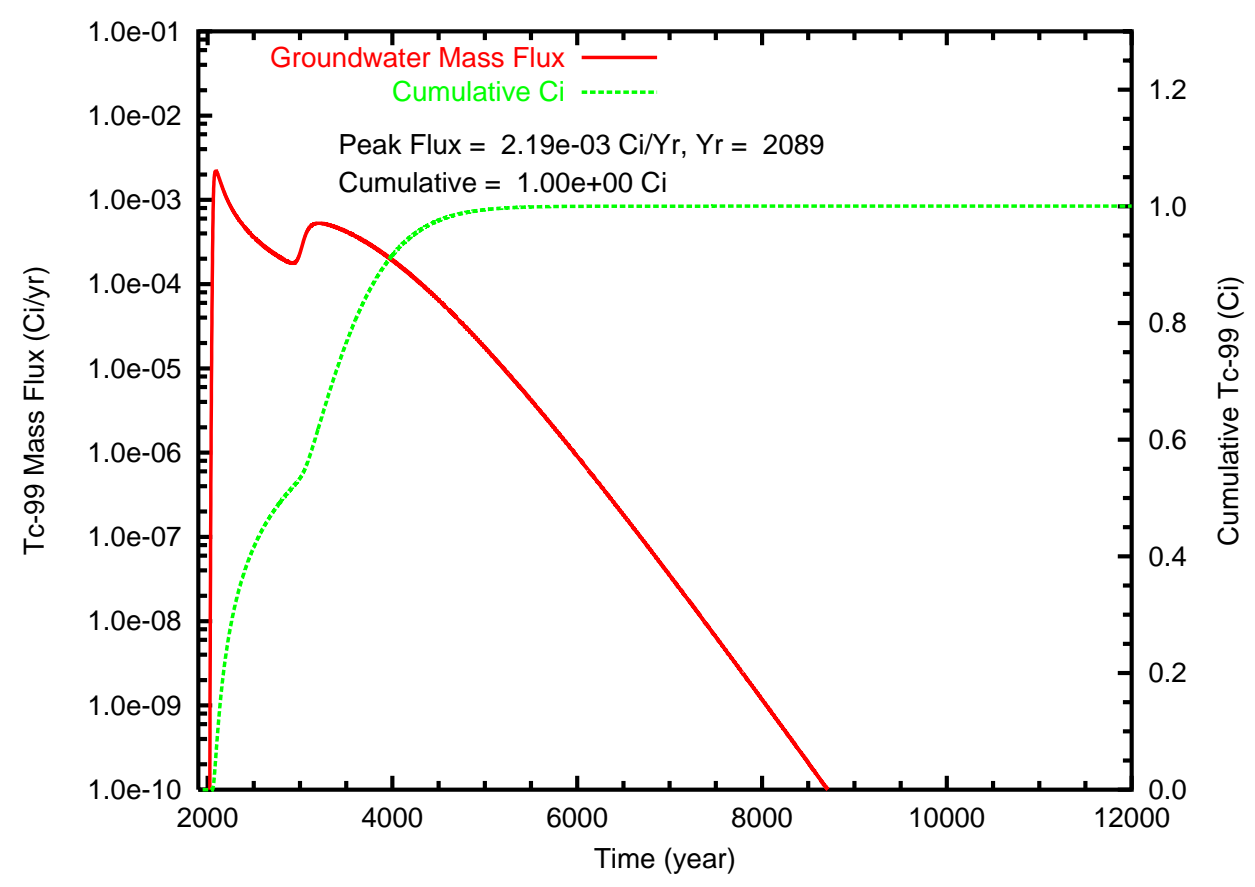

(b)

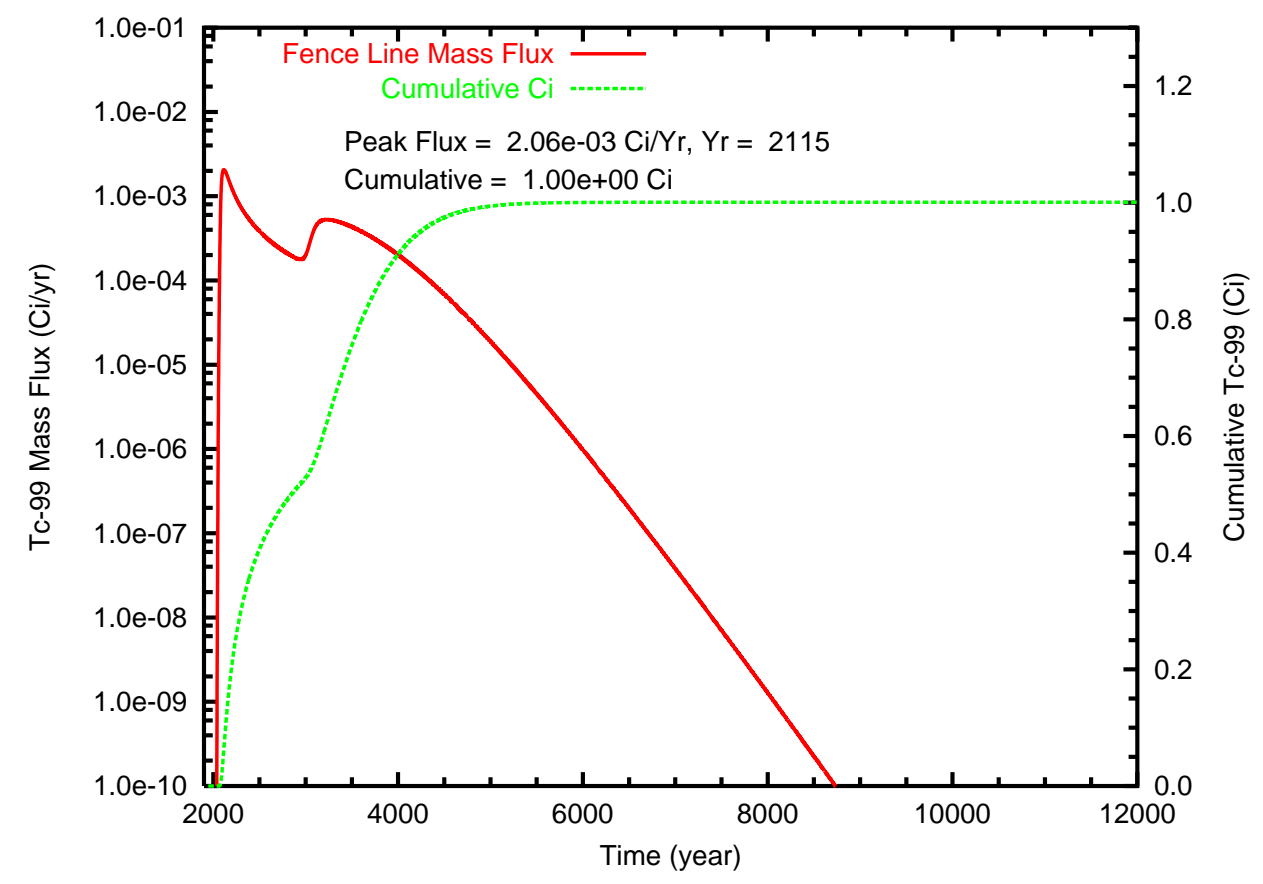

Figure B.41. Case 3, Tc-99 mass flux and cumulative mass at (a) the groundwater table and (b) the fence line 
(a)

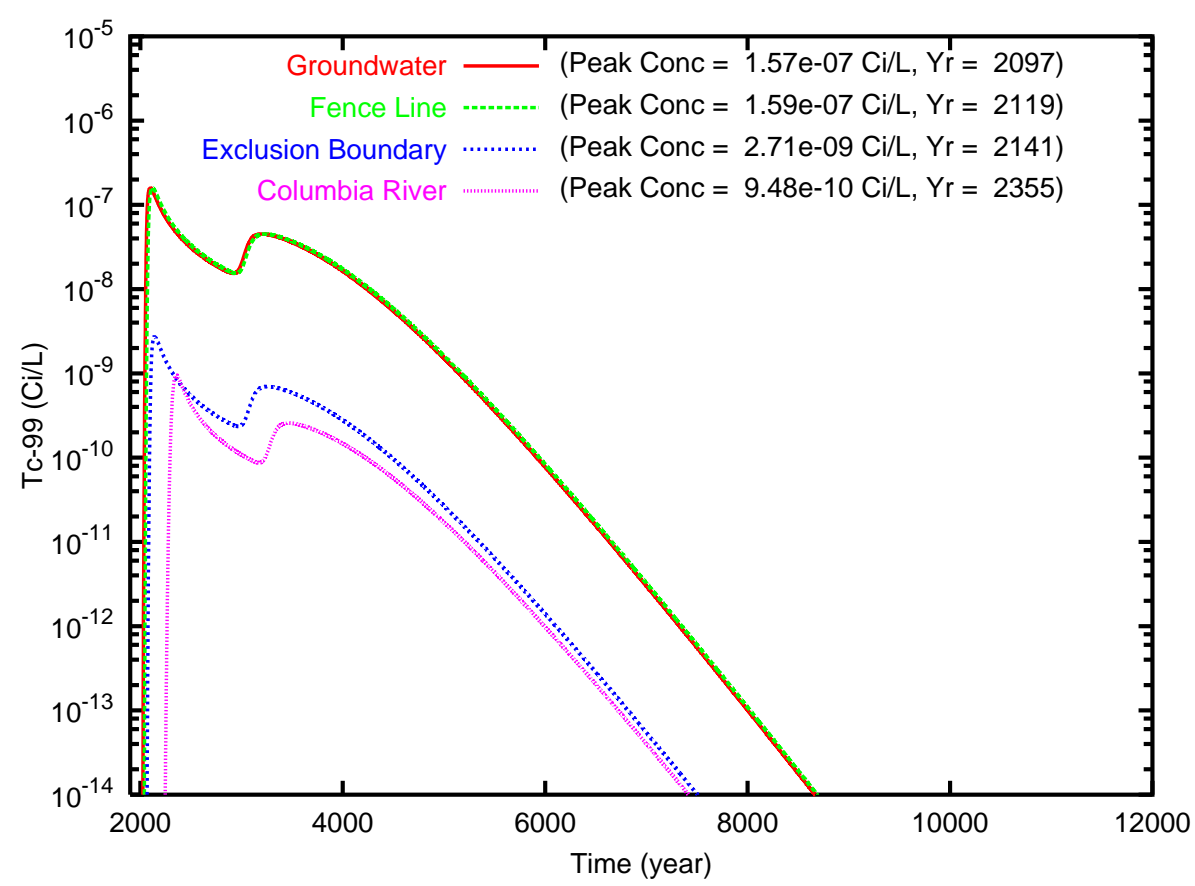

(b)

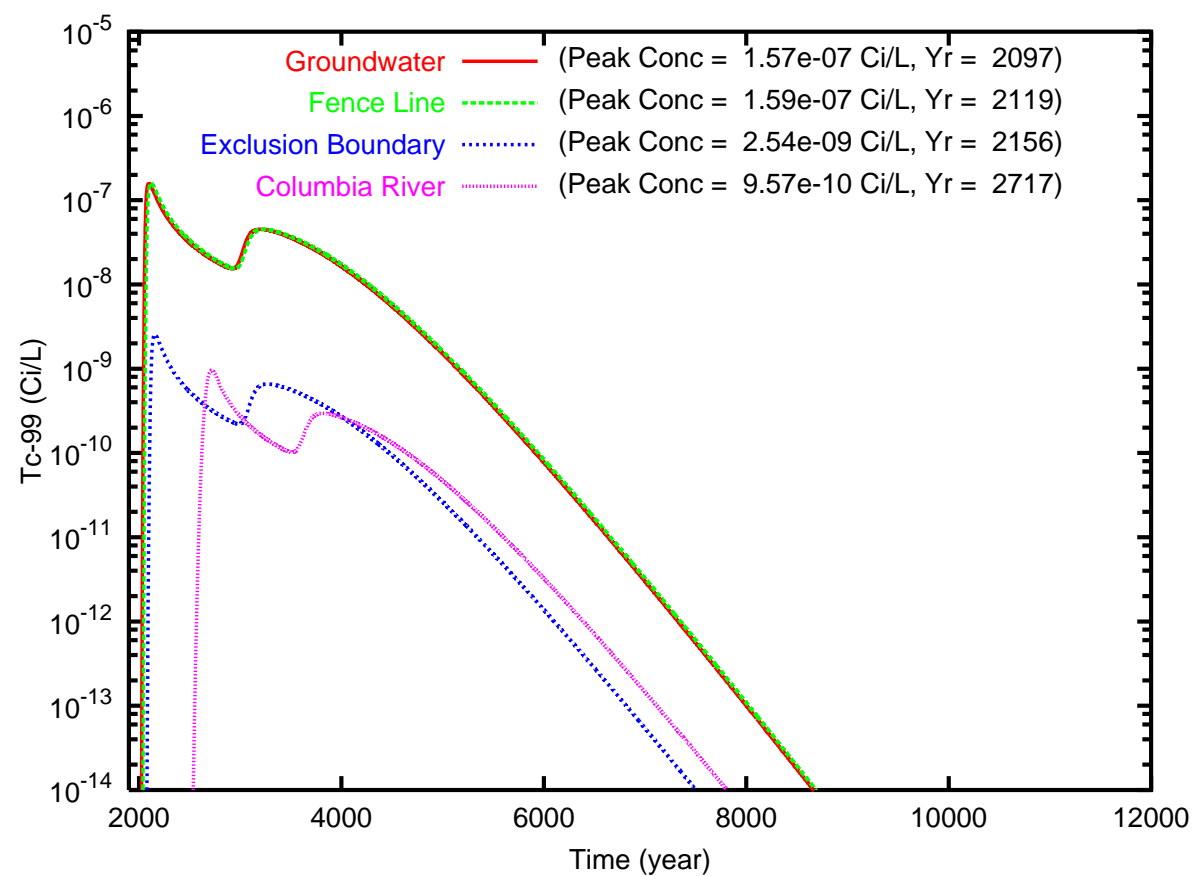

Figure B.42. Case 3, Tc-99 concentration versus time for the fence line, exclusion boundary and Columbia River compliance points for travel paths (a) southeast and (b) north through the gap 
(a)

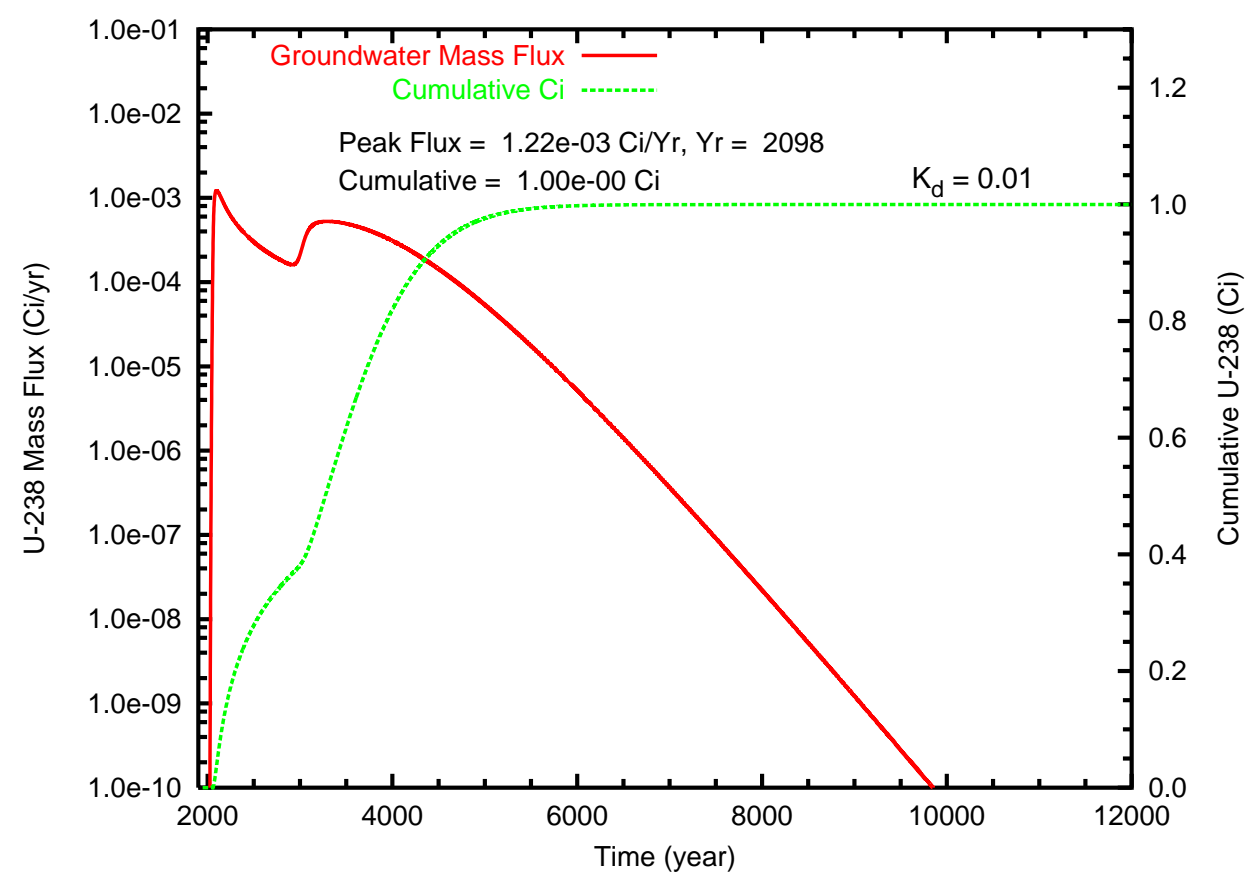

(b)

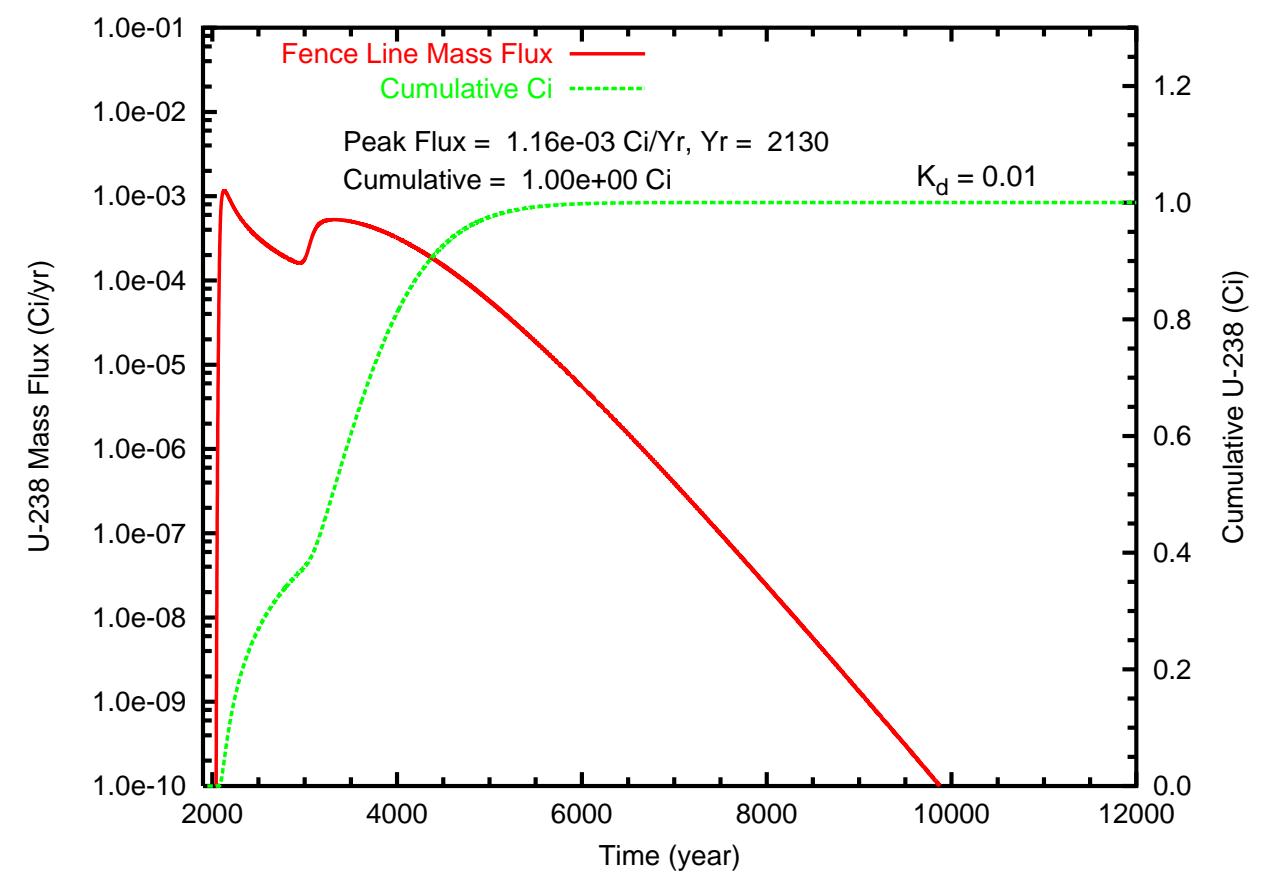

Figure B.43. Case 3, U-238 $\left(\mathrm{K}_{d}=0.01\right)$ mass flux $(\mathrm{Ci} / \mathrm{L})$ and cumulative mass $(\mathrm{Ci})$ at (a) the groundwater table and (b) the fence line 
(a)

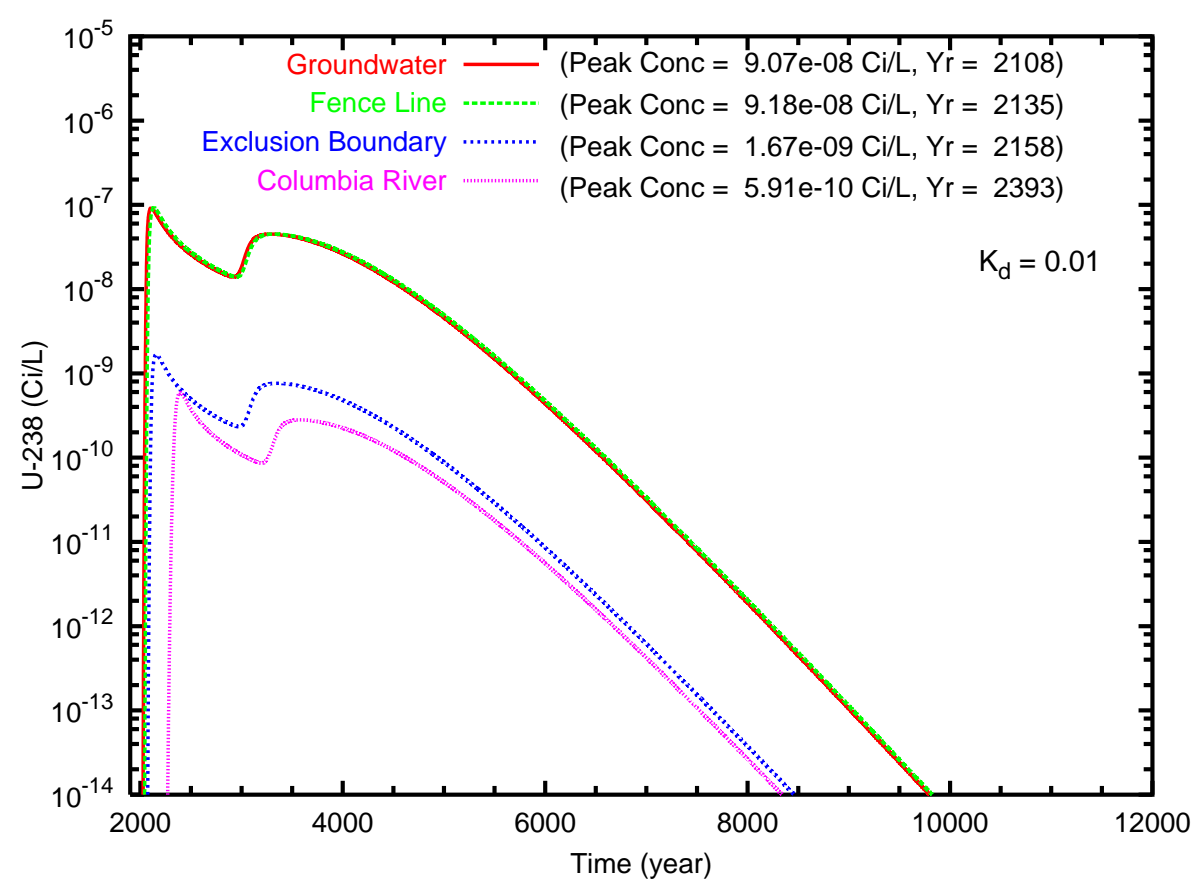

(b)

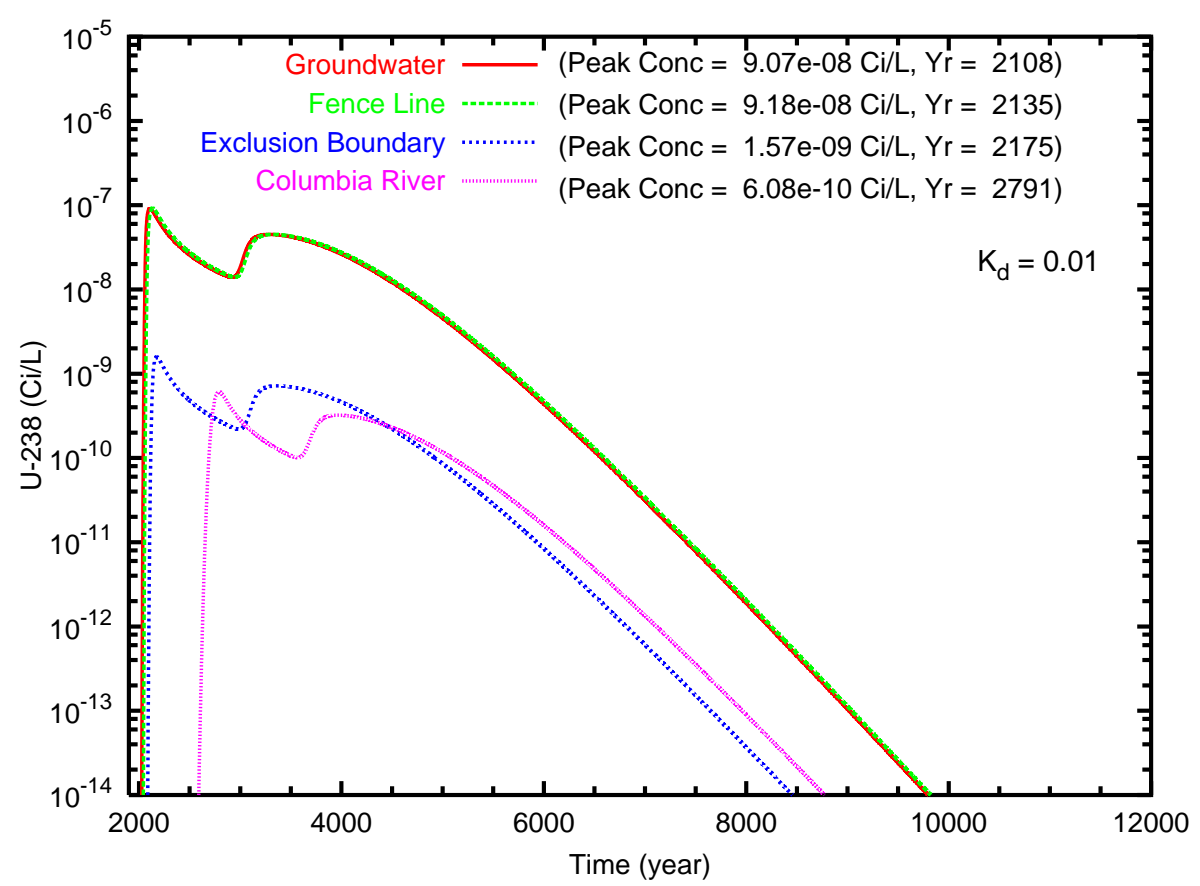

Figure B.44. Case 3, U-238 $\left(\mathrm{K}_{d}=0.01\right)$ concentration versus time for the fence line exclusion boundary and Columbia River compliance points for travel paths (a) southeast and (b) north through the gap 
(a)

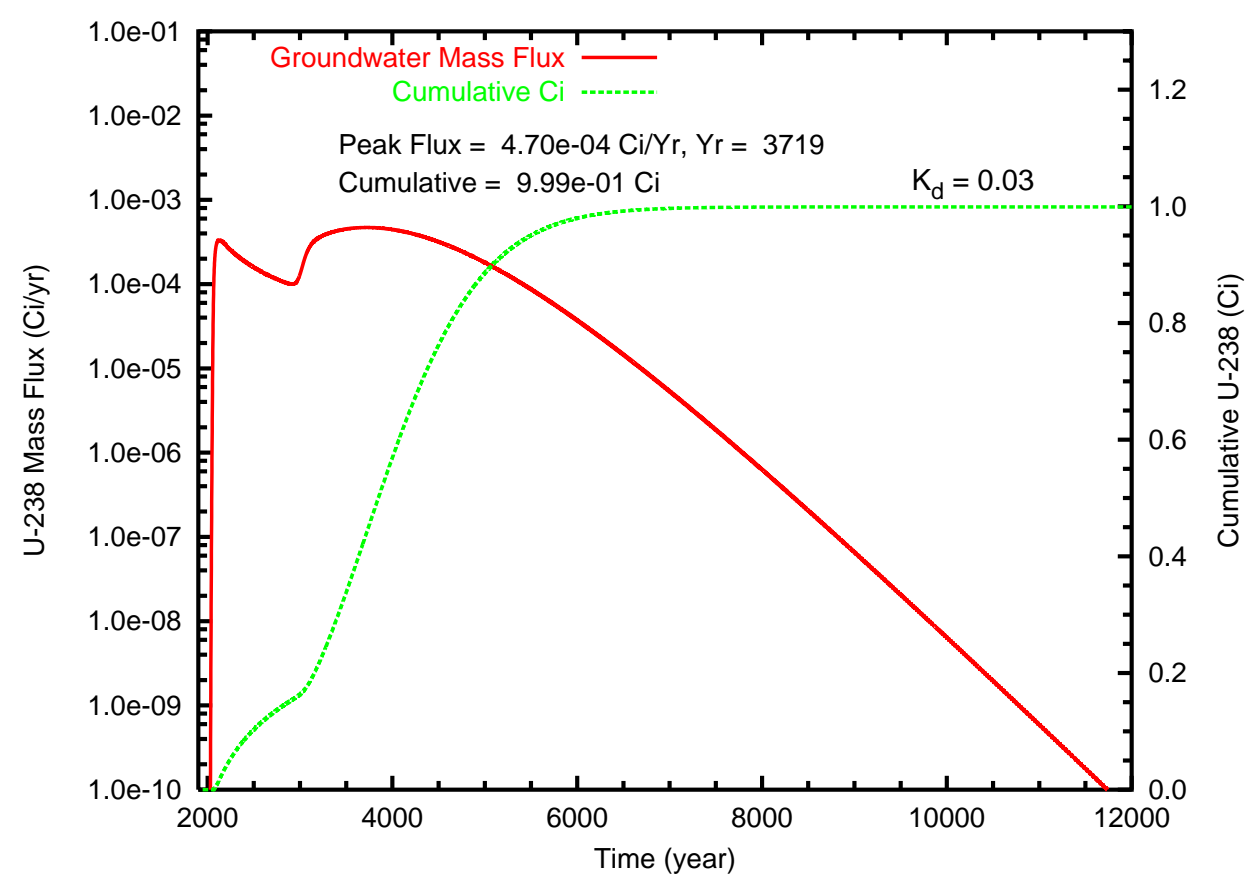

(b)

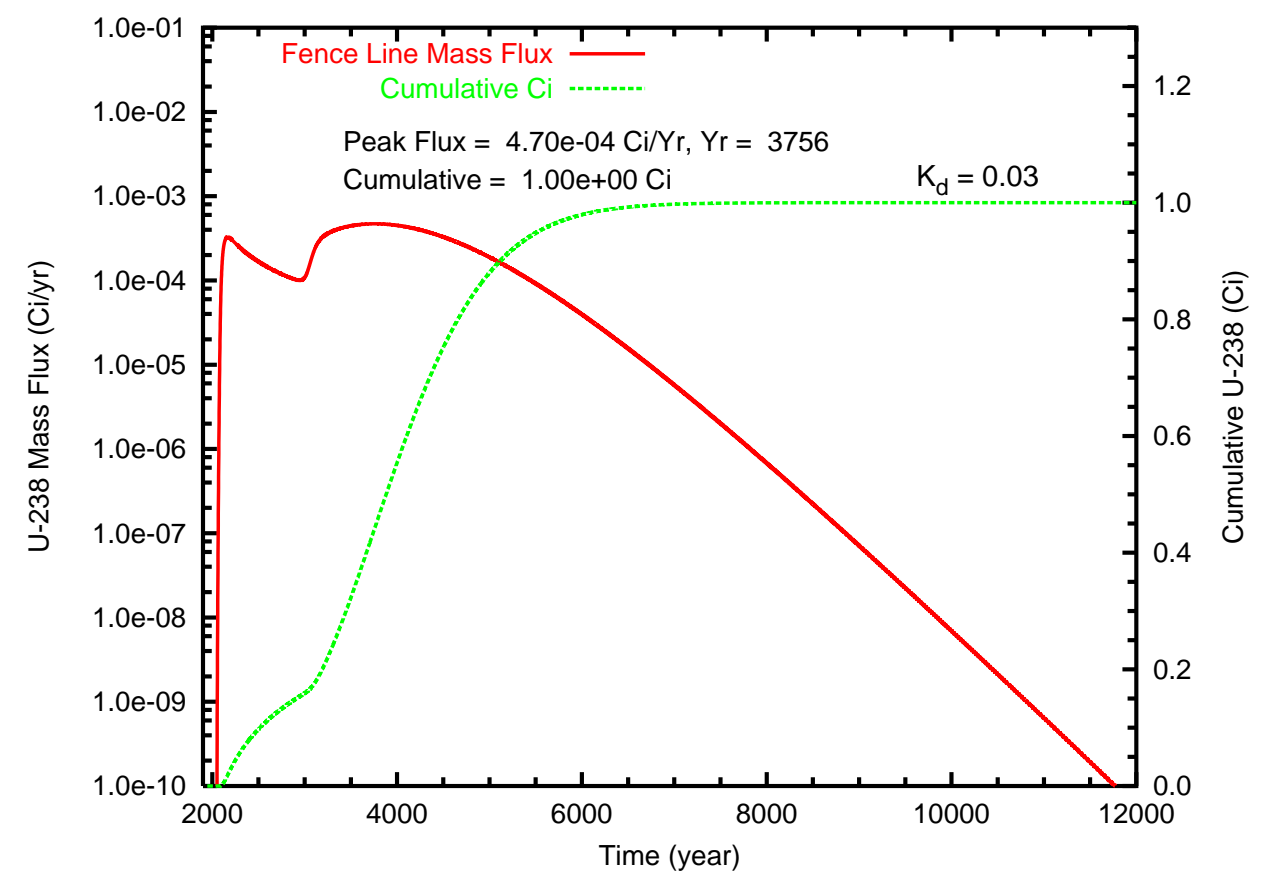

Figure B.45. Case 3, U-238 $\left(\mathrm{K}_{d}=0.03\right)$ mass flux $(\mathrm{Ci} / \mathrm{L})$ and cumulative mass $(\mathrm{Ci})$ at (a) the groundwater table and (b) the fence line 
(a)

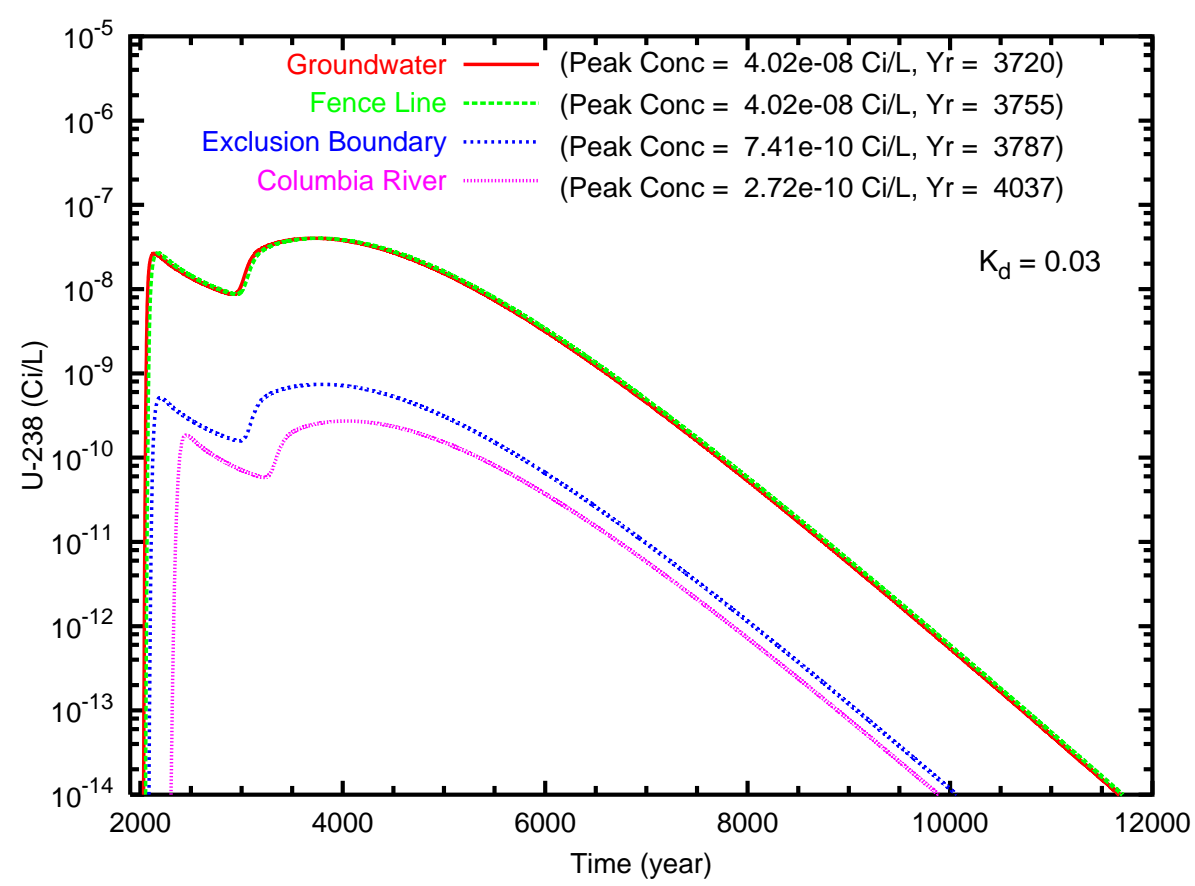

(b)

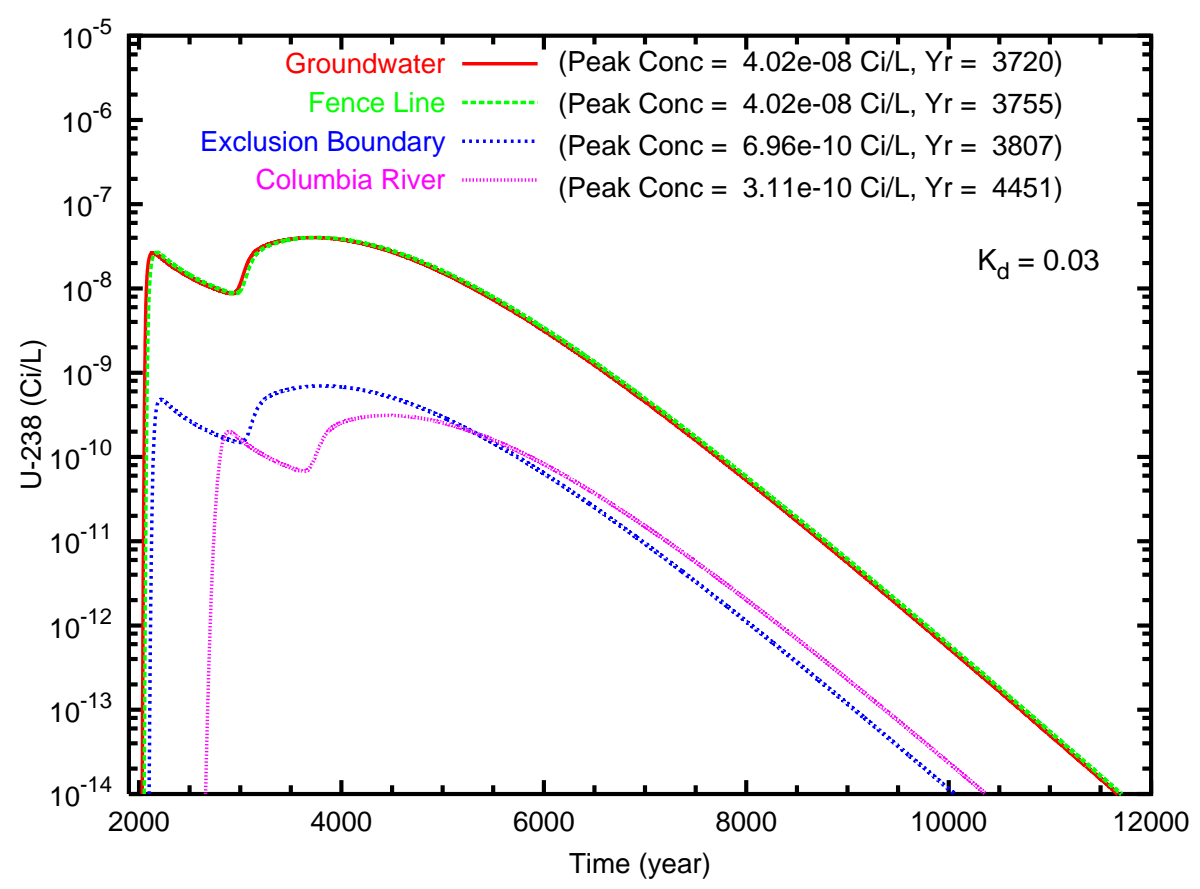

Figure B.46. Case 3, U-238 $\left(\mathrm{K}_{d}=0.03\right)$ concentration versus time for the fence line exclusion boundary and Columbia River compliance points for travel paths (a) southeast and (b) north through the gap 
(a)

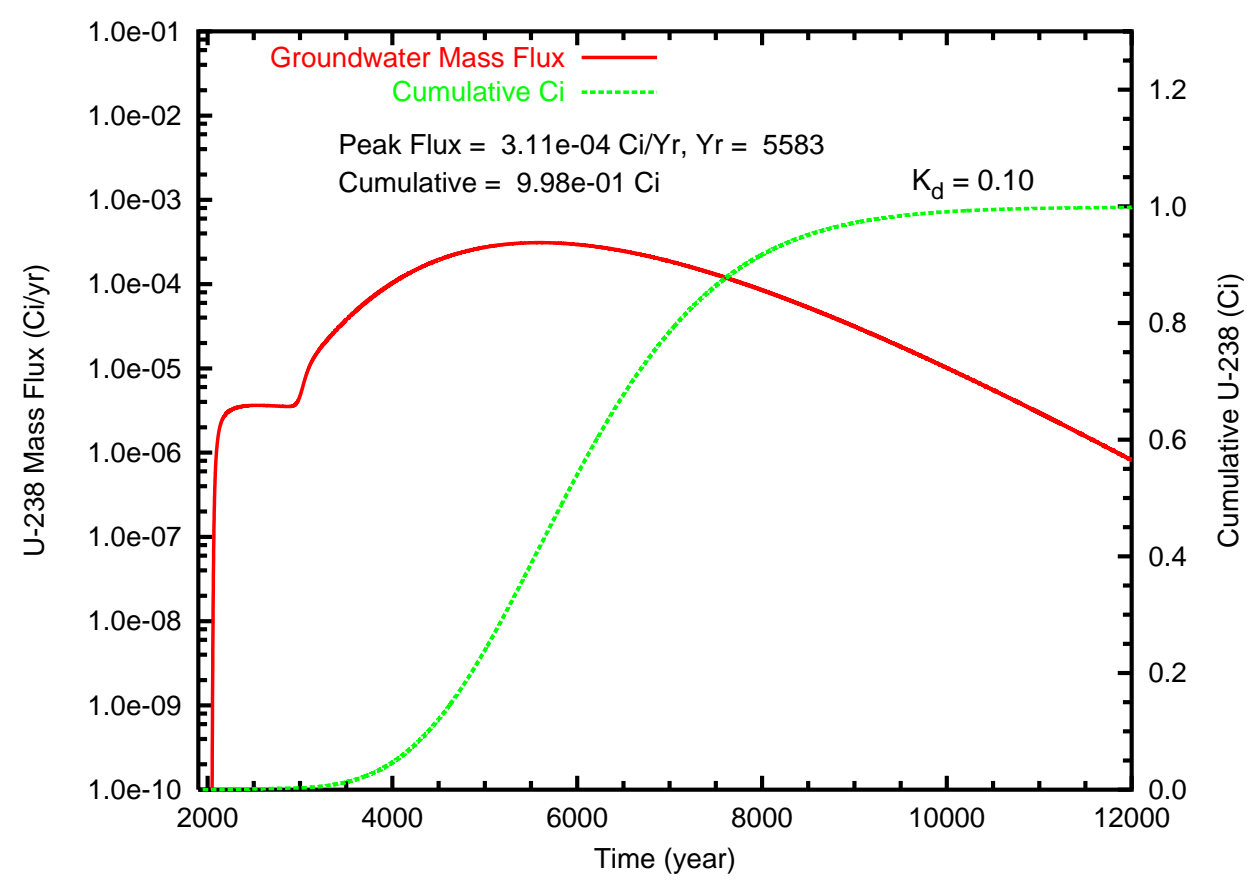

(b)

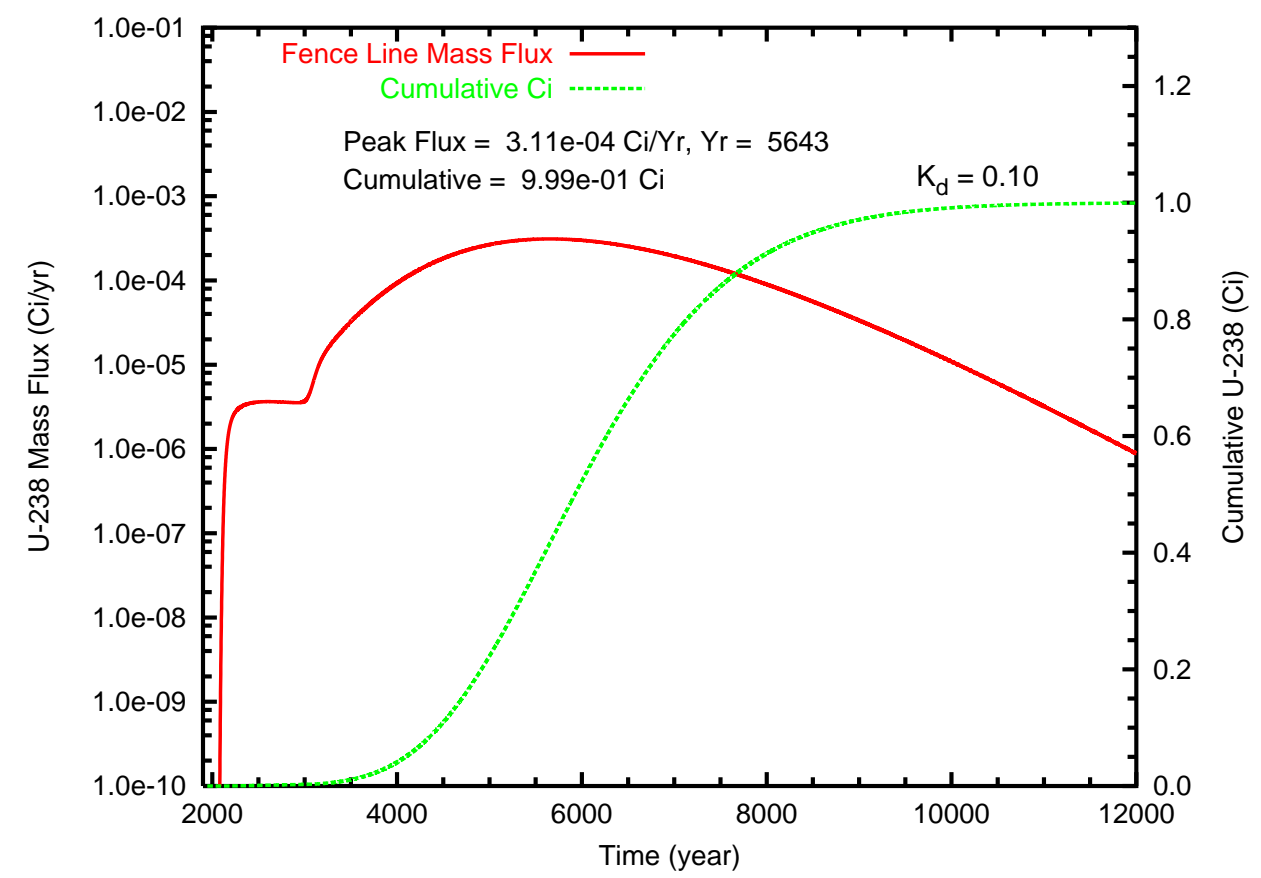

Figure B.47. Case 3, U-238 $\left(\mathrm{K}_{d}=0.10\right)$ mass flux $(\mathrm{Ci} / \mathrm{L})$ and cumulative mass $(\mathrm{Ci})$ at (a) the groundwater table and (b) the fence line 
(a)

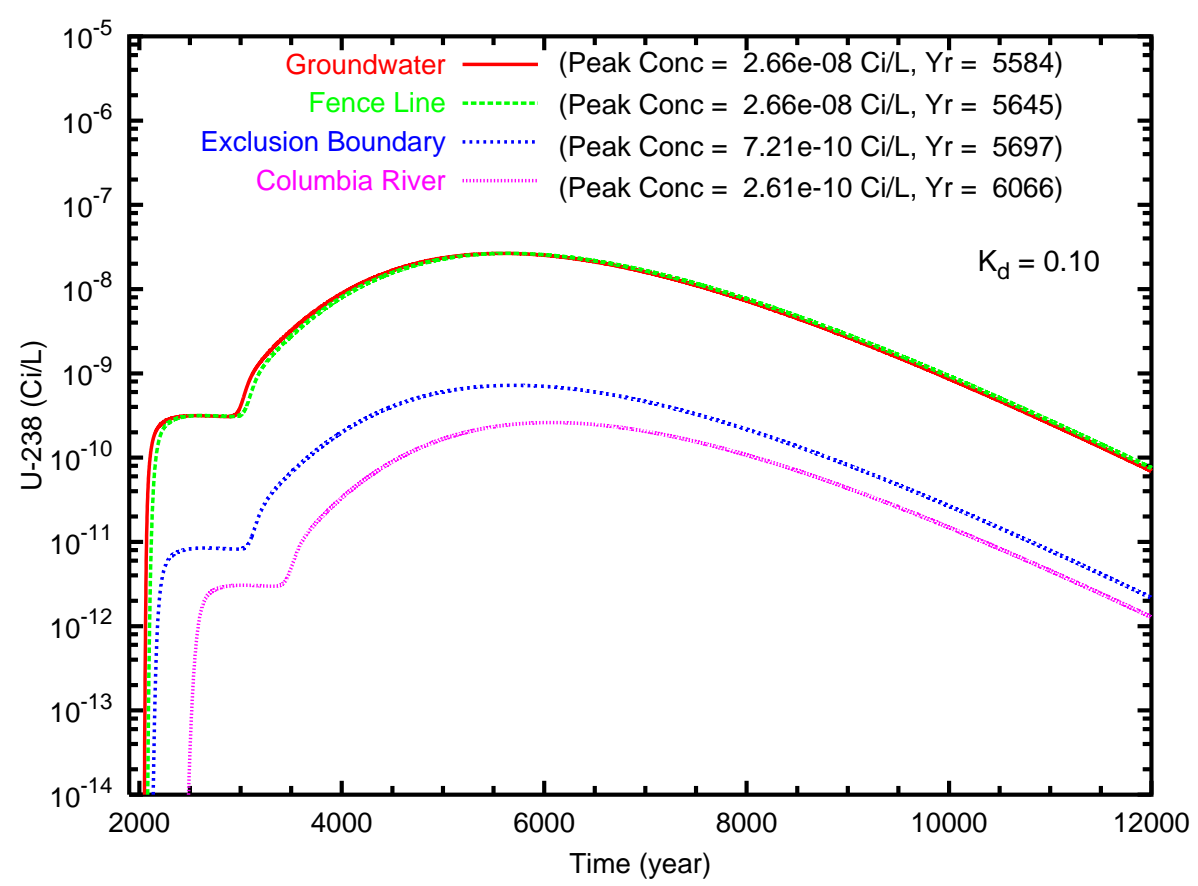

(b)

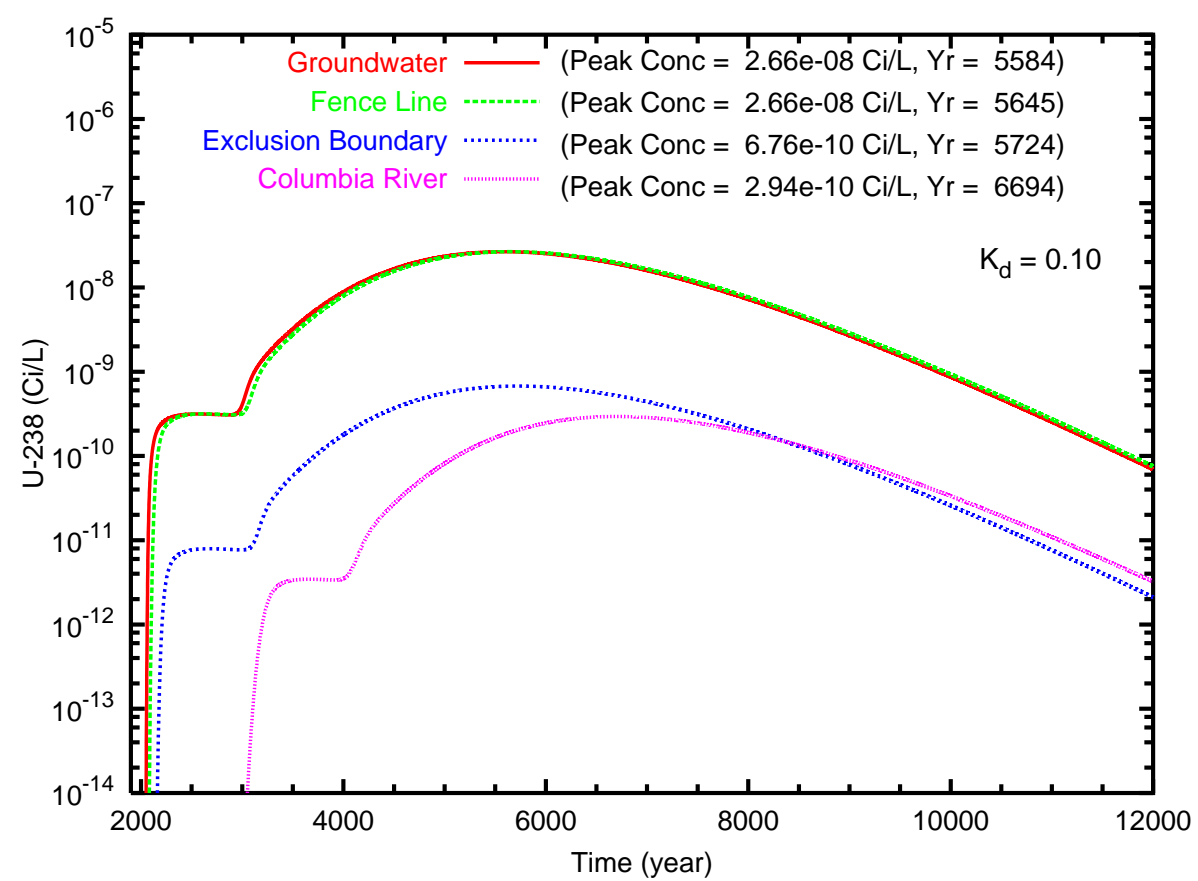

Figure B.48. Case 3, U-238 $\left(\mathrm{K}_{d}=0.10\right)$ concentration versus time for the fence line exclusion boundary and Columbia River compliance points for travel paths (a) southeast and (b) north through the gap 
(a)

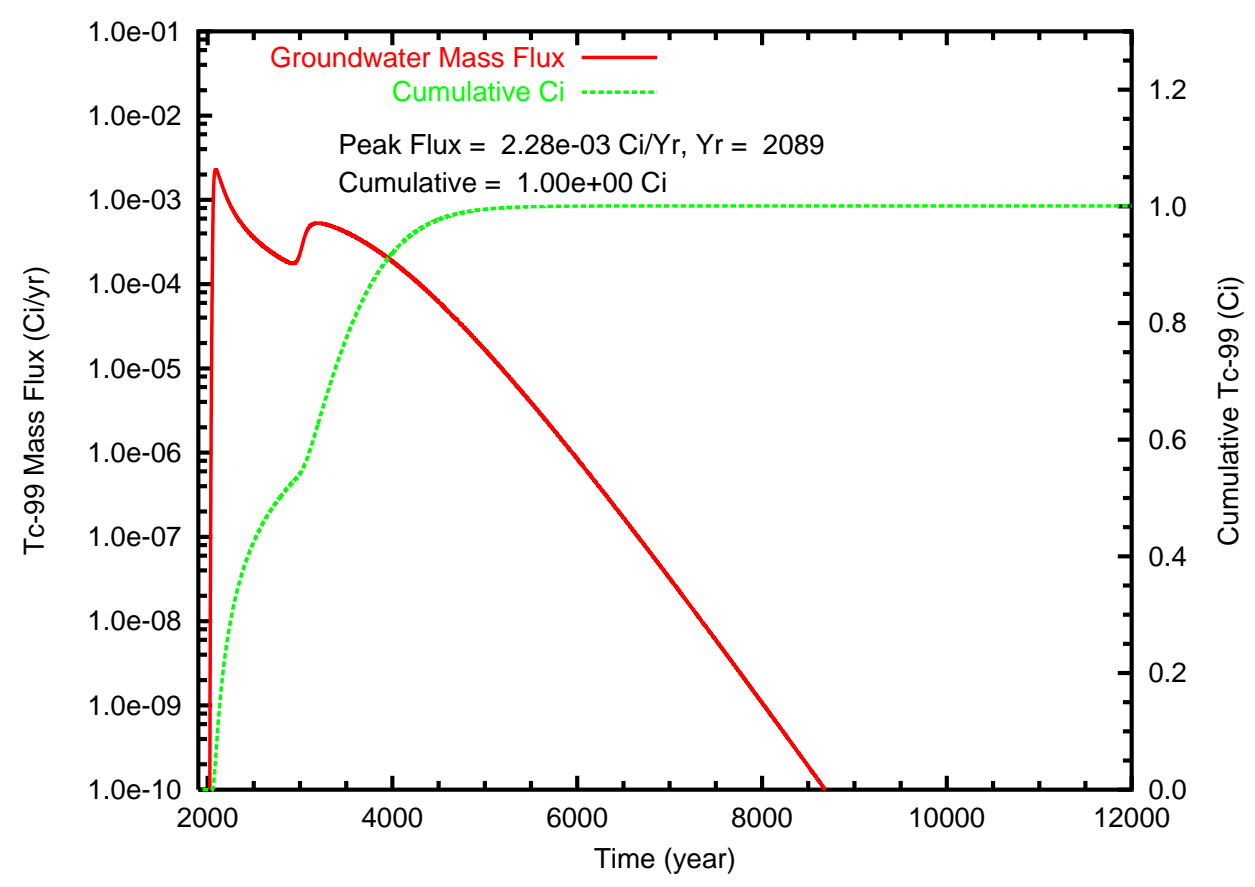

(b)

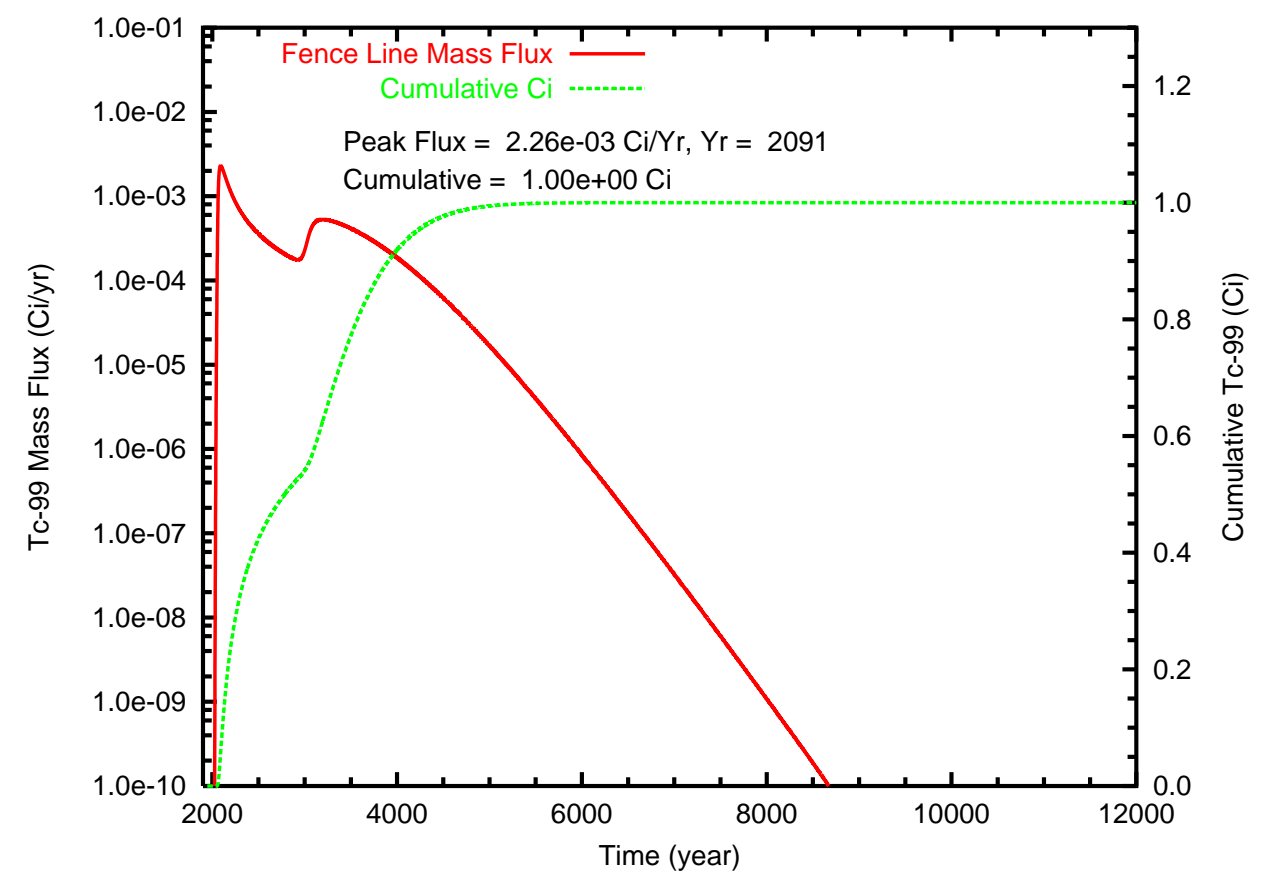

Figure B.49. Case 3-HiK, Tc-99 mass flux and cumulative mass at (a) the groundwater table and (b) the fence line 
(a)

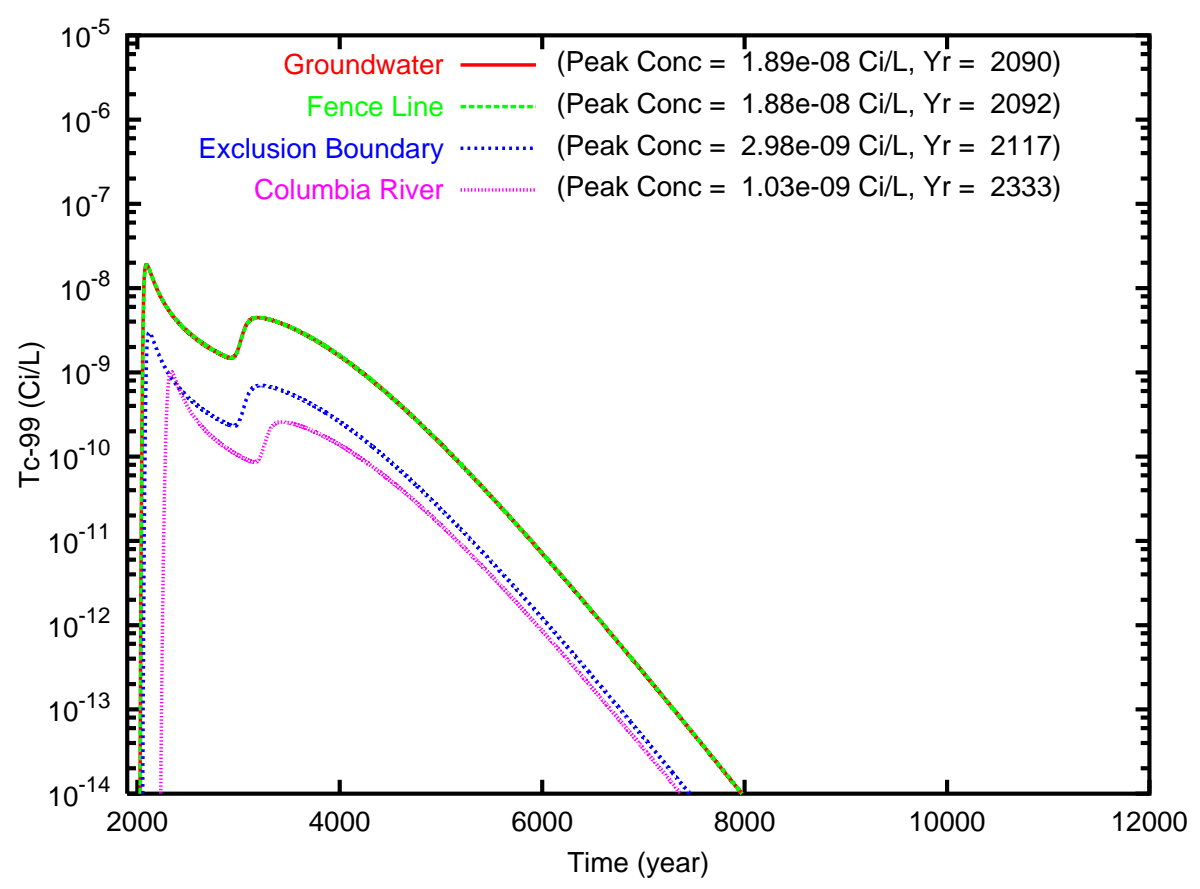

(b)

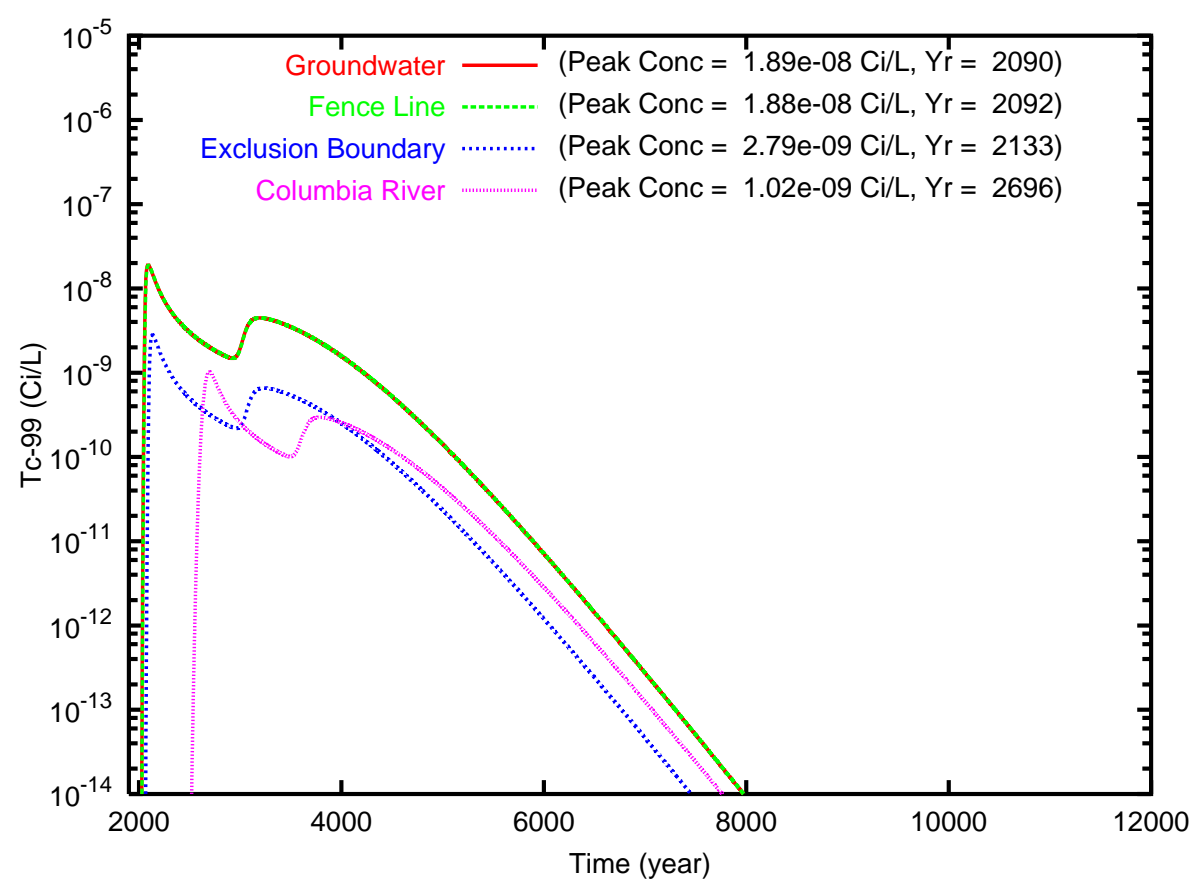

Figure B.50. Case 3-HiK, Tc-99 concentration versus time for the fence line, exclusion boundary and Columbia River compliance points for travel paths (a) southeast and (b) north through the gap 
(a)

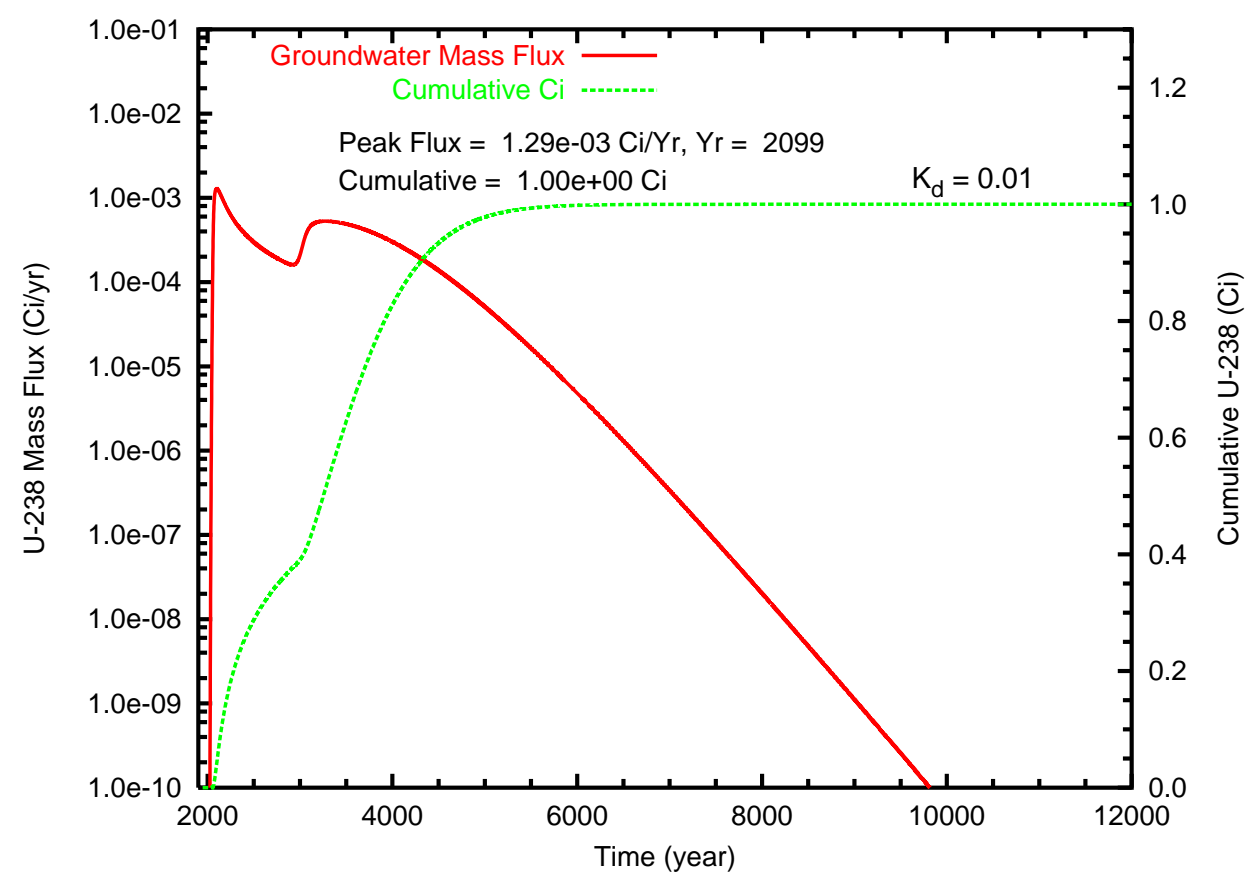

(b)

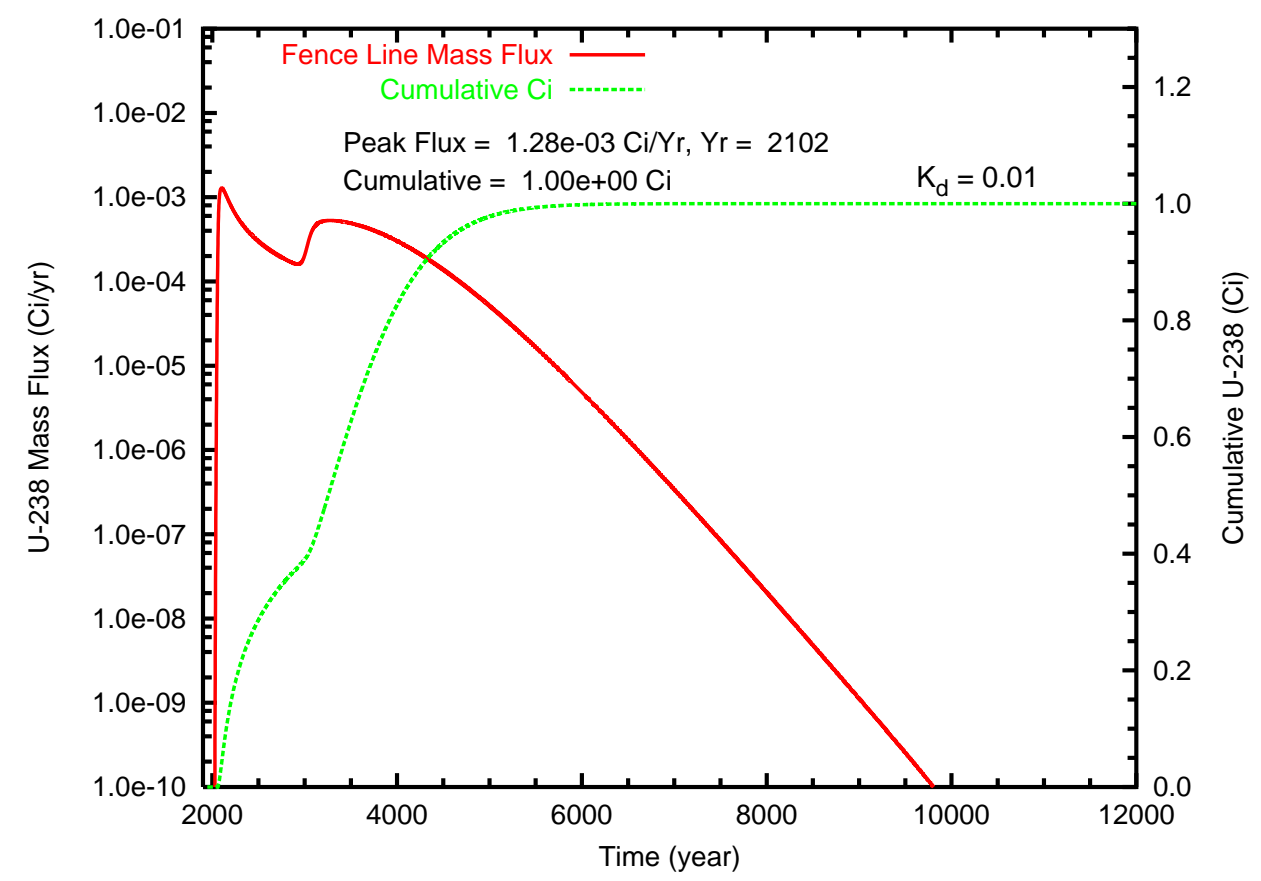

Figure B.51. Case 3-HiK, U-238 $\left(\mathrm{K}_{d}=0.01\right)$ mass flux $(\mathrm{Ci} / \mathrm{L})$ and cumulative mass $(\mathrm{Ci})$ at (a) the groundwater table and (b) the fence line 
(a)

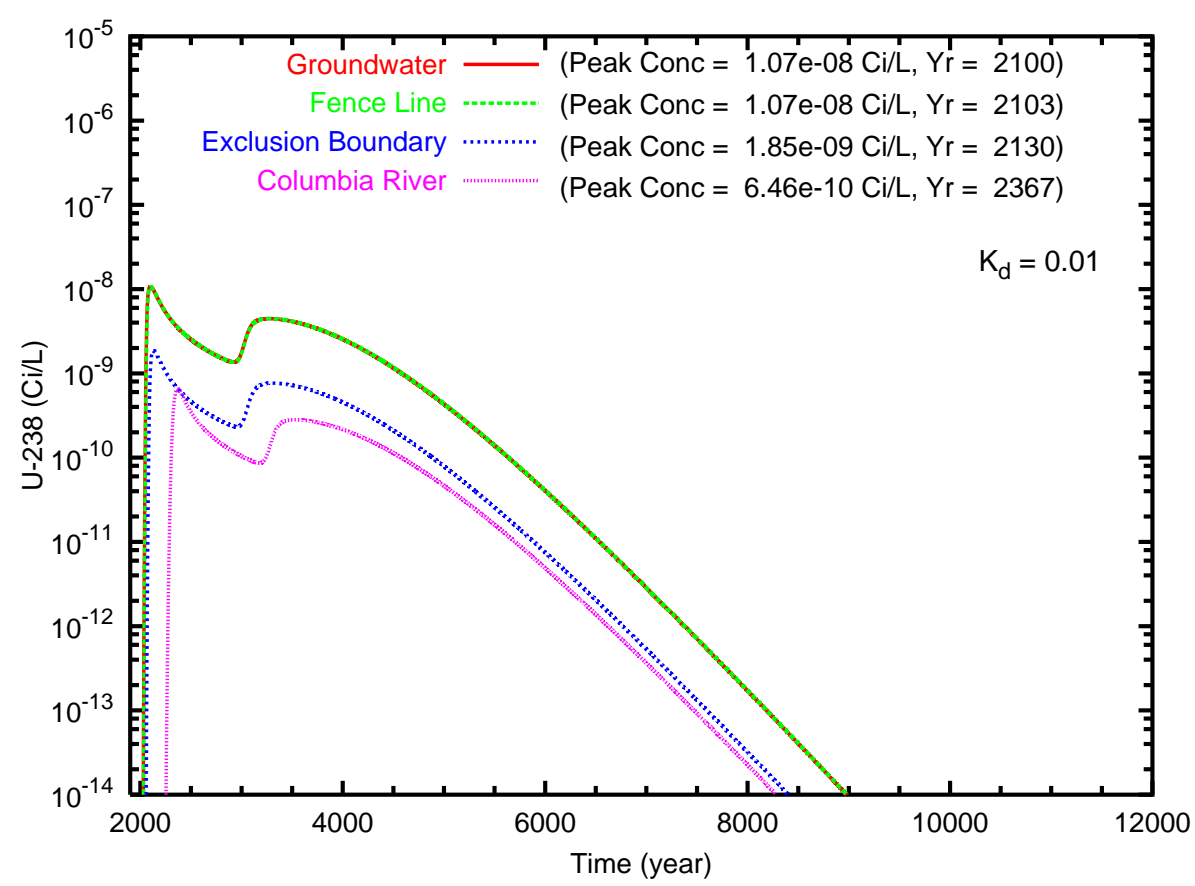

(b)

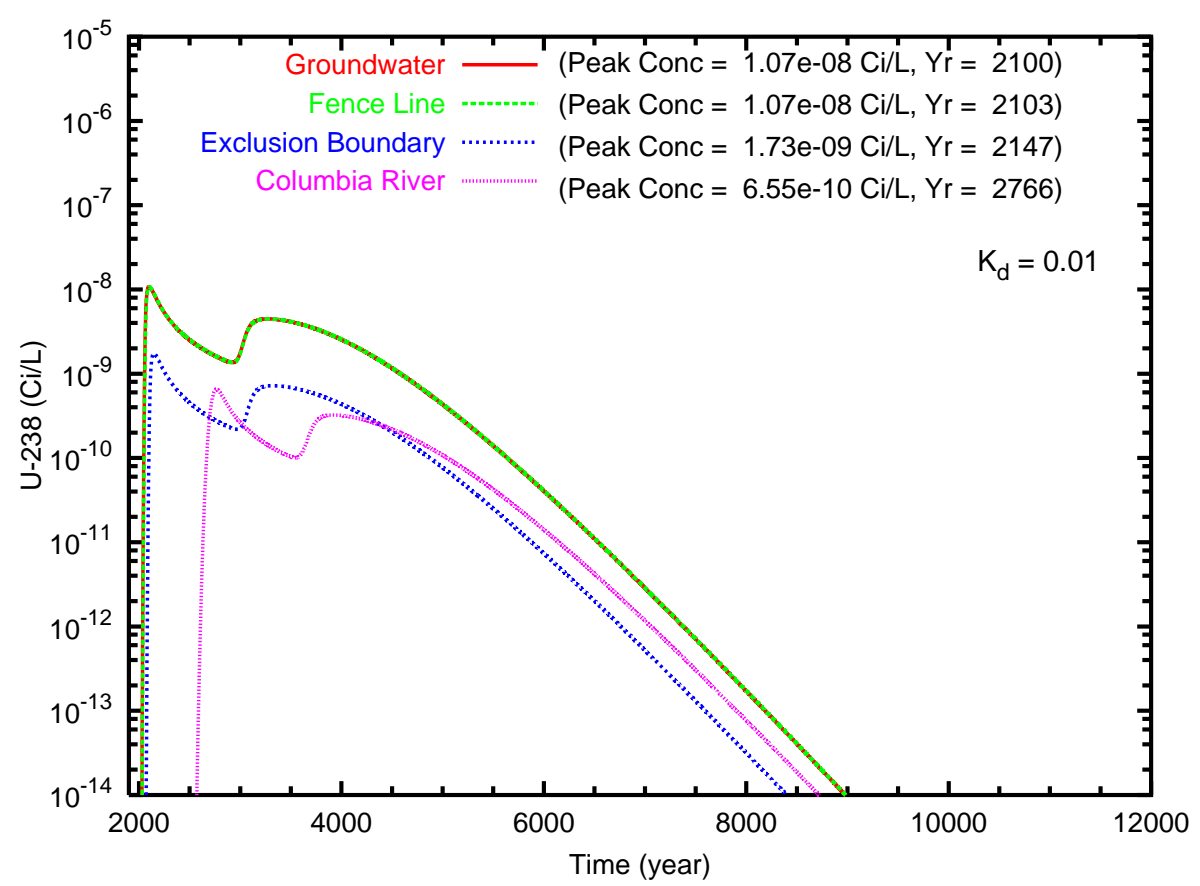

Figure B.52. Case 3-HiK, U-238 $\left(\mathrm{K}_{d}=0.01\right)$ concentration versus time for the fence line exclusion boundary and Columbia River compliance points for travel paths (a) southeast and (b) north through the gap 
(a)

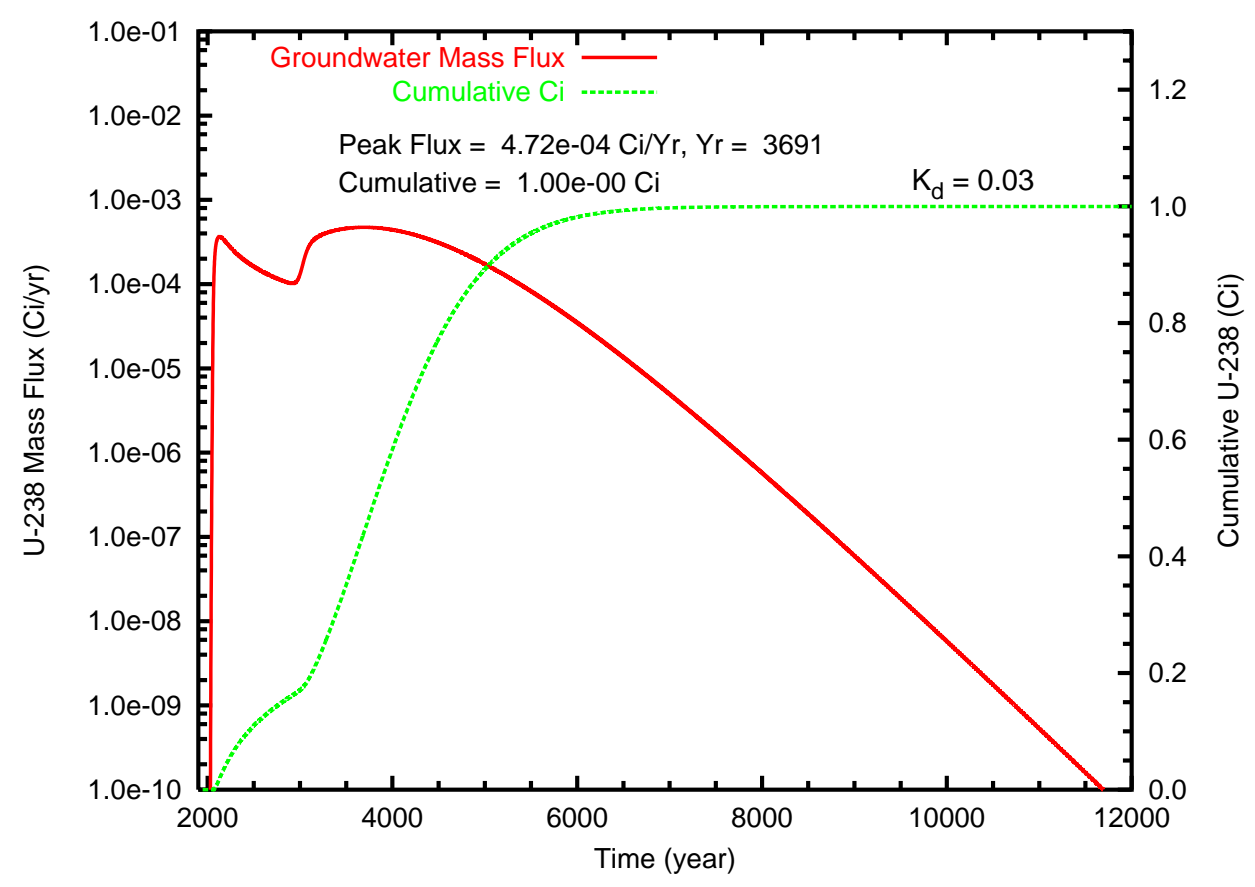

(b)

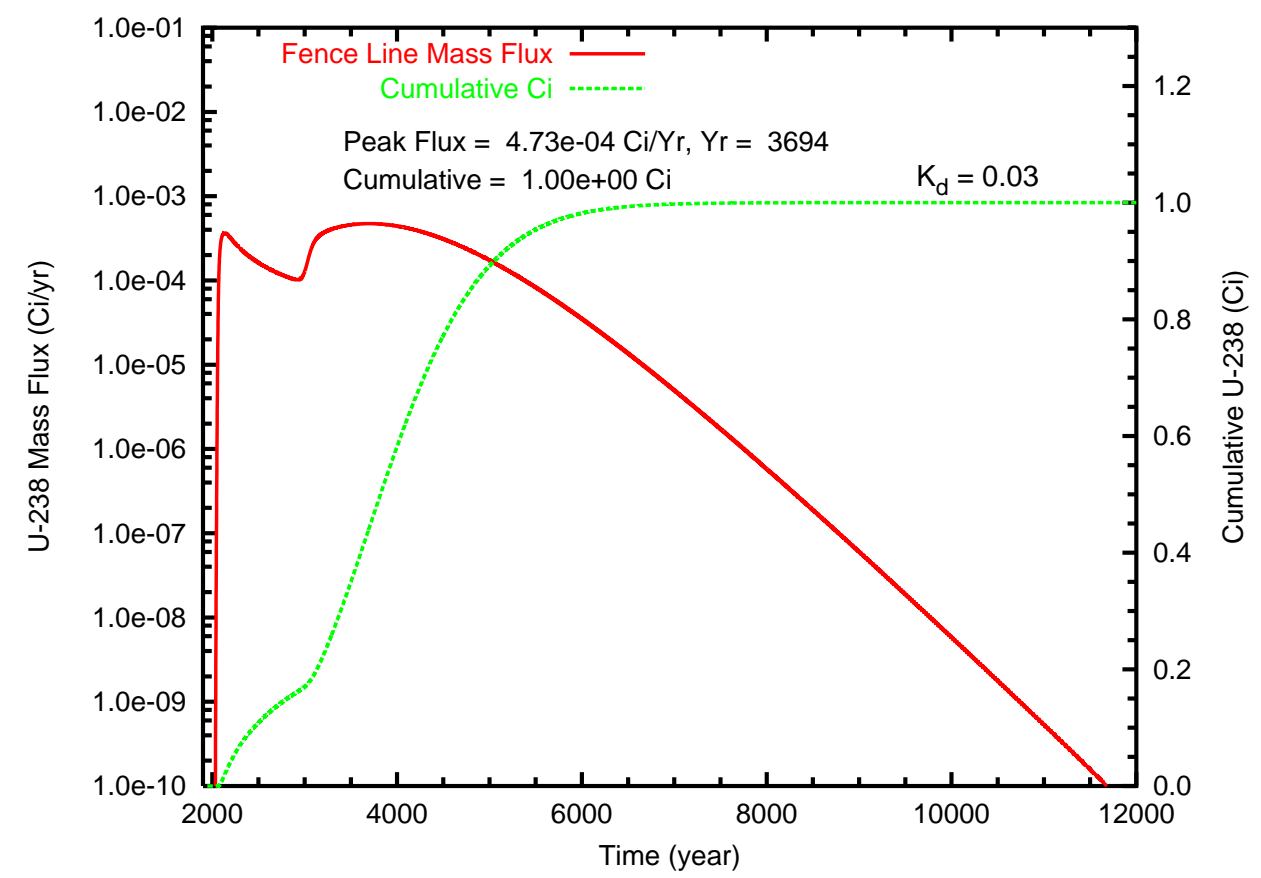

Figure B.53. Case 3-HiK, U-238 $\left(\mathrm{K}_{d}=0.03\right)$ mass flux $(\mathrm{Ci} / \mathrm{L})$ and cumulative mass $(\mathrm{Ci})$ at (a) the groundwater table and (b) the fence line 
(a)

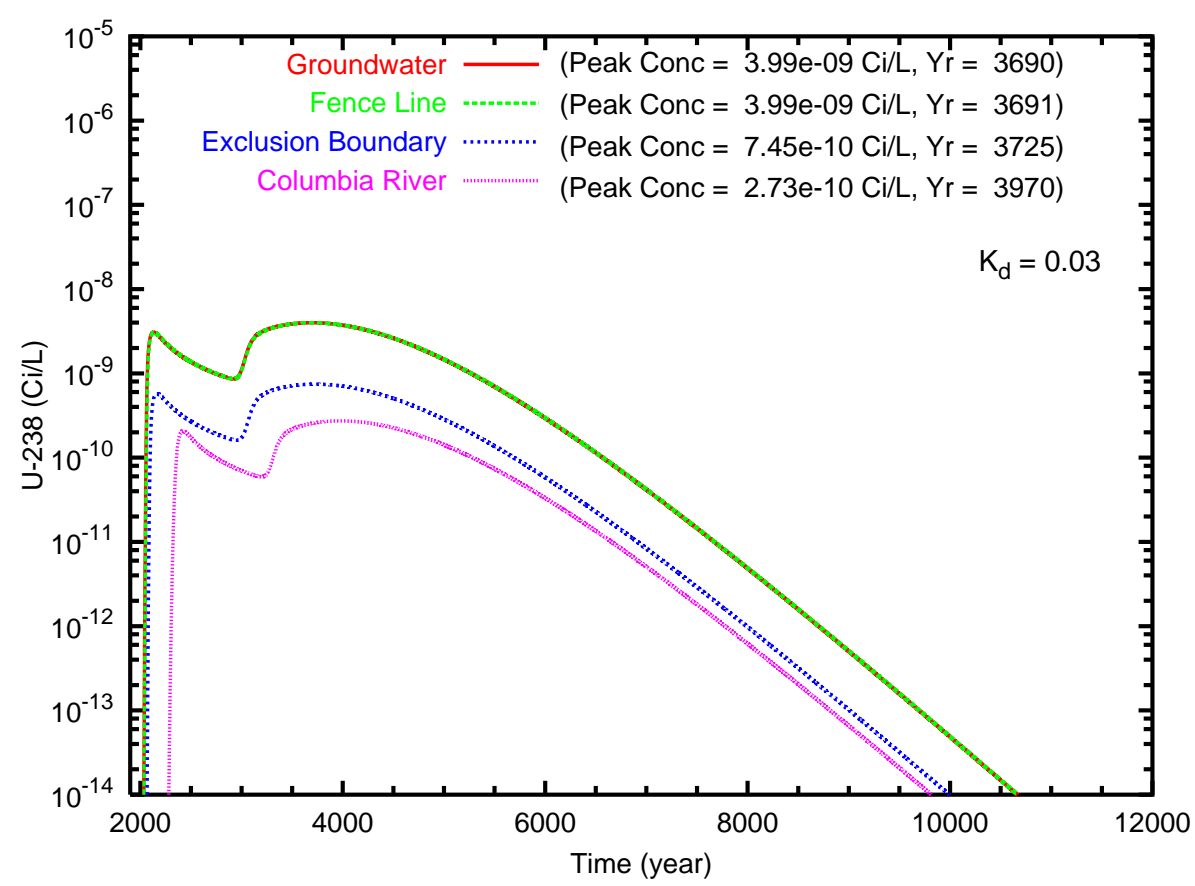

(b)

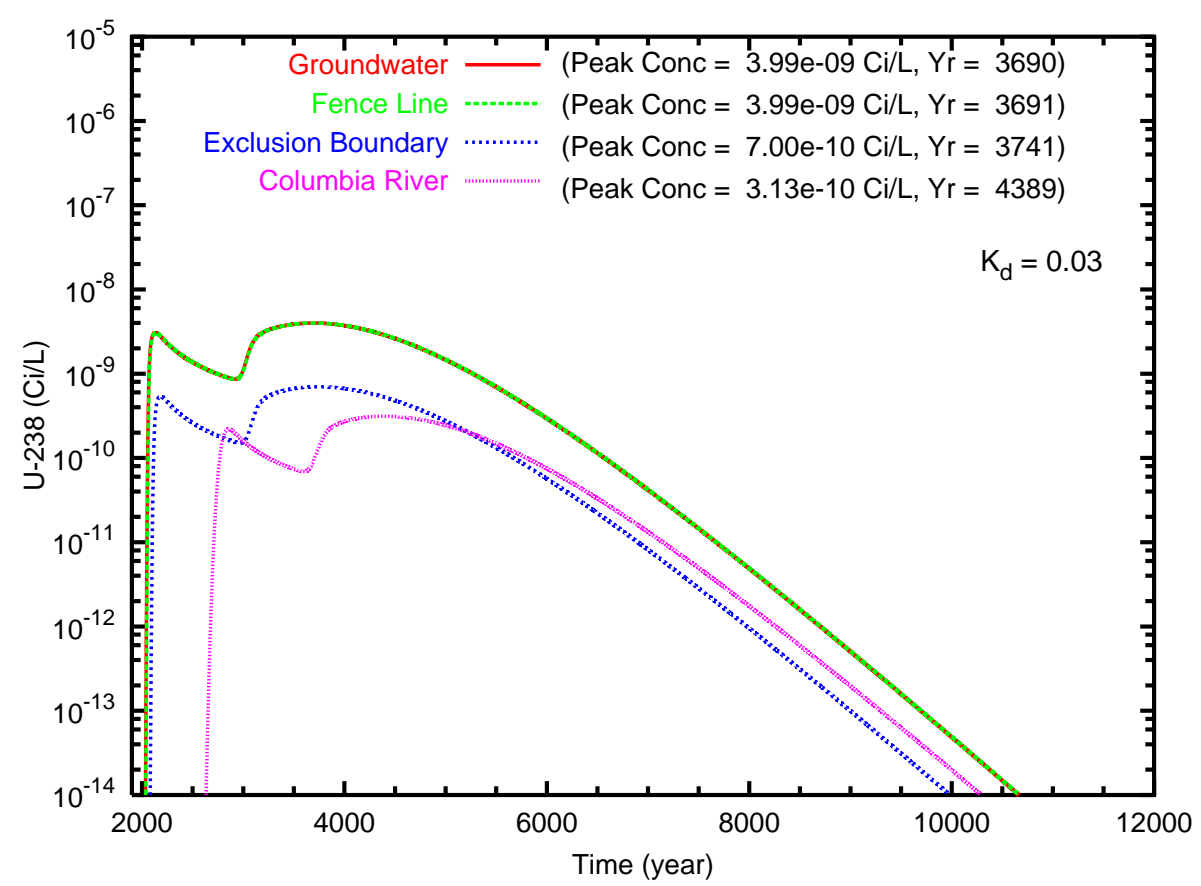

Figure B.54. Case 3-HiK, U-238 $\left(\mathrm{K}_{d}=0.03\right)$ concentration versus time for the fence line exclusion boundary and Columbia River compliance points for travel paths (a) southeast and (b) north through the gap 
(a)

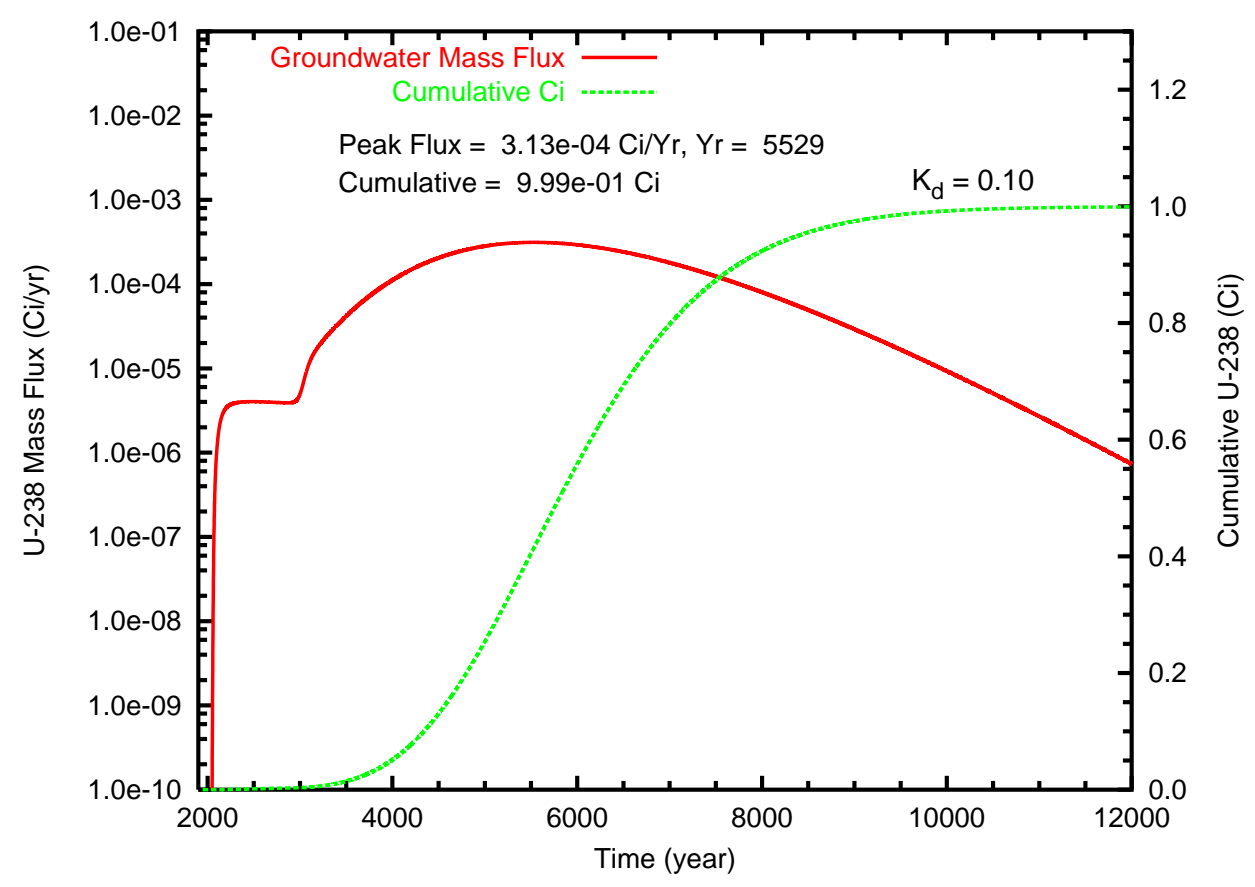

(b)

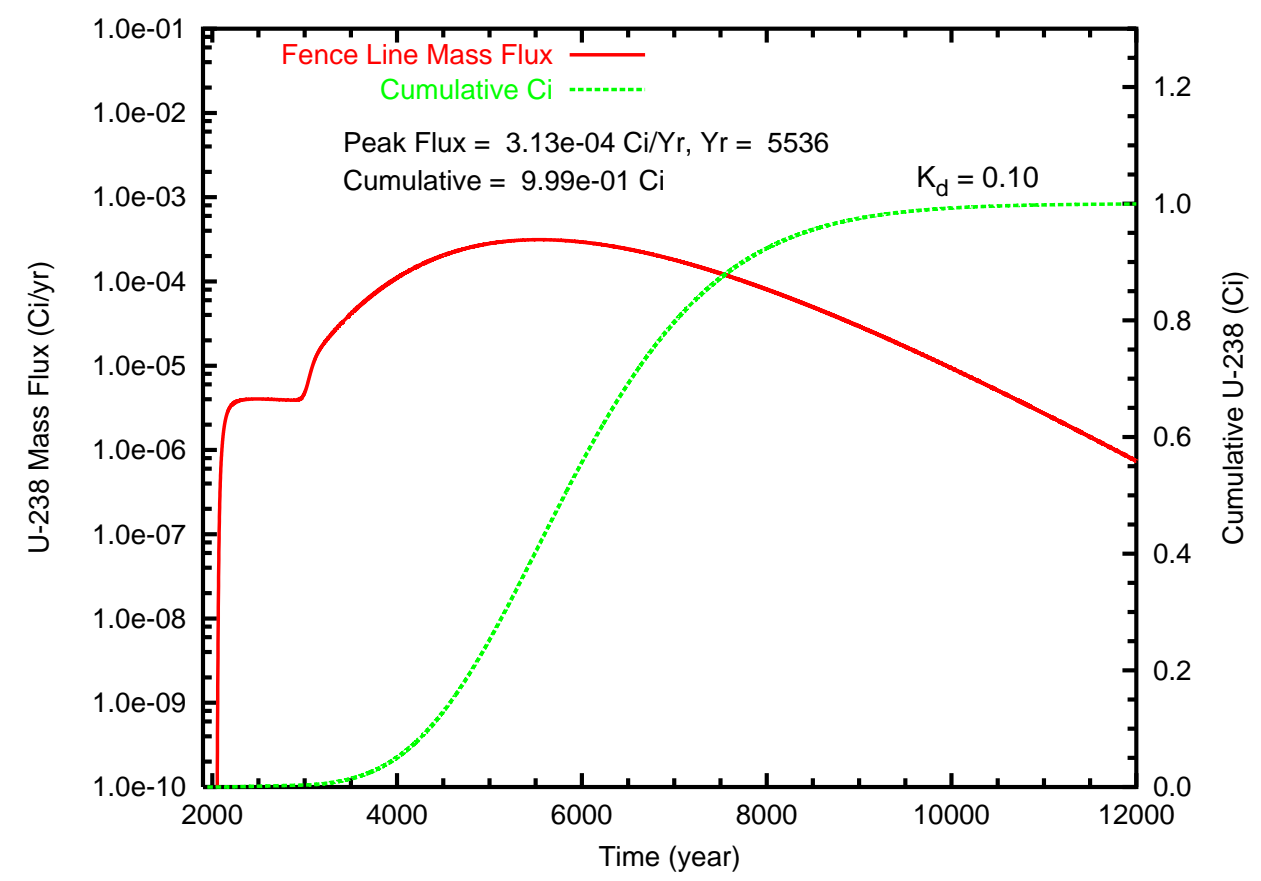

Figure B.55. Case 3-HiK, U-238 $\left(\mathrm{K}_{d}=0.10\right)$ mass flux $(\mathrm{Ci} / \mathrm{L})$ and cumulative mass $(\mathrm{Ci})$ at (a) the groundwater table and (b) the fence line 
(a)

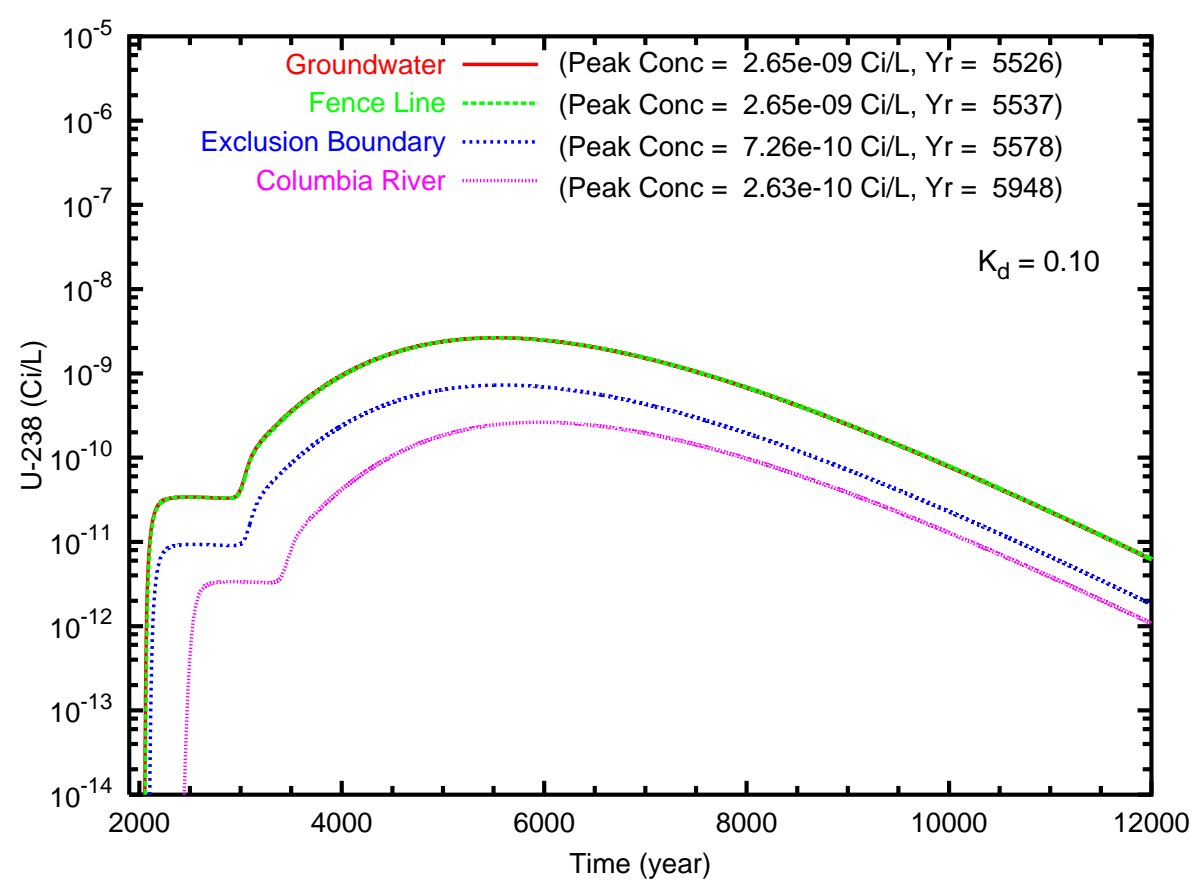

(b)

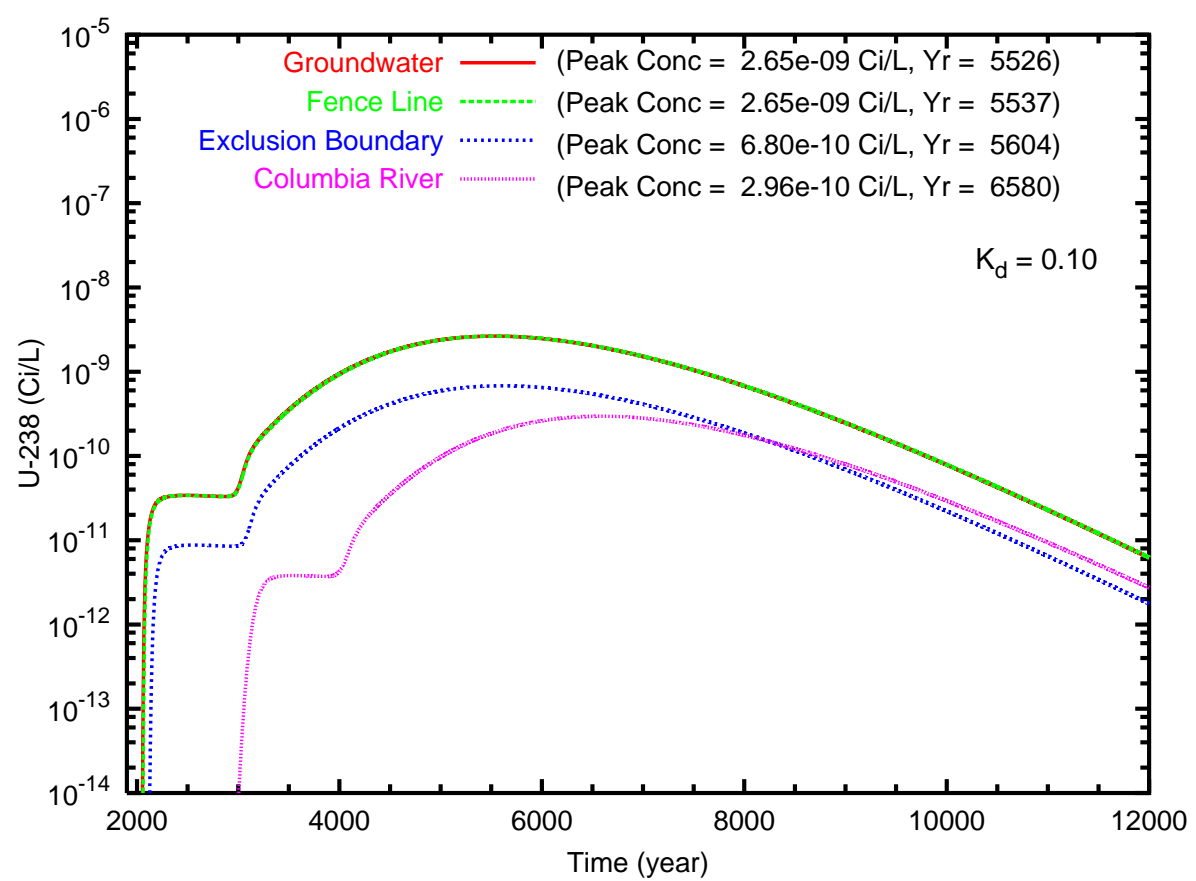

Figure B.56. Case 3-HiK, U-238 $\left(\mathrm{K}_{d}=0.10\right)$ concentration versus time for the fence line exclusion boundary and Columbia River compliance points for travel paths (a) southeast and (b) north through the gap 
(a)

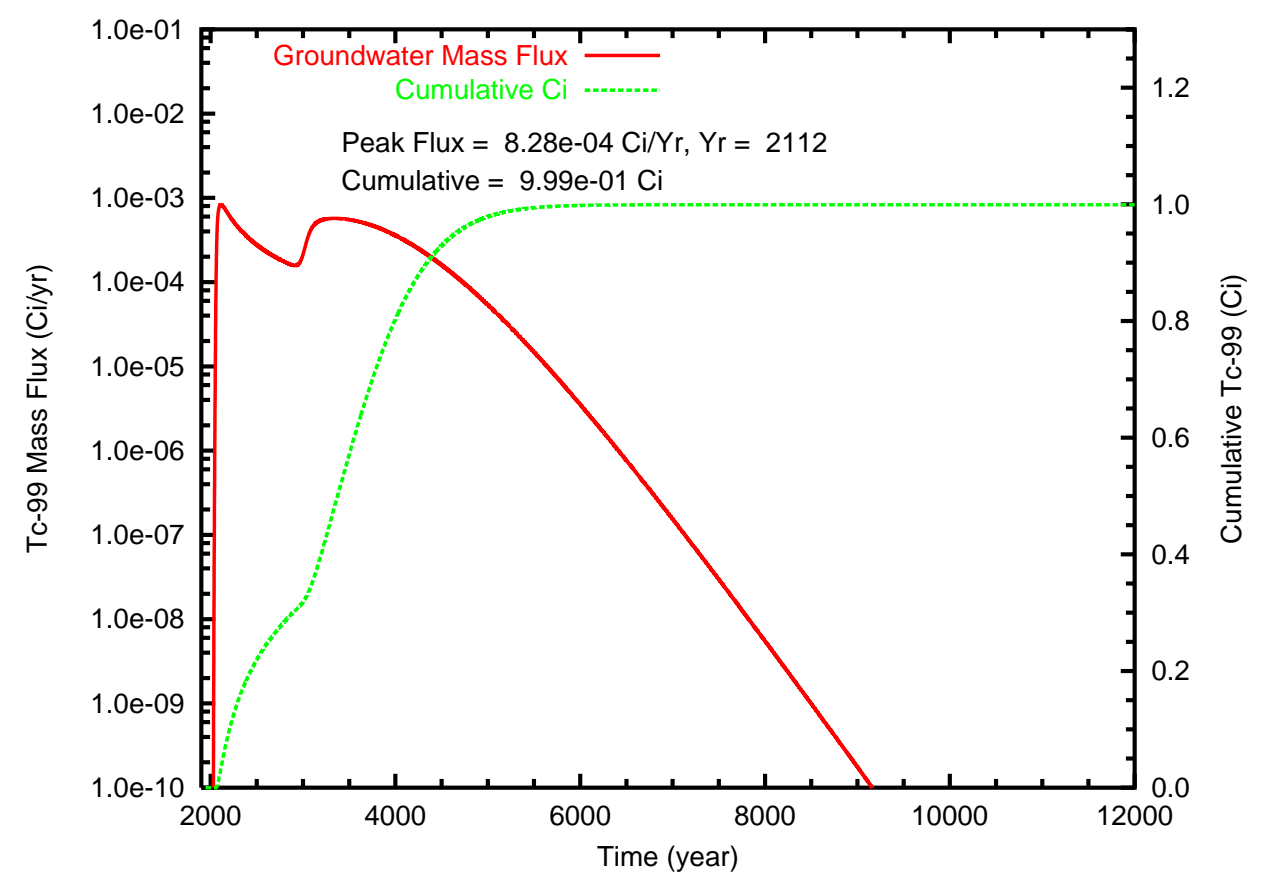

(b)

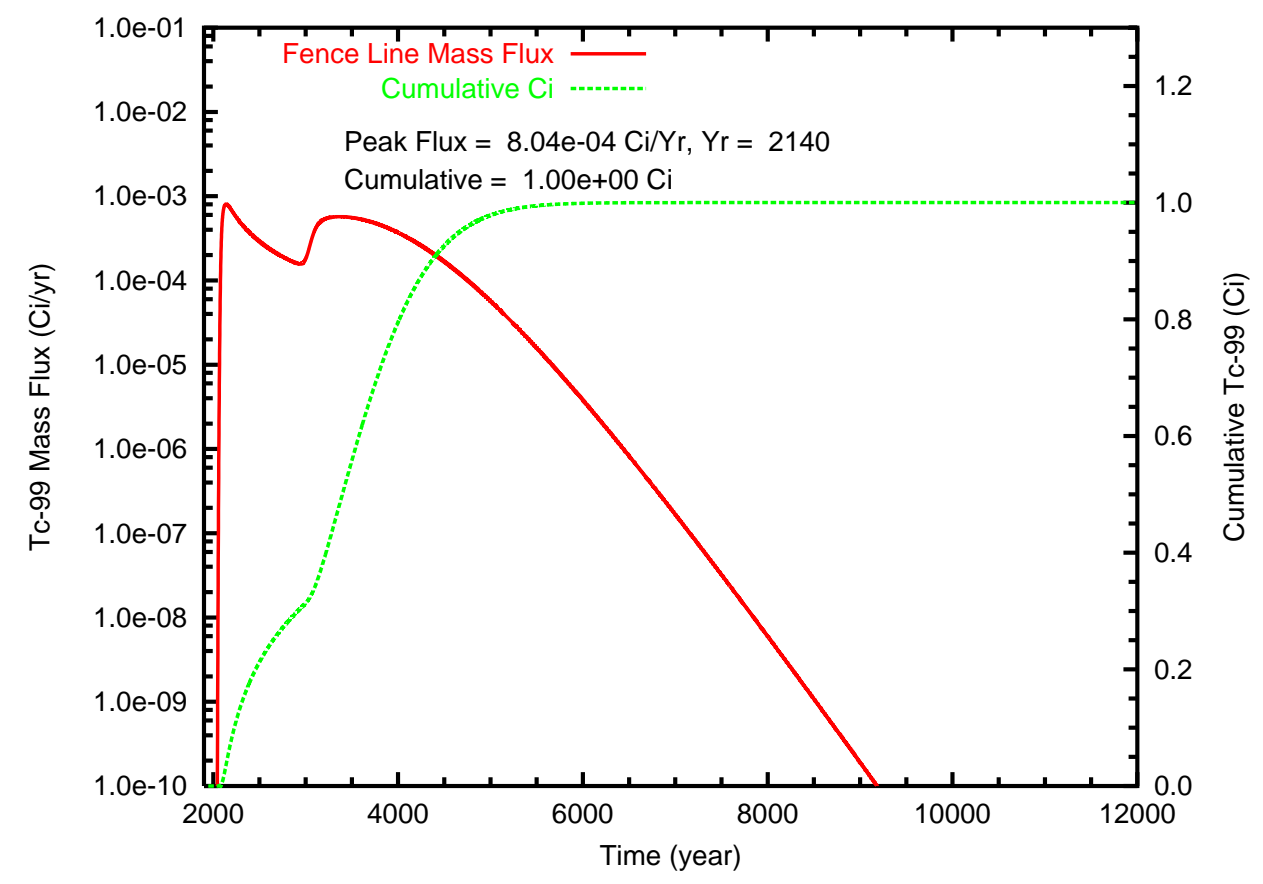

Figure B.57. Case 4, Tc-99 mass flux and cumulative mass at (a) the groundwater table and (b) the fence line 
(a)

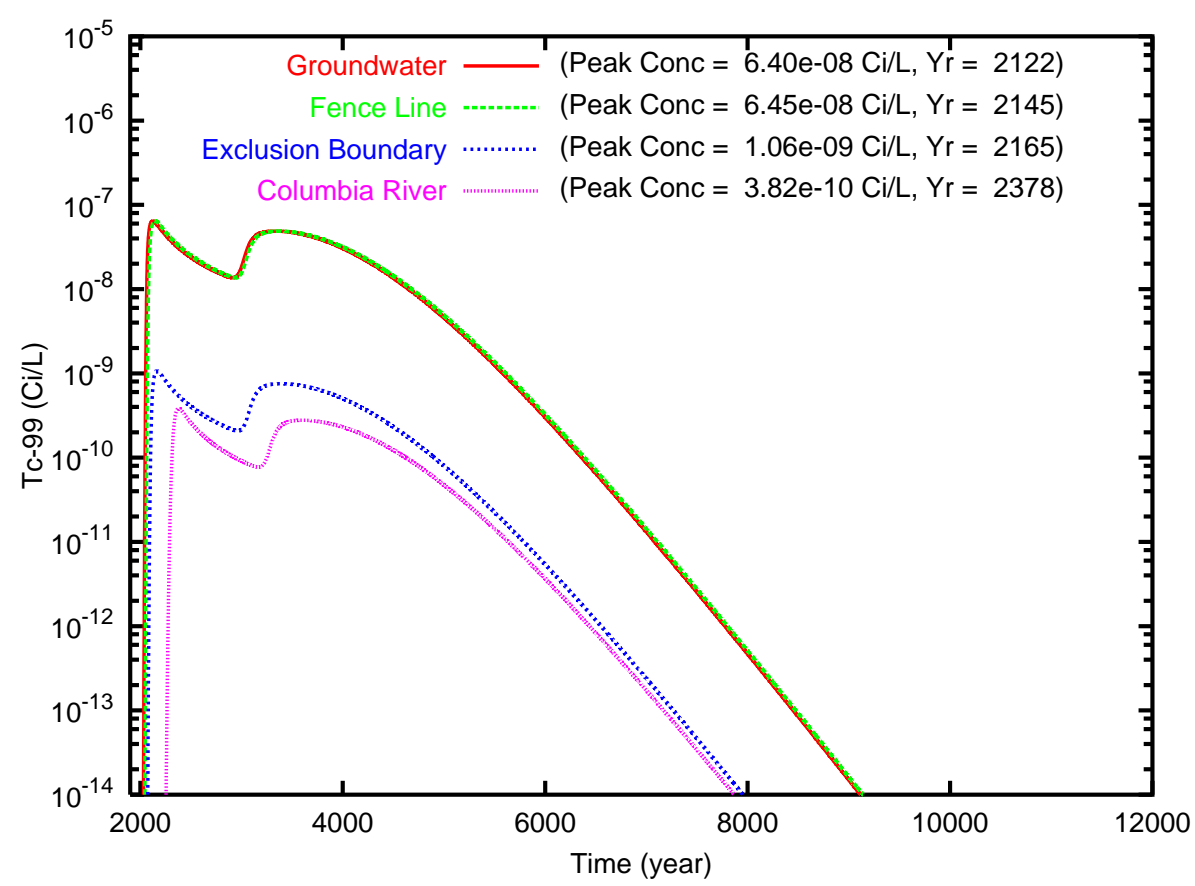

(b)

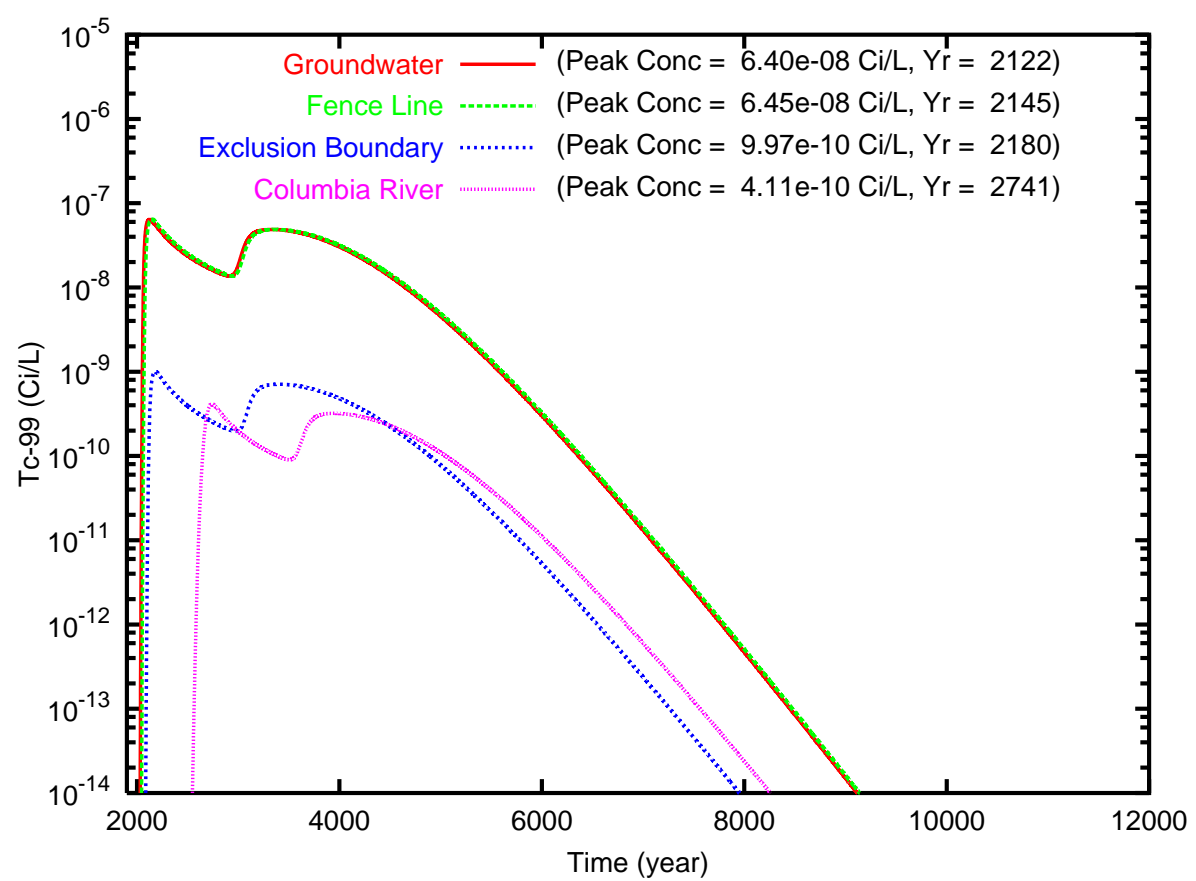

Figure B.58. Case 4, Tc-99 concentration versus time for the fence line, exclusion boundary and Columbia River compliance points for travel paths (a) southeast and (b) north through the gap 
(a)

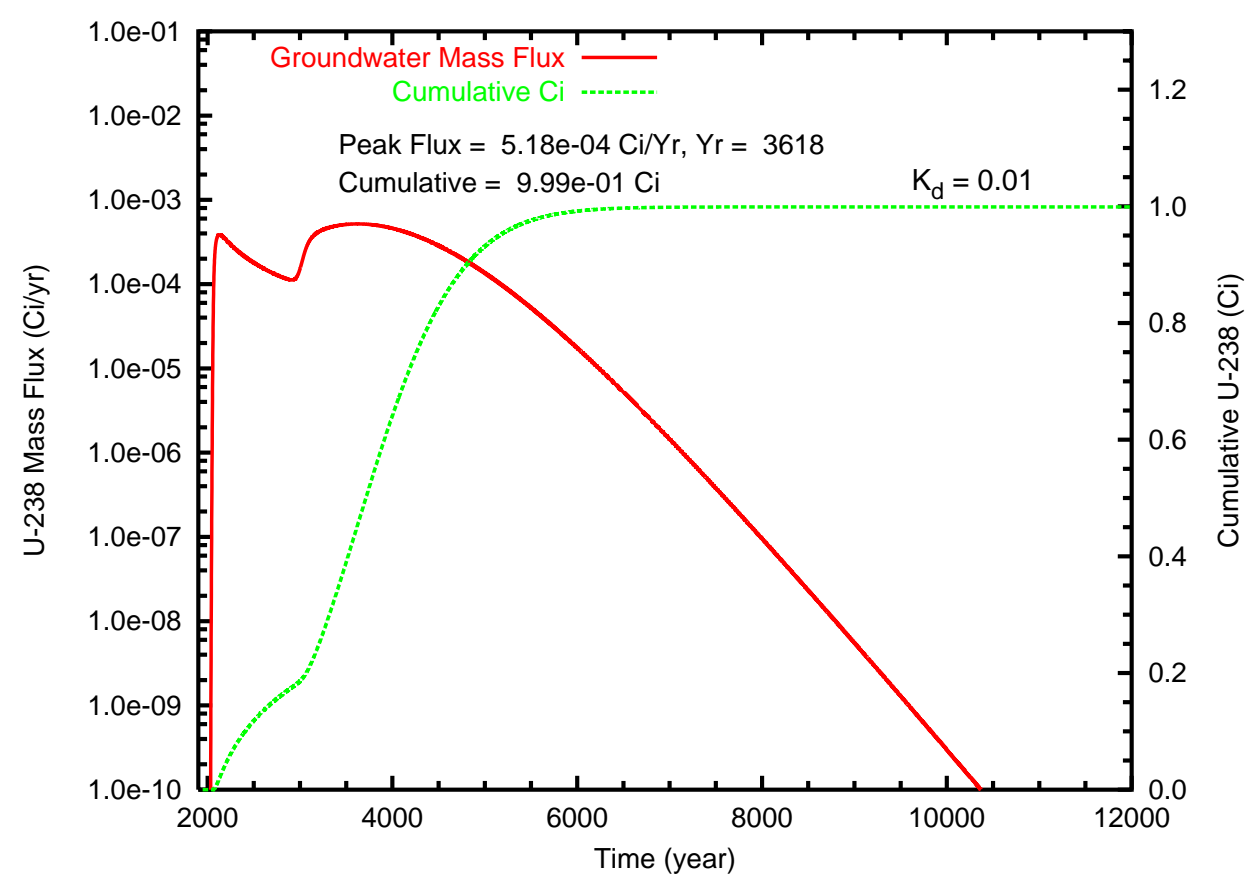

(b)

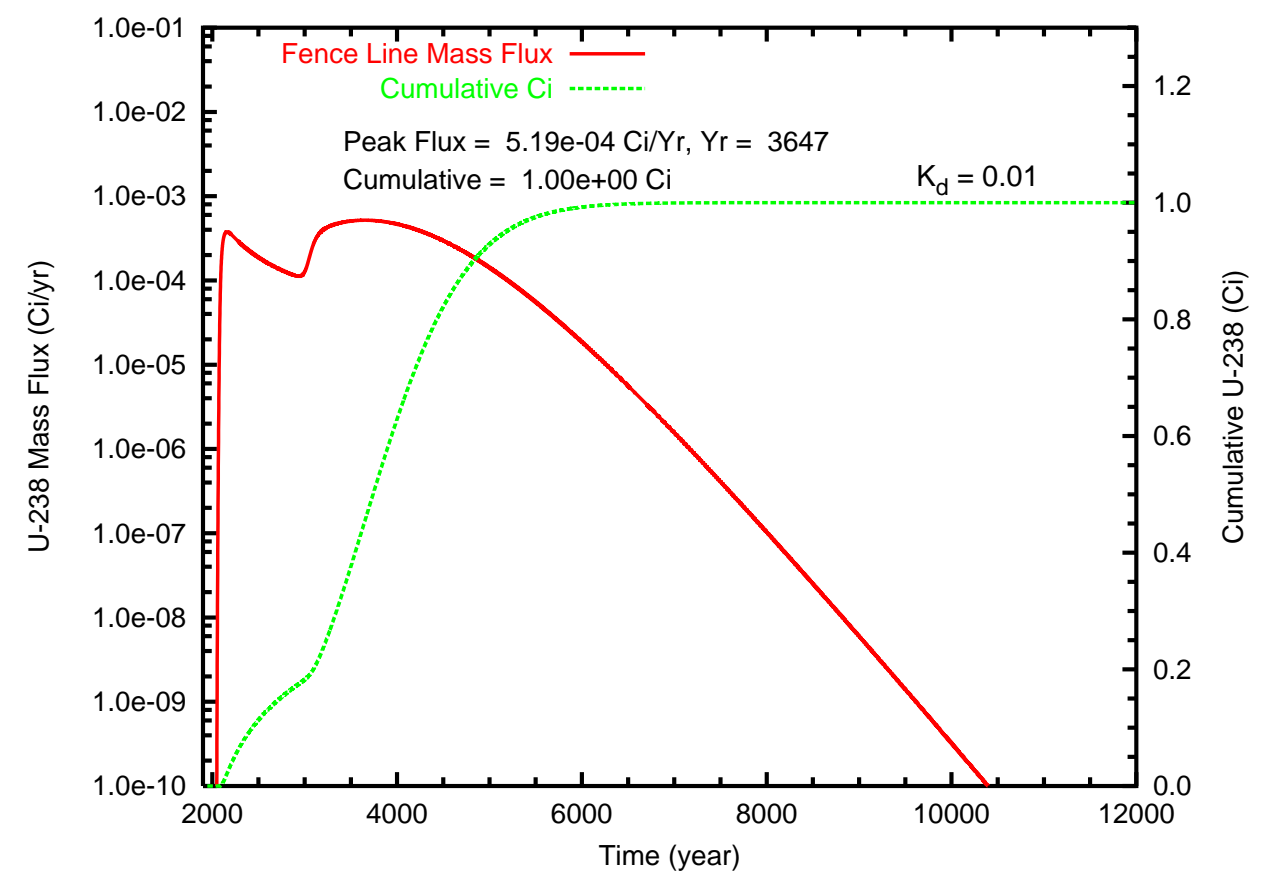

Figure B.59. Case 4, U-238 $\left(\mathrm{K}_{d}=0.01\right)$ mass flux $(\mathrm{Ci} / \mathrm{L})$ and cumulative mass $(\mathrm{Ci})$ at (a) the groundwater table and (b) the fence line 
(a)

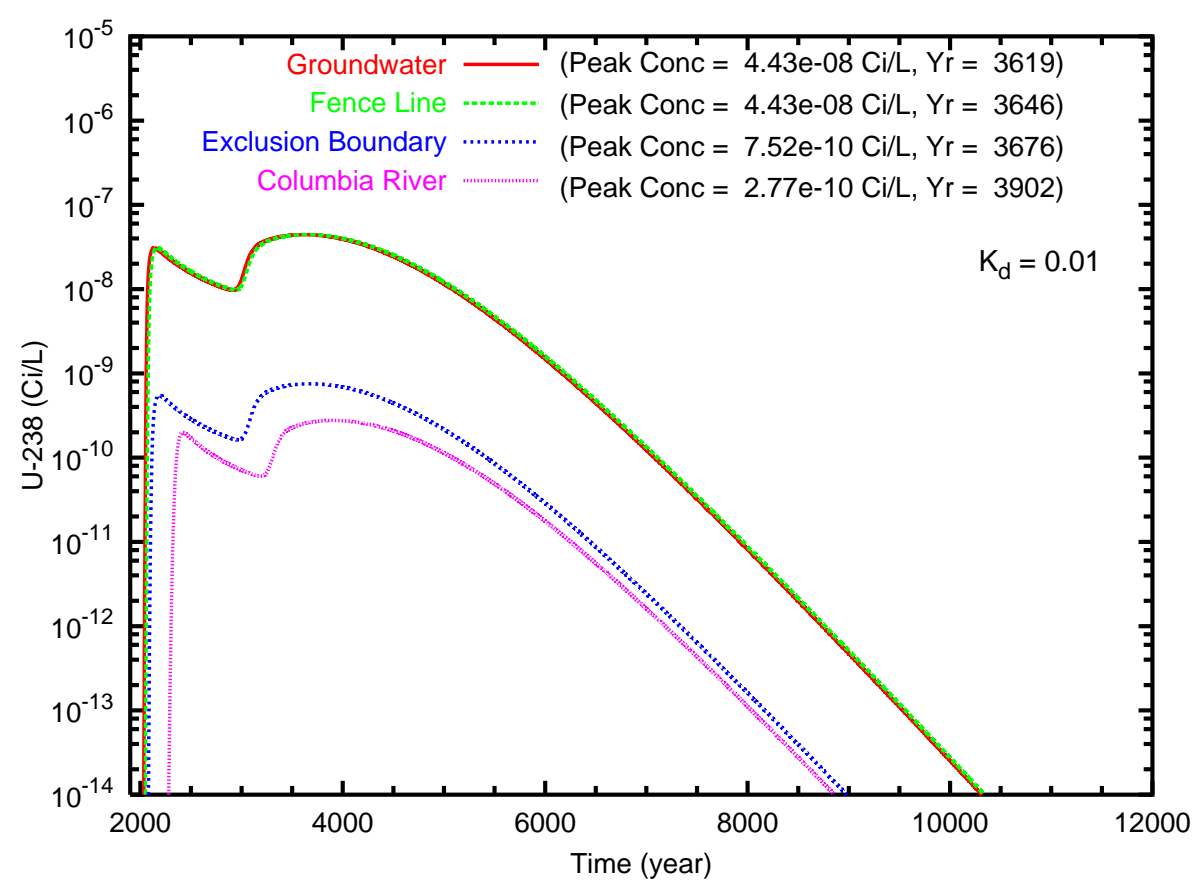

(b)

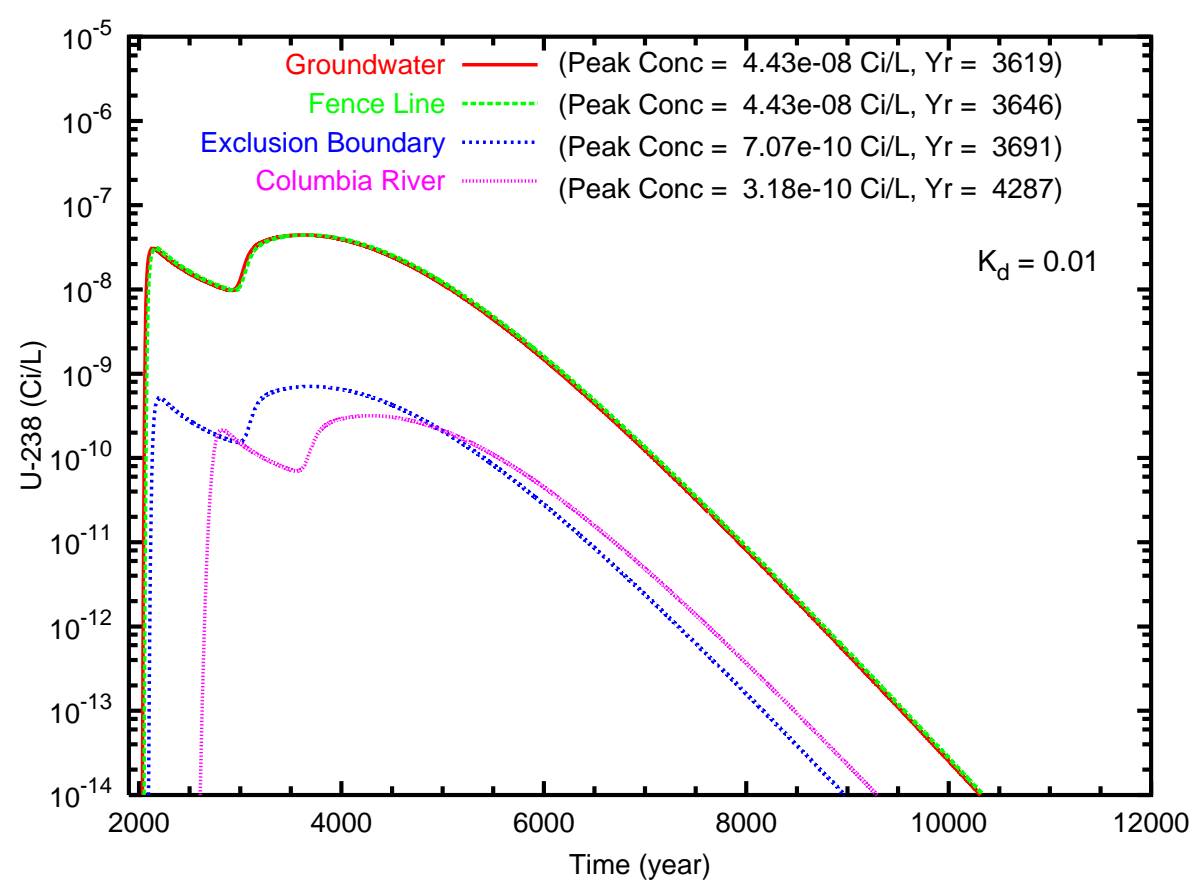

Figure B.60. Case 4, U-238 $\left(\mathrm{K}_{d}=0.01\right)$ concentration versus time for the fence line exclusion boundary and Columbia River compliance points for travel paths (a) southeast and (b) north through the gap 
(a)

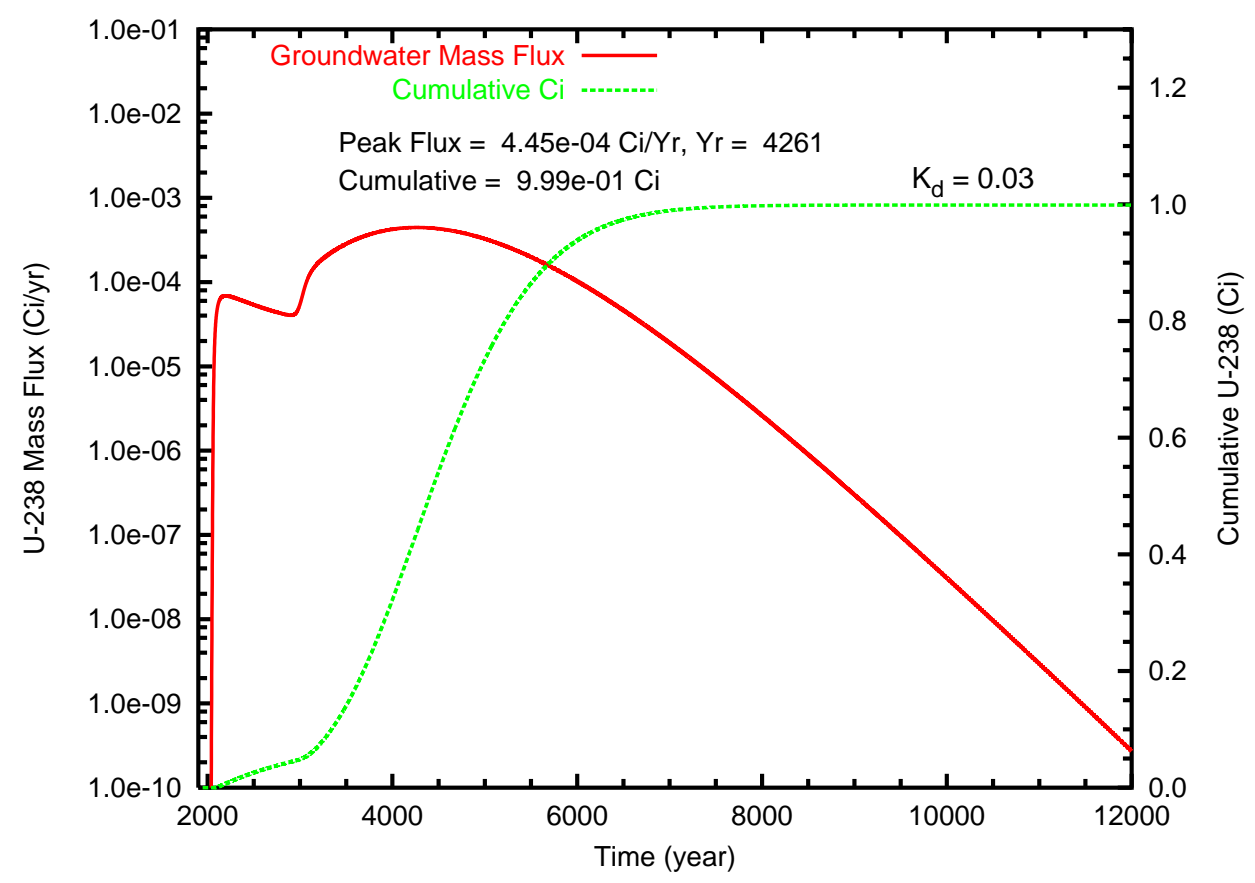

(b)

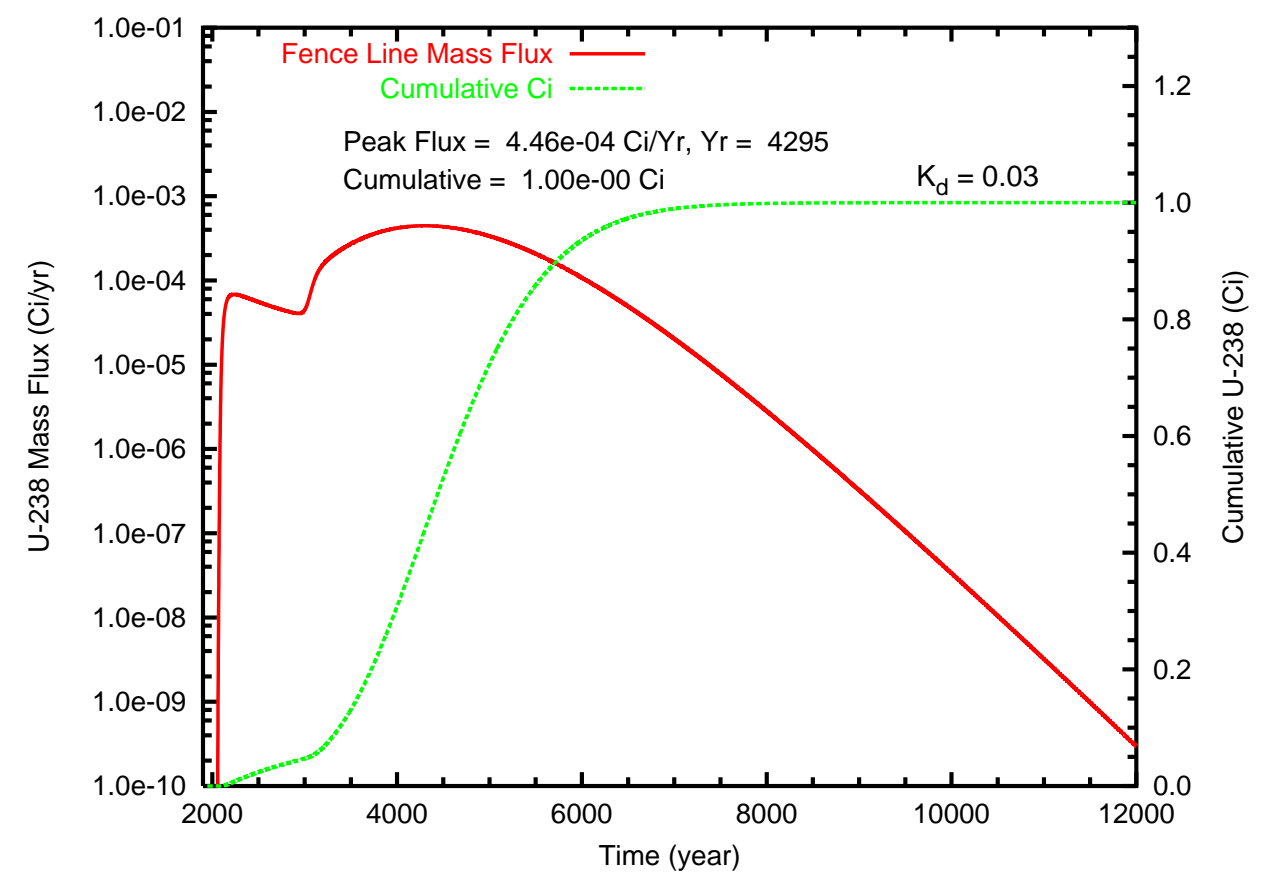

Figure B.61. Case 4, U-238 $\left(\mathrm{K}_{d}=0.03\right)$ mass flux $(\mathrm{Ci} / \mathrm{L})$ and cumulative mass $(\mathrm{Ci})$ at (a) the groundwater table and (b) the fence line 
(a)

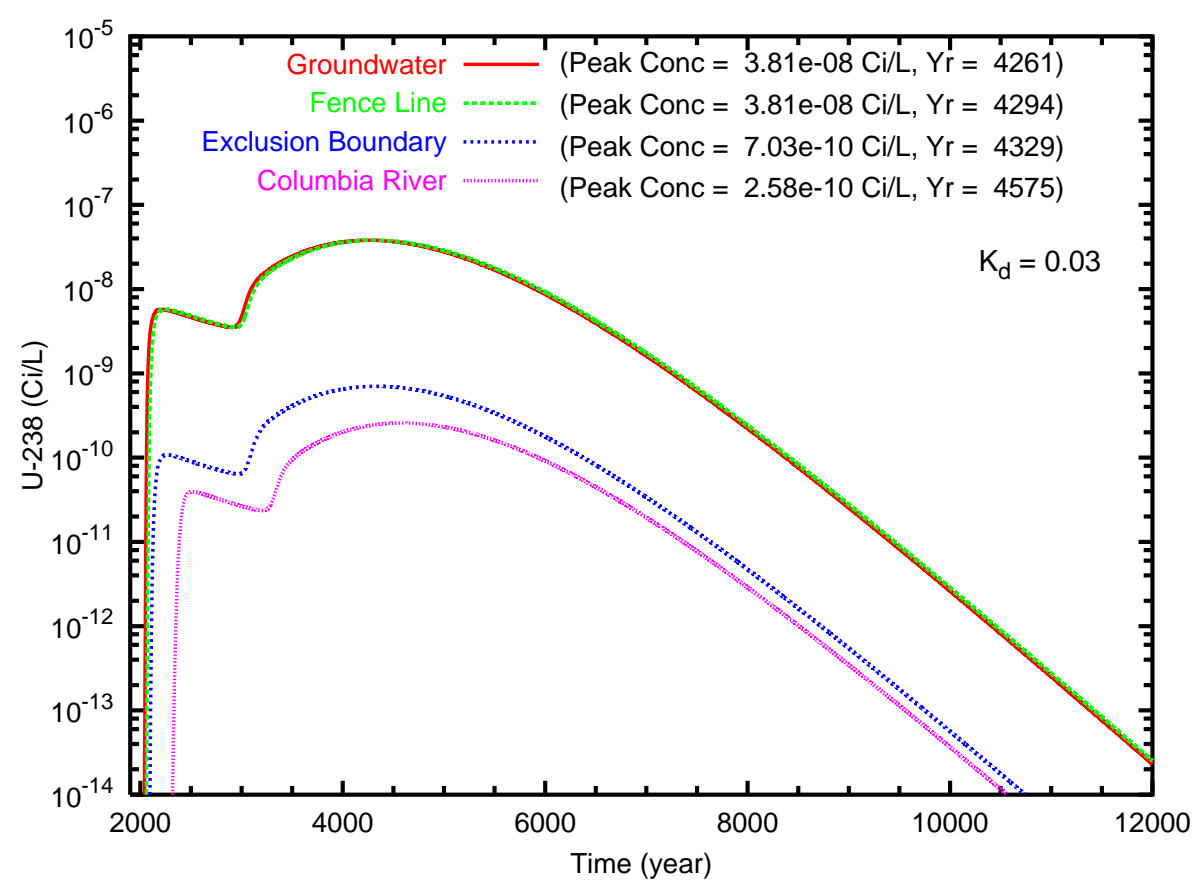

(b)

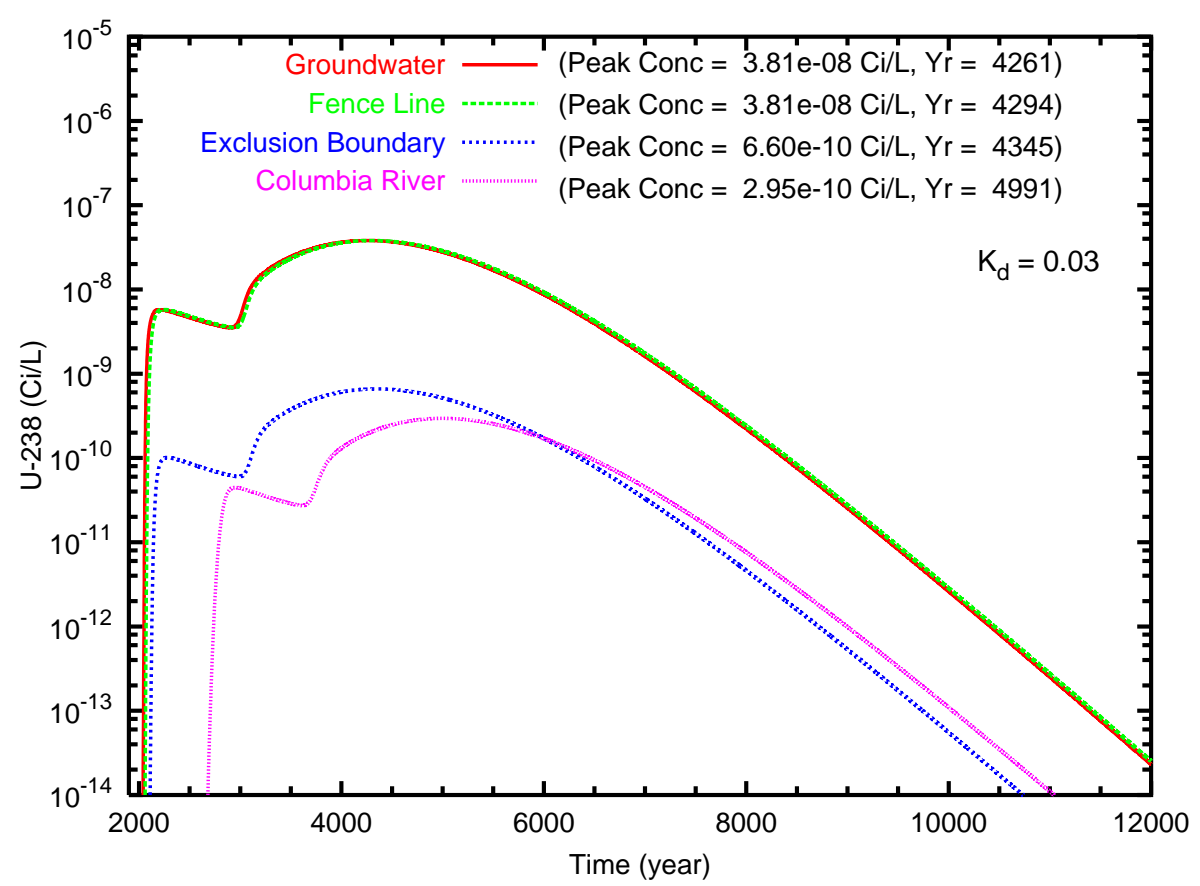

Figure B.62. Case 4, U-238 $\left(\mathrm{K}_{d}=0.03\right)$ concentration versus time for the fence line exclusion boundary and Columbia River compliance points for travel paths (a) southeast and (b) north through the gap 
(a)

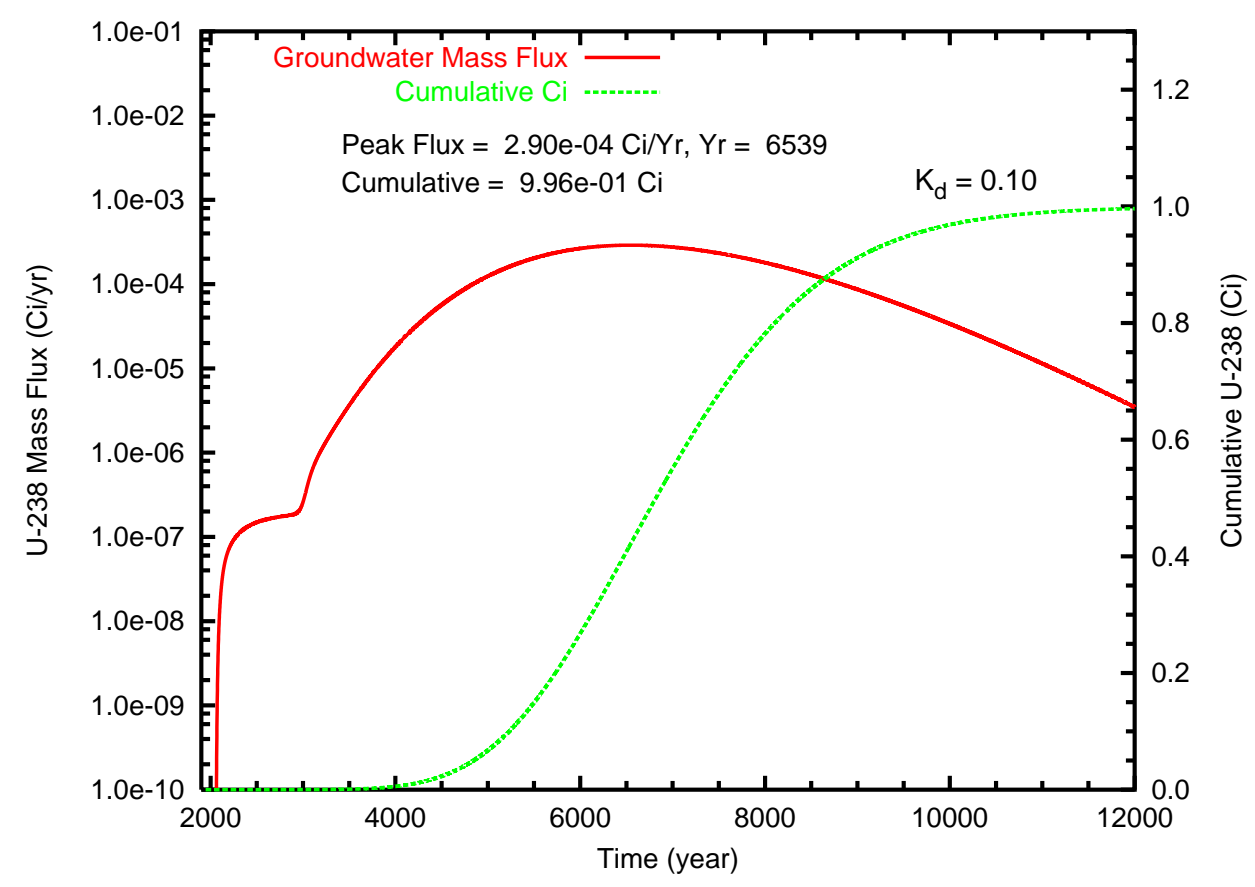

(b)

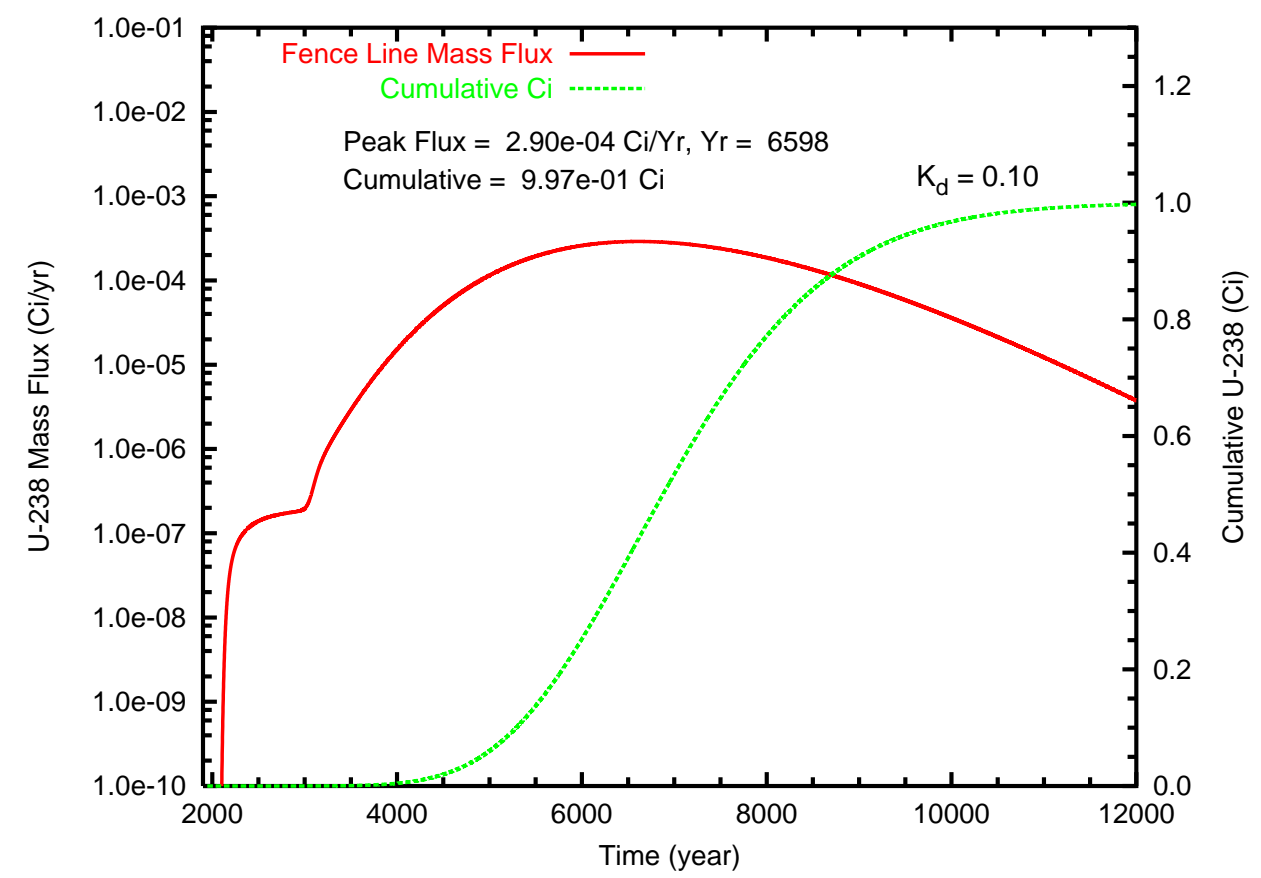

Figure B.63. Case 4, U-238 $\left(\mathrm{K}_{d}=0.10\right)$ mass flux $(\mathrm{Ci} / \mathrm{L})$ and cumulative mass $(\mathrm{Ci})$ at (a) the groundwater table and (b) the fence line 
(a)

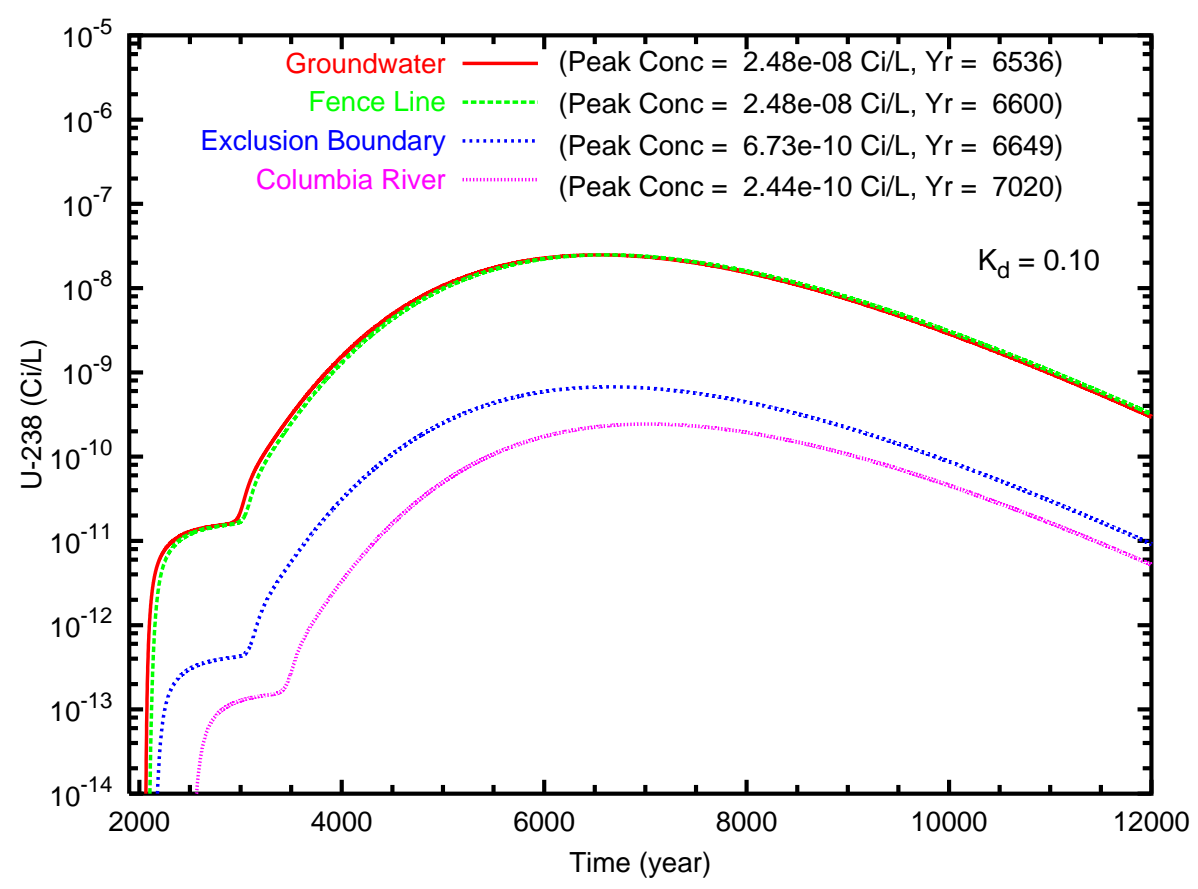

(b)

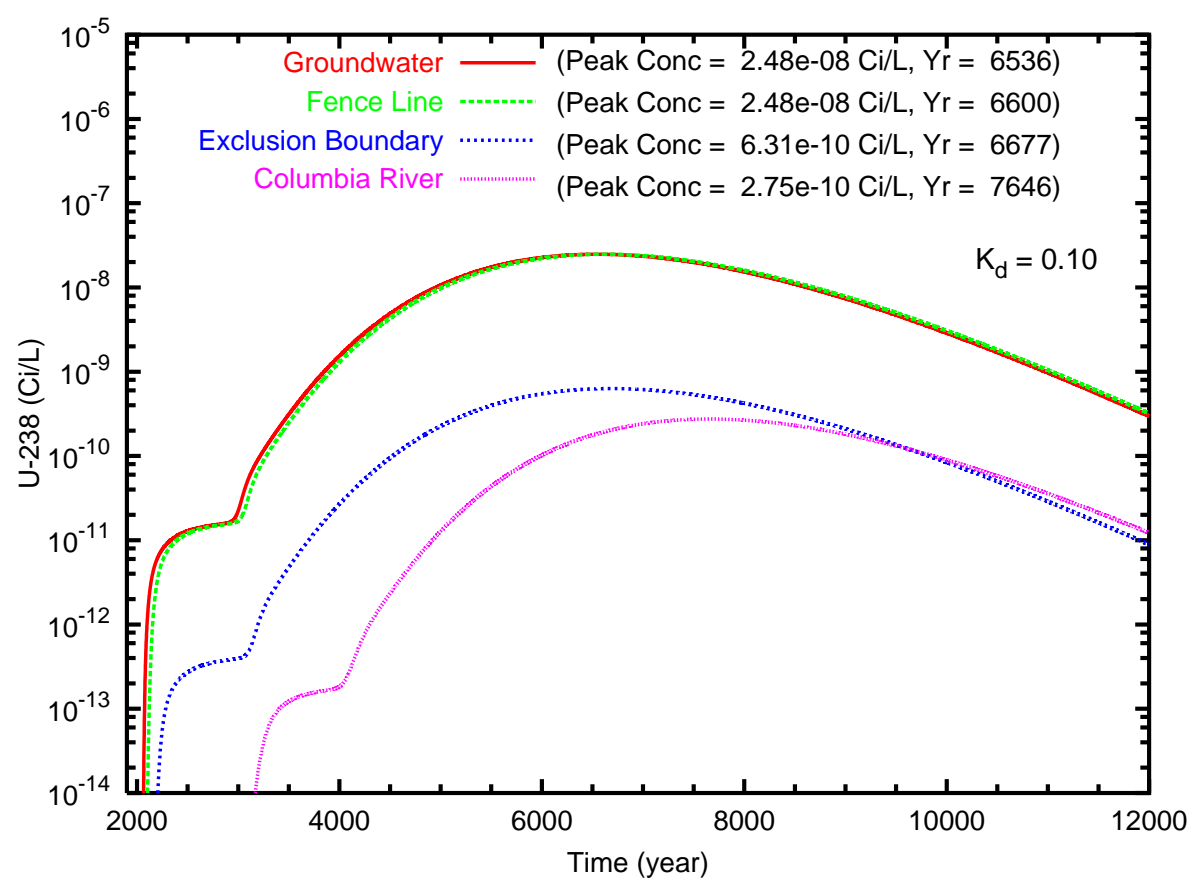

Figure B.64. Case 4, U-238 $\left(\mathrm{K}_{d}=0.10\right)$ concentration versus time for the fence line exclusion boundary and Columbia River compliance points for travel paths (a) southeast and (b) north through the gap 
(a)

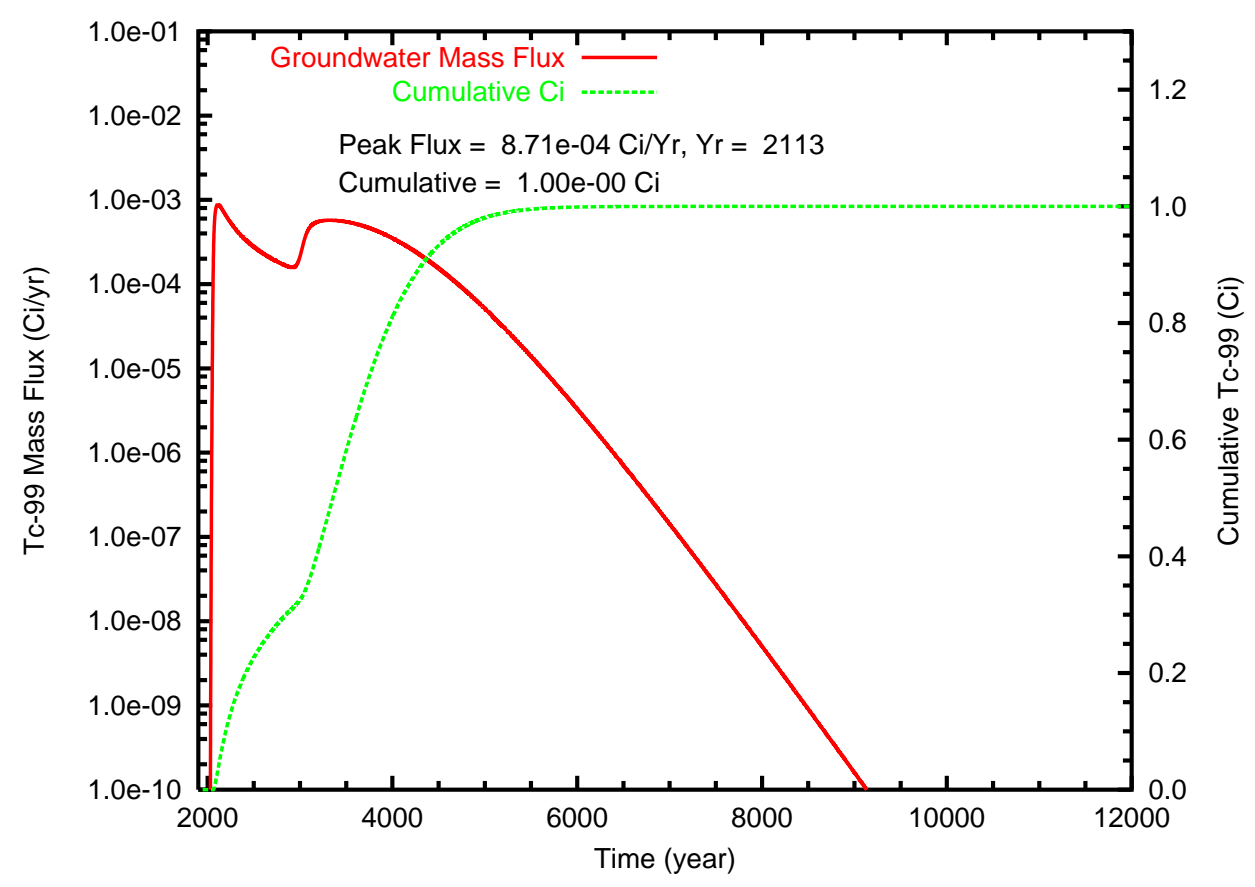

(b)

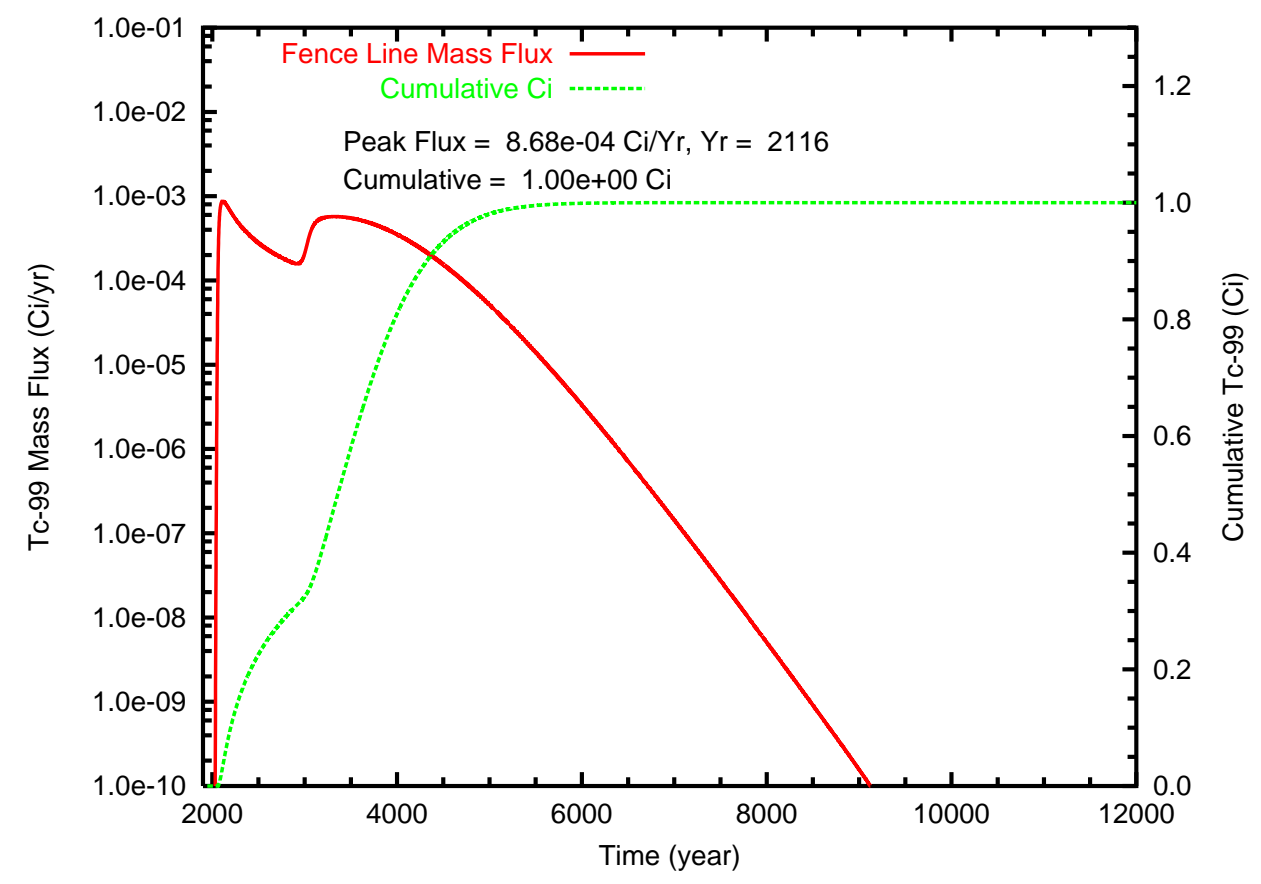

Figure B.65. Case 4-HiK, Tc-99 mass flux and cumulative mass at (a) the groundwater table and (b) the fence line 
(a)

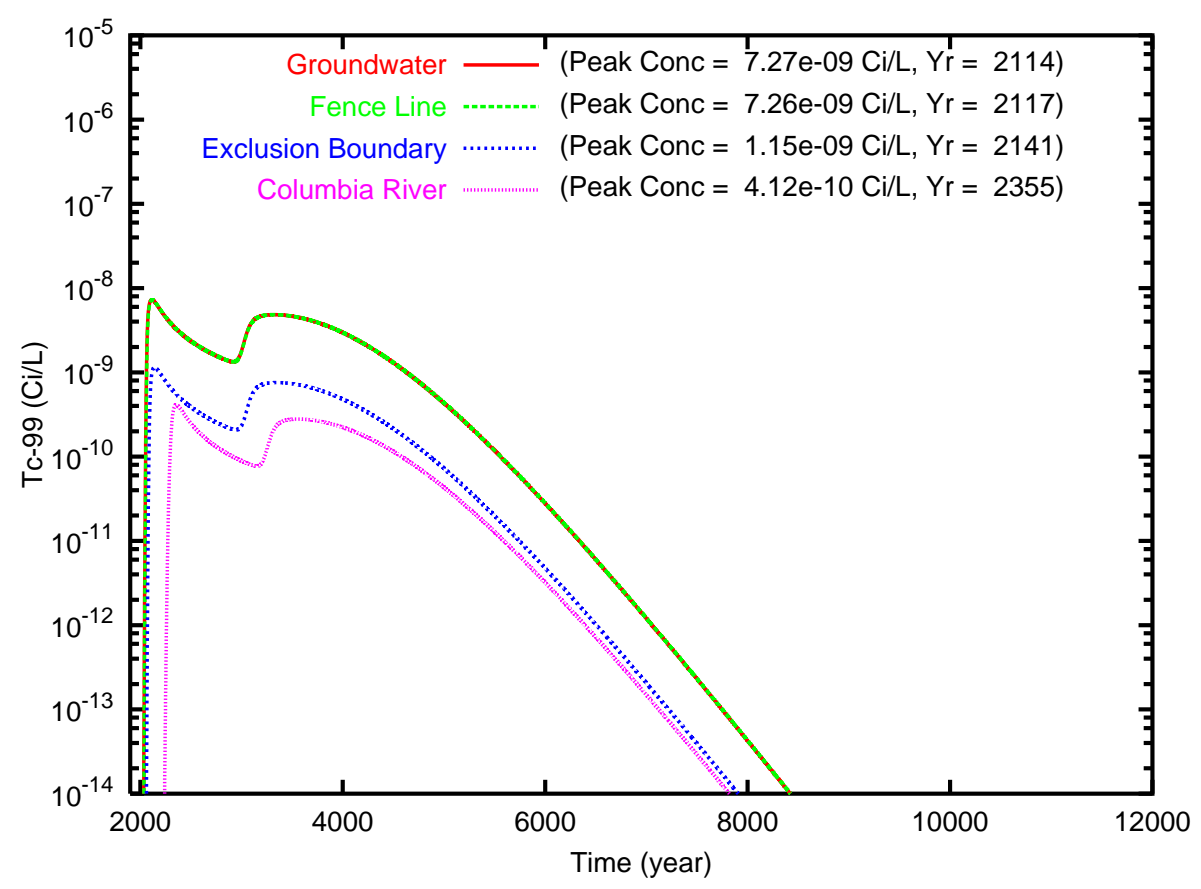

(b)

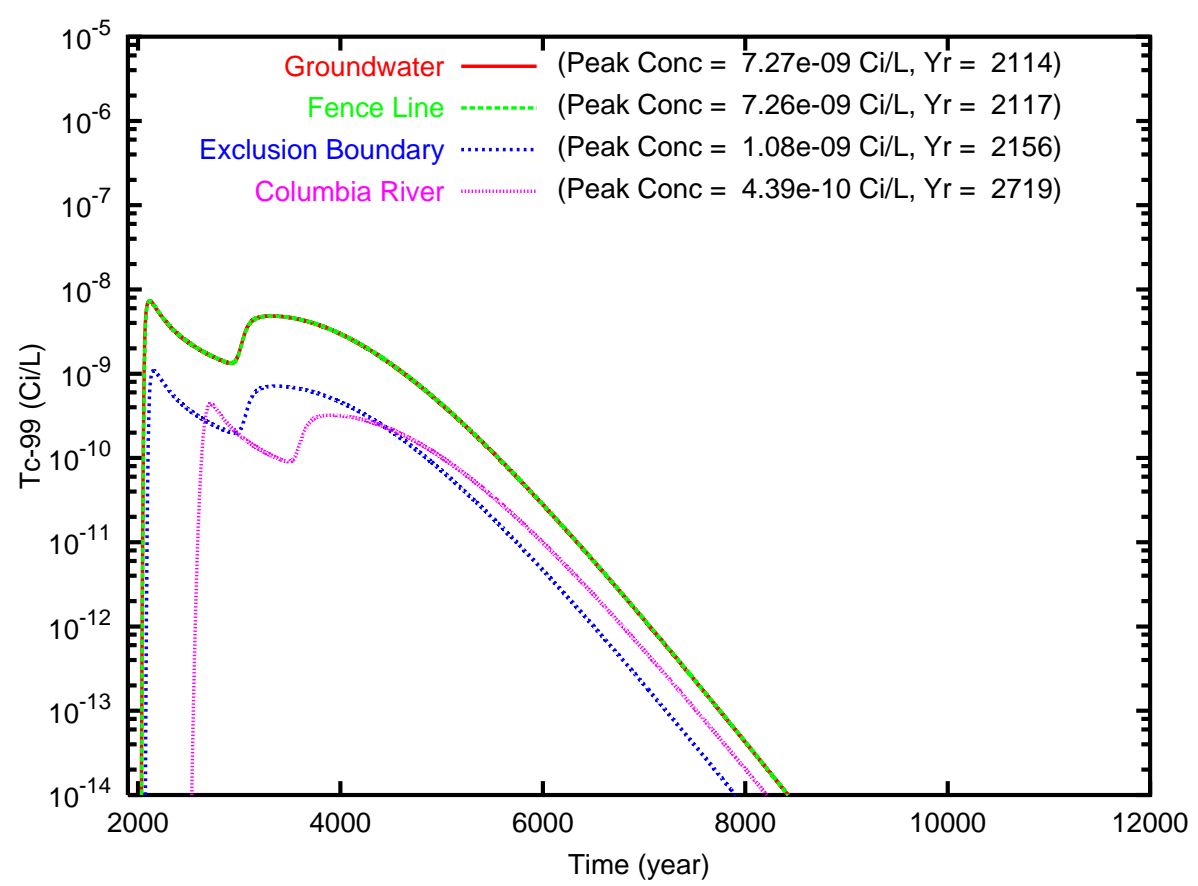

Figure B.66. Case 4-HiK, Tc-99 concentration versus time for the fence line, exclusion boundary and Columbia River compliance points for travel paths (a) southeast and (b) north through the gap 
(a)

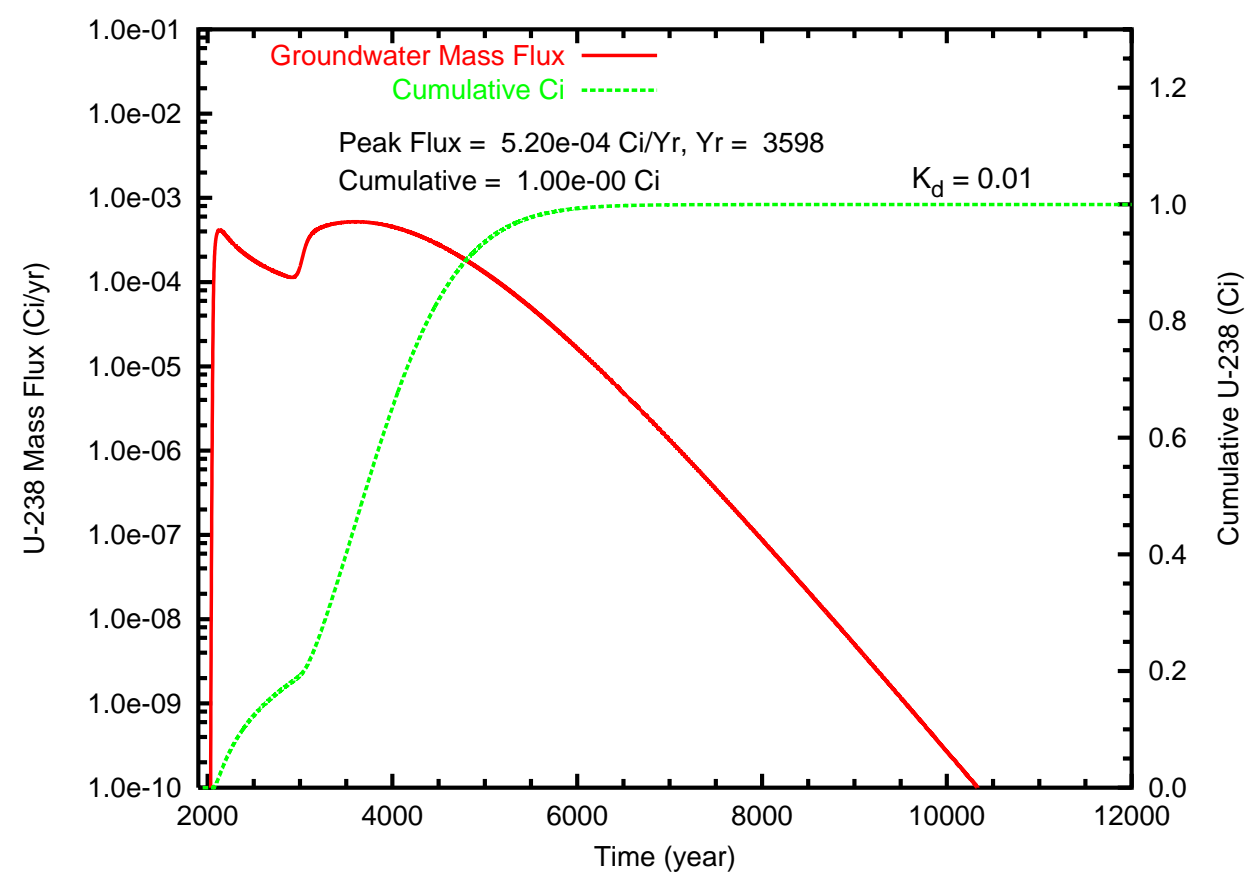

(b)

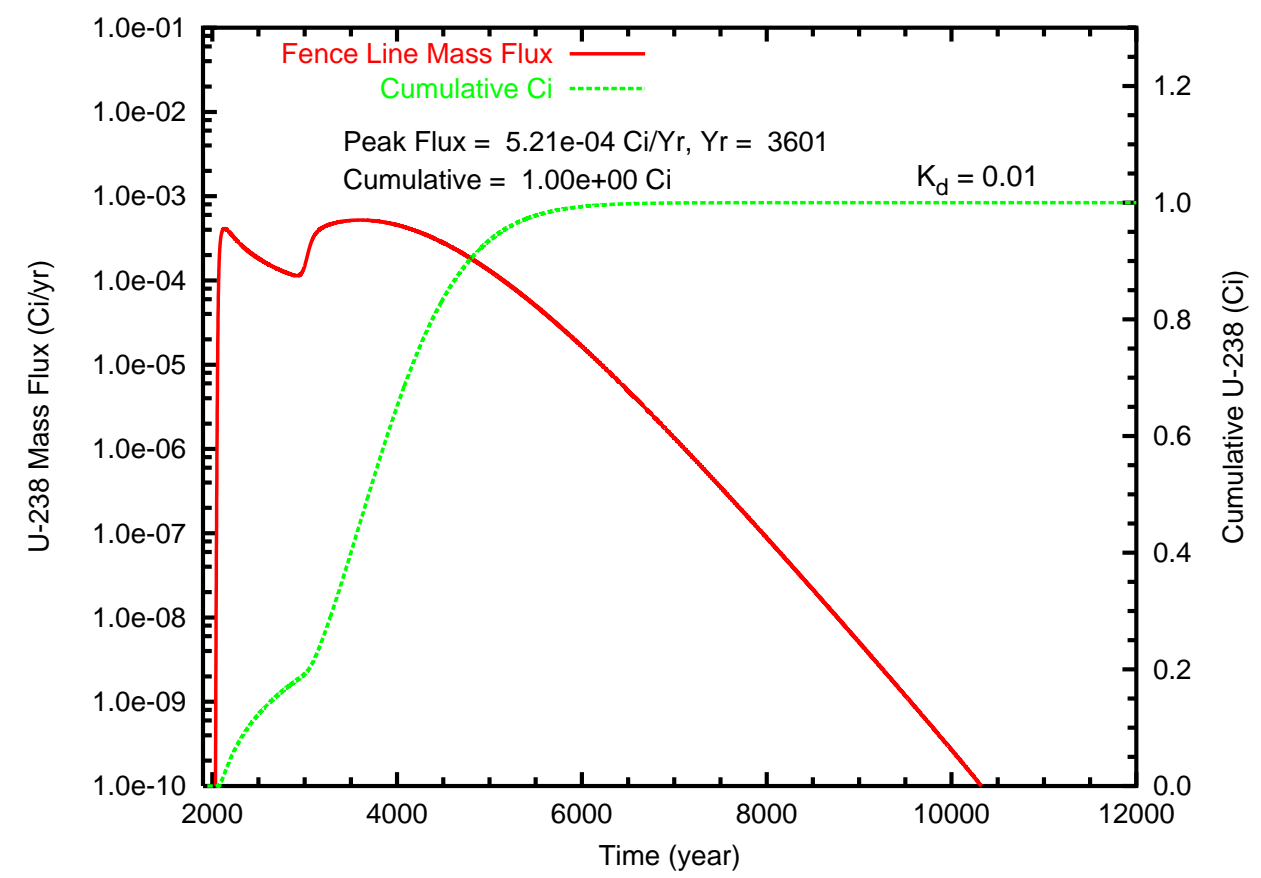

Figure B.67. Case 4-HiK, U-238 $\left(\mathrm{K}_{d}=0.01\right)$ mass flux $(\mathrm{Ci} / \mathrm{L})$ and cumulative mass $(\mathrm{Ci})$ at (a) the groundwater table and (b) the fence line 
(a)

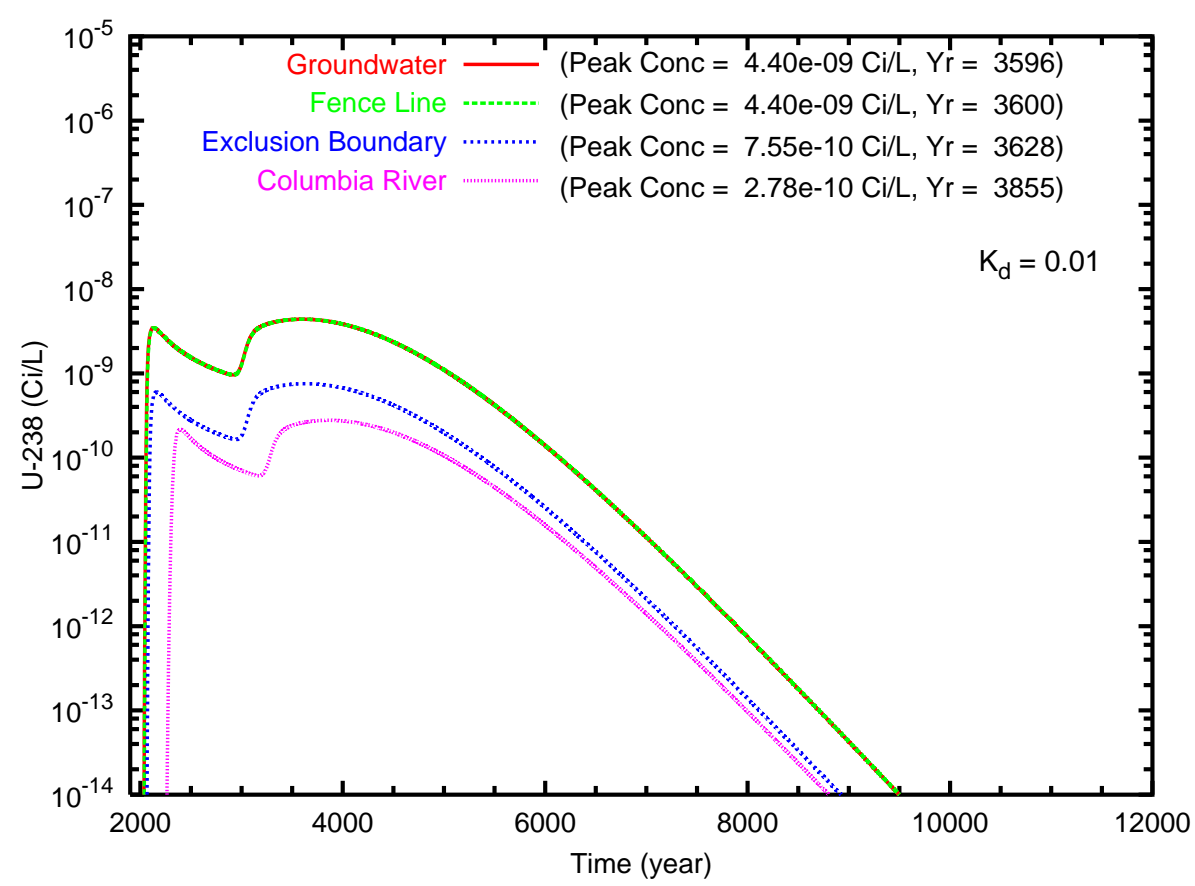

(b)

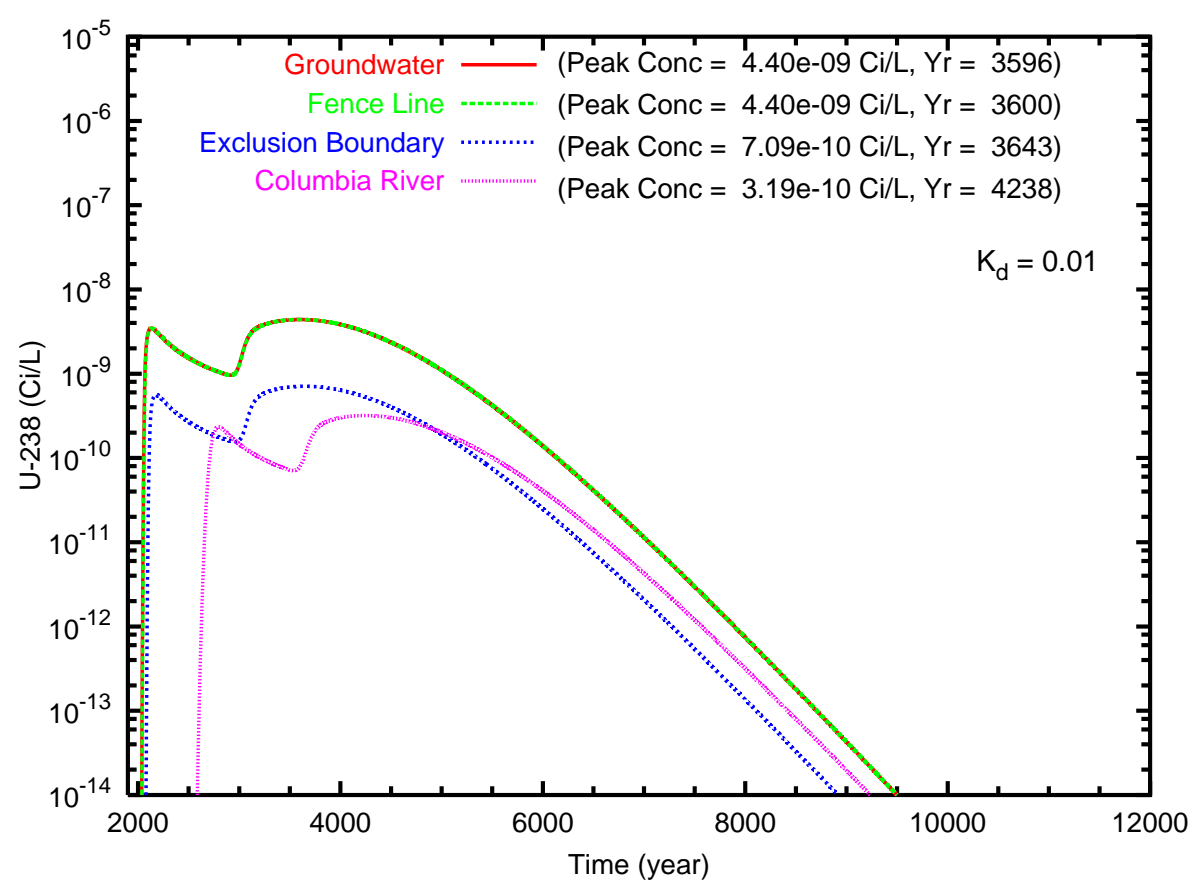

Figure B.68. Case 4-HiK, U-238 $\left(\mathrm{K}_{d}=0.01\right)$ concentration versus time for the fence line exclusion boundary and Columbia River compliance points for travel paths (a) southeast and (b) north through the gap 
(a)

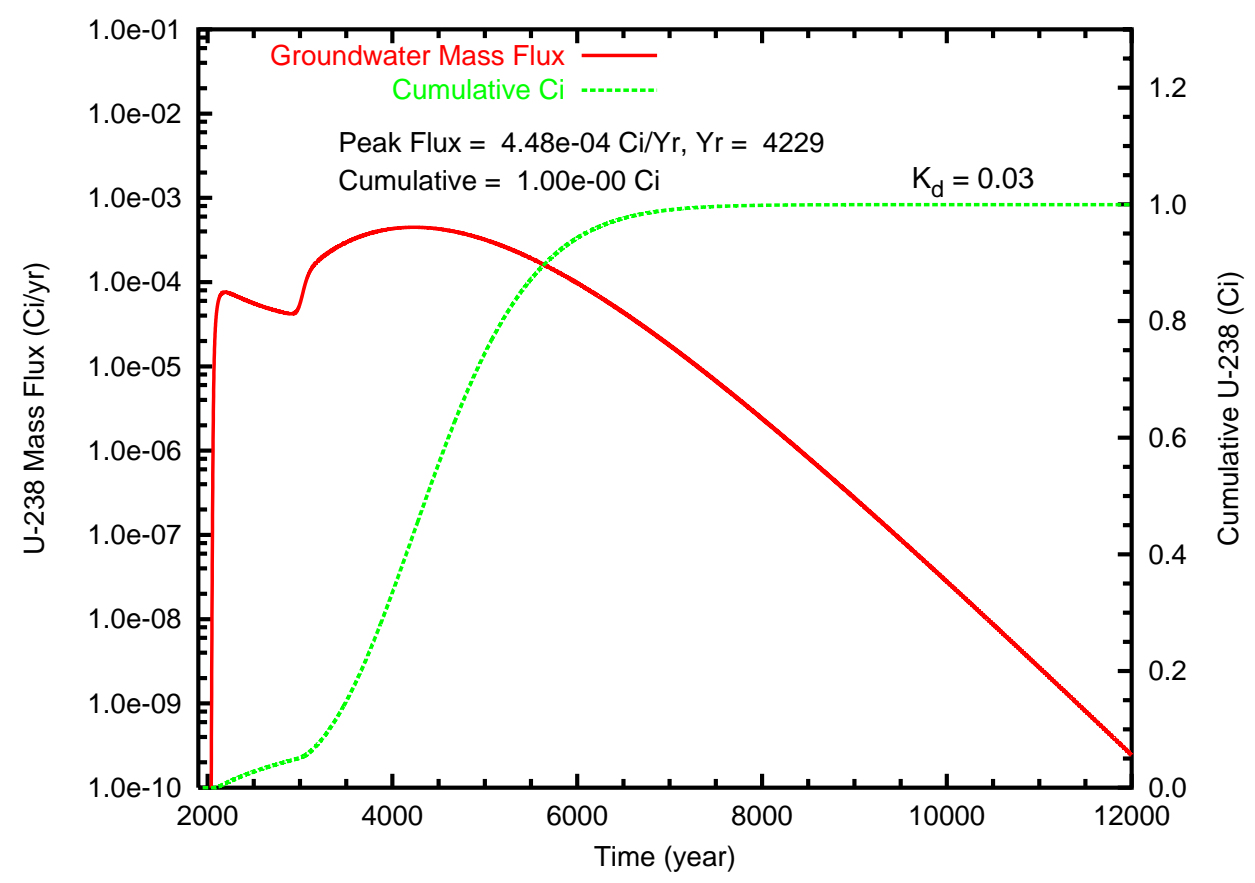

(b)

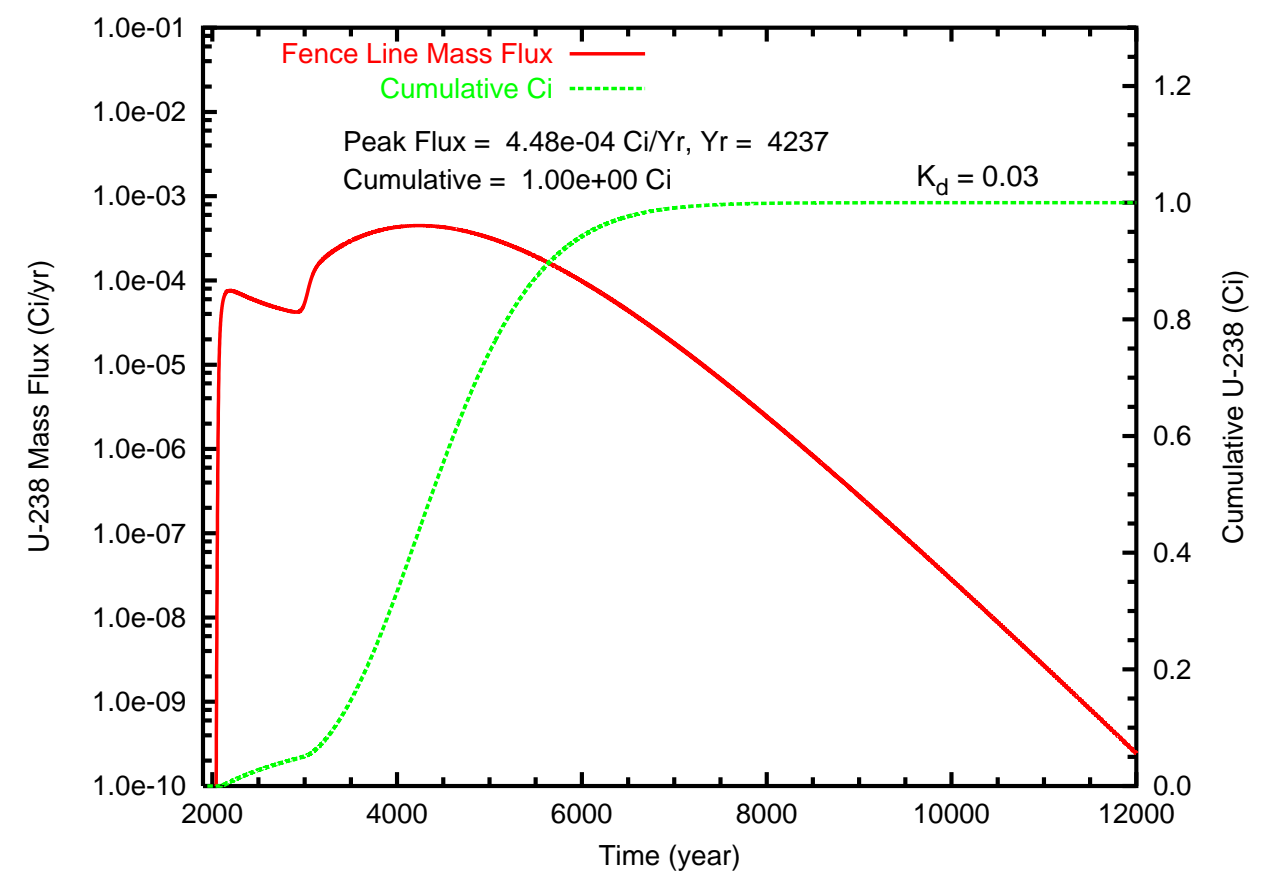

Figure B.69. Case 4-HiK, U-238 $\left(\mathrm{K}_{d}=0.03\right)$ mass flux $(\mathrm{Ci} / \mathrm{L})$ and cumulative mass $(\mathrm{Ci})$ at (a) the groundwater table and (b) the fence line 
(a)

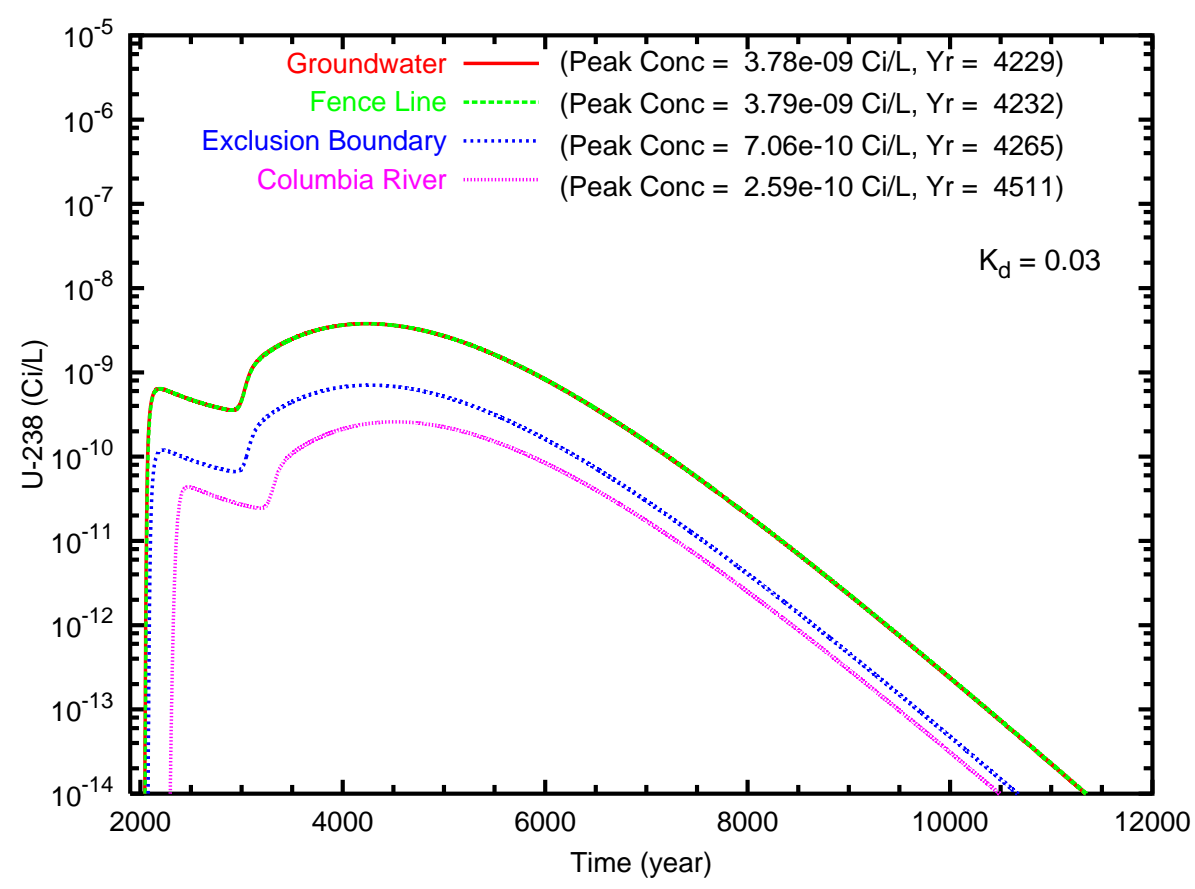

(b)

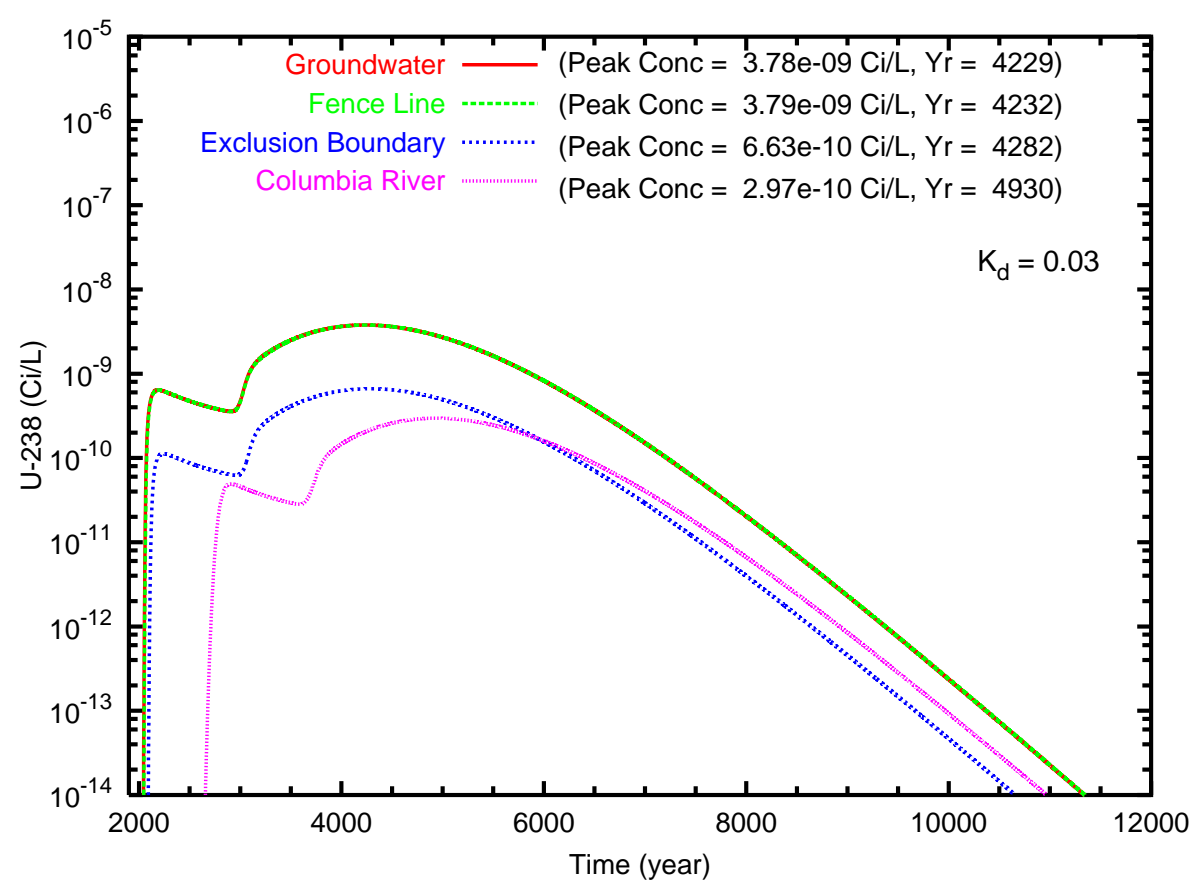

Figure B.70. Case 4-HiK, U-238 $\left(\mathrm{K}_{d}=0.03\right)$ concentration versus time for the fence line exclusion boundary and Columbia River compliance points for travel paths (a) southeast and (b) north through the gap 
(a)

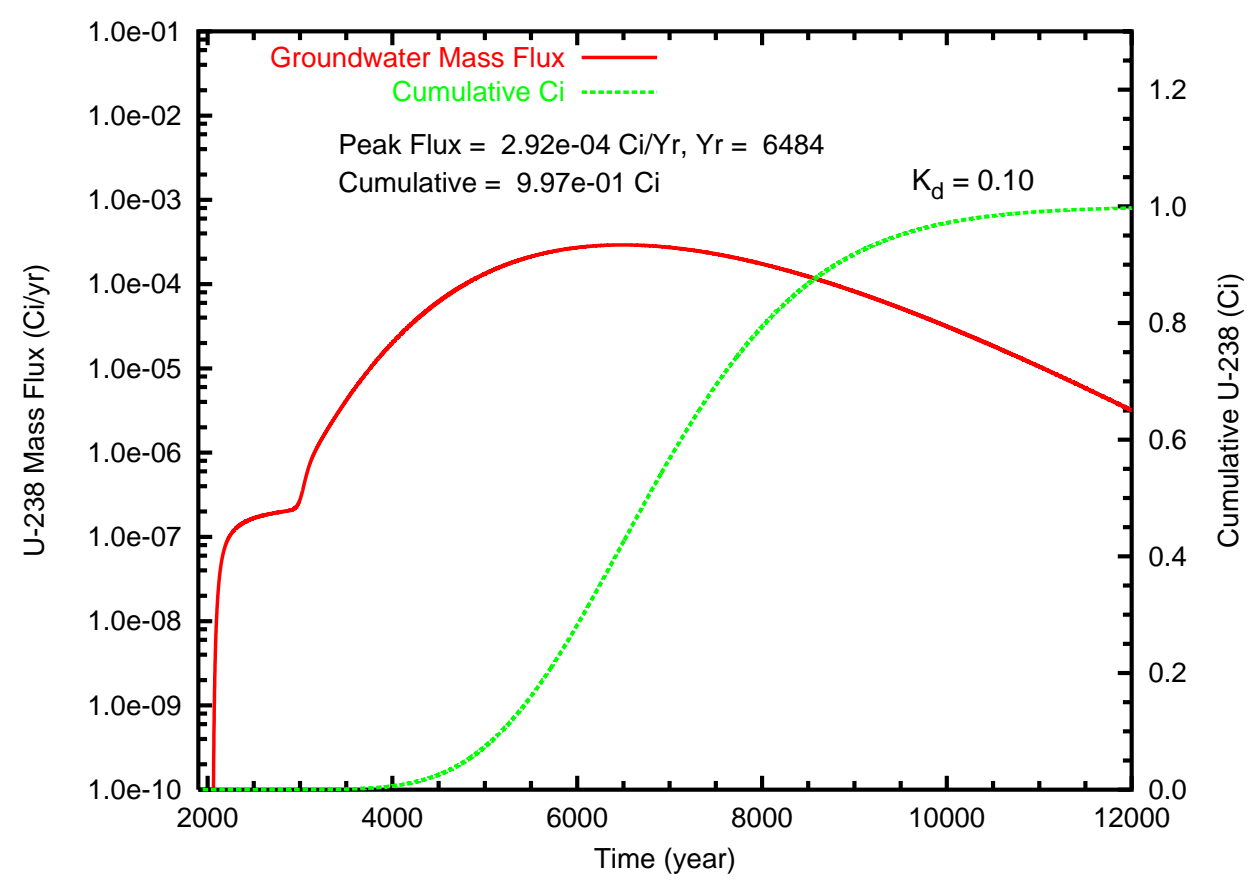

(b)

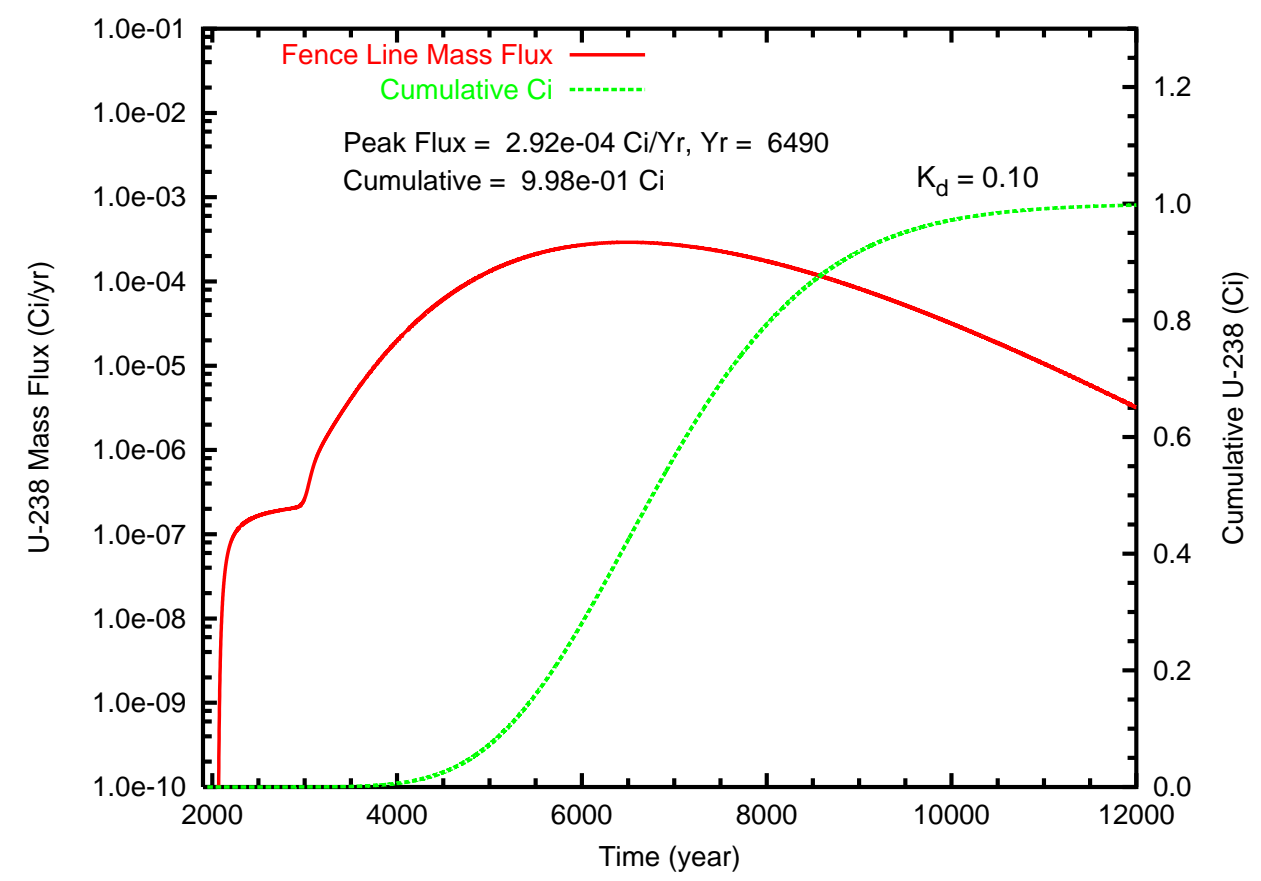

Figure B.71. Case 4-HiK, U-238 $\left(\mathrm{K}_{d}=0.10\right)$ mass flux $(\mathrm{Ci} / \mathrm{L})$ and cumulative mass $(\mathrm{Ci})$ at (a) the groundwater table and (b) the fence line 
(a)

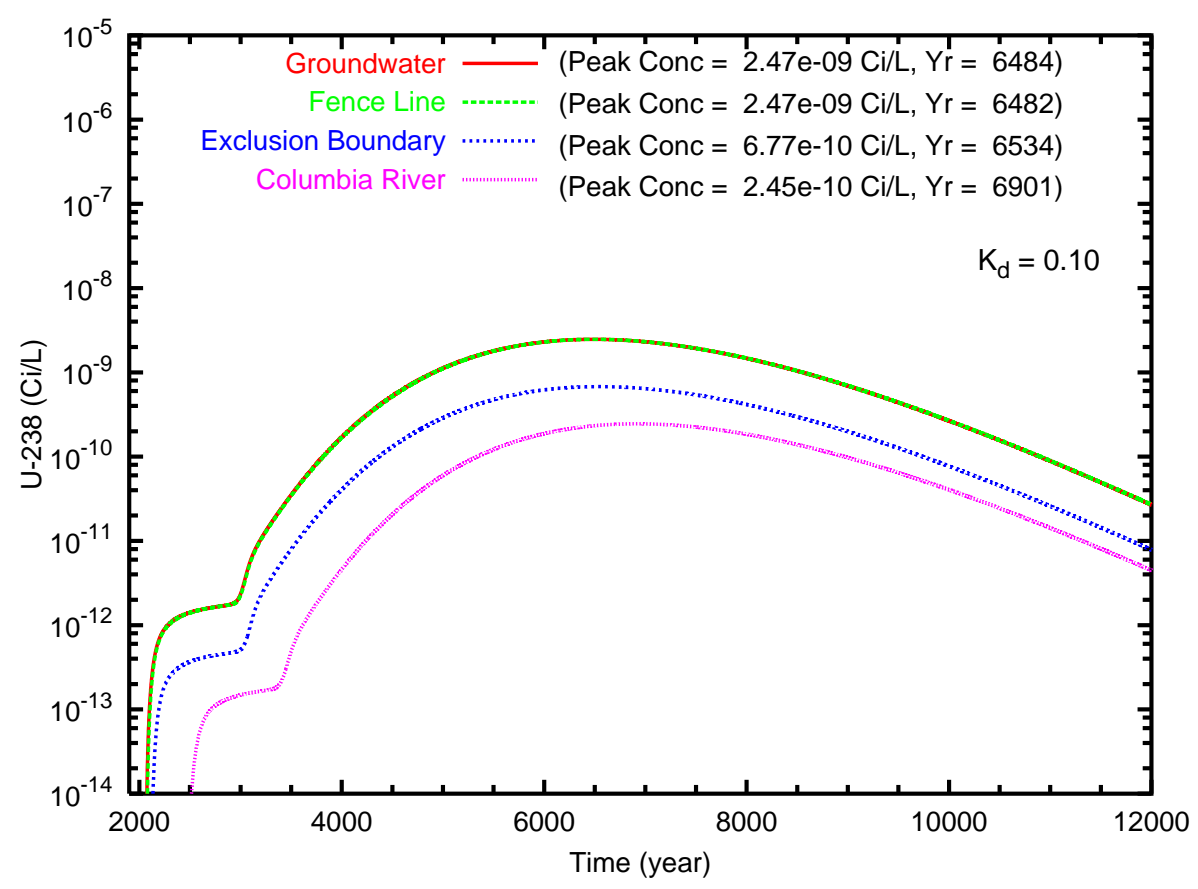

(b)

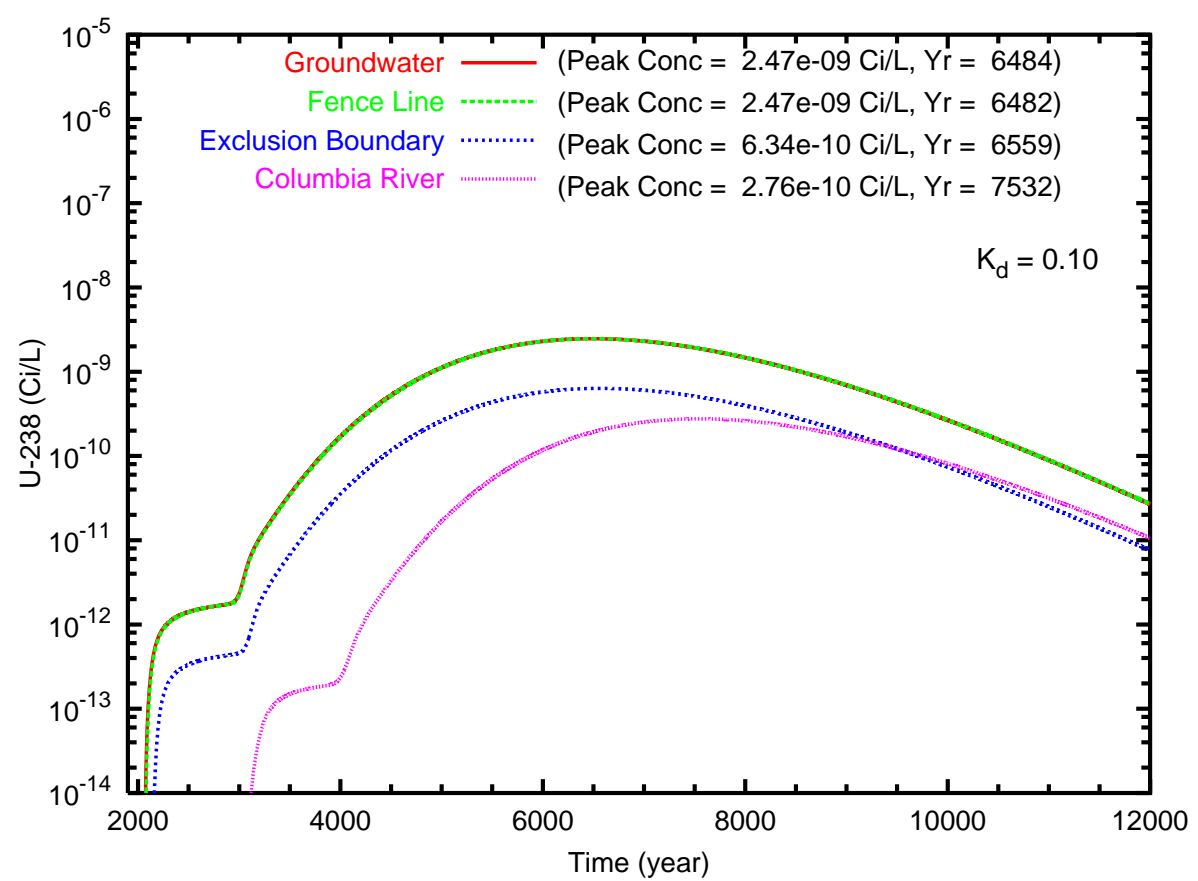

Figure B.72. Case 4-HiK, U-238 $\left(\mathrm{K}_{d}=0.10\right)$ concentration versus time for the fence line exclusion boundary and Columbia River compliance points for travel paths (a) southeast and (b) north through the gap 
(a)

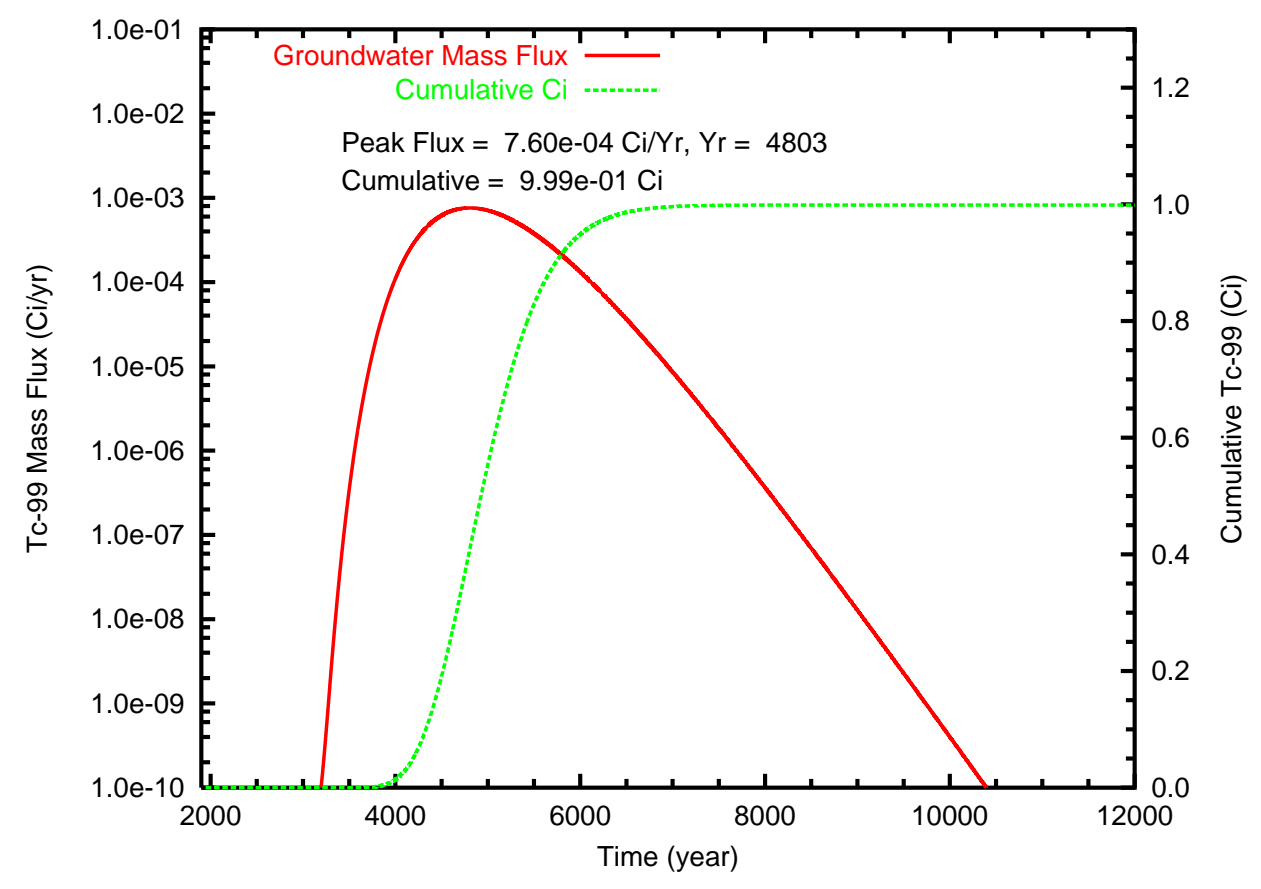

(b)

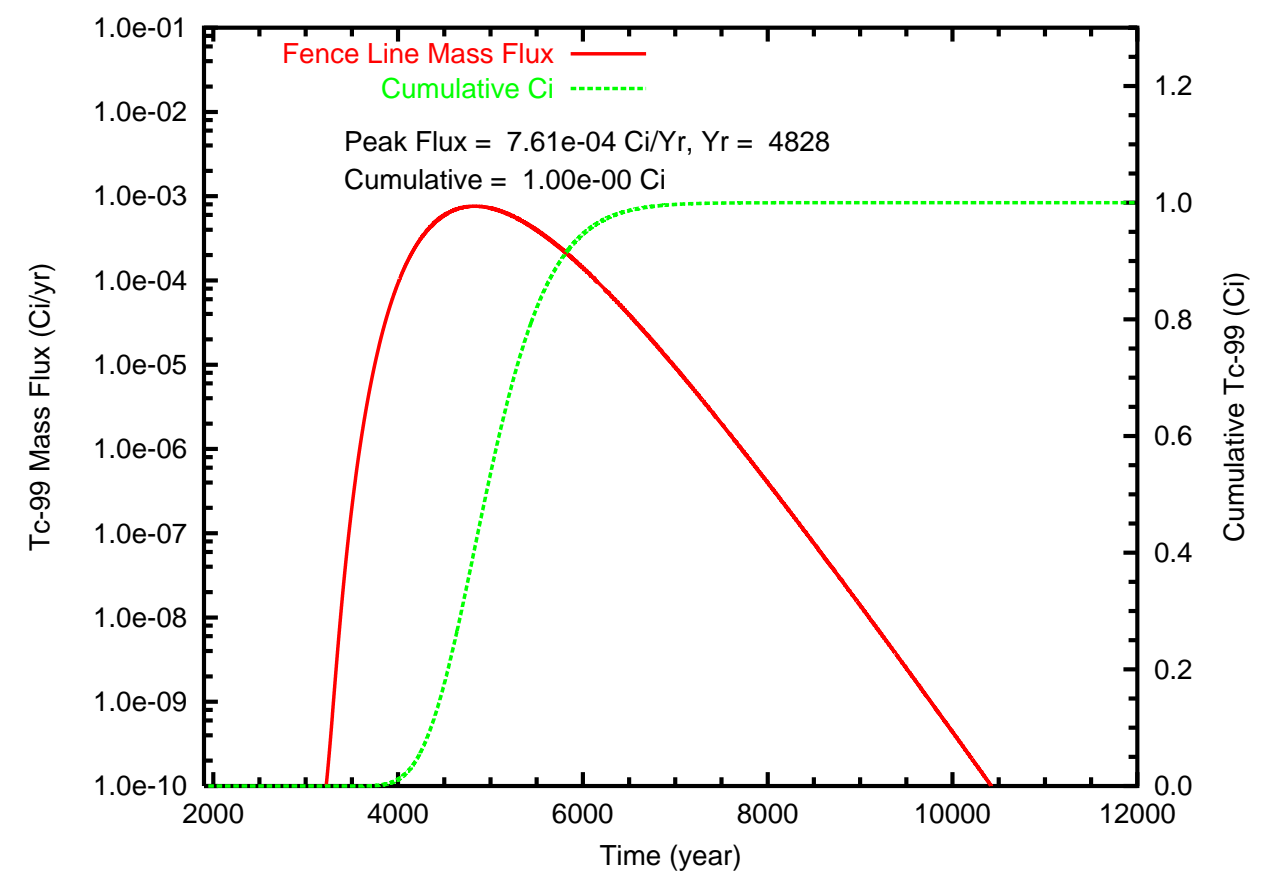

Figure B.73. Case 5, Tc-99 mass flux and cumulative mass at (a) the groundwater table and (b) the fence line 
(a)

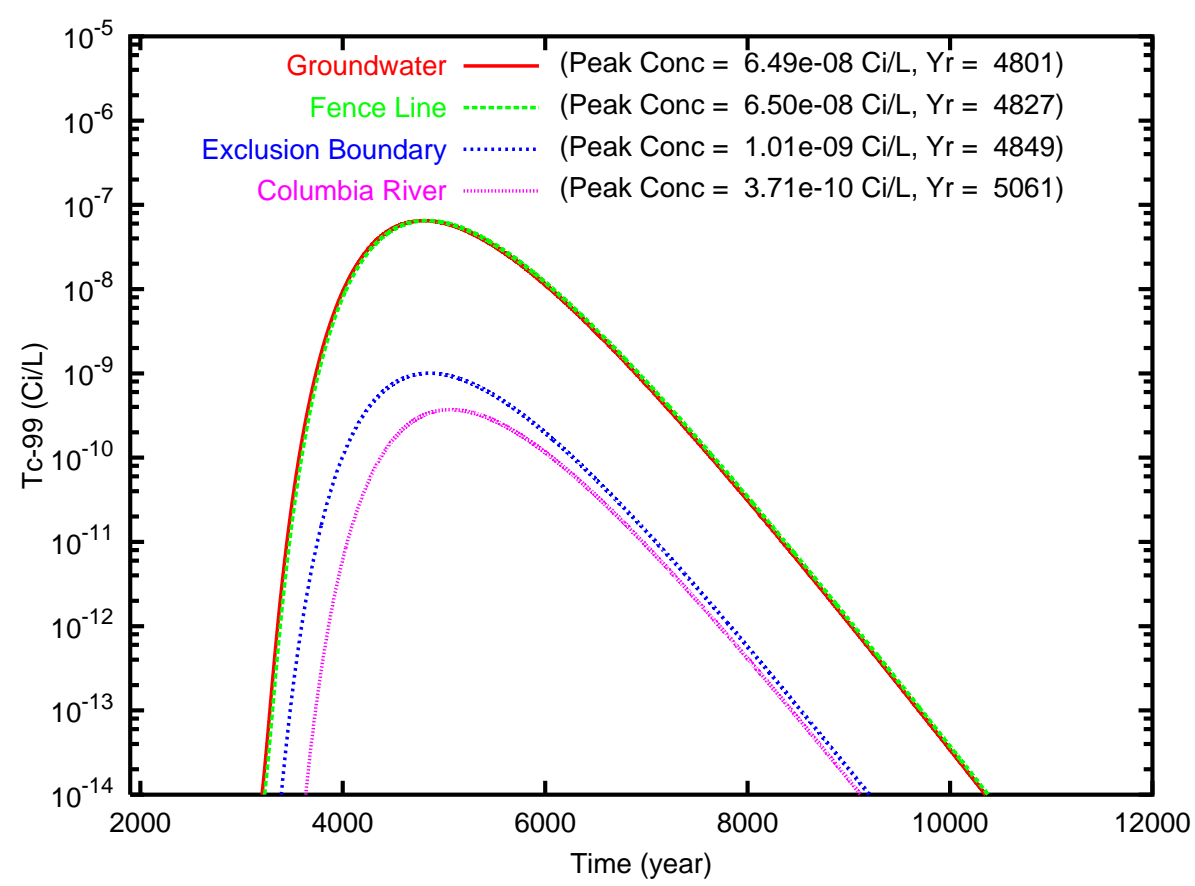

(b)

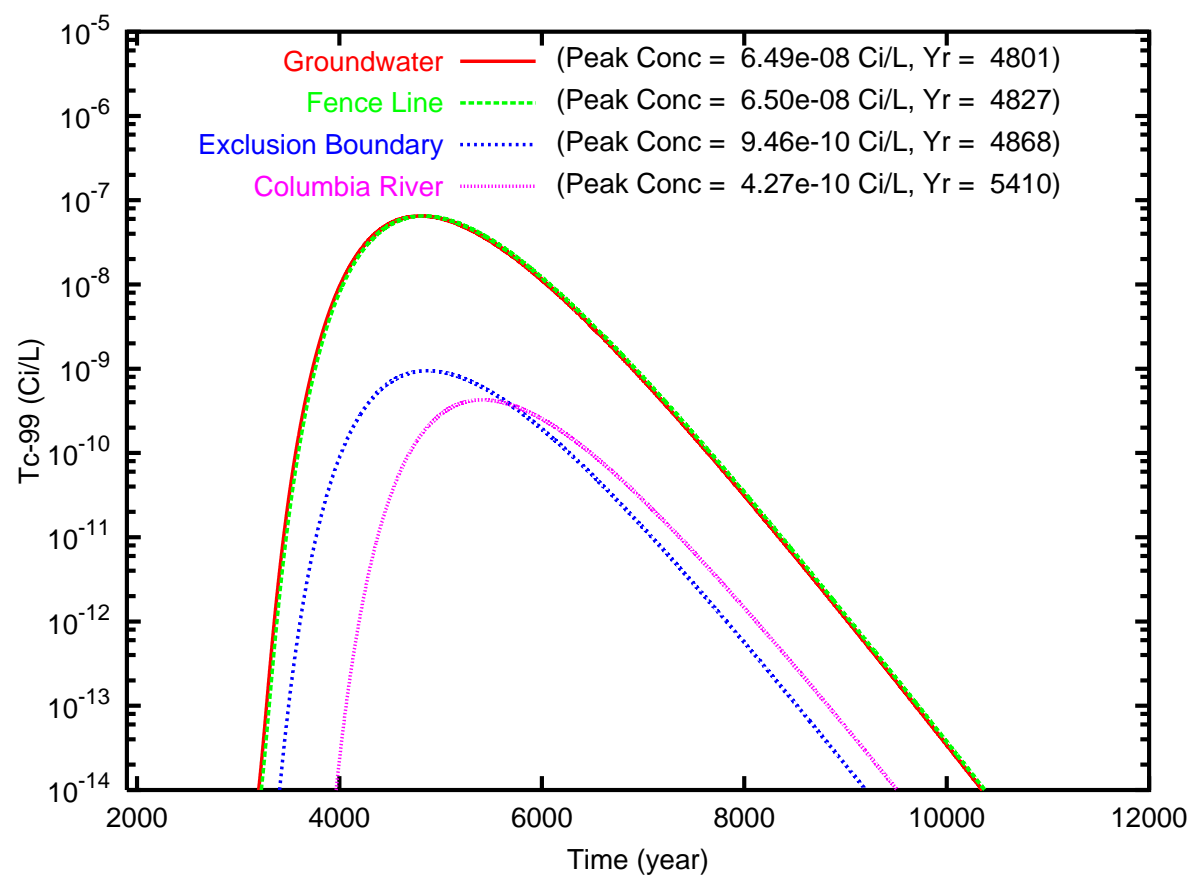

Figure B.74. Case 5, Tc-99 concentration versus time for the fence line, exclusion boundary and Columbia River compliance points for travel paths (a) southeast and (b) north through the gap 
(a)

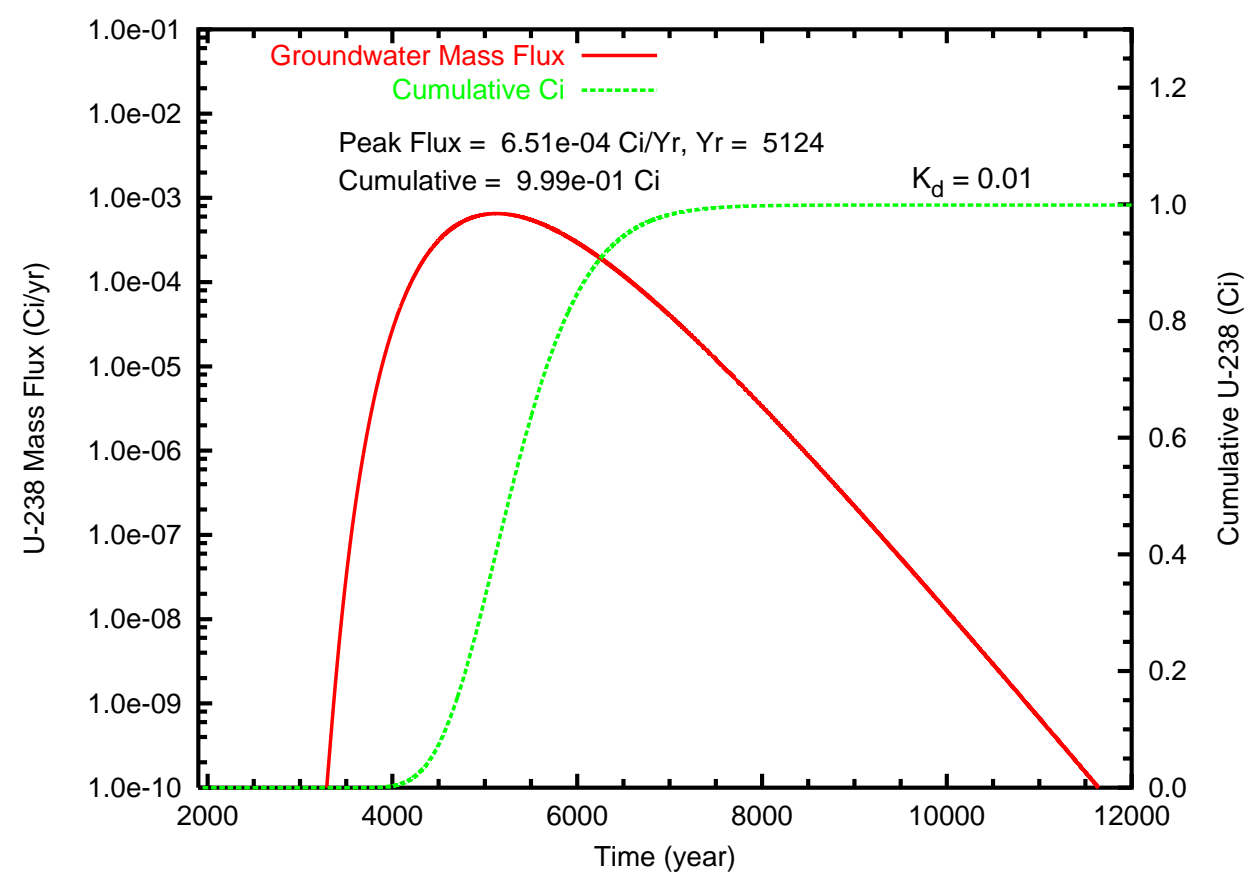

(b)

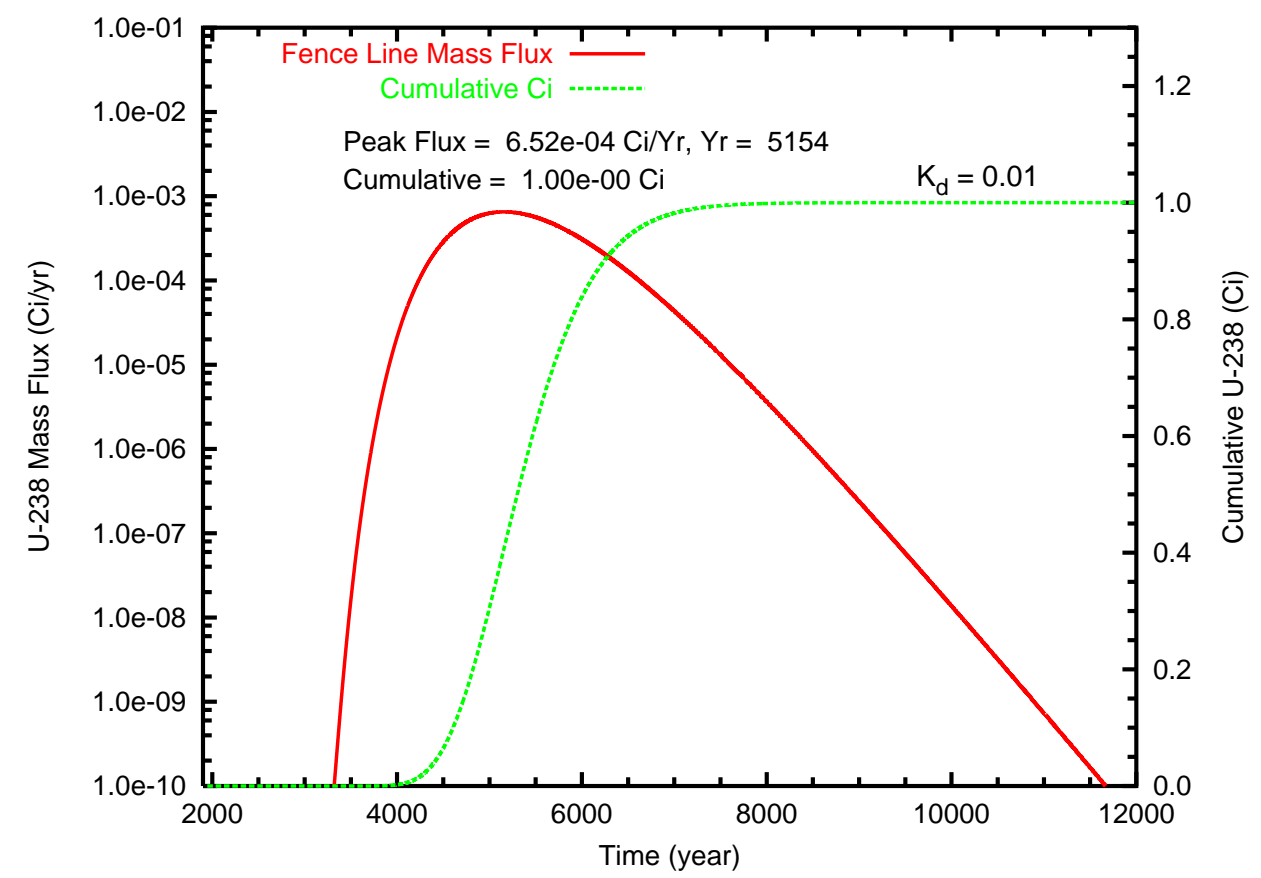

Figure B.75. Case 5, U-238 $\left(\mathrm{K}_{d}=0.01\right)$ mass flux $(\mathrm{Ci} / \mathrm{L})$ and cumulative mass $(\mathrm{Ci})$ at (a) the groundwater table and (b) the fence line 
(a)

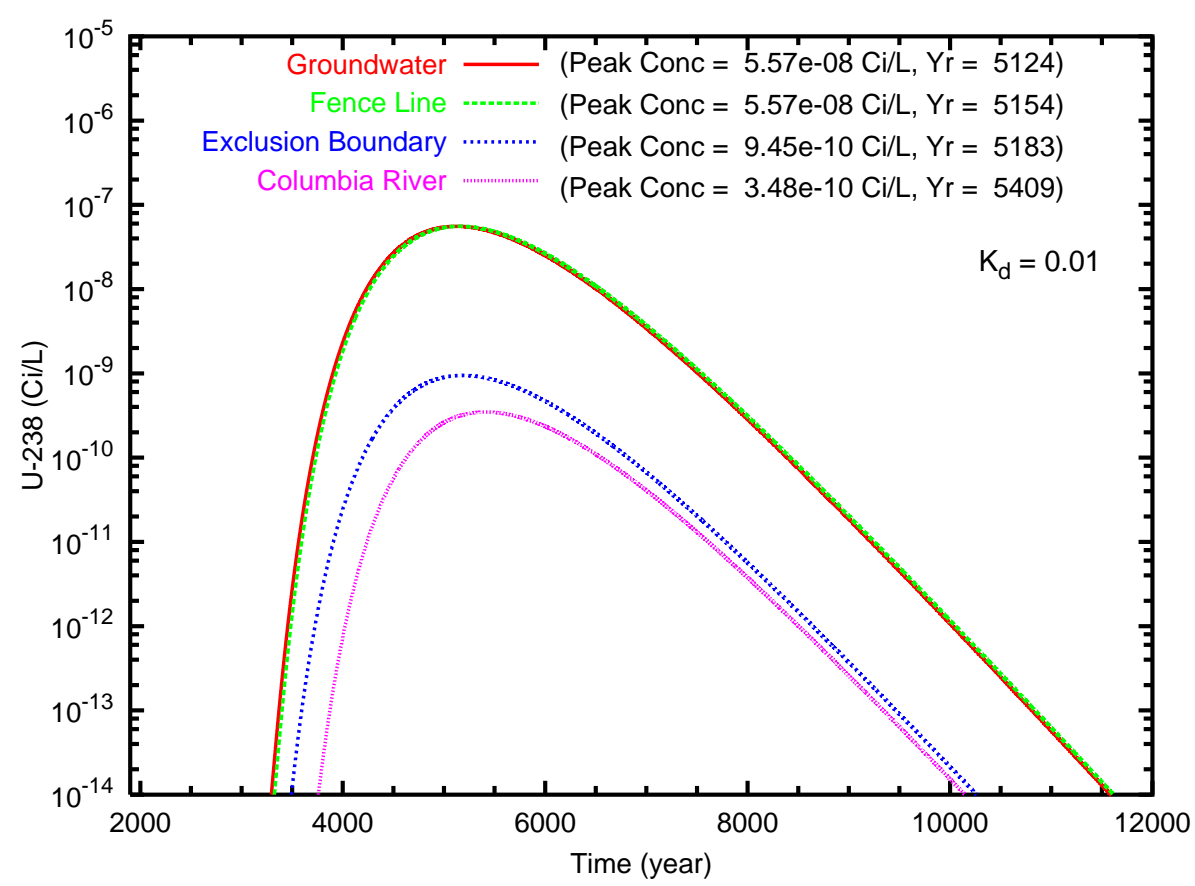

(b)

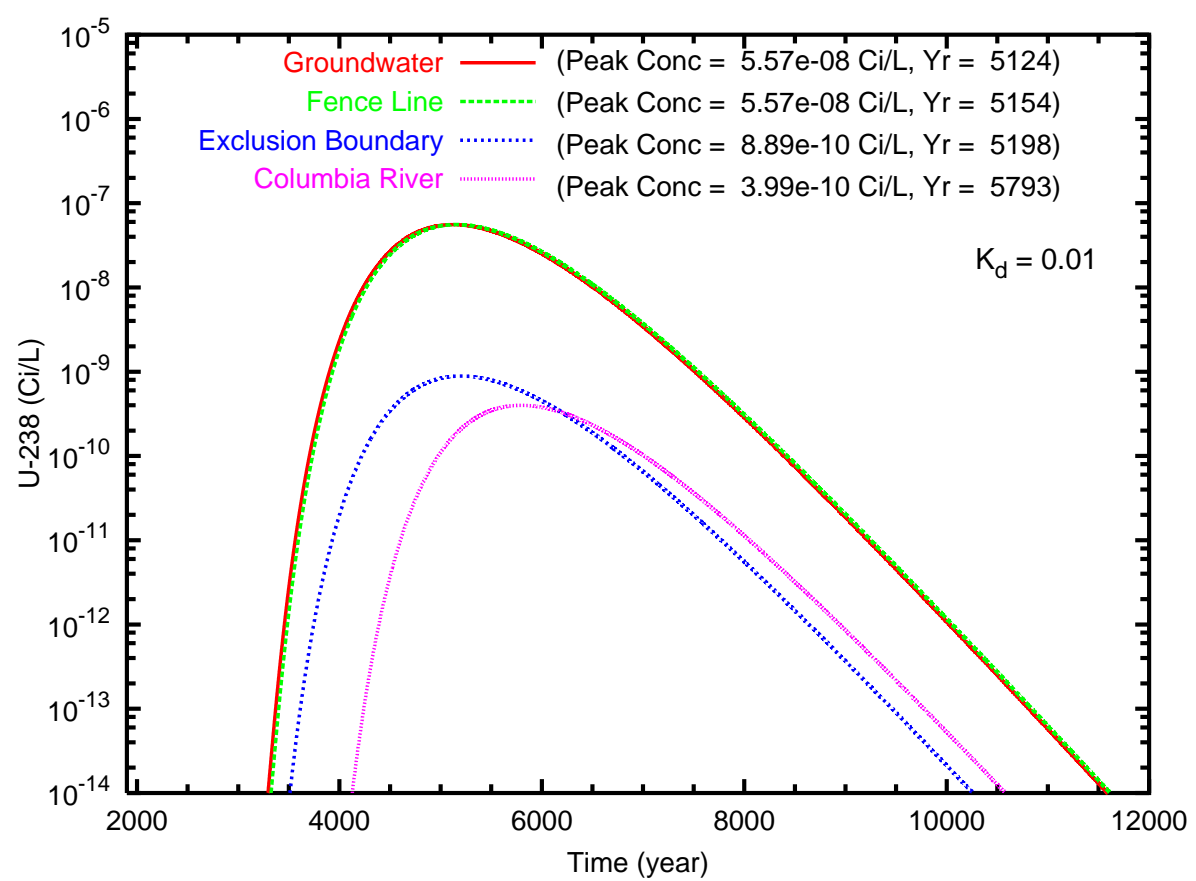

Figure B.76. Case 5, U-238 $\left(\mathrm{K}_{d}=0.01\right)$ concentration versus time for the fence line exclusion boundary and Columbia River compliance points for travel paths (a) southeast and (b) north through the gap 
(a)

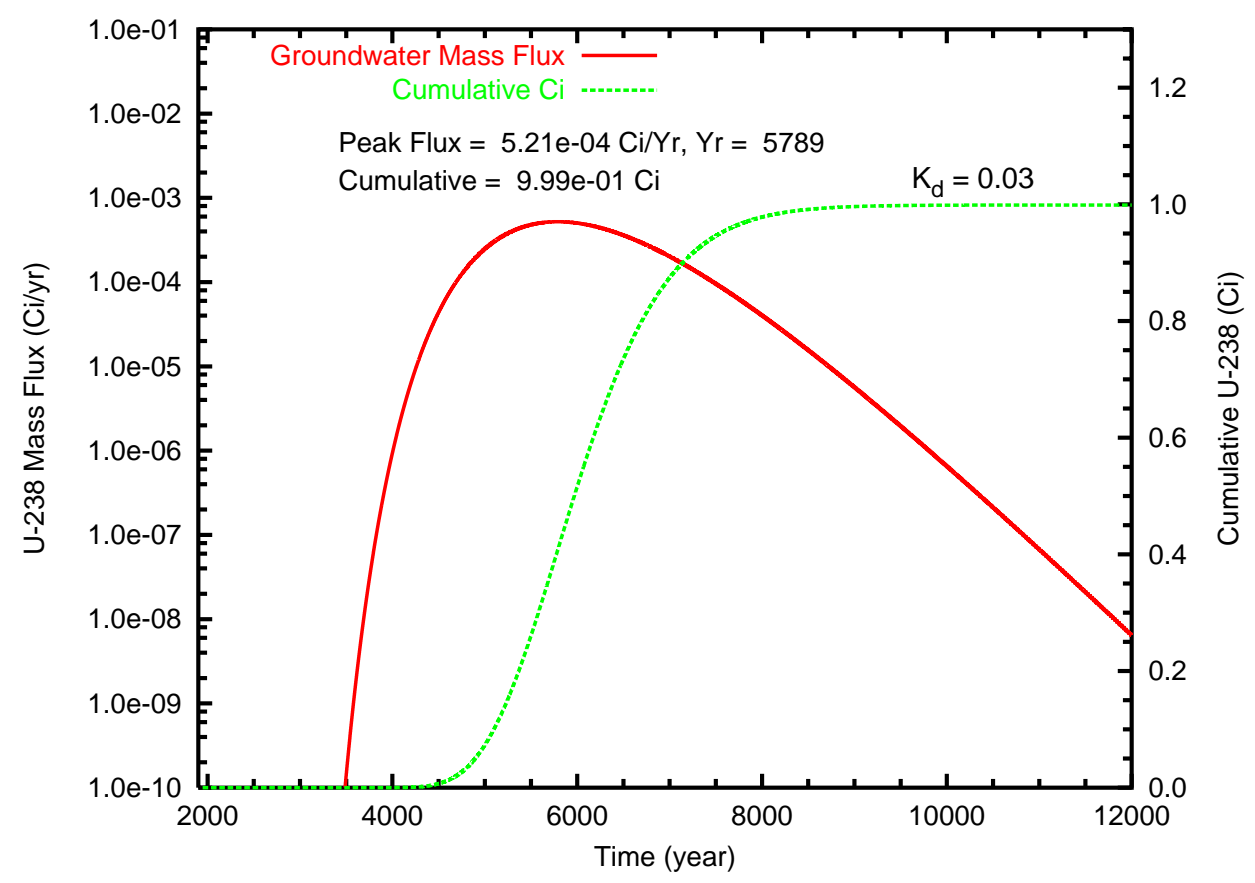

(b)

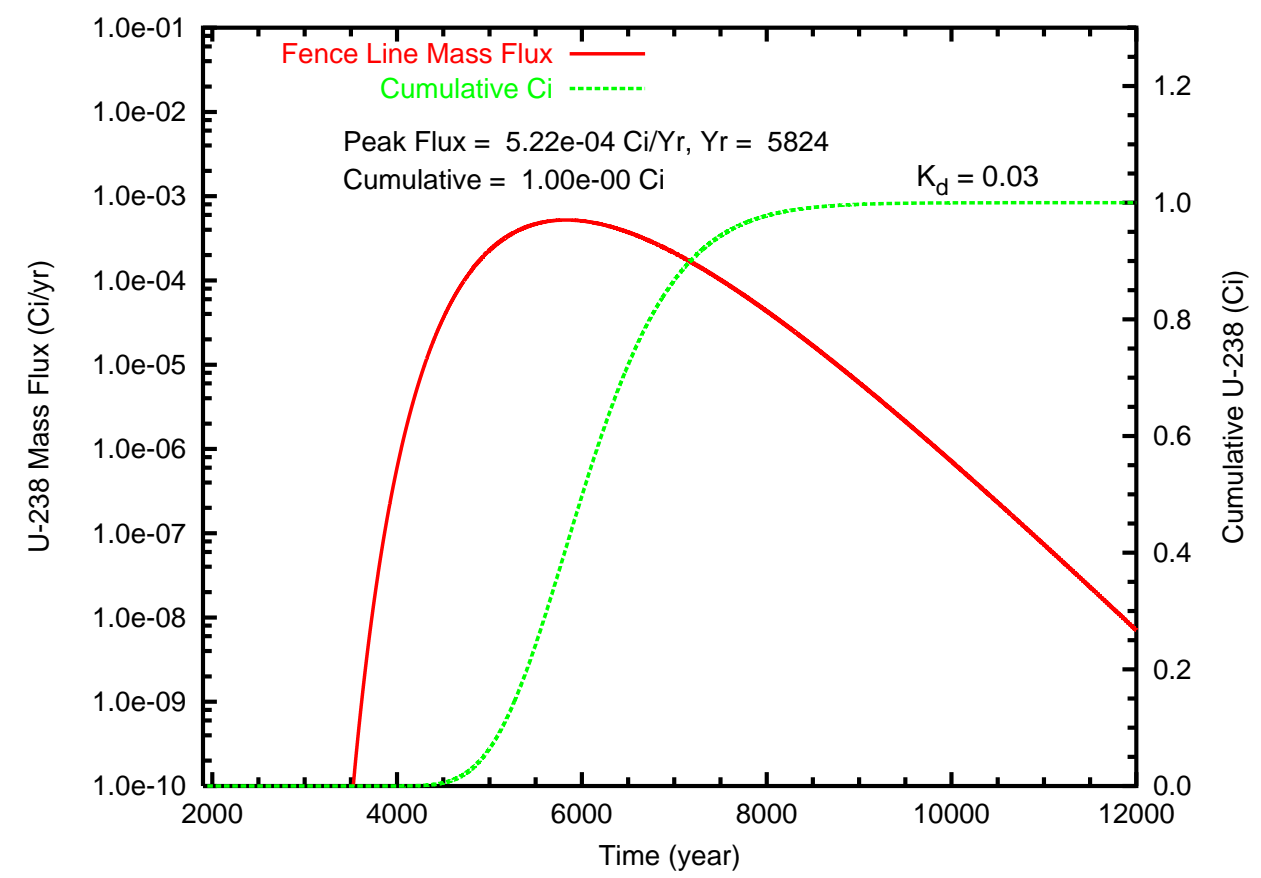

Figure B.77. Case 5, U-238 $\left(\mathrm{K}_{d}=0.03\right)$ mass flux $(\mathrm{Ci} / \mathrm{L})$ and cumulative mass $(\mathrm{Ci})$ at (a) the groundwater table and (b) the fence line 
(a)

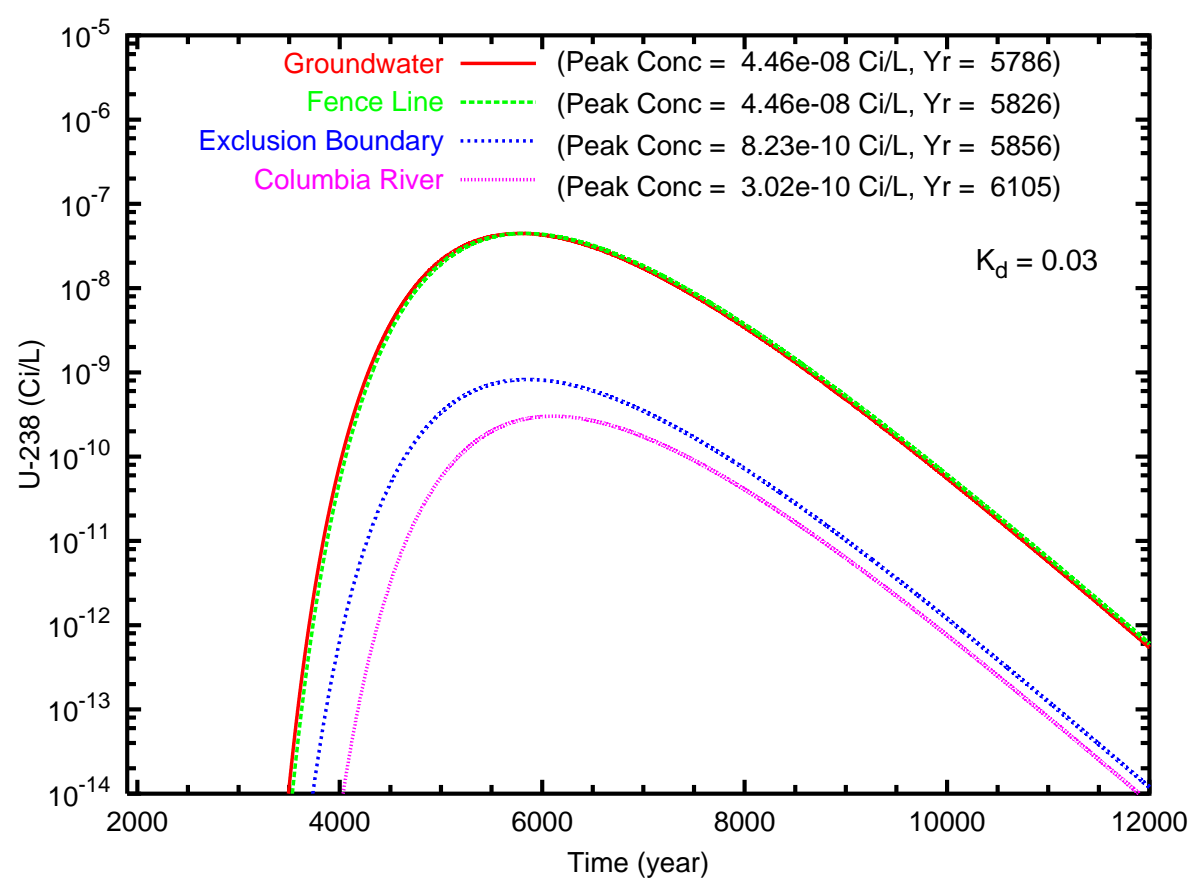

(b)

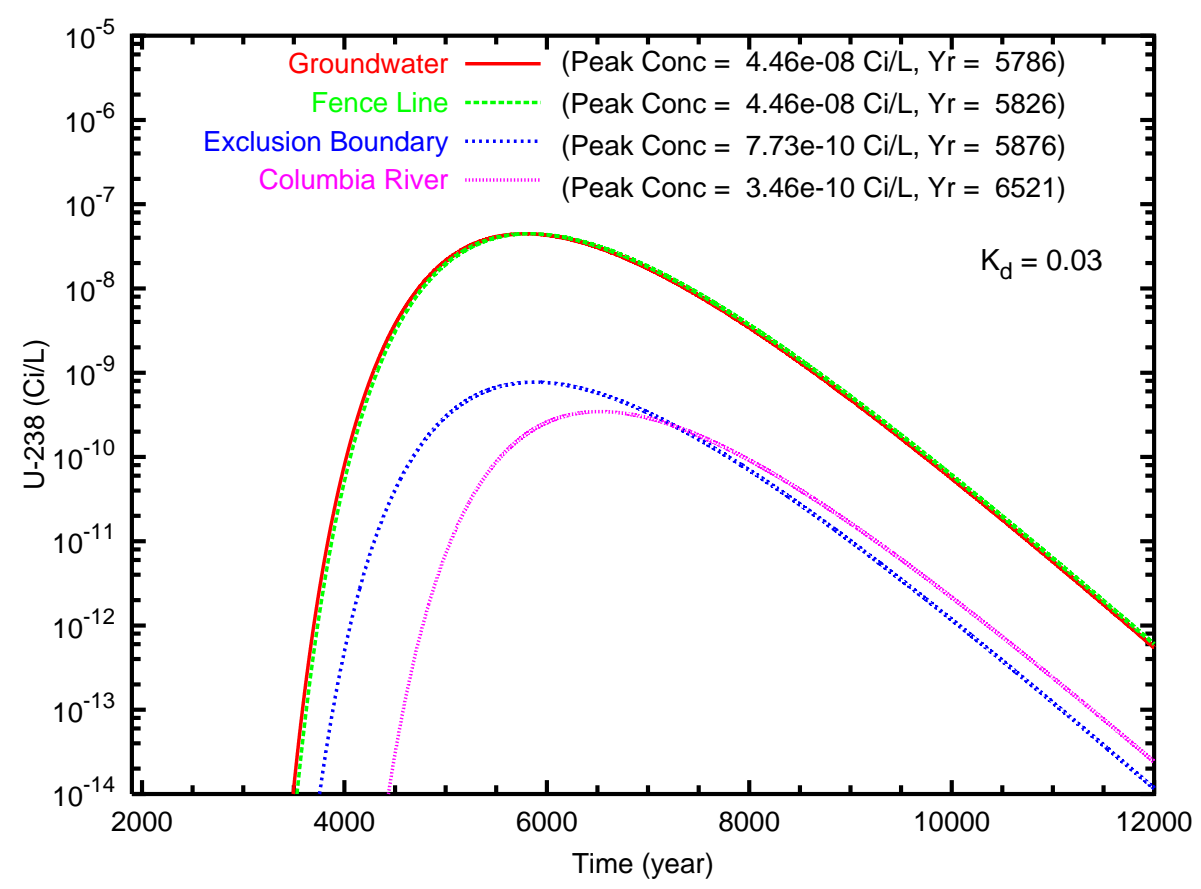

Figure B.78. Case 5, U-238 $\left(\mathrm{K}_{d}=0.03\right)$ concentration versus time for the fence line exclusion boundary and Columbia River compliance points for travel paths (a) southeast and (b) north through the gap 
(a)

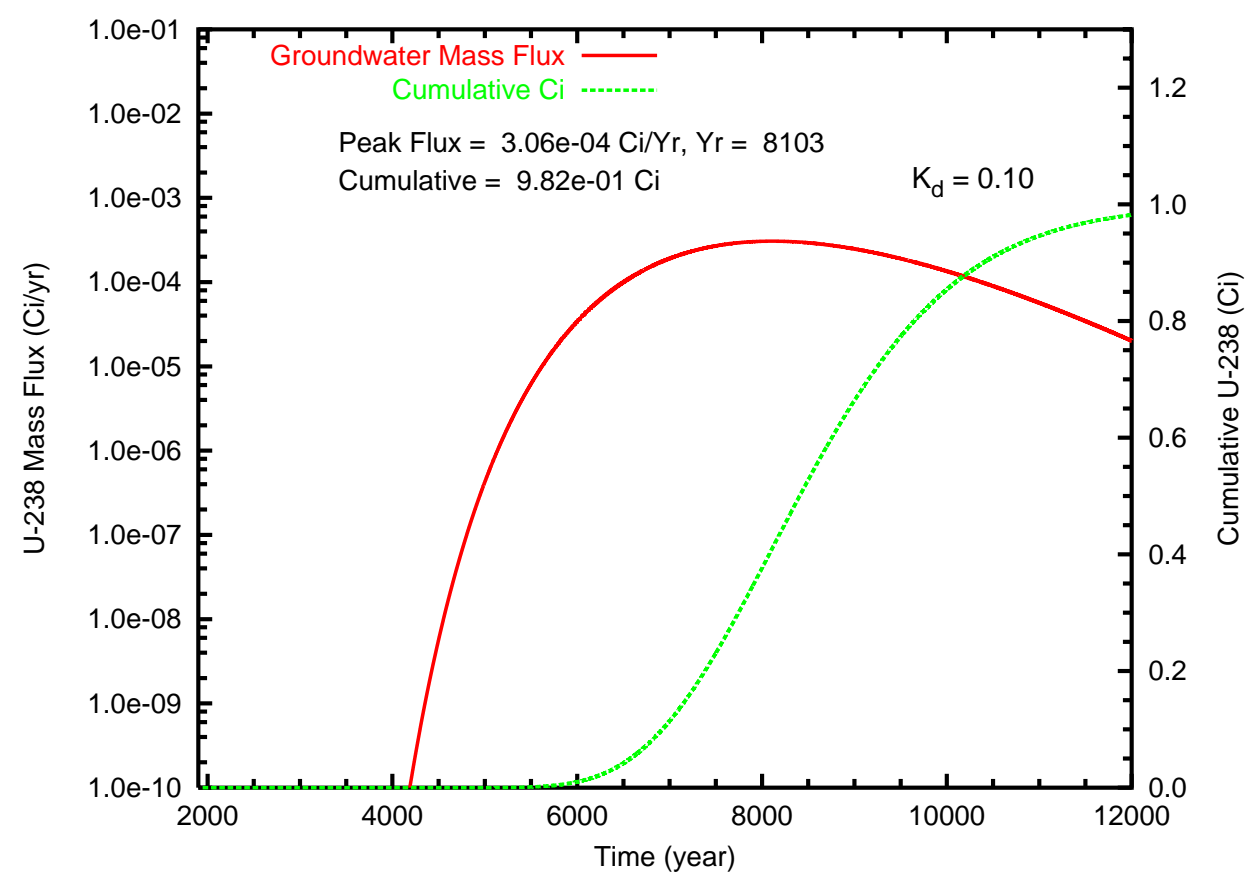

(b)

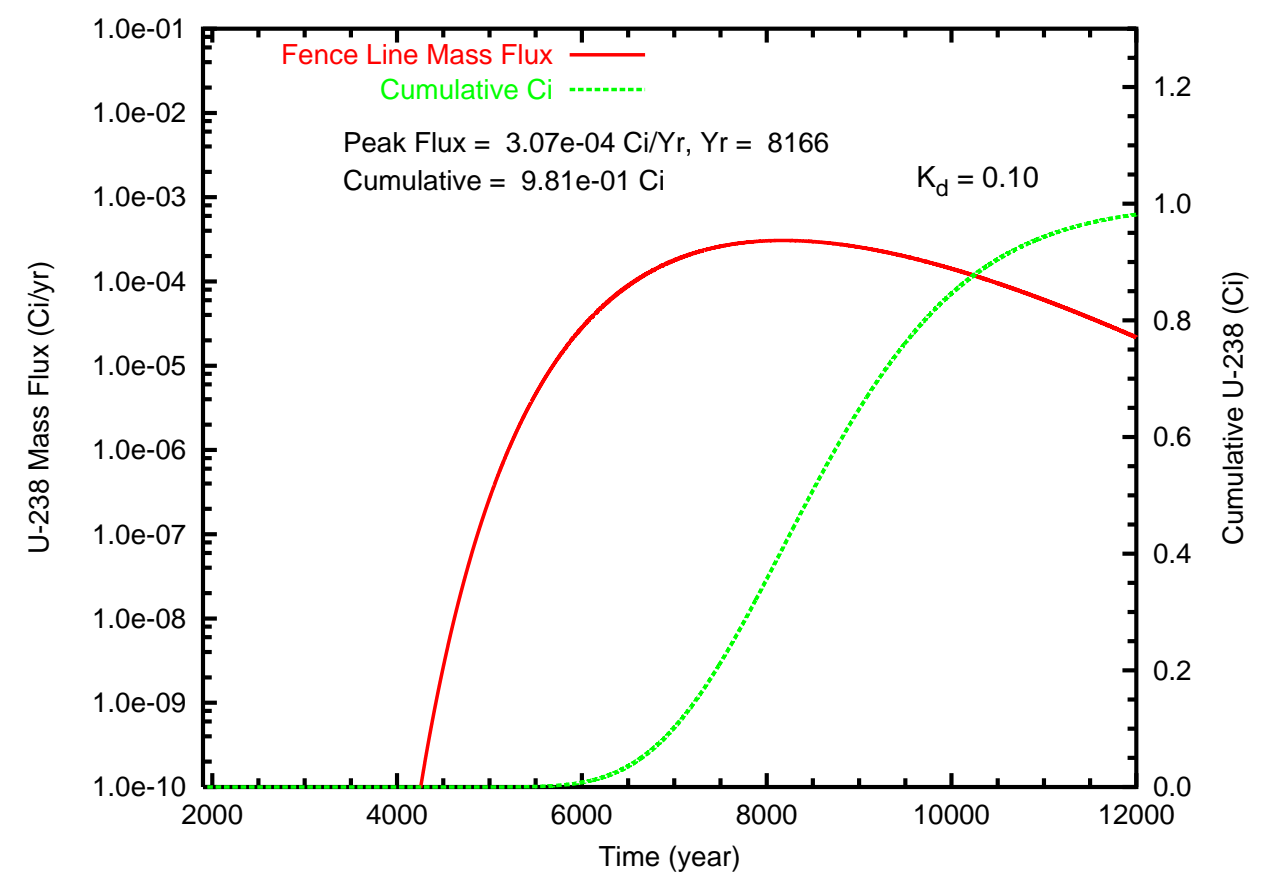

Figure B.79. Case 5, U-238 $\left(\mathrm{K}_{d}=0.10\right)$ mass flux $(\mathrm{Ci} / \mathrm{L})$ and cumulative mass $(\mathrm{Ci})$ at (a) the groundwater table and (b) the fence line 
(a)

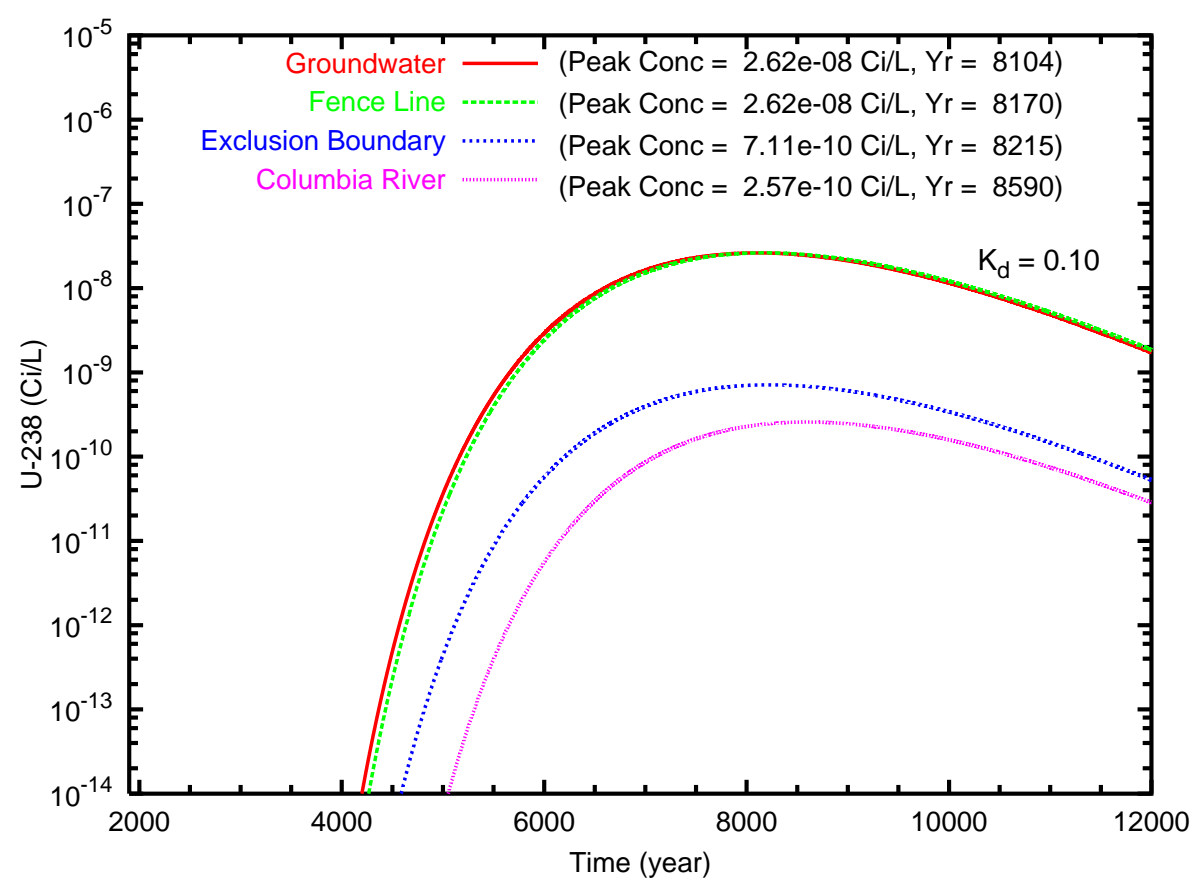

(b)

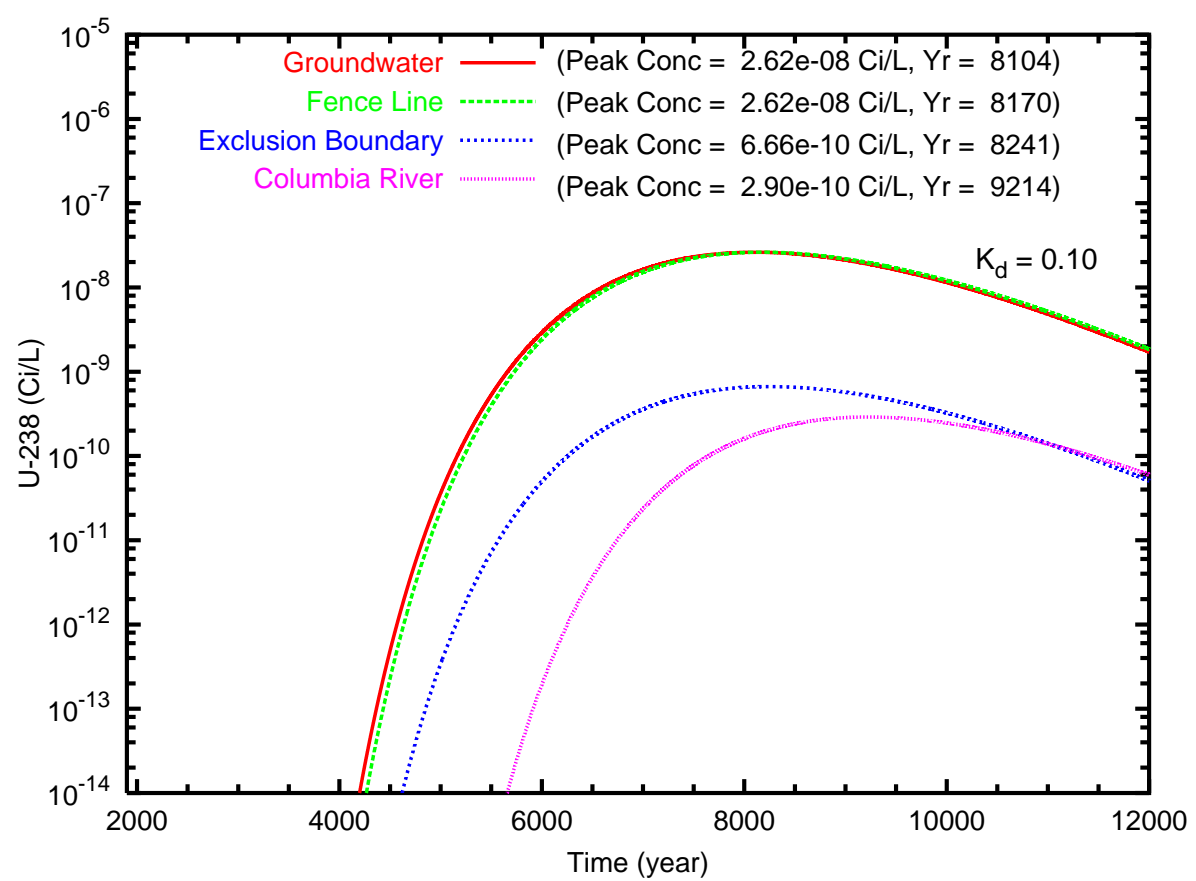

Figure B.80. Case 5, U-238 $\left(\mathrm{K}_{d}=0.10\right)$ concentration versus time for the fence line exclusion boundary and Columbia River compliance points for travel paths (a) southeast and (b) north through the gap 
(a)

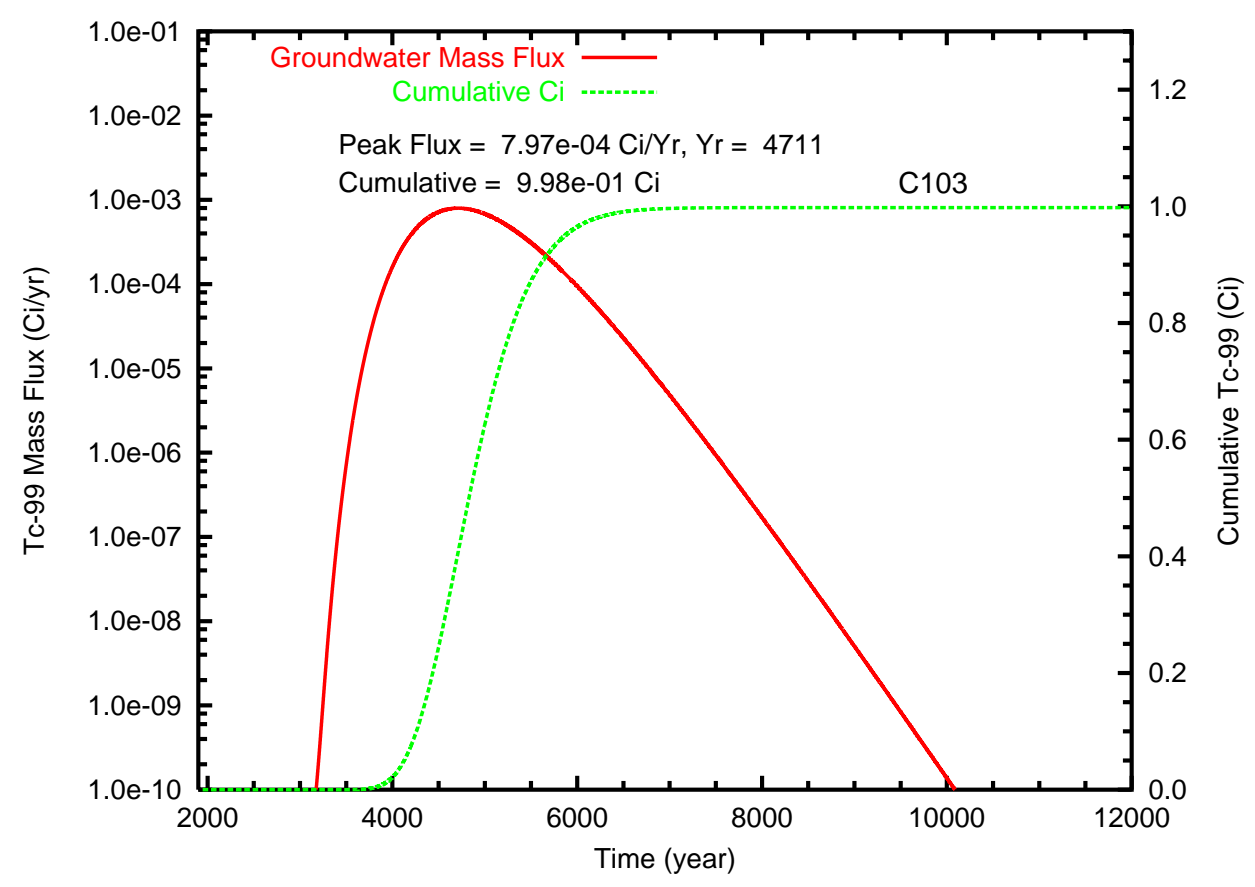

(b)

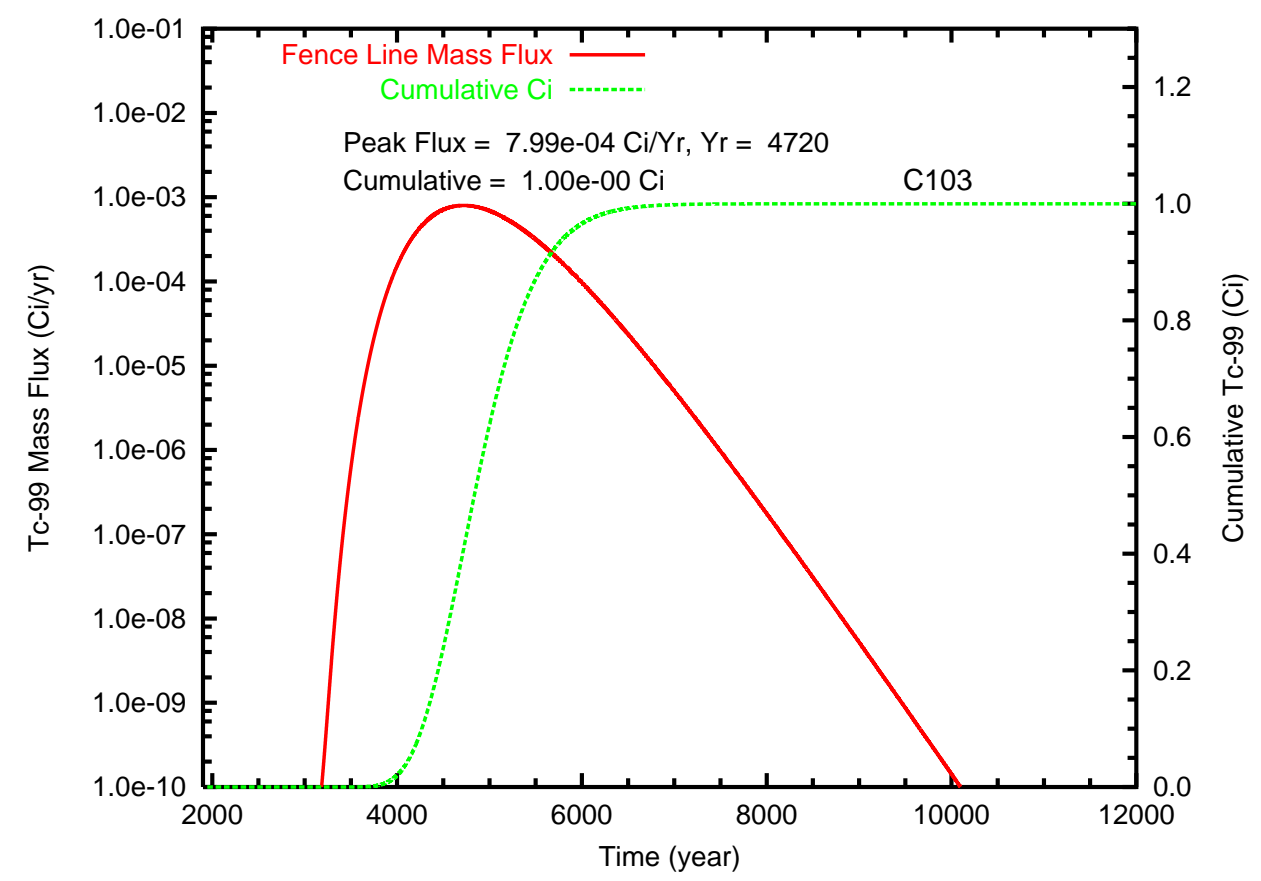

Figure B.81. Case 5v, Tc-99 mass flux and cumulative mass for Tank C-103 at (a) the groundwater table and (b) the fence line 
(a)

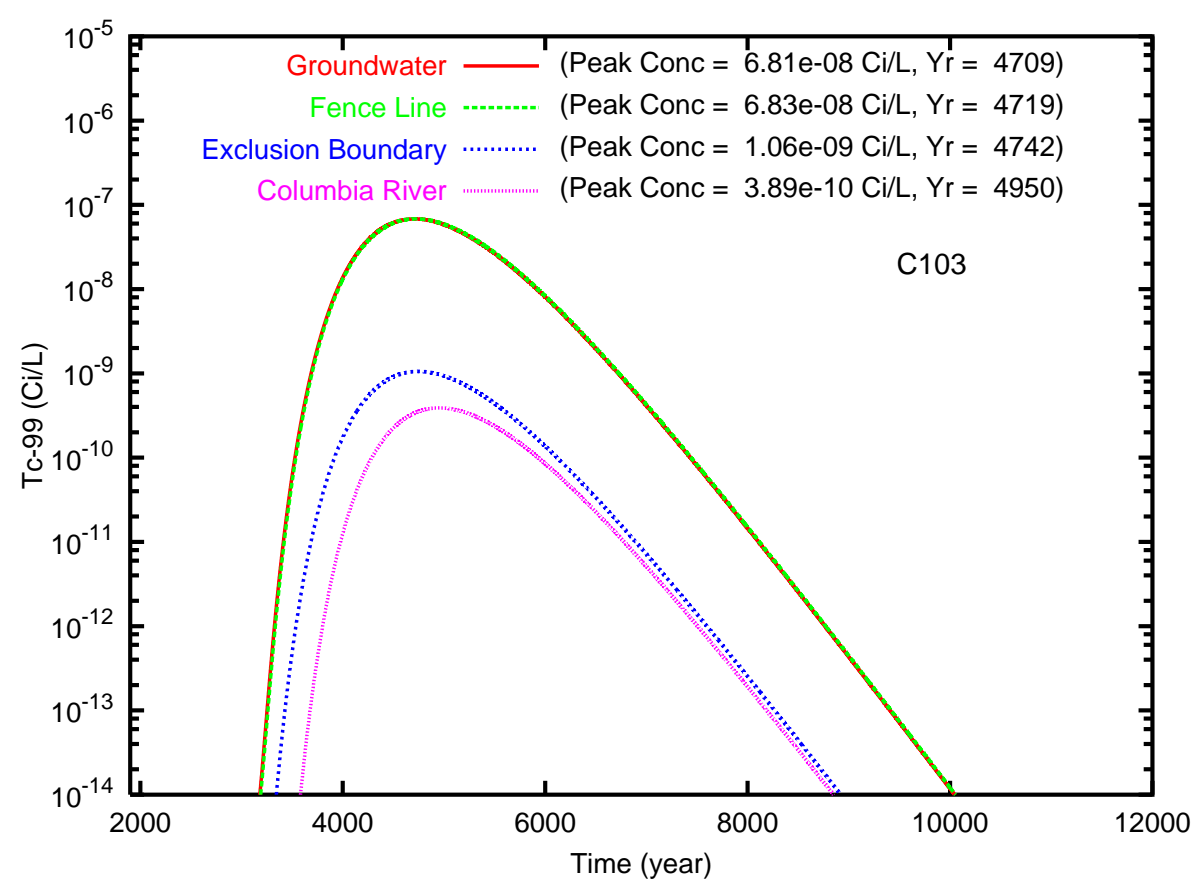

(b)

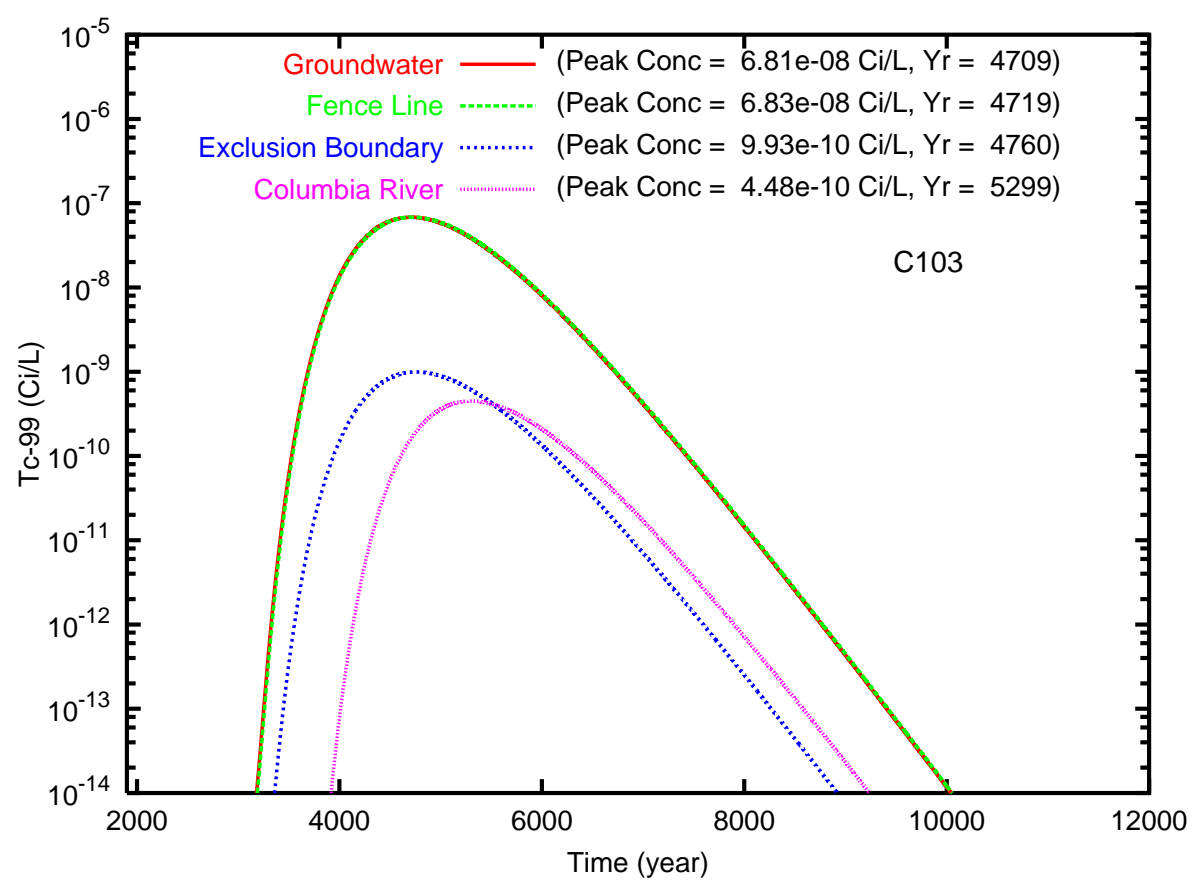

Figure B.82. Case 5v, Tc-99 concentration versus time (Tank C-103) for the fence line, exclusion boundary and Columbia River compliance points for travel paths (a) southeast and (b) north through the gap 
(a)

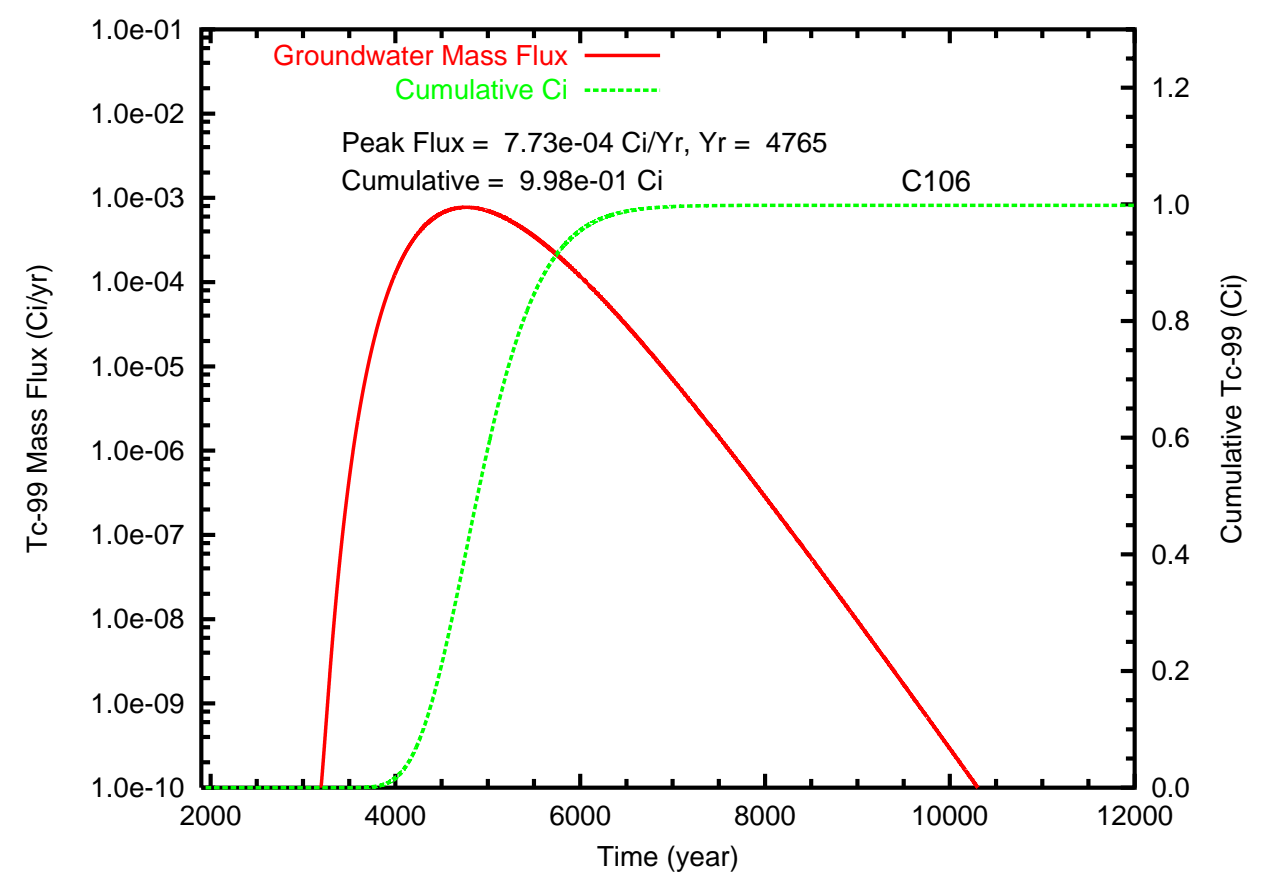

(b)

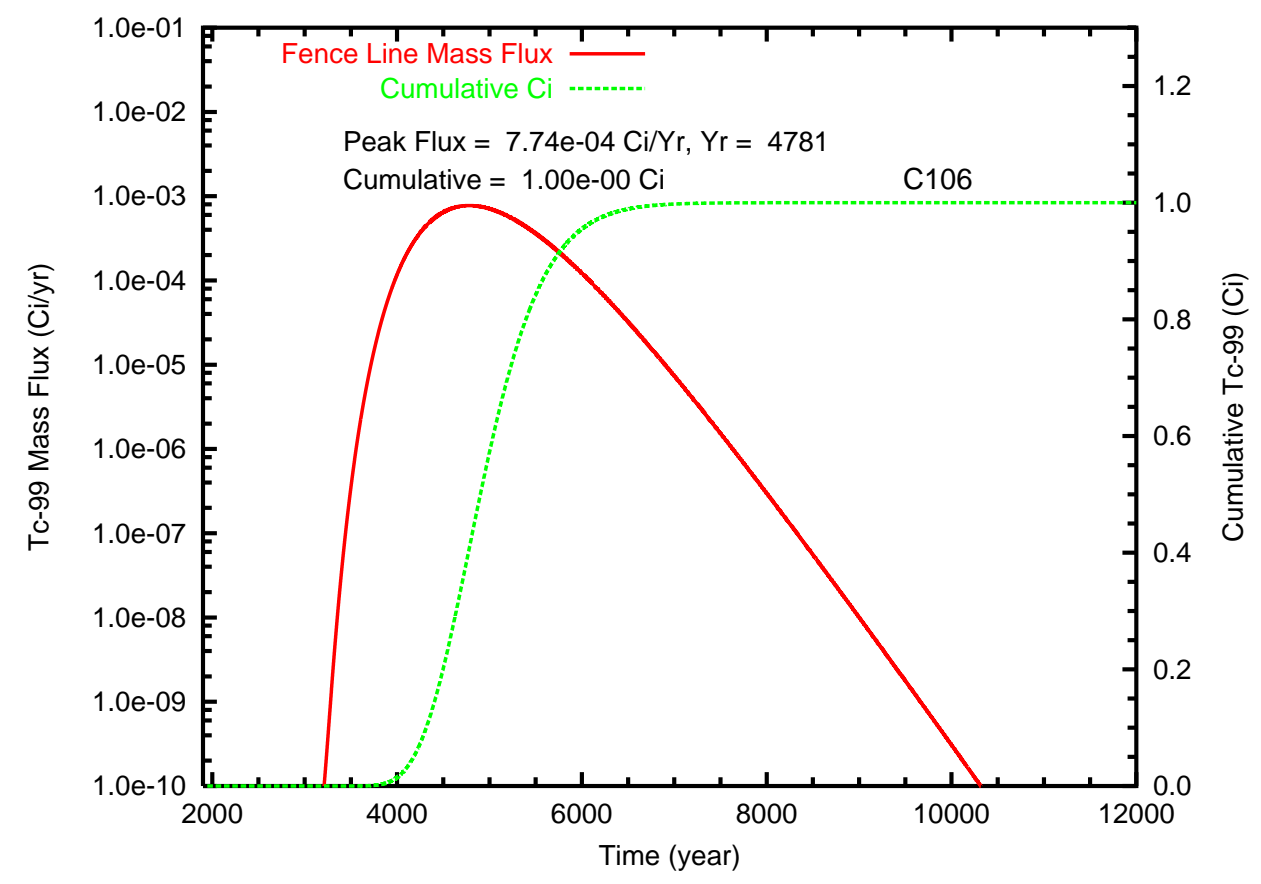

Figure B.83. Case 5v, Tc-99 mass flux and cumulative mass for Tank C-106 at (a) the groundwater table and (b) the fence line 
(a)

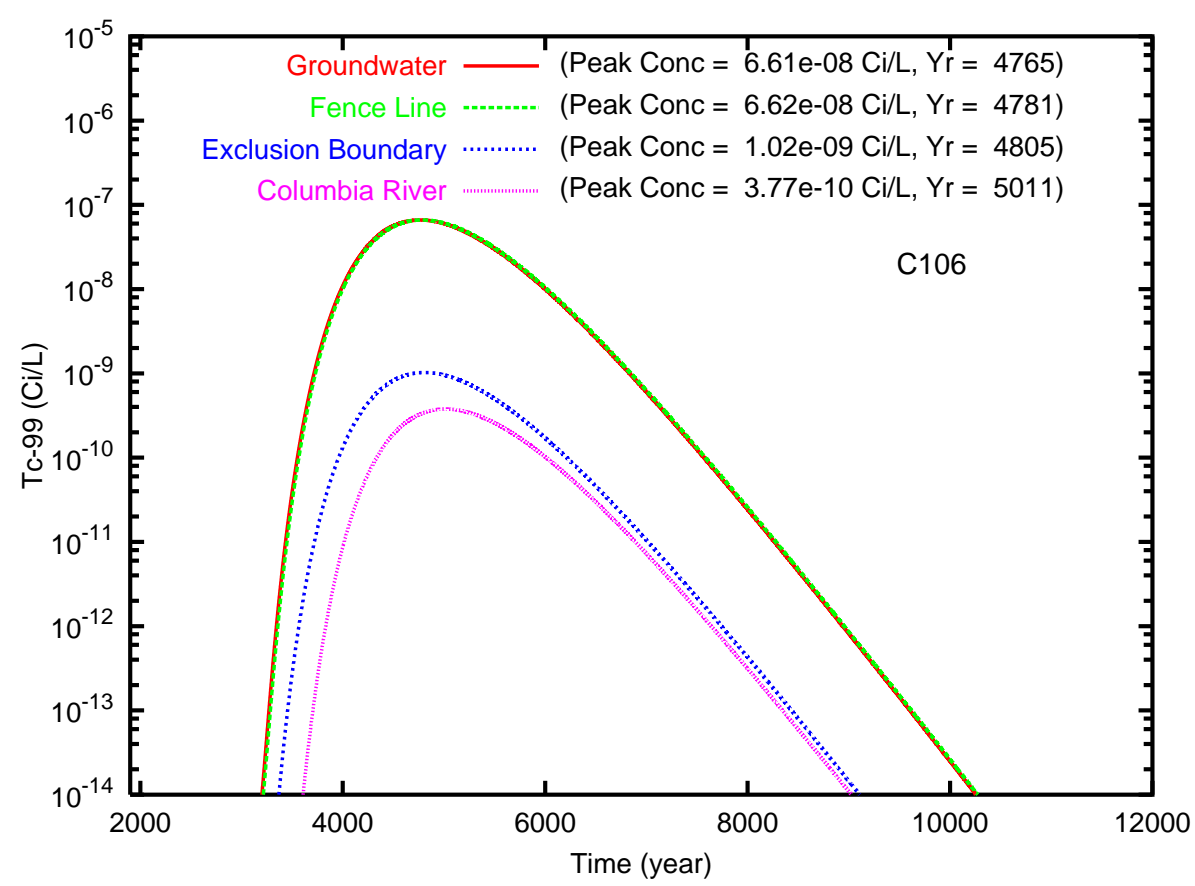

(b)

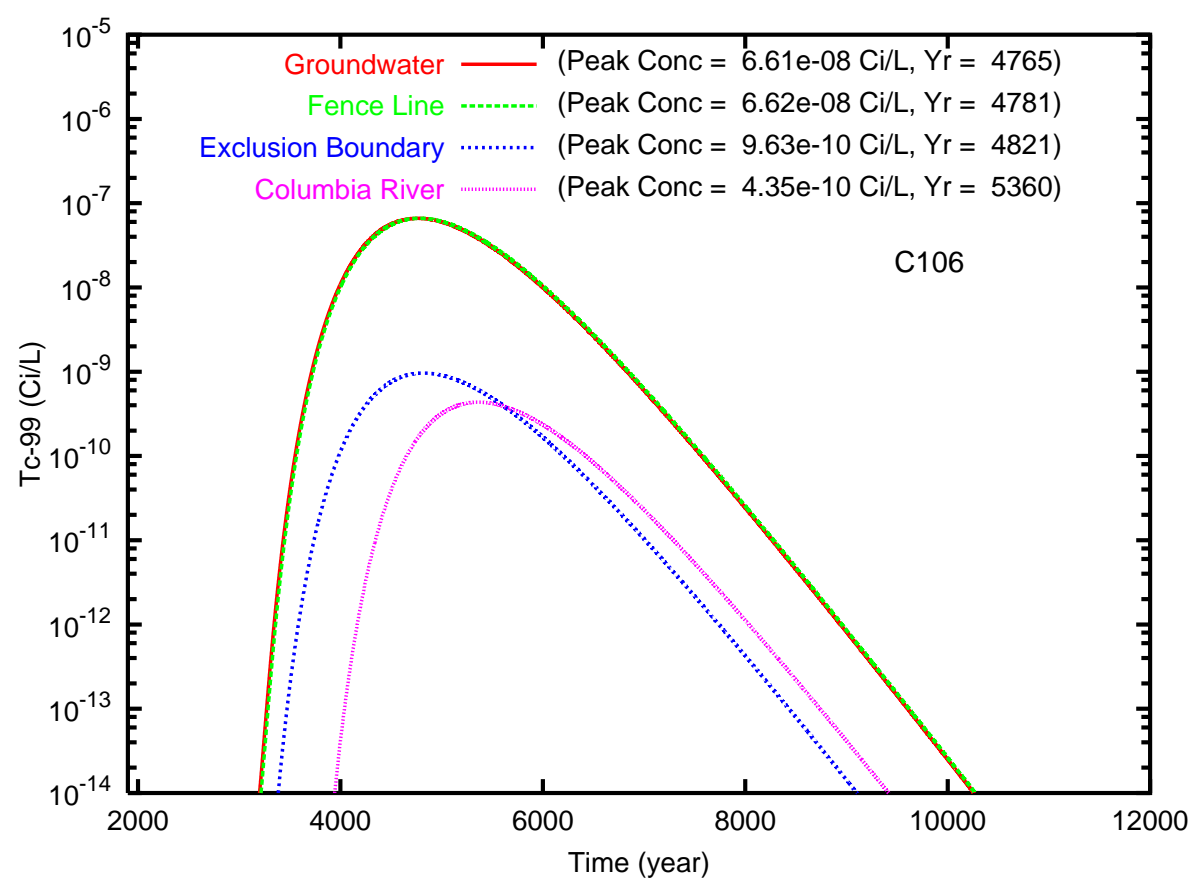

Figure B.84. Case 5v, Tc-99 concentration versus time (Tank C-106) for the fence line, exclusion boundary and Columbia River compliance points for travel paths (a) southeast and (b) north through the gap 
(a)

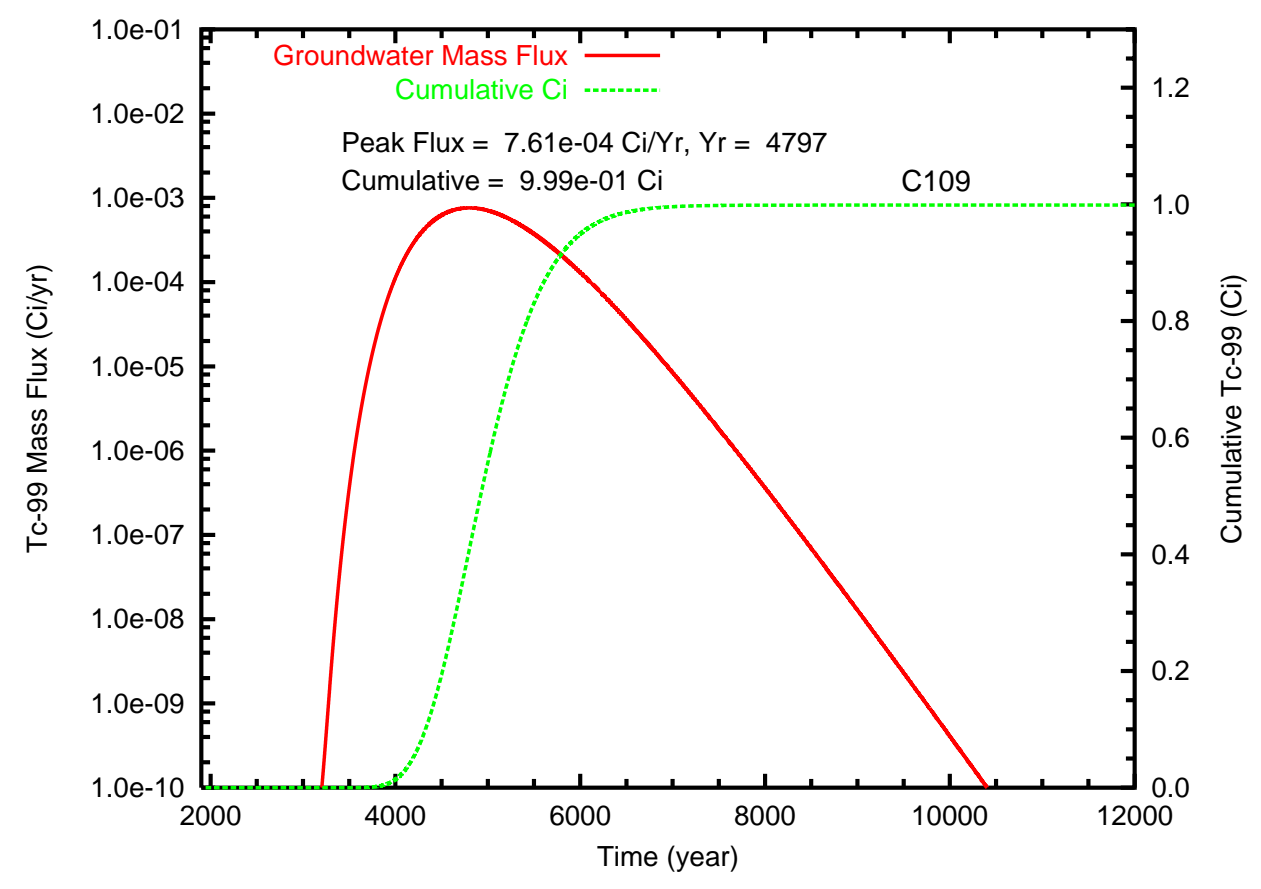

(b)

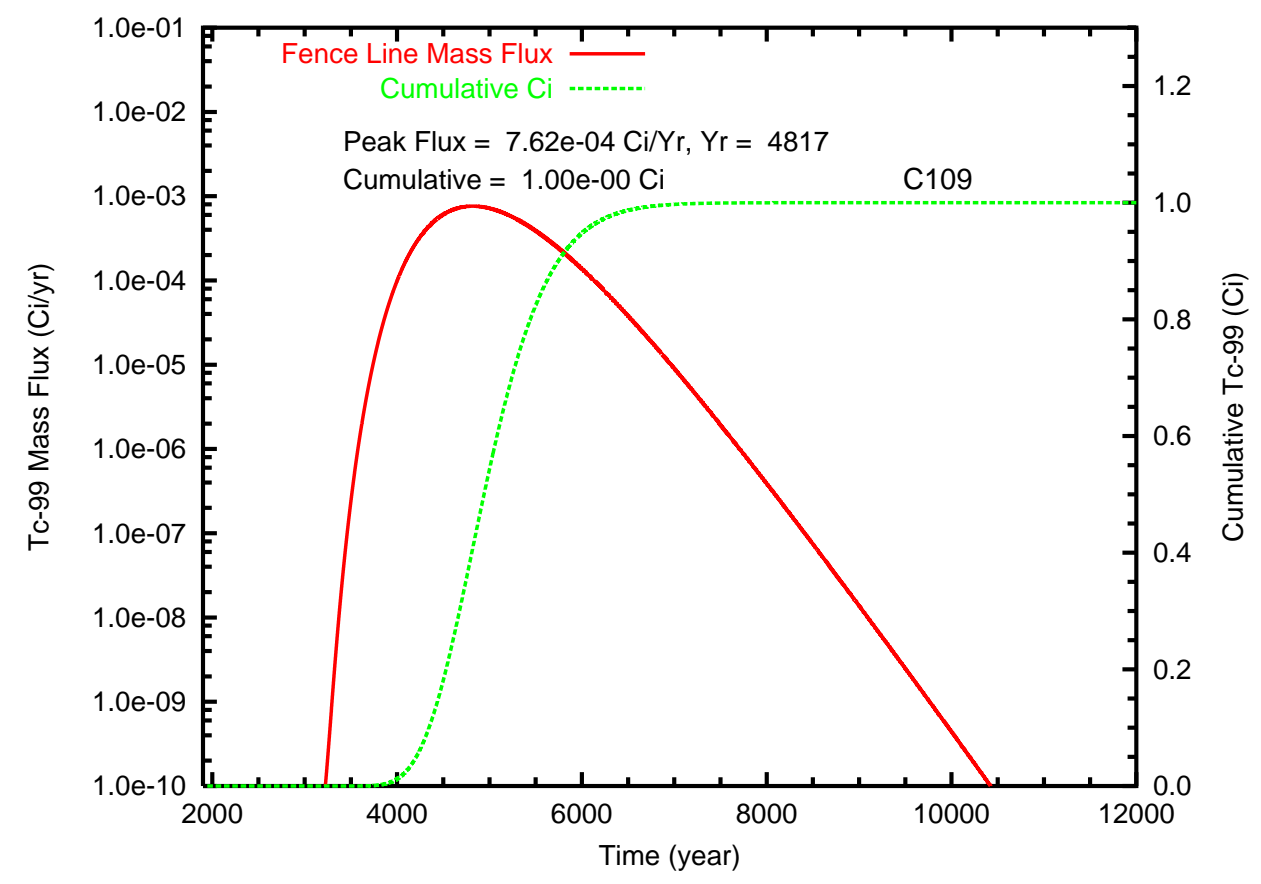

Figure B.85. Case 5v, Tc-99 mass flux and cumulative mass for Tank C-109 at (a) the groundwater table and (b) the fence line 
(a)

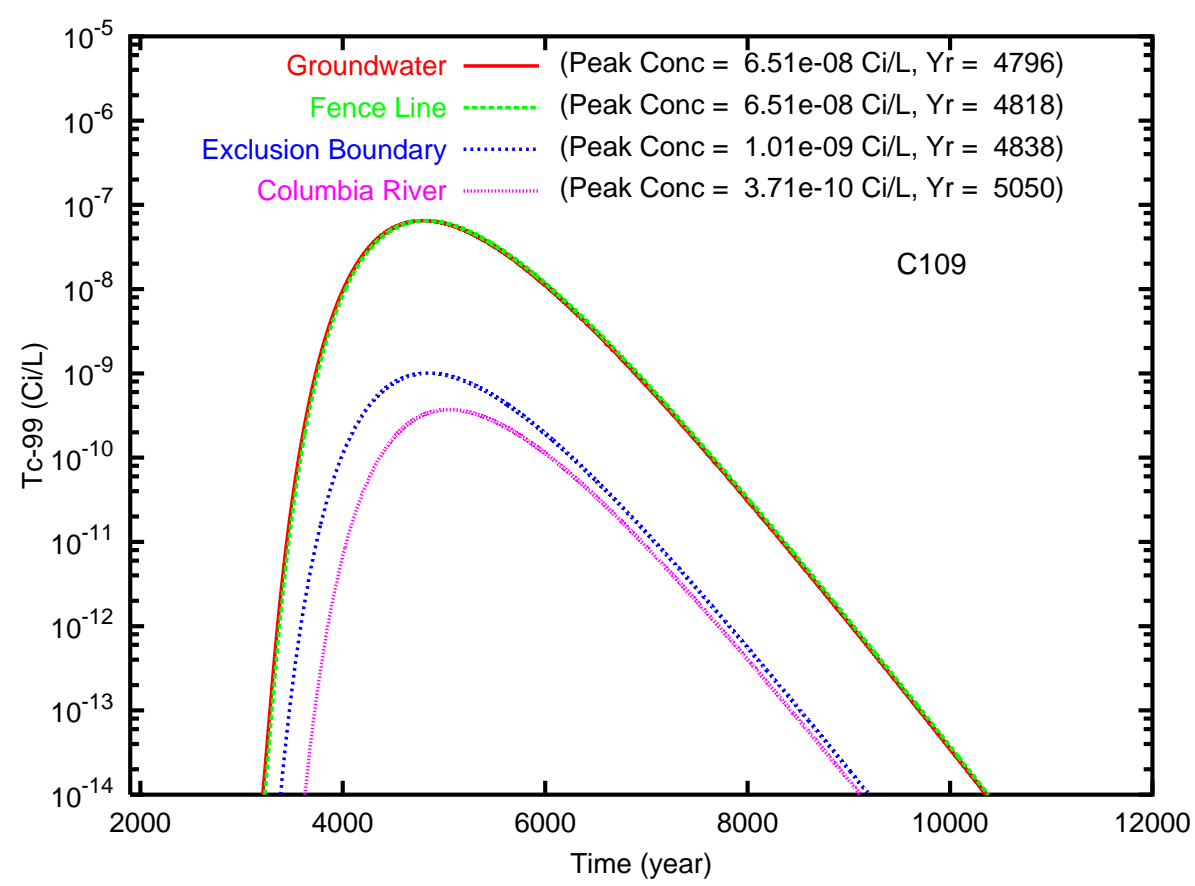

(b)

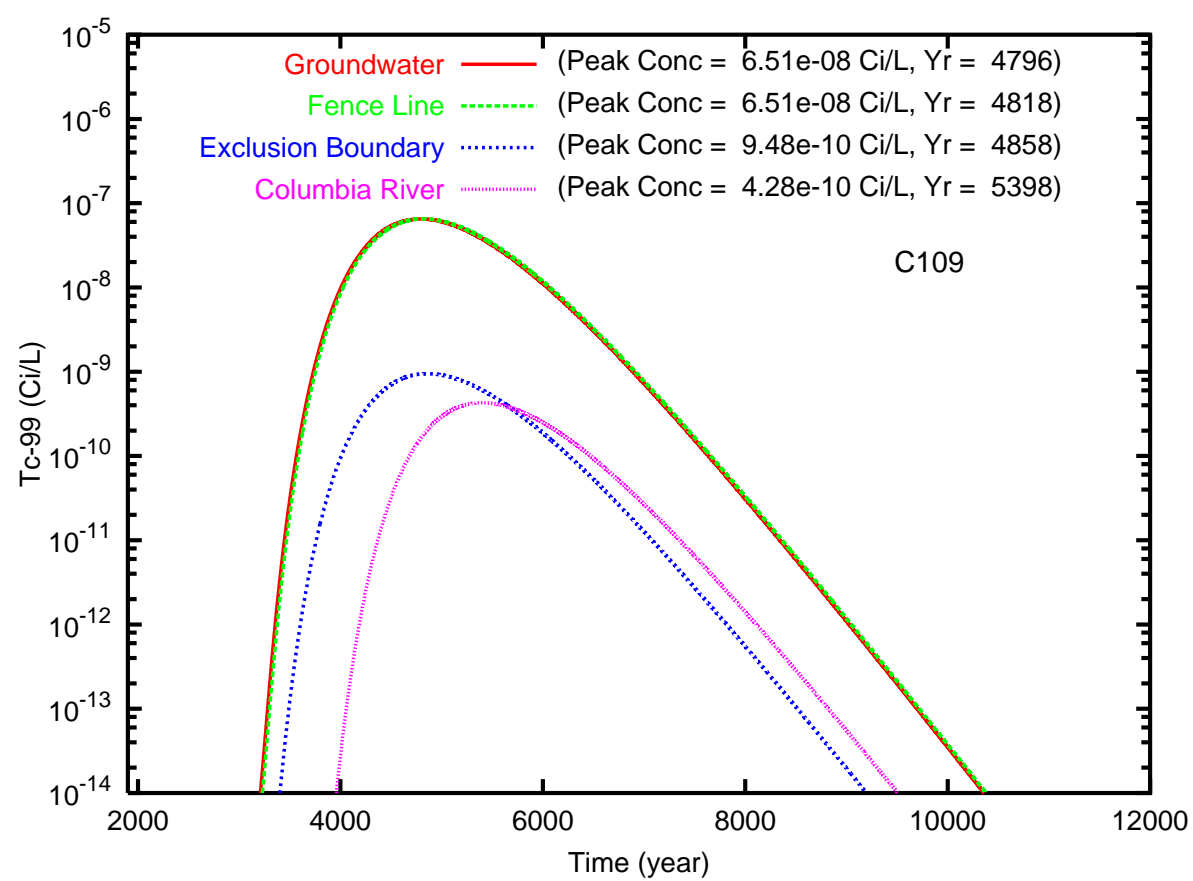

Figure B.86. Case 5v, Tc-99 concentration versus time (Tank C-109) for the fence line, exclusion boundary and Columbia River compliance points for travel paths (a) southeast and (b) north through the gap 
(a)

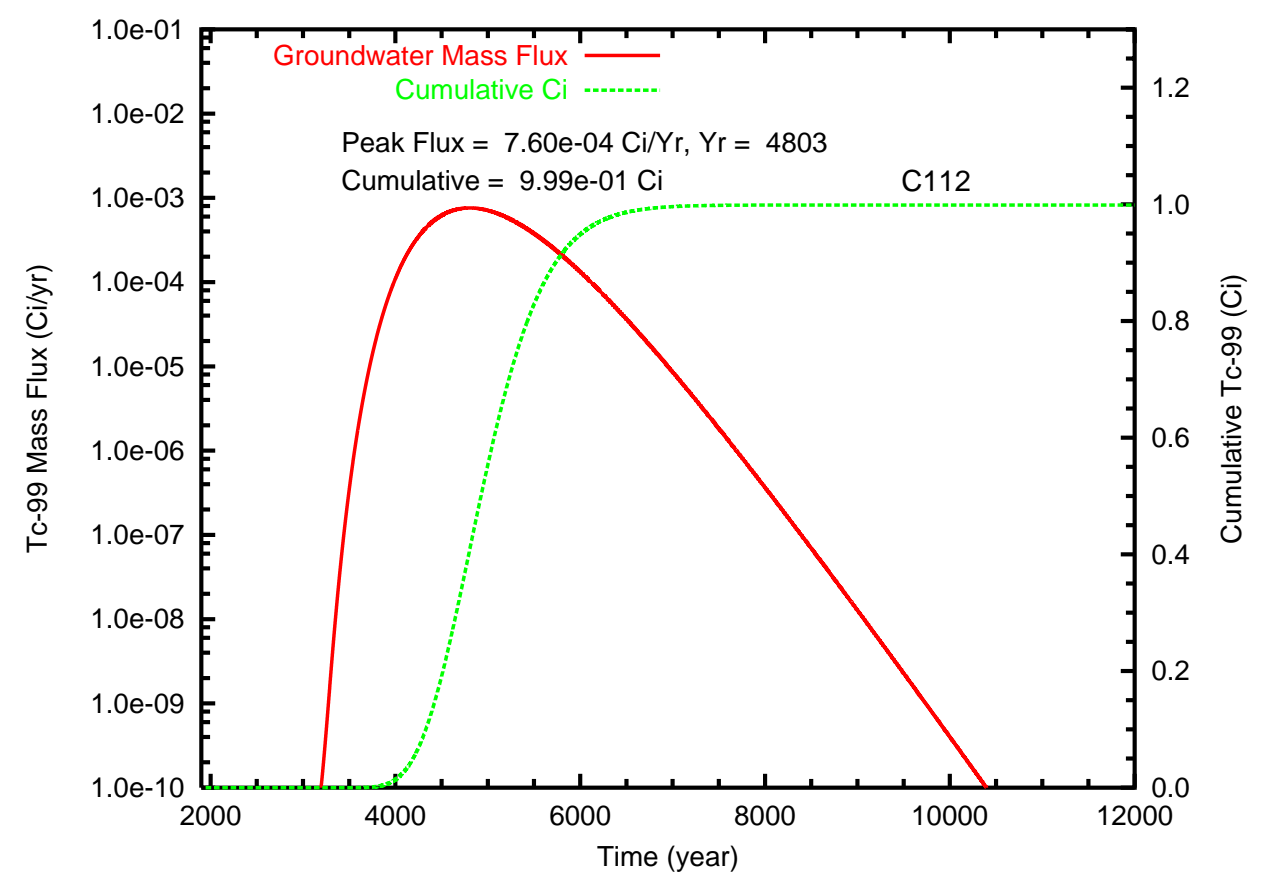

(b)

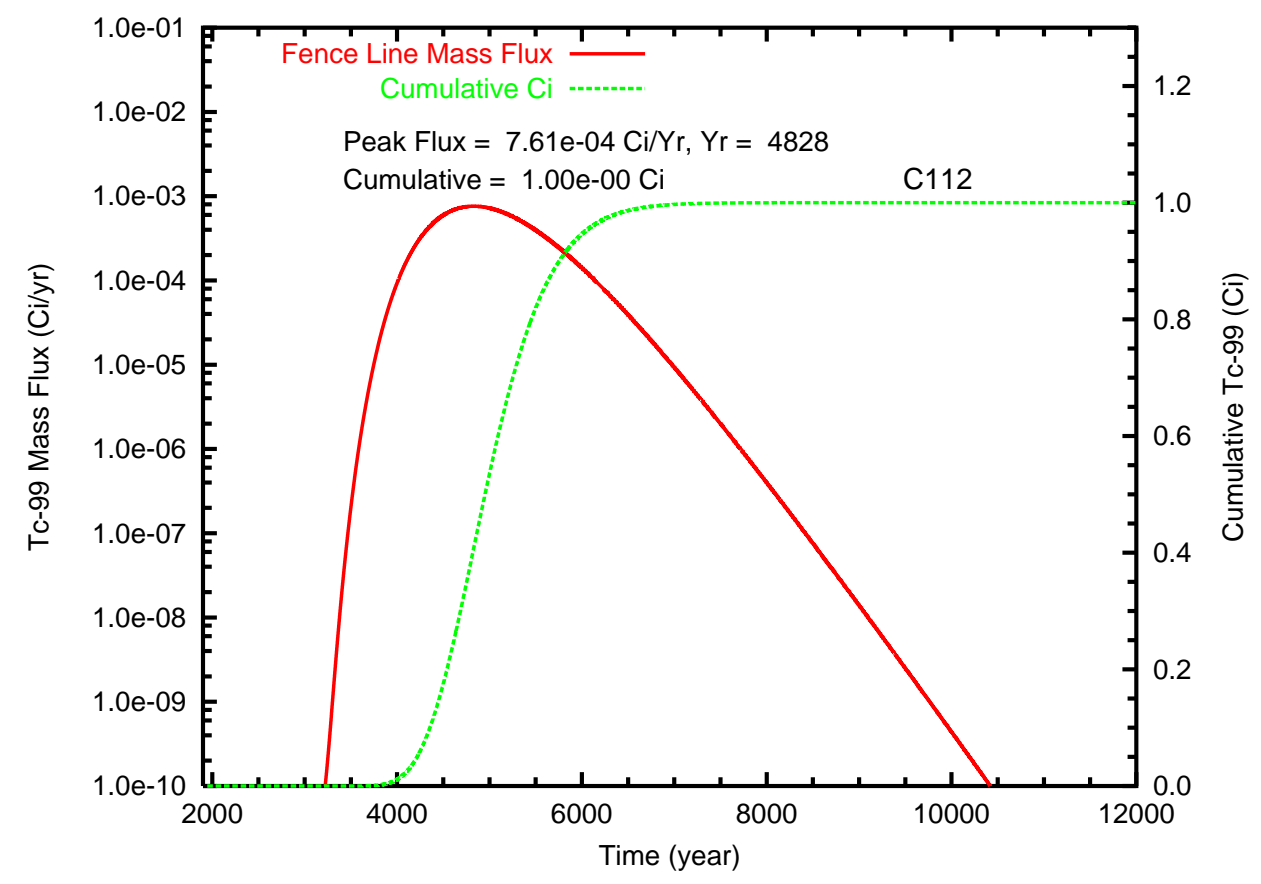

Figure B.87. Case 5v, Tc-99 mass flux and cumulative mass for Tank C-112 at (a) the groundwater table and (b) the fence line 
(a)

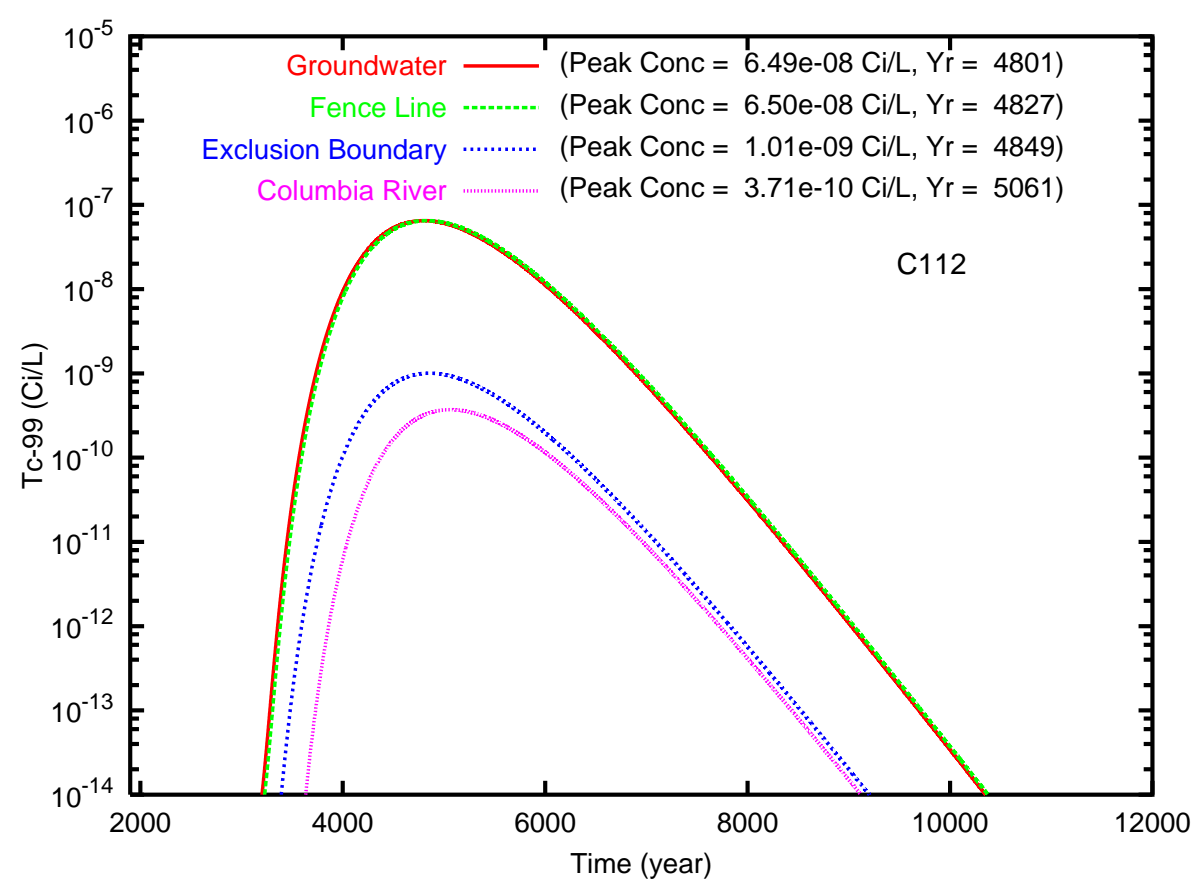

(b)

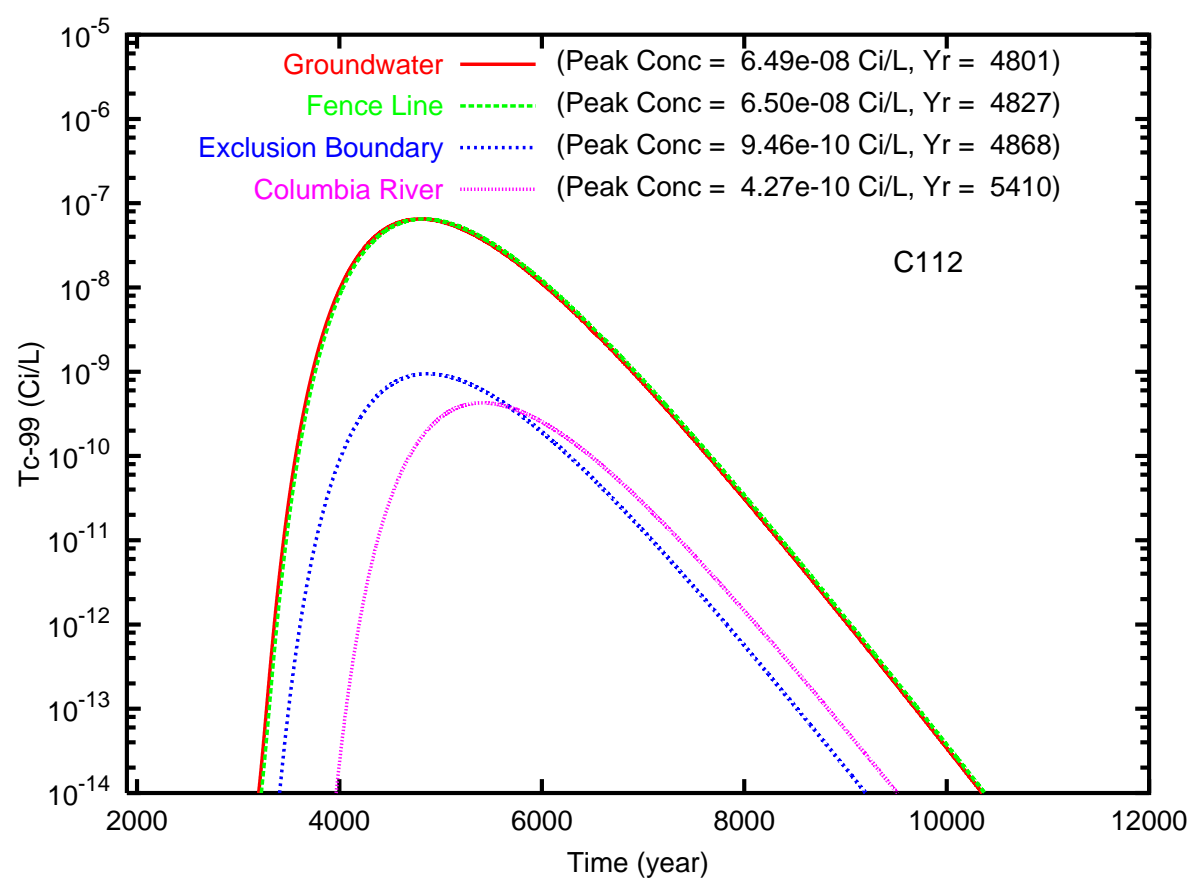

Figure B.88. Case 5v, Tc-99 concentration versus time (Tank C-112) for the fence line, exclusion boundary and Columbia River compliance points for travel paths (a) southeast and (b) north through the gap 
(a)

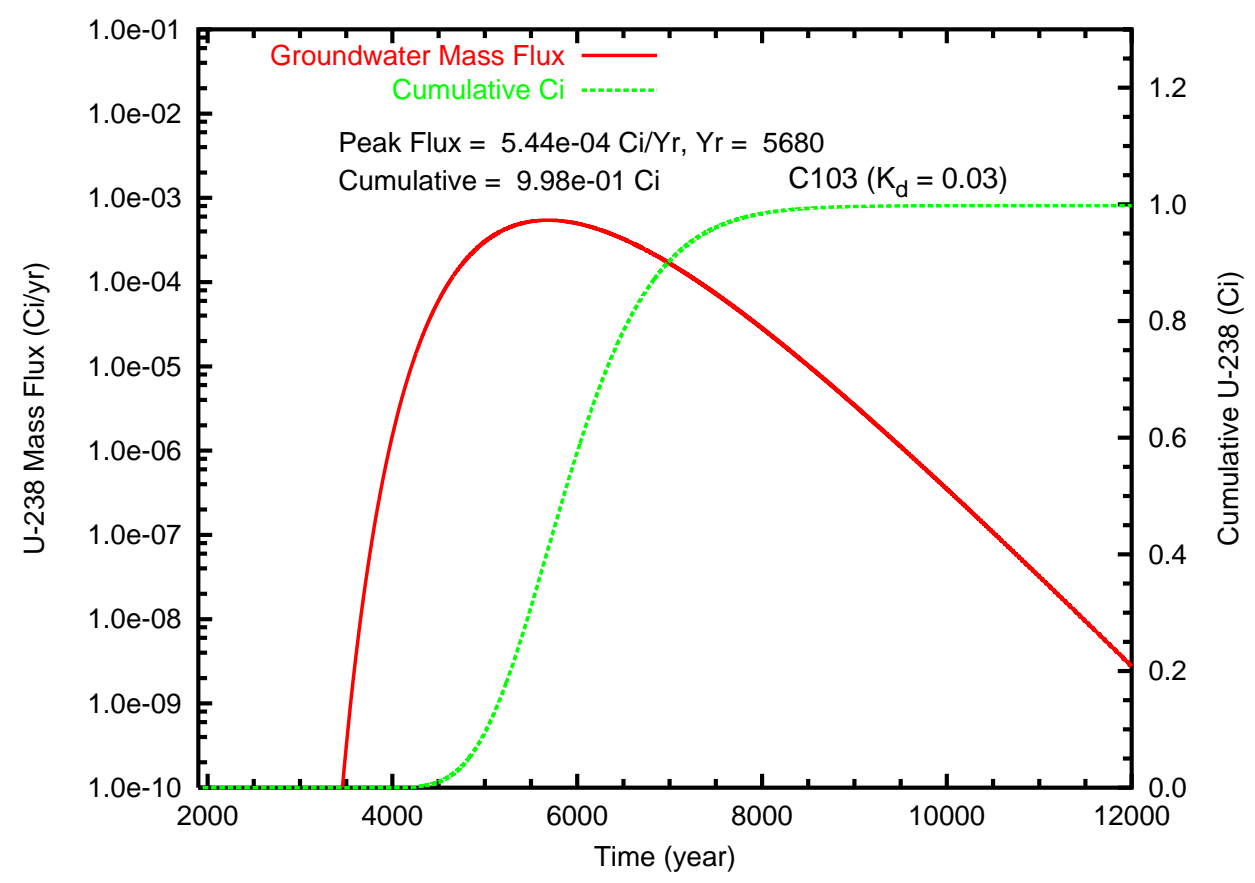

(b)

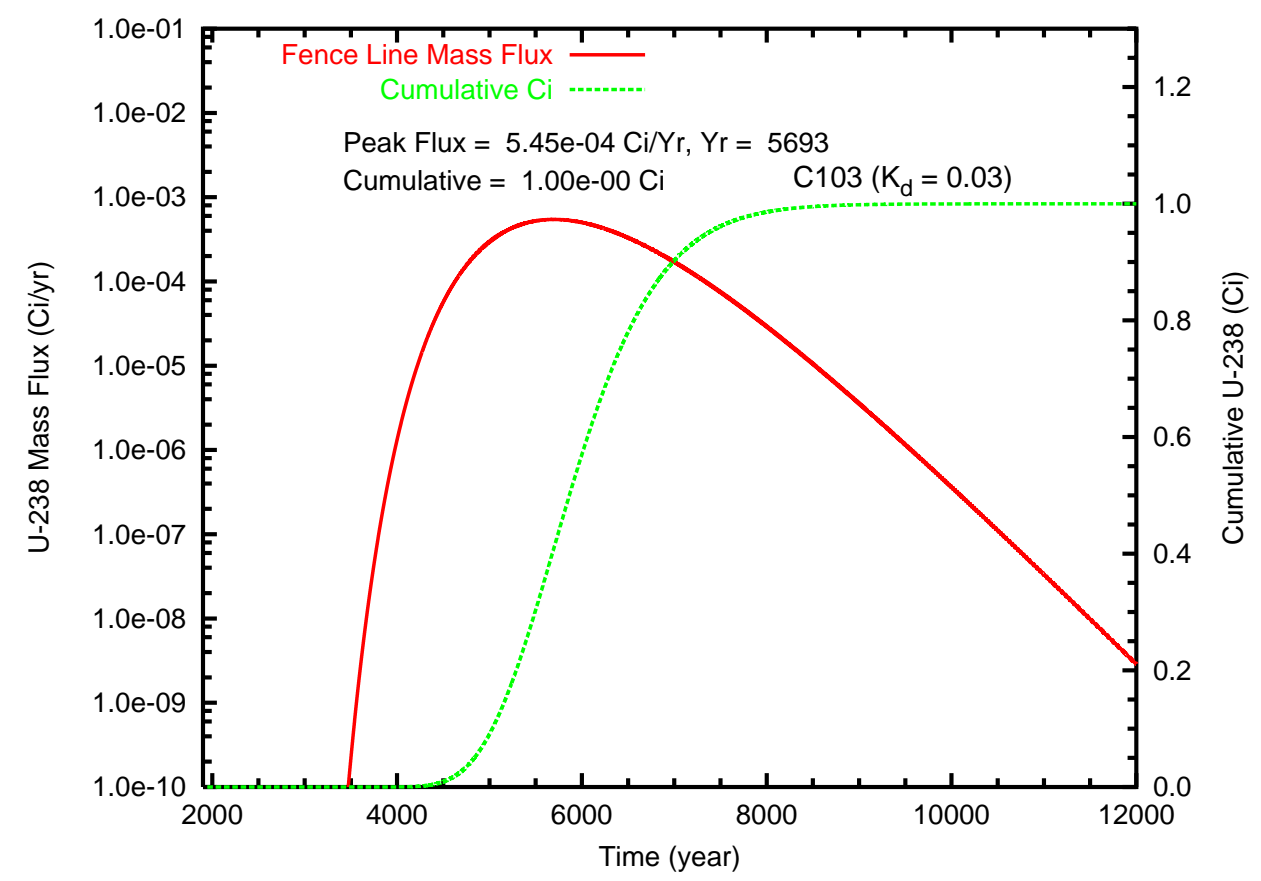

Figure B.89. Case 5v,Tc-99 mass flux and cumulative mass for Tank C-103 at (a) the groundwater table and (b) the fence line 
(a)

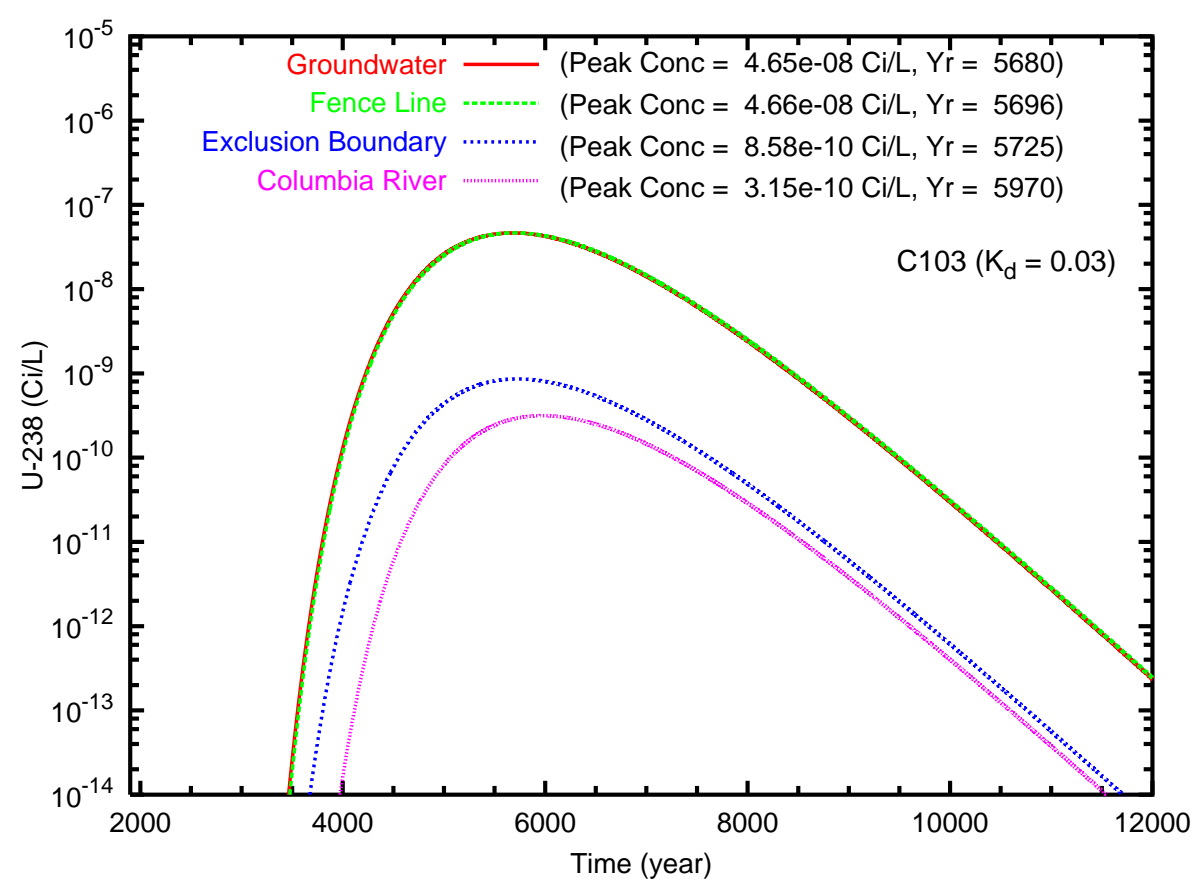

(b)

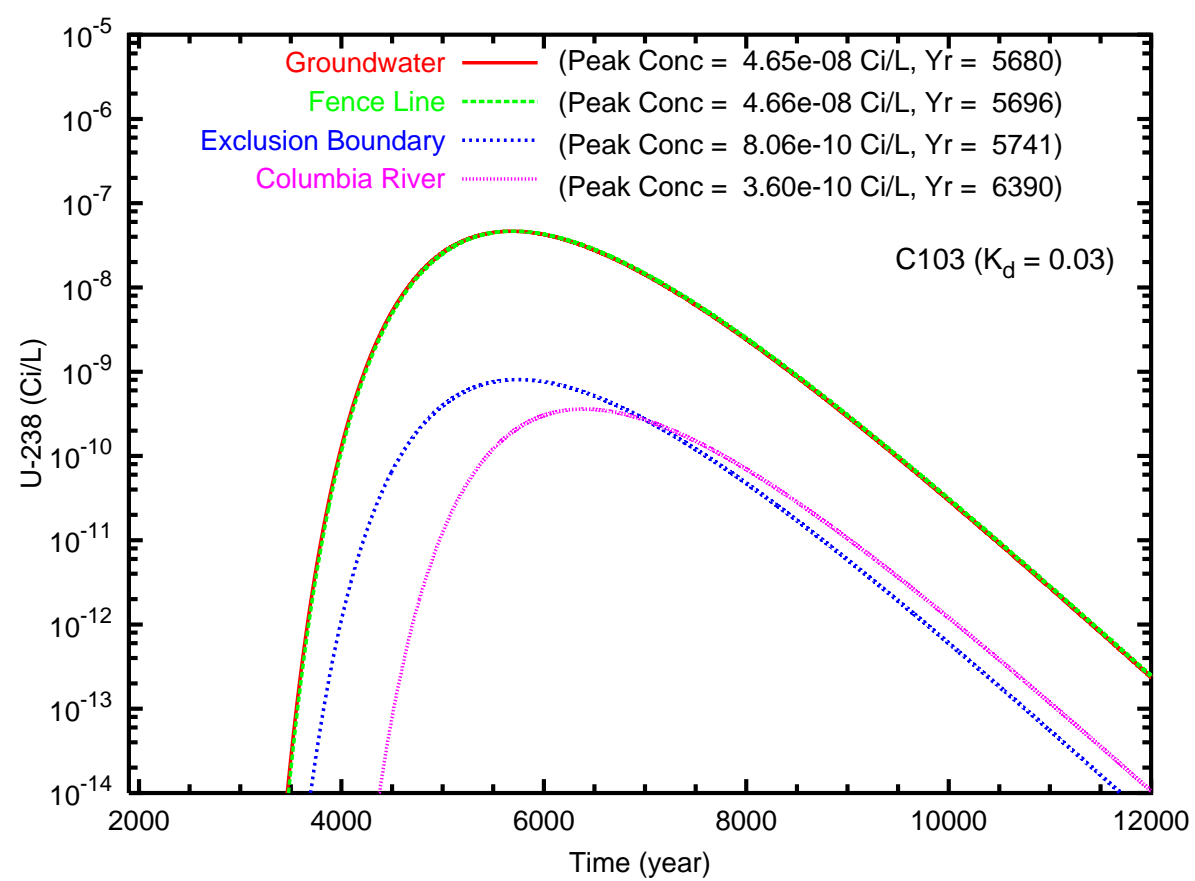

Figure B.90. Case $5 \mathrm{v},\left(\mathrm{K}_{d}=0.03\right)$ concentration versus time (Tank C-103) for the fence line, exclusion boundary and Columbia River compliance points for travel paths (a) southeast and (b) north through the gap 
(a)

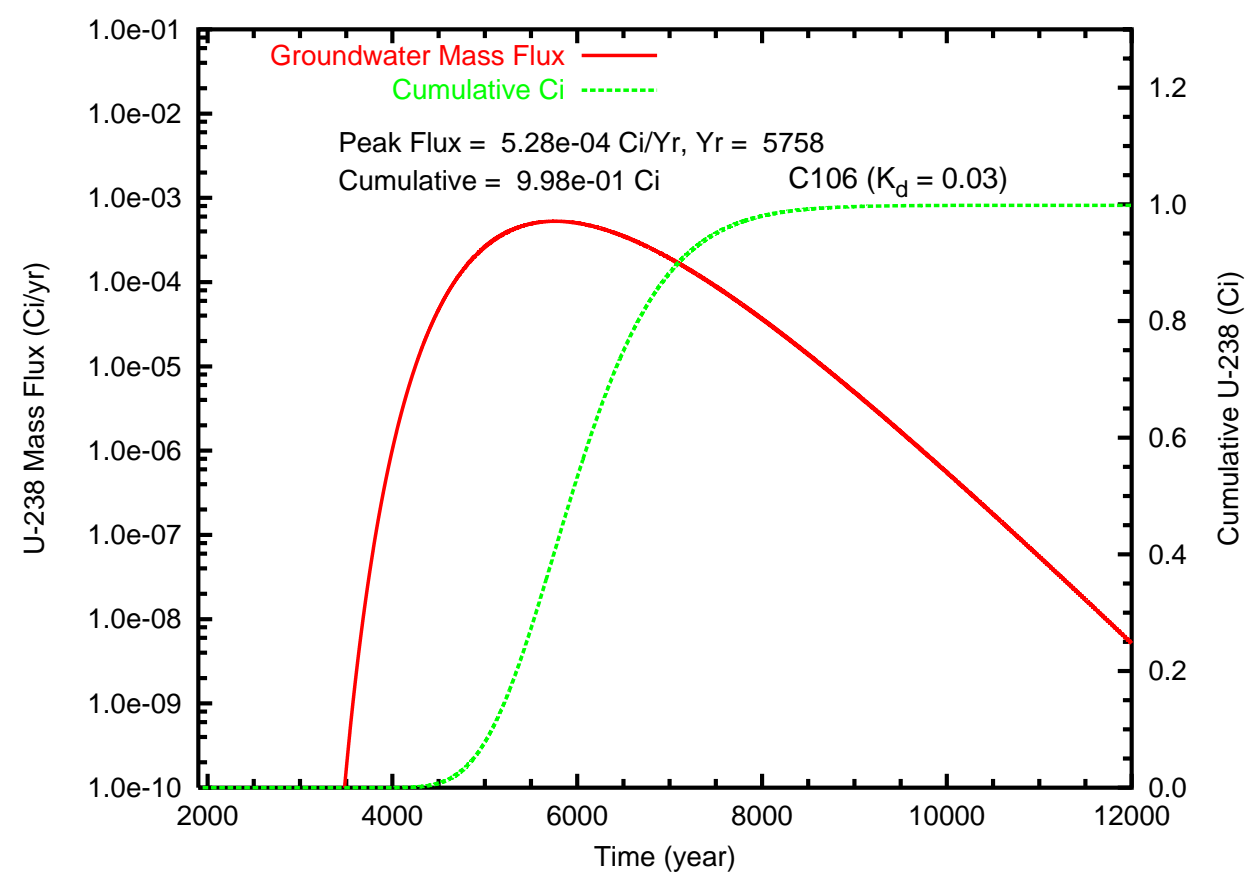

(b)

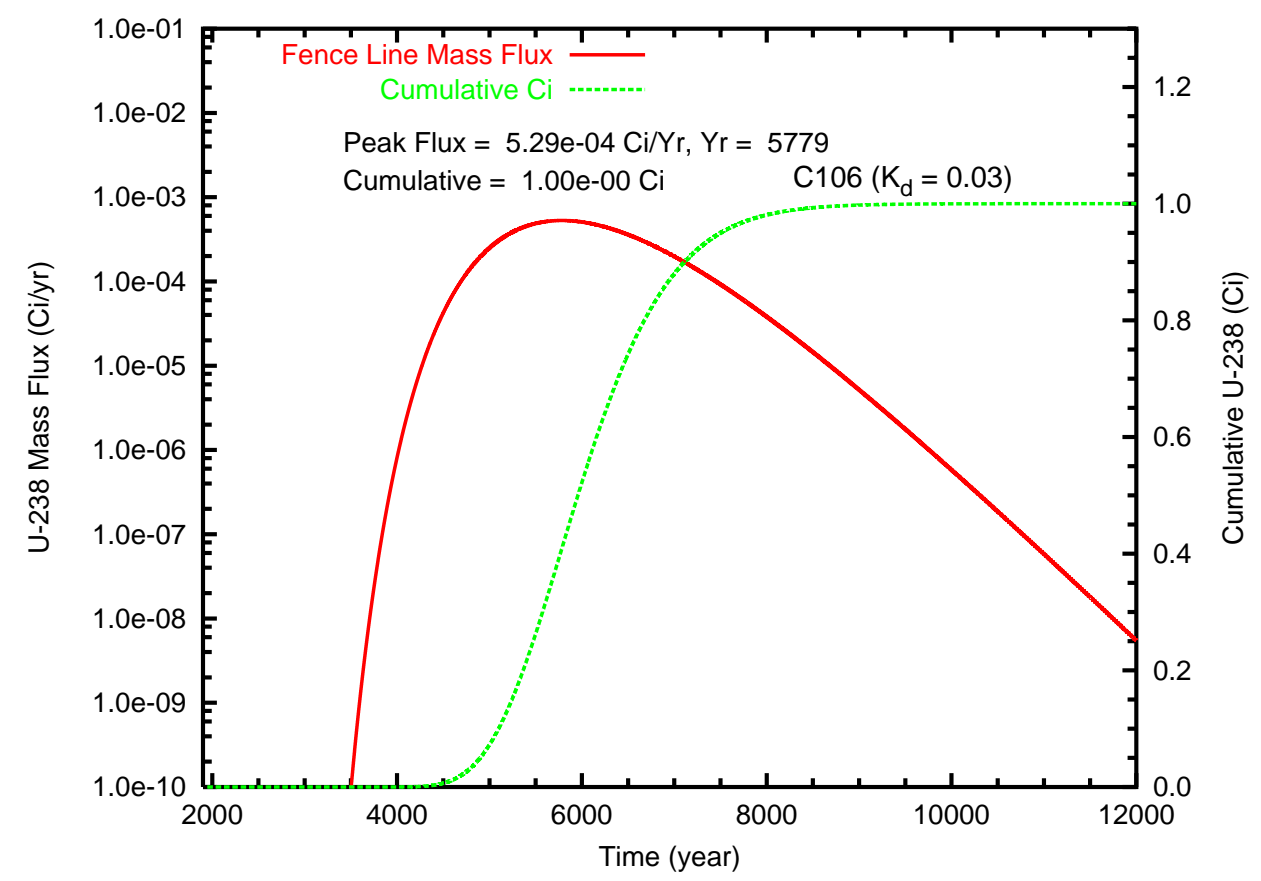

Figure B.91. Case 5v, Tc-99 mass flux and cumulative mass for Tank C-106 at (a) the groundwater table and (b) the fence line 
(a)

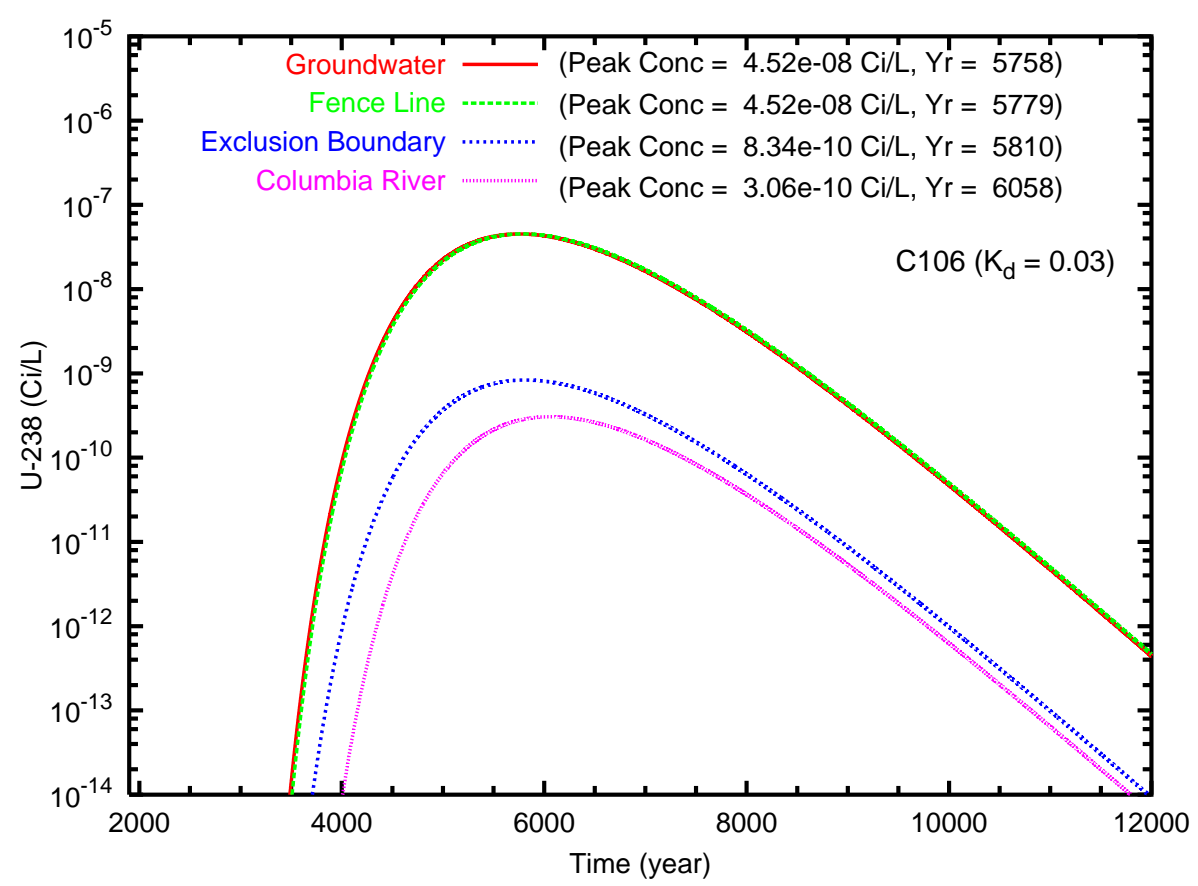

(b)

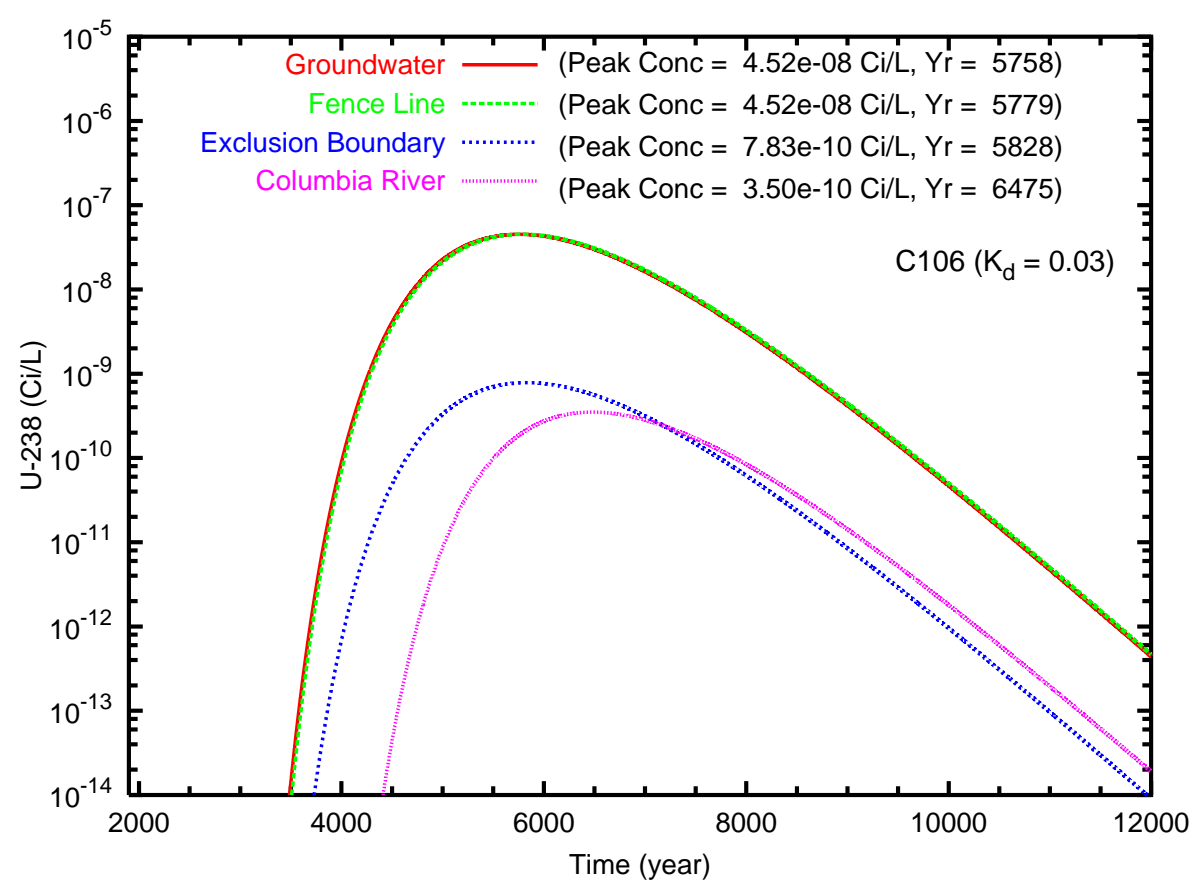

Figure B.92. Case $5 \mathrm{v}, \mathrm{U}-238\left(\mathrm{~K}_{d}=0.03\right)$ concentration versus time (Tank C-106) for the fence line, exclusion boundary and Columbia River compliance points for travel paths (a) southeast and (b) north through the gap 
(a)

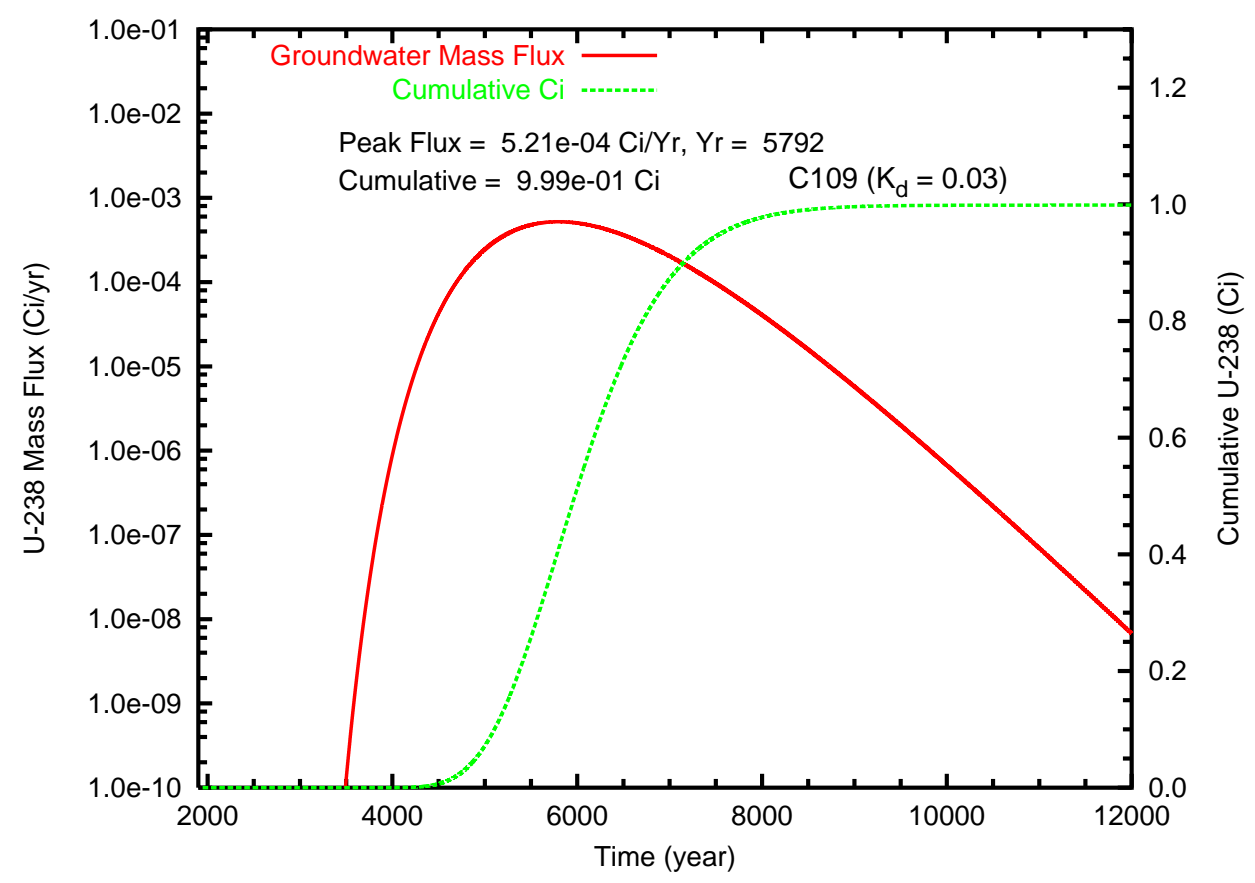

(b)

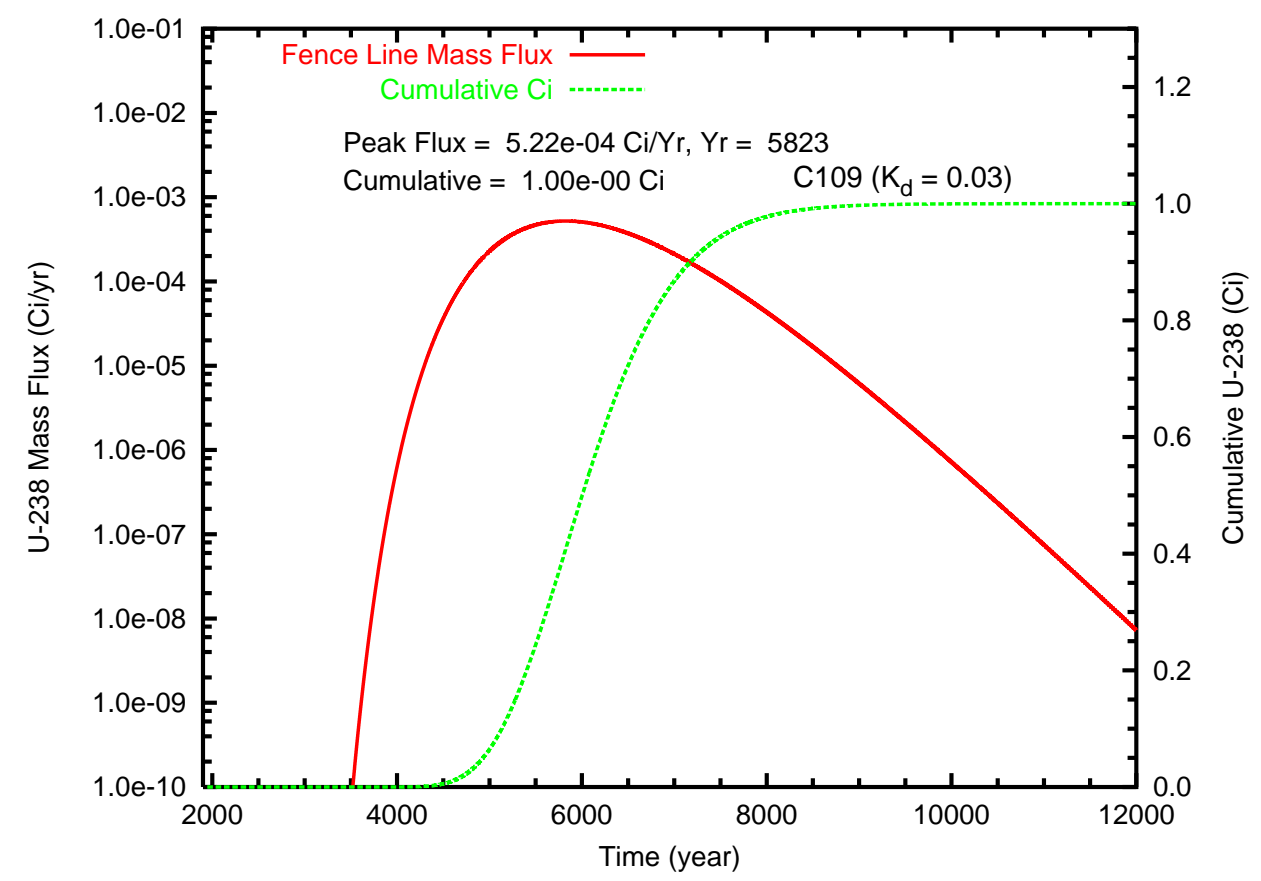

Figure B.93. Case 5v, Tc-99 mass flux and cumulative mass for Tank C-109 at (a) the groundwater table and (b) the fence line 
(a)

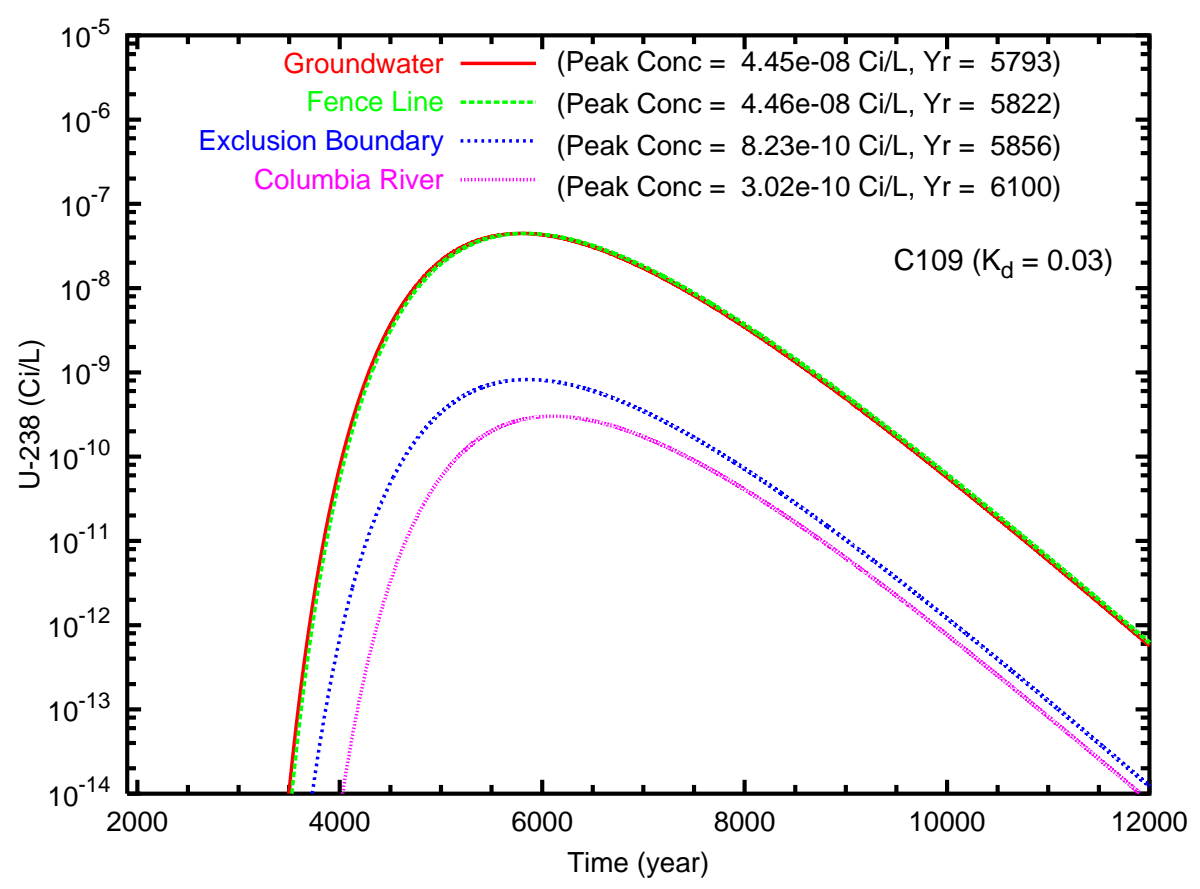

(b)

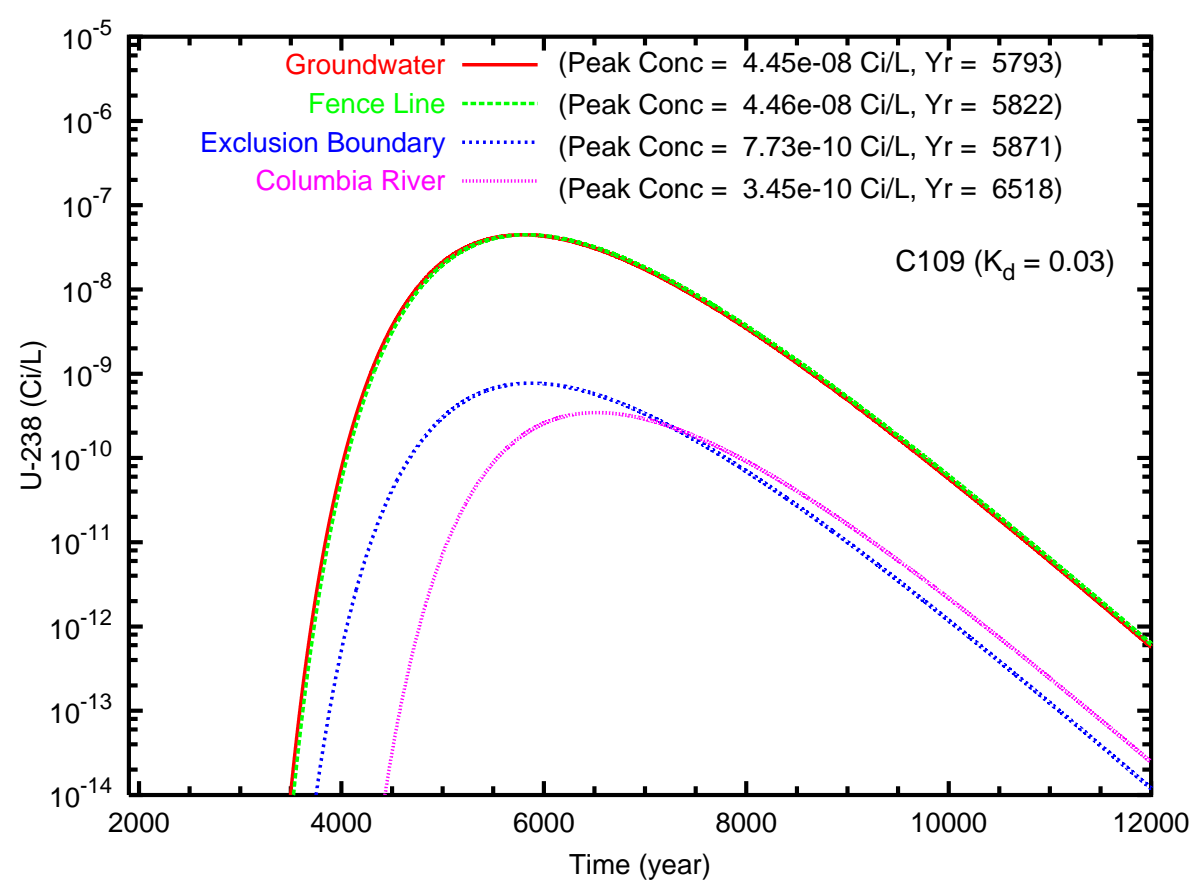

Figure B.94. Case 5v, U-238 $\left(\mathrm{K}_{d}=0.03\right)$ concentration versus time (Tank C-109) for the fence line, exclusion boundary and Columbia River compliance points for travel paths (a) southeast and (b) north through the gap 
(a)

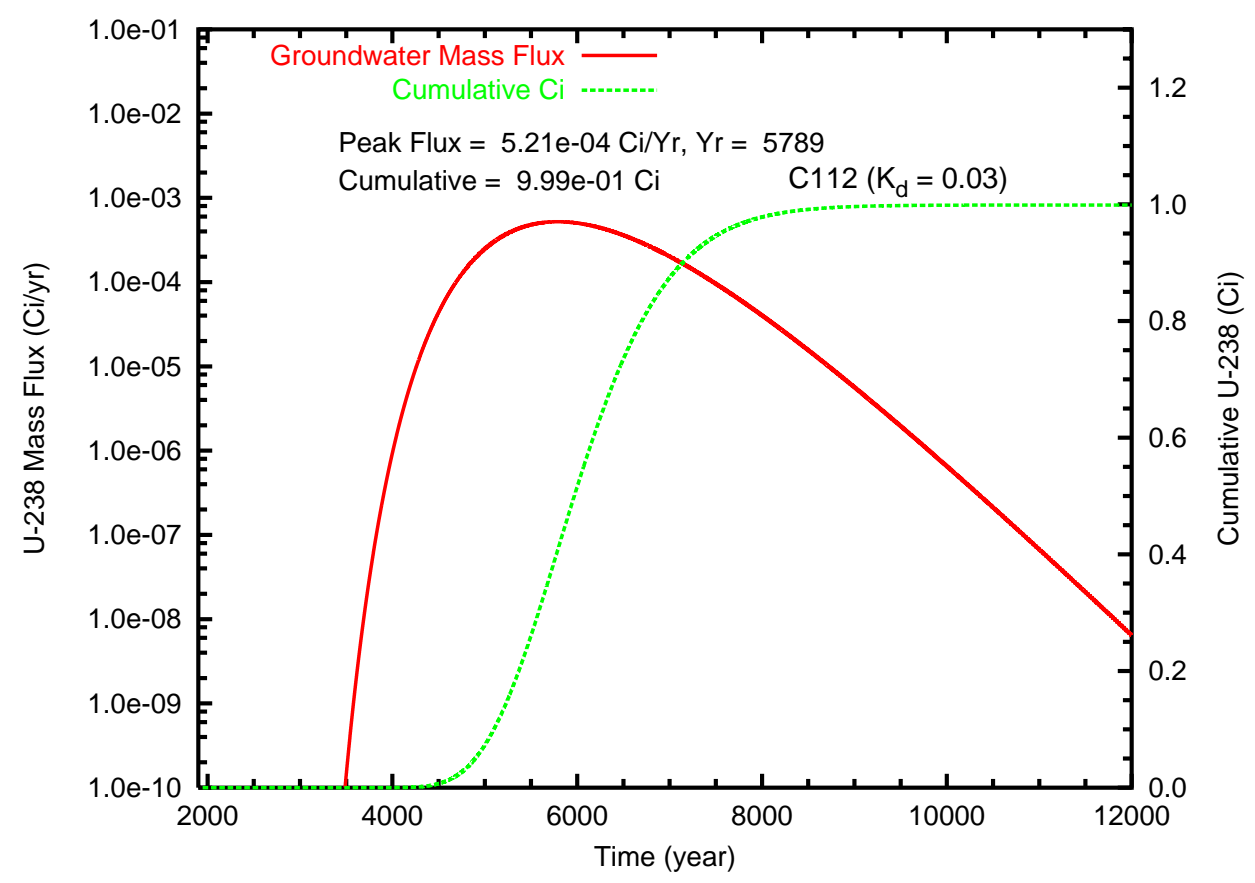

(b)

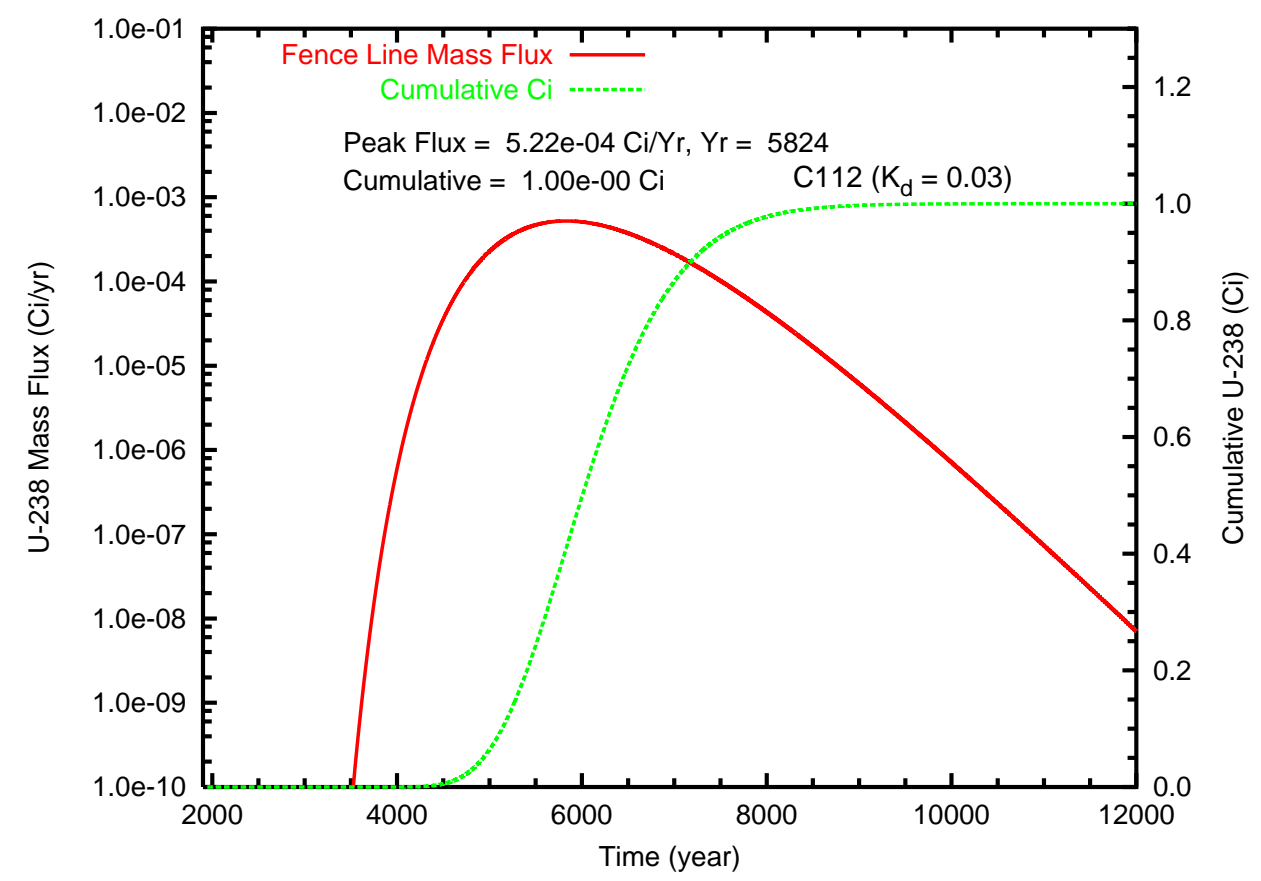

Figure B.95. Case 5v,Tc-99 mass flux and cumulative mass for Tank C-112 at (a) the groundwater table and (b) the fence line 
(a)

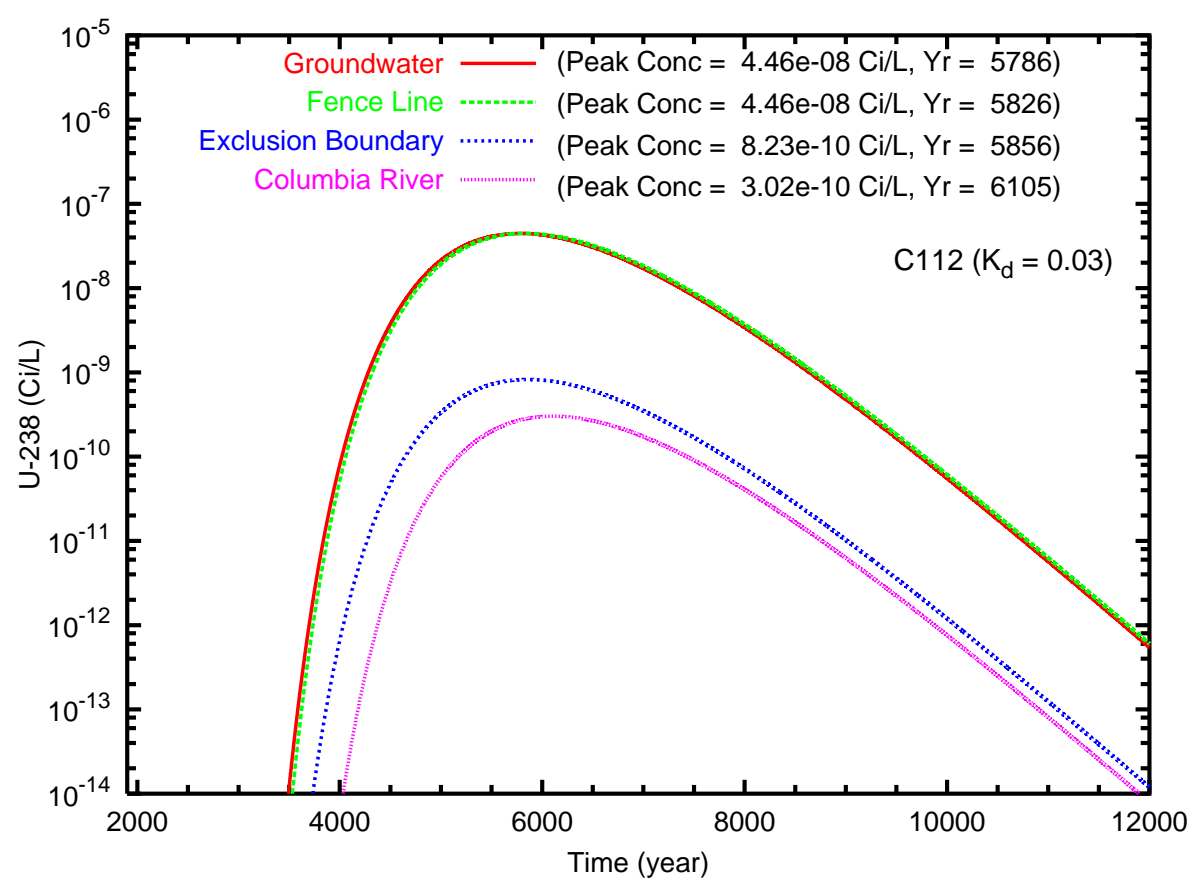

(b)

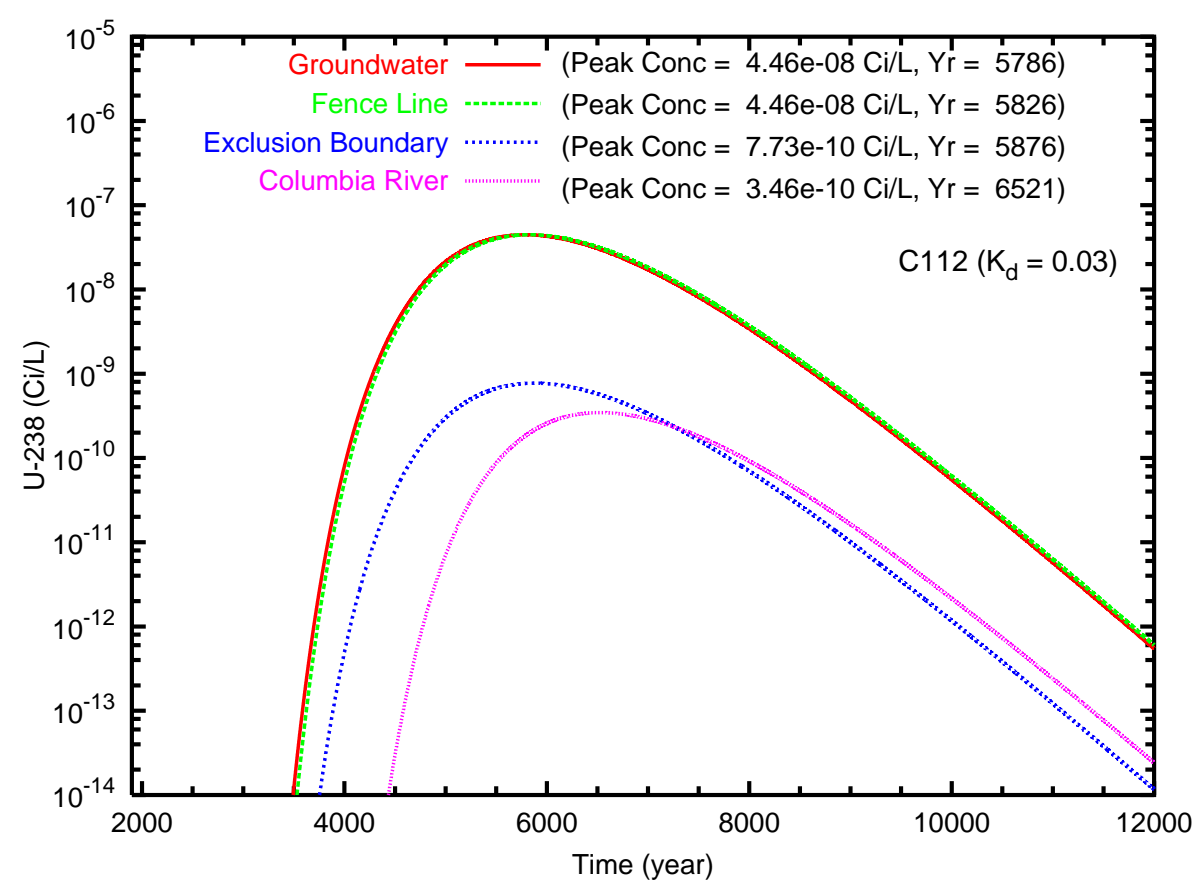

Figure B.96. Case 5v, U-238 $\left(\mathrm{K}_{d}=0.03\right)$ concentration versus time (Tank C-112) for the fence line, exclusion boundary and Columbia River compliance points for travel paths (a) southeast and (b) north through the gap 
(a)

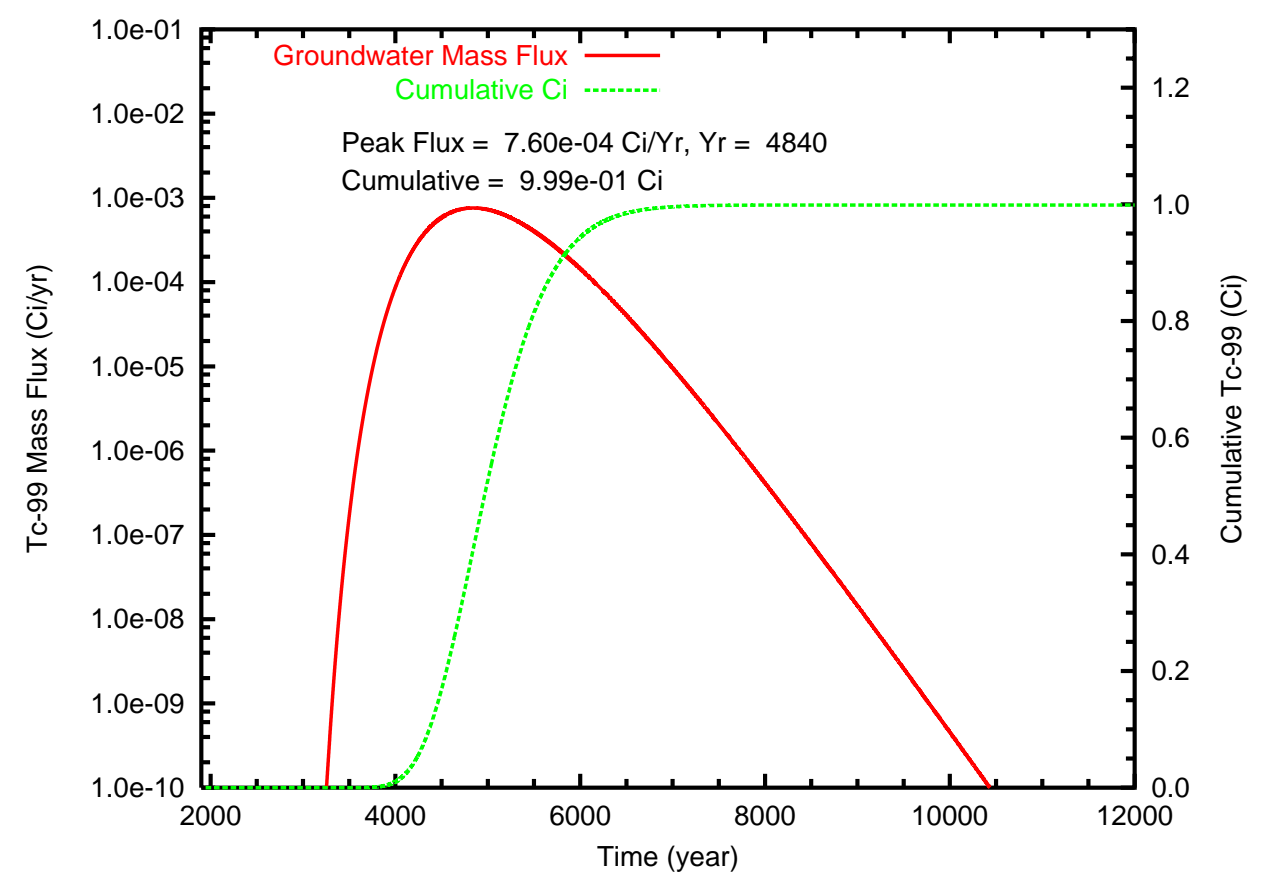

(b)

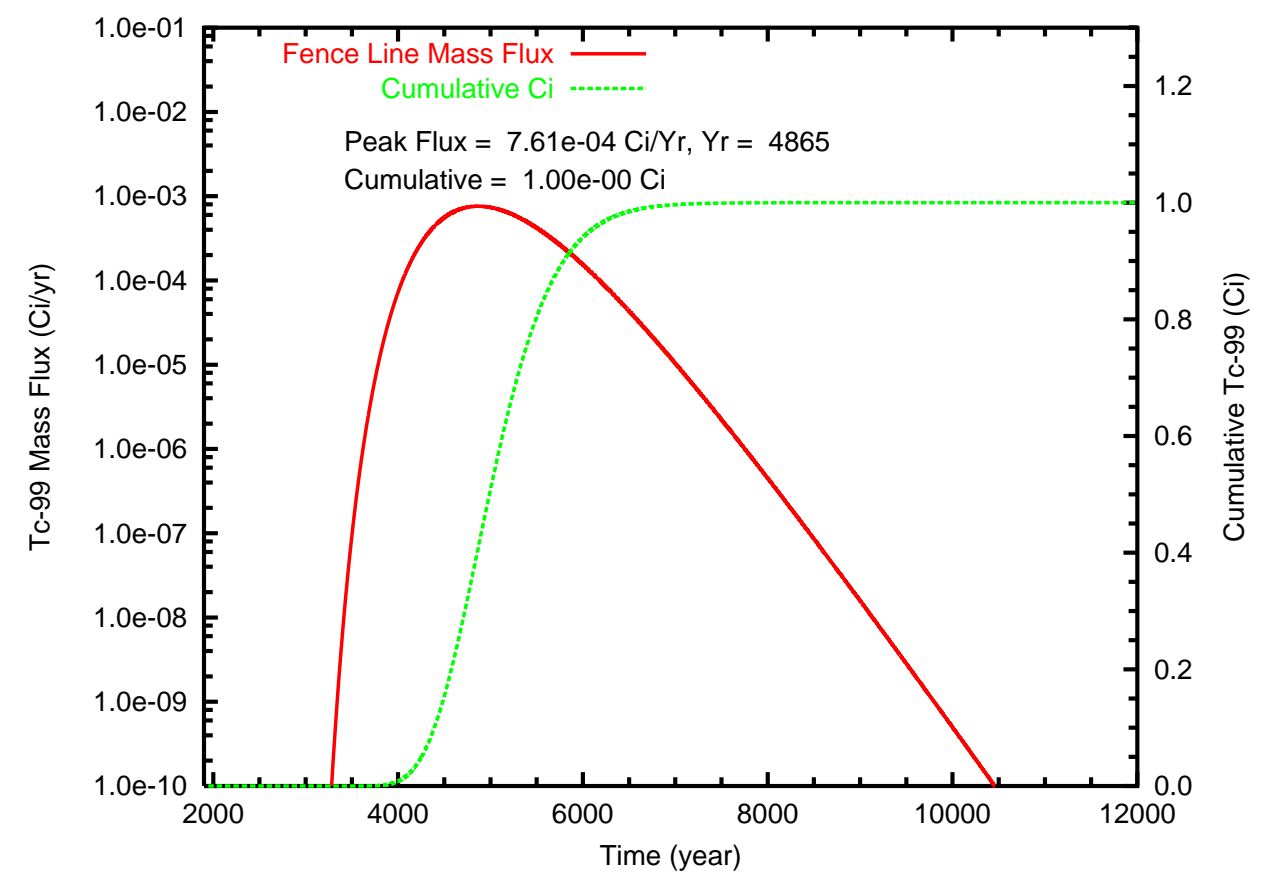

Figure B.97. Case 6, Tc-99 mass flux and cumulative mass at (a) the groundwater table and (b) the fence line 
(a)

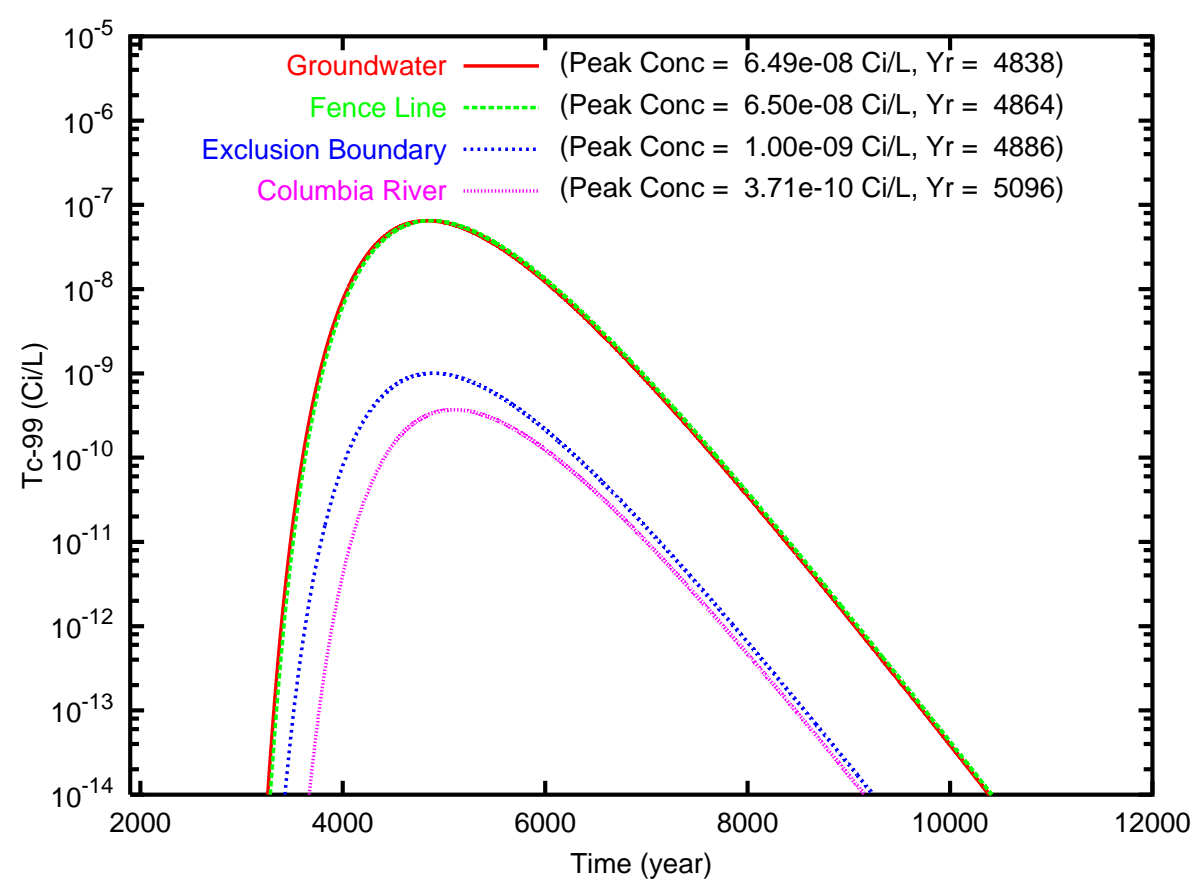

(b)

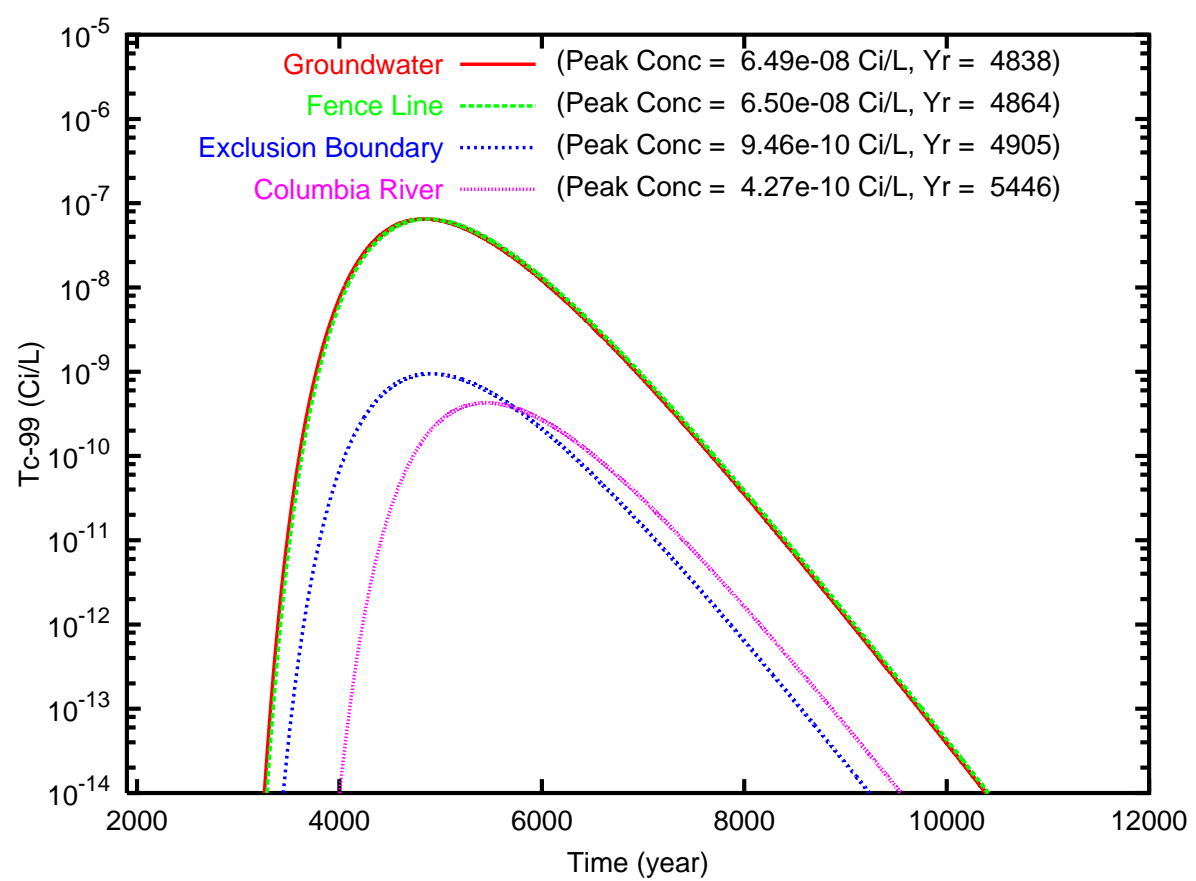

Figure B.98. Case 6, Tc-99 concentration versus time for the fence line, exclusion boundary and Columbia River compliance points for travel paths (a) southeast and (b) north through the gap 
(a)

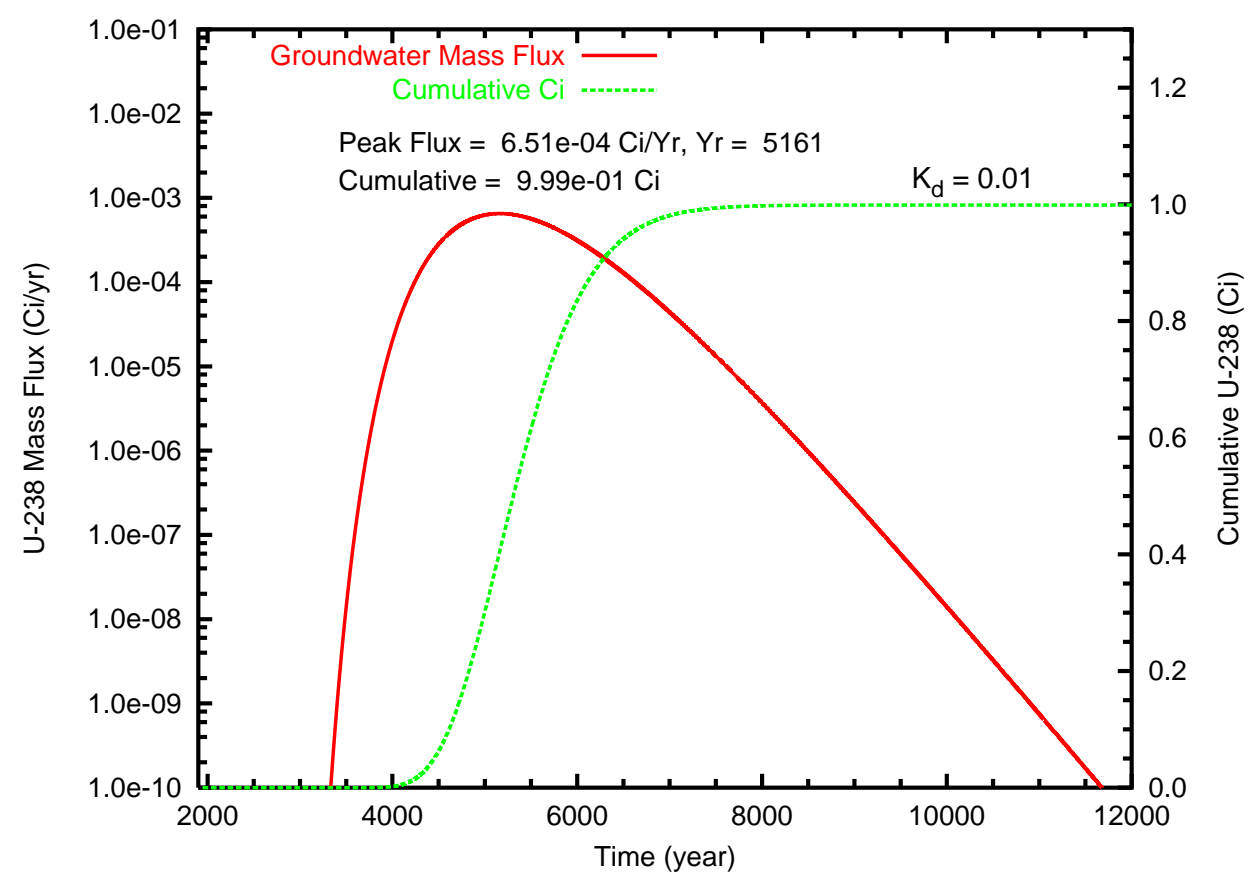

(b)

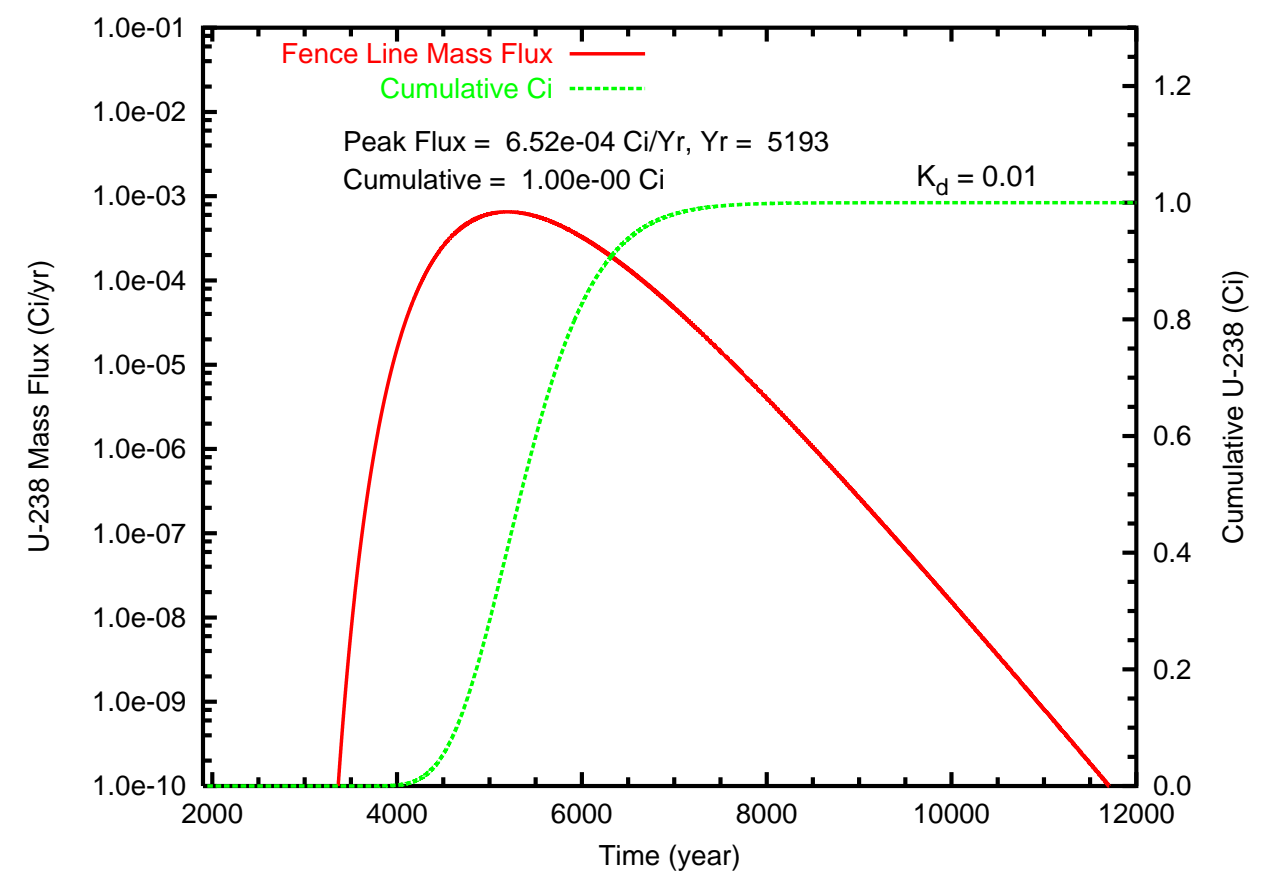

Figure B.99. Case 6, U-238 $\left(\mathrm{K}_{d}=0.01\right)$ mass flux $(\mathrm{Ci} / \mathrm{L})$ and cumulative mass $(\mathrm{Ci})$ at (a) the groundwater table and (b) the fence line 
(a)

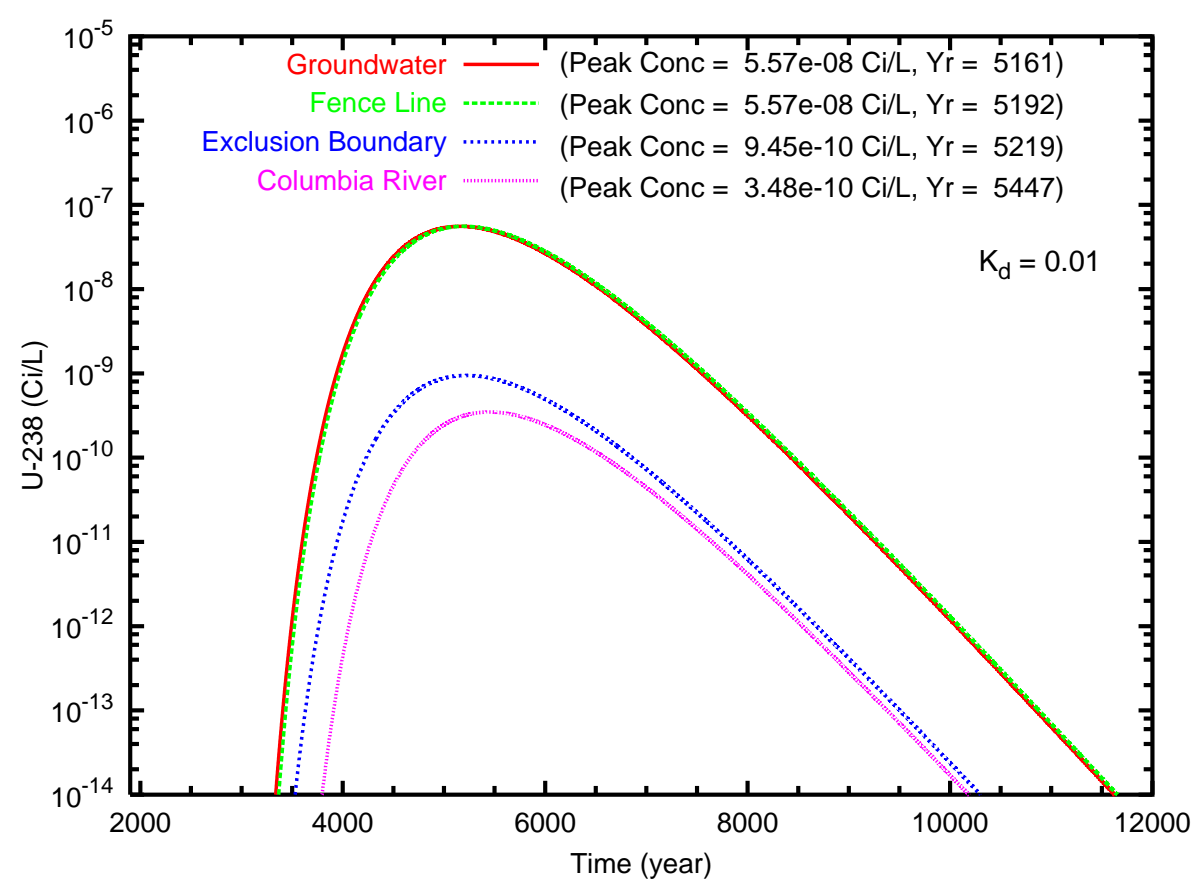

(b)

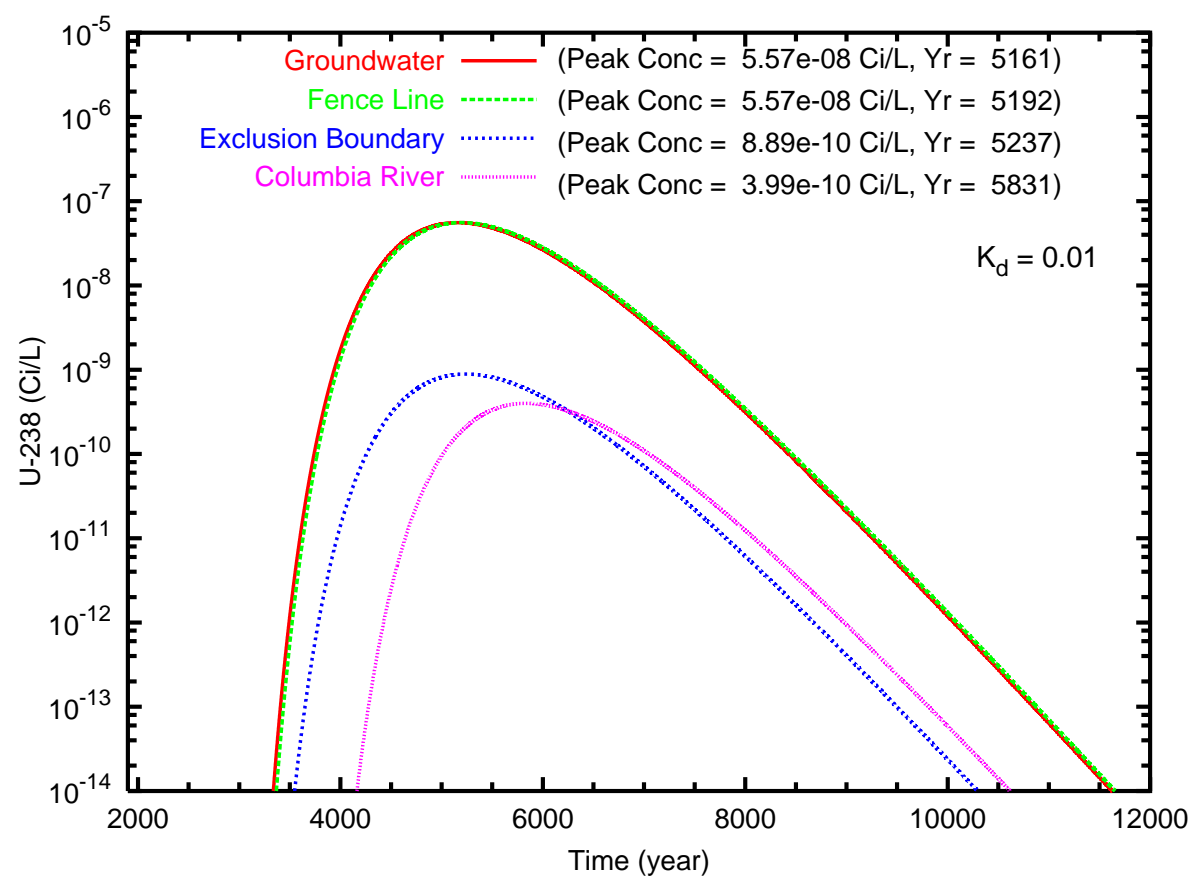

Figure B.100. Case 6, U-238 $\left(\mathrm{K}_{d}=0.01\right)$ concentration versus time for the fence line exclusion boundary and Columbia River compliance points for travel paths (a) southeast and (b) north through the gap 
(a)

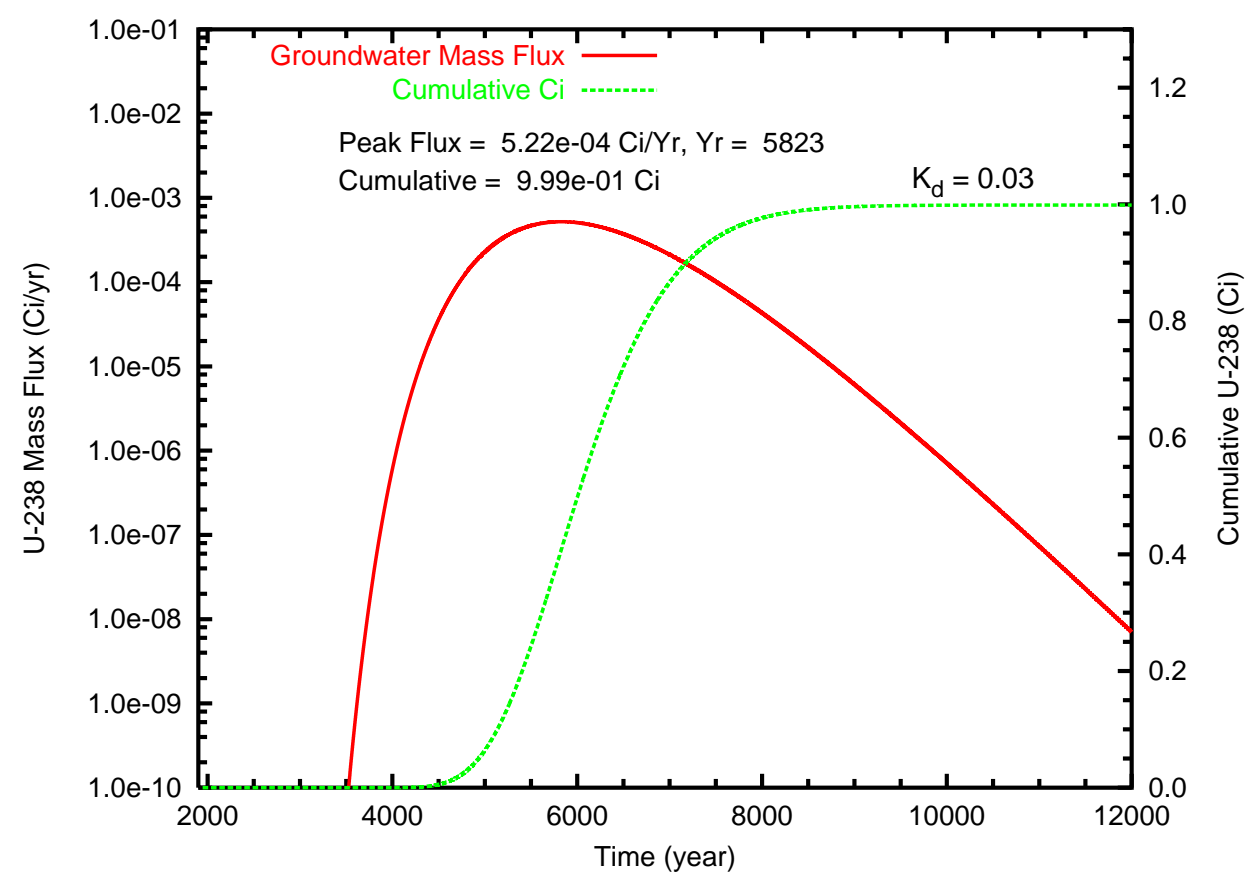

(b)

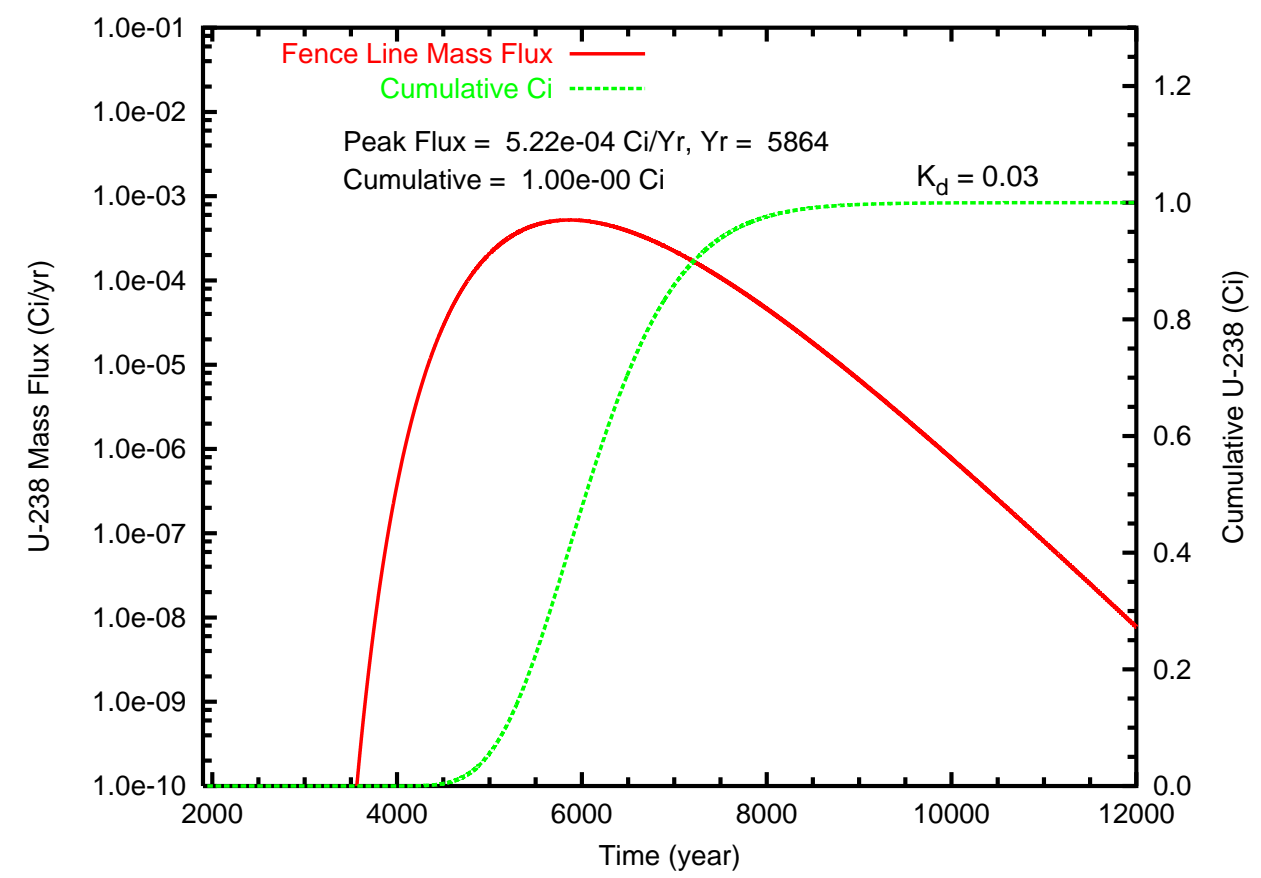

Figure B.101. Case 6, U-238 $\left(\mathrm{K}_{d}=0.03\right)$ mass flux $(\mathrm{Ci} / \mathrm{L})$ and cumulative mass $(\mathrm{Ci})$ at (a) the groundwater table and (b) the fence line 
(a)

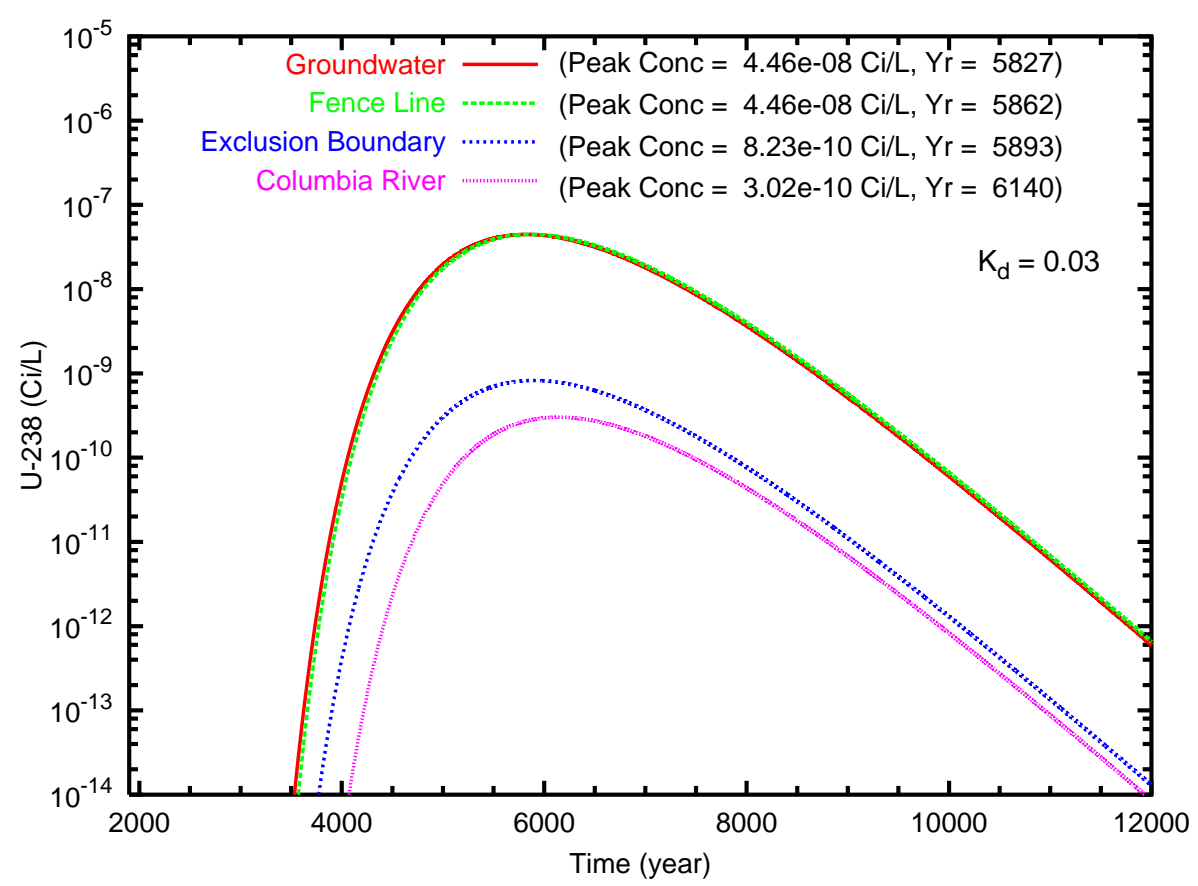

(b)

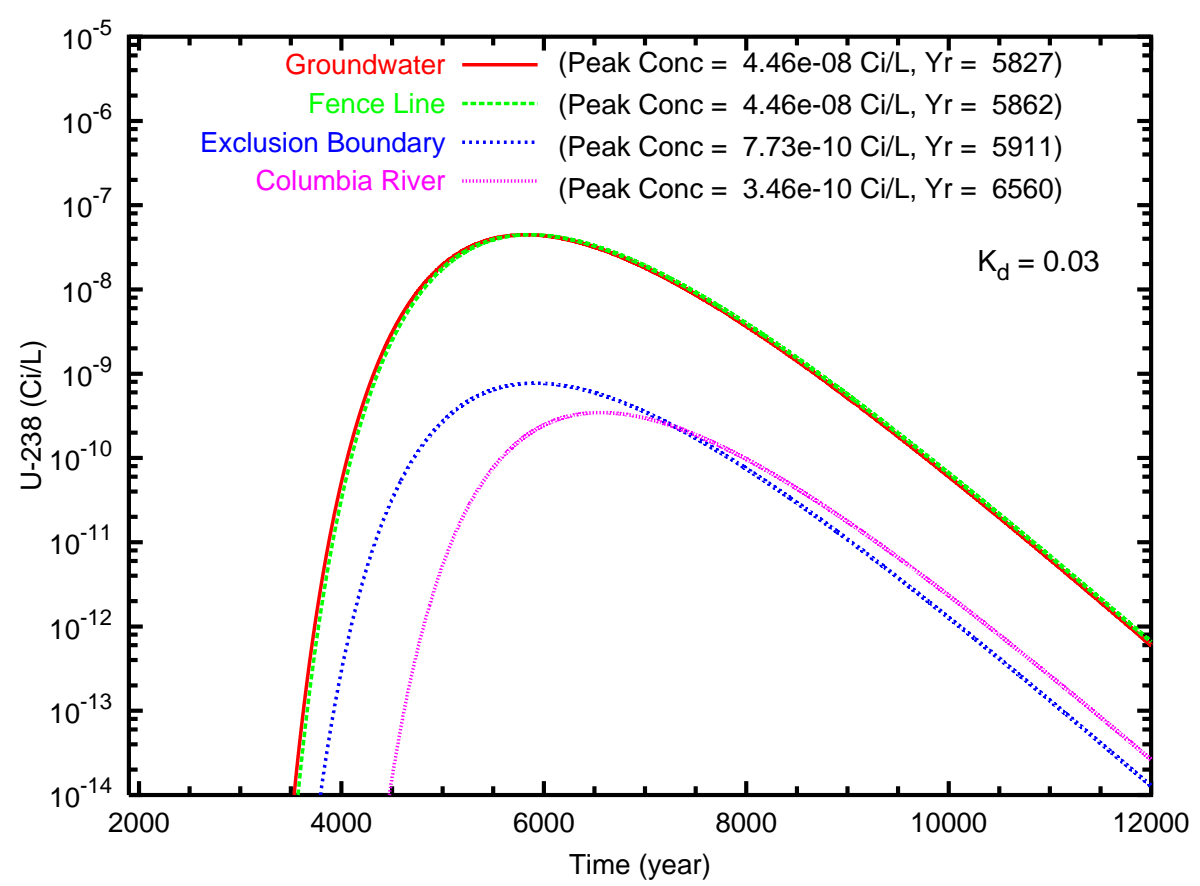

Figure B.102. Case 6, U-238 $\left(\mathrm{K}_{d}=0.03\right)$ concentration versus time for the fence line exclusion boundary and Columbia River compliance points for travel paths (a) southeast and (b) north through the gap 
(a)

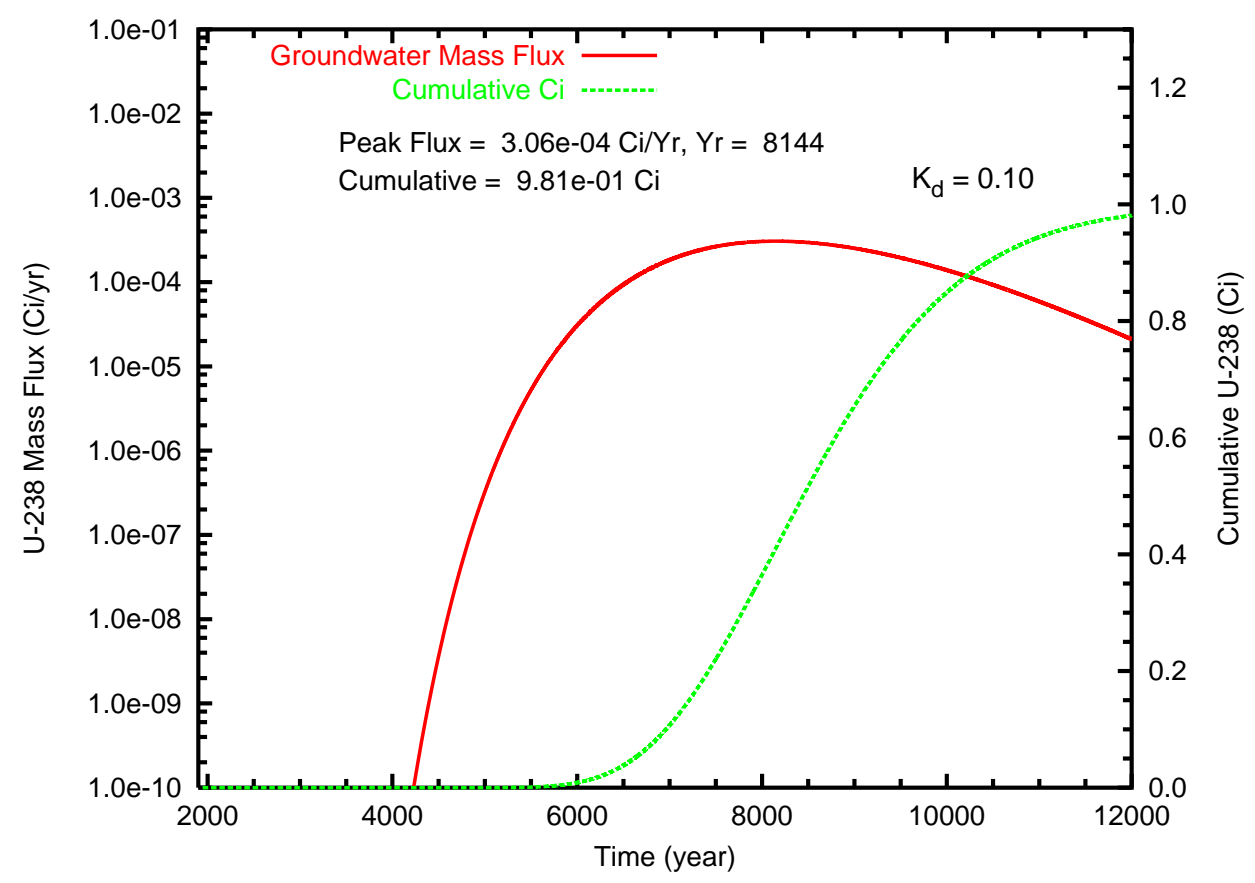

(b)

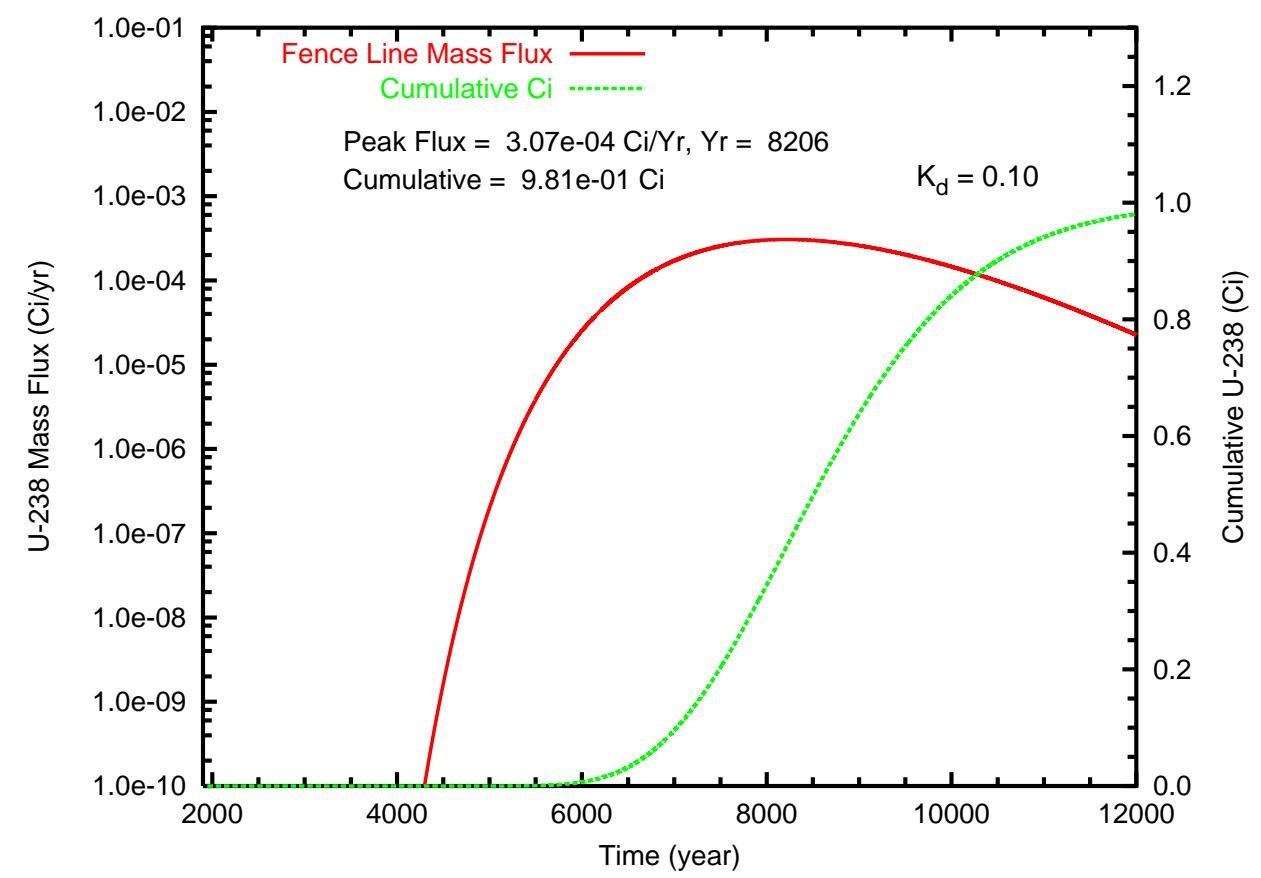

Figure B.103. Case 6, U-238 $\left(\mathrm{K}_{d}=0.10\right)$ mass flux $(\mathrm{Ci} / \mathrm{L})$ and cumulative mass $(\mathrm{Ci})$ at (a) the groundwater table and (b) the fence line 
(a)

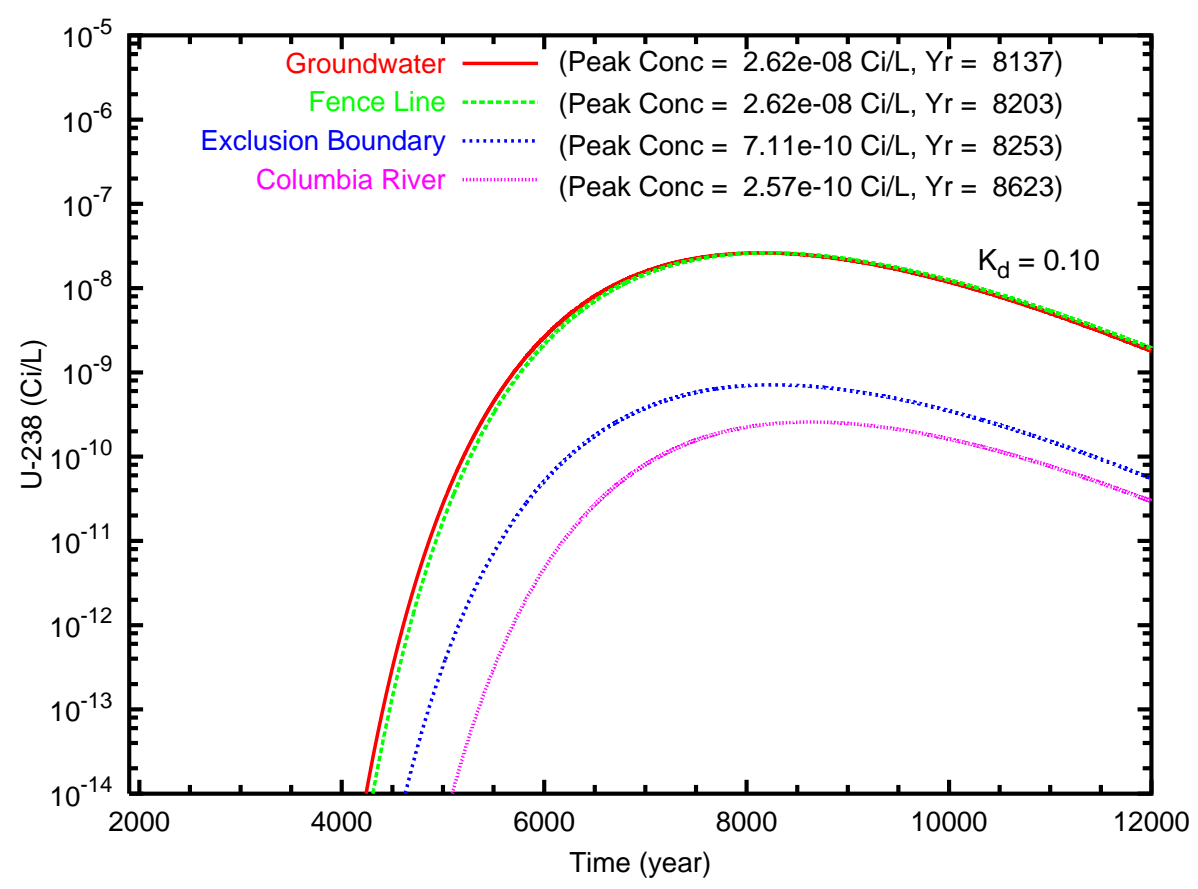

(b)

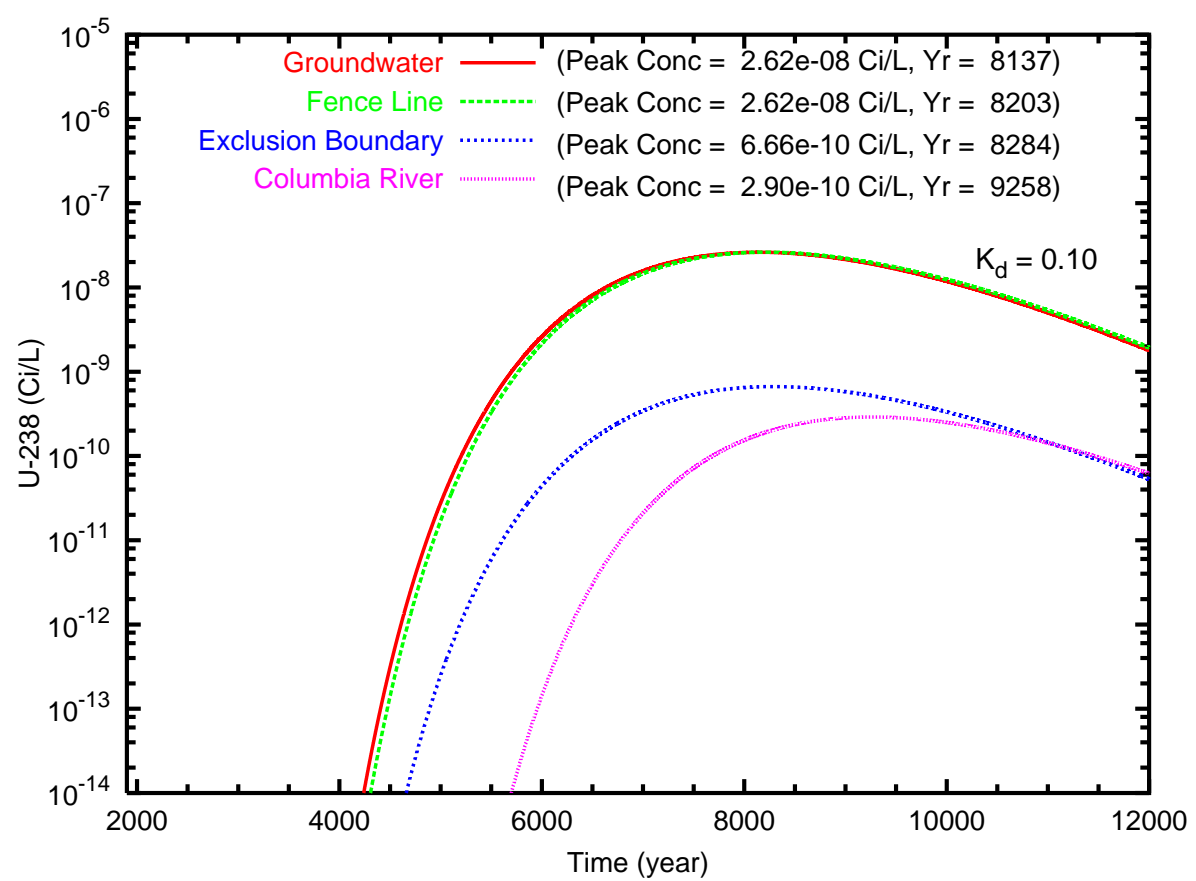

Figure B.104. Case 6, U-238 $\left(\mathrm{K}_{d}=0.10\right)$ concentration versus time for the fence line exclusion boundary and Columbia River compliance points for travel paths (a) southeast and (b) north through the gap 
(a)

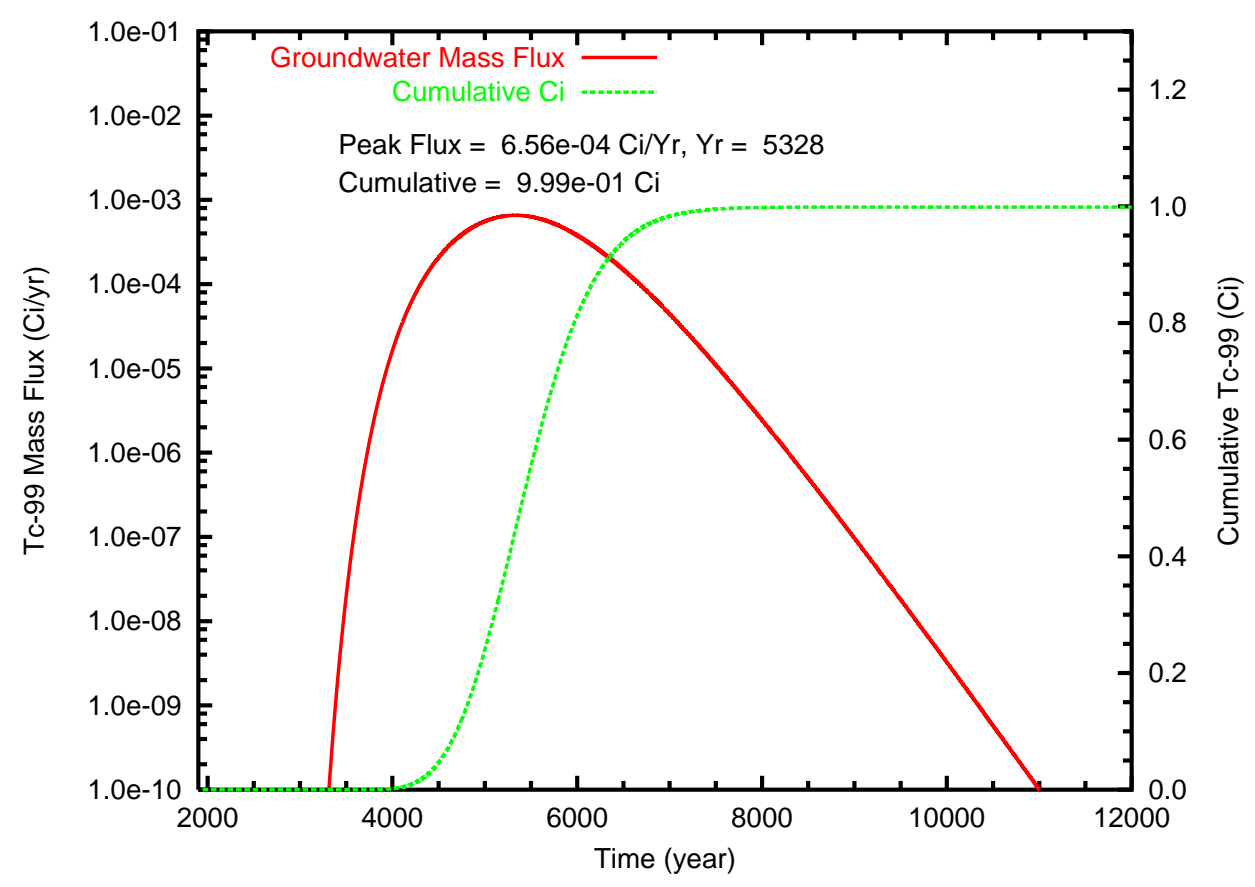

(b)

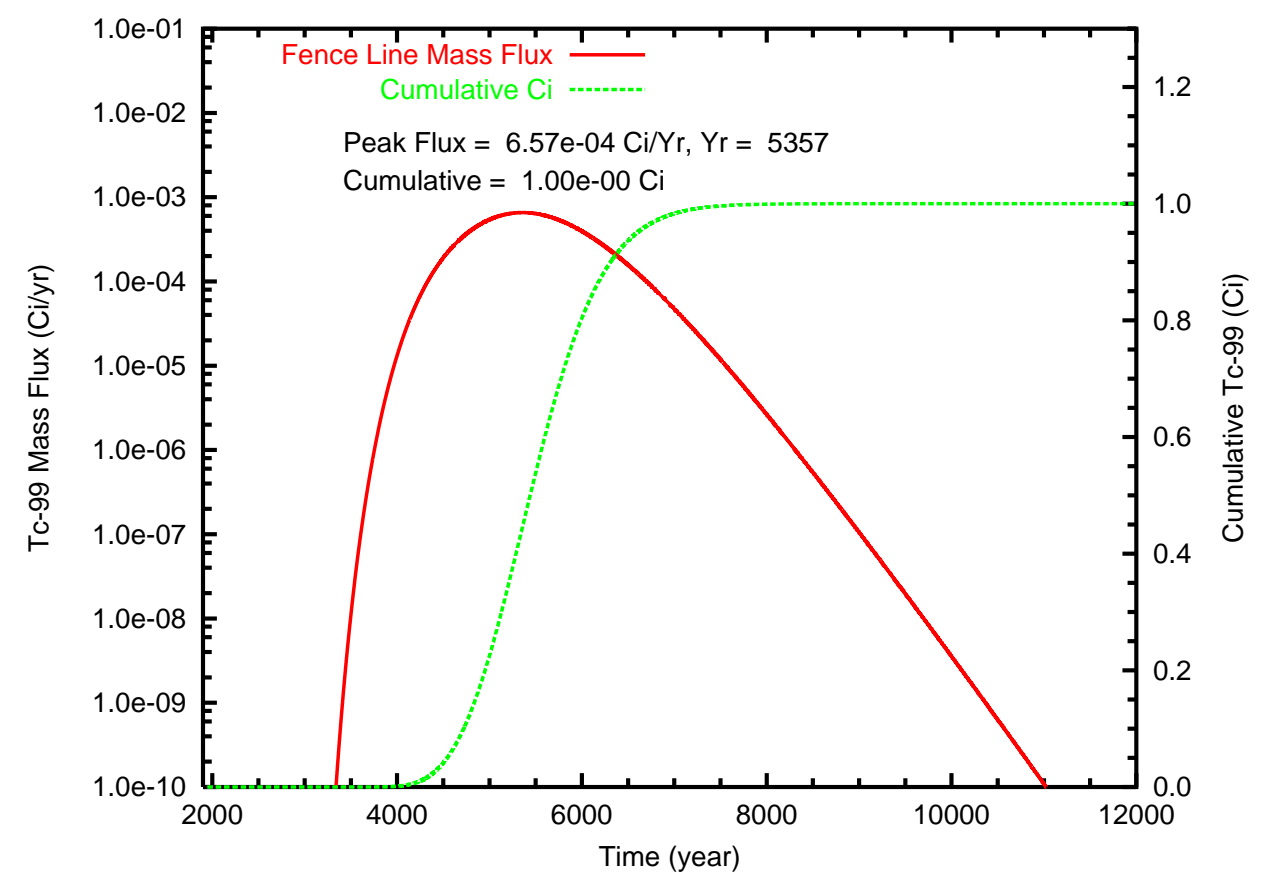

Figure B.105. Case 7, Tc-99 mass flux and cumulative mass at (a) the groundwater table and (b) the fence line 
(a)

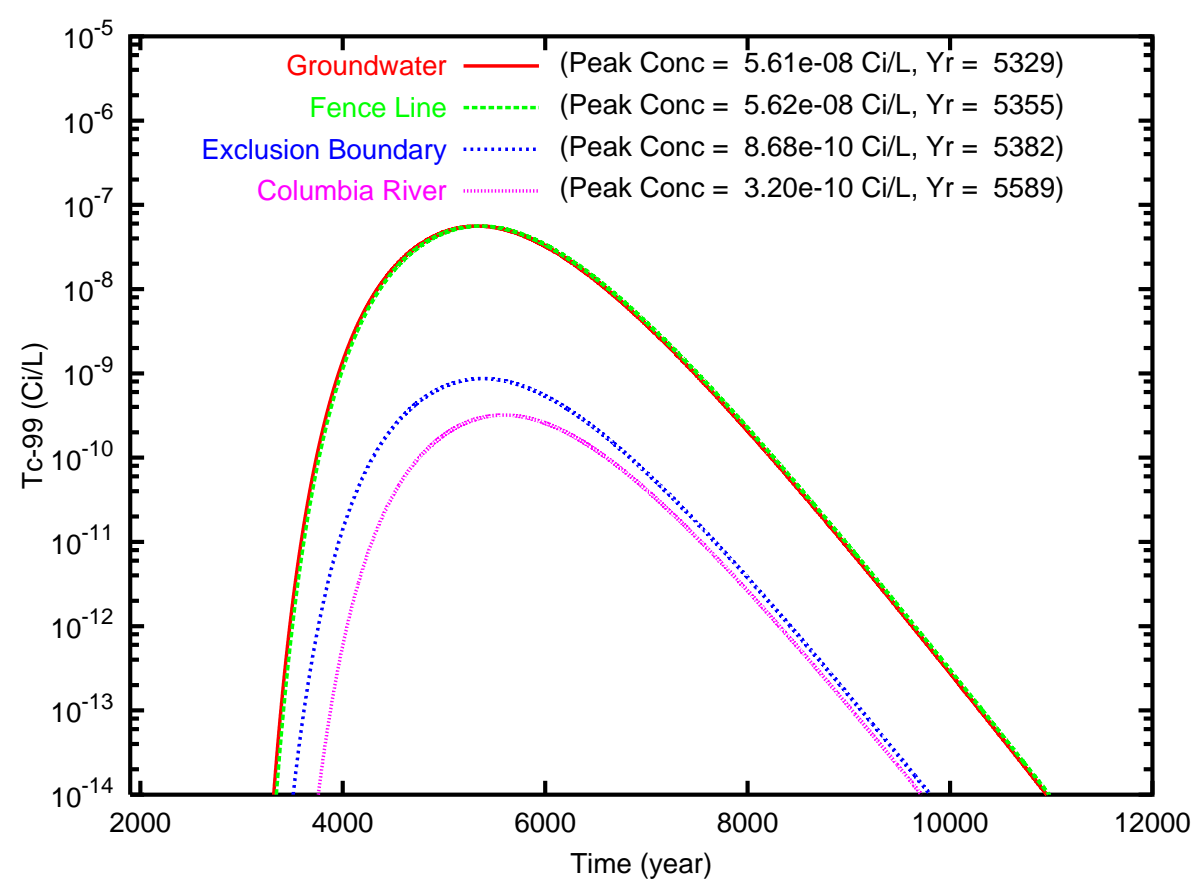

(b)

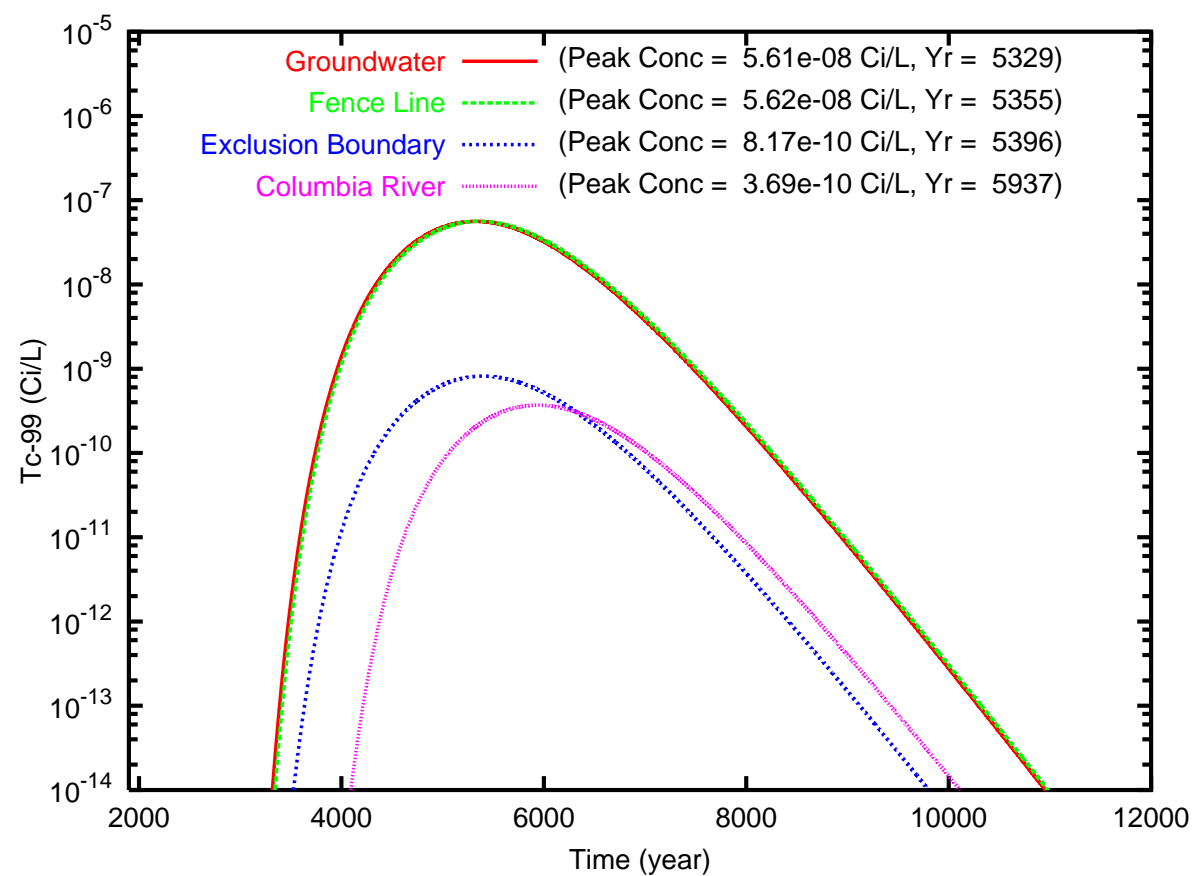

Figure B.106. Case 7, Tc-99 concentration versus time for the fence line, exclusion boundary and Columbia River compliance points for travel paths (a) southeast and (b) north through the gap 
(a)

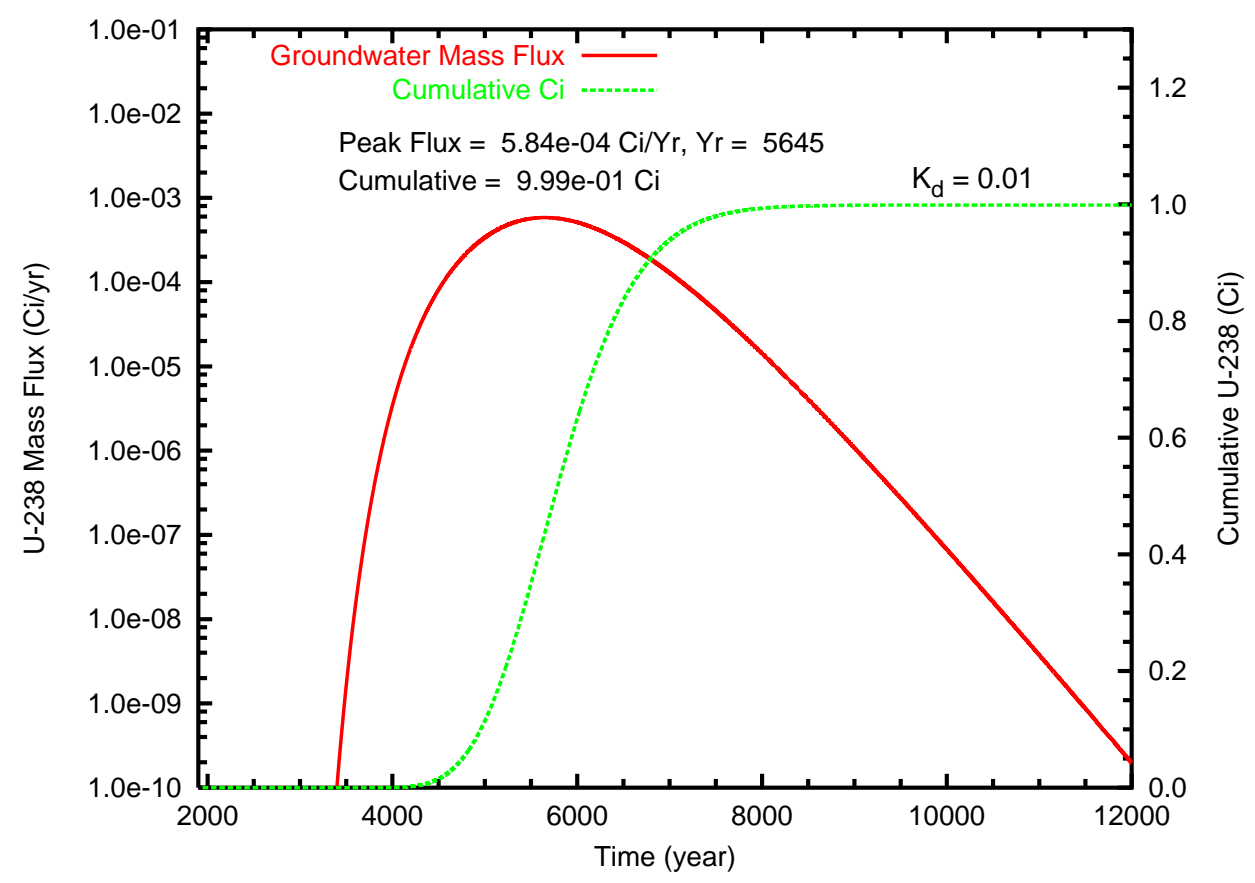

(b)

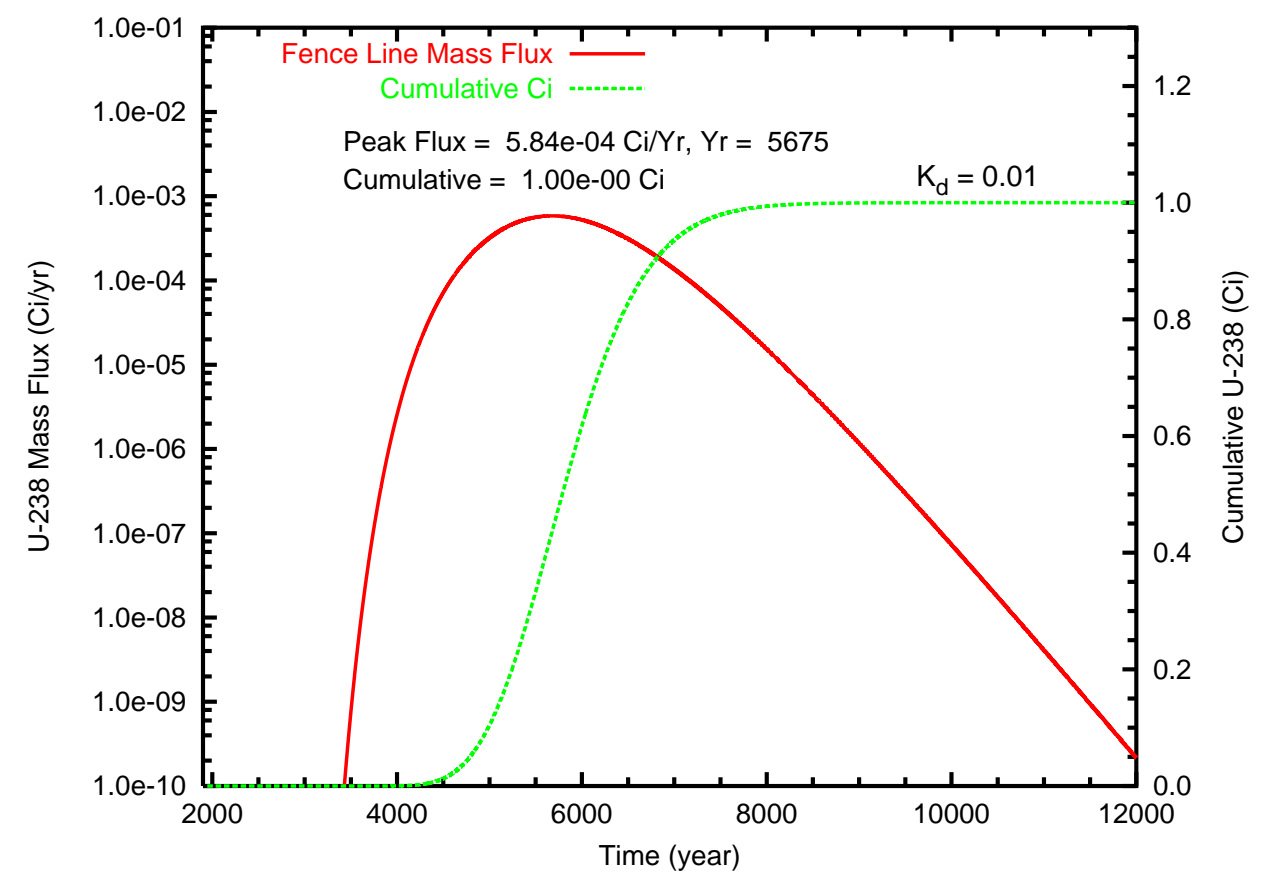

Figure B.107. Case 7, U-238 $\left(\mathrm{K}_{d}=0.01\right)$ mass flux $(\mathrm{Ci} / \mathrm{L})$ and cumulative mass $(\mathrm{Ci})$ at (a) the groundwater table and (b) the fence line 
(a)

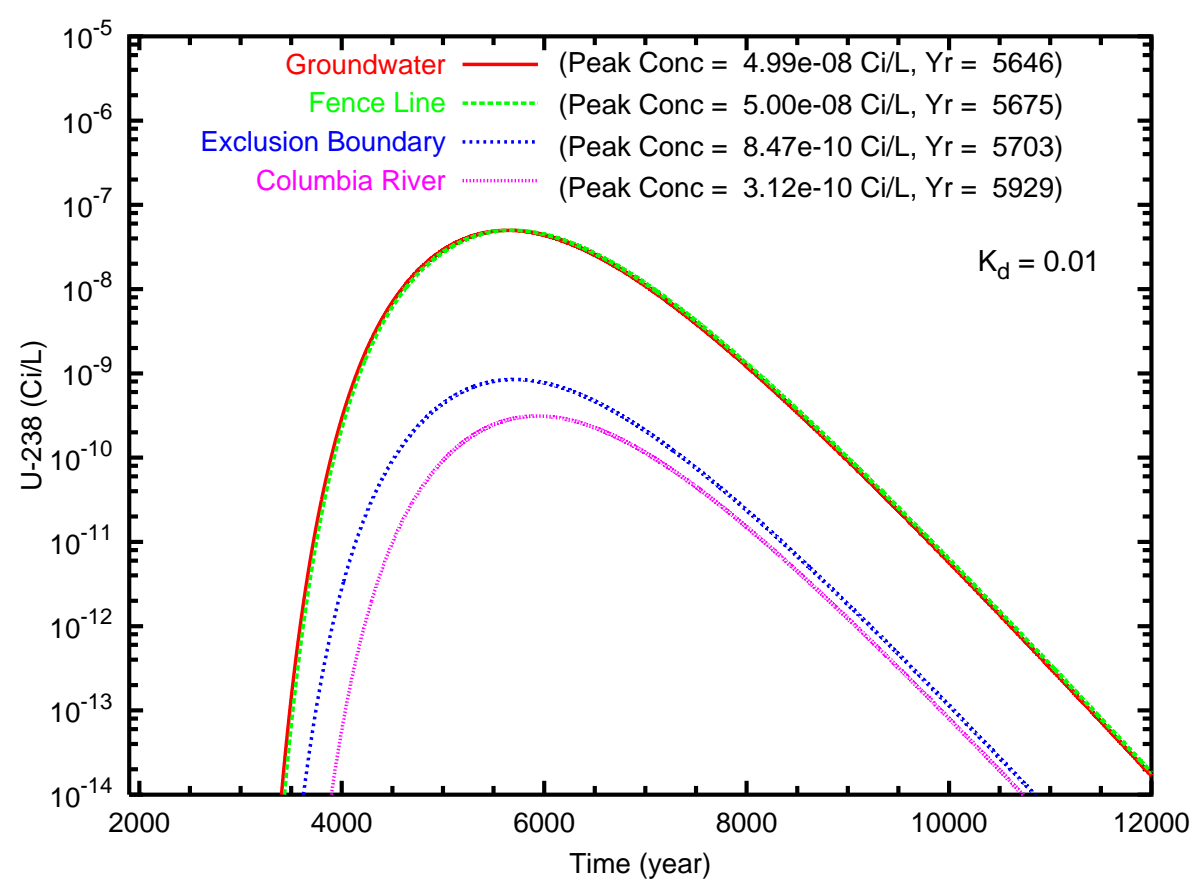

(b)

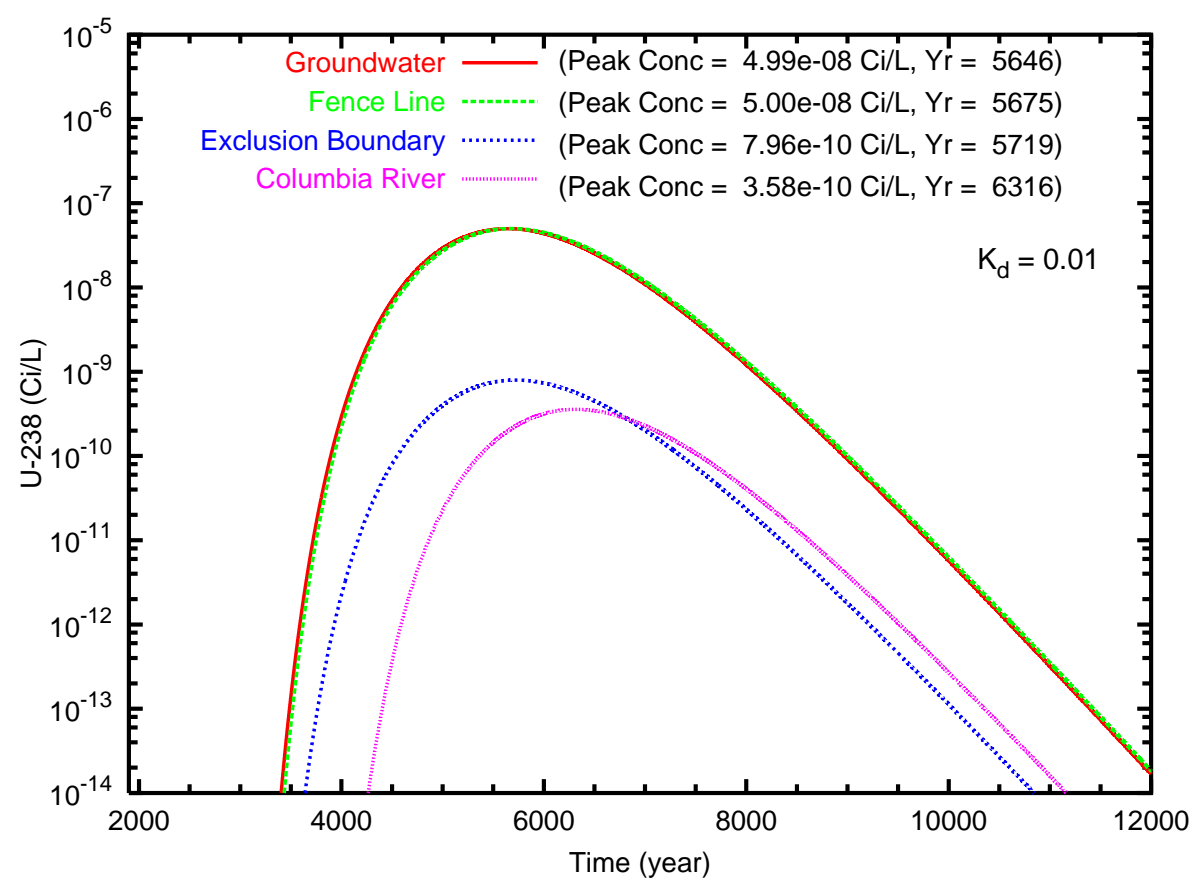

Figure B.108. Case 7, U-238 $\left(\mathrm{K}_{d}=0.01\right)$ concentration versus time for the fence line exclusion boundary and Columbia River compliance points for travel paths (a) southeast and (b) north through the gap 
(a)

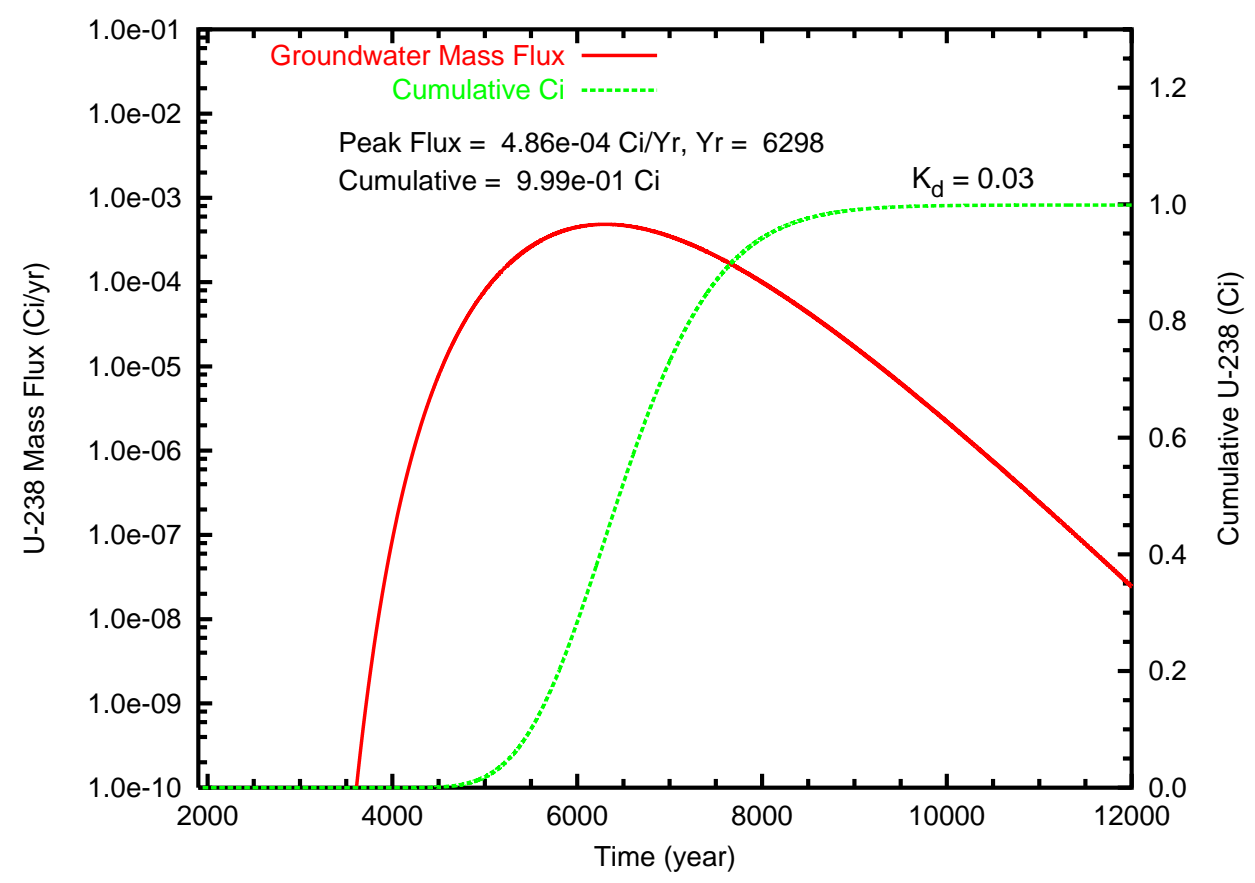

(b)

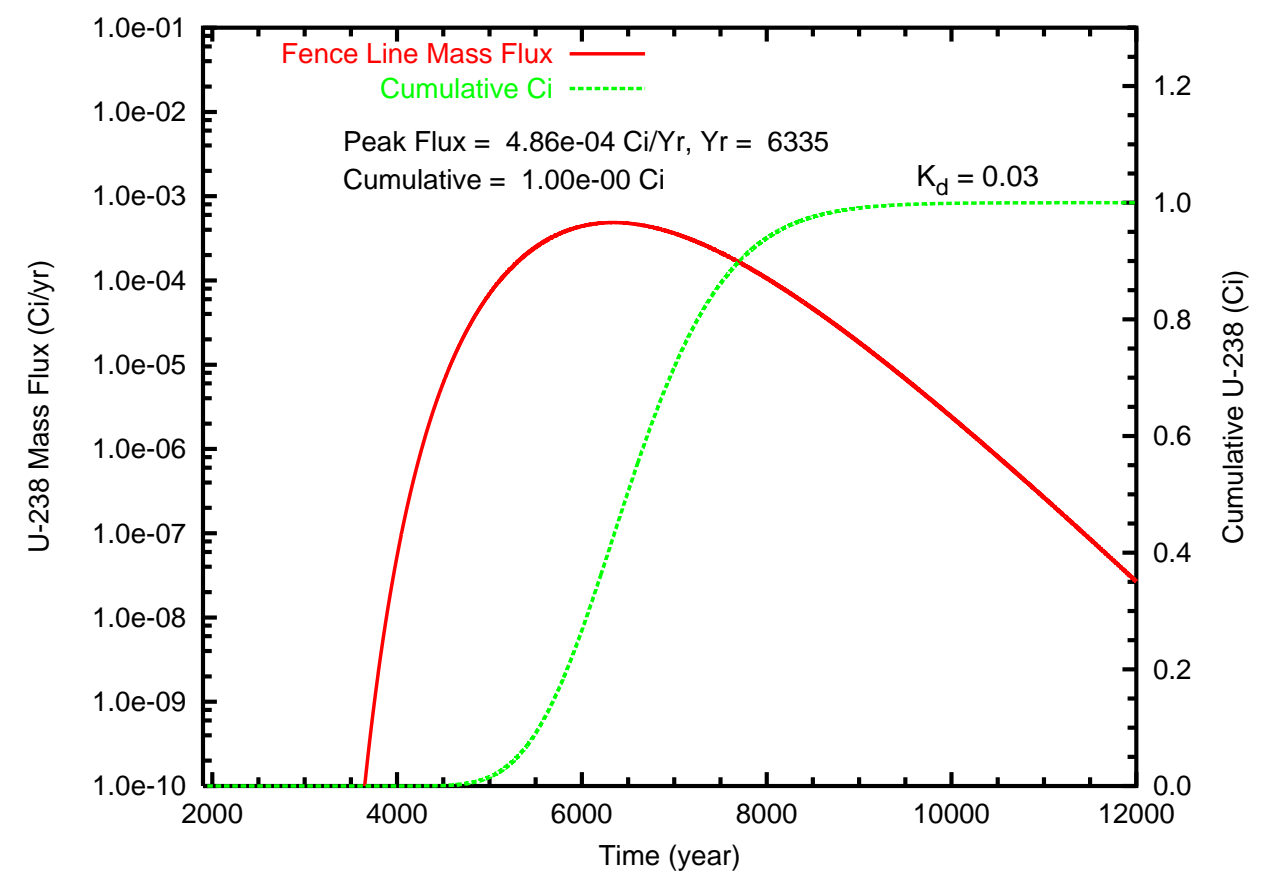

Figure B.109. Case 7, U-238 $\left(\mathrm{K}_{d}=0.03\right)$ mass flux $(\mathrm{Ci} / \mathrm{L})$ and cumulative mass $(\mathrm{Ci})$ at (a) the groundwater table and (b) the fence line 
(a)

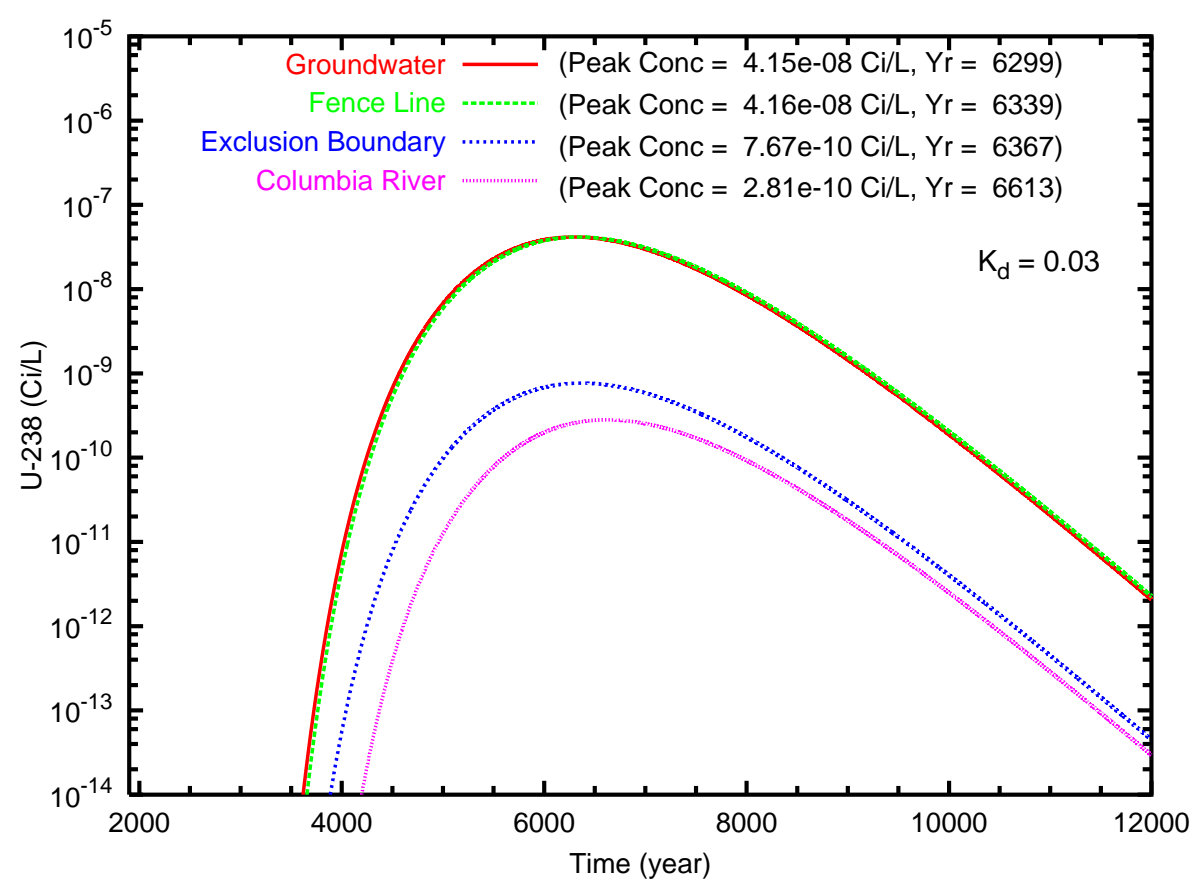

(b)

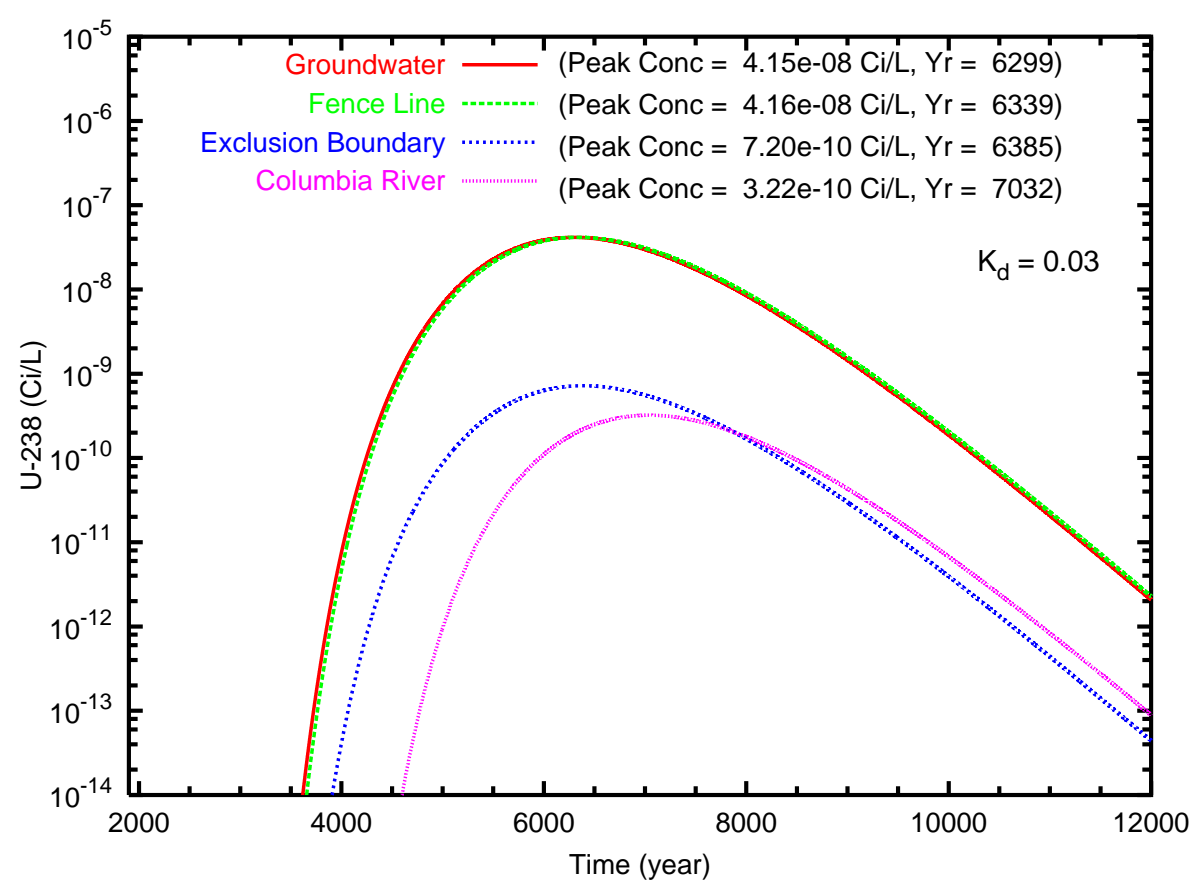

Figure B.110. Case 7, U-238 $\left(\mathrm{K}_{d}=0.03\right)$ concentration versus time for the fence line exclusion boundary and Columbia River compliance points for travel paths (a) southeast and (b) north through the gap 
(a)

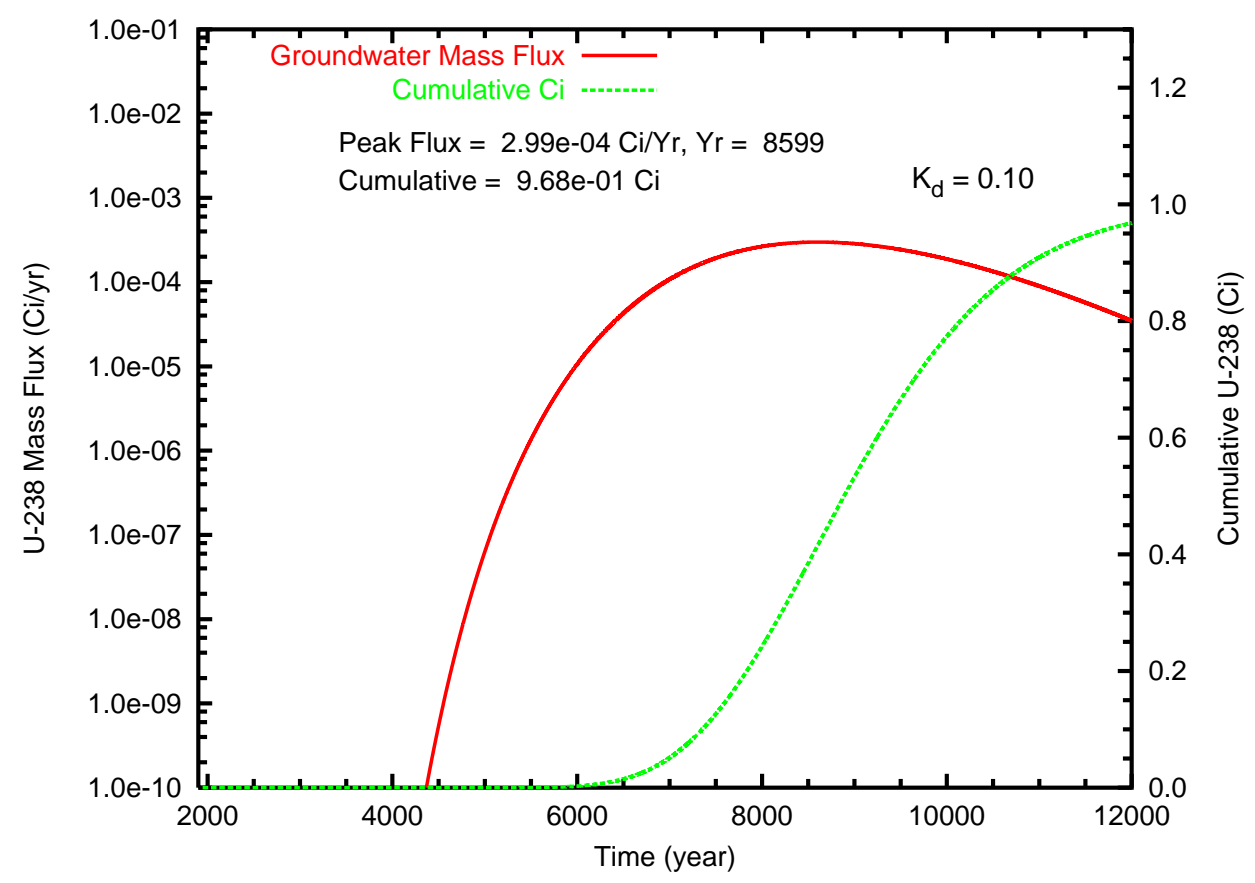

(b)

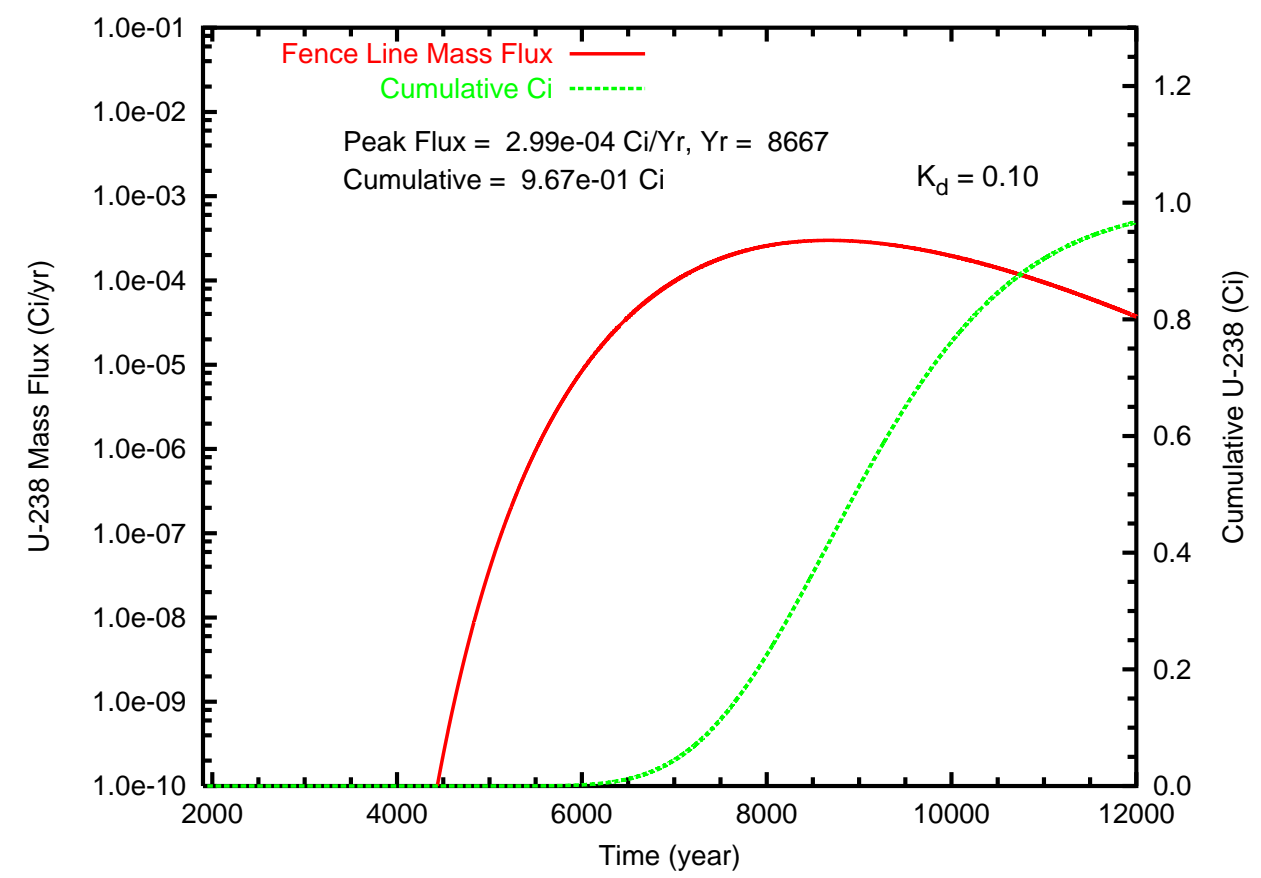

Figure B.111. Case 7, U-238 $\left(\mathrm{K}_{d}=0.10\right)$ mass flux $(\mathrm{Ci} / \mathrm{L})$ and cumulative mass $(\mathrm{Ci})$ at (a) the groundwater table and (b) the fence line 
(a)

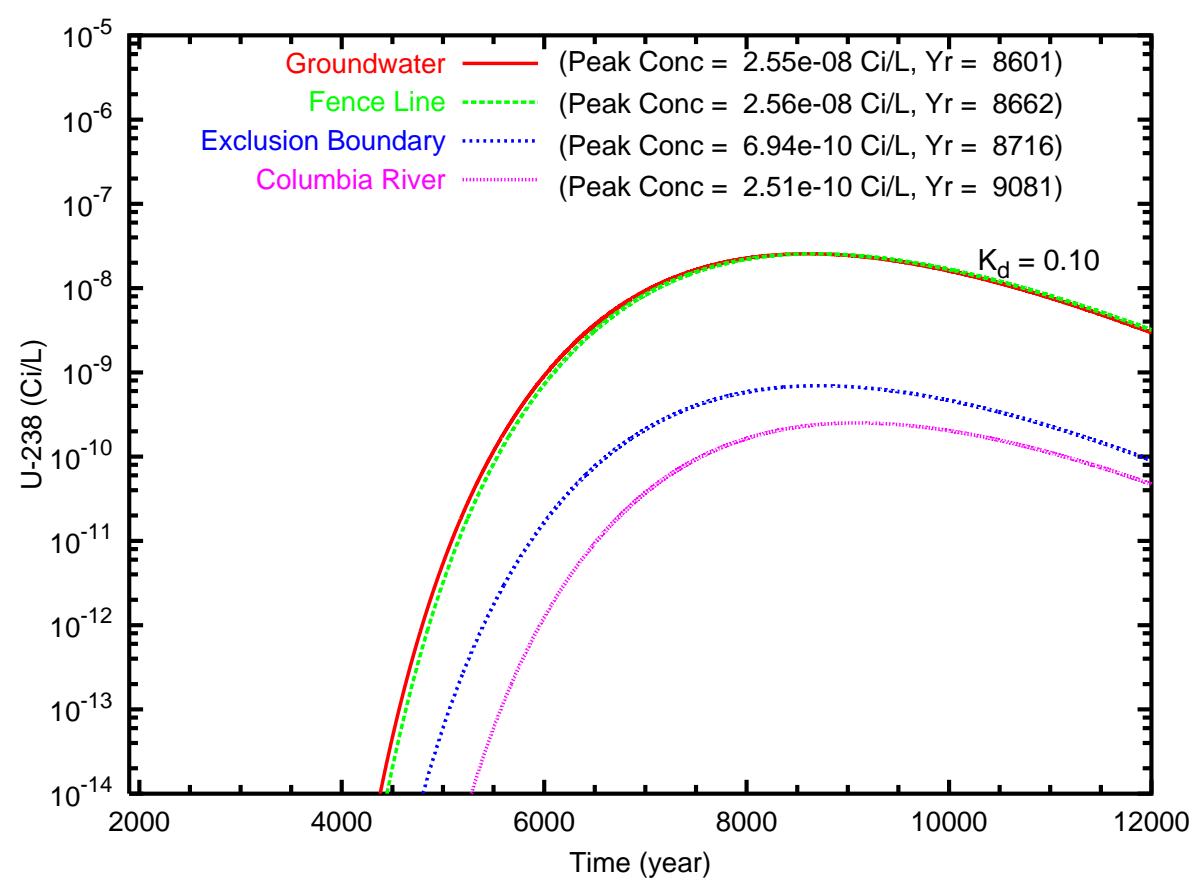

(b)

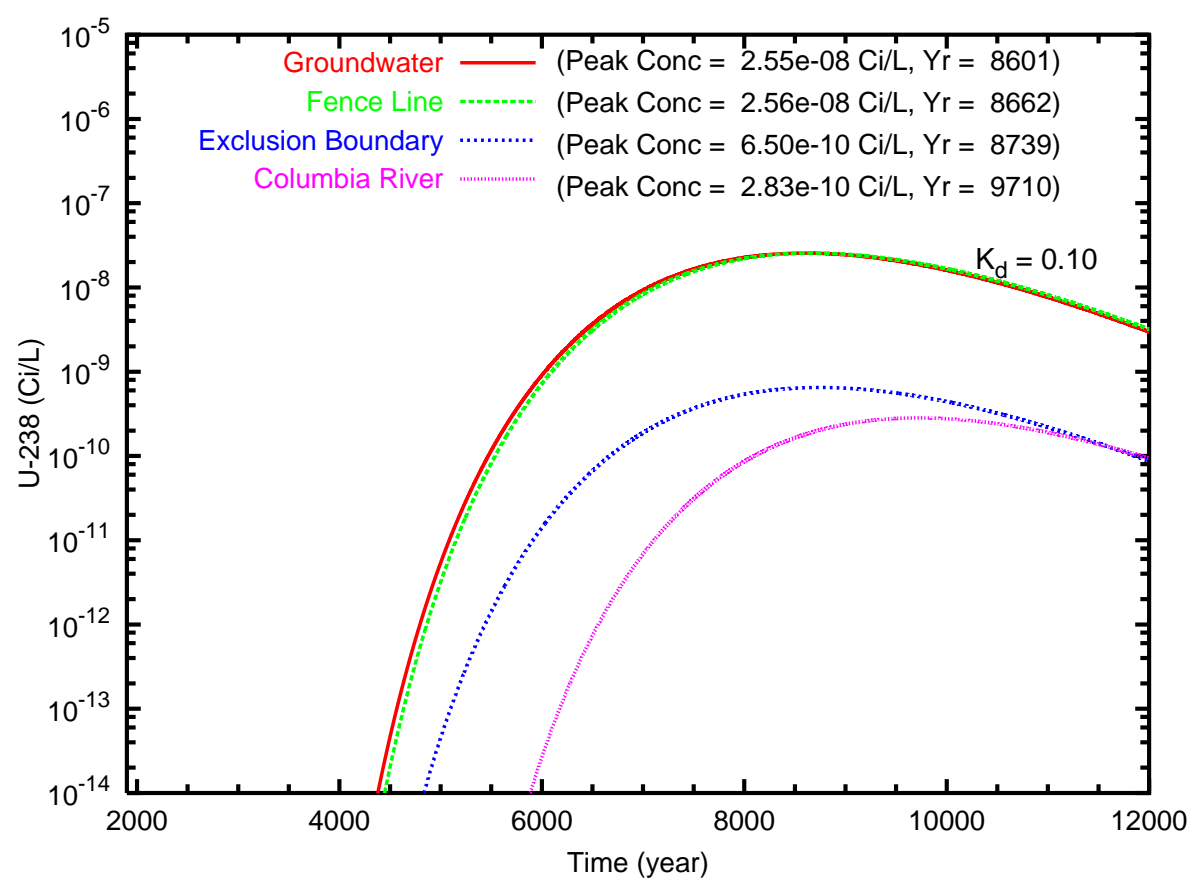

Figure B.112. Case 7, U-238 $\left(\mathrm{K}_{d}=0.10\right)$ concentration versus time for the fence line exclusion boundary and Columbia River compliance points for travel paths (a) southeast and (b) north through the gap 
(a)

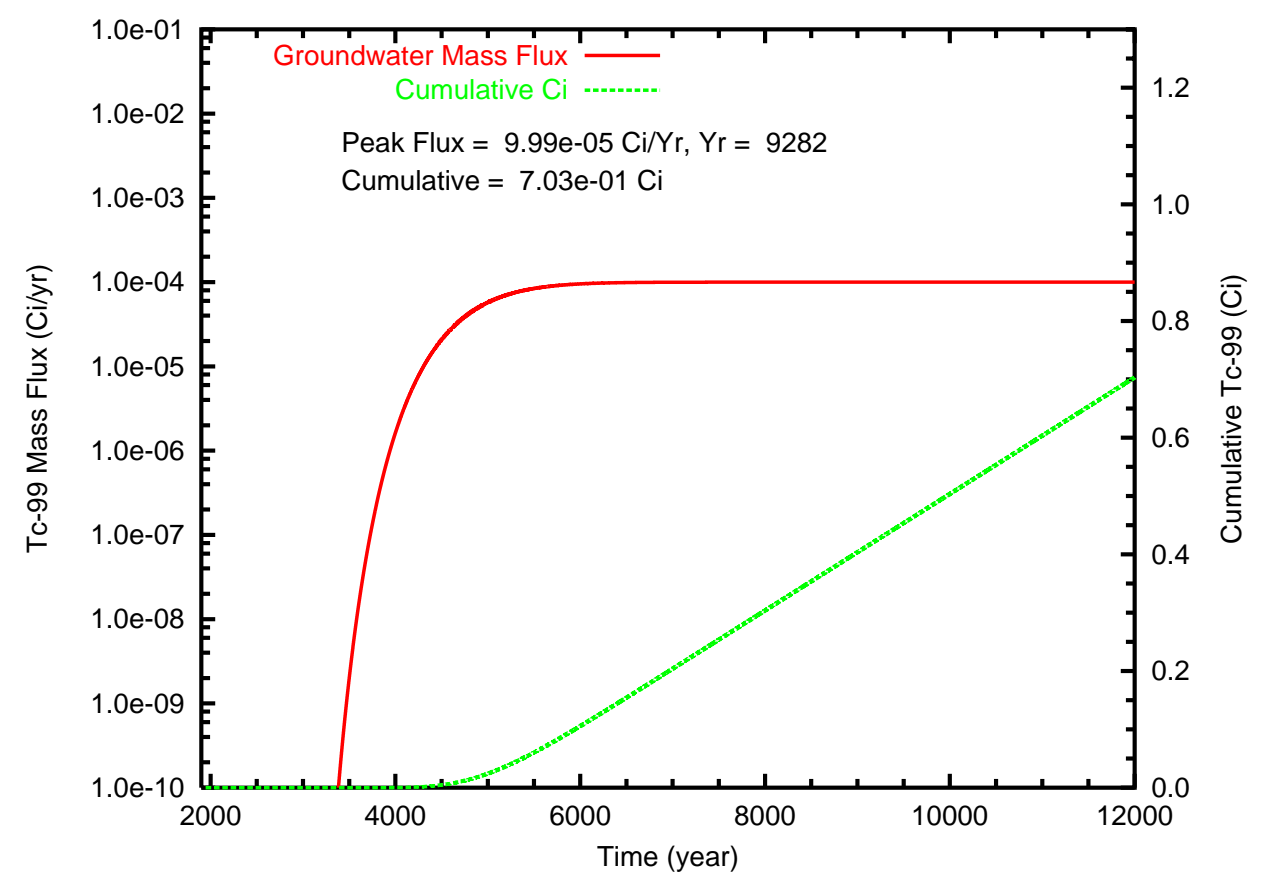

(b)

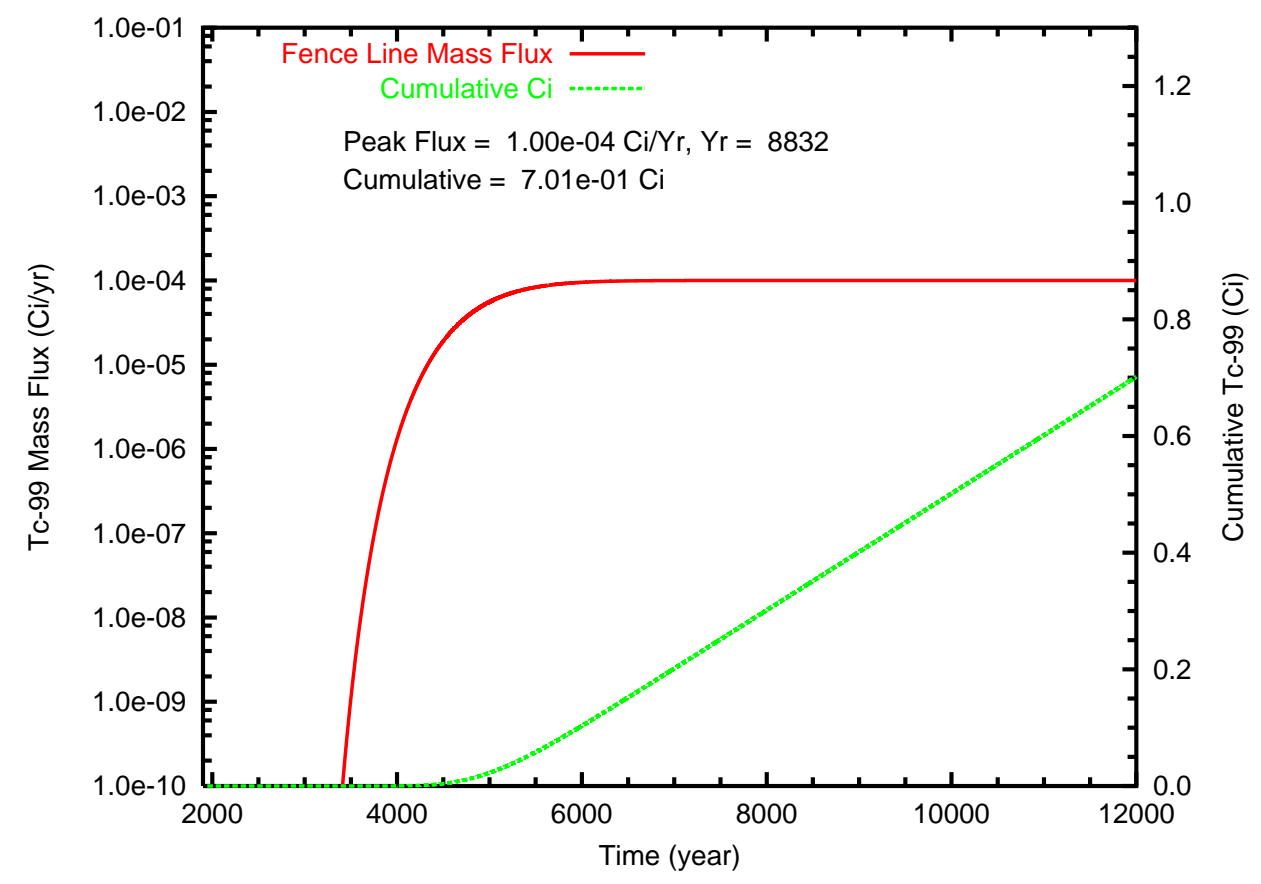

Figure B.113. Case 8, Tc-99 mass flux and cumulative mass at (a) the groundwater table and (b) the fence line 
(a)

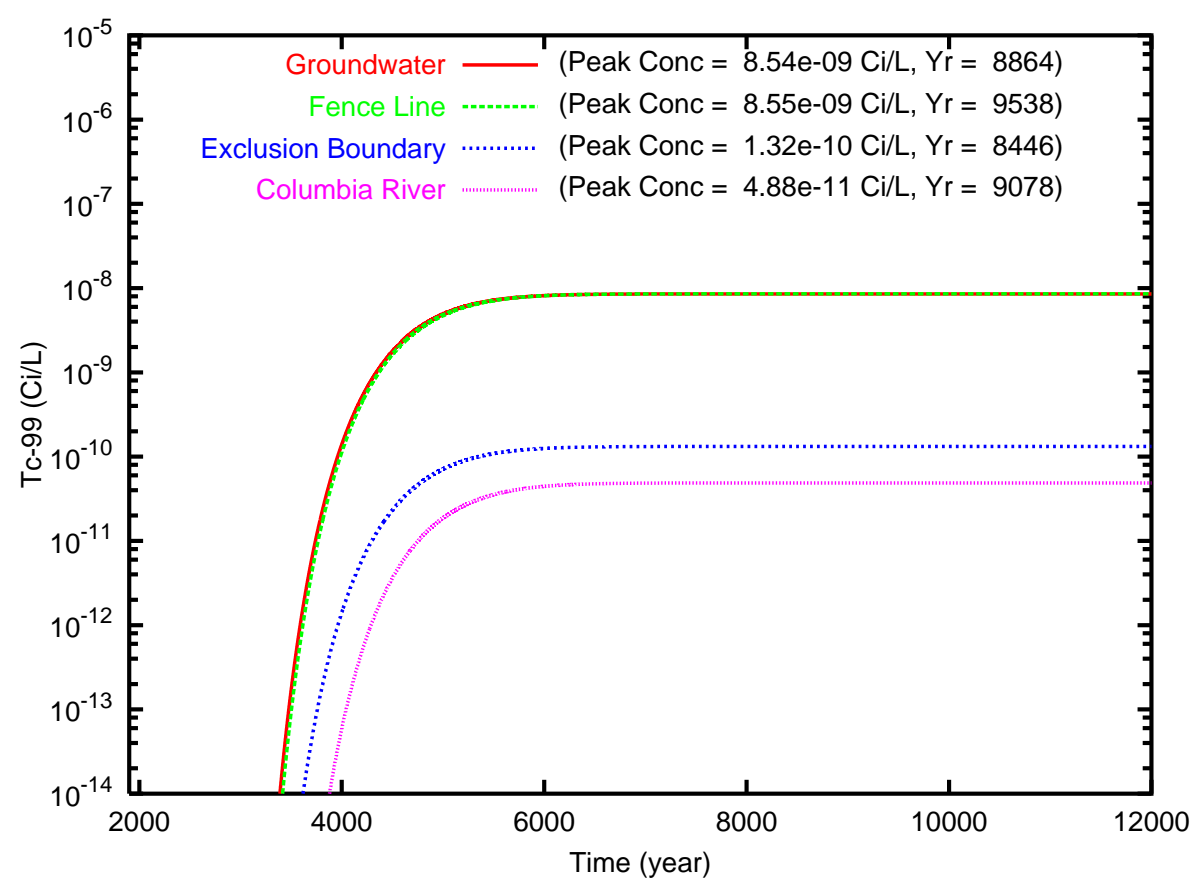

(b)

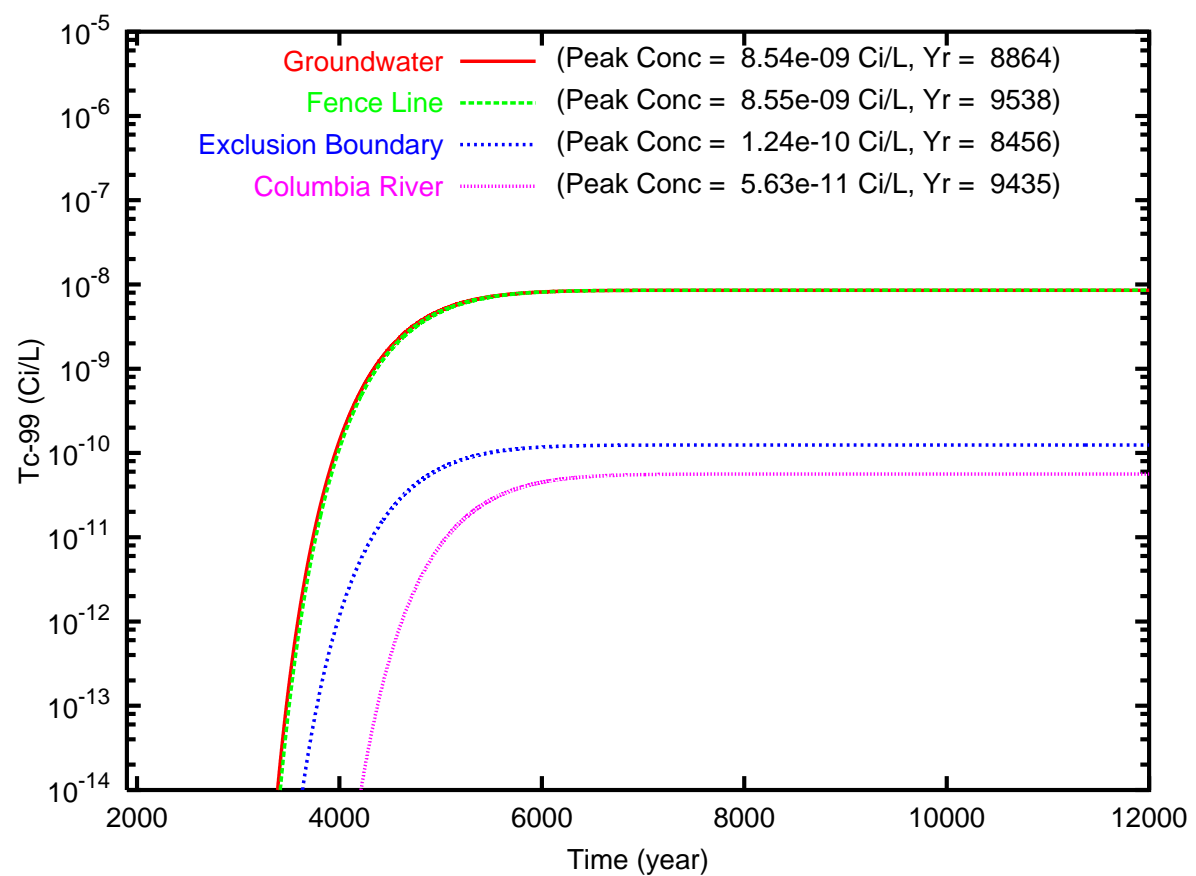

Figure B.114. Case 8, Tc-99 concentration versus time for the fence line, exclusion boundary and Columbia River compliance points for travel paths (a) southeast and (b) north through the gap 
(a)

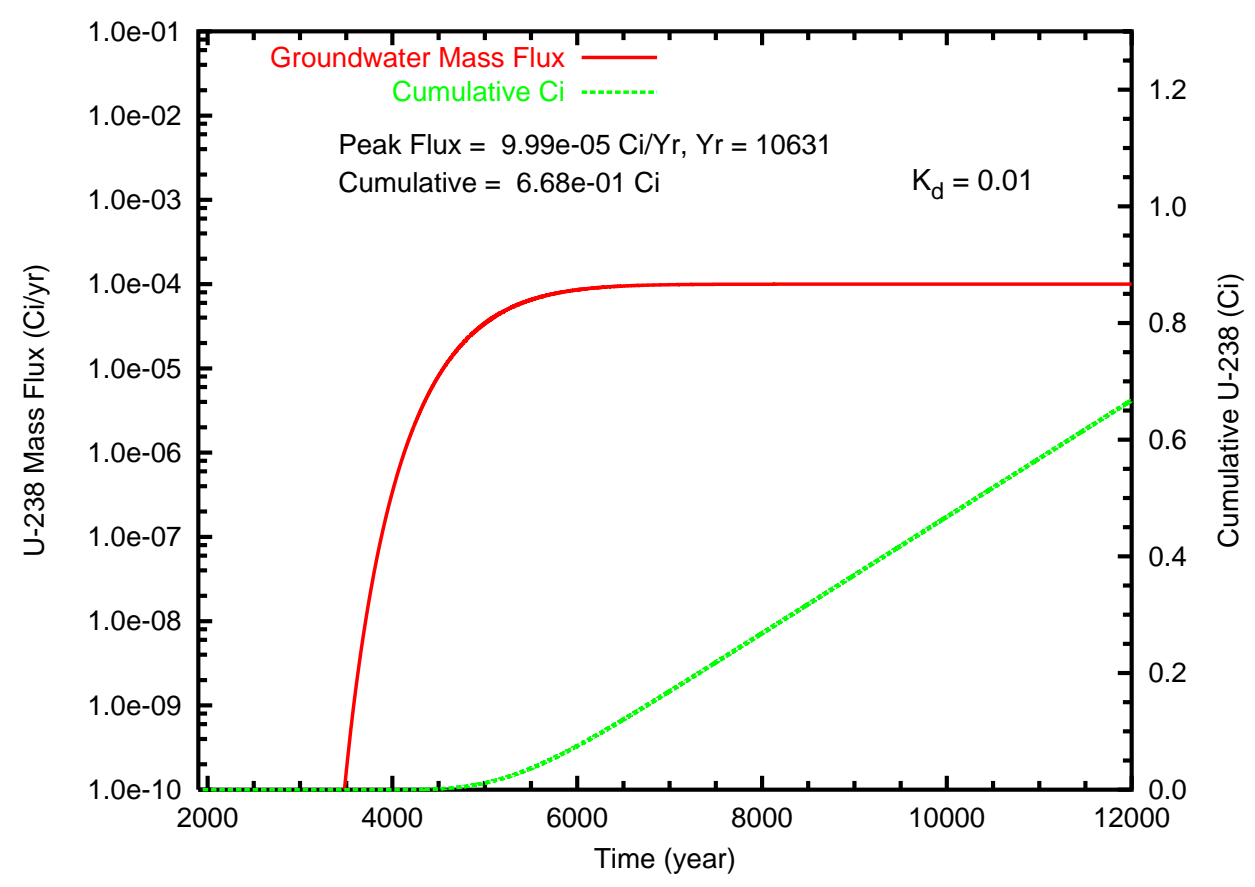

(b)

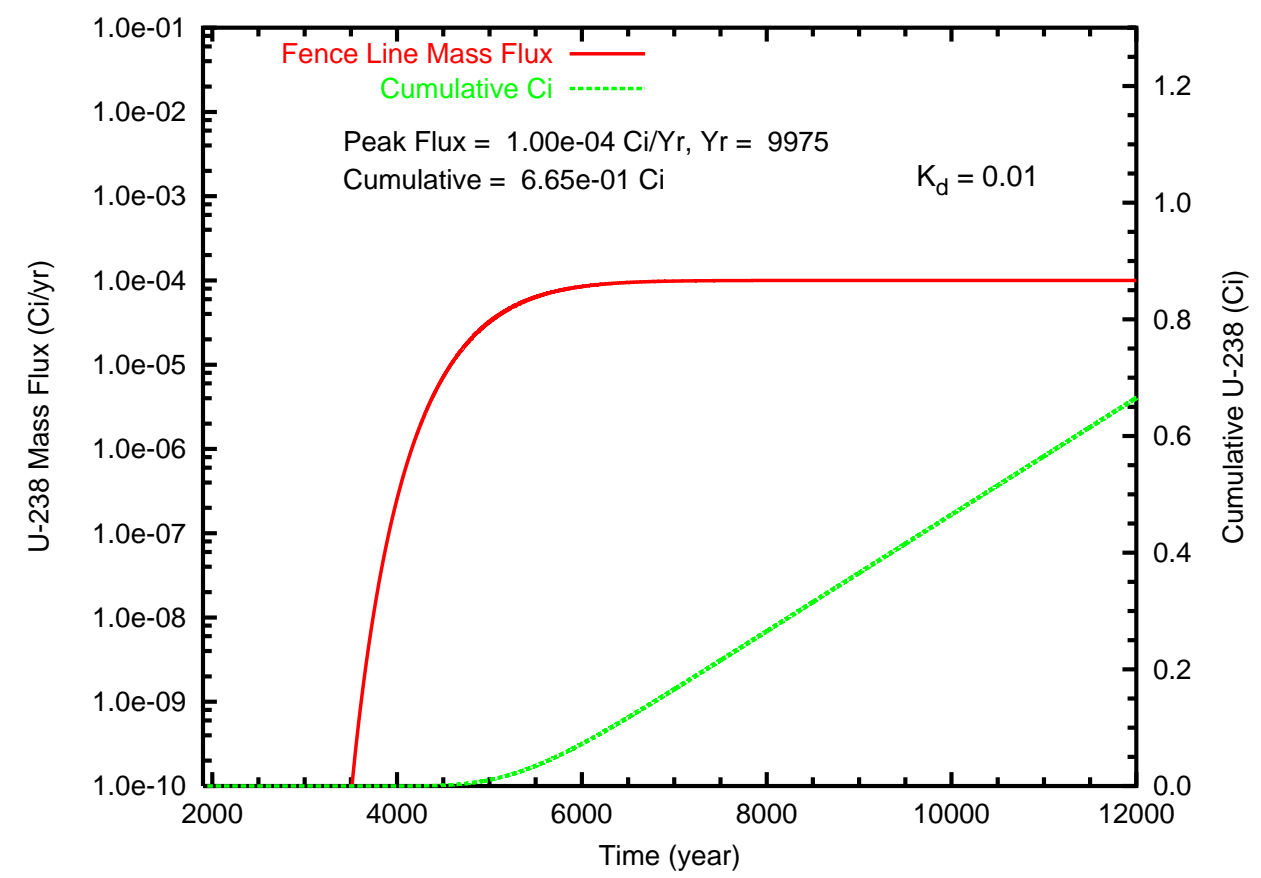

Figure B.115. Case $8, \mathrm{U}-238\left(\mathrm{~K}_{d}=0.01\right)$ mass flux $(\mathrm{Ci} / \mathrm{L})$ and cumulative mass $(\mathrm{Ci})$ at (a) the groundwater table and (b) the fence line 
(a)

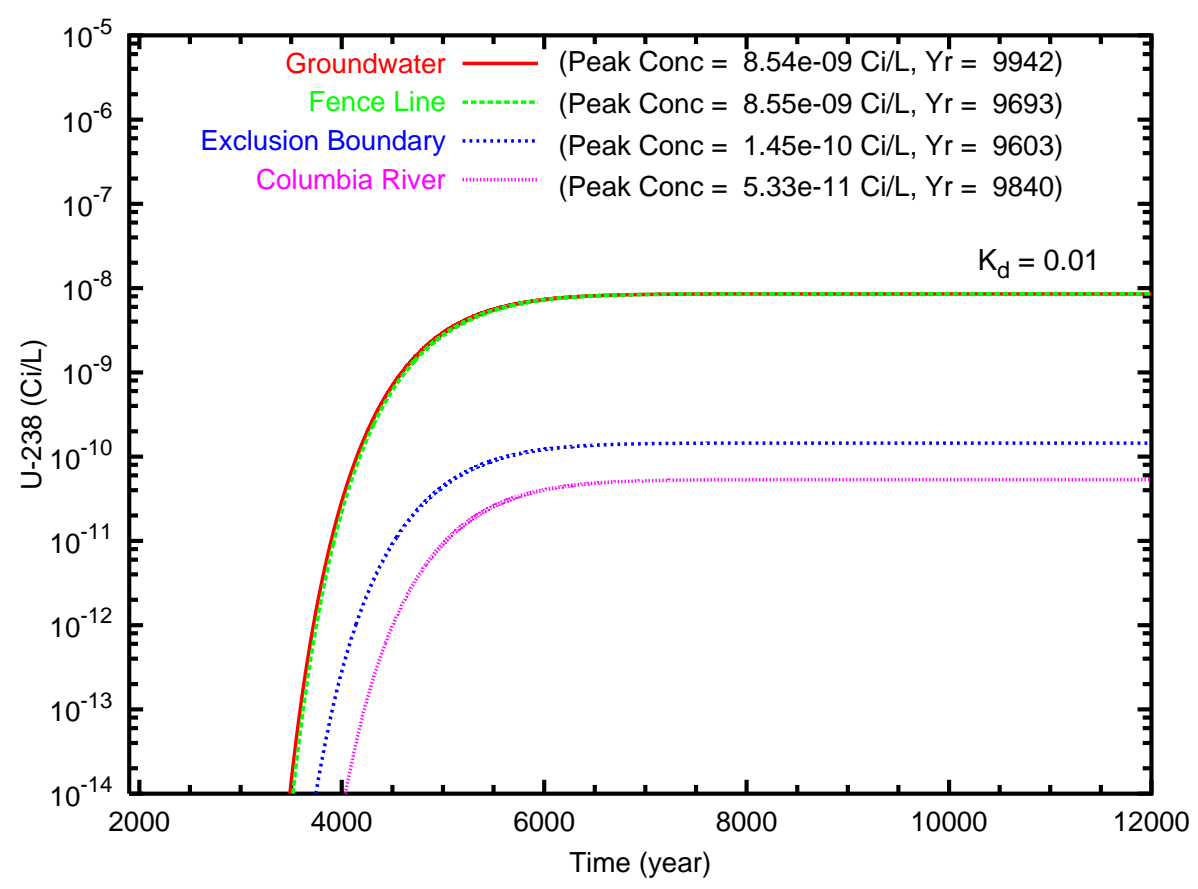

(b)

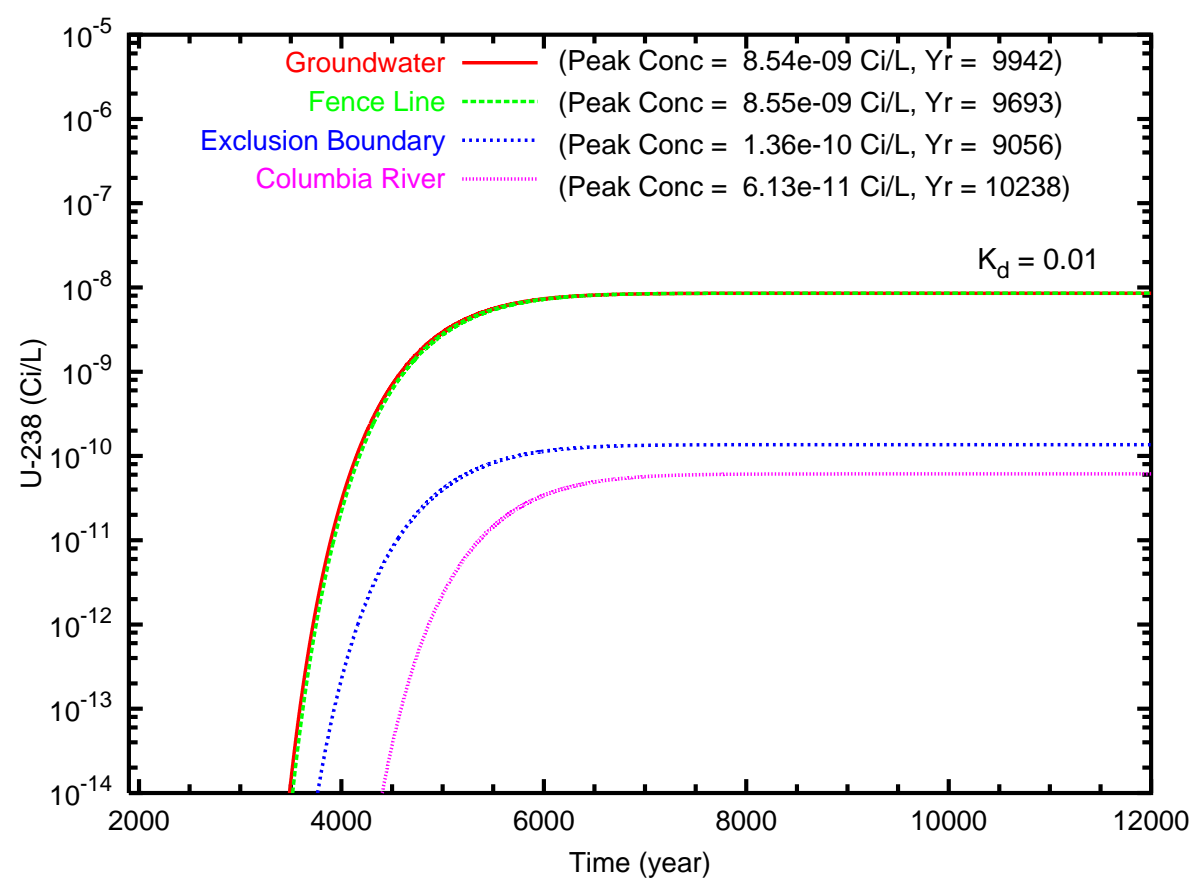

Figure B.116. Case 8, U-238 $\left(\mathrm{K}_{d}=0.01\right)$ concentration versus time for the fence line exclusion boundary and Columbia River compliance points for travel paths (a) southeast and (b) north through the gap 
(a)

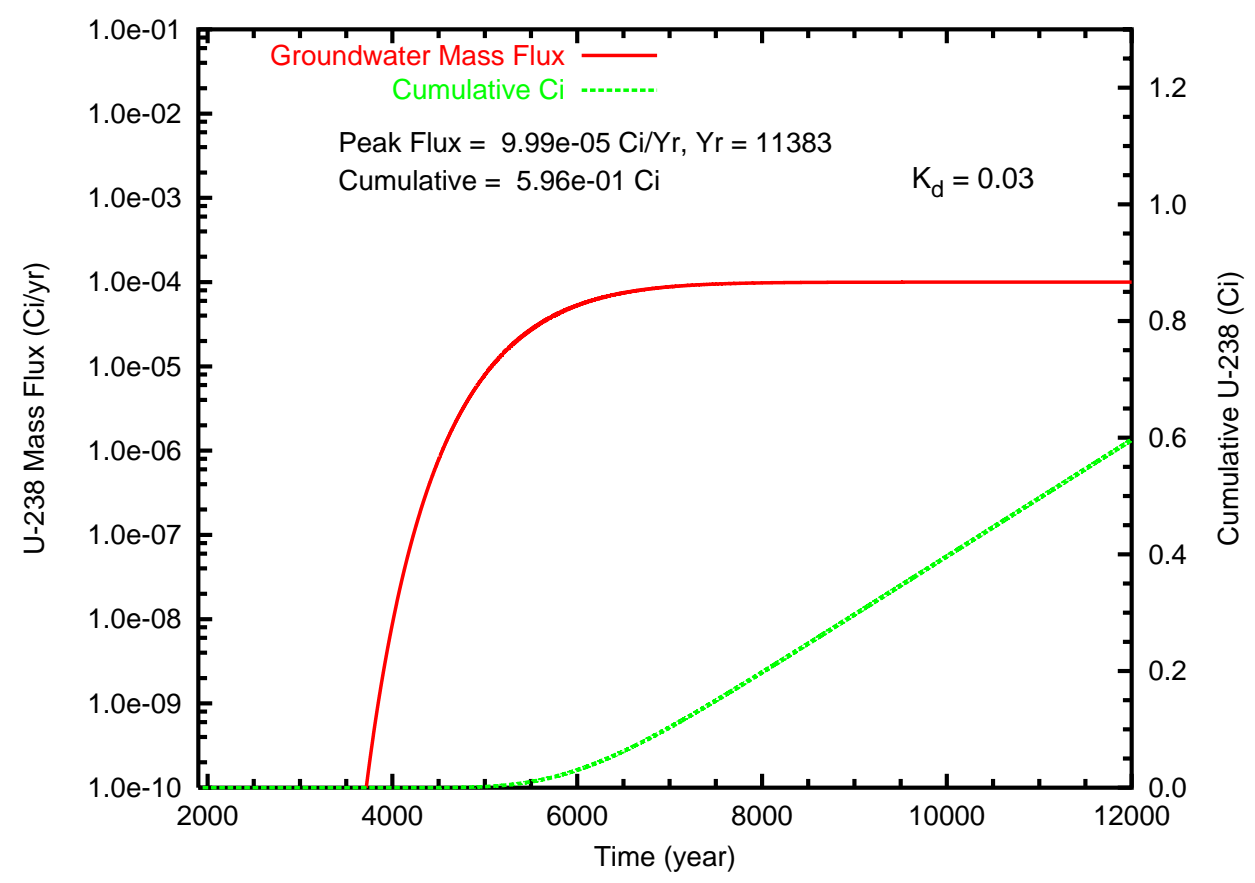

(b)

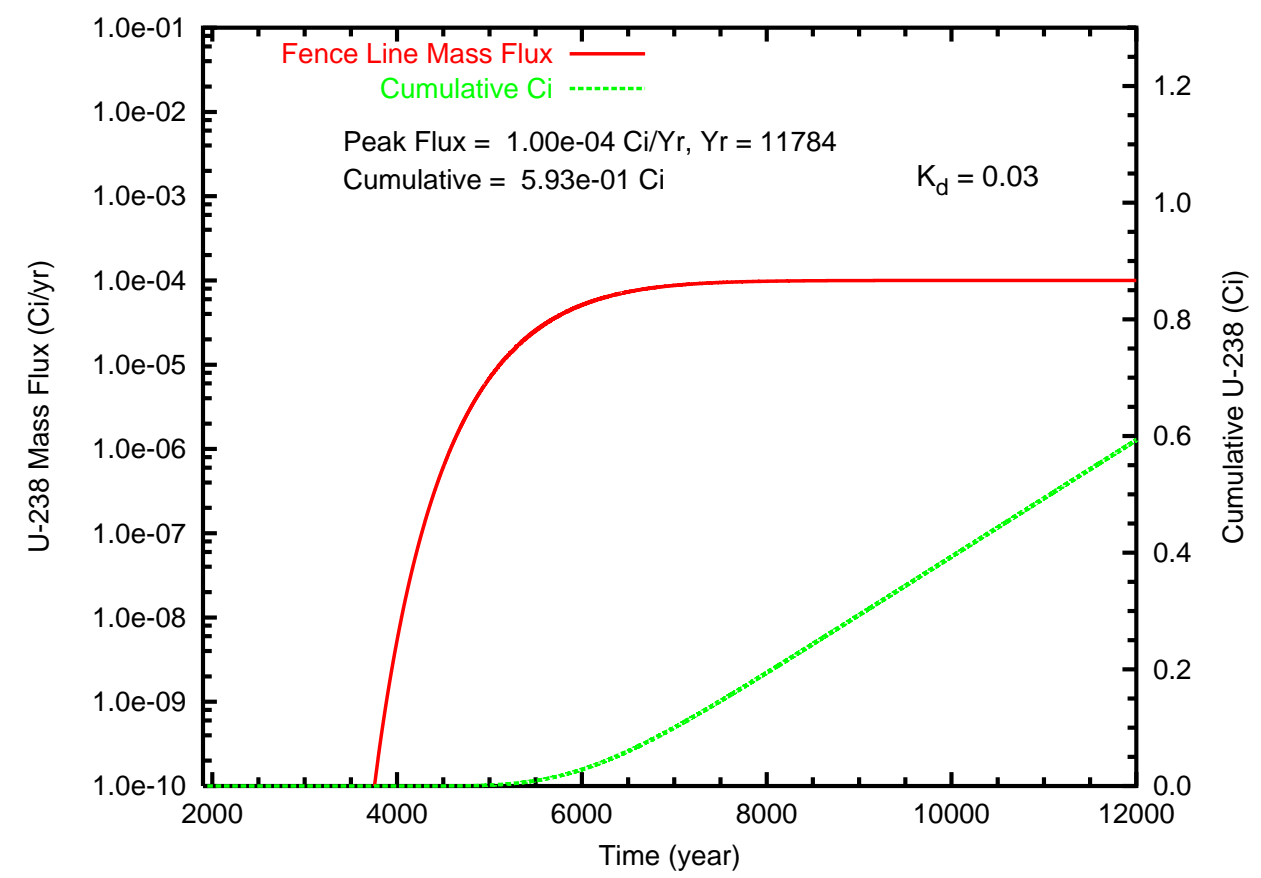

Figure B.117. Case 8, U-238 $\left(\mathrm{K}_{d}=0.03\right)$ mass flux $(\mathrm{Ci} / \mathrm{L})$ and cumulative mass $(\mathrm{Ci})$ at (a) the groundwater table and (b) the fence line 
(a)

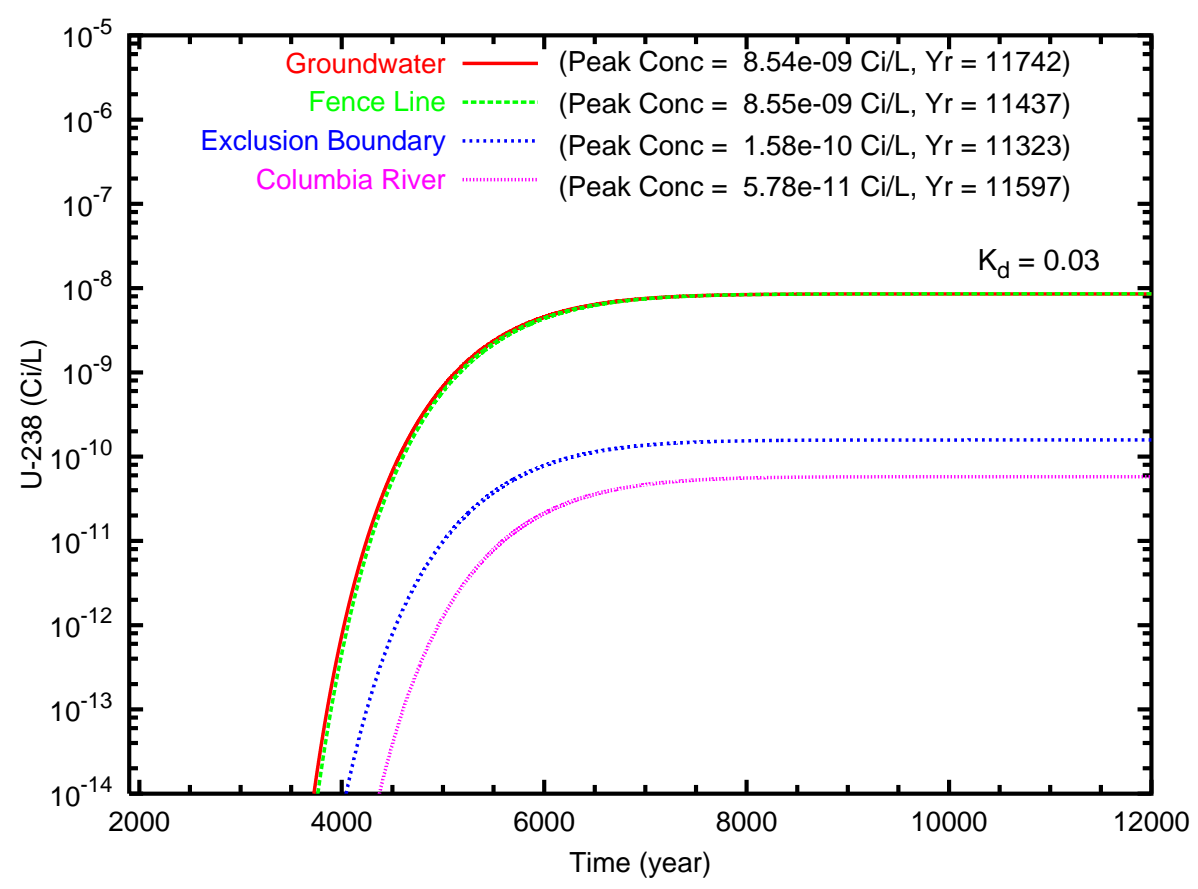

(b)

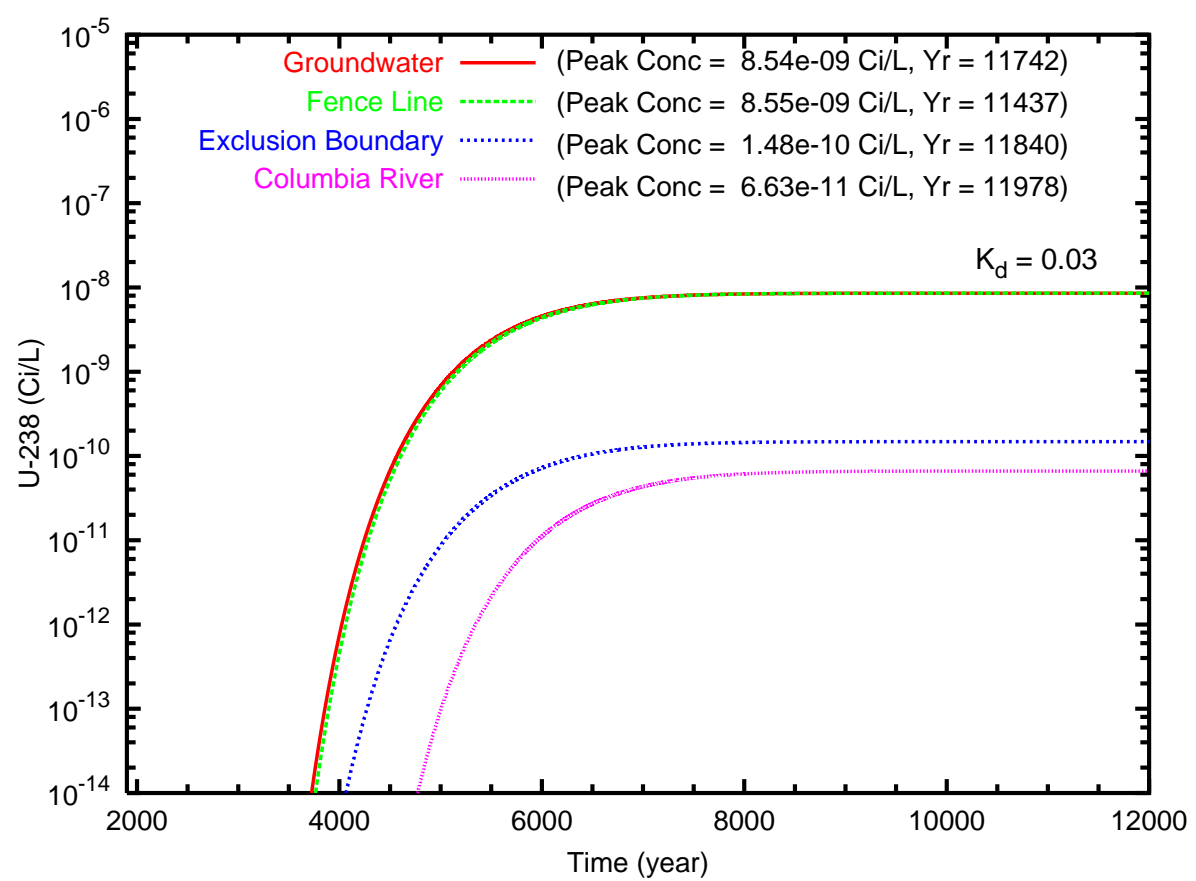

Figure B.118. Case 8, U-238 $\left(\mathrm{K}_{d}=0.03\right)$ concentration versus time for the fence line exclusion boundary and Columbia River compliance points for travel paths (a) southeast and (b) north through the gap 
(a)

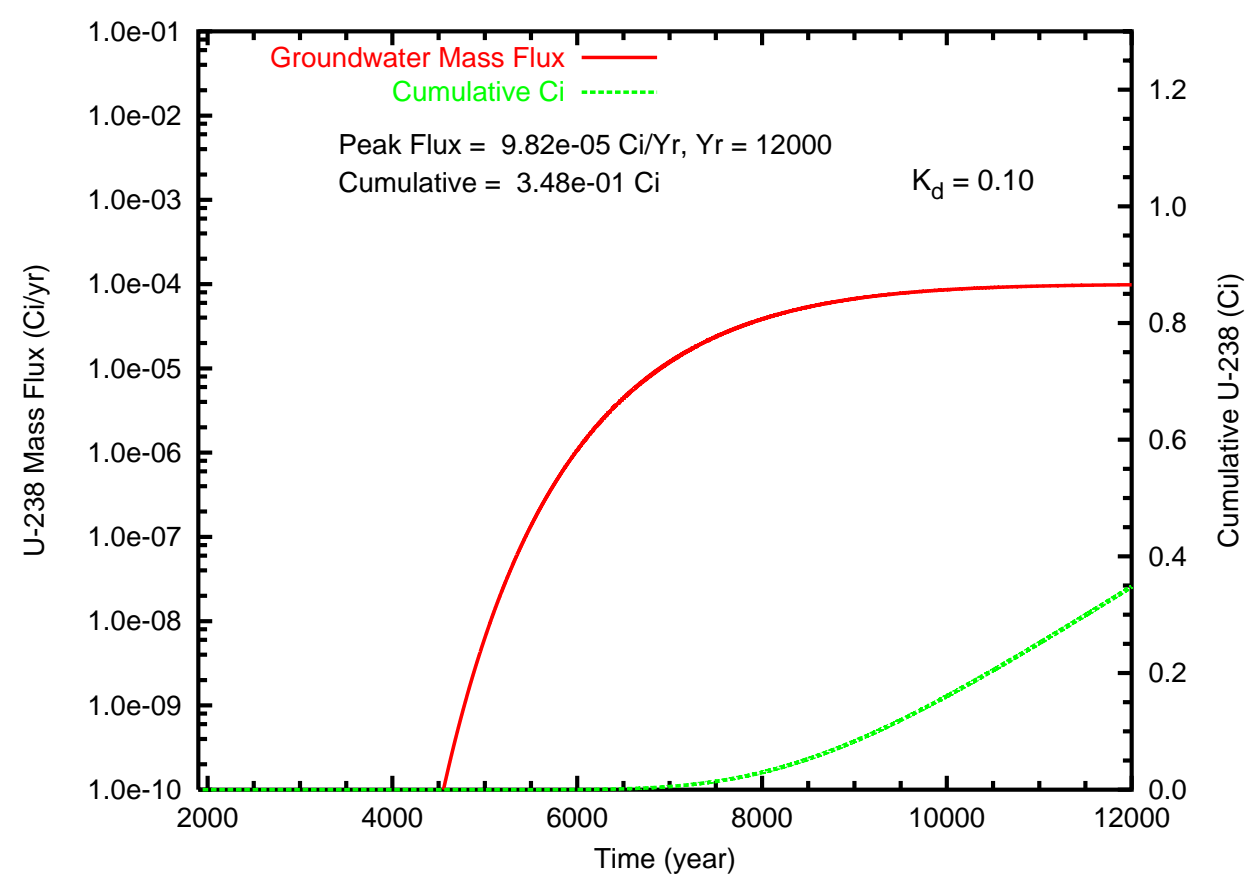

(b)

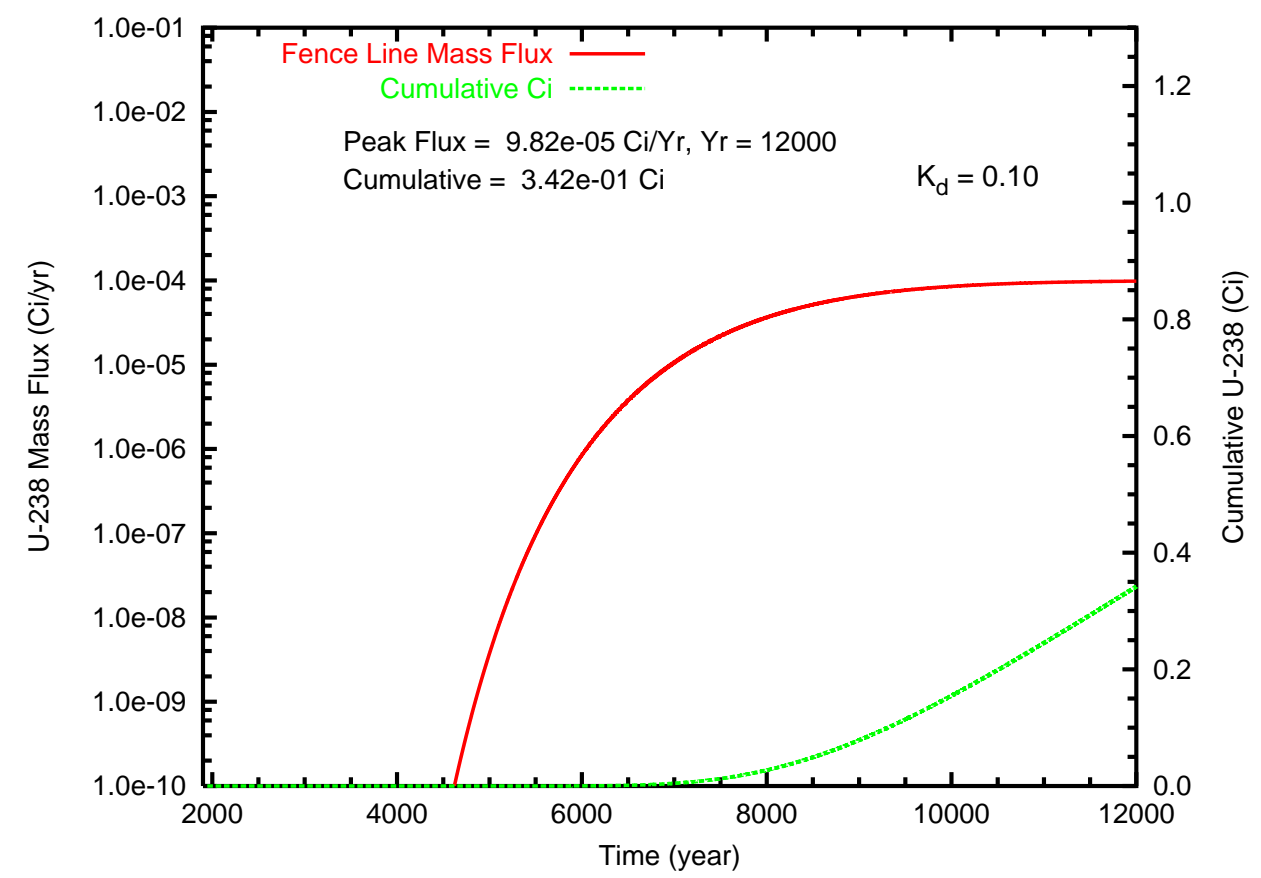

Figure B.119. Case $8, \mathrm{U}-238\left(\mathrm{~K}_{d}=0.10\right)$ mass flux $(\mathrm{Ci} / \mathrm{L})$ and cumulative mass $(\mathrm{Ci})$ at (a) the groundwater table and (b) the fence line 
(a)

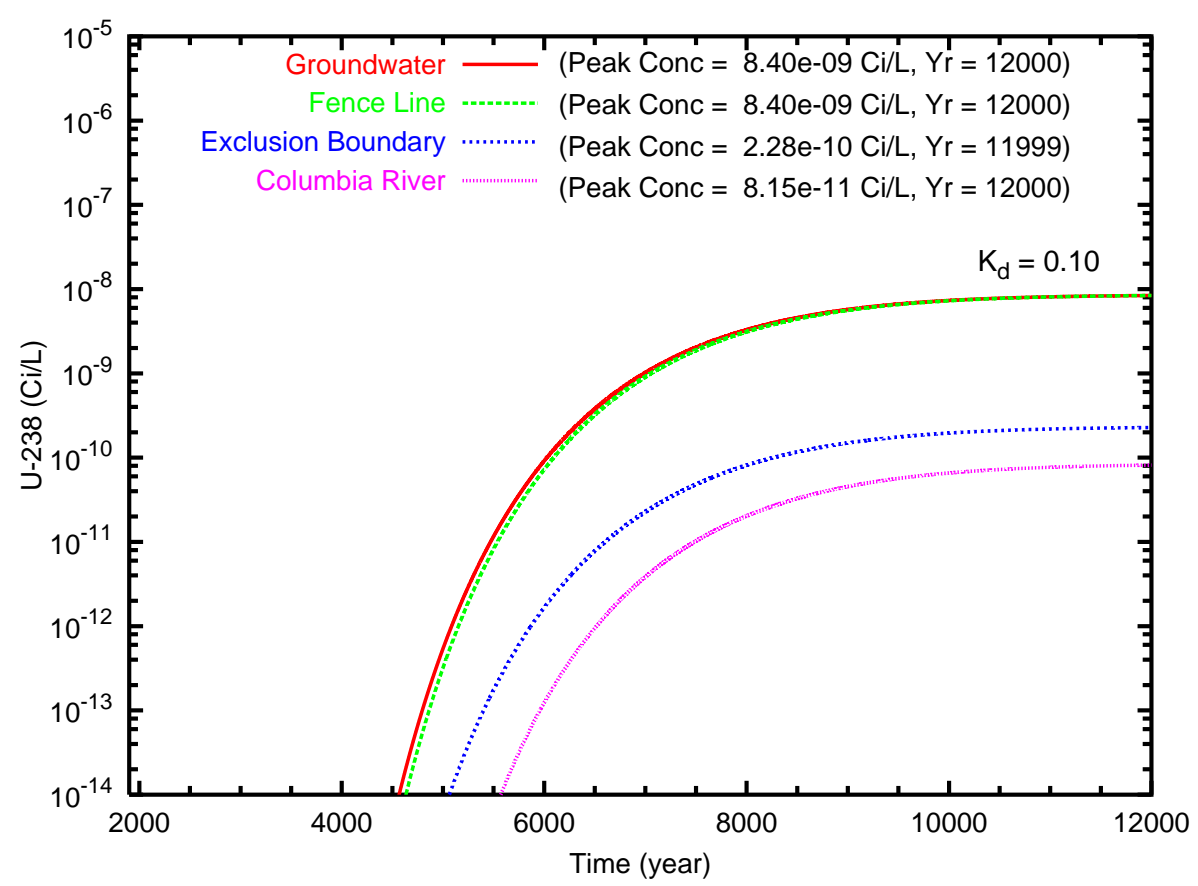

(b)

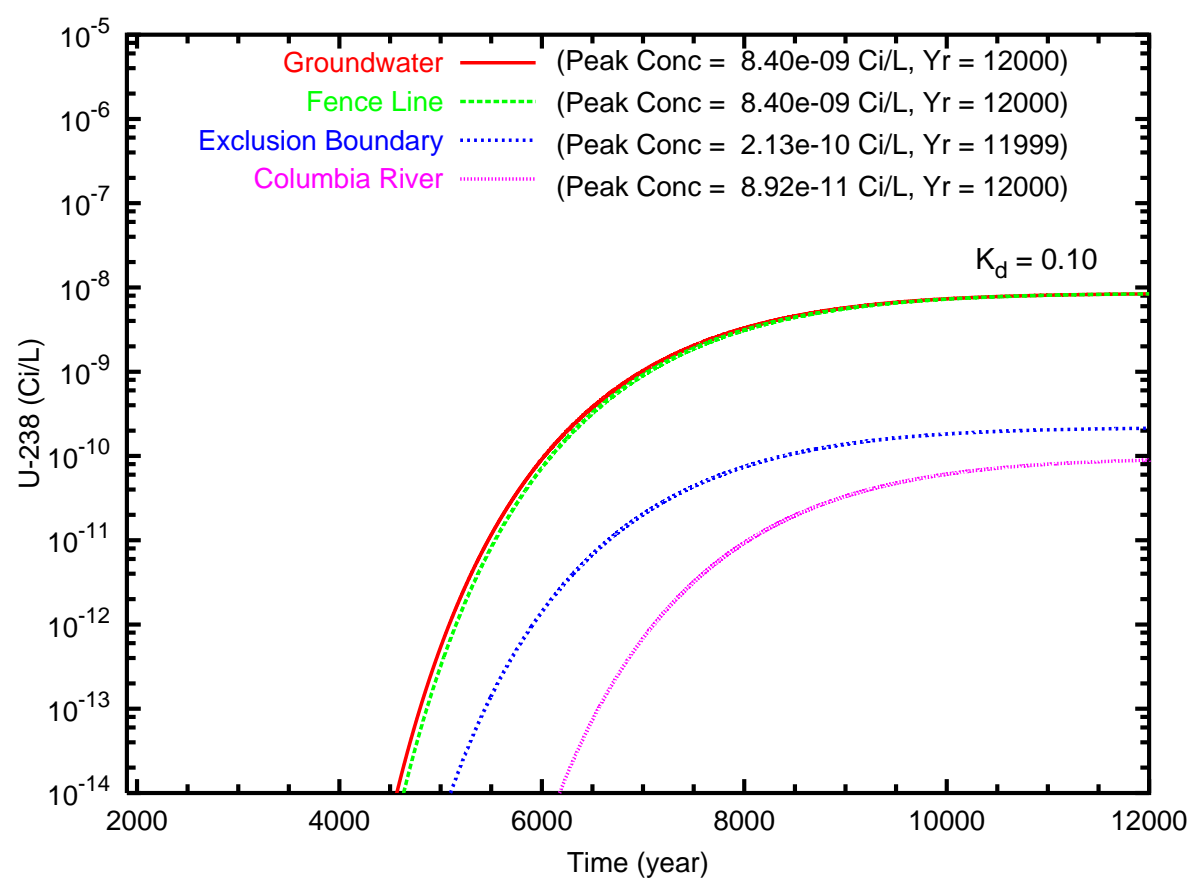

Figure B.120. Case $8, \mathrm{U}-238\left(\mathrm{~K}_{d}=0.10\right)$ concentration versus time for the fence line exclusion boundary and Columbia River compliance points for travel paths (a) southeast and (b) north through the gap 
(a)

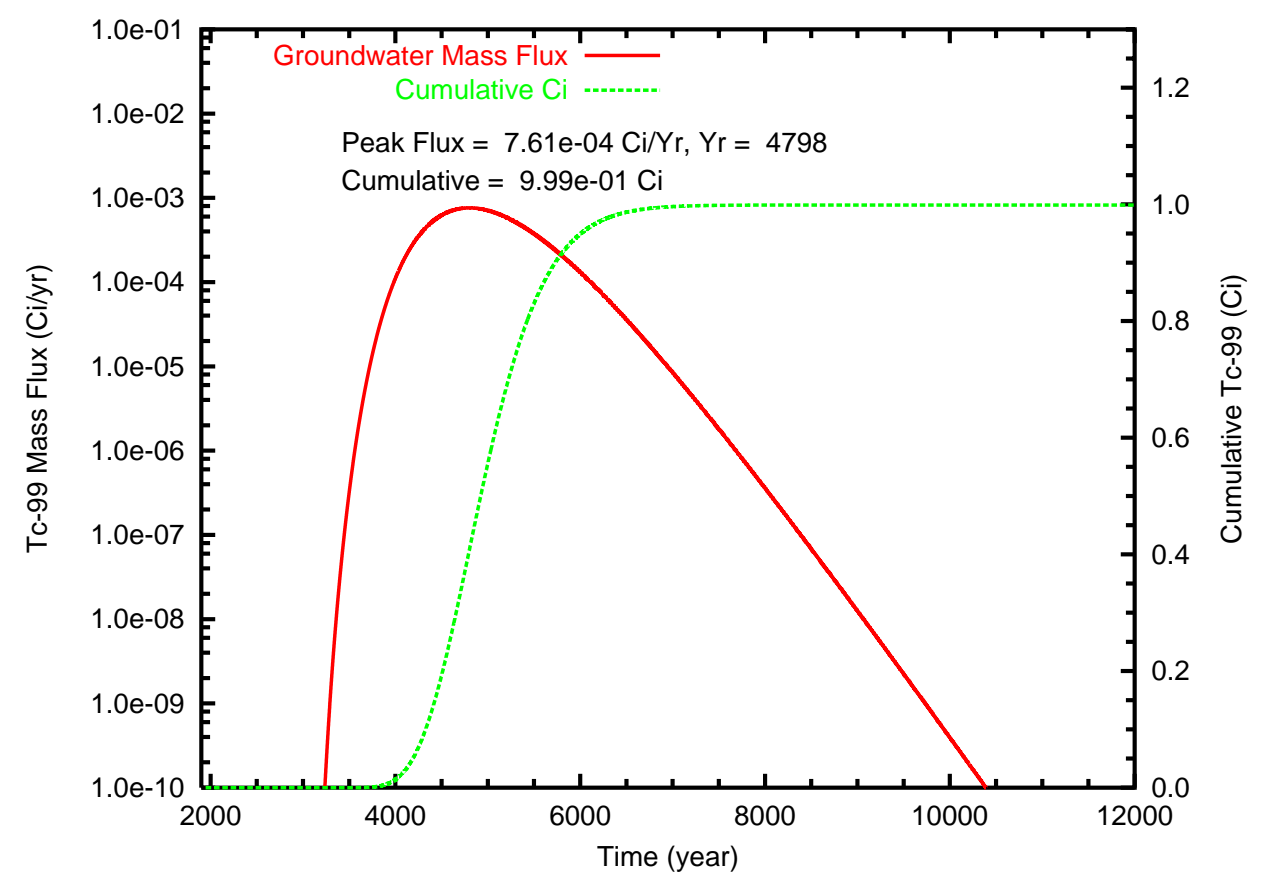

(b)

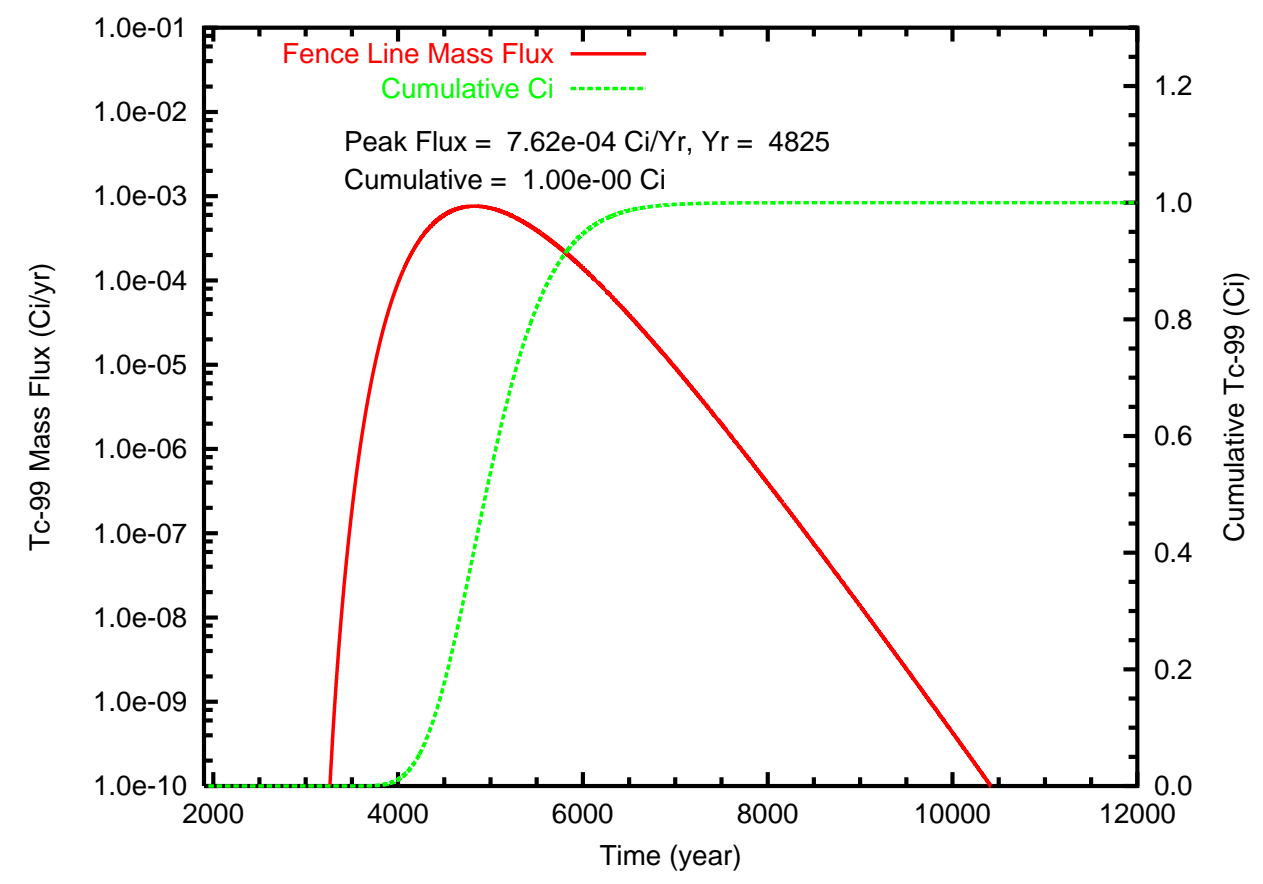

Figure B.121. Case 9, Tc-99 mass flux and cumulative mass at (a) the groundwater table and (b) the fence line 
(a)

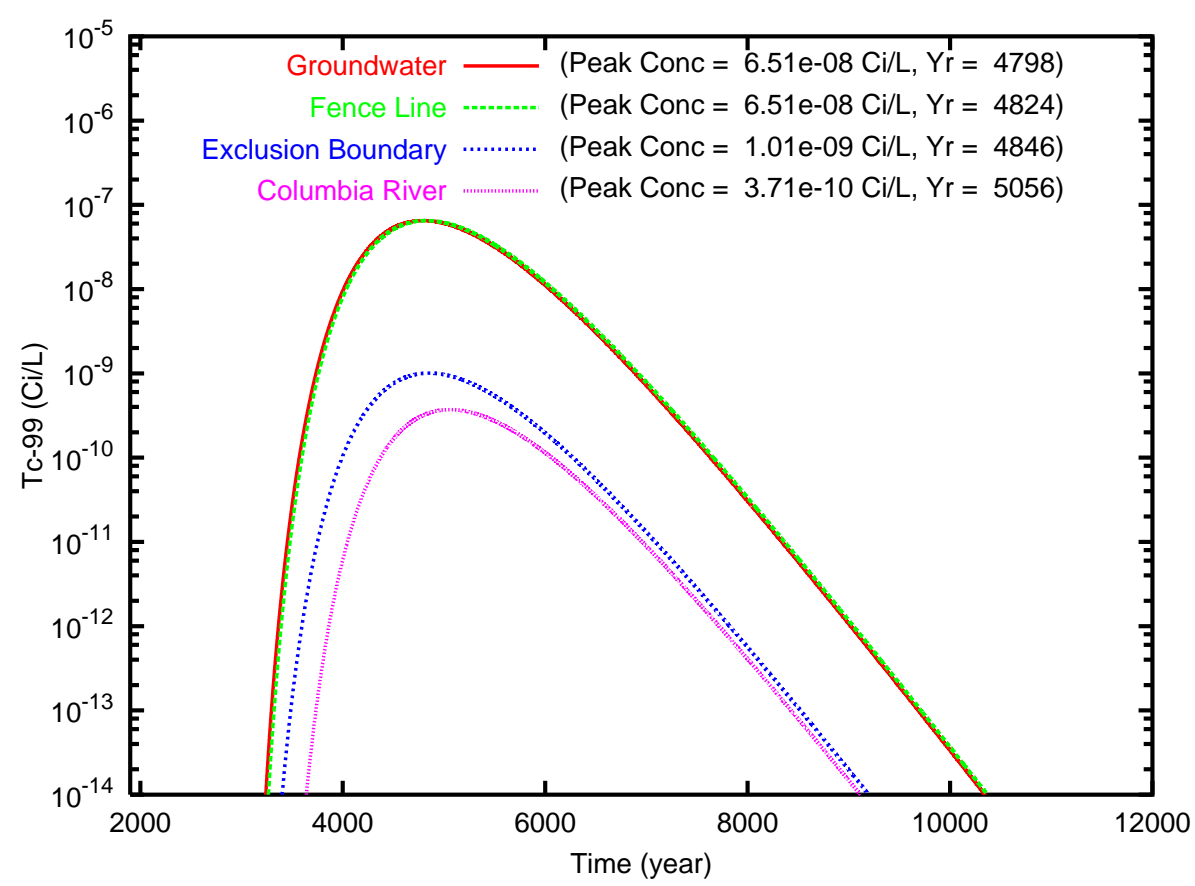

(b)

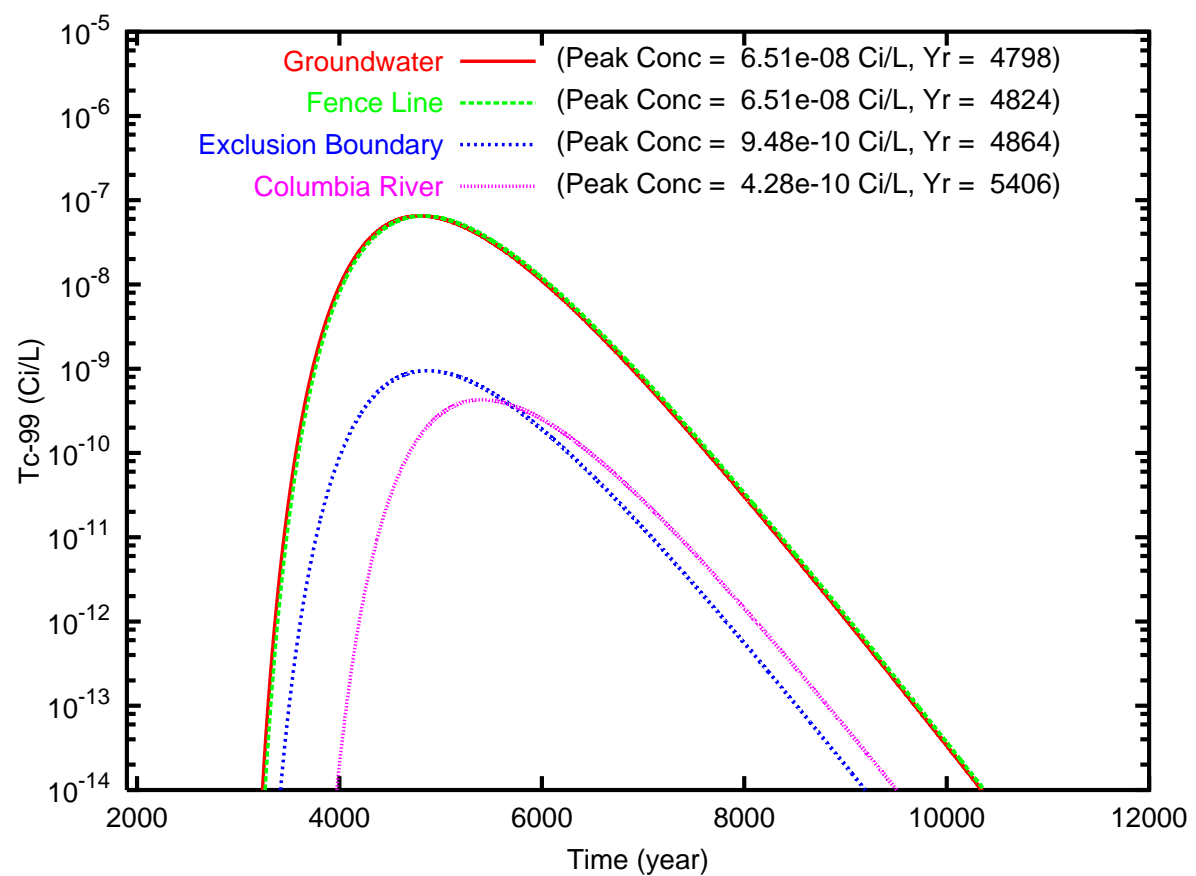

Figure B.122. Case 9, Tc-99 concentration versus time for the fence line, exclusion boundary and Columbia River compliance points for travel paths (a) southeast and (b) north through the gap 
(a)

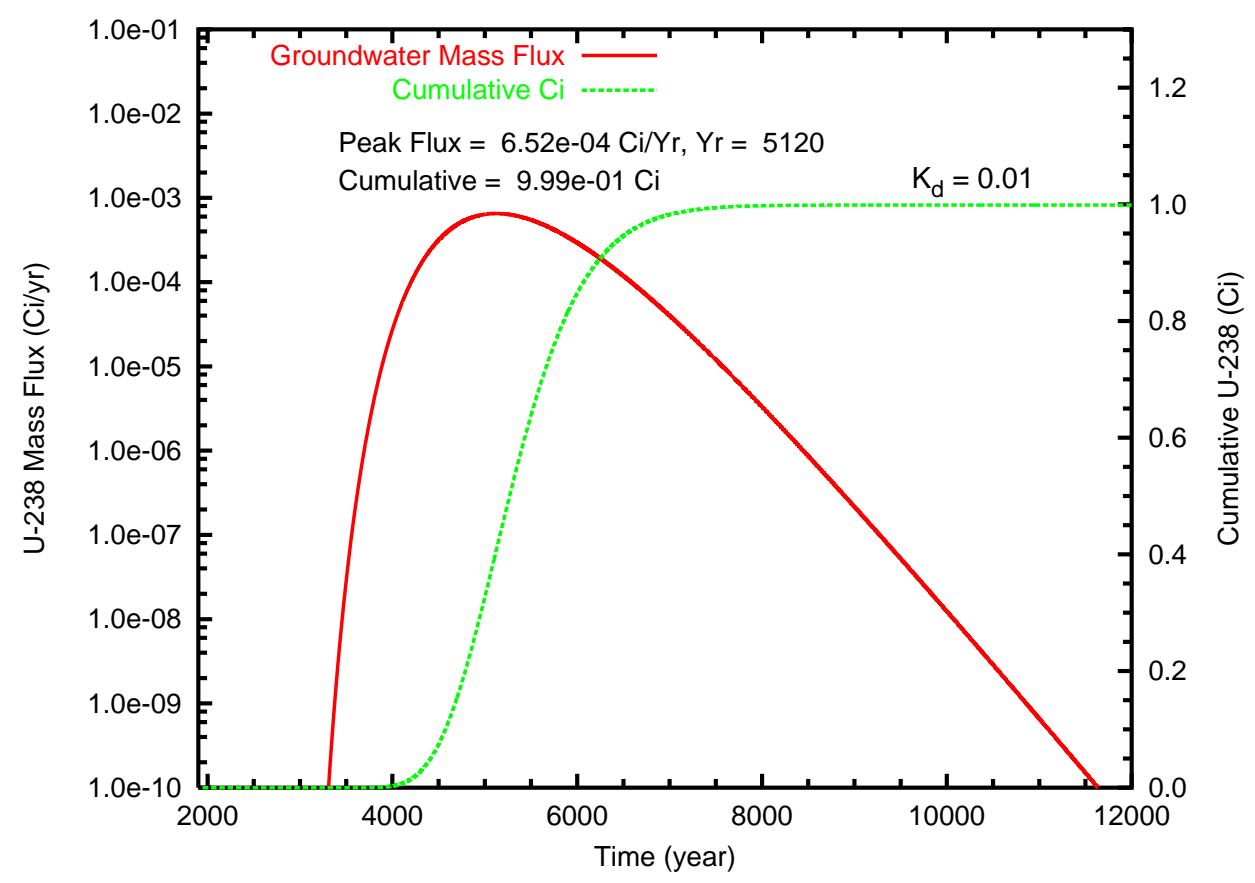

(b)

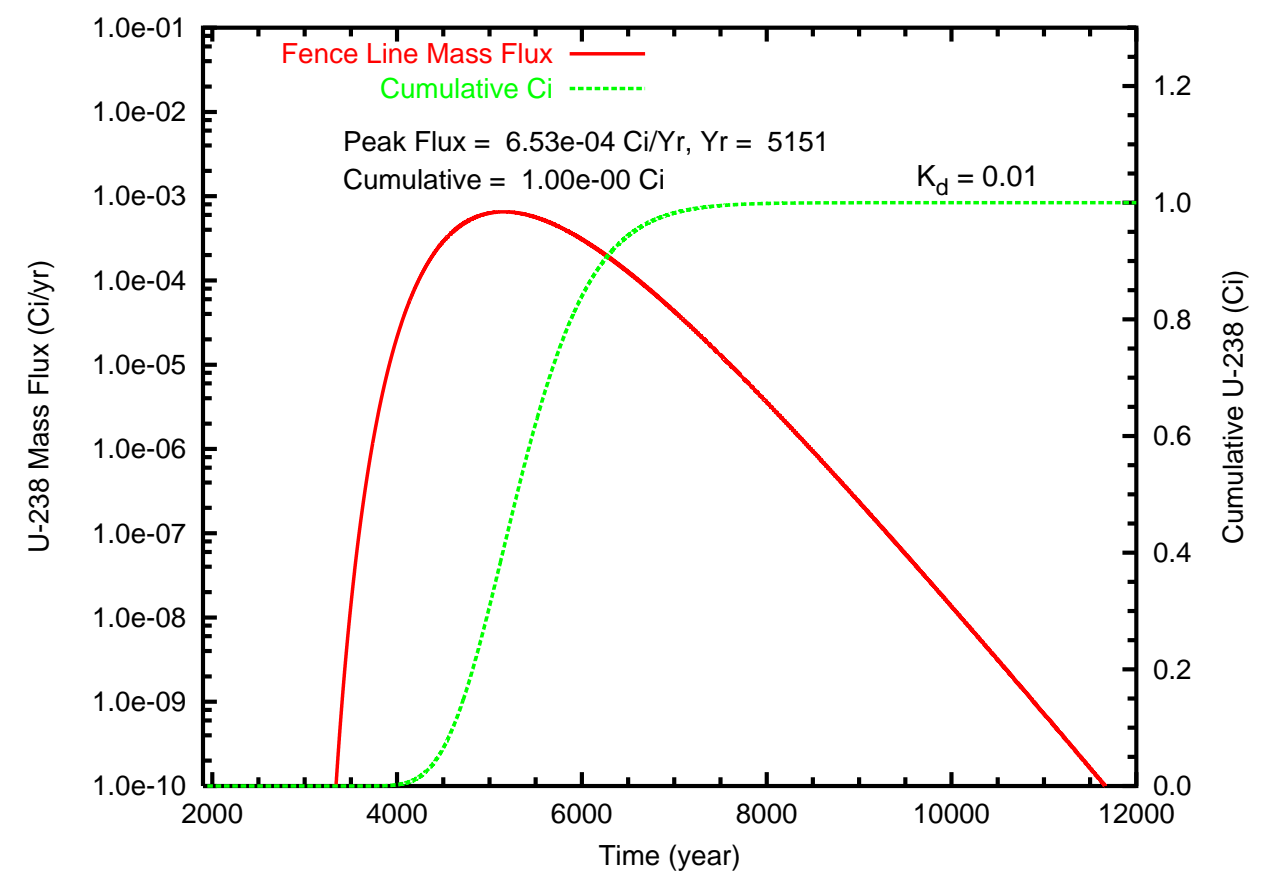

Figure B.123. Case $9, \mathrm{U}-238\left(\mathrm{~K}_{d}=0.01\right)$ mass flux $(\mathrm{Ci} / \mathrm{L})$ and cumulative mass $(\mathrm{Ci})$ at (a) the groundwater table and (b) the fence line 
(a)

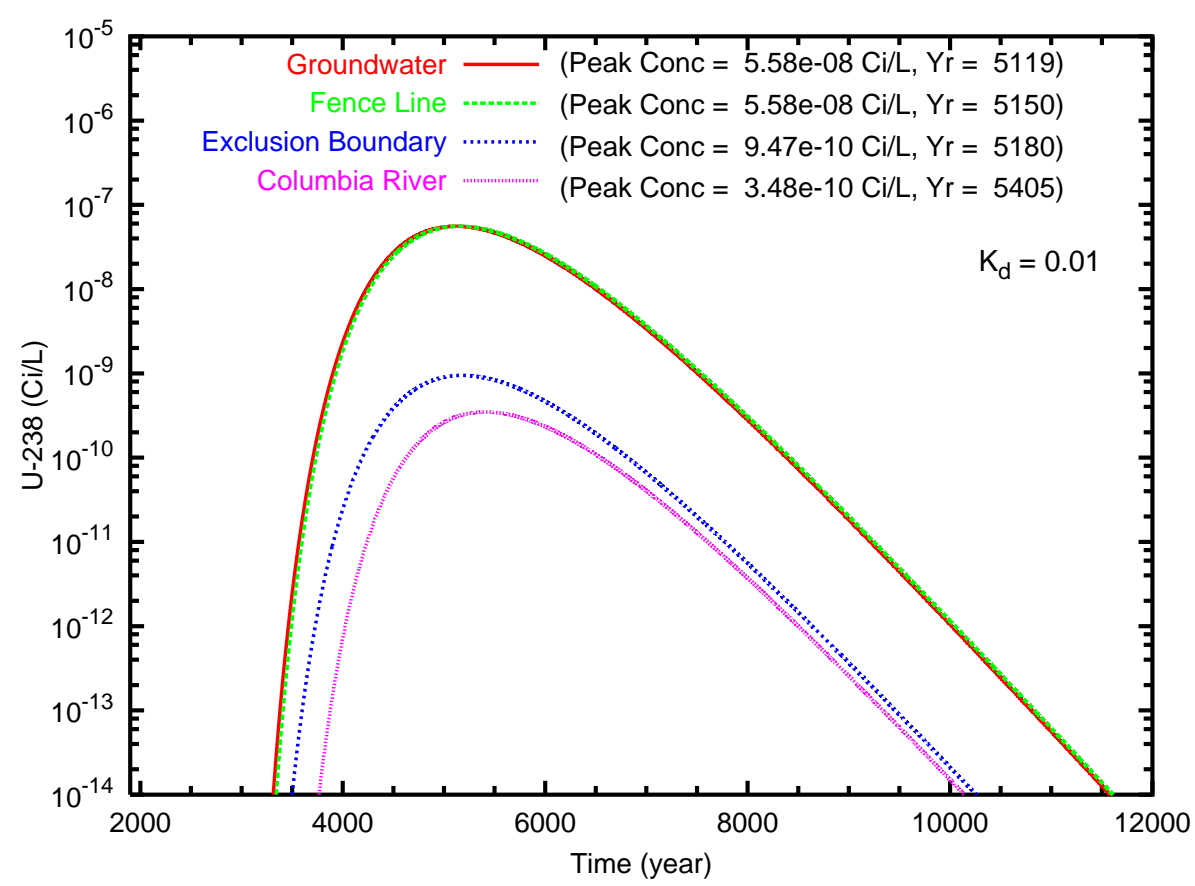

(b)

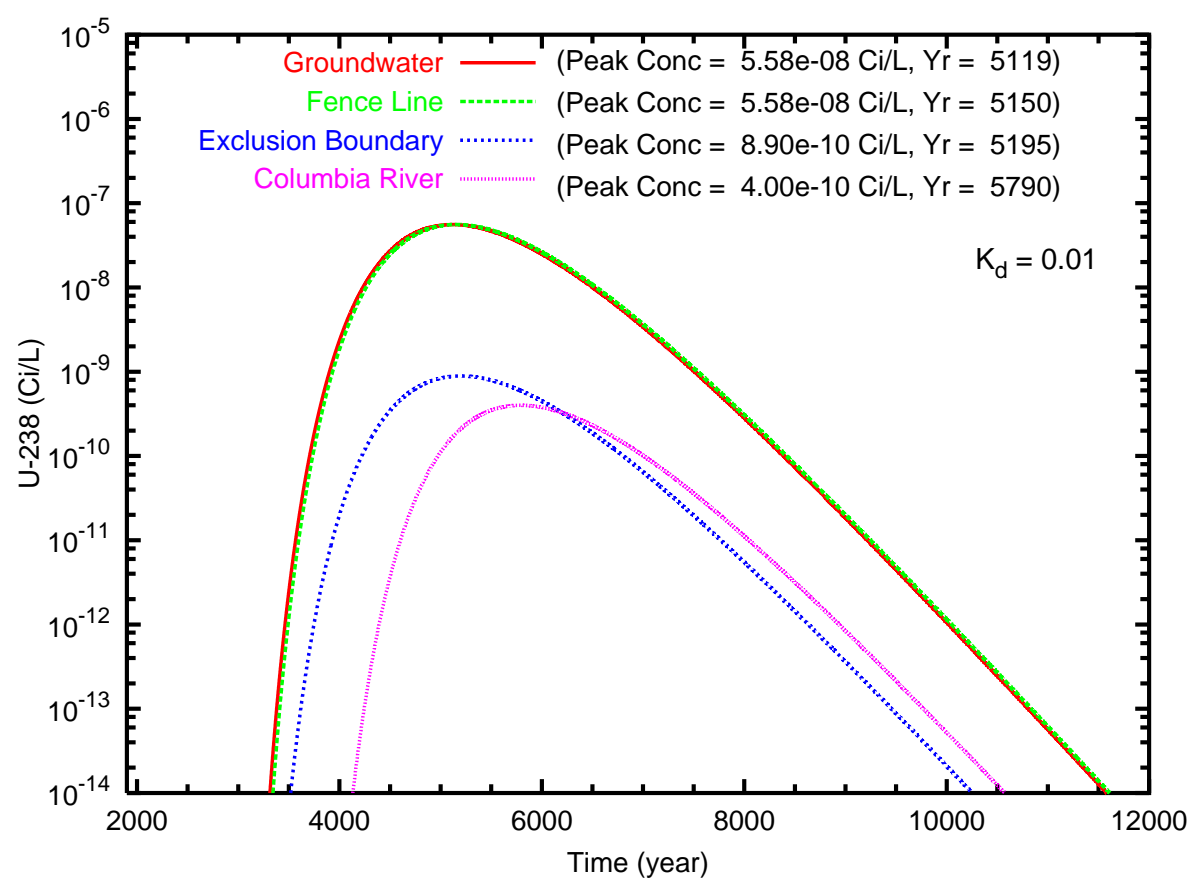

Figure B.124. Case 9, U-238 $\left(\mathrm{K}_{d}=0.01\right)$ concentration versus time for the fence line exclusion boundary and Columbia River compliance points for travel paths (a) southeast and (b) north through the gap 
(a)

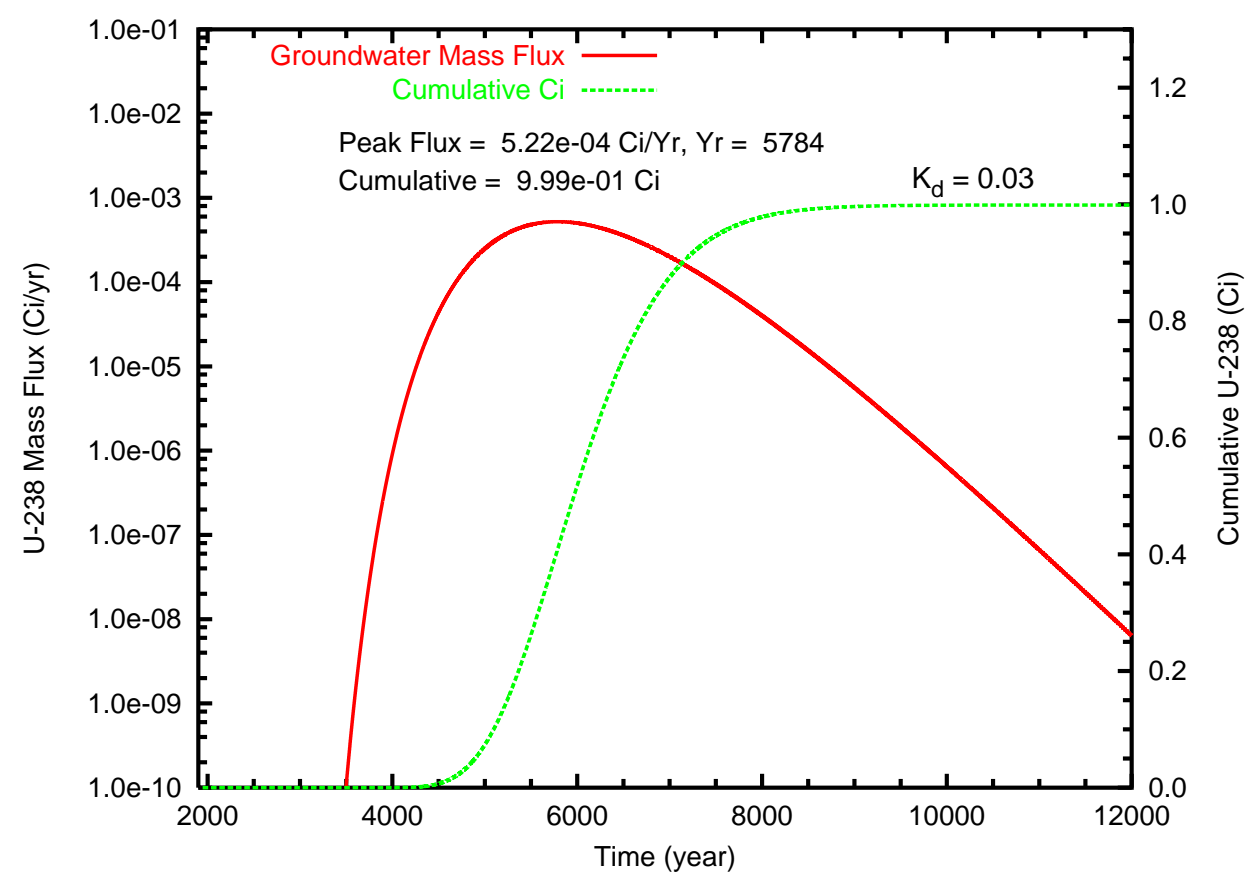

(b)

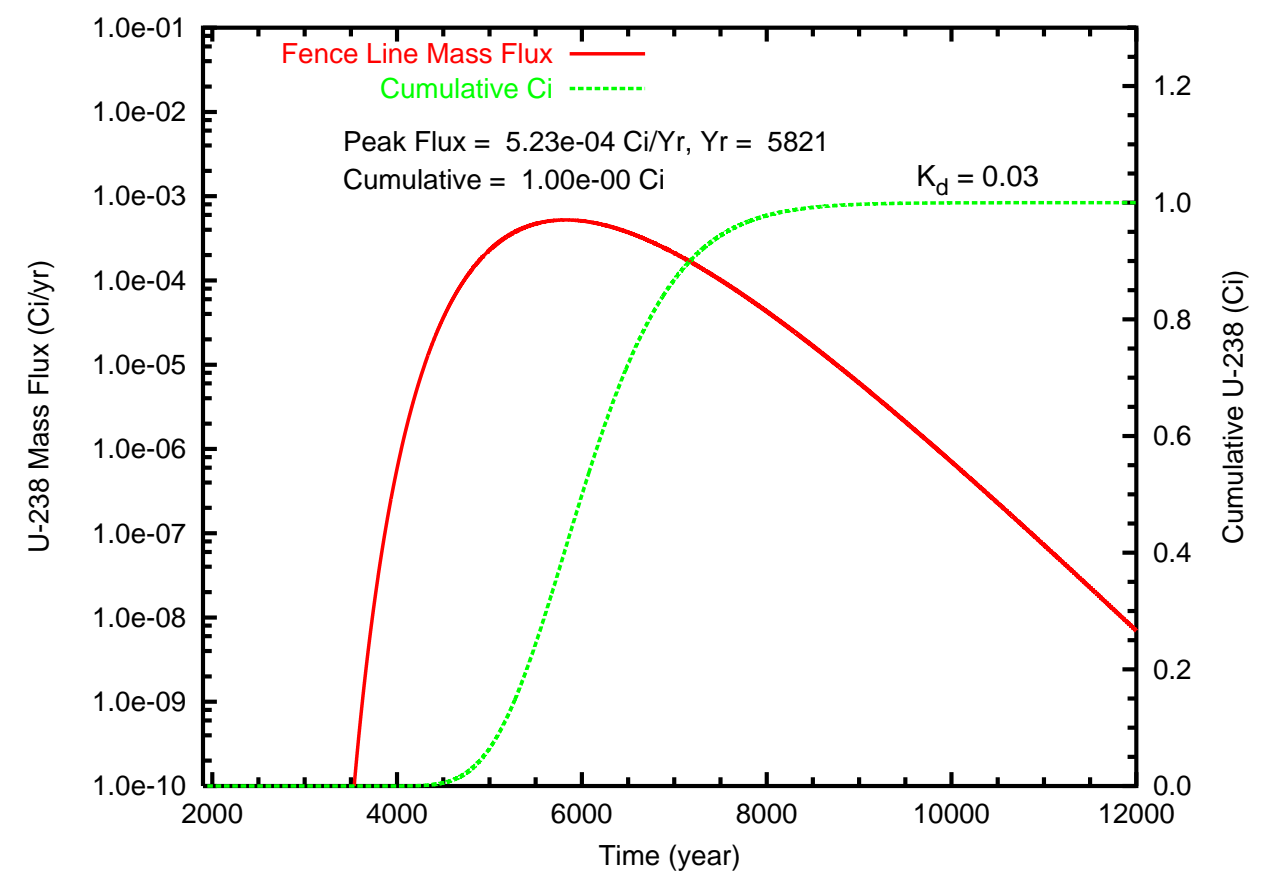

Figure B.125. Case $9, \mathrm{U}-238\left(\mathrm{~K}_{d}=0.03\right)$ mass flux $(\mathrm{Ci} / \mathrm{L})$ and cumulative mass $(\mathrm{Ci})$ at (a) the groundwater table and (b) the fence line 
(a)

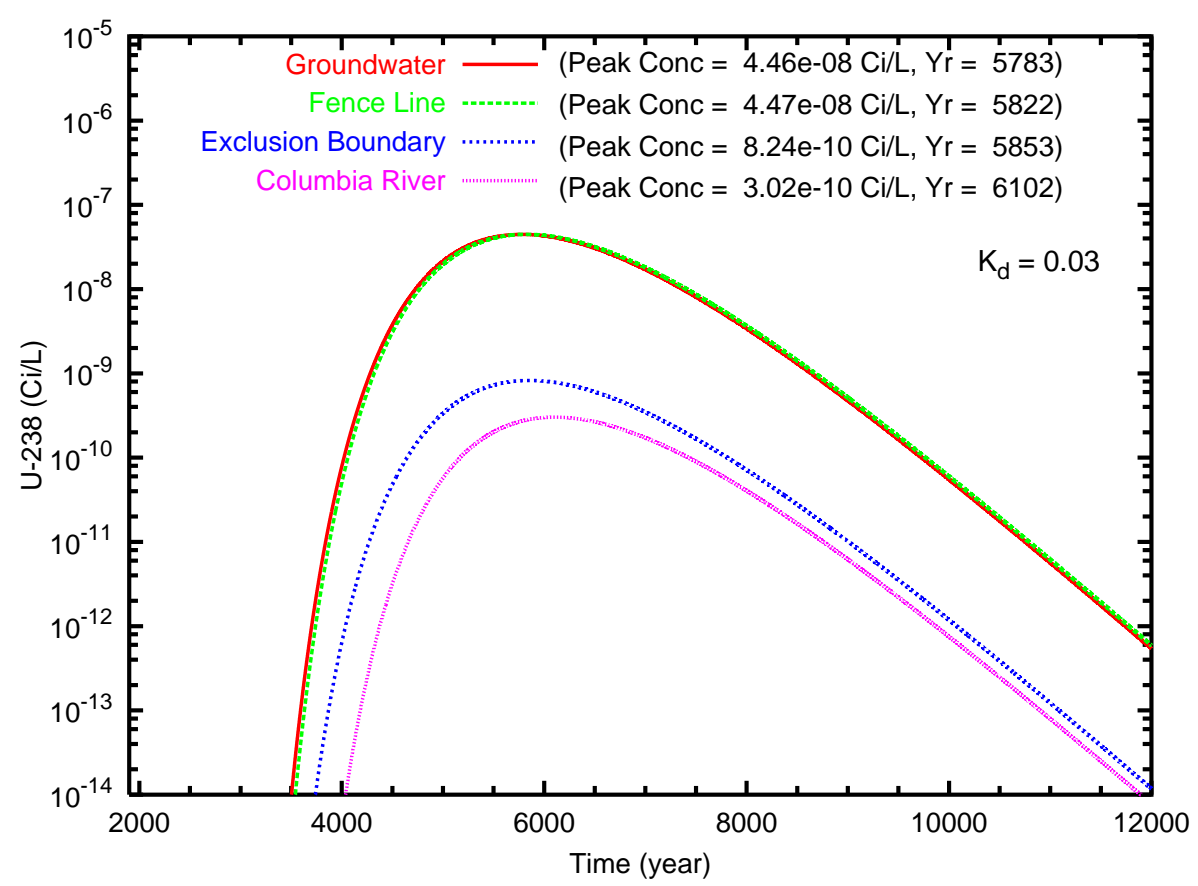

(b)

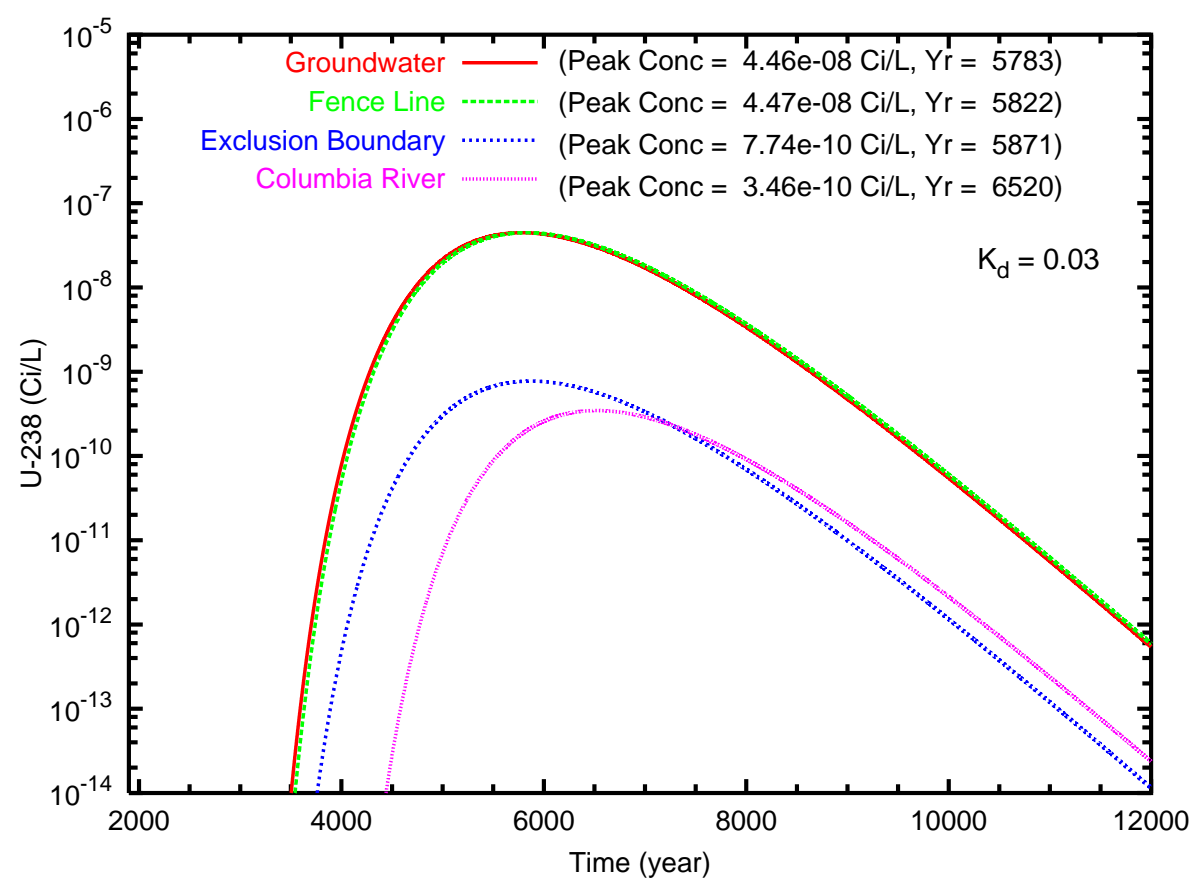

Figure B.126. Case 9, U-238 $\left(\mathrm{K}_{d}=0.03\right)$ concentration versus time for the fence line exclusion boundary and Columbia River compliance points for travel paths (a) southeast and (b) north through the gap 
(a)

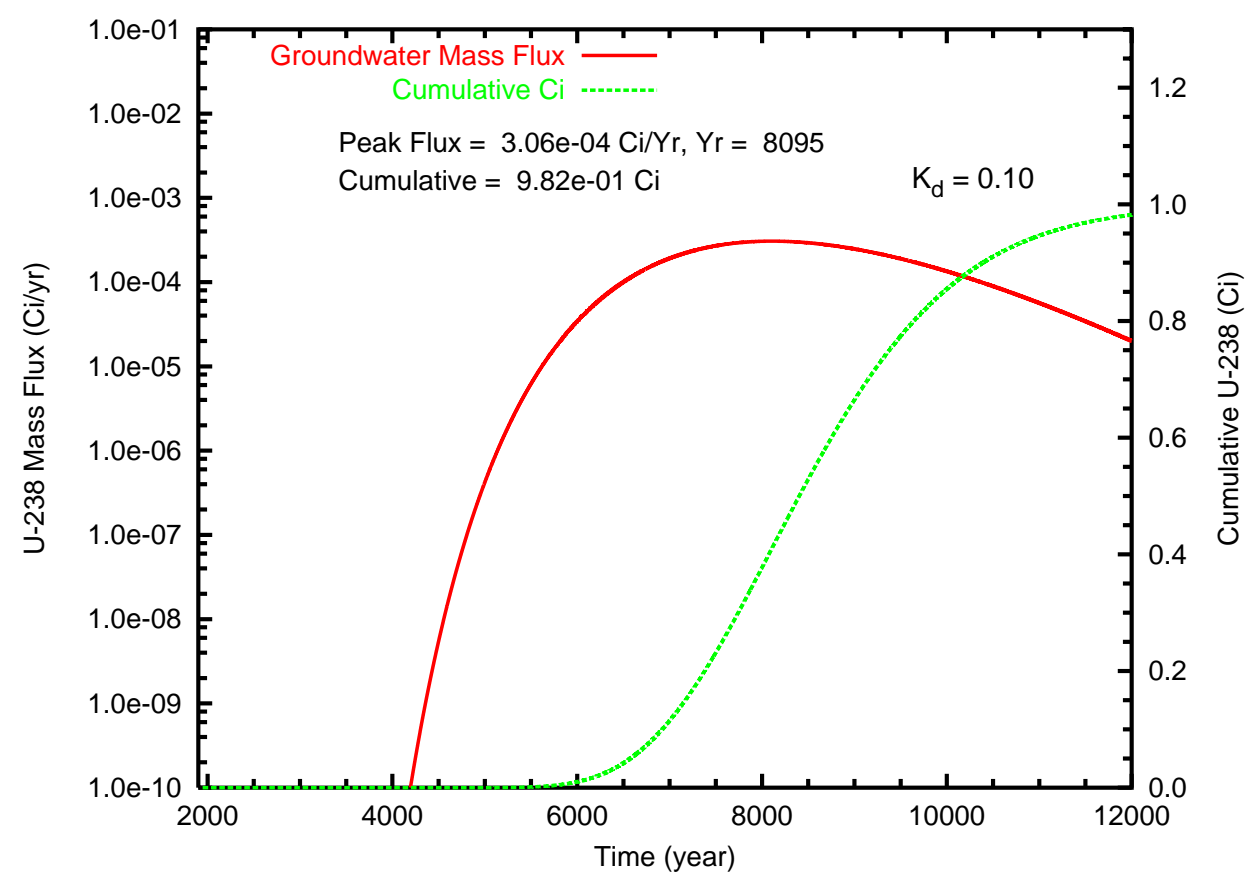

(b)

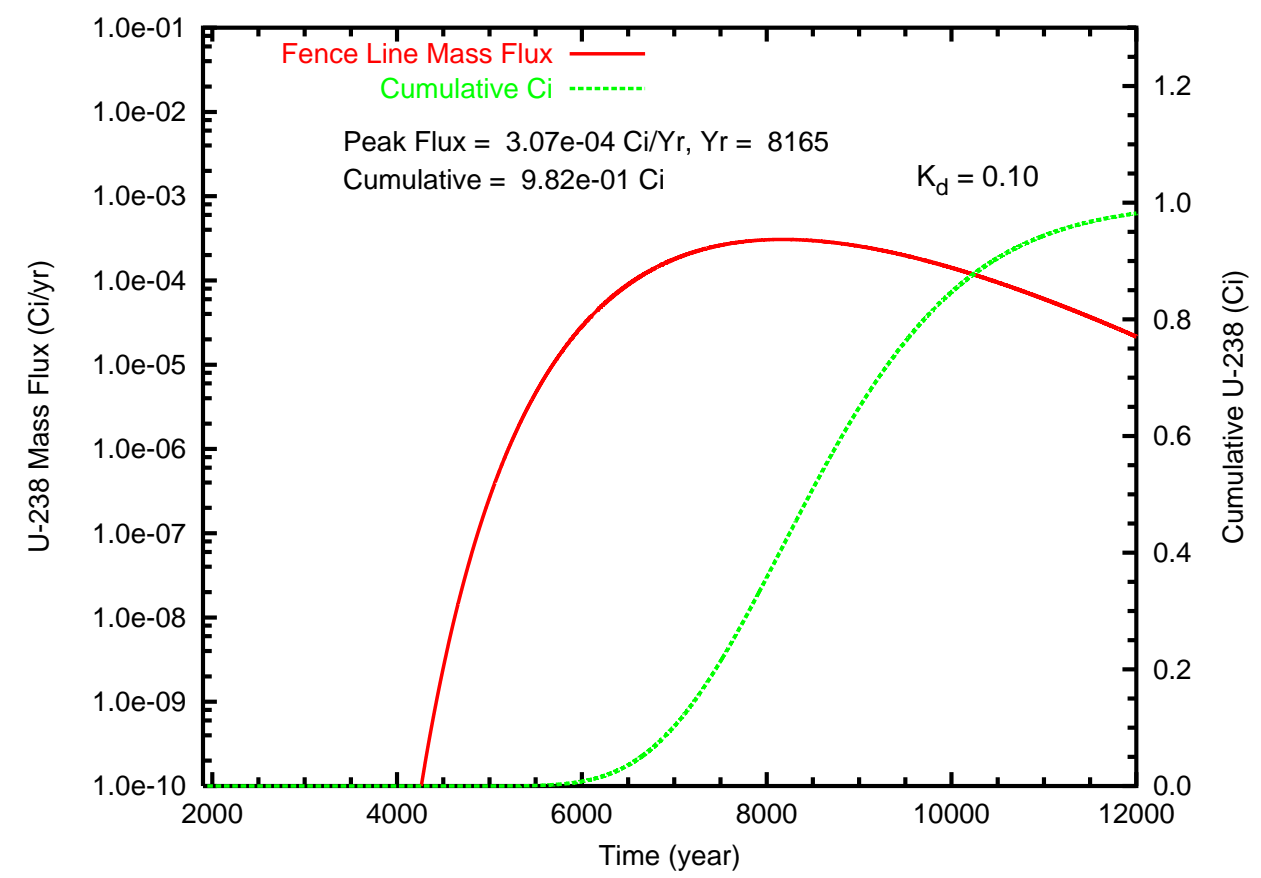

Figure B.127. Case 9, U-238 $\left(\mathrm{K}_{d}=0.10\right)$ mass flux $(\mathrm{Ci} / \mathrm{L})$ and cumulative mass $(\mathrm{Ci})$ at (a) the groundwater table and (b) the fence line 
(a)

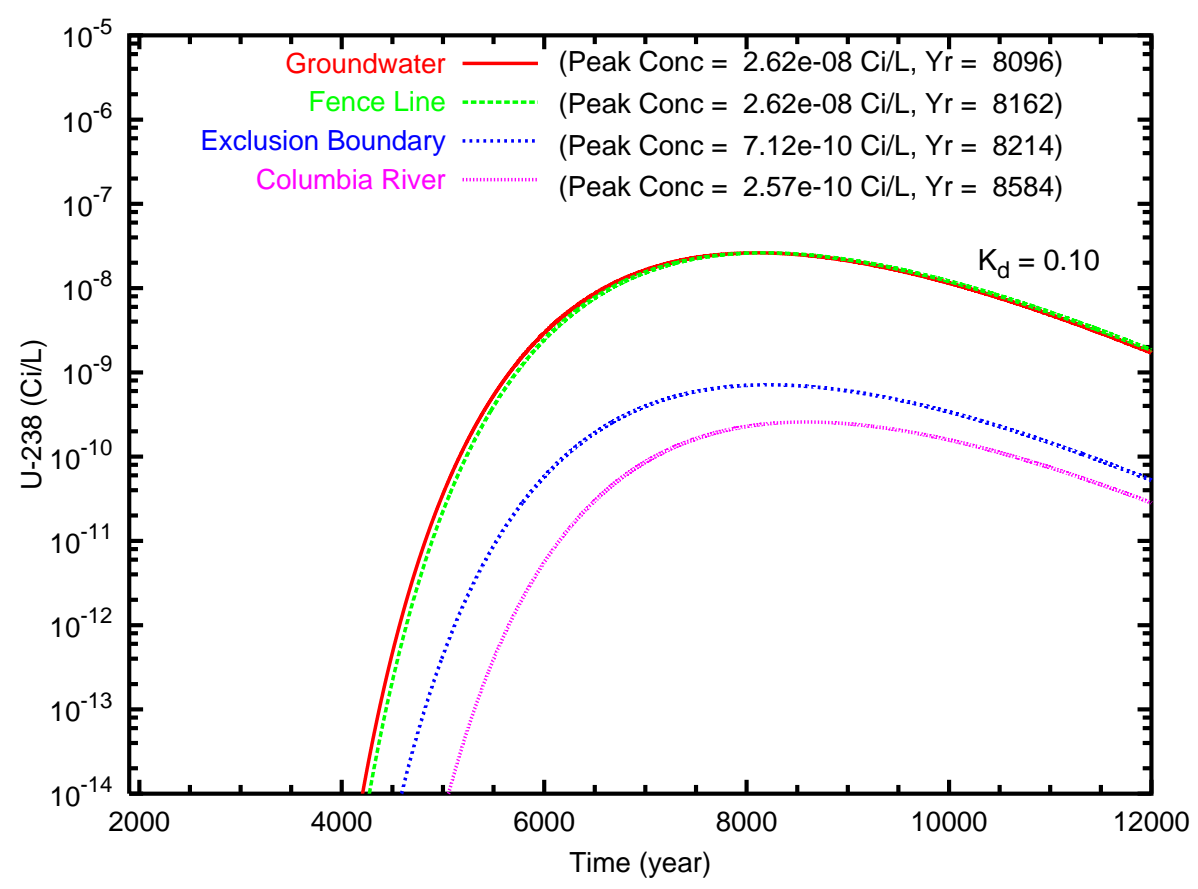

(b)

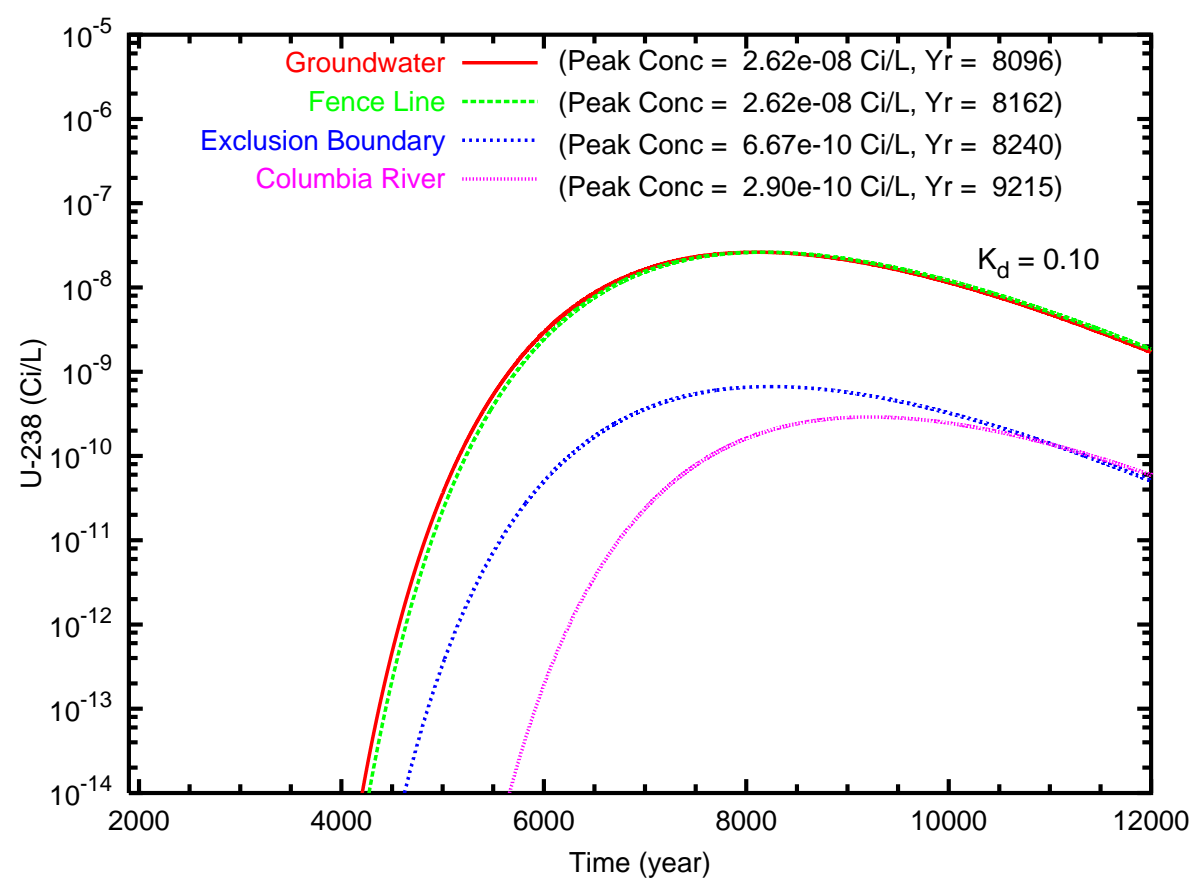

Figure B.128. Case 9, U-238 $\left(\mathrm{K}_{d}=0.10\right)$ concentration versus time for the fence line exclusion boundary and Columbia River compliance points for travel paths (a) southeast and (b) north through the gap 
(a)

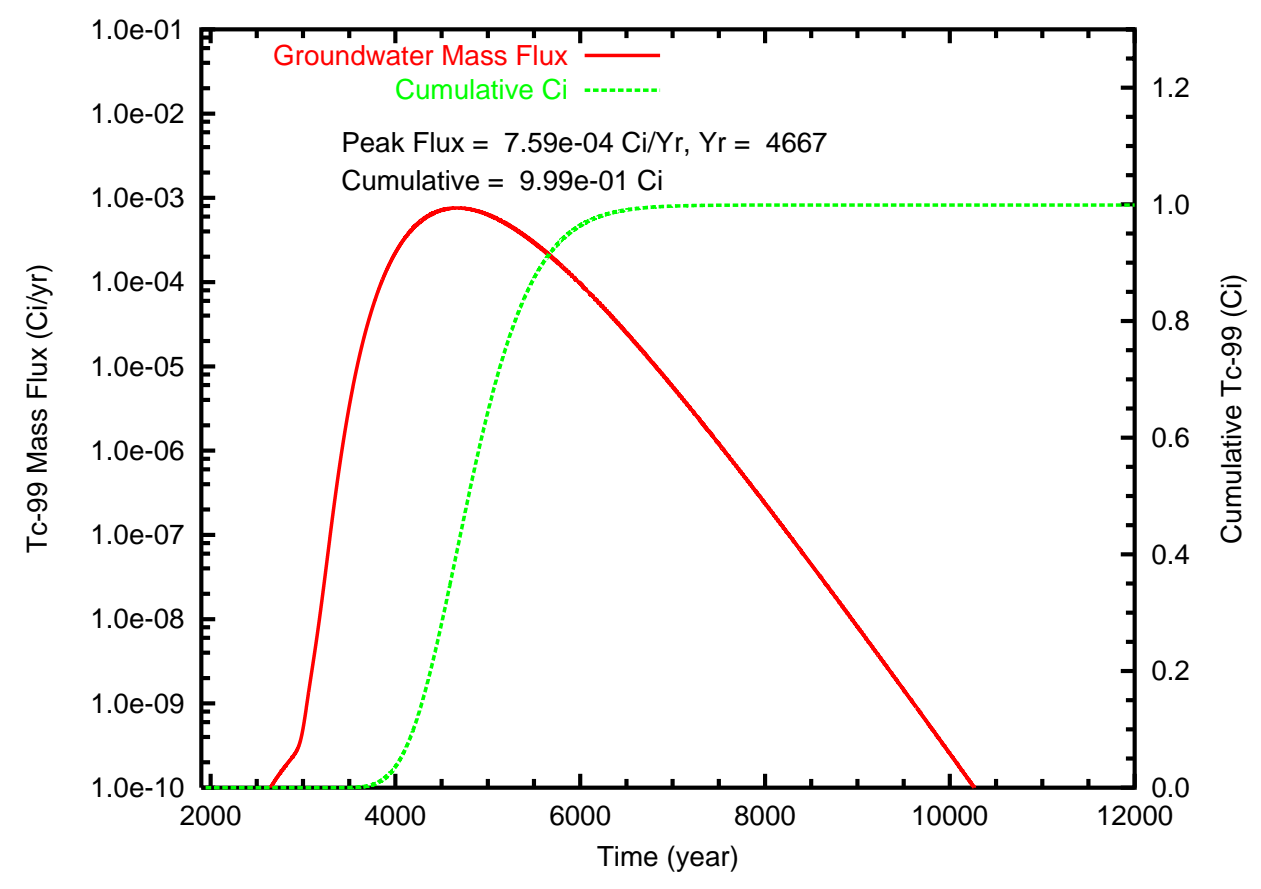

(b)

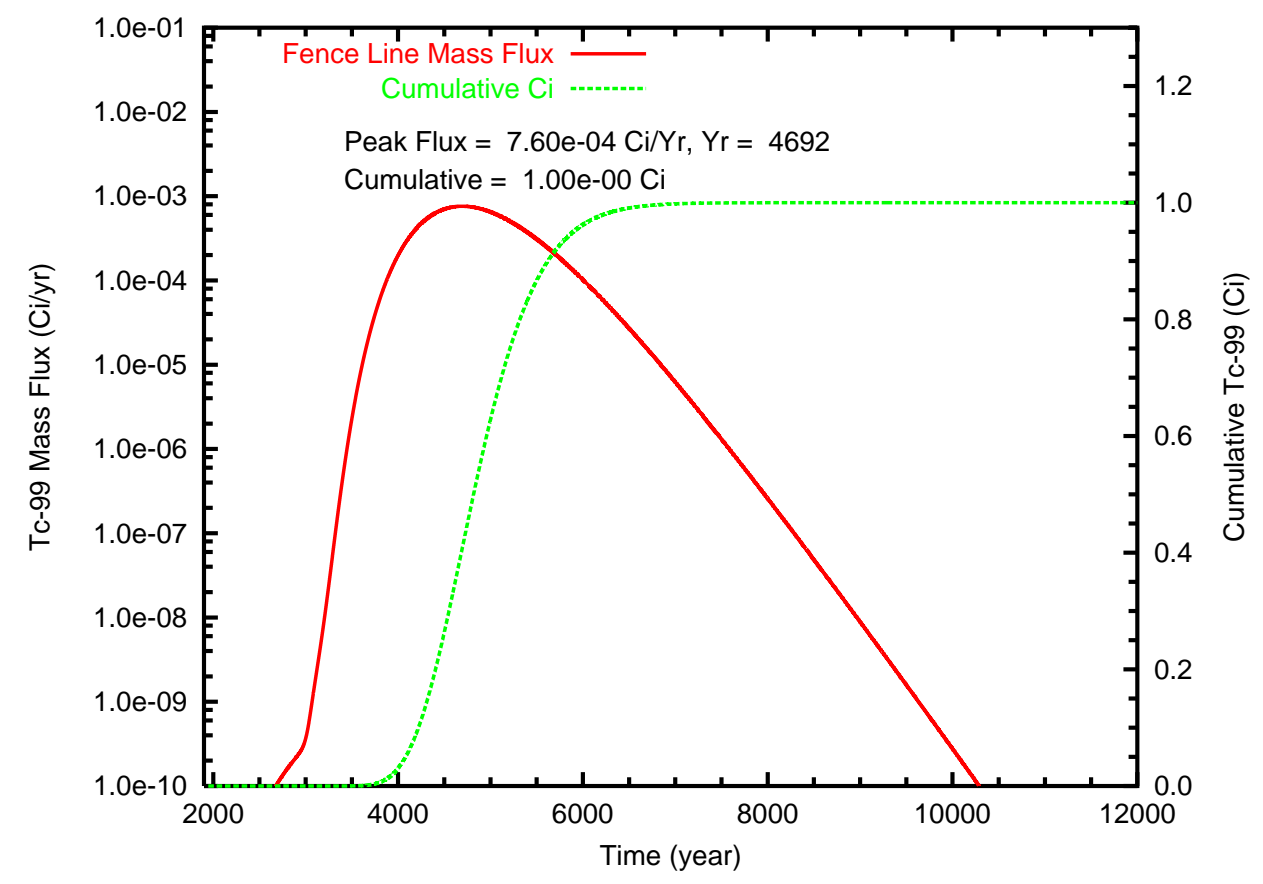

Figure B.129. Case 10, Tc-99 mass flux and cumulative mass at (a) the groundwater table and (b) the fence line 
(a)

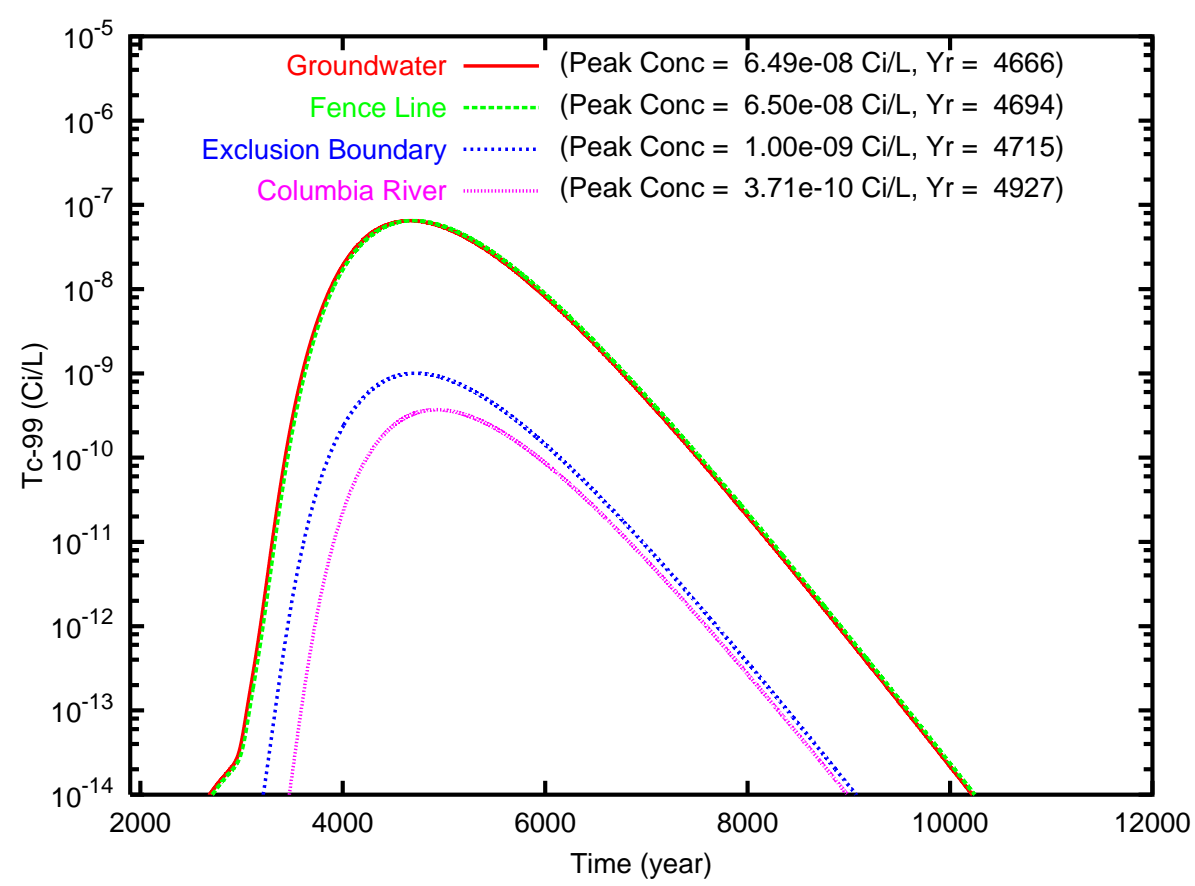

(b)

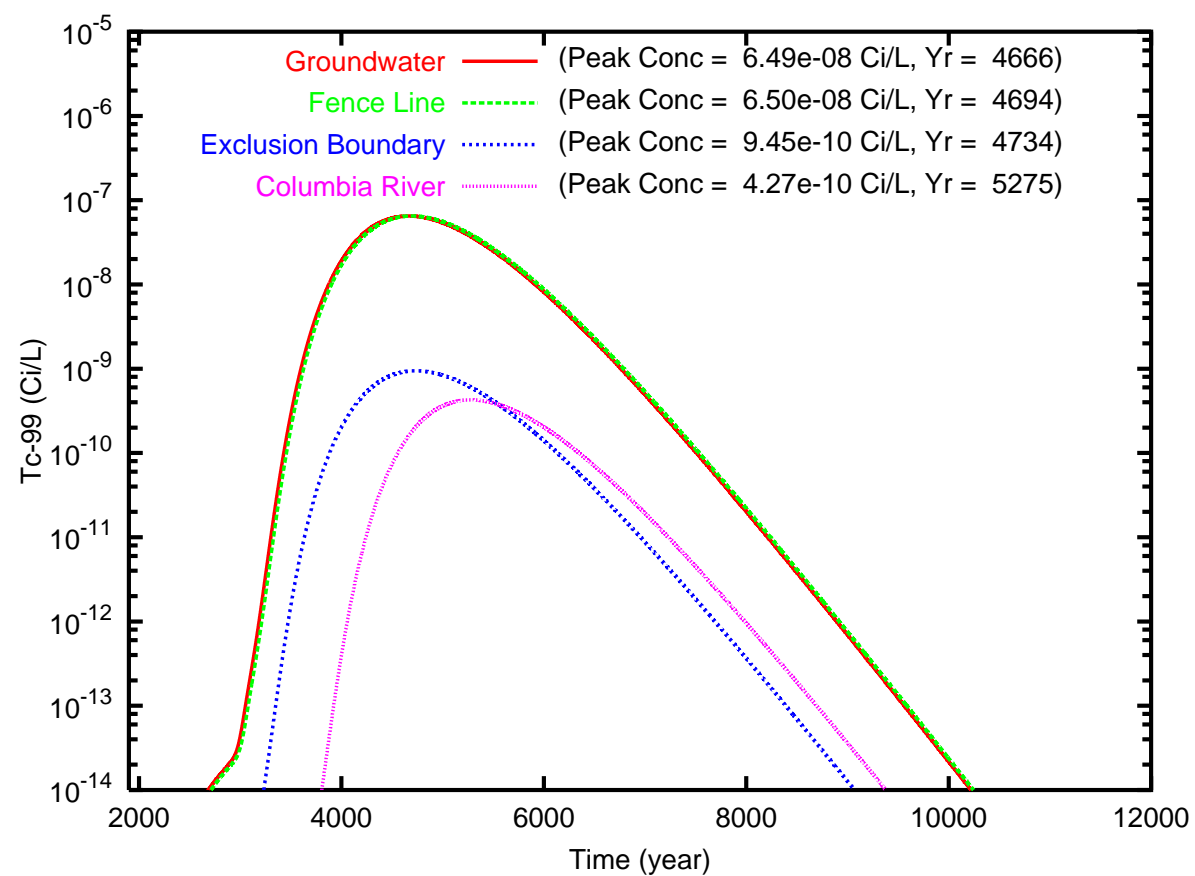

Figure B.130. Case 10, Tc-99 concentration versus time for the fence line, exclusion boundary and Columbia River compliance points for travel paths (a) southeast and (b) north through the gap 
(a)

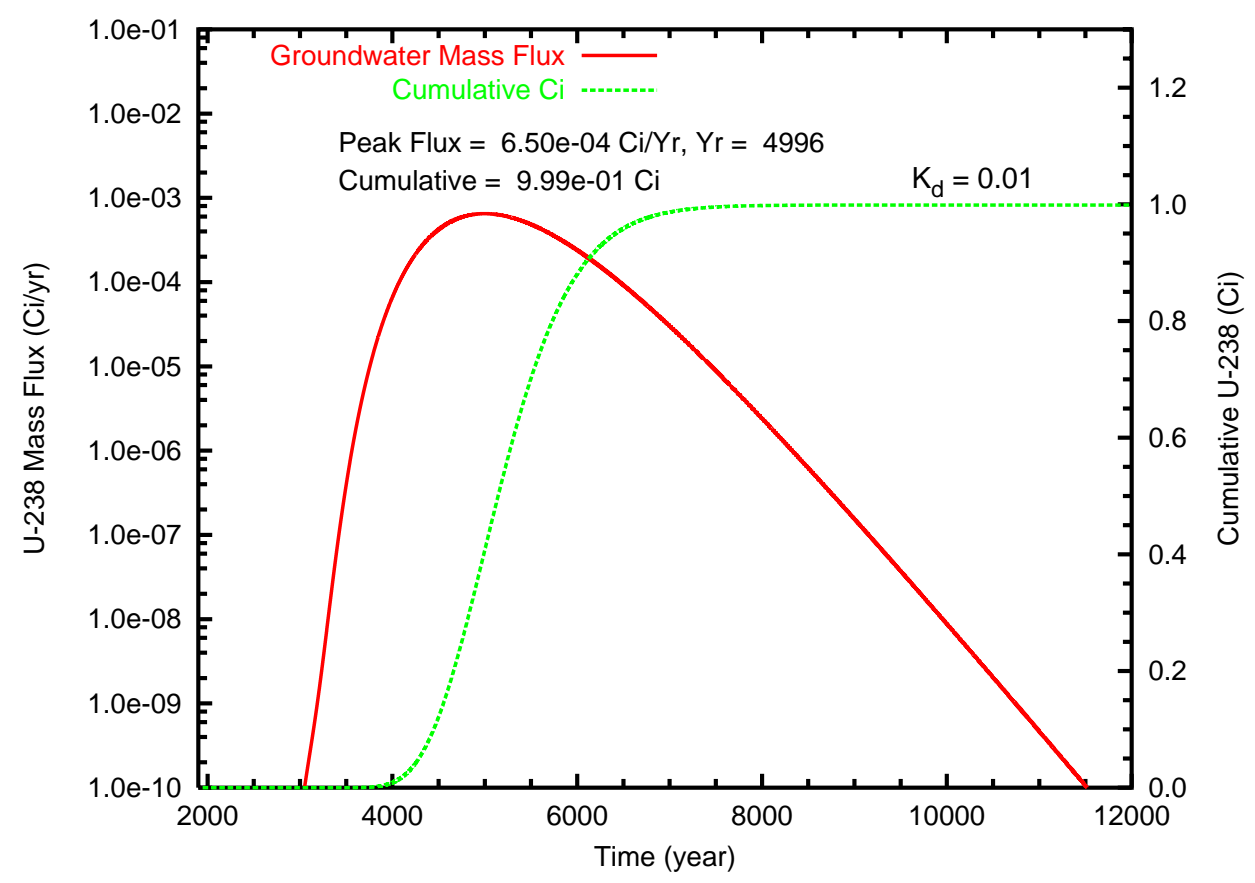

(b)

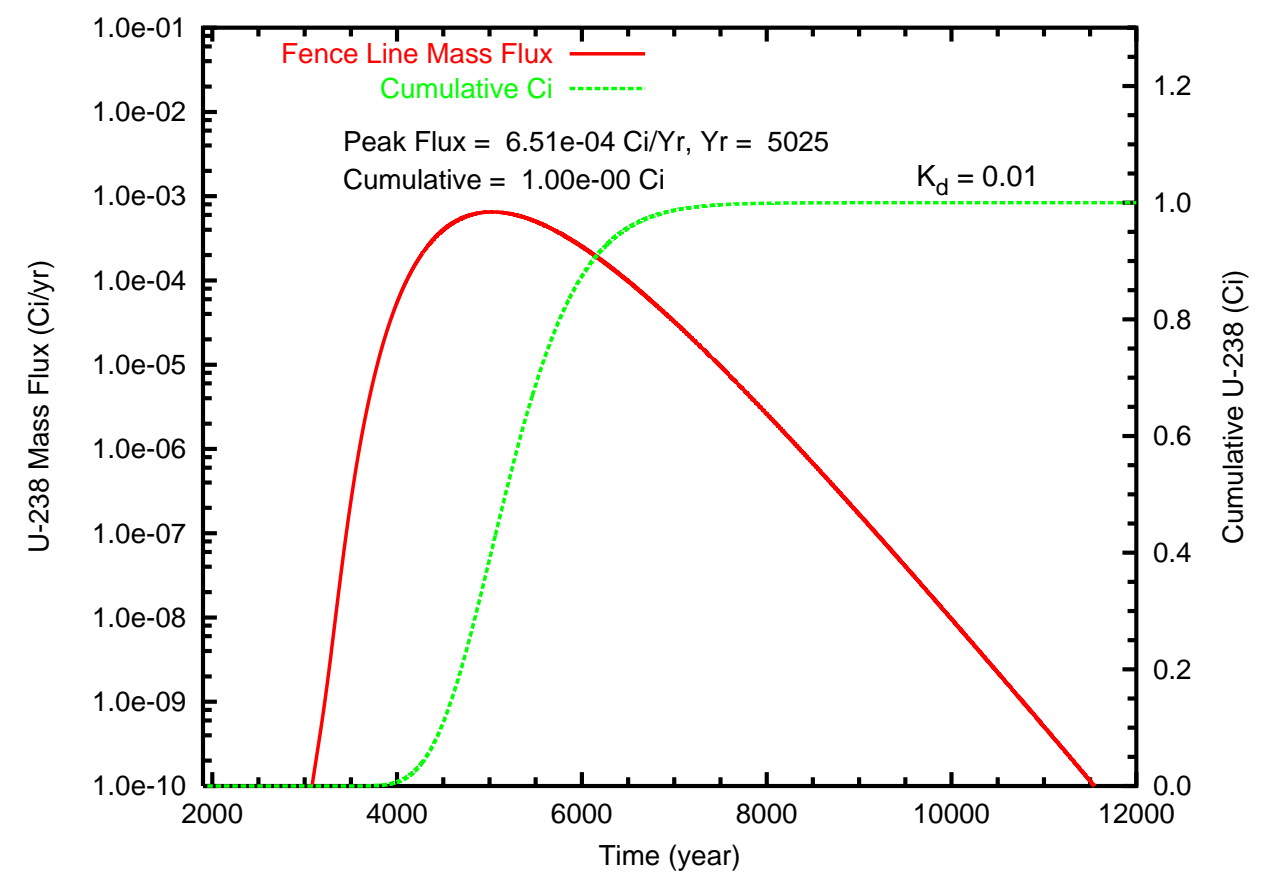

Figure B.131. Case 10, U-238 $\left(\mathrm{K}_{d}=0.01\right)$ mass flux $(\mathrm{Ci} / \mathrm{L})$ and cumulative mass $(\mathrm{Ci})$ at (a) the groundwater table and (b) the fence line 
(a)

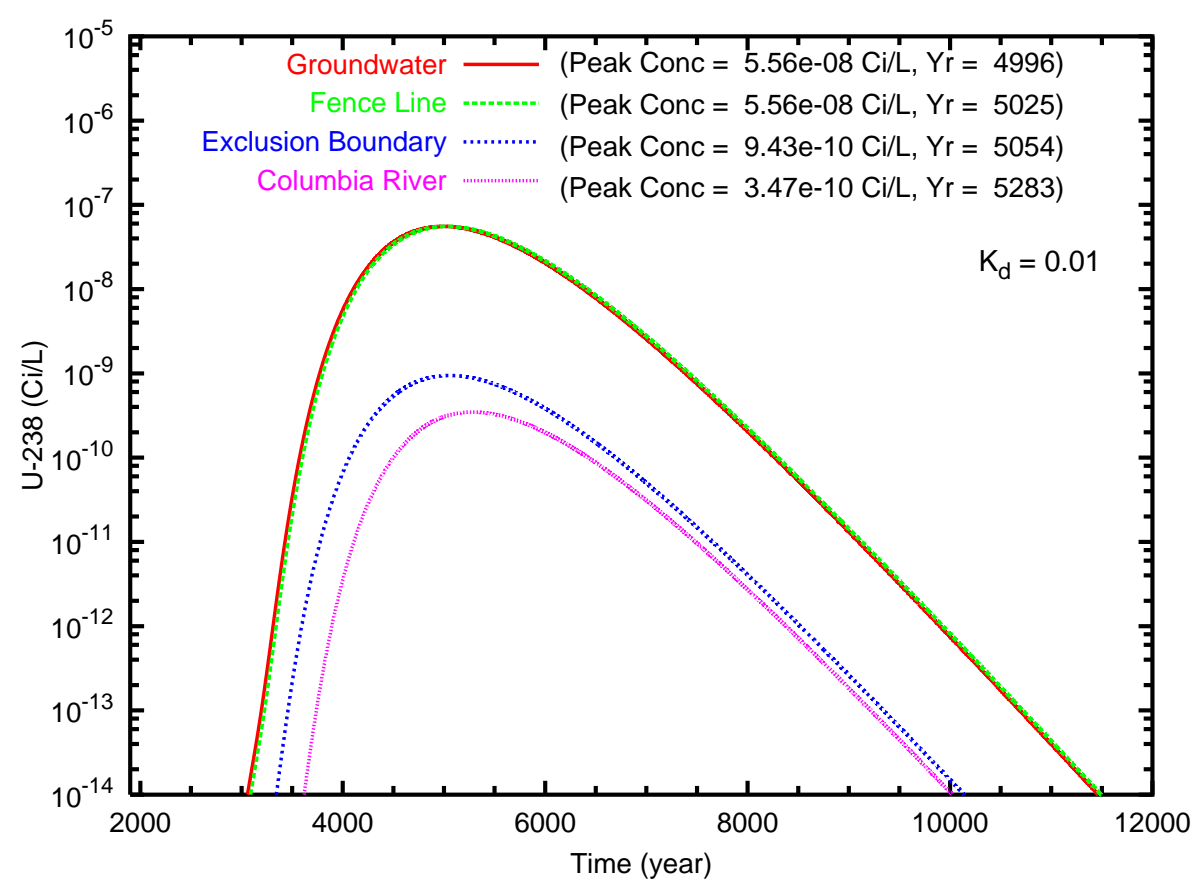

(b)

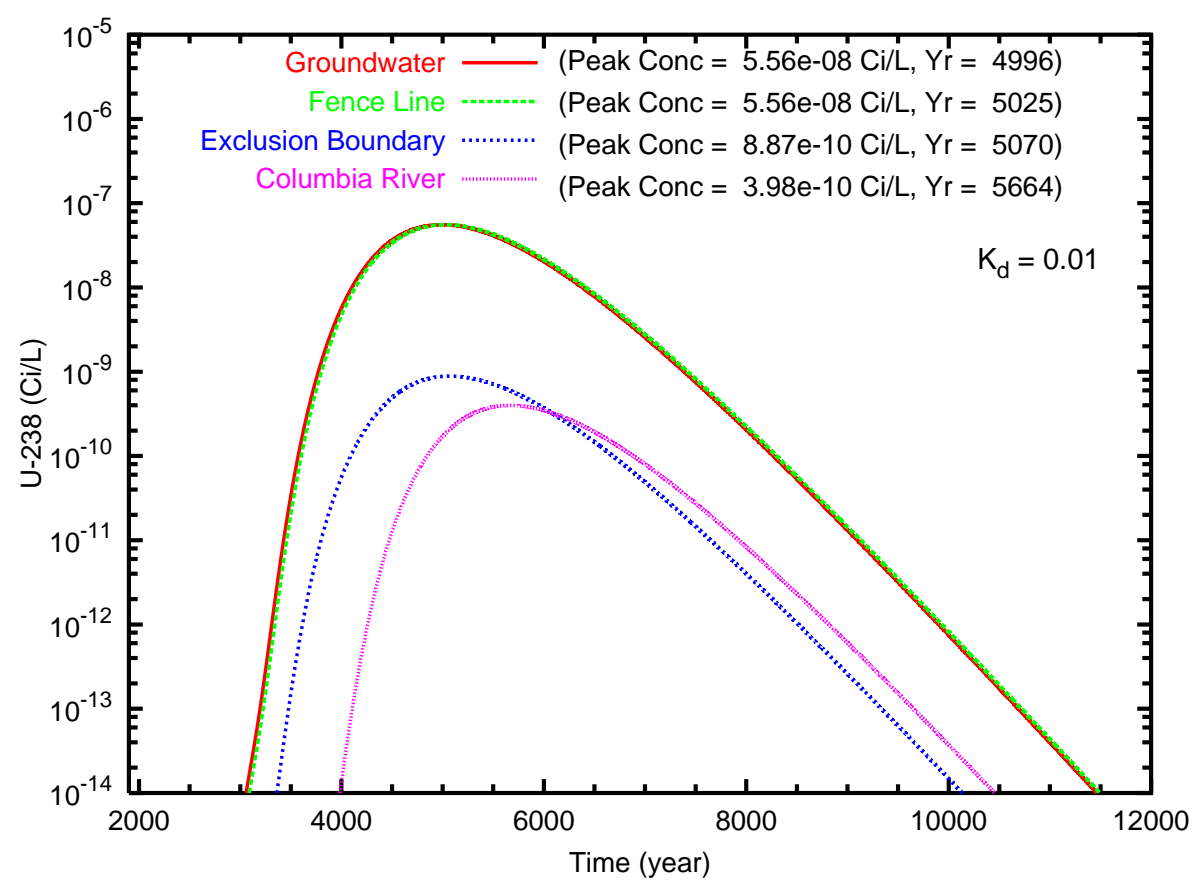

Figure B.132. Case 10, $\mathrm{U}-238\left(\mathrm{~K}_{d}=0.01\right)$ concentration versus time for the fence line exclusion boundary and Columbia River compliance points for travel paths (a) southeast and (b) north through the gap 
(a)

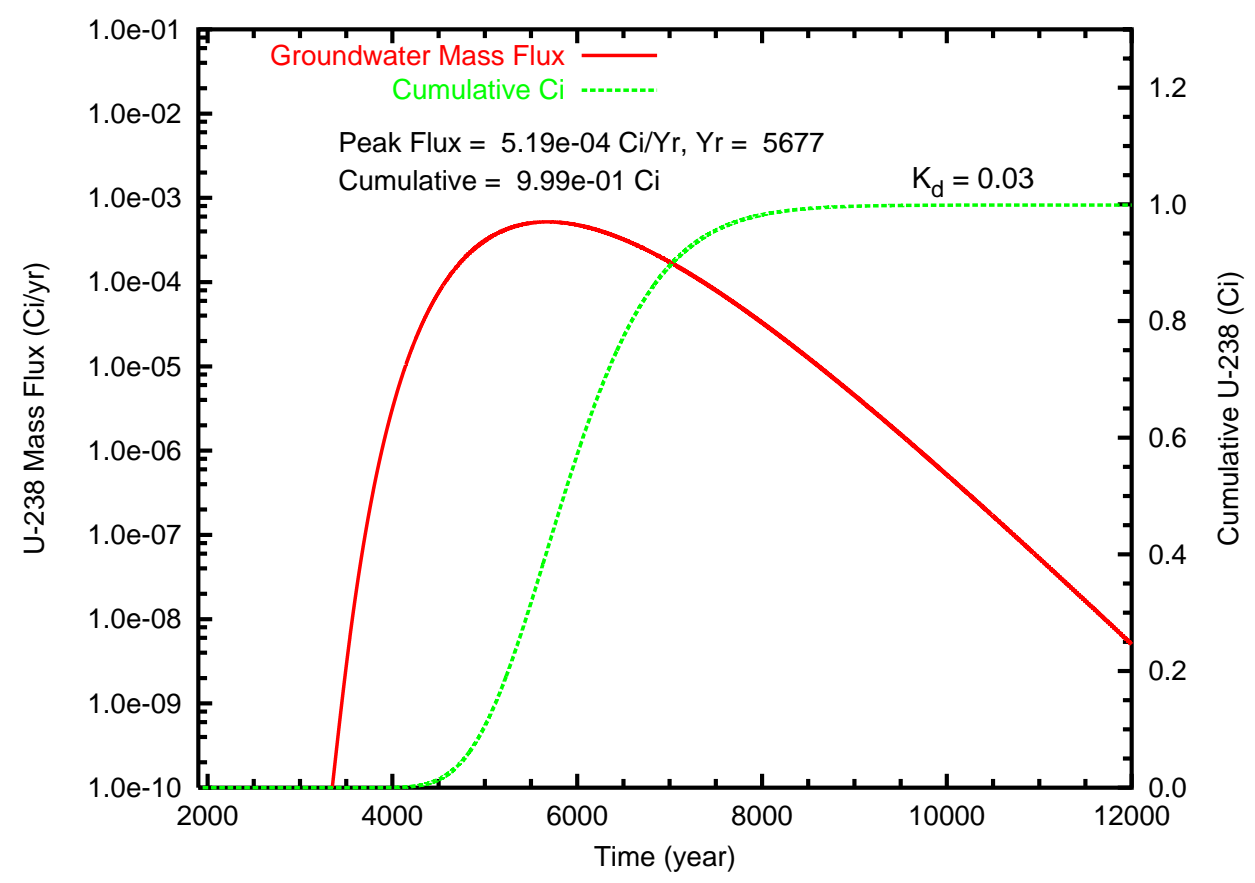

(b)

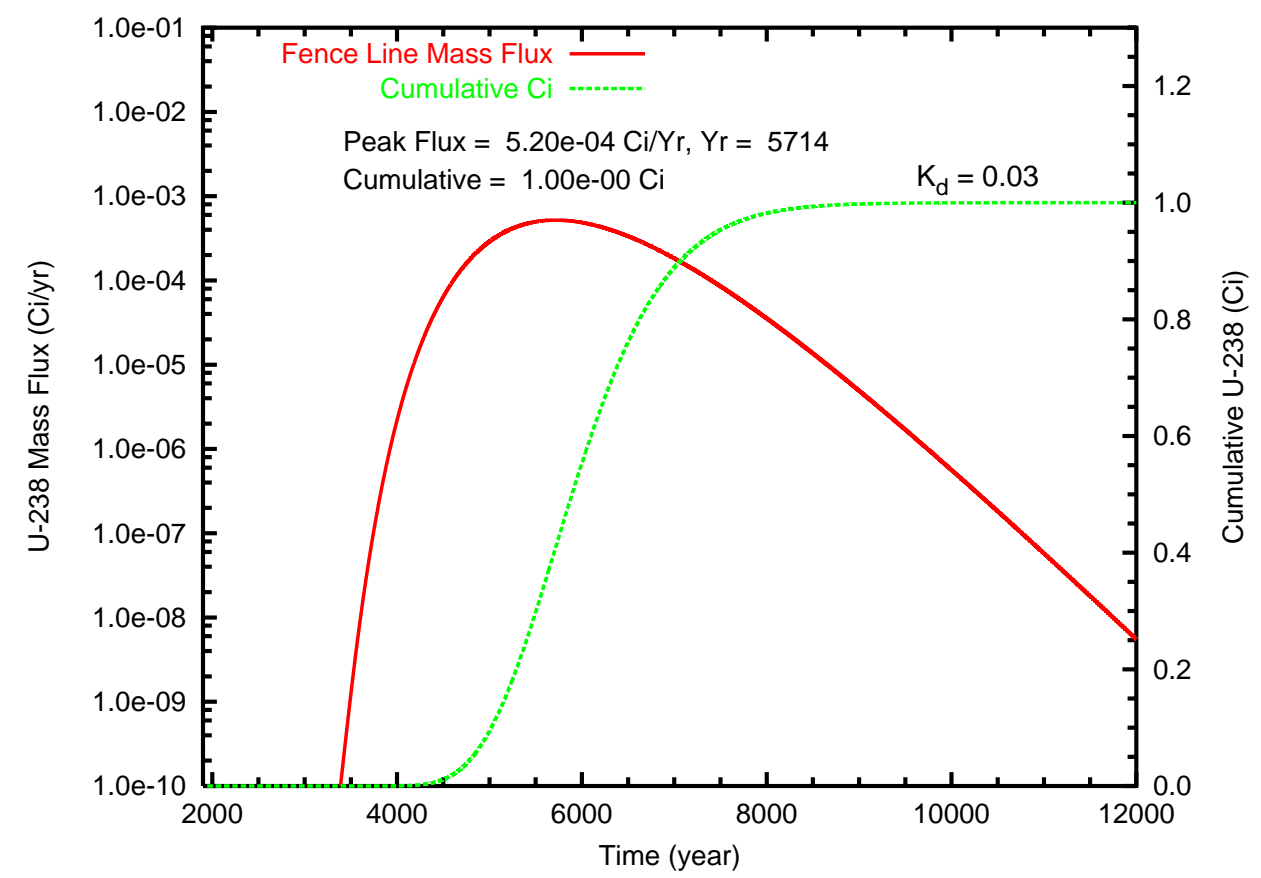

Figure B.133. Case 10, U-238 $\left(\mathrm{K}_{d}=0.03\right)$ mass flux $(\mathrm{Ci} / \mathrm{L})$ and cumulative mass $(\mathrm{Ci})$ at (a) the groundwater table and (b) the fence line 
(a)

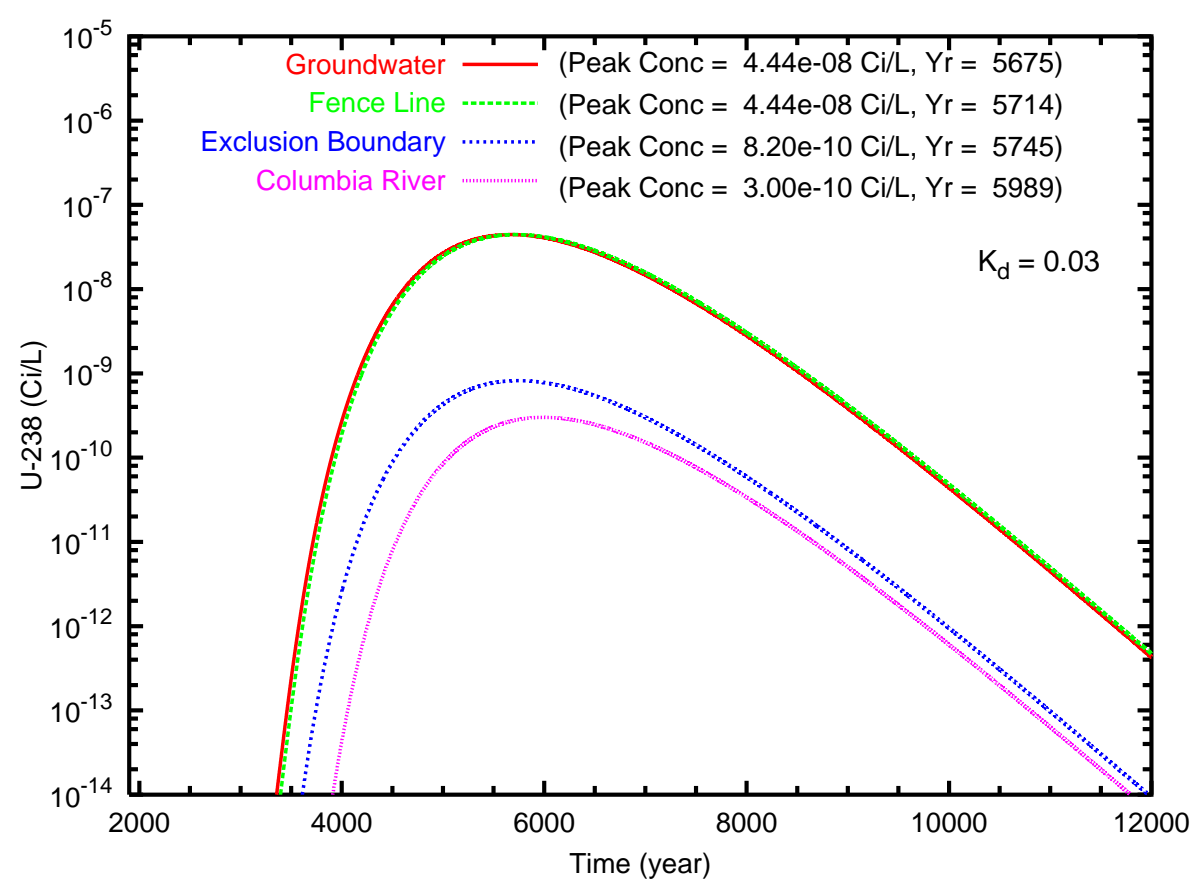

(b)

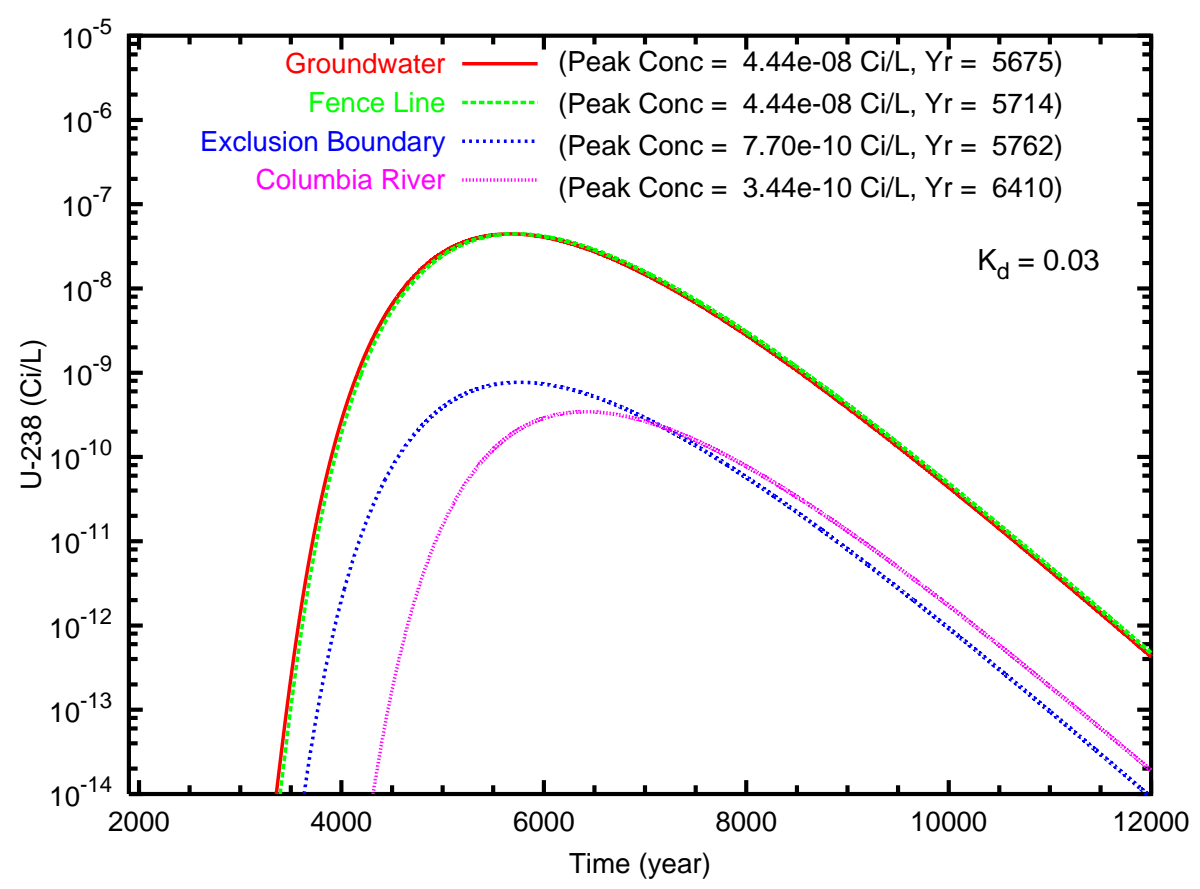

Figure B.134. Case 10, $\mathrm{U}-238\left(\mathrm{~K}_{d}=0.03\right)$ concentration versus time for the fence line exclusion boundary and Columbia River compliance points for travel paths (a) southeast and (b) north through the gap 
(a)

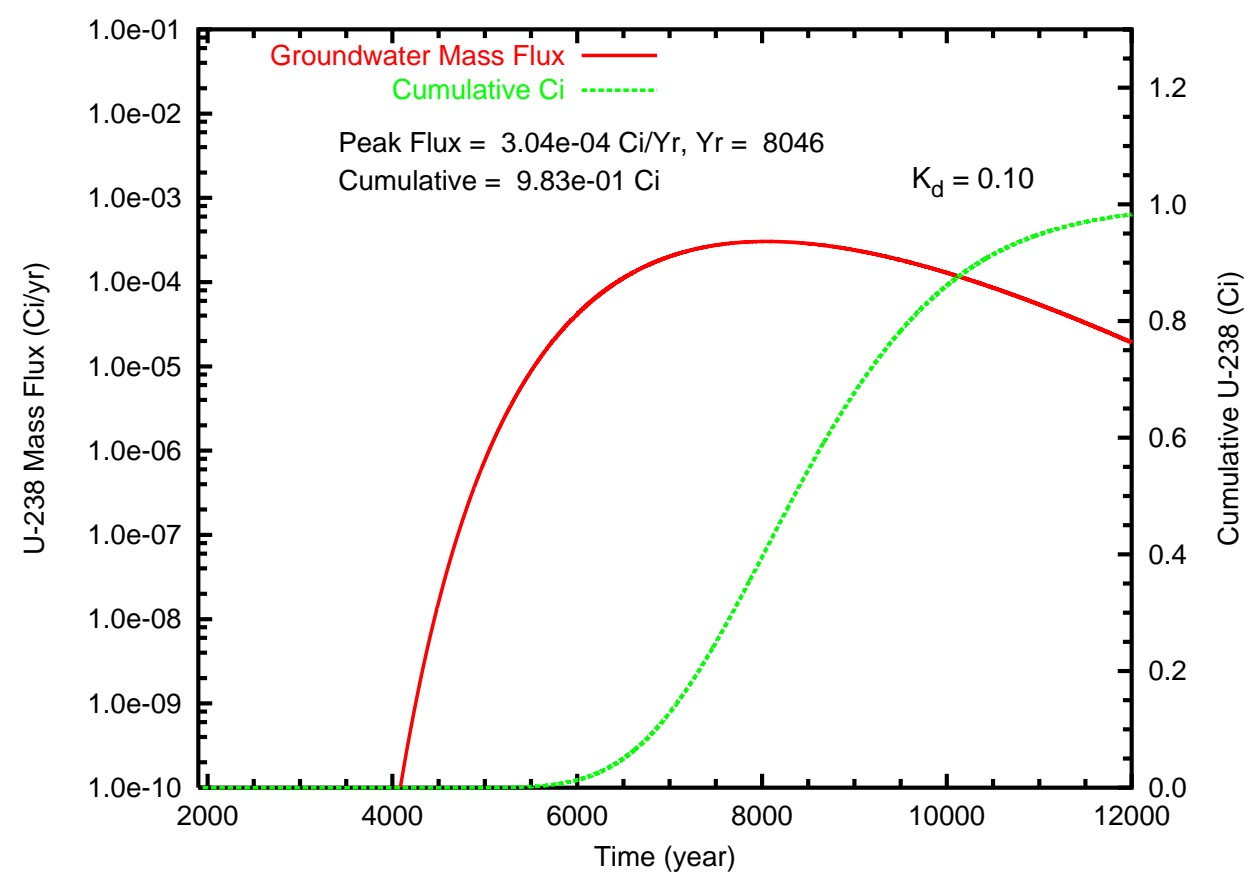

(b)

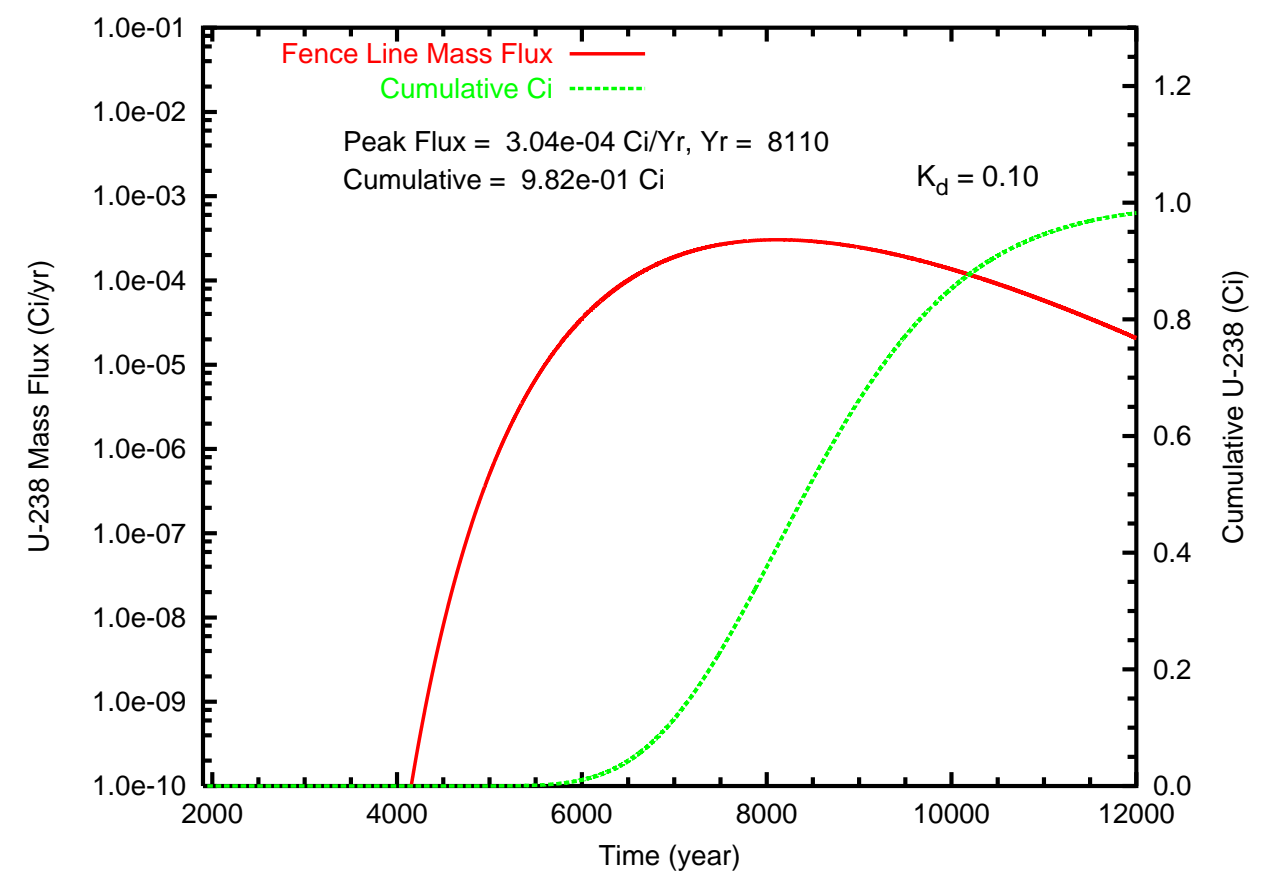

Figure B.135. Case $10, \mathrm{U}-238\left(\mathrm{~K}_{d}=0.10\right)$ mass flux $(\mathrm{Ci} / \mathrm{L})$ and cumulative mass $(\mathrm{Ci})$ at (a) the groundwater table and (b) the fence line 
(a)

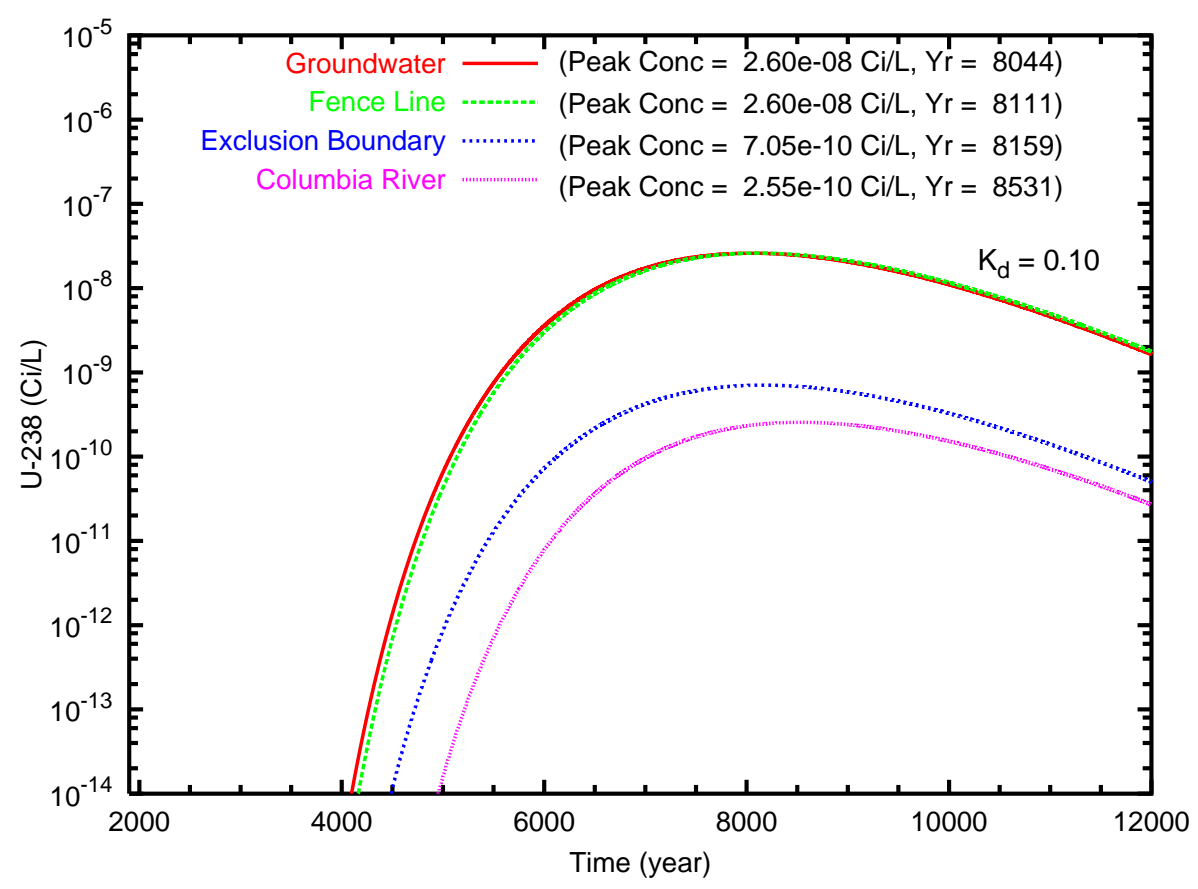

(b)

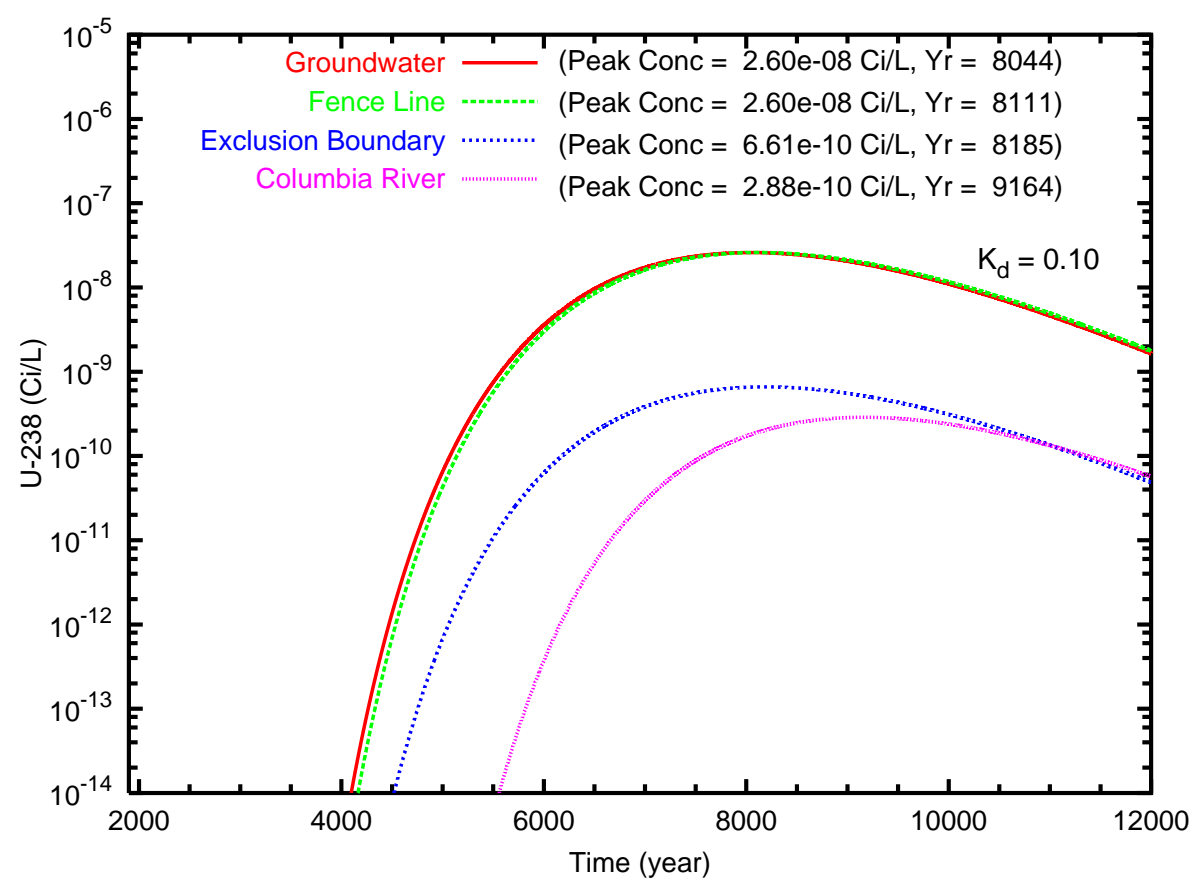

Figure B.136. Case 10, $\mathrm{U}-238\left(\mathrm{~K}_{d}=0.10\right)$ concentration versus time for the fence line exclusion boundary and Columbia River compliance points for travel paths (a) southeast and (b) north through the gap 
(a)

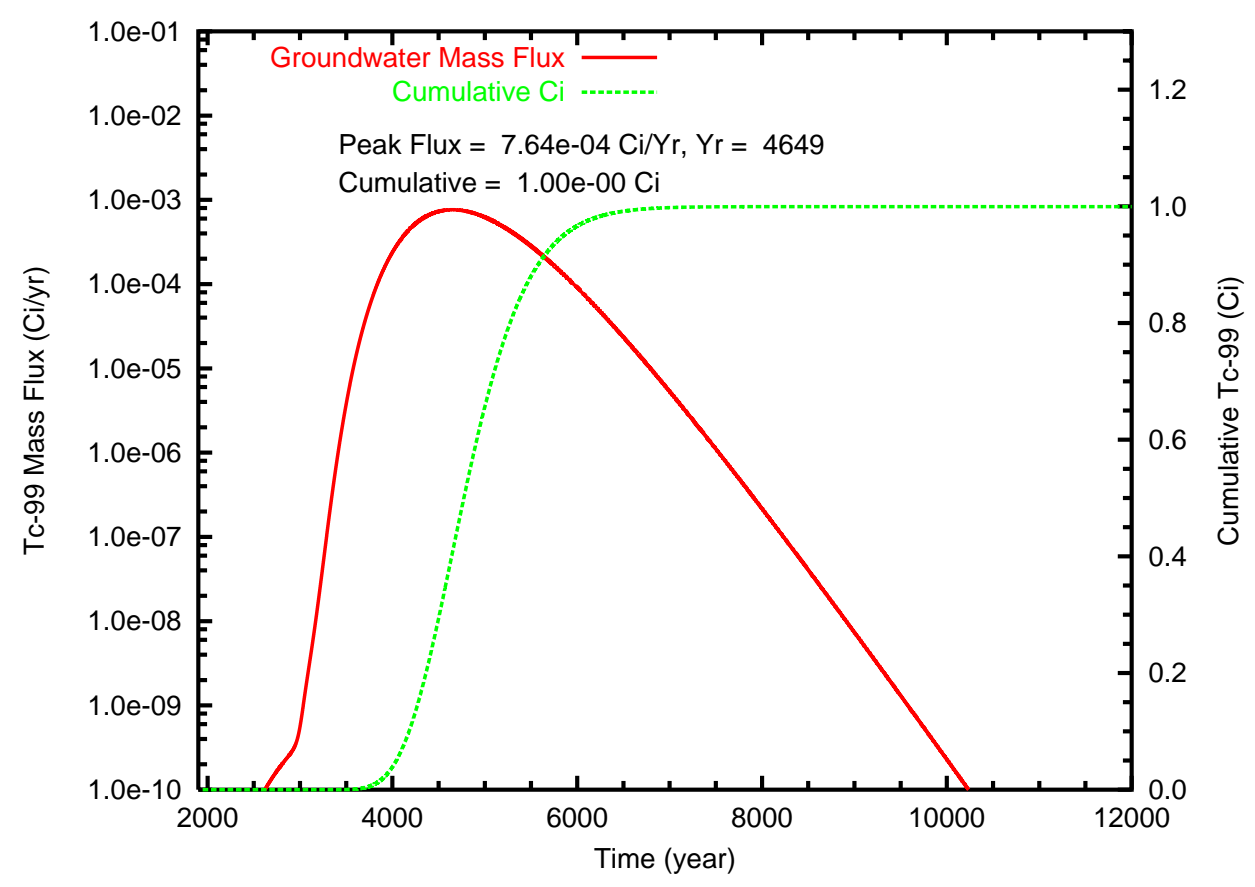

(b)

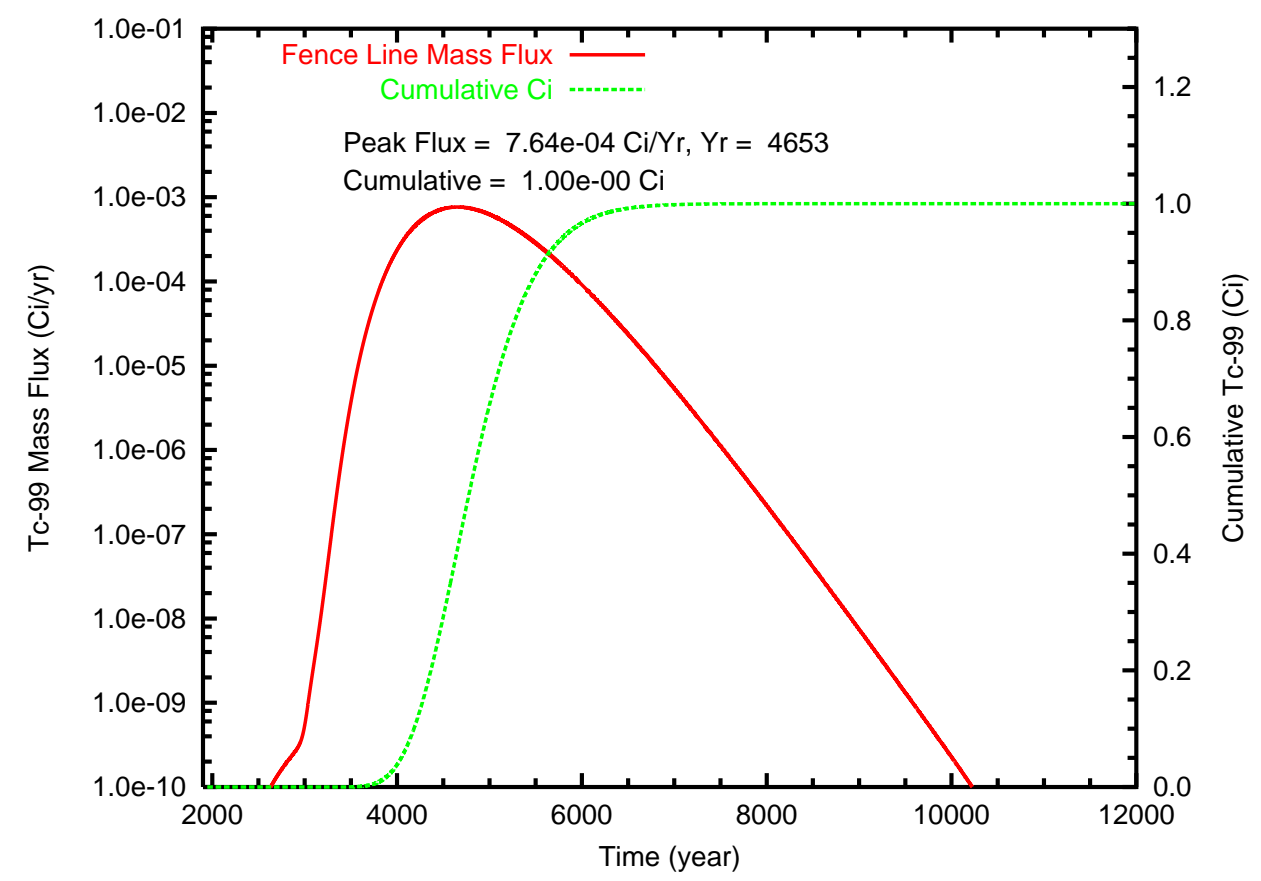

Figure B.137. Case 10-HiK, Tc-99 mass flux and cumulative mass at (a) the groundwater table and (b) the fence line 
(a)

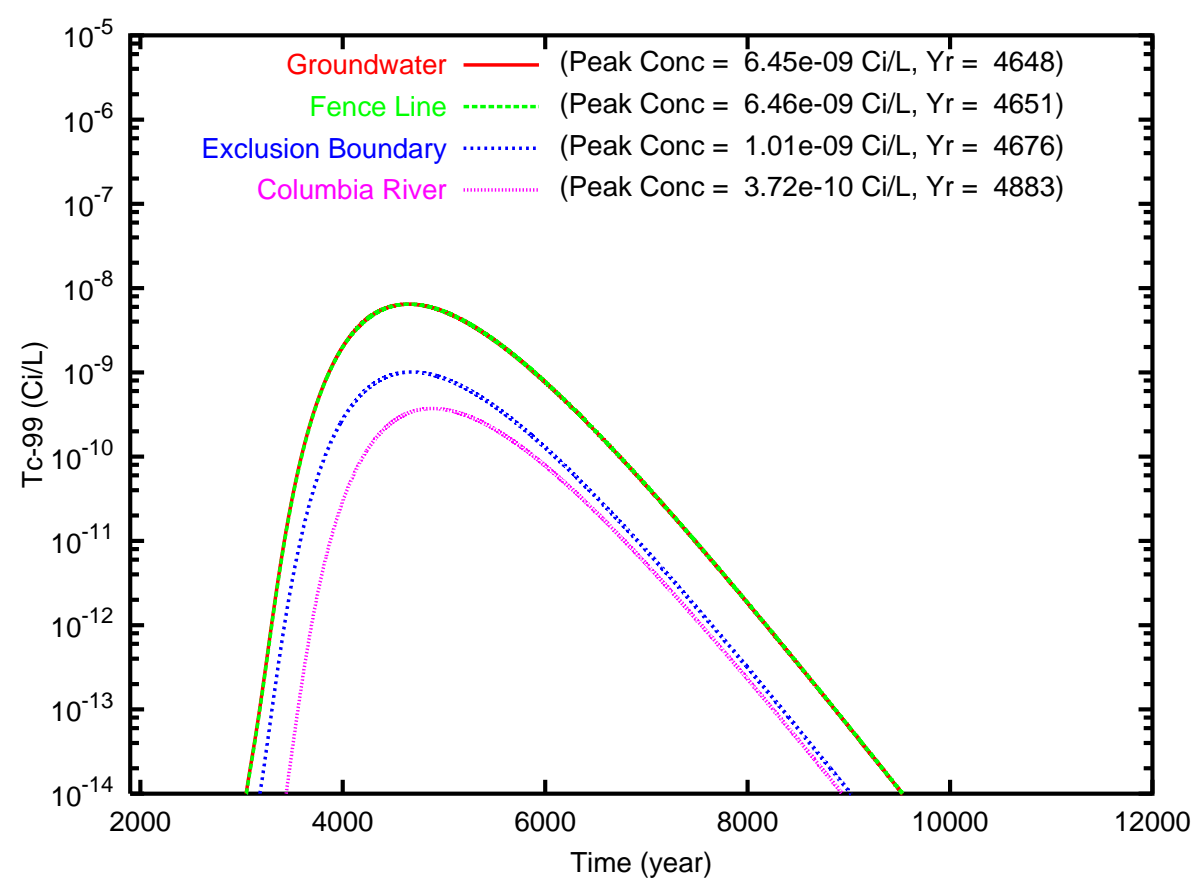

(b)

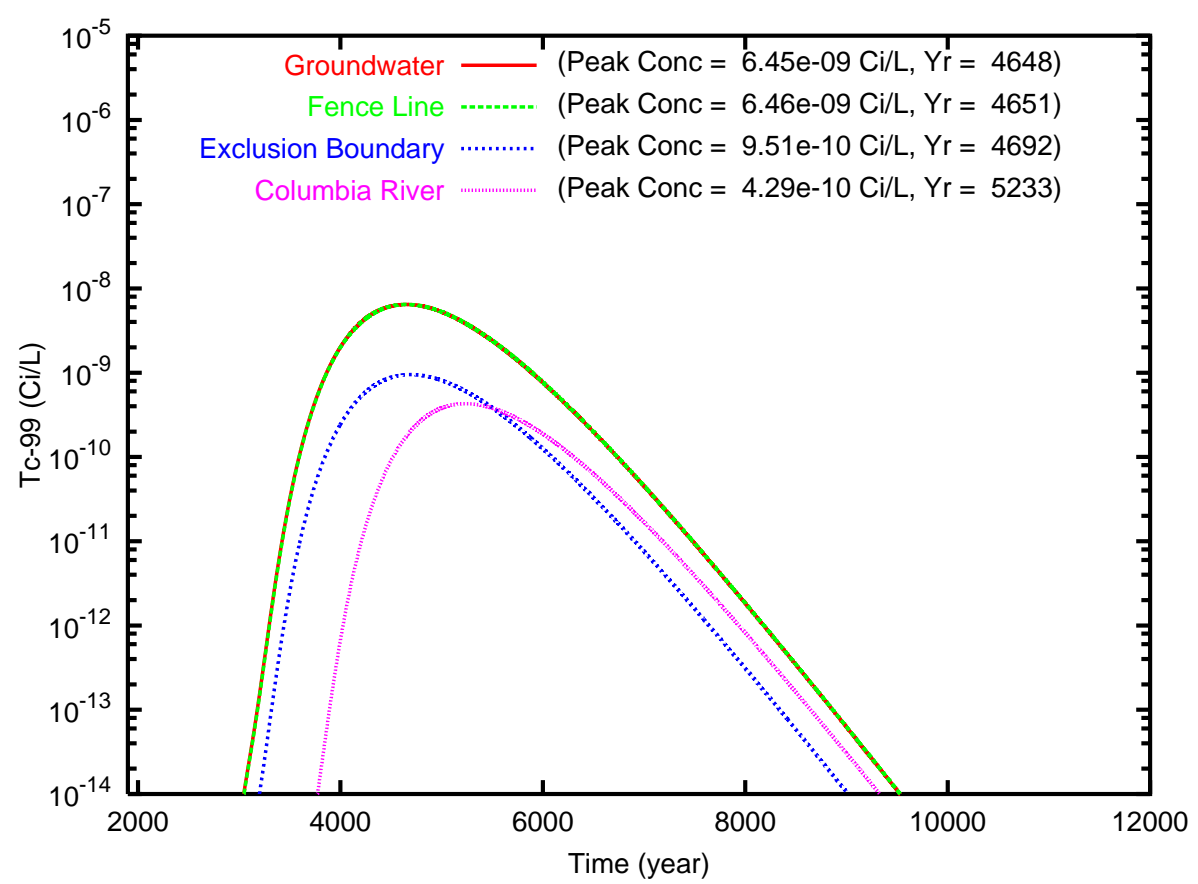

Figure B.138. Case 10-HiK, Tc-99 concentration versus time for the fence line, exclusion boundary and Columbia River compliance points for travel paths (a) southeast and (b) north through the gap 
(a)

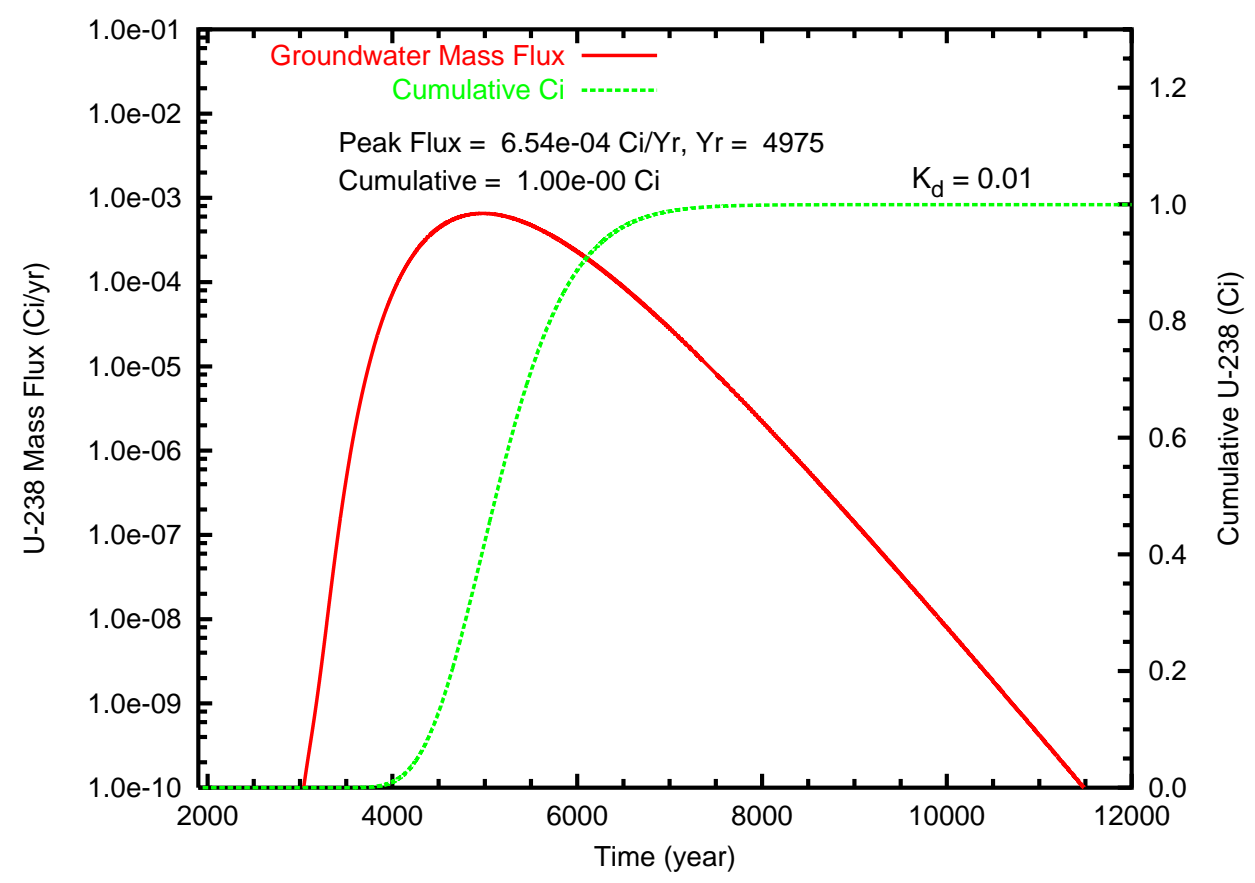

(b)

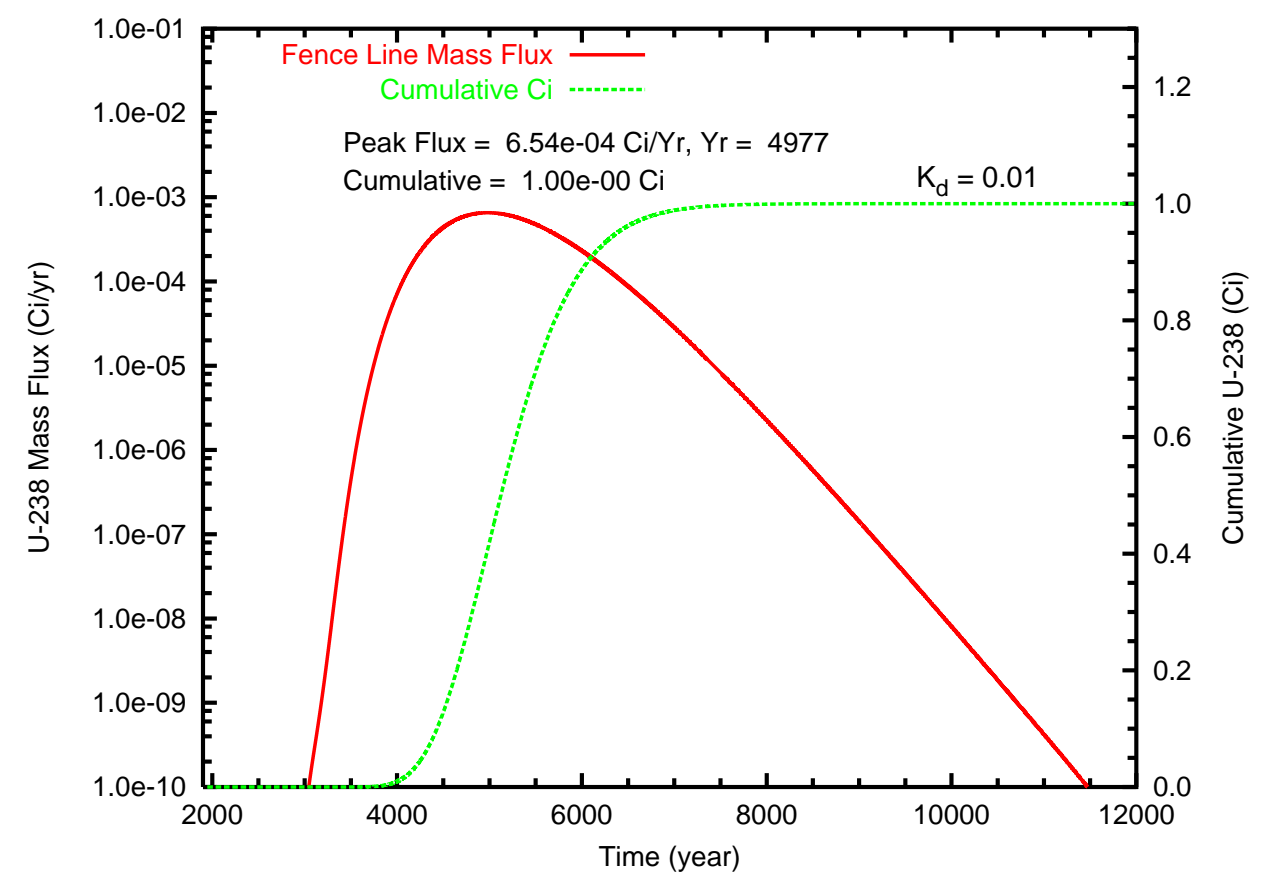

Figure B.139. Case 10-HiK, U-238 ( $\left.\mathrm{K}_{d}=0.01\right)$ mass flux $(\mathrm{Ci} / \mathrm{L})$ and cumulative mass $(\mathrm{Ci})$ at (a) the groundwater table and (b) the fence line 
(a)

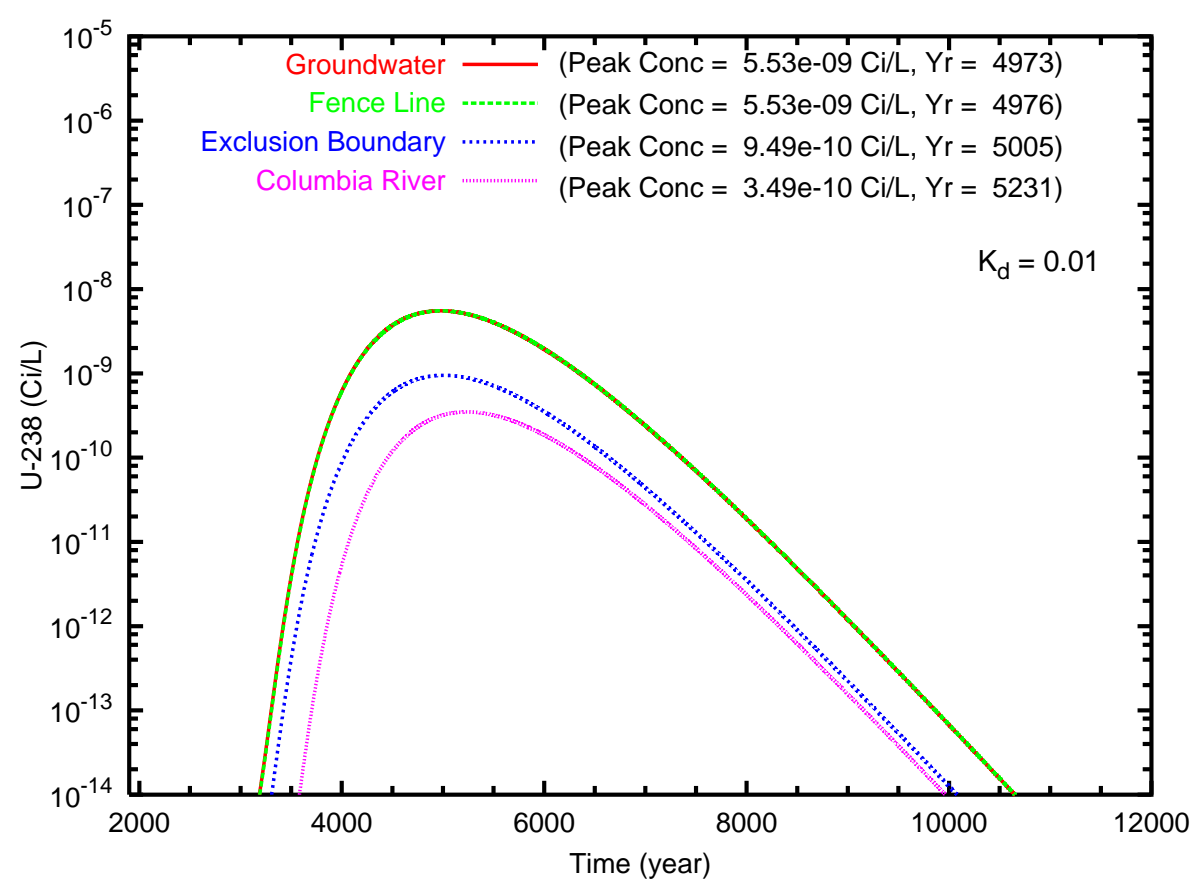

(b)

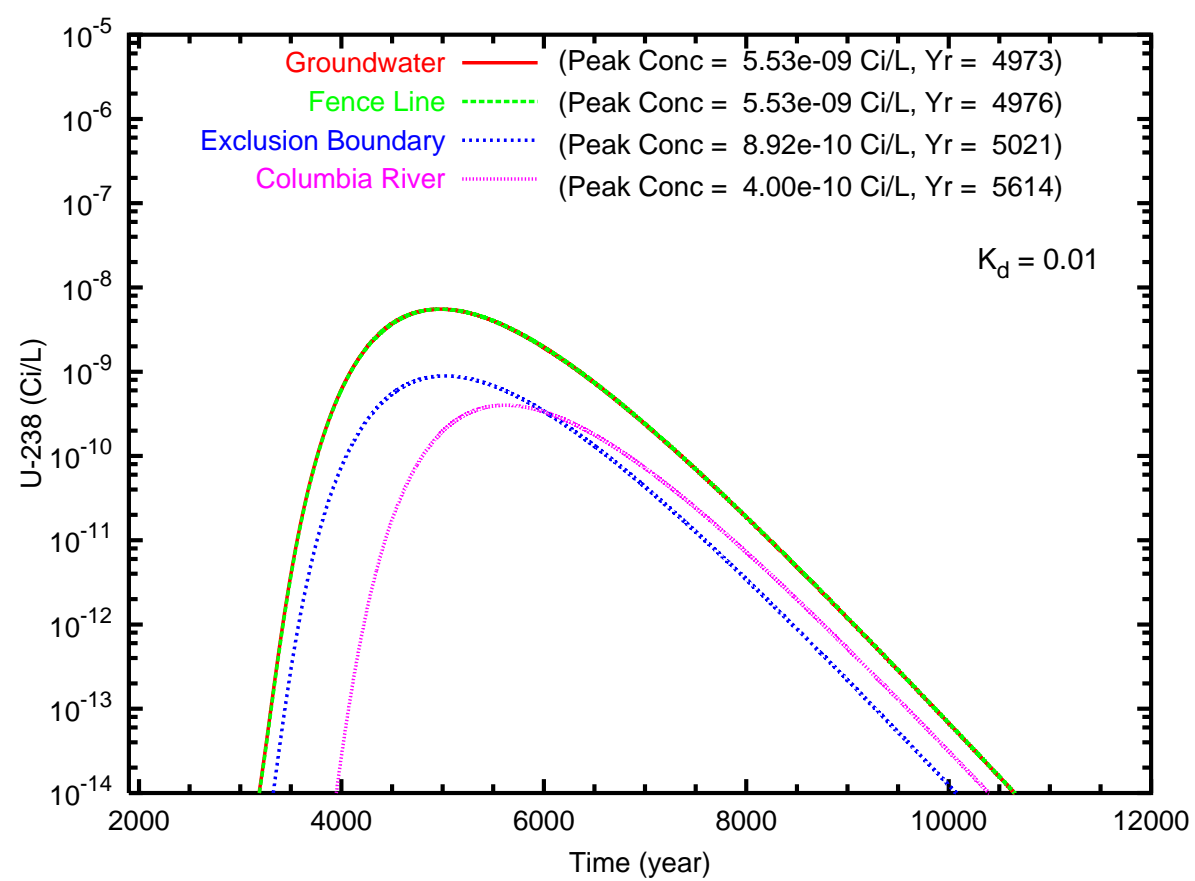

Figure B.140. Case 10-HiK, U-238 $\left(\mathrm{K}_{d}=0.01\right)$ concentration versus time for the fence line exclusion boundary and Columbia River compliance points for travel paths (a) southeast and (b) north through the gap 
(a)

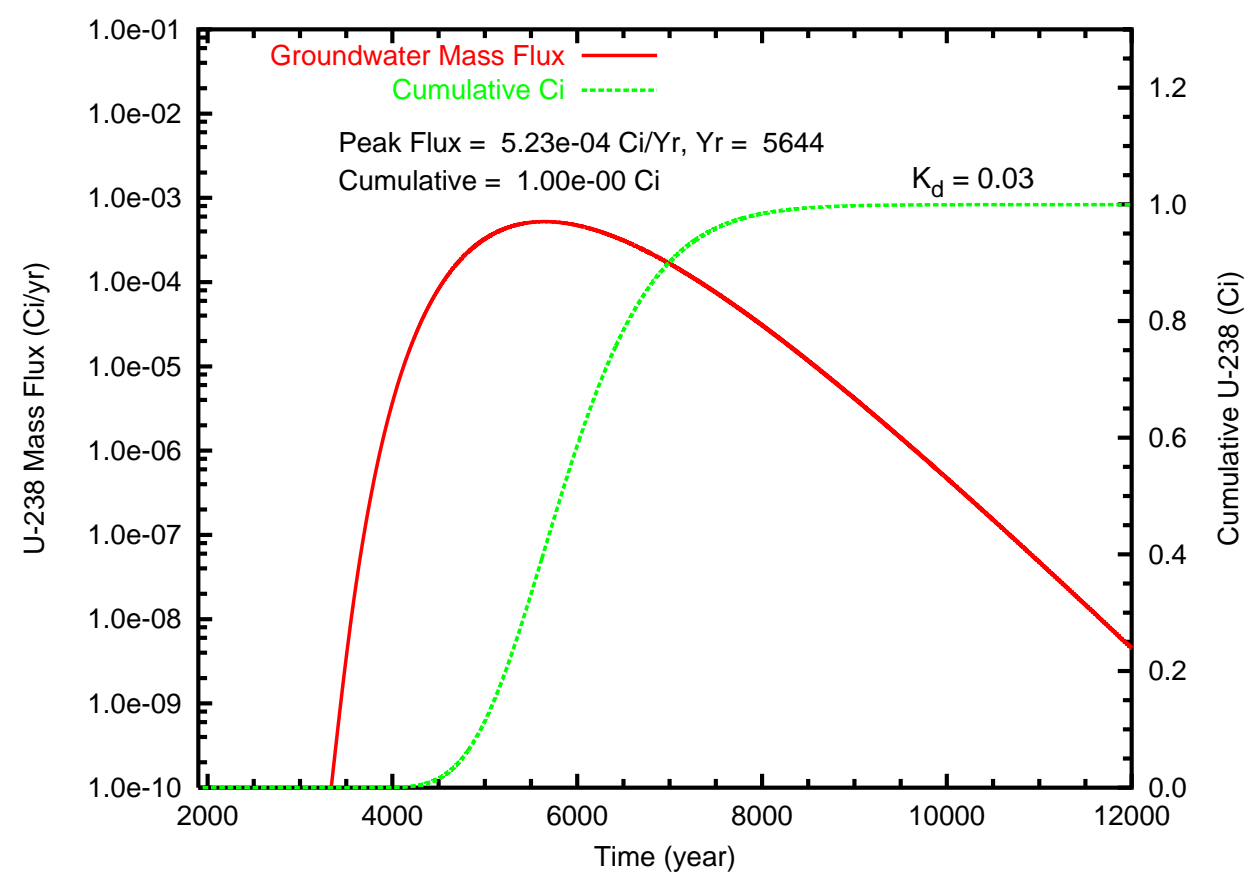

(b)

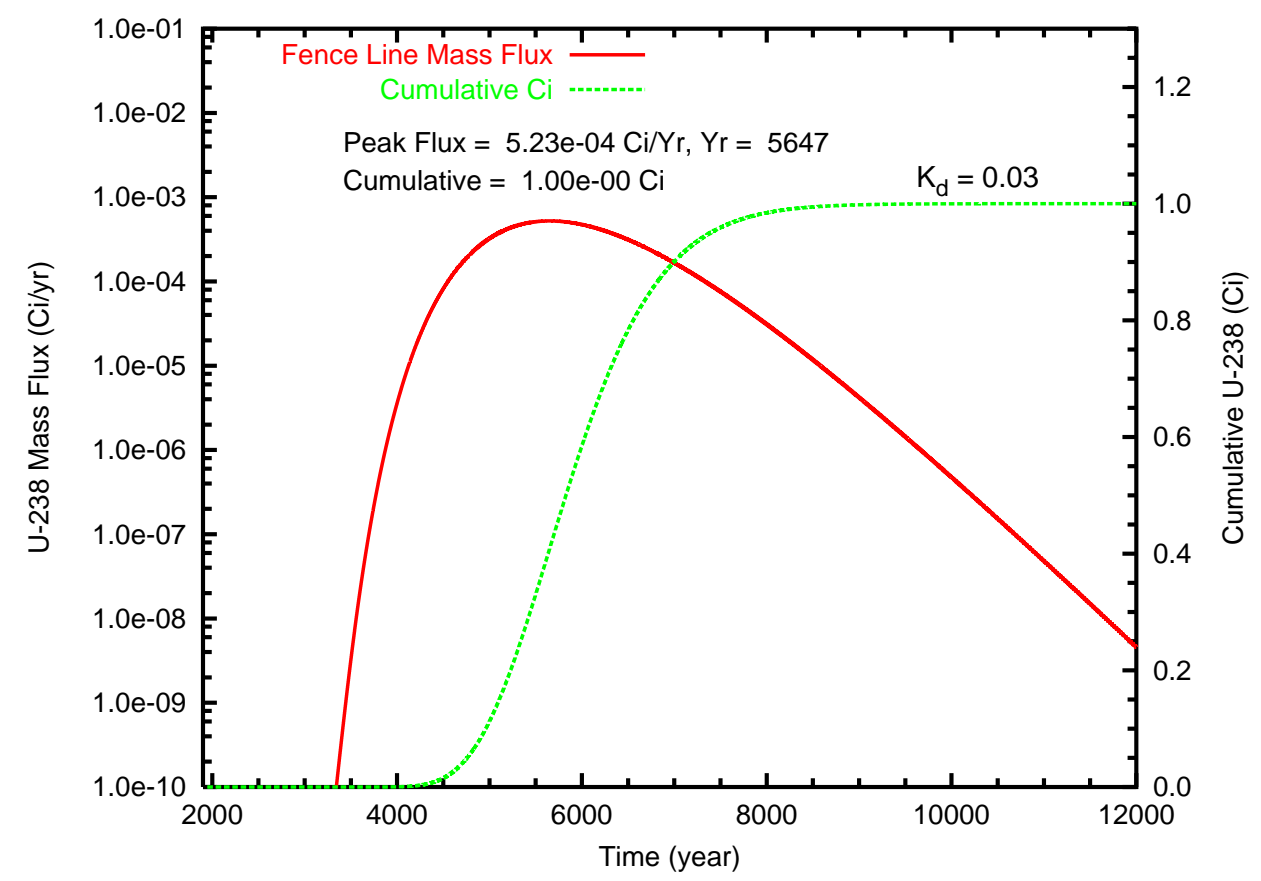

Figure B.141. Case 10-HiK, U-238 ( $\left.\mathrm{K}_{d}=0.03\right)$ mass flux $(\mathrm{Ci} / \mathrm{L})$ and cumulative mass $(\mathrm{Ci})$ at (a) the groundwater table and (b) the fence line 
(a)

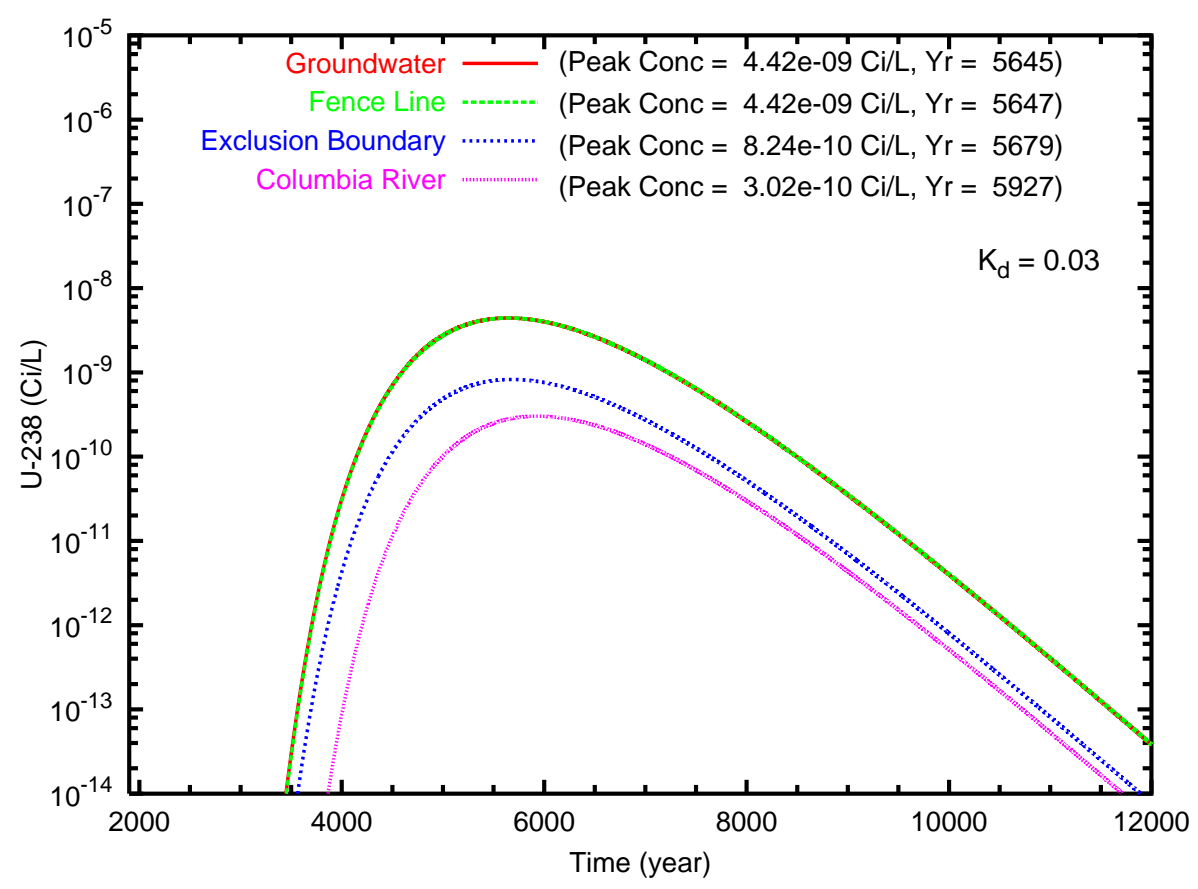

(b)

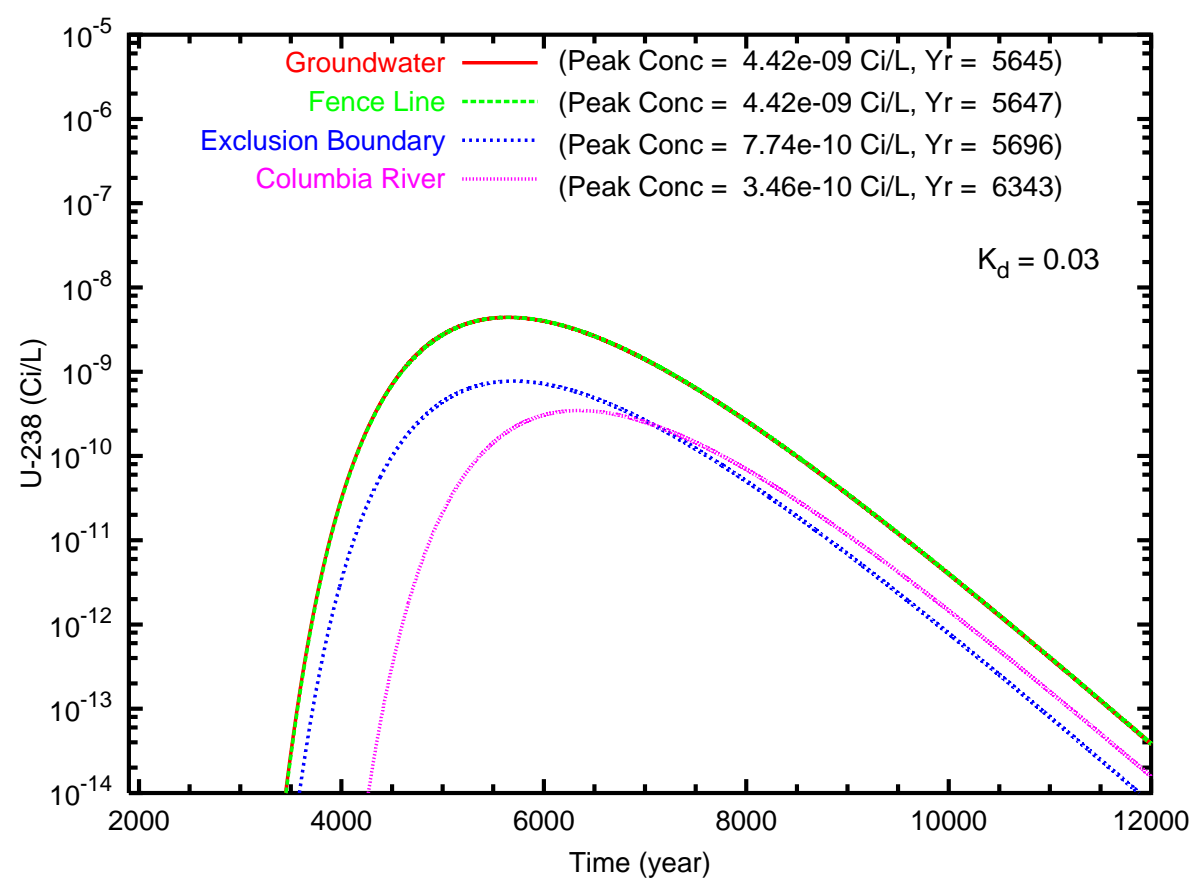

Figure B.142. Case 10-HiK, U-238 $\left(\mathrm{K}_{d}=0.03\right)$ concentration versus time for the fence line exclusion boundary and Columbia River compliance points for travel paths (a) southeast and (b) north through the gap 
(a)

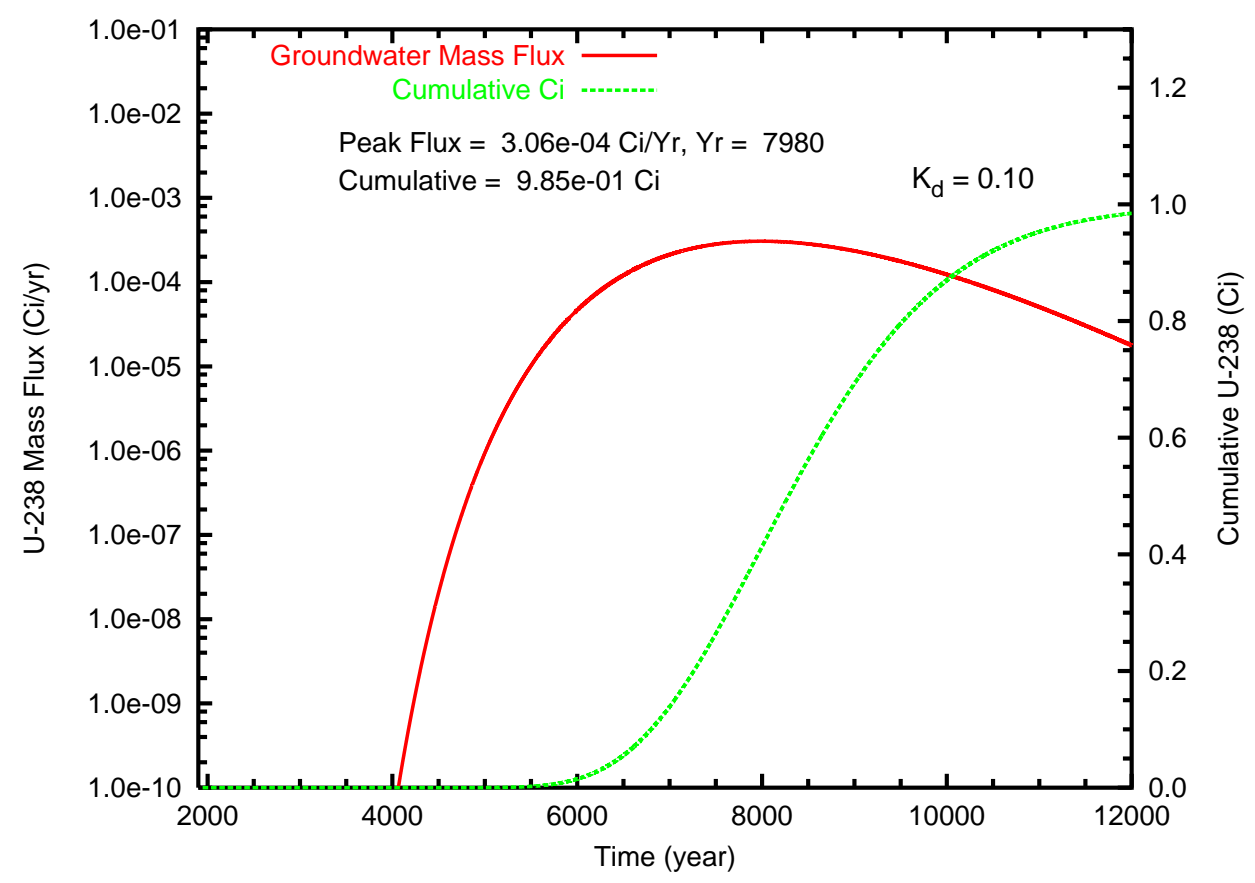

(b)

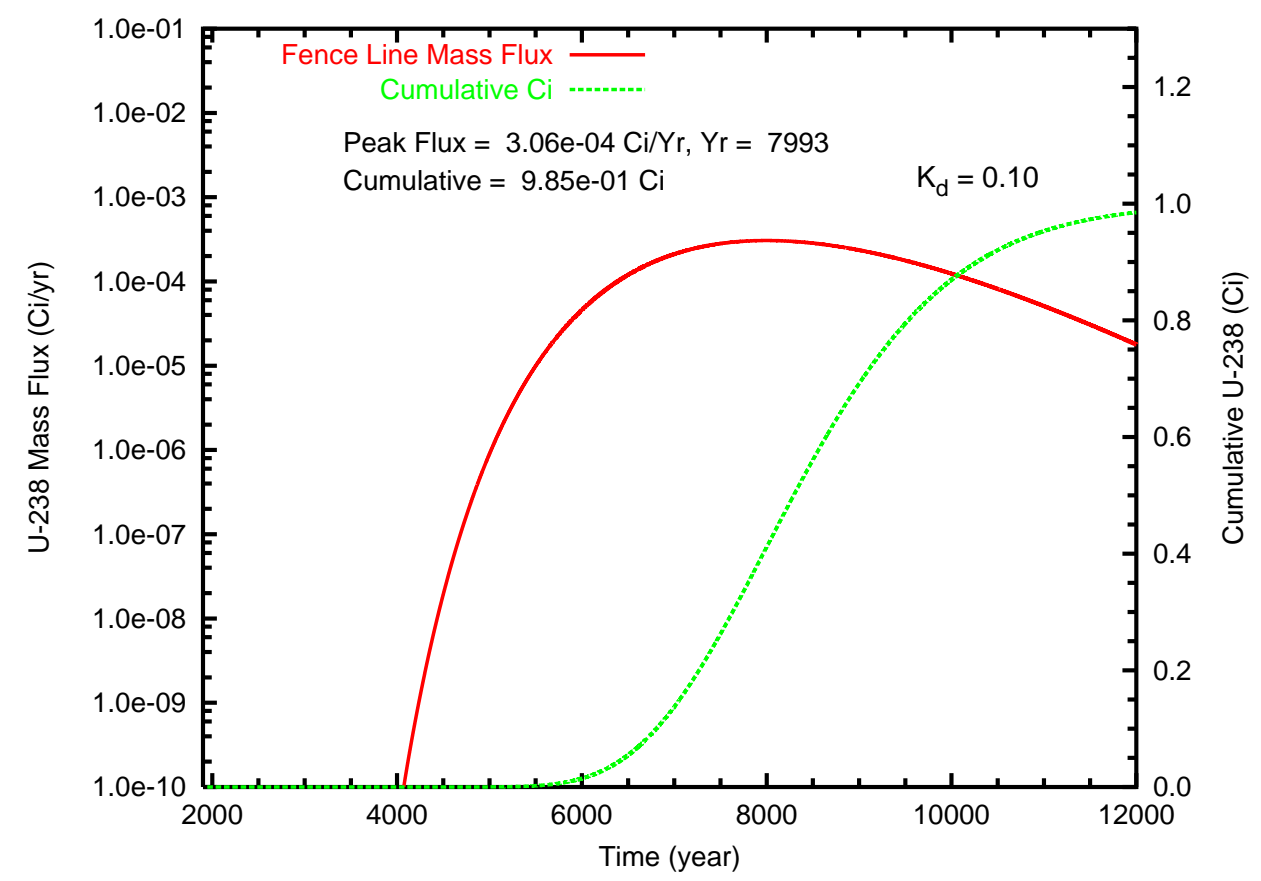

Figure B.143. Case 10-HiK, U-238 ( $\left.\mathrm{K}_{d}=0.10\right)$ mass flux $(\mathrm{Ci} / \mathrm{L})$ and cumulative mass $(\mathrm{Ci})$ at (a) the groundwater table and (b) the fence line 
(a)

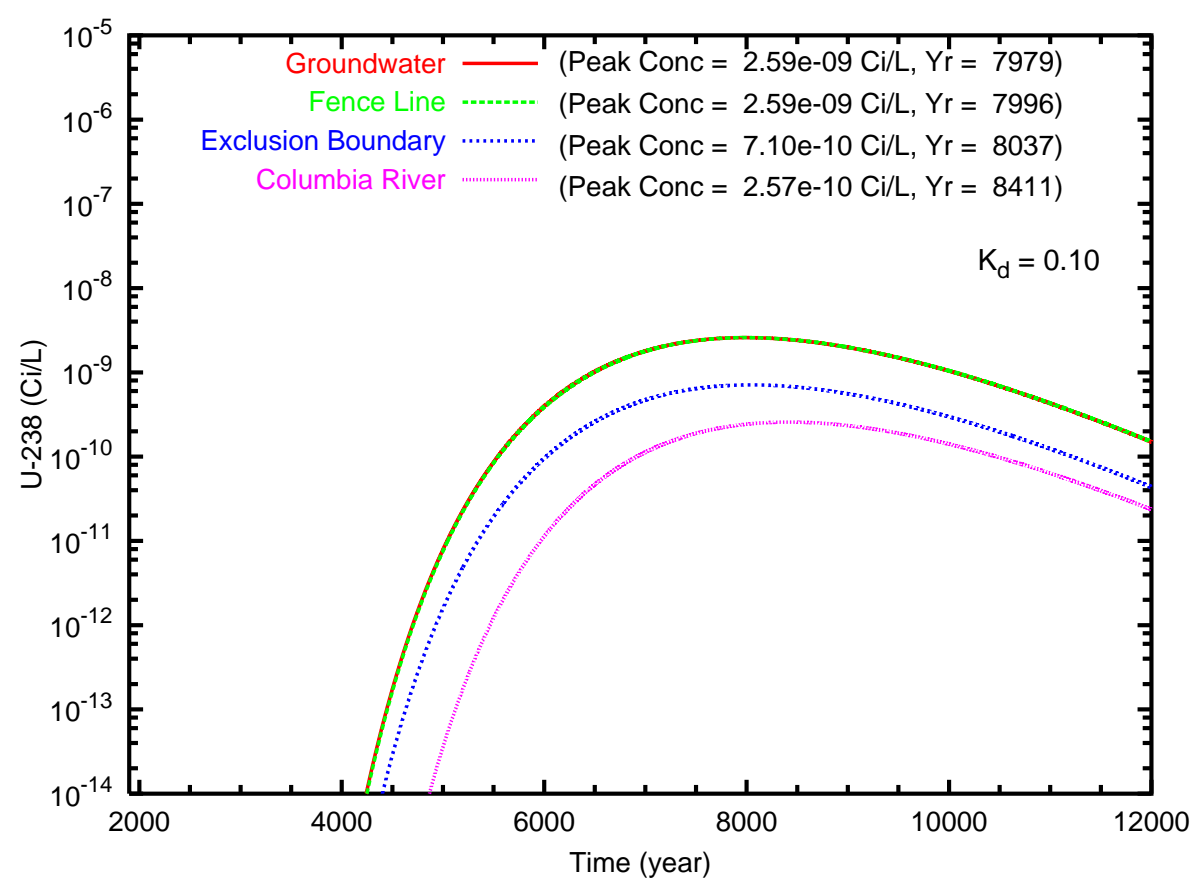

(b)

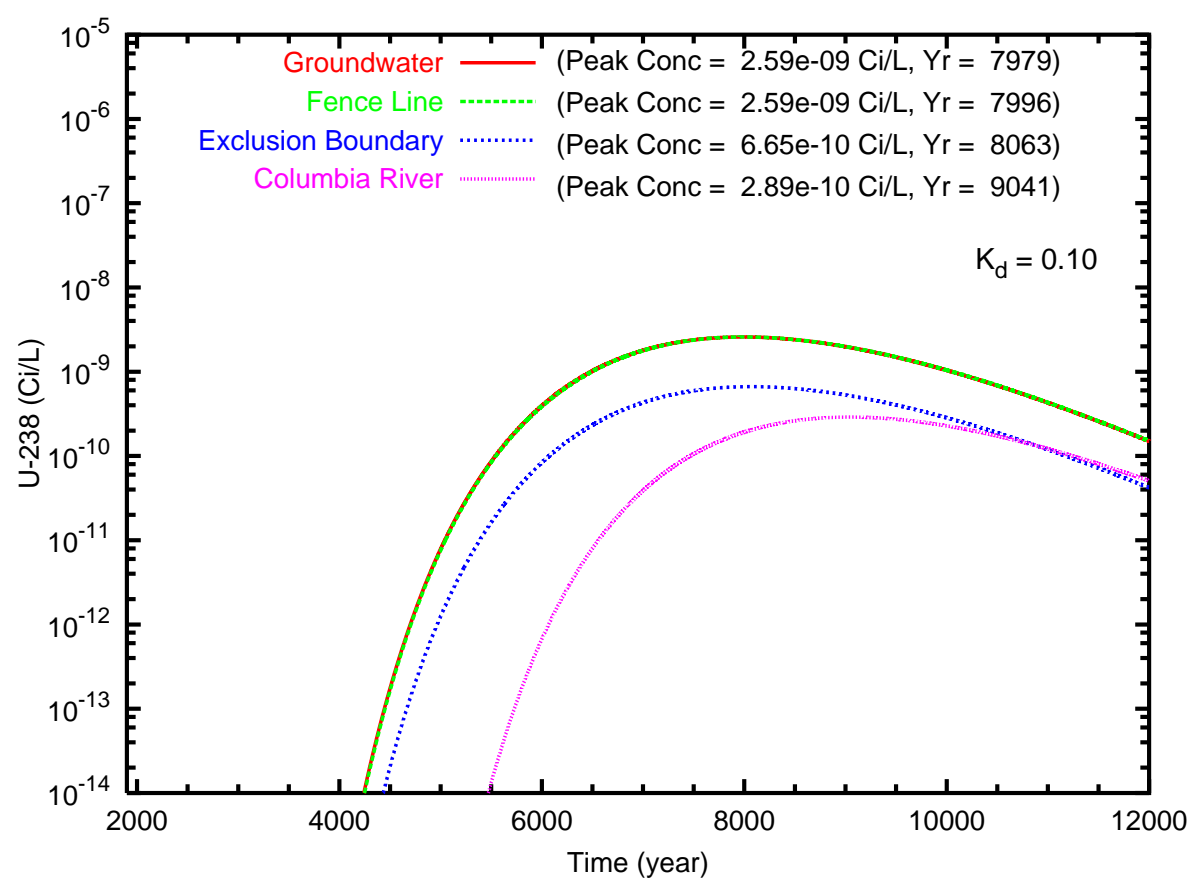

Figure B.144. Case 10-HiK, U-238 $\left(\mathrm{K}_{d}=0.10\right)$ concentration versus time for the fence line exclusion boundary and Columbia River compliance points for travel paths (a) southeast and (b) north through the gap 
(a)

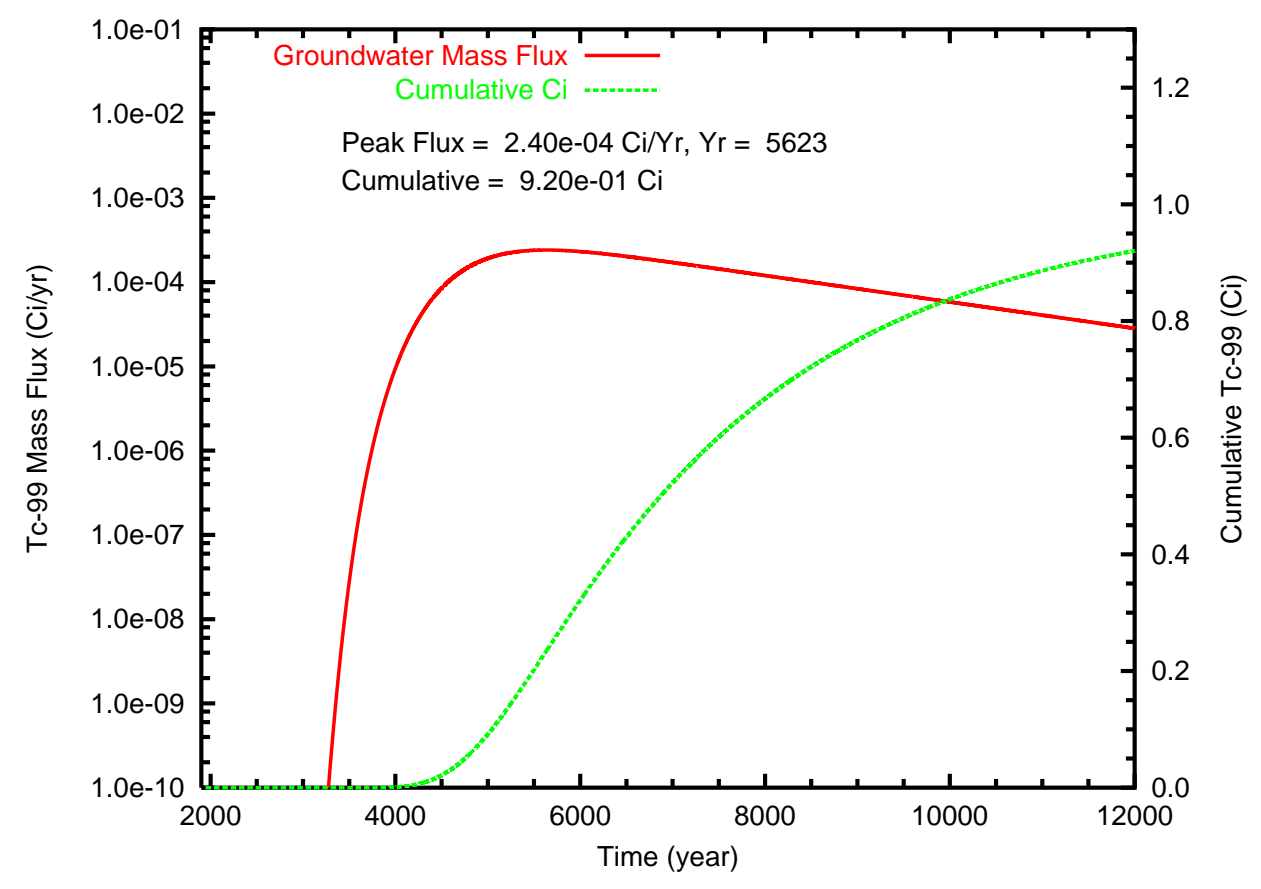

(b)

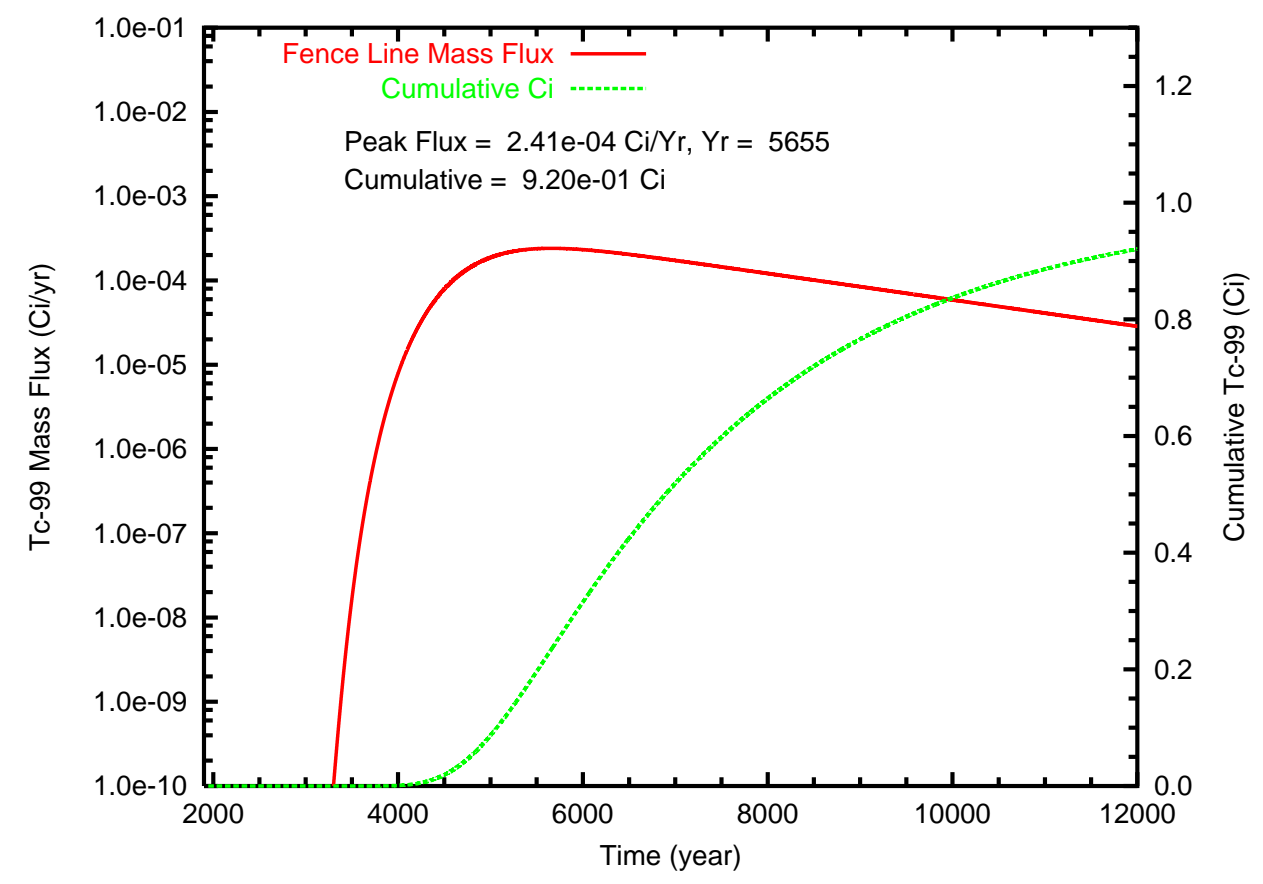

Figure B.145. Case 11, Tc-99 mass flux and cumulative mass at (a) the groundwater table and (b) the fence line 
(a)

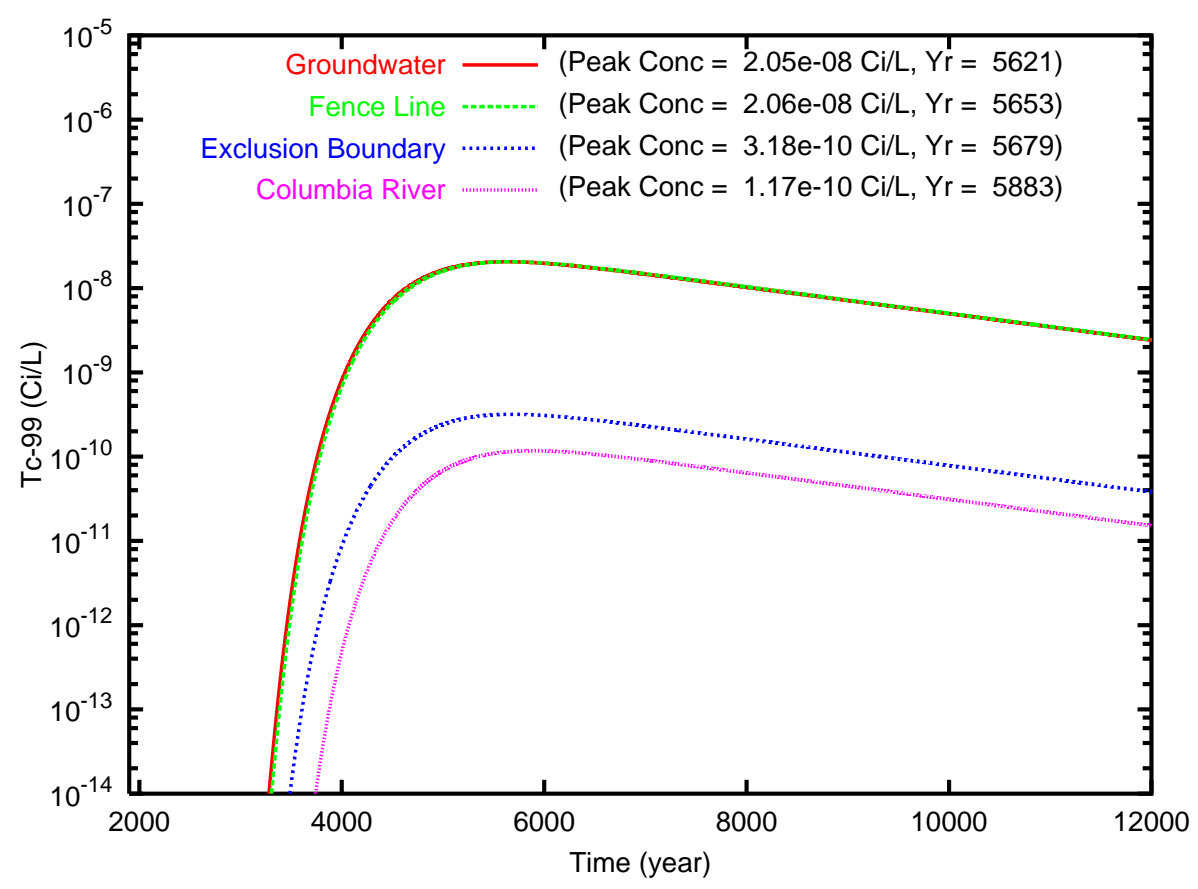

(b)

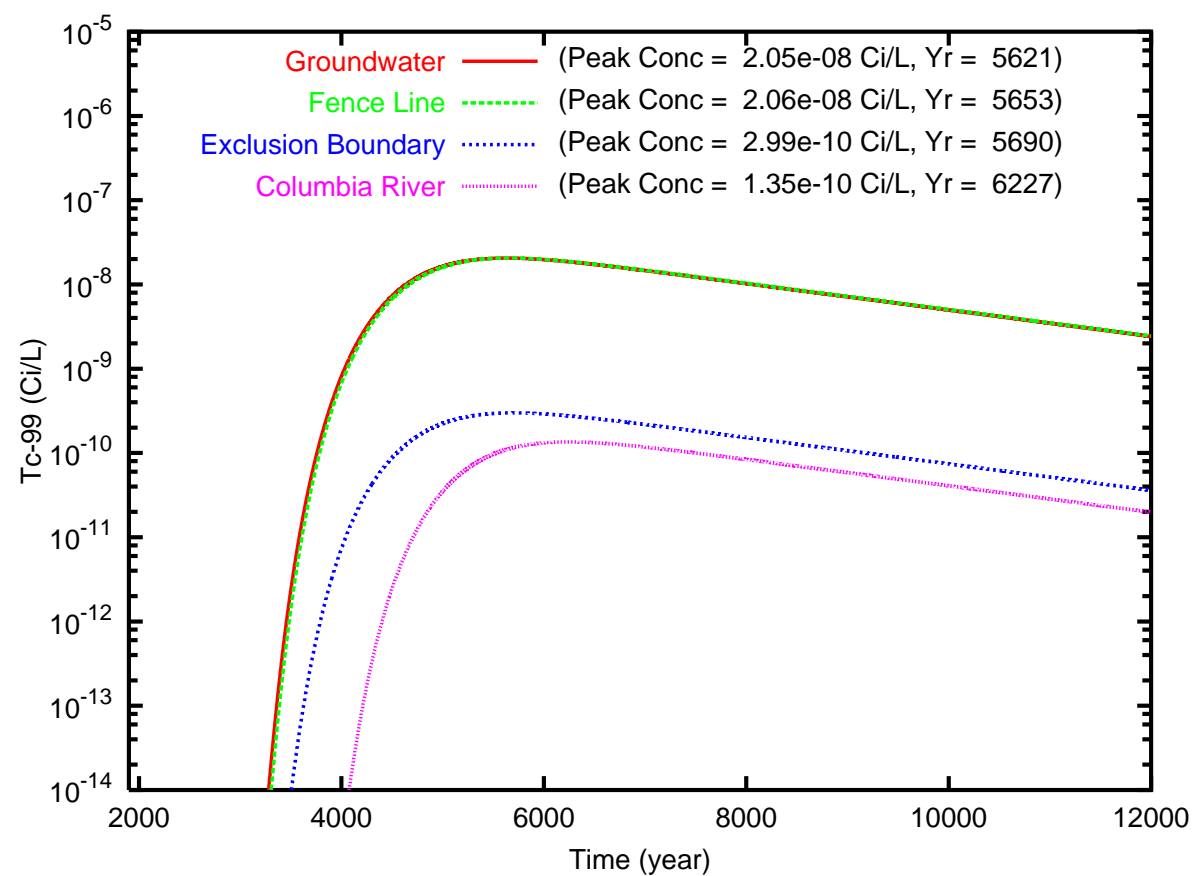

Figure B.146. Case 11, Tc-99 concentration versus time for the fence line, exclusion boundary and Columbia River compliance points for travel paths (a) southeast and (b) north through the gap 
(a)

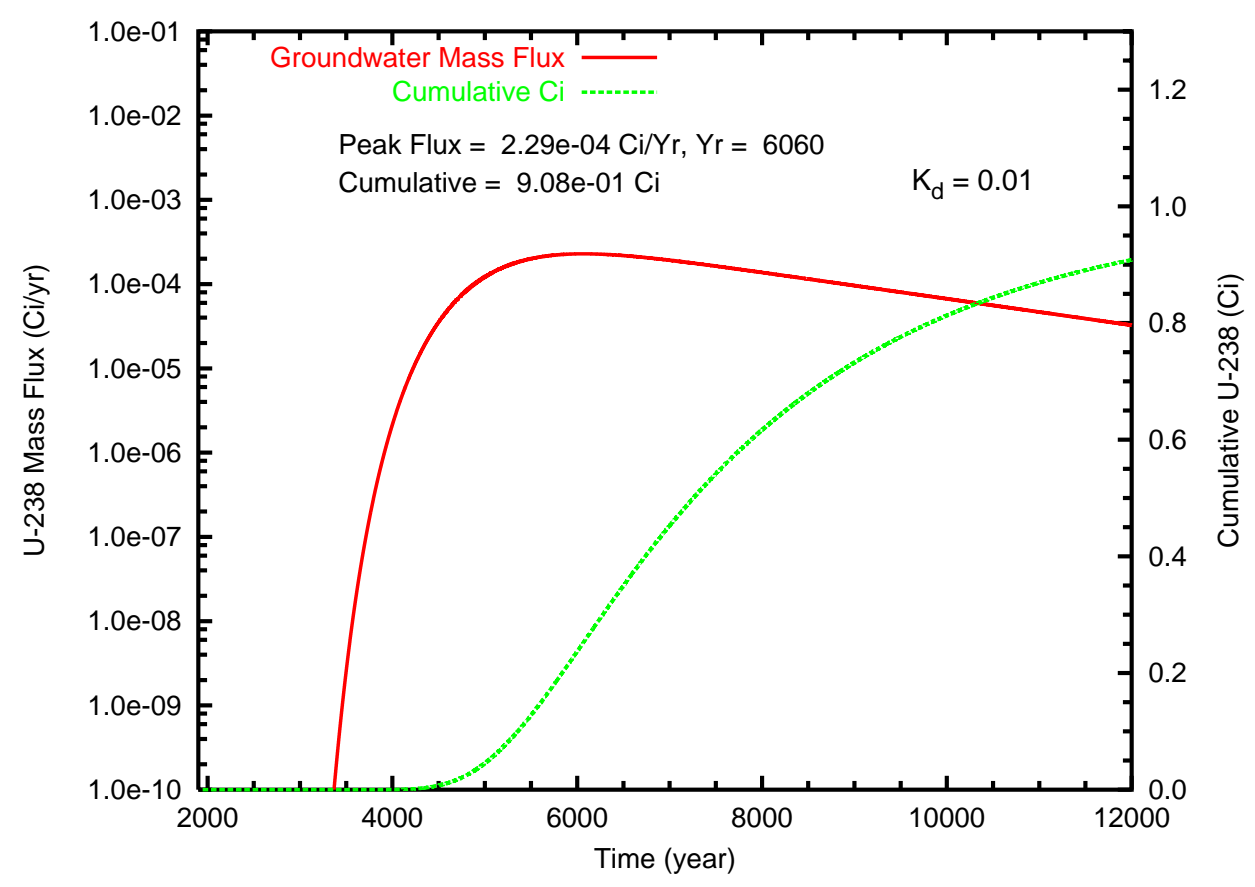

(b)

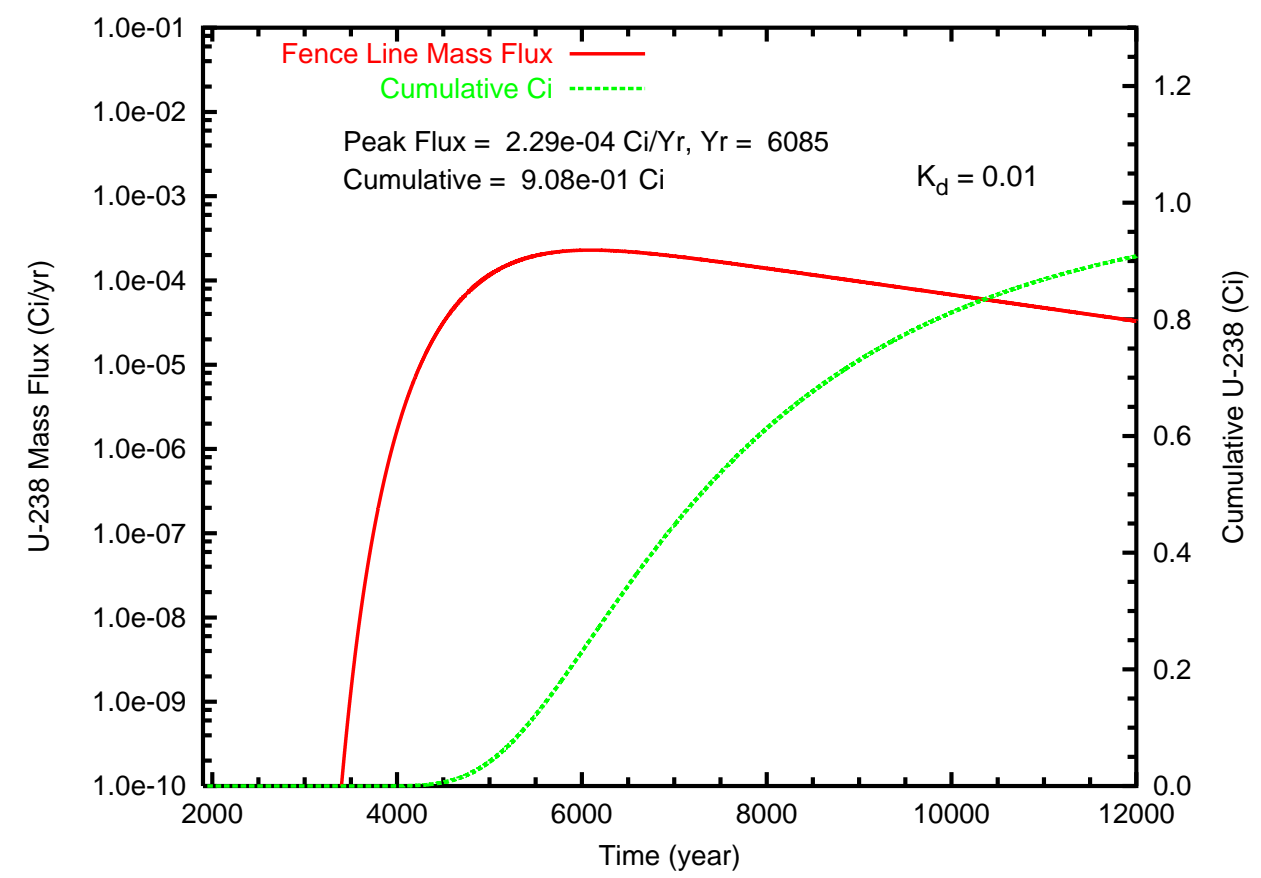

Figure B.147. Case 11, U-238 ( $\left.\mathrm{K}_{d}=0.01\right)$ mass flux $(\mathrm{Ci} / \mathrm{L})$ and cumulative mass $(\mathrm{Ci})$ at $(\mathrm{a})$ the groundwater table and (b) the fence line 
(a)

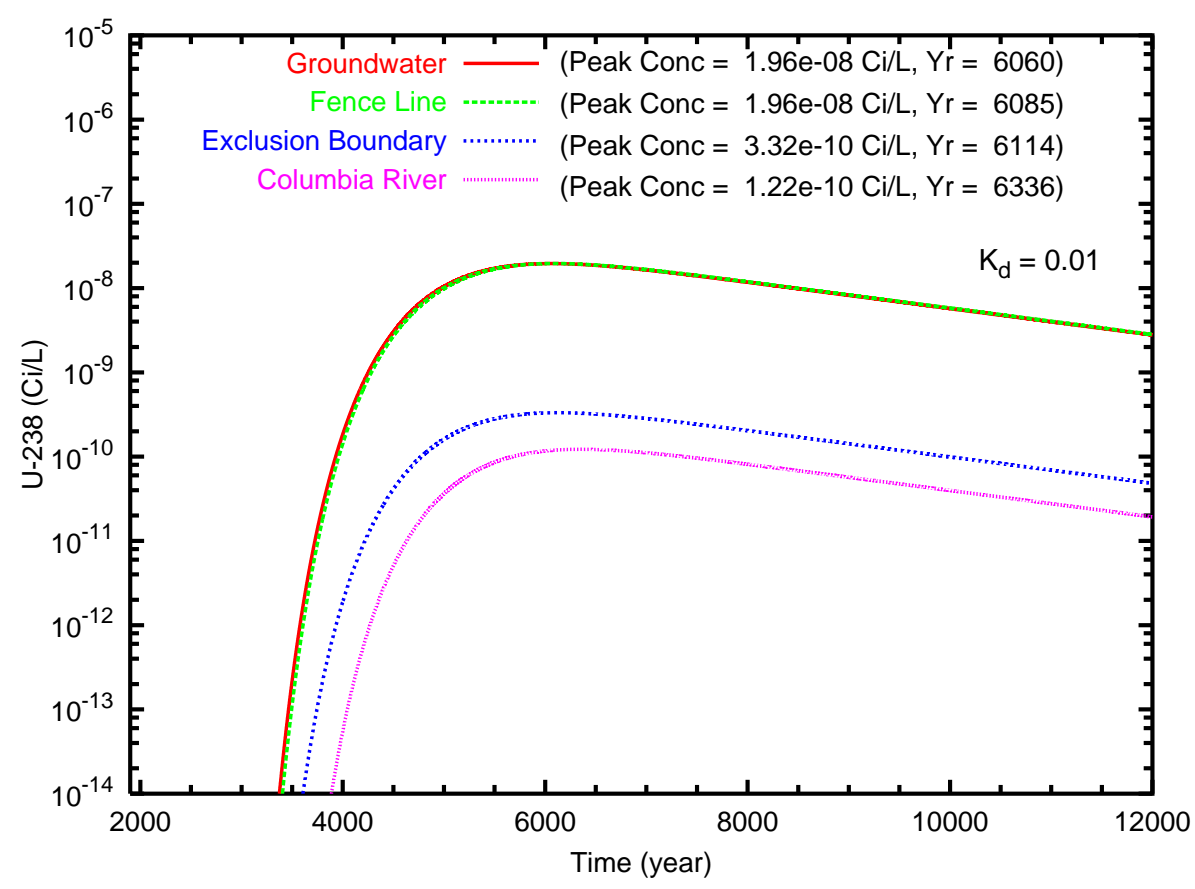

(b)

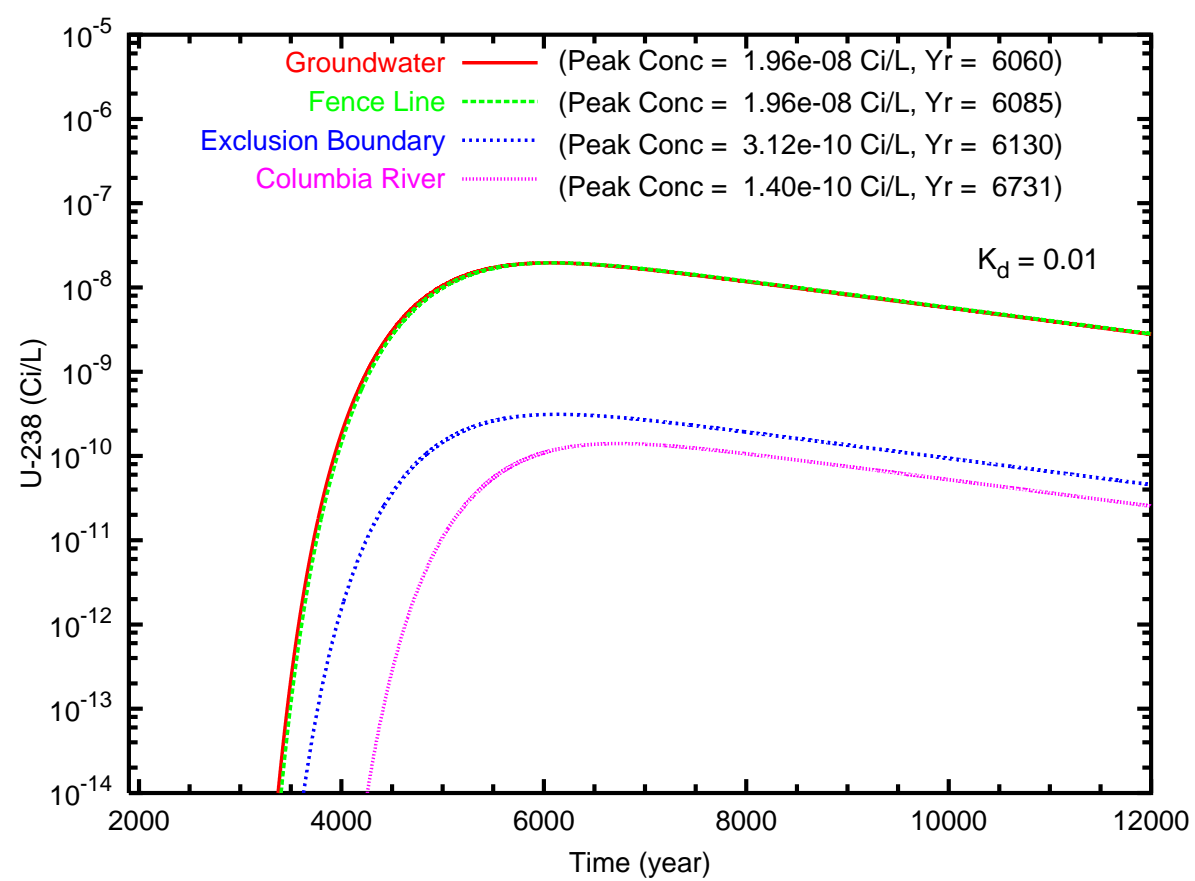

Figure B.148. Case $11, \mathrm{U}-238\left(\mathrm{~K}_{d}=0.01\right)$ concentration versus time for the fence line exclusion boundary and Columbia River compliance points for travel paths (a) southeast and (b) north through the gap 
(a)

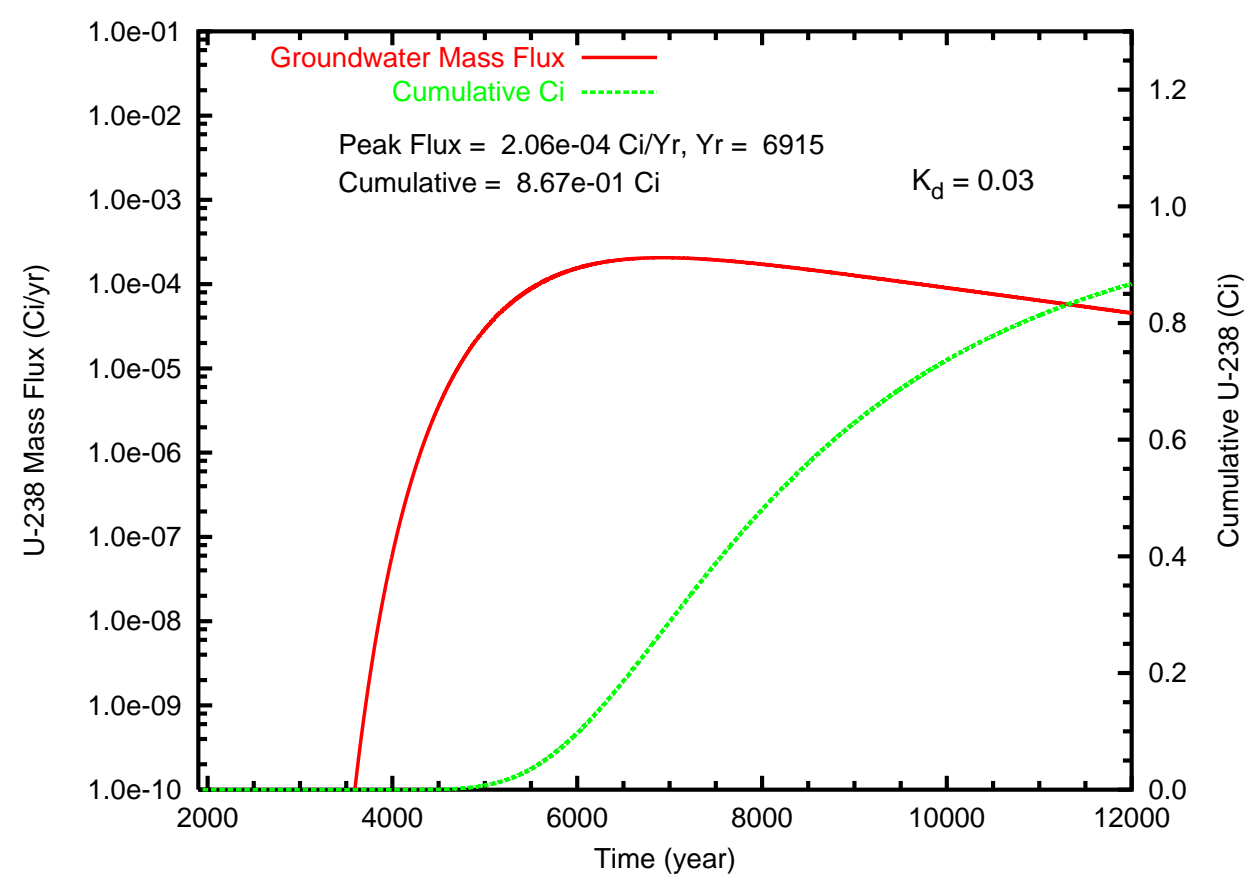

(b)

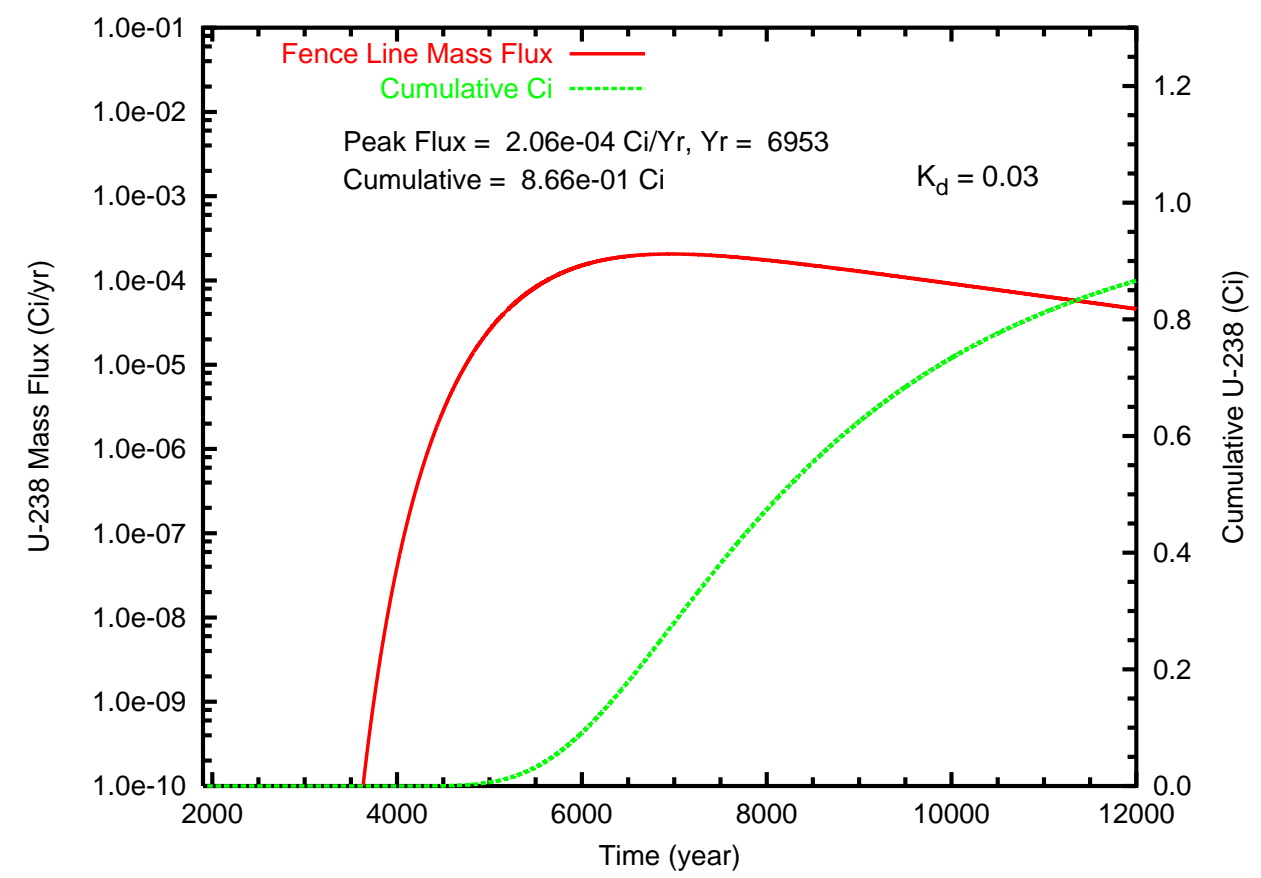

Figure B.149. Case 11, U-238 ( $\left.\mathrm{K}_{d}=0.03\right)$ mass flux $(\mathrm{Ci} / \mathrm{L})$ and cumulative mass $(\mathrm{Ci})$ at $(\mathrm{a})$ the groundwater table and (b) the fence line 
(a)

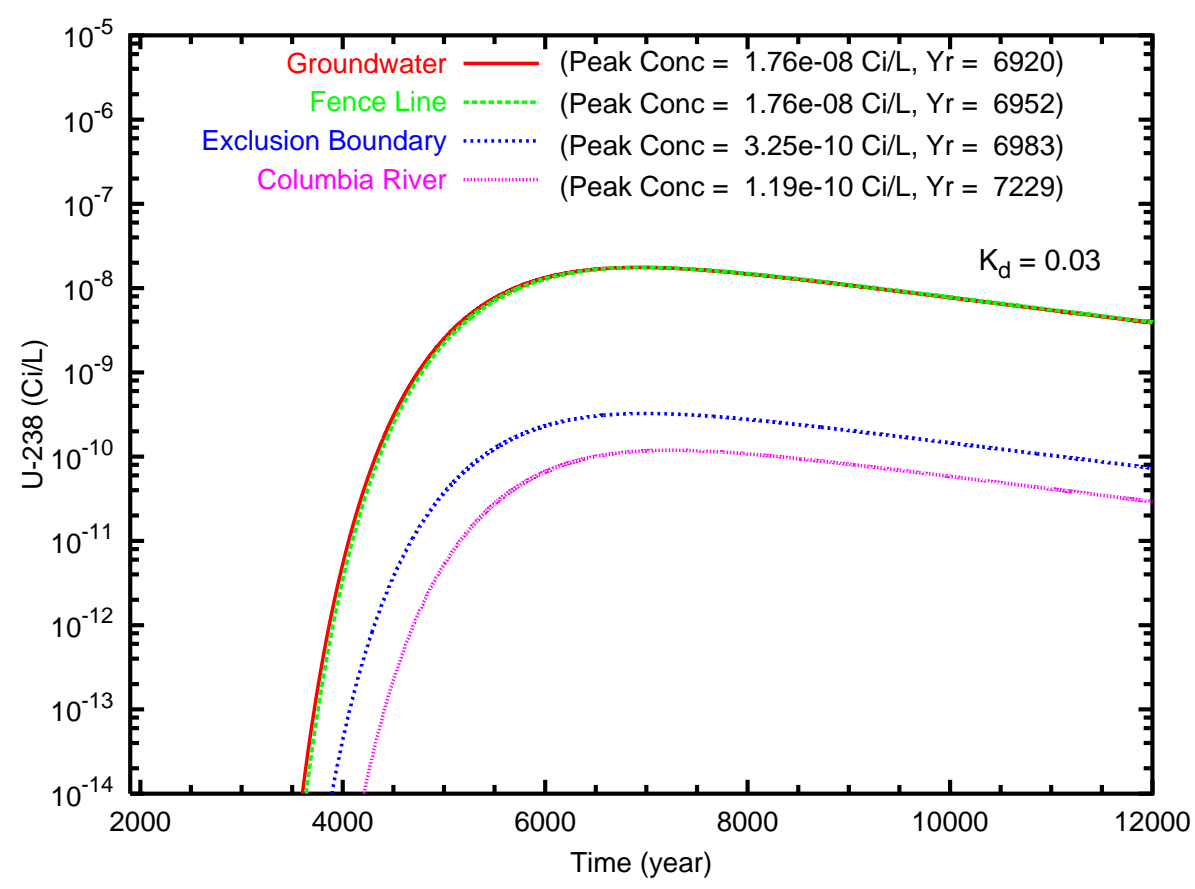

(b)

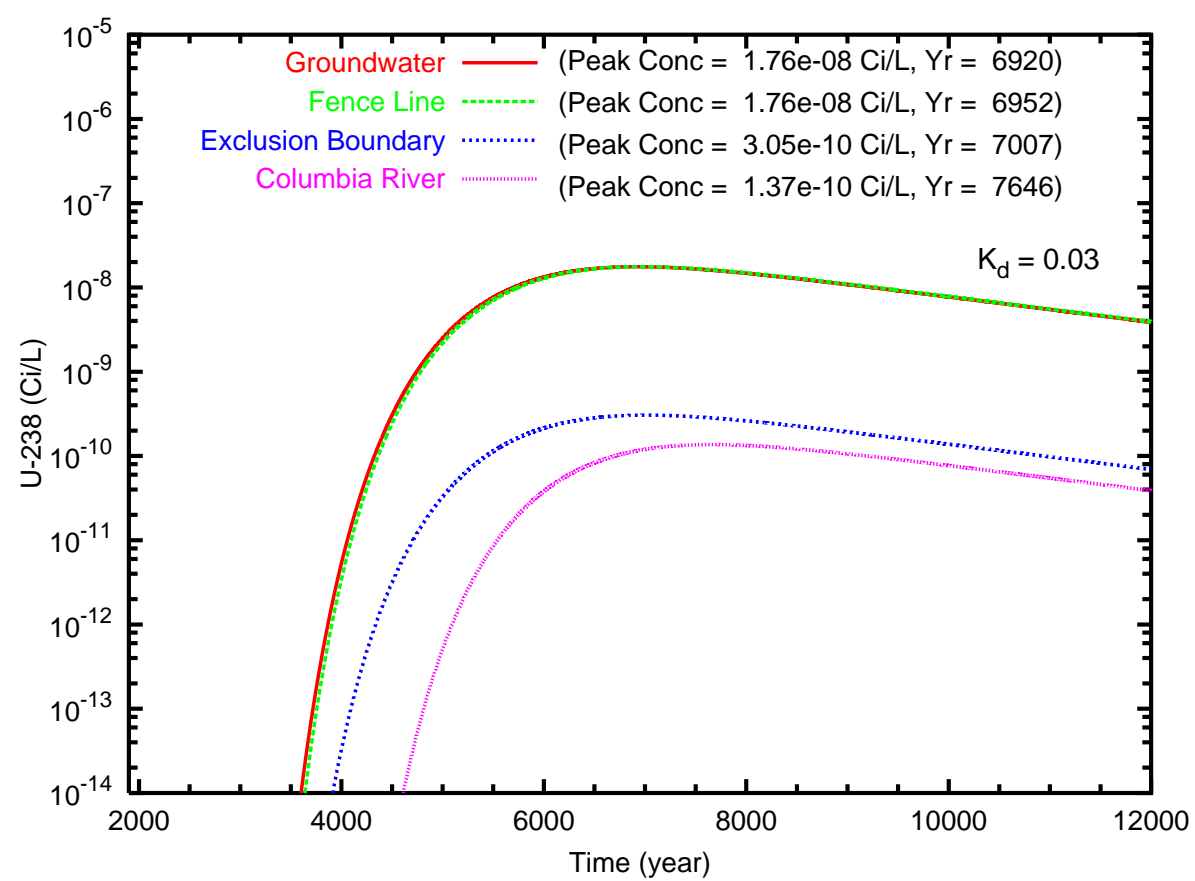

Figure B.150. Case 11, U-238 $\left(\mathrm{K}_{d}=0.03\right)$ concentration versus time for the fence line exclusion boundary and Columbia River compliance points for travel paths (a) southeast and (b) north through the gap 
(a)

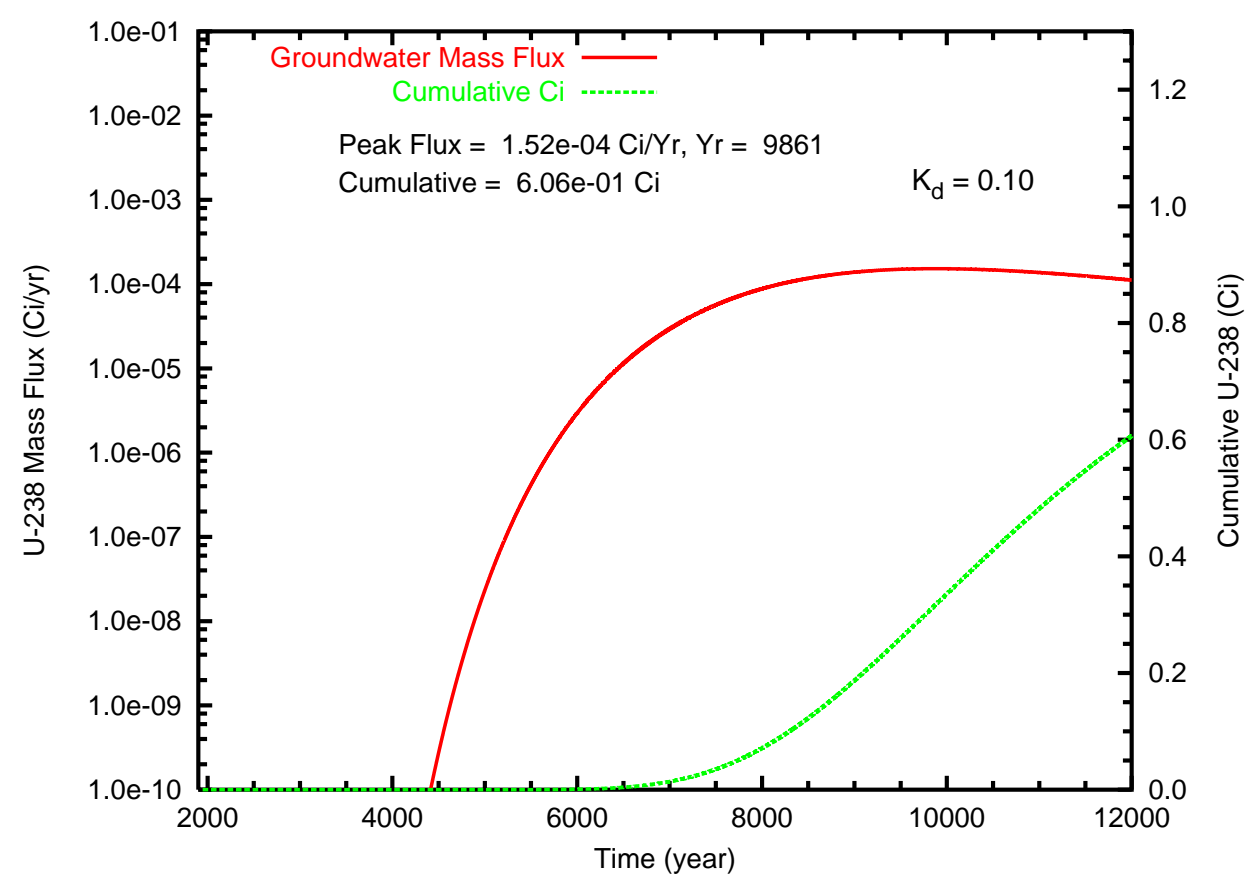

(b)

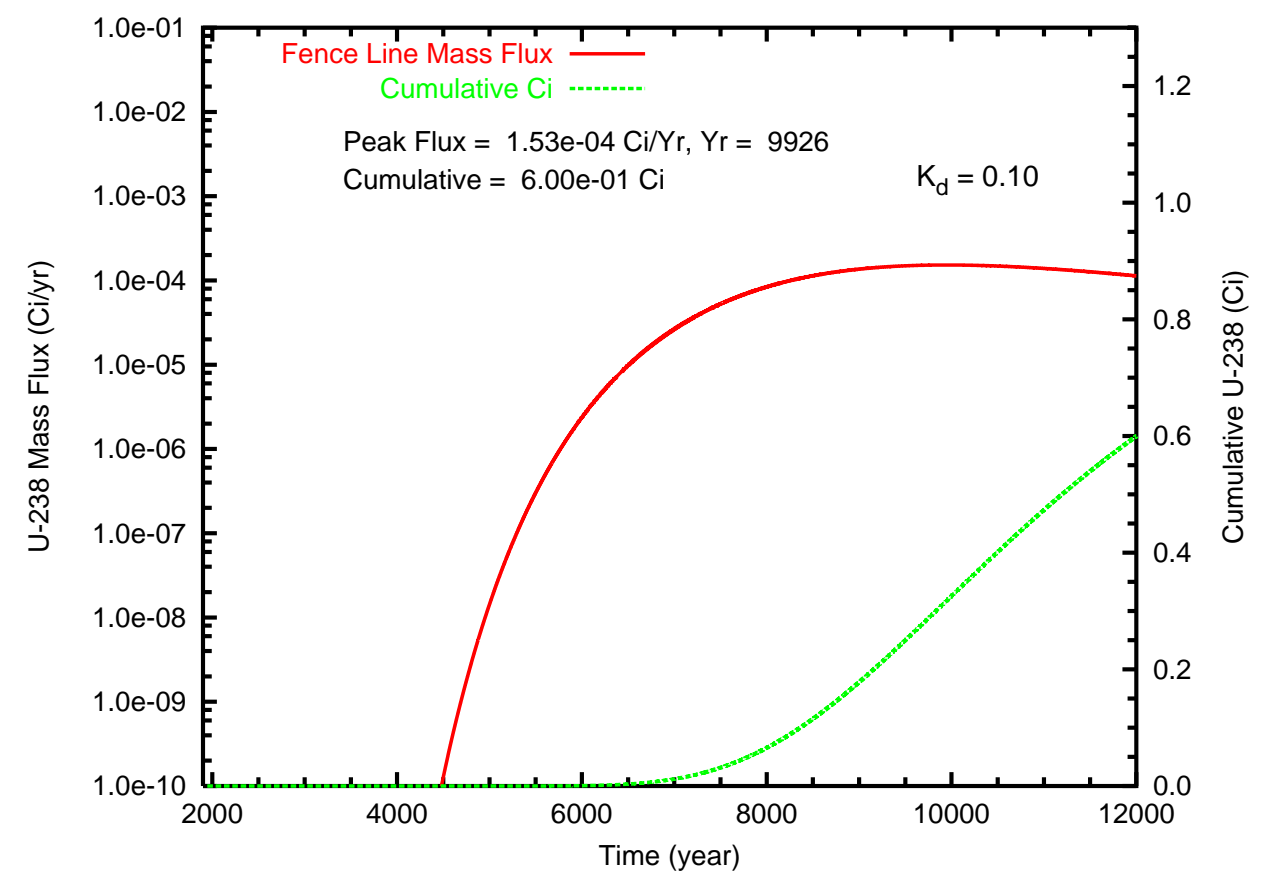

Figure B.151. Case $11, \mathrm{U}-238\left(\mathrm{~K}_{d}=0.10\right)$ mass flux $(\mathrm{Ci} / \mathrm{L})$ and cumulative mass $(\mathrm{Ci})$ at (a) the groundwater table and (b) the fence line 
(a)

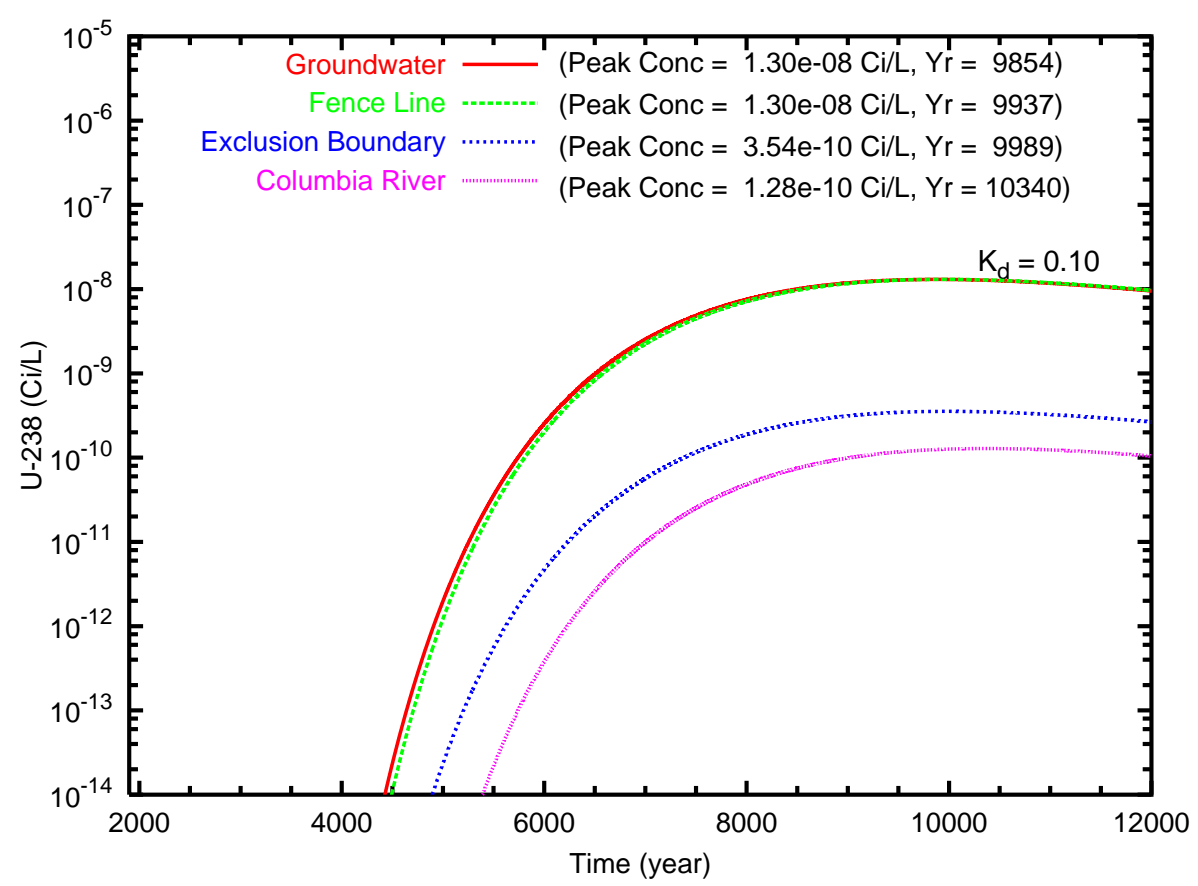

(b)

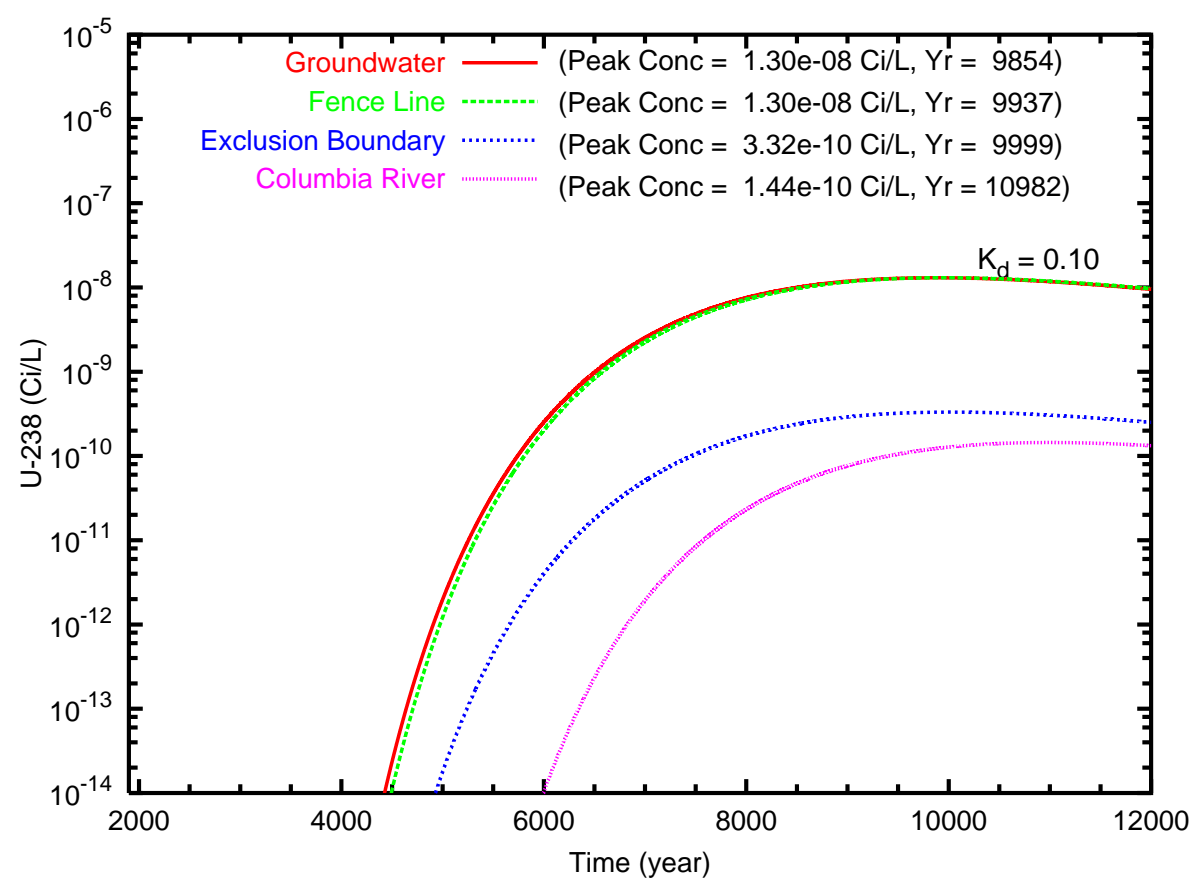

Figure B.152. Case $11, \mathrm{U}-238\left(\mathrm{~K}_{d}=0.10\right)$ concentration versus time for the fence line exclusion boundary and Columbia River compliance points for travel paths (a) southeast and (b) north through the gap 
(a)

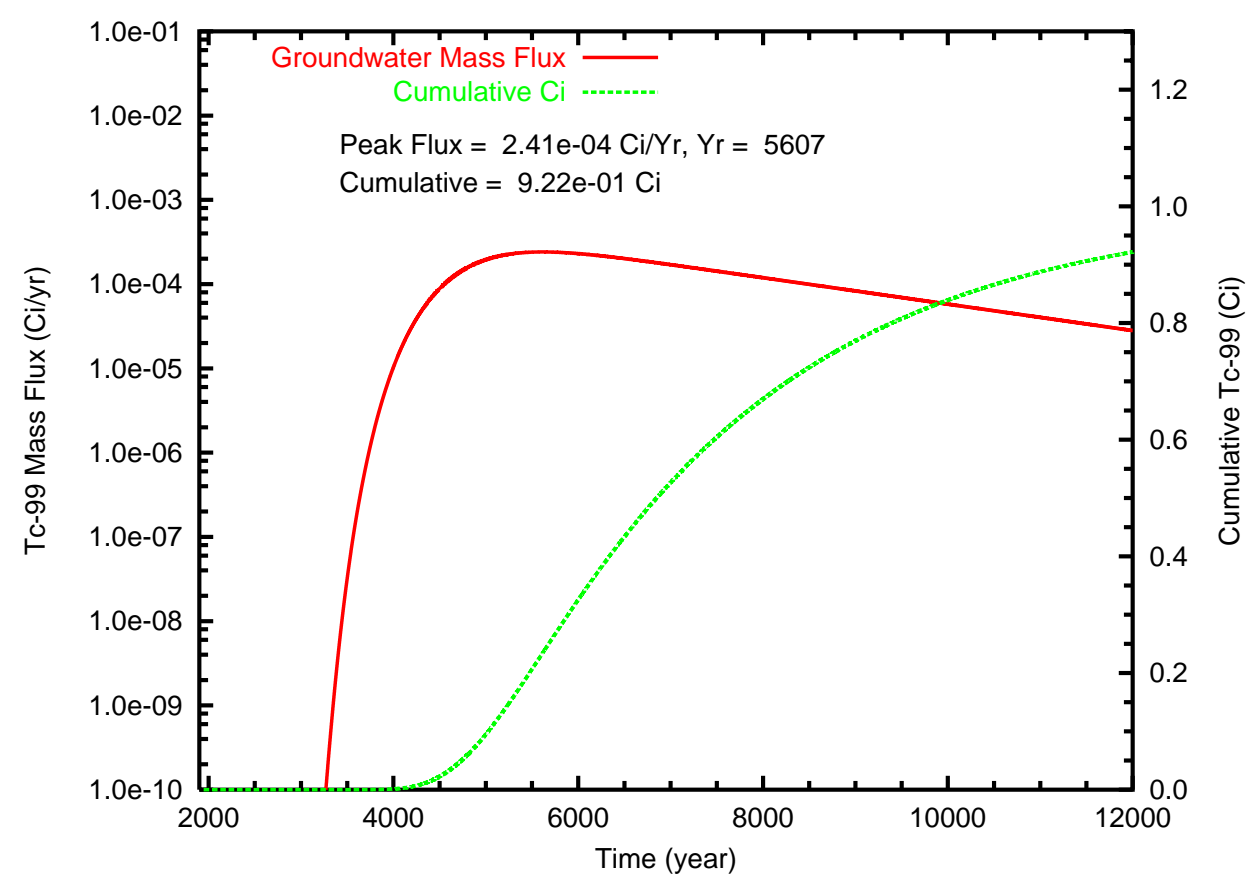

(b)

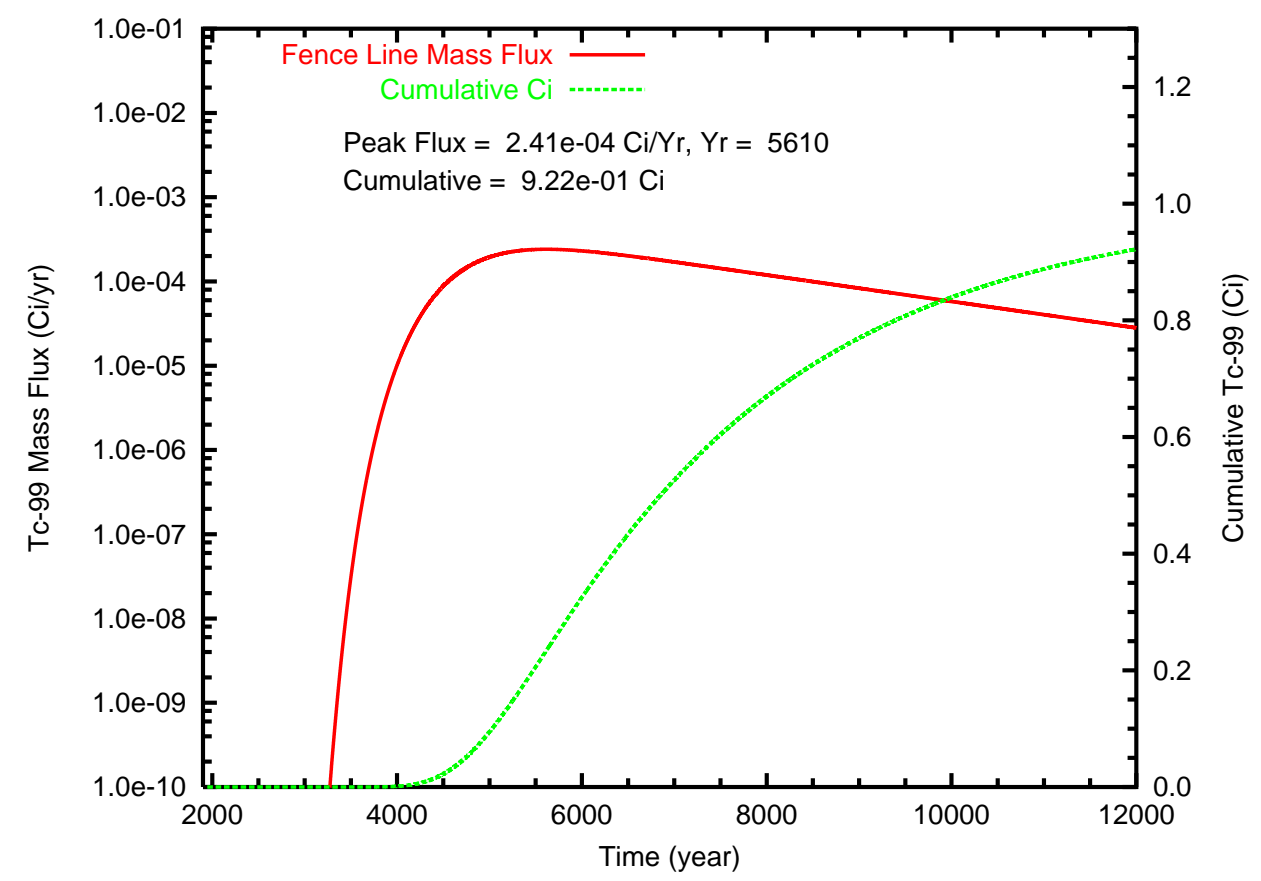

Figure B.153. Case 11-HiK, Tc-99 mass flux and cumulative mass at (a) the groundwater table and (b) the fence line 
(a)

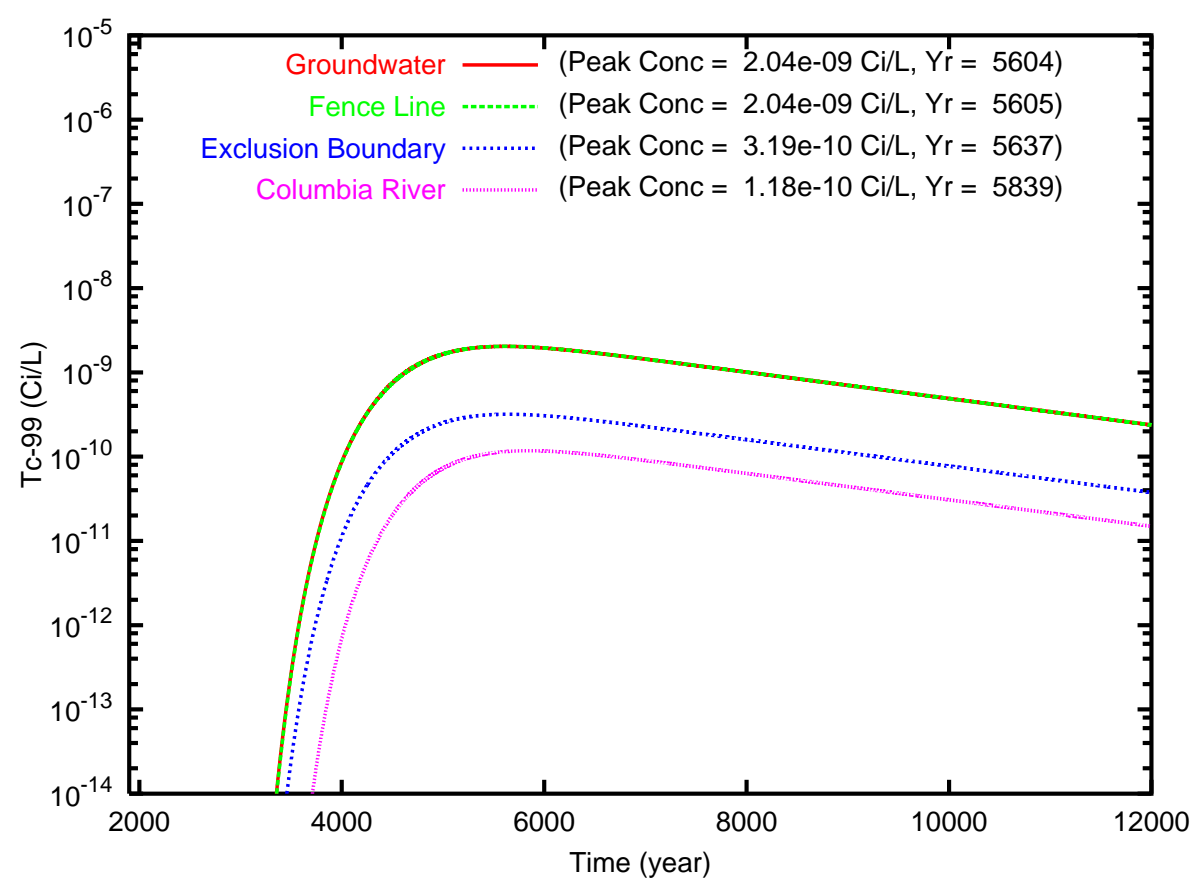

(b)

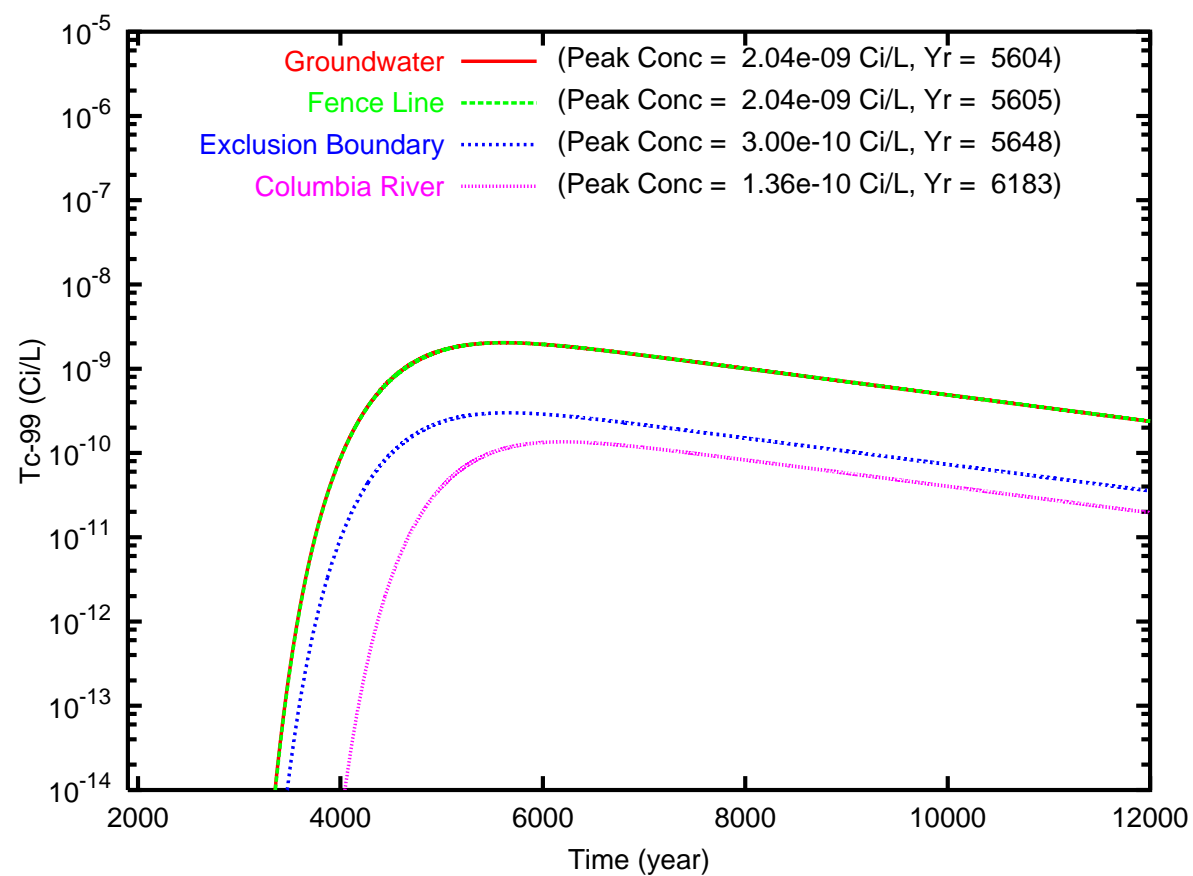

Figure B.154. Case 11-HiK, Tc-99 concentration versus time for the fence line, exclusion boundary and Columbia River compliance points for travel paths (a) southeast and (b) north through the gap 
(a)

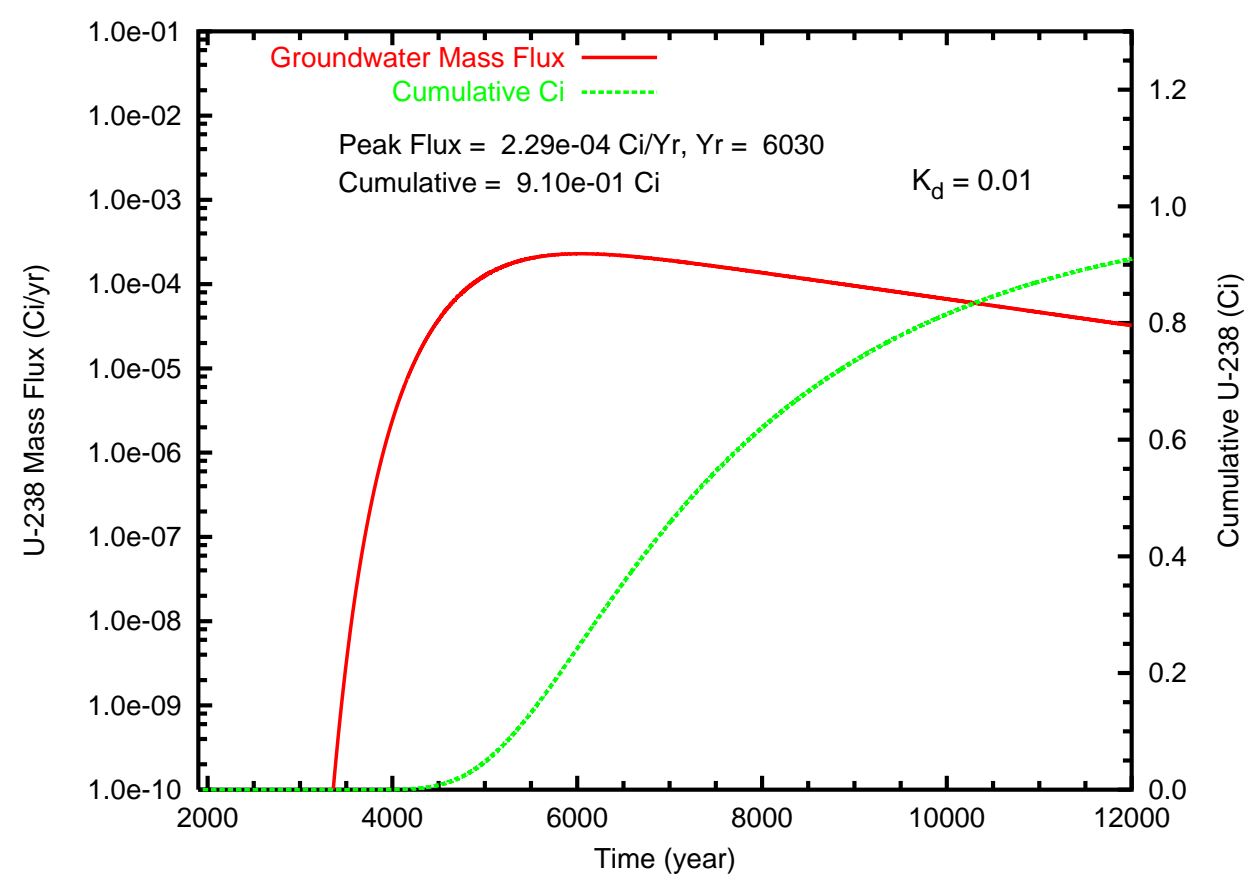

(b)

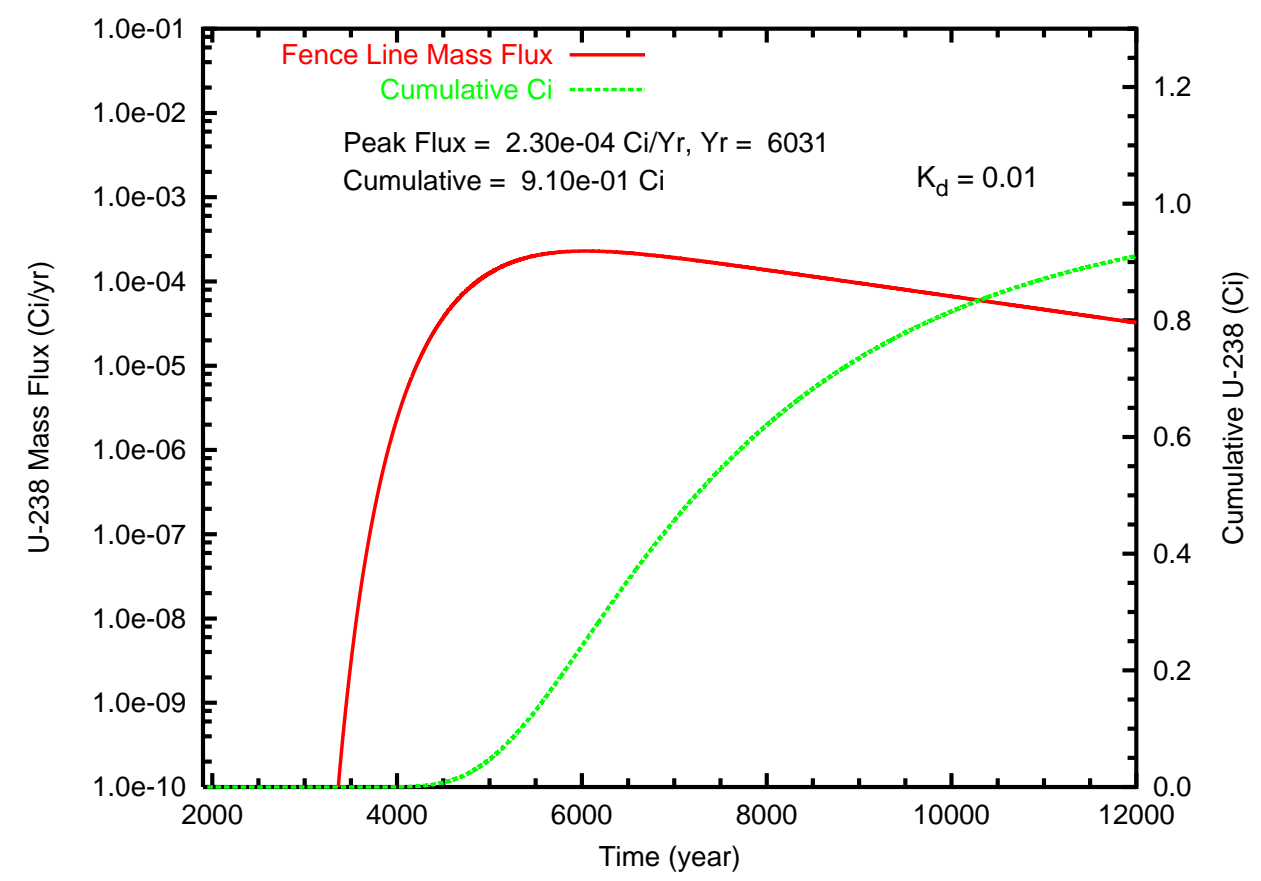

Figure B.155. Case 11-HiK, U-238 ( $\left.\mathrm{K}_{d}=0.01\right)$ mass flux $(\mathrm{Ci} / \mathrm{L})$ and cumulative mass $(\mathrm{Ci})$ at (a) the groundwater table and (b) the fence line 
(a)

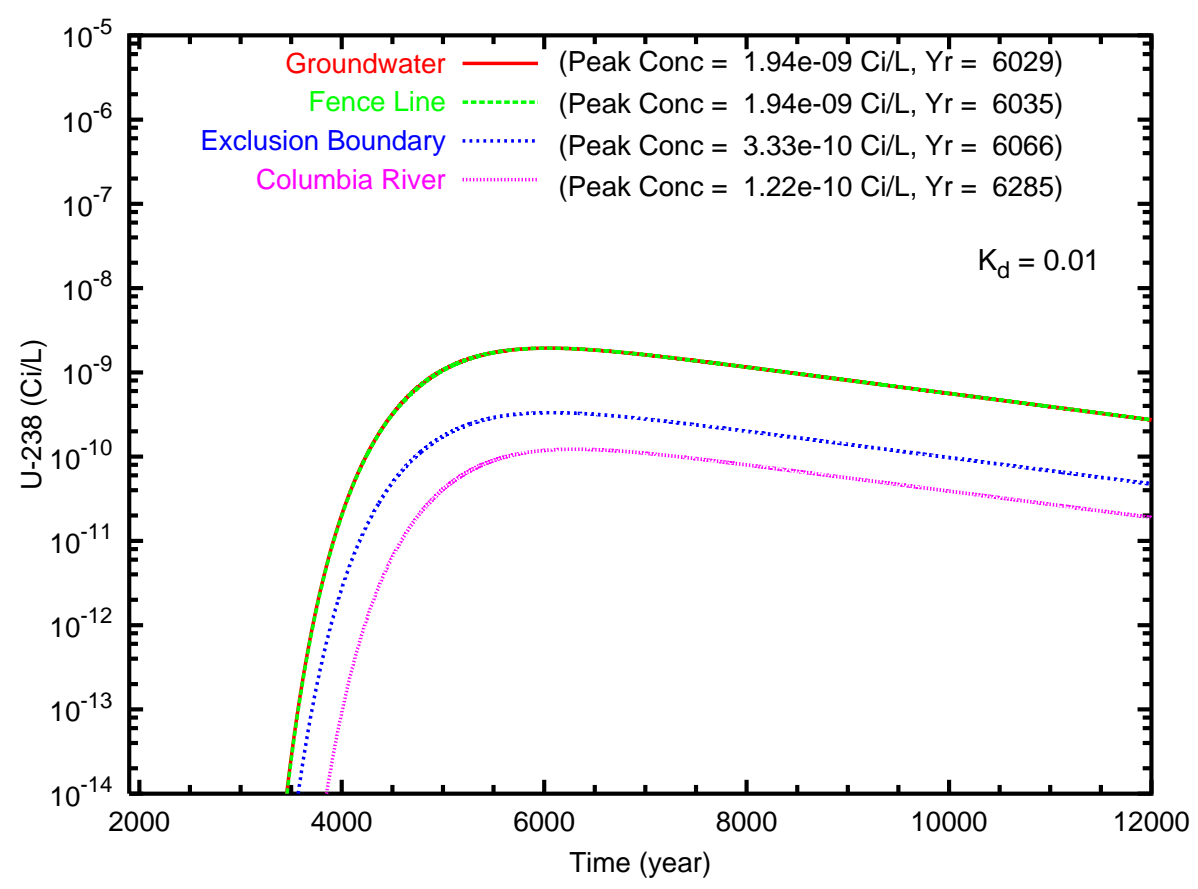

(b)

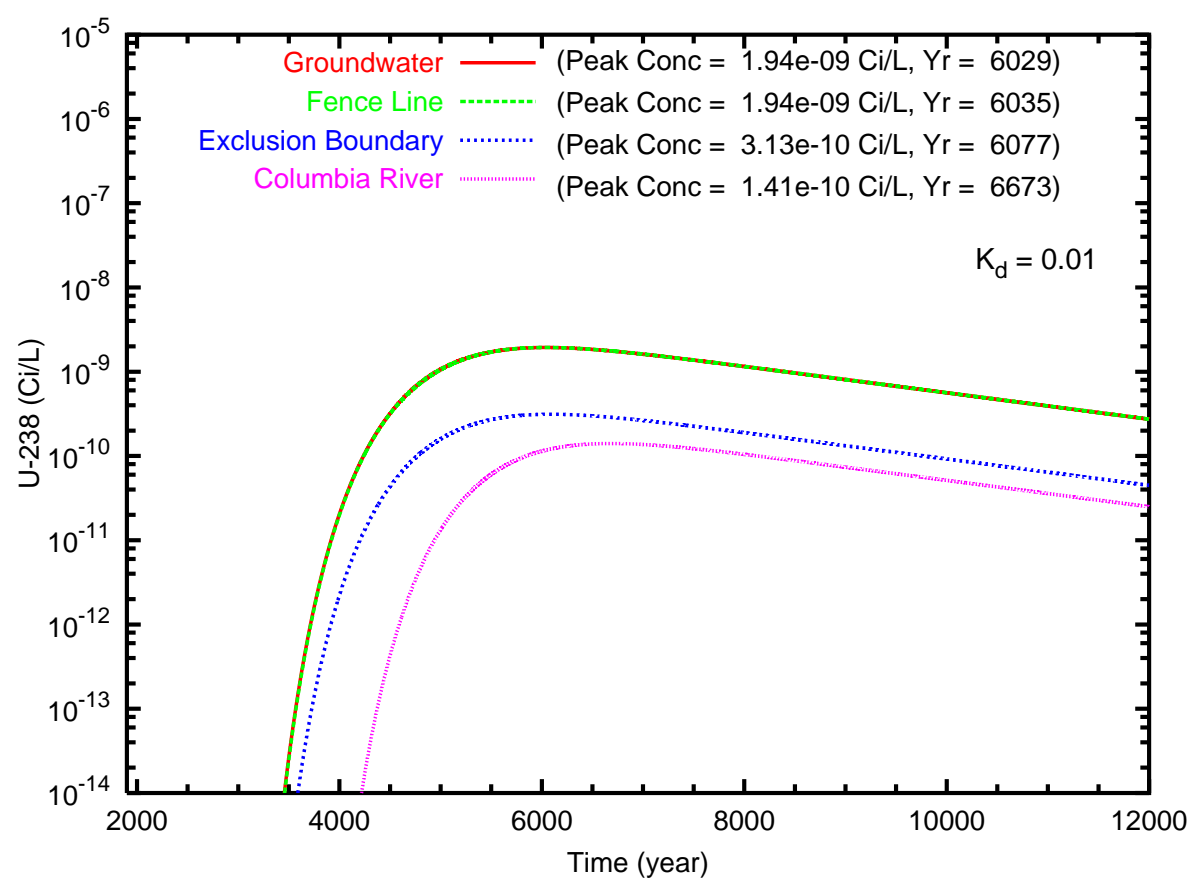

Figure B.156. Case 11-HiK, U-238 $\left(\mathrm{K}_{d}=0.01\right)$ concentration versus time for the fence line exclusion boundary and Columbia River compliance points for travel paths (a) southeast and (b) north through the gap 
(a)

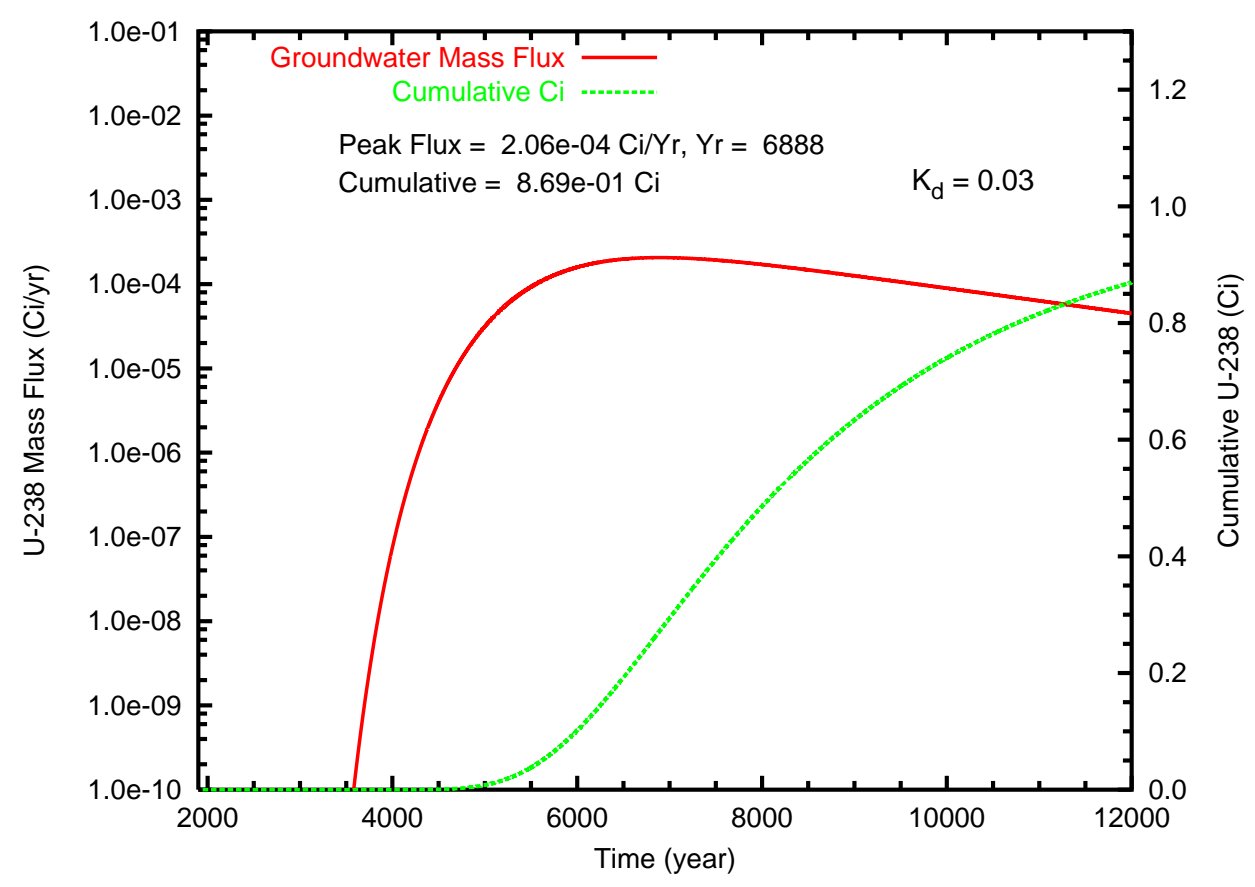

(b)

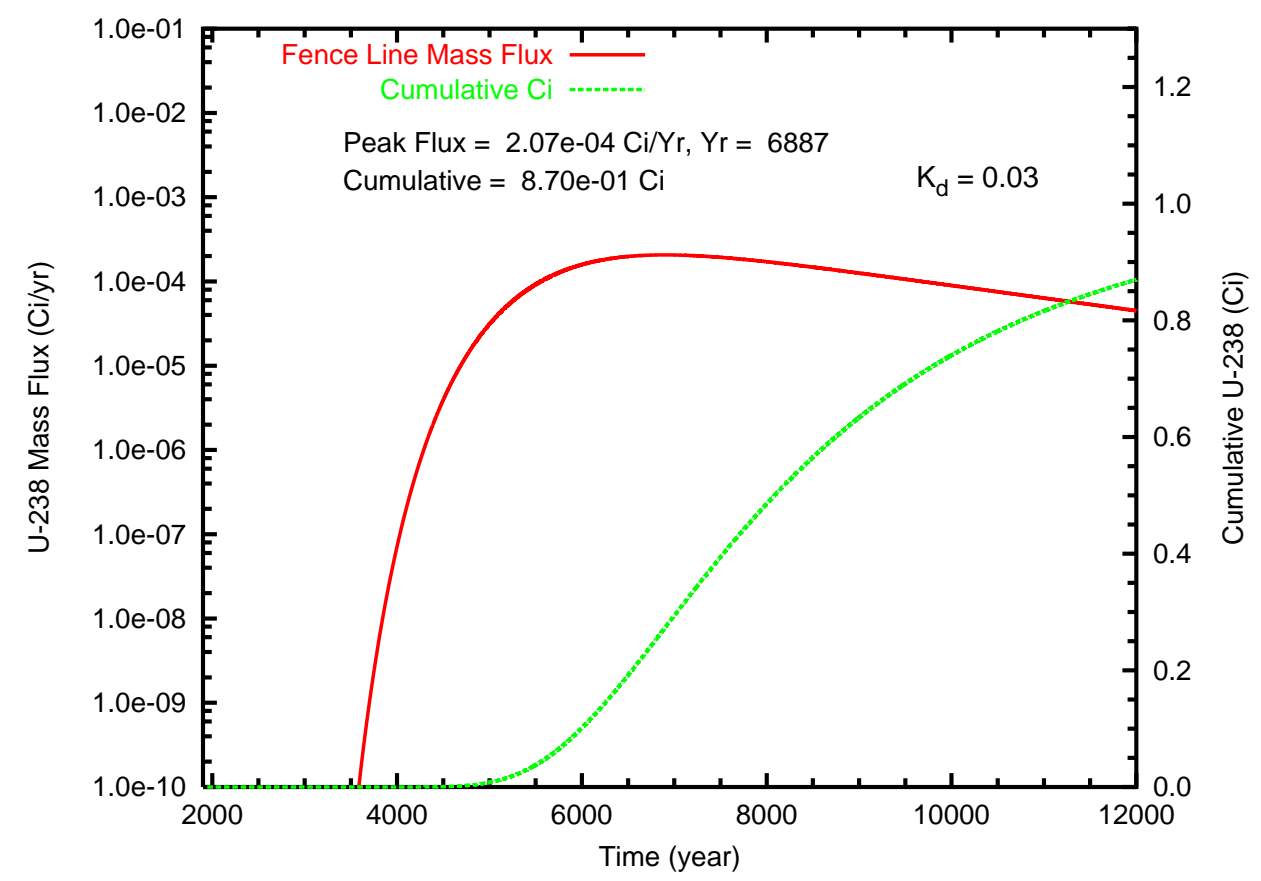

Figure B.157. Case 11-HiK, U-238 ( $\left.\mathrm{K}_{d}=0.03\right)$ mass flux $(\mathrm{Ci} / \mathrm{L})$ and cumulative mass $(\mathrm{Ci})$ at (a) the groundwater table and (b) the fence line 
(a)

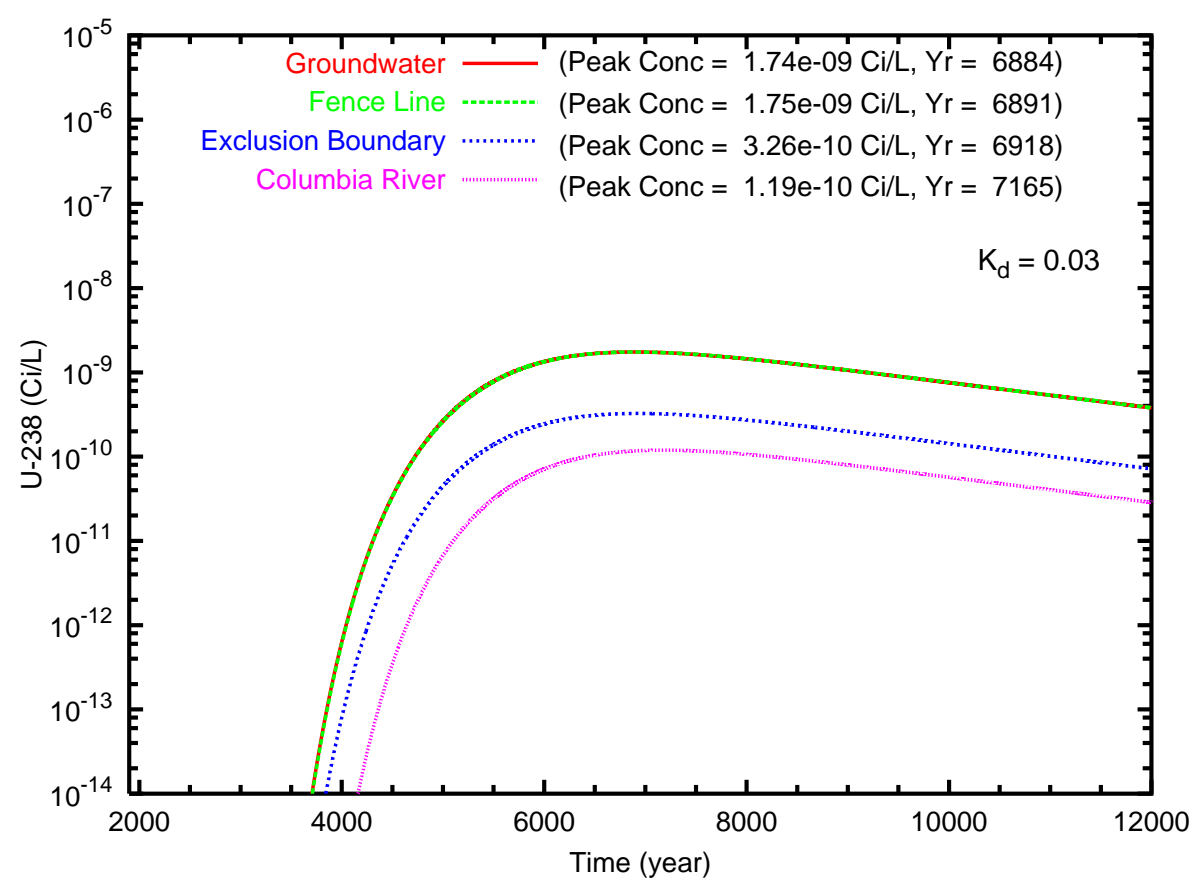

(b)

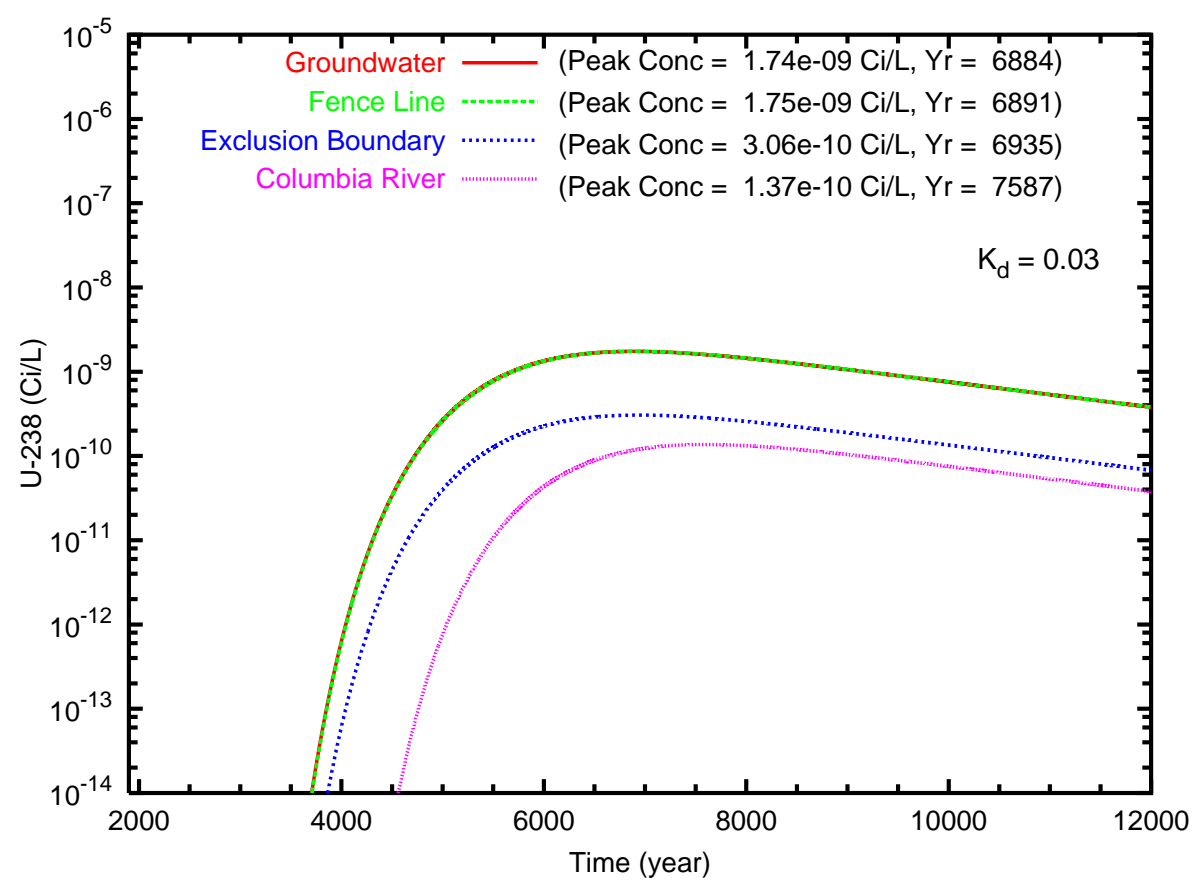

Figure B.158. Case 11-HiK, U-238 $\left(\mathrm{K}_{d}=0.03\right)$ concentration versus time for the fence line exclusion boundary and Columbia River compliance points for travel paths (a) southeast and (b) north through the gap 
(a)

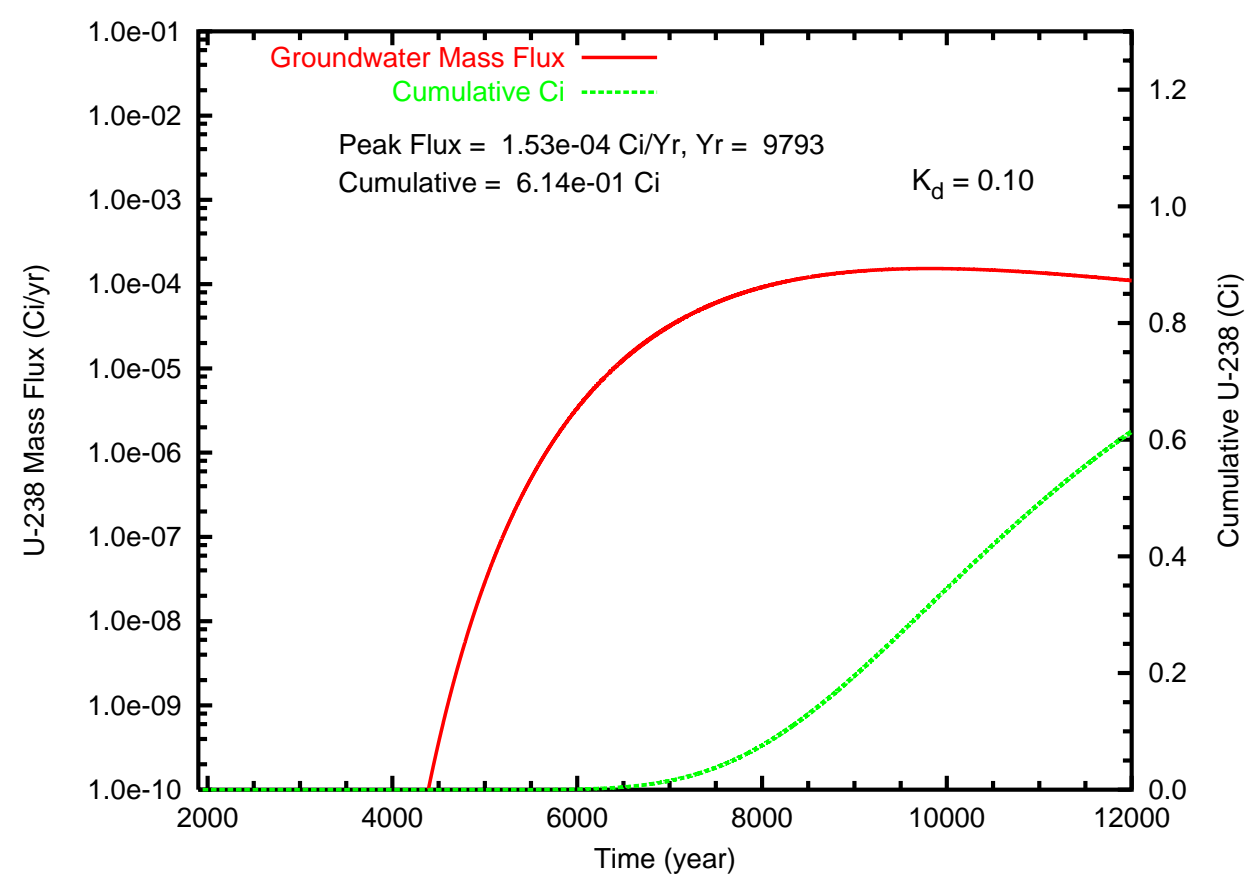

(b)

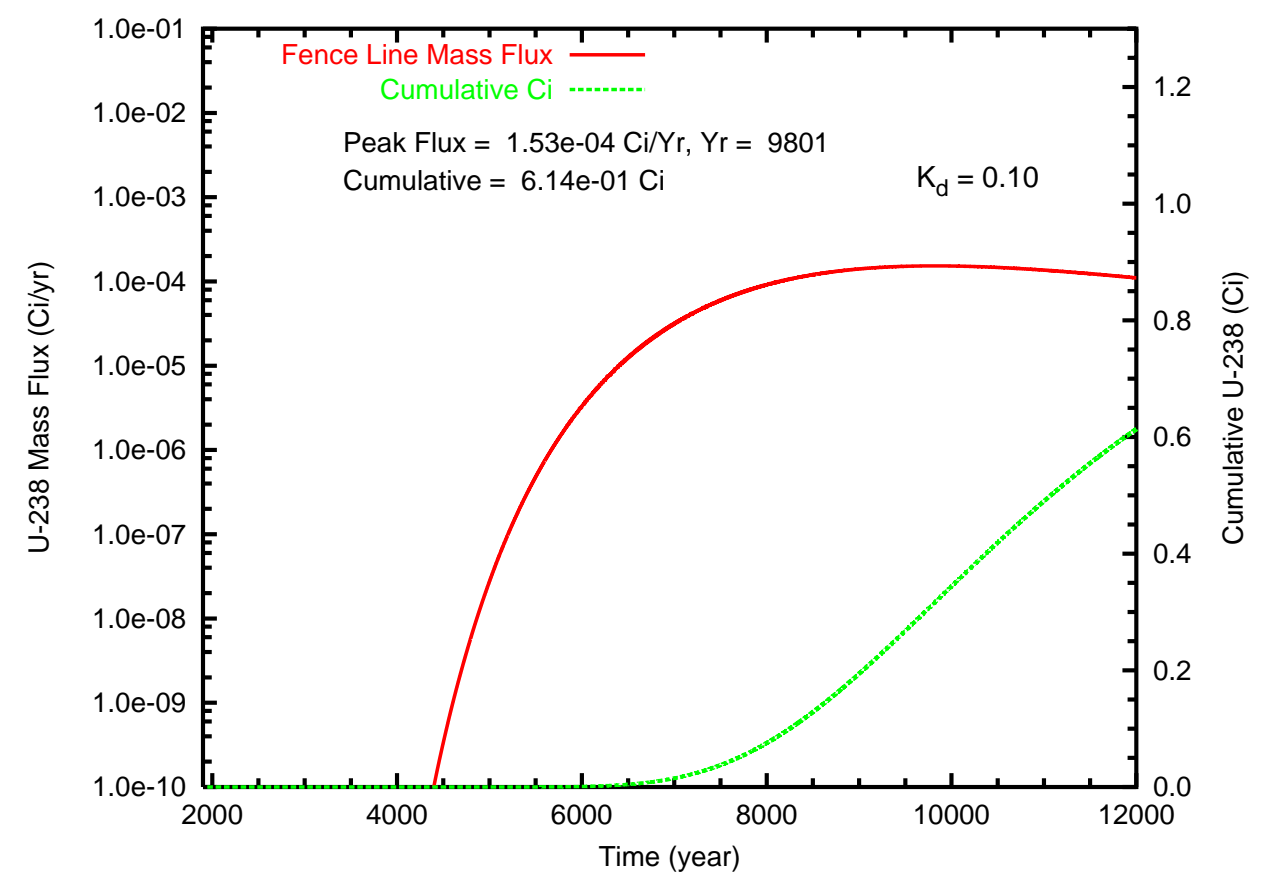

Figure B.159. Case 11-HiK, U-238 ( $\left.\mathrm{K}_{d}=0.10\right)$ mass flux $(\mathrm{Ci} / \mathrm{L})$ and cumulative mass $(\mathrm{Ci})$ at (a) the groundwater table and (b) the fence line 
(a)

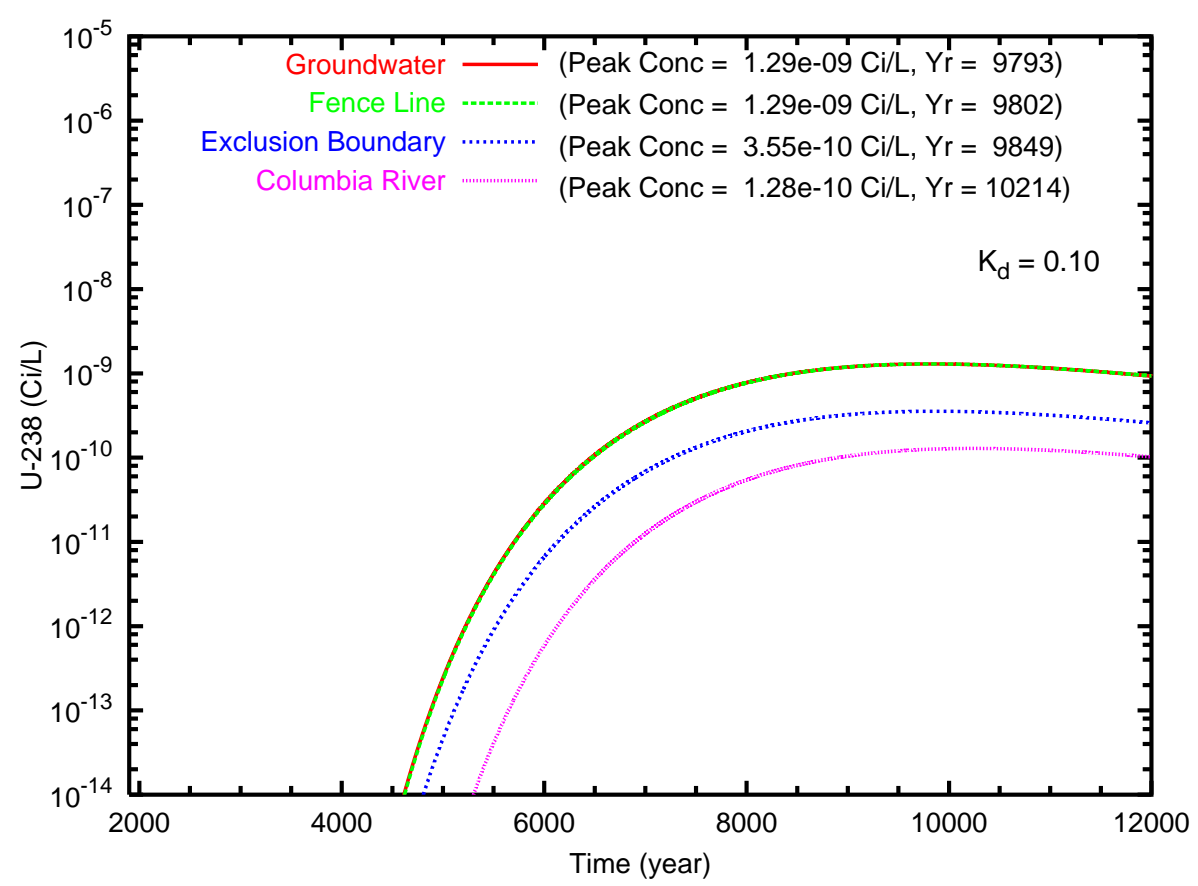

(b)

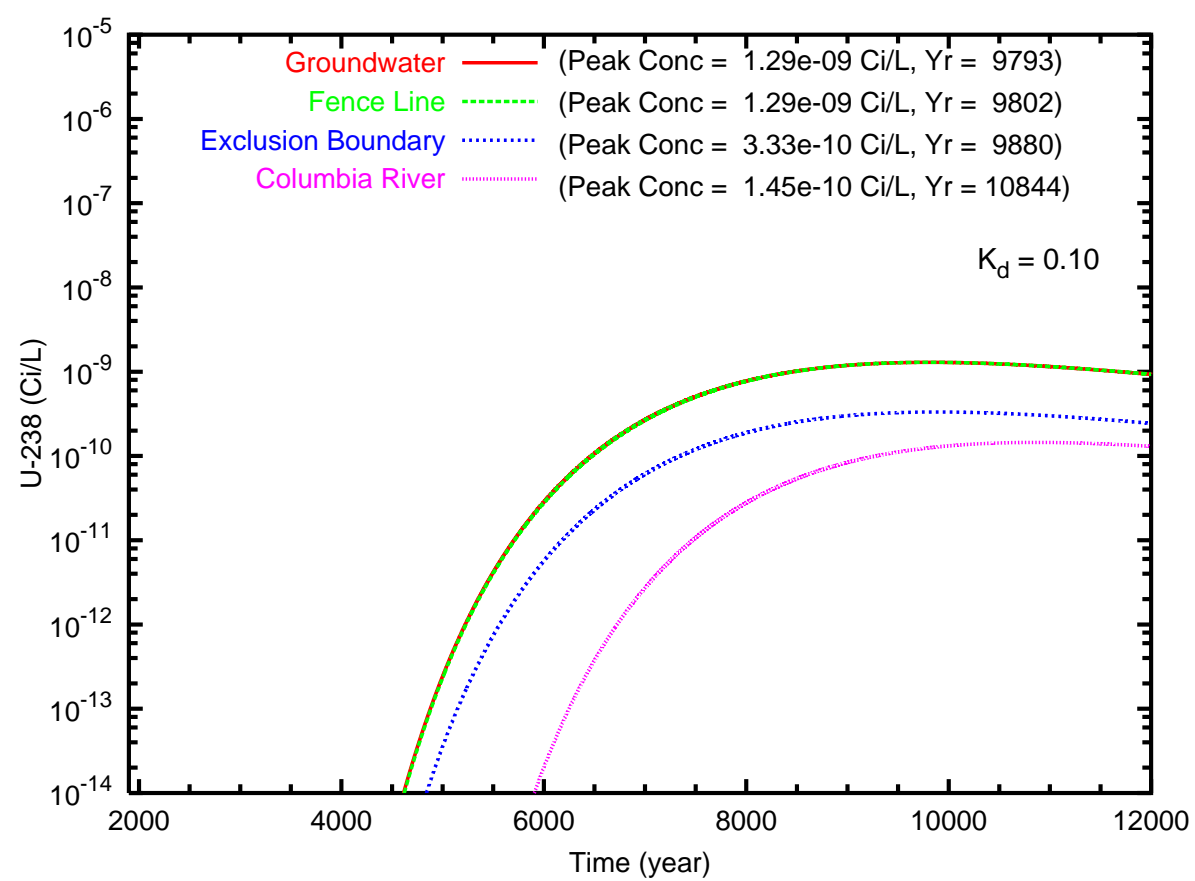

Figure B.160. Case 11-HiK, U-238 $\left(\mathrm{K}_{d}=0.10\right)$ concentration versus time for the fence line exclusion boundary and Columbia River compliance points for travel paths (a) southeast and (b) north through the gap 
(a)

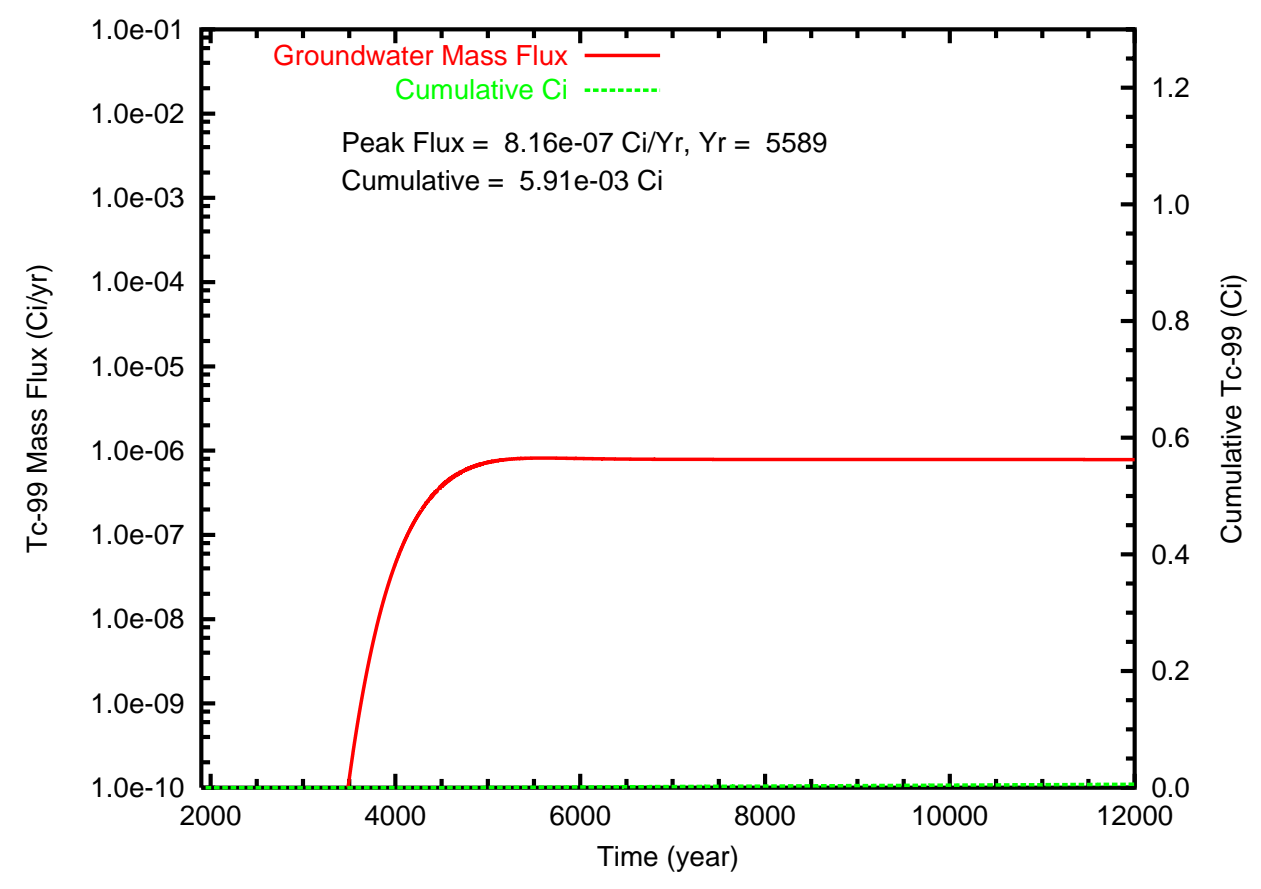

(b)

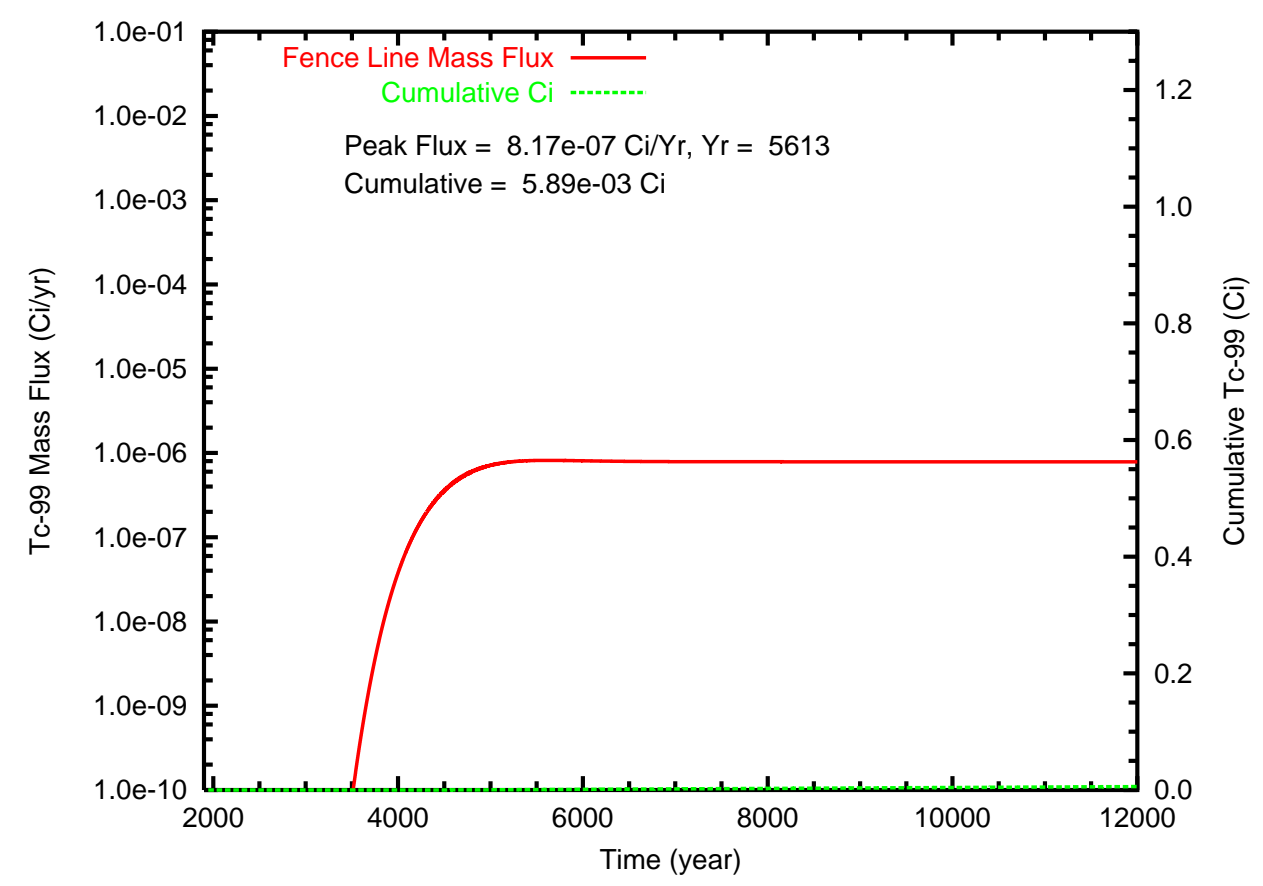

Figure B.161. Case 12, Tc-99 mass flux and cumulative mass at (a) the groundwater table and (b) the fence line 
(a)

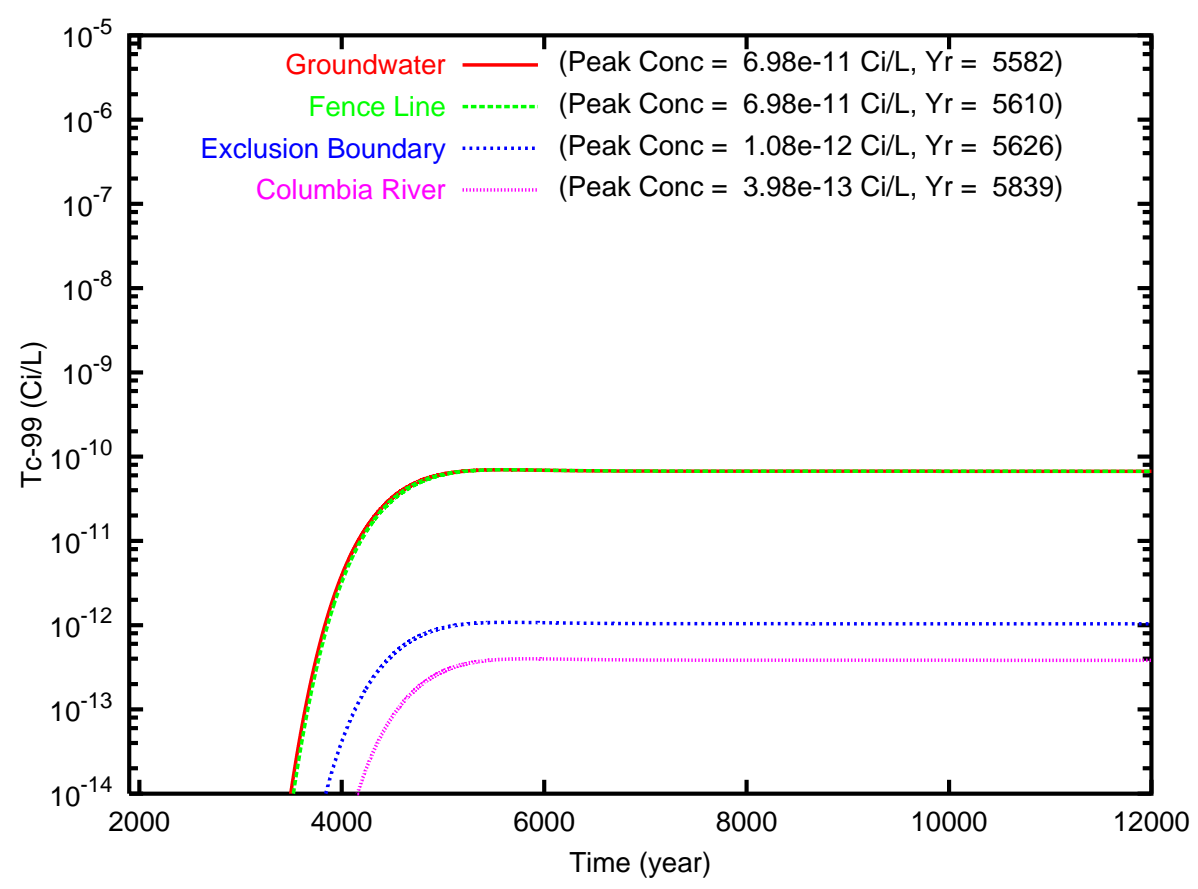

(b)

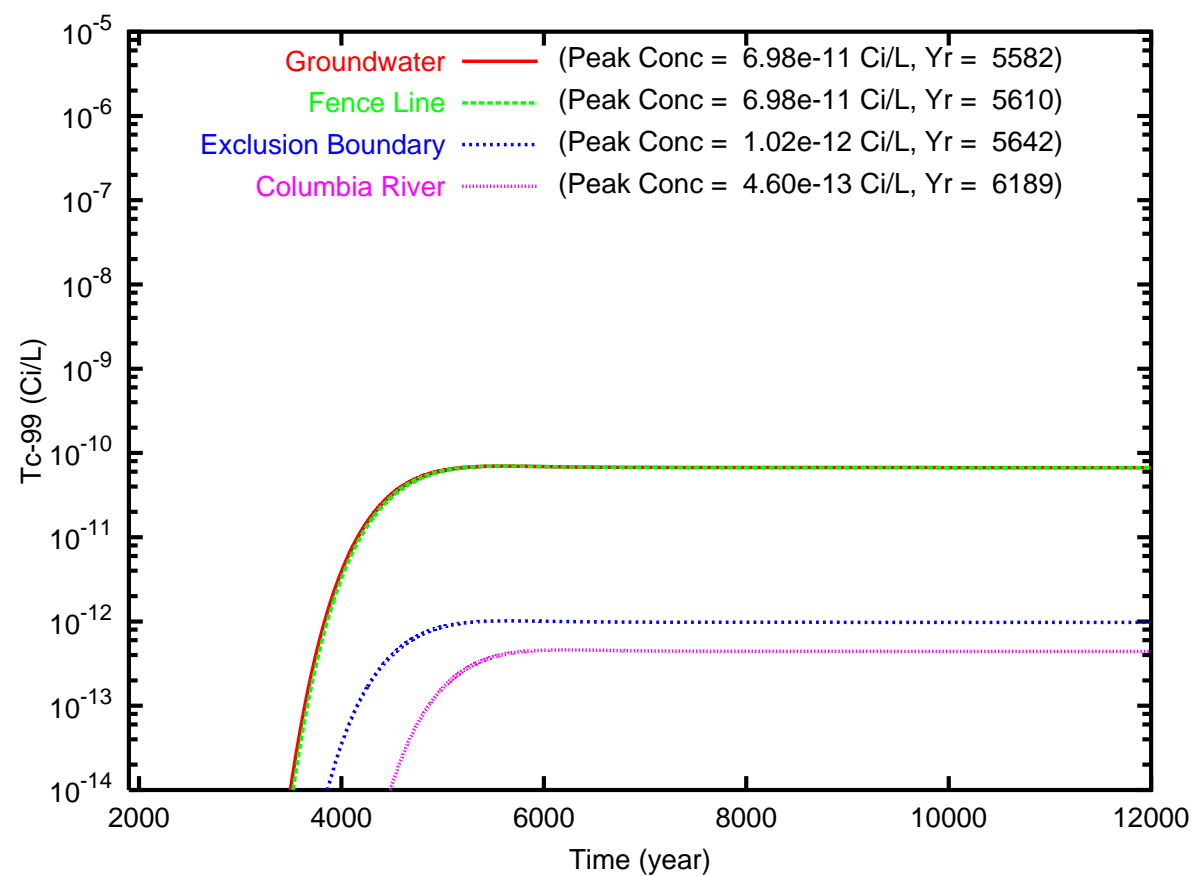

Figure B.162. Case 12, Tc-99 concentration versus time for the fence line, exclusion boundary and Columbia River compliance points for travel paths (a) southeast and (b) north through the gap 
(a)

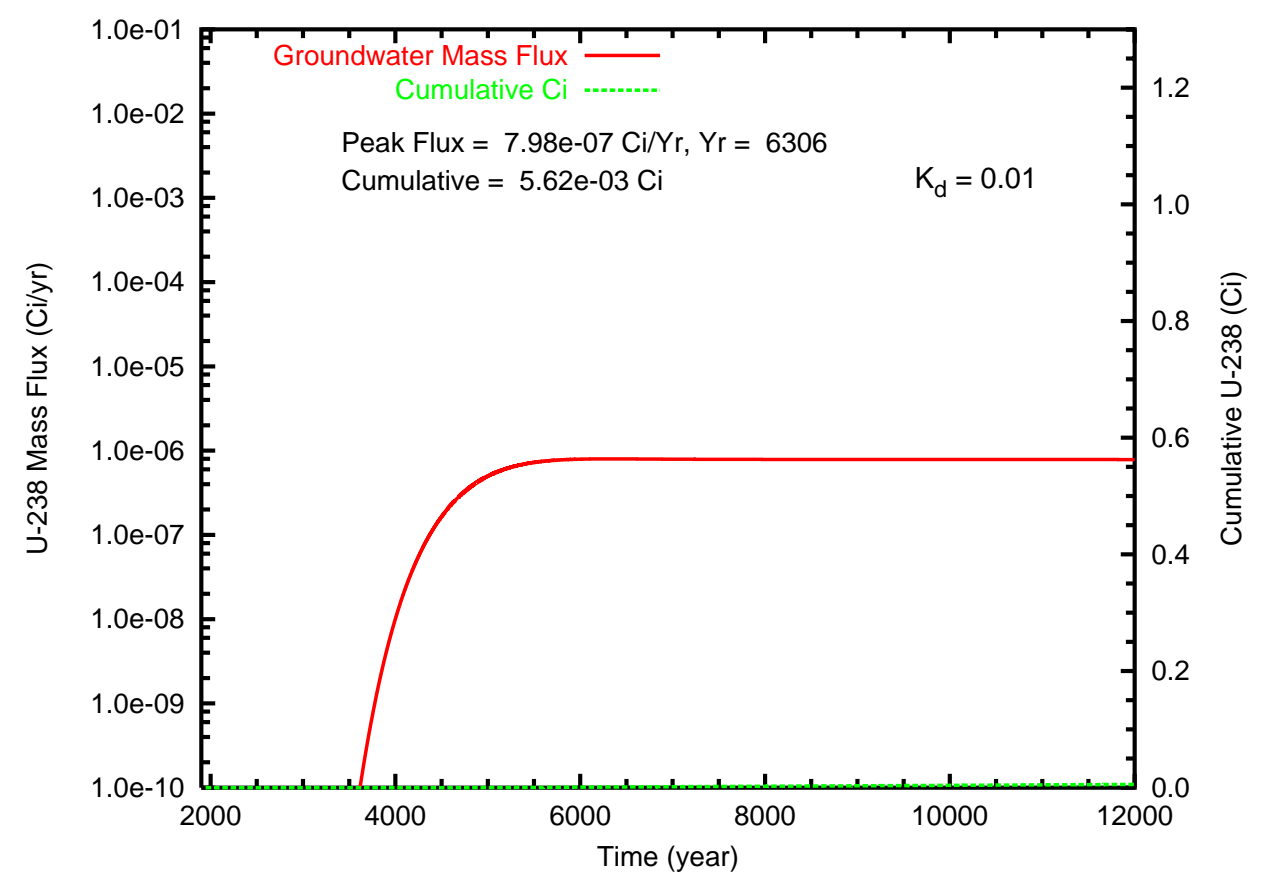

(b)

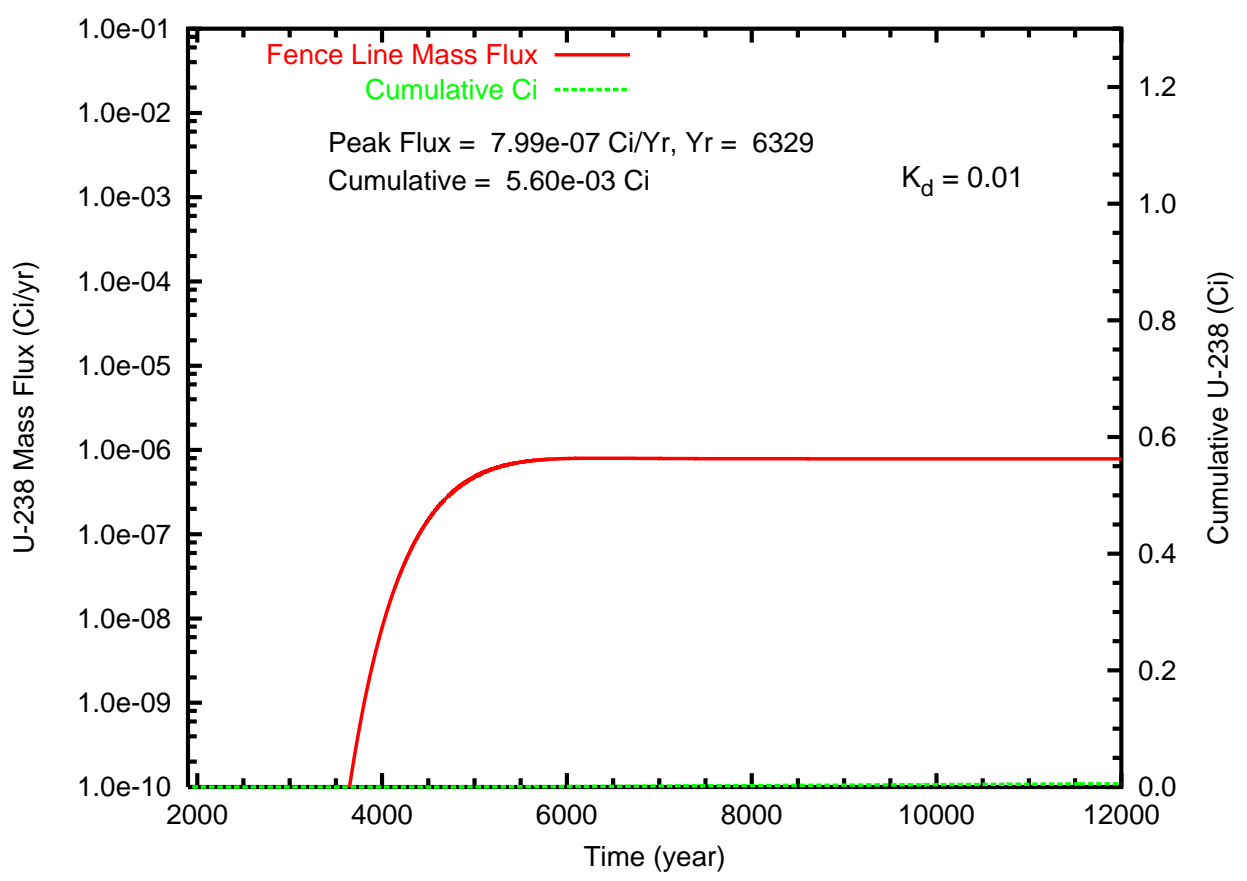

Figure B.163. Case 12, U-238 ( $\left.\mathrm{K}_{d}=0.01\right)$ mass flux $(\mathrm{Ci} / \mathrm{L})$ and cumulative mass $(\mathrm{Ci})$ at $(\mathrm{a})$ the groundwater table and (b) the fence line 
(a)

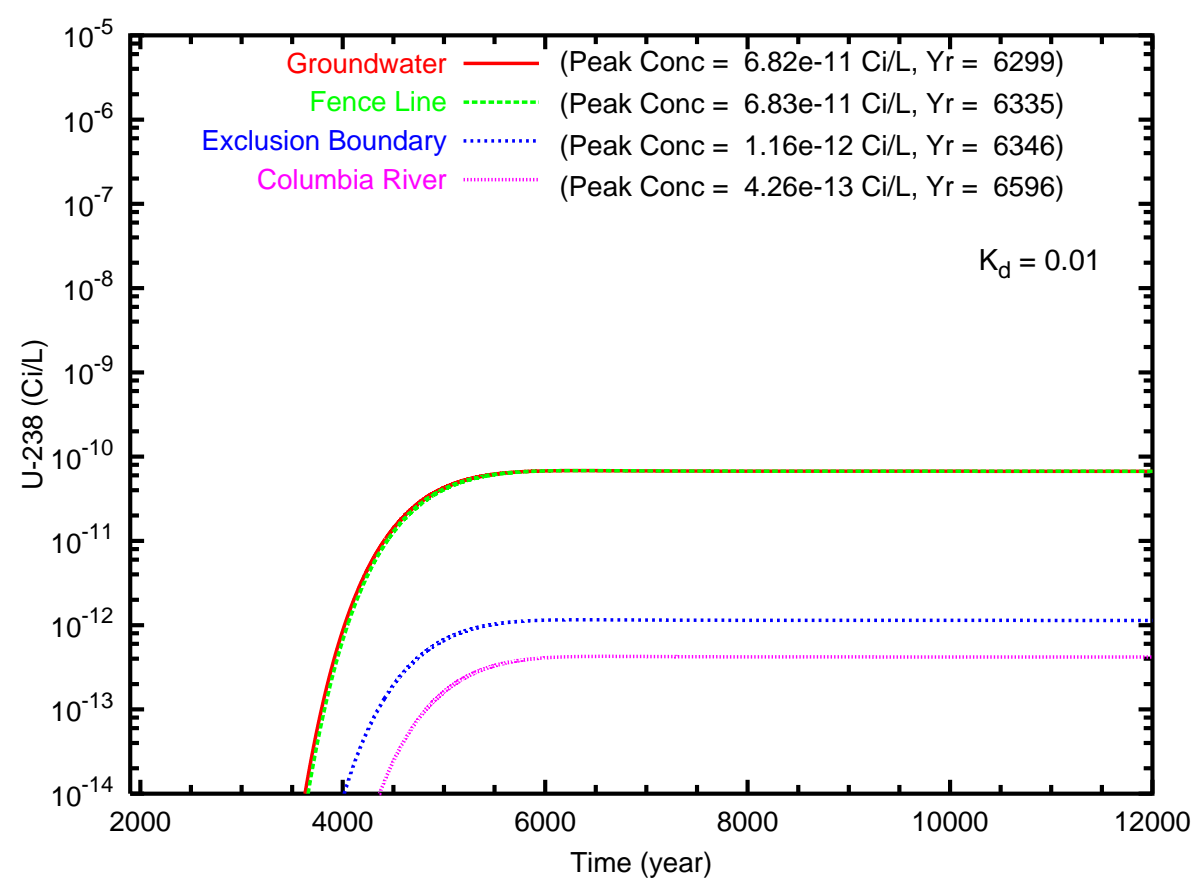

(b)

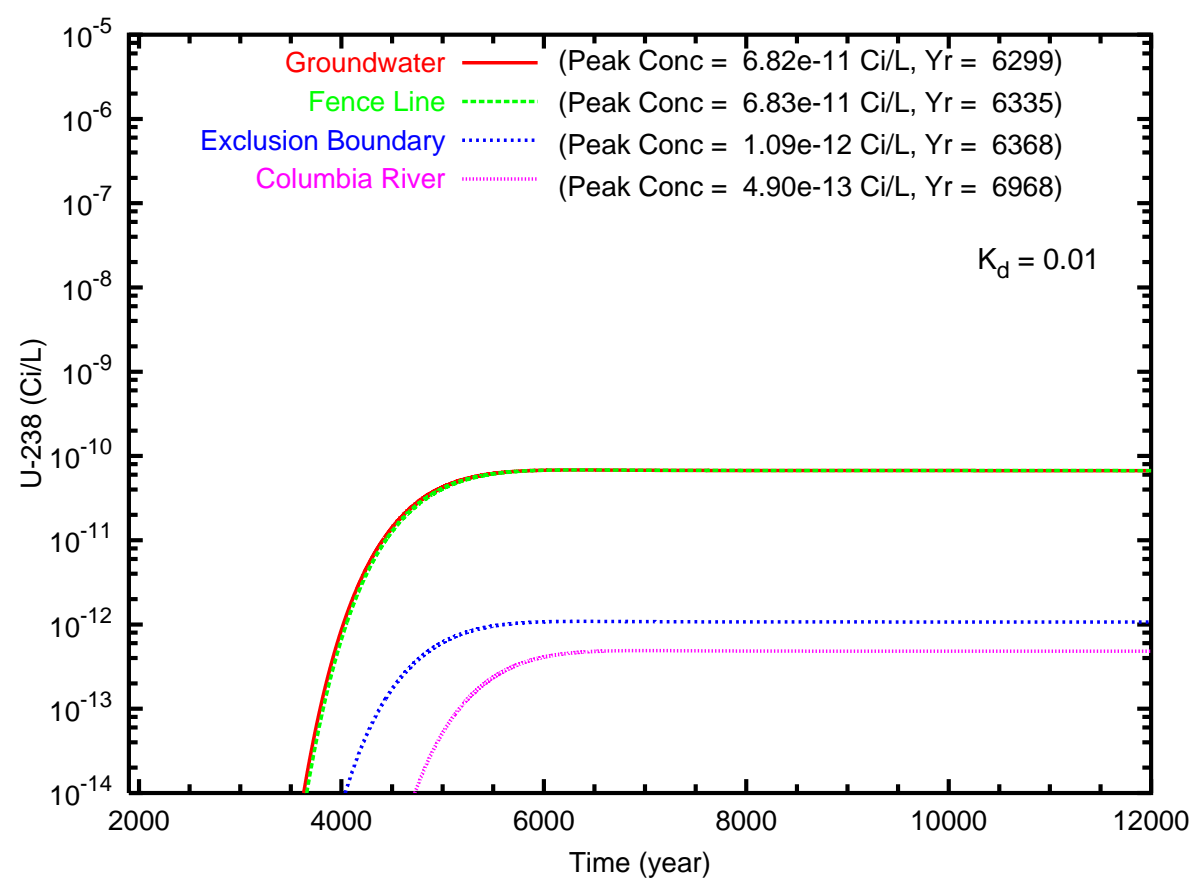

Figure B.164. Case 12, $\mathrm{U}-238\left(\mathrm{~K}_{d}=0.01\right)$ concentration versus time for the fence line exclusion boundary and Columbia River compliance points for travel paths (a) southeast and (b) north through the gap 
(a)

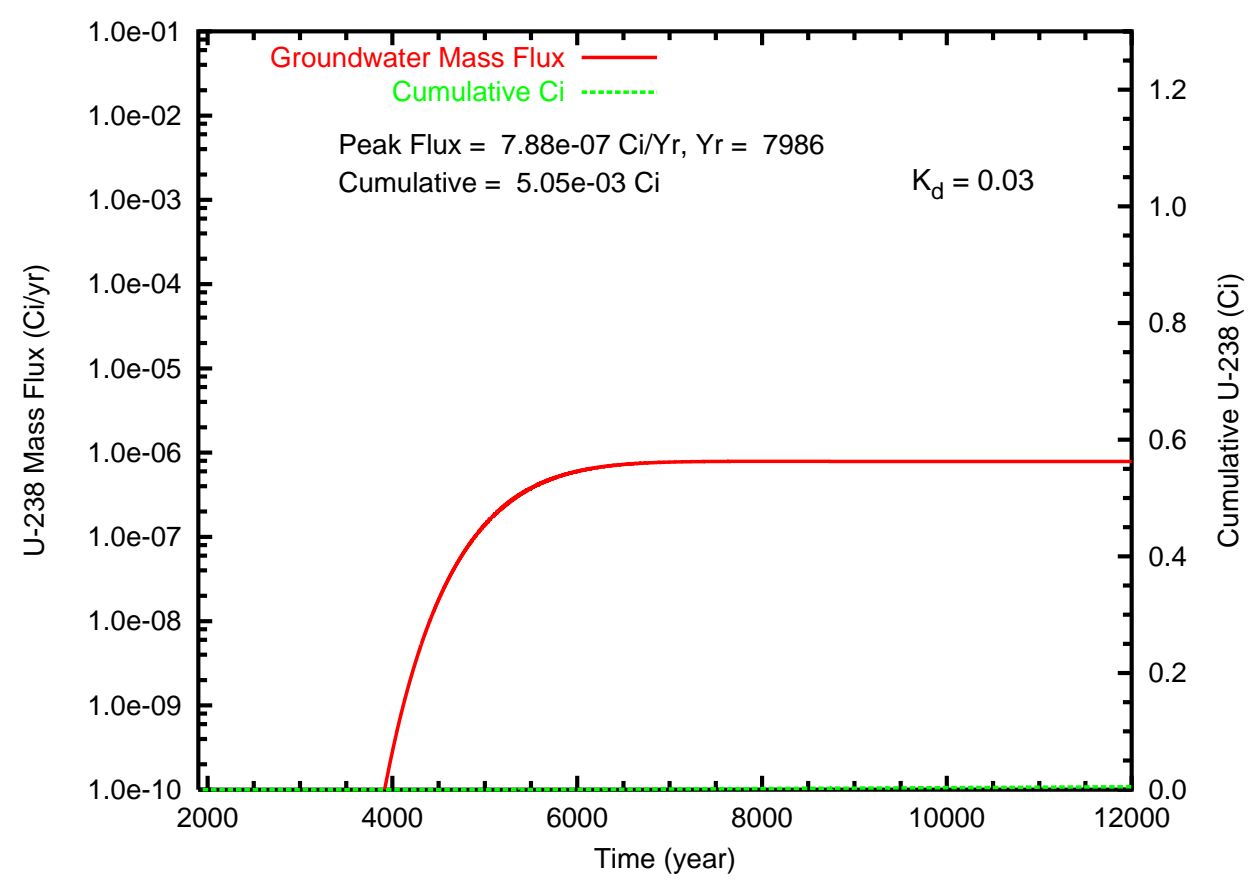

(b)

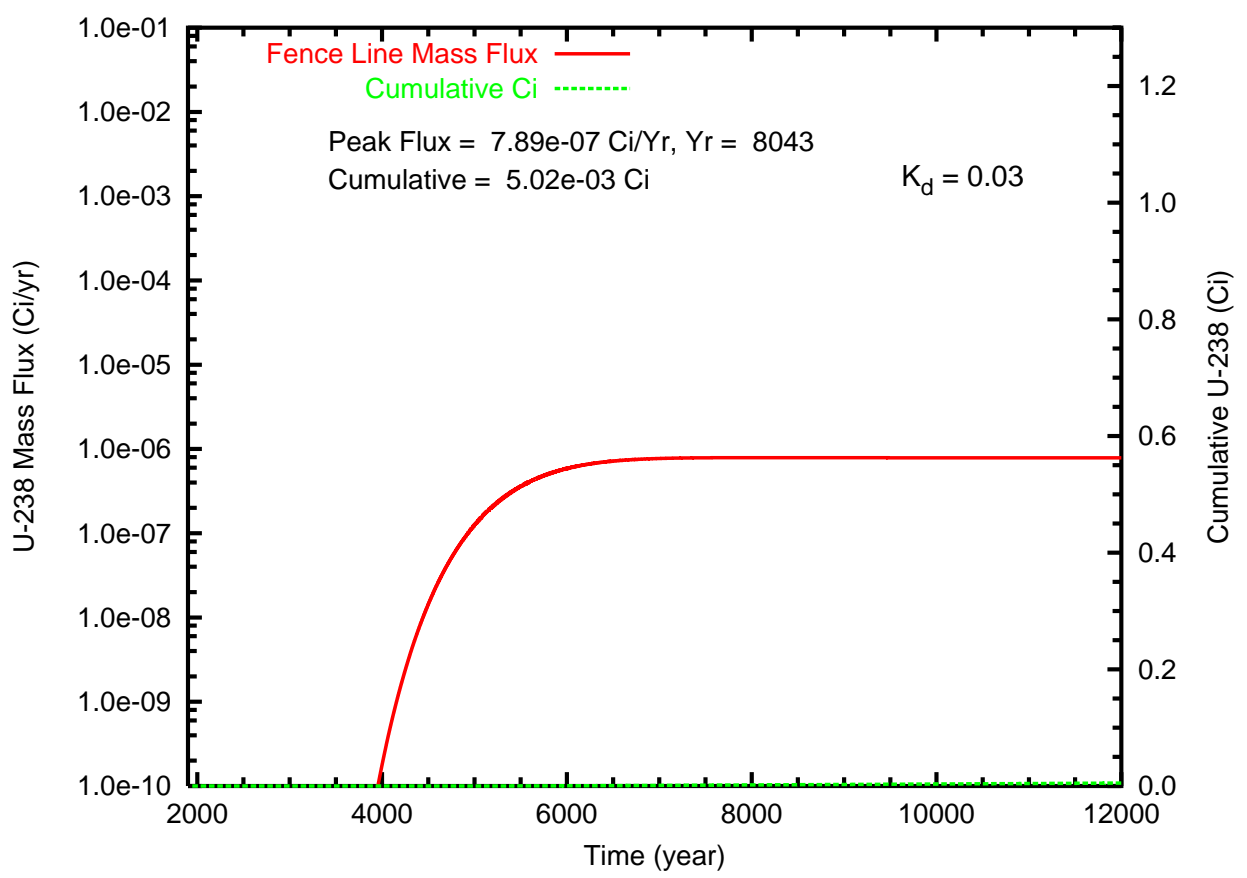

Figure B.165. Case 12, U-238 ( $\left.\mathrm{K}_{d}=0.03\right)$ mass flux $(\mathrm{Ci} / \mathrm{L})$ and cumulative mass $(\mathrm{Ci})$ at $(\mathrm{a})$ the groundwater table and (b) the fence line 
(a)

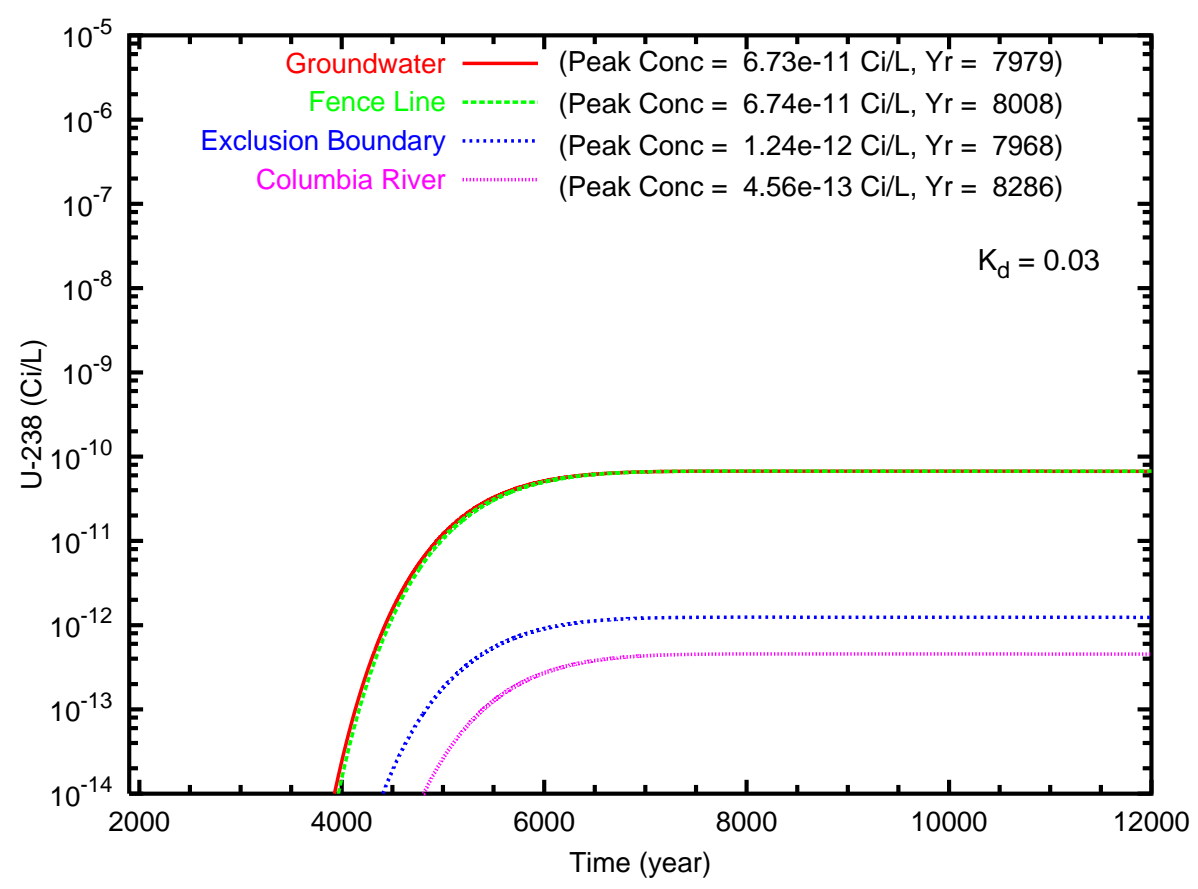

(b)

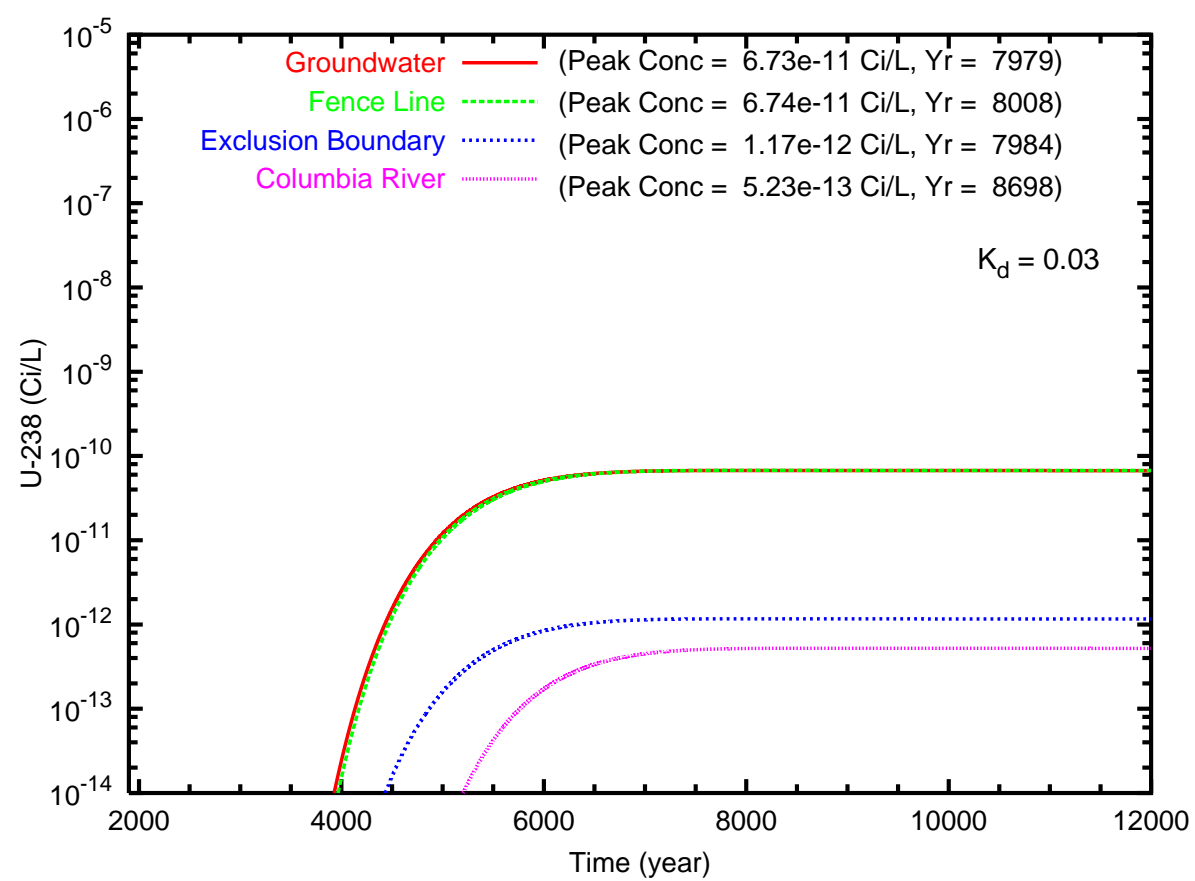

Figure B.166. Case 12, $\mathrm{U}-238\left(\mathrm{~K}_{d}=0.03\right)$ concentration versus time for the fence line exclusion boundary and Columbia River compliance points for travel paths (a) southeast and (b) north through the gap 
(a)

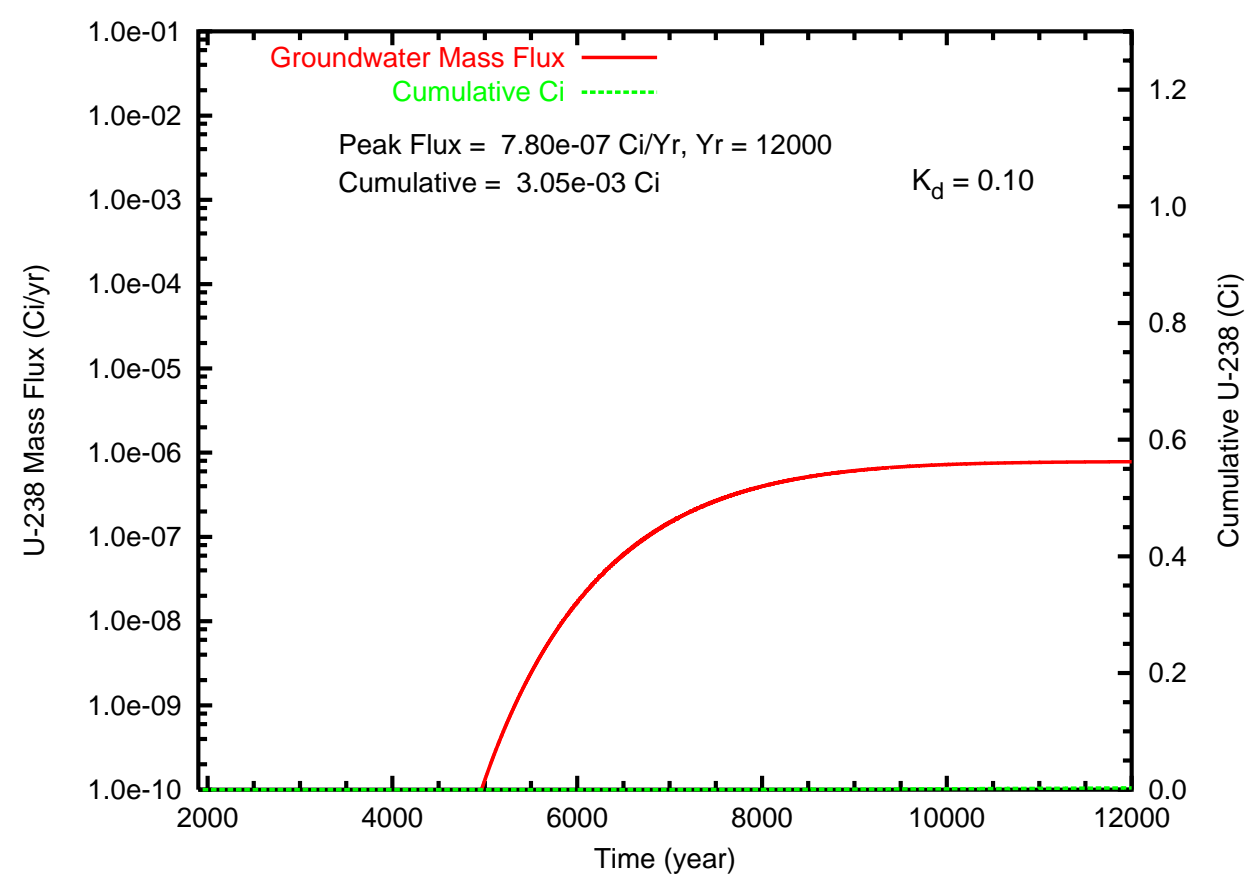

(b)

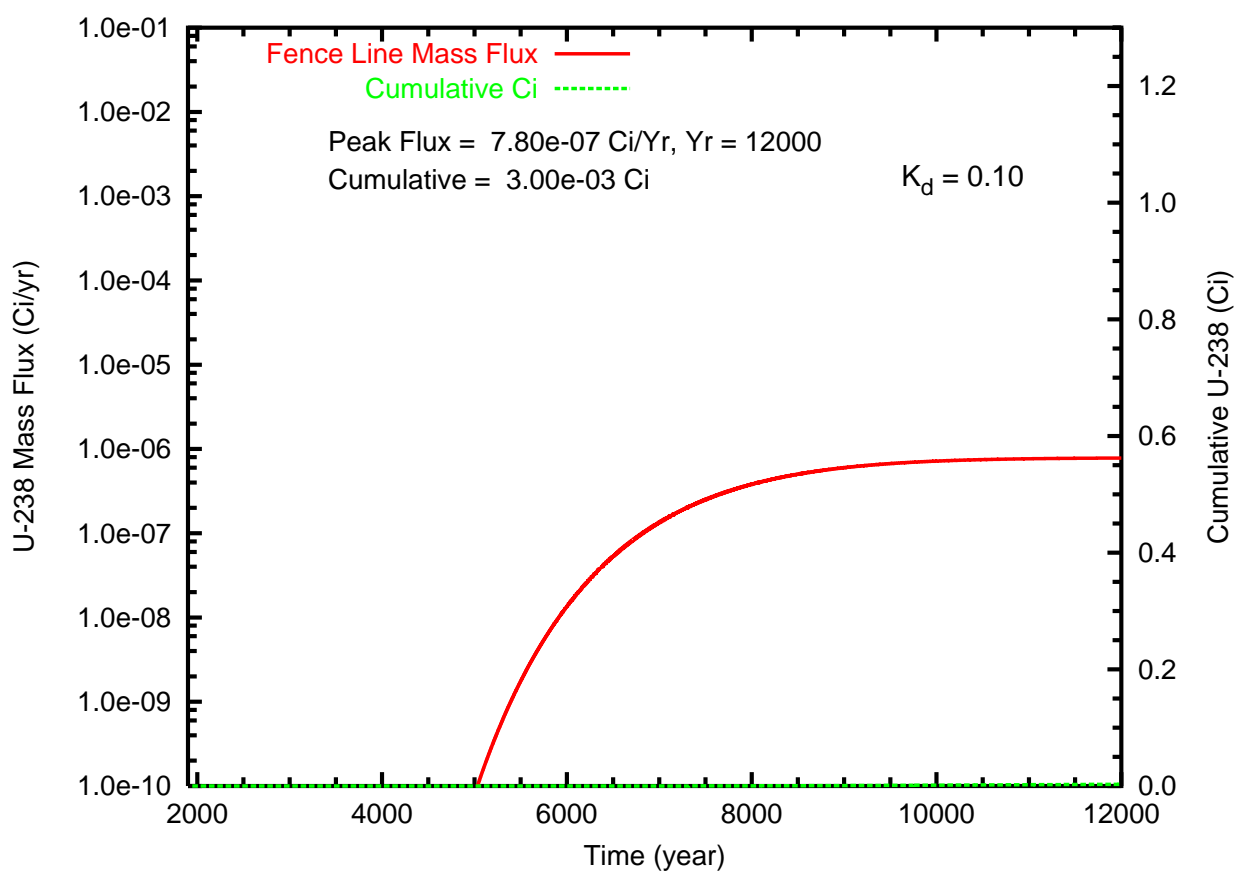

Figure B.167. Case 12, U-238 ( $\left.\mathrm{K}_{d}=0.10\right)$ mass flux $(\mathrm{Ci} / \mathrm{L})$ and cumulative mass $(\mathrm{Ci})$ at $(\mathrm{a})$ the groundwater table and (b) the fence line 
(a)

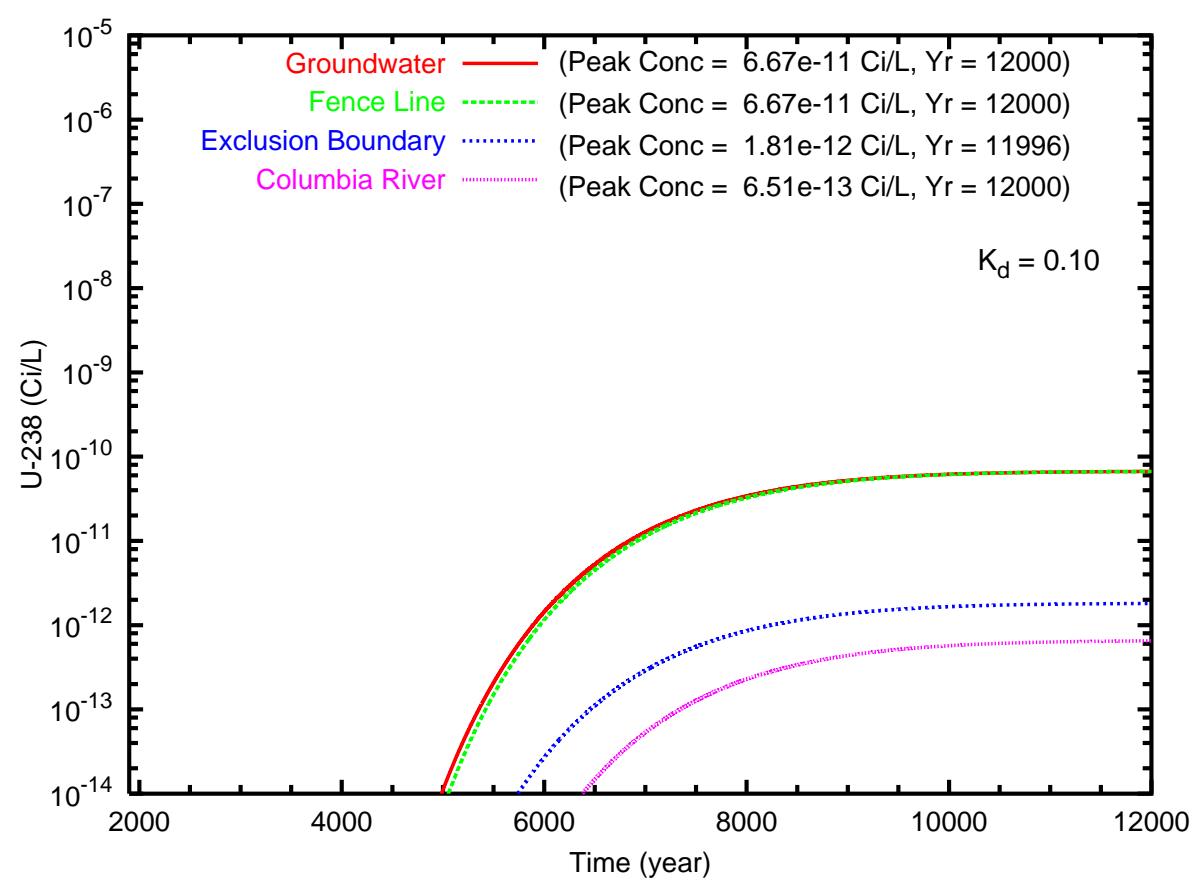

(b)

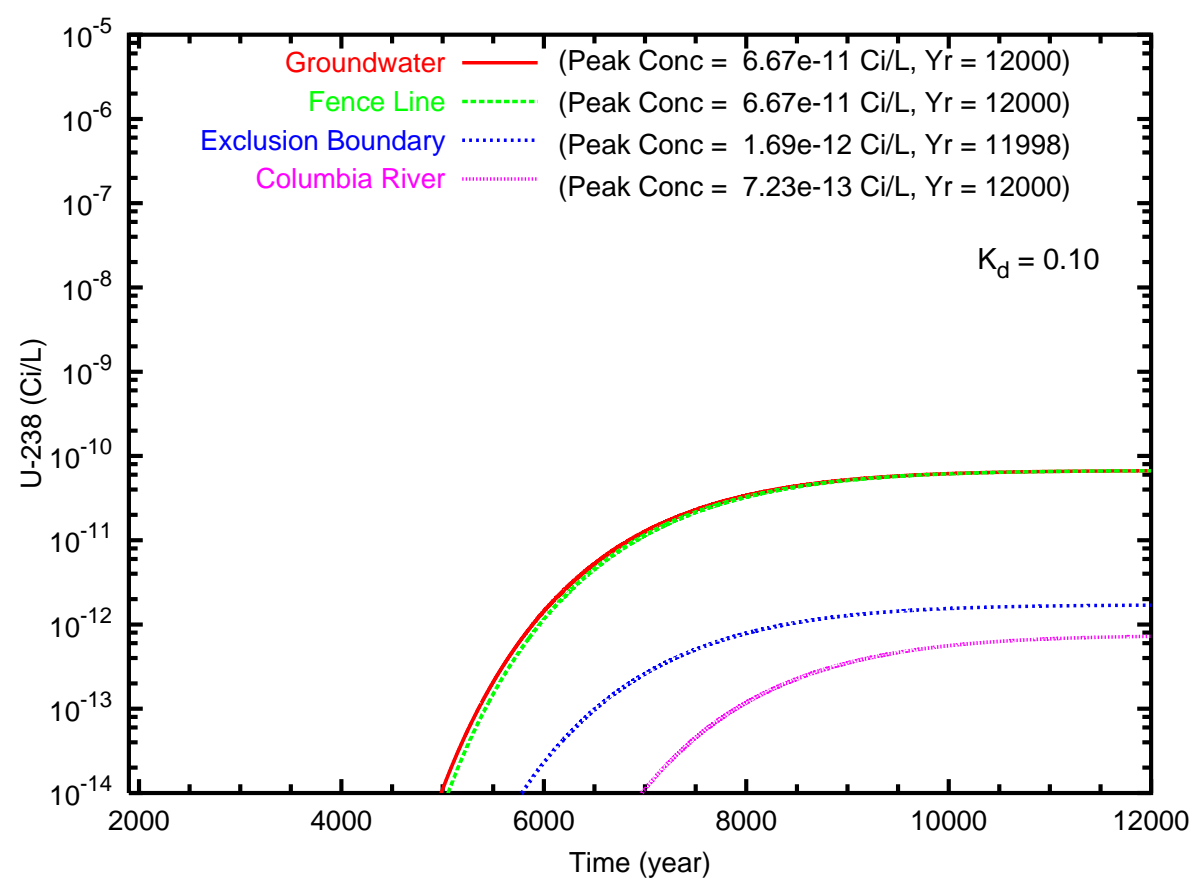

Figure B.168. Case $12, \mathrm{U}-238\left(\mathrm{~K}_{d}=0.10\right)$ concentration versus time for the fence line exclusion boundary and Columbia River compliance points for travel paths (a) southeast and (b) north through the gap 
(a)

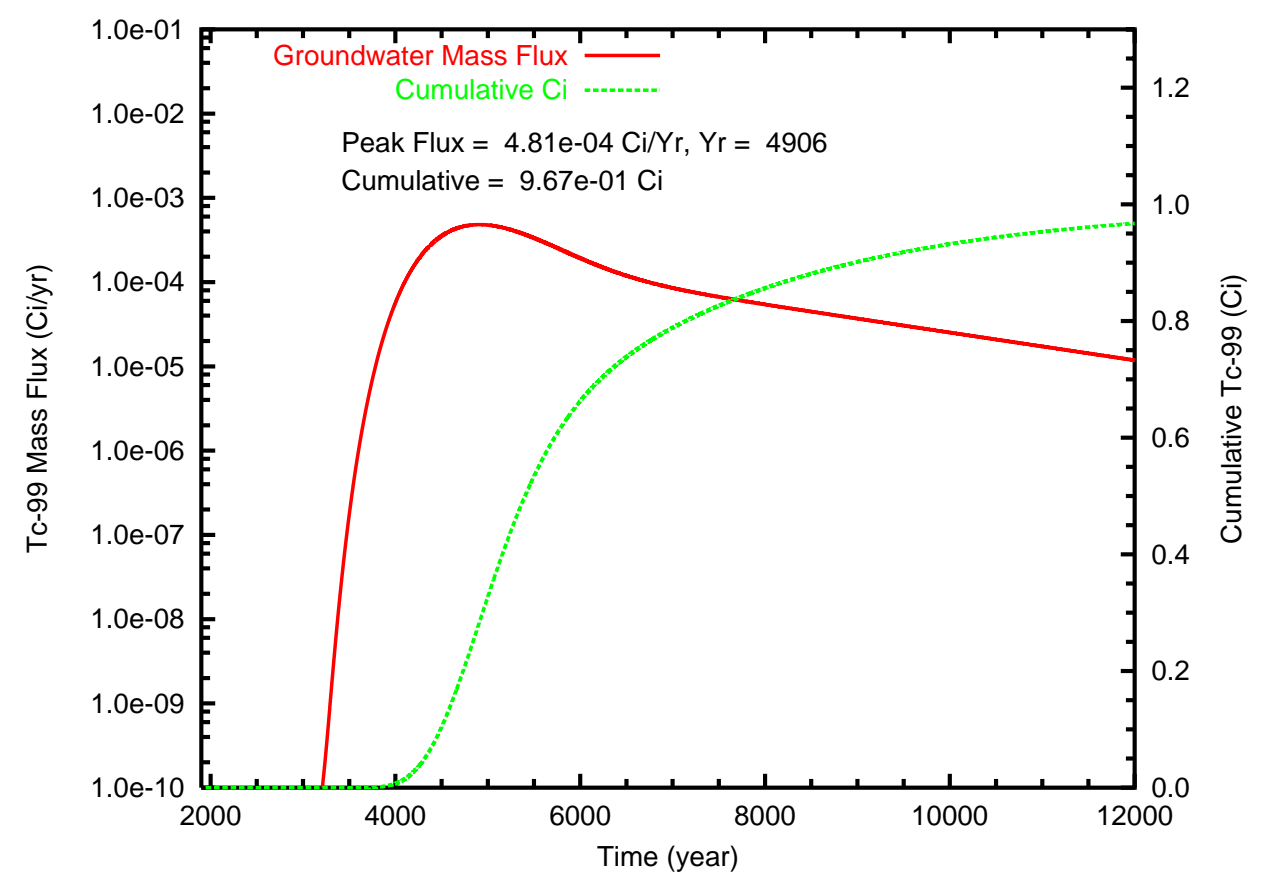

(b)

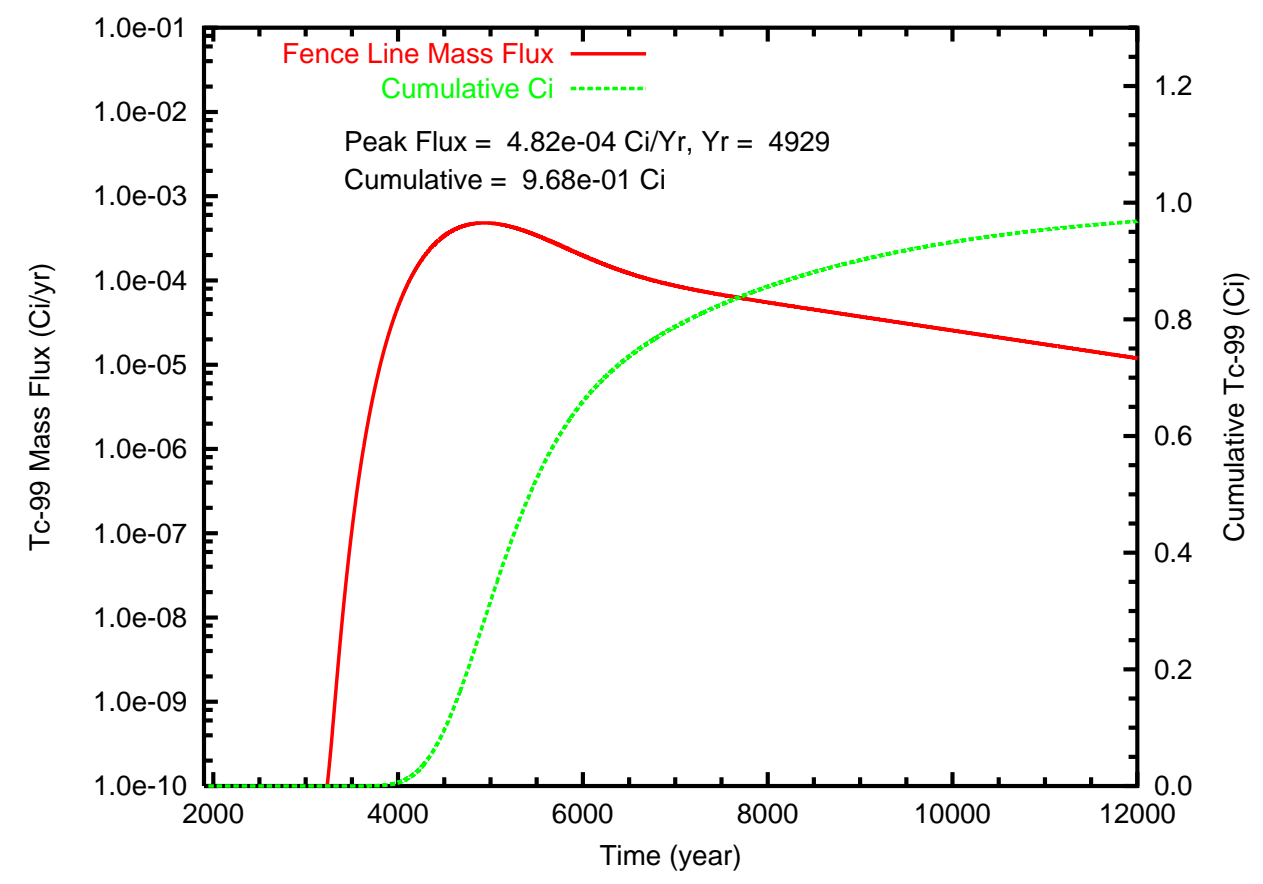

Figure B.169. Case 13, Tc-99 mass flux and cumulative mass at (a) the groundwater table and (b) the fence line 
(a)

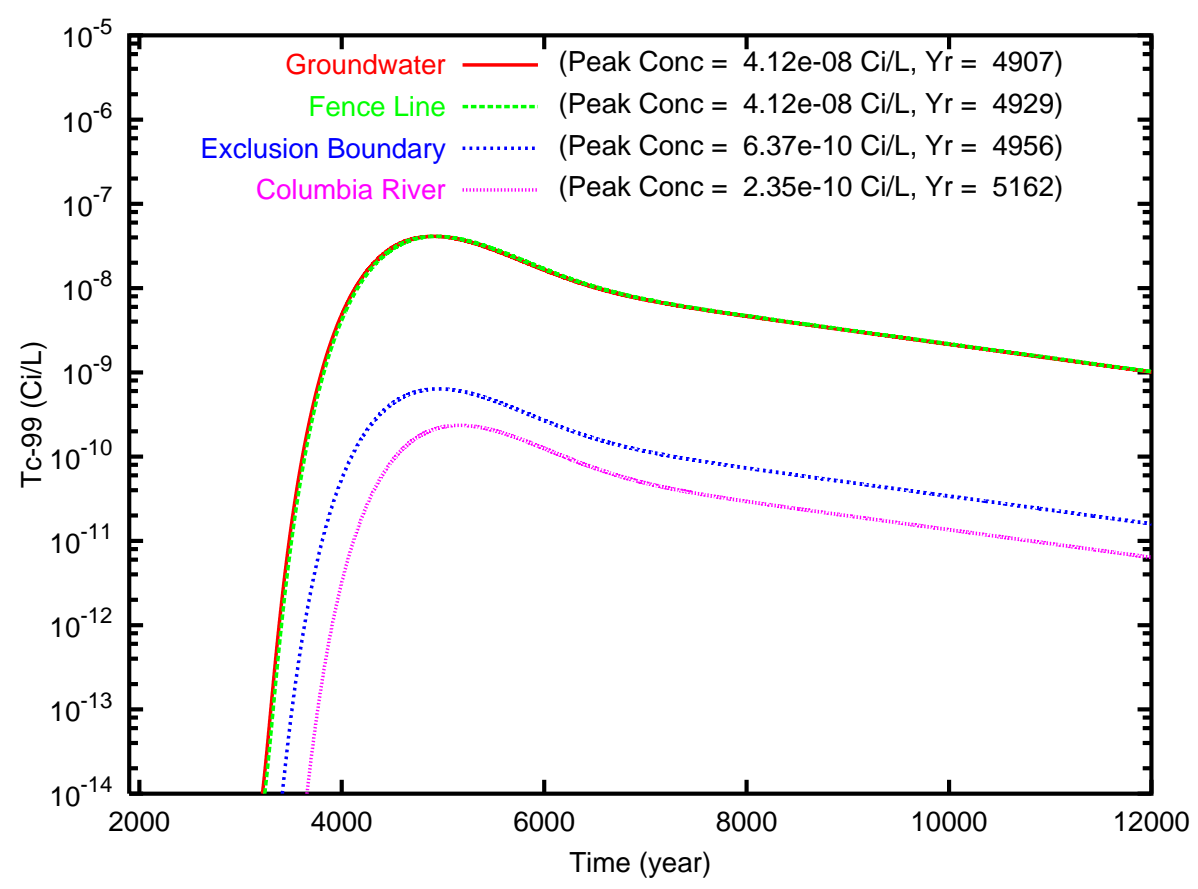

(b)

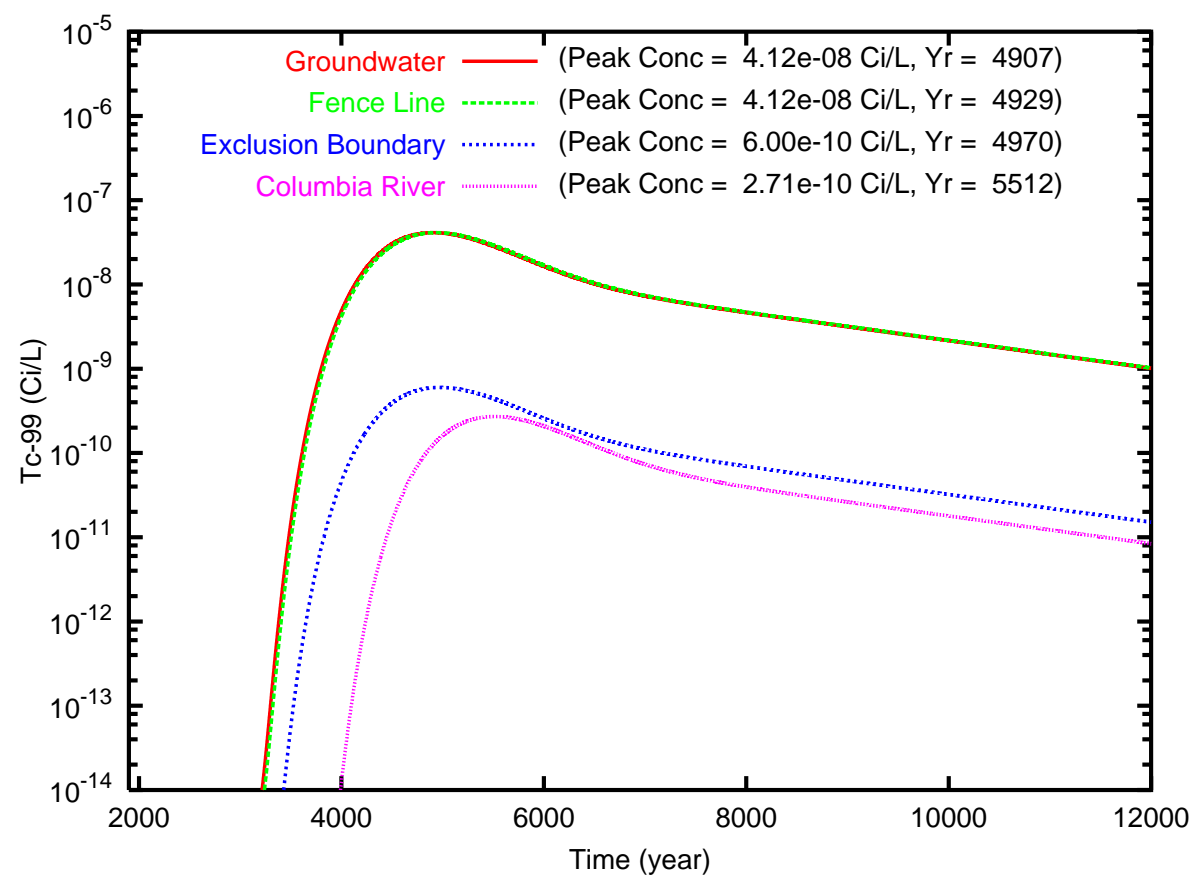

Figure B.170. Case 13, Tc-99 concentration versus time for the fence line, exclusion boundary and Columbia River compliance points for travel paths (a) southeast and (b) north through the gap 
(a)

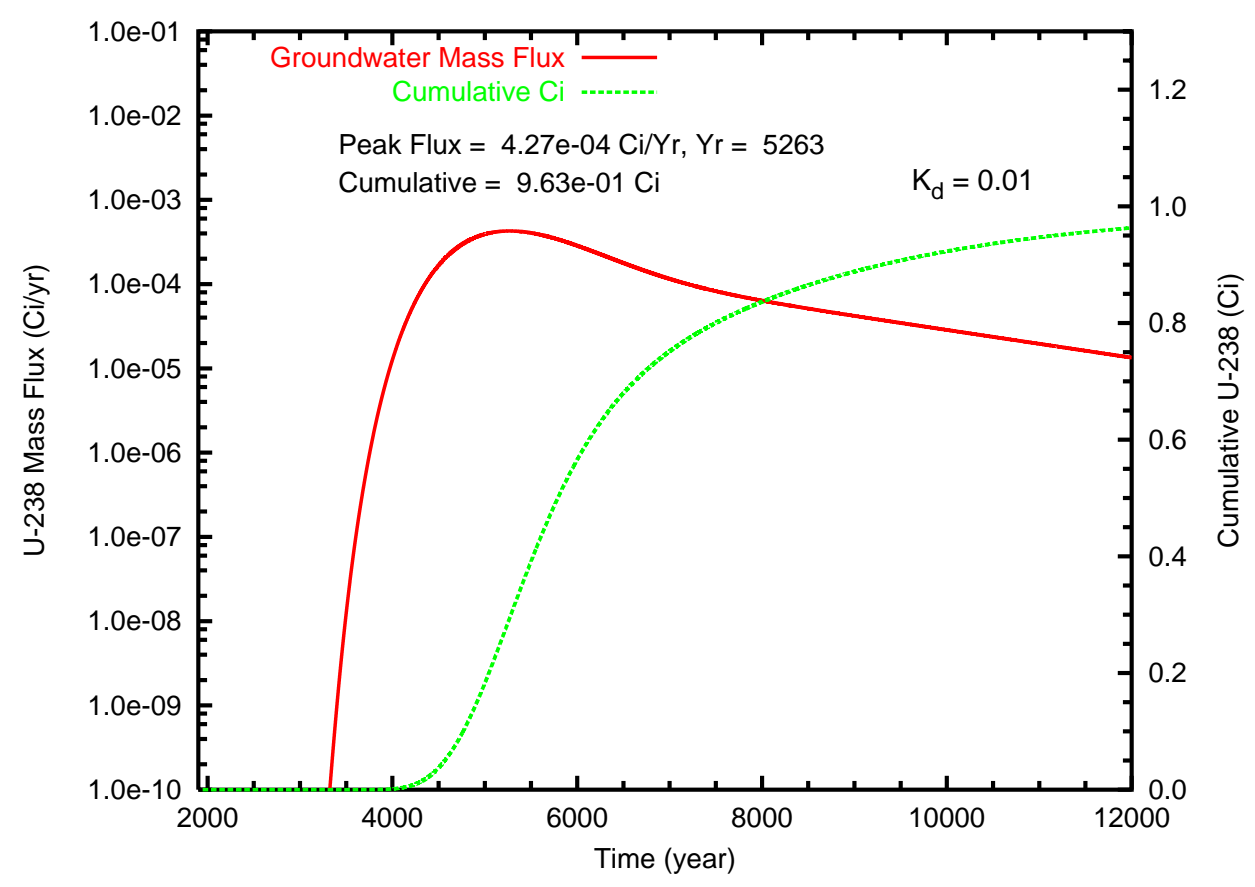

(b)

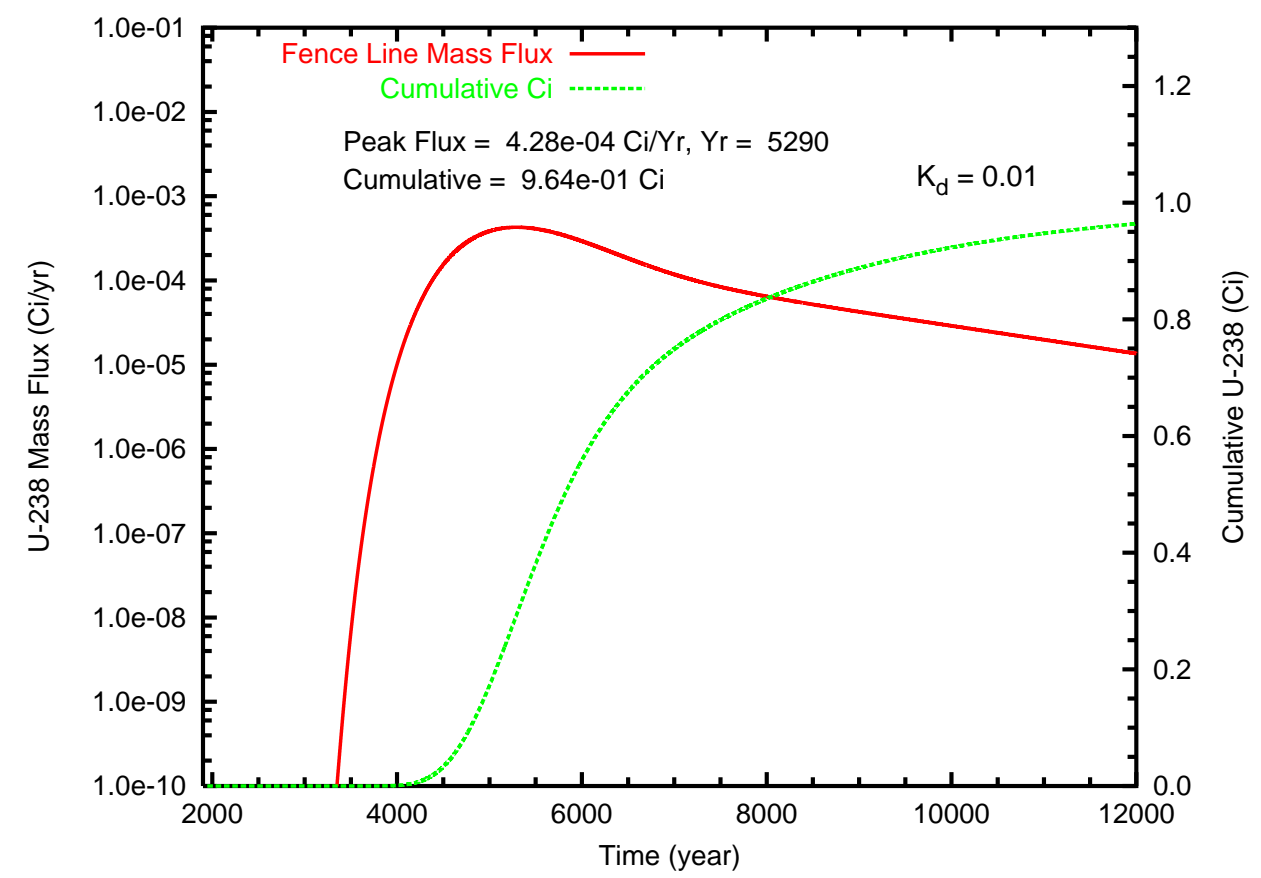

Figure B.171. Case $13, \mathrm{U}-238\left(\mathrm{~K}_{d}=0.01\right)$ mass flux $(\mathrm{Ci} / \mathrm{L})$ and cumulative mass $(\mathrm{Ci})$ at $(\mathrm{a})$ the groundwater table and (b) the fence line 
(a)

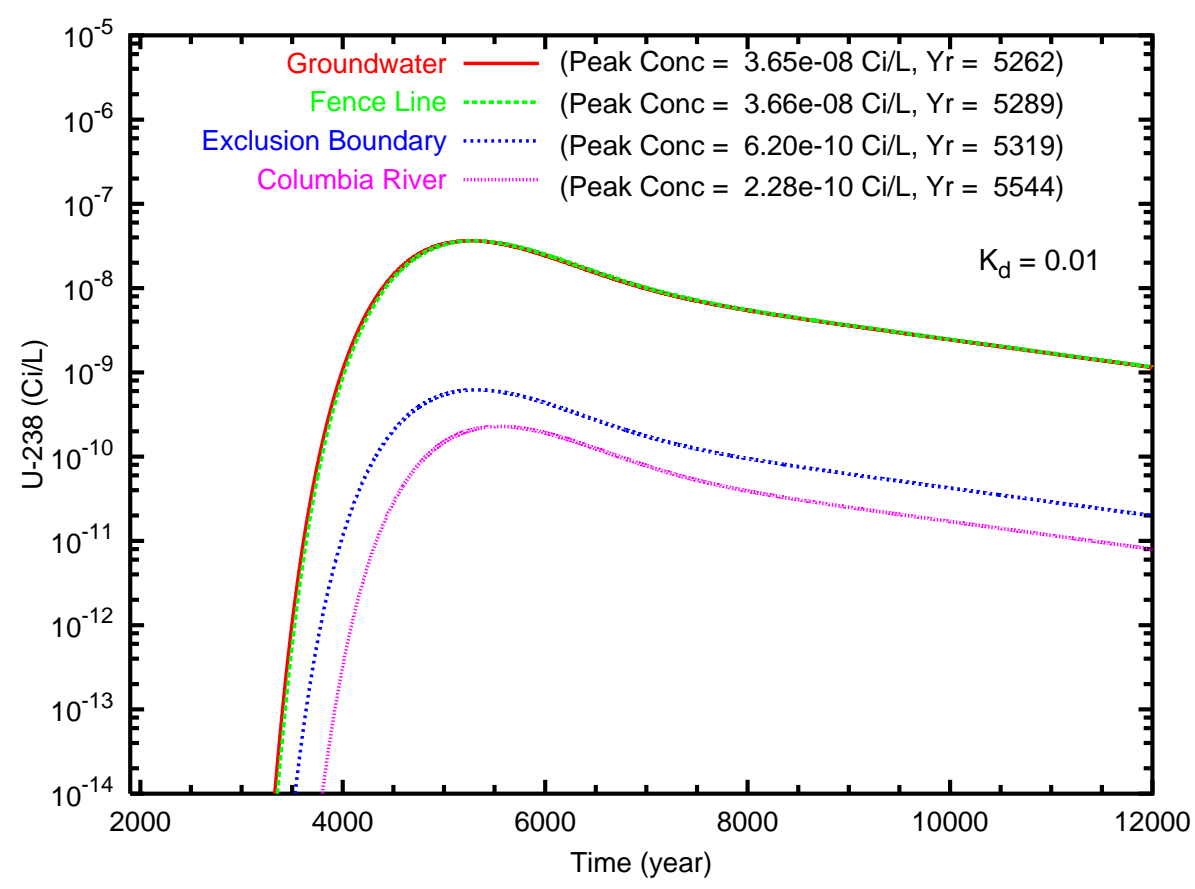

(b)

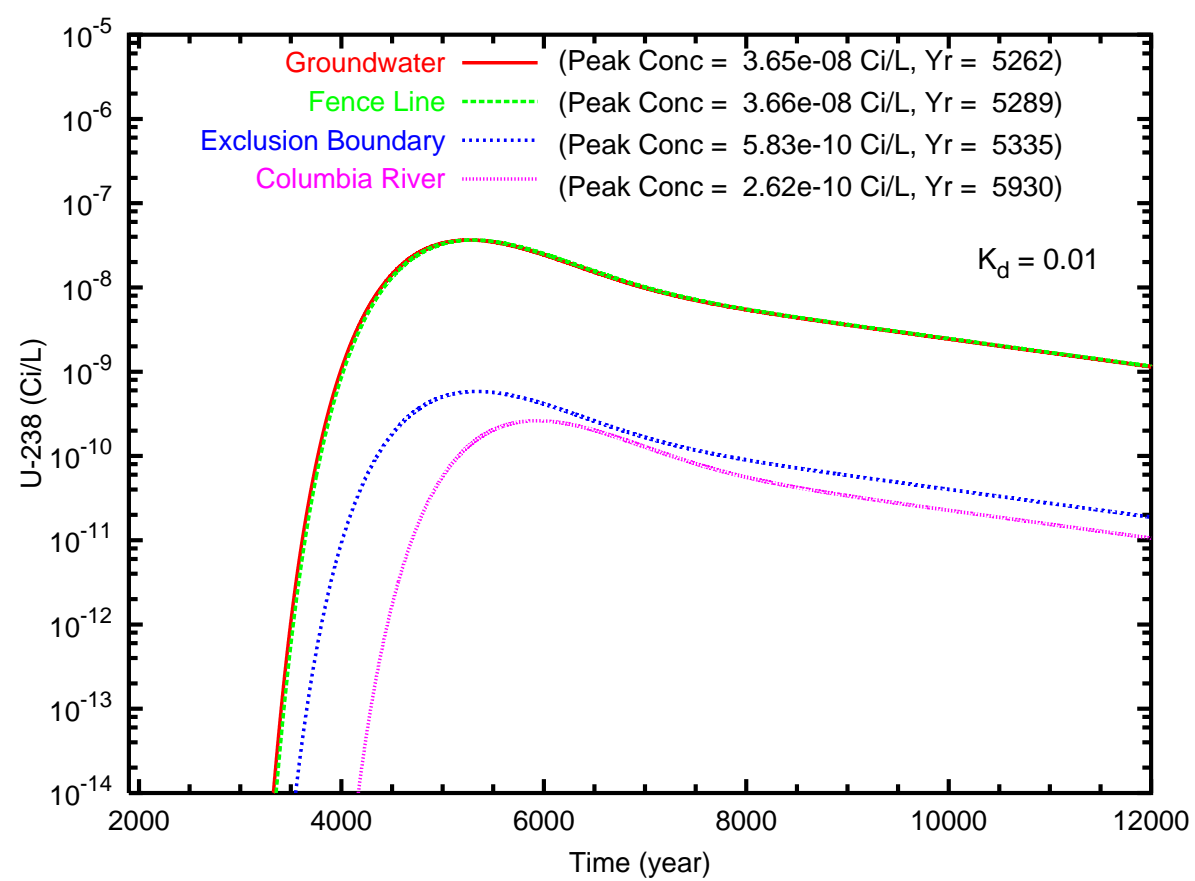

Figure B.172. Case $13, \mathrm{U}-238\left(\mathrm{~K}_{d}=0.01\right)$ concentration versus time for the fence line exclusion boundary and Columbia River compliance points for travel paths (a) southeast and (b) north through the gap 
(a)

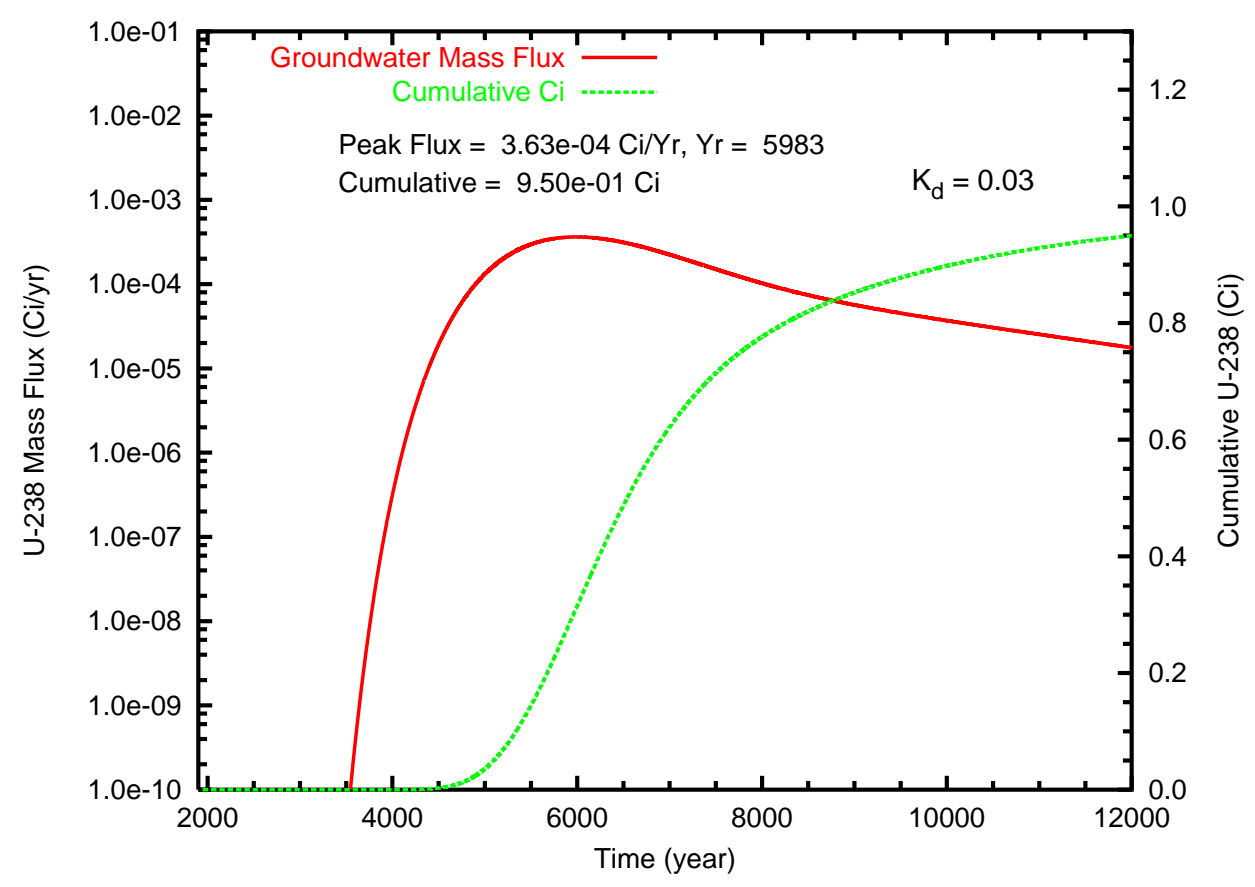

(b)

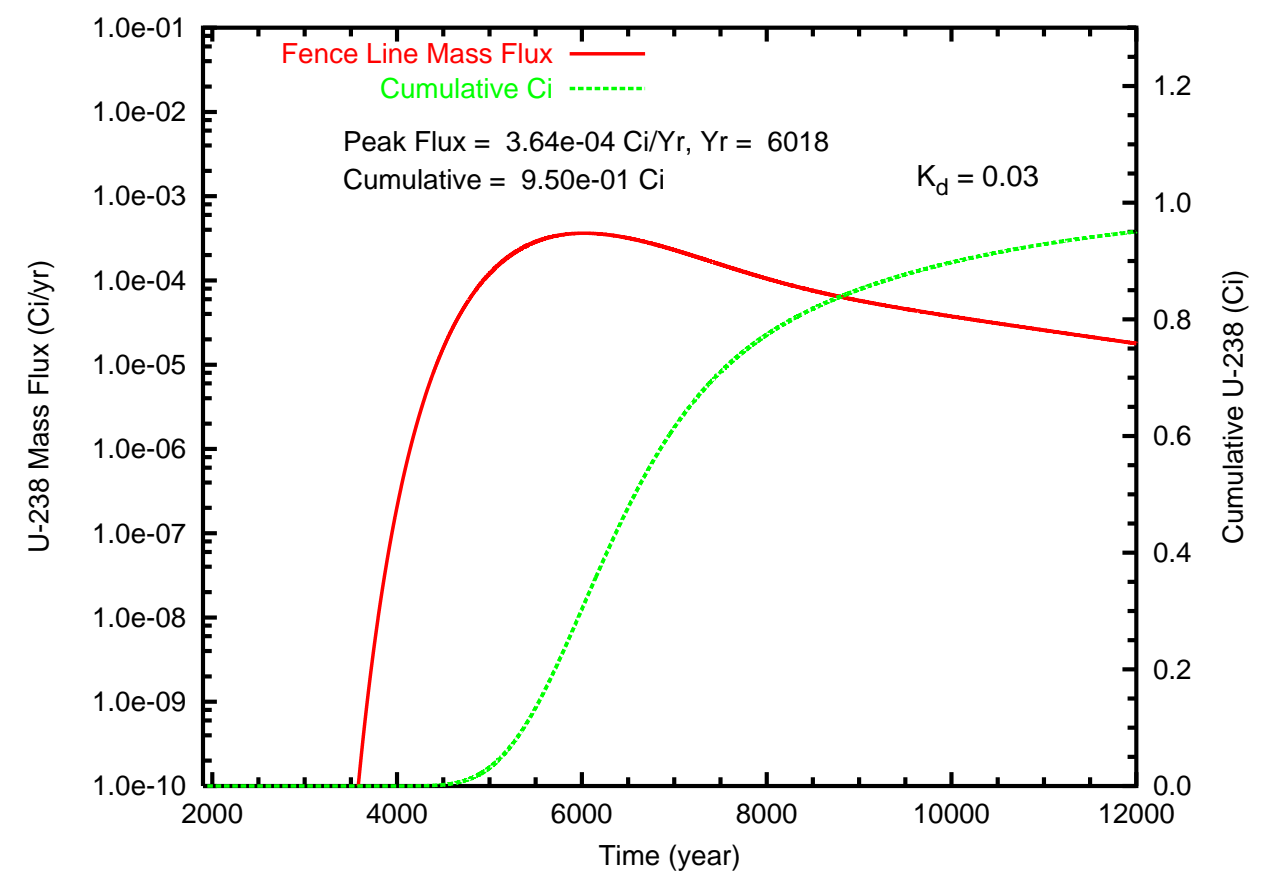

Figure B.173. Case 13, U-238 ( $\left.\mathrm{K}_{d}=0.03\right)$ mass flux $(\mathrm{Ci} / \mathrm{L})$ and cumulative mass $(\mathrm{Ci})$ at $(\mathrm{a})$ the groundwater table and (b) the fence line 
(a)

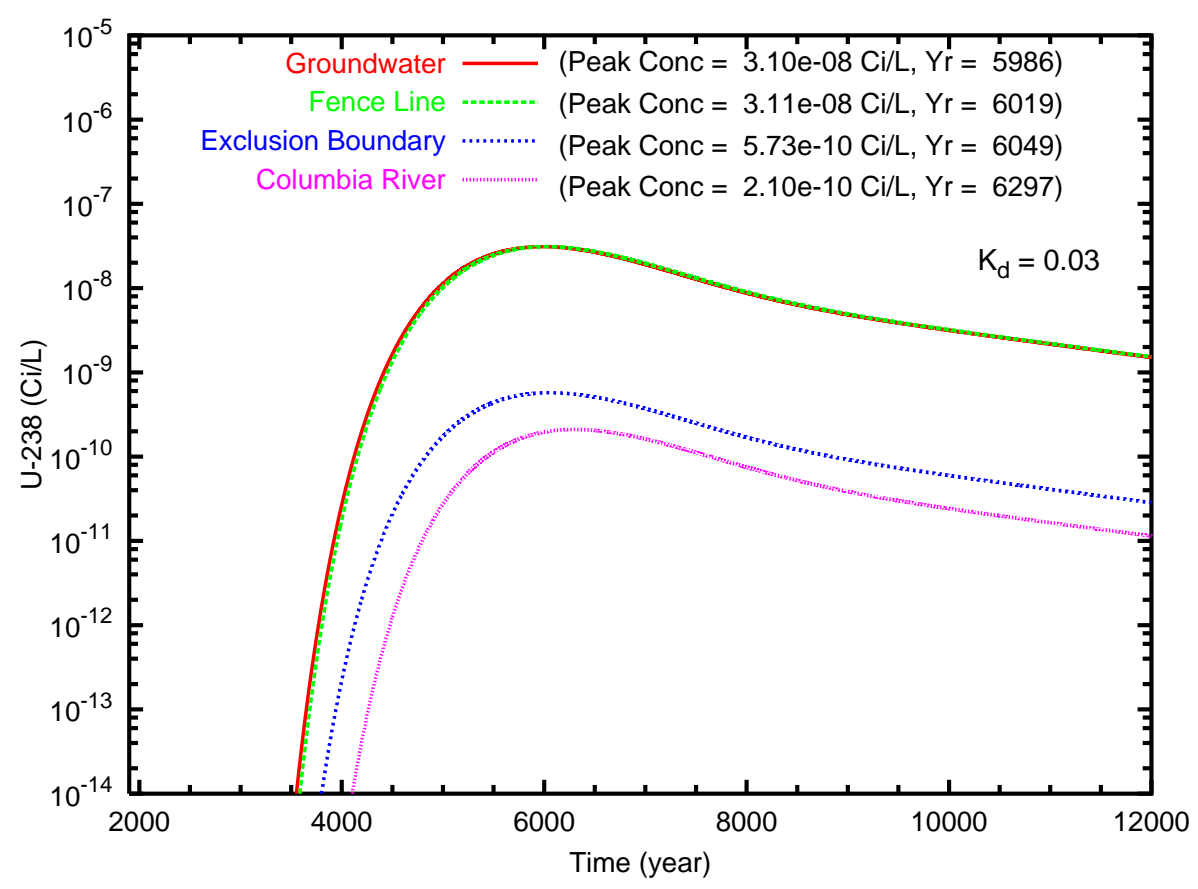

(b)

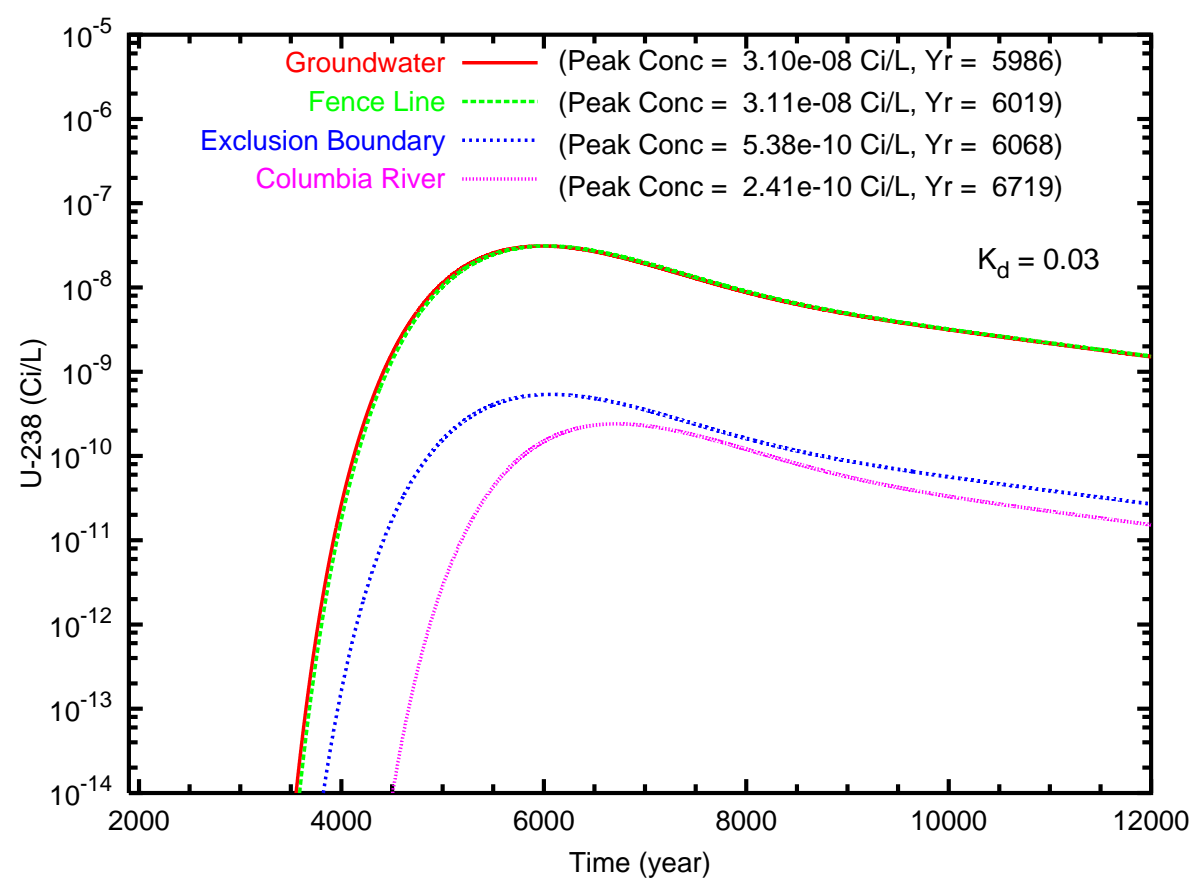

Figure B.174. Case $13, \mathrm{U}-238\left(\mathrm{~K}_{d}=0.03\right)$ concentration versus time for the fence line exclusion boundary and Columbia River compliance points for travel paths (a) southeast and (b) north through the gap 
(a)

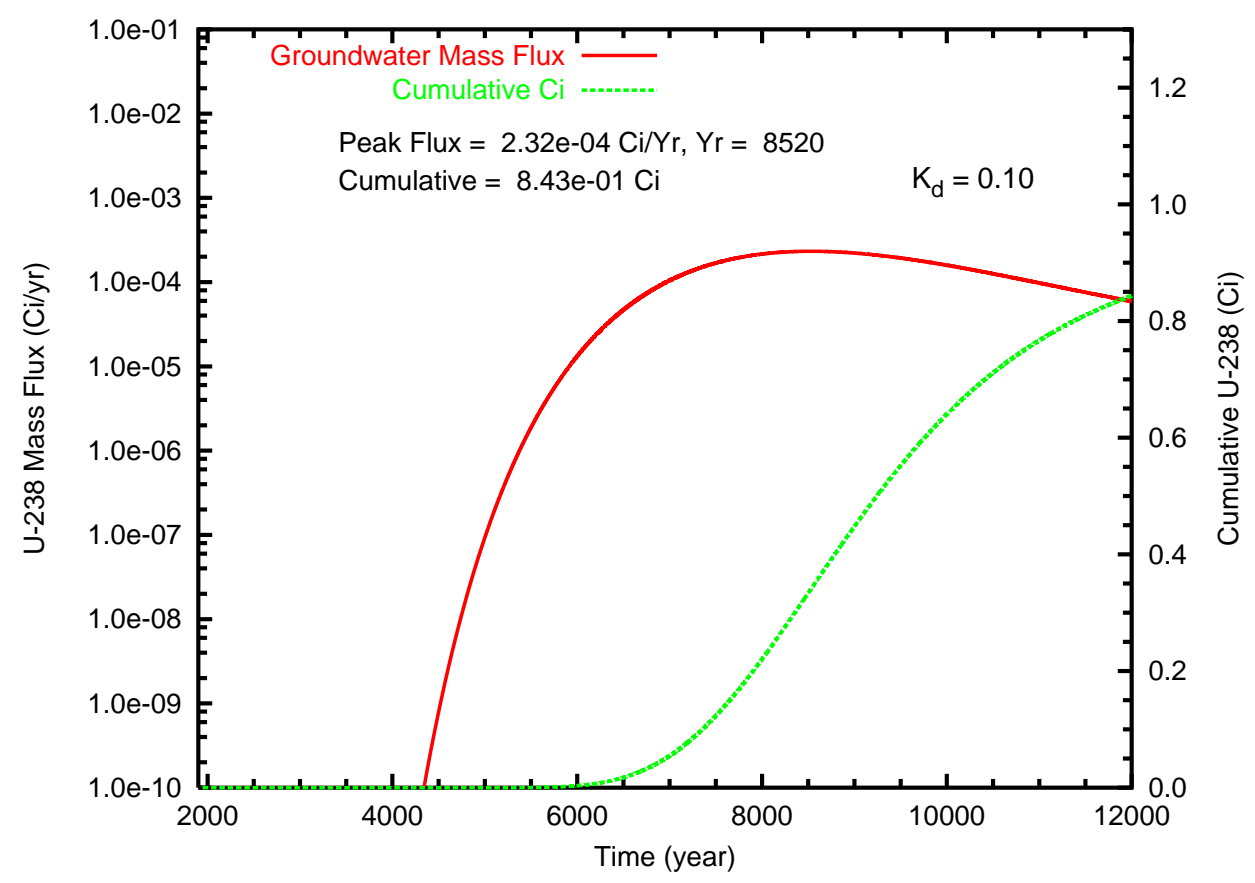

(b)

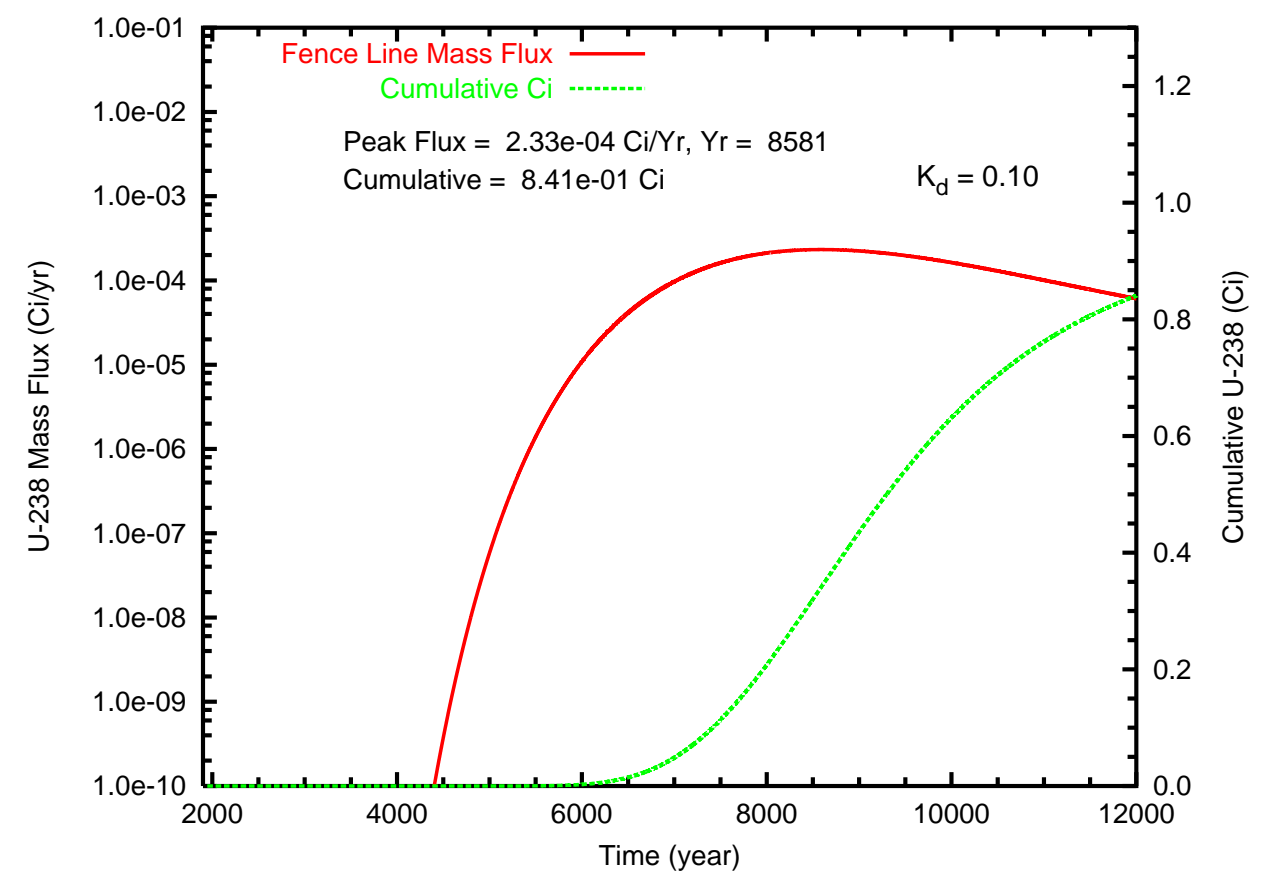

Figure B.175. Case $13, \mathrm{U}-238\left(\mathrm{~K}_{d}=0.10\right)$ mass flux $(\mathrm{Ci} / \mathrm{L})$ and cumulative mass $(\mathrm{Ci})$ at (a) the groundwater table and (b) the fence line 
(a)

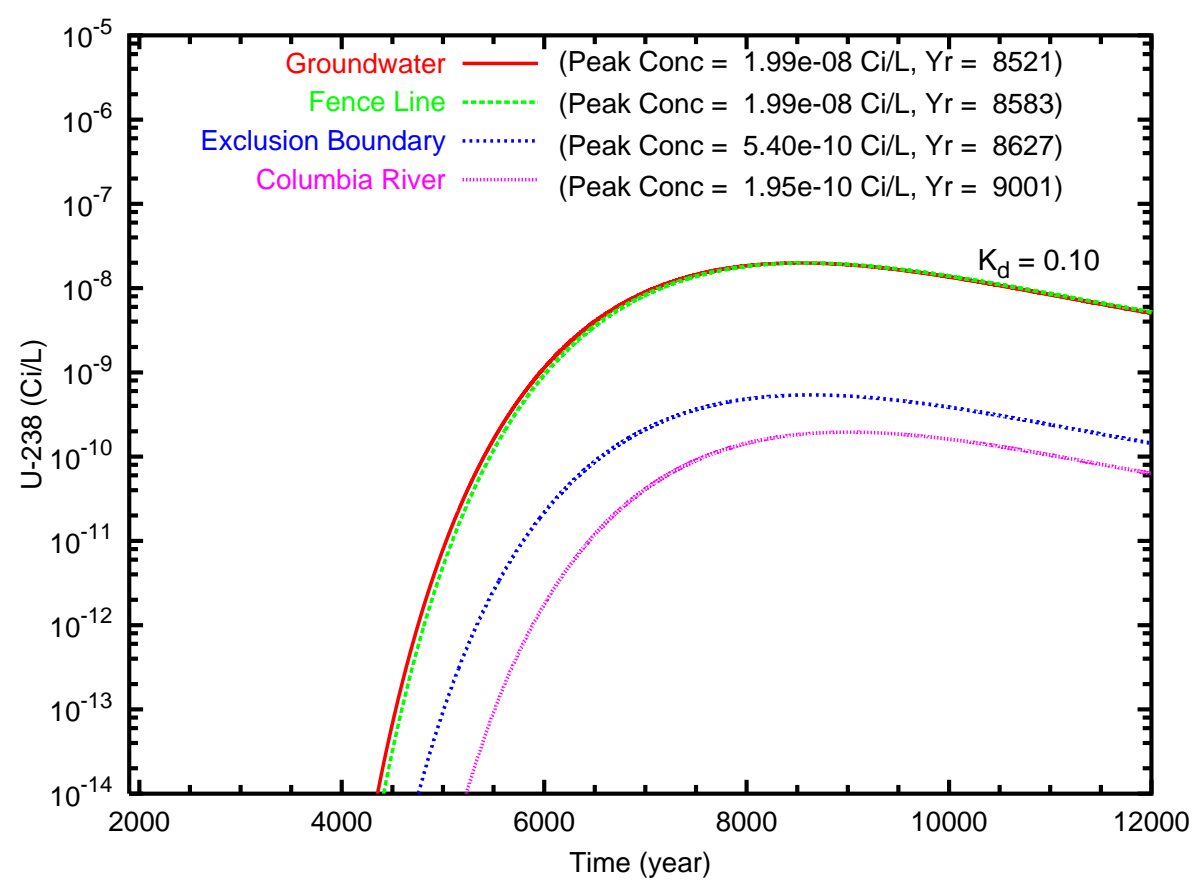

(b)

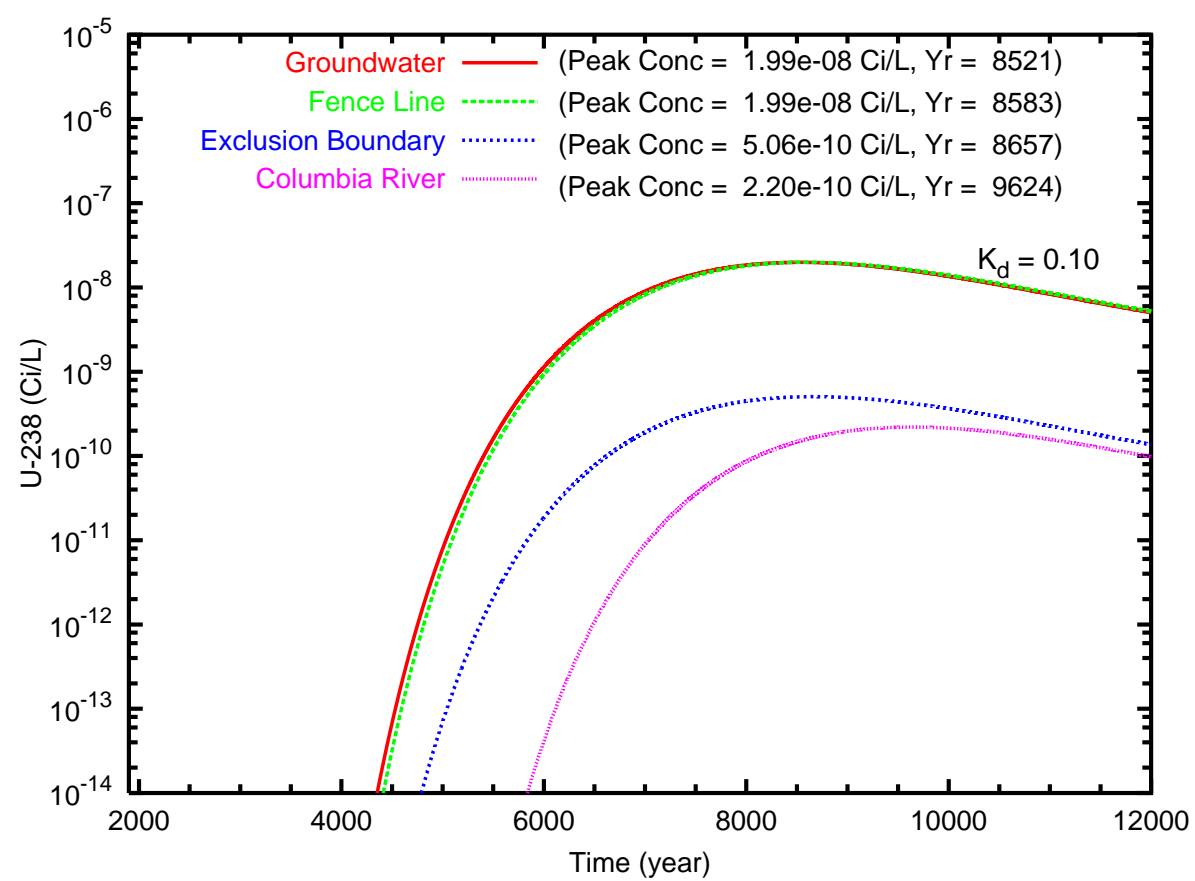

Figure B.176. Case $13, \mathrm{U}-238\left(\mathrm{~K}_{d}=0.10\right)$ concentration versus time for the fence line exclusion boundary and Columbia River compliance points for travel paths (a) southeast and (b) north through the gap 
(a)

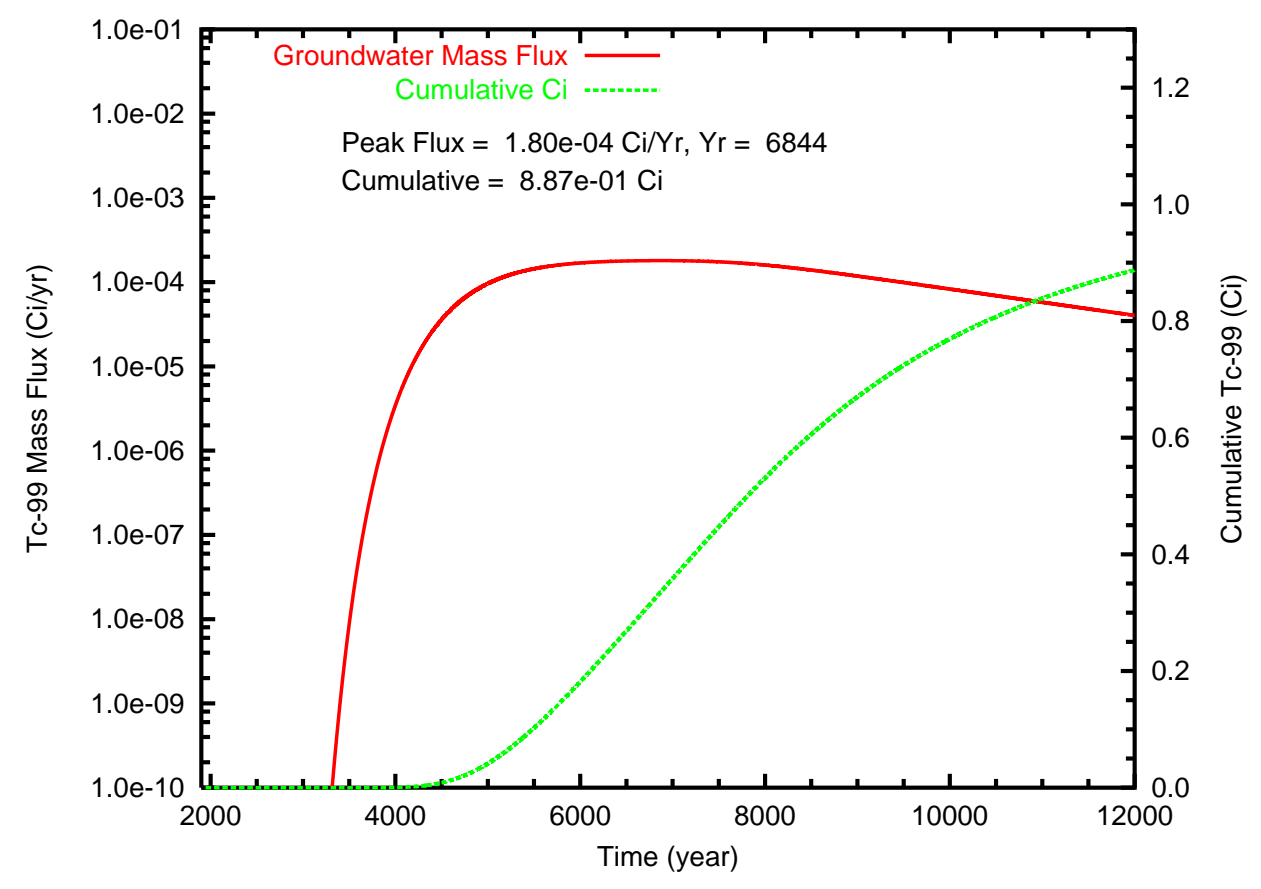

(b)

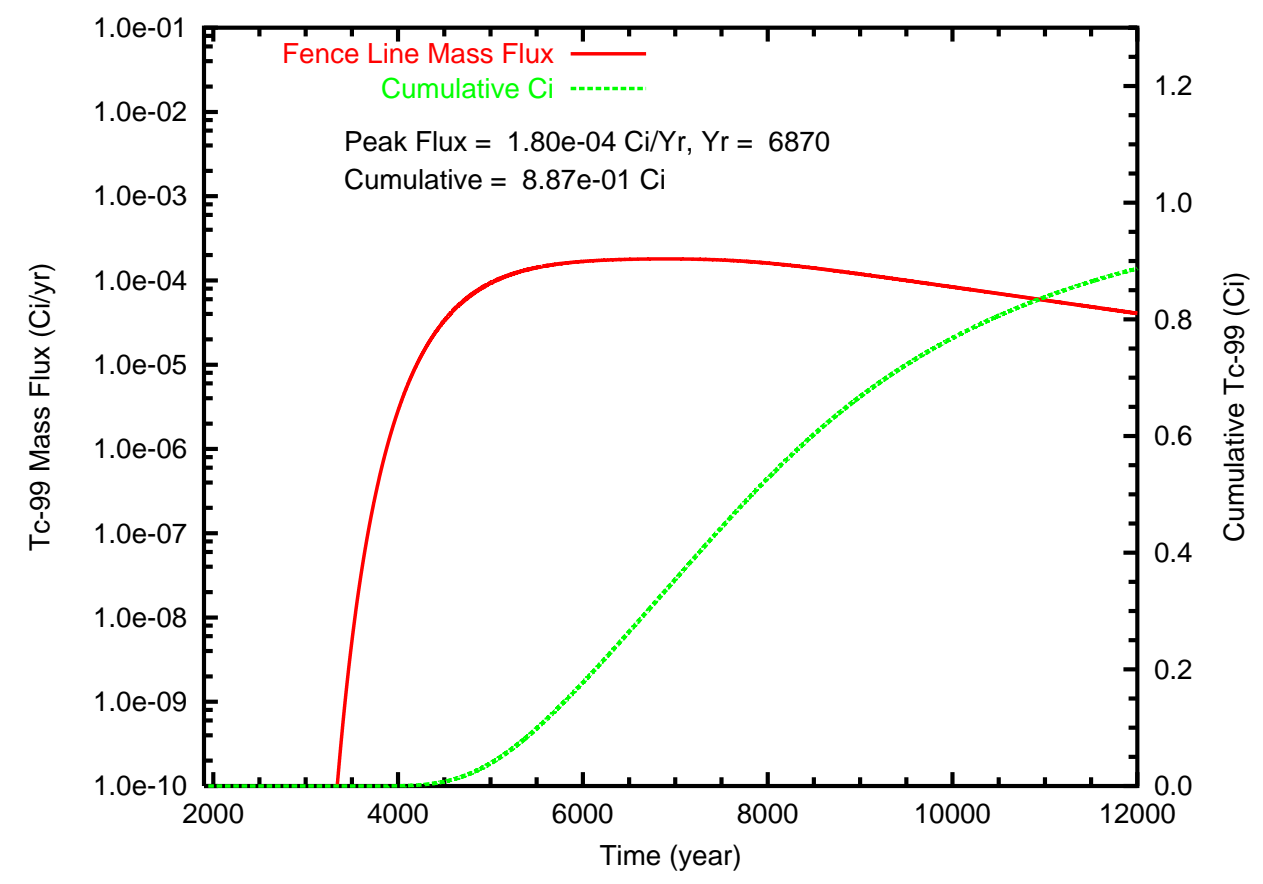

Figure B.177. Case 14, Tc-99 mass flux and cumulative mass at (a) the groundwater table and (b) the fence line 
(a)

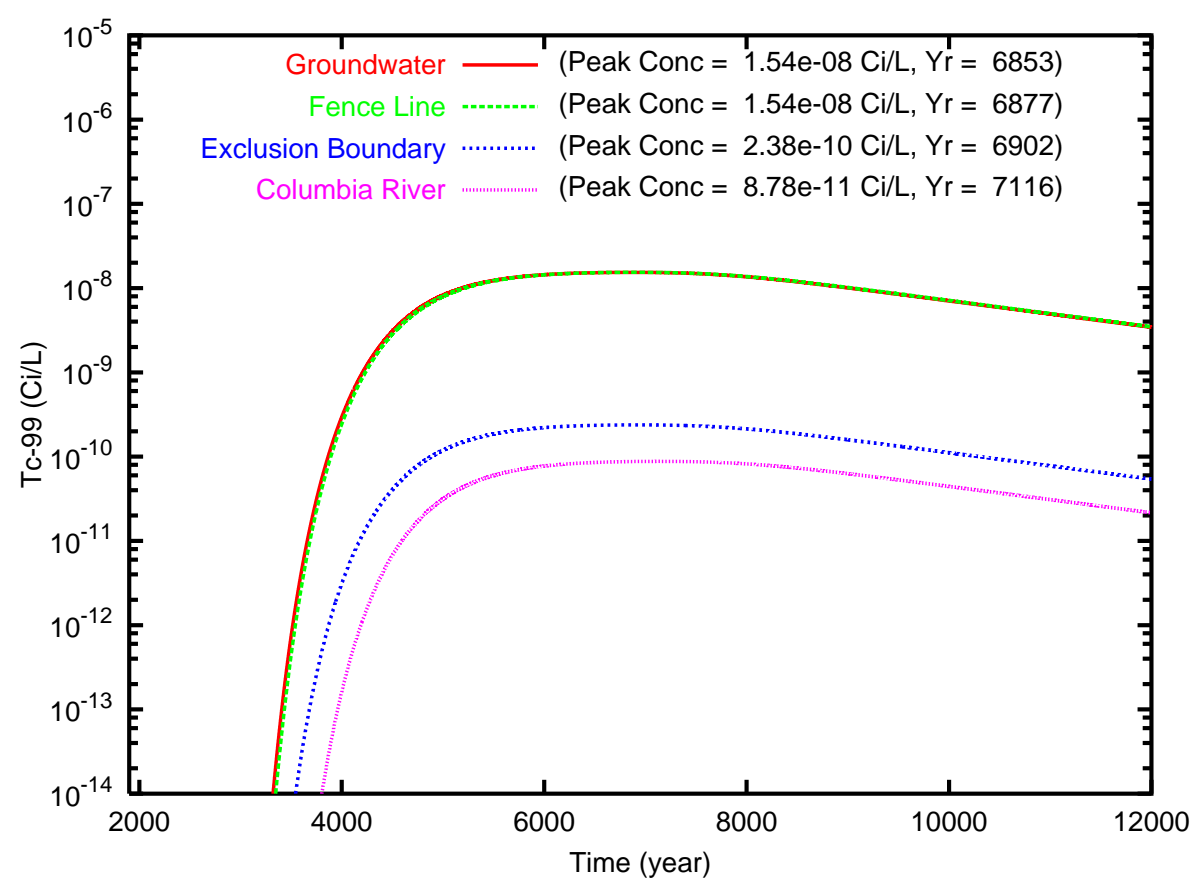

(b)

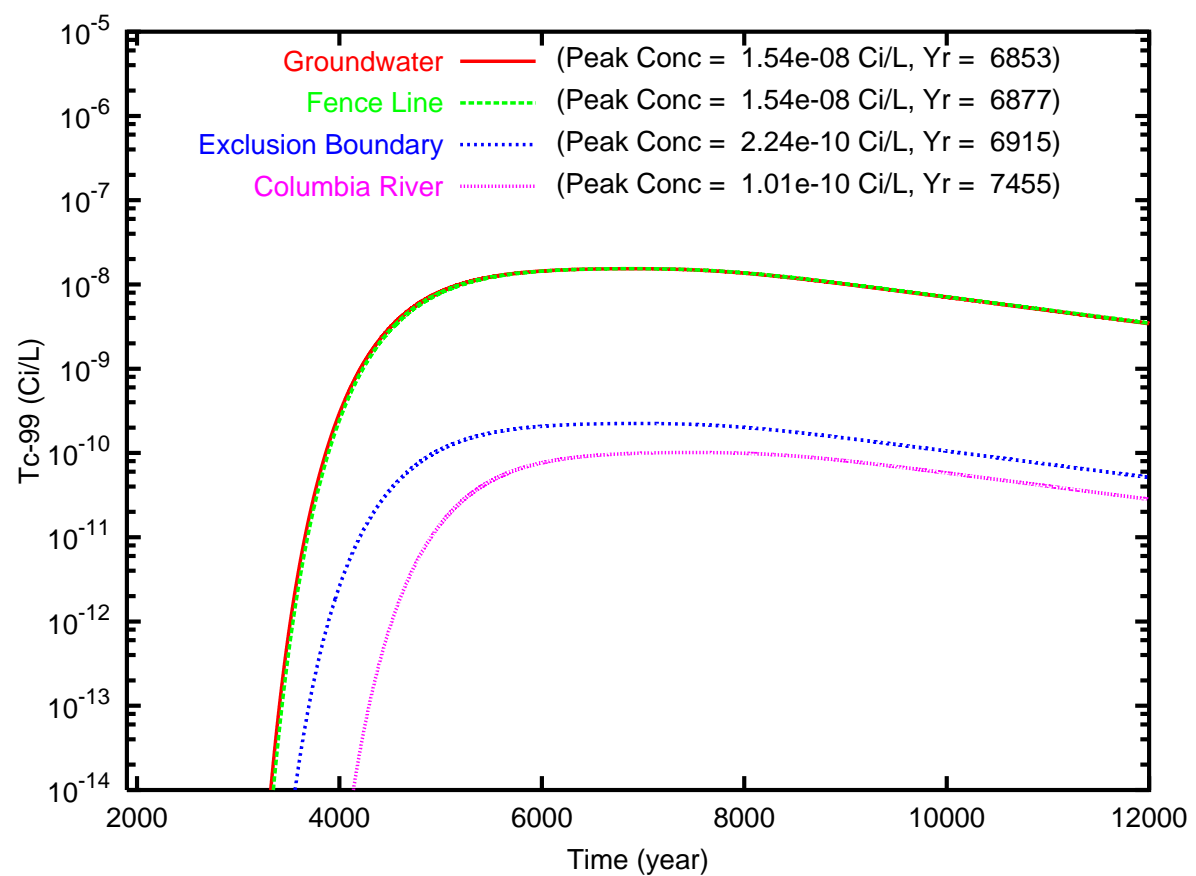

Figure B.178. Case 14, Tc-99 concentration versus time for the fence line, exclusion boundary and Columbia River compliance points for travel paths (a) southeast and (b) north through the gap 
(a)

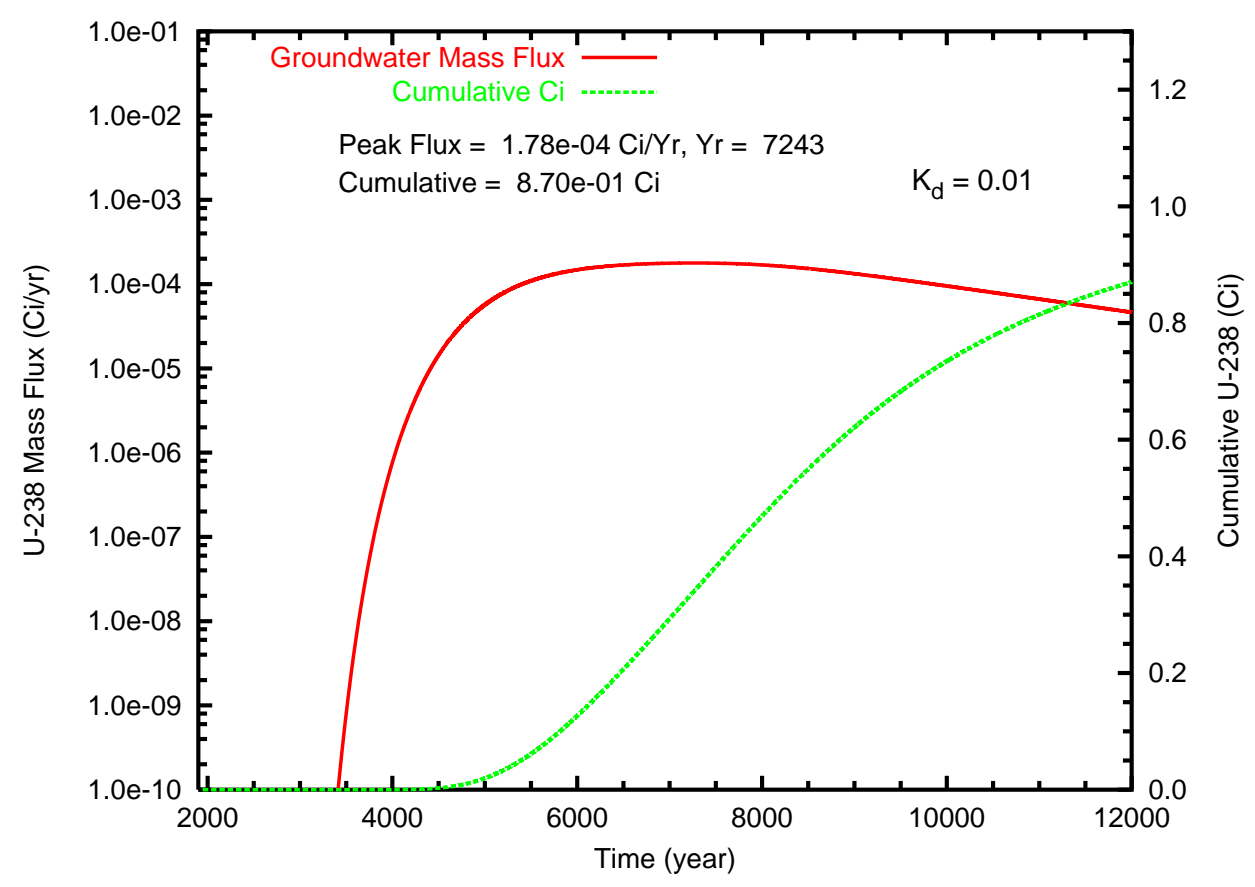

(b)

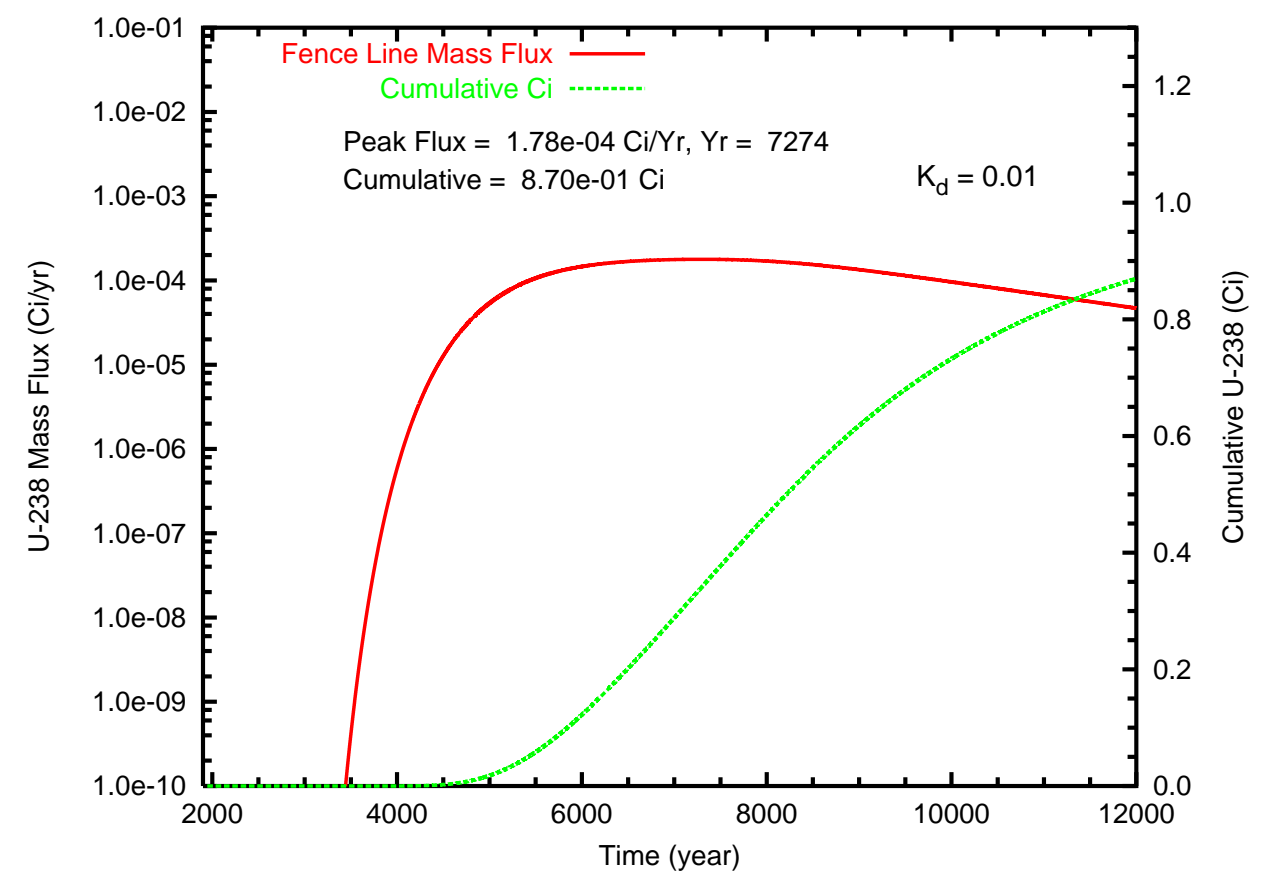

Figure B.179. Case 14 , U-238 $\left(\mathrm{K}_{d}=0.01\right)$ mass flux $(\mathrm{Ci} / \mathrm{L})$ and cumulative mass $(\mathrm{Ci})$ at (a) the groundwater table and (b) the fence line 
(a)

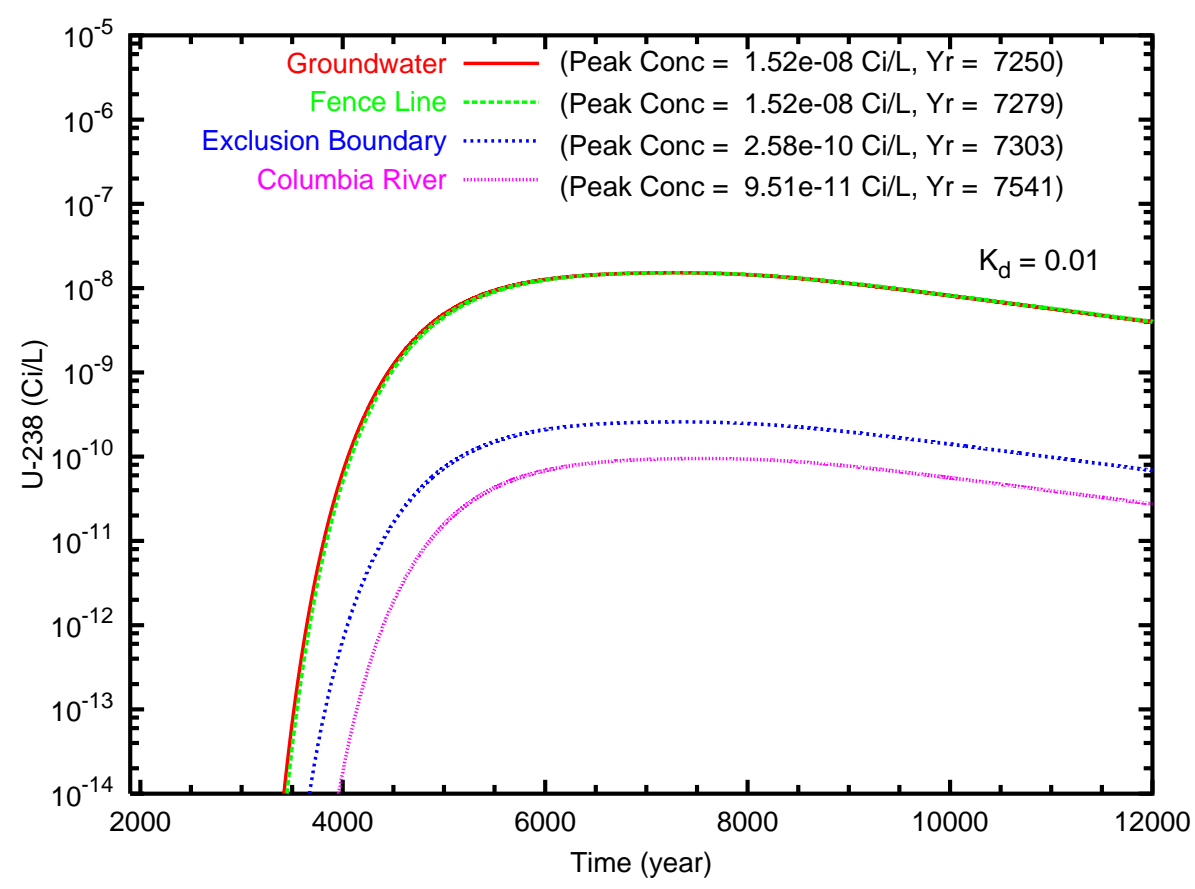

(b)

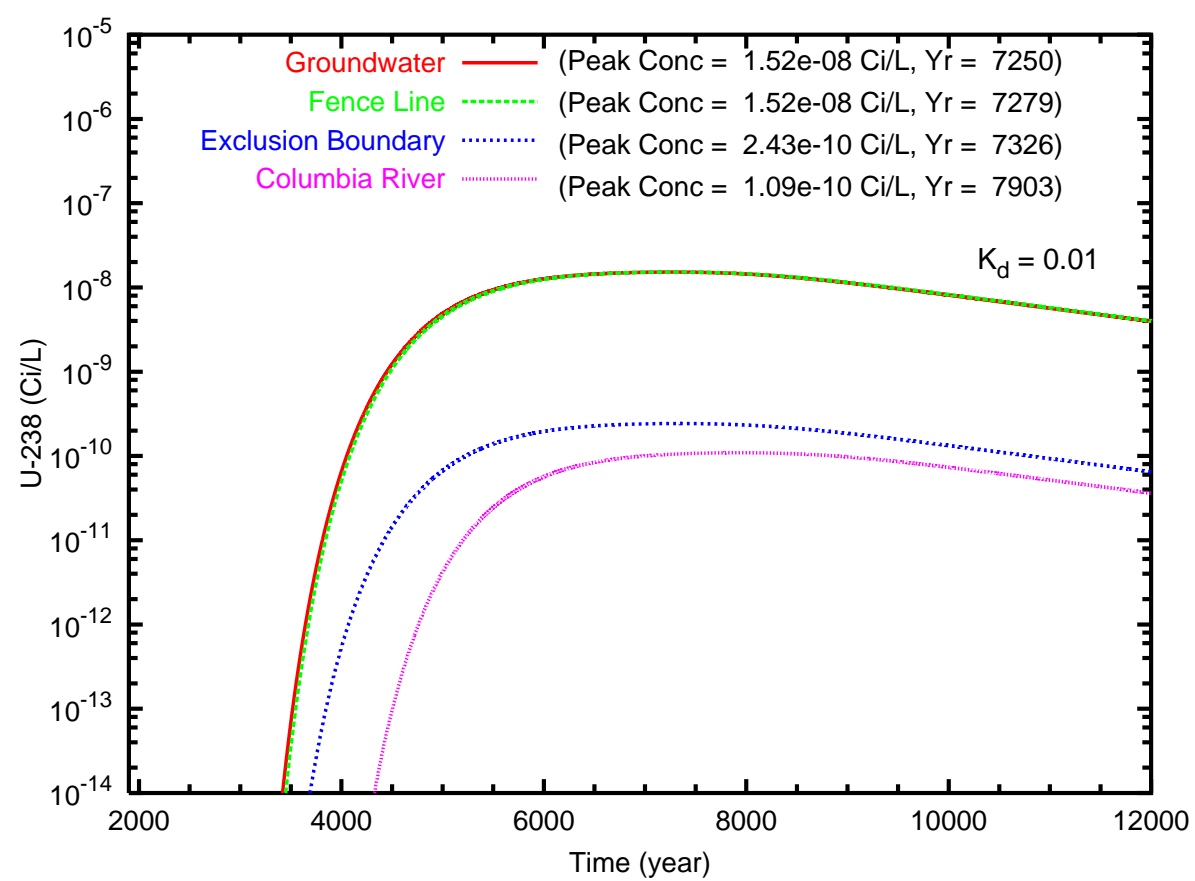

Figure B.180. Case 14, U-238 $\left(\mathrm{K}_{d}=0.01\right)$ concentration versus time for the fence line exclusion boundary and Columbia River compliance points for travel paths (a) southeast and (b) north through the gap 
(a)

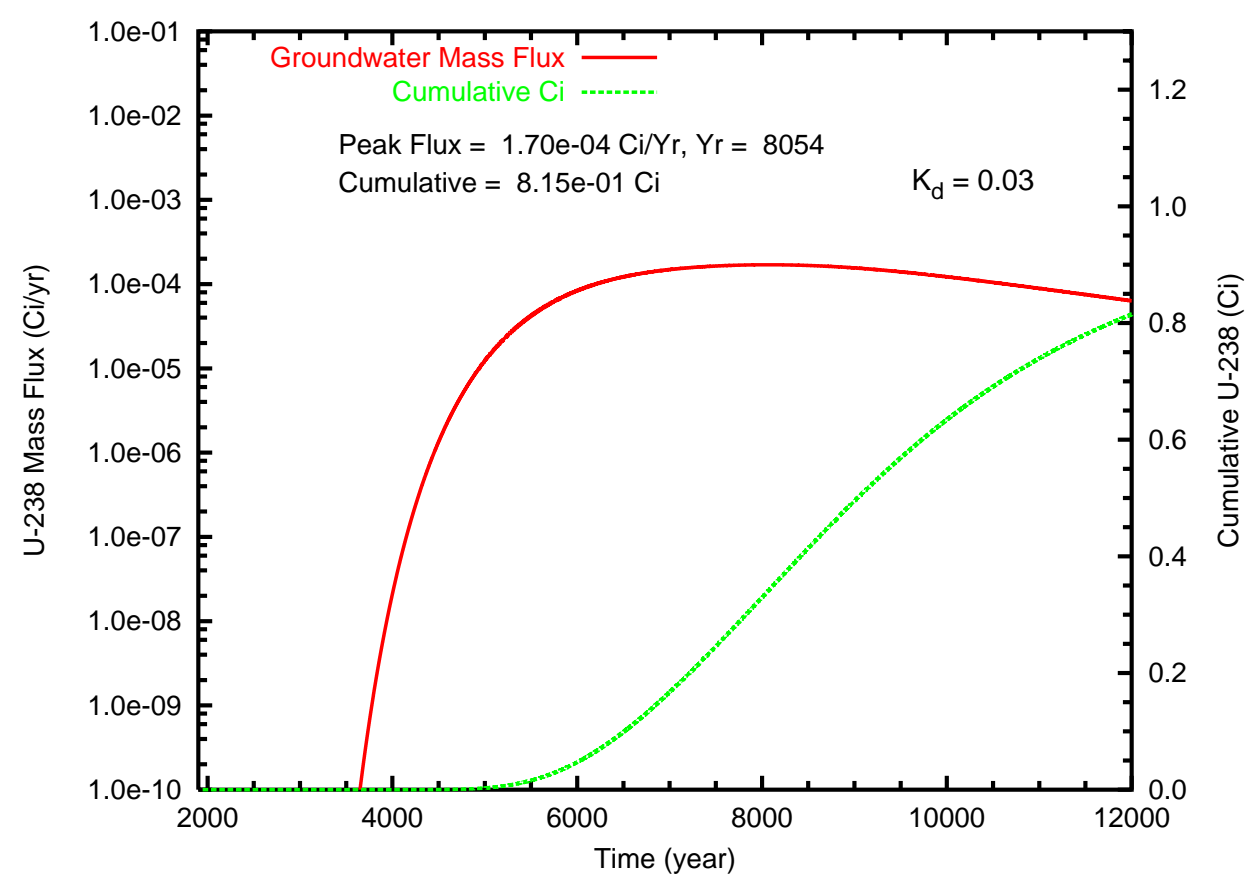

(b)

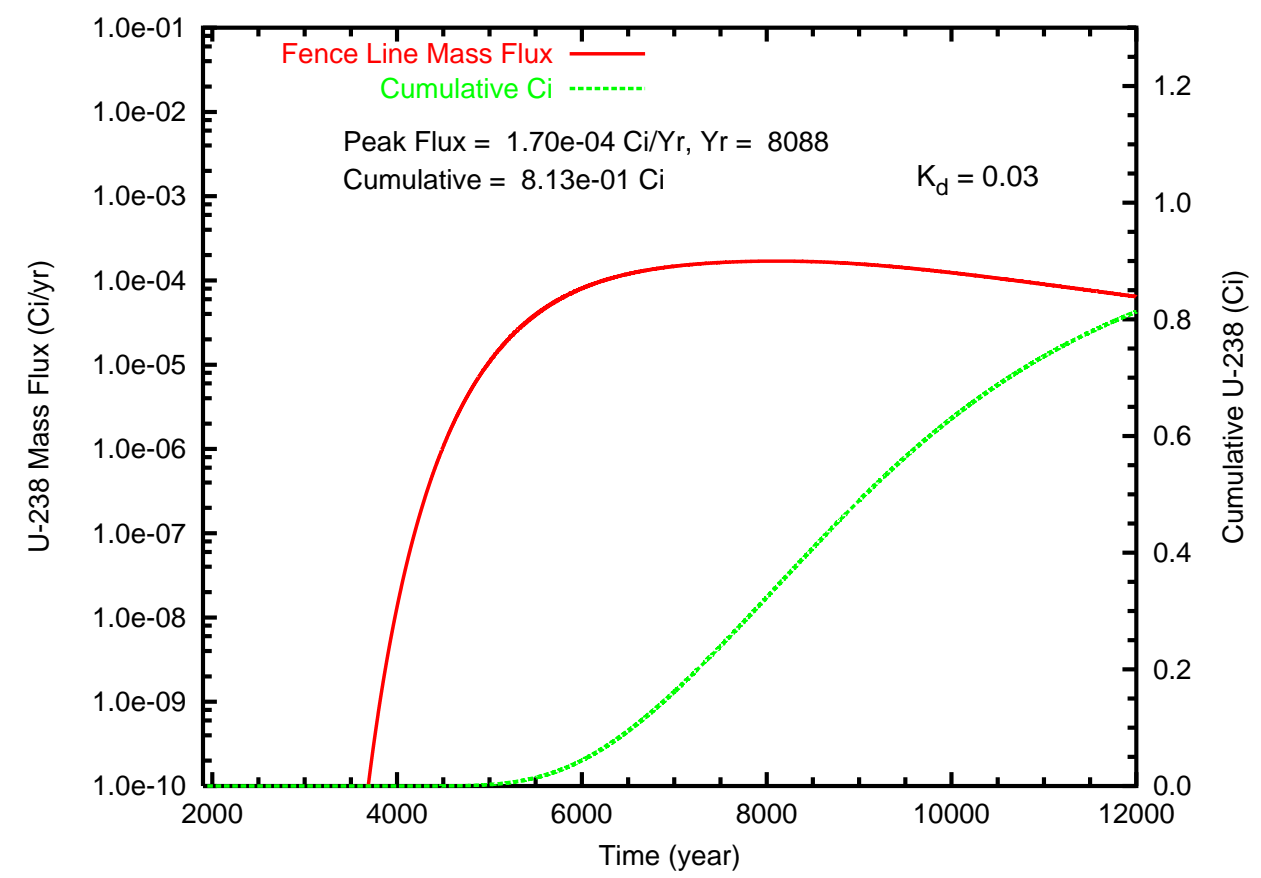

Figure B.181. Case 14, U-238 ( $\left.\mathrm{K}_{d}=0.03\right)$ mass flux $(\mathrm{Ci} / \mathrm{L})$ and cumulative mass $(\mathrm{Ci})$ at (a) the groundwater table and (b) the fence line 
(a)

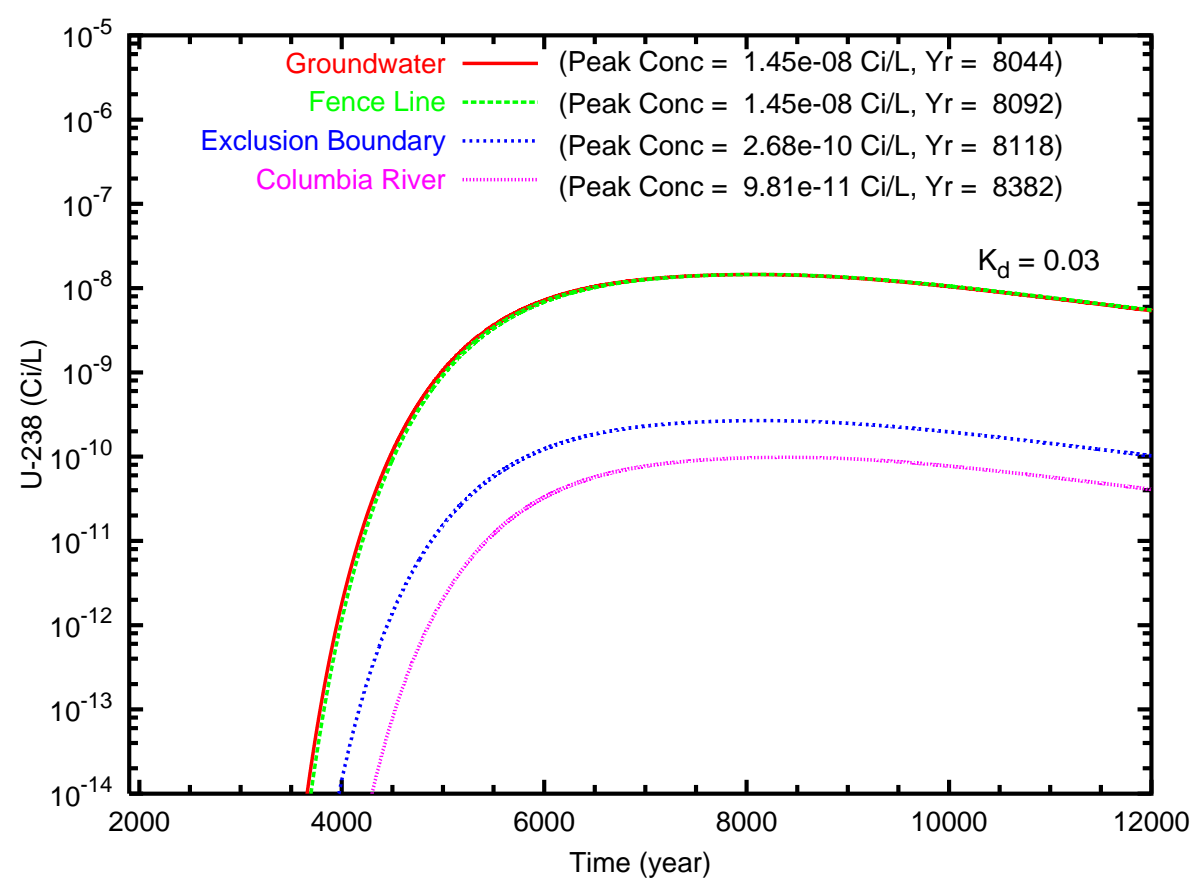

(b)

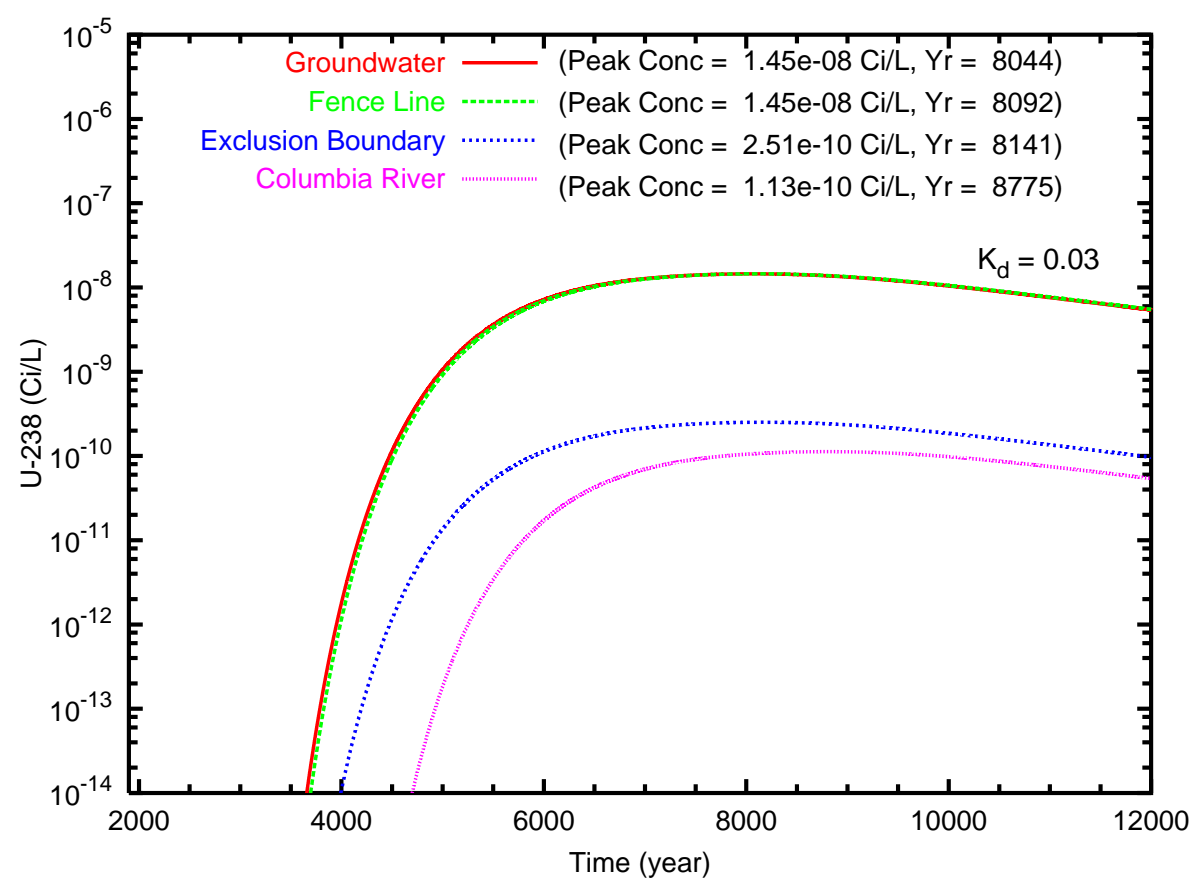

Figure B.182. Case 14, U-238 $\left(\mathrm{K}_{d}=0.03\right)$ concentration versus time for the fence line exclusion boundary and Columbia River compliance points for travel paths (a) southeast and (b) north through the gap 
(a)

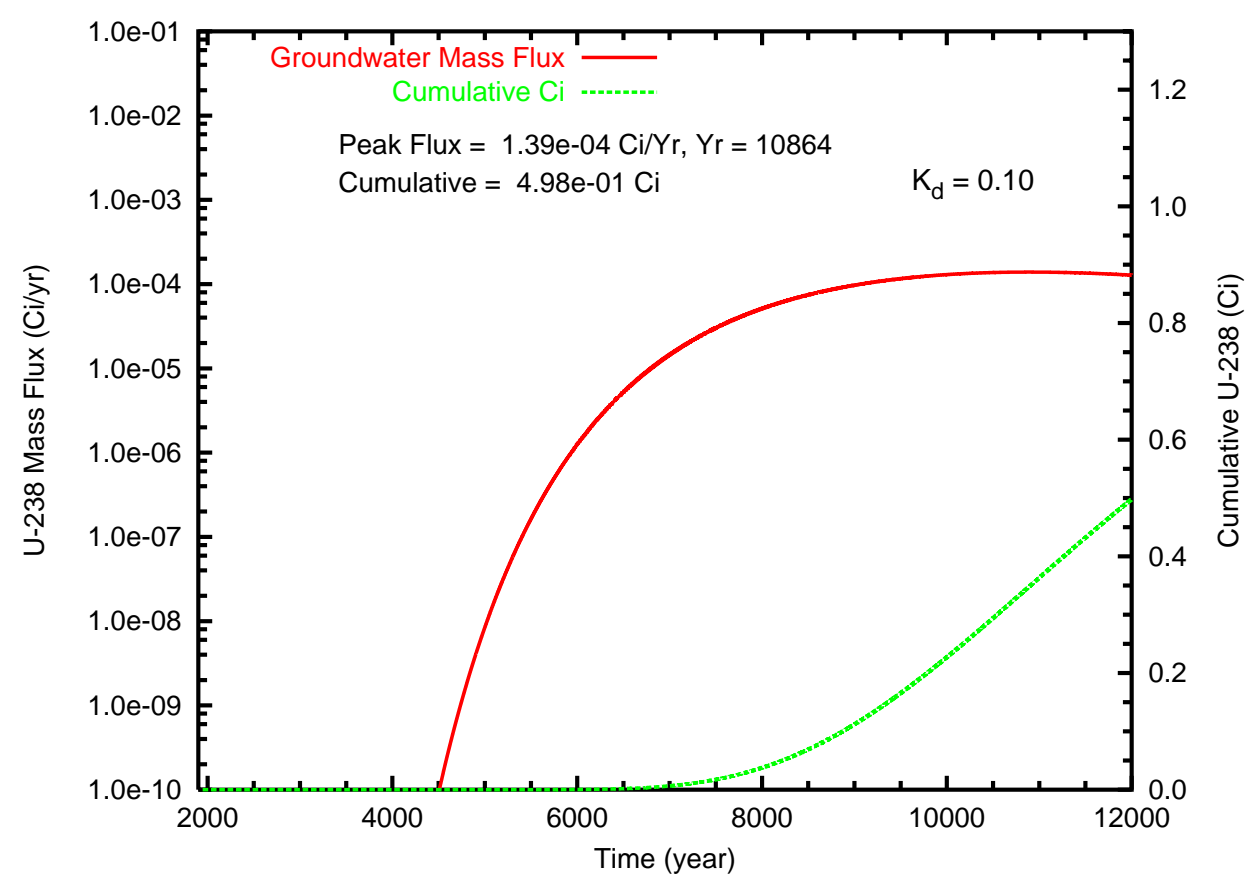

(b)

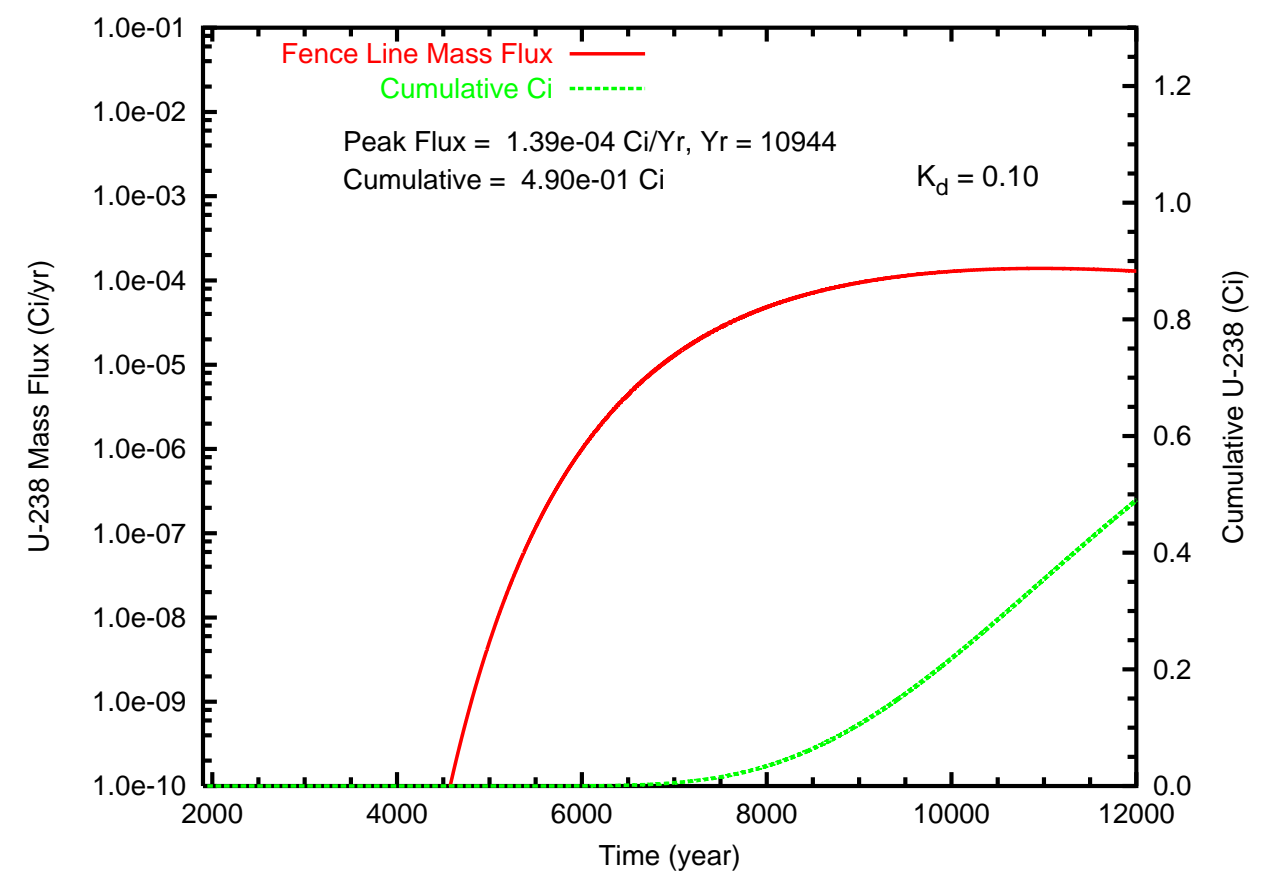

Figure B.183. Case 14 , U-238 $\left(\mathrm{K}_{d}=0.10\right)$ mass flux $(\mathrm{Ci} / \mathrm{L})$ and cumulative mass $(\mathrm{Ci})$ at (a) the groundwater table and (b) the fence line 
(a)

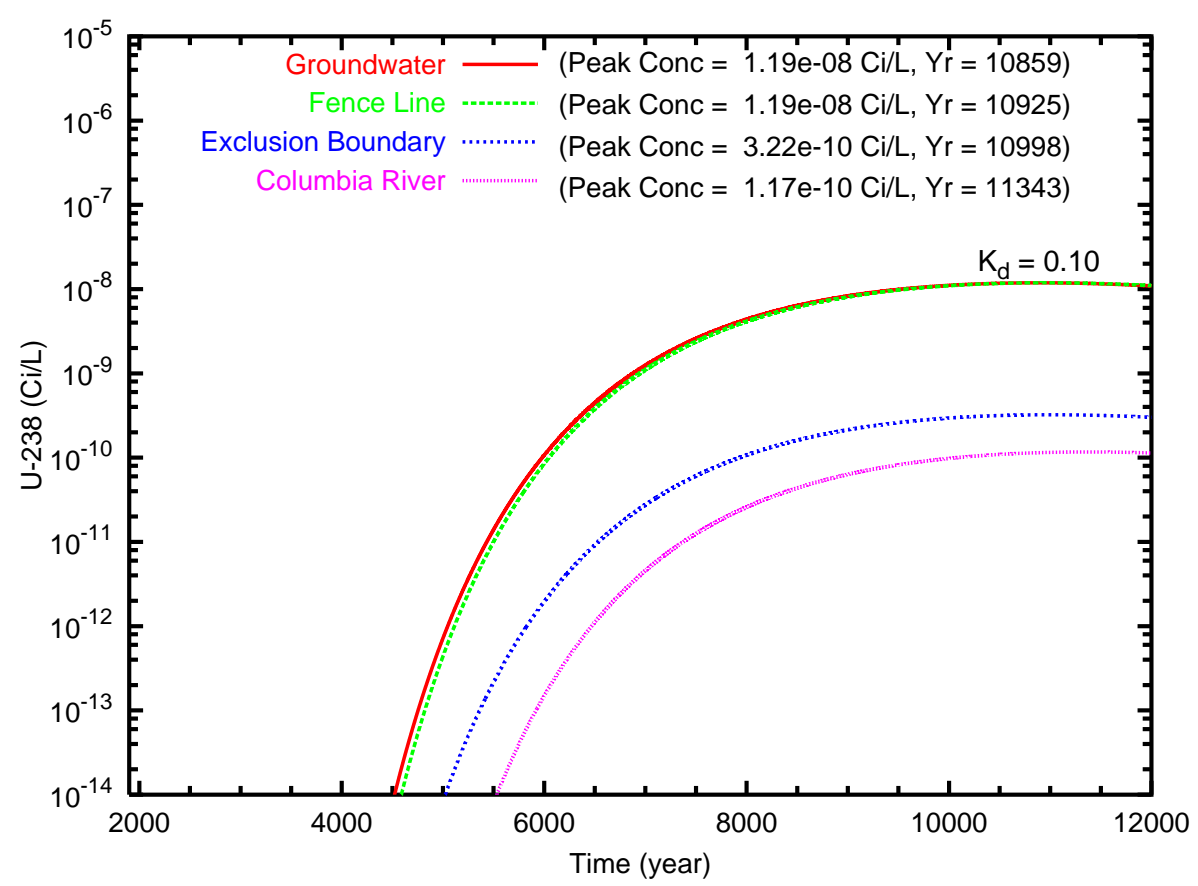

(b)

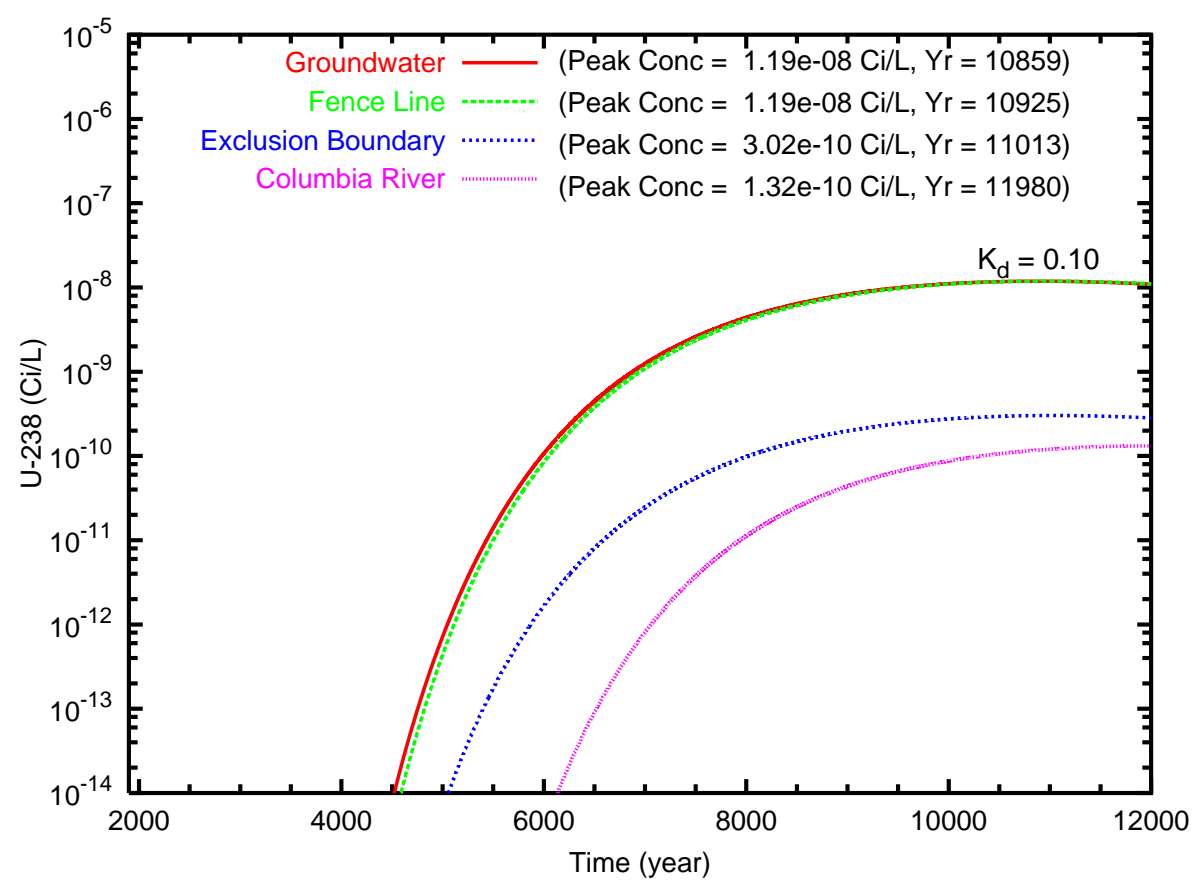

Figure B.184. Case 14, U-238 $\left(\mathrm{K}_{d}=0.10\right)$ concentration versus time for the fence line exclusion boundary and Columbia River compliance points for travel paths (a) southeast and (b) north through the gap 
PNNL-14334

\section{Distribution}

No. of

Copies

\section{Onsite}

$1 \quad \underline{\text { Fluor Federal Services }}$

R. Khaleel E6-17

3 CH2M-HILL Group, Inc.

M. Connelly E6-35

3 Pacific Northwest National Laboratory

V. L. Freedman

K9-36

M.D. White

K9-36

Z.F. Zhang

K9-36

Distr.1 